\title{
Phase II Hydrologic Data for the Groundwater Flow and Contaminant Transport Model of Corrective Action Unit 98: Frenchman Flat, Nye County, Nevada
}
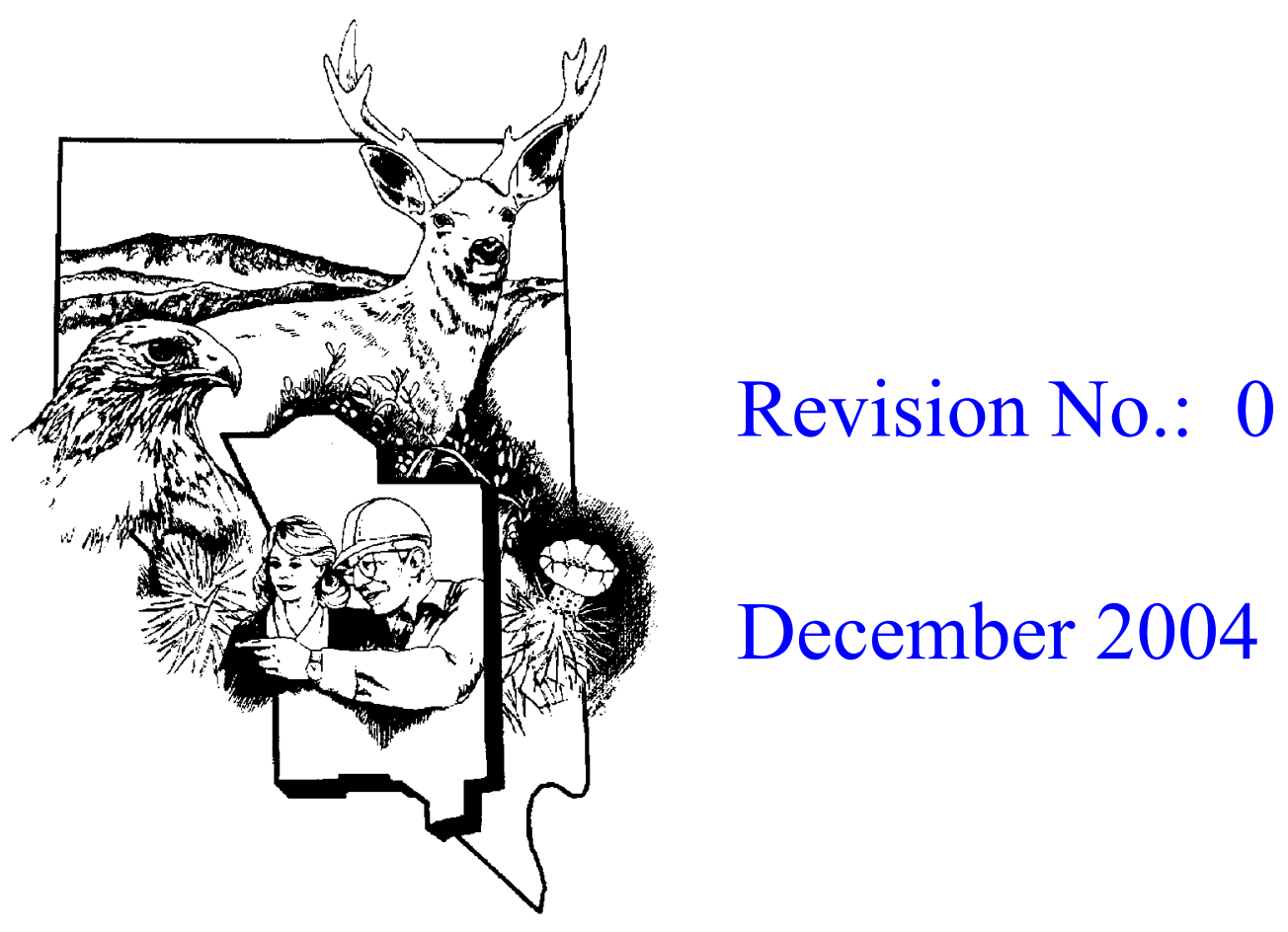

Prepared for U.S. Department of Energy under Contract No. DE-AC52-03NA99205 Approved for public release; further dissemination unlimited. 
Available for public sale, in paper, from:

U.S. Department of Commerce

National Technical Information Service

5285 Port Royal Road

Springfield, VA 22161

Phone: 800.553 .6847

Fax: 703.605.6900

Email: orders@ntis.gov

Online ordering: http://www.ntis.gov/ordering.htm

Available electronically at $\underline{h t t p: / / w w w . o s t i . g o v / b r i d g e ~}$

Available for a processing fee to U.S. Department of Energy and its contractors, in paper, from:

U.S. Department of Energy

Office of Scientific and Technical Information

P.O. Box 62

Oak Ridge, TN 37831-0062

Phone: 865.576 .8401

Fax: 865.576.5728

Email: reports@adonis.osti.gov

Reference herein to any specific commercial product, process, or service by trade name, trademark, manufacturer, or otherwise, does not necessarily constitute or imply its endorsement, recommendation, or favoring by the United States Government or any agency thereof or its contractors or subcontractors. 


\section{PHASE II HYDROLOGIC DATA FOR THE GROUNDWATER FLOW AND CONTAMINANT TRANSPORT MODEL OF CORRECTIVE ACTION UNIT 98: FRENCHMAN FLAT, NYE COUNTY, NEVADA}

Contributors:

Thomas Beard

Keely Brooks

Nicole DeNovio

John Ewing

Irene Farnham

William Fryer

Toya Jones

John McCord

John Pickens

Janice Rose

Revision No.: 0

December 2004

Stoller-Navarro Joint Venture

7710 W. Cheyenne, Bldg 3

Las Vegas, NV 89129 
PHASE II HYDROLOGIC DATA FOR THE GROUNDWATER FLOW AND CONTAMINANT TRANSPORT MODEL OF CORRECTIVE ACTION UNIT 98: FRENCHMAN FLAT, NYE COUNTY, NEVADA

Approved by: Signature Approved Date: 12/2/04

John McCord, UGTA Project Manager

Stoller-Navarro Joint Venture 


\section{Table of Contents}

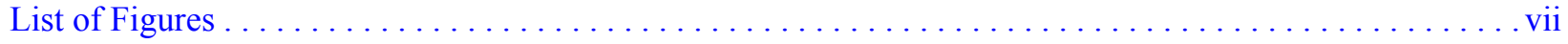

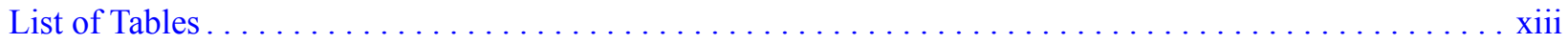

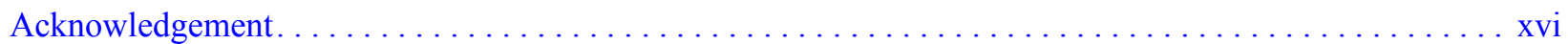

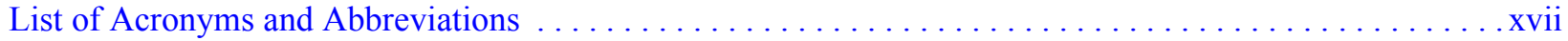

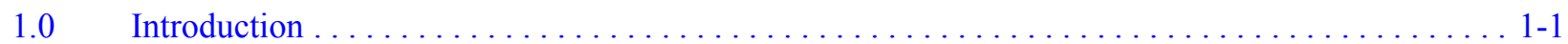

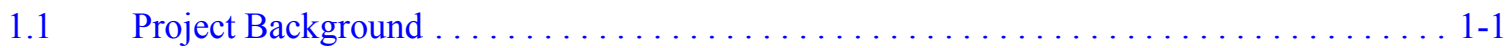

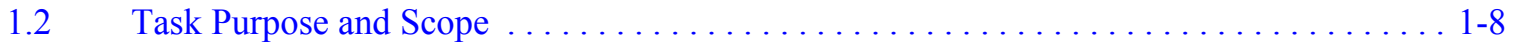

1.3 Documents that Support the Phase II Frenchman Flat CAI . . . . . . . . . . . . . . . . 1-9

1.4 Quality Assurance . . . . . . . . . . . . . . . . . . . . . . . . . . . . . . . 1-12

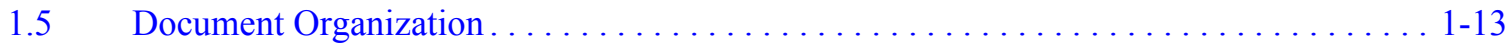

$2.0 \quad$ Regional Setting and the FF CAU Hydrostratigraphic Framework $\ldots \ldots \ldots \ldots \ldots \ldots \ldots \ldots \ldots .2-1$

$2.1 \quad$ Regional Setting. . . . . . . . . . . . . . . . . . . . . . . . . . .

2.1.1 Regional Hydrogeologic Framework ..................... 2-1

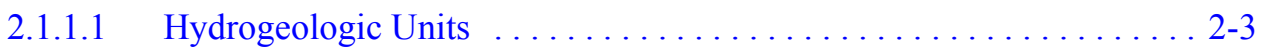

2.1.1.2 Hydrostratigraphic Units $\ldots \ldots \ldots \ldots \ldots \ldots \ldots . \ldots . \ldots . . \ldots \ldots$

2.1.2 Groundwater Occurrence and Movement .................. 2-5

2.1.2.1 Groundwater Occurrence . . . . . . . . . . . . . . . . . 2-5

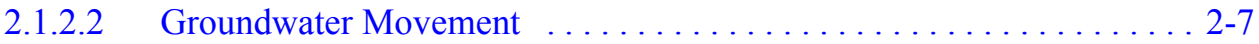

2.2 Frenchman Flat Hydrogeologic Framework . . . . . . . . . . . . . . . . . 2-8

2.2.1 Phase II Data Collection Activities . . . . . . . . . . . . . . . . . . 2-8

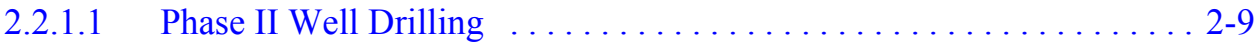

2.2.1.1.1 Well Cluster ER-5-3 . . . . . . . . . . . . . . . . . 2 2-9

2.2.1.1.2 Well Cluster ER-5-4 . . . . . . . . . . . . . . . . . . 2-9

2.2.1.2 Geophysical Investigations $\ldots \ldots \ldots \ldots \ldots \ldots \ldots \ldots \ldots .2-11$

2.2.1.3 Three-Dimensional Seismic Reflection . . . . . . . . . . . . . . . . . . 2-11

2.2.1.4 Natural-Source Magnetotelluric . . . . . . . . . . . . . . . . . 2-12

2.2.2 HSU Model Development . . . . . . . . . . . . . . . . . . . . . . . . 2-12

2.2.2.1 Base Model .............................. 2-13

2.2.2.2 Alternative Models ......................... 2-13

2.2.3 HSU Alternative Model Screening . . . . . . . . . . . . . . . . 2-14

2.2.4 Base HSU Model . . . . . . . . . . . . . . . . . . . . . . . . . . . . . 2-14

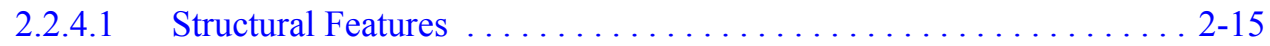

2.2.4.2 Hydrogeologic Units ......................... 2-15

2.2.4.3 Hydrostratigraphic Units . . . . . . . . . . . . . . . . 2-18

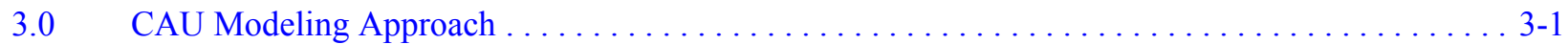

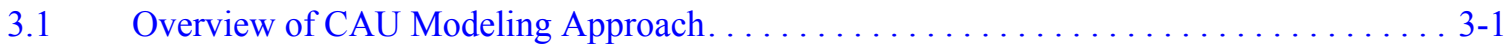

3.2 Historical and Current Modeling Strategy for Frenchman Flat CAU . . . . . . . . . . . . 3-3 


\section{Table of Contents (Continued)}

3.3 Groundwater Flow Modeling Approach and Data Requirements . . . . . . . . . . . . 3-4

3.3.1 Simulation Objectives . . . . . . . . . . . . . . . . . . . . . . . 3-4

3.3.2 Geologic Model . . ............................ 3-4

3.3.3 Model Parameters. . . . . . . . . . . . . . . . . . . . . . . . . . . 3-5

3.3.4 CAU Model Boundaries and Boundary Conditions. . . . . . . . . . . . . . 3-5

3.3.5 Select Computer Code ................................. 3-5

3.3.6 Grid Generation . . . . . . . . . . . . . . . . . . . . . . . . . . . 3-7

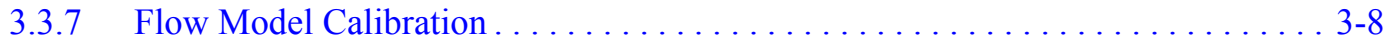

3.3.8 Sensitivity Analysis . . . . . . . . . . . . . . . . . . . . . . . 3-9

3.3.9 Model Documentation ... . . . . . . . . . . . . . . . . . . . . . . . . . 3-10

3.4 Data Requirements.................................. 3-10

$4.0 \quad$ Data Analysis. . . . . . . . . . . . . . . . . . . . . . . . . . . . . . . . . . . 4-1

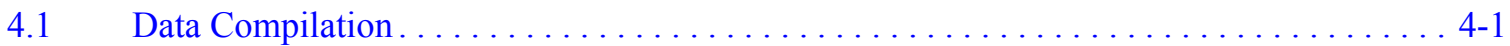

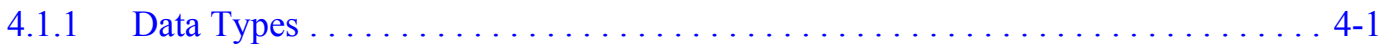

4.1.1.1 Description of Hydrologic Data Types $\ldots . \ldots \ldots \ldots \ldots \ldots . . . \ldots 4-1$

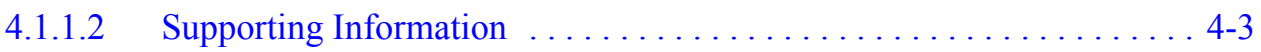

4.1.2 Data Sources. . . . . . . . . . . . . . . . . . . . . . 4 .

4.2 Data Transfer Methodology .............................. 4-5

4.2.1 General Transfer Methodology . . . . . . . . . . . . . . . . . . . . . . 4-6

4.2.2 Factors Influencing Flow and Transport Parameters . . . . . . . . . . . . . 4-6

4.2.3 YMP Data Transfer . . . . . . . . . . . . . . . . . . . . . . 4 4

4.3 Qualification of Data and Data Documentation. . . . . . . . . . . . . . . . . . 4-8

4.3.1 Data Documentation Qualification........................ 4-8

4.3.2 Data Quality Evaluation. . . . . . . . . . . . . . . . . . . . . 4

$4.4 \quad$ Analysis Methods Used . . . . . . . . . . . . . . . . . . . . . . . . . 4-10

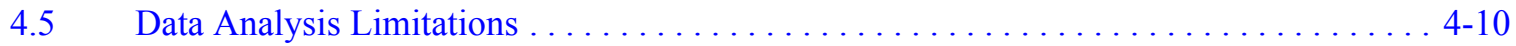

$5.0 \quad$ Hydraulic Parameters. . . . . . . . . . . . . . . . . . . .

$5.1 \quad$ Objectives. . . . . . . . . . . . . .

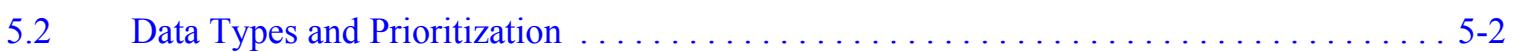

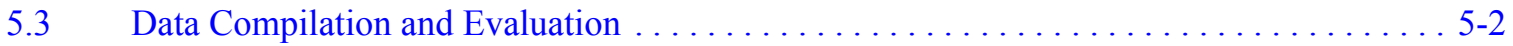

$5.3 .1 \quad$ Data Sources.......................... 5-3

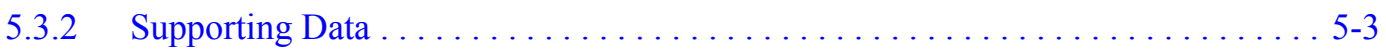

5.3 .3 Data Qualification .............................. 5-4

5.3 .4 Data Transferability . . . . . . . . . . . . . . . . . . . . . . . 5-5

$5.4 \quad$ Hydraulic Parameters. . . . . . . . . . . . . . . . . . . . . . . . . . . . . . . 5-6

5.4.1 Scales of Testing and Associated Uncertainties. . . . . . . . . . . . . . . 5-7 


\section{Table of Contents (Continued)}

5.4.2 Test Analysis and Associated Uncertainties ..................... . 5-8

5.4 .3 Characterization Data. . . . . . . . . . . . . . . . . . . . . . 5-8

5.4.4 Analysis of Different Test Results for a Well . . . . . . . . . . . . . . 5-8

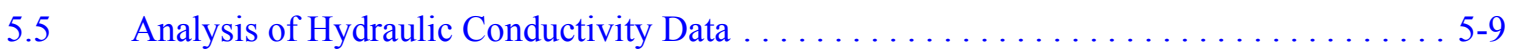

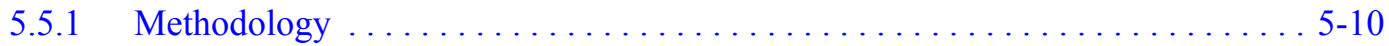

5.5.2 Kolmogorov-Smirnov Test for $\log$ Normality . . . . . . . . . . . . . . 5-12

5.5.3 Spatial Distribution of Data . . . . . . . . . . . . . . . . . . 5-13

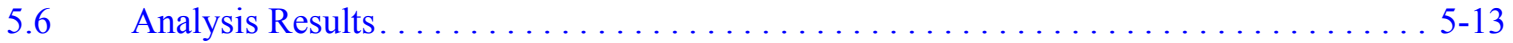

$5.6 .1 \quad$ FF-Specific K-Data Analyses. . . . . . . . . . . . . . . . . . . . . . 5-16

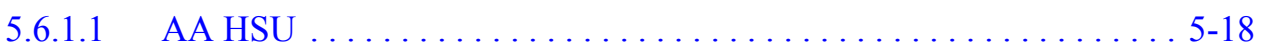

$5.6 .1 .2 \quad$ LCA HSU . . . . . . . . . . . . . . . . . . . . . . . 5-20

5.6.1.3 TM-WTA and TM-LVTA combined HSUs $\ldots \ldots \ldots \ldots \ldots \ldots .5-23$

5.6.2 NTS Investigation Area K Analyses by HSU . . . . . . . . . . . . . . 5-23

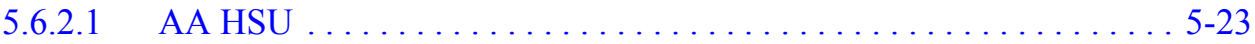

$5.6 .2 .2 \quad$ LCA HSU . . . . . . . . . . . . . . . . . . . . $5-25$

5.6 .2 .3 LCCU HSU ... . . . . . . . . . . . . . . . . . . . . . . 5-27

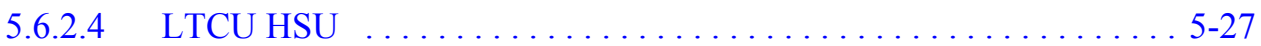

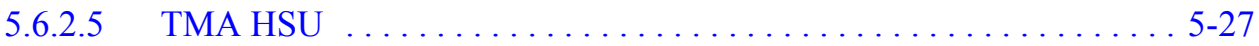

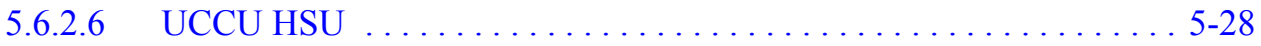

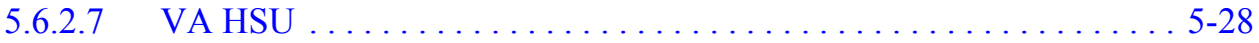

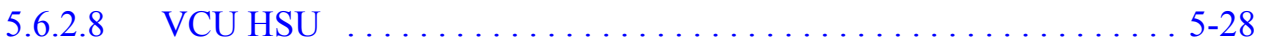

5.6 .3 Test-Scale and Spatial Variability . . . . . . . . . . . . . . . . . . . 5-29

5.6.4 Hydraulic Conductivity Versus Depth................... . 5-30

5.6.5 Aquifer Unit Versus Confining Unit Results . . . . . . . . . . . . . . . . . 5-32

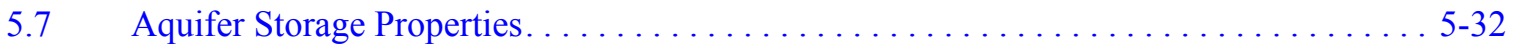

5.8 Temperature Dependence of Hydraulic Conductivity Data. . . . . . . . . . . . . . . . . 5-34

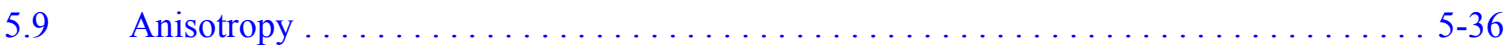

$5.10 \quad$ Limitations . . . . . . . . . . . . .

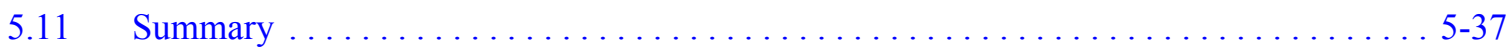

$6.0 \quad$ Precipitation Recharge . . . . . . . . . . . . . . . . . . . . . . . . . . . . . . . . 6-1

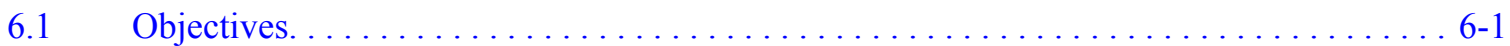

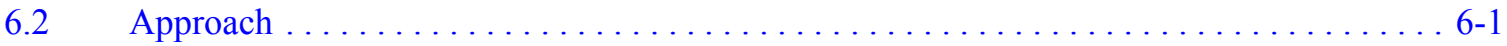

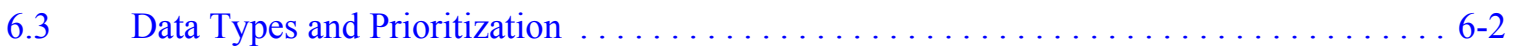

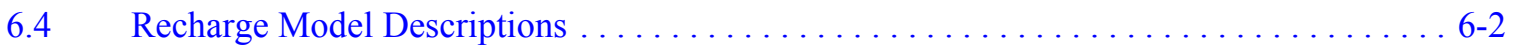

$6.4 .1 \quad$ UGTA Original Recharge Model. ...................... 6-2

6.4.1.1 Maxey and Eakin Method ..................... 6-2

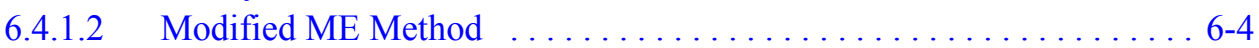

6.4.1.2.1 Methodology.......................6. $6-4$ 


\section{Table of Contents (Continued)}

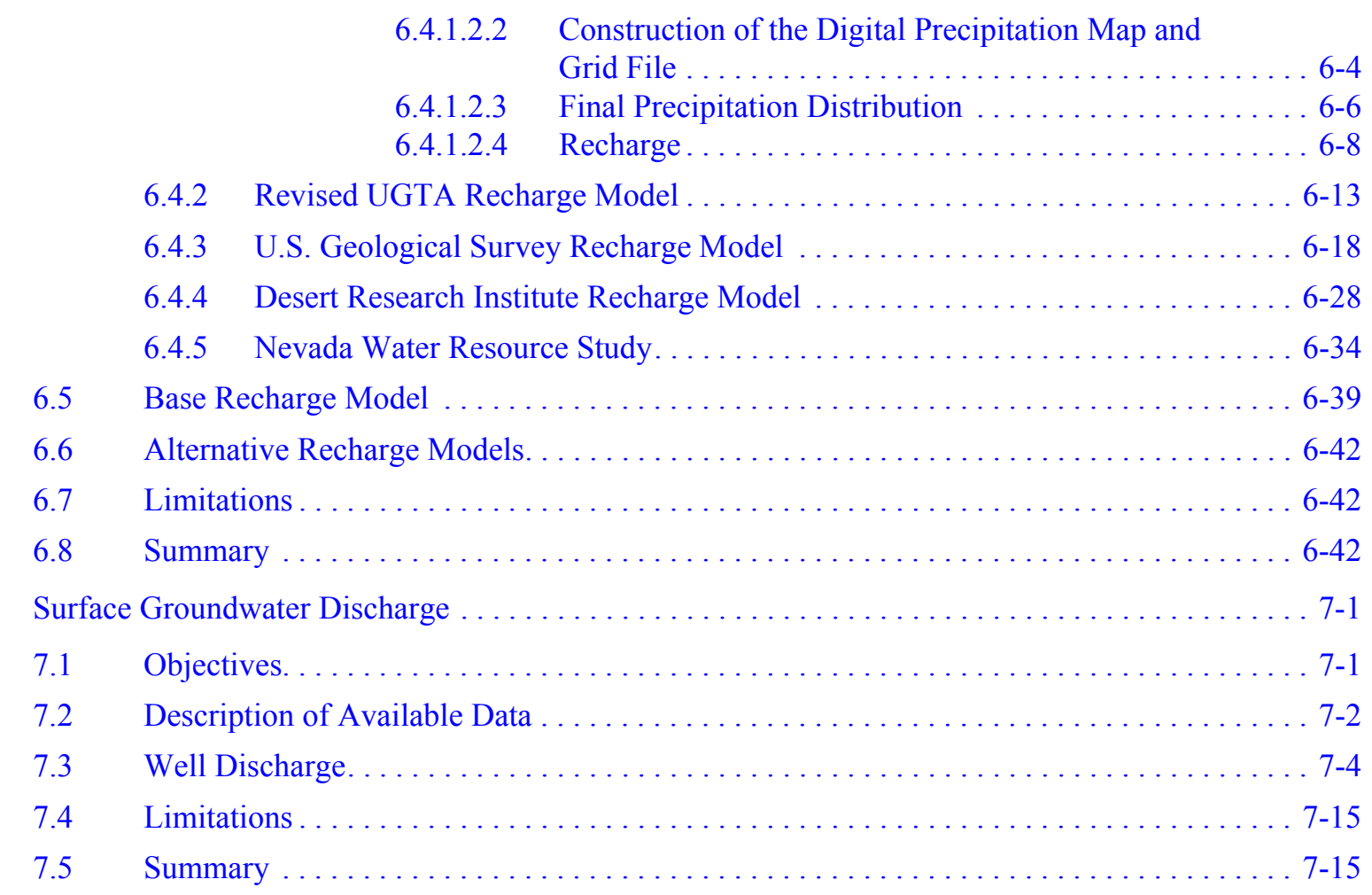

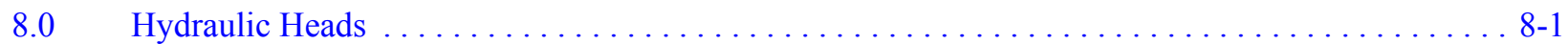

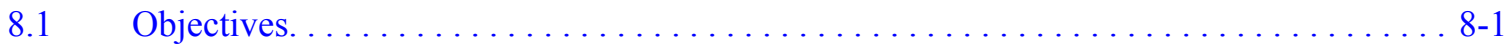

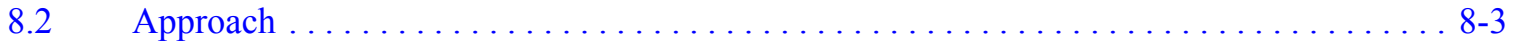

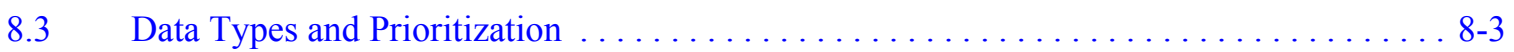

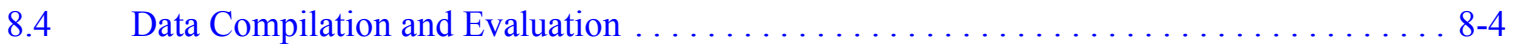

8.4.1 Depth-to-Water Data . . . . . . . . . . . . . . . . . . . . . . . 8 8-4

8.4 .2 General Site Information. . . . . . . . . . . . . . . . . .

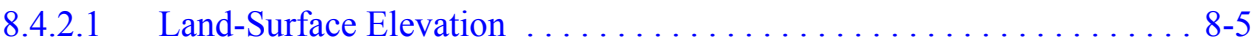

8.4.2.2 Effective Open Interval Definition . . . . . . . . . . . . . 8-5

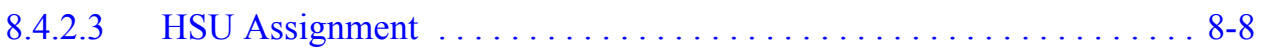

8.5 Water-Level Evaluation Method $\ldots \ldots \ldots \ldots \ldots \ldots \ldots \ldots \ldots \ldots \ldots \ldots \ldots \ldots$

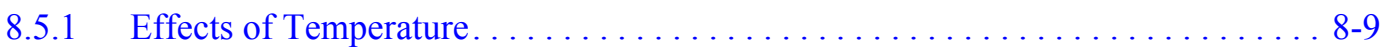

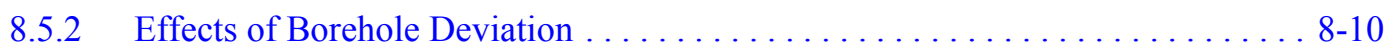

8.6 Steady-State Hydraulic Heads . . . . . . . . . . . . . . . . . . . . . . . . . . . . . . . 8-12

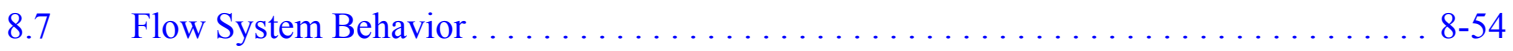

8.7.1 Horizontal Flow Analysis. . . . . . . . . . . . . . . . . . . . . . 8-54

8.7.2 Transient Flow System Behavior . . . . . . . . . . . . . . . . . . . 8-60

8.7.3 Vertical Flow Analysis. . . . . . . . . . . . . . . . . . . 8-64

8.7.3.1 ER-5-3 Well Cluster . . . . . . . . . . . . . . . . . . . . . 8-64 


\section{Table of Contents (Continued)}

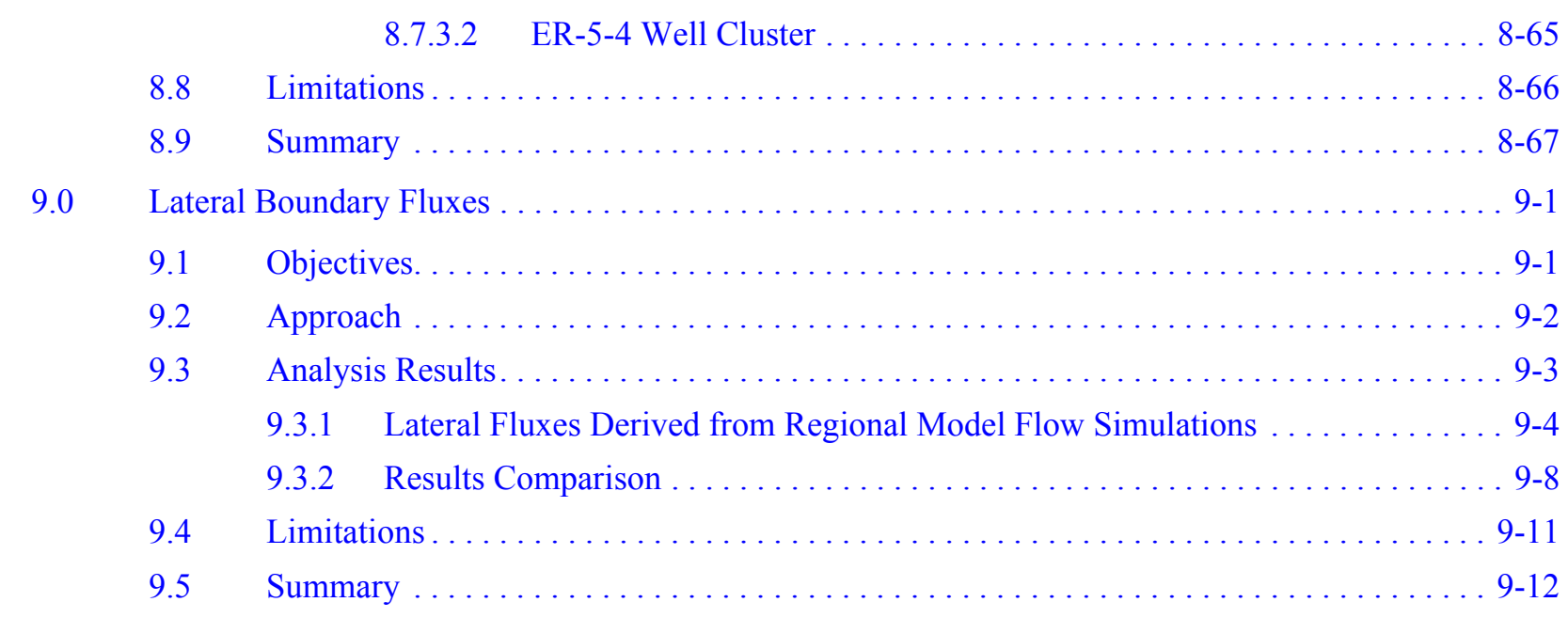

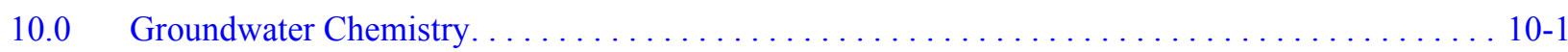

$10.1 \quad$ Objectives. . . . . . . . . . . . . .

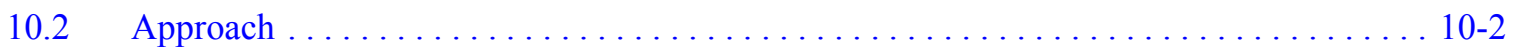

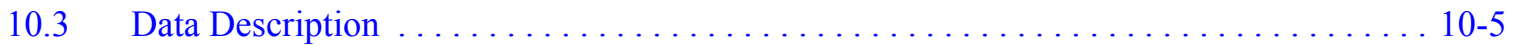

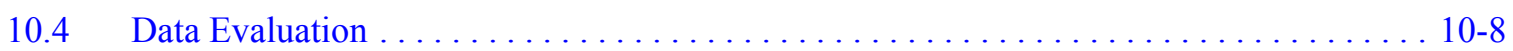

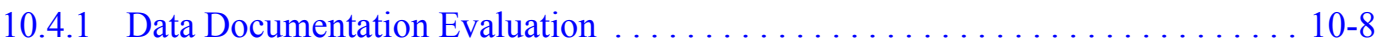

10.4.2 Data Quality Evaluation. . . . . . . . . . . . . . . . . . . . . . . 10-8

10.5 Analysis Process and Results. . . . . . . . . . . . . . . . . . . . . . 10-9

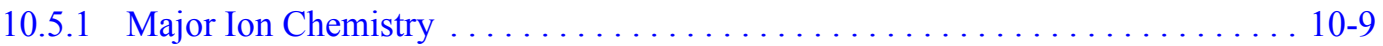

10.5.2 Stable and Environmental Isotopes . . . . . . . . . . . . . . . . . . 10-14

10.5.2.1 Hydrogen and Oxygen Isotopes . . . . . . . . . . . . . . . . 10-15

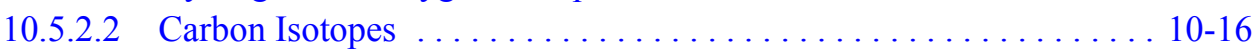

10.5.3 Conservative Tracer Data. . . . . . . . . . . . . . . . . . . . . 10-20

10.5.3.1 Conservative Tracer Evaluation . . . . . . . . . . . . . . 10-21

10.5.3.1.1 North-to-South Flow. . . . . . . . . . . . . . . . . . . . . 10-22

10.5.3.1.2 West-to-East Flow . . . . . . . . . . . . . . . . . . . 10-23

10.5.3.1.3 Bathtub Model ..................... 10-23

10.5.4 Strontium and Strontium Isotope $\left({ }^{87} \mathrm{Sr} /{ }^{86} \mathrm{Sr}\right)$ Evaluation. . . . . . . . . . 10-29

10.5.5 NETPATH Modeling. . . . . . . . . . . . . . . . . . . . . . . . . . 10-33

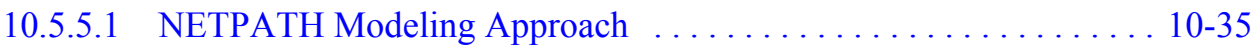

10.5.5.2 NETPATH Geochemical Modeling Results . . . . . . . . . . . 10-36

10.5.5.3 North-to-South Flow . . . . . . . . . . . . . . . . . . . . . . . . . . . 10-39

10.5.5.4 West-to-East Flow . . . . . . . . . . . . . . . . . . . . . 10-40

10.5.5.5 Bathtub Model . . . . . . . . . . . . . . . . . . . . . . . . 10-40

10.6 Limitations . . . . . . . . . . . . . . . . . . . . . . . . . . . . . . . . . . . . 10-41

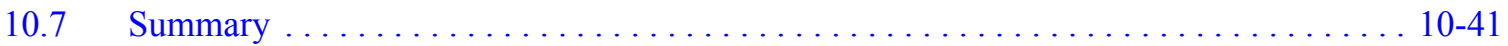




\section{Table of Contents (Continued)}

$11.0 \quad$ References . . . . . . . . . . . . . . . . . . . . . . . . . . . . . . . . . . . 11-1

Appendix A - Hydrostratigraphic Model Supporting Information

A.1.0 Alternative Hydrostratigraphic Models . . . . . . . . . . . . . . . . . . . . . . . A-1

A.2.0 References . . . . . . . . . . . . .

Appendix B - Well Discharge Data

B.1.0 Introduction . . . . . . . . . . . . . . . . . . . . . . . . . . . . . . . . . . B-1

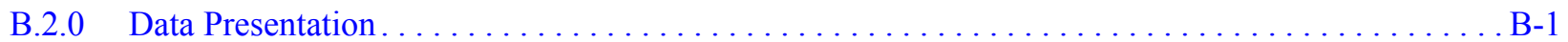

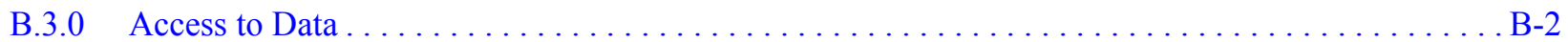

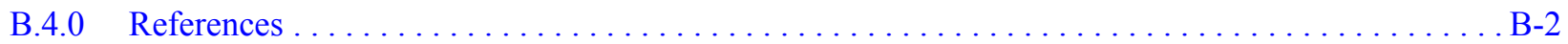

Appendix C - Hydraulic-Head Dataset

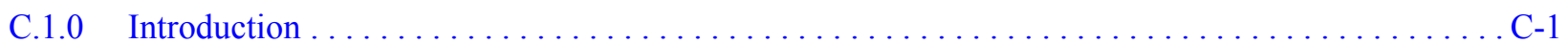

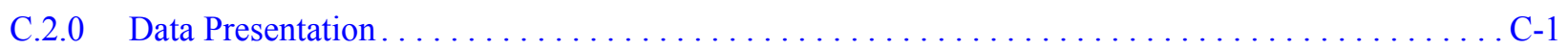

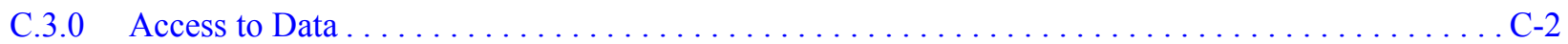

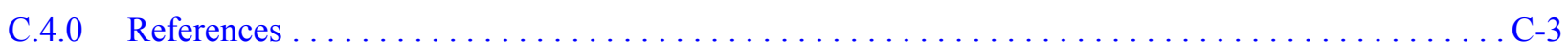

\section{Appendix D - Well Construction Diagrams}

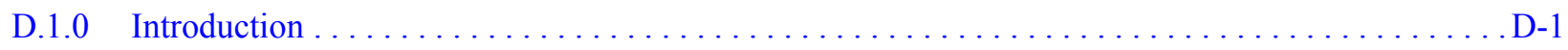

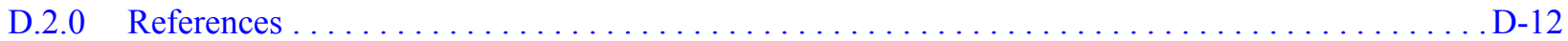

Appendix E - Boundary Flux Calculations

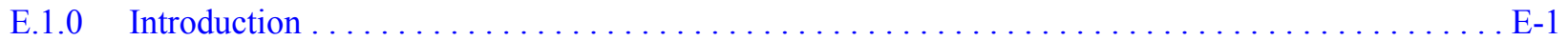

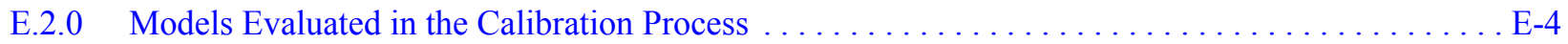

E.2.1 Hydrostratigraphic Model Alternatives . . . . . . . . . . . . . . . . . . . . . . E-4

E.2.2 Recharge Distribution Models . . . . . . . . . . . . . . . . . . . . . . E-4

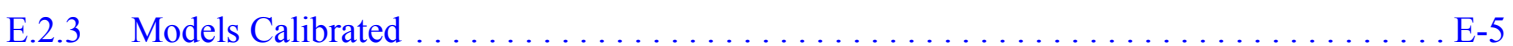

E.3.0 Calibration Process . . . . . . . . . . . . . . . . . . . . . . . . . . . . . . . . . . . E-6

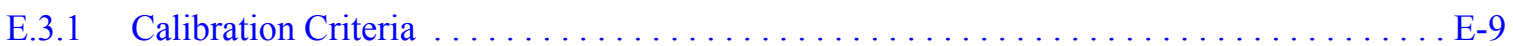

E.4.0 Calibration Results. . . . . . . . . . . . . . . . . . . . . . . . . . . . . . . . . . . . . . E-12

E.5.0 References . . . . . . . . . . . . . . . . . . . . . . . . . . . . . . . . . . . . . . . E-26

Appendix F - Piper and Stiff Diagrams for FF Wells

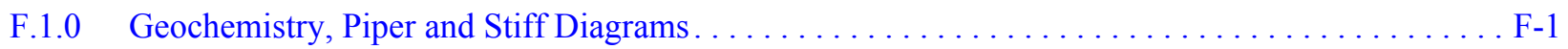

CD Containing this Document and Supporting Datasets $\ldots \ldots \ldots \ldots \ldots \ldots \ldots \ldots \ldots$ Pocket 
Number

1-1 Location of the Frenchman Flat Corrective Action Unit $\ldots \ldots \ldots \ldots \ldots \ldots \ldots \ldots \ldots \ldots$

1-2 Location of Underground Nuclear Tests in Frenchman Flat $\ldots \ldots \ldots \ldots \ldots \ldots \ldots \ldots \ldots$

1-3 Process Flow Diagram for the Underground Test Area Corrective Action Units ..........1-6

1-4 Location of the Frenchman Flat Study Area and Geologic Model Area . . . . . . . . . . . . 1-10

2-1 Features of the Nevada Test Site Regional Groundwater Flow System . . . . . . . . . . . 2-2

2-2 Hydrostratigraphic Unit Surface Map for the Frenchman Flat Model Area. . . . . . . . . . . 2-10

2-3 Hydrostratigraphic Unit Surface Map at the Water Table for the Frenchman Flat Model Area . . . . . . . . . . . . . . . . . . . . . . . . . . . . . . . . . . . .2-16

2-4 3-D Image of Major Fault Structures . . . . . . . . . . . . . . . . . . . . . 2-17

2-5 West to East and Northeast to Southwest Hydrostratigraphic Cross Sections Through the Frenchman Flat Area . . . . . . . . . . . . . . . . . . . . . . . 2-21

2-6 Fence Diagram of Phase II Frenchman Flat Hydrostratigraphic Model Solid Black Spheres Indicate Cavity Locations . . . . . . . . . . . . . . . . 2-22

2-7 Enlarged View of the Central Testing Area on the Frenchman Flat Fence Diagram, Solid Black Spheres Indicate Cavity Locations . . . . . . . . . . . . . . . . . . . 2-23

2-8 Enlarged View of the Northern Testing Area in Frenchman Flat Solid Black Spheres Indicate Cavity Locations . . . . . . . . . . . . . . . . . 2-24

3-1 Data Types and Utilization in the Groundwater Flow Model. . . . . . . . . . . . . . . 3-11

5-1 NTS Investigation Area Locations of Hydraulic Conductivity Data . . . . . . . . . . . . . .5-14

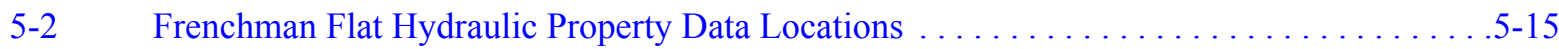

5-3 FF AA Pumping-Scale K Values Probability Distribution. . . . . . . . . . . . . . 5-20

5-4 Frenchman Flat Spatial Variation of K Values for AA HSU . . . . . . . . . . . . . . . . . . .5-21

5-5 Vertical Distribution of FF AA Pumping-Scale K Values . . . . . . . . . . . . . . . .5-22

5-6 FF LCA Pumping-Scale K-Data Distribution . . . . . . . . . . . . . . . . . . . . . .5-22

5-7 FF TM-WTA, TM-LVTA Pumping-Scale K Values Probability Distribution . . . . . . . . . .5-23

5-8 NTS Investigation Area AA Pumping-Scale K Values Probability Distribution. . . . . . . . .5-24

5-9 NTS Investigation Area LCA Pumping-Scale K Values Probability Distribution. . . . . . . . .5-26

5-10 NTS Investigation Area TMA Pumping-Scale K Values Probability Distribution . . . . . . . 5-27

5-11 NTS Investigation Area VA Pumping-Scale K Values Probability Distribution. ........ .5-28

5-12 NTS Investigation Area VCU Pumping-Scale K Values Probability Distribution ........ 5-29

5-13 NTS Investigation Area Log $10 \mathrm{~K}$ Versus Depth...................... $5-31$

5-14 NTS Investigation Area K-Depth Trend. . . . . . . . . . . . . . . . . . . . 5-32 


\section{List of Figures (Continued)}

Number

Title

Page

5-15 NTS Investigation Area Specific Storage Probability Distribution $\ldots \ldots \ldots \ldots \ldots \ldots \ldots .5-33$

5-16 NTS Investigation Area Fracture Specific Storage Probability Distribution . . . . . . . . . . . 5-34

6-1 Precipitation Map for the Nevada Test Site Region Used for the

UGTA Original Recharge Model . . . . . . . . . . . . . . . . . . . . . . . .6-5

6-2 Potential Recharge Redistribution Areas in the Nevada Test Site Region . . . . . . . . . . . 6-12

6-3 NTS Regional Model Recharge Distribution (UGTA Original Recharge Model). ........6-14

6-4 Updated Precipitation Map for the Nevada Test Site Region

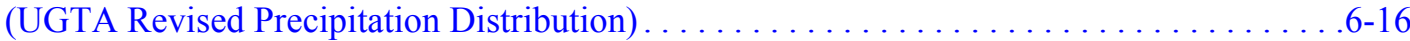

6-5 Revised Maxey and Eakin Based Recharge in the NTS Region

(UGTA Revised Recharge Model) . . . . . . . . . . . . . . . . . . . . . .6-17

6-6 USGS Recharge Distribution Model 1, No Overland Flow . . . . . . . . . . . . . . . . . 6-29

6-7 USGS Recharge Distribution Model 2, Overland Flow . . . . . . . . . . . . . . . . 6-30

6-8 Relationship between UGTA Revised ME Recharge Rate and DRI Models. . . . . . . . . . 6-35

6-9 DRI Recharge Distribution with Alluvial Mask ......................6.

6-10 DRI Recharge Distribution with Alluvial and Elevation Mask . . . . . . . . . . . . . 6-38

6-11 Recharge Rate for all Recharge Models and all HAs . . . . . . . . . . . . . . . . .6-40

7-1 Location of Groundwater Pumping Wells in the Frenchman Flat Area and Vicinity . . . . . . 7-3

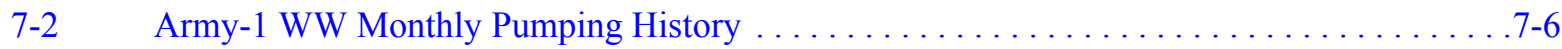

7-3 RNM-2S Monthly Pumping History. . . . . . . . . . . . . . . . . . . . .

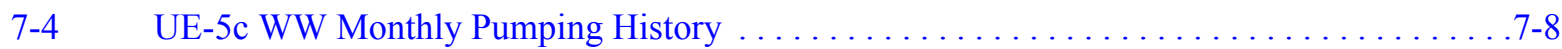

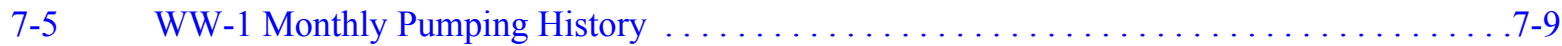

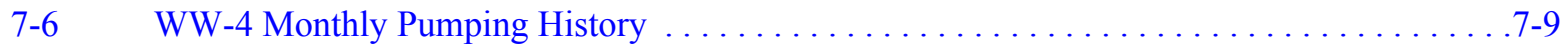

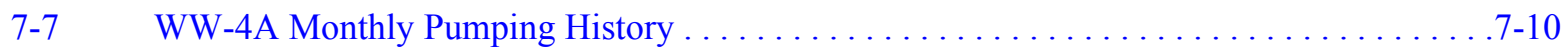

7-8 WW-5A Monthly Pumping History . . . . . . . . . . . . . . . . . . . . . . . 7-11

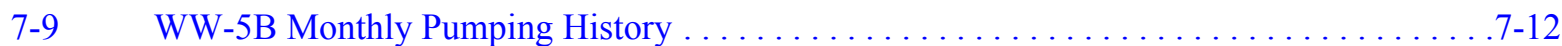

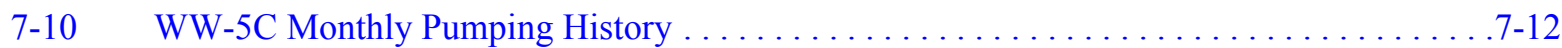

7-11 WW-C Monthly Pumping History . . . . . . . . . . . . . . . . . . . . . . . . . . . 7-13

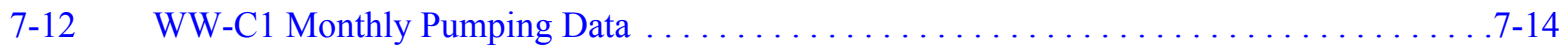

7-13 Total Water Withdrawal from Wells in the Frenchman Flat Area and Vicinity . . . . . . . .7-14

8-1 Location of Wells in the Frenchman Flat Area and Vicinity $\ldots \ldots \ldots \ldots \ldots \ldots \ldots \ldots .2$ 


\section{List of Figures (Continued)}

Number

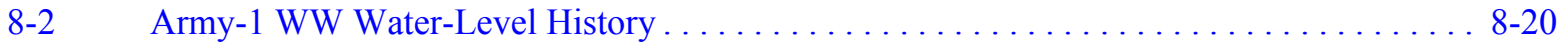

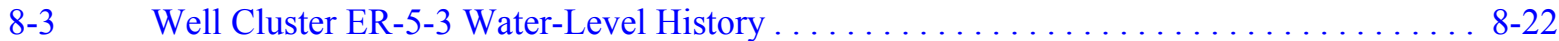

8-4 Well ER-5-3 (Shallow Piezometer) Water-Level History $\ldots \ldots \ldots \ldots \ldots \ldots \ldots \ldots \ldots$. 8 $_{23}$

8-5 Well ER-5-3 (Deep Piezometer) Water-Level History. . . . . . . . . . . . . . . . 8-24

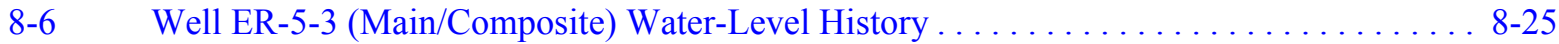

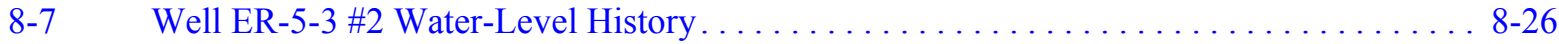

8-8 Well ER 5-3 \#3 Water-Level History . . . . . . . . . . . . . . . . . . . . . 8-27

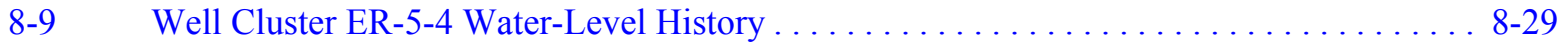

8-10 Well ER-5-4 (Piezometer) Water-Level History $\ldots \ldots \ldots \ldots \ldots \ldots \ldots \ldots \ldots \ldots \ldots . . \ldots \ldots$

8-11 Well ER-5-4 (Main/Composite) Water-Level History . . . . . . . . . . . . . . . . 8-31

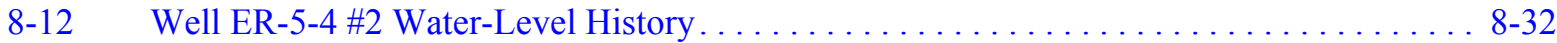

8-13 Well RNM-1 Water-Level History . . . . . . . . . . . . . . . . . . . . . 8 8-34

8-14 Well RNM-2 Water-Level History $\ldots \ldots \ldots \ldots \ldots \ldots \ldots \ldots \ldots \ldots \ldots \ldots \ldots . . \ldots \ldots \ldots$

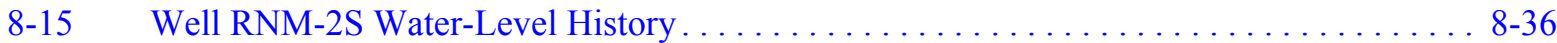

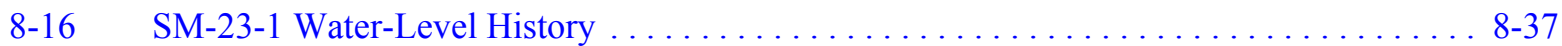

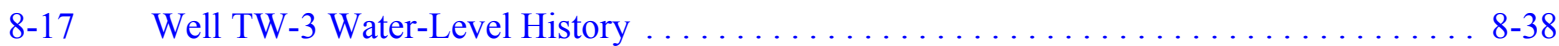

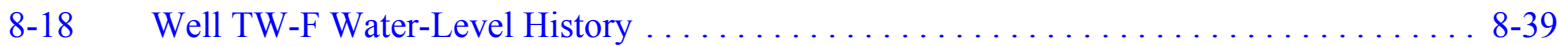

8-19 Well UE-11a Water-Level History . . . . . . . . . . . . . . . . . . . . 8 8-39

8-20 Well UE-11b Water-Level History . . . . . . . . . . . . . . . . . . . . . . . . . . . . . . 8 8-40

8-21 Well UE-5 PW-1 Water-Level History. . . . . . . . . . . . . . . . . . . . . . . . . . 8-41

8-22 Well UE-5 PW-2 Water-Level History. . . . . . . . . . . . . . . . . . . . . . . . . . 8 8-42

8-23 Well UE-5 PW-3 Water-Level History. . . . . . . . . . . . . . . . . . . . . . . . 8-43

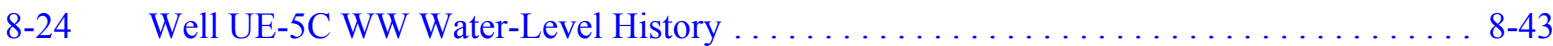

8-25 Well UE-5n Water-Level History . . . . . . . . . . . . . . . . . . . . . . . . . 8-46

8-26 WW-4 Water-Level History . . . . . . . . . . . . . . . . . . . . . . . . . 8 8-47

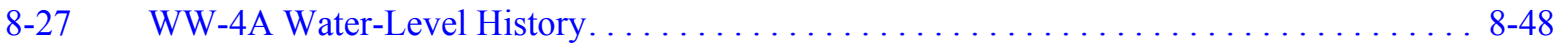

$8-28 \quad$ WW-5A Water-Level History. . . . . . . . . . . . . . . . . . . . . . . 8-49

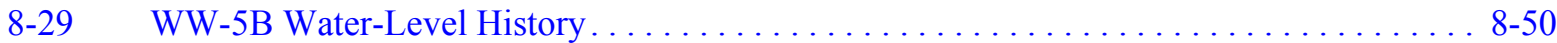

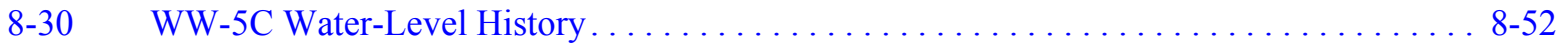

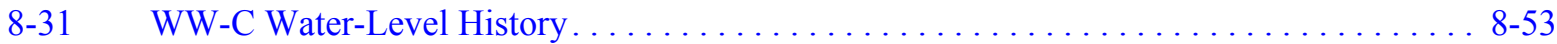

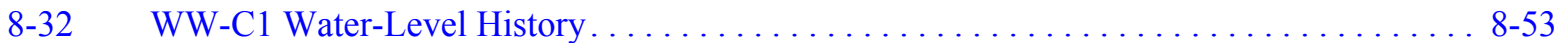




\section{List of Figures (Continued)}

Number

8-33 Post of Historical, Steady-State Heads in the AA

8-34 Post of Contemporary, Steady-State Heads in the AA

8-35 Post of Head Differences in the AA

8-36 Post of Contemporary, Steady-State Heads in the TM-WTA.

8-37

$8-38$

9-1

$10-1$

$10-2$

$10-3$

$10-4$

$10-5$

$10-6$

$10-7$

$10-8$

$10-9$

$10-10$

D.1-1

D. $1-2$

D. $1-3$

D. $1-4$

D. $1-5$

D.1-6

D.1-7

Piper Diagram Showing Percent Milliequivalents per Liter of Major Ions in

Stable Isotopic Plot of $\delta^{18} \mathrm{O}$ vs. $\delta \mathrm{D}$ Values for Springs and Wells Within

Plot of $\delta^{13} \mathrm{C}$ vs. ${ }^{14} \mathrm{C}$ Values for Springs and Wells Within the

Plot of $\delta^{18} \mathrm{O}$ vs. $\mathrm{Cl}$ Values for Springs and Wells Within the

Plot of $\delta \mathrm{D}$ vs. $\mathrm{Cl}$ Values for Springs and Wells Within the

Vicinity Showing One Possible Three Component Mixing Model to Explain

Concentrations of $\mathrm{Sr}$ and $\mathrm{Ca}$ in Selected Groundwater Samples in the

${ }^{87} \mathrm{Sr} /{ }^{86} \mathrm{Sr}$ Ratios and Sr Concentrations for Selected Water Samples in the
Title

Page

Post of Historical, Steady-State Heads in the LCA . . . . . . . . . . . . . . . . 8-61

Post of Contemporary, Steady-State Heads in the LCA . . . . . . . . . . . . . . 8-62

Geologic and Proposed CAU Model Boundaries........................ 9-13

Groundwater Quality Sample Locations. . . . . . . . . . . . . . . . . . . 10-6

Groundwaters of Frenchman Flat and the Vicinity. . . . . . . . . . . . . . . . 10-11

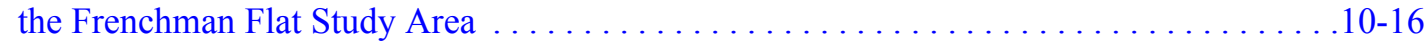

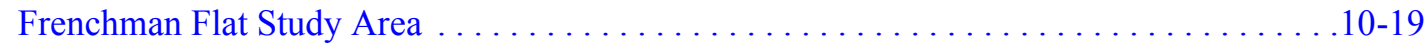

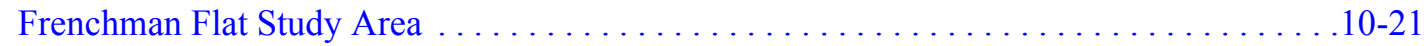

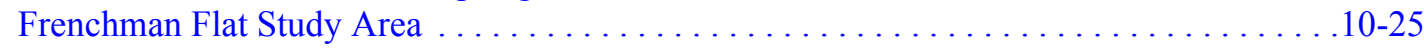

Plot of Cl vs. $\delta \mathrm{D}$ Values for Groundwater Samples From Frenchman Flat and

the Observed Groundwater Composition of Army \#1 WW . . . . . . . . . . . . . 10-26

Plot of ${ }^{36} \mathrm{Cl} / \mathrm{Cl}$ vs. $\mathrm{Cl}$ for Groundwater Samples From Frenchman Flat and Vicinity . . . . . 10-28

Frenchman Flat Vicinity . . . . . . . . . . . . . . . . . . . . . . 10-30

Frenchman Flat Vicinity . . . . . . . . . . . . . . . . . . . . . . . . . . . . 10-32

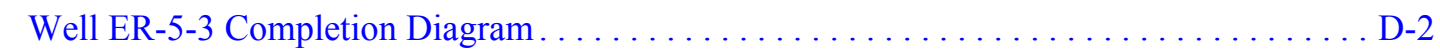

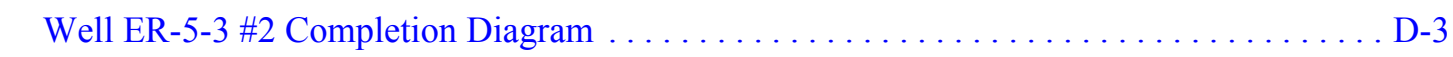

Well ER-5-3 \#3 Completion Diagram $\ldots \ldots \ldots \ldots \ldots \ldots \ldots \ldots \ldots \ldots \ldots \ldots \ldots \ldots \ldots \ldots \ldots \ldots \ldots \ldots \ldots$

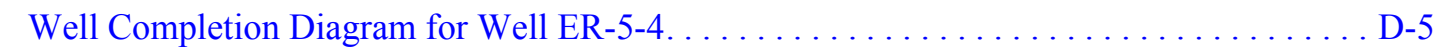

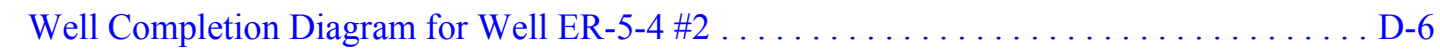

Well Completion Diagram for Well RNM-1 $\ldots \ldots \ldots \ldots \ldots \ldots \ldots \ldots \ldots \ldots \ldots \ldots \ldots \ldots$

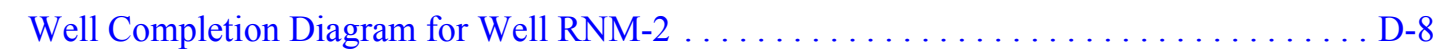




\section{List of Figures (Continued)}

Number

D.1-8 Well Completion Diagram for Well RNM-2S $\ldots \ldots \ldots \ldots \ldots \ldots \ldots \ldots \ldots \ldots \ldots \ldots \ldots$

D.1-9 Well Completion Diagram for Wells WW4 and WW-4A $\ldots \ldots \ldots \ldots \ldots \ldots \ldots \ldots$ D-10

D.1-10 Well Completion Diagrams for Wells WW-5A, WW-5B, and WW-5C . . . . . . . . D-11

E.1-1 Geologic and Proposed CAU Model Boundaries . . . . . . . . . . . . . . . . . . E-2

E.3-1 Property Zone Maps for Frenchman Flat HSUs $\ldots \ldots \ldots \ldots \ldots \ldots \ldots \ldots \ldots \ldots \ldots \ldots$

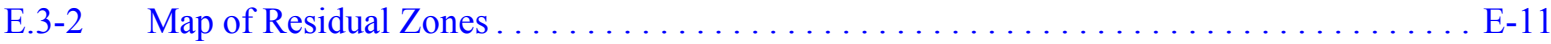

E.4-1 GOR1 Water Table Contours on Topographic Relief Base Map . . . . . . . . . . . . . . . E-17

E.4-2 Water Table Contours ( $\mathrm{m}$ amsl) for Regional Groundwater Flow Model G0R1 . . . . . . . E-18

E.4-3 Water Table Contours (m amsl) for Regional Groundwater Flow Model G0R2 . . . . . . . E-19

E.4-4 Water Table Contours ( $\mathrm{m}$ amsl) for Regional Groundwater Flow Model G0R3 . . . . . . . . E-20

E.4-5 Water Table Contours ( $\mathrm{m}$ amsl) for Regional Groundwater Flow Model G0R4 . . . . . . . E-21

E.4-6 Water Table Contours ( $\mathrm{m}$ amsl) for Regional Groundwater Flow Model G0R5 . . . . . . . E-22

E.4-7 Water Table Contours (m amsl) for Regional Groundwater Flow Model G0R6 . . . . . . . E-23

F.1-1 Piper Diagram for Army \#1 WW (Top) and ER-5-3\#2 (Bottom)

(Solid marker identifies the sample used for geochemical modeling) . . . . . . . . . . F-2

F.1-2 Piper Diagram for Well WW-C (Top) and WW-C1 (Bottom)

(Solid marker identifies the sample used for geochemical modeling) . . . . . . . . . F-3

F.1-3 Piper Diagram for Well TW-3 (Top) and TW-F (Bottom)

(Solid marker identifies the sample used for geochemical modeling) . . . . . . . . . F-4

F.1-4 Piper Diagram for UE-5 PW-1 (Top) and UE-5 PW-2 (Bottom)

(Solid marker identifies the sample used for geochemical modeling) . . . . . . . . . . F-5

F.1-5 Piper Diagram for ER-5-4 (Top) and WW-5a (Bottom)

(Solid marker identifies the sample used for geochemical modeling) . . . . . . . . . . F-6

F.1-6 Piper Diagram for WW-5b (Top) and WW-5c (Bottom)

(Solid marker identifies the sample used for geochemical modeling) . . . . . . . . . F-7

F.1-7 Piper Diagram for WW-1 (Top) and UE-5n (Bottom)

(Solid marker identifies the sample used for geochemical modeling) $\ldots \ldots \ldots \ldots \ldots$. . 8

F.1-8 Piper Diagram for RNM-1 (Top) and RNM-2S (Bottom) . . . . . . . . . . . . . . . F-9

F.1-9 Piper Diagram for ER-5-4 \#2 (Top) and UE-5 PW-3 (Bottom)

(Solid marker identified the sample used for geochemical modeling) . . . . . . . . . . . . F-10

F.1-10 Piper Diagram for Well WW-4 (Top) and WW-4a (Bottom)

(Solid marker identifies the sample used for geochemical modeling) . . . . . . . . . F-11

F.1-11 Piper Diagram for ER-5-3 (Top) and UE-11a (Bottom)

(Solid marker identifies the sample used for geochemical modeling) . . . . . . . . . F-12 


\section{List of Figures (Continued)}

Number

F.1-12 Piper Diagram for UE-5c WW (Solid marker identifies the sample used for

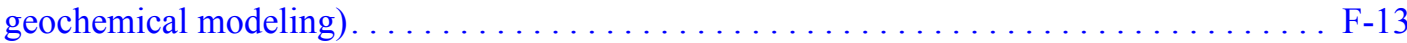

F.1-13 Stiff Diagrams Based on Representative Concentrations

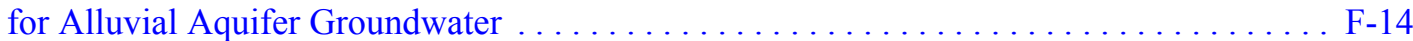

F.1-14 Stiff Diagrams Based on Representative Concentrations for Groundwater of the Volcanic HSUs . . . . . . . . . . . . . . . . . . . . . . . . . . . . F-15

F.1-15 Stiff Diagrams Based on Representative Concentrations for Carbonate Aquifer Groundwater. . . . . . . . . . . . . . . . . . . . . . F-16 


\section{List of Tables}

Number

Title

Page

1-1 Corrective Action Sites in the Frenchman Flat Corrective Action Unit. . . . . . . . . . . . . . 1-4

1-2 Summary of Lessons Learned from the Frenchman Flat CAU Model Related to Data Analysis . . . . . . . . . . . . . . . . . . . . . . . . . . . . . . . . . 1-8

2-1 Hydrogeologic Units of the NTS Regional Model That Occur in the Frenchman Flat Model Area .........................................

2-2 Hydrostratigraphic Units of the Frenchman Flat Area Included in the NTS Regional Hydrostratigraphic Framework Model . . . . . . . . . . . . . . . . . . 2-6

2-3 Hydrostratigraphic Units of the Frenchman Flat Hydrostratigraphic Framework Model . . . . 2-19

2-4 Correlation of Hydrostratigraphic Units of the Frenchman Flat Model and Earlier Models . . 2-20

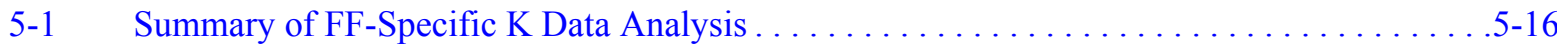

5-2 Summary of NTS Investigation Area K Data Analysis . . . . . . . . . . . . . . . . . . . . .5-17

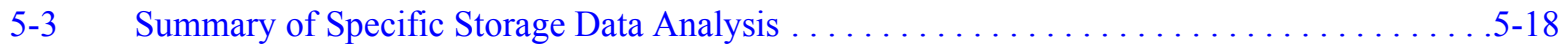

5-4 Summary of Frenchman Flat HSU Assigned Hydraulic Properties . . . . . . . . . . . . . . .5-19

5-5 F-Test, T-Test, and K-S Test Comparison of Pumping-Scale AA K Distributions for the FF and NTS Investigation Area. . . . . . . . . . . . . . . . $5-25$

5-6 F-Test and T-Test Comparison of Pumping-Scale LCA K Distributions for the FF and NTS Investigation Area $\ldots \ldots \ldots \ldots \ldots \ldots \ldots \ldots \ldots \ldots \ldots \ldots \ldots \ldots \ldots \ldots \ldots \ldots \ldots . .26$

5-7 Variation of the Mean and Standard Deviation of K Data by Scale of Measurements,

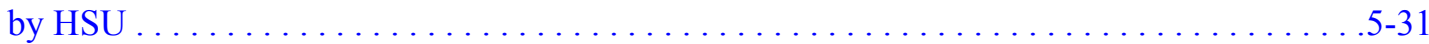

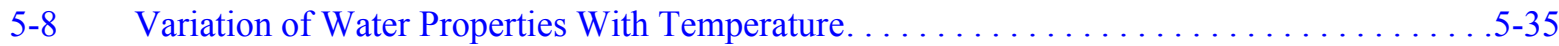

6-1 Precipitation Station Data Used for UGTA Original Recharge Model . . . . . . . . . . . . . .6-7

6-2 Comparison of Precipitation Rates to Published Values by Hydrographic Area . . . . . . . . . . .6-9

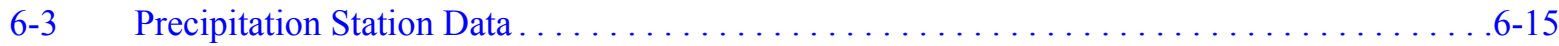

6-4 INFILv3 Input Parameters (as reported by Hevesi et al., 2003) . . . . . . . . . . . .6-22

6-5 Scaled DRI Recharge Rates Using UGTA Revised Maxey and Eakin Model. . . . . . . . . . .6-36

6-6 Recharge Rates for HAs for all Recharge Models . . . . . . . . . . . . . . . . . . . . . . .6-41

7-1 Summary of Pumping Data for Wells in Frenchman Flat and Selected Wells in CP Basin and Southern Yucca Flat. . . . . . . . . . . . . . . . . . 7-4

7-2 Site Information for Pumping Wells Located in the Frenchman Flat Area and Vicinity. . . . . .7-5

7-3 Pump Shut-Down Dates for RNM-2S During the CME $\ldots \ldots \ldots \ldots \ldots \ldots \ldots \ldots \ldots . . .7 .7$

8-1 Site Information for Selected Wells and Boreholes Located in the Frenchman Flat Area

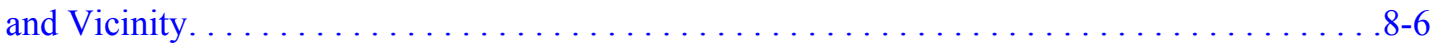

8-2 Equations Used to Adjust Measured Depth to Water for Borehole Deviation (after Bright et al., 2001) . . . . . . . . . . . . . . . . . . . . . . . . . . . .8-11

8-3 Summary of Hydraulic Heads at Sites with the Frenchman Flat Area and Vicinity . . . . . . . 8-14

8-4 Summary of Uncertainty in Estimated Steady-State Head . . . . . . . . . . . . . . . . . 8-17 


\section{List of Tables (Continued)}

Number

8-5 Vertical Hydraulic Heads at the ER 5-3 Well Cluster ......................... 8-64

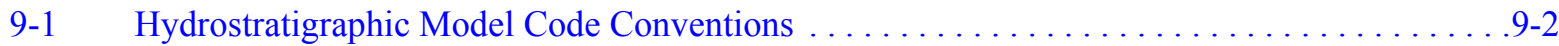

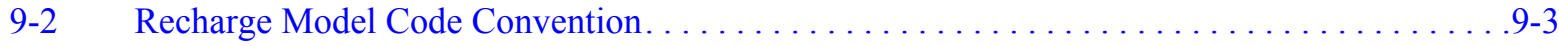

9-3 Regional Model Inflows $\left(\mathrm{m}^{3} / \mathrm{d}\right)$ at Geologic Model Boundaries . . . . . . . . . . . . . 9-5

9-4 Regional Model Outflows $\left(\mathrm{m}^{3} / \mathrm{d}\right)$ at Geologic Model Boundaries . . . . . . . . . . . . . . . . . . . . 9-6

9-5 Total Water Balance $\left(\mathrm{m}^{3} / \mathrm{d}\right)$ for the Geologic Model Boundaries . . . . . . . . . . . . . . . .9-7

9-6 Regional Model Inflows $\left(\mathrm{m}^{3} / \mathrm{d}\right)$ for UGTA Original Recharge Model $\ldots \ldots \ldots \ldots \ldots \ldots . .9-8$

9-7 Regional Model Outflows $\left(\mathrm{m}^{3} / \mathrm{d}\right)$ for UGTA Original Recharge Model . . . . . . . . . . . . . 9-8

9-8 Total Water Balance $\left(\mathrm{m}^{3} / \mathrm{d}\right)$ for Various HSU Models with UGTA

Original Recharge Model . . . . . . . . . . . . . . . . . . . . . . . . . . . . 9-9

9-9 Inflow and Outflow Differences between Base and Alternative HSU Models with UGTA Original Recharge Model . . . . . . . . . . . . . . . . . . . . . . . . . . . . . .9-9

9-10 Regional Model Inflows $\left(\mathrm{m}^{3} / \mathrm{d}\right)$ for Base HSU Model . . . . . . . . . . . . . . . . . . . . 9-9

9-11 Regional Model Outflows $\left(\mathrm{m}^{3} / \mathrm{d}\right)$ for Base HSU Model $\ldots \ldots \ldots \ldots \ldots \ldots \ldots \ldots \ldots . \ldots \ldots$

9-12 Total Water Balance $\left(\mathrm{m}^{3} / \mathrm{d}\right)$ for Various Recharge Models for Base HSU Model. . . . . . . . . 9-10

9-13 Inflow and Outflow Differences from UGTA Original Recharge for Base HSU Model . . . . . . . . . . . . . . . . . . . . . . . . . . . . . . . . 9-10

9-14 Summary of Net Boundary Flux Ranges $\left(\mathrm{m}^{3} / \mathrm{d}\right)$ for HSU Model Boundaries . . . . . . . . . . .9-12

9-15 Summary of Net Boundary Flux Ranges $\left(\mathrm{m}^{3} / \mathrm{d}\right)$ for Proposed CAU-Model Boundaries. . . . . 99-12

10-1 Summary of Groundwater Quality Data Parameters from Wells in and Around the FF CAU. . . . . . . . . . . . . . . . . . . . . . . . . . . . . . . . . . . . . . . . . 10-3

10-2 Carbon Isotope Data for Frenchman Flat Wells . . . . . . . . . . . . . . . . . 10-18

10-3 $\mathrm{DO}^{14} \mathrm{C}$ Calculated Groundwater Ages. . . . . . . . . . . . . . . . . . . . . . 10-20

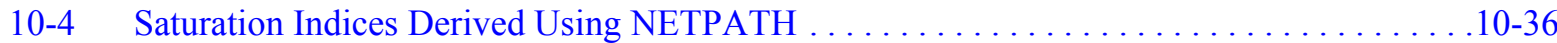

10-5 Summary of Conservative Mixing and NETPATH Geochemical Models. . . . . . . . . . . . . 10-37

A.1-1 Abridged List of Alternative Scenarios for the Frenchman Flat 3-D

Hydrostratigraphic Model. . . . . . . . . . . . . . . . . . . . . . . . . . . . . . . . . . A A-2

E.1-1 Model Layer Elevations and Thickness . . . . . . . . . . . . . . . . . . . . . . . . . . E-3

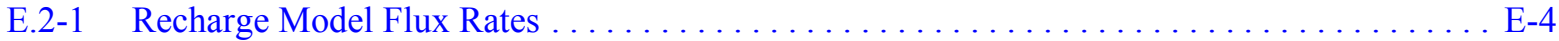

E.2-2 Model Designations for the 30 Combinations of Hydrostratigraphic and Recharge Models . . . . . . . . . . . . . . . . . . . . . . . . . . . . . . . . E-5

E.3-1 Vertical Anisotropy Factors and Depth Decay Coefficients for Frenchman Flat HSUs . . . . . E-7

E.3-2 Calibration Criteria for Weighted Hydraulic Head Residuals by Zone. . . . . . . . . . . . . E-10

E.3-3 Calibration Target Range for Model-Area Discharge . . . . . . . . . . . . . . . . . . . E-10

E.4-1 Root Mean Square (m) of Weighted Residuals for Individual Residual Zones and Combined Zones . . . . . . . . . . . . . . . . . . . . . . . . . . E-13 


\section{List of Tables (Continued)}

Number

Title

Page

E.4-2 Mean Weighted Residuals (m) for Individual Residual Zones and Combined Zones . . . . . . E-14

E.4-3 Residuals $(\mathrm{m})$ in Frenchman Flat Alluvium Wells . . . . . . . . . . . . . . . . . . . . . . . E-15

E.4-4 Simulated Discharge Rates $\left(\mathrm{m}^{3} / \mathrm{d}\right)$ at Discharge Calibration Zones. . . . . . . . . . . . . . . . E-16

E.4-5 Calibrated Horizontal Hydraulic Conductivity $(\mathrm{m} / \mathrm{d})$ at Land Surface $\left(\mathrm{K}_{0}\right)$

for Frenchman Flat HSUs . . . . . . . . . . . . . . . . . . . . . . . . . . . . E-25 


\section{Acknowledgement}

We thank the many individuals who assisted us in creating this report. In particular, the SNJV team acknowledges Sig Drellack and Lance Prothero of Bechtel Nevada for their technical assistance with the geologic model; Jim Thomas of DRI, Tim Rose of LLNL, J. Paces of USGS and Chris Benedict for their technical assistance with the geochemistry; and Tammy Diaz, David Rojas, Sharen Hicks, and Lisa May for their assistance in creating the maps and drawings. We greatly appreciate the efforts of Yvonne Lewis who was instrumental in preparing this document for publication, and Matt Klainer and Carrye Putz for their editing support. We also thank the following individuals for their contributions: Jim Watrus, Syl Hersh, Toni Miller, Chris Miller, and Afief Fadil. 


\section{List of Acronyms and Abbreviations}

$\mathrm{A} \& \mathrm{E}$

AA

amsl

ASTM

$\mathrm{BD}$

BLFA

$\mathrm{BN}$

BOA

BRD

BWSD

BWZ

C

$\mathrm{Ca}$

$\mathrm{CA}$

CADD

CAI

CAIP

CAP

CAS

CAU

CD

cdf

cfd

$\mathrm{Cl}$

$\mathrm{cm}$

CME

$\mathrm{CO}_{2}$

$\mathrm{CO}_{3}$

$\mathrm{CR}$

$\mathrm{CV}$

$\mathrm{D}$

DDE_F
Architect and Engineer

Alluvial Aquifer

Above mean sea level

American Society for Testing and Materials

Borehole depth

Basalt Lava Flow Aquifer

Bechtel Nevada

Base of Alluvium

Biological Resources Division

Beatty Water and Sanitation District

Base of Welded Zone

Carbon

Calcium

Carbonate Aquifer

Corrective Action Decision Document

Corrective Action Investigation

Corrective Action Investigation Plan

Corrective Action Plan

Corrective Action Site

Corrective Action Unit

Compact disk

Cumulative distribution function

Cumulative frequency distribution

Chlorine

Centimeters

Cambric Migration Experiment

Carbon dioxide

Carbonate

Closure Report

Coefficient of variability

Deuterium

Data documentation evaluation flags 


\begin{tabular}{|c|c|}
\hline DEM & Digital Elevation Model \\
\hline DIC & Dissolved inorganic carbon \\
\hline DOC & Dissolved organic carbon \\
\hline DoD & U.S. Department of Defense \\
\hline DOE & U.S. Department Energy \\
\hline $\mathrm{DOE} / \mathrm{NV}$ & U.S. Department of Energy, Nevada Operations Office \\
\hline DPWM & Distributed parameter watershed model \\
\hline DQE_F & Data quality evaluation flags \\
\hline DRI & Desert Research Institute \\
\hline ecdf & Empirical distribution function \\
\hline EMI & Electrical Micro Imager \\
\hline EOI & Effective open interval \\
\hline EPA & U.S. Environmental Protection Agency \\
\hline ET & Evapotranspiration \\
\hline $\mathrm{F} \& \mathrm{~S}$ & Fenix \& Scisson \\
\hline FEHM & Finite-element heat mass transfer code \\
\hline FF & Frenchman Flat \\
\hline FFACO & Federal Facility Agreement and Consent Order \\
\hline $\mathrm{ft}$ & Foot (feet) \\
\hline FY & Fiscal year \\
\hline GAP & Gap Analysis Program \\
\hline GIS & Geographical Information System \\
\hline GMWL & Global Meteoric Water Line \\
\hline $\mathrm{H}$ & Hydrogen \\
\hline HA & Hydrographic Area \\
\hline${ }^{3} \mathrm{H}$ & Tritium \\
\hline $\mathrm{HCO}_{3}$ & Bicarbonate \\
\hline $\mathrm{HGU}$ & Hydrogeologic unit \\
\hline HSU & Hydrostratigraphic Unit \\
\hline ICU & Intrusive Confining Unit \\
\hline in. & Inch \\
\hline $\mathrm{K}$ & Hydraulic conductivity \\
\hline $\mathrm{k}$ & Intrisic permeability \\
\hline
\end{tabular}




\begin{tabular}{|c|c|}
\hline $\mathrm{km}$ & Kilometer \\
\hline $\mathrm{km}^{2}$ & Square kilometer \\
\hline $\mathrm{K}^{+}$ & Potassium ion \\
\hline K-S & Kolmogorov-Smirnov \\
\hline $\mathrm{kt}$ & Kiloton \\
\hline LaGriT & Los Alamos Grid Toolbox \\
\hline LANL & Los Alamos National Laboratory \\
\hline LCA & Lower Carbonate Aquifer \\
\hline LCCU & Lower Carbonate Confining Unit \\
\hline LTCU & Lower Tuff Confining Unit \\
\hline LFA & Lava flow aquifer \\
\hline LLNL & Lawrence Livermore National Laboratory \\
\hline LVTA & Lower Vitric Tuff Aquifer \\
\hline $\mathrm{m}$ & Meter \\
\hline $\mathrm{M} \& \mathrm{O}$ & Management and Operating \\
\hline ME & Maxey-Eakin \\
\hline $\mathrm{m}^{3} / \mathrm{d}$ & Cubic meters per day \\
\hline $\mathrm{Mg}$ & Magnesium \\
\hline $\mathrm{mg} / \mathrm{L}$ & Milligram per liter \\
\hline $\mathrm{mi}$ & Mile \\
\hline $\mathrm{mi}^{2}$ & Square miles \\
\hline mil & Parts per thousand \\
\hline $\mathrm{mm}$ & Millimeters \\
\hline MT & Magnetotelluric \\
\hline MWAT & Multi-Well Aquifer Test \\
\hline $\mathrm{Na}$ & Sodium \\
\hline NDEP & Nevada Division of Environmental Protection \\
\hline NNSA/NSO & U.S. Department of Energy, National Nuclear Security Administration Nevada Site Office \\
\hline NTS & Nevada Test Site \\
\hline NWIS & National Water Information System \\
\hline $\mathrm{O}$ & Oxygen \\
\hline $\mathrm{pCi} / \mathrm{L}$ & Picocurie per liter \\
\hline PCM & Paintbrush Composite Unit \\
\hline
\end{tabular}




\begin{tabular}{|c|c|}
\hline PCU & Playa Confining Unit \\
\hline PDF & Probability density function \\
\hline PEST & Parameter Estimation \\
\hline pmc & Percent modern carbon \\
\hline PRISM & Parameter-Elevation Regressions on Independent Slopes Model \\
\hline psi & Pounds per square inch \\
\hline $\mathrm{Pz}$ & Paleozoic-age sedimentary rocks \\
\hline QA & Quality assurance \\
\hline QAPP & Quality assurance project plan \\
\hline REECo & Reynolds Electrical \& Engineering Co., Inc. \\
\hline RMS & Root mean square \\
\hline RWMS & Radioactive Waste Management Site \\
\hline S & Storage coefficient \\
\hline SENSAN & Sensitivity Analysis \\
\hline $\mathrm{SiO}_{2}$ & Silicon dioxide \\
\hline $\mathrm{SO}_{4}$ & Sulfate \\
\hline SNJV & Stoller-Navarro Joint Venture \\
\hline $\mathrm{Sr}$ & Strontium \\
\hline $\mathrm{S}_{\mathrm{S}}$ & Specific Storage \\
\hline SVOC & Semivolatile organic compounds \\
\hline SWNVF & Southwestern Nevada Volcanic Field \\
\hline TBD & Technical basis document \\
\hline $\mathrm{TC}$ & Tuff cone \\
\hline TD & Total depth \\
\hline TDS & Total dissolved solids \\
\hline TMA & Timber Mountain Aquifer \\
\hline TMCM & Timber Mountain Composite Unit \\
\hline TM-LVTA & Timber Mountain-Lower Vitric Tuff Aquifer \\
\hline TM-WTA & Timber Mountain-Welded Tuff Aquifer \\
\hline TSA & Topopah Springs Aquifer \\
\hline $\mathrm{UCCU}$ & Upper Clastic Confining Unit \\
\hline UGTA & Underground Test Area \\
\hline USGS & U.S. Geological Survey \\
\hline
\end{tabular}


UTCU Upper Tuff Confining Unit

VA

Volcanic Aquifer

VCCU

Volcaniclastic Confining Unit

VCU

Volcanic Confining Unit

VOC

Volatile organic compounds

VSMOW

Vienna Standard Mean Ocean Water

VU

Volcanics undifferentiated

WCU

Wahmonie Unit Confining

WESTVEG

Western Region Vegetation Map

WT

Water Temperature

YMP

Yucca Mountain Project

${ }^{\circ} \mathrm{C}$

Degrees Celsius

1-D

One dimensional

2-D

Two dimensional

3-D

Three dimensional

$\delta$

Delta

$\delta^{14} \mathrm{C}$

Delta carbon-14

$\delta^{18} \mathrm{O}$

Delta oxygen-18 


\subsection{Introduction}

This report documents pertinent hydrologic data and data analyses as part of the Phase II Corrective Action Investigation (CAI) for Frenchman Flat (FF) Corrective Action Unit (CAU): CAU 98. The purpose of this data compilation and related analyses is to provide the primary reference to support the development of the Phase II FF CAU groundwater flow model.

\subsection{Project Background}

Frenchman Flat is an area within the Nevada Test Site (NTS) that was used by the U.S. Department of Energy (DOE) and the U.S. Department of Defense (DoD) for underground nuclear testing for seven years (Figure 1-1). Underground nuclear testing on Frenchman Flat began with Operation Whetstone in 1965 and ended with Operation Grommet in 1971 (DOE/NV, 2000c). Figure 1-2 shows the location of the nuclear tests conducted at Frenchman Flat that are of interest to the Underground Test Area (UGTA) Project. Tests of interest are those that were detonated in deep vertical shafts or drillholes in alluvial and volcanic rock, above and below the water table. Table 1-1 presents information relative to the 10 underground nuclear tests that were conducted in Frenchman Flat from $\mathrm{DOE} / \mathrm{NV}(2000 \mathrm{c})$. Five tests were detonated in Area 5 and five tests were detonated in Area 11 of the NTS. All underground nuclear tests conducted in Frenchman Flat, except for two, (CAMBRIC-750 tons; DERRINGER-7.8 kilotons) have yield ranges specified as "less than 20 kilotons" (kt) (DOE/NV, 2000 a and c, and Bowen et al., 2001). Surface elevation data has been updated with more recent survey information. Media contaminated by the underground nuclear tests on Frenchman Flat are geologic formations within the saturated zone or within 100 meters $(\mathrm{m})$ above or below the water table. Transport in groundwater is the primary mechanism of migration for the subsurface contamination away from the Frenchman Flat underground nuclear tests.

Surface elevation data has been updated from DOE/NV (2000c) with more recent survey information. To address the issue of this groundwater contamination and ensure the protection of the public and the environment, the DOE National Nuclear Security Administration Nevada Site Office (NNSA/NSO) is implementing a corrective action investigation of Frenchman Flat. In addition, the NNSA/NSO has established a long-term program to monitor groundwater for the presence of radionuclides.

Since 1996, the Nevada Division of Environmental Protection (NDEP) has regulated NNSA/NSO's NTS corrective action program through the Federal Facility Agreement and Consent Order (FFACO) (1996). Section 3.0 of 


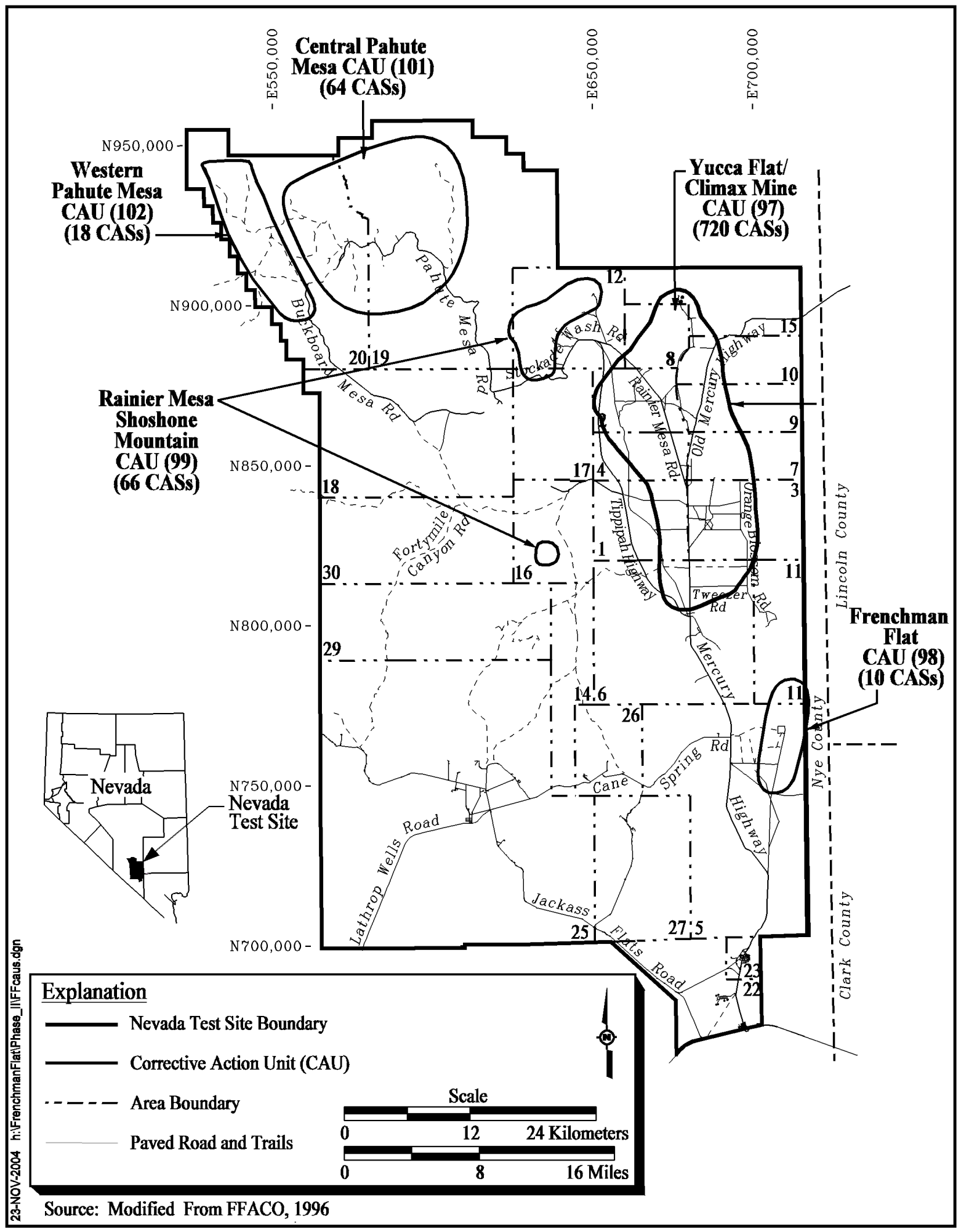

Figure 1-1

Location of the Frenchman Flat Corrective Action Unit 


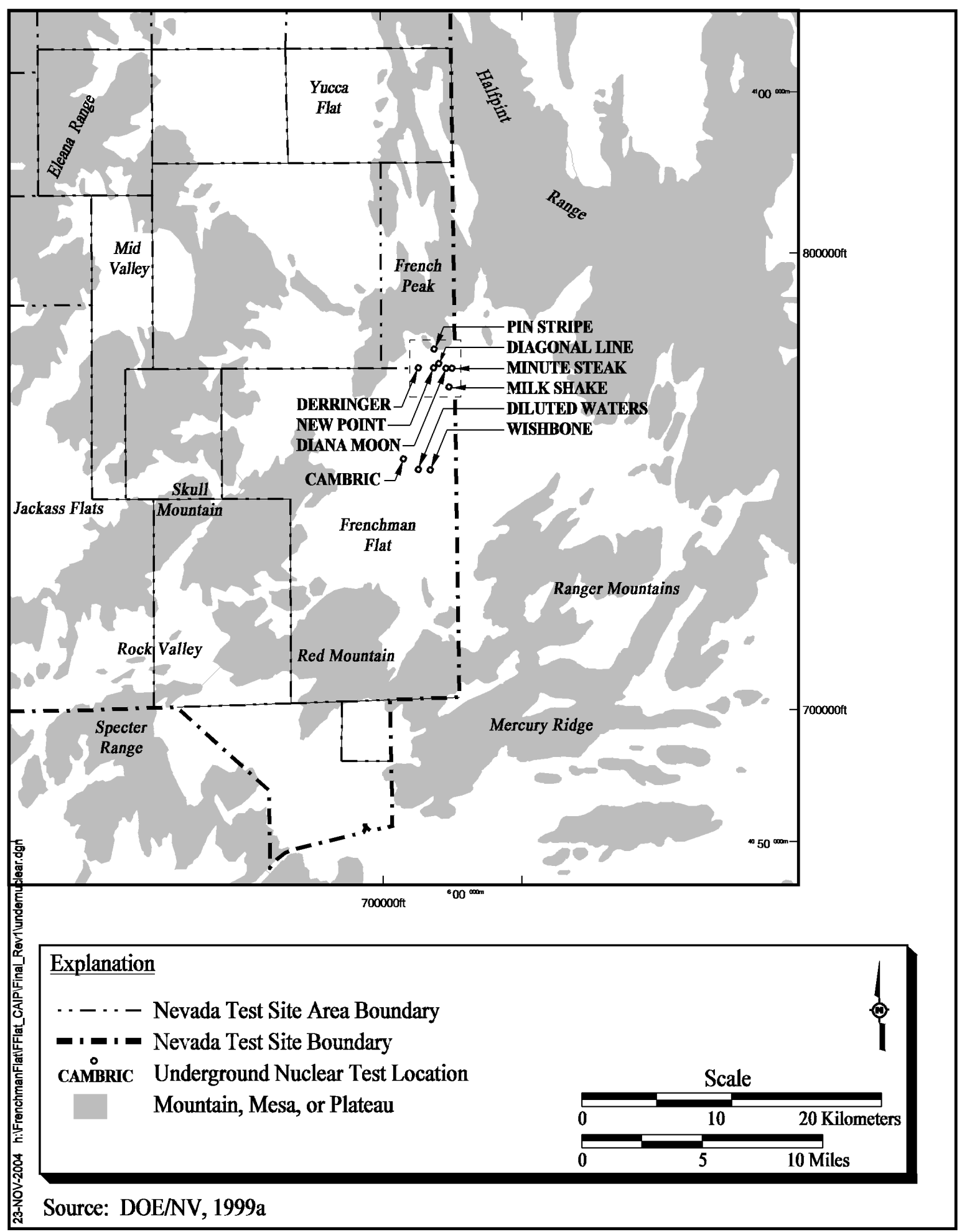

Figure 1-2

Location of Underground Nuclear Tests in Frenchman Flat 
Table 1-1

Corrective Action Sites in the Frenchman Flat Corrective Action Unit

\begin{tabular}{|c|c|c|c|c|c|c|c|c|c|c|}
\hline Test Name & $\begin{array}{c}\text { CAS } \\
\text { Number }\end{array}$ & $\begin{array}{c}\text { Date } \\
\text { Expended }\end{array}$ & $\begin{array}{l}\text { Hole } \\
\text { Name }\end{array}$ & $\begin{array}{l}\text { UTM Zone 11, } \\
\text { NAD } 27 \\
(\mathrm{~m})\end{array}$ & $\begin{array}{c}\text { Yield } \\
\text { Range } \\
\text { (kt) }\end{array}$ & $\begin{array}{l}\text { Hole } \\
\text { Depth } \\
\text { (m/ft) }\end{array}$ & $\begin{array}{c}\text { Working } \\
\text { Point } \\
\text { Depth } \\
\text { (m/ft) }\end{array}$ & $\begin{array}{c}\text { Working } \\
\text { Point } \\
\text { HSU }\end{array}$ & $\begin{array}{c}\text { Surface } \\
\text { Elevation }^{a} \\
\text { (m/ft) }\end{array}$ & $\begin{array}{c}\text { Bottom of } \\
\text { Hole } \\
\text { Elevation } \\
\text { (m/ft amsl) }\end{array}$ \\
\hline CAMBRIC & $05-57-003$ & $05 / 14 / 1965$ & U5e & $\begin{array}{c}\text { E } 592142.7 \\
\text { N } 4075575.4\end{array}$ & 0.75 & $\begin{array}{l}304.8 \\
1,000\end{array}$ & $\begin{array}{l}295 \\
968\end{array}$ & AA & $\begin{array}{l}956.2 \\
3,137\end{array}$ & $\begin{array}{l}651.4 \\
2,137\end{array}$ \\
\hline DERRINGER & $05-57-004$ & 09/12/1966 & U5i & $\begin{array}{c}\text { E } 593518.3 \\
\text { N } 4081415.4\end{array}$ & 7.8 & $\begin{array}{c}249.9 \\
820\end{array}$ & $\begin{array}{l}255 \\
837\end{array}$ & AA & $\begin{array}{c}1,034.8 \\
3,395\end{array}$ & $\begin{array}{l}784.9 \\
2,575\end{array}$ \\
\hline DIAGONAL LINE & $11-57-005$ & $11 / 24 / 1971$ & U11g & $\begin{array}{c}\text { E } 594939.1 \\
\text { N } 4081801.6\end{array}$ & $<20$ & $\begin{array}{c}277.4 \\
910\end{array}$ & $\begin{array}{l}264 \\
866\end{array}$ & AA & $\begin{array}{c}1,037.8 \\
3,405\end{array}$ & $\begin{array}{l}760.4 \\
2,495\end{array}$ \\
\hline DIANA MOON & $11-57-003$ & 08/27/1968 & U11e & $\begin{array}{c}\text { E } 595265.3 \\
\text { N } 4081581.8\end{array}$ & $<20$ & $\begin{array}{c}254.5 \\
835\end{array}$ & $\begin{array}{l}242 \\
794\end{array}$ & AA & $\begin{array}{c}1,031.8 \\
3,385\end{array}$ & $\begin{array}{l}777.3 \\
2,550\end{array}$ \\
\hline DILUTED WATERS & $05-57-002$ & 06/16/1965 & U5b & $\begin{array}{c}\text { E } 593110.1 \\
\text { N } 4074994.0\end{array}$ & $<20$ & $\begin{array}{c}205.7 \\
675\end{array}$ & $\begin{array}{l}193 \\
633\end{array}$ & AA & $\begin{array}{l}943.4 \\
3,095\end{array}$ & $\begin{array}{l}737.7 \\
2,420\end{array}$ \\
\hline MILK SHAKE & $05-57-005$ & $03 / 25 / 1968$ & U5k & $\begin{array}{c}\text { E } 595267.2 \\
\text { N } 4080972.3\end{array}$ & $<20$ & $\begin{array}{c}275.7 \\
905\end{array}$ & $\begin{array}{l}265 \\
869\end{array}$ & AA & $\begin{array}{c}1,020.8 \\
3,049\end{array}$ & $\begin{array}{c}745 \\
2,144\end{array}$ \\
\hline NEW POINT & $11-57-002$ & $12 / 13 / 1966$ & U11c & $\begin{array}{r}\text { E } 594655.9 \\
\text { N } 4081579.7\end{array}$ & $<20$ & $\begin{array}{l}559.3 \\
1,835\end{array}$ & $\begin{array}{l}239 \\
784\end{array}$ & AA & $\begin{array}{c}1,030.5 \\
3,381\end{array}$ & $\begin{array}{l}471.2 \\
1,546\end{array}$ \\
\hline MINUTE STEAK & $11-57-004$ & 09/12/1969 & U11f & $\begin{array}{c}\text { E } 595494.8 \\
\text { N } 4081584.4\end{array}$ & $<20$ & $\begin{array}{c}277.4 \\
910\end{array}$ & $\begin{array}{l}265 \\
869\end{array}$ & AA & $\begin{array}{c}1,034.2 \\
3,393\end{array}$ & $\begin{array}{l}756.8 \\
2,483\end{array}$ \\
\hline WISHBONE & 05-57-001 & 02/18/1965 & U5a & $\begin{array}{c}\text { E } 593719.6 \\
\text { N } 4074996.1\end{array}$ & $<20$ & $\begin{array}{c}191.4 \\
628\end{array}$ & $\begin{array}{l}175 \\
574\end{array}$ & AA & $\begin{array}{l}940.6 \\
3,086\end{array}$ & $\begin{array}{l}749.2 \\
2,458\end{array}$ \\
\hline PIN STRIPE & $11-57-001$ & 04/25/1966 & U11b & $\begin{array}{c}\text { E } 594386.2 \\
\text { N } 4082708.0\end{array}$ & $<20$ & $\begin{array}{c}298.7 \\
980\end{array}$ & $\begin{array}{l}296 \\
971\end{array}$ & TM-LVTA & $\begin{array}{c}1,093.0 \\
3,586\end{array}$ & $\begin{array}{l}794.3 \\
2,606\end{array}$ \\
\hline
\end{tabular}

Sources: DOE/NV, 2000a and BN, 2004a

a Updated from information in DOE/NV, 2000c

$\mathrm{m}=$ Meters

$\mathrm{m} / \mathrm{ft}=$ Meters/feet

$\mathrm{HSU}=$ Hydrostratigraphic unit

amsl = Above mean sea level

$\mathrm{AA}=$ Alluvial aquifer

TM-WTA = Timber Mountain-Welded Tuff Aquifer

TM-LVTA = Timber Mountain-Lower Vitric Tuff Aquifer

Appendix VI of the FFACO (Revision No. 1, December 2000) defines the corrective action strategy that guides the UGTA Project. In this Appendix, Frenchman Flat is identified as consisting of ten Corrective Action Sites (CAS) located on the NTS in the northern portion of Area 5 and the southern part of Area 11.

For the UGTA Project, the corrective action strategy includes two major phases: a regional evaluation addressing all CAUs and a CAI process for each of the individual CAUs. The first major phase was completed with the development of the Regional Groundwater Flow and Tritium Transport Modeling and Risk Assessment of the Underground Test Area, Nevada Test Site, Nevada (DOE/NV, 1997). The regional model (DOE/NV, 1997) provided the initial basis for determining the magnitude of risk from the source areas on the NTS to potential receptors and a regional context for future individual CAU 
investigations. The second phase of the CAI process focuses on refining the results of the regional-scale modeling through acquisition and analysis of CAU-specific data, and development of CAU-scale flow and transport models. The CAU-specific objectives are to estimate movement of contaminants utilizing the acquisition and evaluation of CAU-specific hydrogeologic data and define boundaries that encompass the extent of contamination.

Figure 1-3 shows the process flow diagram for implementing the corrective action strategy for the individual UGTA CAUs. The CAU-specific corrective action process includes six major elements: Corrective Action Investigation Plan (CAIP), Corrective Action Investigation (CAI), Corrective Action Decision Document (CADD), Corrective Action Plan (CAP), Closure Report (CR), and long-term monitoring.

- The CAI planning is documented in the CAIP, an FFACO-required document which provides or references all specific information for planning investigation activities associated with corrective action units or sites.

- The corrective action investigation includes the collection of new data, the evaluation of new and existing data, and the development and use of CAU-specific groundwater flow and transport model(s).

- The CADD is a required report that documents the corrective action investigation. It describes the results of the CAI, the corrective action alternatives considered, the results of their comparative evaluation, the selected corrective action, and the rationale for its selection.

- The CAP is prepared to describe how the selected remedial alternative is to be implemented. The CAP will contain the engineering design and all specifications that are necessary to implement the selected remedial alternative.

- The UGTA strategy has provisions for CAU closure only if the long-term-monitoring alternative is selected. Closure activities include the preparation of a CR, review of the CR by NDEP, and long-term closure monitoring by DOE. The long-term, post-closure monitoring is designed to ensure the compliance boundary is not violated.

The CAI process may be iterative, resulting in several phases of data collection, analysis, and modeling, with assessment of confidence in the results at the completion of each phase. If further data collection, analysis, and modeling are required, a CAIP Addendum will be issued to direct the new phase of activities.

The Phase I CAI for Frenchman Flat was completed with hydrologic data compilation, analysis, and model development. The Frenchman Flat Phase I CAI planning and work are documented in:

- Corrective Action Investigation Plan for Corrective Action Unit 98: Frenchman Flat, Revision 1 (DOE/NV, 1999a) 


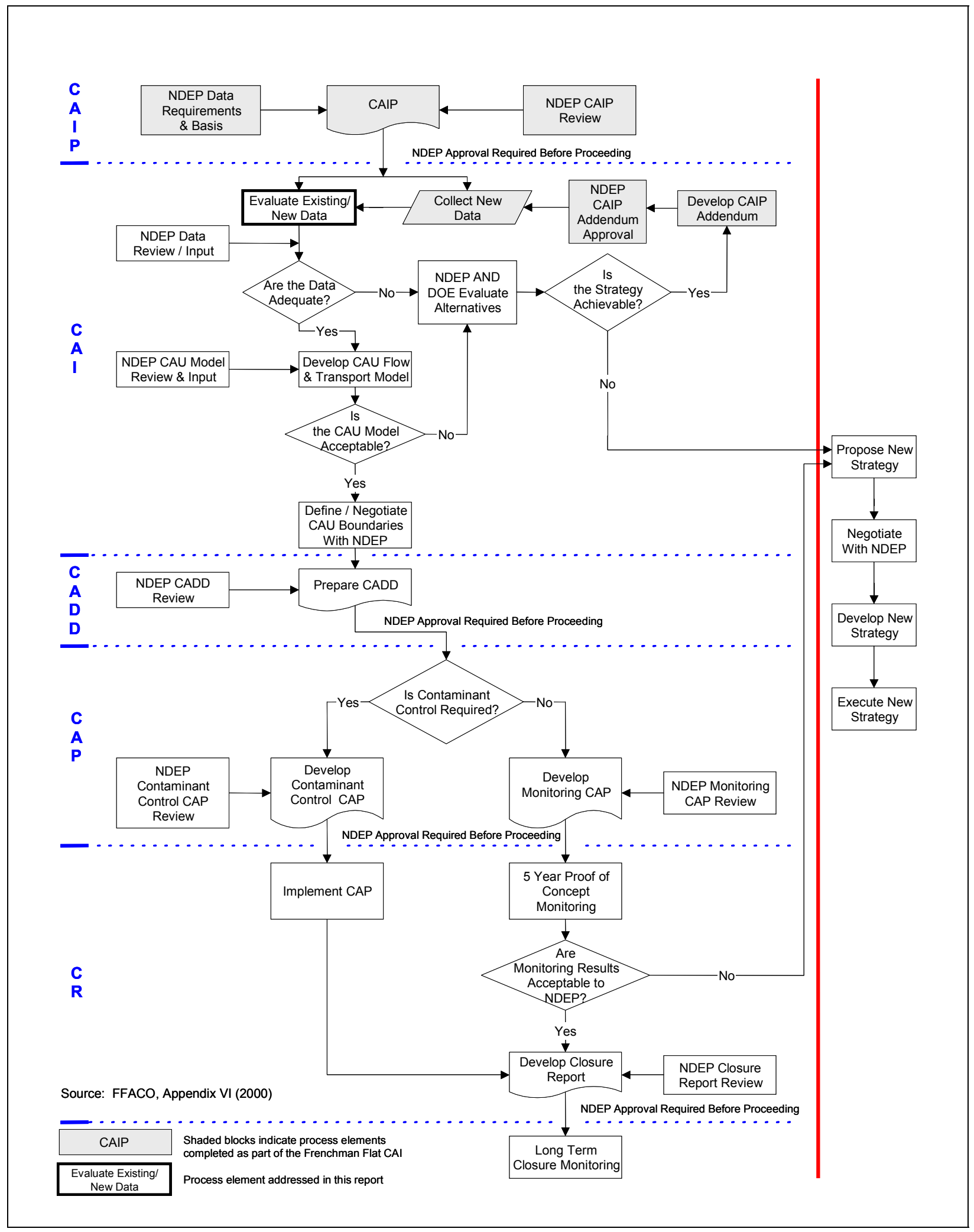

Figure 1-3

Process Flow Diagram for the Underground Test Area Corrective Action Units 
- Value of Information Analysis for Corrective Action Unit No. 98: Frenchman Flat (IT, 1997b).

- Underground Test Area Subproject Corrective Action Unit 98:

Frenchman Flat Data Analysis Task, Volume I-Hydrostratigraphic Model Documentation Package, Revision 0 (IT, 1998)

- Underground Test Area Project Corrective Action Unit 98: Frenchman Flat Data Analysis Task, Volume II - Groundwater Data Documentation Package, Revision 0 (IT, 1999b)

- Underground Test Area Project Corrective Action Unit 98: Frenchman Flat Data Analysis Task, Volume III - Groundwater Flow and Contaminant Transport Model Data Documentation Package, Revision 0 (IT, 1999c)

- Evaluation of the Hydrologic Source Term from Underground Nuclear Tests in Frenchman Flat at the Nevada Test Site: The CAMBRIC Test (LLNL, 1999)

Following the completion and documentation of the Phase I work, comprehensive internal and external peer reviews were conducted. The results of these reviews identified and documented deficiencies in the Phase I work.

The external peer review is documented in External Peer Review Group Report on Frenchman Flat Data Analysis and Modeling Task, Underground Test Area Project, Revision No. 0 (IT, 1999a). Section 2.0 of the peer review document identifies key issues of concern. Section 4.0 of the peer review document provides recommended actions to address the key concerns. These recommended actions included general and specific data enhancement and data acquisition needs; incorporation of alternative conceptual models to evaluate all potential failure scenarios; changing the modeling approach to one that uses a finite-element platform to better address discrete geologic features (e.g., faults and fracture zones); and the development and application of local-scale uncertainty analysis techniques.

The internal peer review is documented in Lessons Learned from the Frenchman Flat Corrective Action Groundwater Flow and Radionuclide Transport Model (IT, 2000b). The lessons learned document concluded that the Phase I Frenchman Flat CAU model was a good first model of groundwater flow and radionuclide transport at the CAU scale. The modeling successfully represented the flow system as defined in the conceptual model and predicted limited radionuclide travel distances. However, the work was not complete and, as recommended by the peer reviews, needed refinement. Section 2.0 of the lessons learned document identifies deficiencies in the Phase I Frenchman Flat CAI and provides recommendations to address the deficiencies. Table 1-2 provides a summary of 
the Phase I CAI deficiencies and recommendations identified in the lessons learned document (IT, 2000b).

Table 1-2

Summary of Lessons Learned from the Frenchman Flat CAU Model Related to Data Analysis

\begin{tabular}{|c|c|c|}
\hline Topic & Deficiency & Recommendation \\
\hline \multirow{4}{*}{ Data Analysis } & Data analysis does not assess data adequacy & $\begin{array}{l}\text { Difficult problem, additional studies would be required to } \\
\text { address this }\end{array}$ \\
\hline & $\begin{array}{l}\text { Justification for transferring data from outside a CAU } \\
\text { is lacking }\end{array}$ & $\begin{array}{l}\text { A methodology for justifying data transfer needs to be } \\
\text { developed and included in the data analysis }\end{array}$ \\
\hline & The statistical treatment of data is not always consistent & $\begin{array}{l}\text { Consultation with appropriate subject matter experts will } \\
\text { be sought to avoid mistakes in the future }\end{array}$ \\
\hline & Hydraulic gradient discussion was missing & This will be added to future data analyses \\
\hline $\begin{array}{l}\text { Sensitivity and } \\
\text { Uncertainty } \\
\text { Analyses }\end{array}$ & Range of uncertainty needs to be better documented & $\begin{array}{l}\text { The data analysis will be expanded to better assess } \\
\text { parameter uncertainty }\end{array}$ \\
\hline
\end{tabular}

Based on the outcome from the external and internal peer reviews, the need for additional work scope (including new data collection and modeling activities), were identified and an addendum to the Frenchman Flat CAIP was developed. This addendum, Addendum to Revision 1 of the Corrective Action Investigation Plan for Corrective Action Unit 98: Frenchman Flat, Nevada Test Site, Nevada (DOE/NV, 2001), details the new data collection and modeling activities to address the documented deficiencies in the Phase I Frenchman Flat CAI. The new data collection activity identified in the Addendum (DOE/NV, 2001) has been completed. The compilation of both the existing and new data and their analyses are the subject of this document.

\subsection{Task Purpose and Scope}

The purpose of the tasks documented in this report was to analyze relevant information available for the hydrologic components of the groundwater flow system of Frenchman Flat and vicinity. This report will provide the primary reference to support the development of the Phase II Frenchman Flat CAU groundwater flow model(s).

Specific task objectives were as follows:

- Compile available hydrologic data and supporting information that may be relevant to the Frenchman Flat CAI.

- Assess the level of quality of the data and associated documentation.

- Analyze the data to derive expected values or spatial distributions, and estimates of the associated uncertainty and variability. 
The scope of this task includes the assessment of data and information relevant to groundwater flow in the Frenchman Flat subsurface. Data types of interest include hydraulic properties, precipitation recharge, natural surface discharge, well discharge, hydraulic heads, and groundwater chemistry. Descriptions of these data types are provided in Section 4.0.

Data analysis includes: (1) literature searches, (2) data/information compilation, (3) data documentation, (4) data documentation qualification, (5) data quality evaluation, and (6), data assessment and interpretation activities. Data analysis includes the use of scientific software to assist in estimating and visualizing each of the hydrologic data types.

The study area, as described in the CAIP (Figure 1-4), was selected to encompass the Frenchman Flat CASs and areas located immediately downgradient that may be impacted by these CASs. This area, an intermontane basin within the Basin and Range physiographic region, is located in the southeastern portion of the NTS. The Frenchman Flat area extends from southern Yucca Flat to the southern NTS area, including Mercury. The area of interest to the modeling activities is limited to Frenchman Flat (Figure 1-4) as the maximum extent of contamination is expected to remain within this area.

Even though the area of interest is limited to the Frenchman Flat area, information considered to be relevant to this task may be obtained from other nearby sites.

Nearby sites include other underground test area CAUs, the Yucca Mountain Site, and other sites located within the NTS region.

\subsection{Documents that Support the Phase II Frenchman Flat CAI}

The Frenchman Flat CAU model is documented in a series of reports describing the data analysis and modeling tasks. The CAU model documentation providing information used in this report includes reports from Phase I of the CAI and recent reports developed as part of Phase II.

Phase I reports include:

- Underground Test Area Subproject Corrective Action Unit 98: Frenchman Flat Data Analysis Task, Volume I - Hydrostratigraphic Model Documentation Package (IT, 1998) - This volume documents the development of the Phase I three-dimensional (3-D) hydrostratigraphic framework model for the Frenchman Flat CAU.

- Underground Test Area Subproject Corrective Action Unit 98: Frenchman Flat Data Analysis Task, Volume II - Groundwater Data Documentation Package (IT, 1999b) - This volume presents the Phase I groundwater data incorporated into the groundwater flow and contaminant transport model for the Frenchman Flat underground test area. 


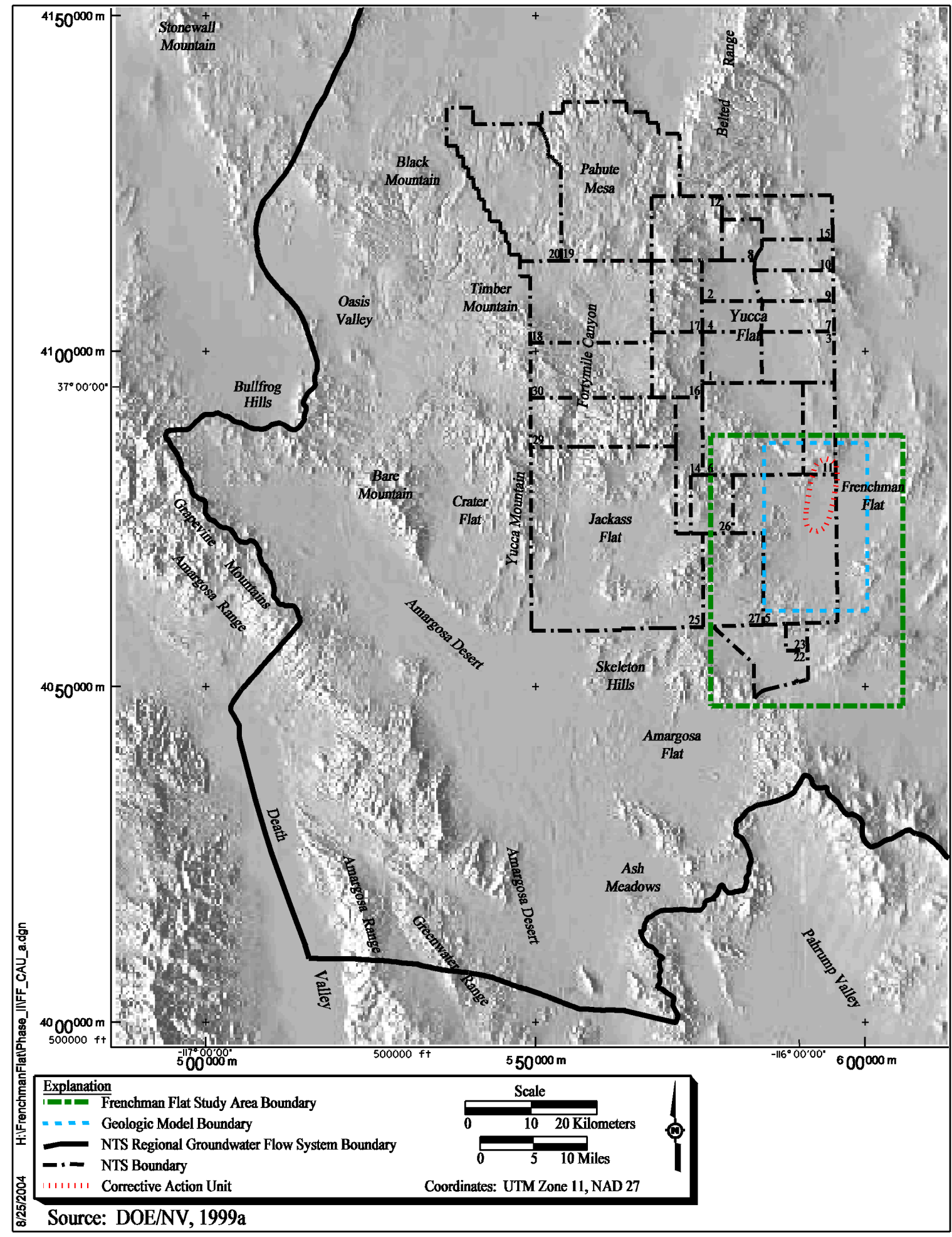

Figure 1-4

Location of the Frenchman Flat Study Area and Geologic Model Area 
- Underground Test Area Subproject Corrective Action Unit 98:

Frenchman Flat Data Analysis Task, Volume III - Groundwater Flow and Contaminant Transport Model Documentation Package (IT, 1999c) This volume presents the Phase I groundwater flow and transport model for Frenchman Flat.

- External Peer Review Group Report on Frenchman Flat Data Analysis and Modeling Task, Underground Test Area Project, Revision No. 0 (IT, 1999a) - The document (IT, 1999a) identifies deficiencies in the Phase I CAI. In the context of this report, specific recommendations related to data sufficiency and uncertainty analysis are addressed.

- Lessons Learned from the Frenchman Flat Corrective Action Groundwater Flow and Radionuclide Transport Model (IT, 2000b) - The document (IT, 2000c) identifies lessons learned during the Phase I CAI. In the context of this report, specific recommendations related to data sufficiency and uncertainty analysis are addressed.

Phase II reports include:

- Interpretation of Hydraulic Test and Multiple-Well Aquifer Test Data at Frenchman Flat Well Cluster ER-5-3 (SNJV, 2004b). This report documents the analysis of the hydraulic data collected for Wells ER-5-3, ER-5-3\#2, and ER-5-3\#3.

- A Hydrostratigraphic Model and Alternatives for the Groundwater Flow and Contaminant Transport Model of Corrective Action Unit 98:

Frenchman Flat, Clark, Lincoln and Nye Counties, Nevada (BN, 2004a).

- Integrated Analysis Report for Single and Multiple Well Aquifer Testing at Frenchman Flat Well Cluster RNM-2s (SNJV, 2004d). This report presents the analysis and interpretation of hydraulic data from the Well ER-5-4 single-well test, the Well ER-5-4 \#2 single-well test, and the well cluster RNM-2S multiple-well aquifer test which included the ER-5-4 wells as well as others.

- Completion Report for Well Cluster ER-5-3 (BN, 2004b).

- Completion Report for Well Cluster ER-5-4 (BN, 2004c).

- Evaluation of Groundwater Movement in the Frenchman Flat CAU Using Geochemical and Isotopic Analysis, Desert Research Institute, Division of Hydrologic Sciences (Hershey et al., 2004).

- Aquifer Test - Analysis of Multiple-Well Aquifer Test RNM-2s, Frenchman Flat, Nevada (Pavelko and Halford, 2004).

- Aquifer Test Report for WW-5c, Area 5, Nevada Test Site (Halford, 2003). 
- Hydraulic Conductivity Profile with Depth for Well ER-5-4 \#2 (Oberlander, 2003).

- Aquifer Test Report for WW-4a, Area 6, Nevada Test Site (Halford, 2002).

- Addendum to the Frenchman Flat Hydrogeologic Investigation Wells Drilling and Completion Criteria (IT, 2001a). This addendum contains two appendices. Appendix B presents the change from one well to two wells at the central Frenchman Flat location. Appendix D documents additional work performed at Well Cluster ER-5-3.

- Modeling Approach for Corrective Action Unit 98, Frenchman Flat, ITLV/13052--141 (IT, 2001b).

- Analysis of Water Levels in the Frenchman Flat Area, Nevada Test Site (Bright, et al., 2001).

- Hydraulic Conductivity Profile with Depth for Monitor Wells ER-5-3, ER-5-3 \#2 and ER-5-4 (Oberlander, 2001).

- Results and Preliminary Analysis of the RNM-2s and UE-5n Aquifer Test (Russell, 2000).

\subsection{Quality Assurance}

Quality assurance (QA) measures consistent with the UGTA Project quality assurance project plan (QAPP) (DOE/NV, 2000b) have been taken to control quality during the performance of all UGTA data analysis tasks. These measures include data documentation qualification, data quality assessment, checking procedures, software quality assurance, use of standard methodologies, technical and peer reviews, and corroboration through models.

\section{Data Documentation Evaluation}

Each data record will be assigned a data documentation evaluation flag (DDE_F) designed to indicate the level of documentation available for that data record. The five levels of data documentation evaluation flags are described in Section 4.0.

\section{Data Quality Assessment}

The criteria used to assess the quality of the different types of required data are dependent on the type and the intended use of the data. The general procedure includes assigning one or more flags to each record compiled in the dataset, indicating the data quality or suitability of the individual data record for the intended usage. Data-type specific quality evaluation procedures are described in detail in the corresponding section of this document.

\section{Checking Procedures}

Various checking procedures were designed for quality control purposes. Checking procedures applicable to the UGTA data analysis include those 
developed for transcription of data; generation of figures, tables; and logs; and performance of calculations. Data compiled by project personnel are subjected to the checking procedures before inclusion in the appropriate dataset. However, the bulk of the available data are comprised of data gathered and compiled by agencies external to the UGTA project. Internal procedures do not govern other UGTA participants; therefore, their data were not subjected to the checking procedures described here.

\section{Standard Methodologies}

Only standard and widely accepted methodologies should be used in the development of the interpretive products. The various methodologies used are too numerous to list here; however, they are described and referenced in the sections of this document which discuss their use in the data analysis process.

\section{Technical and Peer Reviews}

The review process constitutes an important measure of product quality, and is used throughout the performance of the data analysis activities. The review process may include internal and external technical reviews (external reviews may be conducted as directed by NNSA/NSO). The internal reviews are performed by individuals who are independent of the product reviews. These reviews may include representatives of Bechtel Nevada (BN), U.S. Geological Survey (USGS), Desert Research Institute (DRI), Los Alamos National Laboratory (LANL), Lawrence Livermore National Laboratory (LLNL), GeoTrans, and the Stoller-Navarro Joint Venture (SNJV).

\section{Corroboration of Data Through Models}

This step is completed during the development of the groundwater flow and transport model. For example, during the groundwater flow model calibration process, geologic and hydrologic data interpretations are tested and modified as required. This may be accomplished by modifying the extent or thickness of a given HSU or modifying its hydraulic conductivity in areas where no data are available.

\subsection{Document Organization}

This document consists of 11 sections and 7 appendices. Summaries of the section contents follow:

- Section 1.0 provides a description of the project background, the purpose and scope of this data analysis task, a description of the documentation supporting this report, and the QA process implemented herein.

- Section 2.0 describes the regional setting and local hydrostratigraphic framework of the Frenchman Flat area. These descriptions are presented to support the analysis of the hydrologic data presented in this document. 
- Section 3.0 provides a brief overview of the modeling strategy proposed for the Frenchman Flat CAU and a more detailed description of the approach that will be used to simulate groundwater flow.

- Section 4.0 presents the general approach used to assess the available hydrologic data.

- Section 5.0 describes the compilation and analysis of aquifer property data.

- Section 6.0 describes the compilation and analysis of the available precipitation recharge data.

- Section 7.0 describes the compilation and analysis of the available surface discharge data.

- Section 8.0 describes the compilation and analysis of water-level data to derive hydraulic heads.

- Section 9.0 describes the estimation (calculation) of the subsurface boundary fluxes using the NTS regional model.

- Section 10.0 describes the compilation and analysis of groundwater chemistry data.

- Section 11.0 provides a list of references used in the document.

- Appendix A contains information in support of the hydrostratigraphic model described in Section 2.0.

- Appendices B through F contain descriptions of the datasets and supporting information for various hydrologic data types considered (hydrostratigraphic framework, hydraulic properties, surface discharge, hydraulic heads, well completions, lateral boundary fluxes, and geochemistry). 


\title{
2.0 Regional Setting and the FF CAU Hydrostratigraphic Framework
}

\begin{abstract}
An overview of the Phase II hydrostratigraphic framework for FF is provided in this section as background for the analyses presented in the later sections of this report. New data collected since 2001 and as recently as Fall 2003 are incorporated into the CAU-scale Phase II FF hydrostratigraphic model. The data better constrain the basin-forming structural features and provide evidence to support the subdivision of several HSUs that were grouped in the Phase I FF hydrostratigraphic model. The revised FF hydrostratigraphic framework includes 72 fault structures and 17 hydrostratigraphic units (compared to the 48 faults and 9 HSUs in the Phase I model). The Phase II FF geologic model is fully documented in the report: A Hydrostratigraphic Model and Alternatives for the Groundwater Flow and Contaminant Transport Model of Corrective Action Unit 98: Frenchman Flat, Lincoln and Nye Counties, Nevada (BN, 2004a).

A summary of the regional setting for FF and a background of the regional hydrogeologic framework are provided below, followed by a short synopsis of regional groundwater occurrence and movement. The last sections summarize the data collected in Frenchman Flat since Phase I activities and the subsequent revisions to create the Phase II FF structural model and HSU framework.
\end{abstract}

\subsection{Regional Setting}

The Frenchman Flat flow system is part of the NTS regional flow system (Figure 2-1), which is part of the Death Valley flow system. A conceptual model of the regional groundwater flow system of the NTS was developed during the regional evaluation (DOE/NV, 1997). Summary descriptions of the NTS regional hydrogeologic framework, and groundwater occurrence and movement (as conceptualized in the NTS regional flow model [DOE/NV, 1997]), are presented in this section. This information has been updated, where appropriate.

\subsubsection{Regional Hydrogeologic Framework}

The hydrogeologic framework used in the NTS regional model, which is adapted to create the CAU-scale FF hydrogeologic framework, is based on a conceptual hydrologic system established for the NTS area by Winograd and Thordarson (1975) and Blankennagel and Weir (1973). This early work was summarized and updated by Laczniak et al. (1996), and has further been developed by the UGTA Phase I hydrostratigraphic regional modeling team (IT, 1996d). 


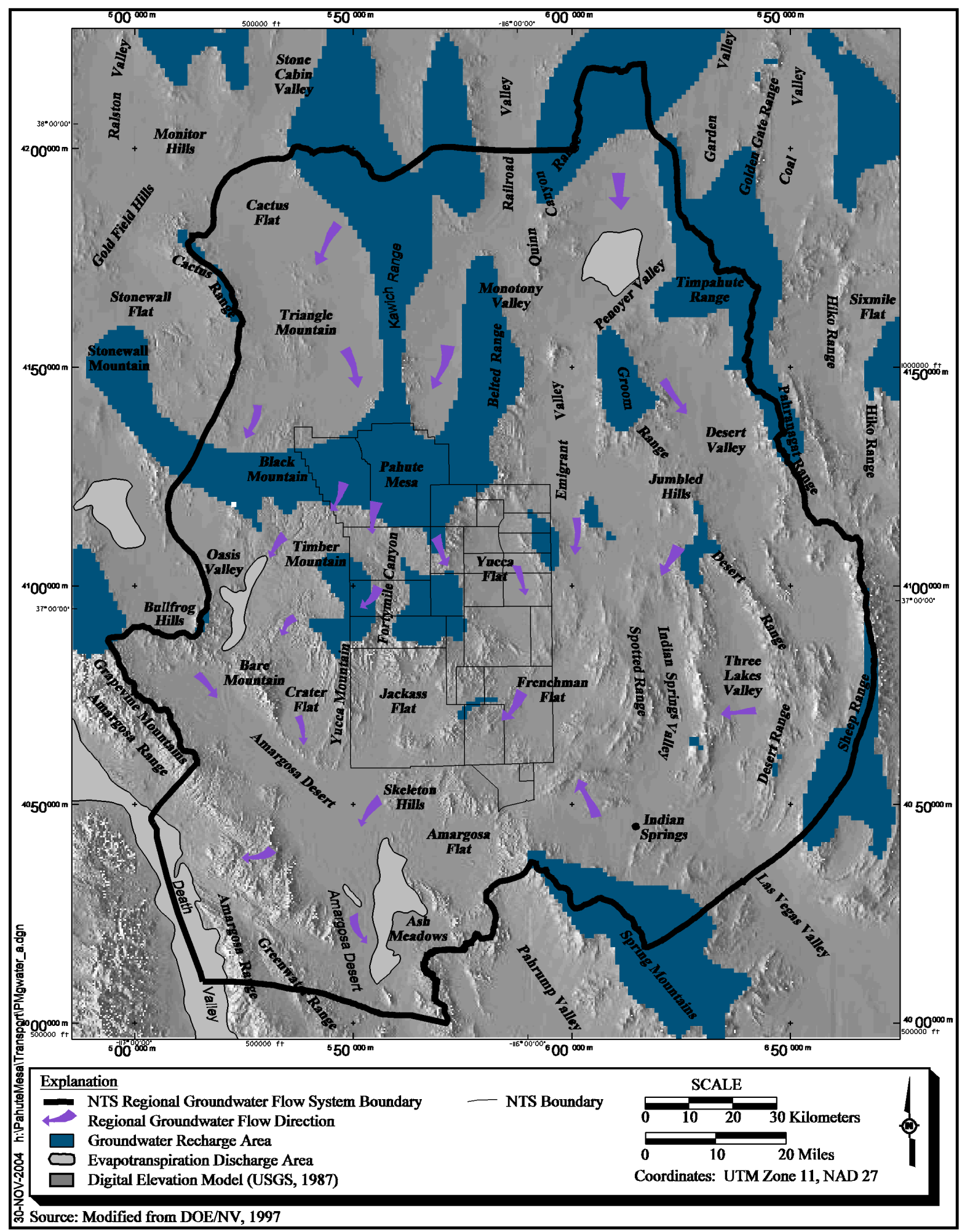

Figure 2-1

Features of the Nevada Test Site Regional Groundwater Flow System 
The rocks of the NTS have been classified using a two-level scheme, in which hydrogeologic units (HGUs) are grouped to form hydrostratigraphic units (HSUs) (IT, 1996d). The HGUs are used to categorize rocks according to their ability to transmit groundwater, which is mainly a function of the primary lithologic properties of the formations, degree of fracturing, and secondary mineral alteration. The complex hydrologic properties of the volcanic rocks of the NTS and vicinity are best addressed in terms of HGUs (Blankennagel and Weir, 1973; Winograd and Thordarson, 1975). The concept of HSUs that are made up of groups of similar HGUs is very useful in volcanic terrains because stratigraphic units can differ greatly in hydrologic character both laterally and vertically. The HSUs serve as "layers" in the NTS regional and CAU-scale hydrostratigraphic framework models.

The following paragraphs summarize the hydrogeologic framework of the NTS, first addressing HGUs, then describing HSUs.

\subsubsection{Hydrogeologic Units}

All rocks of the NTS and vicinity can be classified as one of eight hydrogeologic units, which include the alluvial aquifer, four volcanic HGUs, an intrusive HGU, and two HGUs that represent the pre-Tertiary sedimentary and metasedimentary rocks (Table 2-1).

\section{Alluvium HGU}

The deposits of alluvium (alluvial aquifer [AA]) fill the main basins of the NTS, and generally consist of a loosely consolidated mixture of boulders, gravel, sand, silt, and clay derived from volcanic and Paleozoic sedimentary rocks (Slate et al., 1999).

\section{Volcanic HGUs}

The volcanic rocks within the study area can be categorized into four HGUs based on primary lithologic properties, degree of fracturing, and secondary mineral alteration. In general, the altered volcanic rocks (typically zeolitic or hydrothermally altered near caldera margins) act as confining units, and the unaltered rocks form aquifers. The aquifer units can be further divided into welded-tuff and vitric-tuff aquifers (depending on degree of welding) and lava-flow aquifers. Denser rocks, such as welded ash-flow tuffs and lava flows, tend to fracture more readily; therefore, they have relatively high permeability (Blankennagel and Weir, 1973; Winograd and Thordarson, 1975; Laczniak et al., 1996; IT, 1996d; Prothro and Drellack, 1997).

\section{Pre-Tertiary HGUs}

The pre-Tertiary rocks beneath the study area are also categorized as aquifer or confining unit HGUs based on lithology. The silicic clastic rocks (quartzites, siltstones, shales) typically are aquitards or confining units, while the carbonates (limestone and dolomite) tend to be aquifers (Winograd and Thordarson, 1975; Laczniak et al., 1996). 
Table 2-1

Hydrogeologic Units of the NTS Regional Model That Occur in the Frenchman Flat Model Area

\begin{tabular}{|c|c|c|}
\hline Hydrogeologic Unit & Typical Lithologies & Hydrologic Significance \\
\hline $\begin{array}{l}\text { Alluvial Aquifer (AA) } \\
\text { (AA is also an HSU in } \\
\text { hydrogeologic models) }\end{array}$ & $\begin{array}{l}\text { Unconsolidated to partially } \\
\text { consolidated gravelly sand, aeolian } \\
\text { sand, and colluvium; thin, basalt flows } \\
\text { of limited extent. }\end{array}$ & $\begin{array}{l}\text { Has characteristics of a highly conductive aquifer, but less so } \\
\text { where lenses of clay-rich paleocolluvium or playa deposits are } \\
\text { present. }\end{array}$ \\
\hline Welded-Tuff Aquifer (WTA) & Welded ash-flow tuff, vitric to devitrified & $\begin{array}{l}\text { Degree of welding greatly affects interstitial porosity (less porosity } \\
\text { as degree of welding increases) and permeability (greater fracture } \\
\text { permeability as degree of welding increases). }\end{array}$ \\
\hline Vitric-Tuff Aquifer (VTA) & $\begin{array}{l}\text { Bedded tuff, ash-fall and reworked tuff; } \\
\text { vitric }\end{array}$ & $\begin{array}{l}\text { Constitutes a volumetrically minor HGU; generally does not } \\
\text { extend far below the static water-level due to tendency of tuffs to } \\
\text { become zeolitic (which drastically reduces permeability) under } \\
\text { saturated conditions; significant interstitial porosity ( } 20 \text { to } \\
40 \text { percent); generally insignificant fracture permeability. }\end{array}$ \\
\hline Lava-Flow Aquifer (LFA) & $\begin{array}{l}\text { Rhyolite lava flows; includes flow } \\
\text { breccias (commonly at base) and } \\
\text { pumiceous zones (commonly at top) }\end{array}$ & $\begin{array}{l}\text { Generally a caldera-filling unit and/or of local extent; hydrologically } \\
\text { complex, wide range of transmissivities, fracture density and } \\
\text { interstitial porosity differ with lithologic variations. }\end{array}$ \\
\hline Tuff Confining Unit (TCU) & $\begin{array}{l}\text { Zeolitic bedded tuff with interbedded, } \\
\text { but less significant, zeolitic, nonwelded } \\
\text { to partially welded ash-flow tuff }\end{array}$ & $\begin{array}{l}\text { May be saturated but measured transmissivities are very low; may } \\
\text { cause accumulation of perched and/or semi-perched water in } \\
\text { overlying units. }\end{array}$ \\
\hline $\begin{array}{l}\text { Intrusive Confining Unit } \\
\text { (ICU) }\end{array}$ & Granodiorite, quartz monzonite & $\begin{array}{l}\text { Relatively impermeable; forms local bulbous stocks, north of } \\
\text { Rainier Mesa, Yucca Flat, and scattered elsewhere in the NTS } \\
\text { regional model area; may contain perched water. }\end{array}$ \\
\hline $\begin{array}{l}\text { Clastic Confining Unit } \\
(\mathrm{CCU})\end{array}$ & Argillite, siltstone, quartzite & $\begin{array}{l}\text { Clay-rich rocks are relatively impermeable; more siliceous rocks } \\
\text { are fractured, but with fracture porosity generally sealed due to } \\
\text { secondary mineralization. }\end{array}$ \\
\hline Carbonate Aquifer (CA) & Dolomite, limestone & $\begin{array}{l}\text { Transmissivity values vary greatly and are directly dependent on } \\
\text { fracture frequency. }\end{array}$ \\
\hline
\end{tabular}

Source: Adapted from IT (1996d) and BN (2004a)

\section{Intrusives HGU}

The Intrusive Confining Unit (ICU) category includes the Mesozoic granite stocks north of Rainier Mesa and Yucca Flat and several intrusives scattered throughout the model area (mostly to the north of the NTS). These rocks are considered to behave as a confining unit. The ICU is the eighth HGU in the NTS regional model area. However, this unit does not occur within the FF hydrostratigraphic model area.

\subsubsection{Hydrostratigraphic Units}

Hydrostratigraphic units are groupings of contiguous stratigraphic units that have a particular hydrogeologic character, such as an aquifer (unit through which water moves readily) or confining unit (unit that generally is impermeable to water movement). An HSU may contain several HGUs but is defined so that a single general type of HGU dominates (for example, mostly welded-tuff and vitric-tuff 
aquifers or mostly tuff confining units). Twenty HSUs were defined in the NTS regional HSU model (IT, 1996d).

The regional hydrogeologic framework model covers over 28,000 square kilometers $\left(\mathrm{km}^{2}\right)\left(11,000\right.$ square miles $\left.\left[\mathrm{mi}^{2}\right]\right)$ of which the Frenchman Flat hydrogeologic framework model makes up only approximately 1 percent. The regional-scale model represents a very simplified hydrogeologic framework of the Frenchman flat area, which is located in the southeastern portion of the NTS. The HSUs defined for the NTS regional HSU model that are within the Frenchman Flat model area are listed in Table 2-2. The rocks in this part of the regional model were divided into three Tertiary volcanic HSUs and three pre-Tertiary HSUs. The volcanic rocks east of the NTS were not subdivided and are represented by a single HSU, volcanics undifferentiated (VU). The older Tertiary sedimentary rocks were included in the Volcaniclastic Confining Unit (VCCU) HSU. The Wahmonie volcanic units were included in the Volcanic Aquifer (VA) HSU. These units are listed in approximate order from surface to basement, although some are laterally rather than vertically contiguous, and not all units are present in all parts of the model area.

\subsubsection{Groundwater Occurrence and Movement}

Figure 2-1 is a map depicting the basic characteristics of the NTS regional groundwater flow system including the flow system boundary, areas of recharge, and evapotranspiration (ET) areas. The descriptions provided in this section are based on the data gathered during the regional evaluation (IT, 1996a and c; $\mathrm{DOE} / \mathrm{NV}, 1997)$. Updates have been incorporated where available.

\subsubsection{Groundwater Occurrence}

The following description of groundwater occurrence within the NTS regional flow system is based on the water-level dataset compiled during the regional evaluation (IT, 1996c and DOE/NV, 1997).

Within the NTS region, groundwater occurs in alluvial, volcanic, and carbonate materials. Saturated alluvial materials and Tertiary volcanics are present in central and southern Yucca Flat, Frenchman Flat, and Jackass Flats on the NTS and in the basins located throughout the flow system. The distribution and thickness of AA and VAs are highly variable throughout the region and are not interpreted to be continuous. In most instances, an AA is confined to a basin by surrounding mountain ranges. In some basins, AAs are discontinuous due to structural controls elevating the bottom of the alluvium above the water table. In general, alluvial and volcanic aquifers are considered depositional elements overlying the regional flow system and only influence regional flow in localized areas. The underlying Lower Carbonate Aquifer (LCA) is the principal aquifer of the NTS regional flow system. The LCA forms a nearly continuous aquifer across the region except where interrupted by calderas, truncated by structural controls, or penetrated by intrusive rocks. 
Table 2-2

Hydrostratigraphic Units of the Frenchman Flat Area Included in the NTS Regional Hydrostratigraphic Framework Model

\begin{tabular}{|c|c|c|c|c|}
\hline $\begin{array}{c}\text { Hydrostratigraphic } \\
\text { Unit Number }\end{array}$ & $\begin{array}{l}\text { Hydrostratigraphic } \\
\text { Unit } \\
\text { (Symbol) }\end{array}$ & $\begin{array}{l}\text { Dominant } \\
\text { Hydrogeologic } \\
\text { Unit(s) }^{\mathrm{b}}\end{array}$ & $\begin{array}{l}\text { Stratigraphic } \\
\text { Unit Map } \\
\text { Symbols }^{c}\end{array}$ & General Description \\
\hline 20 & $\begin{array}{l}\text { Alluvial Aquifer (AA) } \\
\text { (this term is also used } \\
\text { to designate a } \\
\text { hydrogeologic unit) }\end{array}$ & AA & $\begin{array}{l}\text { Qay, QTc, } \\
\text { Qam, QTa, } \\
\text { Qtu, Tybf, Tt }\end{array}$ & $\begin{array}{l}\text { Consists mainly of alluvium that fills extensional } \\
\text { basins such as Gold Flat, Crater Flat, Kawich } \\
\text { Valley, and Sarcobatus Flat. Also includes } \\
\text { generally older Tertiary gravels, tuffaceous } \\
\text { sediments, and nonwelded tuffs (where thin) that } \\
\text { partially fill other basins such as Oasis Valley and } \\
\text { the moat of the Timber Mountain caldera } \\
\text { complex. }\end{array}$ \\
\hline 19 & $\begin{array}{l}\text { Timber Mountain Aquifer } \\
\text { (TMA) }\end{array}$ & $\begin{array}{l}\text { Mostly WTA, } \\
\text { minor VTA; TCU } \\
\text { within the Tm } \\
\text { caldera complex }\end{array}$ & $\mathrm{Tm}, \mathrm{Tp}$ & $\begin{array}{l}\text { "The uppermost welded tuffs" in the Frenchman } \\
\text { Flat model area consists mainly of extra-caldera } \\
\text { welded ash-flow tuffs (aquifer-like lithologies). } \\
\text { However, the altered intra-caldera equivalent } \\
\text { rocks within the Timber Mountain caldera are } \\
\text { modeled as confining units. }\end{array}$ \\
\hline 15 & Tuff Confining Unit (TCU) & $\mathrm{TCU}$ & $\begin{array}{c}\text { Th, Tw, Tc, Tn, } \\
\text { To }\end{array}$ & Mostly zeolitized nonwelded tuffs. \\
\hline 14 & Volcanic Aquifer (VA) & WTA, VTA, LFA & Tm, Tp, Tw, Tc & $\begin{array}{l}\text { Imprecisely known grouping of volcanic rocks; } \\
\text { generally with aquifer-like qualities. Also use as } \\
\text { a lumping unit away from the more data-rich } \\
\text { NTS. }\end{array}$ \\
\hline 12 & $\begin{array}{l}\text { Volcaniclastic Confining } \\
\text { Unit (VCCU) }\end{array}$ & $\begin{array}{l}\text { TCU, minor AA, } \\
\text { lesser CA }\end{array}$ & Tgp, Tgw & $\begin{array}{l}\text { Complex three-dimensional distribution of zeolitic } \\
\text { nonwelded tuff, gravels, mudstones, and } \\
\text { limestones. Present in the southern portion of } \\
\text { the Frenchman Flat model area. }\end{array}$ \\
\hline 11 & $\begin{array}{l}\text { Volcanics } \\
\text { undifferentiated (VU) }\end{array}$ & $\begin{array}{c}\text { WTA, TCU, lesser } \\
\text { LFA }\end{array}$ & $\begin{array}{c}\text { Potentially } \\
\text { includes all } \\
\text { Tertiary } \\
\text { volcanic units }\end{array}$ & $\begin{array}{l}\text { All Quaternary and Tertiary volcanics outside the } \\
\text { NTS proper and the proximal NTS caldera } \\
\text { complex. }\end{array}$ \\
\hline 8 & $\begin{array}{l}\text { Upper Clastic Confining } \\
\text { Unit (UCCU) }\end{array}$ & $\mathrm{CCU}$ & MDc, MDe & $\begin{array}{l}\text { Late Devonian through Mississippian siliciclastic } \\
\text { rocks. Present in the northeastern corner (CP } \\
\text { Basin) of the Frenchman Flat model area. }\end{array}$ \\
\hline 7 & $\begin{array}{l}\text { Lower Carbonate Aquifer } \\
\text { (LCA) }\end{array}$ & $\mathrm{CA}$ & Dg through Cc & $\begin{array}{l}\text { Cambrian through Devonian mostly limestone } \\
\text { and dolomite. Widespread throughout the } \\
\text { Frenchman Flat model area. }\end{array}$ \\
\hline 6 & $\begin{array}{l}\text { Lower Clastic Confining } \\
\text { Unit (LCCU) }\end{array}$ & $\mathrm{CCU}$ & $\begin{array}{c}\mathrm{Cc}, \mathrm{Cz}, \mathrm{Czw}, \\
\mathrm{Zs}, \mathrm{Zj}\end{array}$ & $\begin{array}{l}\text { Late Proterozoic through Early Cambrian } \\
\text { siliciclastic rocks. Widespread throughout the } \\
\text { Frenchman Flat model area. }\end{array}$ \\
\hline
\end{tabular}

aUGTA regional model (IT, 1996d)

bSee Table 2-1 for definitions of HGUs

'Refer to Slate et al. (1999) and Ferguson et al. (1994) for definitions of stratigraphic unit map symbols

Based on the water-level dataset compiled during the regional evaluation (IT, 1996c and DOE/NV, 1997), depths to groundwater beneath the NTS and surrounding region vary greatly. Groundwater depths in the southern NTS range from about $23 \mathrm{~m}$ (75 feet [ft]) beneath upper Fortymile Wash to over $213.36 \mathrm{~m}$ $(700 \mathrm{ft})$ beneath Frenchman Flat compared to more than $610 \mathrm{~m}(2,000 \mathrm{ft})$ beneath Pahute Mesa in the northern NTS (IT, 1996c and DOE/NV, 1997). Perched groundwater is found locally throughout the NTS and occurs within the 
tuff-confining units and, to some extent, overlying units. In the highlands, springs emerge from perched groundwater lenses. Spring discharge rates are low and this water is used only by wildlife.

\subsubsection{Groundwater Movement}

Within the NTS regional flow system, groundwater movement is controlled by structural and geologic conditions, and the distribution of recharge and discharge locations.

The general direction of groundwater flow in the NTS regional flow system is from north to south and east to southwest (Figure 2-1). The direction of groundwater flow is locally influenced in areas where structural and geologic conditions have controlled the distribution and thickness of the LCA. In some areas of the NTS regional flow system, groundwater encounters structural and geologic conditions, such as structural highs of the Lower Clastic Confining Unit (LCCU), that promote an upward flow component. The upward flow component may bring water to discharge at the surface in the form of a wet playa or springs. Groundwater flow between basins occurs in the form of subsurface inflow and outflow.

Horizontal hydraulic gradients are generally very low to the east and southwest of the NTS. In other areas, the prevailing flow direction and hydraulic gradients may locally be influenced by the structural position of geologic units with significantly lower transmissivity than that of the LCA. If the units of low transmissivity have structural orientations that are perpendicular to flow, large hydraulic gradients may be observed across the units. If their structural orientation is parallel to the prevailing flow direction, the effect may be insignificant. Structural uplifts of the LCCU and the distribution of the UCCU have caused several of the observed steep gradients within the flow system. Low-permeability sediments along the Funeral Mountains such as the Tertiary Death Valley Section sediments also cause a steep hydraulic gradient between Amargosa Desert and Death Valley.

Groundwater recharge results from precipitation at higher elevations and infiltration along stream courses and in playas. Recharge rates and distribution may be estimated. The estimates are, however, uncertain. The recharge model used in the NTS regional flow model was based on a modification of the Maxey-Eakin method (Maxey and Eakin, 1949). Several new models have recently been proposed and are described in Section 6.0 of this document. Groundwater discharges to the surface in the form of springs, seeps, and ET in several areas. Major areas of natural groundwater discharge include Oasis Valley, Ash Meadows, Alkali Flat, Death Valley, and Penoyer Valley. Estimates of ET have recently been updated by the USGS for the first four areas listed above (Laczniak et al., 2001). Within the NTS region, artificial discharge occurs as groundwater pumpage from drinking water supply wells (public and domestic), agricultural wells, and industrial wells. Public, domestic, and industrial water supply wells for the NTS produce water from the carbonate, volcanic, and valley-fill aquifers. South of the NTS, private and public water supply wells are 
completed in the valley-fill aquifer. Discharge from the Frenchman Flat area is discussed in Section 7.0 of this document.

\subsection{Frenchman Flat Hydrogeologic Framework}

A 3-D hydrostratigraphic framework model and alternatives have been built for the Frenchman Flat area (BN, 2004). The FF hydrogeologic framework is much more detailed than the regional hydrogeologic framework. Several HSUs have been subdivided compared to the regional hydrogeologic framework (i.e., VA in the regional model is subdivided into five units: Timber Mountain-Welded Tuff Aquifer (TMWTA), Timber Mountain-Lower Vitric Tuff Aquifer (TMLVTA), Upper Tuff Confining Unit (UTCU), Topopah Spring Aquifer (TSA), and Lower Vitric Tuff Aquifer (LVTA), in the FF CAU geologic model) and the number of faults is significantly greater in the CAU-scale model.

The acquisition of new data in the FF basin, which helped constrain the structure and stratigraphy in FF, is summarized in the next section. Following a discussion on data acquisition activities, the processes of HSU model development and screening are described, along with a description of the alternative models retained for use in the CAU groundwater flow and transport model. The details for the FF hydrogeologic framework construction may be found in the HSU model report titled: A Hydrostratigraphic Model for the Groundwater Flow and Contaminant Transport Model of Corrective Action Unit 98: Frenchman Flat, Nye County, Nevada (BN, 2004a).

\subsubsection{Phase II Data Collection Activities}

A new, revised (Phase II) 3-D hydrostratigraphic framework model including several variations based on alternative interpretations has been built for the Frenchman Flat area (BN, 2004a). Internal and external reviews of the Phase I Frenchman Flat model (IT, 1998) recommended additional data collection to address uncertainties (IT, 1999a). As a result, the FF CAIP Addendum listed a number of data collection activities that would be implemented to provide data for the Phase II geologic model, including drilling two characterization wells in each of the underground nuclear testing areas, and a seismic geophysical investigation. These activities were completed as well as several other activities that contributed to the understanding of the geology. The results of these activities, which are incorporated in the new geologic model, constrain the structural framework of the main basin, and indicate more variability in the volcanic and alluvial units as compared to the Phase I Frenchman Flat model. The new data are discussed below, followed by an explanation of the HSUs and key structures identified in FF, which are incorporated in the new Frenchman Flat Hydrogeologic Framework. 


\subsubsection{Phase II Well Drilling}

Five new wells were drilled and completed as part of the Phase II Data Acquisition for the Frenchman Flat CAU. The wells were intended to provide confirmatory information and new, detailed information about the geology, hydrogeology, and water chemistry in the immediate vicinity of the two underground nuclear test subareas within Frenchman Flat. Well Cluster ER-5-3 (three wells) is located near the northern group of underground tests in Frenchman Flat (i.e., Figure 2-2), and Well Cluster ER-5-4 (two wells) is located near the southern group of Underground Tests (UGTs) in Frenchman Flat. The purpose and expectations of this drilling initiative are spelled out in the Frenchman Flat Hydrogeologic Investigation Wells Drilling and Completion Criteria (IT, 2000a) and an addendum (IT, 2001a). Information on the well clusters is summarized in the following sections. Data from these wells, combined with the 3-D seismic data, factored prominently in the development of the modified structural model for Frenchman Flat.

\subsection{Well Cluster ER-5-3}

Three separate boreholes were drilled at this site on the same drill pad. The overall objective was to penetrate the saturated alluvium, the volcanic aquifer, the tuff confining unit, and to reach the lower carbonate aquifer. Because of instability problems the first borehole, Well ER-5-3, was terminated in the tuff confining unit before reaching the planned depth of 1,158.2 $\mathrm{m}(3,800 \mathrm{ft})$. Well ER-5-3\#2, was then drilled to $1,732.2 \mathrm{~m}(5,683.4 \mathrm{ft})$ and reached the lower carbonate aquifer. The wells penetrated Quaternary/Tertiary alluvium to the depth of $622.4 \mathrm{~m}(2,042 \mathrm{ft})$. An $8.5-\mathrm{m}(28-\mathrm{ft})$ thick basalt flow was encountered within the alluvium near the water table. Tertiary-age tuffs were penetrated to the depth of approximately $1,425.9 \mathrm{~m}(4,678 \mathrm{ft})$, where the top of the lower carbonate aquifer was encountered in Well ER-5-3\#2. Well ER-5-3\#3 was drilled to a total depth (TD) of $548.6 \mathrm{~m}(1,800 \mathrm{ft})$ and completed in the saturated alluvium for use as an observation well for hydraulic testing. Details of well construction can be found in Appendix D, Figure D.1-1, Figure D.1-2, and Figure D.1-3.

\subsection{Well Cluster ER-5-4}

Well Cluster ER-5-4 is located in central Area 5 of the NTS (Figure 2-2), approximately 1.6 kilometers $(\mathrm{km})(1.0$ mile [mi]) northwest of the Frenchman Lake playa, near the central underground testing area. The cluster consists of two boreholes drilled $30.5 \mathrm{~m}(100 \mathrm{ft})$ apart on the same drill pad. Details of well construction can be found in Appendix D, Figure D.1-4 and Figure D.1-5.

The wells penetrated 1,120.4 m (3,676 ft) of Quaternary and Tertiary alluvium, $242.6 \mathrm{~m}$ (796 ft) of generally unaltered nonwelded and welded ash-flow tuff of Tertiary age, and $770.5 \mathrm{~m}(2,528 \mathrm{ft})$ of mostly zeolitic nonwelded tuff, also of Tertiary age. Electrical Micro Imager (EMI) log data indicate bedding dips of about 30 degrees to the east-southeast, consistent with the seismic data. The wells 

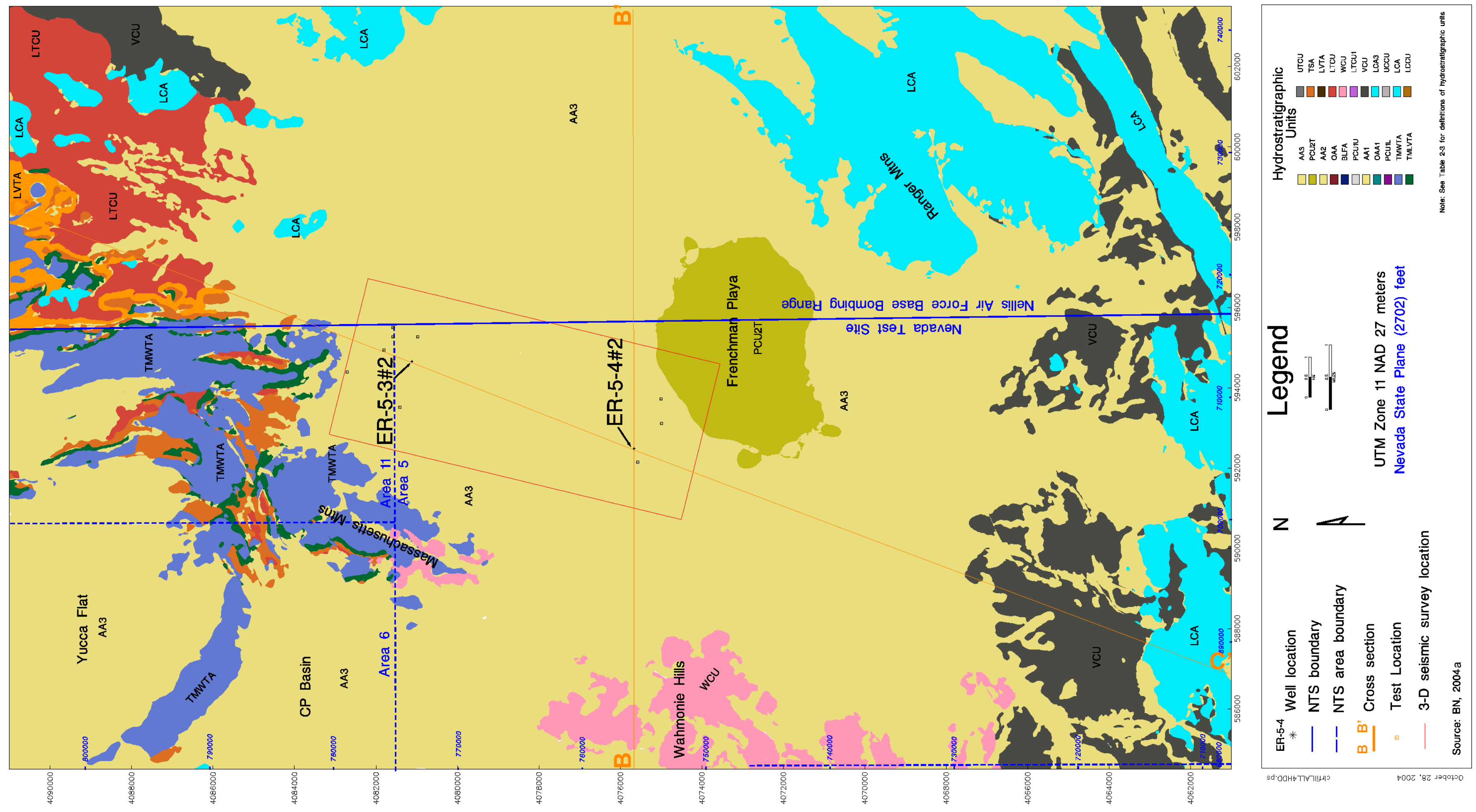
encountered a thicker alluvial section and volcanic rock section than expected. Well ER-5-4\#2 reached TD at 2,133.6 m (7,000 ft) in the Wahmonie Formation, and did not reach the older Tertiary sedimentary rocks or Paleozoic rocks as predicted.

\subsubsection{Geophysical Investigations}

Geophysical data available for the Frenchman Flat area are varied in type and in vintage. Geophysical investigations have been conducted in Frenchman Flat since the 1950s and include seismic, resistivity, magnetic, and gravity. In fiscal year (FY) 2001 and 2002, the UGTA Phase II data acquisition initiative included a 3-D seismic survey of the two testing areas (Figure 2-2), analysis of gravity data using 3-D inversion methods, and a re-analysis of existing aeromagnetic data. A magnetotelluric survey was conducted in Yucca Flat in 2003. The two southern transects are relevant to the Frenchman Flat model. Geophysical data can be used to better define the nature of the structures within the Frenchman Flat basin, and the distribution of the Tertiary-age volcanic units. The Phase II geophysical investigations were designed to better define the structure beneath the two underground test areas, as well as validate and improve the initial 3-D hydrostratigraphic framework model (IT, 1998) for Frenchman Flat. The geophysical data was also utilized during development of alternative scenarios. The 3-D seismic reflection and magnetotelluric survey methods are briefly discussed below. More details regarding these and other geophysical investigations employed during development of the Phase II 3-D hydrostratigraphic model can be found in BN (2004a).

\subsubsection{Three-Dimensional Seismic Reflection}

A 3-D seismic reflection survey was conducted in Frenchman Flat to provide subsurface geologic information to better constrain groundwater flow and contaminant transport models. Three seismic horizons were mapped and include from highest to lowest: (1) the base of the alluvial basin-fill deposits (BOA), (2) the base of a zone of Tertiary-age welded ash-flow tuffs (BWZ), and (3) the top of Paleozoic-age sedimentary rocks $(\mathrm{Pz})$. The mapping of these three horizons effectively delineates the extent, thickness, and structural orientation of the alluvial and volcanic aquifers. In addition, mapping of the BWZ and Pz improves constraints on the extent and thickness of the tuff and volcaniclastic confining units that occur between these two horizons. The Pz surface corresponds to the top of the regional carbonate aquifer and thus improves constraints on the depth to and structural orientation of this important aquifer.

Seismic data also revealed the presence of two large and previously unknown structures. A northwest striking fault zone was identified that separates the Frenchman Flat basin proper from a structural platform on the north. In addition, the seismic data in conjunction with drill hole and outcrop data strongly suggest that much of the northern structural platform overlies a detachment fault within the volcanic rocks. 
Results from the interpretation of the Frenchman Flat 3-D seismic data allows for much more accurate modeling of hydrostratigraphic units in the survey area.

Interpretation results also significantly improve and better constrain the structural model of the basin. The improved accuracy and better constraints provided by the seismic data will allow for more realistic evaluation of potential rapid transport of groundwater from the testing horizons to the regional carbonate aquifer.

\subsubsection{Natural-Source Magnetotelluric}

In the fall of 2003, the USGS collected Magnetotelluric (MT) data at 52 sites in eight generally west-east transects across Yucca Flat and proximal areas. The southern most transect stretches from Mid Valley on the west, across CP Basin, and ends just north of Massachusetts Mountain. Another transect extends west-east across Yucca Lake in extreme southern Yucca Flat. Data from these two southern profiles were incorporated into the Frenchman Flat model. The MT data was collected primarily to provide insights regarding the pre-Tertiary stratigraphy and structure in Yucca Flat. Of particular interest was the presence and extent of the UCCU and the CP thrust fault (both extend into the northwestern corner of the Frenchman Flat model area).

The MT method is utilized to delineate subsurface formations and units of differing resistivity. Because lithology is the primary factor in determining the resistivity of a unit, MT data can be used to map lithologic units, if they are sufficiently thick and have significant resistivity contrasts. The MT method seemed promising because the two primary pre-Tertiary lithologies of interest in constructing hydrostratigraphic models of the Yucca Flat and Frenchman Flat CAUs are thick and have contrasting resistivities. The LCA and Upper Carbonate Aquifer (UCA) carbonate rocks have high resistivities, and the shaley Upper Clastic Confining Unit (UCCU) generally has low resistivity. Several resistivity layers can be identified in the MT data: (1) high resistivity - LCA (carbonate) and welded tuffs (2) low resistivity - UCCU and zeolitic tuffs, and (3) intermediate resistivity - unsaturated alluvium. Several structures can also be discerned within the data: (1) CP Thrust fault and (2) Cane Spring fault. Furthermore, the occurrence and geometry of the UCCU (combined with other data in the vicinity) is interpreted as the east limb of an asymmetric anticline. The interpretation of the MT survey played a large part in revision of the CP basin area of the geologic model.

\subsubsection{HSU Model Development}

The approach followed to develop the base HSU model and alternatives is described in this section. The HSU geologic model area is described in Section 1.0 and shown on Figure 1-4. The Phase II geologic model area extends further to the north than the Phase I geologic model to include structure in the north that affects the FF basin. 
The Frenchman Flat area HSU model(s) were constructed using EarthVision ${ }^{\circledR}$ (Version 7.5, by Dynamic Graphics), a 3-D geologic model building and visualization software package. Input data included drill-hole data, a 3-D seismic survey and MT survey data discussed above, gravity data, magnetic data (both areal and surface surveys), digital elevation model (DEM) data, and outcrop and fault data from surface geologic maps. Where deemed necessary, the data were supplemented with interpretations in the form of "pseudo drill holes," cross sections, and structure-contour maps. A "pseudo drill hole" is a fictitious data point used to facilitate the automated contouring of data. The estimates for the pseudo drill holes are obtained from surficial geology maps and/or geologist's interpretations.

\subsubsection{Base Model}

A base HSU model (Phase I) was constructed using the conceptual model of the NTS hydrologic system described by Winograd and Thordarson (1975). Further developments made by Laczniak et al. (1996), IT (1996a, b, and c), Prothro and Drellack (1997), Gonzales et al. (1998), and BN (2002) were also used in the UGTA base HSU model for Frenchman Flat.

\subsubsection{Alternative Models}

To capture the uncertainty associated with the HSU framework, a number of alternative interpretations were considered in addition to the base HSU model (Table A.1-1). These alternatives were then evaluated and organized into four groups as follows:

- Group A - Recommended changes to the base model. Alternatives interpretations from this group were implemented to improve the base HSU model.

- Group B - Viable alternative HSU models requiring structural changes to the base model.

- Group C - Proposed alternatives that could be addressed during hydrologic modeling through the assignment of hydrologic properties.

- Group D - Suggested alternatives that were deemed to be low priority for modeling.

The main criterion for selecting alternatives for full development was the potential impact of the alternative interpretation on groundwater flow and the transport of contaminants in groundwater. The potential for a significant effect was assessed qualitatively using professional judgement

Following this evaluation of the alternatives, the base HSU model was updated using the Group A alternatives, and the alternatives placed under Group B were 
further developed into EarthVision ${ }^{\circledR}$ models. These alternatives are listed below in descending order of inferred potential impact (BN, 2004a).

- Alternative \#1 - Aquifer juxtaposition alternative

- Alternative \#2 - More extensive basalt flow alternative

- Alternative \#3 - No detachment fault alternative

- Alternative \#4 - CP Basin alternative

The CP Basin alternative model contains the CP Basin configuration of the initial base HSU model. In the spring of 2003, the base model had the UCCU and LCA3 thrust over LCA in the northwest corner of the model, and the layers were relatively flat. Strong evidence provided in the Fall 2003 by the MT survey showed that the UCCU was less extensive and did not exist as a continuous sheet as previously thought, and that in the FF model area this unit appeared to be a leg of an anticline. This alternative model for the $\mathrm{CP}$ Basin configuration was determined to be a superior interpretation and replaced the initial base model. The $\mathrm{CP}$ basin alternative model is now the original base model, and all other alternatives (accept the CP Basin alternative) contain the UCCU anticline leg in the CP basin. When the initial base model and the CP Basin alternative model were swapped late in the geologic model development process, the nomenclature of the model hierarchy remained the same. The lateral boundary flux analysis, discussed in Section 9.0, was initiated before this switch using the initial base model, which is now the CP Basin alternative model. The effect of this situation detailed in Section 9.0.

A summary description of the alternative HSU models is provided in $A$ Hydrostratigraphic Model for the Groundwater Flow and Contaminant Transport Model of Corrective Action Unit 98: Frenchman Flat Nye County, Nevada (BN, 2004a).

\subsubsection{HSU Alternative Model Screening}

HSU-alternative model screening was used for the Frenchman Flat CAU model to reduce the number of geologic conceptualizations developed into full groundwater flow models. From the information currently available, none of the HSU models could be moved from Group B to Group D (described above). Consequently, all of the HSU models developed for Frenchman Flat will be carried forward for groundwater flow modeling. This will provide full identification of potentially important flow paths and comparison of significant differences between alternative models. During groundwater flow modeling, if alternative HSU models are found to have little impact on flow path predictions, those alternatives may be eliminated prior to transport modeling.

\subsubsection{Base HSU Model}

The structural features, hydrogeologic units, and hydrostratigraphic units of the base HSU model developed for the Frenchman Flat area are described in the 
following sections. A two-dimensional (2-D) map of the hydrostratigraphic units at the ground surface is shown in Figure 2-2. Figure 2-3 shows the hydrostratigraphic units at the water table surface. This surface, which extends across several HSUs, is consistent with the contouring of the water table surface as it was implemented in the modeling described in Section 9.0.

\subsubsection{Structural Features}

Geologic structural features are an important part of the hydrologic framework of the groundwater flow system of the Frenchman Flat area. They define the geometric configuration of the flow domain, including the distribution, thickness, and orientation of rock units. The depositional patterns of the geologic units occurring in the area were strongly influenced by paleotopography, including paleovalley and barriers, strike-slip faults (e.g., Rock Valley and Cane Spring faults) and some normal faults. Faulting, for example, may result in juxtaposition of units with different hydrologic properties. Structures themselves may influence flow patterns by acting as conduits for flow or barriers to flow (BN, 2004a).

The structure of the base HSU model is founded in the conceptual model developed by BN (2004a). BN developed a detailed structural model by integrating this conceptual model and 3-D reflection seismic, gravity, magnetic, and drill hole data. The base HSU model includes a total of 72 structural elements which are typically normal faults (Basin and Range style faults) but also includes several strike-slip and older thrust faults. Only faults that were considered to be significant were included in the model. These include the larger ones and the ones that seem to form significant structural boundaries.

One significant structural boundary includes the left-lateral Rock Valley Fault System. This set of faults appears to be responsible for the formation of the deep basin (BN, 2004a). In the southern portion of the FF model area, the Rock Valley faults strike northeast southwest. Figure 2-4 is a 3-D image of the main fault structures on the volcanic aquifer surface. In the north portion of the basin, they strike to the north then turn to the west and flare-out into an extensional imbricate fan along the eastern and northern margins of the basin. The space left by the down-dropped fault blocks on the south, east, and north of the fault system has been filled with more than 9,000 ft of mostly Tertiary volcanic rocks and alluvium.

Another significant structural feature is the Cane Spring fault located in the northwestern part of the FF model area. The Cane Spring fault separates the main $\mathrm{FF}$ basin from the CP basin, which has a hydraulic head significantly higher than the FF basin.

\subsubsection{Hydrogeologic Units}

The hydrogeologic framework for the NTS model established by Blankennagel and Weir (1973) and Winograd and Thordarson (1975) provided the foundation for most subsequent hydrogeologic studies in the area. As described in 


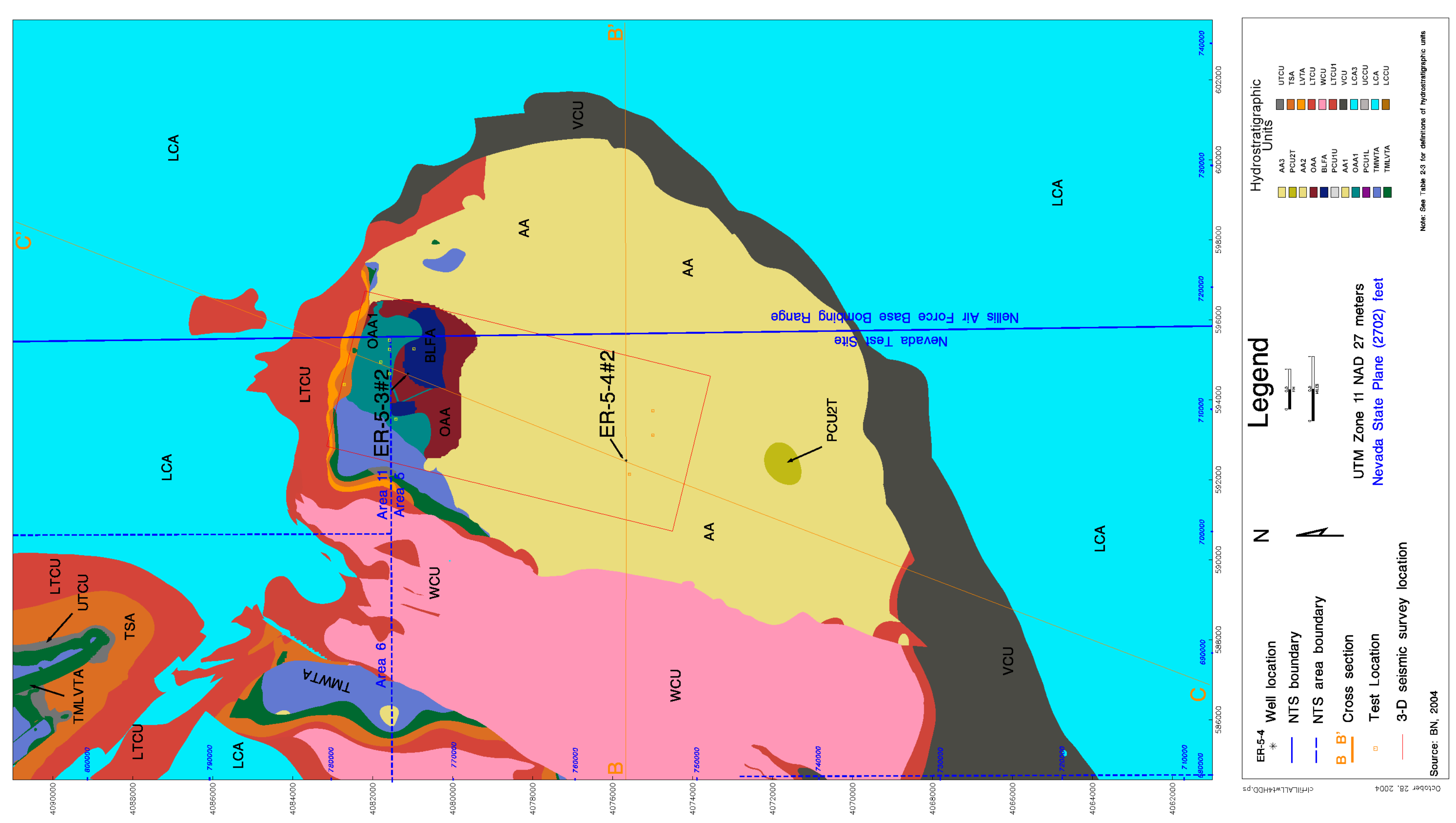




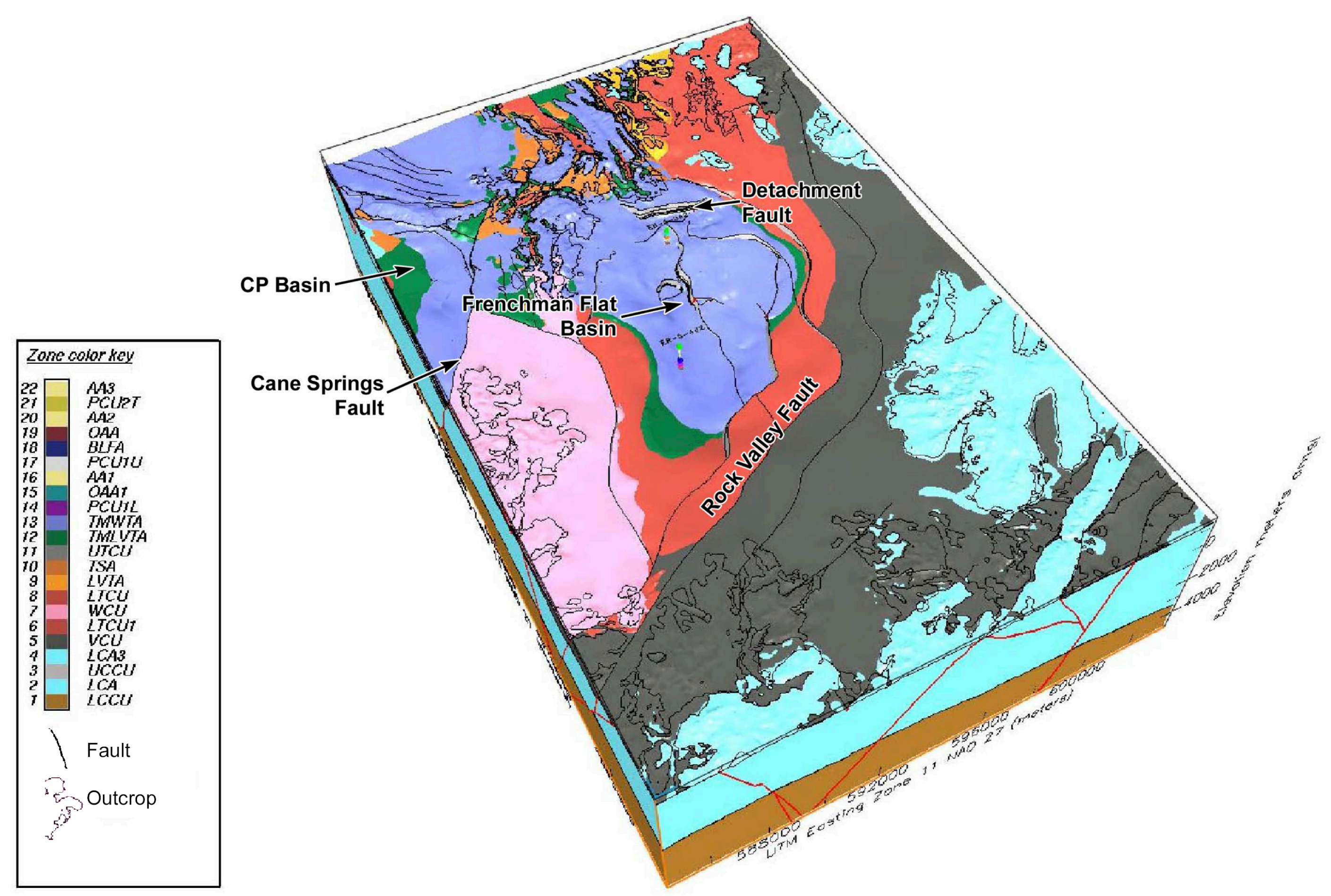


Section 2.1, the rocks of the NTS have been classified for hydrologic modeling using a two-level classification scheme in which HGUs are grouped to form HSUs (IT, 1996d). New units and additional detail have been added to the basic framework definition, but the systems developed by these early workers remain the best way to understand the groundwater of the NTS region. The HGU scheme used for CAU-scale modeling includes eight HGUs as mentioned in Section 2.1.1.2, Table 2-1.

\subsubsection{Hydrostratigraphic Units}

Brief descriptions of all the HSUs used to construct the Frenchman Flat model are provided in Table 2-3, and these are further explained in Appendix A. They are listed in approximate order from surface to basement, although some are laterally rather than vertically contiguous, and not all units are present in all parts of the model area.

Table 2-4 shows the correlation of Frenchman Flat HSUs with HSUs from earlier hydrostratigraphic models for this region. Figure 2-2 is a map showing a plan view of the surficial hydrostratigraphy for the Frenchman Flat model area. Figure 2-5 shows a northeast-southwest hydrostratigraphic cross section (C-C'), along the presumed flow direction in the carbonate aquifer, and an west-east hydrostratigraphic cross section (B-B') (perpendicular to the general groundwater flow direction). The traces of these cross-sections are shown on Figure 2-3. Both of these cross sections are from the Frenchman Flat 3-D framework documentation package (BN, 2004), where additional cross sections and detailed information regarding this CAU-scale model can be found. Figure 2-6 shows a fence diagram of the entire FF geologic model viewed from the southeast. Figure 2-7 shows an enlarged view of the fence diagram for the central testing area, and Figure 2-8 shows an enlarge view of the northern testing area, both from the same angle as the main view.

As can be seen from the information presented in this section, the Frenchman Flat hydrostratigraphic framework model (BN, 2004a) includes considerable structural detail and stratigraphic enhancement over the NTS regional HSU model (IT, 1996d). The total number of HSUs increased from 9 to 17; most of the increase affected the Quaternary-Tertiary alluvial section and the Tertiary volcanic section. The single AA in the regional model has been subdivided into five HSUs. The two Tertiary volcanic HSUs in the southwestern NTS area and the single volcanics undifferentiated HSU outside the NTS (of the NTS regional HSU model) were subdivided into eight HSUs for the Frenchman Flat model. Except for geometry details, the four pre-Tertiary HSUs remain as initially defined. 
Table 2-3

Hydrostratigraphic Units of the Frenchman Flat Hydrostratigraphic Framework Model

\begin{tabular}{|c|c|c|c|}
\hline $\begin{array}{c}\text { Hydrostratigraphic } \\
\text { Unit } \\
\text { (Symbol) }\end{array}$ & $\begin{array}{c}\text { Dominant } \\
\text { Hydrogeologic } \\
\text { Unit(s) }\end{array}$ & $\begin{array}{l}\text { Stratigraphic Unit } \\
\text { Map Symbols }^{b}\end{array}$ & General Description \\
\hline $\begin{array}{l}\text { Alluvial Aquifer (AA, AA1, AA2, } \\
\text { AA3) }\end{array}$ & AA & $\begin{array}{l}\text { Qay, QTc, Qai, QTa, } \\
\text { Tt }\end{array}$ & $\begin{array}{l}\text { Consists mainly of alluvium that fills extensional basins Also includes generally older Tertiary gravels, and very } \\
\text { thin air-fall tuffs. }\end{array}$ \\
\hline Playa Confining Unit (PCU2T) & $\mathrm{PCU}$ & Qp & Clayey silt and sandy silt. Forms the Frenchman Flat playa (dry lake). \\
\hline Basalt Lava Flow Aquifer (BLFA) & LFA & Tybf & $\begin{array}{l}\text { Several (possibly dissected) basalt flows recognized in the middle of the alluvial section of the north eastern } \\
\text { Frenchman Flat. Related to other basalt flows in Nye Canyon. }\end{array}$ \\
\hline $\begin{array}{l}\text { Older Altered Alluvial Aquifer } \\
\text { (OAA and OAA1) }^{\mathrm{C}}\end{array}$ & AA & QTa & Older, denser, zeolitized alluvium recognized only in northern Frenchman Flat. \\
\hline $\begin{array}{l}\text { Older Playa Confining Unit } \\
\text { (PCU1U and PCU1L) }^{\mathrm{C}}\end{array}$ & PCU & QTp & $\begin{array}{l}\text { Deep, subsurface playa deposits in the deepest portion of Frenchman Flat. Recognized in Well ER-5-4\#2 and } \\
\text { with 3-D seismic data. }\end{array}$ \\
\hline $\begin{array}{l}\text { Timber Mountain-Welded Tuff } \\
\text { Aquifer (TM-WTA) }\end{array}$ & $\begin{array}{l}\text { Mostly WTA, } \\
\text { minor VTA }\end{array}$ & Tma, Tmab, Tmr & $\begin{array}{l}\text { Consists mainly of extra-caldera welded ash-flow tuffs of Ammonia Tanks Tuff and Rainier Mesa Tuff. Unit } \\
\text { occurs mostly in north and central Frenchman Flat. Prolific aquifer when saturated. }\end{array}$ \\
\hline $\begin{array}{l}\text { Timber Mountain-Lower Vitric } \\
\text { Tuff Aquifer (TM-LVTA) }\end{array}$ & VTA & $\begin{array}{l}\text { Tma, Tmab, Tmr, } \\
\text { Tmrh, Tp, Th }\end{array}$ & $\begin{array}{l}\text { Defined to include all unaltered (nonzeolitic) nonwelded and bedded tuffs below the welded Tmr and above the } \\
\text { level of pervasive zeolitization. The presence of the welded Tpt (see TSA) complicates this general description. }\end{array}$ \\
\hline $\begin{array}{l}\text { Upper Tuff Confining Unit } \\
\text { (UTCU) }\end{array}$ & TCU & $\begin{array}{l}\text { Tmr (lower most), } \\
\text { Tmrh, Tp }\end{array}$ & Relatively thin TCU above the TSA. Grouped with the LTCU where the TSA is not present. \\
\hline Topopah Spring Aquifer (TSA) & WTA & Tpt & $\begin{array}{l}\text { The welded ash-flow lithofacies of the Topopah Spring Tuff in Massachusetts Mtn/French Peak area and } \\
\text { north-central Frenchman Flat. }\end{array}$ \\
\hline Lower Vitric Tuff Aquifer (LVTA) & VTA & Th & Relatively thin VTA unit below the TSA. Grouped with the TM-LVTA where TSA is not present. \\
\hline $\begin{array}{l}\text { Lower Tuff Confining Unit } \\
\text { (LTCU) }\end{array}$ & $\begin{array}{l}\text { TCU, minor } \\
\text { WTA }\end{array}$ & Th, Tw, Tc, Tn, To & $\begin{array}{l}\text { Generally includes all the zeolitic nonwelded and bedded tuffs in southeastern NTS. May include all units from } \\
\text { base of Tmr to top of Paleozoic-age rocks. }\end{array}$ \\
\hline $\begin{array}{l}\text { Wahmonie Confining Unit } \\
\text { (WCU) }\end{array}$ & TCU, minor LFA & $\begin{array}{l}\text { Tw (Twu, Twm, Twl, } \\
\text { Twls) }\end{array}$ & $\begin{array}{l}\text { Mixture of lava flows debris flows, layers, ash-flows, and air-falls. Typically zeolitic, argillic, or hydrothermally } \\
\text { altered. Grades/interfingers laterally with the LTCU. }\end{array}$ \\
\hline $\begin{array}{l}\text { Volcaniclastic Confining Unit } \\
\text { (VCU) }\end{array}$ & $\begin{array}{l}\text { TCU, minor AA } \\
\text { and CA }\end{array}$ & Tgp, Tgw & $\begin{array}{l}\text { Older Tertiary sedimentary rocks of variable lithologies including silts, clays, limestone, gravels and tuffaceous } \\
\text { units. Present in southeastern half of Frenchman Flat. }\end{array}$ \\
\hline $\begin{array}{l}\text { Lower Carbonate Aquifer - } \\
\text { Thrust Plate (LCA3) }\end{array}$ & $\mathrm{CA}$ & Dg through Cc & $\begin{array}{l}\text { Cambrian through Devonian, mostly limestone and dolomite, rocks that occur in the hanging wall of the Belted } \\
\text { Range thrust fault. Present only in the northwest corner (CP Basin) of the model area. }\end{array}$ \\
\hline $\begin{array}{l}\text { Upper Clastic Confining Unit } \\
\text { (UCCU) }\end{array}$ & $\mathrm{CCU}$ & Mc, MDe & $\begin{array}{l}\text { Late Devonian through Mississippian siliciclastic rocks. Present only in the northwest corner (CP Basin) of the } \\
\text { model area, northwest of the Cane Spring fault and southwest of the Topgallant fault. }\end{array}$ \\
\hline Lower Carbonate Aquifer (LCA) & $\mathrm{CA}$ & Dg through Cc & $\begin{array}{l}\text { Cambrian through Devonian mostly limestone and dolomite. Regional carbonate aquifer present through the } \\
\text { model area. }\end{array}$ \\
\hline $\begin{array}{l}\text { Lower Clastic Confining Unit } \\
\text { (LCCU and LCCU1) }^{\mathrm{C}}\end{array}$ & $\mathrm{CCU}$ & $\mathrm{Cc}, \mathrm{Cz}, \mathrm{Czw}, \mathrm{Zs}, \mathrm{Zj}$ & $\begin{array}{l}\text { Late Proterozoic through Early Cambrian siliciclastic rocks. Hydrologic "basement" present at great depth in } \\
\text { the model area }\end{array}$ \\
\hline
\end{tabular}

Source: BN (2004a)

asee Table A.1-1 for definitions of HGUs.

${ }^{b}$ Refer to Slate et al. (1999) and Ferguson et al. (1994) for definitions of stratigraphic unit map symbols.

${ }^{\mathrm{C}}$ The HSUs are hydrologically equivalent except for position relative to another HSU. The subdivisions are necessary to address operational requirements of the EarthVision ${ }^{\circledR}$ modeling software. 
Table 2-4

Correlation of Hydrostratigraphic Units of the Frenchman Flat Model and Earlier Models

\begin{tabular}{|c|c|c|c|c|c|}
\hline $\begin{array}{c}\text { Hydrostratigraphic } \\
\text { Unit }^{\mathrm{a}}\end{array}$ & $\begin{array}{l}\text { Symbol This } \\
\text { Report }\end{array}$ & $\begin{array}{c}\text { Correlation with } \\
\text { Phase I } \\
\text { Frenchman Flat } \\
\text { Model }^{\mathrm{b}}\end{array}$ & $\begin{array}{l}\text { Correlation } \\
\text { with } \\
\text { NTS Phase I }\end{array}$ & $\begin{array}{c}\text { Correlation } \\
\text { with Yucca Flat } \\
\text { Model }^{d}\end{array}$ & $\begin{array}{c}\text { Correlation with } \\
\text { Pahute Mesa/ } \\
\text { Oasis Valley } \\
\text { Model }^{\mathrm{e}}\end{array}$ \\
\hline Playa Confining Unit & PCU2T & \multirow{5}{*}{$A A^{f}$} & \multirow{5}{*}{$A A^{f}$} & PCU & Not present \\
\hline Alluvial Aquifer & $\begin{array}{c}\mathrm{AA}, \mathrm{AA} 1, \mathrm{AA} 2 \\
\mathrm{AA} 3^{\mathrm{i}}\end{array}$ & & & AA & AA \\
\hline Basalt Lava Flow Aquifer & BLFA & & & BLFA & YVCM \\
\hline Older Altered Alluvial Aquifer & OAA, OAA $1^{i}$ & & & Not present & Not present \\
\hline Older Playa Confining Unit & $\begin{array}{l}\text { PCU1U, } \\
\text { PCU1L }\end{array}$ & & & Not present & Not present \\
\hline $\begin{array}{l}\text { Timber Mountain-Welded Tuff } \\
\text { Aquifer }\end{array}$ & TM-WTA & \multirow{5}{*}{$T_{M A}^{f}$} & \multirow{5}{*}{$V A^{f}$} & TM-WTA & TMA \\
\hline $\begin{array}{l}\text { Timber Mountain-Lower Vitric } \\
\text { Tuff Aquifer }\end{array}$ & TM-LVTA & & & TM-LVTA & PVTA \\
\hline Upper Tuff Confining Unit & UTCU & & & $\begin{array}{c}\text { UTCU }^{d} \\
(Y F-U C U)^{g}\end{array}$ & UPCU, LPCU \\
\hline Topopah Spring Aquifer & TSA & & & TSA & TSA \\
\hline Lower Vitric Tuff Aquifer & LVTA & & & LVTA & PVTA \\
\hline Lower Tuff Confining Unit & LTCU, LTCU $1^{i}$ & TCU & \multirow[t]{2}{*}{$\mathrm{BCU}$} & $\begin{array}{c}\text { LTCU }^{d} \\
(\text { YF-LCU })^{g}\end{array}$ & $\begin{array}{l}\text { CFCU, BFCU, } \\
\text { PBRCM }^{\mathrm{h}}\end{array}$ \\
\hline Wahmonie Confining Unit & WCU & WCU & & Not present & Not present \\
\hline Volcaniclastic Confining Unit & VCU & VCU & VCCU & Not present & Not present \\
\hline $\begin{array}{l}\text { Lower Carbonate } \\
\text { Aquifer-Thrust Plate }\end{array}$ & LCA3 & Not present & LCA3 & LCA3 & LCA3 \\
\hline Upper Clastic Confining Unit & UCCU & Not present & UCCU & UCCU & UCCU \\
\hline Lower Carbonate Aquifer & LCA & \multirow{2}{*}{$\operatorname{PreT}^{f}$} & LCA & LCA & LCA \\
\hline Lower Clastic Confining Unit & LCCU & & LCCU & LCCU & LCCU \\
\hline
\end{tabular}

alf correlative to more than one HSU, all HSUs are listed.

${ }^{b}$ See IT (1998) for explanation initial Frenchman Flat model (1998) nomenclature.

'See IT (1996a) for explanation of the UGTA Phase I HSU nomenclature.

${ }^{\mathrm{d} D o c u m e n t a t i o n}$ for final Yucca Flat model is in progress.

e See BN (2002) for explanation of Pahute Mesa/Oasis Valley HSU nomenclature.

fNot subdivided.

'See Gonzales et al. (1998) for explanation of the Yucca Flat HSU nomenclature.

hMinor embedded ash-flow tuffs may have better aquifer properties than the bulk of this HSU.

iThe HSUs are hydrologically equivalent except for position relative to another HSU. The subdivisions are necessary to address operational requirements of the EarthVision ${ }^{\circledR}$ modeling software. 


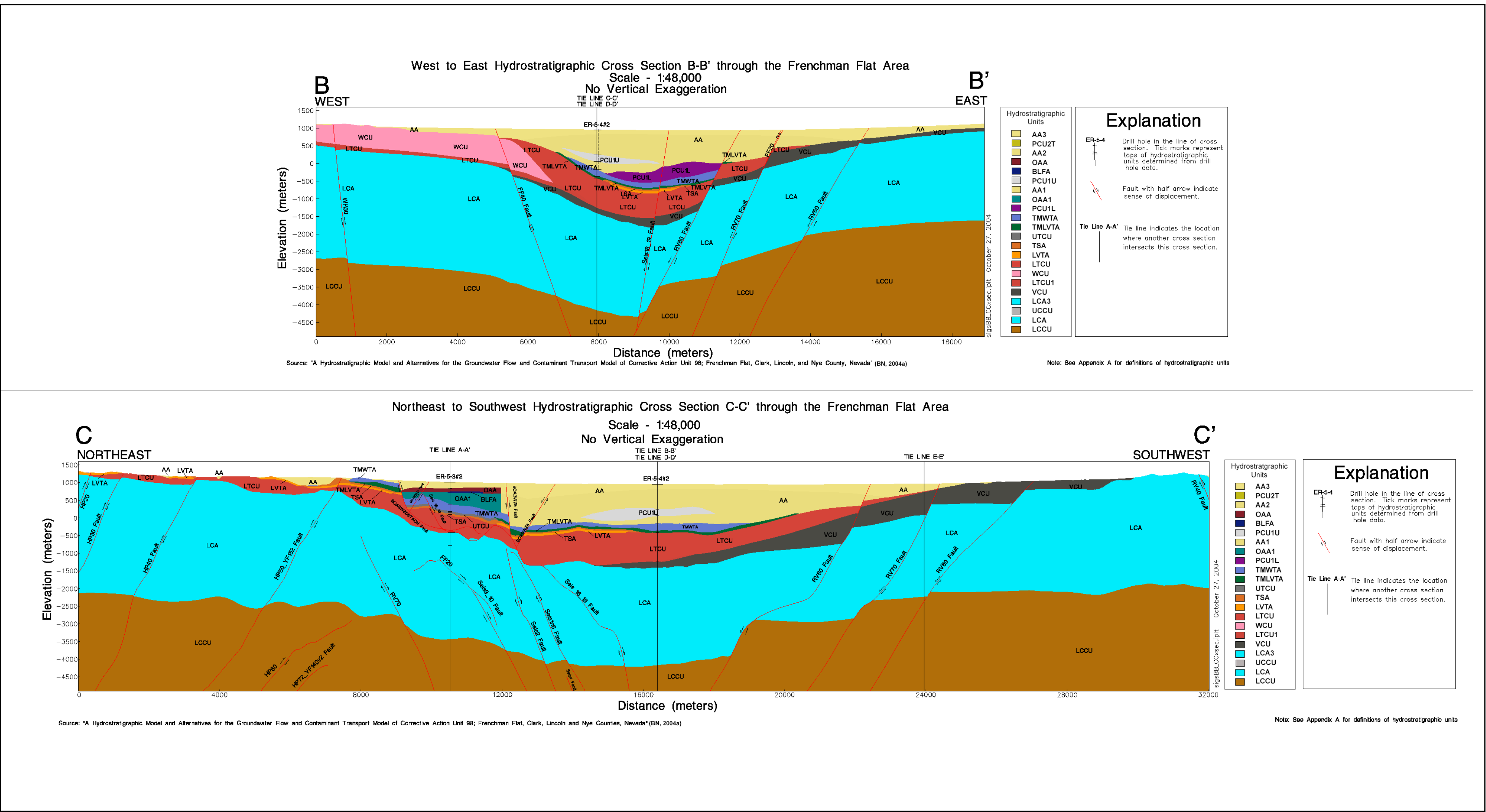

Figure 2-5

West to East and Northeast to Southwest Hydrostratigraphic Cross Sections Through the Frenchman Flat Area 


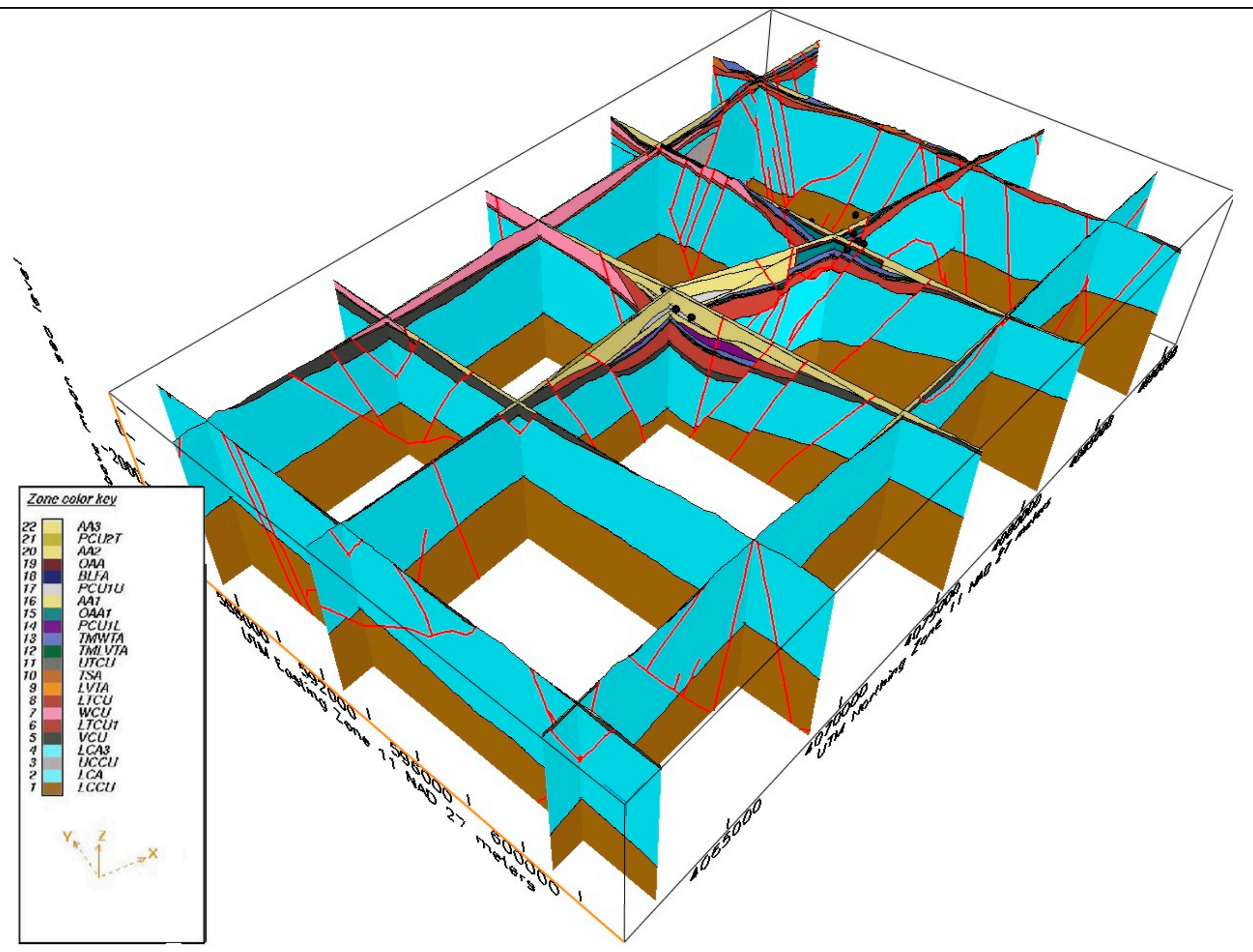

Fence Diagram of Phase II Frengure 2-6 Solid Black Spheres Indicate Cavity Locations 


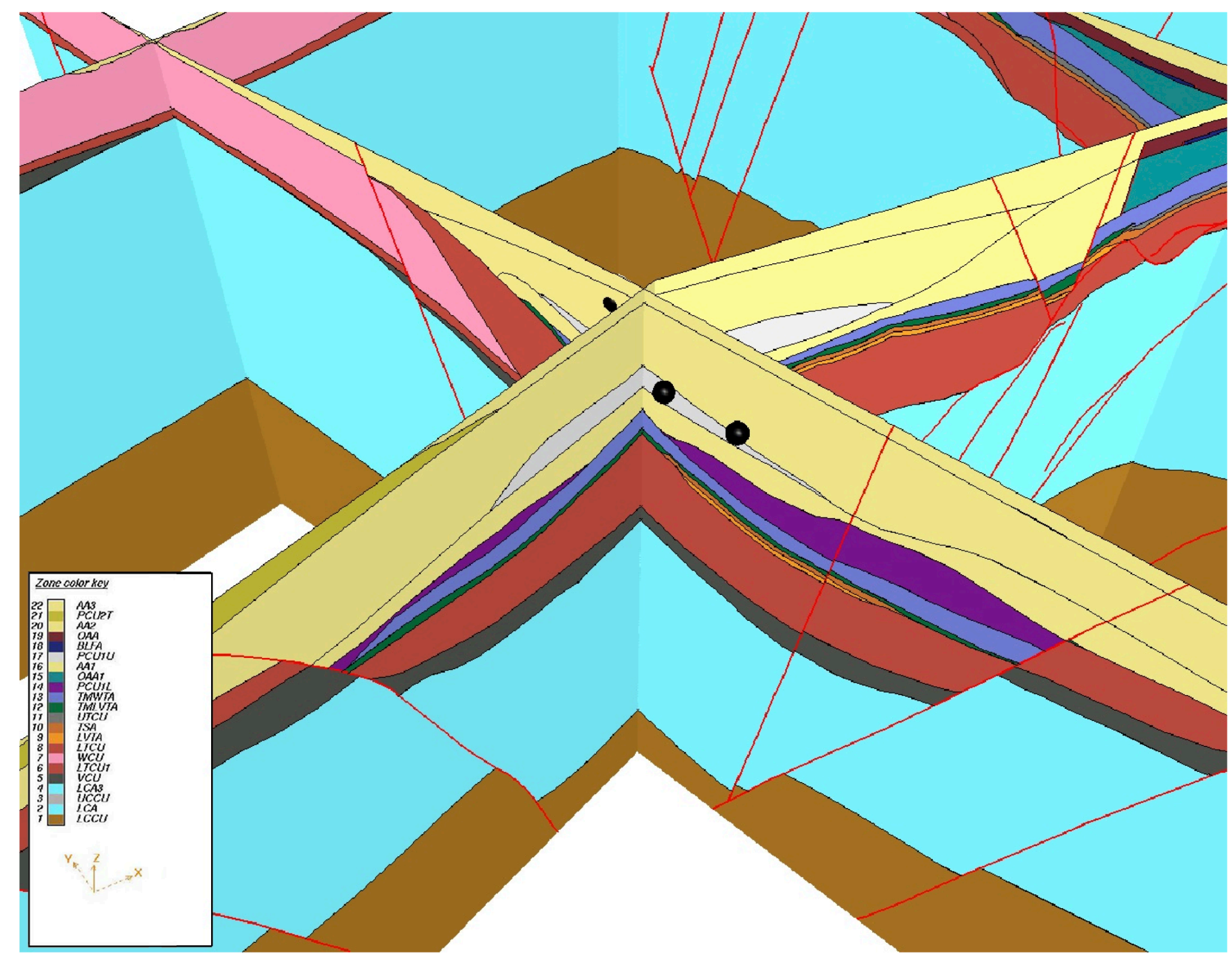




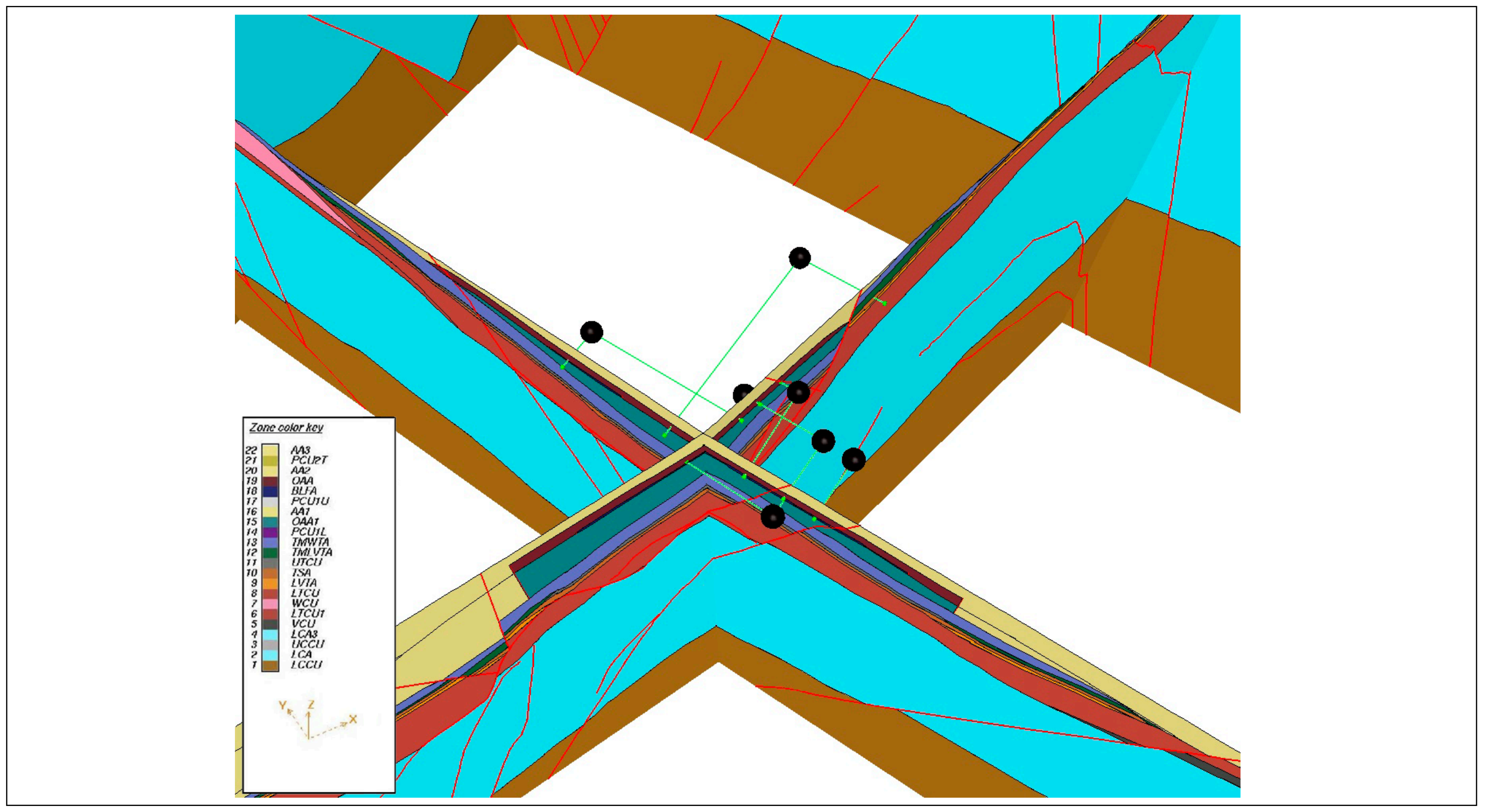

Figure 2-8

Enlarged View of the Northern Testing Area in Frenchman Flat

Solid Black Spheres Indicate Cavity Locations

(Sphere Size is not Propo 


\subsection{CAU Modeling Approach}

The process for achieving the UGTA corrective action strategy includes modeling to define the maximum extent of contaminant transport within a specified time frame. The use of groundwater flow and transport models to achieve the objectives of the corrective action strategy is specified in Appendix VI of FFACO (2000). This section presents an overview of the CAU groundwater flow and transport modeling approach, descriptions of the groundwater flow models, and data requirements. Additional discussion of the modeling approach for Frenchman Flat CAU is included in IT (2001a).

\subsection{Overview of CAU Modeling Approach}

Groundwater flow from the nuclear test locations occurs through diverse and structurally complex rocks (Laczniak et al., 1996). Given the complexity of the system, sources, and processes controlling transport, computer models will be required to meet the objectives of the FFACO strategy. The modeling approach used to develop an integrated 3-D model for flow and transport begins with characterization of the system, development of conceptual models based on assumptions of system processes, and representation of these processes mathematically. Mathematical models representing the system are then implemented on a computer.

\section{Integrated 3-D Model Development}

The CAU flow and transport models will consist of an integrated set of models. Some of these models focus on a small-scale (relative to the CAU) process such as radionuclide release from source regions. Others simplify CAU-scale processes such as reactive transport in fractures to an abstraction for system sensitivity analysis. Combined, the models (referred to as component models) constitute the CAU predictive model. Essential aspects of the processes described by the detailed process models must be accurately represented in the CAU model. This representation must include the uncertainty associated with the process or parameters.

The integrating numerical model will be a 3-D finite-element flow and transport simulator that captures the complex geologic structure including units of variable thickness, faults, and offsets, as well as complex transport processes associated with reactive solutes and fractured rock. The CAU groundwater flow model component requires two other component models: the NTS regional groundwater flow model (DOE/NV, 1997) and the recharge model(s). The CAU contaminant 
transport model component requires the CAU groundwater flow model and the hydrologic source term model.

\section{Total System Model}

The detailed component process models are computationally intensive and are currently not efficient for implementing thorough uncertainty analyses. Therefore, to complement the integrated modeling approach, a modeling platform for dynamic, probabilistic simulations may be used to develop simplified abstraction models that will attempt to reduce the description of the system to capture dominant processes and behaviors in one-dimensional (1-D) models of transport. Using this platform, uncertainty in processes and parameters can be explicitly represented. The simplicity of this approach facilitates a more thorough uncertainty analysis of the governing parameters and processes.

The CAU model approach and the total system model approach complement one another. The total system model results can be used to constrain scenarios to be considered by the CAU model, while the more detailed CAU model can be used to constrain the processes considered and their representation in the total system model. To use the total system transport model, it first must be demonstrated that simplified formulations capture the same general phenomena as the more complex CAU and process models. Then the total system model could be used to efficiently conduct additional sensitivity and uncertainty analyses not feasible with the complex CAU model. However, as computer hardware technology advances, it may become feasible to directly use the CAU process models in the uncertainty analyses. In this case, it will no longer be necessary to develop and use simplified abstraction models.

\section{CAU Model Validation}

The process of model validation, as it applied to the CAU model, involves following a modeling protocol - a series of steps which when followed builds support in demonstrating that a given site-specific model is capable of producing meaningful results. This increases confidence in the model predictions. To ensure fidelity of the CAU model to the physical system, a ten-step protocol will be utilized. These ten steps are: (1) establishment of model purpose, (2) development of conceptual model, (3) selection of a computer code and verification of the code, (4) model design, (5) model calibration, (6) sensitivity and uncertainty analyses, (7) model verification, (8) predictive simulations, (9) presentation of model results, and (10) postaudit.

\section{Data Requirements}

Data requirements for the CAU groundwater flow and transport models fall into the three categories listed below. Data to support the groundwater flow model are the focus of this document.

\section{Groundwater Flow}

Data types required for the groundwater flow model include permeability (or hydraulic conductivity $[\mathrm{K}]$ ), storage parameters, recharge, lateral boundary fluxes, hydraulic heads, and groundwater chemistry. These data types are the subject of this document and are discussed in detail in the following sections. 


\section{Contamination Sources}

Potential contaminant sources are the 10 test locations in Frenchman Flat. One of the tests was conducted $77 \mathrm{~m}$ below the water table and the other nine tests were located from 15 to $62 \mathrm{~m}$ above the water table. Nine of the tests were conducted in alluvium and one test was conducted in the volcanics. In addition, the CAMBRIC Migration Experiment (CME) distributed contaminants from CAMBRIC Test over an area larger than the original source. Well RNM-2S, completed in south-central Frenchman Flat, was pumped from October 1975 to August 1991 at an average rate of 23 million gallons per month. The pumped waters, containing contaminants from the nearby CAMBRIC test, were discharged to a ditch. The contaminated water seeped to the subsurface from the base of the ditch and from the playa area where the ditch ended. The information on the unclassified hydrologic source term and radionuclide data for Frenchman Flat will be documented in separate reports.

\section{Transport Parameters}

Major data types of interest include effective porosity, dispersivity, matrix porosity, matrix diffusion, sorption coefficients, and colloid-facilitated transport parameters. Note that for the purpose of modeling, effective porosity and matrix porosity are considered to be transport parameters rather than hydrologic parameters as they are required input variables in the contaminant transport model. Transport parameters data will be documented in a separate report

\subsection{Historical and Current Modeling Strategy for Frenchman Flat CAU}

Unlike other NTS CAUs, the Frenchman Flat CAI process is in a second iteration of data evaluation. Following a peer review of the Frenchman Flat CAU model (IT, 1999a), DOE and NDEP decided the data for Frenchman Flat were not adequate, and an addendum to the Frenchman Flat CAIP was produced (DOE/NV, 2000a). The addendum described new data to be collected and how the new data would be included in the evaluation of existing/new data. The addendum also addressed modifications to the Frenchman Flat CAU modeling approach.

The modeling approach described in this document enhances and extends the Frenchman Flat CAU model presented by IT Corporation (1999b). The major enhancements and extensions are listed below:

- Incorporate newly collected Frenchman Flat data. This data is derived primarily from two drill hole locations, one near the northern group of underground tests and the other near the southern group of underground tests. The new data includes geologic unit identification and description below the base of the alluvium, surface geophysical data to assess deep basin structure, water-level measurements at several depths to assess vertical hydraulic head relationships, hydraulic conductivity values from aquifer tests to improve the hydraulic parameter dataset, and interpretation of reactive mineral distribution in the alluvium to constrain the source term model. 
- Expand the assessment of uncertainty to include alternative geologic framework models, alternative conceptual flow models, better documented ranges of uncertainty on parameters, and uncertainty in the hydrologic source term.

- Use local-scale models to improve the accuracy of the transport predictions near the underground tests and allow for a more thorough assessment of uncertainty related to transport away from the underground tests.

- Develop a total system model to facilitate a more thorough analysis of uncertainty in the governing parameters, processes, and conceptual models.

\subsection{Groundwater Flow Modeling Approach and Data Requirements}

This section describes the approach used for development of the CAU groundwater flow model and the associated data requirements. The CAU transport modeling approach will be documented in a separate report.

The steps for developing the CAU groundwater flow model include:

- Identify Simulation Objectives

- Define CAU Geologic Model

- Define Parameter Distributions for Model Inputs

- Define CAU Flow Model Boundaries

- Select Computer Code

- Generate CAU Model Grid

- Calibrate CAU Flow Model

- Perform Parameter Sensitivity Analysis.

- Prepare Model Documentation

\subsubsection{Simulation Objectives}

Simulation objectives are defined in Appendix VI of the FFACO (1996). A flow model for each CAU will be constructed to simulate local three-dimensional flow, evaluate the range of flow conditions in the CAU that may be important in determining maximum extent of transport, and provide boundary conditions for transport for predicting contaminant migration from source locations.

\subsubsection{Geologic Model}

The geologic boundaries were chosen such that: (a) they coincide with perceived geologic and hydrologic domains, (b) they include important faults that may impact flow within Frenchman Flat, and (c) the contaminant source areas and perceived migration pathways were included. A base model and four alternative 
geologic models have been developed for the Frenchman flat CAU (Section 2.0). The Frenchman Flat CAU flow and transport models will be developed within the boundaries of the geologic model.

\subsubsection{Model Parameters}

Specific data types needed to support groundwater flow modeling include hydraulic properties, hydraulic conductivity, groundwater recharge, discharge, lateral boundary fluxes, and hydraulic heads. Parameter distributions were developed based on review and analysis of available data and information.

\subsubsection{CAU Model Boundaries and Boundary Conditions}

The next step of the process is identification of the model boundaries and boundary conditions for the CAU-scale model. When selecting boundaries for a flow and transport model, features of the aquifer system such as recharge and discharge zones, low-permeability rock layers (at base of model), or aquifer connections with surface water bodies are preferred because they provide easily described hydraulic boundary information. The characteristics of the Frenchman Flat CAU are such that natural physical boundaries are too distant to be used for the lateral boundaries of the flow and transport model. The boundaries of the CAU flow and transport model were selected to incorporate all relevant sources, important hydrogeologic features, and wells providing hydrologic and geologic information. These boundaries will be similar to the geologic model boundaries, but of more limited extent to the east and south. Lateral boundary conditions will be obtained from the NTS regional groundwater flow model simulations (Section 9.0). The recharge models (Section 6.0) will provide fluxes for the upper model surface. The bottom of the model will be no deeper than the estimated contact between the LCA and the underlying LCCU.

\subsubsection{Select Computer Code}

The FEHM code (Zyvoloski et al., 1997b), developed by LANL, was chosen for the Pahute Mesa CAU-scale flow and transport model (DOE/NV, 1999b) and has been demonstrated to be suitable for development of the calibrated groundwater flow model. The processes of interest for the Frenchman Flat CAU are the same as those of the Pahute Mesa CAU. Therefore, FEHM has been selected for development of the Frenchman Flat CAU model.

FEHM simulates 3-D, time-dependent, multiphase, nonisothermal flow, and multicomponent, reactive transport through porous and fractured media. FEHM's finite-element formulation provides an accurate representation of complex 3-D geologic media and structures and their effects on subsurface flow and transport. Specific capabilities include:

- 3-D 
- $\quad$ Flow of air, water, and heat

- Multiple chemically reactive and sorbing tracers

- Colloid transport

- Finite-element/finite-volume formulation

- Coupled stress module

- $\quad$ Saturated and unsaturated media

- $\quad$ Preconditioned conjugate gradient solution of coupled nonlinear equations

- $\quad$ Porous media equivalent model

- Double-porosity and double-porosity/double-permeability capabilities

- Complex geometries with unstructured grids

- Two different reactive, double-porosity, particle-tracking modules

- Coupled to parameter estimation (PEST) software

- Linked with Los Alamos Grid Toolbox (LaGriT) grid generation software

- $\quad$ Supported on SUN, SGI, ALPHA, and Intel (windows)

Documentation includes a description of the mathematical models and numerical methods used by FEHM (Zyvoloski et al., 1997a), the user's manual (Zyvoloski et al., 1997b), documentation of the functional and performance requirements for FEHM, description of the FEHM software, and verification and validation reports (Dash et al., 1997; Dash, 2000 and 2001). Further, the software is maintained in configuration management at LANL. With each new release, the software is subjected to a rigorous verification test to ensure accuracy and functionality of all capabilities. LaGriT (George, 1997) is an auxiliary code to the FEHM code, developed by LANL to generate finite-element meshes for FEHM models.

Assumptions for the flow and energy transport models in FEHM include fluid flow governed by Darcy's law, thermal equilibrium between fluid and rock, immovable rock phase, and negligible viscous heating. Specific assumptions are discussed further by Zyvoloski, et al. (1997a).

Inputs to the flow model include the finite-element grid, initial conditions, lateral boundary conditions, recharge, and material properties for HSUs and faults. For application to isothermal groundwater flow, the calibrated FEHM model produces values of hydraulic head or pressure for each node in the grid. 
PEST, a software package developed by Watermark Computing (2000), provides a nonlinear parameter estimation routine that can be used to automatically calibrate a flow model. PEST can be used with any existing modeling computer code for model calibration without making any changes to that code. However, FEHM was recently modified to efficiently provide data needed by PEST in each iteration with no additional post-processing.

All three codes (FEHM [Zyvoloski et al., 1997b]), PEST [Watermark Computing, 2000], and LaGriT [George, 1997]) have been used in the Yucca Mountain Project (YMP) modeling activities. Their usage in the development of the YMP saturated zone flow model is documented in a report titled: Calibration of the Site-Scale Saturated Zone Flow Model (CRWMS M\&O, 2000). All YMP models are developed under the YMP quality assurance program (DOE/NV, 2000b).

\subsubsection{Grid Generation}

Simulations of flow and transport, including particle tracking, in 3-D domains representing the complex hydrostratigraphy described in the hydrogeologic models will be conducted on finite-element grids. The grids are discrete interconnected tetrahedra which, when connected together, capture the structure of the hydrostratigraphy. The flexibility of finite elements allows for the resolution of the grid to vary spatially so as to capture source areas and complex structures such as faults with higher resolution than other areas where coarser discretization is sufficient.

The method developed for the flow of information from hydrogeologic interpretation through grid generation has the following steps. The process begins with incorporation of a given hydrogeologic digital model using EarthVision ${ }^{\mathbb{B}}$ (Dynamic Graphics, 2002). EarthVision ${ }^{\circledR}$ is a suite of software applications used for geospatial analyses. Elevations describing the surface of each HSU and traces of each fault are extracted from the EarthVision ${ }^{\circledR}$ model (Dynamic Graphics, 2002) and become inputs to the grid generation software, LaGriT (George, 1997). This code is composed of a suite of grid generation tools and provides an integrated system for all grid generation steps.

Unique properties can be assigned to each HSU and fault in the grid. Grid generation will require decisions on the location of high-resolution areas. Possible candidates for high resolution include fault zones and thin hydrostratigraphic units. A process for transferring hydrogeologic framework model information from an EarthVision ${ }^{\circledR}$ model (Dynamic Graphics, 2002) to inputs required by LaGriT (George, 1997) has been developed, tested, and applied to development of the Pahute Mesa CAU model. Calibration efficiency can be increased by keeping the flow model grids coarse, then adding higher resolution to source regions and plume pathways for the transport simulations. 


\subsubsection{Flow Model Calibration}

Calibration consists of determining model parameter values such that simulated heads and fluxes are consistent with observed or target values. The input parameters for the CAU flow model will include the permeabilities of the HSUs and faults in the model domain (Section 5.0) and fluxes through the top of the model estimated as recharge (Section 6.0). Specified observations for the CAU model will include hydraulic heads measured in wells within the model domain (Section 8.0) and fluxes through lateral model boundaries calculated using the NTS regional flow model (Section 9.0). These data provide "targets" for the calibration process. Data required for calibration includes information from hydrologic data analysis including well locations, locations of open intervals, HSUs represented by open intervals, lateral boundary fluxes from the NTS regional flow model, and fluxes into the water table from the recharge model.

The PEST code is used in conjunction with FEHM to calculate the weighted sum of squared differences between model-generated heads and observed heads and between simulated flux values and regional model fluxes at the model boundary. This sum is referred to as the objective function. PEST then repeatedly runs the flow model to guide the adjustment of parameters until the objective function is minimized. In principle, PEST can be set up to adjust permeabilities until (1) simulated heads reasonably match measured heads within the CAU model domain and (2) simulated fluxes on the CAU model boundary approximately match those calculated by the NTS regional flow model. Due to random and systematic errors, there will always be some discrepancy between modeled and measured values. PEST attempts to minimize this discrepancy and provides estimates of uncertainty in the results. Since the flow model must be run many times during calibration, this part of the process requires heavy usage of computing resources. A model calibration will be specific to the geologic model (Section 2.0) and the recharge specified and the lateral boundary fluxes and hydraulic heads used as calibration targets. Alternative geologic models, alternative recharge models, or changes in calibration targets will require additional calibrations.

The PEST optimization process will produce expected values, estimated 95-percent confidence limits, and a measure of sensitivity for HSU and fault hydraulic properties used as parameters. However, it is recognized that the PEST uncertainty results based on the typical linear assumptions will not be appropriate for full uncertainty analysis. Rather, expert judgement will also be important.

For complex models with sparse data, calibration is expected to be non-unique. That is, more than one set of parameter values provided to the flow model could result in the observed hydraulic heads and fluxes. Analysis of geochemical data will be integrated into the calibration process to provide independent lines of evidence to support parameters leading to the prediction of groundwater flow paths and travel times.

Thermal effects may need to be considered during calibration. Sources of heat include flow of heat from deeper layers toward the surface evidenced by the geothermal gradient (Blankennagel and Weir, 1973) and residual thermal pulses 
from underground nuclear tests. This small-scale phenomenon from nuclear tests, if deemed important, will be handled in the hydrologic source term. The saturated hydraulic conductivity is dependent on both rock and water properties. Therefore, the presence of warmer water in deeper systems may cause an increase in $\mathrm{K}$, but this can be accounted for by increased $\mathrm{K}$ in proportion to the change in temperature, then performing isothermal simulations. Even for steady-state flow fields, FEHM accounts for thermal variation effects based either on elevation in the model or HSU in the model.

Calibration of the CAU model will be conducted in two steps. First, a simplified sensitivity/uncertainty analysis will be performed to bound ranges of flux into the model. The range of boundary fluxes will come from the uncertainty in the NTS regional groundwater flow model. The hydraulic characteristics of each HSU will be treated in a deterministic fashion. Anisotropy and reduction in hydraulic conductivity with depth will be investigated for appropriate geologic units. The steady-state CAU model will be calibrated to observed water-levels and to the range of the fluxes on the boundaries.

Calibration of the Frenchman Flat CAU groundwater flow model will use an approach that will base calibration on evaluation of the weight of evidence. Evidence that should be considered include:

- Appropriateness of geologic representation

- Goodness of fit of head and boundary flux

- Agreement with site characterization data

- Agreement with overall conceptual model

The groundwater flow model for the Frenchman Flat area will be calibrated using American Society for Testing and Materials (ASTM) standard guidance for calibrating groundwater models. The Standard Guide for Calibrating a Ground-Water Flow Model Application (D-5981) (ASTM, 2002f) is a guide for calibrating porous medium (continuum) groundwater flow models. The method can be adjusted to use on other types of groundwater models such as multiphase models, noncontinuum (karst or fracture flow) models, or mass transport models. The ASTM standard procedures that will be used to implement the guidance cover the use of site-specific information (D-5490) (ASTM, 2002a), applying modeling to site-specific problems (D-5447) (ASTM, 1993), defining boundary (D-5609) (ASTM, 2002b) and initial conditions (D-5610) (ASTM, 2002c), performing sensitivity analyses (D-5611) (ASTM, 2002d), and documenting groundwater flow model applications (D-5718) (ASTM, 2002e).

\subsubsection{Sensitivity Analysis}

Sensitivity analysis is a systematic process of varying the magnitude of model inputs such as hydraulic conductivity, recharge, and boundary conditions and determining the effect on model outputs such as hydraulic head and flux. Sensitivity analyses are conducted in conjunction with calibration of the flow model. Sensitivity analyses conducted during model calibration help identify parameters that can be estimated. Formal sensitivity analyses conducted after 
model calibration help identify parameters which affect the model results. The sensitivity analysis process can be automated using the Sensitivity Analysis (SENSAN) utility code contained in PEST.

\subsubsection{Model Documentation}

Documentation of the model documentation for the Frenchman Flat CAU model will include:

- Identification of all components, inputs, and assumptions of the analysis

- Justification of assumptions, simplifications, and parameter ranges and distributions used

- Description of all uncertainties

- Identification of the results of sensitivity analysis

- Description of major alternative model formulations and sensitivity of results to alternatives

- Documentation of final model sufficiently detailed to allow replication of modeling and calculations

- Identification of all significant limitations of the model

- Description of all significant conclusions, limitations, and insights

\subsection{Data Requirements}

Specific data types needed to simulate groundwater flow shown in Figure 3-1 are geologic data, hydraulic head data, groundwater recharge estimates, discharge estimates, hydraulic conductivity, and groundwater chemistry data. Geologic data were described in Section 2.0. Hydraulic head data serve as targets to which the flow model is calibrated. Recharge refers to either lateral flow across the CAU-model boundary into the model or recharge that enters from the land surface and reaches the saturated groundwater system. Discharge is the lateral flow across the CAU-model boundary out of the model or natural discharge to the surface (e.g., ET, springs, seeps) or wells. There is no natural surface discharge in the Frenchman Flat basin. The hydraulic conductivity is a measure of the water-transmitting ability of the aquifer system. Hydraulic conductivity may be heterogeneous and vary from location-to-location within a geologic unit and/or across geologic units. Anisotropy and reduction in hydraulic conductivity with depth may important in some of the geologic units. An understanding of the natural geochemical system may provide constraints on the flow model for the Frenchman Flat CAU. Figure 3-1 presents data types and their utilization in the groundwater flow model (SNJV, 2004a). The various data types are described in 


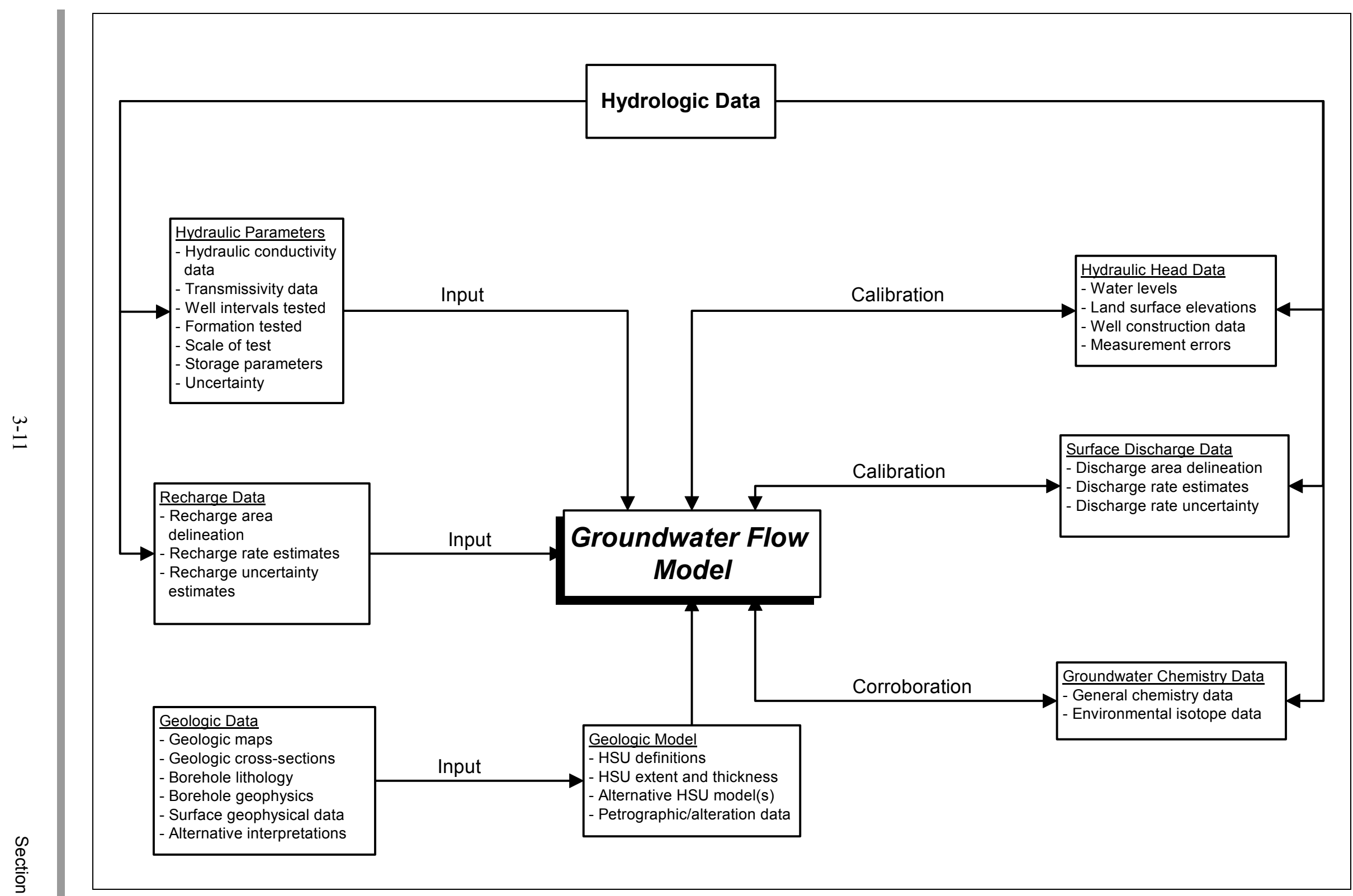

Figure 3-1

Data Types and Utilization in the Groundwater Flow Model (SNJV, 2004a) 
Section 4.0. The summary and discussion of data for hydraulic conductivity and storage properties, recharge, discharge, hydraulic heads, lateral boundary flux, and groundwater geochemistry are presented in Sections 5.0, 6.0, 7.0, 8.0, 9.0, and 10.0 , respectively. 


\subsection{Data Analysis}

Data analysis is the process of compiling, assessing, and interpreting available data in preparation for CAU groundwater flow and transport modeling. The data needed for CAU modeling include a wide variety of types, from a wide variety of sources, and represent a wide variety of measurements and scales of measurement. The process of analyzing the data can be summarized in the following seven steps: (1) compilation of existing data for the FF investigation area, (2) transfer of applicable data from outside the FF area, (3) assignment of data quality indicators, (4) assessment of data representativeness and appropriateness for use in CAU modeling, (5) data reduction and analysis, (6) graphical and tabular presentation of results, and (7) discussion of data limitations and the possible impacts to the model. This document presents data analysis and results used to support the development of a CAU-scale groundwater model.

\subsection{Data Compilation}

The compilation of existing data is a multiple step process of determining needed data, identifying and acquiring available data, and compiling the data into structured databases. As discussed in later sections of this document, certain data types required for CAU modeling are derivative, determined by processing more basic data using models specifically developed for the purpose, such as recharge models used to evaluate uncertainty in recharge distribution. Data types of interest and data sources are discussed in the following sections.

\subsubsection{Data Types}

General descriptions of the various types of information needed for modeling are provided in the following sections. The descriptions are followed by explanations pertinent to the different hydrologic data types.

\subsubsection{Description of Hydrologic Data Types}

Information needed to support groundwater flow modeling include hydraulic properties, precipitation recharge, discharge to the surface, hydraulic heads, lateral boundary fluxes, and groundwater chemistry. Following are brief descriptions of each data type and information on the how the data type is handled in this report. 


\section{Hydraulic Properties}

Hydraulic properties needed for CAU modeling are hydraulic conductivity and storage for the geologic formations included in the model. Hydraulic conductivity controls the rate of movement of groundwater through the system. Two data types relating to hydraulic conductivity are required by the model: horizontal hydraulic conductivity and vertical hydraulic conductivity, which is input to the model as an anisotropy ratio. Values of horizontal-hydraulic conductivity will be used in two ways. First, the range of measured values provides an uncertainty range and distribution for the parameter guiding selection of values used for model calibration. Second, the distribution will be used during the uncertainty analyses to generate a set of realizations that statistically reflects the hydraulic conductivity information. Specific storage is another property of geologic units that controls the distribution of groundwater response during transient conditions. Transient, or non steady-state, flow conditions are caused when natural or artificial stress is placed on an aquifer and the flow distribution must adjust. Data analysis and results for the hydraulic property data analysis are presented in Section 5.0.

\section{Recharge}

Under natural conditions, recharge occurs from precipitation via infiltration through the unsaturated zone to the saturated zone. In general, only a small portion of precipitation becomes recharge. Surface runoff redistributes some of the water available for recharge from the original distribution of precipitation, increasing the potential for recharge in washes and canyons. Recharge is an important component of the hydrologic system, determining the flow through the groundwater system. The areal distribution of recharge affects flow directions, and the amount of recharge entering the flow system affects the velocity of groundwater. Recharge rates must be estimated based on precipitation distribution and infiltration models because recharge cannot be measured directly, especially over the large area of interest. Areal recharge may also be artificially induced by man through placement of water onto the ground surface such as in ponds, drainage ditches, craters, and irrigation. However, the volume of such recharge is negligible within the area of interest and is, therefore, not accounted for. Recharge rates may be adjusted during the groundwater flow model calibration. The analysis provides an assessment of the uncertainty in the recharge distribution. Phase II recharge data analysis information is presented in Section 6.0.

\section{Surface Discharge}

Under natural conditions, discharge from the groundwater system to the ground surface can occur through spring flow and evapotransipration. Natural discharge ranges are used as targets during the flow model calibration process. However, spring flow and evapotransipration from the saturated zone do not occur in the FF CAU. Man-made discharge occurs through pumping of wells, and long-term high-rate pumping can have substantial effects on water-levels. Historic well pumping discharge is tabulated. This well discharge data may be used to simulate transient groundwater responses. Information on surface discharge in FF is presented in Section 7.0. 


\section{Hydraulic Heads}

Hydraulic head information is used to define the pressure distribution in the aquifer system. The head data is mostly in the form of measured water-level elevations although a few discrete-depth pressure measurements are available. Land surface elevations at the locations of known regional springs may also be used to approximate hydraulic heads. However, there is no regional spring data in the FF CAU. The water-level data measured in wells and boreholes located within the FF area and vicinity were analyzed to derive a hydraulic head dataset for each measurement location. The dataset for each location both indicates the uncertainty of the head measurements and shows changes that have taken place during the measurement period. The head distribution across FF is presented as contours of the water-level elevation at two different times: prior to substantial water pumping in the FF basin for NTS activities, and for current time. Hydraulic heads for locations inside of the model area are used as targets during the calibration process of the groundwater flow model with the objective of simulating the head distribution. Hydraulic heads for locations outside of the model area, but within close proximity, may be used to define model boundary conditions. Information on hydraulic heads and analysis of the head distribution is presented in Section 8.0.

\section{Lateral Boundary Fluxes}

Groundwater flow beneath the FF CAU occurs across the defined boundaries of the CAU groundwater flow model. The subsurface inflow and outflow rates at these boundaries are referred to as the lateral boundary fluxes. The ranges for the lateral boundary fluxes are derived from the NTS regional flow model using a base model and four alternative hydrostratigraphic and six recharge models. The lateral boundary flux analysis is used to define model boundary conditions for the CAU modeling. Information on the lateral boundary flux analysis is presented in Section 9.0.

\section{Groundwater Chemistry}

General groundwater chemistry data and stable/environmental isotope data provide important indications of groundwater recharge, discharge, movement, and storage. Groundwater chemistry data are not incorporated as input in the flow model; rather, interpretations of groundwater chemistry data are used to evaluate and verify calibration of the groundwater flow and transport models. These interpretations provide an independent check on groundwater flow paths and travel times. Groundwater geochemistry information and analysis is presented in Section 10.0.

\subsubsection{Supporting Information}

The following types of supporting information for each data type and/or data entry are recorded in the documentation, where applicable and available:

- Identification and location information

- Physical information on the location

- Sample information 
- Chemical constituents

- Method of data collection or type of test

- Scale of measurement

- Date of data collection

- Stratigraphic unit

- Lithology

- Alteration

- Hydrostratigraphic unit

- Method of data analysis

- Observed parameter value

- Parameter spatial distribution

- Uncertainties

- Any references relating to the data records

- Any noted deficiencies

References to the specific sources of information are provided along with the data. A general description of the data sources is provided in Section 4.1.2.

\subsubsection{Data Sources}

A great many sources for the data have been identified. Historic data are available in many publications. Much of this data was incorporated in databases developed as part of the NTS regional groundwater flow and transport modeling

(DOE/NV, 1997), which were supplemented with additional data compilation that supported the development of the FF CAIP and Addendum. The data considered in the FF Phase I data report have been supplemented with new data collected through UGTA field investigations (conducted in accordance with the FF CAIP Addendum DOE/NV, 2000a) and additional existing data not previously incorporated.

Data for the Frenchman Flat Area come from numerous organizations including BN, LLNL, LANL, DRI, USGS, SNJV, and the University of Nevada, Las VegasHarry Reid Center for Environmental Studies. A large amount of historic data had been gathered under the auspices of previous NTS Management and Operating (M\&O) contractors (Reynolds Electrical \& Engineering Co., Inc. [REECO] and Fenix \& Scisson [F\&S]), Architect and Engineer (A\&E) contractor Raytheon Services Nevada, and Environmental Restoration (ER) contractors (IT Corporation, Shaw Environmental, and Stoller-Navarro Joint Venture [SNJV]).

\section{FF-Specific Data}

Data collected from within the FF study area or, more restrictively, from within the FF CAU geologic model area (Figure 1-2), depending upon the data-type and usage, are classified as FF-specific data. These data are directly applicable to the FF CAU and data analysis. 


\section{NTS Investigation Area Data}

Data and analyses for the NTS investigation area are incorporated where applicable. This primarily includes data from other CAUs that have direct relevance or transferability to FF. The use of this transferred data is discussed and justified in this document.

\section{Yucca Mountain Data}

Yucca Mountain is the proposed geologic storage location for commercial and defense high-level radioactive waste in the United Sates. A great deal of high-quality data has been collected and analyzed during investigations of the Yucca Mountain Site. The YMP is located adjacent to the southern edge of the Pahute Mesa investigation area. The volcanic geology in the YMP region is similar to the volcanic geology in the Pahute Mesa CAU, but not exactly the same. A process was developed to assess the transferability of YMP data for use in the Pahute Mesa CAU model. The data were then incorporated in the regional HSU analysis, which is applied to the FF CAU through a crosswalk based on similar HSU characteristics.

\section{Other Data}

Data from more distant locations have been incorporated in the analysis for select purposes. The use of such data is explained and justified in the discussion of data analysis for the particular data-type.

\subsection{Data Transfer Methodology}

It has been proposed that using data from other sites to reduce flow and transport parameter uncertainty is an appropriate approach when developing models in a sparse data environment (Freeze et al., 1990), such as that of the FF area. This approach incorporates flow and transport parameter data from other investigations of similar hydrogeologic environments for parameters to be used in modeling of the study area. Note that in this document, hydraulic and geochemical properties are the only hydrologic data types that may be eligible for data transfer. Utilization of data from other sites can be both a cost-effective and necessary step for a modeling effort in a sparse data environment. Nearby sites considered as sources of additional data for the Frenchman Flat CAU are other UGTA CAUs Yucca Mountain, and the immediate downgradient extension of FF CAU HSUs. General transfer methodology, factors that influence flow and transport parameter transferability, and the transfer of YMP data are described in this section.

A technical basis document (TBD) for data transferability (SNJV, 2004c) was issued June 2004. This TBD provides a comprehensive discussion of approaches and methodologies for data transfer. This document was published after the FF data analysis process was complete, and the recommendations were not explicitly considered during the data analysis process. The concepts and considerations discussed in this document were generally known, and had guided data transfer in previous analyses as well as the analyses in this document. In general, the approach titled "accept unless rejected" (SNJV, 2004c, Section 3.0) was used. 
However, detailed evaluation of individual data was not pursued at the level described in the document.

\subsubsection{General Transfer Methodology}

The use of flow and transport data from one study area to another to develop parameter distributions for flow and transport modeling of UGTA CAUs can be justified by examining specific similarities that exist between the study areas. It must be determined that there is a sufficient similarity to transfer data, taking into account the various factors mentioned in the Section 4.2. A general approach was used for the transfer of data from other study areas to the FF CAU based on the following strategy:

- Flow and transport data were identified for the entire NTS investigation area. This includes the other UGTA CAUs and other nearby areas that had been investigated related to NTS activities. In particular, the Yucca Mountain site characterization project area was included.

- Once the available sources of flow and transport parameter data were identified, the factors affecting the data parameters were evaluated. This was incorporated through the use of the correlation of CAU HSUs assigned to data values to regional HSUs. The correlation was based on the CAU geologic models and the regional model, and incorporates the generalized judgements of the geologists who developed these geologic models. Their judgements combine evaluations of lithology, stratigraphy alteration, stress history, and general hydrogeologic characteristics.

- Finally, if sufficient data were available for the FF study area, separate statistical distributions were developed for both the FF data and all of the data, including FF data and transferred data. The distributions can be compared. The distributions of parameters for the larger dataset may be comparable, and provide more complete information, or may not be comparable.

\subsubsection{Factors Influencing Flow and Transport Parameters}

The geologic history of the subject rocks influences the flow and transport of groundwater in the subsurface environment in a variety of ways. This section focuses on major factors which influence rock properties and hydrologic characteristics and, consequently, flows and transport parameters. These factors include the rock type, deposition and alteration history, structural setting and mechanical alteration, and groundwater chemical composition.

\section{Rock Type}

The specific rock type of a study area has an important impact on the flow and transport of groundwater. Alluvial materials ranging in texture from fine sand to 
coarse gravels that are well sorted would obviously have different hydraulic properties than an indurated, non-fractured carbonate rock.

\section{Deposition and Alteration History}

The depositional environment of a rock can influence things such as the primary porosity of sedimentary rocks or the texture of volcanic rocks. The alteration of rock can play a large factor in the flow and transport of groundwater in the subsurface environment. For example, the formation of zeolitic material in volcanic tuffs can greatly decrease the permeability of a given formation.

\section{Structural Setting and Mechanical Alteration}

The structural setting of a given area has a large impact on the flow and transport of groundwater in the subsurface environment. Structural episodes may increase faulting in a given area that could lead to increase in groundwater flow. The stress field resulting from structural episodes can influence a variety of things such as fracture orientation, aperture distribution, and fracture connectivity. For example, regions of extensional stress tend to form fractures that are open to flow and would tend to increase groundwater movement.

\section{Groundwater Chemical Composition}

Groundwater chemistry can play an important role in the flow and transport characteristics of a groundwater flow system. It can have a large impact on everything from mineral dissolution and precipitation reactions to fracture geometry. For example, mineral precipitation or dissolution reactions within fractures can cause a reduction in permeability from filling fractures with minerals, or it can cause an enhancement of permeability due to dissolution of flow channels.

These factors are considered in the development of the geologic models of the CAUs, and are incorporated in the structural and HSU components of the geologic models. Section 2.1.1.1 and Section 2.1.1.2 discuss the development of HSUs from HGUs, explaining how the factors listed above are considered.

\subsubsection{YMP Data Transfer}

The Yucca Mountain Site Characterization Project has implemented one of the largest hydrologic and geologic characterization studies of volcanic rocks ever conducted. The proximity and similar hydrogeologic environment of the Yucca Mountain Site to Frenchman Flat make it particularly relevant as a source of data for hydraulic properties for similar FF HSUs. A detailed rationale for the transfer of data from the YMP was provided in Appendix B of the hydrologic data documentation package for Pahute Mesa (SNJV, 2004a). The use of this transferred data was more prominent for Pahute Mesa, and applies to FF primarily with respect to data incorporated in the hydraulic property analyses for the regional HSUs within the NTS investigation area. A brief summary of the justification for data transfer is presented here: 
- Both areas are located in the Southwestern Nevada Volcanic Field (SWNVF).

- Volcanic rocks in both areas are the result of similar depositional processes.

- Both areas contain similar lithologic units and even lithologic units from the same source area.

- Both areas have experienced similar types of alteration including devitrification and zeolitization of volcanic material.

- Both areas have undergone similar types of regional tectonic stresses resulting in a similarity in the two areas regional fracture orientations.

- Both have similar groundwater chemistry.

As a result of these similarities between the two areas, the use of flow and transport parameter data from the Yucca Mountain area is justified in helping to develop parameter distributions for the FF modeling effort. Note that the data are actually transferred on an HSU by HSU basis. In others words, data for a given parameter are transferred only between HSUs that have relevant and similar characteristics.

\subsection{Qualification of Data and Data Documentation}

During evaluation of data for use, both the quality of the documentation for the data source and the quality (suitability) of the data for use are evaluated. These subjects are discussed in detail in the document "Transferability of Data Related to the Underground Test Area Project, Nevada Test Site, Nye County, Nevada" (SNJV, 2004c) introduced in Section 4.2, and the approach used for this document is presented below.

\subsubsection{Data Documentation Qualification}

Data documentation provides information on the traceability (or pedigree) of the data. Typically, data collected in the recent past has much better documentation than data collected and reported many years ago. Qualification of the documentation of the data makes it easier to investigate and evaluate the quality of the data used in modeling.

Each data record of a given dataset was assigned a DDE_F value to indicate the level of documentation available for that data record. The process of data qualification ensures that the pedigree of the data is retained for database users. However, it is important to note that the data qualification does not indicate the usefulness of data for Frenchman Flat modeling. Historic data, while often poorly 
documented by today's standards, are often of high quality and extremely useful in the CAU investigations.

The five levels of data documentation evaluation flags are as follows:

\section{Level 1}

Data are collected in accordance with NNSA/NSO Environmental Restoration Program (ERP) QAPPs, approved State of Nevada procedures, and/or participant-specific procedures. This ranking indicates that all supporting documentation for the data is on file and available for review by data users.

\section{Level 2}

Data are collected in accordance with approved plans and procedures as required for Level 1, with the exception that one or more documentation requirements may be deficient in some way. Examples of data documentation deficiencies may include lost or destroyed field-data collection forms or data acquired using interim or draft procedures.

\section{Level 3}

Data are collected using accepted scientific methodology (e.g., ASTM, U.S. Environmental Protection Agency [EPA] methods, USGS procedures) and accompanied by supporting and corroborative documentation such as testing apparatus diagrams, field or laboratory notes, and procedures.

\section{Level 4}

Data are collected by a participating NNSA/NSO ERP organization or another organization not associated with the NNSA/NSO ERP prior to the issuance and implementation of project-approved standard policies, procedures, or practices governing data acquisition and qualification. The methods of data collection are documented and traceable; however, the validity of data use or compliance with reference procedures is indeterminate. Supporting documentation may or may not exist.

\section{Level 5}

Data are obtained under unknown, undesirable, or uncertain conditions. When data documentation is unknown, any available supporting or helpful descriptions of the intended use and conditions of data capture should be described.

\subsubsection{Data Quality Evaluation}

The data qualification process varies depending on the type of parameter. The criteria used to evaluate the different types of required data are dependent on the type and the intended use of the data. Thus, various criteria are used to assess data quality. The general procedure includes assigning one or more data quality evaluation flags (DQE_F) to each record or group of records compiled in the dataset, indicating the data quality or suitability of the individual data record for the intended usage. The data quality evaluation flags and their definitions depend 
on the data type. Data-type specific quality evaluation procedures are described in corresponding sections of this document.

\subsection{Analysis Methods Used}

Methods of analysis used vary depending on the type of hydrologic data considered. See the approach subsections of the analysis sections for information on the specific methods used.

\subsection{Data Analysis Limitations}

Data limitations need to be identified. These limitations may be related to the level of data documentation, the data collection method, the data analysis method, or other factors that may limit confidence in the values. Within the discussion of each dataset, data limitations will be documented. 


\subsection{Hydraulic Parameters}

Values used for the hydraulic properties of HSUs in the simulation of groundwater flow and transport should be consistent with available information to provide confidence in the reasonableness of the simulations. Specifically, hydraulic conductivity is a basic parameter for groundwater flow modeling that determines the volumetric flow rate, and is sufficient for steady-state modeling. Representative hydraulic conductivities for the formations to be modeled, at the scale over which the model is discretized, are integral to producing defensible model predictions. The storage properties of the formations are also of interest as a basic hydraulic parameter needed for transient simulations of groundwater flow. There are uncertainties in the determination of representative parameter values which will be discussed in this section. Consequently, uncertainty analysis accompanies the use of the available data.

The assessment of hydraulic parameter data presented in this section serves several project needs. The dataset compiled for this task provides the hydraulic parameter data for the Frenchman Flat CAU Phase II modeling. The analysis produces statistical estimates for the range of hydraulic conductivity and storage parameter values for the major HSUs in the Frenchman Flat CAU and for equivalent regional HSUs for a larger investigation area encompassing the NTS. The latter analysis is necessary due to the relative paucity of FF-specific data for most of the FF HSUs. Analysis of all of the data available for the NTS area was required to determine representative hydraulic properties for all of the HSUs in the FF geologic model. The analysis also addresses the relationship of hydraulic properties to the scale-of-measurement, the spatial variation of hydraulic properties, and the variation with depth. Information on anisotropy of hydraulic conductivity and variation due to temperature are presented. Finally, the state of knowledge of the hydraulic parameters is assessed and the limitations of the available data are considered.

The specific objectives for the hydraulic parameter assessment include:

- Compile and evaluate available hydraulic parameter data for use in the Frenchman Flat CAU Phase II flow modeling.

- Determine appropriate ranges and distributions for hydraulic conductivity and specific storage for FF HSUs. 
- Assess the relationship of hydraulic conductivity with scale of measurement.

- Assess spatial variation of hydraulic conductivity within the FF CAU.

- Assess the relationship of hydraulic conductivity with depth.

- Assess the dependence of hydraulic conductivity on subsurface temperature.

\subsection{Data Types and Prioritization}

Transmissivity is a primary calibration parameter in the groundwater flow model, and storage is an additional parameter used for calibration in transient simulations. Transmissivity is the product of the hydraulic conductivity and the saturated aquifer thickness. Transmissivity is the only hydraulic parameter needed to simulate groundwater flow under steady-state conditions. The thickness of each hydrostratigraphic unit is determined from the geologic model of the Frenchman Flat area. To modify the transmissivity during calibration, the hydraulic conductivity must be varied because the thickness of the hydrostratigraphic unit is fixed by the geologic model. As a result, the calibration parameter for the flow model becomes the hydraulic conductivity. Hydraulic conductivity is the primary variable that is analyzed for variability and uncertainty. Hydraulic conductivity is either obtained directly from analytic or numeric analysis of the hydraulic response measurements (drawdown or recovery data) or calculated by dividing the transmissivity obtained from analysis by the test interval thickness.

Storage information is a second priority because the transport model will be based on steady-state groundwater flow conditions. This information would be needed to perform transient runs, which may be used for model verification.

\subsection{Data Compilation and Evaluation}

Transmissivity and/or hydraulic conductivity values were compiled for interpretations of aquifer tests, packer tests, slug tests, laboratory permeability analyses, and grain size analyses. When available, storage parameter data were also compiled for multiple-well aquifer tests, which are generally accepted as the only reliable basis for determining storage values. However, fewer values for the storage parameter are available because multiple-well tests are much less common on the NTS. The available data provide a range of storage parameter values applicable to the NTS investigation area and regional HSUs, and a few values for the FF AA HSU.

The database was updated with new data from the FF Phase II data collection activities as well as new data from recent data collection and analysis activities for the Yucca Flat CAU. Additional historical well testing data that had not been previously entered into the database was also identified and added. 
Based on the implementation of objectives listed in the FF CAIP Addendum, new FF hydraulic characterization data was acquired subsequent to the Phase I data analysis (IT, 1998). These objectives had been determined following the reviews of the FF Phase I data analysis and flow modeling. The new data included testing in Well ER-5-3, Well ER-5-3\#2, Well ER-5-4, Well ER-5-4\#2, and performing two multi-well aquifer tests (MWAT) identified as the ER-5-3 MWAT and the RNM-2S MWAT. In addition, new tests were recently run using the well pairs WW-5A and WW-5C (Halford, 2003), and WW-4 and WW-4a (Halford, 2002). The new results were included in the analysis. All of these tests and analyses are documented and discussed in individual reports listed in the references.

\subsubsection{Data Sources}

Hydraulic property data were obtained from published and unpublished sources. Published data were obtained from reports of the USGS, Sandia National Laboratories, LANL, LLNL, DRI, IT Corporation, Shaw Environmental, and SNJV. Publications providing hydraulic parameter values may or may not include the raw and/or reduced drawdown and/or recovery data and specifics for the interpretation. Effort was made to acquire full documentation for each test, and the extent of documentation acquired is reflected in the DDE_F qualifiers, as discussed in Section 5.3.3. Specific references in the text are included in the reference list. Evaluation of the actual drawdown or recovery data available was important for assessing the adequacy of the interpretation and for assigning the data confidence identifiers. Unpublished data and interpretations were obtained from the USGS, DRI, and from the files of the ER Contractor as part of the ERP. Unpublished test interpretations are only preliminary interpretations. SNJV Central Files has copies of all unpublished data and interpretations for entries in the database.

\subsubsection{Supporting Data}

Data needed for the hydraulic parameter data analysis include site information, well construction data, hydrostratigraphic information, and hydrologic test information. These data are stored in the UGTA groundwater database and include the following data types:

\section{Site Information}

- Reporting name

- Site location

- Land surface elevation

\section{Test Interval Information}

- Top and bottom elevations of the tested interval

- Stratigraphic unit for the test interval

- Hydrostratigraphic unit designation 


\section{Hydraulic Test Information}

- Test start date

- Pumping rate

- Pumping duration

- Data availability

\section{Test Interpretation Information}

- Method of analysis

- Organization performing the analysis

- Hydraulic conductivity

- Transmissivity

- Storage coefficient

- Data documentation evaluation flag (DDE_F)

- Data quality evaluation flag (DQE_F)

Most of these categories are self-explanatory except for the data quality identifiers, which are described later in this section.

\subsubsection{Data Qualification}

Data qualification for the hydraulic parameters analysis was based on the requirements described in Section 4.0, applied as described below.

\section{Data Documentation Evaluation}

Documentation of the data for the primary parameters of concern (i.e., hydraulic conductivity, and storage) was evaluated, and values were assigned to the Flag DDE_F in accordance with data documentation requirements described in Section 4.3. Data quality relative to documentation was not used quantitatively in the statistical analysis, but is available in the included database for reference for specific test results.

\section{Data Quality Evaluation}

Data quality relative to the use of the hydraulic parameter analysis results is a function of the representativeness of the parameter value statistics derived. It was decided that the most representative statistics would be determined using all of the data rather than only the highest quality data. In cases where there were many data values for an HSU, the statistical analysis is expected to preclude the undue influence of any particular unreliable data value. In cases where there were few data values for an HSU, there may not be enough data to identify unreliable data values. As had been recognized in the NTS regional model report (DOE/NV, 1997), many historical test results may actually be high quality, but cannot be objectively identified as such from the available records. Consequently, DQE_F flags were not assigned as they had been in the regional model report. Data quality evaluation procedures have been re-evaluated in the Data Transfer TBD (SNJV, 2004c), and revised procedures will be considered for future 
analyses. For the FF Phase II data analysis, data quality evaluation was handled according to ranking the suitability of the data for use in CAU modeling.

The scale of the test, which had been incorporated into regional model DQE_F flags was recognized as a very important factor in the representativeness of the test result for use in modeling. For the purpose of modeling groundwater flow on a large scale, parameter values representative of groundwater flow at larger scales are more appropriate than values representative of smaller scales. The larger-scale data better reflect the overall hydraulic character of formations. In addition, in fractured rocks, the scale of the data is important to capture the effect of fracturing on the overall properties. The data was analyzed in separate groups for the three distinct scales of tests as follows:

- Pumping-scale tests are considered to provide the most appropriate data for use in large-scale modeling because they provide results representative of the greatest aquifer volume. They are more likely to reflect high hydraulic conductivity structure in tested formations.

- $\quad$ Slug test-scale tests (including packer tests) are representative of smaller volumes of the tested aquifers and also may be more affected by local variability and effects related to well drilling and construction.

- Laboratory-scale tests may provide data somewhat applicable to generally unfractured, granular media formations, but are not appropriate for any HSU that is dominated by fractures.

The test data were separated into these three groups by filtering the database using the field describing the test type. This leaves the DQE_F flag field available for another use.

\subsubsection{Data Transferability}

Data transferability (see Section 4.2 for a general discussion) pertains to the use of hydraulic property data from the NTS investigation area to characterize the FF HSUs. All of the data from within the NTS investigation area were analyzed with respect to regional HSUs and the scale of the test. Data transfer of hydraulic property data from outside of the FF CAU was handled as a function of correlating the regional HSUs to the FF HSUs according to the tables in Section 2.0. The analysis provides both FF-specific results and results from tests in similar formations. The latter provides guidance where there was insufficient FF-specific data to establish representative statistics on the variability of hydraulic parameter values. Comparison of FF-specific distributions and the correlated regional HSU distribution provides guidance to modelers in the use of the two distributions.

The datasets for the regional-scale HSUs are substantially similar to the datasets utilized to develop the NTS regional groundwater flow model (DOE/NV, 1997 and IT, 1996b). However, additional data has been identified since and included in this analysis, especially from wells drilled specifically for the ER program to characterize the NTS CAUs. There was also a conceptual change in the analysis 
for this regional HSUs, which now incorporates all data for those HSUs rather than only data from outside the subject CAU. The regional model serves as a constraint on the boundary conditions for the FF CAU model. The parameter distributions established in this work are similar to those of the regional model. This consistency provides continuity between the two models.

A substantial amount of the data used in the NTS investigation area analysis were obtained from the YMP, which is located east of the FF study area. Justification for the use of YMP data was provided in Section 4.2.3 and Appendix B of the Hydrologic Data for the Groundwater Flow and Contaminant Transport Model of Corrective Action Units 101 and 102: Central and Western Pahute Mesa, Nye County, Nevada (SNJV, 2004a).

\subsection{Hydraulic Parameters}

Two hydraulic parameters are characterized in this section, hydraulic conductivity and specific storage. Hydraulic conductivity is the primary parameter of interest and is sufficient for steady-state modeling. The storage properties of the rock units are characterized in the form of specific storage, which would be used for transient modeling.

Hydraulic conductivity is a property that varies by location within a rock unit, and is necessarily averaged over a volume of rock in the process of testing. The value measured for hydraulic conductivity depends on the particular volume of rock tested (i.e., well location and radius of influence). Different test methods and specifications can produce different results at a location as a function of the scale of the test (i.e., the specific volume of rock tested). Characterization of hydraulic conductivity of an HSU can take several forms, and the appropriate form of the characterization depends on the intended use of the data. Conducting many tests at different locations or of different volumes within a particular rock unit (defined by HSUs for this analysis) will produce a range of hydraulic conductivity values.

The data can be presented as location specific, pertaining to a specified volume of the rock unit for each test value. This characterizes the variability as a spatial property. However, when the subject rock unit (HSU across the area of interest) is very large, even many tests typically will characterize only a small percentage of the total volume of the subject unit leaving much of the unit uncharacterized. An alternate type of characterization is determination of a parametric probability model for the test parameter values which can then be used to define a probability density function (PDF) for the data. The distribution fitted to the data provides information that can be used to constrain the fitting of generalized values for hydraulic conductivity to rock volumes that do not correspond to the original test volumes. Comparison of the parameter values used for HSUs in the calibrated model to the PDFs for the HSUs can provide confidence in the appropriateness of the calibrated value. This latter type of characterization is the primary approach used in this analysis.

In addition to the variability of the hydraulic conductivity values across the HSU, there are a variety of uncertainties inherent in the determination of the values that 
are embedded in the data. Uncertainty is related to the suitability of the test method, test measurement accuracy, appropriateness of the analysis method for the test, and assumptions made about the test and tested interval. The uncertainty in the analyses results are difficult to quantify, and are not readily separable from the variability described by the parametric probability model. The total uncertainty resulting from these factors may be very great, and potentially exaggerate the apparent variability. This is evident in cases where several different analyses of the same test or analyses of different tests on the same well produced very different results.

\subsubsection{Scales of Testing and Associated Uncertainties}

Testing used to determine hydraulic conductivity is conducted at three generalized scales: laboratory scale, slug and packer test scale, and pumping test scale.

The laboratory scale comprises measurements made on small samples (typically of about 1,000 to 2,000 cc volume) removed from the natural environment by various means and placed into a test apparatus in the laboratory. Samples may be chosen to be representative for the purpose, but the criteria used to determine representativeness are not always documented or are necessarily consistent between different test sets. Rock/core samples tested are necessarily intact, and exclude features (such as fractures) that are not preserved in handling.

Measurements are then made that generally represent the $\mathrm{K}$ of the intact matrix. Unconsolidated materials may be reasonably preserved in their natural state or repacked for testing. In some cases, the $\mathrm{K}$ for unconsolidated samples may be calculated from a grain size analysis.

The slug- and packer-test scale tests are conducted in situ on fairly short test intervals (typically in the range of about 5 to $50 \mathrm{ft}$ ) using small volumes of water (from several gallons to several hundred gallons) to induce pressure pulses that equilibrate in a relatively short period (ranging from several seconds to several days). These methods test a relatively small volume of rock in the immediate area of the borehole. The results may be substantially influenced by near-borehole conditions that reflect drilling damage to the formation and effects from the well completion. The small volumetric stress on the rock unit associated with these methods do not produce good results in high-conductivity media.

The pumping-scale tests are conducted in situ on short to long test intervals (typically in the range of 100 to $1,000 \mathrm{ft}$ or more), moving relatively large volumes of water to induce pressure and possibly dewatering responses in the test formation over relatively long periods of time (typically 12 hours to 90 days). These methods test much larger volumes of rock extending relatively large distances from the borehole. The response in the pumping well may be substantially affected by near borehole conditions reflecting drilling damage, but responses measured in remote observation wells provide data unaffected by local formation damage. Tests with observation wells can also provide directional property data. Depending on the length of the test, the test may reveal different aspects of the formation response that are related to time or distance from the well. 


\subsubsection{Test Analysis and Associated Uncertainties}

The larger-scale tests average hydraulic responses across larger volumes of rock, but inhomogeneities that may be present within the larger test interval introduce uncertainties in the analysis of the test. The uncertainties are a function of both undefined conditions in the test interval that are not accounted for in the test analysis, and the interaction of more than one test condition resulting in a response that does not strictly conform to one or another analysis model. Often insufficient detail characterization data is collected during testing to determine the variation in response that is occurring in the test interval. Analysis methods are generally based on relatively simple models reflecting one presumably dominant type of response. In many cases, it can be difficult to determine which of several potentially appropriate types of response are dominant, much less separate out the parts of the overall response that may be attributed to different conditions. Consequently, analysis results often reflect a sort of average of different additive responses. In many cases, there may be multiple results in the database for a single test from different analyses, resulting from different understandings of the test conditions and assumptions about the appropriate model by the analyzer.

\subsubsection{Characterization Data}

The best approach to collecting data for characterizing the hydrologic characteristics of a rock unit requires that testing be based on specific objectives defined to support a specific type of characterization. However, only a very limited amount of testing could be conducted specifically for this characterization effort. New testing data were only collected in two small areas, and only for several of the HSUs. These data are referenced specifically in this document, and detailed reporting of results are contained in the referenced documents. Use of the considerable volume of existing testing data available for both the FF study area and the NTS was required to more completely evaluate the variability of hydraulic conductivity for all of the FF HSUs within the FF geologic model area. The use of data from other areas, collected with a variety of methods using a variety of criteria for conducting the testing and analysis, necessarily introduces uncertainty into the characterization. However, this approach was adopted to provide the broadest view of both variability and uncertainty of the hydraulic parameters for the HSUs at the scale of the geologic model because the specific data collected for this phase of analysis was too limited to provide such information. These analyses will be used as a guide during modeling for the appropriate ranges for these parameters rather than as the specific determination for the parameter values.

\subsubsection{Analysis of Different Test Results for a Well}

The characterization of variability of $\mathrm{K}$ for an HSU requires that any particular volume of an HSU be represented by only one value for K. Different values from different sources for the same test volume represent uncertainty in the correct value. Several different situations were found involving different results for a well. In some cases, there were different analyses of the same test conducted on a 
well. These were averaged if they used the same assumptions for test volume, but left independent if they made substantially different assumptions. In other cases there were analyses for different tests conducted on a well for the same completion interval. These were also averaged if they used the same assumptions for test volume, but left independent if they made substantially different assumptions. Results of tests on different completion intervals within a single well were left independent.

\subsection{Analysis of Hydraulic Conductivity Data}

Analysis of the hydraulic conductivity data included separate evaluations of pumping-scale, slug test-scale, and laboratory-scale data to determine statistics for the hydraulic conductivity at each scale. More in-depth analysis was conducted on the pumping-scale data because it is the most appropriate data for use in large-scale modeling. Analysis was conducted using all data from within the FF CAU, as defined by the FF CAU geologic model boundary, according to the FF HSUs. This provides the most specific data available for the FF HSUs. All data in the database were included in the general analysis according to regional model HSUs that correlate to FF HSUs. The relationship of the regional HSUs to those of the FF CAU were previously presented in Section 2.0. These HSUs are more generalized, but can be clearly related to FF HSUs according to relevant factors such as genesis, lithology, alteration, other lithologic characteristics, fracturing, etc.

The analysis provides statistics for each HSU at each test scale, including the mean, standard deviation, number of data points, and range of the data. Each CAU, HSU-specific dataset having more than a few data points was evaluated for conformance to a log-normal distribution (see Section 5.5.2). The 95-percent confidence interval was calculated for datasets for which a distribution was determined. Summary tables of the results are presented for both FF-specific data and all data within the NTS investigation area. Following is information on the FF results showing the log-normality test results, spatial distribution of $\mathrm{K}$ for the AA, relationship of depth to $\mathrm{K}$ for the AA, and the probability distribution for specific storage for FF HSUs. Similar information is then presented for the NTS investigation area analyses. Analysis followed the methodology outlined in Section 5.5.1, and was conducted using Excel ${ }^{\circledR}$ for XP spreadsheets.

The spatial distribution of the hydraulic conductivity data is discussed first to show the extent to which the available data represent both the FF CAU and the NTS investigation area overall. The variation of hydraulic conductivity with depth was evaluated for the FF AA HSU specifically (for which there were a number of values available over a range of depths) and for all of the hydraulic conductivity data in the NTS investigation area in general. This relationship is generally evident over the large scale, but is masked by the variation of hydraulic conductivity values within the smaller scale of individual HSU data sets with limited individual depth ranges. 


\subsubsection{Methodology}

This subsection summarizes the approach and methods used during the Phase II assessment of the hydraulic parameter dataset for the Frenchman Flat CAU. The following approach was used to define ranges for hydraulic conductivity and storage parameters for the major HSUs in the Frenchman Flat CAU and for the regional HSUs in the NTS investigation area.

- Hydraulic parameter data were compiled from published and unpublished sources. Information associated with each entry included the location, tested interval top and bottom, type of test, method of analysis, hydrostratigraphic unit or units corresponding to the tested interval, and the source of the information.

- The hydraulic parameter dataset included information for wells within a large area encompassing the NTS. Analysis was limited to wells within the NTS investigation area. Data analysis is conducted on two scales: FF-specific data from wells located within the FF geologic model boundaries, and data within a larger investigation area which encompasses the NTS. The FF-specific data is analyzed using the FF HSUs from the Phase II geologic model; however, there is very limited data available within the FF CAU. The NTS investigation area data is analyzed using the regional model HSUs, which are more generalized and more closely related to HGUs. These regional model HSUs can be correlated with the FF HSUs to provide generalized hydraulic parameters value ranges for similar formations.

- The analysis was conducted on hydraulic conductivity and specific storage parameter values. Hydraulic conductivity is essentially a unit value for formation transmissivity and specific storage is a unit value for storativity. These parameter values are applied to the HSUs by scaling with the formation thickness. All hydraulic conductivity values are associated with a defined interval of the formation tested. Some test analysis methods return transmissivity values, which are scaled to hydraulic conductivity using the tested interval thickness, and others return hydraulic conductivity values based on the input interval thickness. In all cases, hydraulic conductivity values are based on interpretations of the tested interval thickness. The situation is similar for specific storage versus storativity. These normalized parameters allow evaluation of variations with depth and location.

- In fractured rock materials such as are present within the Frenchman Flat CAU, three types of hydraulic conductivities can be defined: bulk hydraulic conductivity, fracture hydraulic conductivity, and matrix hydraulic conductivity. A generalized measurement over a vertical interval is termed the bulk hydraulic conductivity. In cases where the formations are fractured, the hydraulic conductivity associated with the fracture system and associated with the matrix, may be determined separately, depending upon the measurement and analysis method. In general, the bulk hydraulic conductivity will be similar to the 
fracture-associated hydraulic conductivity, and matrix hydraulic conductivity will be significantly lower.

- The hydraulic conductivity data were separated into three datasets on the basis of the scale of the test from which the parameter value was derived. The three scales were pumping-scale, slug-test scale, and laboratory-scale data. Pumping-scale test data include data collected from pumping or injection tests that represent a large volumetric stress over a long period of time, over a relatively large test interval. These tests evaluate the largest volume of the formation and the largest radius of investigation, and provide the most generally representative information for use as input to a groundwater flow model. The slug-test scale data includes both slug tests and packer-injection tests. This data is collected from short duration, low water volume tests generally conducted over relatively short formation intervals. The radius of investigation in the formation is much smaller, and the data may be more substantially affected by borehole skin effects and well construction. The slug and pumping-scale tests typically measure the bulk hydraulic conductivity. Laboratory-scale data are generally obtained from measurements of hydraulic conductivity of intact core samples that have been taken to a laboratory for analysis. The core samples are necessarily selected from nonfractured intervals of the core. Consequently, laboratory measurements provide information on matrix hydraulic conductivity for fractured formations. In unconsolidated formation, the tested samples may be repacked. The scale of these measurements is the size of the core sample, which may be selected to be generally representative based on examination of the core. This data is least representative of the bulk parameter values.

- Within each scale-dependent data set, the data were further subdivided by hydrostratigraphic unit. A nominal hydraulic conductivity was identified for each data entry, using (in priority order) the transmissivity value divided by the specified transmissive interval thickness, the horizontal hydraulic conductivity value, the average hydraulic conductivity value, or the fracture hydraulic conductivity value. The mid-point depth of the test interval for each test result was also determined from the transmissive interval data.

- In some cases, more than one test result or interpretation of a test for a test interval is available. Prior to further analysis, multiple results for a single test interval were arithmetically averaged. Results were not averaged when different test intervals were specified. The hydraulic conductivity data were then transformed to log base 10 values for analysis based on the expectation of a log-normal distribution for this property.

- The resulting sets of unique location and depth-specific $\mathrm{K}$ values were then statistically analyzed to determine the range, mean, standard deviation, the correspondence to a log normal probability distribution, and the 95-percent confidence interval where there were sufficient data. The results are presented in tables and displayed graphically. 
- The database was screened for storage parameter values from multi-well aquifer tests. The data were normalized to specific storage by dividing with the transmissive interval thickness, and mean and standard deviation for these data were calculated on an HSU basis. Probability distributions were calculated for specific storage and are displayed graphically.

The scale-specific data sets were then used for various other analyses including the spatial variability of hydraulic conductivity and the depth-dependence of hydraulic conductivity, as appropriate.

\subsubsection{Kolmogorov-Smirnov Test for Log Normality}

Typically hydraulic conductivity variability has been found to be distributed according to a log normal distribution. To the extent possible, it was desirable to determine whether the $\mathrm{K}$ values for each HSU conformed to such a distribution. Where there was sufficient data, the datasets for each HSU at each scale were tested for conformance with a log normal distribution. A Kolmogorov-Smirnov (K-S) test (Benjamin and Cornell, 1970) was applied at the 5 percent level of significance to the empirical distribution function (ECDF) of the measured data. The test for log normality and an estimate of the range of uncertainty in the log normal parameters is determined from the K-S statistic, D. D is a measure of the maximum difference in cumulative probability between the data ECDF and the theoretical (log normal) cumulative density function (CDF). The difference is calculated for each measured datum(i), therefore the data frequency is defined as $\mathrm{i} / \mathrm{n}$, where $\mathrm{n}$ is the total number of data. This differs from a normal probability plot which is calculated using a frequency of $i /(n+1)$. A critical K-S statistic, $D^{*}$, is then defined based on the number of data samples and the significance level (0.05). If the observed difference between the ECDF and CDF, D, is greater than the critical difference between distributions, $\mathrm{D}^{*}$, the null hypothesis (i.e., that the measured and theoretical distributions are statistically equal) is rejected.

For the figures illustrating the results of the K-S test, D is used to construct upper and lower bounding curves that define the smallest region of uncertainty for which the null hypothesis is not rejected. Similarly, D* could be used to define the complete region of uncertainty for the measured data when the theoretical distribution and significance level are specified. Within the K-S bounds, it is possible to observe the range of parameters describing the log normal CDF. If the standard deviation is held fixed (i.e., holding the slope constant), the mean can be shifted some amount and remain within the bounds. Similarly, if the mean is held fixed but the slope of the CDF is varied, the standard deviation could vary some amount. The two ranges cannot be varied simultaneously to their limits, or the model would no longer remain within the K-S bounds. 


\subsubsection{Spatial Distribution of Data}

Figure 5-1 is a map showing the locations of wells and boreholes for which hydraulic conductivity (or permeability) data is in the database. This constitutes all the data identified for this area that has been verified. The locations are identified with three different symbols corresponding to the three scales of test information. In some cases, more than one scale of test is available at a single location. The data are not uniformly distributed throughout the NTS investigation area. Rather the data are clustered in areas on the NTS where nuclear testing was performed, where major construction facilities were located, or where ER drilling and testing activities have taken place. Off the NTS, data are generally located in areas of human settlement and activity, or in areas of interest for resources. Note the cluster of data on the southwestern border of the NTS associated with the Yucca Mountain Project.

Figure 5-2 shows the distribution of data within the FF CAU, and the HSU to which the data pertains. As can be seen from the map, there is not a great amount of data for the FF CAU, and most of what is available is for the surficial alluvial aquifer. There are only a few tests in deeper formations in the FF CAU. The FF Phase II data collection activities included conducting pumping tests near the northern FF nuclear tests (ER-5-3 and ER-5-3\#2 single-well tests and ER-5-3 MWAT) and near the central FF nuclear tests (ER-5-4 and ER-5-4\#2 single-well tests and the RNM-2S MWAT). These tests provided several additional $\mathrm{K}$ values for the AA, and one $\mathrm{K}$ value each for the TM-WTA, Lower Tuff Confining Unit (LTCU), and LCA.

\subsection{Analysis Results}

Table 5-1 presents a summary of the analyses of the FF-specific $\mathrm{K}$ data and Table 5-2 presents a summary of the analyses for all of the K data within the NTS investigation area. These tables show the results by scale of the test for each HSU for which there was data at that scale. The extent to which statistics could be developed for each set of data are dependent upon the number of unique data values that were in the dataset. The ultimate aim was to determine the type of distribution for the property and fully define it; however, this requires a substantial number of values in the dataset. The column "Count" in these tables indicates the number of unique data values for each analysis. As can be seen in Table 5-1, extensive datasets were generally not available for FF-specific data except at the laboratory-scale, which is the least representative. The datasets for the entire NTS investigation area were generally large enough to determine meaningful statistics. "Yes" in the column "Accept Log-Normality Hypothesis" indicates that the K-S test (Section 5.5.2) did not reject the log-normality hypotheses. For all of the pumping-scale K-value distributions, the log-normal hypothesis was not rejected. For several slug test-scale and laboratory-scale distribution, the test criteria were not met, and the distributions may not be considered to support the log-normal hypothesis. Table 5-3 presents a summary of the analyses for specific storage for both FF HSUs and regional HSUs. The 95-percent confidence interval bounds for the log-normal distributions determined from the data analyses were calculated for 


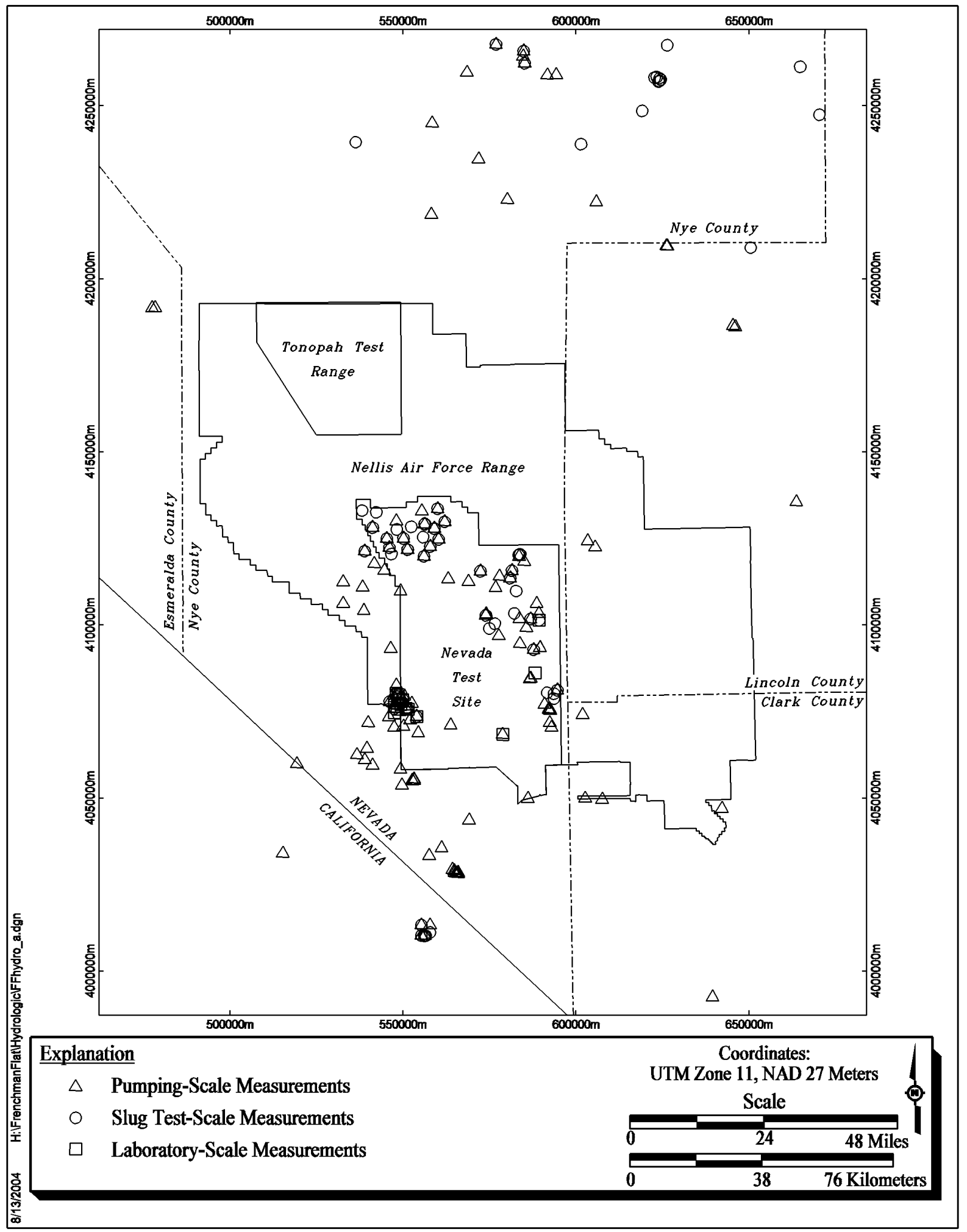

Figure 5-1

NTS Investigation Area Locations of Hydraulic Conductivity Data 


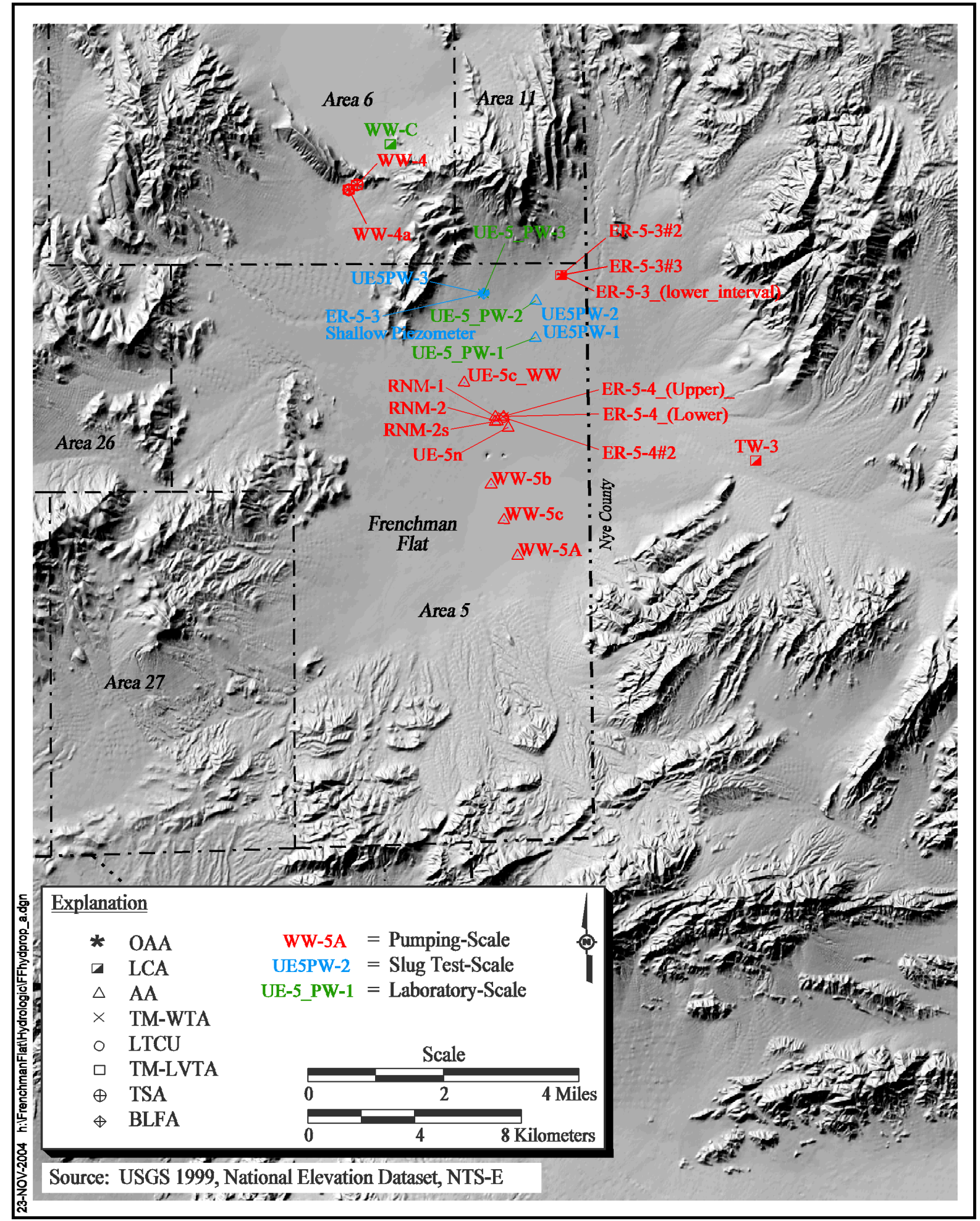

Figure 5-2

Frenchman Flat Hydraulic Property Data Locations 
Table 5-1

Summary of FF-Specific K Data Analysis

\begin{tabular}{|c|c|c|c|c|c|c|c|c|c|c|}
\hline \multirow{3}{*}{ HSU } & \multirow{2}{*}{ Mean } & \multirow{3}{*}{$\begin{array}{l}\text { Standard } \\
\text { Deviation }\end{array}$} & \multirow{3}{*}{ Count } & \multirow{2}{*}{ Minimum } & \multirow{3}{*}{ Maximum } & \multirow{3}{*}{$\begin{array}{c}\text { K-S } \\
\text { Critical } \\
\text { Statistic } \\
\text { D* }^{*}\end{array}$} & \multirow{3}{*}{$\begin{array}{c}\text { K-S } \\
\text { Statistic } \\
\text { D }\end{array}$} & \multirow{3}{*}{$\begin{array}{c}\text { Accept Log } \\
\text { Normal } \\
\text { Hypothesis }\end{array}$} & \multicolumn{2}{|c|}{$\begin{array}{l}\text { 95\% Confidence } \\
\text { Interval Bounds }\end{array}$} \\
\hline & & & & & & & & & Lower & Upper \\
\hline & $\log 10$ K (m/day) & & & $\log 10$ K (m/day) & & & & & \multicolumn{2}{|c|}{$\log 10 \mathrm{~K}$ (m/day) } \\
\hline \multicolumn{11}{|c|}{ Pumping-Scale Data } \\
\hline AA & -0.22 & 0.80 & 17 & -1.22 & 1.66 & 0.20 & 0.33 & Yes & -1.79 & 1.34 \\
\hline LCA & -0.13 & 1.43 & 5 & -1.51 & 2.10 & 0.21 & 0.61 & Yes & -2.93 & 2.66 \\
\hline $\begin{array}{l}\text { TM-WTA } \\
\text { TM-LVTA }\end{array}$ & 1.29 & 0.22 & 5 & 0.95 & 1.57 & 0.15 & 0.61 & Yes & 0.85 & 1.73 \\
\hline LTCU & -1.08 & $\mathrm{~N} / \mathrm{A}$ & 1 & $\mathrm{~N} / \mathrm{A}$ & $\mathrm{N} / \mathrm{A}$ & $\mathrm{N} / \mathrm{A}$ & $\mathrm{N} / \mathrm{A}$ & $\mathrm{N} / \mathrm{A}$ & $\mathrm{N} / \mathrm{A}$ & $\mathrm{N} / \mathrm{A}$ \\
\hline \multicolumn{11}{|c|}{ Slug Test-Scale Data } \\
\hline AA & -0.25 & $\mathrm{~N} / \mathrm{A}$ & 2 & -0.53 & 0.03 & $\mathrm{~N} / \mathrm{A}$ & $\mathrm{N} / \mathrm{A}$ & $\mathrm{N} / \mathrm{A}$ & $\mathrm{N} / \mathrm{A}$ & $\mathrm{N} / \mathrm{A}$ \\
\hline BLFA & -0.38 & $\mathrm{~N} / \mathrm{A}$ & 1 & $\mathrm{~N} / \mathrm{A}$ & $\mathrm{N} / \mathrm{A}$ & $\mathrm{N} / \mathrm{A}$ & $\mathrm{N} / \mathrm{A}$ & $\mathrm{N} / \mathrm{A}$ & $\mathrm{N} / \mathrm{A}$ & $\mathrm{N} / \mathrm{A}$ \\
\hline TM-WTA & 0.08 & $\mathrm{~N} / \mathrm{A}$ & 2 & 0.08 & 0.09 & $\mathrm{~N} / \mathrm{A}$ & $\mathrm{N} / \mathrm{A}$ & $\mathrm{N} / \mathrm{A}$ & $\mathrm{N} / \mathrm{A}$ & $\mathrm{N} / \mathrm{A}$ \\
\hline \multicolumn{11}{|c|}{ Laboratory-Scale Data } \\
\hline AA & -0.34 & 0.73 & 50 & -2.92 & 0.70 & 0.10 & 0.19 & Yes & -1.78 & 1.09 \\
\hline TM-WTA & -0.47 & 0.76 & 11 & -1.89 & 0.45 & 0.13 & 0.41 & Yes & -1.96 & 1.03 \\
\hline LCA & -3.68 & 1.38 & 9 & -6.00 & -1.70 & 0.15 & 0.45 & Yes & -6.38 & -0.98 \\
\hline
\end{tabular}

$\mathrm{N} / \mathrm{A}=$ Not applicable

pumping-scale results. Some analysis datasets had an insufficient number of independent values to calculate statistics. The cells for these cases are marked N/A for not applicable.

Table 5-4 presents $\mathrm{K}$ distributions determined to be applicable to each of the FF HSUs based on pumping-scale data analyses. Both FF-specific distributions and distributions for regional equivalent HSUs are shown where available. The FF-specific distributions correspond to FF HSUs while the NTS investigation area derived distributions are for the regional HSUs identified in the crosswalk as equivalent.

The following subsections provide more detail on the individual HSU-specific analyses for both the FF-specific analyses and the NTS investigation area analyses. Where available data supported testing for log-normal distributions, a graph of the K-S test result is shown. Discussions of the results are presented in the following sections.

\subsubsection{FF-Specific K-Data Analyses}

Data from wells located within the FF geologic model area were sorted into individual datasets for each scale of test, and then sorted for each HSU. Analyses were conducted at the HSU level for each scale of test. As can be seen in 
Table 5-2

Summary of NTS Investigation Area K Data Analysis

\begin{tabular}{|c|c|c|c|c|c|c|c|c|c|c|}
\hline \multirow{3}{*}{ HSU } & \multirow{2}{*}{ Mean } & \multirow{3}{*}{$\begin{array}{l}\text { Standard } \\
\text { Deviation }\end{array}$} & \multirow{3}{*}{ Count } & \multirow{2}{*}{ Minimum } & \multirow{3}{*}{ Maximum } & \multirow{3}{*}{$\begin{array}{c}\text { K-S } \\
\text { Critical } \\
\text { Statistic } \\
D^{*}\end{array}$} & \multirow{3}{*}{$\begin{array}{c}\text { K-S } \\
\text { Statistic } \\
\text { D }\end{array}$} & \multirow{3}{*}{$\begin{array}{c}\text { Accept Log } \\
\text { Normal } \\
\text { Hypothesis }\end{array}$} & \multicolumn{2}{|c|}{$\begin{array}{l}\text { 95\% Confidence } \\
\text { Interval Bounds }\end{array}$} \\
\hline & & & & & & & & & Lower & Upper \\
\hline & $\log 10$ K (m/day) & & & $\log 10$ K (m/day) & & & & & \multicolumn{2}{|c|}{$\log 10 \mathrm{~K}$ (m/day) } \\
\hline \multicolumn{11}{|c|}{ Pumping-Scale Data } \\
\hline AA & 0.25 & 0.88 & 29 & -1.22 & 2.12 & 0.13 & 0.25 & Yes & -1.47 & 1.96 \\
\hline LCA & -0.02 & 1.30 & 57 & -2.12 & 2.65 & 0.12 & 0.18 & Yes & -2.56 & 2.52 \\
\hline LCCU & 0.40 & 0.36 & 2 & 0.14 & 0.65 & N/A & N/A & $\mathrm{N} / \mathrm{A}$ & $\mathrm{N} / \mathrm{A}$ & $\mathrm{N} / \mathrm{A}$ \\
\hline LTCU & -1.08 & $\mathrm{~N} / \mathrm{A}$ & 1 & $\mathrm{~N} / \mathrm{A}$ & $\mathrm{N} / \mathrm{A}$ & $\mathrm{N} / \mathrm{A}$ & $\mathrm{N} / \mathrm{A}$ & $\mathrm{N} / \mathrm{A}$ & $\mathrm{N} / \mathrm{A}$ & $\mathrm{N} / \mathrm{A}$ \\
\hline TMA & -0.24 & 0.93 & 28 & -2.25 & 1.67 & 0.12 & 0.26 & Yes & -2.06 & 1.59 \\
\hline UCCU & -2.22 & 1.26 & 2 & -3.11 & -1.33 & $\mathrm{~N} / \mathrm{A}$ & $\mathrm{N} / \mathrm{A}$ & $\mathrm{N} / \mathrm{A}$ & N/A & $\mathrm{N} / \mathrm{A}$ \\
\hline VA & 0.21 & 0.98 & 38 & -1.77 & 1.79 & 0.09 & 0.22 & Yes & -1.70 & 2.12 \\
\hline VCU & -1.03 & 1.51 & 110 & -5.02 & 1.90 & 0.06 & 0.13 & Yes & -4.00 & 1.93 \\
\hline \multicolumn{11}{|c|}{ Slug Test-Scale Data } \\
\hline AA & -1.11 & 1.33 & 23 & -4.02 & 0.75 & 0.08 & 0.28 & Yes & -3.71 & 1.49 \\
\hline LCA & -0.82 & 0.40 & 8 & -1.48 & -0.32 & 0.13 & 0.48 & Yes & -1.60 & -0.04 \\
\hline TMA & -2.27 & 1.15 & 23 & -4.98 & -1.11 & 0.16 & 0.28 & Yes & -4.51 & -0.02 \\
\hline UCCU & -1.64 & 0.79 & 7 & -2.65 & -0.42 & 0.17 & 0.51 & Yes & -3.18 & -0.09 \\
\hline VA & -1.67 & 1.02 & 11 & -3.53 & 0.09 & 0.12 & 0.41 & Yes & -3.67 & 0.34 \\
\hline VCU & -2.16 & 1.23 & 86 & -6.00 & -0.01 & 0.12 & 0.15 & Yes & -4.58 & 0.26 \\
\hline \multicolumn{11}{|c|}{ Laboratory-Scale Data } \\
\hline AA & -0.37 & 0.79 & 63 & -3.09 & 0.84 & 0.09 & 0.17 & Yes & -1.92 & 1.18 \\
\hline LCA & -5.25 & 1.67 & 45 & -7.54 & -1.67 & 0.11 & 0.20 & Yes & -8.52 & -1.98 \\
\hline LCCU & -6.11 & 0.62 & 14 & -7.39 & -4.69 & 0.16 & 0.36 & Yes & -7.33 & -4.88 \\
\hline UCCU & -5.11 & 0.41 & 3 & -5.52 & -4.70 & $\mathrm{~N} / \mathrm{A}$ & $\mathrm{N} / \mathrm{A}$ & $\mathrm{N} / \mathrm{A}$ & $\mathrm{N} / \mathrm{A}$ & $\mathrm{N} / \mathrm{A}$ \\
\hline VA & -3.67 & 2.20 & 365 & -7.67 & 2.51 & 0.10 & 0.07 & $\mathrm{~N} / \mathrm{A}$ & -7.99 & -0.65 \\
\hline VCU & -4.41 & 1.55 & 596 & -8.13 & 4.60 & 0.07 & 0.06 & $\mathrm{~N} / \mathrm{A}$ & -7.44 & -1.37 \\
\hline
\end{tabular}

$\mathrm{N} / \mathrm{A}=$ Not applicable

Table 5-1, pumping-scale data, there are 17 data values for the AA, 5 data values for the TM-WTA and TM-LVTA combined HSUs, and 5 for the LCA. The AA and the TM-WTA/TM-LVTA combined HSUs datasets were tested for conformance to the log-normality hypothesis. The TM-WTA/TM-LVTA combined HSU category results from the test interval to which the results apply. There were no data for the other FF HSUs. All test results were included in the analysis, but there are some uncertain or questionable data values. The following subsections discuss the HSU datasets for which there were sufficient data to test for conformance to a log-normality hypothesis. 
Table 5-3

Summary of Specific Storage Data Analysis

\begin{tabular}{|c|c|c|c|c|c|c|c|c|c|c|}
\hline \multicolumn{11}{|c|}{ Frenchman Flat Geologic Model Area } \\
\hline \multirow{2}{*}{ HSU } & \multicolumn{5}{|c|}{ Specific Storage (1/m) } & & & & & \\
\hline & Mean & $\begin{array}{l}\text { Standard } \\
\text { Deviation }\end{array}$ & Count & Minimum & Maximum & & & & & \\
\hline$\overline{\mathrm{AA}}$ & 8.0E-05 & 1.35E-04 & 3 & 8.35E-07 & $2.36 \mathrm{E}-04$ & & & & & \\
\hline LCA & $2.81 \mathrm{E}-05$ & 3.64E-04 & 2 & $2.40 \mathrm{E}-05$ & 5.38E-04 & & & & & \\
\hline $\begin{array}{l}\text { TM-WTA, } \\
\text { TM-LVTA }\end{array}$ & $6.81 \mathrm{E}-06$ & $9.63 \mathrm{E}-06$ & 3 & 1.07E-06 & 1.79E-05 & & & & & \\
\hline \multicolumn{11}{|c|}{ NTS Investigation Area } \\
\hline \multirow{2}{*}{ HSU } & \multicolumn{5}{|c|}{ Specific Storage (1/m) } & \multicolumn{5}{|c|}{ Fracture Specific Storage $(1 / \mathrm{m})$} \\
\hline & Mean & $\begin{array}{l}\text { Standard } \\
\text { Deviation }\end{array}$ & Count & Minimum & Maximum & Mean & $\begin{array}{l}\text { Standard } \\
\text { Deviation }\end{array}$ & Count & Minimum & Maximum \\
\hline AA & 7.70E-05 & $2.04 \mathrm{E}-04$ & 15 & $1.40 \mathrm{E}-07$ & 7.90E-04 & N/A & $\mathrm{N} / \mathrm{A}$ & $\mathrm{N} / \mathrm{A}$ & N/A & $\mathrm{N} / \mathrm{A}$ \\
\hline LCA & 5.22E-03 & 1.07E-02 & 14 & 2.30E-07 & 3.17E-02 & 1.27E-05 & 7.34E-06 & 3 & 8.33E-06 & $2.12 \mathrm{E}-05$ \\
\hline LCCU & $3.45 \mathrm{E}-03$ & N/A & 2 & $4.60 \mathrm{E}-05$ & 6.86E-03 & N/A & N/A & $\mathrm{N} / \mathrm{A}$ & $N / A$ & $\mathrm{~N} / \mathrm{A}$ \\
\hline UCCU & 3.02E-05 & 5.61E-05 & 10 & 8.51E-08 & 1.82E-04 & N/A & N/A & 1 & 1.79E-06 & 1.79E-06 \\
\hline VCU & $6.82 \mathrm{E}-05$ & $1.75 E-04$ & 30 & $4.38 \mathrm{E}-10$ & 8.44E-04 & 7.47E-06 & $1.04 \mathrm{E}-06$ & 5 & 5.91E-07 & 2.43E-05 \\
\hline
\end{tabular}

$\mathrm{N} / \mathrm{A}=$ Not applicable

\subsubsection{AA HSU}

Most of the data available for the FF CAU pertains to the AA HSU, which was used for water supply, and that data is generally from test intervals in the upper part of the AA. As can be seen in the geologic model (Section 2.0), the AA is up to about $4,000 \mathrm{ft}$ thick in the central basin, and the water table is less than $1,000 \mathrm{ft}$ deep, providing up to $3,000 \mathrm{ft}$ of saturated thickness; much more than was needed for water supply wells. The reported $\mathrm{K}$ values come from analyses of both single-well and multi-well tests (tests with observation wells). The results of single-well tests may be significantly different from multi-well tests because of difficulties in accounting for well losses and other effects for single-well tests. Multi-well tests provide more accurate results, and may also provide information on anisotropy. Figure 5-3 shows the results of the log normality test for the AA data.

Figure 5-4 shows the spatial variation of the pumping-scale hydraulic conductivity test analysis values for the AA. The relative magnitude of the values for hydraulic conductivity for each test are indicated by the area of the circle around the well coordinates for the test well. The circles do not represent areas of drawdown response. Most of the data are for locations in central FF, near the nuclear tests in Area 5. There is data for only one location near the northern nuclear tests. There is no simple pattern apparent to the variation spatially. In fact, large values for $\mathrm{K}$ 
Table 5-4

Summary of Frenchman Flat HSU Assigned Hydraulic Properties

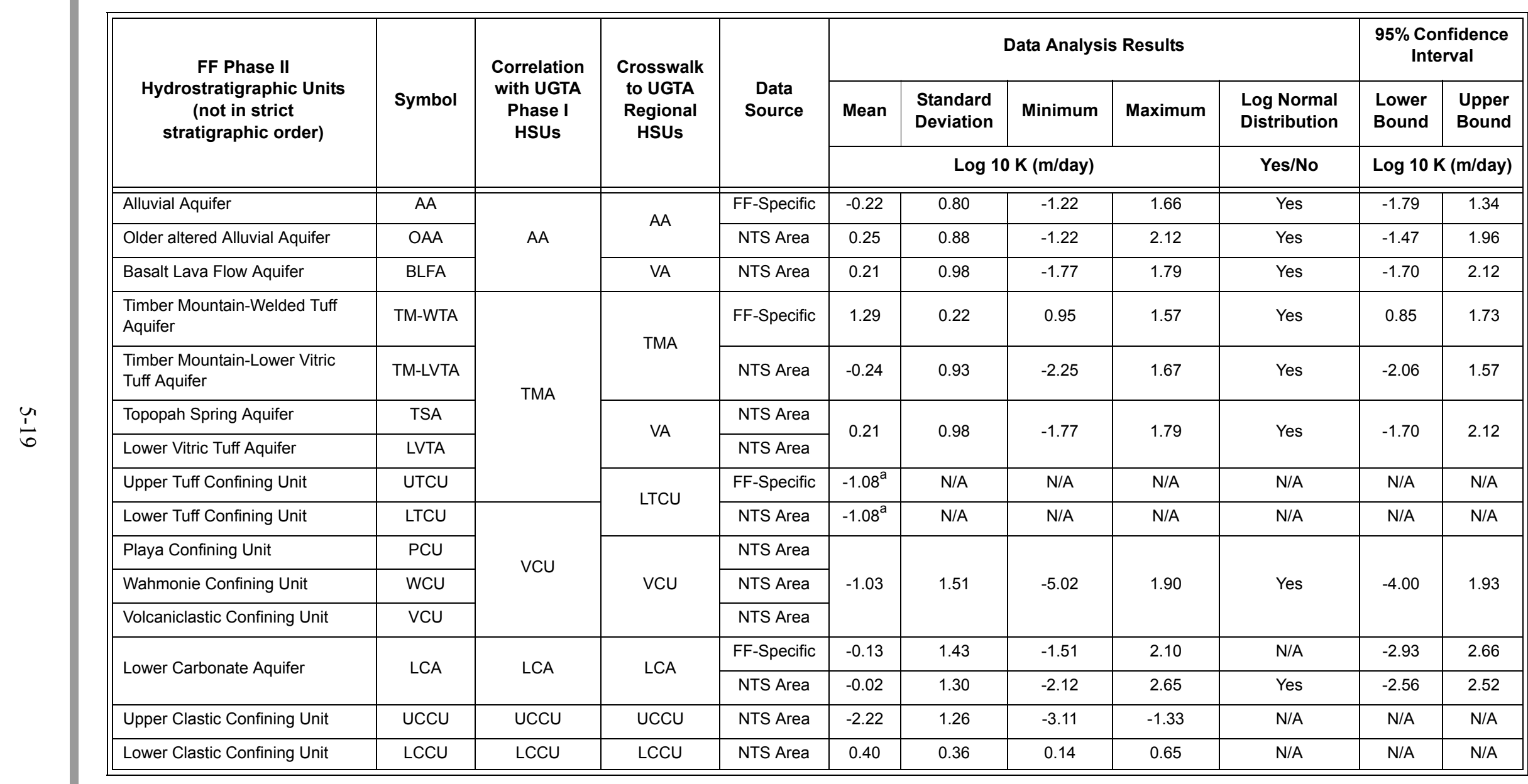

${ }^{\mathrm{a} O n e ~ V a l u e ~}$ 


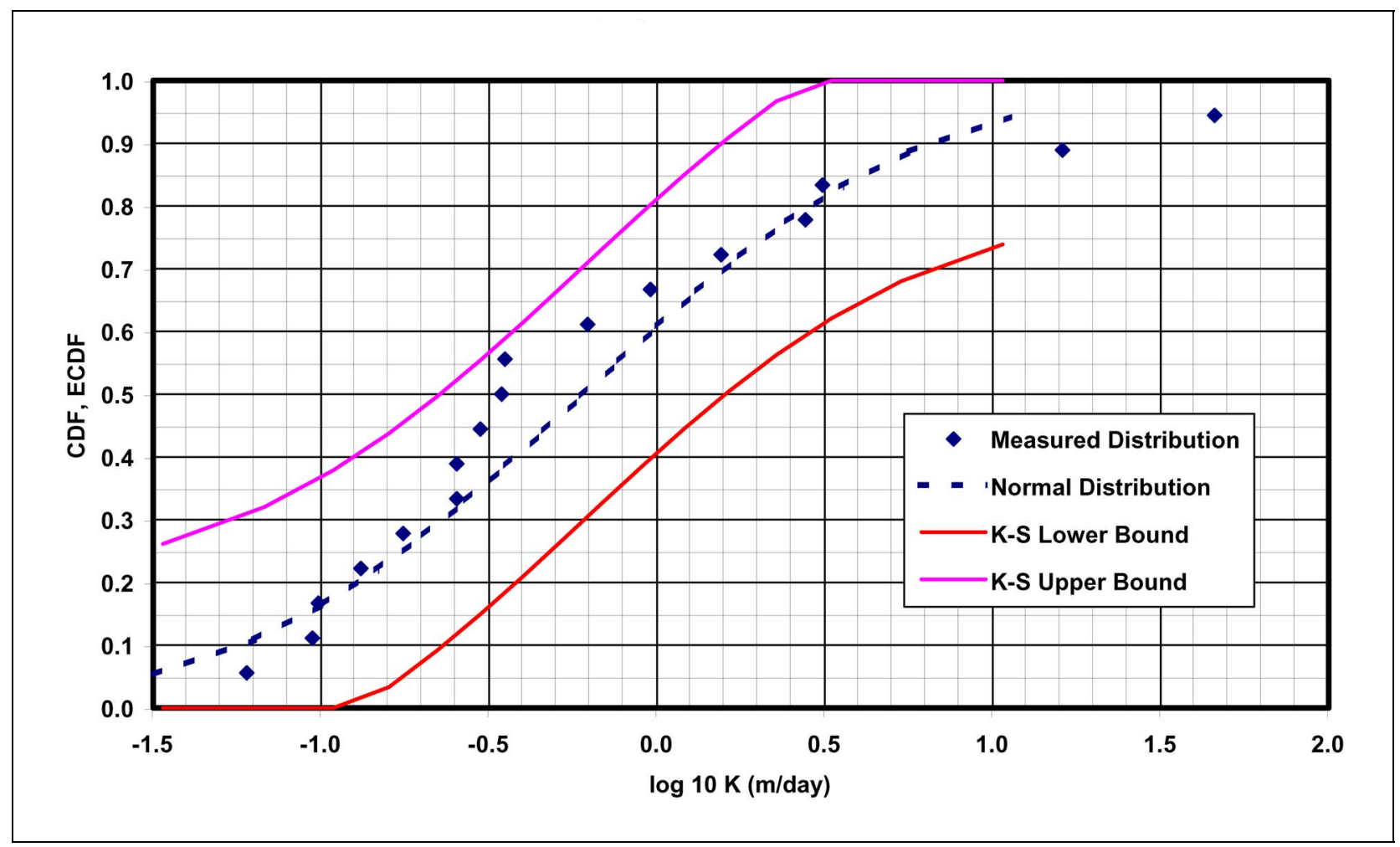

Figure 5-3

FF AA Pumping-Scale K Values Probability Distribution

and much smaller values are found in the same general area, and similarly different values are even listed for the same well. Figure 5-5 shows K plotted versus depth for these same wells to evaluate whether the variation within the same area was related to depth of the test interval. No clear pattern of variation with depth is apparent. There appears to be two distinct depth ranges in which tests were conducted, but the variation in results within the two ranges is similar. There may be substantial uncertainty in the test results as indicated by the fact that for two wells (RNM-1, RNM-2S) there are two test results each with significantly different values. These situations may be due in large part, to differences in test interpretation rather than actual differences in hydraulic properties of the tested interval. In these cases, the different results represent analysis uncertainty, the variability of the property and uncertainty in determination of the property are not separable.

\subsubsection{LCA HSU}

A graph of the hydraulic conductivity probability distribution of the LCA is shown on Figure 5-6. This distribution is based on results from only four wells (one with multiple results). 


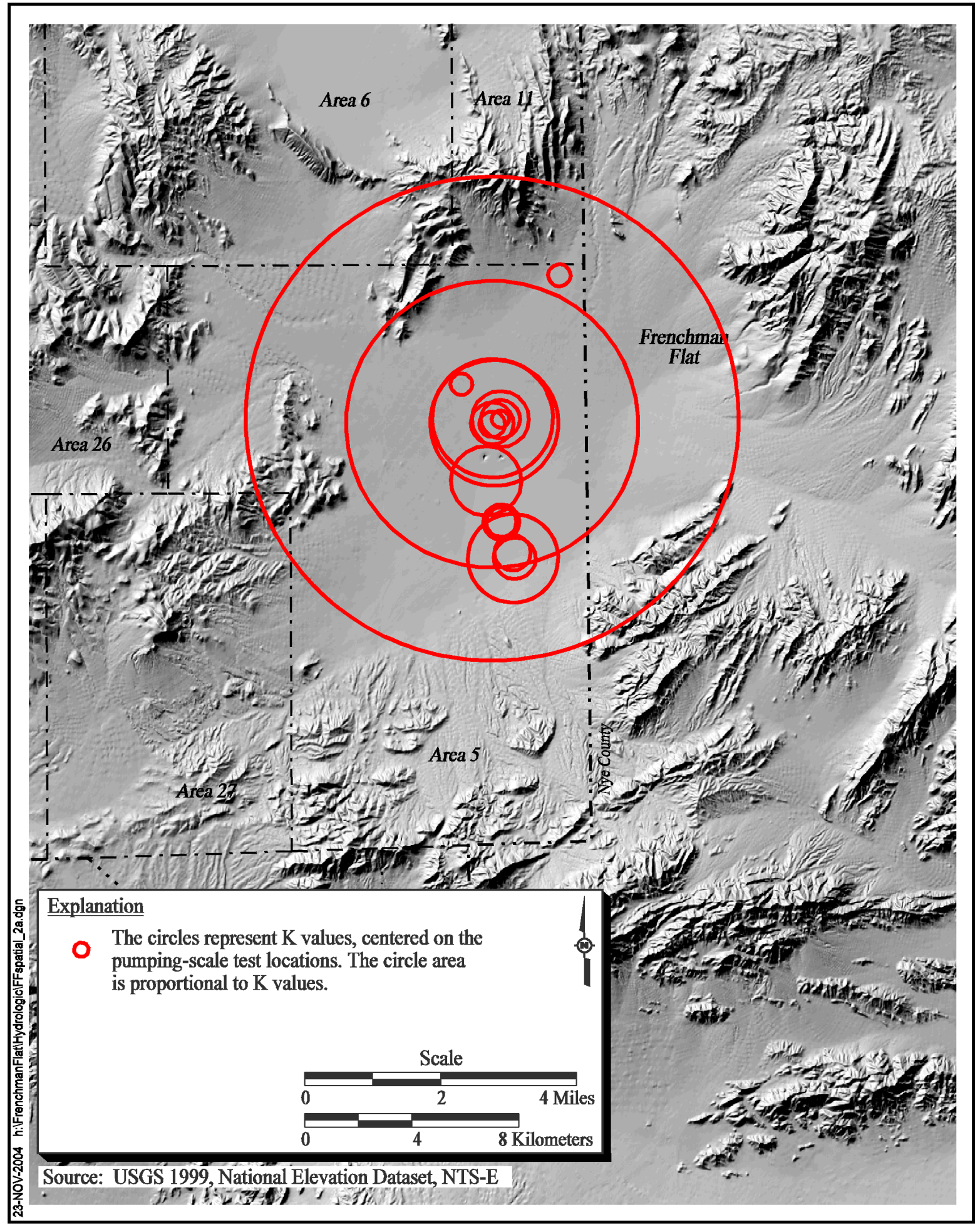

Figure 5-4

Frenchman Flat Spatial Variation of K Values for AA HSU 


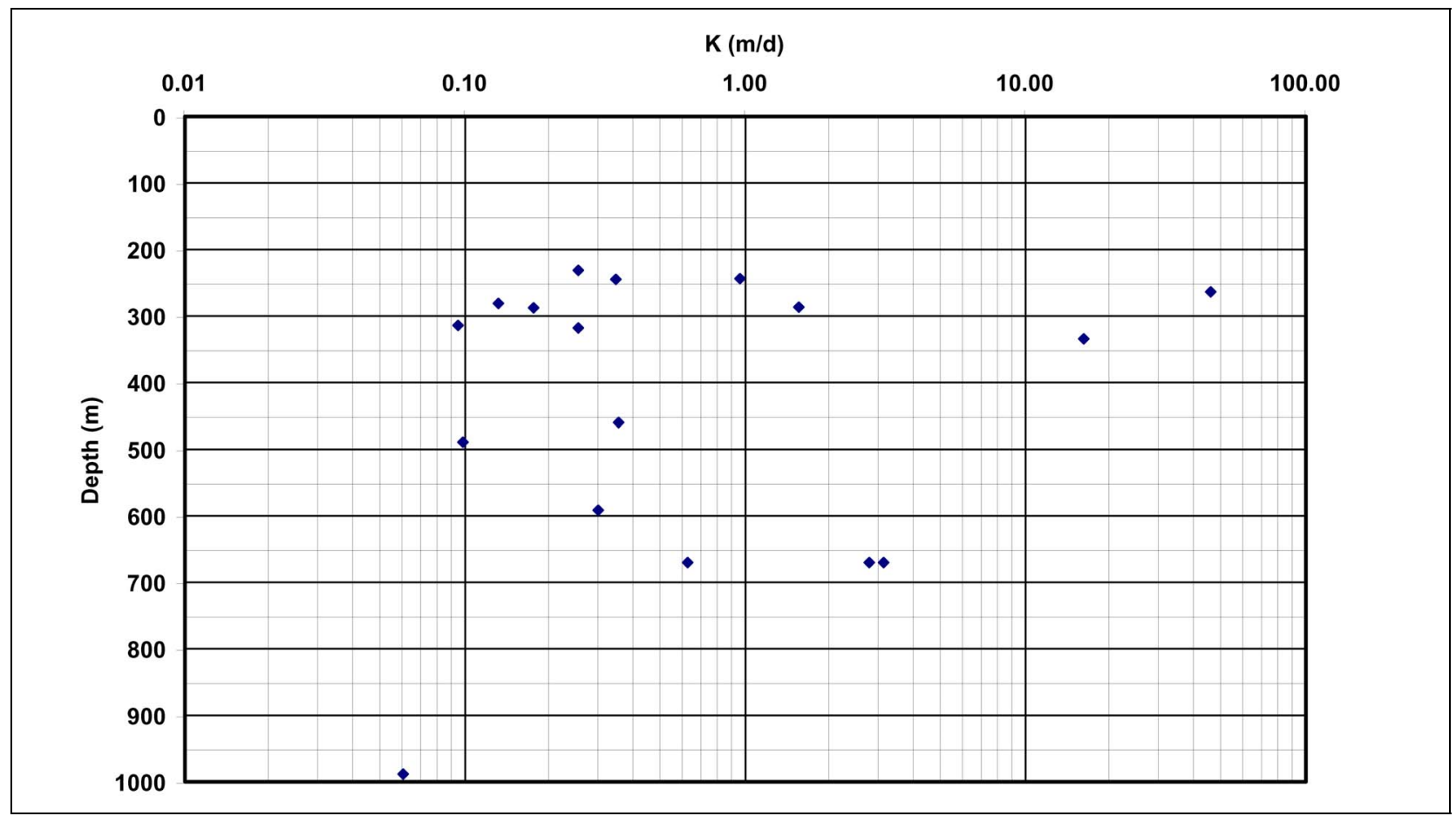

Figure 5-5

Vertical Distribution of FF AA Pumping-Scale K Values

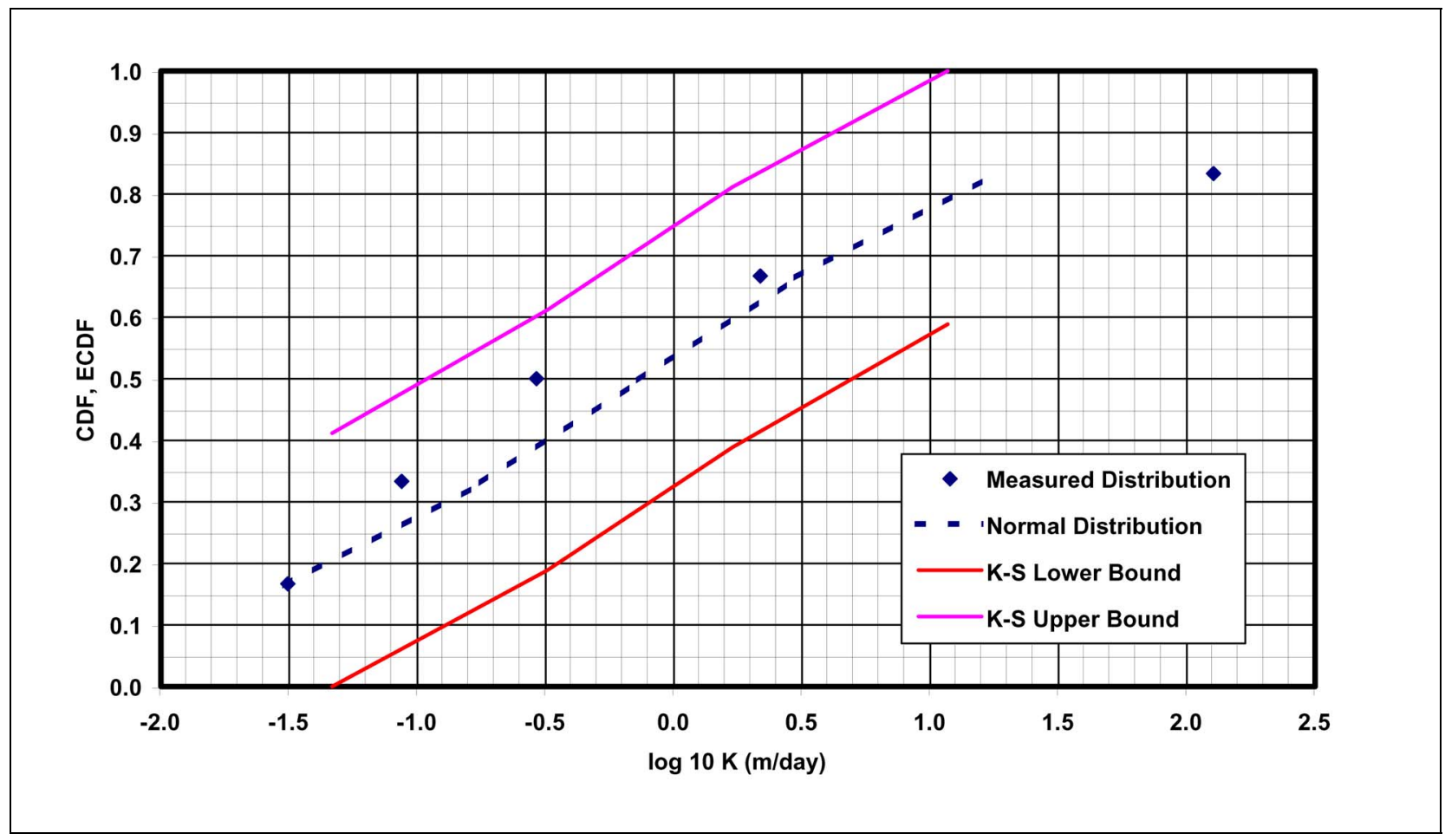

Figure 5-6

FF LCA Pumping-Scale K-Data Distribution 


\subsubsection{TM-WTA and TM-LVTA combined HSUs}

A graph of the hydraulic conductivity probability distribution of the TM-WTA and TM-LVTA is shown on Figure 5-7. This distribution is based on results from only three wells, two with multiple test results.

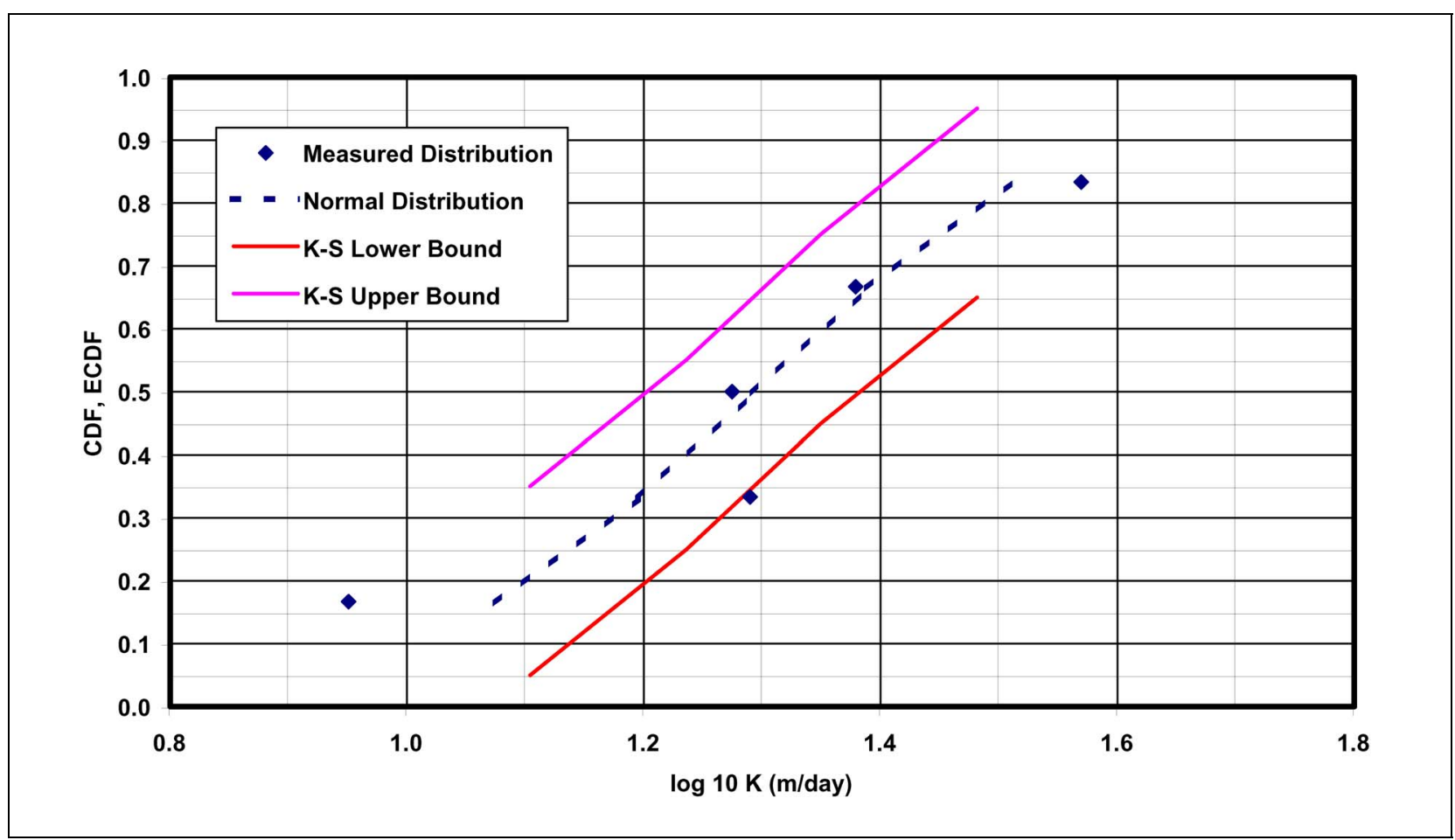

Figure 5-7

FF TM-WTA, TM-LVTA Pumping-Scale K Values Probability Distribution

\subsubsection{NTS Investigation Area K Analyses by HSU}

Test results from all of the wells within the NTS investigation area were used in the following analyses. This provides much larger datasets, and consequently better defined distributions. However, these distributions are not specific to FF, but are for regional HSUs that can be compared to the FF HSUs based on data transferability criteria.

\subsubsection{AA HSU}

The pumping-scale data for the AA were sufficient to define the hydraulic parameter distribution. Figure 5-8 shows the probability distribution for K. The pumping-scale data for the AA were sufficient to define the hydraulic parameter distribution. Figure 5-7 shows the probability distribution for K. The FF AA distribution can be compared to this distribution using three different statistical tests, the F-test for comparing variances of the two datasets, the t-test to compare 


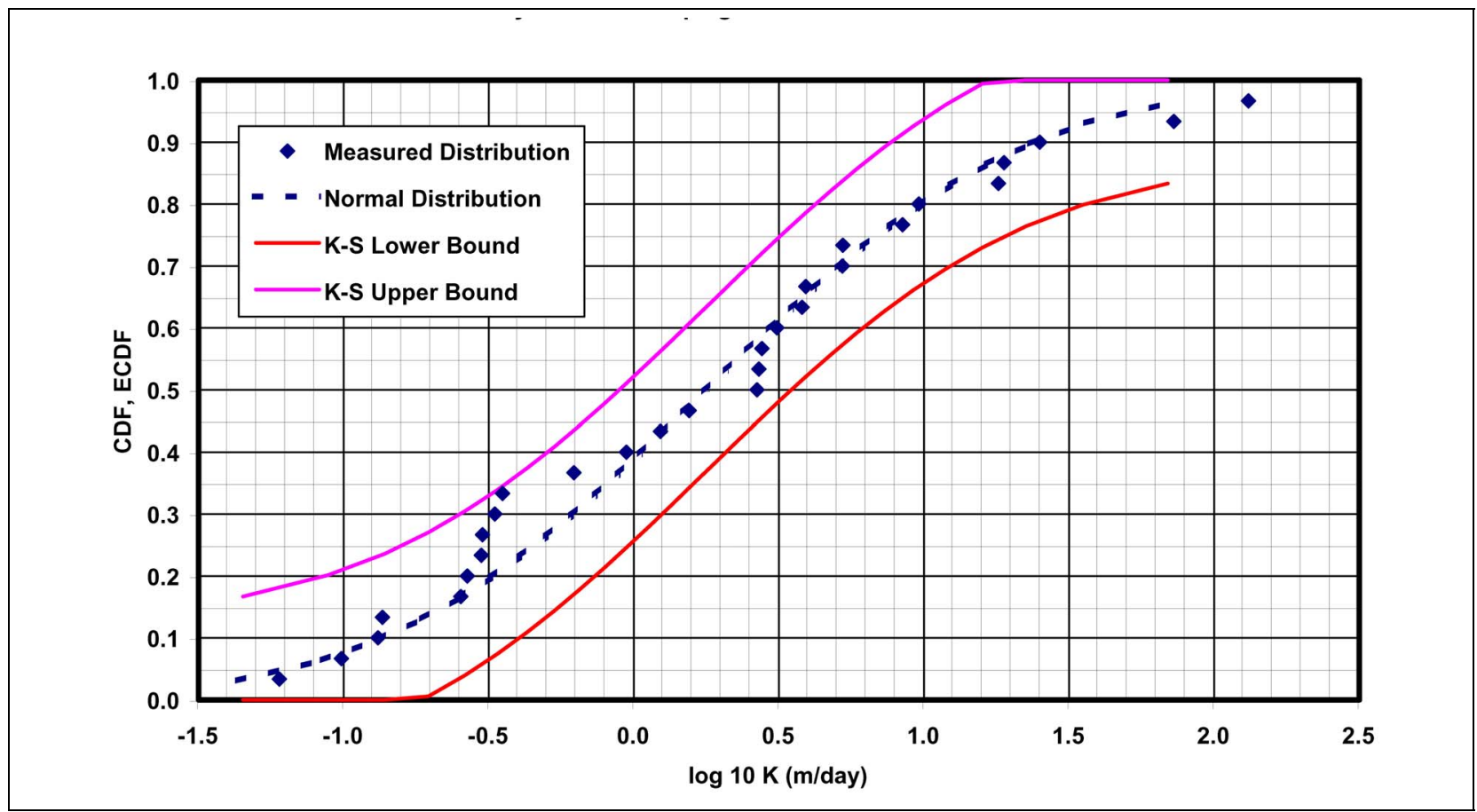

Figure 5-8

NTS Investigation Area AA Pumping-Scale K Values Probability Distribution

the sample means for datasets with different variances, and the K-S test for differences between the dataset. The results of these two tests are shown in Table 5-5. The tests were conducted at the 5-percent significance level and indicate that the two dataset do not have statistically different variances or means. The K-S test indicates little probability that the datasets are the same. There was also a large amount of data at the slug-test scale and the laboratory-scale; however, the analysis of those datasets produced substantially different results (see Table 5-2). 
Table 5-5

F-Test, T-Test, and K-S Test Comparison of Pumping-Scale AA K Distributions for the FF and NTS Investigation Area

\begin{tabular}{|c|c|c|}
\hline \multicolumn{3}{|c|}{ F-Test Two-Sample for Variances } \\
\hline \multicolumn{3}{|c|}{ Level of Significance 0.05} \\
\hline & FF Area & NTS Investigation Area \\
\hline Mean & -0.22115 & 0.24630 \\
\hline Variance & 0.63851 & 0.76776 \\
\hline Observations & 17 & 29 \\
\hline df & 16 & 28 \\
\hline $\mathrm{F}$ & & 1.20243 \\
\hline$P(F<=f)$ one-tail & & 0.35686 \\
\hline F Critical one-tail & & 2.20587 \\
\hline \multicolumn{3}{|c|}{ t-Test: Two-Sample Assuming Equal Variances } \\
\hline \multicolumn{3}{|c|}{ Level of Significance 0.05} \\
\hline & FF Area & NTS Investigation Area \\
\hline Mean & -0.22115 & 0.24630 \\
\hline Variance & 0.63851 & 0.76776 \\
\hline Observations & 17 & 29 \\
\hline Pooled Variance & & 0.72076 \\
\hline Hypothesized Mean Difference & & 0 \\
\hline df & & 44 \\
\hline t Stat & & 1.80253 \\
\hline $\mathrm{P}(\mathrm{T}<=\mathrm{t})$ one-tail & & 0.03916 \\
\hline t Critical one-tail & & 1.68023 \\
\hline $\mathrm{P}(\mathrm{T}<=\mathrm{t})$ two-tail & & 0.07831 \\
\hline t Critical two-tail & & 2.01537 \\
\hline \multicolumn{3}{|c|}{ K-S Test: Comparison of Two Data Sets } \\
\hline K-S Statistic - D & 0.2921 & \\
\hline $\mathrm{P}$ & 0.269 & \\
\hline
\end{tabular}

\subsubsection{LCA HSU}

There were a substantial number of test results for the LCA, from both within FF and distributed around it within the NTS investigation area. Figure 5-9 shows the probability distribution for the LCA K data within the NTS investigation area. There was also a large amount of slug test-scale and laboratory-scale data; however, the analysis of those datasets produced substantially different results (see Table 5-2). Table 5-6 shows the statistical comparison of the FF LCA dataset to the NTS investigation area dataset. The tests results indicate that the datasets are not statistically different. 


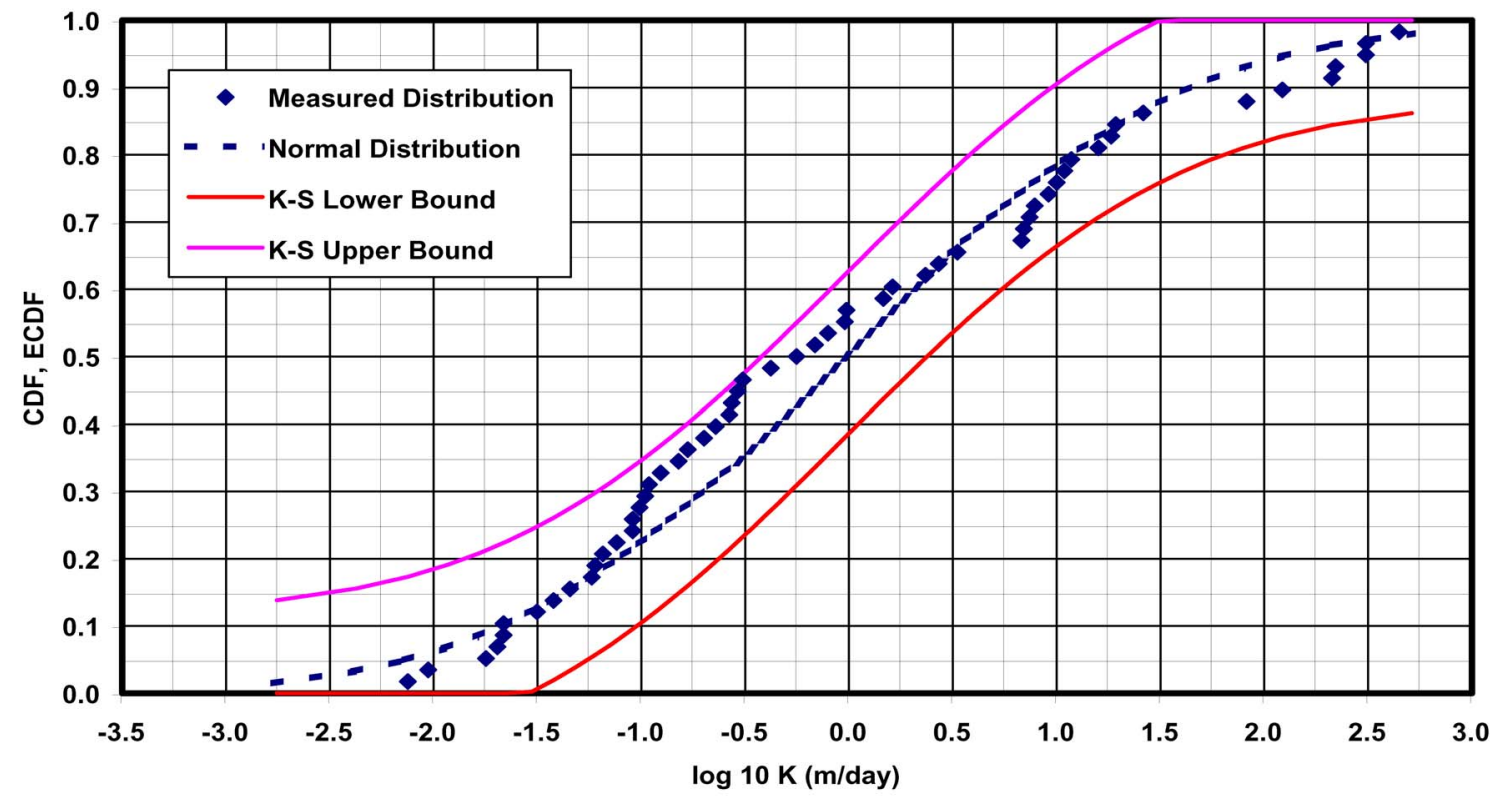

Figure 5-9

NTS Investigation Area LCA Pumping-Scale K Values Probability Distribution

Table 5-6

F-Test and T-Test Comparison of Pumping-Scale LCA K Distributions for the FF and NTS Investigation Area

\begin{tabular}{|c|c|c|}
\hline \multicolumn{3}{|c|}{ F-Test Two-Sample for Variances } \\
\hline \multicolumn{3}{|c|}{ Level of Significance 0.05} \\
\hline & FF Area & NTS Investigation Area \\
\hline Mean & -0.13263 & -0.022576921 \\
\hline Variance & 2.032734 & 1.681021435 \\
\hline Observations & 5 & 57 \\
\hline $\mathrm{df}$ & 4 & 56 \\
\hline $\mathrm{F}$ & 1.209226 & \\
\hline$P(F<=f)$ one-tail & 0.317156 & \\
\hline F Critical one-tail & 2.536581 & \\
\hline \multicolumn{3}{|c|}{ t-Test: Two-Sample Assuming Equal Variances } \\
\hline \multicolumn{3}{|c|}{ Level of Significance 0.05} \\
\hline & FF Area & NTS Investigation Area \\
\hline Mean & -0.13263 & -0.022576921 \\
\hline Variance & 2.032734 & 1.681021435 \\
\hline Observations & 5 & 57 \\
\hline Pooled Variance & 1.704469 & \\
\hline Hypothesized Mean Difference & 0 & \\
\hline df & 60 & \\
\hline t Stat & -0.18073 & \\
\hline $\mathrm{P}(\mathrm{T}<=\mathrm{t})$ one-tail & 0.428593 & \\
\hline t Critical one-tail & 1.670649 & \\
\hline $\mathrm{P}(\mathrm{T}<=\mathrm{t})$ two-tail & 0.857186 & \\
\hline t Critical two-tail & 2.000297 & \\
\hline
\end{tabular}




\subsubsection{LCCU HSU}

\subsubsection{LTCU HSU}

There were only two test results for the LCCU which was insufficient to evaluate the log-normality of the data. There was some data at the laboratory-scale, which may be representative of the matrix rock properties, but does not provide any information relative to the overall properties that may result from fracturing of the formation. Analysis of the laboratory-scale results distribution did not violate the hypothesis for log normality.

There was only one pumping-scale data entry for the LTCU, which is insufficient to evaluate the log-normality of the data. There was no data at the other two scales.

\subsubsection{TMA HSU}

Figure 5-10 shows the probability distribution for the Timber Mountain Aquifer (TMA) pumping-scale K data within the NTS investigation area, which conformed to the log-normality hypothesis. There were also considerable data at the slug test-scale, which also conformed to the log-normality hypothesis. The data at the smaller scale of measurement produced a much lower value for the mean $\mathrm{K}$.

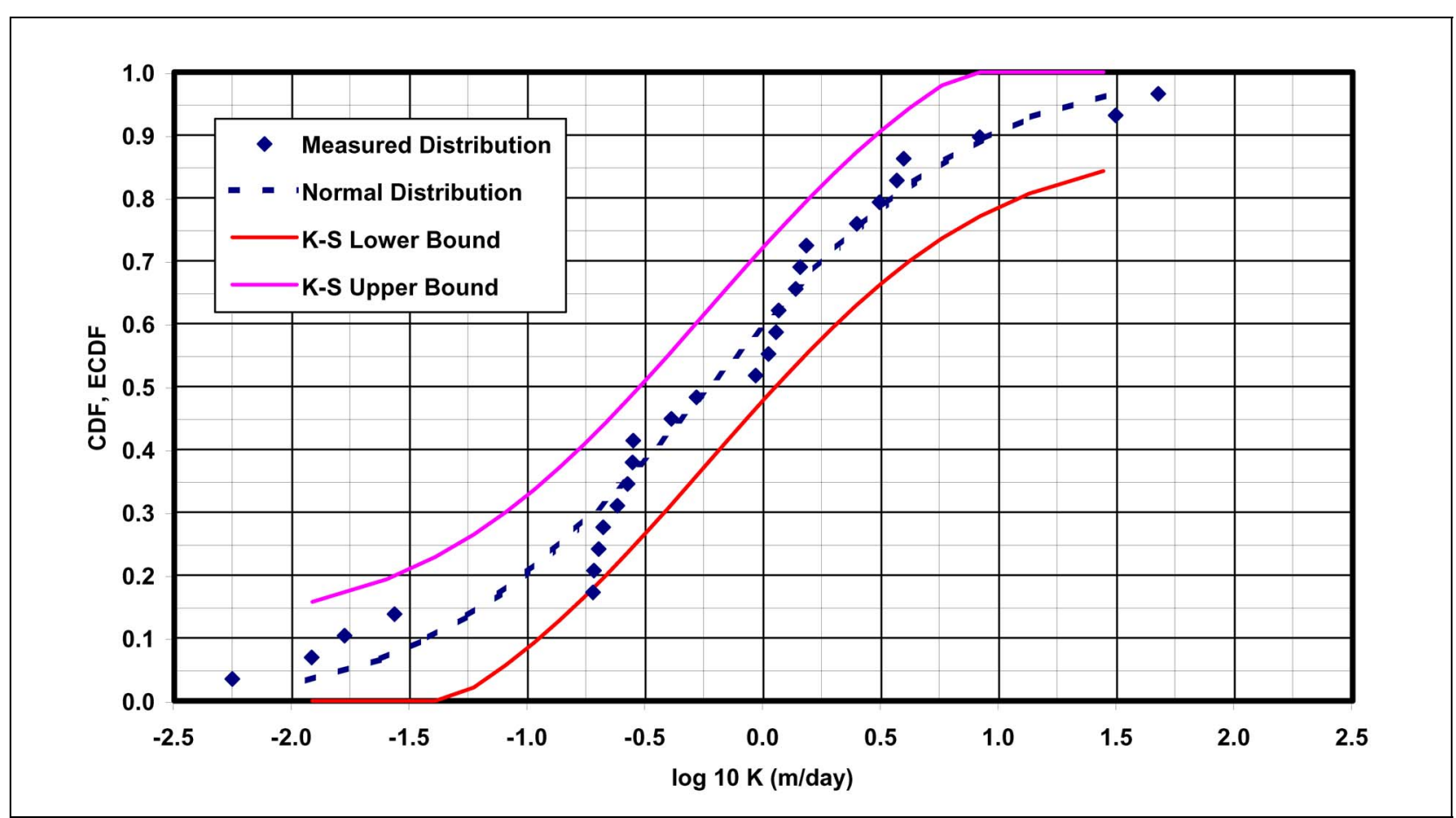

Figure 5-10

NTS Investigation Area TMA Pumping-Scale K Values Probability Distribution 


\subsubsection{UCCU HSU}

There were only two data points at the pumping scale, which was insufficient data to evaluate the log normality of the data. There were some data at the other two scales. At the slug test scale, the data conformed to the log-normality hypothesis.

\subsubsection{VA HSU}

Figure 5-11 shows the probability distribution for the VA K data within the NTS investigation area, which conformed to the log-normality hypothesis. There were also considerable data at the other two scales. The data for the slug test-scale also conformed to the log-normality hypothesis, but the data at the laboratory-scale just failed the test. The data at the smaller scales of measurement produced much lower values for the mean $\mathrm{K}$.

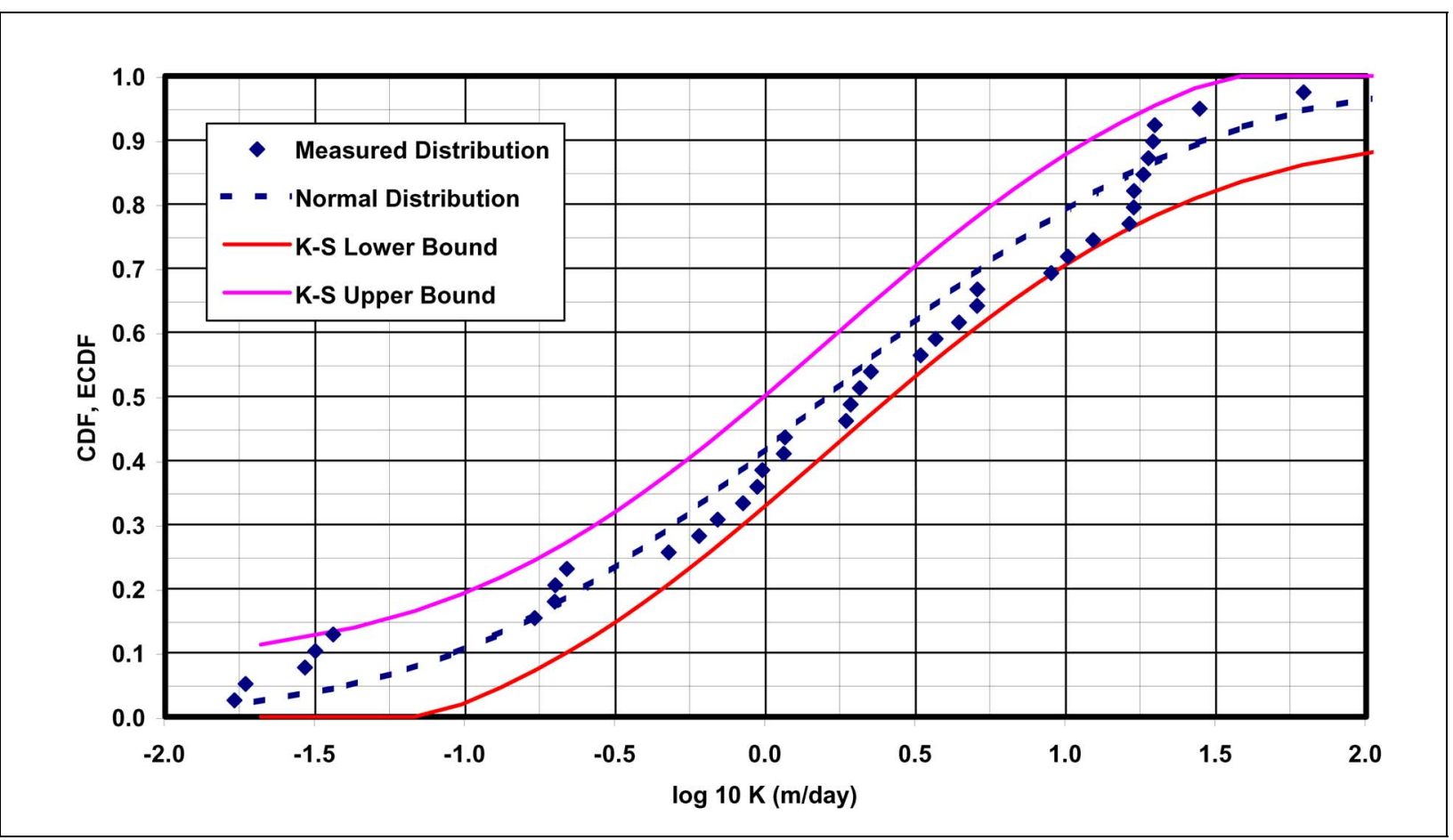

Figure 5-11

NTS Investigation Area VA Pumping-Scale K Values Probability Distribution

\subsubsection{VCU HSU}

Figure 5-12 shows the probability distribution for the Volcanic Confining Unit (VCU) K data within the NTS investigation area, which conformed to the log-normality hypothesis. There were also considerable data at the other two scales. The data for the slug test-scale also conformed to the log-normality 


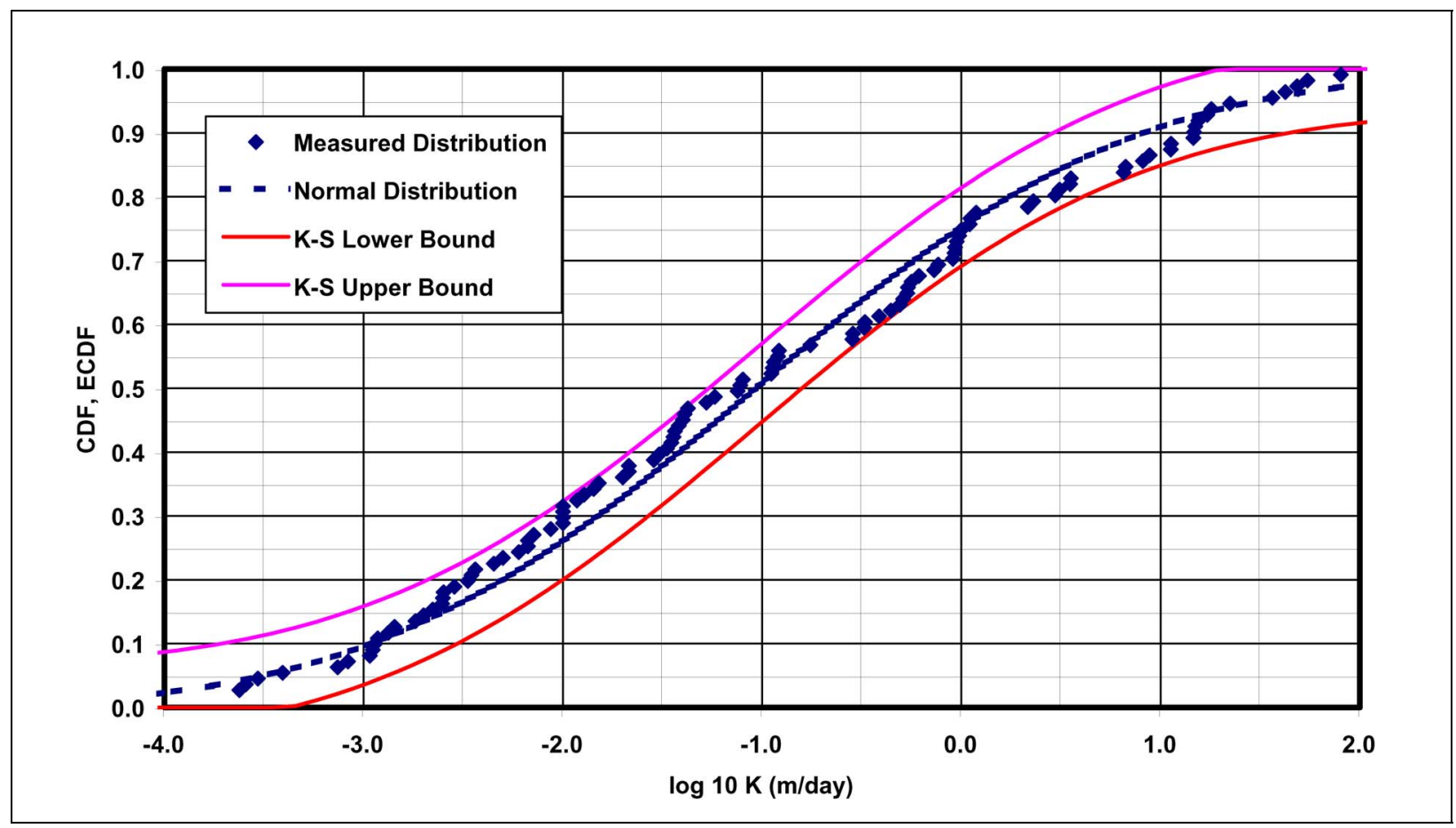

Figure 5-12

NTS Investigation Area VCU Pumping-Scale K Values Probability Distribution

hypothesis, but the data at the laboratory-scale just failed the test. The data at the smaller scales of measurement produced much lower values for the mean $\mathrm{K}$.

\subsubsection{Test-Scale and Spatial Variability}

The hydraulic conductivity of natural geologic formations is known to be spatially variable. The data presented in this report support that observation. Not only is the hydraulic conductivity variable with depth, it varies laterally as demonstrated by distinctly different ranges of values of hydraulic conductivity at different well locations in the same HSU.

Vanmarcke (1983) has shown that as the scale of averaging increases, the variance of a random process decreases and the correlation length increases. Rubin and Gomez-Hernandez (1990) present theoretical and numerical examples of the impact of scaling as a function of block size. As the block size increases relative to the correlation scale, the mean value of the block approaches the geometric mean, and the variance of the mean value is significantly reduced. In their examples, the variance was reduced by a factor of 10 when the block size was 6.5 times the correlation length. The difficulty with application of approaches such as Rubin and Gomez-Hernandez (1990) is that covariance information, especially correlation length, is needed. In reality, this covariance information is never available. However, several key observations from the theoretical studies can be made. First, the geometric mean is a reasonable estimate of the average hydraulic conductivity of a block. Second, the uncertainty in the hydraulic 
conductivity as characterized by the log 10 standard deviation is larger than the uncertainty in the block-scale value assuming that the available data represent the full range of variability in the formation. These scaling relationships are all based on the assumption of a constant mean and uniform statistical properties within an HSU. If these assumptions are incorrect, the conclusions of the theoretical studies may not apply.

Table 5-7 shows the variation of the mean and standard deviation with the scale of measurement for each HSU. It can be seen that as the scale of measurement increases, the measured value of log 10 hydraulic conductivity increases and log 10 standard deviation decreases. Similar observations have been made in other studies reported in the literature. In contrast, Zlotnik et al. (2000) have reviewed many of these other studies and conclude that there is little evidence for a scale effect in hydraulic conductivity. They conclude, as did we, that the large increases in mean hydraulic conductivity from laboratory- to field-scale measurements are most likely due to sampling bias, not true scale dependence. They also point out the difficulty of quantifying the scale of measurement for field techniques such as pumping tests and slug tests. The analysis generalizes the scale of measurement by slug and constant rate, but does not quantify the difference. In addition, Zlotnik et al. (2000) provide six general principles to apply to screening and comparing data. One of the principles is coverage. They caution that comparison of data collected by two different techniques over two different subdomains is not possible. In other words, if the slug-test data were not collected in the same borehole and same depth interval as the pumping data, the comparison of results is not meaningful. Most, if not all cases, generated under this analysis do not have overlapping domains. For the purposes of large-scale flow modeling, the pumping-scale data will be the primary choice and the slug test-scale data will be consulted only for secondary reference. Laboratory-scale data are not applicable to formations characterized by fracture flow, but may have limited usefulness in defining hydraulic conductivity in porous formations.

\subsubsection{Hydraulic Conductivity Versus Depth}

Figure 5-13 displays all of the pumping-scale K data from the NTS investigation area plotted against depth on the y-axis. This figure is intended to give the presentation a physical orientation. The data are shown with symbols corresponding to HSUs so that the K versus depth variation within an HSU can be observed. However, on an individual HSU basis, the trend may vary. Figure 5-14 is a plot with the axes transposed for fitting a linear trendline to the data, which is in $\log 10 \mathrm{~K}$. The equation for the trendline is displayed on the plot. The $\mathrm{K}$ values can range up to two orders of magnitude on either side of the trend line at any particular depth, for a number of HSUs, which is reflected in the low $\mathrm{R}^{2}$ value. However, there appears to be a definite decrease in $\mathrm{K}$ with depth, albeit with large uncertainty in application. Due to the depth of the flow model, the decrease in K with depth can make a significant difference. 
Table 5-7

Variation of the Mean and Standard Deviation of K Data by Scale of Measurements, by HSU

\begin{tabular}{|c|c|c|c|c|c|c|c|}
\hline \multirow{2}{*}{ Data Analysis HSUs } & \multirow[b]{2}{*}{ Data Source } & \multicolumn{2}{|c|}{ Pumping-Scale Data } & \multicolumn{2}{|c|}{ Slug-Test-Scale Data } & \multicolumn{2}{|c|}{ Laboratory-Scale Data } \\
\hline & & Mean & $\begin{array}{l}\text { Standard } \\
\text { Deviation }\end{array}$ & Mean & $\begin{array}{l}\text { Standard } \\
\text { Deviation }\end{array}$ & Mean & $\begin{array}{l}\text { Standard } \\
\text { Deviation }\end{array}$ \\
\hline \multirow{2}{*}{$\mathrm{AA}$} & FF-Specific & -0.22 & 0.80 & -0.25 & N/A & -0.34 & 0.73 \\
\hline & Study Area & 0.25 & 0.88 & -1.11 & 1.33 & -0.37 & 0.79 \\
\hline \multirow{2}{*}{ TMA } & FF-Specific & 1.29 & 0.22 & 0.08 & N/A & -0.47 & 0.76 \\
\hline & Study Area & -0.24 & 0.93 & -2.27 & 1.15 & N/A & N/A \\
\hline VA & Study Area & 0.21 & 0.98 & -1.67 & 1.02 & -3.67 & 2.20 \\
\hline VCU & Study Area & -1.03 & 1.51 & -2.16 & 1.23 & -4.41 & 1.55 \\
\hline LCA & FF-Specific & -0.13 & 1.43 & $\mathrm{~N} / \mathrm{A}$ & N/A & -3.68 & 1.38 \\
\hline UCCU & Study Area & -2.22 & 1.26 & -1.64 & 0.79 & -5.11 & 0.41 \\
\hline LCCU & Study Area & 0.40 & 0.36 & N/A & N/A & -6.11 & 0.62 \\
\hline
\end{tabular}

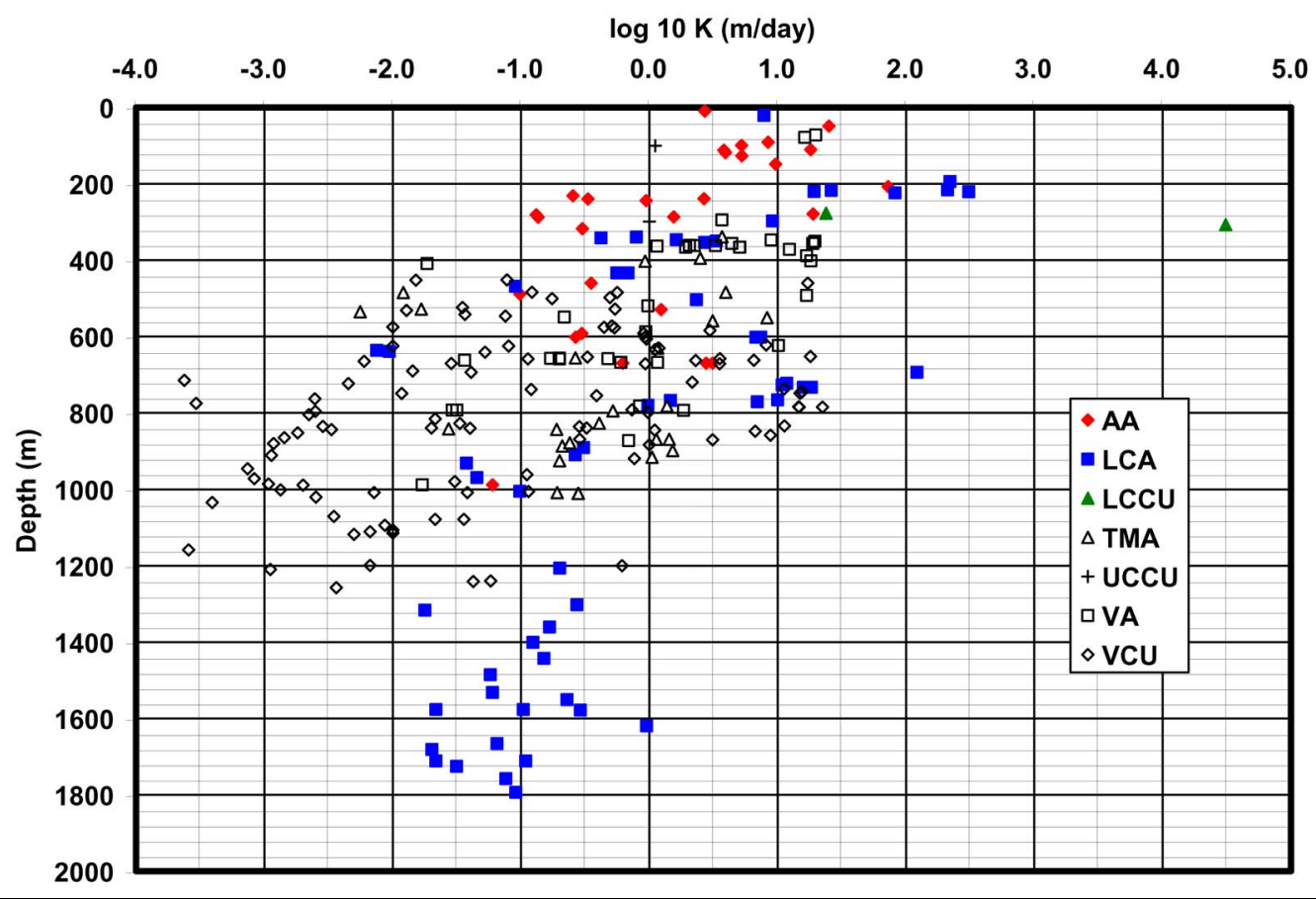

Figure 5-13

NTS Investigation Area Log 10 K Versus Depth 


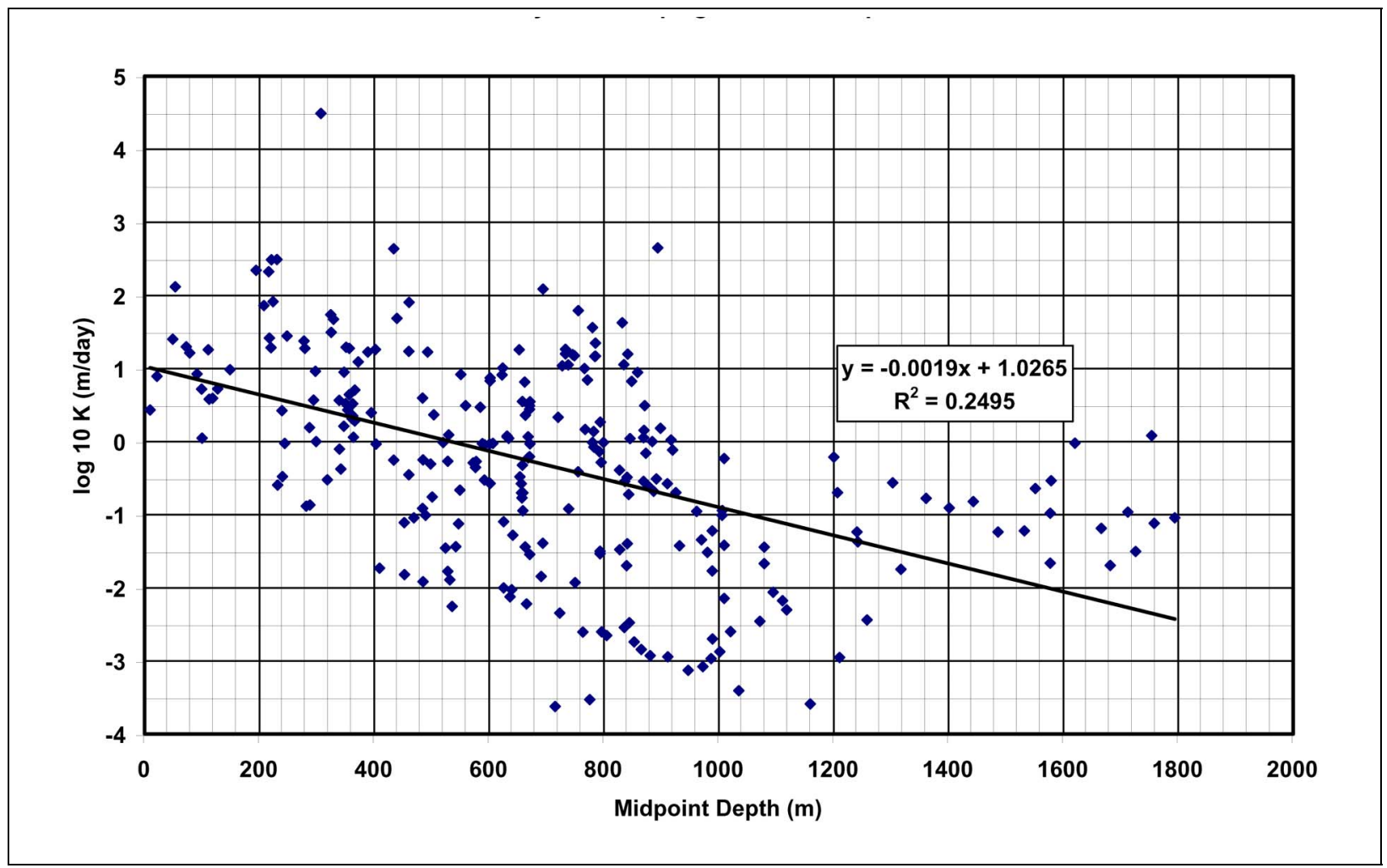

Figure 5-14

NTS Investigation Area K-Depth Trend

\subsubsection{Aquifer Unit Versus Confining Unit Results}

Hydrostratigraphic units are generally considered aquifer units or confining units. Hydraulic properties analysis results (Table 5-1 and Table 5-2) indicate that aquifer units generally have higher $\mathrm{K}$ values than confining units. However, there is considerable overlap in the K ranges, and in several cases, HSUs considered confining units have higher mean $\mathrm{K}$ values than some aquifer units. The LCCU pumping-scale analysis results are shown on Table 5-2. This may be due to several factors. In this case, the tests in the LCCU were conducted in productive, fractured intervals of a generally low K, unfractured HSU. Fractured rocks may have low matrix $\mathrm{K}$, and would be effective confining units where they are not fractured. This is evident from the laboratory-scale data analysis for these units, which measures matrix properties.

\subsection{Aquifer Storage Properties}

The storage coefficient (S) is defined as the volume of water that an aquifer releases from or takes into storage per unit surface area of the aquifer per unit change in head (Freeze and Cherry, 1979). It is a dimensionless variable that is generally smaller than 0.005 in confined aquifers. It is called the specific yield in unconfined aquifers and is a measure of the drainable porosity, typically less than 
0.30. Specific storage $\left(\mathrm{S}_{\mathrm{s}}\right)$ is the amount of water that an aquifer releases from or takes into storage per unit volume, and is calculated by dividing the storage coefficient by the saturated thickness (b): $\mathrm{S}=\mathrm{S}_{\mathrm{s}}{ }^{*}$ b. Specific storage is used to assess storage parameter variability because it removes the effects of unequal test interval lengths from the data.

Storage coefficient data have been compiled from aquifer tests with at least two wells, one pumping and the other(s) as observation wells, and converted into specific storage. Figure 5-15 is a plot of the probability distribution of specific

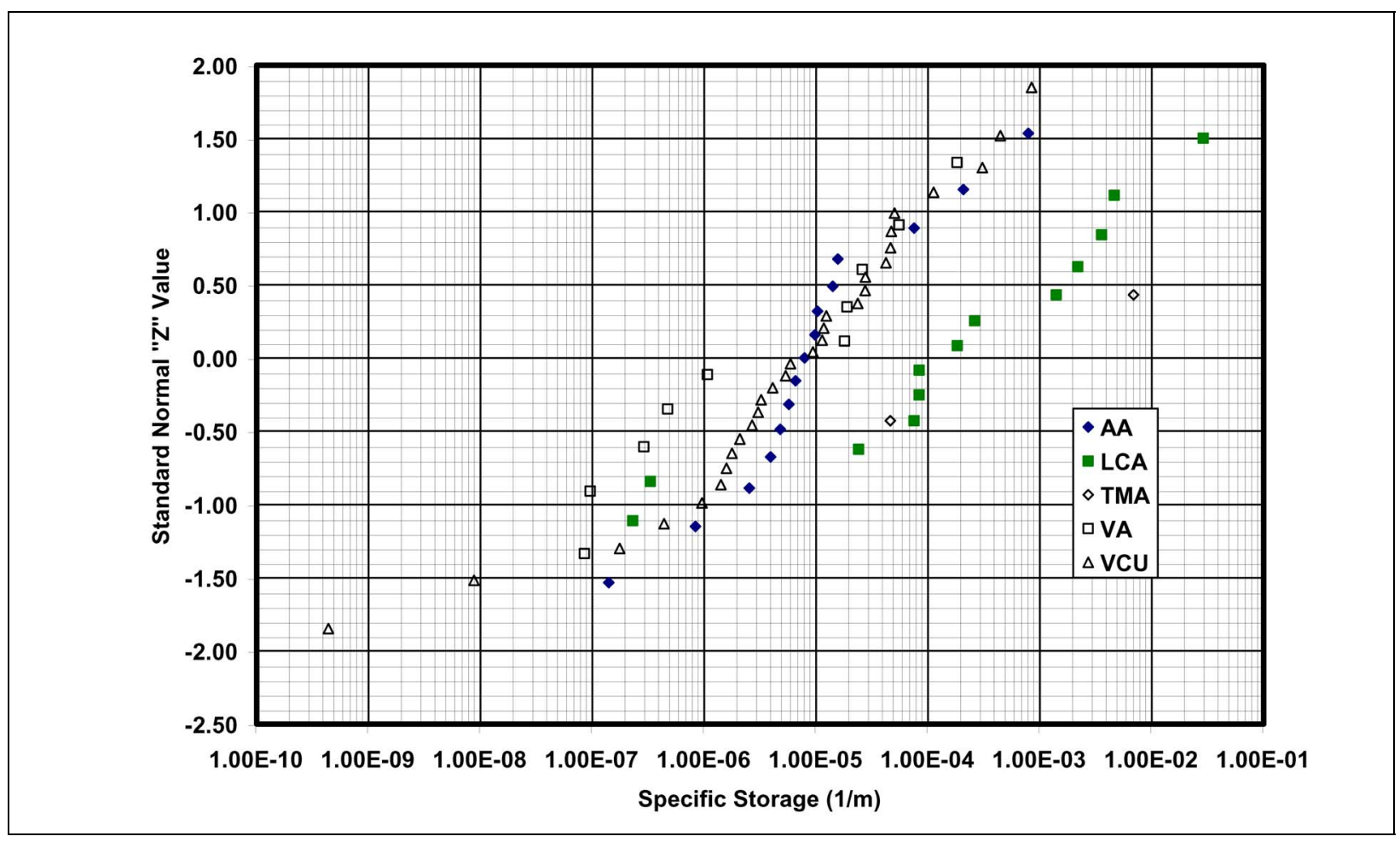

Figure 5-15

NTS Investigation Area Specific Storage Probability Distribution

storage data for the NTS investigation area, with the data categorized by HSU. The data come from a variety of locations. The alluvium data comes primarily from locations in FF and off the NTS. The LCA data is from the USGS Amargosa tracer test site and also one site in Yucca Flat. The VA data are from several locations in northern Frenchman Flat (i.e., water wells WW-4 and WW-4a, completed in the TM-WTA FF HSU). The VCU data is from Yucca Mountain locations.

The data values span six orders of magnitude. The specific storage values that are greater than $10^{-3}$ are suspect because the associated storativities would require excessively high porosity. These very high storativity values are for the LCA from a location where the LCA is shallow and karstic and may have been dewatered during testing. These data likely do not represent the conditions in the 
LCA where it is deeply buried within the model area. At the lower end, the values represent fracture specific storage (Figure 5-16).

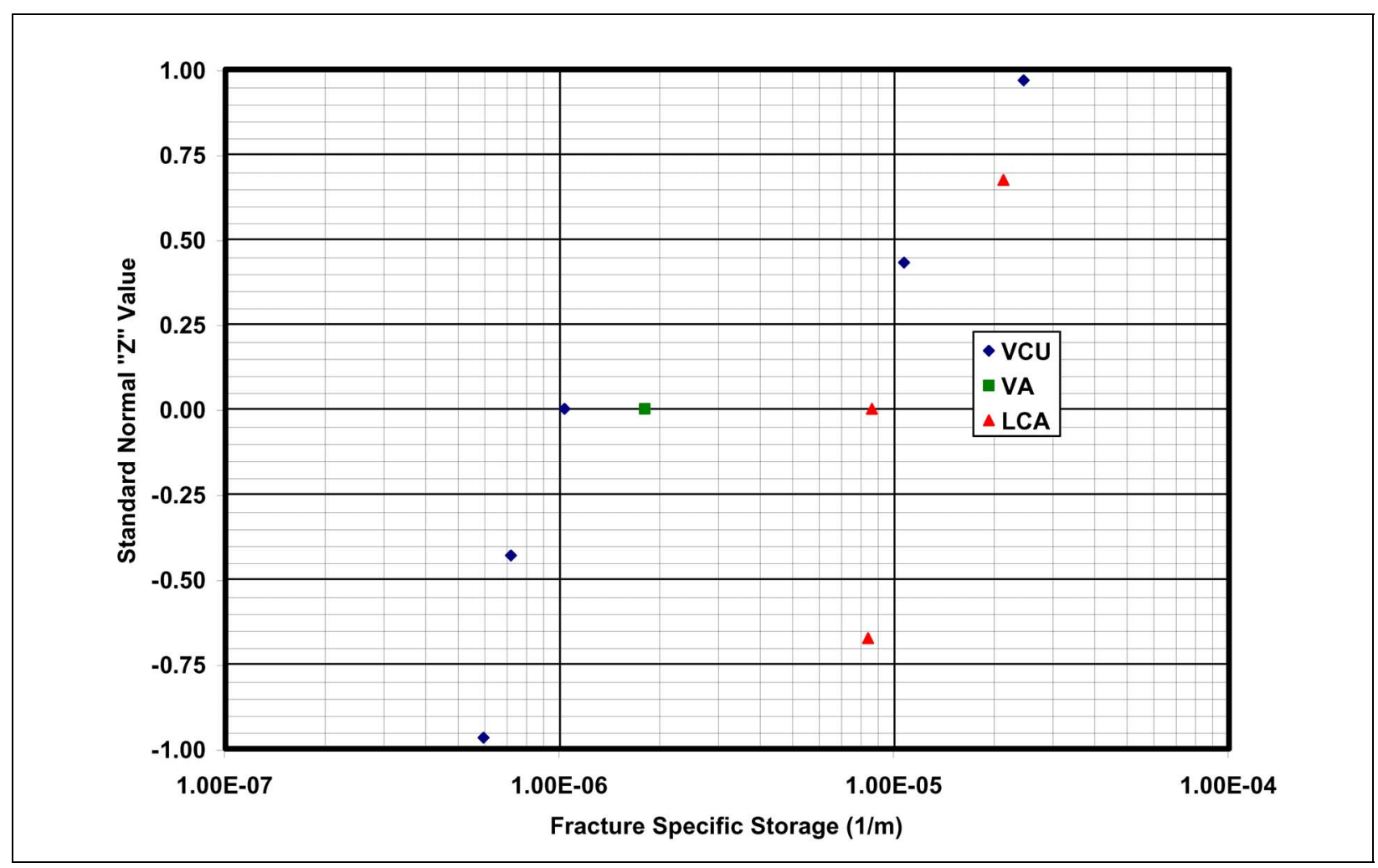

Figure 5-16

NTS Investigation Area Fracture Specific Storage Probability Distribution

The distributions for the HSUs with more than a few data points (the AA, VA, VCU, and LCA) are quite similar. However, it is not clear how representative the data are of the broader distribution over the entire NTS investigation area.

Sanchez-Vila et al. (1999) show that in the presence of heterogeneity, which always occurs in reality, storativity estimates will often vary strongly as a function of the relative transmissivity of the flow path between the pumping and observation well. Thus, storativity estimates depend on the degree of transmissivity heterogeneity. Sanchez-Vila et al. (1999) also suggest that a good estimate of true storativity is rarely obtained in practice from pumping tests. It is possible that much of the apparent scatter in specific storage values is unrelated to the actual variability of storage properties.

\subsection{Temperature Dependence of Hydraulic Conductivity Data}

The effective hydraulic conductivity determined from testing can be substantially influenced by the temperature of the water in the completion interval. The temperature of the water in formations on the NTS varies widely, both spatially in 
relation to geologic features and with depth related to the geothermal gradient. For example, the temperature observed in well ER-5-3\#2 in central Frenchman Flat ranged from about 30 degrees Celsius $\left({ }^{\circ} \mathrm{C}\right)$ at the water table to almost $50^{\circ} \mathrm{C}$ at a depth of 6,600 ft. Tests have been conducted in Frenchman Flat from the water table down to a maximum depth of $7,000 \mathrm{ft}$. Even higher water temperatures have been observed in produced water from other nearby wells (TW-F), presumably related to the local geology.

Intrinsic permeability $(\mathrm{k})$ can be calculated from the hydraulic conductivity $(\mathrm{K})$ if the temperature of the water produced from the formation is known. The relationship is $\mathrm{k}=\mathrm{K} \mu / \rho \mathrm{g}$, where $\mu$ is the dynamic viscosity of water, $\rho$ is the density of water, and $\mathrm{g}$ is the force of gravity (Freeze and Cherry, 1979). Both $\mu$ and $\rho$ vary with the temperature of the water. Table 5-8 shows the variation of $\mu$ and $\rho$ with temperature. Determining the intrinsic $\mathrm{k}$ for each test would normalize the hydraulic conductivity data to remove the effect of the variation in temperature. However, temperature information is not available for many of the older tests. It would be possible to develop standard temperature gradients for many locations on the NTS, and to determine the approximate average temperature for formation water within the completion intervals from which water was produced for many of the tests. This would not provide exact information for most sites, but would allow an approximate calculation of the intrinsic permeability. The subsurface temperature gradients vary spatially, so the accuracy of this approach would depend upon the nearby location of good subsurface temperature data. Also, it has been observed that the produced water during testing does not always approximate the temperature at the production depth determined from non-pumping temperature logs. This situation could not readily be accounted for without well-specific pumping temperature data.

Table 5-8

Variation of Water Properties With Temperature

\begin{tabular}{|c|c|c|}
\hline $\begin{array}{c}\text { Temperature } \\
\left({ }^{\circ} \mathrm{C}\right)\end{array}$ & $\rho$ - Density $\mathbf{g m} / \mathrm{cm}^{3}$ & $\begin{array}{c}\mu \text { - Dynamic Viscosity } \\
\mathrm{gm} /(\mathrm{cm})(\mathrm{sec})\left(10^{2}\right)\end{array}$ \\
\hline 0 & 0.99984 & 1.793 \\
\hline 10 & 0.99970 & 1.307 \\
\hline 20 & 0.99821 & 1.002 \\
\hline 30 & 0.99565 & 0.798 \\
\hline 40 & 0.99222 & 0.653 \\
\hline 50 & 0.98803 & 0.547 \\
\hline 60 & 0.98320 & 0.467 \\
\hline 70 & 0.97778 & 0.404 \\
\hline 80 & 0.97182 & 0.354 \\
\hline
\end{tabular}

Data from CRC Handbook of Chemistry and Physics, $73^{\text {rd }}$ Edition (CRC, 1992) $\mathrm{gm} / \mathrm{cm}^{3}=$ Grams per cubic centimeter 
The hydraulic response during testing is typically observed by measuring elevation changes in the free-water surface in the well. The magnitude of the changes reflects the hydraulic conductivity, but is also substantially affected by the density of the water in the water column, which varies as a function of temperature. The calculation of intrinsic permeability discussed above does not deal with the problem of measurement of the hydraulic response during testing related to the effect of the variation in density in water columns. This correction would typically require even more complete downhole temperature information during the test. During more recent testing on the NTS, temperature information has been collected which allows approximate corrections for the effect on the head change measurements, and this is incorporated in the $\mathrm{K}$ values reported for those tests. Due to the lack of temperature information for most of the data, correction or normalization for temperature has not been included in the K-data analysis.

\subsection{Anisotropy}

In the general case, hydraulic conductivity is not a scalar value, but a second rank tensor, where hydraulic conductivity at a point in space is a function of direction. The determination of horizontal anisotropy requires data from multiple observation wells completed in the same depth interval as the pumping well during aquifer testing. There are no data in the database for horizontal anisotropy at the pumping scale. Anisotropy in the vertical direction can be determined from observation wells set at depths that differ from the pumped well. However, such analyses are difficult and uncertain because the tests are affected by other factors that are poorly constrained. Laboratory data are generally not appropriate for large-scale model parameters such as those needed for the FF CAU model.

Vertical anisotropy data from aquifer testing are presented in the database. Because the dataset is limited, it is not possible to provide anisotropy values for each HSU.

\subsection{Limitations}

The data presented in this summary come from a variety of sources and represent data measured at different scales. Measurements have not been made in all FF HSUs. The largest amount of FF-specific K-data exists for the AA, but the data only represents a limited area of the FF basin. The AA is the only HSU for which there was sufficient data to define the $\mathrm{K}$ distribution. A few $\mathrm{K}$ values are available for the combined TM-WTA/TM-LVTA and the LCA HSUs, but not enough to determine statistics with confidence. The distributions of hydraulic conductivity used for other FF HSUs must be based on similarity to regional HSUs determined from data for the NTS investigation area. Data from slug test-scale measurements are potentially useful, but appear to generally have smaller mean values than corresponding pumping-scale data. Consequently, the slug test-scale analysis results must be viewed as only providing guidance and requiring adjustment. Results for the laboratory-scale measurements cannot be used for the CAU-scale modeling because of the sampling bias during core recovery and testing, 
especially in fracture flow dominated formations. The core data do provide lower bound estimates of the hydraulic conductivity of the bedded and non-fractured confining units.

The effect of spatial averaging that will occur when values are assigned to model grids cells has been noted, but cannot be quantified. Nonetheless, it is apparent that the range of values observed in the data should not be assumed to represent the range of uncertainty at the model scale. During modeling, scaling relationships will be developed, where possible. If satisfactory scaling relationships cannot be obtained, the full range of uncertainty will be used. Model scale and measurement scale are not equal. The values used in modeling represent some type of average of measured values, and model-scale parameter values should have less variability than the measurements. For uncertainty analysis, use of the measurement range will tend to produce greater estimation uncertainty. However, if the data is insufficient or biased, the measurement range may underestimate the range of variability. Use of the results from the larger NTS investigation area dataset may better encompass the variability, but introduce additional uncertainty related to data transferability.

\subsection{Summary}

The hydraulic conductivity and storage parameter data have been compiled and analyzed. Hydraulic conductivity measurements appear to be scale-dependent with the pumping-scale data having a larger mean and somewhat smaller variance than the slug-scale data. However, the apparent scale dependence would also be affected by sampling bias. As previously stated, for purposes of modeling groundwater flow in the FF flow domain, data derived from pumping tests are considered to be the most reliable, followed by data derived from slug tests.

There is significant overlap in the ranges of hydraulic conductivity for volcanic units designated as aquifers and confining units. It is believed that a reason for this is the overlap of lithologies within these broad classifications. Some confining units contain small portions of aquifer lithologies and aquifers contain some portion of confining unit lithology. In addition, the hydraulic properties of the deep formations are often primarily a function of the fracturing in the unit, which may extend across units of different character and lead to overlap in the distributions. 


\subsection{Precipitation Recharge}

In the arid environment of the NTS region, quantification of precipitation recharge is an important aspect of the groundwater flow system, and is difficult to achieve. The groundwater flow system of the Frenchman Flat area is replenished by areal recharge from precipitation and by underflow from adjacent groundwater basins. Artificial or secondary recharge has occurred in Frenchman Flat as a result of the CAMBRIC experiment when groundwater pumped from the alluvial aquifer was discharged to the ground surface in the central portion of the alluvial basin (Hokett and French, 1998). This section reviews three methods to estimate precipitation recharge for the NTS region: an empirical mass-balance method and its derivatives, a deterministic method, and a chloride mass-balance method. These recharge models will be used to support the development of the CAU-scale groundwater flow model for the Frenchman Flat area. The estimates are presented by hydrographic areas (HAs), referred to as hydrographic "basins" in some of the source references used.

\subsection{Objectives}

The objective of these data analyses is to update estimated regional precipitation recharge rates and develop alternative recharge models to examine the bounds of uncertainty in recharge estimates. The resulting alternative recharge distributions are used in the NTS regional groundwater flow model to generate a range of lateral boundary fluxes for use in the Frenchman Flat CAU groundwater flow model (see Section 9.0).

\subsection{Approach}

The approach was to review all reports concerning precipitation and recharge for the NTS region, and to determine if the current, available methodologies are applicable for defining a range and areal distribution of recharge volumes for use in numerical modeling. Calculated recharge within HAs and areal recharge distribution was evaluated and compared among methodologies to identify trends and relationships. Limitations to the models were also evaluated. This approach yielded a range of recharge volumes and areal distributions for the differing methodologies that can be used to provide reasonable bounds to precipitation recharge in the NTS area. 


\subsection{Data Types and Prioritization}

The specific data types, their sources, and their prioritization for further evaluation are discussed in this section. Types of information needed for the creation of the steady-state flow model are:

- Primary recharge documents and data sets

- Precipitation station data

- Interpolated precipitation rate distribution

- Land surface elevation

- Method of recharge estimate

Recharge data were compiled for the Frenchman Flat area of investigation and surrounding region. The main sources of information included DRI, USGS, and various reports cited herein. Information was obtained in the form of published and unpublished documents and data sets. Precipitation data were compiled from various federal, state, and local agencies. Land surface elevation data were obtained from the USGS or USGS topographic maps.

\subsection{Recharge Model Descriptions}

The following sections describe the recharge models considered in support of the Frenchman Flat groundwater flow model. The recharge models include: two UGTA models (UGTA Original and UGTA Revised), two USGS models (USGS no redistribution and USGS with redistribution), and two DRI models (DRI alluvial mask and DRI alluvial and elevation mask).

\subsubsection{UGTA Original Recharge Model (DOE/NV, 1997; IT, 1996a)}

The UGTA Original recharge model was first developed during the regional model evaluation (DOE/NV, 1997; IT, 1996a). This recharge model was derived using a modification to the Maxey and Eakin (ME) method (Maxey and Eakin, 1949) that involved reallocating recharge into canyons and washes. Descriptions of the ME method (Maxey and Eakin, 1949) and the modification to the ME method presented in this section were obtained from the recharge-discharge documentation package (IT, 1996a). An updated version of the modified ME method was also developed to incorporate new precipitation data and correct errors and inconsistencies found in the UGTA Original recharge model. A description of this updated UGTA recharge model (hereafter referred to as UGTA Revised) is also provided in Section 6.4.2.

\subsubsection{Maxey and Eakin Method}

Maxey and Eakin (1949) first described a method of estimating recharge to groundwater from precipitation in a report on groundwater in White River Valley, Nevada. Maxey and Eakin (1949) employed a Nevada precipitation map 
containing hydrographic-area designations developed by Hardman (1936). This approach estimates recharge by assuming that a relationship exists between a zone-specific percentage of precipitation and the recharge to groundwater. The ME coefficient is defined as the percentage of precipitation that recharges groundwater. Groundwater recharge is the amount of water that enters the saturated zone.

Maxey and Eakin (1949) originally divided the recharge-precipitation ranges into zones and estimated coefficients for each zone. These zones are: 0 percent recharge for precipitation of less than 20.3 centimeters $(\mathrm{cm}) /$ year; 3 percent for 20.3 to $30.5 \mathrm{~cm} /$ year; 7 percent for 30.5 to $38 \mathrm{~cm} /$ year; 15 percent for 38 to $50.8 \mathrm{~cm} /$ year; and 25 percent for greater than $50.8 \mathrm{~cm} /$ year.

These coefficients were developed by empirically comparing precipitation volumes with estimates of groundwater discharges for 13 groundwater basins in east-central Nevada. Maxey and Eakin (1949) were able to apply this method successfully to the White River Valley Hydrologic basin, which is at an elevation greater than 1,670 $\mathrm{m}$ (approximately 5,500 feet).

The ME method may be described mathematically for a given HA by:

$$
\mathrm{R}=\Sigma \mathrm{r}_{\mathrm{i}} \mathrm{P}_{\mathrm{i}}
$$

where:

$$
\begin{array}{ll}
\mathrm{R} & =\text { Total ME recharge for a given } \mathrm{HA} \\
\mathrm{r}_{\mathrm{i}} & =\text { ME recharge coefficient for each delineated precipitation zone } \\
\mathrm{P}_{\mathrm{i}} & =\text { Precipitation for each delineated precipitation zone }
\end{array}
$$

Using consistent units, either recharge volumetric rates or fluxes may be calculated using this equation. Customarily, using precipitation rates the recharge fluxes are calculated.

The ME method has been modified and used in several studies in Nevada to estimate recharge for various HAs (Eakin et al., 1951; Walker and Eakin, 1963; Malmberg, 1967; and Czarnecki, 1985). Eakin et al. (1951) changed the ME method to account for both physiographic and topographic variability. To accomplish this, ME coefficients were assigned to ranges of altitudes, rather than to ranges or zones of precipitation. Recharge is assumed to occur where the mean annual precipitation is above $20.3 \mathrm{~cm}$ in the ME method or the land surface elevation is above $1,700 \mathrm{~m}$ in the Eakin et al. (1951) method. Recharge then increases with elevation according to the ME coefficients. Note that for all the studies in which the ME method has been utilized, ME coefficients are the same for all precipitation zones, except for the lowest zone with the lowest altitude. For this zone (20.3 to $30.5 \mathrm{~cm} /$ year), Maxey and Eakin (1949) used 3 percent, Eakin et al. (1951) used 2 percent, and Walker and Eakin (1963) used 1 percent. 


\subsubsection{Modified ME Method}

The recharge distribution used in the regional groundwater flow model (DOE/NV, 1997) was constructed using a modification of the ME method (Maxey and Eakin, 1949).

The method included the following procedures, which is described in this section:

- Construction and update of a precipitation map using new and existing data

- Calculate recharge using ME coefficients

- Calculate total recharge volumes for individual HAs

- Redistribute a percentage of the total recharge within selected sub-areas to low-lying areas in wash or canyon reaches

- Multiply resulting recharge estimates for the entire model area by a coefficient calculated to make the estimated recharge value match the estimated discharge.

\subsection{Methodology}

The "Precipitation Map of Nevada" (Hardman, 1965) was used as a basis for construction of the precipitation map. The "Precipitation Map of Nevada" was adapted by Hardman in 1965 from an earlier version constructed by Hardman in 1936. The map coverage includes the entire state of Nevada, but does not include the Death Valley portion of the NTS regional groundwater flow system. To complete this portion of the precipitation map, the Death Valley section developed by James et al. (1993) was used. Additional data used in the construction of the precipitation map included the precipitation station data (Jacobson, 1996; French, 1996), the DEM from the USGS (1987), and a "Nevada Test Site Image Map" prepared by BN (1996). These data were used to validate the existing precipitation maps and changes to the existing maps during construction of the updated precipitation map. A modified ME approach was then applied to the precipitation map to calculate recharge.

\subsection{Construction of the Digital Precipitation Map and Grid File}

A digital precipitation map (Plate 1; DOE/NV, 1997) of the NTS groundwater flow system was used. Two existing precipitation maps were combined to construct a digital precipitation map. The final precipitation distribution is presented as Figure 6-1. In this section, a brief description of the process of constructing this map is presented and a more detailed discussion of its pertinent areas is discussed in the following subsection. 


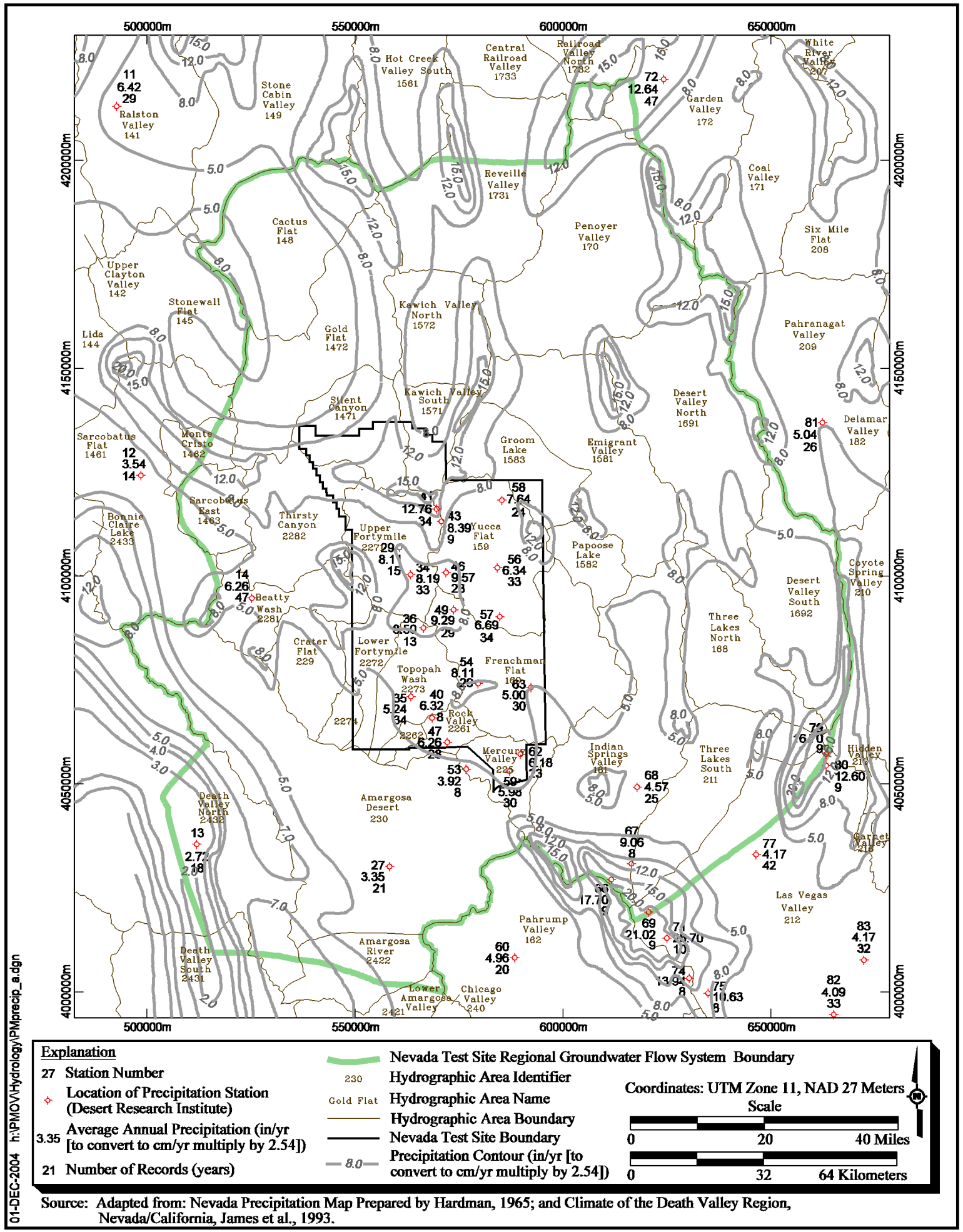

Figure 6-1

Precipitation Map for the Nevada Test Site Region Used for the UGTA Original Recharge Model 
First, precipitation contours from the existing precipitation maps of Hardman (1965) and James et al. (1993) were digitized and geographically registered. The U.S. Department of Energy, Nevada Operations Office (DOE/NV, 1997) used the most recently available precipitation station data to develop an updated precipitation map, which was then validated using satellite imagery and land surface elevation data. Only those stations with greater than eight years of record were used based on the criteria developed during discussions with regional experts and providers of the data (Jacobson, 1996; French, 1996). The selected precipitation stations are listed in Table 6-1.

Precipitation contours in selected areas of the precipitation map were modified by reshaping the contours to incorporate the new data from the selected precipitation stations Table 6-1. In most instances, the precipitation station data validated the existing precipitation contours and only minimal modifications were required. The satellite imagery and DEM data were examined prior to modifying the contours. Contour lines were only modified where there was sufficient data to substantiate any changes. The most notable modifications were made in areas between east Timber Mountain and west Yucca Flat (Figure 6-1), south Timber Mountain extending from Yucca Mountain to east of Mercury, and on Spring Mountain in order to accommodate precipitation stations with more recent data. The least notable modification was made at the southern portion of the Grant Range just north of the Worthington Mountains.

The precipitation map was validated using the DEM and satellite imagery. The DEM grid was contoured according to the land-area model of Eakin et al. (1951) to show the 1,524- to 2,439-m contour lines. The precipitation map was validated by superposing the precipitation data (contours and station data) on the digital elevation model. The accuracy of the DEM is 92 meters. The plot was used to ensure the contours were positioned correctly relative to elevation. In general, the contour shape coincides with the shape of the topographic features of the mountain ranges. Due to the poor quality of the copy and large scale of the Hardman map, the validation process proved to be a very important step in constructing the digital precipitation map as error was introduced in the tracing and scanning the maps developed by Hardman (1965) and James et al. (1993). The validated digital precipitation map was then used in the modified ME method to calculate the recharge distribution on a 1 x 1 kilometer node spacing.

\subsection{Final Precipitation Distribution}

The final precipitation distribution is presented as Figure 6-1, with precipitation depth contours and the precipitation station data, the NTS groundwater flow system boundary, and the digital elevation model. As indicated by Figure 6-1, the precipitation rate increases with land surface elevation and follows the general topography. The Spring Mountains in the south receive the highest amount of precipitation (13.9 to $26.7 \mathrm{~cm} /$ year), followed by the Sheep Range to the east (12.6 to greater than $17 \mathrm{~cm} /$ year). Other mountain ranges in the NTS groundwater flow system receive approximately 30.5 to $38.1 \mathrm{inch} /$ year. Death Valley receives the least amount of precipitation with approximately $5.1 \mathrm{~cm} /$ year. 
Table 6-1

Precipitation Station Data Used for UGTA Original Recharge Model

\begin{tabular}{|c|c|c|c|c|c|c|}
\hline \multirow{2}{*}{$\begin{array}{l}\text { Station } \\
\text { Number }\end{array}$} & \multirow{2}{*}{ Station Name } & \multicolumn{2}{|c|}{$\begin{array}{l}\text { UTM Zone 11, } \\
\text { NAD } 27\end{array}$} & \multirow{2}{*}{$\begin{array}{l}\text { Land } \\
\text { Surface } \\
\text { Elevation } \\
\text { (m) }\end{array}$} & \multicolumn{2}{|c|}{$\begin{array}{l}\text { Average Annual } \\
\text { Precipitation }\end{array}$} \\
\hline & & $\begin{array}{c}\text { Easting } \\
\text { (meters }[\mathrm{m}])\end{array}$ & $\begin{array}{l}\text { Northing } \\
\quad(\mathrm{m})\end{array}$ & & $\begin{array}{c}\text { Depth } \\
\text { cm/year (inches/year) }\end{array}$ & $\begin{array}{l}\text { Years } \\
\text { Record }\end{array}$ \\
\hline 11 & Tonopah Airport & 492,689 & $4,213,009$ & 1,655 & $16.3(6.42)$ & 29 \\
\hline 12 & Sarcobatus & 498,522 & $4,124,251$ & 1,225 & $9.0(3.54)$ & 14 \\
\hline 13 & Death Valley & 511,946 & $4,035,517$ & -52 & $6.9(2.72)$ & 18 \\
\hline 14 & Beatty & 525,210 & $4,094,706$ & 1,082 & $15.9(6.26)$ & 47 \\
\hline 27 & Lathrop Wells & 558,275 & $4,030,159$ & 664 & $8.5(3.35)$ & 21 \\
\hline 29 & Little Feller 2 & 560,698 & $4,106,882$ & 1,573 & $20.6(8.11)$ & 15 \\
\hline 34 & $40 \mathrm{MN}$ & 563,341 & $4,100,364$ & 1,469 & $20.8(8.19)$ & 33 \\
\hline 35 & $4 \mathrm{JA}$ & 563,445 & $4,071,032$ & 1,043 & $13.3(5.24)$ & 34 \\
\hline 36 & Shoshone Basin & 566,464 & $4,087,547$ & 1,725 & $21.6(8.50)$ & 13 \\
\hline 40 & Skull Mountain Pass & 568,500 & $4,065,887$ & 1,186 & $16.1(6.32)$ & 8 \\
\hline 41 & Area 12 Mesa & 569,624 & $4,116,171$ & 2,283 & $32.4(12.76)$ & 34 \\
\hline 43 & Stockade Pass & 570,759 & $4,113,178$ & 2,053 & $21.3(8.39)$ & 9 \\
\hline 46 & Tippipah Spring 2 & 571,887 & $4,100,851$ & 1,518 & $24.3(9.57)$ & 28 \\
\hline 47 & $\mathrm{RV}-1$ & 572,151 & $4,060,050$ & 1,036 & $15.9(6.26)$ & 28 \\
\hline 49 & Mid Valley & 573,701 & $4,091,914$ & 1,420 & $23.6(9.29)$ & 29 \\
\hline 53 & RV-Wash & 576,721 & $4,053,568$ & 866 & $10.0(3.92)$ & 8 \\
\hline 54 & Cane Springs & 579,583 & $4,074,185$ & 1,219 & $20.6(8.11)$ & 29 \\
\hline 56 & BJY & 584,209 & $4,102,022$ & 1,241 & $16.1(6.34)$ & 33 \\
\hline 57 & Yucca & 584,791 & $4,090,231$ & 1,195 & $17.0(6.69)$ & 34 \\
\hline 58 & PHS Farm & 585,301 & $4,118,280$ & 1,391 & $19.4(7.64)$ & 24 \\
\hline 59 & Desert Rock & 587,122 & $4,053,108$ & 1,005 & $15.2(5.98)$ & 30 \\
\hline 60 & Pahrump & 588,385 & $4,008,227$ & 823 & $12.6(4.96)$ & 20 \\
\hline 62 & Mercury & 589,740 & $4,057,169$ & 1,149 & $15.7(6.18)$ & 23 \\
\hline 63 & Well 5B & 592,263 & $4,073,193$ & 939 & $12.7(5.00)$ & 30 \\
\hline 66 & Trough Spring & 610,107 & $4,026,349$ & 2,512 & $45.0(17.70)$ & 9 \\
\hline 67 & Cold Creek & 613,563 & $4,030,708$ & 1,862 & $23.0(9.06)$ & 8 \\
\hline 68 & Indian Springs & 617,793 & $4,049,256$ & 951 & $11.6(4.57)$ & 25 \\
\hline 69 & Lee Canyon & 619,087 & $4,018,516$ & 2,594 & $53.4(21.02)$ & 9 \\
\hline 71 & Kyle Canyon & 623,466 & $4,012,260$ & 2,365 & $67.8(26.70)$ & 10 \\
\hline 72 & Adaven & 624,188 & $4,219,501$ & 1,905 & $32.1(12.64)$ & 47 \\
\hline 74 & Roberts Ranch & 627,418 & $4,003,163$ & 1,862 & $35.4(13.94)$ & 8 \\
\hline 75 & Red Rock Summit & 631,972 & $3,999,532$ & 1,984 & $27.0(10.63)$ & 8 \\
\hline 79 & Hayford Peak & 660,932 & $4,058,248$ & 2,999 & $42.4(16.70)$ & 9 \\
\hline 80 & Hidden Forest & 660,934 & $4,055,504$ & 2,304 & $32.0(12.60)$ & 9 \\
\hline 81 & Alamo & 662,347 & $4,136,921$ & 1,049 & $12.8(5.04)$ & 26 \\
\hline 82 & Las Vegas Airport & 665,072 & $3,994,546$ & 661 & $10.4(4.09)$ & 33 \\
\hline 83 & Sunrise Manor & 672,321 & $4,007,633$ & 555 & $10.6(4.17)$ & 32 \\
\hline
\end{tabular}

Source: Jacobson, 1996; French, 1996 
Table 6-2 lists the total precipitation rates calculated for each HA. The total calculated precipitation rates shown in column 3 only include the precipitation within the NTS groundwater flow system boundary. Any precipitation outside the groundwater flow system boundary is not included in the total for the HA. Total precipitation rates reported by Scott et al. (1971) are included in columns 4 and 5 for comparison. The total precipitation reported for Scott et al., (1971) in Table 6-2 is prorated based on the area within the flow system boundary using the following equation:

$$
P_{p}=\frac{P_{t s} \times A_{f s}}{A_{h a}}
$$

where:

$$
\begin{array}{ll}
\mathrm{P}_{\mathrm{p}} & =\text { Prorated precipitation rate } \\
\mathrm{P}_{\mathrm{ts}} & =\text { Published total precipitation rate } \\
\mathrm{A}_{\mathrm{fs}} & =\text { Area within flow system boundary } \\
\mathrm{A}_{\mathrm{ha}} & =\text { Total area of HA }
\end{array}
$$

In general, the calculated total precipitation and total published precipitation from Scott et al. (1971) compare reasonably well. The difference between the two totals is about 118,000 cubic meters per day $\left(\mathrm{m}^{3} / \mathrm{d}\right)$. The maximum precipitation is found in the Tikaboo and Emigrant Valley HAs. The calculated total precipitation rates for those HAs including testing areas (Gold Flat, Yucca Flat, and Frenchman Flat) are similar to the published data. The HAs with the largest discrepancy between totals are the Las Vegas Valley and Amargosa Desert. These HAs have very little, if any, recharge to the NTS groundwater flow system and should not affect the modeling results.

Possible causes of discrepancies between the calculated precipitation and the published totals are:

- Error introduced during the tracing and scanning of the Hardman (1965) and James et al. (1993) maps

- The use of different methods to construct the precipitation map

- The use of different techniques to calculate the totals (i.e., summing individual grid nodes versus averaging contours within the HA)

- Rounding errors

The most likely source of error is the use of different methods of calculations.

\subsection{Recharge}

In Nevada, the ME method has been used to calculate the total volume of recharge to groundwater in a given HA. Although the method indirectly correlates recharge magnitude to precipitation zones, the method does not take into account the 
Table 6-2

Comparison of Precipitation Rates to Published Values by Hydrographic Area

\begin{tabular}{|c|c|c|c|c|}
\hline \multicolumn{2}{|c|}{ Hydrographic Area } & \multirow{2}{*}{$\begin{array}{l}\text { Total Precipitation } \\
\text { Calculated from } \\
\text { Distribution }^{\mathrm{a}} \\
\left(\mathrm{m}^{3} / \mathrm{d}\right)\end{array}$} & \multicolumn{2}{|c|}{$\begin{array}{l}\text { Published Precipitation Data } \\
\qquad \text { (Scott et al., 1971) }\end{array}$} \\
\hline $\begin{array}{l}\text { Hydrographic } \\
\text { Area No. }\end{array}$ & Hydrographic Area Name & & $\begin{array}{l}\text { Total Precipitation } \\
\text { within Flow System } \\
\left(\mathrm{m}^{3} / \mathrm{d}\right)\end{array}$ & $\begin{array}{l}\text { Total Precipitation in } \\
\text { Hydrographic Area } \\
\qquad\left(\mathrm{m}^{3} / \mathrm{d}\right)\end{array}$ \\
\hline 145 & Stonewall Flat & 2,546 & 4,878 & 371,737 \\
\hline 146 & Sarcobatus Flat & 202,290 & 311,556 & 642,091 \\
\hline 147 & Gold Flat & 889,195 & 844,856 & 844,856 \\
\hline 148 & Cactus Flat & 491,956 & 439,325 & 439,325 \\
\hline 149 & Stone Cabin Valley & 1,471 & 2,402 & $1,182,799$ \\
\hline 156 & Hot Creek Valley & 1,846 & 2,544 & $1,317,976$ \\
\hline 157 & Kawich Valley & 622,296 & 506,914 & 506,914 \\
\hline 158 & Emigrant Valley & $1,164,236$ & 959,757 & 959,757 \\
\hline 159 & Yucca Flat & 461,941 & 337,942 & 337,942 \\
\hline 160 & Frenchman Flat & 511,223 & 506,914 & 506,914 \\
\hline 161 & Indian Springs Valley & 728,691 & 912,445 & 912,445 \\
\hline 162 & Pahrump Valley & 1,531 & 5,397 & $1,419,358$ \\
\hline 168 & Three-Lakes Valley North & 276,120 & 371,737 & 371,737 \\
\hline 169 & Tikaboo Valley & $1,260,641$ & $1,284,181$ & $1,284,181$ \\
\hline 170 & Penoyer Valley & $1,127,129$ & 912,445 & 912,445 \\
\hline 171 & Coal Valley & 835 & 1,249 & 574,502 \\
\hline 172 & Garden Valley & 68,283 & 115,092 & 777,268 \\
\hline 173 & Railroad Valley South & 681,245 & 844,856 & 844,856 \\
\hline 209 & Pahranagat Valley & 1,446 & 3,564 & 912,445 \\
\hline 210 & Coyote Spring Valley & 13,005 & 18,106 & 743,473 \\
\hline 211 & Three-Lakes Valley South & 359,289 & 439,325 & 439,325 \\
\hline 212 & Las Vegas Valley & 248,265 & 613,223 & $2,230,420$ \\
\hline 225 & Mercury Valley & 104,576 & 128,418 & 128,418 \\
\hline 226 & Rock Valley & 85,759 & 87,865 & 87,865 \\
\hline 227 & Fortymile Canyon & 715,443 & 669,126 & 669,126 \\
\hline 228 & Oasis Valley & 660,013 & 506,914 & 506,914 \\
\hline 229 & Crater Flat & 153,895 & 206,145 & 206,145 \\
\hline 230 & Amargosa Desert & $1,131,415$ & 811,062 & 811,062 \\
\hline 242 & Amargosa River & 117,067 & $117,067^{b}$ & \\
\hline 243 & Death Valley & 398,318 & $398,318^{b}$ & \\
\hline & Total Precipitation: & $12,481,966$ & $12,363,623$ & \\
\hline
\end{tabular}

Source: IT, 1996a

${ }^{\mathrm{a} C}$ Calculation only includes precipitation within the NTS groundwater flow system boundary.

${ }^{\mathrm{b}}$ Calculated hydrographic area total included in published precipitation total. Published data for this hydrographic area not available at time of printing.

$\mathrm{m}^{3} / \mathrm{d}=$ Cubic meters per day 
specific locations where recharge actually occurs. DOE/NV (1997) assumed that the majority of the recharge occurs at higher elevations as assumed in the ME method. However, smaller portions of the recharge have been shown to occur at lower elevations, in washes and in canyons. In a study of groundwater recharge in Fortymile Canyon, Savard (1994) reported that recharge does occur along the canyon after streamflow events, as evidenced by rising water-levels.

Consequently, for the purpose of the NTS regional model investigation, recharge was determined in two major steps: generation of a preliminary recharge

distribution and reallocation of a fraction of this recharge to canyons and washes.

\section{Preliminary Recharge Distribution}

A preliminary recharge distribution was generated using the updated precipitation map and the ME coefficients. The area of the NTS regional groundwater flow system was subdivided according to the boundaries of HAs as defined by

Harrill et al. (1988). Thirty major HAs were identified within the model area.

Recharge rate was calculated for each of the HAs using the $1 \times 1 \mathrm{~km}$ precipitation grid and three sets of ME coefficients.

The recharge rates were first calculated for each $1 \times 1 \mathrm{~km}$ grid cell by multiplying the corresponding precipitation value by the ME coefficients. For the lower precipitation zone (20.3 to $30.5 \mathrm{~cm} / \mathrm{yr}$ ), recharge was calculated using a ME coefficient of two percent. Alternative total recharge rates for the groundwater flow system were also calculated using one percent and three percent as the ME coefficient for the lowest precipitation zone. These alternatives were then used to determine the optimum ME coefficient for the NTS regional model area.

Important recharge areas are located in the Belted, Groom, and Timpahute ranges in the north, in the Pahranagat and Sheep ranges to the east, and in the Spring Mountains on the southeastern boundary. The total recharge rate estimated for the NTS regional groundwater flow system is $218,000 \mathrm{~m}^{3} / \mathrm{d}$ (DOE/NV, 1997).

\section{Recharge Allocation}

A method was developed to calculate recharge rates for HAs where infiltration through canyons and washes contribute to recharge. In this method, types of recharge allocation zones are first identified, which correspond to the canyons and washes. Then portions of the total HA recharge are allocated to these identified zones. A given HA may be subdivided into three types of recharge zones: A, B, and $\mathrm{C}$.

- Type A Zone: Up gradient recharge areas that receive greater than $20.3 \mathrm{~cm}$ of annual precipitation per year. This is where the majority of infiltration occurs.

- Type B Zone: Canyon-wash recharge areas that receive less than $20.3 \mathrm{~cm}$ of precipitation per year, but include alluvial fans and streams through which recharge may occur. 
- Type C Zone: Areas of no recharge that receive less than $20.3 \mathrm{~cm}$ of precipitation per year, but contain no alluvial fans or stream reaches to facilitate infiltration.

Recharge volumes were calculated for each sub-area as outlined above. Nine hydrographic areas where type B zones occur were identified on the NTS and vicinity. The HAs are Topopah Wash, Beatty Wash, Thirsty Canyon, Lower Fortymile Canyon, Upper Fortymile Canyon, Frenchman Flat, Yucca Flat, Silent Canyon, Kawich Valley South, and Groom Lake (Figure 6-2).

Each of these nine HAs were subdivided into Types A, B, and C. Type B zones were further subdivided into three types of recharge areas: B1, B2, and B3. Type B1 represents upland canyon and valley washes and stream reaches, Type B2 represents mountain front washes and stream reaches, and Type B3 represents valley bottom washes and stream reaches.

For each HA where Type B zones occur, a portion of the HA recharge volume was re-allocated from Type A areas to Type B areas. It is important to emphasize that the total recharge rates calculated for each area was not modified; only the areal distribution was modified.

The following relations were used to proportion the volume of recharge to each zone:

$$
\begin{array}{r}
\mathrm{V}_{\mathrm{a}}=\alpha \mathrm{V}_{\mathrm{T}} \\
\mathrm{V}_{\mathrm{B}}=(1-\alpha) \mathrm{V}_{\mathrm{T}}
\end{array}
$$

where

$\mathrm{V}_{\mathrm{T}} \quad=$ The total recharge volume calculated using ME method

$\mathrm{V}_{\mathrm{A}} \quad=$ Recharge rate in Type $\mathrm{A}$ areas

$\mathrm{V}_{\mathrm{B}} \quad=$ Recharge rate in Type $\mathrm{B}$ areas

$\alpha=$ Redistribution factor in fraction of the total recharge volume (0 to 1$)$

As an example, if $\mathrm{V}_{\mathrm{T}}=100$ and $\alpha=0.30$, then $\mathrm{V}_{\mathrm{A}}=30$ and $\mathrm{V}_{\mathrm{B}}=70$.

The recharge volumes in Type B zones were further re-distributed to each recharge sub-area (B1, B2, and B3) using assigned fractions $\beta, \gamma$, and $\delta$, respectively.

Following mass-balance equation was used for redistribution:

$$
\beta+\gamma+\delta=1
$$

where:

$\beta=$ Fraction of $\mathrm{V}_{\mathrm{B}}$ assigned to Type $\mathrm{B} 1$ sub-areas

$\gamma=$ Fraction of $\mathrm{V}_{\mathrm{B}}$ assigned to Type $\mathrm{B} 2$ sub-areas

$\delta=$ Fraction of $\mathrm{V}_{\mathrm{B}}$ assigned to Type $\mathrm{B} 3$ sub-areas 


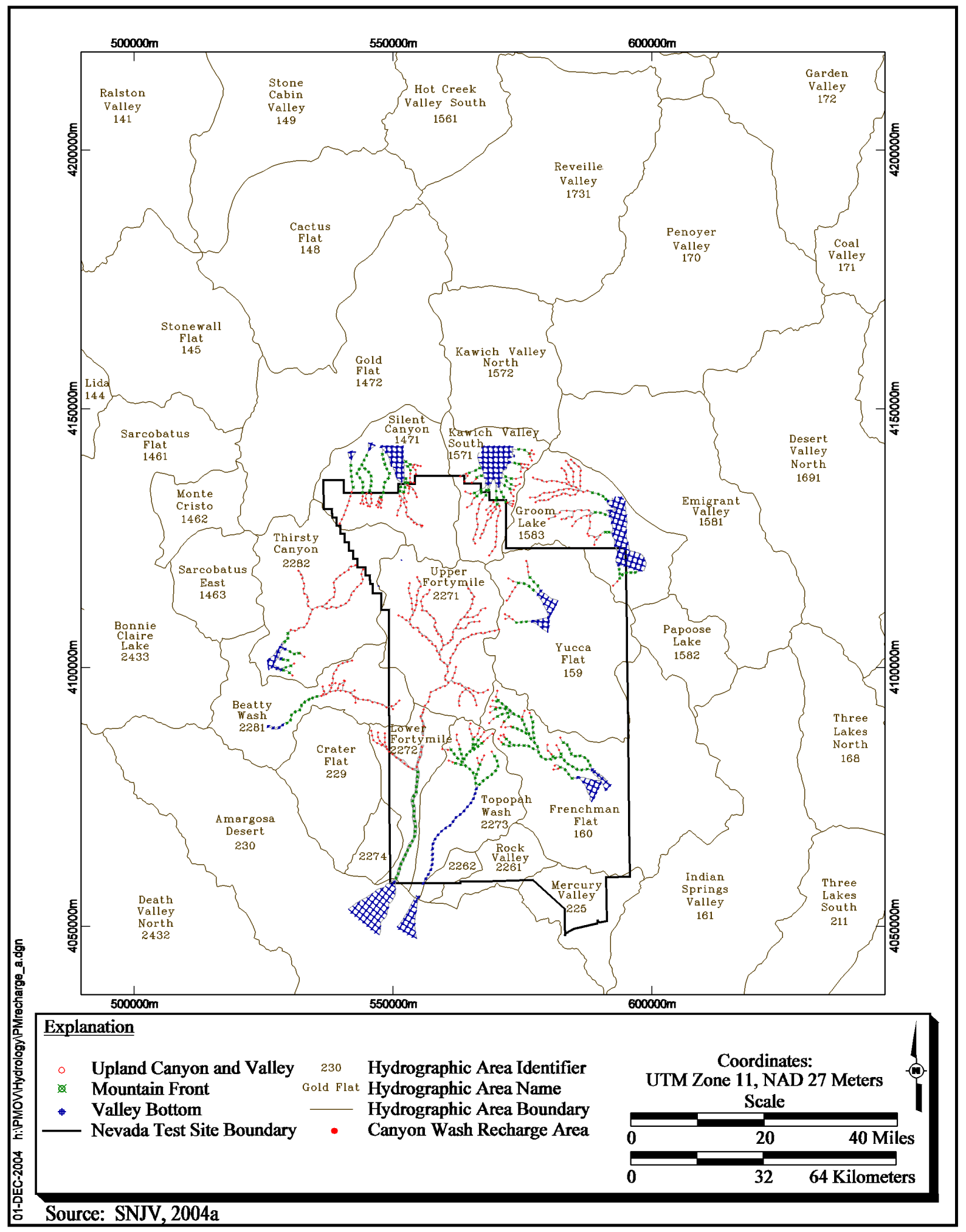

Figure 6-2

Potential Recharge Redistribution Areas in the Nevada Test Site Region 
Within a given HA, each of B1, B2, and B3 sub-areas was subdivided into several wash or canyon reaches. Recharge volumes for each reach were then obtained by dividing the recharge volumes assigned to a given sub-area type (B1, B2, or B3) by the number of reaches available within the given HA. This process of subdividing and reallocating recharge volumes to zones and sub-areas is referred to as the modified ME method.

A utility FORTRAN code was developed to implement the modified ME method. The code required the ME recharge distribution by HA; the spatial distribution of different types of recharge areas described above; and values for $\alpha, \beta, \gamma$, and $\delta$, based on estimates of recharge volumes for B-zone and subtype areas. The code calculates a new recharge distribution for the upper cells of the regional groundwater flow model grid. This was an important feature that allowed adjusting the regional groundwater flow model recharge grid during the calibration process. The code listing and QA requirements are provided in the Groundwater Flow Model Documentation Package (IT, 1997a).

The recharge reallocation coefficients $(\alpha, \beta, \gamma$, and $\delta)$ were unknown because the recharge in Type B areas were unknown. Arbitrary initial values were assigned to these coefficients to generate an initial recharge grid. These values were adjusted during the groundwater-flow model calibration process. The process and results are presented in the Groundwater Flow Model Documentation Package (IT, 1997a). The recharge distribution used in the NTS Regional Groundwater Flow Model was remapped for this document and shown in Figure 6-3 (IT, 1996a).

\subsubsection{Revised UGTA Recharge Model}

An additional recharge distribution map was generated by updating the UGTA Original recharge model. The update included the re-digitization and re-contouring of the precipitation map, correction of errors in the digitization of the HAs, and incorporating new precipitation station data described in Table 6-3. Following the update, a comparison to other recharge models was conducted to ensure no new errors were introduced during the re-digitization.

The main precipitation map was re-digitized to correct minor localized errors in the initial precipitation distribution. A different contouring program (EarthVision ${ }^{\circledR}$ [Dynamic Graphics, 2002]) was used to grid the data. The USGS precipitation distribution in the southeast portion of the NTS area was not included in this version. The final precipitation map with updated precipitation information and revised contours is presented in Figure 6-4. All other aspects of the recharge calculations remained the same, including the redistribution. The total recharge estimate was also uniformly increased by a factor of 1.0678 based on the recharge balance to discharge estimates reported in DOE/NV (1997). This was deemed appropriate because the modest change in total recharge was less than the uncertainty associated with many discharge estimates for the NTS regional model area. The results of this version of the UGTA recharge distribution are shown in Figure 6-5. 


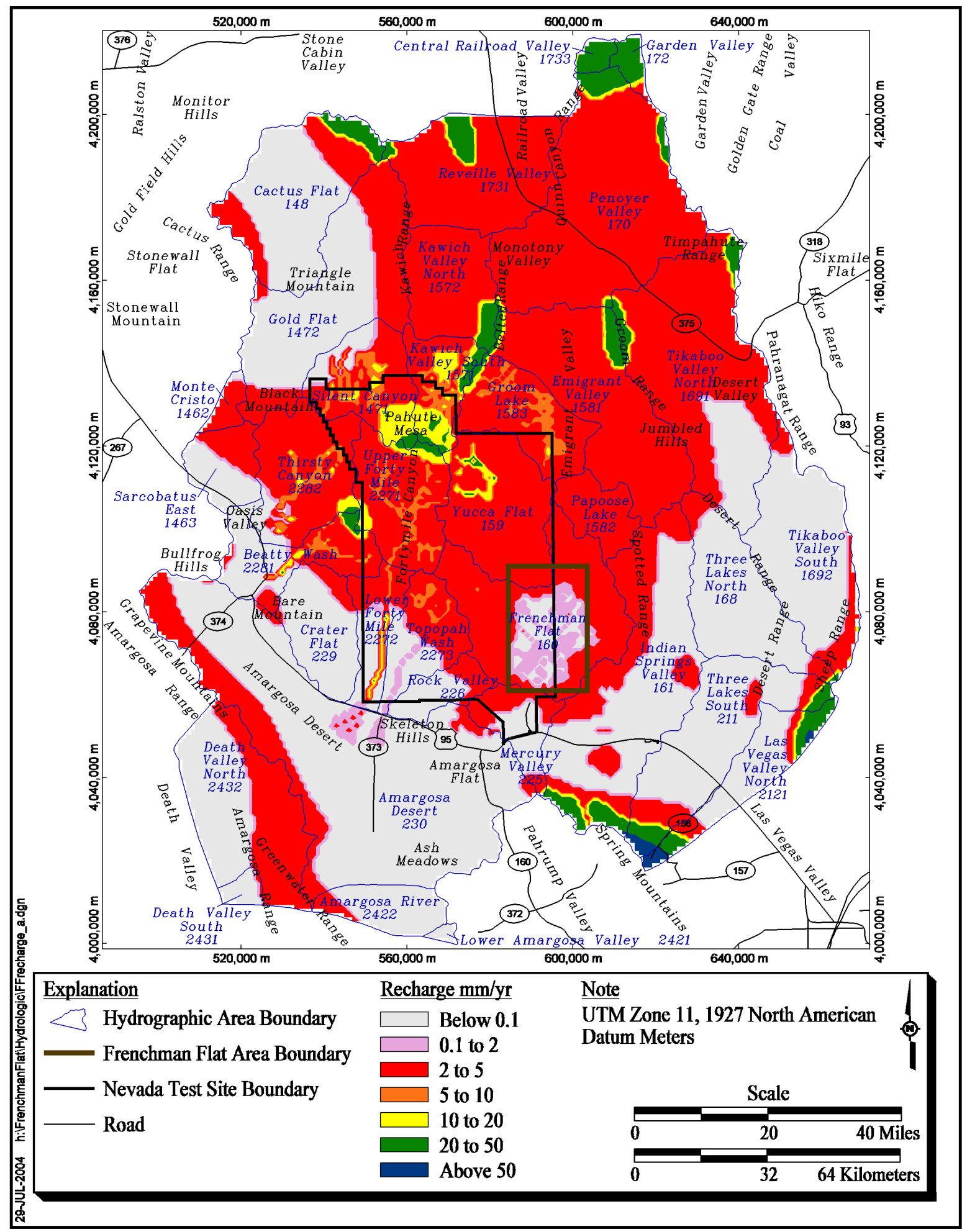

Figure 6-3

NTS Regional Model Recharge Distribution (UGTA Original Recharge Model) 
Table 6-3

Precipitation Station Data

\begin{tabular}{|c|c|c|c|c|c|c|c|}
\hline \multirow{2}{*}{$\begin{array}{l}\text { Station } \\
\text { Number }\end{array}$} & \multirow{2}{*}{ Station Name } & \multicolumn{2}{|c|}{$\begin{array}{l}\text { UTM Zone 11, } \\
\text { NAD } 27\end{array}$} & \multirow{2}{*}{$\begin{array}{c}\text { Land } \\
\text { Surface } \\
\text { Elevation } \\
(\mathrm{m})\end{array}$} & \multicolumn{2}{|c|}{$\begin{array}{l}\text { Average Annual } \\
\text { Precipitation }\end{array}$} & \multirow{2}{*}{$\begin{array}{l}\text { Percent } \\
\text { Change }\end{array}$} \\
\hline & & $\begin{array}{c}\text { Easting } \\
\text { (meters }[\mathrm{m}])\end{array}$ & $\begin{array}{l}\text { Northing } \\
\quad(\mathrm{m})\end{array}$ & & $\begin{array}{c}\text { Depth } \\
\mathrm{cm} / \mathrm{yr} \\
\text { (inches/yr) }\end{array}$ & $\begin{array}{l}\text { Years } \\
\text { Record }\end{array}$ & \\
\hline 11 & Tonopah Airport & 4492,689 & $4,213,009$ & 1,655 & $13.5(5.32)$ & 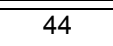 & $\begin{array}{c}-17.1 \\
\end{array}$ \\
\hline 12 & Sarcobatus & 498,522 & $4,124,251$ & 1,225 & $9.0(3.54)$ & 14 & NA \\
\hline 13 & Death Valley & 511,946 & $4,035,517$ & -52 & $5.9(2.34)$ & 34 & -13.8 \\
\hline 14 & Beatty & 525,210 & $4,094,706$ & 1,082 & $15.9(6.26)$ & 47 & NA \\
\hline 27 & Lathrop Wells & 558,275 & $4,030,159$ & 664 & $8.5(3.35)$ & 21 & NA \\
\hline 29 & Little Feller 2 & 560,698 & $4,106,882$ & 1,573 & $20.1(7.93)$ & 27 & -2.3 \\
\hline 34 & $40 \mathrm{MN}$ & 563,341 & $4,100,364$ & 1,469 & $20.5(8.06)$ & 43 & -1.5 \\
\hline 35 & $4 J A$ & 563,445 & $4,071,032$ & 1,043 & $14.1(5.56)$ & 46 & 6.2 \\
\hline 36 & Shoshone Basin & 566,464 & $4,087,547$ & 1,725 & $21.6(8.50)$ & 13 & NA \\
\hline 40 & Skull Mountain Pass & 568,500 & $4,065,887$ & 1,186 & $16.1(6.32)$ & 8 & NA \\
\hline 41 & Area 12 Mesa & 569,624 & $4,116,171$ & 2,283 & $31.5(12.42)$ & 41 & -2.7 \\
\hline 43 & Stockade Pass & 570,759 & $4,113,178$ & 2,053 & $21.3(8.39)$ & 9 & NA \\
\hline 46 & Tippipah Spring 2 & 571,887 & $4,100,851$ & 1,518 & $21.6(8.52)$ & 43 & -11.0 \\
\hline 47 & $\mathrm{RV}-1$ & 572,151 & $4,060,050$ & 1,036 & $15.8(6.22)$ & 40 & -0.7 \\
\hline 49 & Mid Valley & 573,701 & $4,091,914$ & 1,420 & $22.8(8.99)$ & 39 & -3.3 \\
\hline 53 & RV-Wash & 576,721 & $4,053,568$ & 866 & $10.0(3.92)$ & 8 & NA \\
\hline 54 & Cane Springs & 579,583 & $4,074,185$ & 1,219 & $19.5(7.68)$ & 39 & -5.3 \\
\hline 56 & BJY & 584,209 & $4,102,022$ & 1,241 & $16.1(6.36)$ & 43 & 0.3 \\
\hline 57 & Yucca & 584,791 & $4,090,231$ & 1,195 & $16.8(6.62)$ & 45 & -1.0 \\
\hline 58 & PHS Farm & 585,301 & $4,118,280$ & 1,391 & $18.8(7.41)$ & 39 & -3.0 \\
\hline 59 & Desert Rock & 587,122 & $4,053,108$ & 1,005 & $14.5(5.72)$ & 40 & -4.4 \\
\hline 60 & Pahrump & 588,385 & $4,008,227$ & 823 & $11.6(4.58)$ & 30 & -7.7 \\
\hline 62 & Mercury & 589,740 & $4,057,169$ & 1,149 & $14.7(5.81)$ & 32 & -6.1 \\
\hline 63 & Well 5B & 592,263 & $4,073,193$ & 939 & $12.4(4.88)$ & 41 & -2.3 \\
\hline 66 & Trough Spring & 610,107 & $4,026,349$ & 2,512 & $45.0(17.70)$ & 9 & NA \\
\hline 67 & Cold Creek & 613,563 & $4,030,708$ & 1,862 & $23.0(9.06)$ & 8 & NA \\
\hline 68 & Indian Springs & 617,793 & $4,049,256$ & 951 & $11.6(4.57)$ & 25 & NA \\
\hline 69 & Lee Canyon & 619,087 & $4,018,516$ & 2,594 & $53.4(21.02)$ & 9 & NA \\
\hline 71 & Kyle Canyon & 623,466 & $4,012,260$ & 2,365 & $67.8(26.70)$ & 10 & NA \\
\hline 72 & Adaven & 624,188 & $4,219,501$ & 1,905 & $32.1(12.64)$ & 47 & NA \\
\hline 74 & Roberts Ranch & 627,418 & $4,003,163$ & 1,862 & $35.4(13.94)$ & 8 & NA \\
\hline 75 & Red Rock Summit & 631,972 & $3,999,532$ & 1,984 & $27.0(10.63)$ & 8 & NA \\
\hline 79 & Hayford Peak & 660,932 & $4,058,248$ & 2,999 & $42.4(16.70)$ & 9 & NA \\
\hline 80 & Hidden Forest & 660,934 & $4,055,504$ & 2,304 & $32.0(12.60)$ & 9 & NA \\
\hline 81 & Alamo & 662,347 & $4,136,921$ & 1,049 & $12.8(5.04)$ & 26 & NA \\
\hline 82 & Las Vegas Airport & 665,072 & $3,994,546$ & 661 & $10.5(4.15)$ & 59 & 1.5 \\
\hline 83 & Sunrise Manor & 672,321 & $4,007,633$ & 555 & $10.6(4.17)$ & 32 & NA \\
\hline
\end{tabular}

aThe percent change in precipitation values with the inclusion of the new data for 2004.

Source: Jacobson, 1996; French, 1996; WRCC, 2004; ARL/SORD, 2004

NA = Not Applicable 


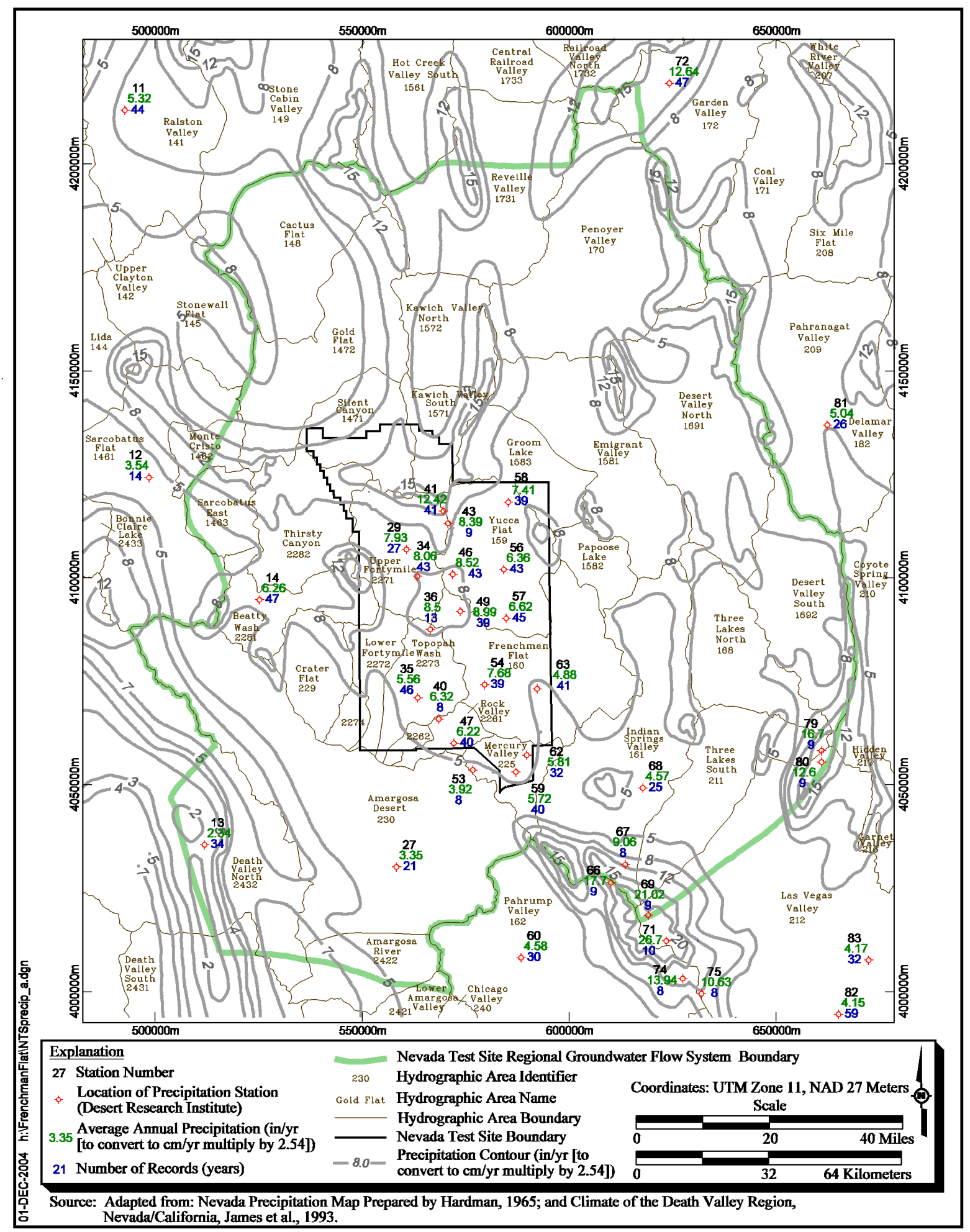

Figure 6-4

Updated Precipitation Map for the Nevada Test Site Region (UGTA Revised Precipitation Distribution) 


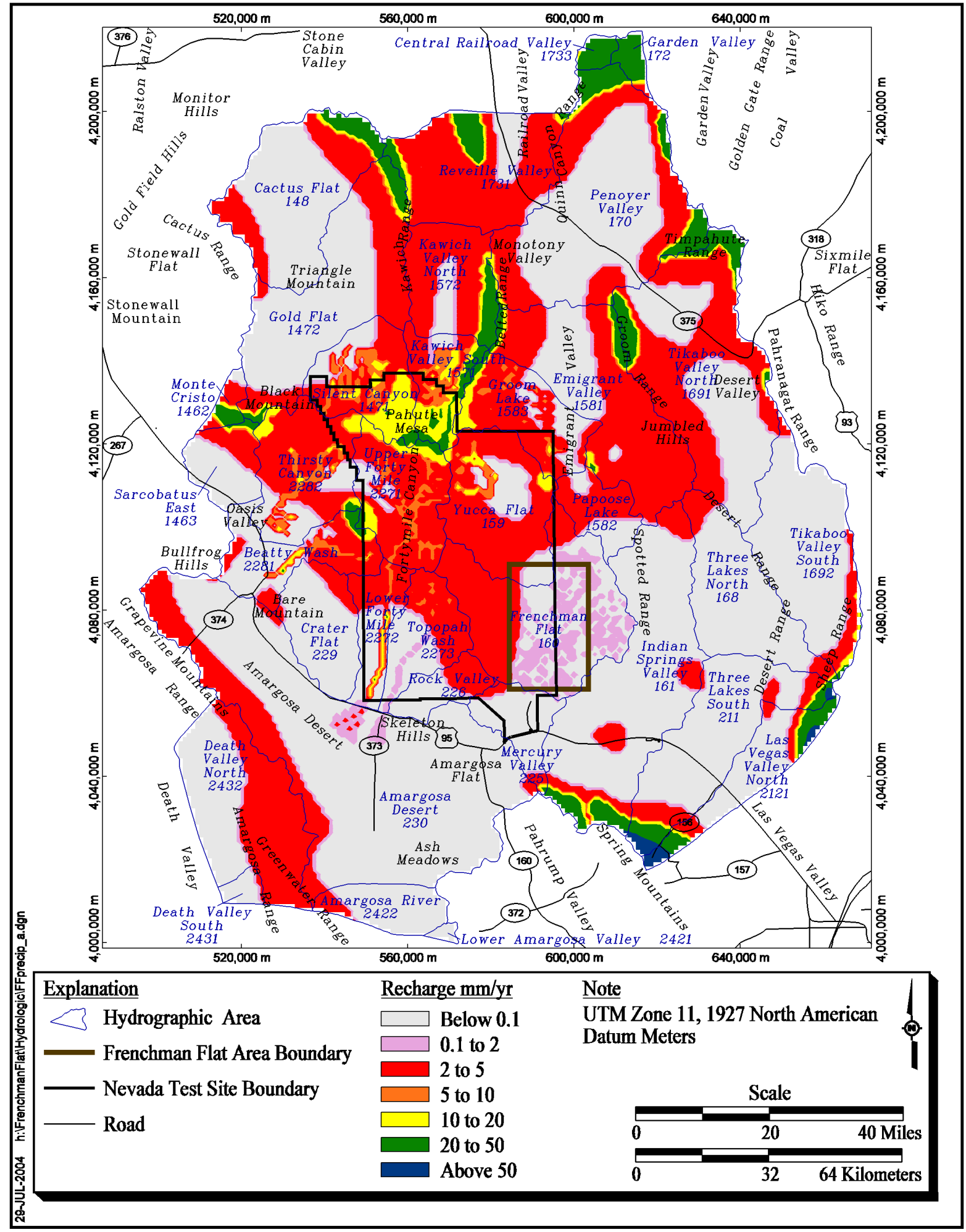

Figure 6-5

Revised Maxey and Eakin Based Recharge in the NTS Region (UGTA Revised Recharge Model) 
The digitization of the original HA boundaries were found to be inaccurate. As a result, a grid cell would be included in the volumetric totals for a neighboring HA. In addition, because of the digitization inaccuracies, several HAs were inadvertently included in the NTS region because one or two grid cells fell into the wrong peripheral HA. These inaccuracies have been corrected by re-digitization of the HA boundaries at a finer resolution.

Comparisons to other recharge models can be found in the summary section table (Table 6-6). The recharge rates for both UGTA-based recharge distributions differ from the original values found in the NTS regional model report because of the changes to the definitions of the HAs.

\subsubsection{U.S. Geological Survey Recharge Model (Hevesi et al., 2003)}

USGS (Hevesi et al., 2003), in support of the regional saturated-zone groundwater flow model for Death Valley region (D'Agnese et al., 1997), developed a net-infiltration model referred to as distributed parameter watershed model (DPWM). The following briefly describes this model. The purpose of the development of the DPWM was to help define the upper-boundary condition of the regional groundwater-flow model (i.e., recharge).

The DPWM estimates the temporal and spatial distribution of net infiltration in the Death Valley Region. Hevesi et al. (2003) used net-infiltration estimates to quantify the downward percolation of water across the lower boundary of the root zone and interpreted it as potential recharge under current climatic conditions. Net infiltration is that portion of the precipitation that infiltrates the ground surface and is not taken up by plants or lost to evaporation. Net infiltration may not necessarily become recharge, which is that portion of the infiltration that reaches the water table. For example, in mountainous terrains with complex geology, such as in Nevada Test Site, the net infiltration may percolate long distances in the unsaturated zone at relatively shallow depths. The fate of this water may be an intermittent spring or loss to localized evapotranspiration or runoff to a nearby playa lake. In either case, net infiltration may be lost to evapotranspiration.

The DWPM uses the Priesley Taylor (1972) model to simulate ET from the surface. This model applies the water-balance method, which is based on daily precipitation and air temperature and a spatially detailed representation of the watershed characteristics to simulate daily, net infiltration at all locations in the watershed, including active stream channels. Watershed characteristics include topography, slope, aspect, watershed area, land type, average root-zone layer thickness, etc. These authors also concluded that the short-term (daily, monthly, and annual) temporal distribution of the calculated net infiltration could be used to evaluate the potential impact of future climatic conditions on potential recharge.

Geographical information system (GIS) was used to define the set of spatially distributed parameters over a modeling grid defined by DEM. The DEM had a resolution of 278.5 meters in both north-south and east-west directions. The model grid consisted of $1,252,418$ cells. The DEM was used to define shading effects and surface-water flow routing. Shading effect of a slope is determined by 
the orientation of the surface of the slope with respect to the direction of solar radiation. North-facing slopes receive less solar energy during winter (in the Northern Hemisphere) than the south-facing slopes. Shading effects were based on calculation of the slope relative to the direction and position of the solar radiation. Flow routing is based on calculation of the slope and relative elevation potential of adjacent grid cells. A six-layered root zone system, consisting of five soil layers and one bedrock layer was used in calculation of evapotranspiration, drainage, and redistribution of moisture in the root zone. Daily root-zone water balance, including evapotranspiration, infiltration, drainage, and redistribution of moisture in the root zone were simulated. Evapotranspiration from each root-zone layer was modeled as a function of potential ET, the estimated root density for each layer, and the simulated water content for each layer. Downward drainage through each layer was modeled as a function of soil-saturated hydraulic conductivity, soil texture, and the simulated water content. Snowfall, sublimation, and snowmelt were modeled as functions of the spatially distributed daily climate input and the simulated solar radiation component of the potential ET model. Net infiltration across the bottom of the root zone was eventually calculated from this six-layered model.

The DPWM was calibrated to qualitative and quantitative comparisons of simulated stream flow to historical stream flow records in the Death Valley region and comparison of the calculated net infiltration with the basin-wide average recharge estimates. Parameters that were adjusted to arrive at the qualitative calibration included bedrock saturated hydraulic conductivity, root density, storm duration, and parameters defining stream-channel characteristics (soil saturated hydraulic conductivity and wetted area). Results of the calibration indicated that, for many locations, the spatial daily climate records in Death Valley region is not adequate to represent local-scale, high-intensity summer storms that cause a significant portion of the recorded stream flows, especially for smaller-area, higher-elevation watersheds. The calibration results also revealed the high sensitivity of the simulated stream flow to the parameters defining stream channel characteristics. The net-infiltration calibration results were sensitive to variation in bedrock hydraulic conductivity and root density.

One of the models was selected to simulate a 50-year (1950 to 1999) period of net infiltration for the Death Valley region. They estimated that an average net infiltration of 2.8 millimeters $(\mathrm{mm}) /$ year, or a total potential recharge of 342,000 cubic meters per day for the area of the Death Valley Regional Groundwater Flow Model. The net-infiltration rate calculated is equivalent to 1.6 percent of the average precipitation rate $(171.3 \mathrm{~mm} /$ year) for 1950 to 1999 period simulated. Their model also estimated an average runoff generation of $2.2 \mathrm{~mm} / \mathrm{year}$ and an average run-on (it is assumed this is interflow) infiltration rate of $2.0 \mathrm{~mm} /$ year. Average surface-water inflow into playa lake beds is simulated to be $0.2 \mathrm{~mm} /$ year by their model (equivalent to 24,800 cubic meters per day), which is less than 10 percent of the runoff. The flow into the playas is assumed to evaporate.

Three alternative models were used to evaluate the sensitivity to parameters for the 50 -year simulation period. Stream flow was found to be most sensitive to storm duration and stream channel characteristics. To a lesser extent, stream flow was sensitive to bedrock hydraulic conductivity. Net-infiltration calculations were 
found to be most sensitive to bedrock hydraulic conductivity and root density. Both stream flow and net infiltration were highly sensitive to precipitation and soil thickness. These authors suggested that more robust results may be obtained by averaging the results of several alternative models as opposed to a single representation.

Among the three alternative models, infiltration from surface water run-on was estimated to account for about 14 percent of total net infiltration. In some basins, surface-water flow may contribute as much as 40 percent to the total net-infiltration volume (for the basin).

These simulated net-infiltration rates were compared with the estimates of stream-flow records and previous basin-wide recharge estimates for 42 HAs and sub-areas in the Death Valley region. The results of simulations were found to be generally in good agreement with the observations and the results of previous studies. Net infiltration calculations showed less variability on a basin-wide scale than the variation of recharge estimates. Basin-wide net-infiltration volumes calculated by DPWM were less than recharge volumes estimated by previous investigators for most areas with high recharge, such as Pahrump Valley and Las Vegas Valley. On the other hand, DPWM estimated larger volumes than previously estimated for areas with low recharge estimates (Stonewall Flat, the Lower Amargosa Valley, and Fortymile Canyon). Good agreements were found between net-infiltration calculations of DPWM and recharge estimates for Gold Flat, Kawich Valley, Lida Valley, Amargosa Desert, and Tikaboo Valley.

The model with the best-combined agreement between the DPWM calculations and the historical stream flow records, and between DPWM net infiltration calculations and previous recharge estimates was selected for use in estimating recharge volumes. This model predicted a total net-infiltration volume of $413,000 \mathrm{~m}^{3} / \mathrm{d}$ for all HAs having estimates of recharge, which was in good agreement with the basin-wide recharge volume estimate of $431,000 \mathrm{~m}^{3} / \mathrm{d}$ for the same area. A net infiltration of $342,000 \mathrm{~m}^{3} / \mathrm{d}$ using the same model is reported. Here, it is interpreted that the total net-infiltration rate of 413,000 cubic meters per year $\left(\mathrm{m}^{3} / \mathrm{yr}\right)$ reported includes the net infiltration rate of $342,000 \mathrm{~m}^{3} / \mathrm{d}$ and run-on infiltration. With this interpretation, the run-on infiltration would be $71,000 \mathrm{~m}^{3} / \mathrm{d}$.

It is important to note that the values just cited for volumes of recharge are for a larger area than was applied in the UGTA study. Corresponding volumes on an HA by HA basis and total equivalent area volumes will be presented later in this section. The USGS study incorporated many parameters that are important to understanding how this methodology was applied. The following discussion elaborates on these parameters and their effects on the resultant recharge distribution and magnitude.

The USGS used PRISM (Parameter-Elevation Regressions on Independent Slopes Model) (Hevesi et al., 2003) to calculate precipitation, which is generally consistent with other elevation-correlation models used to estimate precipitation in the Death Valley region. Hevesi et al. (2003) point out that an "extraordinarily high degree of uncertainty remains in estimated precipitation" because of sparse data, and that the uncertainty is highest for remote high elevation locations 
because of limited records and measurement error associated with snow. For lower elevations, the estimates are more consistent. It should also be noted that most of the credible precipitation models, such as PRISM, have been calibrated for humid or semi-arid regions. Their applicability to an arid region such as the study area is uncertain because of the sparsity of data.

Vegetation was also analyzed to develop spatial distribution of types and density of vegetation cover. Vegetation was mapped from satellite imagery and other records as part of the USGS/Biological Resources Division (BRD) National Gap Analysis Program (GAP). The Western region vegetation map (WESTVEG) was used for this study. This information is critical in estimating the ET component for this model because vegetation cover is probably the most significant consumer of the precipitation water in the arid portions of the study area.

This model incorporated soils in a quasi-3D methodology by not only inputting the soil types but also their thickness in a layered properties dataset using from one to six layers. A state-compiled geospatial database for soil properties (STATSGO) was used as the base for mapping soil units. Using STATSGO, the maximum and minimum thickness for the layers including their averaged thickness and percent coverage was developed. This produced an input map of calculated averaged soil textures and particle size-based soil properties for the model. The lowest layer in the soil profile was designated as bedrock. The bedrock was also mapped where soil units were thin or absent so that infiltration rates into the bedrock could be incorporated into the model.

Overland flow originates as excess water within each cell that exceeds the infiltration and ET rate for that cell. This excess runoff is routed to downstream cells where it is added to the net water input to the soils in the downstream run-on cells. Stream channel characteristics are a sensitive input parameter for this model as stated previously.

In the USGS model, these major components formed the conceptual model of precipitation with infiltration of rain, snowmelt, or surface water into the soil or bedrock, with subsequent bare-soil evaporation and transpiration from the root zone. All water percolating past the root zone was considered net infiltration. All excess water could become overland flow to downstream cells.

The model inputs for the INFILv3 (Table 6-4) model consisted of:

- Climatic: daily climate inputs, model coefficients for monthly climate models, and monthly atmospheric parameters.

- Digital Maps: DEM, spatial distribution of rock types, soil types, and vegetation types.

- Attribute Tables: bedrock and deep alluvium, soil, and vegetation properties. 
Table 6-4

INFILv3 Input Parameters (as reported by Hevesi et al., 2003)

(Page 1 of 6 )

\begin{tabular}{|c|c|c|c|c|c|c|c|}
\hline $\begin{array}{l}\text { Source } \\
\text { Data }\end{array}$ & Preprocessing & $\begin{array}{l}\text { Input } \\
\text { File }\end{array}$ & $\begin{array}{l}\text { Parameter } \\
\text { Name }\end{array}$ & $\begin{array}{l}\text { Parameter } \\
\text { Description }\end{array}$ & $\begin{array}{l}\text { Parameter } \\
\text { Use }\end{array}$ & Units & $\begin{array}{l}\text { Parameter } \\
\text { Accuracy }\end{array}$ \\
\hline \multicolumn{8}{|c|}{ DEM and Topographic Parameters Developed Using the DEM } \\
\hline \multirow[t]{12}{*}{ DEM } & \multirow[t]{7}{*}{$\begin{array}{c}\text { GIS } \\
\text { Calculated }\end{array}$} & Watershed File & $\mathrm{EIEV}$ (rows,cols) & Land surface elevation & $\begin{array}{l}\text { Potential evapotranspiration, spatial } \\
\text { interpolation models }\end{array}$ & $\mathrm{m}$ & High \\
\hline & & Watershed File & SLP(rows,cols) & Land surface slope & $\begin{array}{l}\text { Potential evapotranspiration, } \\
\text { Streamflow routing }\end{array}$ & u & High \\
\hline & & Watershed File & ASP(rows,cols) & Land surface aspect & Potential evapotranspiration & u & High \\
\hline & & Watershed File & EAST(rows,cols) & $\begin{array}{l}\text { DEM grid cell east-west } \\
\text { coordinate }\end{array}$ & $\begin{array}{l}\text { Grid cell location, spatial interpolation } \\
\text { models }\end{array}$ & $\mathrm{m}$ & High \\
\hline & & Watershed File & NORTH $(r, c)$ & $\begin{array}{l}\text { DEM grid cell east-west } \\
\text { coordinate }\end{array}$ & $\begin{array}{l}\text { Grid cell location, spatial interpolation } \\
\text { models }\end{array}$ & $\mathrm{m}$ & High \\
\hline & & Watershed File & $\operatorname{LAT}(r, c)$ & DEM grid cell latitude & Potential evapotranspiration & dd & High \\
\hline & & Watershed File & $\operatorname{LON}(\mathrm{r}, \mathrm{c})$ & DEM grid cell latitude & Potential evapotranspiration & dd & High \\
\hline & \multirow{2}{*}{$\begin{array}{l}\text { SKYVIEW } \\
\text { Calculated }\end{array}$} & Watershed File & RIDGE(r,c,36) & 36 blocking ridge angles & Potential evapotranspiration & $d$ & Medium \\
\hline & & Watershed File & SKYVIEW $(r, c)$ & Reduction in total skyview & Potential evapotranspiration & u & Medium \\
\hline & \multirow{3}{*}{$\begin{array}{c}\text { GRDSORT01 } \\
\text { Calculated } \\
\text { ROUTER03 } \\
\text { Calculated }\end{array}$} & Watershed File & $\operatorname{LOCID}(r, c)$ & $\begin{array}{l}\text { Location identifier for upstream } \\
\text { cell }\end{array}$ & Streamflow routing & u & Medium \\
\hline & & Watershed File & IROUT $(r, c)$ & $\begin{array}{l}\text { Location identifier for downstream } \\
\text { cell }\end{array}$ & Streamflow routing & u & Medium \\
\hline & & Watershed File & UPCELLs(r,c) & Number of upstream cells & Streamflow routing & u & Medium \\
\hline \multicolumn{8}{|c|}{ Soil Properties Associated with the STATSGO Database } \\
\hline \multirow[t]{6}{*}{ STATSGO } & \multirow{6}{*}{ STATSGO34 } & Watershed File & SOILTYPE $(r, c)$ & Map code for STATSGO soil units & Spatial distribution of soil properties & u & Medium \\
\hline & & Watershed File & SOILTHCK(r,c) & $\begin{array}{l}\text { Estimated soil thickness for } \\
\text { root-zone }\end{array}$ & Root-zone layer thickness & $\mathrm{m}$ & Low \\
\hline & & $\begin{array}{l}\text { Soil-Attribute } \\
\text { Table }\end{array}$ & SPOR(soiltype) & Soil porosity & Root-zone storage capacity & u & Medium \\
\hline & & $\begin{array}{l}\text { Soil-Attribute } \\
\text { Table }\end{array}$ & SWP(soiltype) & Soil wilting point & $\begin{array}{l}\text { Root-zone storage capacity, } \\
\text { evapotranspiration model }\end{array}$ & u & Medium \\
\hline & & $\begin{array}{l}\text { Soil-Attribute } \\
\text { Table }\end{array}$ & SKS(soiltype) & $\begin{array}{l}\text { Soil saturated hydraulic } \\
\text { conductivity }\end{array}$ & $\begin{array}{l}\text { Root-zone infiltration and drainage } \\
\text { function }\end{array}$ & $\mathrm{mm} / \mathrm{day}$ & Medium \\
\hline & & $\begin{array}{l}\text { Soil-Attribute } \\
\text { Table }\end{array}$ & SOILB(soiltype) & Soil drainage function coefficient & $\begin{array}{l}\text { Root-zone infiltration and drainage } \\
\text { function }\end{array}$ & u & Medium \\
\hline
\end{tabular}


Table 6-4

INFILv3 Input Parameters (as reported by Hevesi et al., 2003)

(Page 2 of 6 )

\begin{tabular}{|c|c|c|c|c|c|c|c|}
\hline $\begin{array}{l}\text { Source } \\
\text { Data }\end{array}$ & Preprocessing & $\begin{array}{l}\text { Input } \\
\text { File }\end{array}$ & $\begin{array}{l}\text { Parameter } \\
\text { Name }\end{array}$ & $\begin{array}{l}\text { Parameter } \\
\text { Description }\end{array}$ & $\begin{array}{l}\text { Parameter } \\
\text { Use }\end{array}$ & Units & $\begin{array}{l}\text { Parameter } \\
\text { Accuracy }\end{array}$ \\
\hline \multicolumn{8}{|c|}{ Bedrock and Deep Alluvium Properties Associated with the Digital Map of Hydrogeologic Units } \\
\hline $\begin{array}{c}\text { Faunt and } \\
\text { others }(1997)^{*}\end{array}$ & \multirow[t]{4}{*}{ GIS } & Watershed File & ROCKTYPE $(r, c)$ & Map code for Hydrogeologic units & $\begin{array}{l}\text { Spatial distribution of bedrock and deep } \\
\text { properties }\end{array}$ & u & Medium \\
\hline \multirow[t]{3}{*}{ User defined } & & $\begin{array}{l}\text { Bedrock } \\
\text { Attribute } \\
\text { Table }\end{array}$ & RPOR(rocktype) & $\begin{array}{l}\text { Effective root-zone porosity for } \\
\text { bedrock layer }\end{array}$ & $\begin{array}{l}\text { Defines storage capacity of root-zone in } \\
\text { bedrock layer }\end{array}$ & u & Low \\
\hline & & $\begin{array}{l}\text { Bedrock } \\
\text { Attribute } \\
\text { Table }\end{array}$ & $\begin{array}{c}\mathrm{RK}_{\mathrm{LO}} \\
\text { (rocktype) }\end{array}$ & $\begin{array}{l}\text { Effective unsaturated hydraulic } \\
\text { conductivity for hydrogeologic unit }\end{array}$ & $\begin{array}{l}\text { Defines lower bedrock hydraulic } \\
\text { conductivity }\end{array}$ & $\mathrm{mm} / \mathrm{day}$ & Low \\
\hline & & $\begin{array}{l}\text { Bedrock } \\
\text { Attribute } \\
\text { Table }\end{array}$ & $\begin{array}{c}\mathrm{RK}_{\mathrm{HI}} \\
\text { (rocktype) }\end{array}$ & $\begin{array}{l}\text { Effective saturated hydraulic } \\
\text { conductivity for hydrogeologic unit }\end{array}$ & $\begin{array}{l}\text { Defines upper bedrock and deep alluvium } \\
\text { hydraulic conductivity }\end{array}$ & $\mathrm{mm} / \mathrm{day}$ & Low \\
\hline \multicolumn{8}{|c|}{ Vegetation and Root-Zone Properties Associated with the GAP Database } \\
\hline \multirow[b]{2}{*}{ User defined } & GIS & Watershed File & VEGTYPE(r,c) & $\begin{array}{l}\text { Map code for GAP vegetation } \\
\text { units }\end{array}$ & $\begin{array}{l}\text { Spatial distribution of vegetation } \\
\text { properties, root zone layer properties }\end{array}$ & u & Medium \\
\hline & GIS & Watershed File & VEGCOV $(r, c)$ & Vegetation cover & Evapotranspiration model & $\%$ & Medium \\
\hline User defined & \multirow[t]{2}{*}{ None } & $\begin{array}{l}\text { Vegetation } \\
\text { Attribute } \\
\text { Table }\end{array}$ & RZDEN(vegtype,I) & Root density for layer I & Evapotranspiration model & $\%$ & Low \\
\hline User defined & & $\begin{array}{l}\text { Vegetation } \\
\text { Attribute } \\
\text { Table }\end{array}$ & RZDPTH(vegtype,I) & Root-zone layer thickness & $\begin{array}{l}\text { Evapotranspiration model, root-zone } \\
\text { drainage model }\end{array}$ & $\mathrm{m}$ & Low \\
\hline \multicolumn{8}{|c|}{ Snowmelt and Sublimation Parameters } \\
\hline \multirow[t]{4}{*}{$\begin{array}{l}\text { Maidment } \\
(1993)^{\star}\end{array}$} & \multirow[t]{4}{*}{ None } & Control File & SNODAY1 & Day number 1 for snowmelt model & $\begin{array}{l}\text { Define timing of early spring snowmelt } \\
\text { model }\end{array}$ & Day no. & Medium \\
\hline & & Control File & SNOPAR1 & Snowmelt parameter 1 & Degree-day snowmelt rate & $\mathrm{mm} / \mathrm{day}$ & Medium \\
\hline & & Control File & SNODAY2 & Day number 2 for snowmelt model & $\begin{array}{l}\text { Define timing of late spring snowmelt } \\
\text { model }\end{array}$ & Day no. & Medium \\
\hline & & Control File & SNOPAR2 & Snowmelt parameter 2 & Degree-day snowmelt rate & $\mathrm{mm} / \mathrm{day}$ & Medium \\
\hline \multirow[t]{3}{*}{ User defined } & \multirow[t]{3}{*}{ None } & Control File & MELTIME & Duration of daily snowmelt & Controls intensity of snowmelt & Hours & Medium \\
\hline & & Control File & SUBPAR1 & Sublimation rate parameter \#1 & Sublimation & u & Low \\
\hline & & Control File & SUBPAR2 & Sublimation rate parameter \#2 & Sublimation & $\mathrm{u}$ & Low \\
\hline
\end{tabular}


Table 6-4

INFILv3 Input Parameters (as reported by Hevesi et al., 2003)

(Page 3 of 6)

\begin{tabular}{|c|c|c|c|c|c|c|c|}
\hline $\begin{array}{l}\text { Source } \\
\text { Data }\end{array}$ & Preprocessing & $\begin{array}{l}\text { Input } \\
\text { File }\end{array}$ & $\begin{array}{l}\text { Parameter } \\
\text { Name }\end{array}$ & $\begin{array}{l}\text { Parameter } \\
\text { Description }\end{array}$ & $\begin{array}{l}\text { Parameter } \\
\text { Use }\end{array}$ & Units & $\begin{array}{l}\text { Parameter } \\
\text { Accuracy }\end{array}$ \\
\hline \multicolumn{8}{|c|}{ Simulation-Time Parameters } \\
\hline \multirow[t]{6}{*}{ User defined } & \multirow[t]{6}{*}{ None } & Control File & YRSTART & Simulation start year & Identifies simulation start date & $\mathrm{u}$ & NA \\
\hline & & Control File & MOSTART & Simulation start month & Identifies simulation start date & $\mathrm{u}$ & NA \\
\hline & & Control File & DYSTART & Simulation start day & Identifies simulation start date & $u$ & NA \\
\hline & & Control File & YREND & Simulation end year & Identifies simulation end date & u & NA \\
\hline & & Control File & MOEND & Simulation end month & Identifies simulation end date & u & NA \\
\hline & & Control File & DYEND & Simulation end day & Identifies simulation end date & u & NA \\
\hline \multicolumn{8}{|c|}{ Storm Duration Parameters } \\
\hline \multirow{3}{*}{ User defined } & \multirow{3}{*}{ None } & Control File & DYSUMBEG & $\begin{array}{l}\text { Start day number for summer } \\
\text { storms }\end{array}$ & $\begin{array}{l}\text { Defines beginning day number for } \\
\text { summer storm events }\end{array}$ & Day & Medium \\
\hline & & Control File & DYSUMEND & $\begin{array}{l}\text { End day number for summer } \\
\text { storms }\end{array}$ & $\begin{array}{l}\text { Defines ending day number for summer } \\
\text { storm events }\end{array}$ & Day & Medium \\
\hline & & Control File & STORMSUM & $\begin{array}{l}\text { Duration of summer precipitation } \\
\text { and streamflow }\end{array}$ & $\begin{array}{l}\text { Defines precipitation and streamflow } \\
\text { intensity for summer storms }\end{array}$ & Hours & Low \\
\hline User defined & None & Control File & STORMWIN & $\begin{array}{l}\text { Duration of winter precipitation } \\
\text { and streamflow }\end{array}$ & $\begin{array}{l}\text { Defines precipitation and streamflow } \\
\text { intensity for winter storms }\end{array}$ & Hours & Low \\
\hline \multicolumn{8}{|c|}{ Evapotranspiration Parameters } \\
\hline \multirow[t]{4}{*}{$\begin{array}{c}\text { Flint and } \\
\text { Childs }(1987)^{*}\end{array}$} & \multirow[t]{4}{*}{ None } & Control File & BSEA & $\begin{array}{l}\text { Preistley-Taylor model coefficient } \\
\# 1 \text { for bare soil evaporation }\end{array}$ & $\begin{array}{l}\text { ET model coefficient for modified } \\
\text { Preistley-Taylor equation, for bare-soil } \\
\text { evaporation }\end{array}$ & $\mathrm{u}$ & Medium \\
\hline & & Control File & BSEB & $\begin{array}{l}\text { Preistley-Taylor model coefficient } \\
\text { \#2 for bare soil evaporation }\end{array}$ & $\begin{array}{l}\text { ET model coefficient for modified } \\
\text { Preistley-Taylor equation, for bare-soil } \\
\text { evaporation }\end{array}$ & $\mathrm{u}$ & Medium \\
\hline & & Control File & HSTEP & POTEVAP time step & $\begin{array}{l}\text { Define hourly time-step for potential } \\
\text { evapotranspiration model }\end{array}$ & Hours & NA \\
\hline & & Control File & ETA & $\begin{array}{l}\text { Preistley-Taylor model coefficient } \\
\# 1 \text { for transpiration }\end{array}$ & $\begin{array}{l}\text { ET model coefficient for modified } \\
\text { Preistley-Taylor equation, for transpiration }\end{array}$ & u & Medium \\
\hline User defined & None & Control File & ETB & $\begin{array}{l}\text { Preistley-Taylor model coefficient } \\
\text { \#2 for transpiration }\end{array}$ & $\begin{array}{l}\text { ET model coefficient for modified } \\
\text { Preistley-Taylor equation, for transpiration }\end{array}$ & u & Medium \\
\hline
\end{tabular}


Table 6-4

INFILv3 Input Parameters (as reported by Hevesi et al., 2003)

(Page 4 of 6)

\begin{tabular}{|c|c|c|c|c|c|c|c|}
\hline $\begin{array}{l}\text { Source } \\
\text { Data }\end{array}$ & Preprocessing & $\begin{array}{l}\text { Input } \\
\text { File }\end{array}$ & $\begin{array}{l}\text { Parameter } \\
\text { Name }\end{array}$ & $\begin{array}{l}\text { Parameter } \\
\text { Description }\end{array}$ & $\begin{array}{l}\text { Parameter } \\
\text { Use }\end{array}$ & Units & $\begin{array}{l}\text { Parameter } \\
\text { Accuracy }\end{array}$ \\
\hline \multicolumn{8}{|c|}{ Stream-Channel Parameters } \\
\hline \multirow[t]{4}{*}{ User defined } & \multirow[t]{4}{*}{ None } & Control File & CHAN1 & $\begin{array}{l}\text { Surface-water minimum wetted } \\
\text { area factor }\end{array}$ & $\begin{array}{l}\text { Defines wetted area for stream-channel } \\
\text { grid cell }\end{array}$ & u & Low \\
\hline & & Control File & CHAN2 & $\begin{array}{l}\text { Surface-water wetted area model } \\
\text { coefficient }\end{array}$ & $\begin{array}{l}\text { Defines wetted area for stream-channel } \\
\text { grid cell }\end{array}$ & u & Low \\
\hline & & Control File & CHAN3 & $\begin{array}{l}\text { Surface-water headwater wetted } \\
\text { area factor }\end{array}$ & $\begin{array}{l}\text { Defines wetted area for stream-channel } \\
\text { grid cell }\end{array}$ & u & Low \\
\hline & & Control File & CHAN4 & $\begin{array}{l}\text { Surface-water maximum wetted } \\
\text { area factor }\end{array}$ & $\begin{array}{l}\text { Defines wetted area for stream-channel } \\
\text { grid cell }\end{array}$ & u & Low \\
\hline \multirow{3}{*}{ User defined } & \multirow{3}{*}{ None } & Control File & KSCHN1 & $\begin{array}{l}\text { Model coefficient for stream } \\
\text { channel characteristics }\end{array}$ & $\begin{array}{l}\text { Minimum number of upstream cells for } \\
\text { using KSCHN2 }\end{array}$ & u & Low \\
\hline & & Control File & KSCHN2 & $\begin{array}{l}\text { Model coefficient for stream } \\
\text { channel characteristics }\end{array}$ & $\begin{array}{l}\text { Scaler for adjusting soil saturated } \\
\text { hydraulic conductivity in channels }\end{array}$ & u & Low \\
\hline & & Control File & KSCHN3 & $\begin{array}{l}\text { Soil saturated hydraulic } \\
\text { conductivity }\end{array}$ & $\begin{array}{l}\text { Maximum soil saturated hydraulic } \\
\text { conductivity in channels }\end{array}$ & u & Low \\
\hline \multicolumn{8}{|c|}{ Daily Climate Inputs Developed From NOAA/NCDC } \\
\hline \multirow{5}{*}{$\begin{array}{l}\text { NOAA/ } \\
\text { NCDC }\end{array}$} & \multirow{5}{*}{ DAYINP14 } & Control File & INITOPT & Initial condition option & $\begin{array}{l}\text { Defines method for setting initial } \\
\text { conditions }\end{array}$ & u & NA \\
\hline & & Control File & VWCFACT & $\begin{array}{l}\text { Scaler for setting initial water } \\
\text { content for root-zone }\end{array}$ & $\begin{array}{l}\text { Defines initial water content for soil layers } \\
\text { in root zone }\end{array}$ & u & Low \\
\hline & & Precip. File & PPT(day,st) & Daily precipitation & Daily precipitation input & $\mathrm{mm}$ & High \\
\hline & & $\begin{array}{l}\text { Maximum } \\
\text { Air Temp. } \\
\quad \text { File }\end{array}$ & TMAX(day,st) & Maximum daily air temperature & $\begin{array}{l}\text { Snowfall, snowmelt, sublimation, potential } \\
\text { evapotranspiration }\end{array}$ & ${ }^{\circ} \mathrm{C}$ & High \\
\hline & & $\begin{array}{l}\text { Minimum } \\
\text { Air temp. } \\
\quad \text { File }\end{array}$ & TMIN(day,st) & Minimum daily air temperature & $\begin{array}{l}\text { Snowfall, snowmelt, sublimation, potential } \\
\text { evapotranspiration }\end{array}$ & ${ }^{\circ} \mathrm{C}$ & High \\
\hline User defined & EXCEL & $\begin{array}{l}\text { Monthly } \\
\text { Climate } \\
\text { Model }\end{array}$ & PPTMOD(month) & $\begin{array}{l}\text { Model type for monthly } \\
\text { precipitation-elevation regression } \\
\text { model }\end{array}$ & $\begin{array}{l}\text { Defines model type for daily precipitation } \\
\text { spatial interpolation model }\end{array}$ & u & Medium \\
\hline
\end{tabular}


Table 6-4

INFILv3 Input Parameters (as reported by Hevesi et al., 2003)

(Page 5 of 6 )

\begin{tabular}{|c|c|c|c|c|c|c|c|}
\hline $\begin{array}{l}\text { Source } \\
\text { Data }\end{array}$ & Preprocessing & $\begin{array}{l}\text { Input } \\
\text { File }\end{array}$ & $\begin{array}{l}\text { Parameter } \\
\text { Name }\end{array}$ & $\begin{array}{l}\text { Parameter } \\
\text { Description }\end{array}$ & $\begin{array}{l}\text { Parameter } \\
\text { Use }\end{array}$ & Units & $\begin{array}{l}\text { Parameter } \\
\text { Accuracy }\end{array}$ \\
\hline \multicolumn{8}{|c|}{ Daily Climate Inputs Developed From NOAA/NCDC - Continued } \\
\hline & & $\begin{array}{l}\text { Monthly } \\
\text { Climate } \\
\text { Model }\end{array}$ & PPTA(month) & $\begin{array}{l}\text { Regression model coefficient for } \\
\text { precipitation-elevation regression } \\
\text { model }\end{array}$ & $\begin{array}{l}\text { Coefficient for daily precipitation spatial } \\
\text { interpolation model }\end{array}$ & u & Medium \\
\hline & & $\begin{array}{l}\text { Monthly } \\
\text { Climate } \\
\text { Model }\end{array}$ & PPTB(month) & $\begin{array}{l}\text { Regression model coefficient for } \\
\text { precipitation-elevation regression } \\
\text { model }\end{array}$ & $\begin{array}{l}\text { Coefficient for daily precipitation spatial } \\
\text { interpolation model }\end{array}$ & u & Medium \\
\hline & & $\begin{array}{l}\text { Monthly } \\
\text { Climate } \\
\text { Model }\end{array}$ & PPTC(month) & $\begin{array}{l}\text { Regression model coefficient for } \\
\text { precipitation-elevation regression } \\
\text { model }\end{array}$ & $\begin{array}{l}\text { Coefficient for daily precipitation spatial } \\
\text { interpolation model }\end{array}$ & u & Medium \\
\hline & & $\begin{array}{l}\text { Monthly } \\
\text { Climate } \\
\text { Model }\end{array}$ & TMAXMOD(month) & $\begin{array}{l}\text { Model type for monthlymaximum } \\
\text { air temperature-elevation } \\
\text { regression model }\end{array}$ & $\begin{array}{l}\text { Defines model type for maximum daily air } \\
\text { temperature spatial interpolation model }\end{array}$ & u & High \\
\hline & & $\begin{array}{l}\text { Monthly } \\
\text { Climate } \\
\text { Model }\end{array}$ & TMAXA(month) & $\begin{array}{l}\text { Regression model coefficient for } \\
\text { maximum air } \\
\text { temperature-elevation model }\end{array}$ & $\begin{array}{l}\text { Coefficient for maximum daily air } \\
\text { temperature spatial interpolation model }\end{array}$ & u & High \\
\hline & & $\begin{array}{l}\text { Monthly } \\
\text { Climate } \\
\text { Model }\end{array}$ & TMAXB(month) & $\begin{array}{l}\text { Regression model coefficient for } \\
\text { maximum air } \\
\text { temperature-elevation model }\end{array}$ & $\begin{array}{l}\text { Coefficient for maximum daily air } \\
\text { temperature spatial interpolation model }\end{array}$ & u & High \\
\hline & & $\begin{array}{l}\text { Monthly } \\
\text { Climate } \\
\text { Model }\end{array}$ & TMAXC(month) & $\begin{array}{l}\text { Regression model coefficient for } \\
\text { maximum air } \\
\text { temperature-elevation model }\end{array}$ & $\begin{array}{l}\text { Coefficient for maximum daily air } \\
\text { temperature spatial interpolation model }\end{array}$ & u & High \\
\hline & & $\begin{array}{l}\text { Monthly } \\
\text { Climate } \\
\text { Model }\end{array}$ & TMINMOD(month) & $\begin{array}{l}\text { Model type for monthly } \\
\text { minimum air temperature- } \\
\text { elevation regression model }\end{array}$ & $\begin{array}{l}\text { Defines model type for minimum daily air } \\
\text { temperature spatial interpolation model }\end{array}$ & u & High \\
\hline & & $\begin{array}{l}\text { Monthly } \\
\text { Climate } \\
\text { Model }\end{array}$ & TMINA(month) & $\begin{array}{l}\text { Regression model coefficient for } \\
\text { minimum air } \\
\text { temperature-elevation model }\end{array}$ & $\begin{array}{l}\text { Coefficient for minimum daily air } \\
\text { temperature spatial interpolation model }\end{array}$ & u & High \\
\hline & & $\begin{array}{l}\text { Monthly } \\
\text { Climate } \\
\text { Model }\end{array}$ & TMINB(month) & $\begin{array}{l}\text { Regression model coefficient for } \\
\text { minimum air } \\
\text { temperature-elevation model }\end{array}$ & $\begin{array}{l}\text { Coefficient for minimum daily air } \\
\text { temperature spatial interpolation model }\end{array}$ & u & High \\
\hline & & $\begin{array}{l}\text { Monthly } \\
\text { Climate } \\
\text { Model }\end{array}$ & TMINC(month) & $\begin{array}{l}\text { Regression model coefficient for } \\
\text { minimum air } \\
\text { temperature-elevation model }\end{array}$ & $\begin{array}{l}\text { Coefficient for minimum daily air } \\
\text { temperature spatial interpolation model }\end{array}$ & $\mathrm{u}$ & High \\
\hline
\end{tabular}


Table 6-4

INFILv3 Input Parameters (as reported by Hevesi et al., 2003)

(Page 6 of 6)

\begin{tabular}{|c|c|c|c|c|c|c|c|}
\hline $\begin{array}{l}\text { Source } \\
\text { Data }\end{array}$ & Preprocessing & $\begin{array}{l}\text { Input } \\
\text { File }\end{array}$ & $\begin{array}{l}\text { Parameter } \\
\text { Name }\end{array}$ & $\begin{array}{l}\text { Parameter } \\
\text { Description }\end{array}$ & $\begin{array}{l}\text { Parameter } \\
\text { Use }\end{array}$ & Units & $\begin{array}{l}\text { Parameter } \\
\text { Accuracy }\end{array}$ \\
\hline \multicolumn{8}{|c|}{ Monthly Atmospheric Parameters } \\
\hline \multirow[t]{5}{*}{ NWS } & \multirow[t]{5}{*}{ None } & $\begin{array}{c}\text { Monthly } \\
\text { Atmospheric } \\
\text { Parameter }\end{array}$ & OZONE(month) & Ozone layer thickness & $\begin{array}{l}\text { Potential evapotranspiration model, } \\
\text { incoming solar radiation }\end{array}$ & $\mathrm{cm}$ & Medium \\
\hline & & $\begin{array}{c}\text { Monthly } \\
\text { Atmospheric } \\
\text { Parameter }\end{array}$ & WP(month) & Precipitable water in atmosphere & $\begin{array}{l}\text { Potential evapotranspiration model, } \\
\text { incoming solar radiation }\end{array}$ & $\mathrm{cm}$ & Medium \\
\hline & & $\begin{array}{c}\text { Monthly } \\
\text { Atmospheric } \\
\text { Parameter }\end{array}$ & $\mathrm{BETA}$ (month) & Mean atmospheric turbidity & $\begin{array}{l}\text { Potential evapotranspiration model, } \\
\text { incoming solar radiation, net radiation }\end{array}$ & u & Medium \\
\hline & & $\begin{array}{c}\text { Monthly } \\
\text { Atmospheric } \\
\text { Parameter }\end{array}$ & CSR(month) & Circumsolar radiation & $\begin{array}{l}\text { Potential evapotranspiration model, } \\
\text { incoming solar radiation, net radiation }\end{array}$ & u & Medium \\
\hline & & $\begin{array}{c}\text { Monthly } \\
\text { Atmospheric } \\
\text { Parameter }\end{array}$ & $P G$ (month) & Surface reflectivity & $\begin{array}{l}\text { Potential evapotranspiration model, } \\
\text { incoming solar radiation, net radiation }\end{array}$ & u & Medium \\
\hline
\end{tabular}

*Source: Hevesi et al., 2003

$r=$ Row

$\mathrm{C}=$ Column

$\mathrm{m}=$ Meters

$\mathrm{cm}=$ Centimeters

$\mathrm{mm}=$ Millimeters

$\%=$ Percentage

$\mathrm{u}=$ Unitless

$\mathrm{dd}=$ Decimal degrees

$d$ = Degrees

NA = Not applicable 
- Model Control Options: simulation period, initial conditions, seasonal duration, stream channel characteristics, snowmelt and sublimation parameters, and input and output format options.

Table 6-4 from the USGS report details all of the input parameters including the source data, preprocessing (if any), parameter name, description, use, and the units and estimated accuracy of the data. Two of the four USGS models documented in their report are included here. Model 1 (Figure 6-6) does not include a runoff/run-on component in recharge, and Model 2 (Figure 6-7) does. The table for HA volumetric totals is discussed in the summary section.

\subsubsection{Desert Research Institute Recharge Model (Russell and Minor, 2002)}

The Desert Research Institute Recharge Model extended the chloride mass-balance approach to refine recharge estimates in the NTS region and provide information about the spatial variability of recharge within HAs (Russell and Minor, 2002). This model used a methodology similar to that of Dettinger (1989) to determine recharge rates from multiple spring watersheds in and around the NTS. In this methodology, discharge rates of the springs within each watershed are quantified, chloride concentration of the springs is measured, and precipitation and atmospheric flux of chloride falling on the watershed above the spring(s) is estimated. The mass of chloride is then balanced between spring discharge and precipitation chloride concentrations. Precipitation chloride is estimated from atmospheric chloride flux. The result of the mass balance yields multiple estimates of spatially varied recharge. Uncertainties in the aforementioned input parameters were used in a Monte Carlo analysis to estimate uncertainty in the resultant recharge estimates. One thousand realizations of recharge rates were generated for each spring. A single set of assumptions regarding precipitation rates and chloride flux to land surface were common for all springs within a given realization. The results of the recharge rate for a given realization were related to elevation via a nonlinear regression analysis. The results of the regression analysis were extrapolated across the study area.

The DRI recharge model incorporated spatial variability within recharge areas, attempted to develop a more defensible lower limit of recharge, and differentiated local recharge from recharge emanating as inter-basin flux. This was accomplished by measuring discharge rates and chloride and bromide concentrations at 17 springs. These springs are located in the Sheep Range, Spring Mountains, and within the Nevada Test Site. In addition, measured discharge and chloride concentrations from these springs were compared to estimates provided by previously published reports. Data from various sources for ${ }^{36} \mathrm{Cl} / \mathrm{Cl}$ ratios and discharge rates of the three largest springs in the Amargosa Springs area were compiled.

In addition, 40 boreholes were drilled in alluvial sediments and sampled to support the argument that the areal distribution of alluvial sediments can be used to define a zone of negligible recharge. The vadose zone portion of the boreholes was used to develop chloride concentration versus depth profiles for locations in alluvial deposits. The chloride profiles exhibited three signature profiles: bulge, 


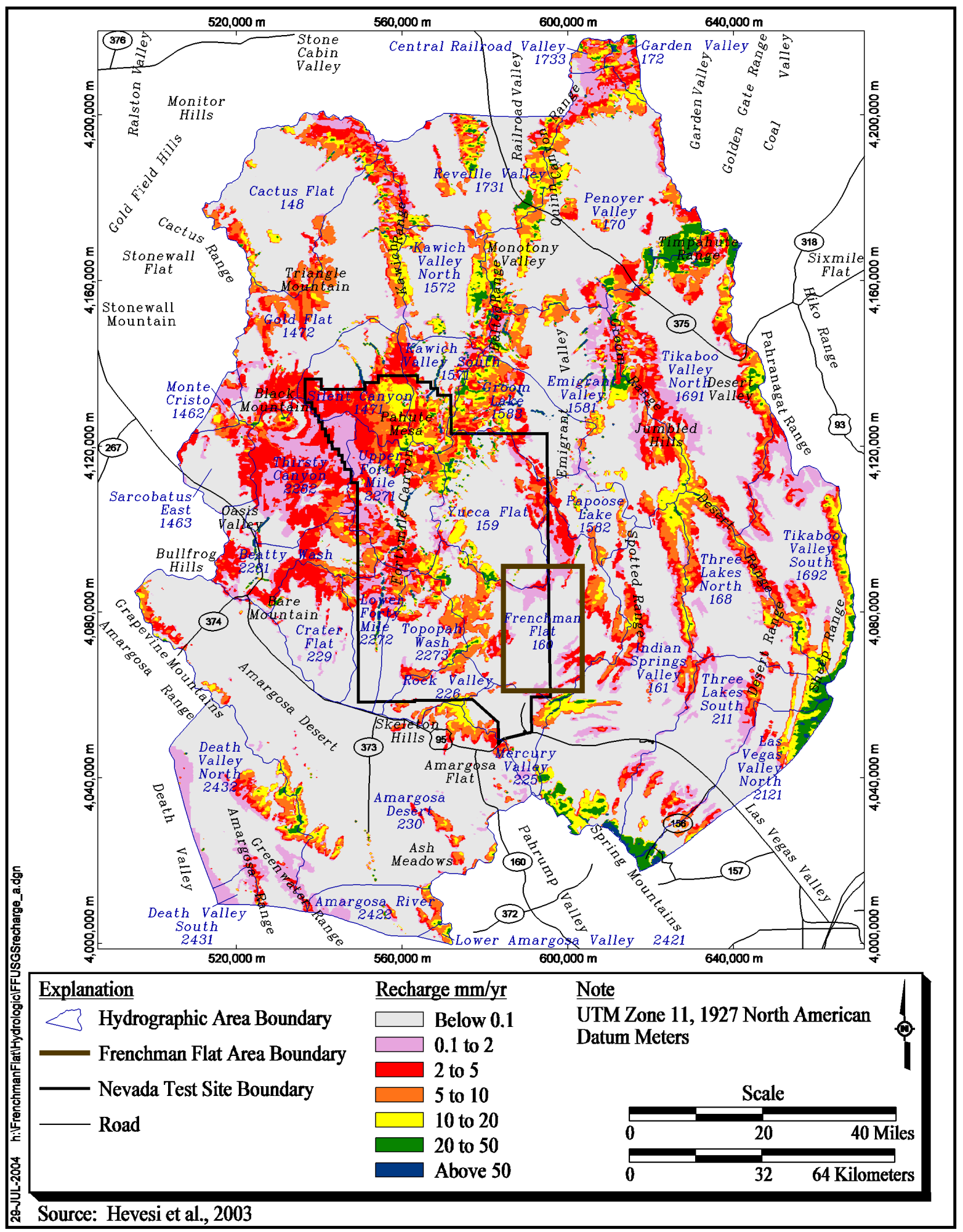

Figure 6-6

USGS Recharge Distribution Model 1, No Overland Flow 


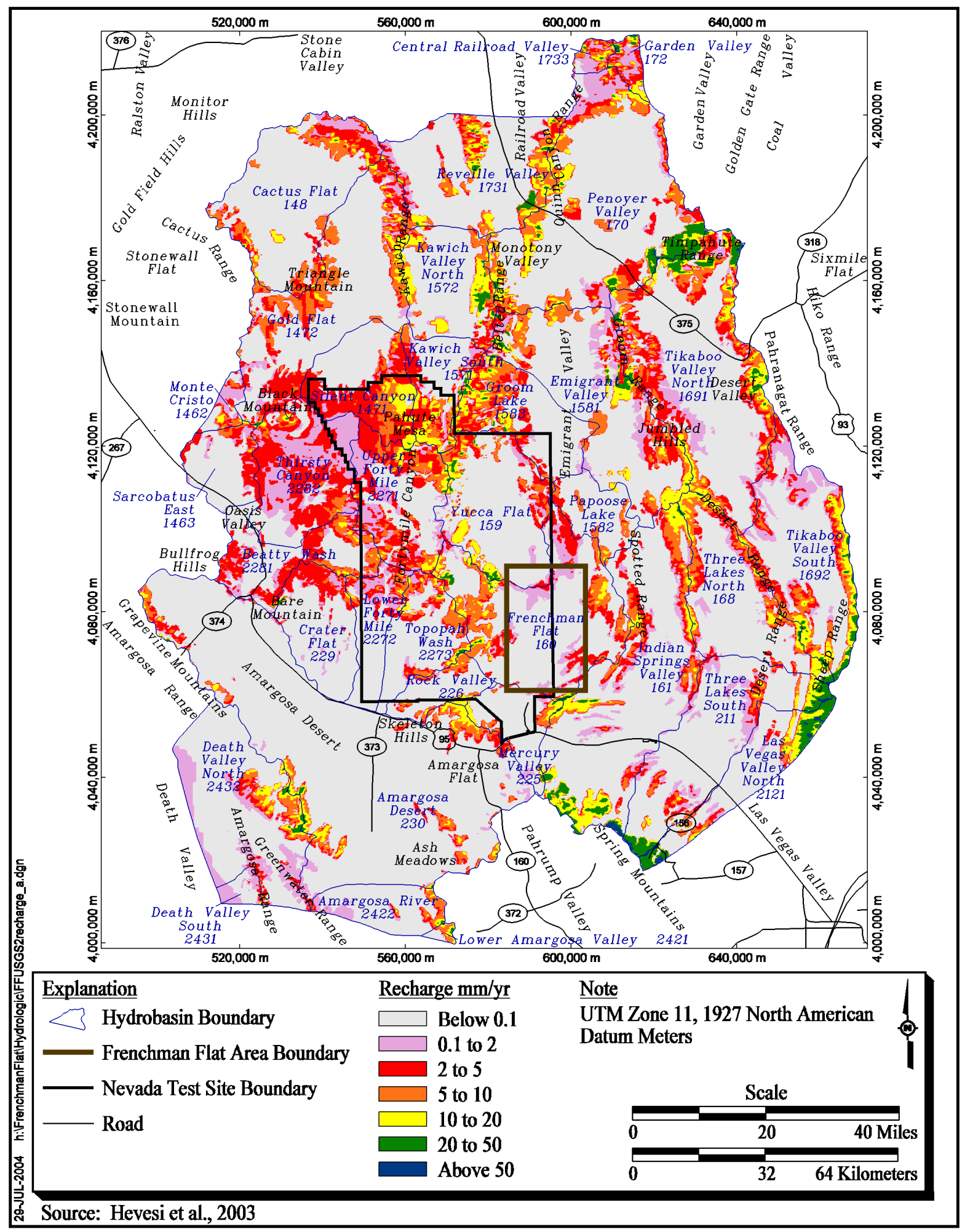

Figure 6-7

USGS Recharge Distribution Model 2, Overland Flow 
multipeak, and surface maximum. This information was used to determine net-infiltration rates for the landforms investigated (e.g., ephemeral streams and alluvial fans).

Geologic input was primarily obtained from Wahl et al. (1997), with additional definition of the Sheep and Spring ranges from Burchfield et al. (1974) and Guth (1986). This data was digitized and added to the GIS database to delineate alluvial formation distributions in the study area.

All this information was incorporated in a GIS model and was used in Monte Carlo simulations to determine recharge of precipitation occurring in the study area and the uncertainty in its estimates.

Results of the Monte Carlo analysis yielded estimates of the mean and standard deviation of volumetric recharge rates occurring within the study area for two sets of simulations using alternate definitions of the lower limit of recharge. The mean and standard deviations were $28.168 \times 10^{6} \pm 7.008 \times 10^{6} \mathrm{~m}^{3} / \mathrm{yr}$ for the first set and $26.838 \times 10^{6} \pm 6.928 \times 10^{6} \mathrm{~m}^{3} / \mathrm{yr}$ for the second set, respectively. They concluded, based on sensitivity analysis, that recharge estimates were most sensitive to uncertainty in the chloride concentration of the spring discharge. Also, the uncertainty associated with the mean precipitation was determined to be the second most sensitive parameter affecting recharge rates within the study area.

It is important to note that the values cited by Russell and Minor (2002) for volumetric rates of recharge are for an area smaller than the area of the present study. In order to better understand the comparison between the present study and that of Russell and Minor (2002), their approach, assumption, and basis for their methodology are summarized in the following.

Statistical procedures were used to evaluate the uncertainty in measurements of the chloride concentration from individual springs, disagreement among isohyetal maps of the area, the spatial and temporal variability in the chloride flux, and uncertainty in the elevation of the watershed for any given spring. The uncertainty associated with each of the variables was incorporated into Monte Carlo simulations to estimate the uncertainty in the prediction of recharge rates.

The precipitation models used by Russell and Minor (2002) included the PRISM model, the revised Hardman precipitation map (1965), and the Rush (1970) precipitation-elevation relationships. Precipitation data from 1961 to 1990 was used in the PRISM model at a grid resolution of $16 \mathrm{~km}^{2}$. The resolution was further refined to $4 \mathrm{~km}^{2}$ using kriging with a Gaussian distribution variogram. The Hardman map was used to recreate the precipitation amounts and distribution. The results were used in the ME method to estimate recharge rates for comparison. The Rush (1970) method was also recreated for comparison purposes using the elevation-precipitation relationships for that isohyetal map.

Chloride ion is used as a tracer by investigators for evaluation of recharge because it is conservative when dissolved in water. It does not enter oxidation or reduction reactions, forms no important solute complexes with other ions unless the chloride concentration is extremely high, does not form salts of low solubility, is unlikely to 
be sorbed on mineral surfaces, and plays few vital biogeochemical roles (Hem, 1985). Chloride occurs in the subsurface as part of the composition and mineralogy of soils and rocks. It is generally restricted to evaporites, incompletely leached marine sediments, or porous rocks that have been in contact with the ocean (Hem, 1985). However, volcanic rocks, inherently have substantial amount of chloride trapped within the interstitial structure that is not readily dissolved except due to erosion and accelerated weathering processes. A significant source of chloride in areas where the aforementioned conditions are absent is precipitation and dry deposition. Chloride is present in rain and snow and is originated at the surface of the ocean (Hem, 1985). Chloride is transported in the atmosphere and reaches land via precipitation (wet-fall) or as an aerosol (dry-fall). It is transported though subsurface material as precipitation infiltrates the ground. Some of the infiltrated water is lost to evapotranspiration by plants, concentrating the chloride in the upper soil layers. The chloride concentration of the water that percolates below the zone of evapotranspiration remains relatively constant and can be an indicator of recharge (Fouty, 1989; Eriksson and Khunakasem, 1969). Therefore, if the amount of precipitation and its chloride concentration are known, the total rate of chloride infiltration may be calculated. Similarly, if the amount of spring, other surface discharges, and their concentrations are known, the amount of total chloride discharge can be calculated. A rigorous chloride mass-balance approach requires quantitative knowledge of all sources and sinks of the chloride ion. If the sole source of chloride is assumed to be the combined mass of wet-fall and dry-fall atmospheric deposition, expressed as concentration of chloride ion in precipitation $(\mathrm{Cp}$, milligram per liter $[\mathrm{mg} / \mathrm{L}])$, then the quantity of recharge $\mathrm{R}$ (liters per year [L/yr]) is defined as (Maurer et al., 1996):

$$
\mathrm{R}=\left(\mathrm{C}_{\mathrm{p}} \mathrm{P}\right) /\left(\mathrm{C}_{\mathrm{r}}\right)-\left(\mathrm{C}_{\mathrm{SW}} \mathrm{S}_{\mathrm{W}}\right) /\left(\mathrm{C}_{\mathrm{r}}\right)
$$

where:

$\mathrm{P}(\mathrm{L} / \mathrm{yr}) \quad=$ Mean annual precipitation

$\mathrm{C}_{\mathrm{SW}} \mathrm{S}_{\mathrm{W}}=$ Quantity of chloride $(\mathrm{mg} / \mathrm{L})$ and water $(\mathrm{L} / \mathrm{yr})$ that is removed due to surface-water runoff

$\mathrm{C}_{\mathrm{r}}(\mathrm{mg} / \mathrm{L})=$ Quantity of chloride in water that has recharged.

This equation assumes steady-state chloride precipitation and total mass conservation, which means, no changes in the subsurface storage. The validity of the assumptions made by Russell and Minor (2002) within the study area are analyzed in the following.

The first assumption in this study is that the runoff component is considered negligible. Secondly, steady-state conditions are assumed. Third, no authigenic chloride is found in soils and groundwater, and that all chloride is attributable to atmospheric origin. These assumptions affect the balance of chloride mass in the system.

Russell and Miner (2002) developed a relationship between the elevation of 17 spring watersheds and the rate of recharge using regression analysis. A selected simulation set for the 17 area-weighted mean elevations of springs in the study area was linked to 17 simulations of chloride concentrations within each spring. 
The randomly sampled chloride concentrations from all 17 springs were divided by a single estimate of effective chloride concentration in precipitation. The results consisted of a set of estimated area-weighted mean elevations of spring watersheds and the ratio describing the relative enrichment of chloride in the precipitation water due to evapotranspiration within each watershed. The resulting regression equation is:

$$
\left(\mathrm{C}_{\mathrm{r}} / \mathrm{C}_{\mathrm{p}}\right)=1.0+\mathrm{c} 1 * \mathrm{e}^{(\mathrm{c} 2 * \mathrm{elev})}
$$

where:

$\mathrm{C}_{\mathrm{r}} / \mathrm{C}_{\mathrm{p}}=$ Ratio of recharge to precipitation chloride concentration $\mathrm{c} 1$ and $\mathrm{c} 2=$ Regression coefficients

elev $=$ Area-weighted mean elevation of the watershed of interest.

The digital elevation model, a modified version of the PRISM isohyetal map, and the alluvial mask developed from the geologic models were used with this equation to determine the distribution of recharge across the study area.

Modification of the PRISM dataset ensured consistency of precipitation estimates required to calculate recharge as a function of elevation. To calculate recharge, they used the 100-m resolution DEM to calculate the area-weighted mean elevation of 4- $\mathrm{km}^{2}$ grids that coincided with the spatial distribution for the 4-km² resolution of the PRISM isohyetal map (Daley et al., 1994). Area-weighted mean elevation and mean precipitation for the $4-\mathrm{km}^{2}$ sample was used as input to Equation 6-6 to calculate $\mathrm{C}_{\mathrm{r}} / \mathrm{C}_{\mathrm{p}}$. The corresponding precipitation value for the 4- $\mathrm{km}^{2}$ area was divided by $\mathrm{C}_{\mathrm{r}} / \mathrm{C}_{\mathrm{p}}$ to determine recharge for that area using Equation 6-5. Results were summed across the study area and ranked. The $50^{\text {th }}$ percentile result was used to map the distribution of recharge across the study area. In addition, the results of the $5^{\text {th }}, 50^{\text {th }}$, and $95^{\text {th }}$ percentile were summarized by HAs for comparison to previously published results of recharge.

Two versions of the recharge model were developed. One version assumed no recharge in alluvial areas, and the other assumed no recharge in alluvial areas as well as areas below an elevation of $1,237 \mathrm{~m}$. These two models differ in the area of alluvium cover where recharge is allowed to occur.

Sensitivity analysis indicated that the model was most sensitive to the spring chloride concentration and accounted for 50 percent of the total variance. Mean precipitation was the second most sensitive (26 percent), followed closely by watershed elevation ( 21 percent). The model was least sensitive to chloride concentration in precipitation ( 2 percent). Validation of the results was performed semi-independently with an independent set of 13 springs in the Spring Mountains Range. These authors concluded that results were favorable and indeed validated the approach.

The recharge models developed by Russell and Minor (2002) are for an area that immediately surrounds the NTS. This area is not entirely coincident with the areas for which recharge estimates were developed by the USGS and the UGTA project. In some instances, recharge estimates reported by Russell and Minor (2002) were only for portions of hydrographic basins. DRI, in support of the UGTA project, 
revisited and expanded Russell and Minor's (2002) study and estimated recharge for the entire area of the hydrographic basins that fell within Russell and Minor's original study area. However, the original recharge models still did not include all of the HAs in the UGTA model area. Therefore, another method was identified by the UGTA project to estimate recharge rates using Russell and Minor's method for those HAs that were not included in their report. This methodology is described below.

Recharge volumes were calculated for a number of HAs using different methods and were compared to the results of Russell and Minor (2002) method. A simple linear regression model was selected because it provided the best fit with the fewest fitting parameters (Figure 6-8). The best correlation was between the recharge calculated in the UGTA Revised ME method and Russell and Minor's alluvial and elevation masked recharge data $50^{\text {th }}$ percentile distribution $\left(\mathrm{R}^{2}=0.98\right)$. A good correlation was observed between the UGTA Revised ME method and the results of Russell and Minor's alluvial mask $50^{\text {th }}$ percentile distribution with a correlation coefficient of $\mathrm{R}^{2}=0.97$.

Kawich Valley recharge was removed from the DRI dataset because it was more than two standard deviations away from the mean of the entire dataset, suggesting it was an outlier (Figure 6-8). The regression formula was then applied to the remaining valleys outside of the DRI dataset, but within the NTS regional model area to calculate recharge for these HAs. Because linear correlations were used for both the alluvial and the elevation masks, all HAs had identical multipliers within one of the models, these multipliers were 1.36 and 1.34, respectively. Calculated HA-specific recharge rates are reported in Table 6-5 in the estimated $50^{\text {th }}$ percentile recharge columns. DRI model results and the UGTA Revised recharge model results are reported for comparison. These estimated recharge rates were used in the regional model recharge distributions for those HAs not included in Russell and Minor's study area.

The resultant recharge distributions for the entire NTS regional model area for the alluvial mask $50^{\text {th }}$ percentile are shown in Figure 6-9. The recharge distribution for the alluvial and elevation mask $50^{\text {th }}$ percentile distribution is shown in Figure 6-10. Note that the values for some of the HAs presented in Table 6-5, Figure 6-9, and Figure 6-10 have been extrapolated from recharge data for areas that are quite distant from the UGTA area. The farther the extrapolation distance, the less reliable the recharge estimates become. This is one reason why the value calculated for Kawich is an outlier. Finally, there are few low- to mid-elevation springs on the NTS; thus, 10 of the 17 springs used in the analysis were located in the Spring Mountains or Sheep Range. The recharge processes at these springs may be impacted by orographic affects and, as a result, may be over-estimating recharge in some of the hydrographic basins. Tabulated volumetric totals for these recharge distributions are presented in the summary section.

\subsubsection{Nevada Water Resource Study}

The following description of recharge estimation is based on a report titled: Water Resources - Reconnaissance Series Report 54 by F.E. Rush (1970). 

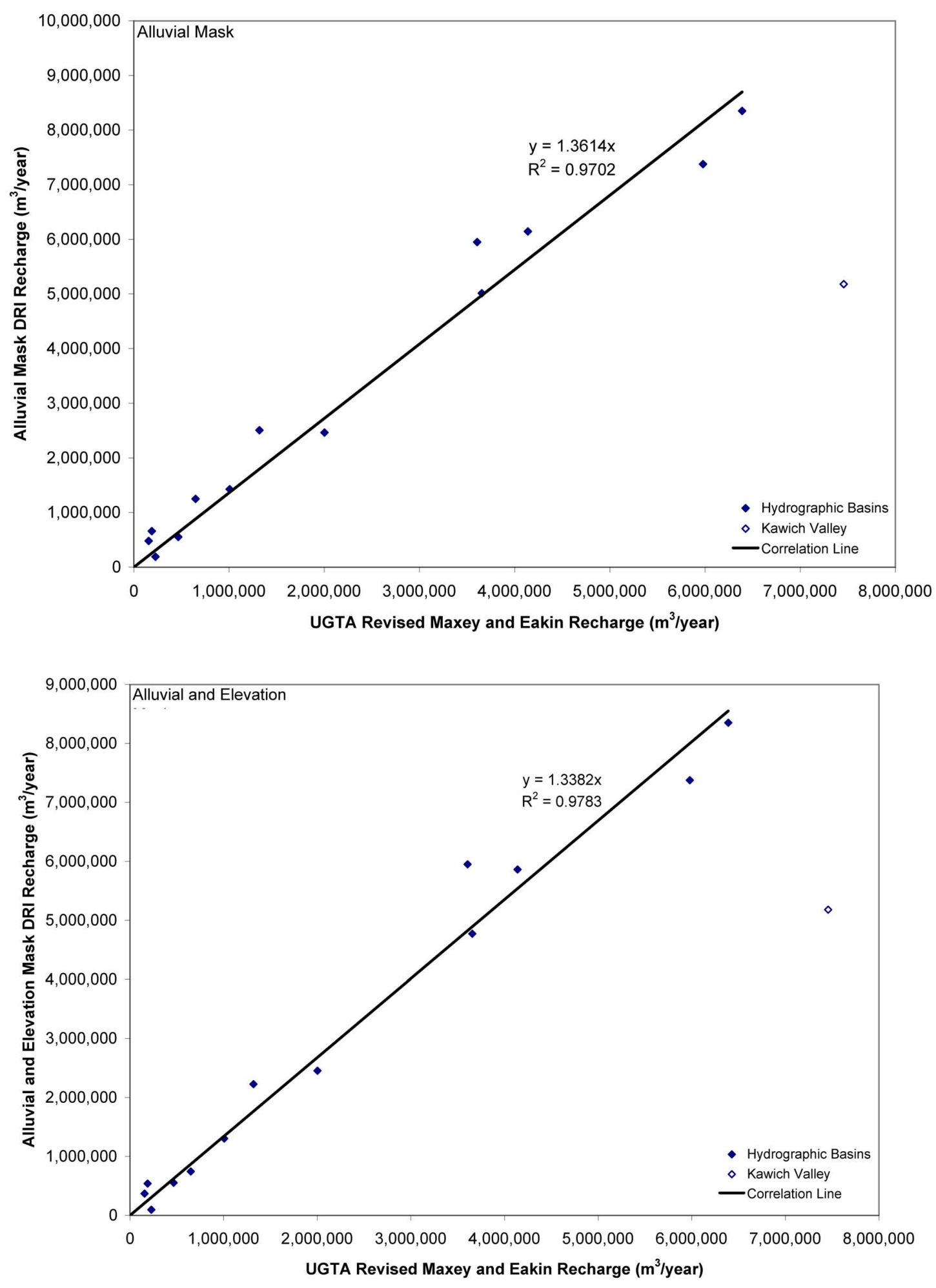

Figure 6-8

Relationship between UGTA Revised ME Recharge Rate and DRI Models 
Table 6-5

Scaled DRI Recharge Rates Using UGTA Revised Maxey and Eakin Model

\begin{tabular}{|c|c|c|c|c|c|c|c|}
\hline \multirow[b]{2}{*}{$\begin{array}{c}\text { Sub-basin } \\
\text { Number }\end{array}$} & \multirow[b]{2}{*}{ Area Name } & \multirow[b]{2}{*}{ Secondary Name } & \multirow{2}{*}{$\begin{array}{c}\text { UGTA } \\
\begin{array}{c}\text { Revised } \\
\text { Maxey-Eakin Based } \\
\left(\mathrm{m}^{3} / \mathrm{yr}\right)\end{array}\end{array}$} & \multicolumn{2}{|c|}{ Alluvial Mask } & \multicolumn{2}{|c|}{ Alluvial and Elevation Mask } \\
\hline & & & & $\begin{array}{c}\text { 50th Percentile } \\
\text { DRI } \\
\left(\mathrm{m}^{3} / \mathrm{yr}\right)\end{array}$ & $\begin{array}{c}\text { Estimated 50th } \\
\text { Percentile } \\
\text { Recharge } \\
\left(\mathrm{m}^{3} / \mathrm{yr}\right)\end{array}$ & $\begin{array}{c}\text { 50th Percentile } \\
\text { DRI } \\
\left(\mathrm{m}^{3} / \mathrm{yr}\right)\end{array}$ & $\begin{array}{l}\text { Estimated 50th } \\
\text { Percentile } \\
\text { Recharge } \\
\left(\mathrm{m}^{3} / \mathrm{yr}\right)\end{array}$ \\
\hline 1462 & Sarcobatus Flat-2 & Monte Cristo & $794,532.94$ & & $1,081,677.14$ & & $1,063,085.07$ \\
\hline 1463 & Sarcobatus Flat-3 & Sarcobatus East & $568,888.63$ & & $774,484.98$ & & $761,172.99$ \\
\hline 148 & Cactus Flat & & $3,304,087.75$ & & $4,498,185.06$ & & $4,420,869.41$ \\
\hline $1571 \& 1572$ & Kawich Valley & & $7,456,053.50$ & $5,176,836$ & $10,150,671.23$ & $5,176,836$ & $9,976,199.58$ \\
\hline 168 & Three Lakes Valley North & & $319,001.72$ & & $434,288.94$ & & $426,824.30$ \\
\hline 1691 & Tikaboo Valley-1 & Tikaboo Valley North & $6,451,646.00$ & & $8,783,270.86$ & & $8,632,302.35$ \\
\hline 1692 & Tikaboo Valley-2 & Tikaboo Valley South & $760,359.69$ & & $1,035,153.68$ & & $1,017,361.27$ \\
\hline 170 & Penoyer Valley & & $6,487,366.00$ & & $8,831,900.07$ & & $8,680,095.71$ \\
\hline 172 & Garden Valley & & $2,476,189.50$ & & $3,371,084.39$ & & $3,313,141.55$ \\
\hline 1731 & Railroad Valley South-1 & Reveille Valley & $5,464,048.00$ & & $7,438,754.95$ & & $7,310,896.22$ \\
\hline 1733 & Railroad Valley South-3 & Central Railroad Valley & $1,920,031.88$ & & $2,613,931.40$ & & $2,569,002.66$ \\
\hline 211 & Three Lakes Valley South & & $4,219,934.50$ & & $5,745,018.83$ & & $5,646,272.36$ \\
\hline 2121 & Las Vegas Valley-1 & & $5,015,045.00$ & & $6,827,482.26$ & & $6,710,130.21$ \\
\hline 2301 & Amargosa Desert & NV Portion & $648,360.13$ & $1,250,517$ & $882,677.48$ & 743,668 & $867,505.85$ \\
\hline 2302 & Amargosa Desert & CA Portion & $807,342.19$ & & $1,099,115.66$ & & $1,080,223.85$ \\
\hline 2421 & Amargosa River-1 & Lower Amargosa Valley & 0.00 & & 0.00 & & 0.00 \\
\hline 2422 & Amargosa River-2 & Amargosa River & $103,701.07$ & & $141,178.64$ & & $138,752.03$ \\
\hline 2431 & Death Valley Central-1 & Death Valley South & $23,983.49$ & & $32,651.12$ & & $32,089.91$ \\
\hline 2432 & Death Valley Central-2 & Death Valley North & $1,559,098.63$ & & $2,122,556.87$ & & $2,086,073.97$ \\
\hline $1471 \& 1472$ & Gold Flat & & $6,389,207.25$ & $8,349,933$ & $8,698,266.75$ & $8,349,933$ & $8,548,759.30$ \\
\hline 1582 & Emigrant Valley & & $466,867.94$ & 552,945 & $635,594.01$ & 552,945 & $624,669.30$ \\
\hline $1581 \& 1583$ & Emigrant Valley & & $5,978,079.75$ & $7,376,521$ & $8,138,557.77$ & $7,376,521$ & $7,998,670.71$ \\
\hline 159 & Yucca Flat & & $2,001,385.63$ & $2,464,376$ & $2,724,686.40$ & $2,454,338$ & $2,677,853.97$ \\
\hline 160 & Frenchman Flat & & $1,319,063.50$ & $2,506,705$ & $1,795,773.05$ & $2,225,121$ & $1,764,906.96$ \\
\hline 161 & Indian Springs Valley & & $3,655,435.50$ & $5,014,868$ & $4,976,509.89$ & $4,773,754$ & $4,890,972.70$ \\
\hline 225 & Mercury Valley & & $154,914.28$ & 480,655 & $210,900.30$ & 370,761 & $207,275.31$ \\
\hline 226 & Rock Valley & & $227,355.69$ & 193,150 & $309,522.04$ & 94,962 & $304,201.91$ \\
\hline 2271 & Fortymile Canyon & & $3,606,419.00$ & $5,951,107$ & $4,909,778.83$ & $5,951,107$ & $4,825,388.62$ \\
\hline 2272,2273 & Fortymile Canyon & & $1,006,677.44$ & $1,426,551$ & $1,370,490.67$ & $1,302,880$ & $1,346,934.41$ \\
\hline $2281 \& 2282$ & Oasis Valley & & $4,138,336.50$ & $6,145,495$ & $5,633,931.31$ & $5,862,809$ & $5,537,094.24$ \\
\hline 229 & Crater Flat & & $187,842.58$ & 661,209 & $255,728.89$ & 540,229 & $251,333.37$ \\
\hline
\end{tabular}




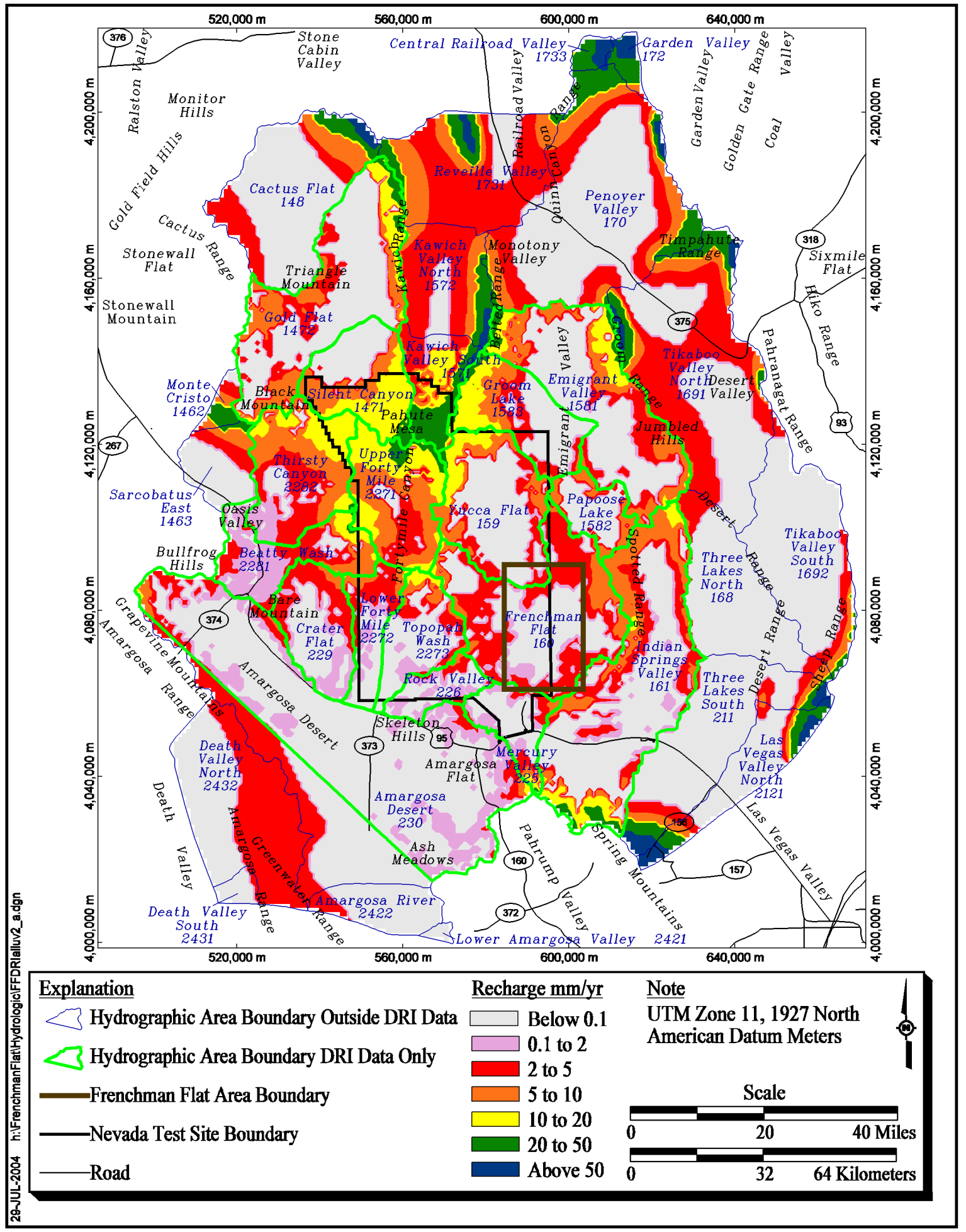

Figure 6-9

DRI Recharge Distribution with Alluvial Mask

(Russell and Minor, 2002) 


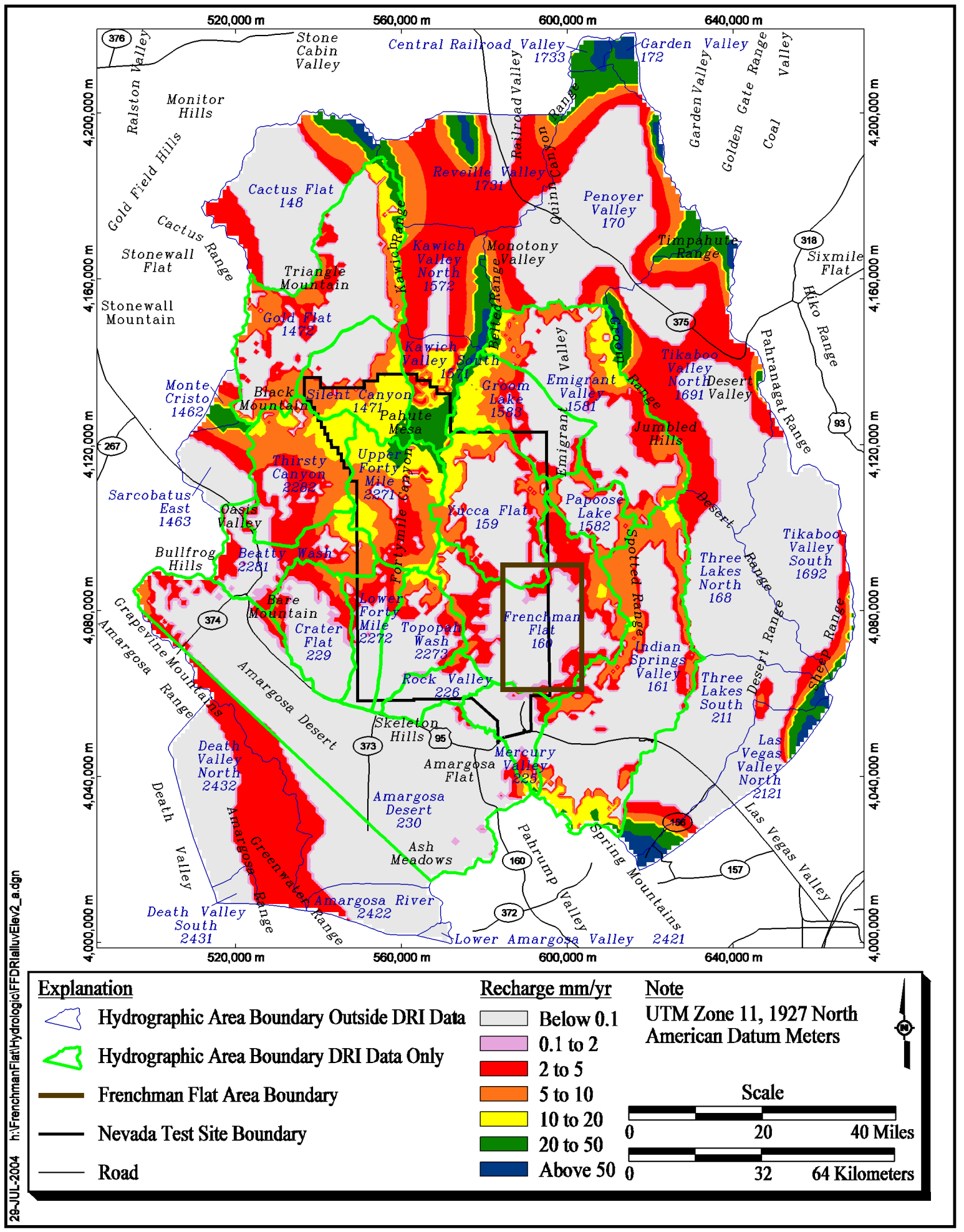

Figure 6-10

DRI Recharge Distribution with Alluvial and Elevation Mask (Russell and Minor, 2002) 
This study is referred to in most of the literature as the Rush (1970) study and is based primarily on the ME approach. The difference is the base precipitation model used to derive the percentage recharge estimates. Instead of using the precipitation distribution developed by Hardman $(1936,1965)$, Rush (1970) used the elevation-based version of the method, as a strong correlation exists between the precipitation and land surface elevation within the study area. The elevation cutoffs were dependent on the HA under study and were set to 304.8 m elevation zones, with each zone directly correlating to the ME recharge zone. For example, instead of using precipitation zones of 22.3 to $30.5 \mathrm{~cm}$ empirically set to a 3 percent recharge rate, the 1,524 to $1,828.8 \mathrm{~m}$ elevation zone was set to a 3 percent recharge rate. This, however, was not the case for all recharge zones. For example, recharge zones starting at land surface elevations of $1,524 \mathrm{~m}$; $1,828.8 \mathrm{~m}$; and in one case 2,133.6 m produced recharge volumes that differed from those derived using the ME method by more than a minor amount. The results of this study are summarized in Table 6-6.

\subsection{Base Recharge Model}

The recharge rates calculated by various methods are listed in Table 6-6 and graphed in Figure 6-11 for each HA or sub-area with available data. Comparison of the recharge rates depicts a general trend in the relationships of the methods. The UGTA Revised recharge model, which is based on the modified ME method, was selected as the base recharge model for this report. This model provides a good starting point for groundwater modeling because, in general, the recharge estimates from this model fall in the middle of the ranges of all the recharge estimates. Additionally, the DRI models are likely to have high uncertainty when used in conjunction with the lateral boundary fluxes (Section 9.0), because these models were extrapolated to distant HAs for which there were no measured recharge values using chloride mass-balance. The USGS recharge models were not selected as the base recharge models because they have the lowest overall recharge which may result in unconservative estimates of contaminant transport.

The recharge rates for the base model are generally bracketed by the volumes of all other models (Figure 6-11). Furthermore, the base model rates tend to fall within the $5^{\text {th }}$ and $95^{\text {th }}$ percentile of the confidence intervals of the recharge volumes predicted by the DRI models, where predictions are available. It is important to note that all the HAs with missing 5 and 95 percent DRI recharge values in Table 6-6 are those that were predicted by the UGTA Revised recharge model using regression formula discussed earlier in the DRI recharge model section. The UGTA Revised recharge model has not undergone calibration resulting in a simpler model than the calibrated UGTA Original recharge model used in the NTS regional groundwater flow model. The UGTA Revised model was judged to be more appropriate in light of the more recent data.

The recharge model may be modified locally during the calibration of the Frenchman Flat CAU model. The modifications may consist of simply scaling the entire dataset up or down or just within a specific hydrographic basin. Every effort will be made to avoid modifying recharge outside the range of values identified by the alternative recharge models. 


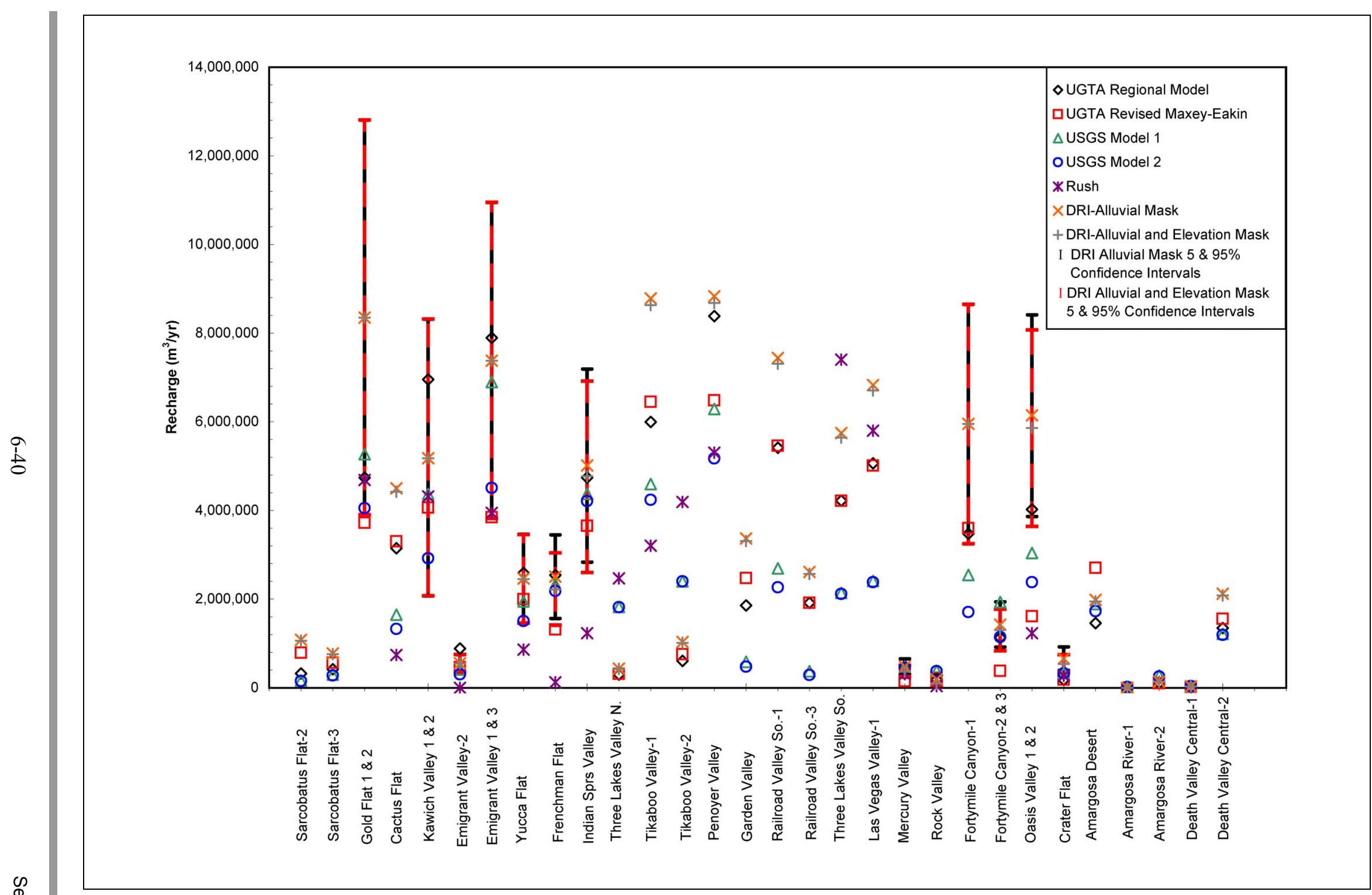

Figure 6-11

Recharge Rate for all Recharge Models and all HAs 
Table 6-6

Recharge Rates for HAs for all Recharge Models

\begin{tabular}{|c|c|c|c|c|c|c|c|c|c|c|c|c|c|}
\hline \multirow{3}{*}{$\begin{array}{c}\text { Sub-basin } \\
\text { Number }\end{array}$} & \multirow{3}{*}{ Area Name } & \multirow{3}{*}{ Secondary Name } & \multirow{3}{*}{$\begin{array}{c}\begin{array}{c}\text { UGTA } \\
\text { Original } \\
\text { modified } \\
\text { ME }\end{array} \\
\left(\mathrm{m}^{3} / \mathrm{yr}\right)\end{array}$} & \multirow{3}{*}{$\begin{array}{c}\begin{array}{c}\text { UGTA } \\
\text { Revised } \\
\text { modified } \\
\text { ME }\end{array} \\
\left(\mathrm{m}^{3} / \mathrm{yr}\right)\end{array}$} & \multirow{3}{*}{$\begin{array}{c}\begin{array}{c}\text { USGS } \\
\text { Model } 1\end{array} \\
\left(\mathrm{~m}^{3} / \mathrm{yr}\right)\end{array}$} & \multirow{3}{*}{$\begin{array}{c}\begin{array}{c}\text { USGS } \\
\text { Model } 2\end{array} \\
\left(\mathrm{~m}^{3} / \mathrm{yr}\right)\end{array}$} & \multirow{3}{*}{$\begin{array}{c}\begin{array}{c}\text { Rush } \\
(1970)\end{array} \\
\left(\mathrm{m}^{3} / \mathrm{yr}\right)\end{array}$} & \multirow{2}{*}{\multicolumn{3}{|c|}{$\begin{array}{c}\text { DRI-Alluvial Mask Only } \\
\text { Percentile }\end{array}$}} & \multirow{2}{*}{\multicolumn{3}{|c|}{$\begin{array}{c}\text { DRI-Alluvial and Elevation Mask } \\
\text { Percentile }\end{array}$}} \\
\hline & & & & & & & & & & & & & \\
\hline & & & & & & & & $\begin{array}{c}5^{\text {th }} \\
\left(\mathrm{m}^{3} / \mathrm{yr}\right)\end{array}$ & $\begin{array}{c}50 \mathrm{th}^{\mathrm{b}} \\
\left(\mathrm{m}^{3} / \mathrm{yr}\right)\end{array}$ & $\begin{array}{c}95 \text { th } \\
\left(\mathrm{m}^{3} / \mathrm{yr}\right)\end{array}$ & $\begin{array}{c}\text { 5th } \\
\left(\mathrm{m}^{3} / \mathrm{yr}\right)\end{array}$ & $\begin{array}{l}50 \mathrm{th}^{\mathrm{b}} \\
\left(\mathrm{m}^{3} / \mathrm{yr}\right)\end{array}$ & $\begin{array}{c}95 \text { th } \\
\left(\mathrm{m}^{3} / \mathrm{yr}\right)\end{array}$ \\
\hline 1462 & Sarcobatus Flat-2 & Monte Cristo & 324,700 & 794532.94 & 162,400 & 153,300 & & & $1,082,000$ & & & $1,063,000$ & \\
\hline 1463 & Sarcobatus Flat- 3 & Sarcobatus East & 420,300 & 568,889 & 297,400 & 280,800 & & & 774,500 & & & 761,200 & \\
\hline 1471 & Gold Flat-1 \& 2 & Silent Canyon & $4,739,000$ & $3,726,785$ & $5,269,000$ & $4,052,000$ & $4,687,000$ & $3,902,375$ & $8,349,933$ & $12,806,618$ & $3,902,375$ & $8,349,933$ & $12,806,618$ \\
\hline 148 & Cactus Flat & & $3,147,000$ & $3,304,088$ & $1,653,000$ & $1,326,000$ & 740,100 & & $4,498,000$ & & & $4,421,000$ & \\
\hline 1571 & Kawich Valley-1 \& 2 & Kawich Valley South & $6,952,000$ & $4,068,436$ & $4,372,000$ & $2,923,000$ & $4,317,000$ & $2,074,601$ & $5,179,836$ & $8,317,501$ & $2,074,601$ & $5,179,836$ & $8,317,501$ \\
\hline 1582 & Emigrant Valley-2 & Papoose Lake & 887,800 & 466,868 & 412,600 & 305,300 & 1,233 & 353,077 & 552,945 & 752,863 & 353,077 & 552,945 & 752,863 \\
\hline 1581 & Emigrant Valley-1 \& 3 & Emigrant Valley & $7,891,000$ & $3,851,189$ & $6,897,000$ & $4,510,000$ & $3,947,000^{a}$ & $3,821,622$ & $7,376,521$ & $10,947,605$ & $3,821,622$ & $7,376,521$ & $10,947,605$ \\
\hline 159 & Yucca Flat & & $2,589,000$ & $2,001,386$ & $1,950,000$ & $1,508,000$ & 863,500 & $1,460,381$ & $2,464,376$ & $3,462,957$ & $1,458,825$ & $2,454,338$ & $3,454,159$ \\
\hline 160 & Frenchman Flat & & $2,542,000$ & $1,319,064$ & $2,340,000$ & $2,183,000$ & 123,400 & $1,563,499$ & $2,506,705$ & $3,451,927$ & $1,412,403$ & $2,225,121$ & $3,043,080$ \\
\hline 161 & Indian Springs Valley & & $4,741,000$ & $3,655,436$ & $4,376,000$ & $4,210,000$ & $1,234,000$ & $2,836,248$ & $5,014,868$ & $7,189,613$ & $2,596,903$ & $4,773,754$ & $6,913,761$ \\
\hline 168 & Three Lakes Valley North & & 300,600 & 319,002 & $1,824,000$ & $1,819,000$ & $2,467,000$ & & 434,300 & & & 426,800 & \\
\hline 1691 & Tikaboo Valley-1 & Tikaboo Valley North & $5,997,000$ & $6,451,646$ & $4,595,000$ & $4,241,000$ & $3,207,000$ & & $8,783,000$ & & & $8,632,000$ & \\
\hline 1692 & Tikaboo Valley-2 & Tikaboo Valley South & 606,700 & 760,360 & $2,401,000$ & $2,402,000$ & $4,194,000$ & & $1,035,000$ & & & $1,017,000$ & \\
\hline 170 & Penoyer Valley & & $8,382,000$ & $6,487,366$ & $6,289,000$ & $5,175,000$ & $5,304,000$ & & $8,832,000$ & & & $8,680,000$ & \\
\hline 172 & Garden Valley & & $1,859,000$ & $2,476,190$ & 587,500 & 478,600 & & & $3,371,000$ & & & $3,313,000$ & \\
\hline 1731 & Railroad Valley South-1 & Reveille Valley & $5,416,000$ & $5,464,048$ & $2,696,000$ & $2,266,000$ & & & $7,439,000$ & & & $7,311,000$ & \\
\hline 1733 & Railroad Valley South-3 & Central Railroad Valley & $1,914,000$ & $1,920,032$ & 373,500 & 290,000 & & & $2,614,000$ & & & $2,569,000$ & \\
\hline 211 & Three Lakes Valley South & & $4,221,000$ & $4,219,935$ & $2,143,000$ & $2,117,000$ & $7,401,000$ & & $5,745,000$ & & & $5,646,000$ & \\
\hline 2121 & Las Vegas Valley-1 & & $5,063,000$ & $5,015,045$ & $2,412,000$ & $2,382,000$ & $5,797,000$ & & $6,827,000$ & & & $6,710,000$ & \\
\hline 225 & Mercury Valley & & 424,800 & 154,914 & 475,000 & 446,400 & 308,400 & 307,595 & 480,655 & 653,026 & 235,827 & 370,761 & 505,057 \\
\hline 226 & Rock Valley & & 176,700 & 227,356 & 385,200 & 374,600 & 37,010 & 103,387 & 193,150 & 282,715 & 58,471 & 94,962 & 131,371 \\
\hline 2271 & Fortymile Canyon-1 & Upper Fortymile & $3,477,000$ & $3,606,419$ & $2,545,000$ & $1,709,000$ & & $3,249,834$ & $5,951,107$ & $8,648,052$ & $3,249,834$ & $5,951,107$ & $8,648,052$ \\
\hline 2272 & Fortymile Canyon-2 \& 3 & Lower Fortymile & $1,129,300$ & 383,188 & $1,932,900$ & $1,146,300$ & & 918,752 & $1,426,551$ & $1,937,465$ & 832,277 & $1,302,880$ & $1,769,044$ \\
\hline 2281 & Oasis Valley-1 \& 2 & Beatty Wash & $4,022,000$ & $1,616,471$ & $3,041,000$ & $2,380,800$ & $1,234,000$ & $3,865,340$ & $6,145,495$ & $8,411,821$ & $3,638,233$ & $5,862,809$ & $8,069,781$ \\
\hline 229 & Crater Flat & & 179,800 & 187,843 & 347,500 & 327,500 & 271,400 & 395,357 & 661,209 & 926,301 & 337,018 & 540,229 & 744,761 \\
\hline $2301 \& 2302$ & Amargosa Desert & & $1,457,000$ & $1,455,702$ & $1,893,000$ & $1,730,000$ & & & $1,981,700$ & & & $1,947,500$ & \\
\hline 2421 & Amargosa River-1 & Lower Amargosa Valley & 0 & 0 & 17,920 & 17,600 & & & 0 & & & 0 & \\
\hline 2422 & Amargosa River-2 & Amargosa River & 105,000 & 103,701 & 279,900 & 257,300 & & & 141,000 & & & 138,800 & \\
\hline 2431 & Death Valley Central-1 & Death Valley South & 15,870 & 23,983 & 41,670 & 37,180 & & & 32,650 & & & 32,090 & \\
\hline 2432 & Death Valley Central-2 & Death Valley North & $1,348,000$ & $1,559,099$ & $1,216,000$ & $1,195,000$ & & & $2,123,000$ & & & $2,086,000$ & \\
\hline
\end{tabular}

C) Source: PM Hydrologic Data Document, Final (SNJV, 2004a)

${ }^{a}$ The reported recharge volume from Rush (1970) is only for the Emigrant Valley-3 basin not both.

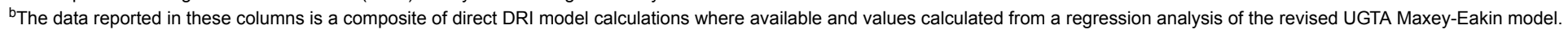




\subsection{Alternative Recharge Models}

Groundwater flow modeling of the Frenchman Flat CAU will consider recharge rates estimated by alternative models described in this section. These models will provide a range of recharge-rate estimates that will be used for sensitivity analysis and evaluation of alternative scenarios during the course of flow model

construction and calibration. The range of recharge for any given HA can vary by more than a factor of 3 or 4 from model to model. In addition, the recharge areal distributions from model to model vary greatly, which is expected to have an effect on the flow model predictions. These will be considered during sensitivity and uncertainty analysis.

\subsection{Limitations}

Numerous limitations are documented in the development of each of the reported recharge models. The reader is directed to those reports to obtain a complete description of each limitation, including how and at what point in the application of the methodology it affects the resultant recharge estimate. However, there are several limitations that all the authors of the reports found to be in common. These limitations are discussed in this section.

First, all authors agree that the sparsity of precipitation data, especially at higher elevations, and in remote areas greatly increases the uncertainty in the resultant recharge. In addition, the length of record and conversion of snowpack to liquid precipitation have a significant impact on the outcome of the estimates. Second, the other data types necessary to support each of the methods discussed in this section are limited (e.g., chloride and bromide concentrations in the DRI method (Russell and Minor, 2002). The regional aspect of the model makes it very difficult and costly to collect sufficient detailed data to develop more than coarse estimates of recharge. Recharge models with many uncertain parameters may introduce more uncertainty as variability in each parameter would potentially compound the overall uncertainty in the recharge distribution.

Third, the ME method and to a smaller extent the other methods have depended on a mass balance approach that involves quantification of discharge, which may or may not be accurate. Current studies suggest that the earlier (pre-1980s) estimates of discharge in some locations were low and more recent studies support higher discharge values. The recent discharge estimates may be double, or more, than previous estimates in some cases, which increase the recharge estimates by as much (DOE/NV, 1997). These changes in discharges have been to areas that tend to have a small effect on the total discharge in the Death Valley regional flow system.

\subsection{Summary}

This section summarizes three major methods of estimating recharge for the NTS region and proposes application of the recharge models to subsequent groundwater 
flow modeling activities for the Frenchman Flat CAU. The ME approach is an empirically-derived method relating recharge to precipitation zones from a base precipitation map. Several modified versions of this approach are analyzed, including a model from the original NTS regional groundwater flow modeling results, a revised UGTA ME model using a revised and updated base precipitation map, and the Rush (1970) approach which uses elevation contours instead of precipitation contours to determine zonation for recharge estimates.

The USGS deterministic approach models the processes that affect the net rate of infiltration past the root zone. These parameters include precipitation, evapotranspiration, soil type, percent and type of vegetative cover, bedrock type and numerous other input parameters. The USGS approach has two versions. The first includes the overland flow of excess precipitation and redistribution of this water to downstream areas where it can flow onto more permeable soils and infiltrate in those channel locations. The second version excludes this redistribution and the water is allowed to infiltrate locally.

The DRI chloride mass balance approach estimates recharge by analyzing the chloride ratios of precipitation and groundwater. Higher chloride concentrations in groundwater discharged from springs result from evapotranspiration of precipitation that contains low amounts of conservative atmospheric chloride ion, thus providing a relative gauge for recharge. This information, in conjunction with soil chloride profiles in contrasting terrain (wash versus non-wash), allowed DRI to determine recharge estimates and associated confidence intervals. Two versions of this method are presented, one in which DRI assumed that no recharge was occurring in alluvial deposits (alluvial mask), and the other in which DRI assumed no recharge was occurring in alluvium and up to an elevation of 1,237 m (alluvium and elevation mask).

The UGTA Revised ME method was selected as the base recharge model for use in groundwater flow modeling because, in general, the method yields recharge rates that are within the ranges of the other models. The other alternative methods will also be evaluated during the sensitivity analysis of the CAU groundwater flow model.

Although each method has distinct limitations associated with various steps and assumptions used to determine the resultant recharge, all authors agree that one of the greatest uncertainty can be attributed to the sparsity of precipitation data and length of record over the regional area of investigation. 


\subsection{Surface Groundwater Discharge}

The only mechanism for discharge of groundwater to the surface in the Frenchmen Flat area and vicinity is withdrawal through wells. The purpose, approach, and results of the analysis of the data available on groundwater discharge to the surface in the area of interest are presented in this section.

\subsection{Objectives}

The purpose of this data analysis activity is definition of locations and rates of groundwater discharge to the surface occurring within the Frenchman Flat area and vicinity.

The specific objectives are:

- Identify locations of discharge wells

- Provide historical records of well discharge rates

- Assess and quantify uncertainties in discharge rates

Wells of interest to this activity are only those that pumped or have been pumping for longer than a year. Discharge data collected during short-term pumping such as that conducted during well testing are not included. The approach to analysis of the well discharge data was:

- Compilation of available historical well pumping data

- Assessment of pumping record completeness

- Data types and prioritization

Data types needed for assessment of well discharge are:

- Well identification number

- Well reporting name

- Well coordinates

- Effective open interval

- Date of discharge rate measurement

- Measured discharge rate

The level of documentation (DDE_F [Section 4.3.1]) for most of the well-discharge data is 3 and most of the data are considered to be of high quality. The data type prioritized for this activity is the well discharge rate. 
Surface discharge due to pumping of wells in the Frenchman Flat area and vicinity will not be incorporated into the steady-state predevelopment model of the CAU. Although not used in the model, discharge information is included in this report for several reasons. First, this report summarizes hydraulic data available for Frenchman Flat. Since pumping effects the behavior of the flow systems, it is included for completeness. Second, information regarding pumping in the Frenchman Flat area and vicinity helps in evaluating the changes in water-levels observed in the basin. Third, pumping data are documented in a single location for possible use in future modeling.

\subsection{Description of Available Data}

Groundwater is withdrawn from the Frenchman Flat area and vicinity by 10 NTS water-supply wells. In addition, groundwater was also withdrawn from RNM-2S for 16 years during the CAMBRIC Migration Experiment (CME). The locations of the groundwater pumping wells are provided in Figure 7-1. The analysis included WW-4 and WW-4A in CP Basin and WW-C and WW-C1 in southern Yucca Flat. These wells were included in the analysis because they are close to Frenchman Flat and, based on the hydraulic head analysis (see Section 8.0), help define the regional hydraulic flow.

Pumping data for the NTS water supply wells and RNM-2S are available on a monthly and yearly basis on the USGS website http://nevada.usgs.gov/doe_nv/. These data consists of report date, withdrawal in million gallons, withdrawal in acre-feet, withdrawal in million liters, days reported, and source of water-use data. A summary of the pumping record for each well is presented in Table 7-1 and detailed monthly records for each well are provided in Appendix B, in the pdf version on the $\mathrm{CD}$ only.

It should be noted that for an equivalent time period, the actual net loss by pumping from the Frenchman Flat Basin is probably less than the loss calculated using groundwater withdrawal records. This is because the groundwater pumped by some wells is stored in ponds (Baugh, 2004) that likely leak, which could potentially return a significant amount of water back to the subsurface. A pond associated with WW-5B has been used for the past 14 years and is still in use. Well UE-5c WW had a pond until the late 1980s. During the 16 years of the CME, the water pumped from RNM-2S was discharged to an approximately 1-mile long ditch that flowed into a pond (Bryant, 1992).

Large gaps exist in the pumping records for some of the NTS water-supply wells. Records for WW-5A, WW-5B, and WW-5C are not available from the start of pumping in the well through August 1958, and from July 1967 through December 1982. Data for this latter time period are also not available for Army-1 WW, WW-C, and WW-C1. Annual pumping during these time periods were estimated by the USGS using reported and estimated values from Claassen (1973) or values reported in Moreo et al. (2003). To calculate a monthly volume withdrawn, the annual withdrawal estimated by the USGS minus any known monthly data were assumed to be evenly distributed over the months lacking data. For example, a yearly estimate and monthly data for the first six months are available for 1967. 


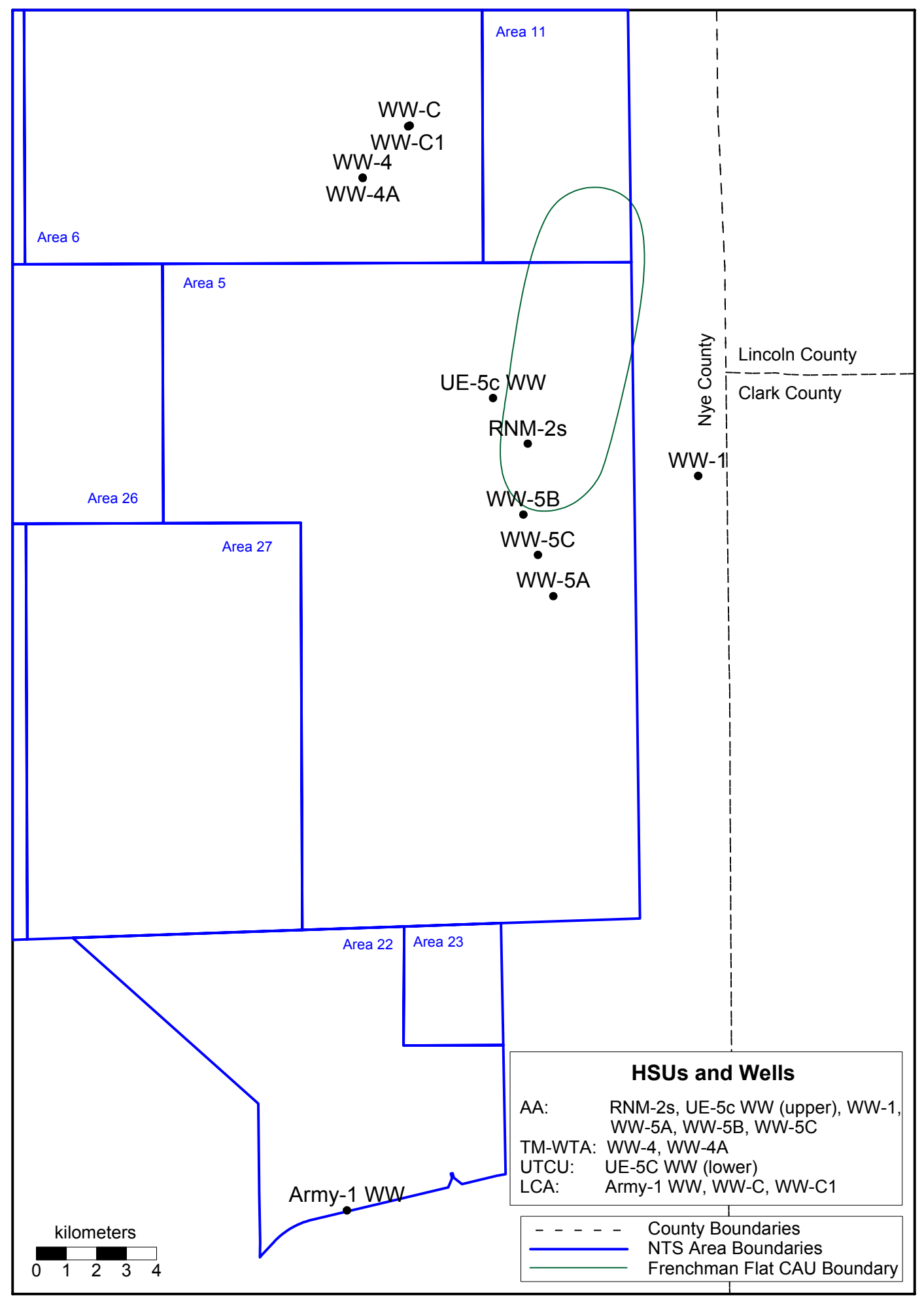

Figure 7-1

Location of Groundwater Pumping Wells in the Frenchman Flat Area and Vicinity 
Table 7-1

Summary of Pumping Data for Wells in Frenchman Flat and Selected Wells in CP Basin and Southern Yucca Flat

\begin{tabular}{|c|c|c|}
\hline Well Name & Period of Record & $\begin{array}{c}\text { Average Discharge Rate (million } \\
\text { gallons per month) }\end{array}$ \\
\hline \hline Army-1 WW & $7 / 1962$ to $12 / 2003$ & 4.9 \\
\hline RNM-2S & $10 / 1975$ to $8 / 1991$ & 23.4 \\
\hline UE-5c WW & $2 / 1967$ to $12 / 2003$ & unknown ${ }^{\text {a }}$ \\
\hline WW-1 & $2 / 1964$ to $3 / 1967$ & 2.9 \\
\hline WW-4 & $1 / 1983$ to $12 / 2003$ & 3.6 \\
\hline WW-4A & $12 / 1993$ to $12 / 2003$ & 4.2 \\
\hline WW-5A & $3 / 1951$ to $12 / 1970$ & 1.1 \\
\hline WW-5B & $5 / 1951$ to $12 / 2003$ & 3.4 \\
\hline WW-5C & $3 / 1954$ to $12 / 2003$ & 3.4 \\
\hline WW-C & $9 / 1961$ to $7 / 1995$ & 2.1 \\
\hline WW-C1 & $6 / 1962$ to $12 / 2003$ & \\
\hline
\end{tabular}

Source: USGS, 2004

ansufficient or no data to calculate monthly total from 7/1967 through 12/1982

To calculate estimated monthly withdrawals for the last six months of 1967, the known monthly withdrawals were subtracted from the estimated annual withdrawal and the resulting volume was divided by six to calculate an estimated monthly withdrawal for the months with no known data. This process is summarized in the following equation:

$$
M U_{w}=\frac{\left(A_{w}-\Sigma M K_{w}\right)}{M U_{n}}
$$

where:

$\mathrm{MU}_{\mathrm{w}}=$ Calculated withdrawal for months without data

$\mathrm{A}_{\mathrm{w}}=$ USGS estimated annual withdrawal

$\mathrm{MK}_{\mathrm{w}}=$ Withdrawal for months with data

$\mathrm{MU}_{\mathrm{n}}=$ Number of months without data

\subsection{Well Discharge}

Groundwater discharge from wells in the Frenchman Flat area and vicinity is discussed in this section. Site information for the pumping wells is summarized in Table 7-2.

\section{Army-1 WW}

Army -1 WW is a water-supply well located southwest of Frenchman Flat on the southern border of Area 22 (see Figure 7-1). This well was completed in July 
Table 7-2

Site Information for Pumping Wells Located in the Frenchman Flat Area and Vicinity

\begin{tabular}{|c|c|c|c|c|c|c|c|c|c|}
\hline Well Reporting Name & $\begin{array}{c}\text { Well } \\
\text { Completion } \\
\text { Date }^{\mathrm{a}}\end{array}$ & $\begin{array}{l}\text { UTM Easting } \\
(\mathbf{m})^{\mathrm{b}}\end{array}$ & $\begin{array}{l}\text { UTM Northing } \\
(\mathrm{m})^{\mathrm{b}}\end{array}$ & 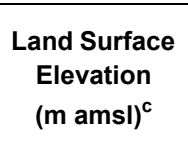 & $\begin{array}{c}\text { Total } \\
\text { Depth } \\
(\mathbf{m} \text { bgs })^{d}\end{array}$ & 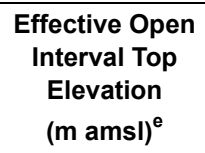 & $\begin{array}{l}\text { Effective Open } \\
\text { Interval Bottom } \\
\text { Elevation } \\
(m \text { ams })^{f}\end{array}$ & $\begin{array}{c}\text { Primary } \\
\text { HSU }^{\mathrm{g}}\end{array}$ & $\begin{array}{c}\text { Secondary } \\
\text { HSU }^{\text {h }}\end{array}$ \\
\hline Army-1 WW & $7 / 15 / 1962$ & $586,119.84$ & $4,049,799.54$ & 9961.1 & $2595.3^{1}$ & $2687.1^{1}$ & $365.8^{1}$ & $\overline{\mathrm{LCA}}$ & \\
\hline RNM-2S & $4 / 1 / 1974^{k}$ & $592,134.10$ & $4,075,477.14$ & 954.2 & $352.4^{k}$ & $734.6^{1}$ & $601.8^{k}$ & $A A^{m}$ & \\
\hline UE-5c WW upper & $11 / 1964^{i}$ & $590,978.01$ & $4,077,005.63$ & 980.3 & $817.5^{\mathrm{k}}$ & $645.0^{j}$ & $584.1^{j}$ & $A A^{m}$ & \\
\hline UE-5c WW lower & $11 / 1964^{i}$ & $590,978.01$ & $4,077,005.63$ & 980.3 & $817.5^{\mathrm{k}}$ & $467.6^{n}$ & $162.8^{n}$ & UTCU $^{m}$ & \\
\hline WW-1 & $1950^{n}$ & $597,789.78$ & $4,074,403.55$ & 944.9 & $265.2^{n}$ & $727.3^{1}$ & $700.5^{n}$ & $\mathrm{AA}^{\mathrm{m}}$ & \\
\hline WW-4 & $11 / 18 / 1981^{\circ}$ & $586,961.76$ & $4,084,575.71$ & $1,097.7$ & $450.8^{j}$ & $824.0^{j}$ & $646.9^{j}$ & TM-WTA $^{\mathrm{m}}$ & TSA/LTCU ${ }^{\mathrm{m}}$ \\
\hline WW-4A & $2 / 21 / 1990^{\circ}$ & $586,647.95$ & $4,084,372.25$ & $1,099.1$ & $462.1^{j}$ & $811.4^{j}$ & $641.3^{j}$ & TM-WTA $^{\mathrm{m}}$ & TM-LVTA/TSA $^{\mathrm{m}}$ \\
\hline WW-5A & $3 / 23 / 1951^{\circ}$ & $592,982.61$ & $4,070,370.54$ & 943.0 & $277.4^{\mathrm{k}}$ & $730.9^{1}$ & $665.6^{p}$ & $\mathrm{AA}^{\mathrm{m}}$ & \\
\hline WW-5B & $5 / 7 / 1951^{q}$ & $591,986.26$ & $4,073,102.55$ & 942.8 & $274.3^{\mathrm{k}}$ & $729.4^{j}$ & $668.5^{j}$ & $\mathrm{AA}^{\mathrm{m}}$ & \\
\hline WW-5C & $3 / 24 / 1954^{\circ}$ & $592,471.81$ & $4,071,751.81$ & 939.7 & $365.8^{k}$ & $669.3^{j}$ & $573.9^{j}$ & $\mathrm{AA}^{\mathrm{m}}$ & \\
\hline WW-C & $3 / 30 / 1961^{r}$ & $588,207.91$ & $4,086,129.96$ & $1,196.1$ & $518.5^{j}$ & $721.1^{j}$ & $677.6^{j}$ & $\mathrm{LCA}^{\mathrm{r}}$ & \\
\hline WW-C1 & $6 / 1962^{i}$ & $588,156.98$ & $4,086,102.86$ & $1,195.9$ & $502.9^{j}$ & $727.6^{1}$ & $693.0^{j}$ & LCA & \\
\hline
\end{tabular}

andicates date completed to HSU for depth-to-water measurements.

bUniversal Transverse Mercator Zone 11, North American Datum 1927 in meters; source is the UGTA Borehole Index Database.

'Land-surface elevation in meters above mean sea level; source is the UGTA Borehole Index Database (NNSA/NSO, 2004).

${ }^{\mathrm{d}}$ Total drilled depth in meters below ground surface.

eEffective open interval top elevation in meters above mean sea level; calculated as land-surface elevation minus depth to top of effective open interval.

${ }^{f}$ Effective open interval bottom in meters above mean sea level; calculated as land-surface elevation minus depth to bottom of effective open interval.

gPrimary hydrostratigraphic unit.

${ }^{\mathrm{h}}$ Secondary hydrostratigraphic unit.

'Hydrogeologic Data from Selected Wells and Test Holes In and Adjacent to the Nevada Test Site, Nye County, Nevada, Through 1986. Freddy E. Arteaga, Charles S. Savard Michael E. Johnson, and J. Christopher Stone. USGS Open File Report 87-536 (USGS, 1991).

'Nevada Test Site Water-Supply Wells. David Gillespie, Dee Donithan, and Paul Seaber (Gillespie et al., 1996).

kIntegrated Analysis Report for Single Multiple-Well Aquifer Testing at Frenchman Flat, Well Cluster RNM-2s, Nevada Test Site, Nevada. Rev. No: 0. Stoller-Navarro, (SNJV, 2004d).

'Defined as the elevation of the steady-state water-level (see Section 8.0)

mHydrostratigraphic Database for Drill Holes in Frenchman Flat Area.

${ }^{n}$ Records of Wells and Test Holes in the Nevada Test Site and Vicinity (through December 1966). William Thordarson, R.Q. Young, and I.J. Winogrd. December 1967.

USGS TEI-872 (Thordarson et al., 1967).

${ }^{\circ}$ Ground-Water Data for the Nevada Test Site and Selected Other Areas in South-Central Nevada, 1992-1993. Steven R. Reiner, Glenn L. Locke, and Leanne S. Robie.

USGS Open-File Report 95-160 (USGS, 1995).

Well Recompletion Report For Water Well 5a Groundwater Characterization Project (IT, 1993)

'Water Wells in Frenchman and Yucca Valleys, Nevada Test Site; Nye County, Nevada. J.W. Hood. 1961. USGS Trace Elements Investigations Report 788 (USGS, 1961).

'Ground Water Test Well C, Nevada Test Site, Nye County, Nevada. M.S. Garber and William Thordarsen. 1962. USGS Report TEI-818 (USGS, 1962 ).

amsl = Above mean sea level

bgs $=$ Below ground surface 
1958 and recompleted to the LCA in July 1962. Pumping of this well began in July 1962. The monthly pumping record for Army-1 WW is shown in Figure 7-2. Monthly pumping was estimated from yearly totals for the last six months of 1962 and for the period July 1967 through December 1982. Pumpage from this well has ranged from zero to 13.9 million gallons per month and has averaged 4.9 million gallons per month. Army-1 WW is an active pumping well.

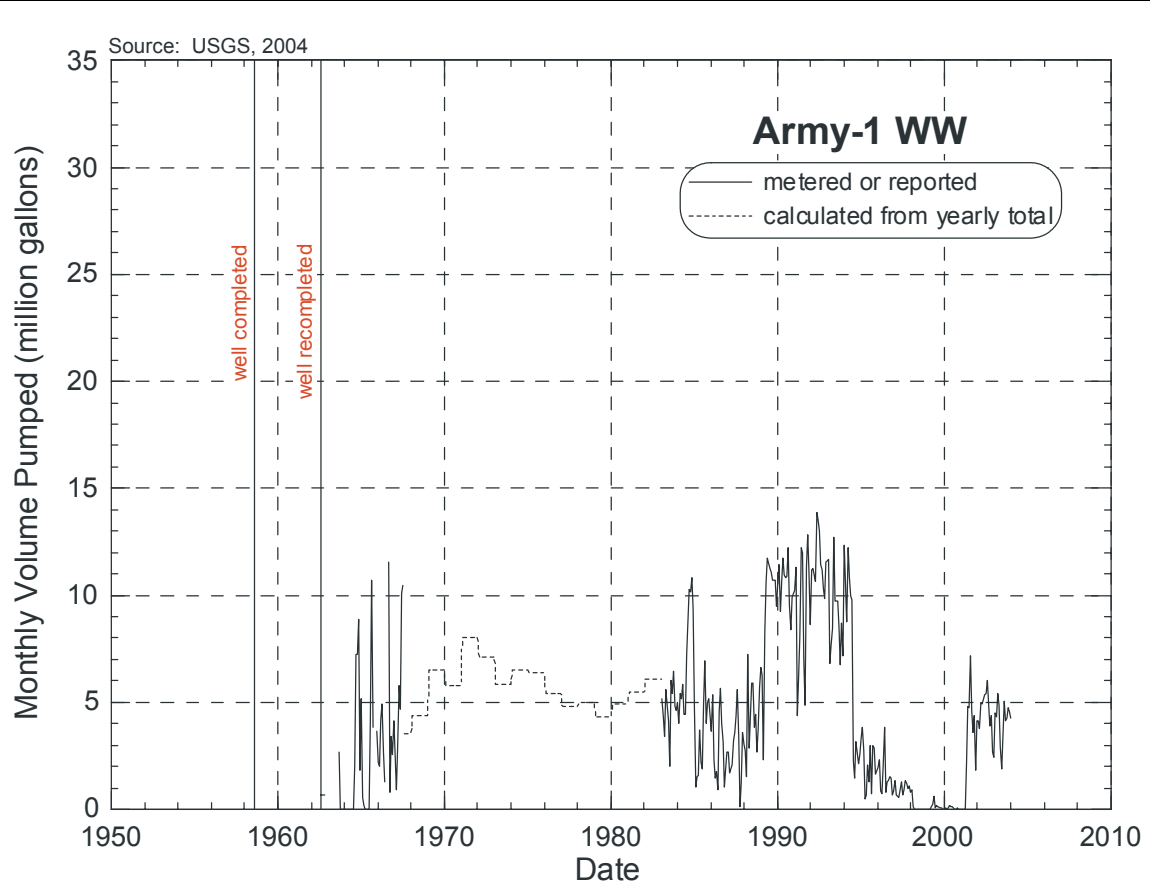

Figure 7-2

Army-1 WW Monthly Pumping History

\section{$R N M-2 S$}

RNM-2S, completed to the AA, is located in central Frenchman Flat (see Figure 7-1). This well was drilled in April 1974 as part of the CME (Bryant, 1992). This experiment was designed to evaluate migration of radionuclides from the CAMBRIC cavity to a nearby well under an artificially induced hydraulic gradient. RNM-2S was pumped from October 1975 to August 1991 at an average rate of about 23 million gallons per month during the experiment. Pumping in the well was suspended for a few days on several occasions as indicated in Table 7-3. The well was sampled on a regular basis for tritium and other radioactive species. The monthly pumping record for RNM-2S is shown in Figure 7-3. Pumpage from this well ranged from 0 to 31.2 million gallons per month. The rate of groundwater withdrawal from RNM-2S was significantly higher than that from any other pumping well in the Frenchman Flat area and vicinity (see Table 7-1). RNM-2S is currently (as of the Spring 2004) inactive as a pumping well. 


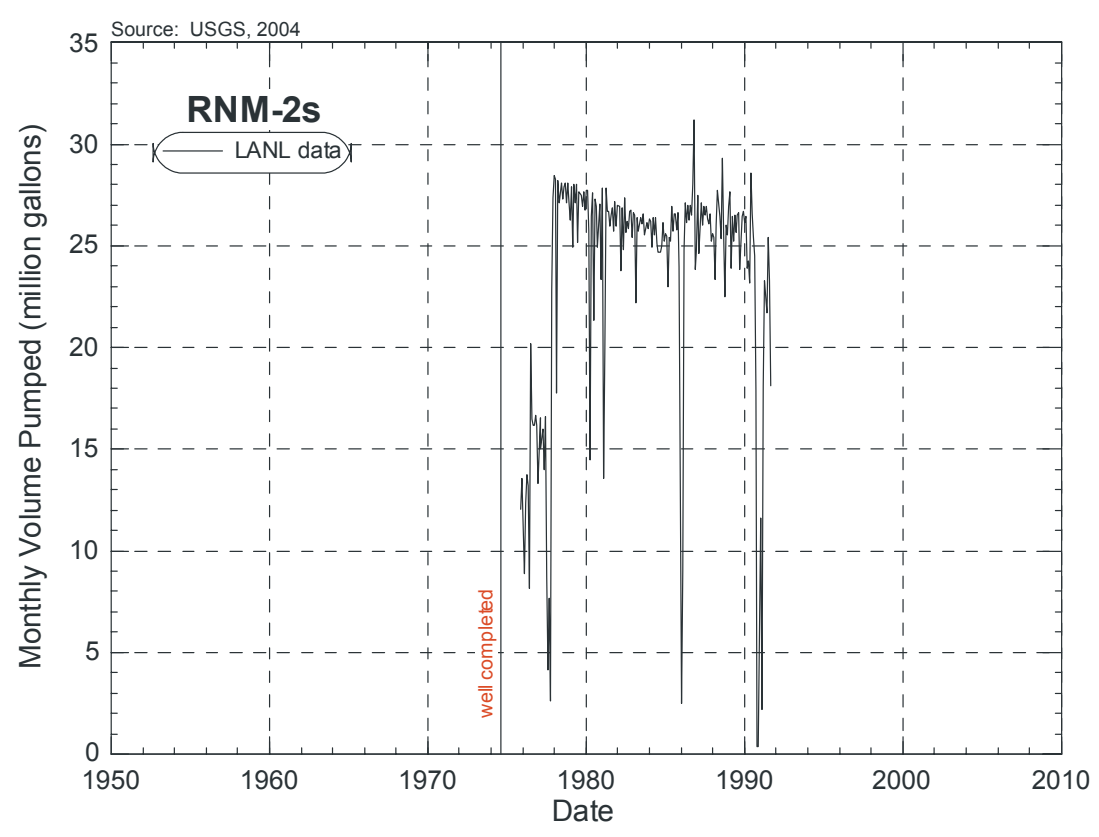

Note: LANL data $=$ Data supplied by Los Alamos National Laboratory (LANL) as it appears on the referenced USGS/DOE website

Figure 7-3

RNM-2S Monthly Pumping History

Table 7-3

Pump Shut-Down Dates for RNM-2S During the CME

\begin{tabular}{|c|c|c|}
\hline Date Pump Turned Off & $\begin{array}{c}\text { Date Pump } \\
\text { Turned On }\end{array}$ & Number of Days Pump Off \\
\hline \hline $3 / 7 / 1980$ & $3 / 24 / 1980$ & 17 \\
\hline $6 / 6 / 1980$ & $6 / 16 / 1980$ & 10 \\
\hline $11 / 10 / 1980$ & $11 / 19 / 1980$ & 9 \\
\hline $1 / 13 / 1981$ & $2 / 10 / 1981$ & 28 \\
\hline
\end{tabular}

Source: Bryant, 1992

\section{$U E-5 c W W$}

UE-5c WW is located in central Frenchman Flat (see Figure 7-1). This well was drilled in November 1964. UE-5c WW has two open intervals; an upper interval completed to the AA and a lower interval completed to the UTCU. The exact date at which pumping of this well began is unknown due to insufficient data. Pumping records are available from February 1967 through June 1967, and January 1983 through the present (Spring 2004). The pumping record for UE-5c WW is shown in Figure 7-4. Pumpage from this well has ranged from zero to 6.7 million gallons per month based on the available data. The lack of data for this well prevents determination of an average pumping rate. The volume of 


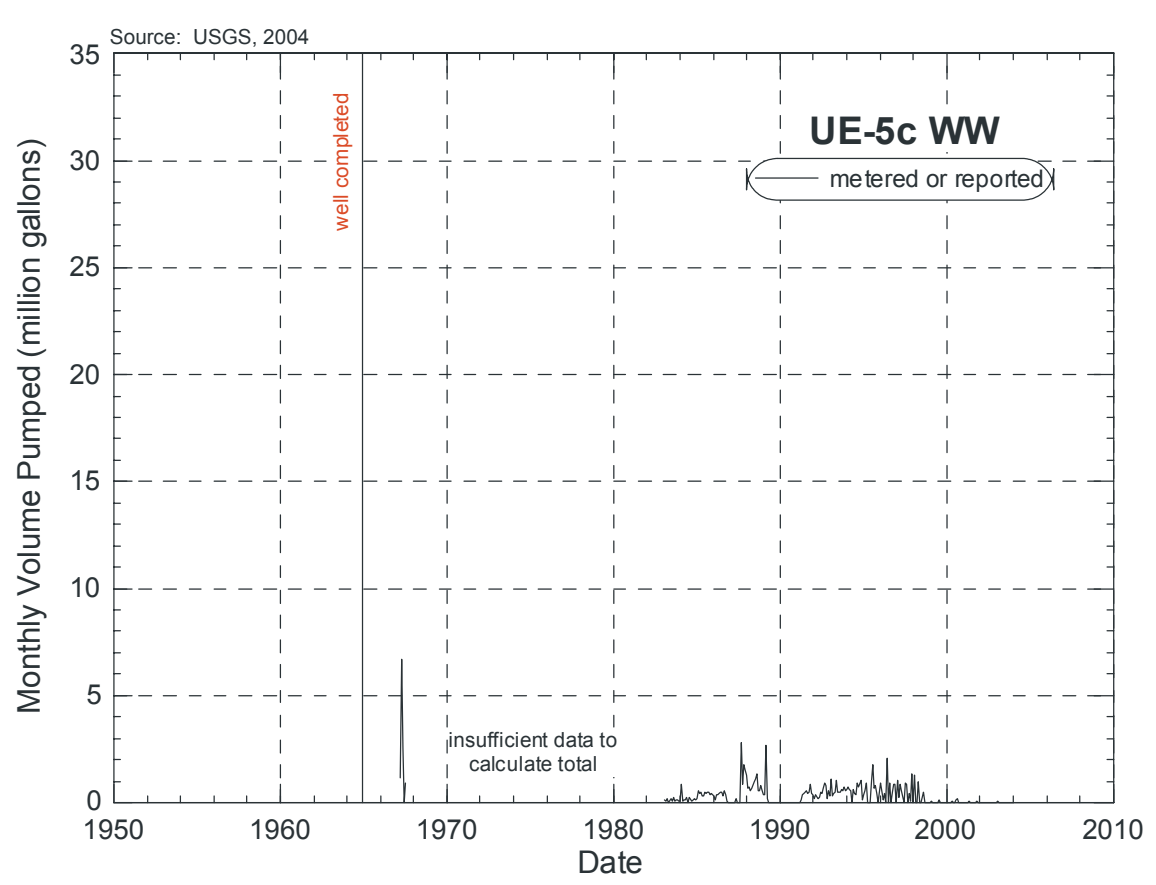

Figure 7-4

UE-5c WW Monthly Pumping History

groundwater withdrawal from this well is smaller than for any other pumping well in the Frenchman Flat area and vicinity. UE-5c WW is considered an active pumping well although the data shows that very little groundwater has been withdrawn from this well since August 1998.

\section{$W W-1$}

WW-1 is a water-supply well located east of Frenchman Flat (see Figure 7-1). This well was completed in 1950 to the AA. The exact date pumping began in WW-1 is unknown. Pumping records are available for this well only from February 1964 to March 1967 (Figure 7-5). Pumpage from this well has ranged from zero to 8.3 million gallons per month and has averaged 2.9 million gallons per month based on the available data. WW-1 is currently inactive.

\section{$W W-4$}

WW-4 is a water-supply well located in CP Basin northwest of Frenchman Flat in Area 6 (see Figure 7-1). This well was completed in November 1981 and is open across the lower $89 \mathrm{~m}$ of the TM-WTA and the underlying TM-LVTA, TSA, and LTCU. Pumping of this well began in January 1983 according to the data. The pumping record for WW-4 is shown in Figure 7-6. Pumpage from this well has ranged from zero to 25.6 million gallons per month and has averaged 3.6 million gallons per month. WW-4 is an active pumping well. 


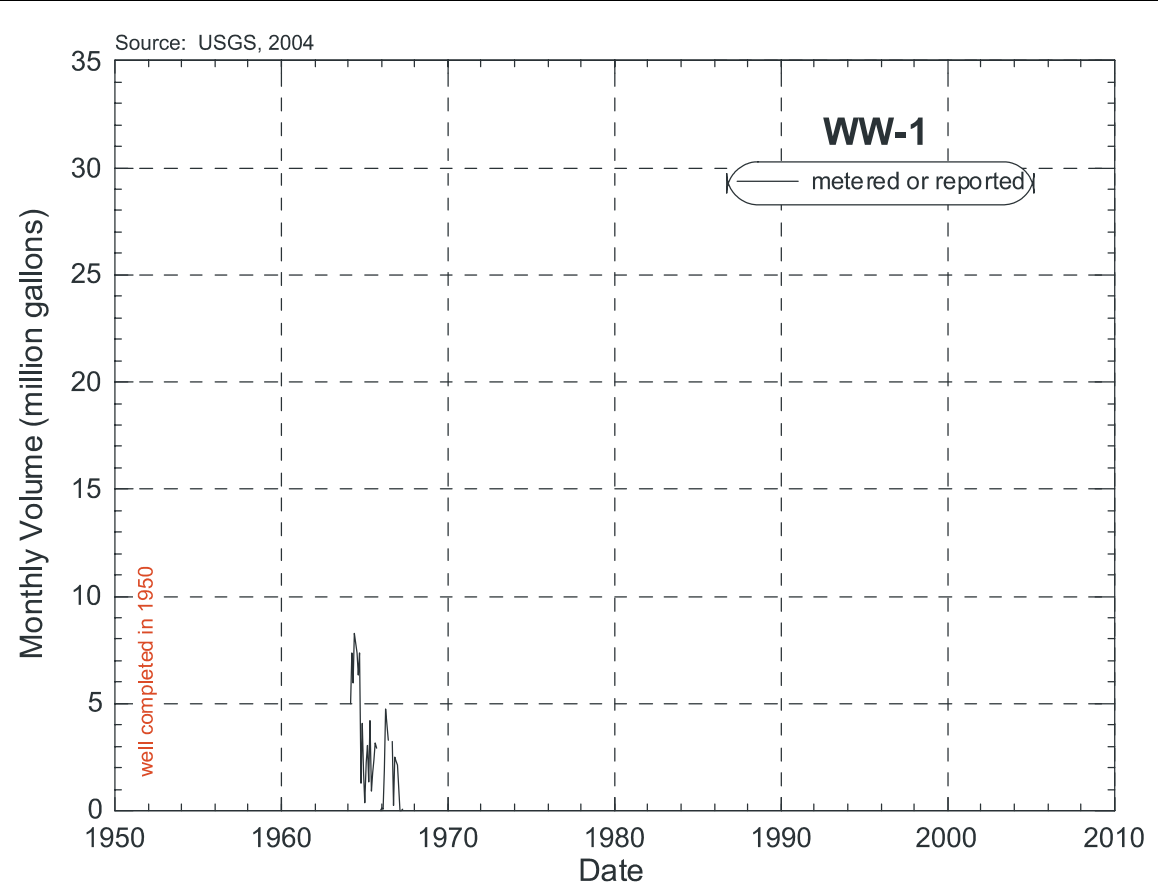

Figure 7-5

WW-1 Monthly Pumping History

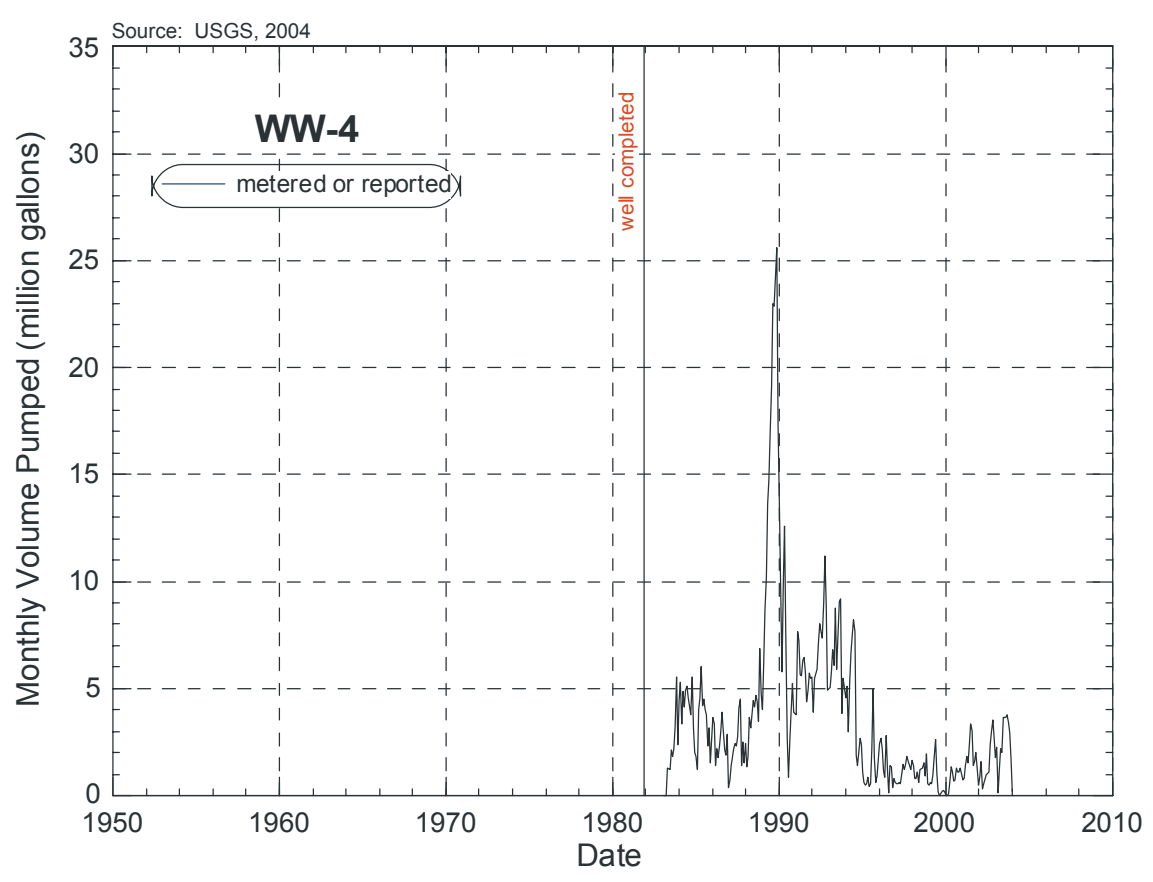

Figure 7-6

WW-4 Monthly Pumping History 


\section{$W W-4 A$}

WW-4A is a water-supply well located in CP Basin northwest of Frenchman Flat in Area 6 (see Figure 7-1). This well was completed in February 1990 and is open across the lower $99 \mathrm{~m}$ of the TM-WTA, the underlying TM-LVTA and TSA, and the upper $16 \mathrm{~m}$ of the LTCU. According to the available data, pumping in WW-4A began in December 1993. The pumping record for this well is shown in Figure 7-7. Pumpage from WW-4A has ranged from zero to 10.9 million gallons per month and has averaged 4.2 million gallons per month. WW-4A is an active pumping well.

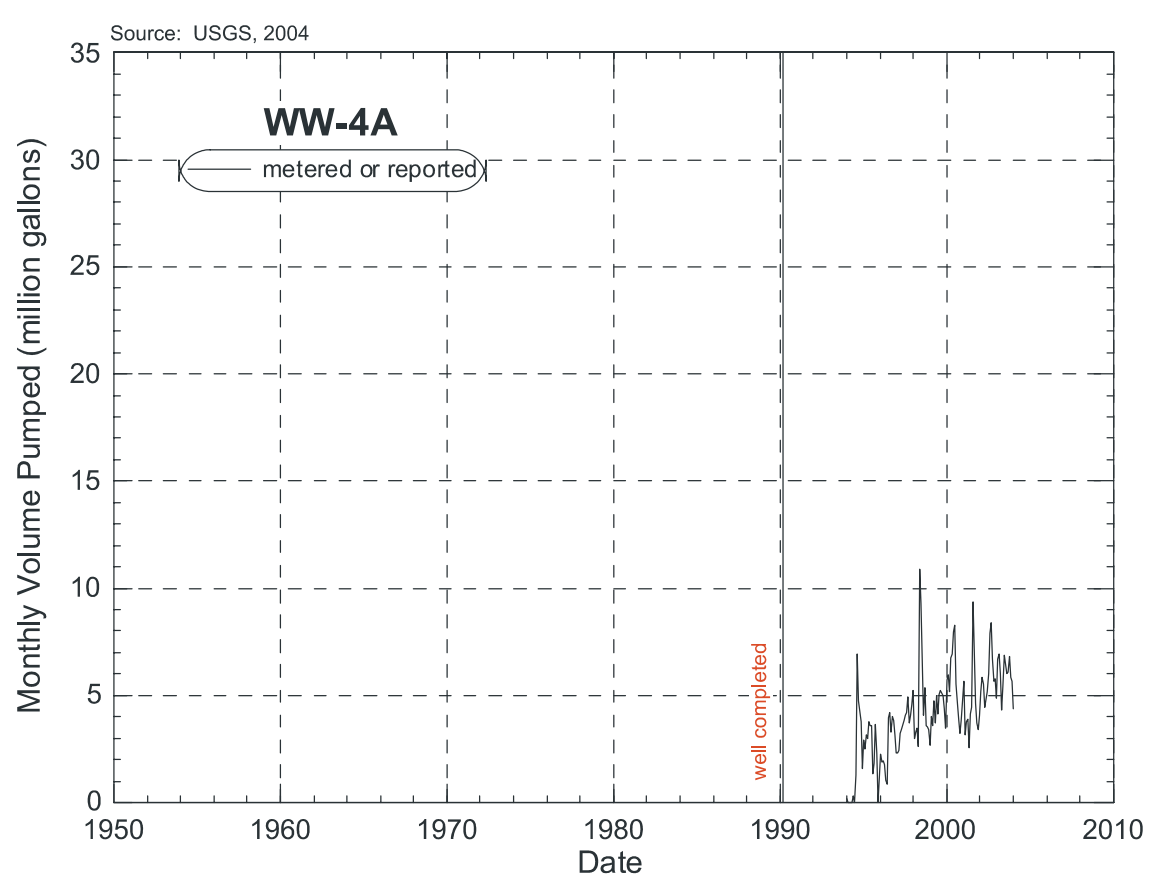

Figure 7-7

WW-4A Monthly Pumping History

\section{WW-5A}

WW-5A is a water-supply well located in central Frenchman Flat (see Figure 7-1). This well was completed to the AA in March 1951. According to the available data, pumping in WW-5A began in March 1951 and continued until December 1970. The pump in this well was removed in July 1971. The monthly pumping record for WW-5A is shown in Figure 7-8. Monthly pumping was estimated from yearly totals for the period from March 1951 through August 1958 and again for July 1967 through December 1970. Pumpage from WW-5A ranged from zero to 4.3 million gallons per month and averaged 1.1 million gallons per month. No pumping is reported for WW-5A since 1970 . WW-5A is currently inactive. 


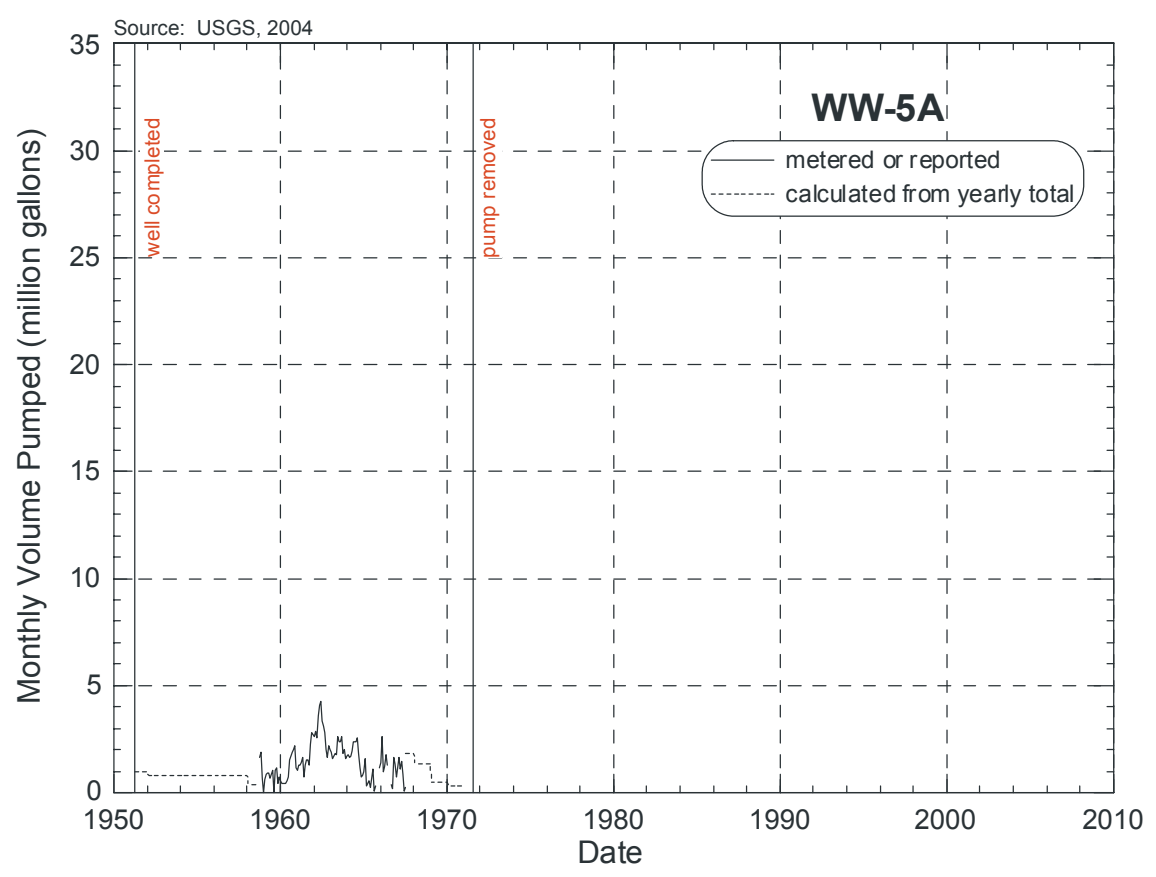

Figure 7-8

WW-5A Monthly Pumping History

$W W-5 B$

WW-5B is a water-supply well located in central Frenchman Flat (see Figure 7-1). This well was completed to the AA in May 1951. Pumping of this well began in May 1951 according to the available data. The monthly pumping record for WW-5B is shown in Figure 7-9. Monthly pumping was estimated from yearly totals for the periods from May 1951 through August 1958, and again for July 1967 through December 1970. Pumpage from WW-5B has ranged from zero to 10.0 million gallons per month and has averaged 2.4 million gallons per month. WW-5B is an active pumping well.

\section{$W W-5 C$}

WW-5C is a water-supply well located in central Frenchman Flat (see Figure 7-1). This well was completed to the AA in March 1954. Pumping of this well began in March 1954 according to the available data. The monthly pumping record for WW-5C is shown in Figure 7-10. Monthly pumping was estimated from yearly totals for the periods from March 1954 through August 1958 and again for July 1967 through December 1982. Pumpage from WW-5C has ranged from zero to 9.7 million gallons per month and has averaged 3.3 million gallons per month. WW-5C is an active pumping well.

\section{$W W-C$}

WW-C is a water-supply well located in southern Yucca Flat northwest of Frenchman Flat in Area 6 (see Figure 7-1). This well was initially completed to 


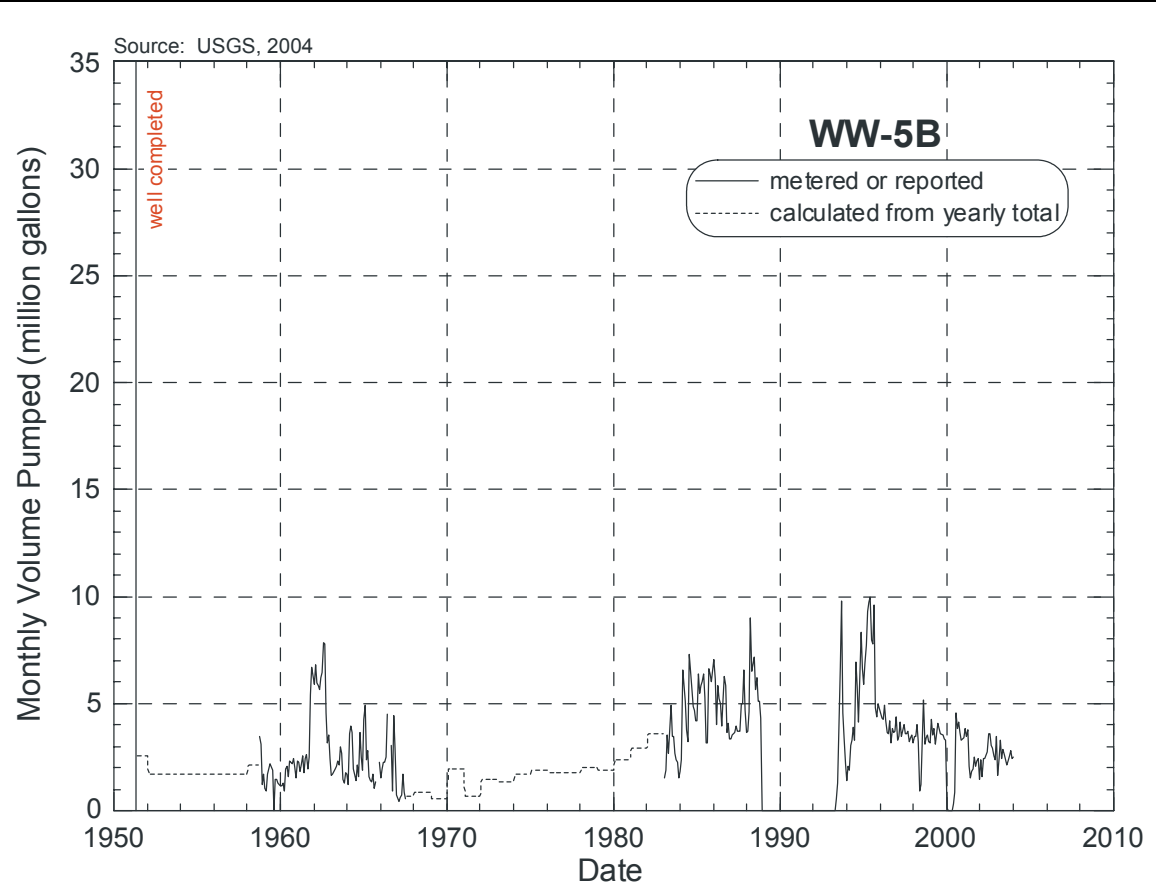

Figure 7-9

WW-5B Monthly Pumping History

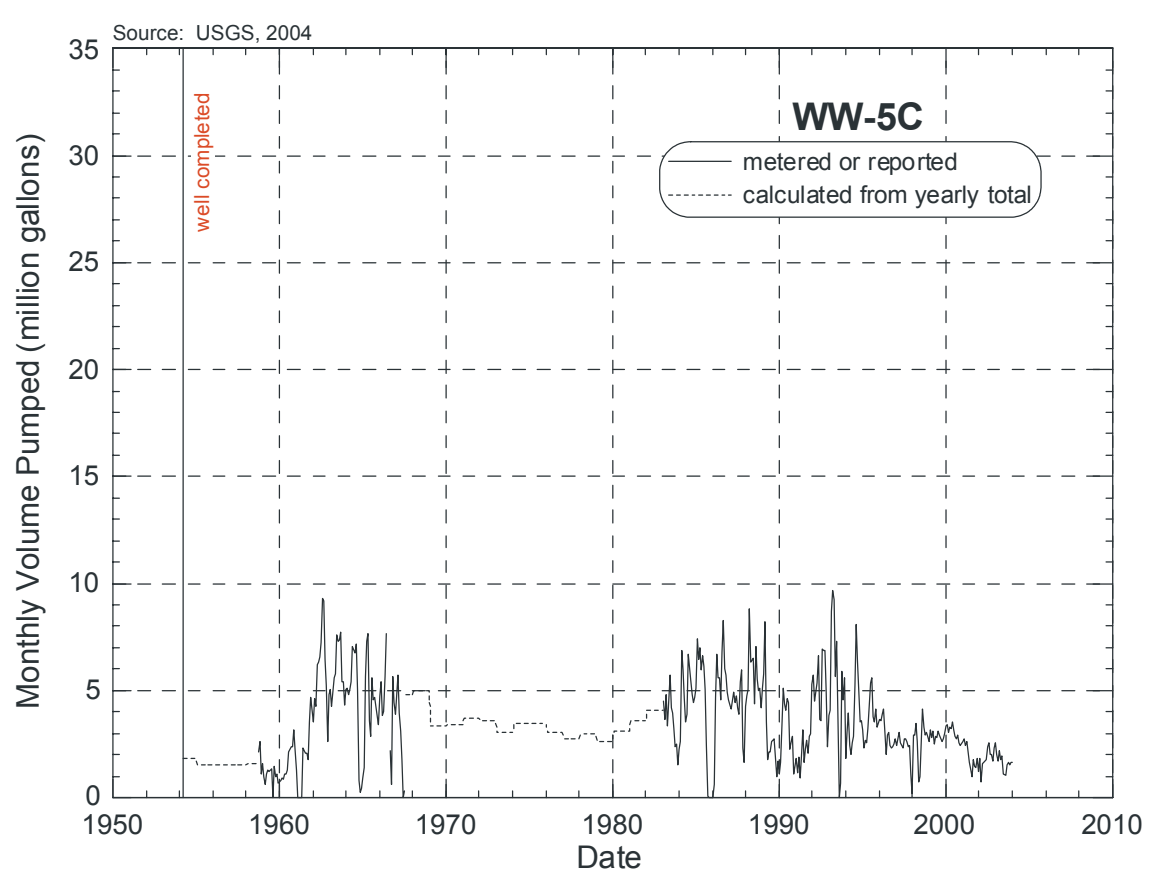

Figure 7-10

WW-5C Monthly Pumping History 
the LCA in March 1961 and recompleted in the LCA in April 1967. Pumping of this well began in September 1961 according to the available data. The monthly pumping record for WW-C is shown in Figure 7-11. Monthly pumping was estimated from yearly totals for the time period from July 1967 through December 1982. Pumpage from WW-C has ranged from zero to 11.4 million gallons per month and has averaged 3.4 million gallons per month. WW-C is currently inactive.

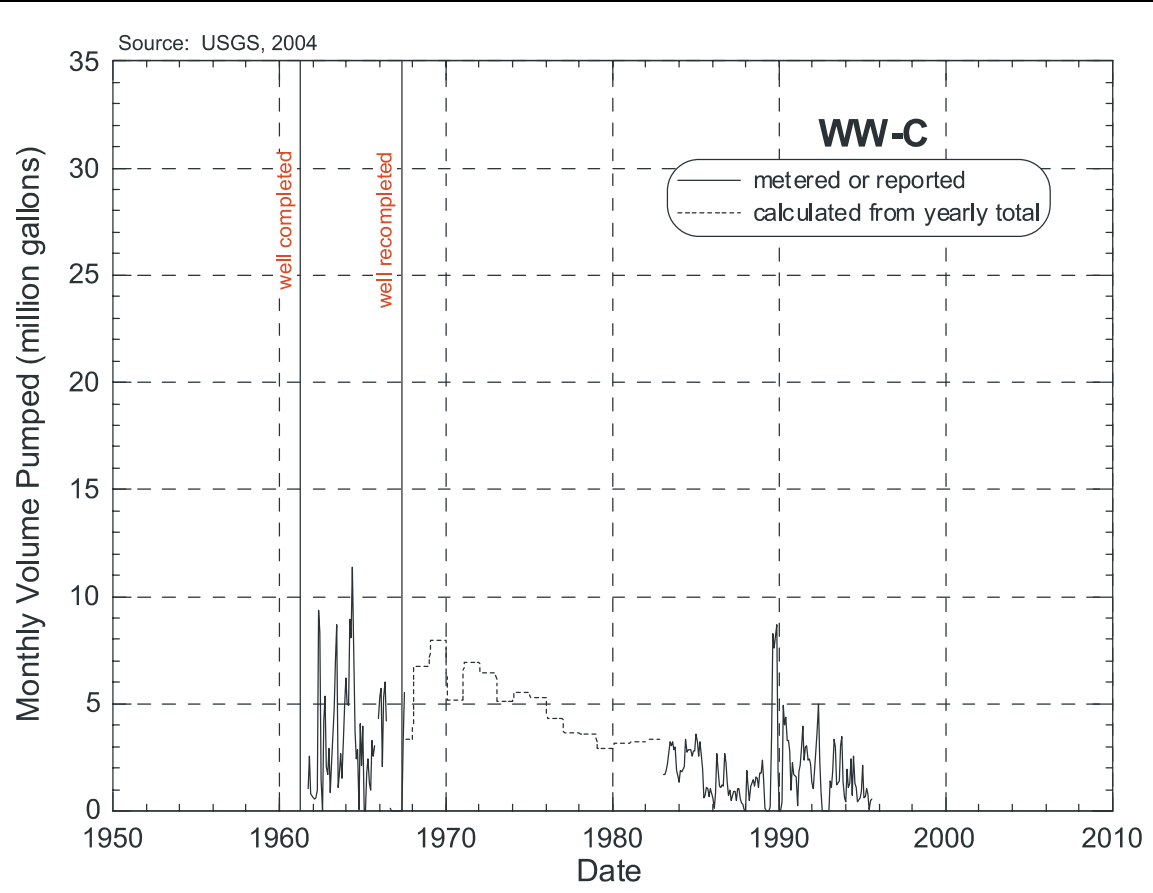

Figure 7-11

WW-C Monthly Pumping History

\section{$W W-C 1$}

WW-C1 is a water-supply well located in southern Yucca Flat northwest of Frenchman Flat in Area 6 (see Figure 7-1). This well was completed to the LCA June 1962. According to the available data, pumping of this well began in June 1962. The monthly pumping record for WW-C1 is shown in Figure 7-12.

Monthly pumping was estimated from yearly totals for the time period from July 1967 through December 1982. Pumpage from WW-C1 has ranged from zero to 11.7 million gallons per month and has averaged 2.1 million gallons per month. WW-C1 is an active pumping well.

\section{All Wells}

Total water withdrawal from wells in the Frenchman Flat area and vicinity is illustrated in Figure 7-13. Totals are shown for all wells combined and also for just the water-supply wells (i.e., RNM-2S not included). Due to the large volumes pumped from RNM-2S during the CME, surface discharge of water was greatest during that time. Water pumped from RNM-2S during the CME was discharged 


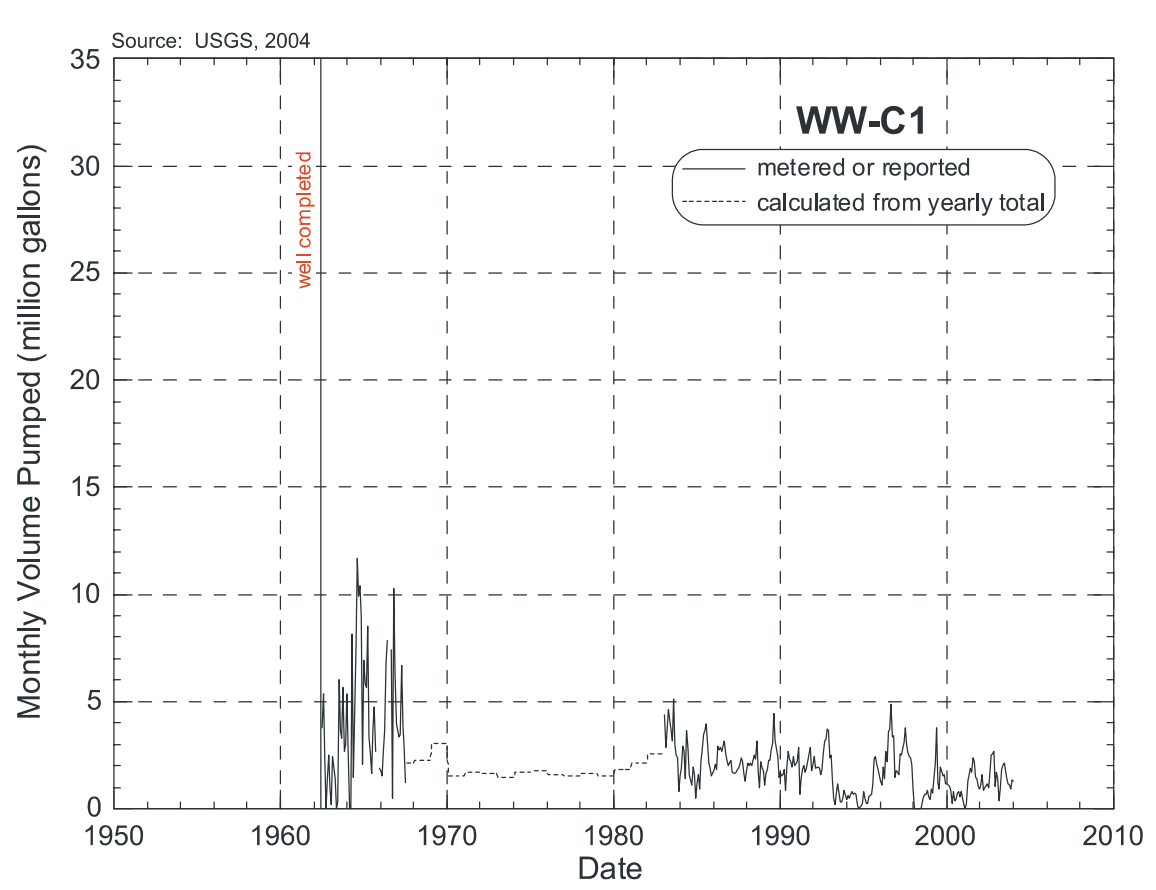

Figure 7-12

WW-C1 Monthly Pumping Data

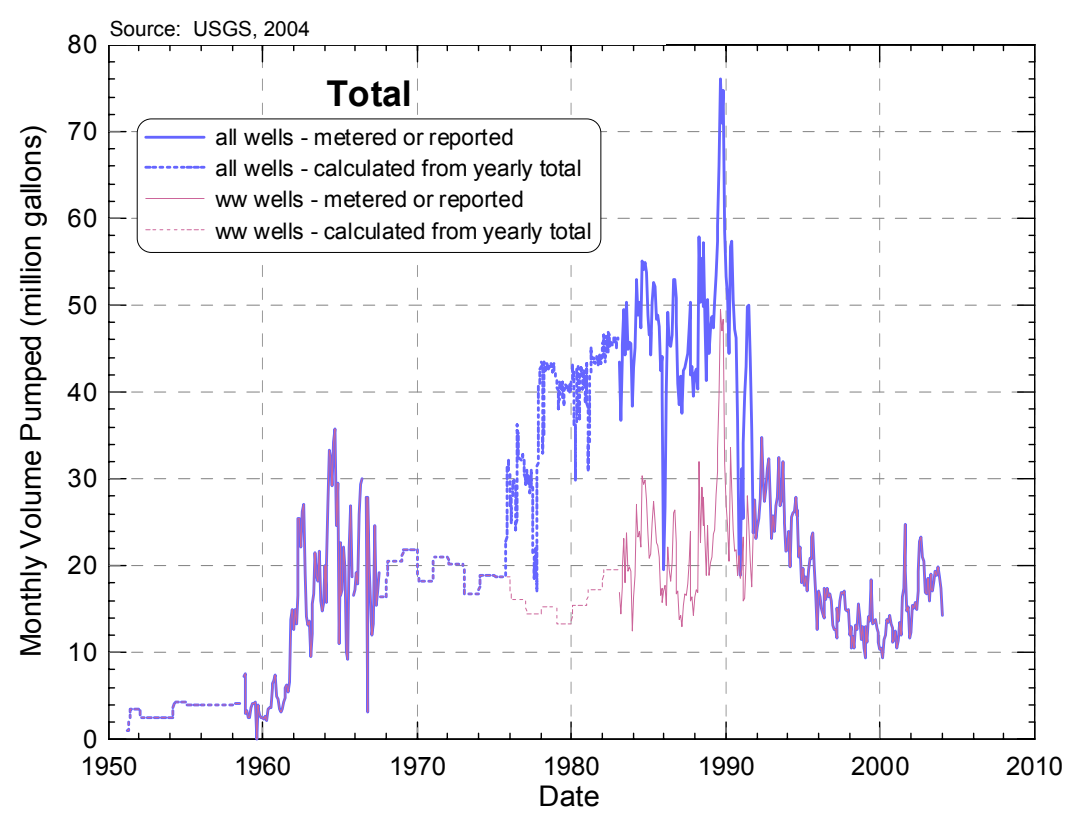

Figure 7-13

Total Water Withdrawal from Wells in the Frenchman Flat Area and Vicinity 
to a ditch running from the location of the experiment to a pond located southeast of the site. Researchers estimate that some of the water in the ditch and pond infiltrated back into the subsurface (Buddemeir and Isherwood, 1985; Buddemeir, 1988). Therefore, the actual net loss of water from the basin due to pumping for the CME is probably less than the loss calculated from groundwater project records.

Based on production from the water-supply wells only, groundwater withdrawal peaked during the mid-1960s and then decreased. Another peak in withdrawal occurred in the late 1980s and early 1990s. Water withdrawal via pumping declined between the early 1990s and about 2000 and has slightly increased since that time.

\subsection{Limitations}

Limitations associated with the well discharge data are missing pumping records for the NTS water-supply wells from July 1967 through December 1982. The wells affected by this gap in data are Army-1 WW, UE-5c WW, WW-5A, WW-5B, WW-5C, WW-C, and WW-C1. Wells WW-4 and WW-4A are not affected by this gap because they were not completed until after December 1982. A gap in data also exists for WW-5A, WW-5B, and WW-5C from the time the well was completed until August 1958.

For most of the history of WW-1, it was unknown whether the well was available or used for water supply according to the USGS website. Therefore, the pumping data for this well is very uncertain.

The actual net loss of water from the basin is unknown. Water pumped from RNM-2S during the CME was discharged to surface impoundments. In addition, some of the water pumped from WW-5B over the past 14 years and from UE-5c WW until the late 1980s was also discharge to surface impoundments (Baugh, 2004). The amount of water that infiltrated back into the subsurface from these impoundments is unknown.

\subsection{Summary}

The only mechanism by which groundwater discharges to the surface in the Frenchman Flat area and vicinity is withdrawal from wells. Water is, or has been, pumped from the AA by six wells, from the TM-WTA by two wells, and from the LCA by three wells. All of these wells are NTS water-supply wells with the exception of RNM-2S, which was pumped for 16 years as part of the CME.

The largest volume of groundwater removal from the subsurface occurred as a result of pumping RNM-2S for the CME. However, some of that discharged water may have returned to the subsurface via infiltration from the ditch and pond into which the pumped water was disposed (see Section 6.0). 
In general, groundwater withdrawal in the Frenchman Flat area and vicinity increased from the early 1950s to the mid-1960s. The variability between 1968 and 1976 (approximately eight years) is unknown since withdrawals during that time are estimated. A large increase in groundwater discharge occurred between about 1976 and 1990. The discharge volume decreased significantly from 1990 to 2000 and has slightly increased since that time.

A majority of the pumping data have been determined by the USGS from water production reports provided by Bechtel Nevada or REECo. The quality of that data is considered to be high. In some cases, the pumping data were estimated by the USGS from values reported in the literature. This applies to all data for the water-supply wells from July 1967 through December 1982. For the three water-supply wells completed prior to August 1958, this also includes the time period from well completion to August 1958. All of the estimated data are considered to be uncertain. 


\subsection{Hydraulic Heads}

Potentiometric data for the Frenchman Flat area and vicinity were analyzed to support development of a steady-state CAU groundwater flow model for Frenchman Flat. Observed hydraulic heads are derived from depth-to-water measurements and well information. This section provides a description of the objectives of the potentiometric data analysis including the data types and their prioritization, data compilation and evaluation, data analysis, and analysis results.

\subsection{Objectives}

The purpose of this data analysis activity was to evaluate the existing potentiometric data for use in the CAU-scale steady-state groundwater flow model for the Frenchman Flat area.

The specific objective was to determine representative steady-state hydraulic heads for the Frenchman Flat area and vicinity from the available potentiometric data, for use in interpretation of flow direction and gradient, and for flow model calibration. In addition, an attempt was made to evaluate the groundwater flow system behavior under both steady-state and transient conditions in support of the groundwater flow modeling of the Frenchman Flat area.

During steady-state conditions, all aspects of groundwater flow remain constant, including recharge, discharge, water-level elevations and geochemical properties. Geochemical data from the NTS suggest that groundwater flow in the Frenchman Flat basin was not at steady state even before human activities (pumping and underground testing) began in the area. Consequently, data are not available for determining flow conditions and hydraulic heads in the basin that are representative of true steady state. Although true steady state could not be determined, calibration of the steady-state model for the CAU requires observed heads to which simulated heads can be compared. For the purposes of this analysis, every attempt was made to select heads representative of stable flow conditions in the basin for use in the model calibration. Stable flow conditions are considered to be those under which the water level remains reasonably constant. In the remainder of this section, the term steady state is used to describe the heads, and associated flow, under stable conditions even though these heads and flow do not represent true steady state.

The wells in the Frenchman Flat area and vicinity for which water-level data were analyzed are shown in Figure 8-1. Representative heads were determined for two different conditions in the Frenchman Flat basin; prior to groundwater development and contemporary. This is discussed in detail in Section 8.5. 


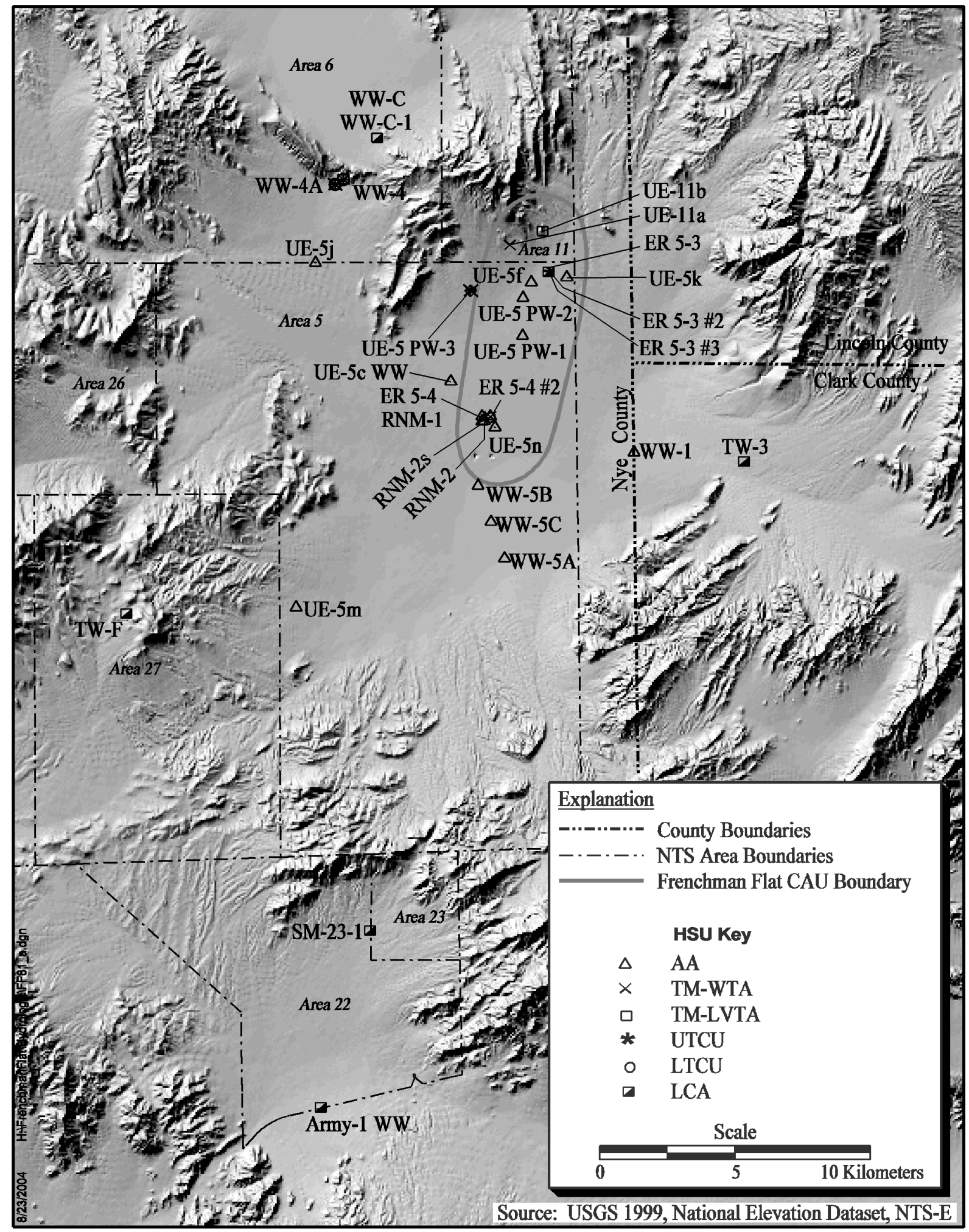

Figure 8-1

Location of Wells in the Frenchman Flat Area and Vicinity 


\subsection{Approach}

The approach used to analyze the available potentiometric data was:

- Collect, compile, and qualify existing potentiometric data for the Frenchman Flat area and vicinity, including depth-to-water measurements.

- Analyze temporal trends in the potentiometric data using hydrographs and statistical analysis of the water elevations.

- Identify a subset of the hydraulic head data that is representative of steady-state conditions for the Frenchman Flat area and vicinity; this dataset includes the location of the measurement point, the water-level elevation and associated uncertainty, and the HSU(s) represented.

- Create potentiometric-surface maps, if possible, using the steady-state hydraulic head dataset for the Frenchman Flat area and vicinity.

- Analyze vertical gradients, if possible, using the steady-state hydraulic head dataset for the Frenchman Flat area and vicinity.

- Identify and evaluate transient responses to groundwater pumping based on the hydrograph analysis.

\subsection{Data Types and Prioritization}

The data types needed and their prioritization for quality evaluation are presented in this section.

Data needed to assess hydraulic heads include general site information, depth-to-water data, well construction information, and hydrostratigraphic information for the Frenchman Flat area and vicinity. A site is defined as a well, a test hole, or a separate completion zone within a well. The data types needed are:

\section{General Site Information}

- Unique site identifier

- Site location

- Land-surface elevation

- Uncertainty in land-surface measurement

\section{Depth-to-Water Data}

- Depth-to-water measurement

- Date of measurement

- Site status at the time of the depth-to-water measurement

- Status of nearby sites at the time of the depth-to-water measurement

- Water temperature 
- Accuracy of the depth-to-water measurement

\section{Well Construction Information}

- Total depth of well

- Slotted casing interval(s) (top and bottom)

- Gravel/sand pack interval(s) (top and bottom)

- Well deviation

- Open hole interval(s) (top and bottom)

\section{Stratigraphic/Hydrostratigraphic Data}

- Well hydrostratigraphy

- Well stratigraphy

- Well lithology

- Source hydrostratigraphic unit

Measurements of land surface-elevation and depth-to-water are the primary data required to calculate hydraulic heads. The additional data are used for site description, data qualification, uncertainty evaluation, and HSU assignment. The well construction data are used to identify the effective open interval (EOI).

\subsection{Data Compilation and Evaluation}

Well data for the Frenchman Flat area and vicinity were obtained from several sources. The USGS National Water Information System (NWIS) on-line database was the primary source of this data (USGS, 2001). Additional data were obtained from the USGS and DOE Nevada website (USGS, 2004), NTS reports including the Potentiometric Data Documentation Package (IT, 1996c), and depth-to-water measurement forms from the UGTA Project records. More than 1,280 depth-to-water records were compiled and analyzed for 28 sites as part of this study. The period of record spans from 1951 to Spring 2004. The number of records available for each site ranges from 1 to 139 .

The following text describes the well data relevant for the hydraulic head analysis.

\subsubsection{Depth-to-Water Data}

Depth-to-water measurements are available for 34 wells or separate well completion intervals in the Frenchman Flat study area. Note that 37 completions are given in Table 8-1 because the upper and lower completion intervals are listed for three wells (ER-5-3, ER-5-4, and UE-5cWW) even though only one composite water-level is obtained from these wells. During analysis of these water-levels, 17 wells or completions were selected as appropriate for estimating steady-state hydraulic heads representative of predevelopment conditions in the Frenchman Flat area and vicinity. 


\subsubsection{General Site Information}

General site information for wells, boreholes, or completions, is presented in Table 8-1. The general site information of interest includes location, land-surface elevation, well construction, and hydrostratigraphy. The latter two are used to identify the EOI and the HSU for each site. Also included in Table 8-1 are the well completion dates. These dates were used to evaluate depth-to-water data relative to drilling activities in the well or in nearby wells.

\subsubsection{Land-Surface Elevation}

Land-surface elevations at well locations have been determined using a wide variety of methods ranging from reading them off of a topographic map to the use of a global positioning system. The level of documentation (DDE_F

[Section 4.3.1]) for all land-surface elevations is a Level 5 documentation qualifier due to the lack of standard procedures and documentation for these measurements.

\subsubsection{Effective Open Interval Definition}

Well construction data were used to identify the EOI for a given site. The EOI and stratigraphy information were then used to identify the HSU(s) or units associated with each site. The process of defining an EOI is described below. The EOIs for the wells in the Frenchman Flat area and vicinity are provided in Table 8-1.

Well construction data of primary interest are the depths to the top and bottom of open intervals or the total depth for open boreholes. The term "open interval" refers to any type of opening through which water may flow from the rock formation into the borehole. Examples of open intervals include open boreholes (uncased) or the intervals in which well screens and perforated casing are gravel packed.

An EOI was defined for each site for which well construction data are available. Determination of the top of the EOI was based upon whether the water-level was above or below the top of the open interval. The bottom of the EOI was defined as the bottom of the open interval. If the average water-level was below the top of the open interval, the top of the EOI was defined as the average depth-to-water and the bottom of the EOI was defined as the greater of the depths to either the bottom of the screen or gravel pack. If the average water-level was above the top of the open interval, then the top of the EOI was defined as the top of the open interval and the bottom of the EOI was defined as the greater of the depths to either the bottom of the screen or gravel pack. For cases where the borehole was open, the EOI was defined as the length of the saturated thickness. 
Table 8-1

Site Information for Selected Wells and Boreholes Located in the Frenchman Flat Area and Vicinity (Page 1 of 2)

\begin{tabular}{|c|c|c|c|c|c|c|c|c|c|}
\hline $\begin{array}{l}\text { Well Reporting } \\
\text { Name }\end{array}$ & $\begin{array}{c}\text { Well } \\
\text { Completion } \\
\text { Date }^{a}\end{array}$ & $\begin{array}{l}\text { UTM Easting } \\
\qquad(\mathrm{m})^{\mathrm{b}}\end{array}$ & $\begin{array}{l}\text { UTM Northing } \\
(\mathrm{m})^{\mathrm{b}}\end{array}$ & $\begin{array}{c}\text { Land- } \\
\text { Surface } \\
\text { Elevation. } \\
\text { (m amsl) }^{c}\end{array}$ & $\begin{array}{c}\text { Total } \\
\text { Depth } \\
(\mathbf{m} \text { bgs })^{d}\end{array}$ & $\begin{array}{l}\text { Effective Open } \\
\text { Interval Top } \\
\text { Elevation } \\
\text { (m amsl) }^{\mathrm{e}}\end{array}$ & $\begin{array}{c}\text { Effective Open } \\
\text { Interval Bottom } \\
\text { Elevation } \\
(m \text { amsl })^{f}\end{array}$ & $\begin{array}{c}\text { Primary } \\
\text { HSU }^{9}\end{array}$ & $\begin{array}{c}\text { Secondary } \\
\text { HSU }^{\mathrm{h}}\end{array}$ \\
\hline Army-1 WW & $7 / 15 / 1962^{p}$ & $\overline{586,119.84}$ & 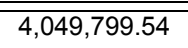 & 961.13 & $2595.3^{j}$ & $\overline{6687.1^{j}}$ & $365.8^{j}$ & 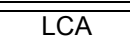 & \\
\hline ER 5-3 (3" deep) & $3 / 16 / 2000^{k}$ & $594,575.20$ & $4,081,314.60$ & $1,017.24$ & $681.2^{k}$ & $409.1^{\mathrm{k}}$ & $336.0^{k}$ & TM-WTA' & $\mathrm{AA}^{\prime}$ \\
\hline ER 5-3 (3" shallow) & $3 / 16 / 2000^{k}$ & $594,575.20$ & $4,081,314.60$ & $1,017.24$ & $329.2^{\mathrm{k}}$ & $734.7^{\mathrm{m}}$ & $688.0^{k}$ & $A A^{\prime}$ & BLFA' $^{\prime}$ \\
\hline ER 5-3 upper (main) & $3 / 16 / 2000^{k}$ & $594,575.20$ & $4,081,314.60$ & $1,017.24$ & $794.3^{k}$ & $576.5^{\mathrm{k}}$ & $474.0^{k}$ & OAA $^{\prime}$ & \\
\hline ER 5-3 lower (main) & $3 / 16 / 2000^{k}$ & $594,575.20$ & $4,081,314.60$ & $1,017.24$ & $794.3^{\mathrm{k}}$ & $294.2^{\mathrm{k}}$ & $240.3^{k}$ & TM-WTA' & \\
\hline ER 5-3 \#2 & $5 / 19 / 2000^{k}$ & $594,544.70$ & $4,081,317.00$ & $1,017.24$ & $1,732.2^{\mathrm{k}}$ & $-407.3^{\mathrm{k}}$ & $-715.0^{k}$ & LCA $^{\prime}$ & \\
\hline ER 5-3 \#3 & $2 / 6 / 2001^{n}$ & $594,643.00$ & $4,081,151.00$ & $1,017.24$ & $548.6^{n}$ & $587.2^{\mathrm{n}}$ & $468.6^{n}$ & $\mathrm{OAA}^{\prime}$ & \\
\hline ER 5-4 upper (main) & $3 / 31 / 2001^{n}$ & $592,450.00$ & $4,075,696.00$ & 954.54 & $1,137.5^{n}$ & $431.8^{n}$ & $286.4^{\mathrm{n}}$ & $A A^{\prime}$ & \\
\hline ER 5-4 lower (main) & $3 / 31 / 2001^{n}$ & $592,450.00$ & $4,075,696.00$ & 954.54 & $1,137.5^{n}$ & $35.8^{n}$ & $-183.0^{n}$ & $\mathrm{AA}^{\prime}$ & TM-WTA' $^{1}$ \\
\hline ER 5-4 (piezometer) & $3 / 31 / 2001^{n}$ & $592,450.00$ & $4,075,696.00$ & 954.54 & $247.8^{n}$ & $733.5^{\mathrm{m}}$ & $706.7^{n}$ & $A A^{\prime}$ & \\
\hline ER 5-4 \#2 & $9 / 18 / 2002^{n}$ & $592,450.00$ & $4,075,665.00$ & 954.54 & $2,113.6^{n}$ & $-1,022.5^{n}$ & $-1,074.8^{n}$ & LTCU' $^{\prime}$ & \\
\hline RNM-1 & $5 / 10 / 1974^{n}$ & $592,131.76$ & $4,075,692.84$ & 955.60 & $396.8^{n}$ & $675.5^{\mathrm{n}}$ & $627.9^{n}$ & $A A^{\prime}$ & \\
\hline RNM-2 & $8 / 21 / 1974^{n}$ & $592,221.27$ & $4,075,528.53$ & 953.66 & $285.0^{n}$ & $733.6^{\mathrm{m}}$ & $668.7^{n}$ & $A A^{\prime}$ & \\
\hline RNM-2S & $4 / 1 / 1974^{n}$ & $592,134.10$ & $4,075,477.14$ & 954.16 & $352.4^{n}$ & $734.6^{m}$ & $601.8^{n}$ & $A A^{\prime}$ & \\
\hline SM-23-1 & $1 / 29 / 1996^{v}$ & $587,943.71$ & $4,056,449.43$ & $1,079.91$ & $672.09^{w}$ & $683.06^{\mathrm{w}}$ & $673.92^{w}$ & $\mathrm{LCA}^{\mathrm{x}}$ & \\
\hline TW-3 & $5 / 1962^{\mathrm{i}}$ & $601,938.92$ & $4,074,016.96$ & $1,061.96$ & $566.9^{n}$ & $698.7^{\circ}$ & $497.2^{\circ}$ & $\mathrm{LCA}^{\mathrm{n}}$ & \\
\hline TW-F & $6 / 12 / 1962^{p}$ & $578,870.02$ & $4,068,348.73$ & $1,262.69$ & $1,036.3^{i}$ & $305.6^{\circ}$ & $226.4^{\circ}$ & $\mathrm{LCA}^{\prime}$ & \\
\hline UE-11a & $9 / 4 / 1982^{p}$ & $593,170.64$ & $4,082,194.90$ & $1,078.48$ & $426.7^{i}$ & $733.8^{m}$ & $651.8^{\circ}$ & TM-WTA' & \\
\hline UE-11b & $10 / 1965^{i}$ & $594,393.85$ & $4,082,708.07$ & $1,093.01$ & $397.2^{i}$ & $743.7^{m}$ & $700.4^{\circ}$ & TM-LVTA' & TM-WTA/TSA $^{1}$ \\
\hline UE-5 PW-1 & $9 / 29 / 1992^{p}$ & $593,655.59$ & $4,078,714.21$ & 968.73 & $255.7^{q}$ & $733.8^{\mathrm{m}}$ & $713.0^{p}$ & $A A^{\prime}$ & \\
\hline UE-5 PW-2 & $2 / 19 / 1993^{p}$ & $593,669.53$ & $4,080,138.47$ & 989.54 & $280.4^{q}$ & $733.7^{m}$ & $709.2^{p}$ & $A A^{\prime}$ & \\
\hline UE-5 PW-3 & $1 / 5 / 1993^{p}$ & $591,708.10$ & $4,080,410.46$ & $1,004.50$ & $291.1^{q}$ & $733.8^{m}$ & $713.4^{p}$ & TM-WTA' & \\
\hline UE-5c WW upper & $11 / 1964$ & $590,978.01$ & $4,077,005.63$ & 980.32 & $817.5^{n}$ & $645.0^{\mathrm{j}}$ & $584.1^{j}$ & $A A^{\prime}$ & \\
\hline UE-5c WW lower & $11 / 1964$ & $590,978.01$ & $4,077,005.63$ & 980.32 & $817.5^{n}$ & $467.6^{\circ}$ & $162.8^{\circ}$ & LTCU' $^{\prime}$ & \\
\hline UE-5f & $6 / 1965^{i}$ & $593,974.25$ & $4,080,786.51$ & $1,006.09$ & $335.3^{i}$ & $734.8^{\mathrm{m}}$ & $670.8^{\circ}$ & $\mathrm{AA}^{\prime}$ & \\
\hline UE-5j & $3 / 1966^{i}$ & $585,926.56$ & $4,081,520.84$ & $1,090.57$ & $378.6^{i}$ & Unknown ${ }^{r}$ & $712.0^{i}$ & $\mathrm{AA}^{1}$ & TM-WTA' \\
\hline UE-5k & $2 / 1968^{i}$ & $595,297.94$ & $4,080,972.44$ & $1,020.65$ & $526.7^{i}$ & Unknown & $494.0^{i}$ & $\mathrm{AA}^{\prime}$ & BLFA/TM-WTA' \\
\hline UE-5m & $4 / 1966^{i}$ & $585,209.92$ & $4,068,567.15$ & $1,066.80$ & $458.4^{i}$ & Unknown ${ }^{r}$ & $608.4^{i}$ & $\mathrm{AA}^{\prime}$ & AA/LTCU/VCU' \\
\hline UE-5n & $3 / 1 / 1976^{p}$ & $592,626.58$ & $4,075,285.05$ & 948.95 & $514.2^{n}$ & $729.5^{n}$ & $726.5^{n}$ & $\mathrm{AA}^{\prime}$ & \\
\hline WW-1 & $1950^{\circ}$ & $597,789.78$ & $4,074,403.55$ & 944.88 & $265.2^{\circ}$ & $727.3^{m}$ & $700.5^{\circ}$ & $A A^{\prime}$ & \\
\hline
\end{tabular}


Table 8-1

Site Information for Selected Wells and Boreholes Located in the Frenchman Flat Area and Vicinity

(Page 2 of 2)

\begin{tabular}{|c|c|c|c|c|c|c|c|c|c|}
\hline $\begin{array}{l}\text { Well Reporting } \\
\text { Name }\end{array}$ & $\begin{array}{c}\text { Well } \\
\text { Completion } \\
\text { Date }^{a}\end{array}$ & $\begin{array}{l}\text { UTM Easting } \\
\qquad(\mathrm{m})^{\mathrm{b}}\end{array}$ & $\begin{array}{l}\text { UTM Northing } \\
\qquad(\mathrm{m})^{\mathrm{b}}\end{array}$ & $\begin{array}{c}\text { Land- } \\
\text { Surface } \\
\text { Elevation. } \\
(\mathrm{m} \text { amsl) }\end{array}$ & 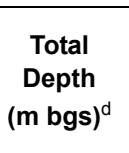 & $\begin{array}{l}\text { Effective Open } \\
\text { Interval Top } \\
\text { Elevation } \\
\text { (m amsl) }^{\mathrm{e}}\end{array}$ & $\begin{array}{l}\text { Effective Open } \\
\text { Interval Bottom } \\
\text { Elevation } \\
(m \text { ams })^{f}\end{array}$ & $\begin{array}{l}\text { Primary } \\
\text { HSU }^{g}\end{array}$ & $\begin{array}{c}\text { Secondary } \\
\text { HSU }^{h}\end{array}$ \\
\hline$\overline{\text { WW-4 }}$ & 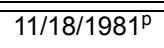 & $\overline{5866,961.76}$ & 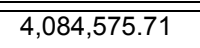 & 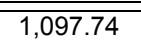 & $4 \overline{450.8^{j}}$ & $824.0^{j}$ & $2646.9^{j}$ & $\overline{\text { TM-WTA }^{1}}$ & 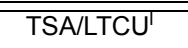 \\
\hline WW-4A & $2 / 21 / 1990^{p}$ & $586,647.95$ & $4,084,372.25$ & $1,099.11$ & $462.1^{j}$ & $811.4^{j}$ & $641.3^{j}$ & TM-WTA' $^{1}$ & TM-LVTA/TSA' \\
\hline WW-5A & $3 / 23 / 1951^{p}$ & $592,982.61$ & $4,070,370.54$ & 942.97 & $277.4^{n}$ & $730.9^{m}$ & $665.6^{s}$ & $\mathrm{AA}^{\prime}$ & \\
\hline WW-5B & $5 / 7 / 1951^{t}$ & $591,986.26$ & $4,073,102.55$ & 942.83 & $274.3^{n}$ & $729.4^{j}$ & $668.5^{j}$ & $\overline{A A^{\prime}}$ & \\
\hline WW-5C & $3 / 24 / 1954^{p}$ & $592,471.81$ & $4,071,751.81$ & 939.73 & $365.8^{n}$ & $669.3^{j}$ & $573.9^{j}$ & $\mathrm{AA}^{\prime}$ & \\
\hline WW-C & $3 / 30 / 1961^{\mathrm{u}}$ & $588,207.91$ & $4,086,129.96$ & $1,196.08$ & $518.5^{j}$ & $721.1^{j}$ & $677.6^{j}$ & $\mathrm{LCA}^{\mathrm{u}}$ & \\
\hline WW-C1 & $6 / 1962^{i}$ & $588,156.98$ & $4,086,102.86$ & $1,195.93$ & $502.9^{j}$ & $727.6^{m}$ & $693.0^{j}$ & LCA & \\
\hline
\end{tabular}

a Indicates date completed to HSU for depth-to-water measurements

b Universal Transverse Mercator Zone 11, North American Datum 1927 in meters; source is the UGTA Borehole Index Database.

Land-surion in meters above mean sea level; source is the UGTA Borehole Index Database.

e Effective open interval top elevation in meters above mean sea level; calculated as land-surface elevation minus depth to top of effective open interval.

'Effective open interval bottom in meters above mean sea level; calculated as land-surface elevation minus depth to bottom of effective open interval.

g Primary hydrostratigraphic unit.

Secondary hydrostratigraphic unit.

Hydrogeologic Data from Selected Wells and Test Holes In and Adjacent to the Nevada Test Site, Nye County, Nevada, Through 1986 (Arteaga et al., Charles S. Savard, Michael E. Johnson, and

J. Christopher Stone. USGS Open File Report 87-536 (USGS, 1991).

iNevada Test Site Water-Supply Wells. David Gillespie, Dee Donithan, and Paul Seaber. May 1996 (Gillespie et al., 1996).

kFrenchman Flat Well Cluster ER-5-3 Data Report for Development and Hydraulic Testing. Preliminary, Rev. No: 0. (IT, 2001c).

' Hydrostratigraphic Database for Drill Holes in Frenchman Flat Area.

$m$ Defined as the elevation of the steady-state water-level.

"Integrated Analysis Report for Single and Multiple-Well Aquifer Testing at Frenchman Flat Well Cluster RNM-2s, Nevada Test Site, Nevada. Rev. No: 0. (SNJV, 2004d).

${ }^{\circ}$ Records of Wells and Test Holes in the Nevada Test Site and Vicinity (through December 1966). William Thordarson, R.Q. Young, and I.J. Winograd. December 1967. USGS TEI-872 (USGS, 1967). ${ }^{\mathrm{P}}$ Ground-Water Data for the Nevada Test Site and Selected Other Areas in South-Central Nevada, 1992-1993. Steven R. Reiner, Glenn L. Locke, and Leanne S. Robie. USGS Open-File Report 95-160 (USGS, 1995).

Analysis of Water Levels in the Frenchman Flat Area, Nevada Test Site. Daniel J. Bright, Sharon A. Watkins, and Barbara A. Lisle. 2001. USGS Water-Resources Investigations Report 00-4272 (USGS, 2001)

The borehole is open from near ground surface to total depth so the top of the open interval would be defined as the location of the steady-state hydraulic head. Since a steady-state hydraulic head could not be determined, the top of the effective open interval could not be determined.

Well Recompletion Report For Water Well 5a Groundwater Characterization Project. (IT, 1993).

Water Wells in Frenchman and Yucca Valleys, Nevada Test Site, Nye County, Nevada. J.W. Hood. 1961. USGS Trace Elements Investigations Report 788 (USGS, 1961$).$

Ground Water Test Well C, Nevada Test Site, Nye County, Nevada. M.S. Garber and William Thordarsen. 1962. USGS Report TEI-818 (USGS, 1962).

UGTA Borehole Index Database.

p://nwis.waterdata.usgs.gov/vsa/nwis/gwlevels/?site_no=363905116005801 (USGS, 2001)

Sig Drellack, personal communication, July 8, 2004 (Drellack, 2004).

Note: Blank cells indicate no data are available. 


\subsubsection{HSU Assignment}

Water-levels were assigned to HSUs based on the identified EOI of each well and the HSUs structures of the base HSU model described in Section 2.0. A list of these HSUs is provided in Section 2.0. These same wells were used to develop the HSU model, so the assignment is very accurate at the well locations.

\subsection{Water-Level Evaluation Method}

For the purposes of calibrating a steady-state groundwater flow model, hydraulic heads consistent with natural, undisturbed groundwater flow conditions is necessary. In theory, these heads would be derived from water-levels measured during a time when groundwater flow in the Frenchman Flat area and vicinity was at steady-state. This time would be prior to the start of pumping and underground nuclear testing in the Frenchman Flat. Geochemical data from the NTS suggest that flow in the basin was not at steady state even before human activities in the area began. Therefore, it was not possible to determine true steady-state heads, but only heads that are considered to be representative of stable (not changing) flow conditions.

Pumping in and around Frenchman Flat began in the early 1950s with the drilling of water-supply wells WW-1, WW-5A, WW-5B, and WW-5C. The first underground test in Frenchman Flat was conducted in February 1965. Of the wells investigated in this analysis, eight were drilled prior to the first underground test (Table 8-1). Six of those are water-supply wells that began pumping shortly after completion. Sufficient documentation of depth-to-water measurements is available for only one of the remaining two wells, TW-3, which is located east of Frenchman Flat. Therefore, an undisturbed hydraulic head could be determined at only one location within the Frenchman Flat area and vicinity. Since true steady-state hydraulic conditions could not be determined based on the available data, the entire period of record for each site was used in the data evaluation and reduction process in order to develop estimates of hydraulic heads representative of stable conditions.

Hydraulic heads were calculated in terms of water-level elevation adjusted for borehole deviation and anomalous water temperature. Generally, barometric pressure was not recorded at the time of the water level measurements. In confined aquifers, earth tides also have a daily, periodic effect on water levels. However, there is not sufficient available information on earth tides to determine the magnitude of the effect for the individual wells. Consequently, the water level data have not been corrected to normalize the effects of either barometric pressure variation or earth tides. For each depth-to-water measurement, the water-level elevation was calculated as the difference between the reference-point elevation, which is the land-surface elevation for all wells, and the depth-to-water measurement. The effects of borehole deviation were evaluated and adjustments were made to derive hydraulic head values for wells with available deviation information (see Section 8.5.2). The water-level in TW-F was adjusted for the effects of the anomalous temperature of the water in the well (see Section 8.5.1). For the measurements for which the effects of temperature are negligible and 
deviation data are not available, the hydraulic heads were assigned equal to the unadjusted water-level elevations. A temporal evaluation, which assessed water-level data as part of steady-state or transient conditions, was performed for each site.

\subsubsection{Effects of Temperature}

Water column temperatures affect the water-levels by altering the density of the column of water in the well and, thus, the length of the water column above the completion interval. For wells completed to the same HSU but with different water temperatures, the water level in the well with the higher temperature will be greater than the water level in the well with the lower temperature. The different temperatures in wells can be caused by areal differences in the temperature of the water in a specific HSU. For example, the water in the LCA is at a temperature of about $147^{\circ} \mathrm{F}\left(63.9^{\circ} \mathrm{C}\right)$ at the location of TW-F and is at a temperature of about $94^{\circ} \mathrm{F}\left(34.4^{\circ} \mathrm{C}\right)$ at Army-1 WW, TW-3, WW-C, and WW-C1 (Bright et al., 2001). In order to compare water-levels between different wells completed to the same HSU, the density of the water column in each of the wells needs to be similar. Therefore, the density of the water column in wells with anomalously high temperatures must be adjusted to match wells with typical temperatures. This type of adjustment was made to the water level in TW-F.

For deep wells, the water in the well will not be a single temperature but will have a gradient from the depth of the completion interval to the water surface. Ideally, the density correction due to elevated temperatures would consider this gradient. For wells in which temperature profiles are available, these profiles show a nearly linear increase with depth. This type of increase was observed in ER-5-4 \#2 (Shaw, 2003) and ER-5-3 (IT, 2001). For TW-F, detailed information regarding the temperature gradient of the water in the well is not available. What is available is a temperature of about $47.9^{\circ} \mathrm{C}$ at $5 \mathrm{ft}(1.5 \mathrm{~m})$ below the water surface (USGS, 2004) and a temperature of about $147^{\circ} \mathrm{F}\left(63.9^{\circ} \mathrm{C}\right)$ at the depth of the completion interval (Bright et al., 2001). Assuming a linear gradient, the average temperature of the water in $\mathrm{TW}-\mathrm{F}$ is $55.9^{\circ} \mathrm{C}$.

The other wells completed to the LCA in the Frenchman Flat area and vicinity are Army-1 WW, ER-5-3 \#2, SM-23-1, TW-3, WW-C, and WW-C1. At the location of Army-1 WW, TW-3, WW-C, and WW-C1, the water in the LCA has a temperature of about $94^{\circ} \mathrm{F}\left(34.4^{\circ} \mathrm{C}\right)$ (Bright et al., 2001). The completion depths for these wells averages about $610 \mathrm{~m}(2,000 \mathrm{ft})$ shallower than the completion depth for TW-F. The geothermal gradient in the Pahute Mesa area is estimated to be $0.014^{\circ} \mathrm{F} / \mathrm{ft}$ (Bright et al., 2001). Using this gradient and a typical LCA temperature of $94^{\circ} \mathrm{F}$ at the depth of Army-1 WW, TW-3, WW-C, and WW-C1, the typical temperature at the depth of TW-F would be $122^{\circ} \mathrm{F}\left(50^{\circ} \mathrm{C}\right)$, which is about $25^{\circ} \mathrm{F}\left(14^{\circ} \mathrm{C}\right)$ lower than the observed temperature of $147^{\circ} \mathrm{F}\left(63.9^{\circ} \mathrm{C}\right)$. In ER-5-3 \#2 and SM-23-1, the temperature of the water in the well at a location $5 \mathrm{ft}(1.5 \mathrm{~m})$ below the water surface averages about $27^{\circ} \mathrm{C}$ (USGS, 2004), which is about $21^{\circ} \mathrm{C}$ lower than the temperature of the water in TW-F $\left(47.9^{\circ} \mathrm{C}\right)$ at the same location. Assuming a typical near surface temperature of $27^{\circ} \mathrm{C}$, a typical temperature at the depth of the LCA of $50^{\circ} \mathrm{C}$, and a linear gradient, the typical average temperature of 
water in TW-F would be $38.5^{\circ} \mathrm{C}$, which is $17.4^{\circ} \mathrm{C}$ lower than the actual average temperature.

The elevated and typical average temperatures for the column of water in TW-F were used to correct the water-levels in TW-F to typical temperature conditions. The length of the observed water column is a function of the actual water temperature. The length of the water column for typical water temperature can be calculated by (Bright et al., 2001):

$$
\eta^{\prime}=\eta\left(\frac{\rho}{\rho^{\prime}}\right)
$$

where:

$$
\begin{aligned}
& \eta^{\prime} \quad=\quad \text { length of the water column between the static water-level and the top } \\
& \text { of the open interval for the typical water temperature (m) } \\
& \eta=\text { measured length of the water column between the static water-level } \\
& \text { and the interval top for the elevated water temperature }(\mathrm{m}) \\
& \rho=\quad=\text { density of the water in the column at the elevated water temperature } \\
& \left(\mathrm{kg} / \mathrm{m}^{3}\right) \\
& \rho^{\prime}=\text { density of the water in the column at the typical water temperature } \\
& \left(\mathrm{kg} / \mathrm{m}^{3}\right)
\end{aligned}
$$

The average density of the water column in TW-F for an elevated water temperature of $55.9^{\circ} \mathrm{C}$ is $0.9852 \mathrm{~g} / \mathrm{cm}^{3}$ and for a typical water temperature of $38.5^{\circ} \mathrm{C}$ is $0.9928 \mathrm{~g} / \mathrm{cm}^{3}$ (Lambe, 1951). The average length of the water column at elevated temperatures is $428.11 \mathrm{~m}$ based on measured depths to water (UGTA Borehole Index Database). Substituting these values into Equation 8-1 yields an average water column at typical temperatures of $424.83 \mathrm{~m}$, which indicates an average adjustment (reduction) of slightly over $3 \mathrm{~m}$. Equation 8-1 was used to adjust all of the individual water-level measurments for TW-F.

\subsubsection{Effects of Borehole Deviation}

Borehole deviation may result in groundwater depth measurements that are greater than the true depth to water due to deviation of the borehole from true vertical. Borehole deviation surveys have been conducted in approximately half of the wells investigated in this analysis. In most cases, deviation of the borehole is slight. The only exception is RNM-1, which was designed to deviate 21 degrees in order to intercept the detonation cavity resulting from the CAMBRIC explosion.

Using the results of the borehole deviation surveys, Bright et al. (2001) developed linear equations to adjust the depth to water for deviation of the boreholes in the Frenchman Flat area and vicinity. The linear equation is of the form (Bright et al., 2001):

$$
\mathrm{WL}_{\text {adj }}=\left(\mathrm{WL}_{\mathrm{m}}-\mathrm{M}_{\text {top }}\right) \times \Delta \mathrm{V}_{\text {int }} / \Delta \mathrm{M}_{\text {int }} \mathrm{V}_{\text {top }}
$$


where:

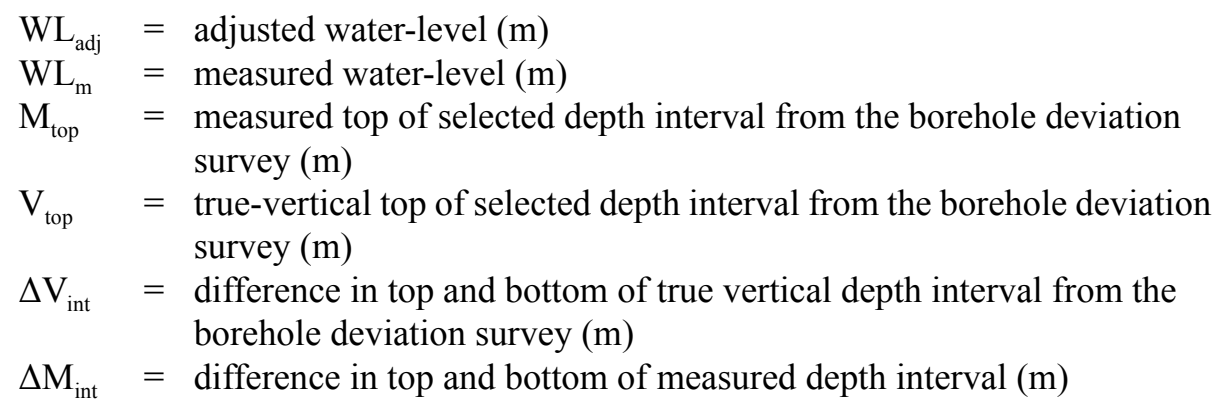

Table 8-2 summarizes the equations from Bright et al. (2001) that were used in this analysis to correct depth-to-water measurements for borehole deviation. Five wells have been drilled in the Frenchman Flat area since Bright et al. (2001). They are the three wells in the ER-5-3 well cluster and the two wells in the ER-5-4 well cluster. Borehole deviation only affects the water-level in ER-5-4 \#2. Using Equation 8-2, a linear equation was developed based on the borehole deviation survey for ER-5-4 \#2. That equation is also provided in Table 8-2.

Table 8-2

Equations Used to Adjust Measured Depth to Water for Borehole Deviation (after Bright et al., 2001)

\begin{tabular}{|c|c|c|c|}
\hline $\begin{array}{l}\text { Well Reporting } \\
\text { Name }\end{array}$ & $\begin{array}{l}\text { Deviation Survey } \\
\text { Depth Interval (m) }\end{array}$ & Equation Used for Adjustment ${ }^{a}$ & $\begin{array}{c}\text { Average } \\
\text { Adjustment }^{\mathrm{b}}(\mathrm{m})\end{array}$ \\
\hline Army-1 WW & 0 to 593.1 & $V_{d}=M_{d}^{*} 0.99923$ & 0.18 \\
\hline RNM-1c & NA & $V_{d}=M_{d}^{*} \cos \left(21^{\circ}\right)$ & 16 \\
\hline UE-5 PW-1 & 234.7 to 236.2 & $V_{d}=M_{d}^{*} 0.998+0.387 m$ & 0.08 \\
\hline UE-5 PW-2 & 254.5 to 257.6 & $V_{d}=M_{d}^{*} 0.999+0.05 m$ & 0.20 \\
\hline UE-5 PW-3 & 269.7 to 271.3 & $\mathrm{~V}_{\mathrm{d}}=\mathrm{M}_{\mathrm{d}}-0.02 \mathrm{~m}$ & 0.02 \\
\hline TW-F & 525.8 to 533.4 & $V_{d}=M_{d}^{*} 0.9996+0.15 m$ & 0.06 \\
\hline UE-5c & 243.8 to 251.5 & $V_{d}=M_{d}-0.006 m$ & 0.01 \\
\hline UE-11a & 342.9 to 350.5 & $V_{d}=M_{d}^{*} 0.9996+0.11 m$ & 0.03 \\
\hline WW-4 & 243.8 to 304.8 & $V_{d}=M_{d}-0.015$ & 0.02 \\
\hline WW-C & 0 to 469.4 & $V_{d}=M_{d}^{*} 0.99959$ & 0.19 \\
\hline WW-C1 & 464.8 to 472.4 & $V_{d}=M_{d}^{*} 0.9848+5.856 m$ & 1.3 \\
\hline ER 5-4 \#2 & 7.6 to 373.4 & $V_{d}=M_{d}^{*} 0.9999+0.0008$ & 0.02 \\
\hline
\end{tabular}

${ }^{a} V_{d}=$ True vertical depth to water $(m)$

$M_{d}=$ Measured depth to water $(m)$

${ }^{\mathrm{b}}$ Average adjustments are an increase in water-level elevation

${ }^{c}$ Estimated based on design deviation of 21 degrees since no borehole deviation survey was found

NA $=$ Not applicable 
Depth-to-water measurements were also adjusted for RNM-1. Recall that the design of this well called for a 21-degree angle when drilling. A boreholedeviation survey for this well could not be found. Therefore, the depth-to-water measured in this well was corrected based on the design angle of 21 degrees. The equation used to adjust the water-level in RNM-1 is also included in Table 8-2.

Notice from Table 8-2 that most corrections for borehole deviation are less than $0.3 \mathrm{~m}$. The only exceptions are $\mathrm{WW}-\mathrm{C} 1$, which has a correction of about $1.3 \mathrm{~m}$ due to borehole deviation, and RNM-1, which was intentionally drilled with a high deviation from vertical.

\subsection{Steady-State Hydraulic Heads}

The selection of steady-state hydraulic heads and a measure of their uncertainty are discussed in this section. Steady-state heads were determined through analysis of the water-level data for each site based on evaluation of the hydrographs. The hydrographs were prepared with the objective of presenting information relevant to understanding the hydraulic head and any site activities that may have impacted the head measurements. The hydrographs include:

- Water-level elevations

- Completion and, if applicable, recompletion dates

- Date of first underground test in Frenchman Flat

- Site status, if any, at the time of the water-level measurement

- Status at nearby sites, if any, at the time of the water-level measurement

- Identification of measurements for use in determining the steady-state hydraulic head

- Value of the steady-state hydraulic head

- HSU well is completed in

- Top and bottom of the HSU interval in the well

- Top and bottom of the EOI in the well

The status of a site or nearby sites prior to, or during, a water-level measurement could effect whether the measurement represents undisturbed or disturbed conditions. The different status of sites include, but are not limited to: undisturbed drilling activities, pumping of the site, recent pumping of the site, pumping at a nearby site tapping the same aquifer, and tool installation. The most common site status shown on the hydrographs is a $\mathrm{Z}$ status. This status indicates that some activity, other than pumping, occurred at the site and this activity could have effected the water-level measurement. The $\mathrm{Z}$ site status is typically given to 
reflect activities related to preparation of the site for testing. These activities include, but are not limited to: installation and removal of transducers, and installation and removal of bridge plugs. The site status at the time of each water-level measurement is provided in the UGTA Borehole Index Database.

All of the hydrographs are shown on a horizontal scale of 60 years from 1950 to 2010. For the ER-5-3 and ER-5-4 well clusters, which were completed in 2000 to 2002 , an additional hydrograph is shown with a horizontal scale of 5 years from January 2000 to January 2005 . When possible, a 10-m vertical scale was used for the hydrographs. In cases where the data span greater than $10 \mathrm{~m}$, the scale was increased to fit the data. An attempt was made to use the same vertical scale for wells located in close proximity to one another.

The primary purpose for evaluating the hydrographs was development of hydraulic heads representative of predevelopment steady-state conditions (i.e., before human activity) for use in the CAU-scale groundwater steady-state flow model for the Frenchman Flat area. During the analysis, two temporal trends in the water-level data were identified. One trend shows the water-level remaining fairly constant over the past 30 to 40 years. The other trend shows the water-level in some wells located in the southern portion of the study area, declining between the 1960s and the early 1990s, and then remaining fairly constant since that time. This decline is small at some locations (e.g., less than $1 \mathrm{~m}$ at UE-5n) but quite large at others (e.g., about $9 \mathrm{~m}$ at WW-5C). Since the lower water-level has remained stable over the last 10 years, it was assumed to indicate a new (contemporary) steady-state condition.

As a result of observing these two trends, an attempt was made to determine both a historical and a contemporary steady-state head at each site. For sites with long water-level records, the historical and contemporary heads are the same in some cases and are different in others. In wells that have been drilled since the late 1980 s, only a contemporary, steady-state head was determined. Table 8-3 summarizes the steady-state hydraulic heads determined for each site in the Frenchman Flat area and vicinity. Also included in this table is the number, minimum, maximum, and standard deviation of the measurements used to determine the steady-state values. The historical, steady-state water-levels are assumed to be representative of predevelopment, steady-state conditions, and are the target heads for the predevelopment, steady-state flow model for the CAU. Identification of contemporary, steady-state water-levels was done for analysis purposes only. Use of the contemporary, steady-state water-levels for any specific purposes is not planned at this time. However, they may be useful if future modeling of the CAU includes pumping.

A total uncertainty was estimated for each steady-state hydraulic head value. The total uncertainty includes uncertainties associated with:

- Land-surface elevation

- Water-level elevation

- Depth-to-water measurement

- Barometric effects

- Borehole deviation correction

- Data frequency 
Summary of Hydraulic Heads at Sites with the Frenchman Flat Area and Vicinity (Page 1 of 2)

\begin{tabular}{|c|c|c|c|c|c|c|c|c|c|}
\hline Well Reporting Name & $\begin{array}{c}\text { Historical } \\
\text { Steady-State } \\
\text { Water-Level } \\
\text { Elevation } \\
\text { (m amsl) }\end{array}$ & $\begin{array}{l}\text { Contemporary } \\
\text { Steady-State } \\
\text { Water-Level } \\
\text { Elevation } \\
\text { (m amsl) }\end{array}$ & Count & $\begin{array}{l}\text { Minimum } \\
\text { Water-Level } \\
\text { Elevation } \\
\text { (m amsl) }\end{array}$ & $\begin{array}{c}\text { Maximum } \\
\text { Water-Level } \\
\text { Elevation } \\
(\mathrm{m} \text { amsl) }\end{array}$ & $\begin{array}{l}\text { Standard } \\
\text { Deviation } \\
\text { (m) }\end{array}$ & $\begin{array}{c}\text { Total } \\
\text { Uncertainty } \\
\text { (m) }\end{array}$ & Primary HSU & $\begin{array}{c}\text { Type } \\
\text { Correction }\end{array}$ \\
\hline Army-1 WW & \multicolumn{2}{|c|}{721.87} & 12 & 721.43 & 722.26 & 0.24 & 1.15 & LCA & $\mathrm{BD}$ \\
\hline $\begin{array}{l}\text { ER-5-3 } \\
\text { (3" shallow) }\end{array}$ & & 734.57 & 17 & 734.46 & 734.70 & 0.06 & 1.06 & AA & \\
\hline ER-5-3 (3" deep) & & 734.08 & 15 & 733.76 & 734.56 & 0.19 & 1.19 & TM-WTA & \\
\hline $\begin{array}{l}\text { ER-5-3 } \\
\text { (main/composite) }\end{array}$ & & 734.55 & 18 & 734.42 & 734.68 & 0.07 & 1.07 & $\begin{array}{l}\text { AA and } \\
\text { TM-WTA }\end{array}$ & \\
\hline ER-5-3 \#2 & \multicolumn{7}{|c|}{ could not be determined } & LCA & \\
\hline ER-5-3 \#3 & & 734.59 & 13 & 734.49 & 734.67 & 0.06 & 1.05 & $A A$ & \\
\hline $\begin{array}{l}\text { ER-5-4 } \\
\text { (piezometer) }\end{array}$ & & 733.49 & 6 & 733.35 & 733.54 & 0.07 & 0.43 & $A A$ & \\
\hline $\begin{array}{l}\text { ER-5-4 } \\
\text { (main/composite) }\end{array}$ & & 733.34 & 7 & 733.28 & 733.44 & 0.06 & 0.43 & AA & \\
\hline ER 5-4 \#2 & \multicolumn{7}{|c|}{ could not be determined } & LTCU & $\mathrm{BD}$ \\
\hline RNM-1 & \multicolumn{2}{|c|}{731.31} & 6 & 730.90 & 731.94 & 0.36 & 1.60 & AA & $\mathrm{BD}$ \\
\hline RNM-2 & \multicolumn{2}{|c|}{733.58} & 1 & 733.58 & 733.58 & & 0.88 & AA & \\
\hline \multirow{2}{*}{ RNM-2S } & 734.60 & & 1 & 734.60 & 734.60 & & 1.16 & \multirow{2}{*}{$\mathrm{AA}$} & \\
\hline & & 733.64 & 24 & 733.49 & 733.78 & 0.07 & 0.46 & & \\
\hline SM-23-1 & & 725.01 & 20 & 724.91 & 725.10 & 0.04 & 0.68 & LCA & \\
\hline TW-3 & \multicolumn{2}{|c|}{725.52} & 26 & 725.10 & 726.13 & 0.23 & 1.21 & LCA & \\
\hline TW-F & \multicolumn{2}{|c|}{730.51} & 25 & 730.05 & 730.80 & 0.17 & 1.24 & LCA & $\mathrm{BD}, \mathrm{WT}$ \\
\hline UE-11a & & 733.79 & 1 & 733.79 & 733.79 & & 1.21 & TM-WTA & $\mathrm{BD}$ \\
\hline UE-11b & \multicolumn{2}{|c|}{743.71} & 1 & 743.71 & 743.71 & & 1.16 & TM-LVTA & \\
\hline UE-5 PW-1 & & 733.79 & 71 & 733.65 & 734.01 & 0.05 & 0.71 & $A A$ & $\mathrm{BD}$ \\
\hline UE-5 PW-2 & & 733.74 & 88 & 733.63 & 733.98 & 0.07 & 0.75 & AA & $\mathrm{BD}$ \\
\hline UE-5 PW-3 & & 733.75 & 44 & 733.62 & 733.88 & 0.07 & 0.71 & TM-WTA & $B D$ \\
\hline
\end{tabular}


Table 8-3

Summary of Hydraulic Heads at Sites with the Frenchman Flat Area and Vicinity (Page 2 of 2 )

\begin{tabular}{|c|c|c|c|c|c|c|c|c|c|}
\hline Well Reporting Name & $\begin{array}{c}\text { Historical } \\
\text { Steady-State } \\
\text { Water-Level } \\
\text { Elevation } \\
\text { (m amsl) }\end{array}$ & $\begin{array}{c}\text { Contemporary } \\
\text { Steady-State } \\
\text { Water-Level } \\
\text { Elevation } \\
\text { (m amsl) }\end{array}$ & Count & $\begin{array}{l}\text { Minimum } \\
\text { Water-Level } \\
\text { Elevation } \\
\text { (m amsl) }\end{array}$ & $\begin{array}{l}\text { Maximum } \\
\text { Water-Level } \\
\text { Elevation } \\
(\mathrm{m} \text { amsl) }\end{array}$ & $\begin{array}{l}\text { Standard } \\
\text { Deviation } \\
\text { (m) }\end{array}$ & $\begin{array}{c}\text { Total } \\
\text { Uncertainty } \\
\text { (m) }\end{array}$ & Primary HSU & $\begin{array}{c}\text { Type } \\
\text { Correction }^{\mathrm{a}}\end{array}$ \\
\hline \multirow{2}{*}{ UE-5c WW } & 734.50 & & 5 & 734.35 & 734.84 & 0.21 & 0.62 & \multirow{2}{*}{ AA } & \multirow{2}{*}{$\mathrm{BD}$} \\
\hline & & 733.28 & 1 & 733.28 & 733.28 & & 0.91 & & \\
\hline UE-5f & 734.82 & & 1 & 734.82 & 734.82 & & 1.43 & AA & \\
\hline UE-5j & \multicolumn{7}{|c|}{ could not be determined } & AA & \\
\hline UE-5k & \multicolumn{7}{|c|}{ could not be determined } & AA & \\
\hline UE-5m & \multicolumn{7}{|c|}{ could not be determined } & AA & \\
\hline UE-5n & & 733.84 & 15 & 733.70 & 734.04 & 0.08 & 0.47 & AA & \\
\hline WW-1 & 727.25 & & 1 & 727.25 & 727.25 & & 4.40 & AA & \\
\hline WW-4 & 844.62 & & 2 & 844.62 & 844.63 & 0.01 & 2.02 & TM-WTA & $\mathrm{BD}$ \\
\hline WW-4A & 844.59 & & 6 & 844.42 & 844.72 & 0.12 & 1.21 & TM-WTA & \\
\hline \multirow{2}{*}{$W W-5 A$} & 730.91 & & 1 & 730.91 & 730.91 & & 1.14 & \multirow{4}{*}{ AA } & \\
\hline & & 726.17 & 98 & 725.31 & 726.68 & 0.26 & 0.90 & & \\
\hline \multirow{2}{*}{ WW-5B } & 734.68 & & 24 & 734.33 & 735.14 & 0.23 & 1.15 & & \\
\hline & & 733.31 & 6 & 733.20 & 733.43 & 0.08 & 1.00 & & \\
\hline \multirow{2}{*}{ WW-5C } & 729.68 & & 1 & 729.68 & 729.68 & & 1.29 & \multirow{2}{*}{ AA } & \\
\hline & & 720.59 & 1 & 720.59 & 720.59 & & 1.29 & & \\
\hline WW-C & 726.00 & & 13 & 725.25 & 727.83 & 0.70 & 1.45 & LCA & $\mathrm{BD}$ \\
\hline WW-C1 & \multicolumn{2}{|c|}{727.62} & 13 & 727.40 & 728.06 & 0.22 & 1.02 & LCA & $\mathrm{BD}$ \\
\hline
\end{tabular}

$\mathrm{a}_{\mathrm{BD}}=$ Corrected for borehole deviation $\mathrm{WT}=$ Corrected for water temperature 
Recent measurements of land-surface elevation with high precision GPS (not yet published) differ from the land-surface elevations used for this analysis. The difference between the two values was assumed to represent the uncertainty in the steady-state head due to the uncertainty in the land-surface elevation. For the wells recently surveyed, the difference between the new land-surface elevation and the land-surface elevation used for this analysis ranges from 0.03 to $0.89 \mathrm{~m}$ and averages a little over $0.22 \mathrm{~m}$. Not all of the wells included in this analysis were recently surveyed. An uncertainty in land-surface elevation for those wells had to be assumed. The uncertainty assumed for those wells is a value of $0.30 \mathrm{~m}$ which is slightly higher than the average difference of $0.27 \mathrm{~m}$. The uncertainty assigned to each steady-state head due to the uncertainty in the land-surface elevation is provided in Table 8-4.

The uncertainty associated with the water-level elevations derives from the averaging of several individual values to obtain a single steady-state value. Table 8-3 shows that the number of measurements used to calculate the steady-state value ranged from 1 to 98 . The uncertainty in the water-level elevations is represented by the standard deviation given in Table 8-3.

The uncertainty associated with the depth-to-water measurements derives from the method used to measure the water level. The methods most frequently used by the USGS to measure the water level in wells in the Frenchman Flat area and vicinity are the calibrated electric tape device and the steel tape device (USGS and DOE, 2004). The accuracy of these devices is given as one tenth of a foot $(0.03 \mathrm{~m})$ for the calibrated electric tape and $1 \mathrm{ft}(0.3 \mathrm{~m})$ for the steel tape (USGS and DOE, 2004). Table 8-4 summarizes the uncertainty associated with the depth-to-water measurements for each well, which was applied to the steady-state heads.

The uncertainty associated with borehole deviation derives from the accuracy of the equipment used to determine the true vertical depth. For wells in the ER-5-3 and ER-5-4 well clusters, the deviation surveys were assumed to be 100 percent accurate. For other wells surveyed, information regarding the accuracy is not available and was assumed. The accuracy in the surveys was assumed to be 0.5 degrees for wells completed, and assumed surveyed, before 1990 and 0.25 degrees for wells completed, and assumed surveyed, since 1989. Borehole deviation surveys were not conducted in 12 wells in the Frenchman Flat area and vicinity. Since it is unknown whether these wells deviated or not, a deviation was assumed for the purposes of assessing the uncertainty in steady-state head. The assumed deviation was 1.0 degrees for wells completed prior to 1990 and 0.5 degrees for wells completed in or later than 1990. A deviation of 1.0 degrees is slightly lower than the average borehole deviation for wells with deviation surveys, with the exception of WW-C1 which deviates by 10 degrees in the interval containing the water-level. Table 8-4 summarizes the uncertainty assigned to each steady-state head due to the assumed uncertainty in borehole deviation.

Changes in barometric pressure can cause fluctuations in water-levels of confined and semi-confined aquifers. Barometric pressure and water level are inversely related, with increased barometric pressure causing a decreased water level and visa versa. As stated in Section 8.5, water-level elevations presented in this report were not corrected for barometric pressure. Therefore, an uncertainty in the water 
Summary of Uncertainty in Estimated Steady-State Head (Page 1 of 2)

\begin{tabular}{|c|c|c|c|c|c|c|c|}
\hline Well Reporting Name ${ }^{a}$ & $\begin{array}{l}\text { Accuracy of the } \\
\text { Reference Point } \\
\text { Elevation }(m)^{b}\end{array}$ & $\begin{array}{l}\text { Uncertainty in } \\
\text { Estimated } \\
\text { Steady-State } \\
\text { Water-Level } \\
\text { Elevation }(\mathrm{m})^{\mathrm{c}}\end{array}$ & $\begin{array}{c}\text { Accuracy of Depth } \\
\text { to Water } \\
\text { Measurements } \\
(\mathrm{m})^{\mathrm{b}}\end{array}$ & $\begin{array}{l}\text { Uncertainty Due to } \\
\text { Barometric Effects } \\
\qquad(\mathrm{m})^{d}\end{array}$ & $\begin{array}{l}\text { Accuracy of } \\
\text { Borehole Deviation } \\
\text { Correction }(\mathrm{m})\end{array}$ & $\begin{array}{l}\text { Accuracy Due to } \\
\text { Data Frequency } \\
(\mathrm{m})^{\mathrm{e}}\end{array}$ & $\begin{array}{l}\text { Total Uncertainty } \\
(\mathrm{m})\end{array}$ \\
\hline Army $1 \mathrm{WW}$ & $0.30^{f}$ & 0.24 & 0.03 & 0.30 & $0.08^{\mathrm{k}}$ & 0.20 & 1.15 \\
\hline ER 5-3 (3" shallow) & $0.67^{9}$ & 0.06 & 0.03 & 0.30 & $0.00^{1}$ & 0.00 & 1.06 \\
\hline ER 5-3 (3" deep) & $0.67^{9}$ & 0.19 & 0.03 & 0.30 & $0.00^{1}$ & 0.00 & 1.19 \\
\hline ER- 5-3 (main) & $0.67^{9}$ & 0.07 & 0.03 & 0.30 & $0.00^{1}$ & 0.00 & 1.07 \\
\hline ER 5-3 \#2 & \multicolumn{7}{|c|}{ No steady-state head determined } \\
\hline ER 5-3 \#3 & $0.66^{g}$ & 0.06 & 0.03 & 0.30 & $0.00^{1}$ & 0.00 & 1.05 \\
\hline ER 5-4 (piezometer) & $0.04^{9}$ & 0.07 & 0.03 & 0.30 & $0.00^{1}$ & 0.00 & 0.44 \\
\hline ER 5-4 (main) & $0.04^{9}$ & 0.06 & 0.03 & 0.30 & $0.00^{1}$ & 0.00 & 0.43 \\
\hline ER 5-4 \#2 & \multicolumn{7}{|c|}{ No steady-state head determined } \\
\hline RNM-1 & $0.06^{9}$ & 0.36 & $0.03^{j}$ & 0.30 & $0.75^{\mathrm{k}}$ & 0.10 & 1.60 \\
\hline RNM-2 & $0.03^{g}$ & $\mathrm{i}$ & $0.03^{j}$ & 0.30 & $0.02^{m}$ & 0.50 & 0.88 \\
\hline RNM-2S (historical) & $0.04^{\mathrm{g}}$ & $\mathrm{i}$ & 0.30 & 0.30 & $0.02^{m}$ & 0.50 & 1.16 \\
\hline RNM-2S (contemporary) & $0.04^{g}$ & 0.07 & 0.03 & 0.30 & $0.02^{\mathrm{m}}$ & 0.00 & 0.46 \\
\hline SM-23-1 & $0.30^{f}$ & 0.04 & 0.03 & 0.30 & $0.01^{\text {n }}$ & 0.00 & 0.68 \\
\hline TW-3 & $0.30^{f}$ & 0.23 & 0.30 & 0.30 & $0.03^{m}$ & 0.05 & 1.21 \\
\hline TW-F & $0.30^{f}$ & 0.17 & 0.30 & 0.30 & $0.07^{\mathrm{k}}$ & 0.10 & 1.24 \\
\hline UE-11a & $0.07^{g}$ & $\mathrm{i}$ & 0.30 & 0.30 & $0.04^{\mathrm{k}}$ & 0.50 & 1.21 \\
\hline UE-11b & $0.30^{f}$ & $\mathrm{i}$ & 0.03 & 0.30 & $0.03^{m}$ & 0.50 & 1.16 \\
\hline UE-5 PW-1 & $0.30^{f}$ & 0.05 & 0.03 & 0.30 & $0.03^{\circ}$ & 0.00 & 0.71 \\
\hline UE-5 PW-2 & $0.30^{f}$ & 0.07 & 0.03 & 0.30 & $0.05^{\circ}$ & 0.00 & 0.75 \\
\hline UE-5 PW-3 & $0.30^{f}$ & 0.07 & 0.03 & 0.30 & $0.01^{\circ}$ & 0.00 & 0.71 \\
\hline UE-5c WW (historical) & $0.06^{9}$ & 0.21 & 0.03 & 0.30 & $0.02^{\mathrm{k}}$ & 0.00 & 0.62 \\
\hline UE-5c WW (contemporary) & $0.06^{9}$ & $\mathrm{i}$ & $0.03^{j}$ & 0.30 & $0.02^{\mathrm{k}}$ & 0.50 & 0.91 \\
\hline UE-5f & $0.08^{g}$ & $\bar{i}$ & 0.03 & 0.30 & $0.02^{m}$ & 1.00 & 1.43 \\
\hline UE-5j & \multicolumn{7}{|c|}{ No steady-state head determined } \\
\hline UE-5k & \multicolumn{7}{|c|}{ No steady-state head determined } \\
\hline UE-5m & \multicolumn{7}{|c|}{ No steady-state head determined } \\
\hline
\end{tabular}


Table 8-4

Summary of Uncertainty in Estimated Steady-State Head

(Page 2 of 2 )

\begin{tabular}{|c|c|c|c|c|c|c|c|}
\hline Well Reporting Name ${ }^{a}$ & $\begin{array}{l}\text { Accuracy of the } \\
\text { Reference Point } \\
\text { Elevation }(m)^{b}\end{array}$ & $\begin{array}{l}\text { Uncertainty in } \\
\text { Estimated } \\
\text { Steady-State } \\
\text { Water-Level } \\
\text { Elevation }(\mathrm{m})^{\mathrm{c}}\end{array}$ & $\begin{array}{l}\text { Accuracy of Depth } \\
\text { to Water } \\
\text { Measurements } \\
(\mathrm{m})^{\mathrm{b}}\end{array}$ & $\begin{array}{l}\text { Uncertainty Due to } \\
\text { Barometric Effects } \\
\qquad(\mathrm{m})^{\mathrm{d}}\end{array}$ & $\begin{array}{l}\text { Accuracy of } \\
\text { Borehole Deviation } \\
\text { Correction }(\mathrm{m})\end{array}$ & $\begin{array}{l}\text { Accuracy Due to } \\
\text { Data Frequency } \\
(\mathrm{m})^{\mathrm{e}}\end{array}$ & $\begin{array}{l}\text { Total Uncertainty } \\
(\mathrm{m})\end{array}$ \\
\hline UE-5n & 0.049 & 0.08 & 0.03 & 0.30 & $0.02^{m}$ & 0.00 & 0.47 \\
\hline WW-1 & $3.05^{h}$ & $\mathrm{i}$ & $0.03^{j}$ & 0.30 & $0.02^{\mathrm{m}}$ & 1.00 & 4.40 \\
\hline WW-4 & $0.89^{9}$ & 0.01 & 0.30 & 0.30 & $0.02^{k}$ & 0.50 & 2.02 \\
\hline WW-4A & $0.48^{9}$ & 0.12 & 0.30 & 0.30 & $0.005^{n}$ & 0.00 & 1.21 \\
\hline WW-5A (historical) & $0.29^{9}$ & $\mathrm{i}$ & 0.03 & 0.30 & $0.02^{\mathrm{m}}$ & 0.50 & 1.14 \\
\hline WW-5A (contemporary) & $0.29^{9}$ & 0.26 & 0.03 & 0.30 & $0.02^{\mathrm{m}}$ & 0.00 & 0.90 \\
\hline WW-5B (historical) & $0.30^{f}$ & 0.23 & 0.30 & 0.30 & $0.02^{\mathrm{m}}$ & 0.00 & 1.15 \\
\hline WW-5B (contemporary) & $0.30^{f}$ & 0.08 & 0.30 & 0.30 & $0.02^{\mathrm{m}}$ & 0.00 & 1.00 \\
\hline WW-5C (historical) & 0.449 & $\mathrm{i}$ & 0.03 & 0.30 & $0.02^{\mathrm{m}}$ & 0.50 & 1.29 \\
\hline WW-5C (contemporary) & 0.449 & $\mathrm{i}$ & 0.03 & 0.30 & $0.02^{\mathrm{m}}$ & 0.50 & 1.29 \\
\hline WW-C & $0.30^{f}$ & 0.70 & 0.03 & 0.30 & $0.12^{k}$ & 0.00 & 1.45 \\
\hline WW-C-1 & $0.07^{9}$ & 0.22 & $0.03^{j}$ & 0.30 & $0.30^{k}$ & 0.10 & 1.02 \\
\hline
\end{tabular}

When both a historical and a contemporary steady-state head was determined for a well, historical indicates this is the uncertainty for the historical steady-state head and

contemporary indicates this is the uncertainty for the contemporary steady-state head.

b Source is UGTA Borehole Index Database

Standard deviation of water-level measurements used to determined the steady-state head

${ }^{\mathrm{d}}$ Accuracy assumed to be $1 \mathrm{ft}$ based on discussion in Bright et al. (2001)

e The uncertainty was assumed to be zero for cases when many measurements of nearly the same value over a significant time period were used to estimate the steady-state head, was assumed to by $0.5 \mathrm{~m}$ when only one measurement was used to estimate the steady-state head, was assumed to be between 0.1 and $0.25 \mathrm{~m}$ when several measurements were used to estimate the steady-state head but those measurements constituted single measurements or only a few measurements at different time periods, and was assumed to be $1.0 \mathrm{~m}$ for wells having only a single water-level measurement

f Uncertainty assumed to be $0.30 \mathrm{~m}$, which is slightly higher than the average difference between recently obtained land-surface elevation measurements made with high precision GPS (not yet published) and the land-surface elevations used in this analysis

$g$ Uncertainty is the difference between recently obtained land-surface elevation measurements made with high precision GPS (not yet published) and the land-surface elevations used in this analysis

${ }^{\mathrm{h}}$ The accuracy of the reference point elevation measurement as given in the UGTA Borehole Index Database

Steady-state head determined from only one measurement

j No accuracy available in UGTA Borehole Index Database and uncertainty is estimated

${ }^{k}$ The accuracy of the borehole deviation survey conducted in the well was assumed to be 0.5 degrees

' The borehole deviation survey was assumed to be 100 percent accurate

$\mathrm{m}$ No borehole deviation was conducted in the well and an uncertainty in deviation of 1.0 degrees was assumed

${ }^{n}$ No borehole deviation was conducted in the well and an uncertainty in deviation of 0.5 degrees was assumed

- The accuracy of the borehole deviation survey conducted in the well was assumed to be 0.25 degrees 
levels due to the effects of barometric pressure was estimated. For wells in the vicinity of Frenchman Flat, Bright et al (2001) state that, "The magnitude of short-term (less than 10 days) water-level fluctuations in wells vary throughout the year but commonly have a maximum amplitude of about $1 \mathrm{ft}$ during the winter season when changes in barometric pressure are greatest." This maximum fluctuation of $1 \mathrm{ft}(0.3 \mathrm{~m})$ was assumed to represent the maximum uncertainty in the water-level elevations due to barometric pressure, and was applied to the steady-state heads.

Another source of uncertainty is the temporal distribution of water-level measurements (i.e., data frequency). In instances where many measurements are available, there is a high likelihood that those values accurately represent aquifer conditions over the measurement time period. On the other hand, when just a single measurement is available, there is a significant potential that measurement does not reflect overall aquifer conditions. For this analysis, it was assumed that the uncertainty in a single water-level measurement's accuracy to reflect aquifer conditions is $0.5 \mathrm{~m}$. Therefore, in instances where only one measurement was used to estimate the steady-state head (e.g., for RNM-2), the uncertainty in that head due to data frequency was assumed to be $0.5 \mathrm{~m}$. In instances where many measurements of nearly the same value over a significant time period were used to estimate the steady-state head, (e.g., for the shallow piezometer in ER-5-3), no uncertainty was considered to be in the steady-state head due to data frequency. In instances where several measurements were used to estimate the steady-state head but those measurements constitute single measurements or only a few measurements at different time periods (e.g., Army-1 WW), the uncertainty in that head was assumed to range from 0.1 to $0.25 \mathrm{~m}$ depending on the specifics for the individual wells. For UE-5f and WW-1, the water level in the well has been measured only once and that measurement was made in the same month that the well was drilled. Because the exact date of well completion is unknown for these two wells, the relationship between the water-level measurement and drilling activities is unknown. For these two wells, the uncertainty in the water level due to data frequency is higher than for any other wells and was assumed to be $1.0 \mathrm{~m}$.

Table 8-4 summarizes the uncertainties for each steady-state head. Included in this table are the total uncertainties as well as the individual uncertainties for the various sources as discussed above. The total uncertainties are also provided on Table 8-3, which summarizes the estimated steady-state heads.

Historical water-level data for each site in the Frenchman Flat area and vicinity are tabulated in Appendix C, in the pdf version on the CD only. The following paragraphs discuss transient water-levels in the individual wells located in and around Frenchman Flat.

\section{Army-1 WW}

Army-1 WW is a water-supply well located in Area 22 south of Frenchman Flat (Figure 8-1). This well, originally drilled in July 1958 and recompleted in July 1962, is completed in the LCA. A brief description of drilling records and the lithologic log for the Army-1 WW original completion can be found in Moore (1962). A summary of drilling records for the recompletion of this well can be 
found in Gillespie et al. (1996). The pumping record for this well can be found in Figure 7-2 (see Section 7.0).

Several water-level measurements were made in Army-1 WW around the time it was recompleted (Figure 8-2). Those measurements are unreliable due to a lack of documentation. A few additional measurements were taken during the late 1960s, early 1970s, and mid 1980s. These measurements indicate a reduction in the water level from recompletion until about 1972. However, three of these measurements, were taken shortly after the well had been pumping and probably represent recovery conditions. Multiple measurements have been taken at this site over the last ten years. A site status of $\mathrm{Z}$ is given for most of these measurements. Unfortunately, the activities resulting in the assignment of this status were not documented at the time of the water-level measurement and are unknown.

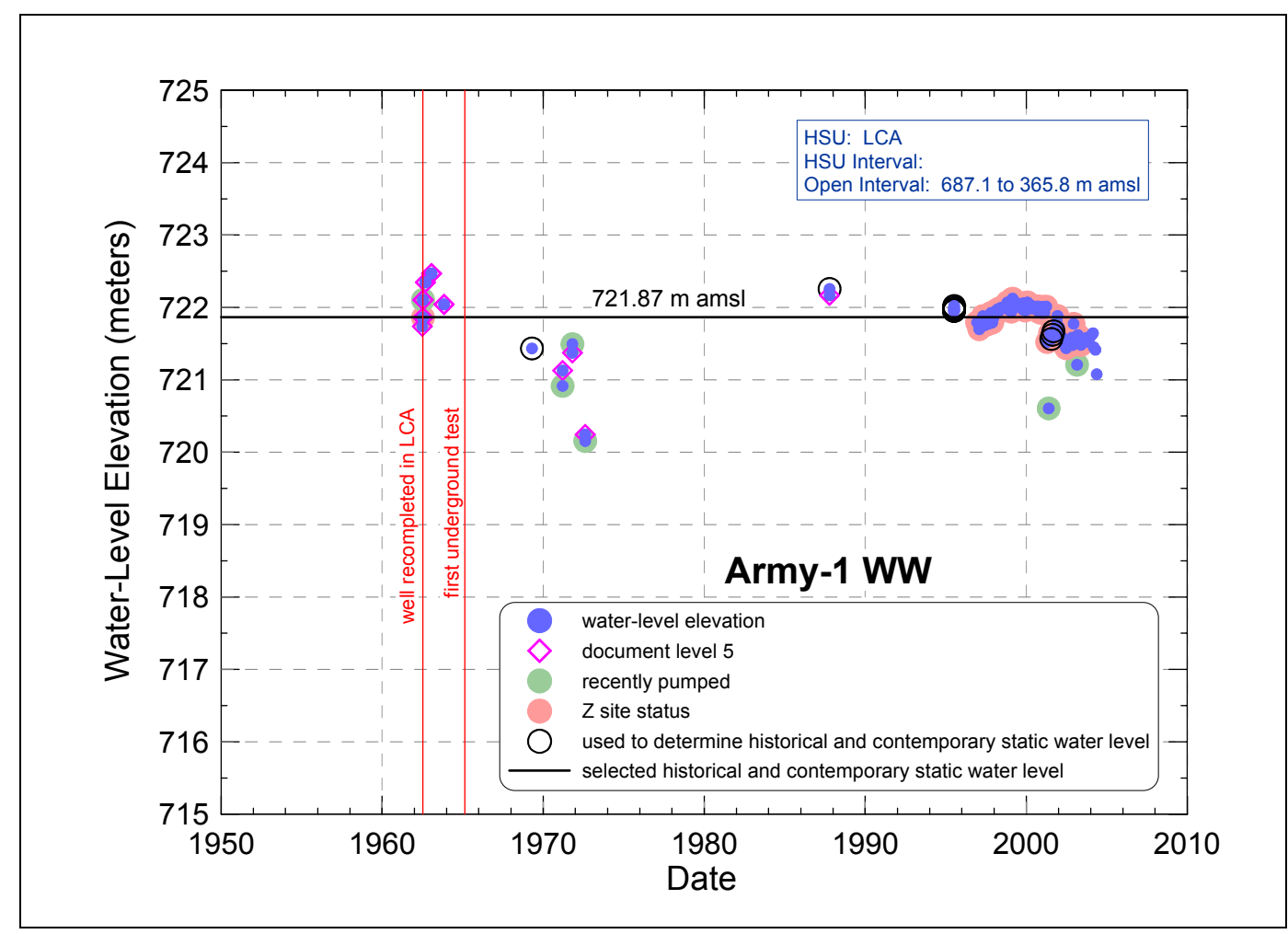

\section{Figure 8-2}

Army-1 WW Water-Level History

In general, the water level in this well has remained fairly stable $( \pm 2.5 \mathrm{~m})$ over the $40+$ years of record even though pumping has varied (see Figure 7-2). The only exception is a possible declining trend indicated by recent measurements. A hydraulic head representative of both historical and contemporary steady-state conditions was determined by eliminating:

- All measurements associated with a recently pumped status

- All measurements associated with a Z site status

- All measurements with a document level 5 
- The final few measurements which indicate a decline in head

The resultant 12 measurements, indicated with an open black circle on the hydrograph, were averaged to obtain a steady-state head of $721.87 \mathrm{~m}$ above mean sea level (amsl). This value is assumed to be representative of both historical and contemporary conditions. Due to the sparsity of data associated with some of the measurements used to determine the steady-state head, the uncertainty in the head due to data frequency is $0.20 \mathrm{~m}$. The overall uncertainty in the steady-state head for Army- $1 \mathrm{WW}$ is $1.15 \mathrm{~m}$.

\section{ER-5-3 Well Cluster}

The ER-5-3 well cluster is located in the northern portion of Frenchman Flat (Figure 8-1) and consists of three wells: ER-5-3, ER-5-3 \#2, and ER-5-3 \#3. ER-5-3 was completed in March 2000 and consists of a main borehole, a shallow piezometer, and a deep piezometer. The main borehole has two open intervals. The upper interval is open to the AA and the lower interval is open to the TM-WTA. Both of these intervals were open to the borehole when the water-levels shown on the hydrographs were measured. The shallow piezometer is open across $45 \mathrm{~m}$ of the AA and $9 \mathrm{~m}$ of the Basalt Lava Flow Aquifer (BLFA). The deep piezometer is open across $14 \mathrm{~m}$ of the AA and $59 \mathrm{~m}$ of the TM-WTA. ER-5-3 \#2 was completed to the LCA in May 2000. ER-5-3 \#3 was completed to the AA in February 2001. Wells in the ER-5-3 well cluster were drilled as part of the DOE Environmental Restoration Project. Complete discussions of well drilling, developing, and testing activities in these wells along with detailed descriptions of the well completions can be found in IT (2001c) and/or IT (2002b). Completion diagrams for the wells in this cluster can be found in Appendix D, Figure D.1-1.

The measured water-level in all three of these wells, including the two piezometers in ER-5-3, are shown on the hydrographs in Figure 8-3a and $b$ at two different time scales on the horizontal axis: 1950 to 2010 and January 2000 to January 2005. These two hydrographs show all of the water-level data which span about $375 \mathrm{~m}$. One of the high water-level measurements in ER-5-3 was made during drilling. Comments in the UGTA Borehole Index Database indicate that the two high water-levels measured in ER-5-3 \#2 were measurements to see if the check valve was holding. At this vertical scale, the water-level in all completions in the cluster appear identical with the exception of the water-level in ER-5-3 \#2 which appear slower. The water-level in each of the completions in this cluster was plotted separately in Figure 8-4a and b for the ER-5-3 shallow piezometer, Figure 8-5a and $\mathrm{b}$ for the ER-5-3 deep piezometer, Figure 8-6a and $\mathrm{b}$ for the main completions in ER-5-3, Figure 8-7a and $\mathrm{b}$ for ER-5-3 \#2, and Figure 8-8 a and $\mathrm{b}$ for ER-5-3 \#3.

The water-level in the ER-5-3 shallow piezometer has remained essentially constant over the period of record (Figure 8-4b). A Z site status is indicated for about four of these measurements. Excluding those measurements, the remaining measurements were averaged to determine a contemporary, steady-state head of $734.57 \mathrm{~m}$ amsl. The uncertainty in this steady-state value is estimated to be $1.06 \mathrm{~m}$. 


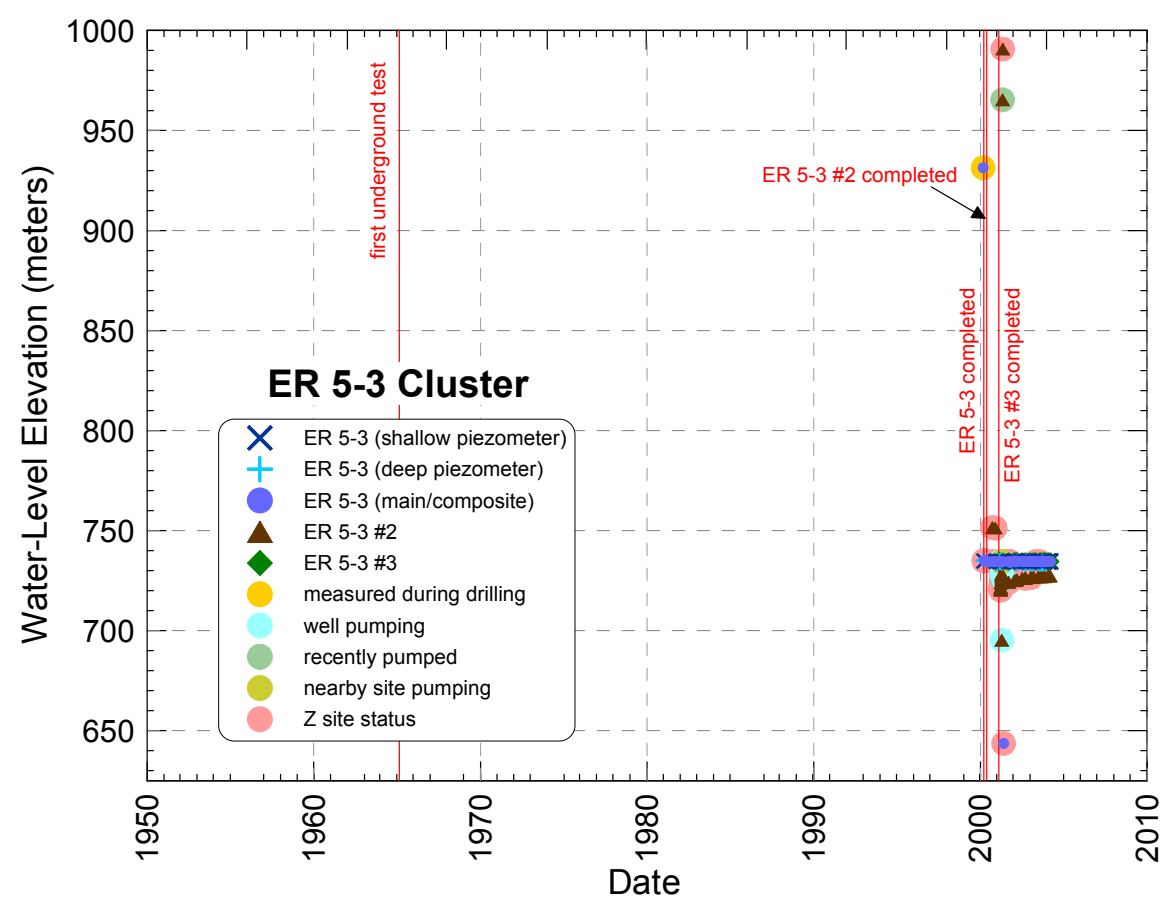

A

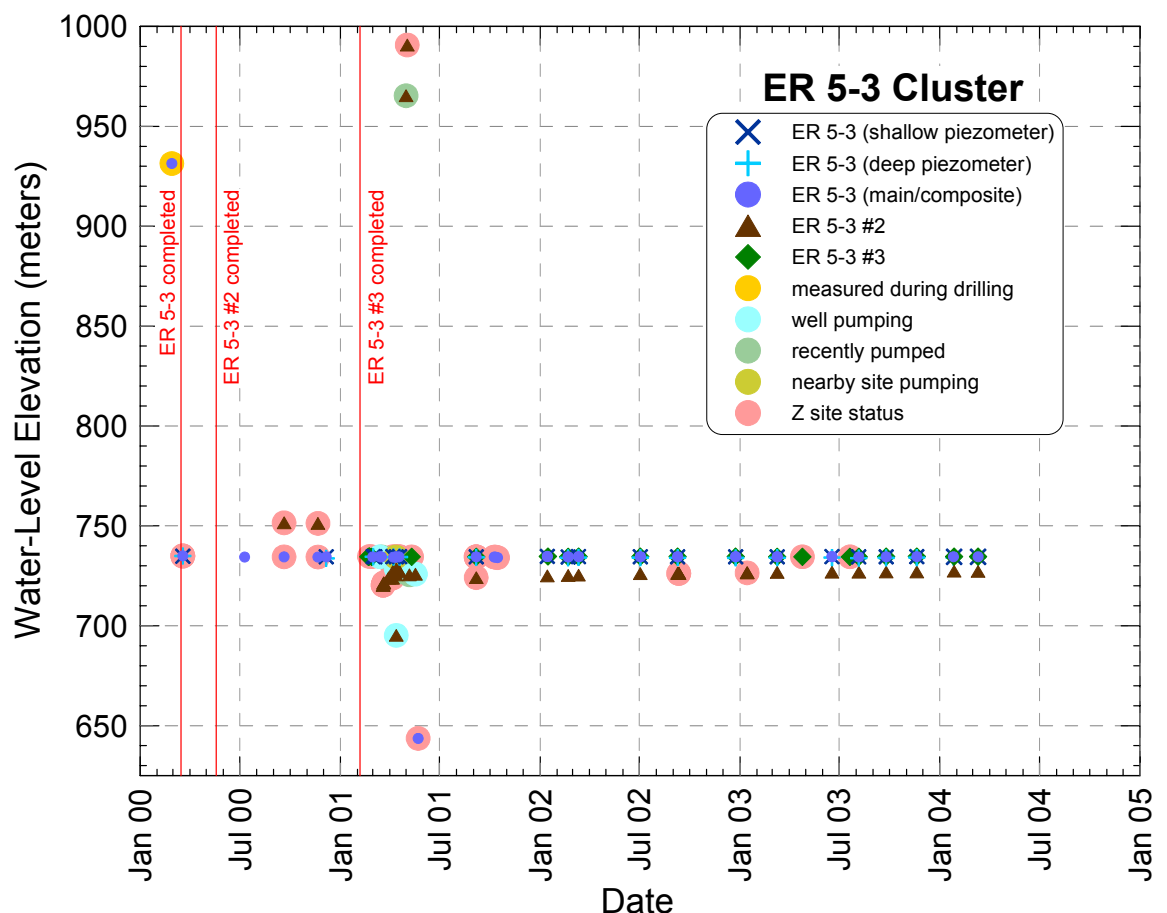

B

Figure 8-3

Well Cluster ER-5-3 Water-Level History 


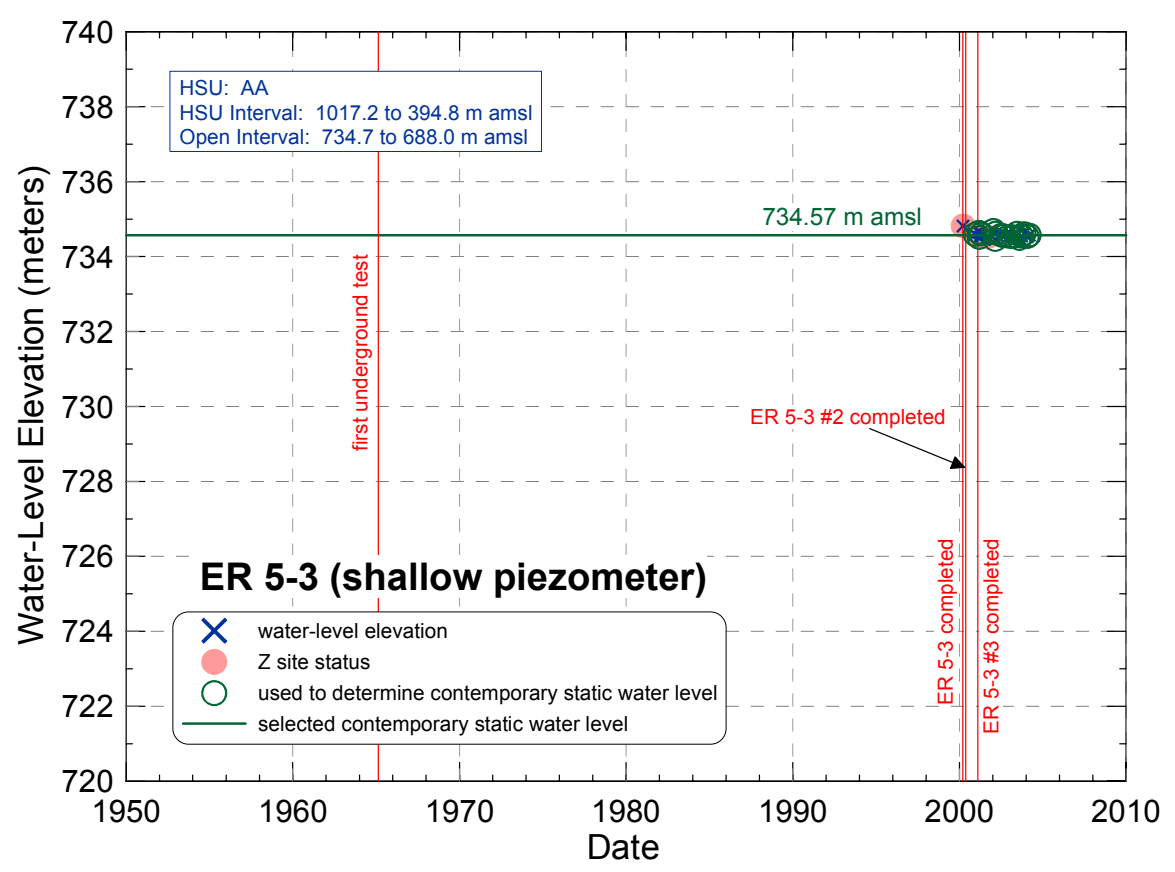

A

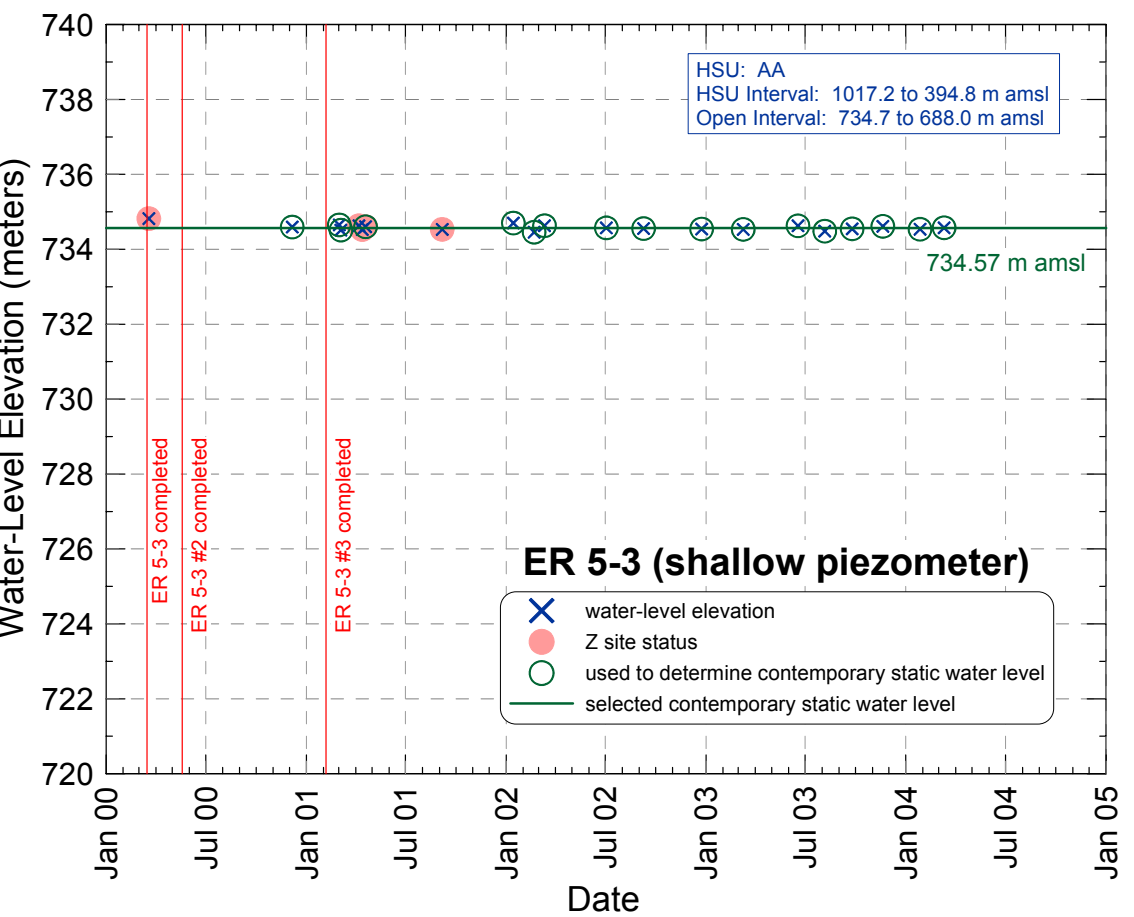

B

Figure 8-4

Well ER-5-3 (Shallow Piezometer) Water-Level History 


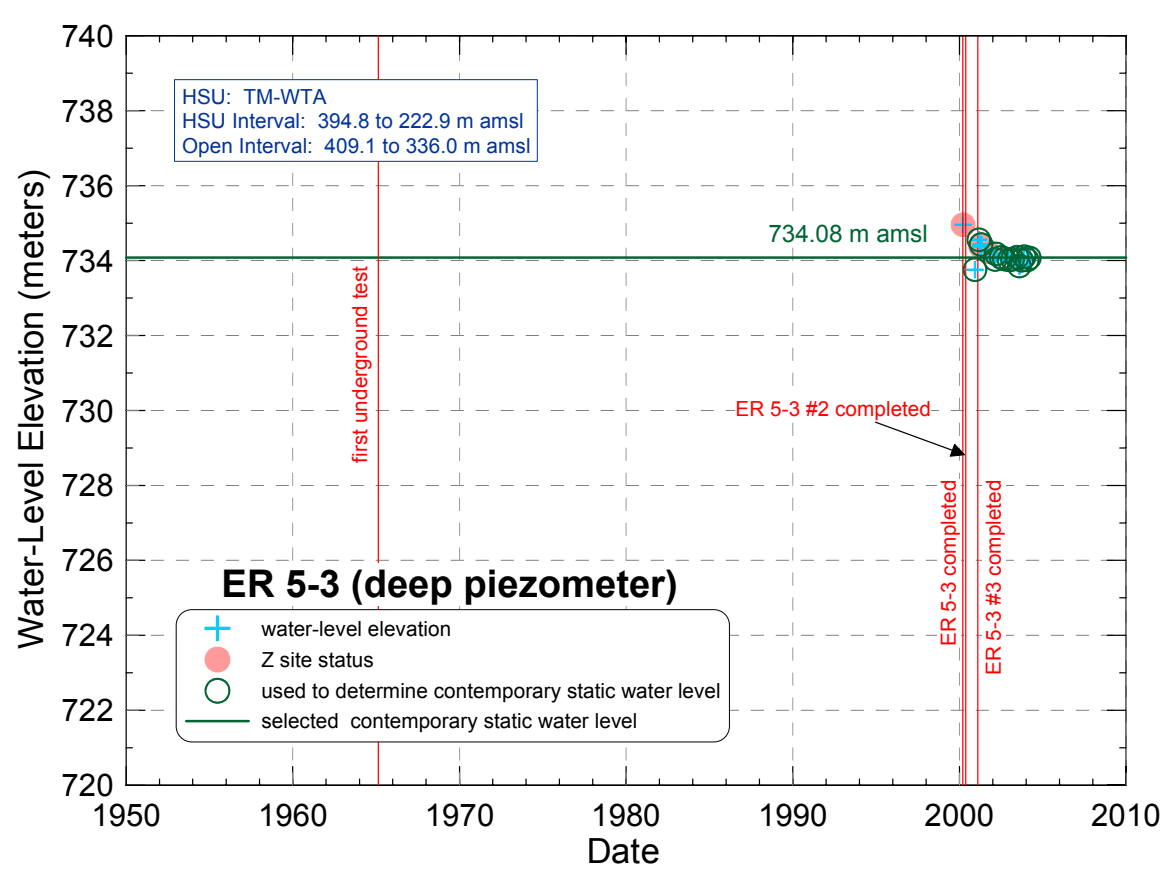

A

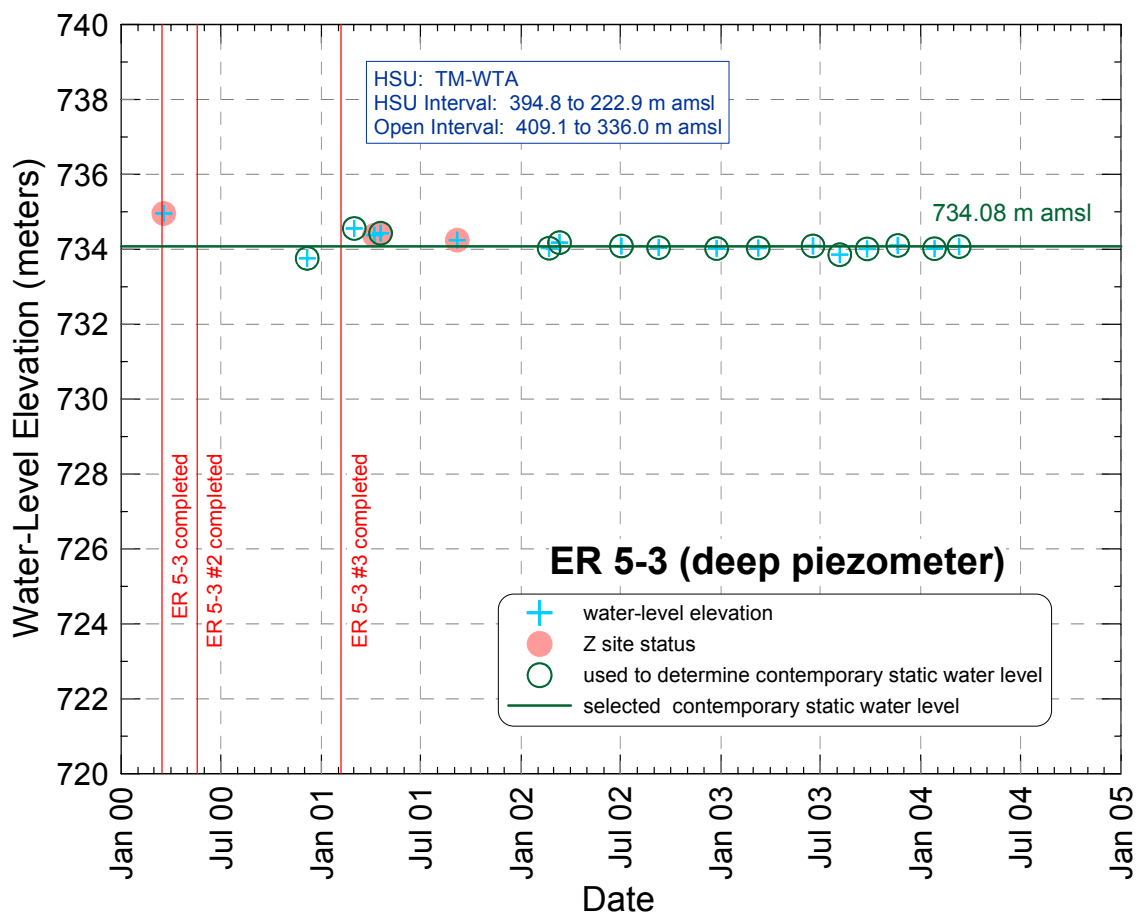

B

Figure 8-5

Well ER-5-3 (Deep Piezometer) Water-Level History 


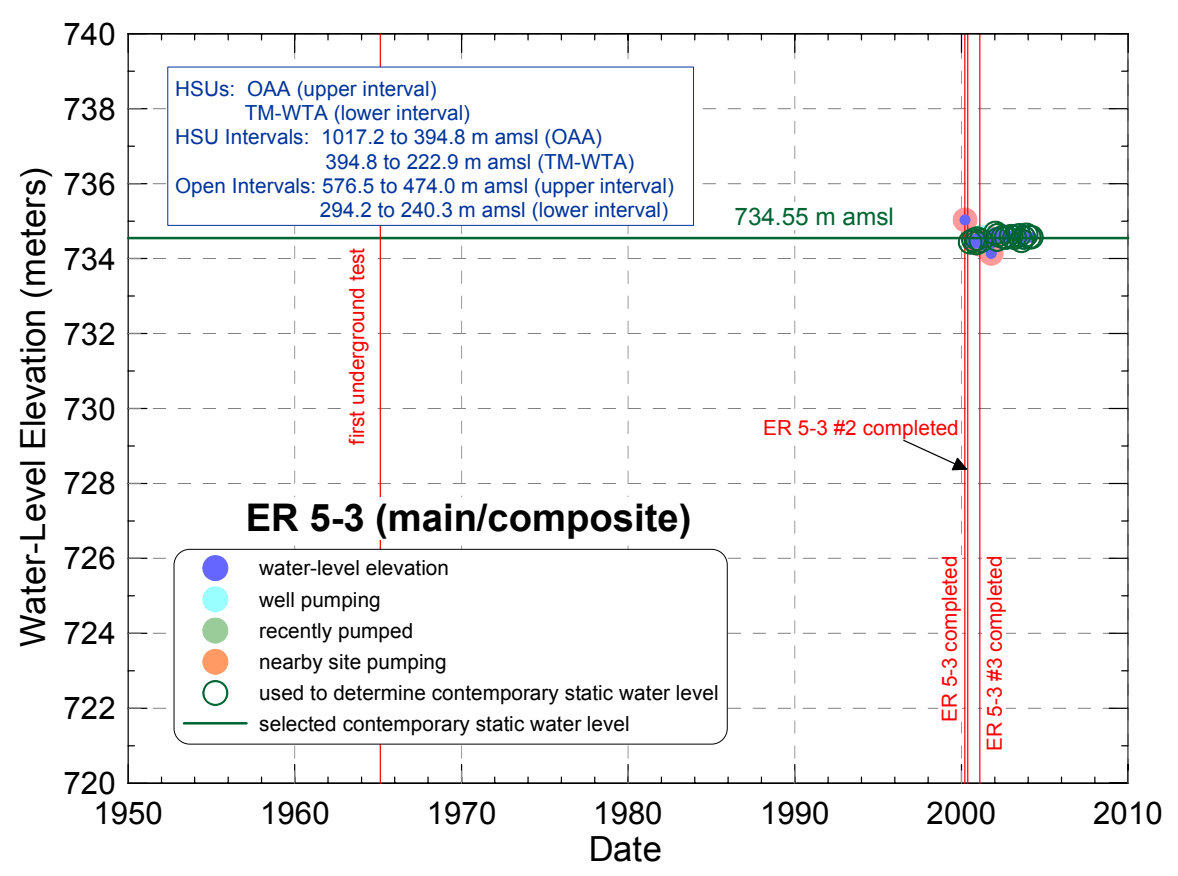

A

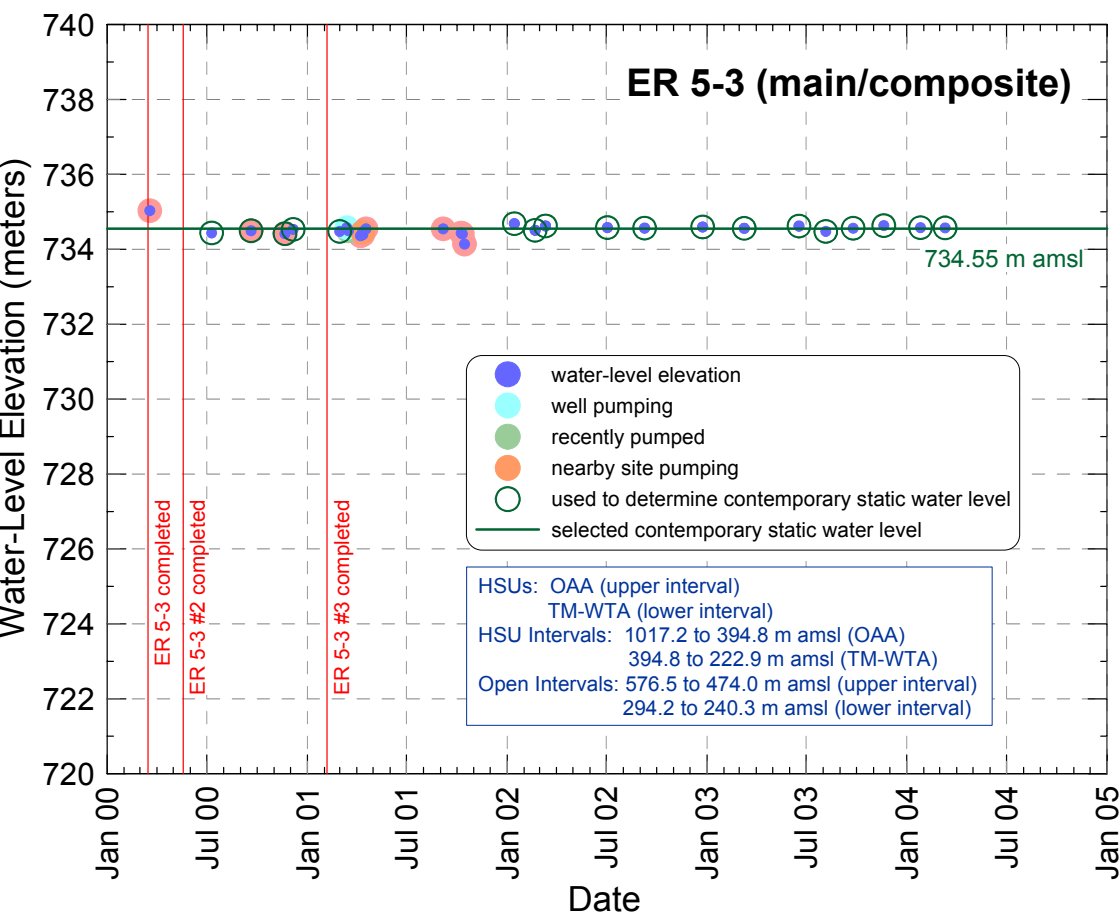

B

Figure 8-6

Well ER-5-3 (Main/Composite) Water-Level History 


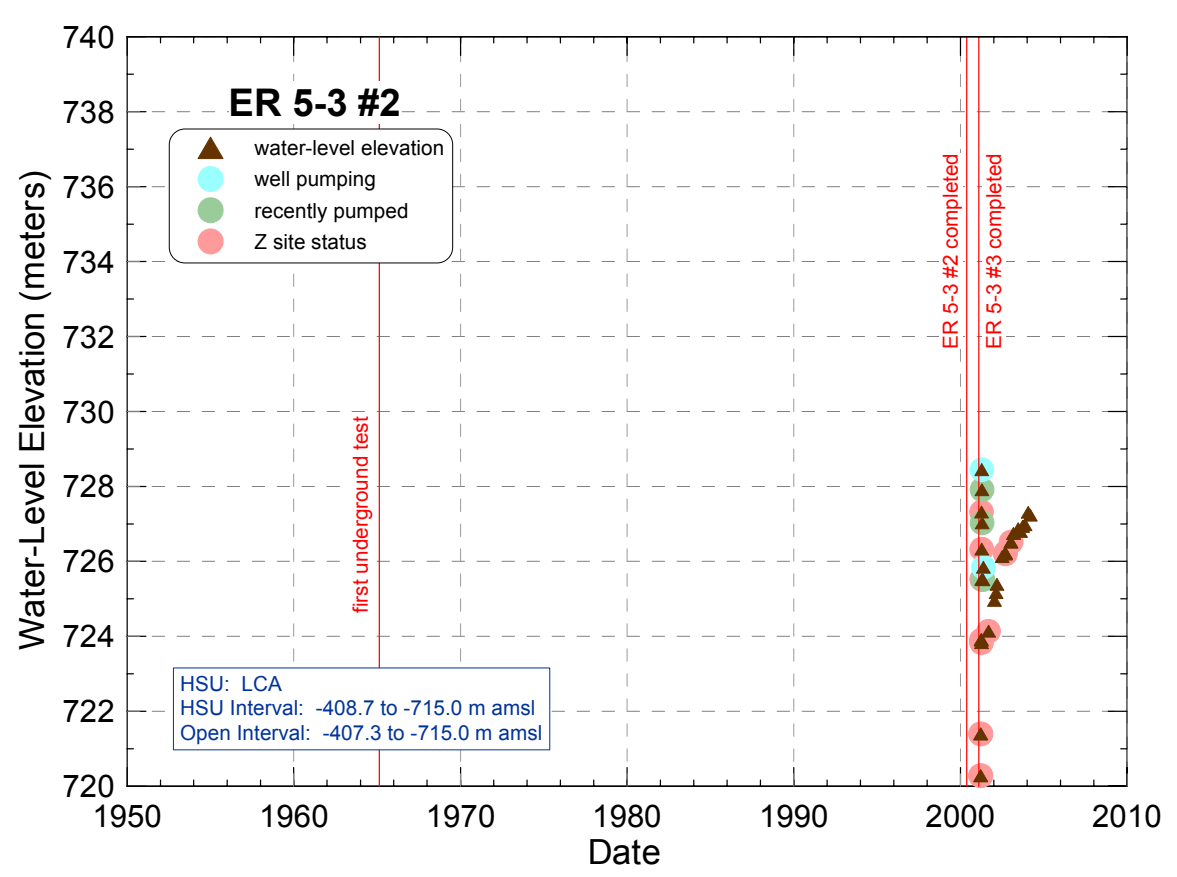

A

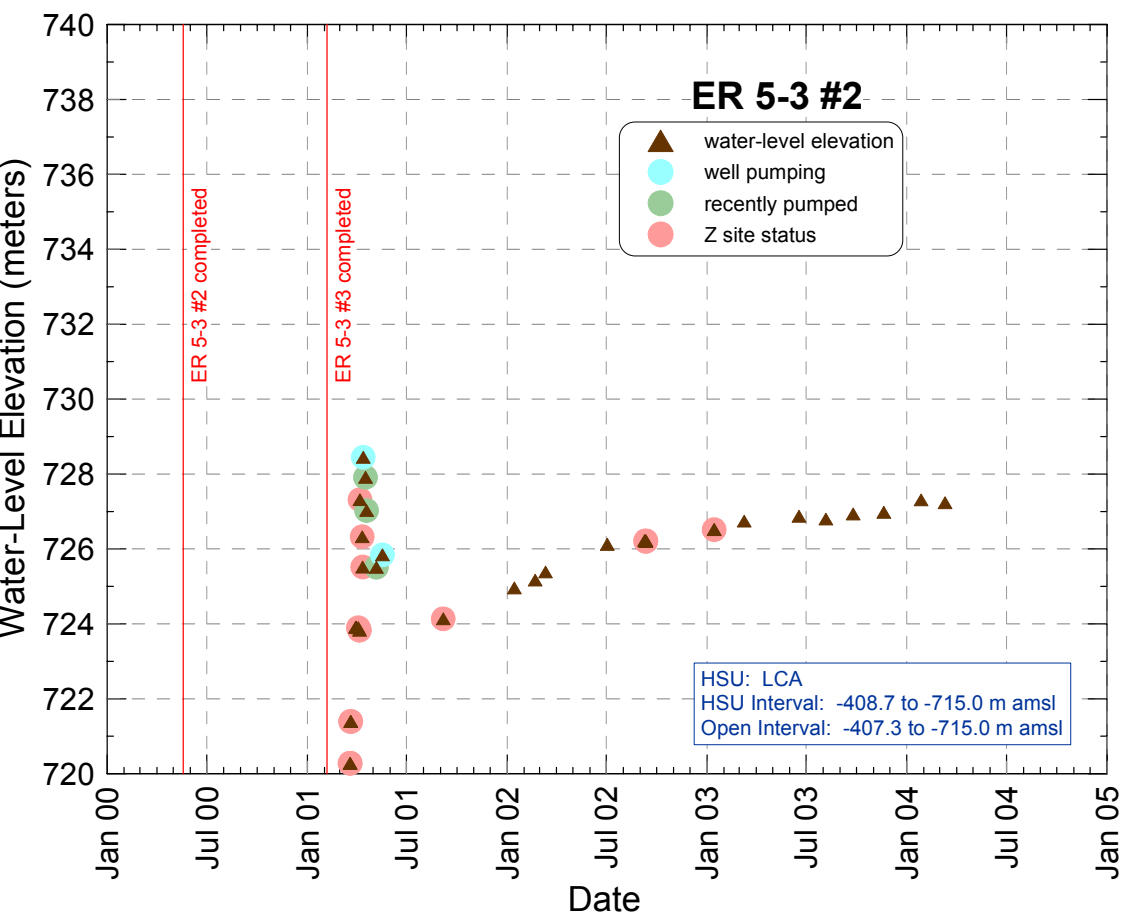

B

Figure 8-7

Well ER-5-3 \#2 Water-Level History 


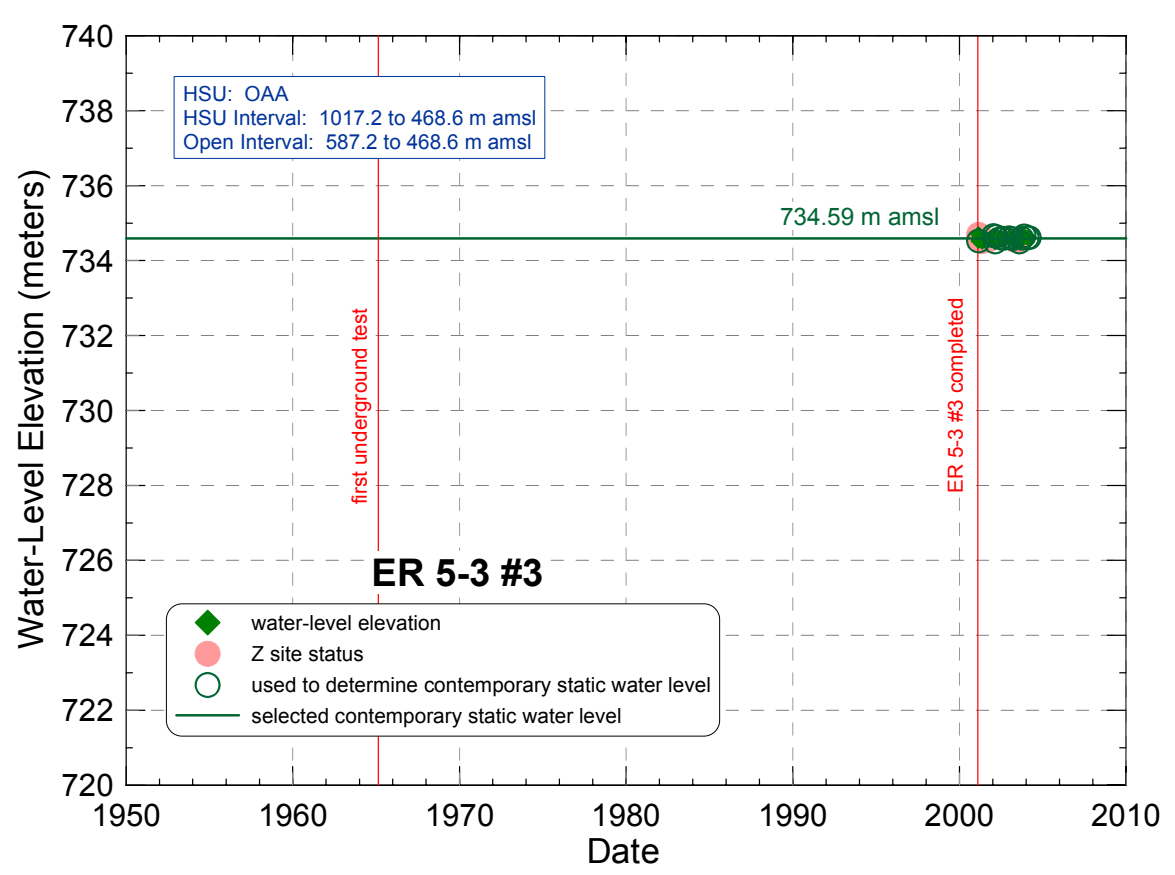

A

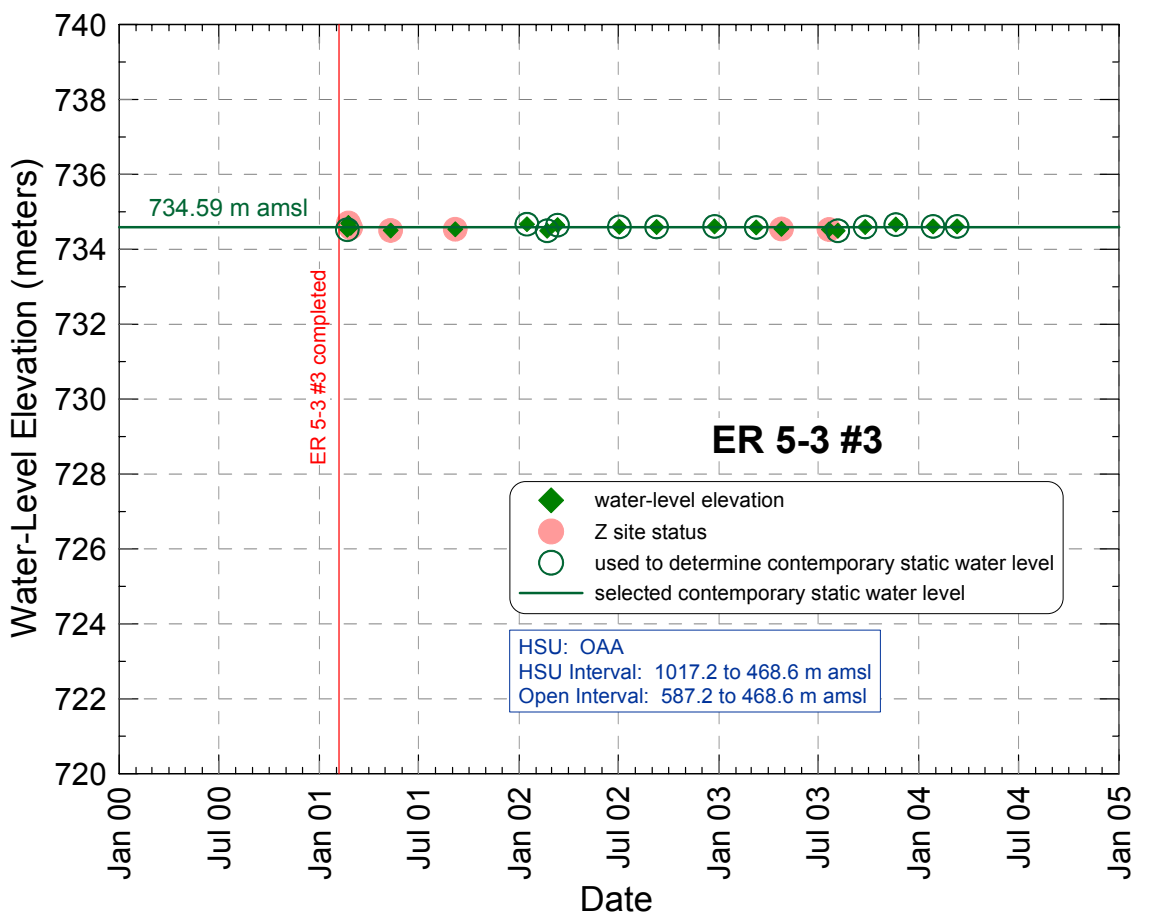

B

Figure 8-8

Well ER 5-3 \#3 Water-Level History 
The water-level in the ER-5-3 deep piezometer has also remained essentially constant over the period of record (Figure 8-5b). A Z site status is indicated for four of the measurements. The remaining measurements were averaged to obtain a contemporary, steady-state head of $734.08 \mathrm{~m}$ amsl. The uncertainty in this steady-state value is estimated to be $1.19 \mathrm{~m}$.

The composite water-level for the two completions in the ER-5-3 main borehole has remained essentially constant over the period of record. As indicated on Figure 8-6b, several water-level measurements were associated with site activities such as recent pumping or pumping at a nearby site. The average of the water-level measurements taken in ER-5-3 main when the site was undisturbed is $734.55 \mathrm{~m}$ amsl. The uncertainty in this steady-state value is estimated to be $1.07 \mathrm{~m}$.

The water-level in ER-5-3 \#2 (Figure 8-7b) has risen steadily since the latter half of 2001. The cause for this rise is not clearly understood at this time. Because the water level in this well has not yet stabilized and the cause of the rise in the water level is unknown, a steady-state head was not determined for this well.

The water level in ER-5-3 \#3 has remained essentially constant over the period of record (Figure 8-8b). The average of all measurements not associated with site activity yield a contemporary, steady-state head of $734.59 \mathrm{~m}$ amsl. The uncertainty in this steady-state value is estimated to be $1.05 \mathrm{~m}$.

\section{ER-5-4 Well Cluster}

The ER-5-4 well cluster is located in the southern portion of Frenchman Flat (Figure 8-1) and consists of two wells: ER-5-4 and ER-5-4 \#2. ER-5-4 was completed in March 2001 and consists of a main borehole and a piezometer. The main borehole has two open intervals. The upper interval is open to the AA and the lower interval is open to $200 \mathrm{~m}$ of the AA and $19 \mathrm{~m}$ of the TM-WTA. Both of these intervals were open to the borehole at the time the water levels shown on the hydrographs were measured. The shallow piezometer is also open to the AA. ER-5-4 \#2 was completed to the LTCU in September 2002. Wells in the ER-5-4 well cluster were drilled as part of the DOE Environmental Restoration Project. Complete discussions of well drilling, developing, and testing activities in these wells along with detailed descriptions of the well completions can be found in IT (2001e) and/or Shaw (2003). Completion diagrams for the wells in this cluster can be found in Appendix D, Figure D.1-4.

The water level in all completions at the ER-5-4 cluster are shown in Figure 8-9a and $\mathrm{b}$. Measured water levels span about $400 \mathrm{~m}$. In general, the anomalously high and low water levels were measured during drilling and do not reflect completion interval conditions. Most of the measurements are fairly stable with the exception of those in ER-5-4 \#2 during drilling. Hydrographs for the individual completions in this cluster are found in Figure 8-10a and $b$ for the ER-5-4 piezometer, in Figure 8-11 $\mathrm{a}$ and $\mathrm{b}$ for the ER-5-4 main completion, and in Figure 8-12a and $\mathrm{b}$ for ER-5-4 \#2.

Little change in water level has been observed in the ER-5-4 piezometer (Figure 8-10b). Early measurements show a slight decline of about $0.7 \mathrm{~m}$. All 


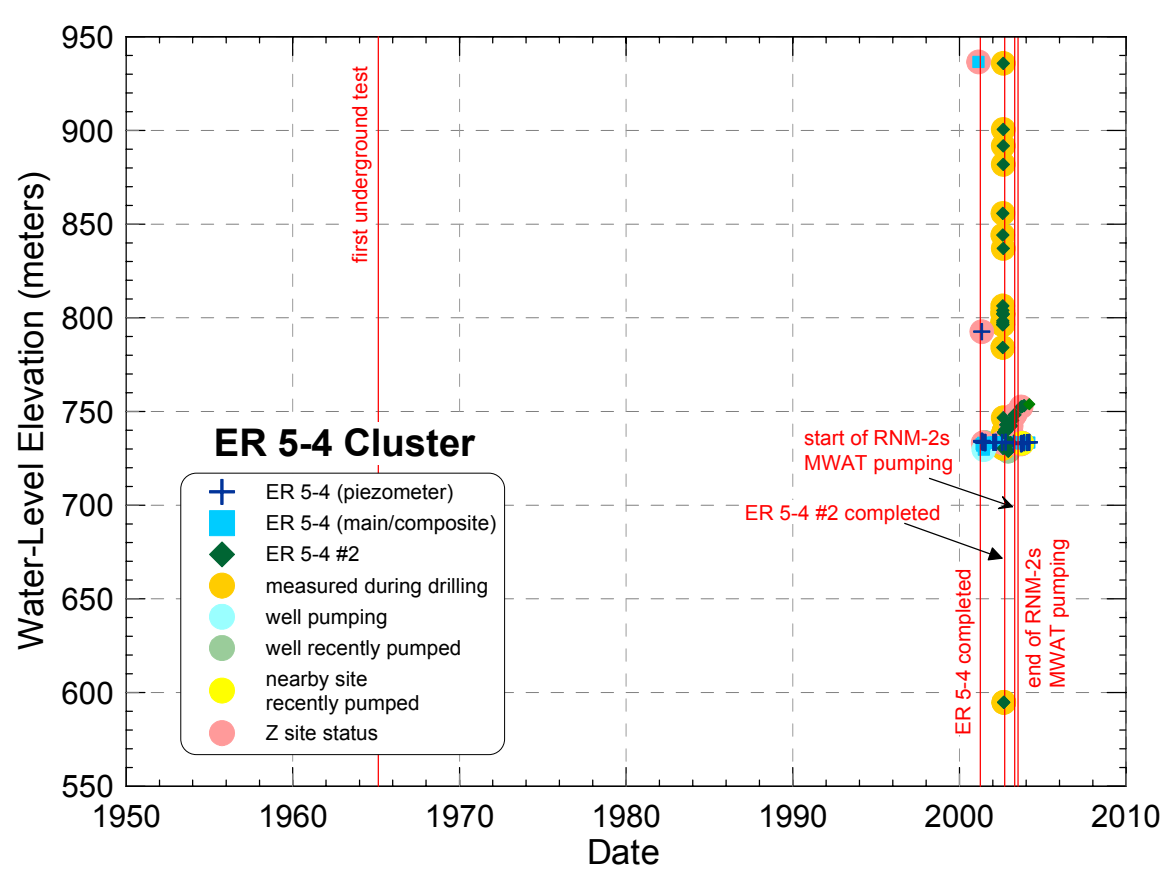

A

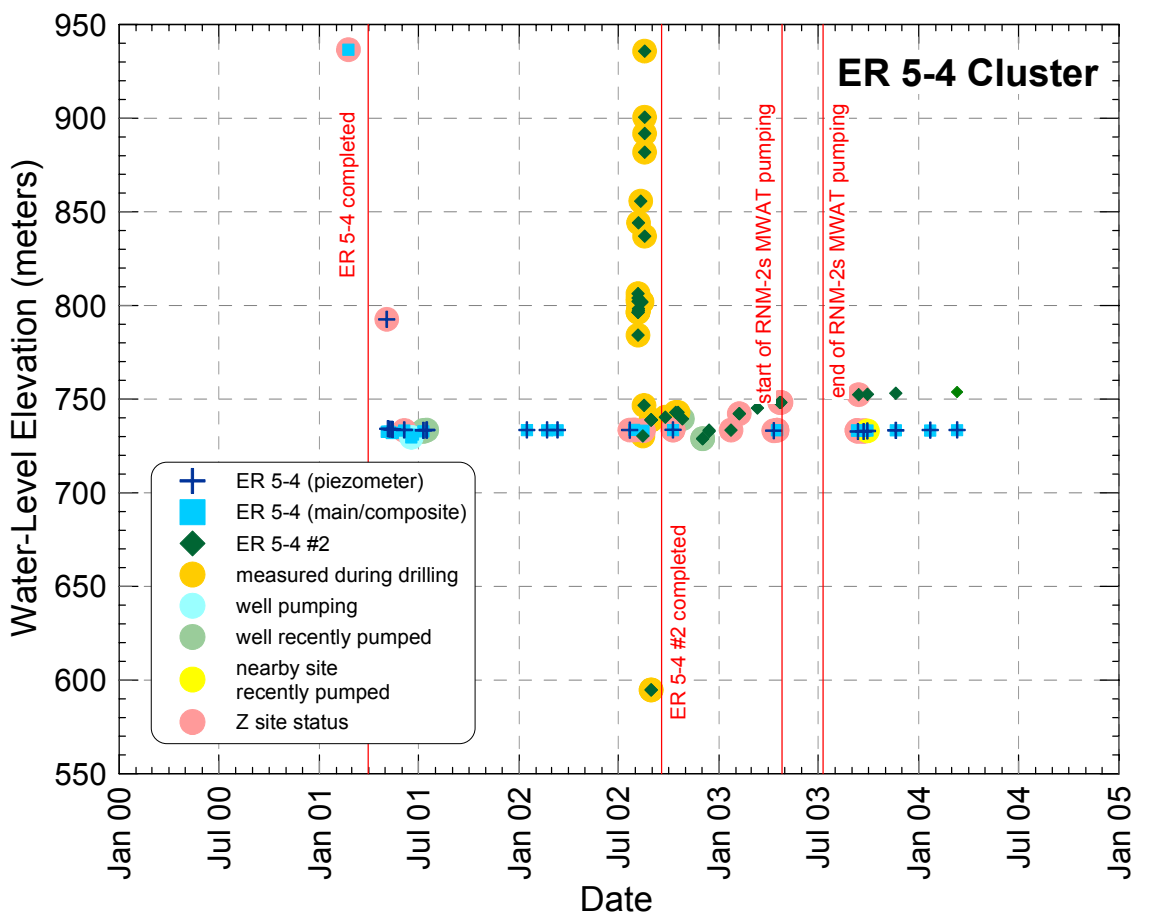

B

Figure 8-9

Well Cluster ER-5-4 Water-Level History 


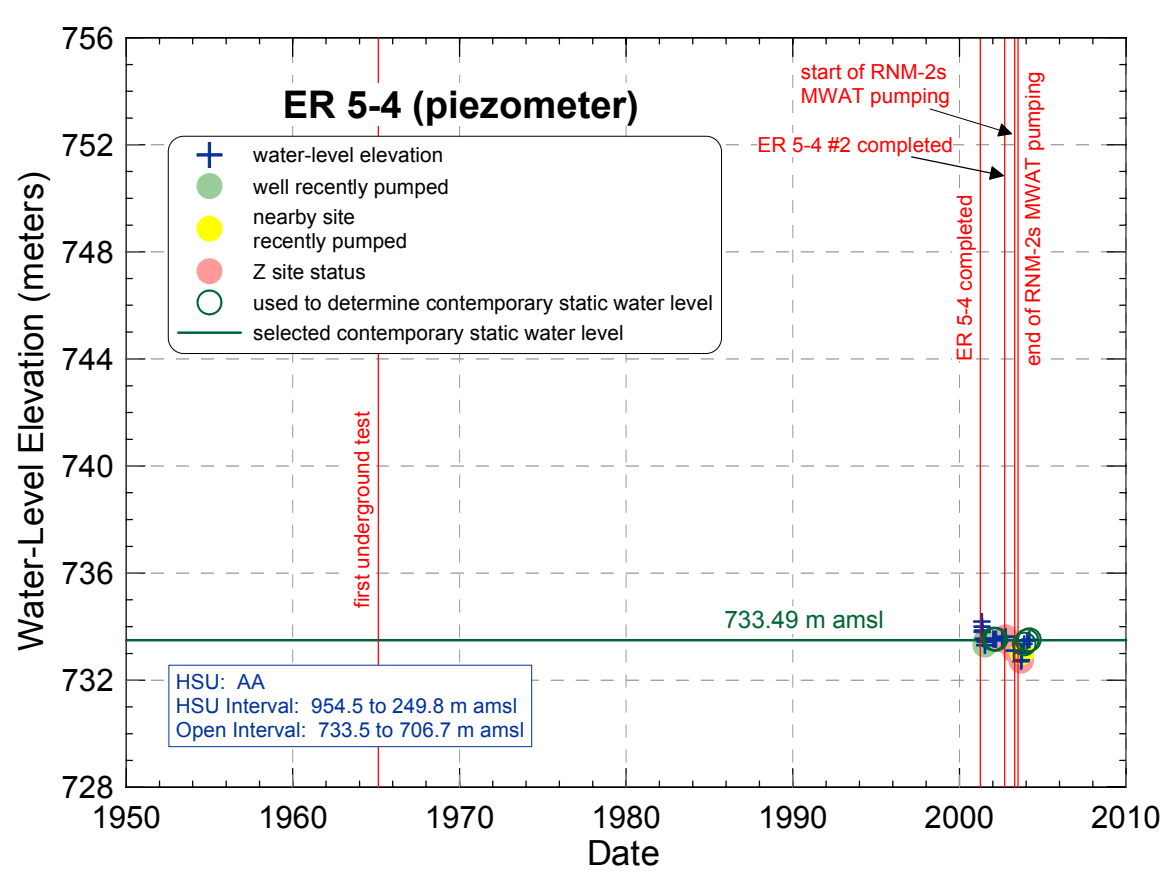

A

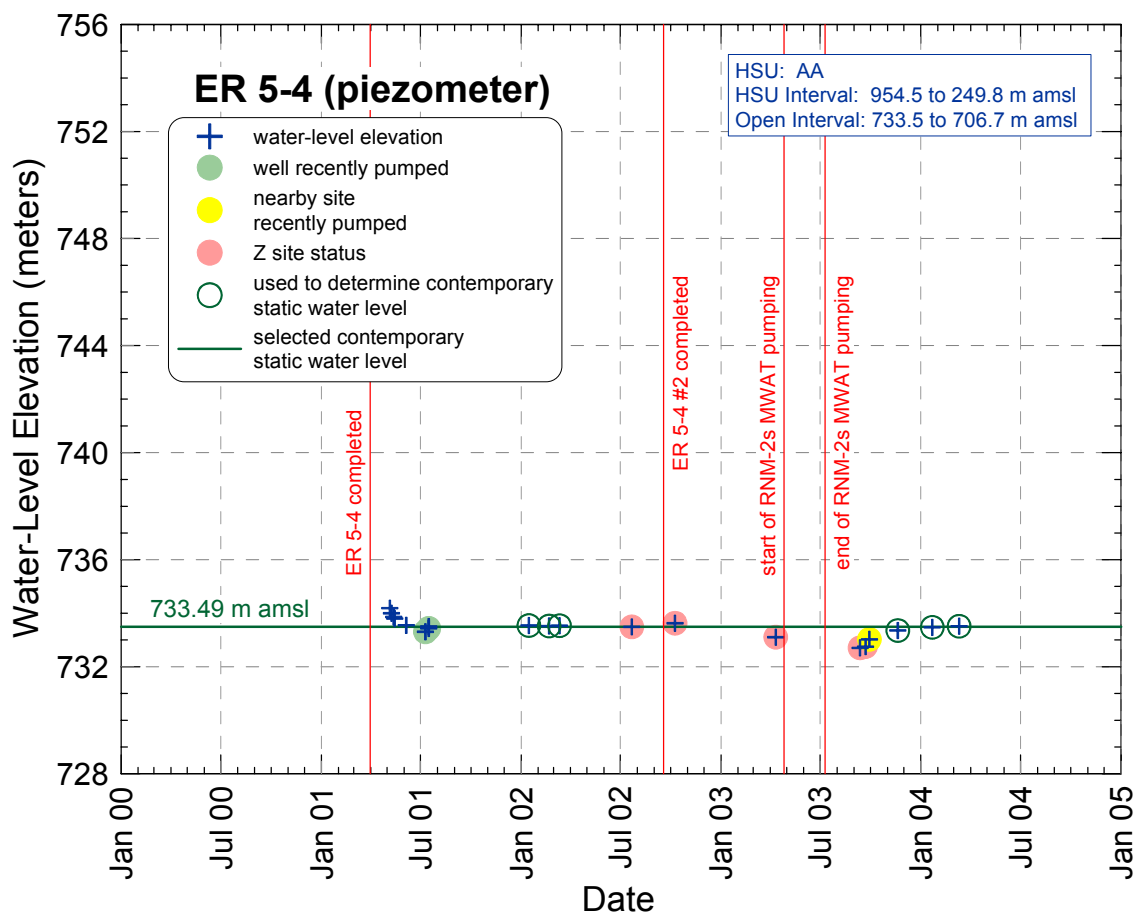

B

Figure 8-10

Well ER-5-4 (Piezometer) Water-Level History 


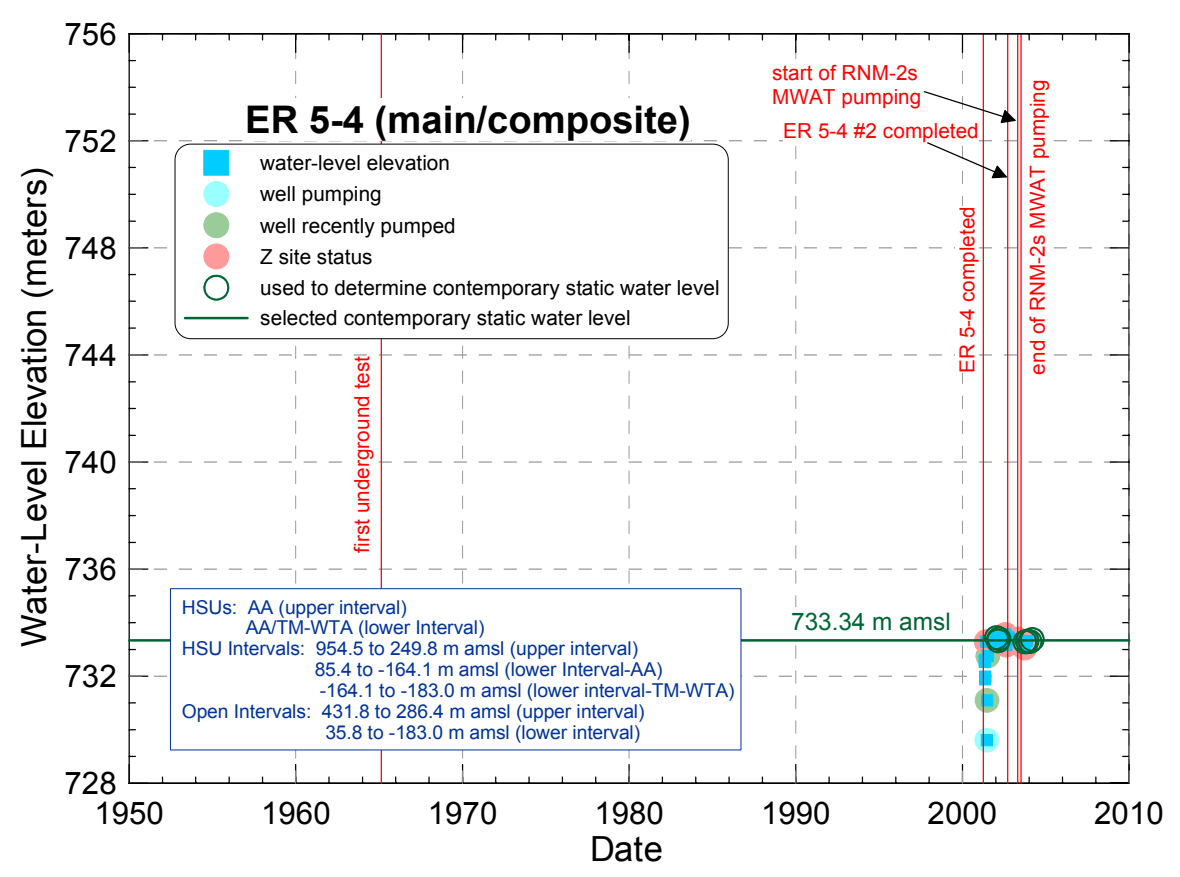

A

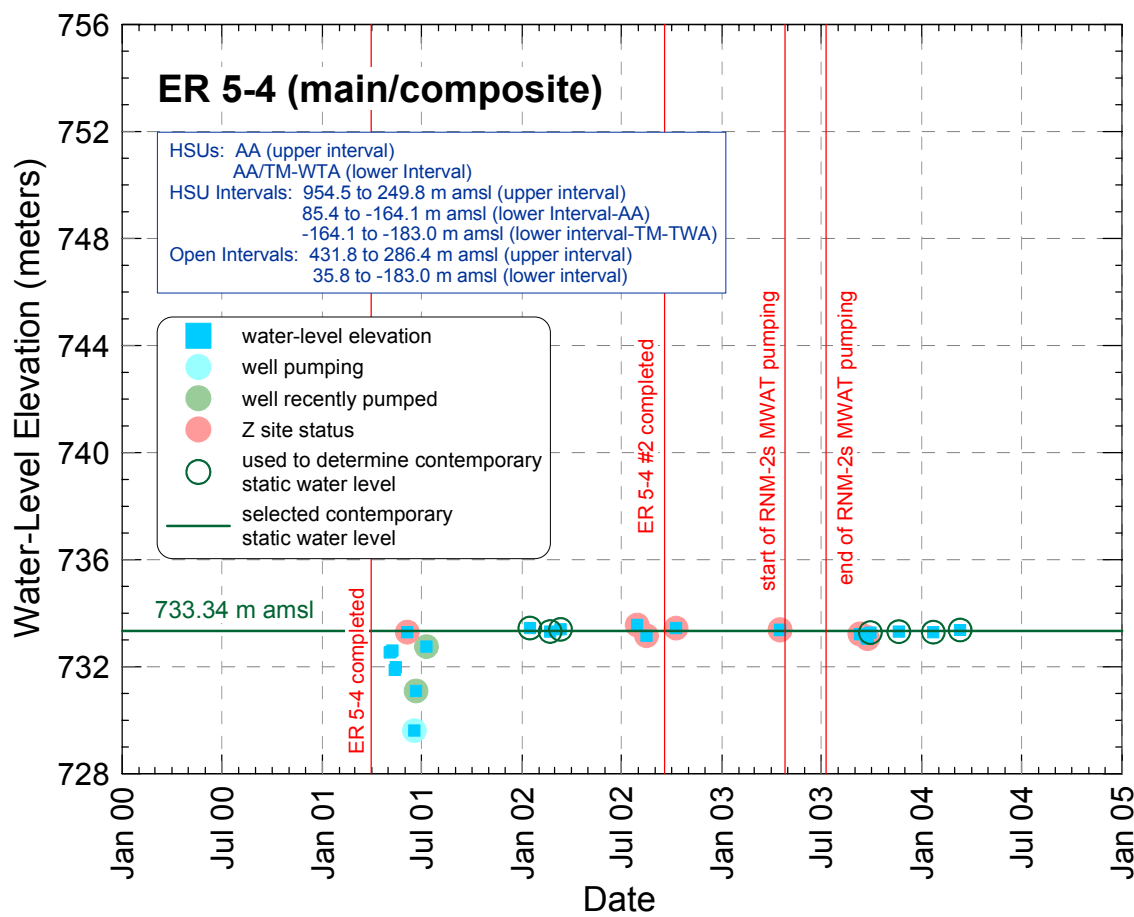

B

Figure 8-11

Well ER-5-4 (Main/Composite) Water-Level History 


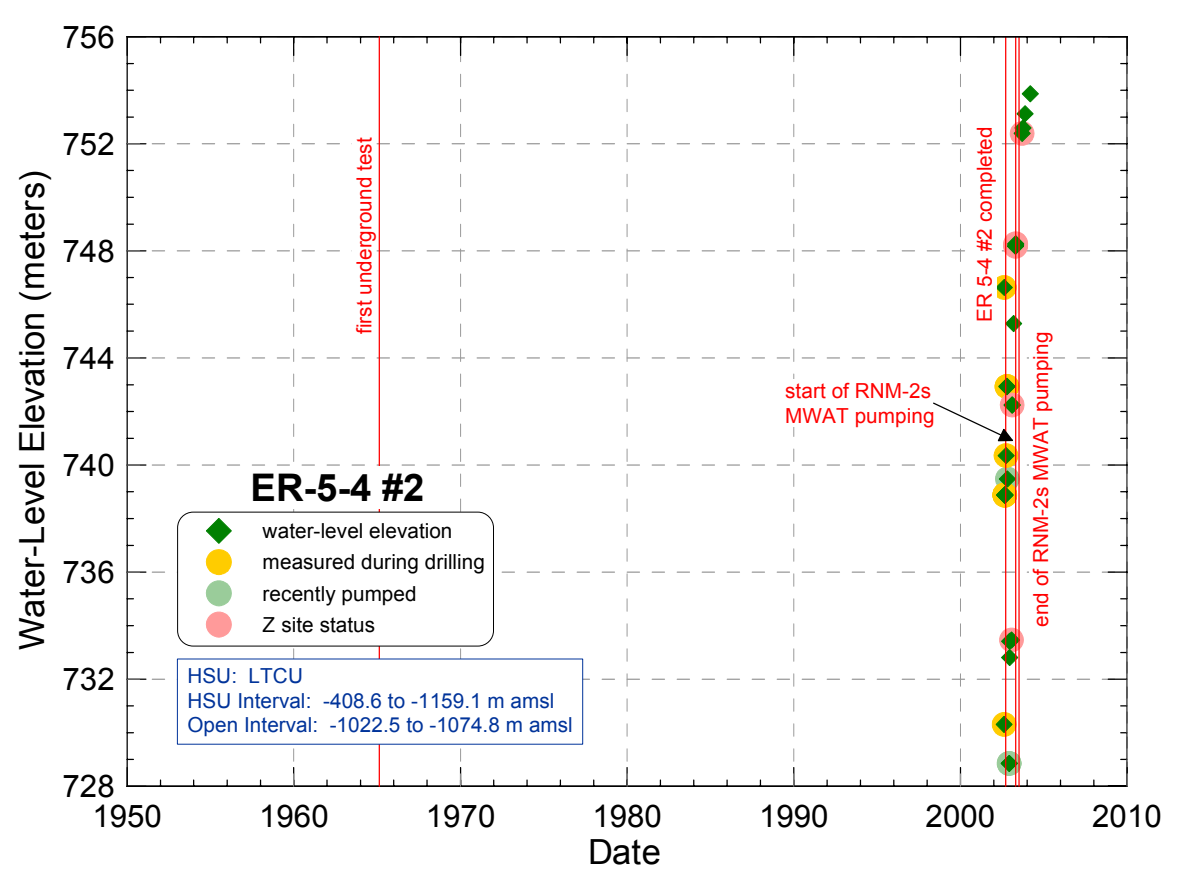

A

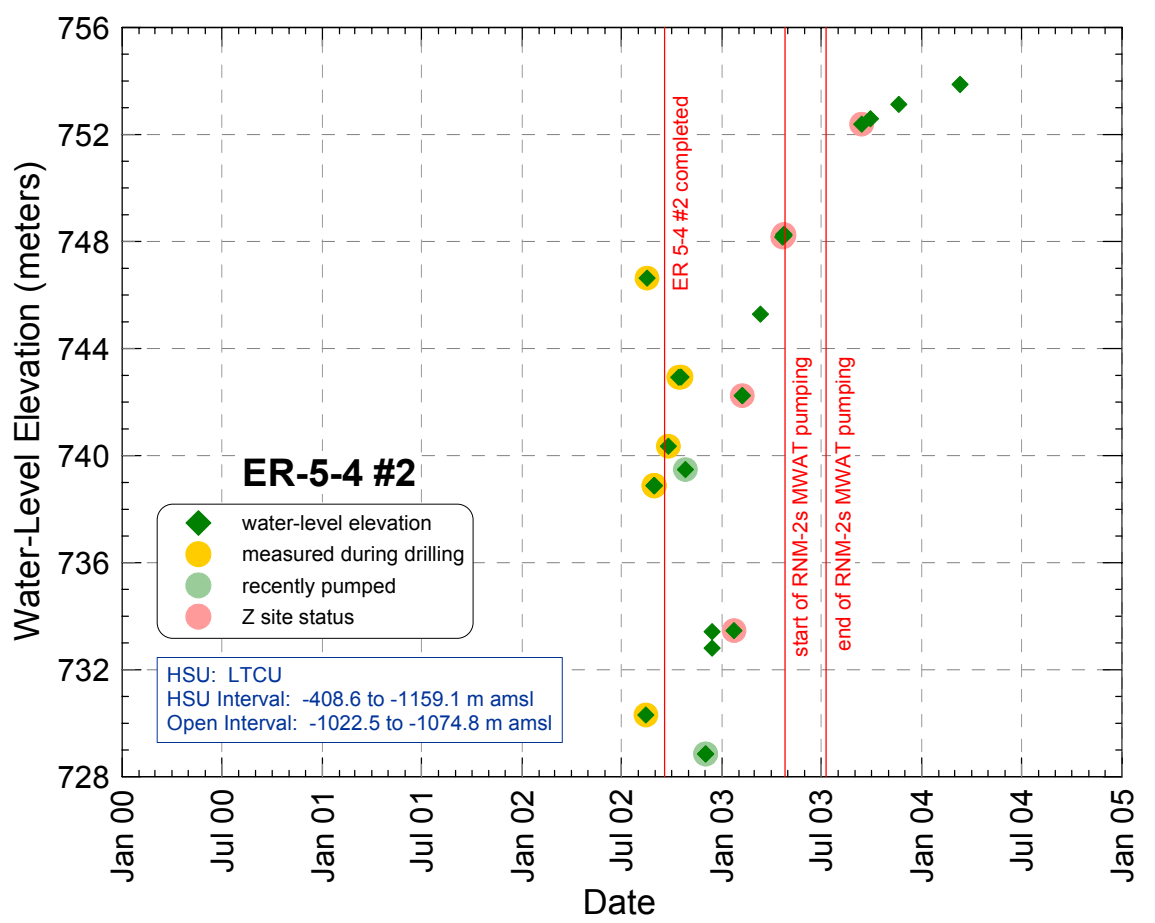

B

Figure 8-12

Well ER-5-4 \#2 Water-Level History 
subsequent measurements show an essentially stable water level with the exception of those associated with some site or nearby site activity. All measurements after the initial decline and during undisturbed conditions at the site were averaged to obtain a contemporary, steady-state head of $733.49 \mathrm{~m}$ amsl. The uncertainty in this steady-state value is estimated to be $0.44 \mathrm{~m}$.

Equilibration of the composite water level for the two open intervals in the ER-5-4 main borehole appears to have occurred for a little over three months after well completion (Figure 8-11b). Subsequent measurements show essentially no change in water-level. Of these later measurements, all those taken during undisturbed conditions at the site were averaged to obtain a contemporary, steady-state head of $733.34 \mathrm{~m}$ amsl. The uncertainty in this steady-state value is estimated to be $0.43 \mathrm{~m}$.

The water level in ER-5-4 \#2 before and several months after well completion appears to have been erratic (Figure 8-12b). After well completion, the water level in the well has steadily risen but has not yet stabilized. Because the water level in ER-5-4 \#2 has not stabilized, no steady-state head was determined for this well.

\section{RNM-1}

RNM-1 is a radionuclide monitoring well located in the southern portion of Frenchman Flat near the ER-5-4 well cluster, RNM-2, RNM-2S, and UE-5n (Figure 8-1). This well was drilled in May 1974 as part of the CME

(Bryant, 1992). RNM-1 was drilled at approximately a 21-degree angle so that it intercepted the underground cavity resulting from the CAMBRIC explosion. This well is completed in the AA. A schematic of the well completion diagram for RNM-1 can be found in Appendix D, Figure D.1-6.

The water level was measured in RNM-1 near and shortly after the start of pumping in RNM-2S for the CME and in association with the MWAT conducted in RNM-2S in 2003 (Figure 8-13). No water-level measurements were taken in this well between July 1977 and February 2003. Two of the recent measurements were taken during site activities as indicated by the $\mathrm{Z}$ site status. Since the water level was not measured in this well during pumping of RNM-2S for the CME, the effects of that pumping on the water-level in RNM-1 is unknown. Very little trend is observed in the available data. The highest and lowest water-level measurements in this well appear to be anomalous. Excluding those two anomalous values, all other measurements taken during undisturbed conditions at the site were averaged to obtain a steady-state head of $731.31 \mathrm{~m}$ amsl which is considered to be representative of both historical and contemporary conditions. The uncertainty in this steady-state value is estimated to be $1.60 \mathrm{~m}$.

\section{RNM-2}

RNM-2 is a radionuclide monitoring well located in the southern portion of Frenchmen Flat near the ER-5-4 well cluster, RNM-1, RNM-2S, and UE-5n (see Figure 8-1). This well, drilled in August 1974, is completed to the AA. A schematic of the well completion diagram for RNM-2 can be found in Appendix D, Figure D.1-7. 


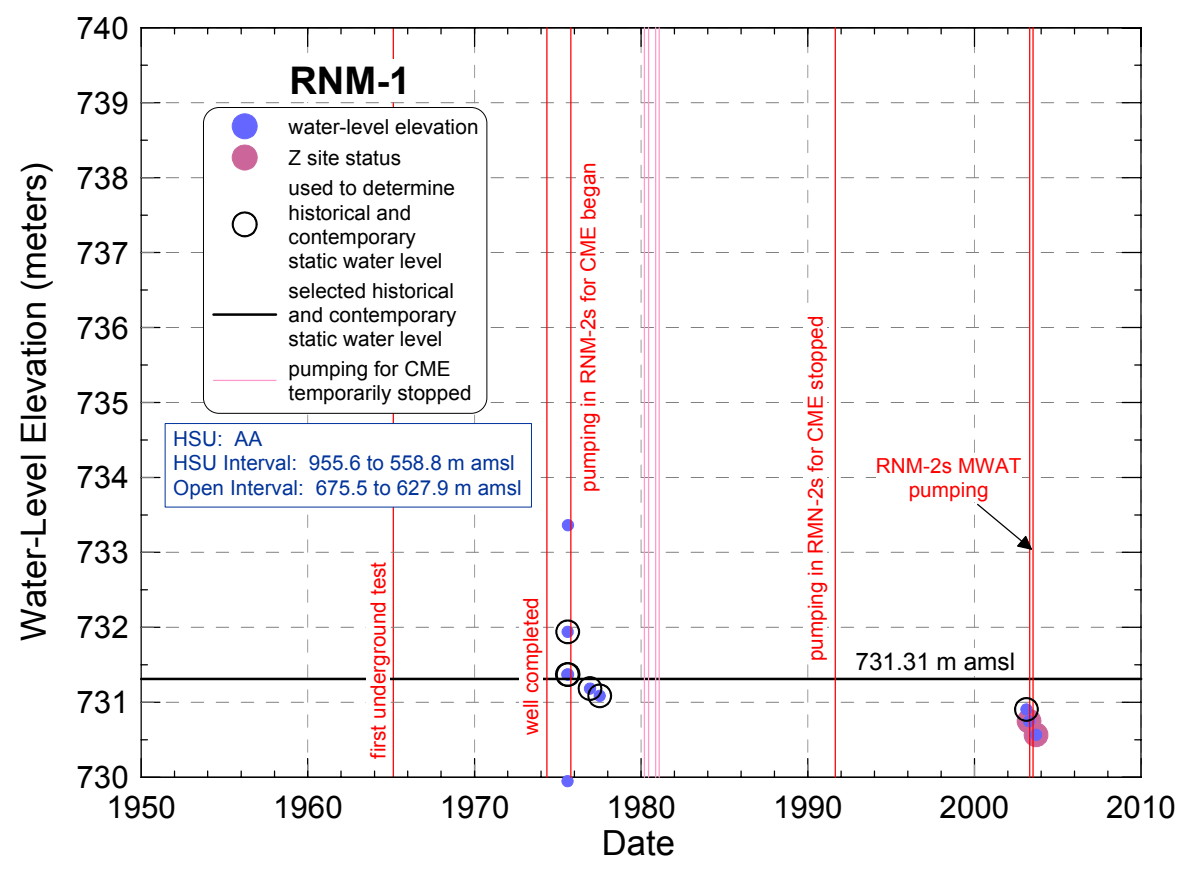

Figure 8-13

Well RNM-1 Water-Level History

The water level in this well was measured consistently between March 1974 and March 1985 (Figure 8-14). No additional measurements were made until 2003 at the time of the MWAT in RNM-2S, which is located nearby. The earliest measurements of water level in this well are associated with drilling activities. Subsequent measurements appear to reflect the effects of pumping in RNM-2S for the CME. The first water level measured in association with the RNM-2S MWAT was assigned a $\mathrm{Z}$ site status because the water level in the well was measured in association with setting a pressure transducer. Since no activity had occurred in the well before that measurement, it is assumed to be representative of undisturbed conditions in this well. This measurement was taken 10 years after pumping in RNM-2S for the CME had stopped. Because this measurement agrees with a measurement taken shortly after pumping began in RNM-2S for the CME, that measurement of $733.58 \mathrm{~m}$ amsl is assumed to represent both historical and contemporary steady-state conditions. The uncertainty in this steady-state value is estimated to be $0.88 \mathrm{~m}$.

\section{RNM-2S}

RNM-2S is a radionuclide monitoring well located in the southern portion of Frenchman Flat near the ER-5-4 well cluster, RNM-1, RNM-2, and UE-5n (see Figure 8-1). This well was drilled in April 1974 as part of the CME experiment (Bryant, 1992). A well completion diagram for RNM-2S, which is completed to the AA, can be found in Appendix D, Figure D.1-8. Pumping of this well for the CME began in October 1975 and stopped in August 1991. During this time, the 


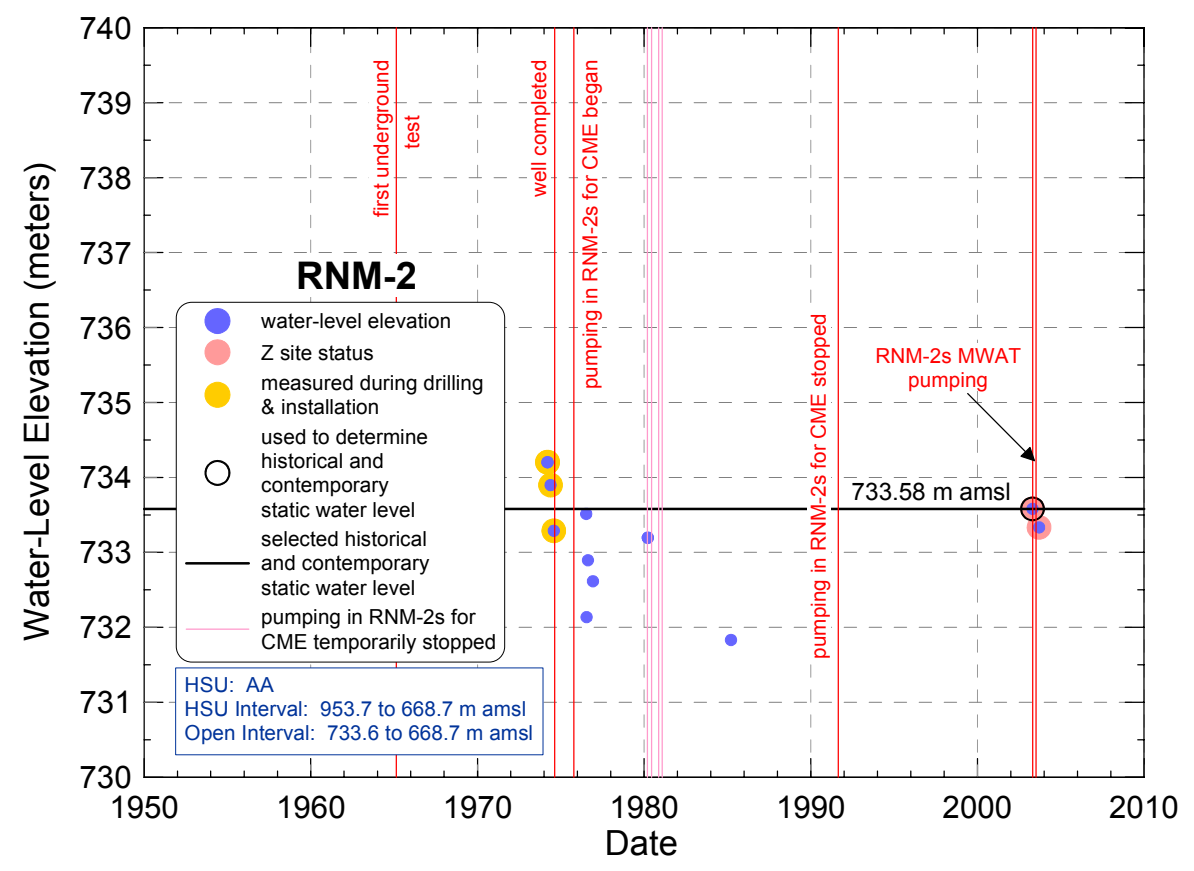

Figure 8-14

Well RNM-2 Water-Level History

well was pumped at an average rate of about 23 million gallons per month (see Figure 7-3 in Section 7.0).

Two hydrographs were created for this well. One includes all of the data, which span about $58 \mathrm{~m}$ (Figure 8-15a) and the other has a 10-m vertical scale so that the majority of the data can be more clearly seen (Figure 8-15b). Very few measurements of the water level in RNM-2S were made prior to 1990, which includes the majority of the time the well was pumping for the CME. However, those few data suggest that pumping lowered the water level in the well by about $2.5 \mathrm{~m}$. After pumping for the CME stopped, the water level in the well recovered approximately $1.5 \mathrm{~m}$.

The first water level measured in RNM-2S (734.60 m amsl) is assumed to be representative of historical, steady-state conditions. The uncertainty in this steady-state value is estimated to be $1.16 \mathrm{~m}$. Once pumping stopped, the water level in the well recovered to an approximately stable value of about $733.64 \mathrm{~m}$ amsl based on numerous measurements taken in the 1990s (see Figure 8-15b). This value is assumed to be representative of contemporary, steady-state conditions in the well. The uncertainty in this steady-state value is estimated to be $0.46 \mathrm{~m}$. The difference between the historical and contemporary heads is $0.96 \mathrm{~m}$.

\section{SM-23-1}

SM-23-1 is an environmental monitoring well located in Mercury Valley south of Frenchman Flat in Area 22 (see Figure 8-1). This well was completed to the LCA 

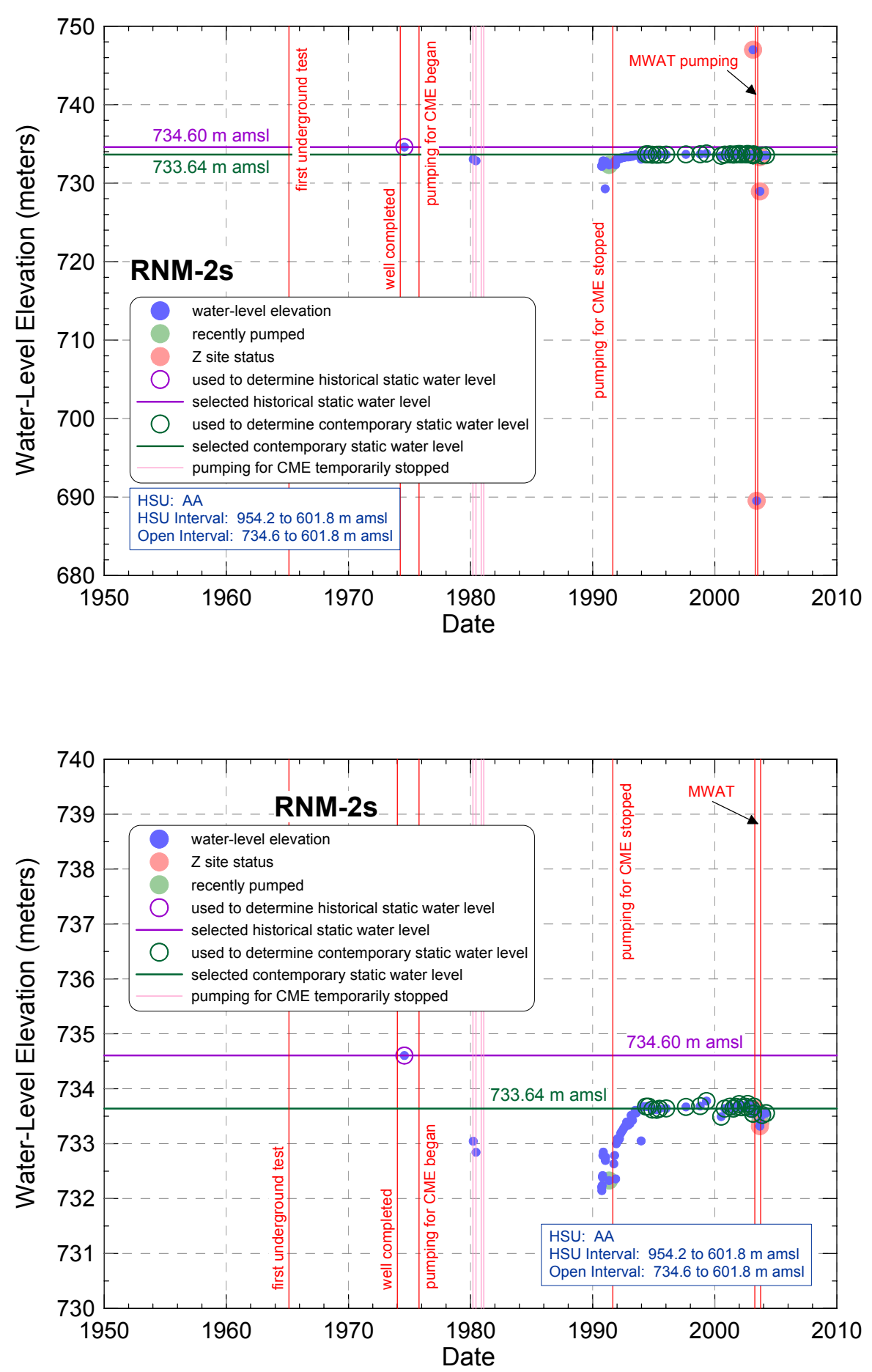

B

Figure 8-15

Well RNM-2S Water-Level History 
in January 1996. The water level in this well has been measured consistently since June 1996 (Figure 8-16). In general, the water level initially increased slightly and then has remained stable. A contemporary, steady-state head of $725.01 \mathrm{~m}$ amsl was determined for SM-23-1 by averaging all measurements after the water-level in the well became stable. The uncertainty in this steady-state value is estimated to be $0.68 \mathrm{~m}$.

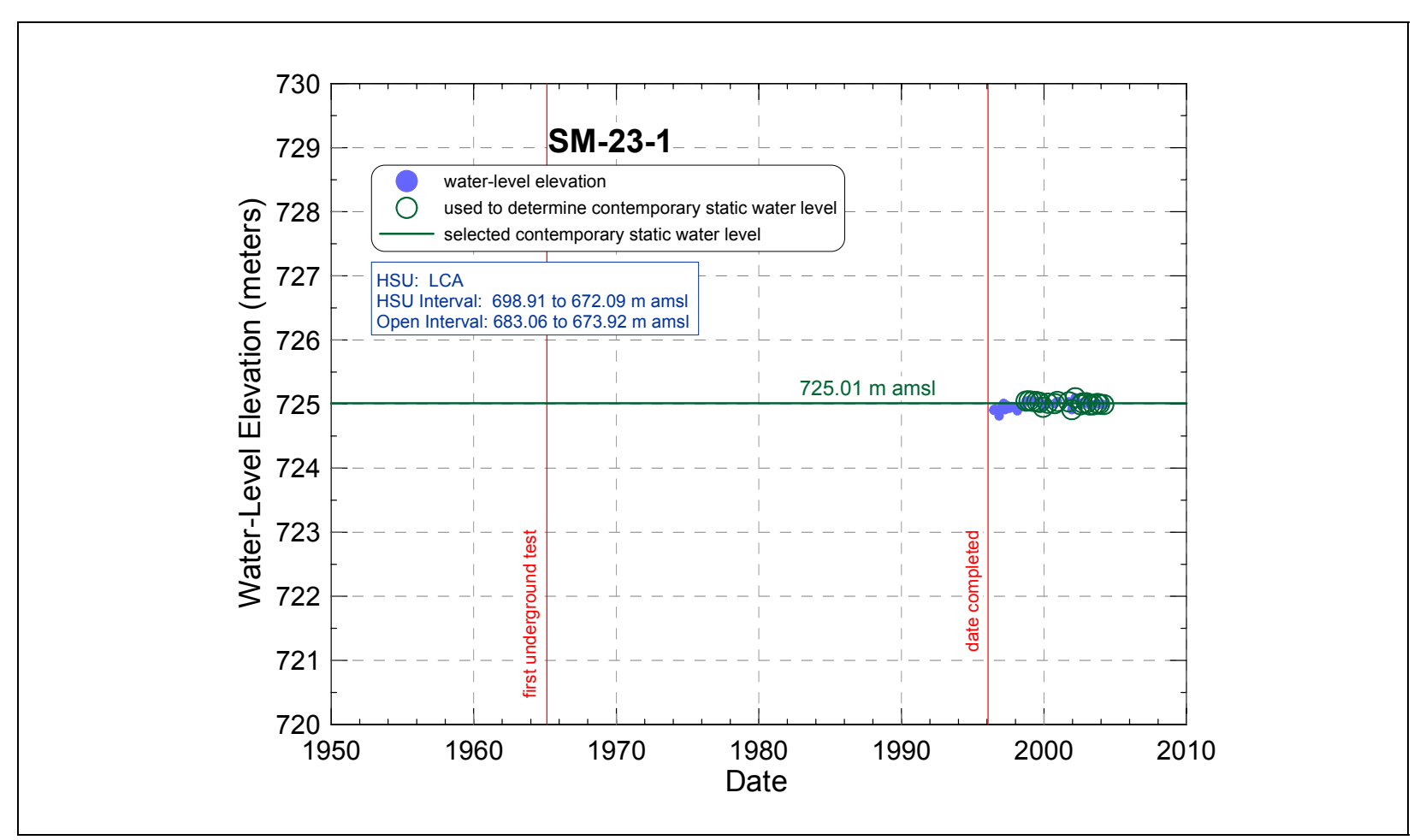

Figure 8-16

SM-23-1 Water-Level History

$T W-3$

TW-3 is a test well located east of Frenchmen Flat (see Figure 8-1). This well was drilled in May 1962 and is completed in the LCA. TW-3 is one of the few wells in the area completed prior to detonation of the first underground test in Frenchman Flat. The water level in this well has been measured periodically since it was completed, with the highest density of data occurring in the 1990s (Figure 8-17). The water level in TW-3 has varied about $1 \mathrm{~m}$ over the period of record. The first two measurements were associated with drilling activities. The remainder of the measurements were averaged to obtain a steady-state head of $725.52 \mathrm{~m}$ amsl considered to be representative of both historical and contemporary conditions. The uncertainty in this steady-state value is estimated to be $1.21 \mathrm{~m}$.

$T W-F$

TW-F is a test well located in Area 27 southwest of Frenchmen Flat (see Figure 8-1). This well was completed in August 1961 and recompleted to the LCA in June 1962, prior to detonation of the first underground test in Frenchman 


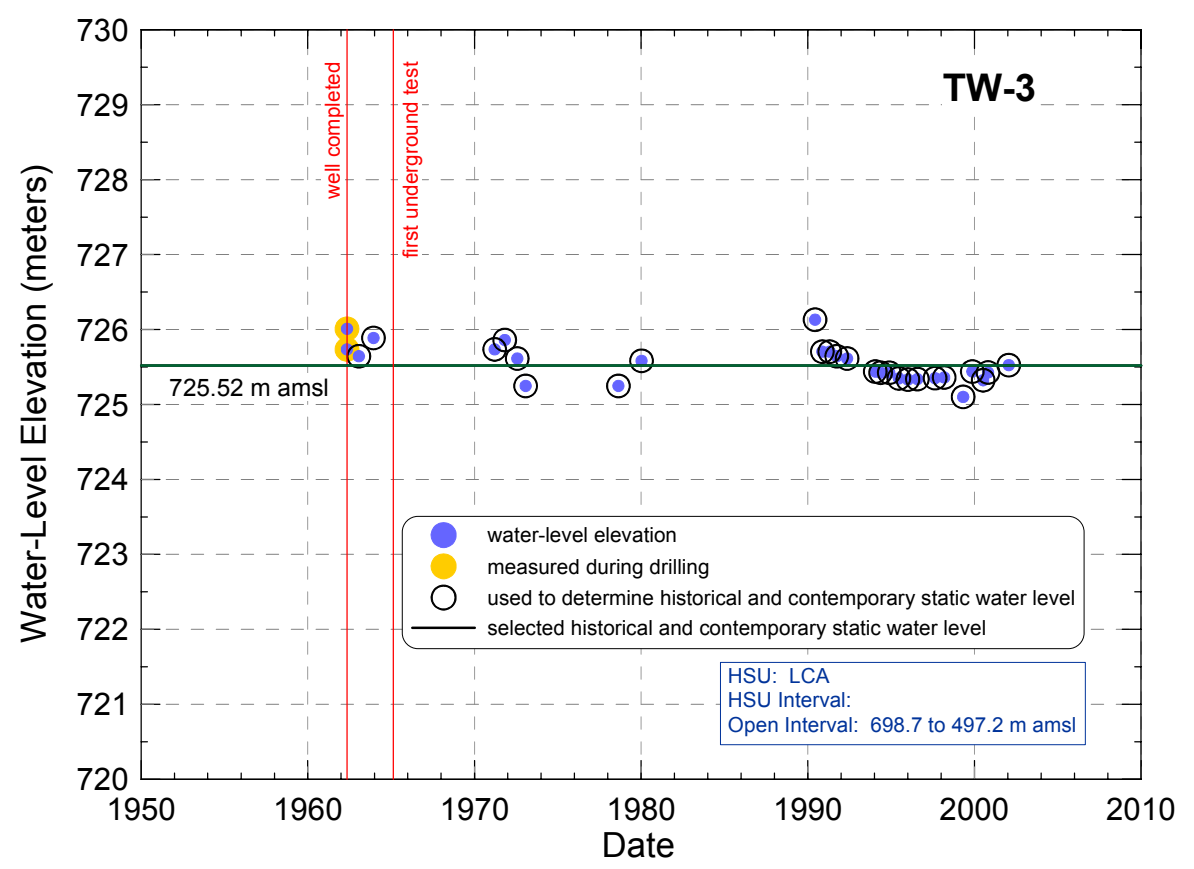

Figure 8-17

Well TW-3 Water-Level History

Flat. The water level in TW-F has been measured periodically since its recompletion with the highest density of data in the late 1980s, 1990s, and 2000s, and the lowest density of data in the 1970s (Figure 8-18). Note that the water-level elevations in Figure 8-18 have been corrected for temperature as discussed in Section 8.5.1. Much of the water-level data for TW-F has been given a document level of 5 due to lack of traceability. All measurements without a document level of 5 are assumed to be representative of historical and contemporary, steady-state conditions. The average of those measurements is $730.51 \mathrm{~m}$ amsl. The uncertainty in this steady-state value is estimated to be $1.24 \mathrm{~m}$.

\section{UE-11a}

UE-11a is an underground exploratory well located in Area 11 north of Frenchman Flat (see Figure 8-1). This well was first spudded in September 1965 and recompleted in September or October 1982. UE-11a is completed to the TM-WTA. Water-level data for this well is sparse (Figure 8-19). Water-level measurements were taken in 1965 when the well was first spudded and then not again until 1982 during recompletion activities. Therefore, these measurements do not reflect undisturbed conditions at the site. The water level in the well was measured several times in the early 1990s. During seven attempts to measure the water-level from October 1998 to November 2003, the well was found to be dry. Collapse of the well up to and above the depth of the water table is attributed to the current dry condition of the well. The current depth of the well is $343.81 \mathrm{~m}$ (734.66 m amsl). The last measured water level of $733.79 \mathrm{~m}$ amsl was selected as 


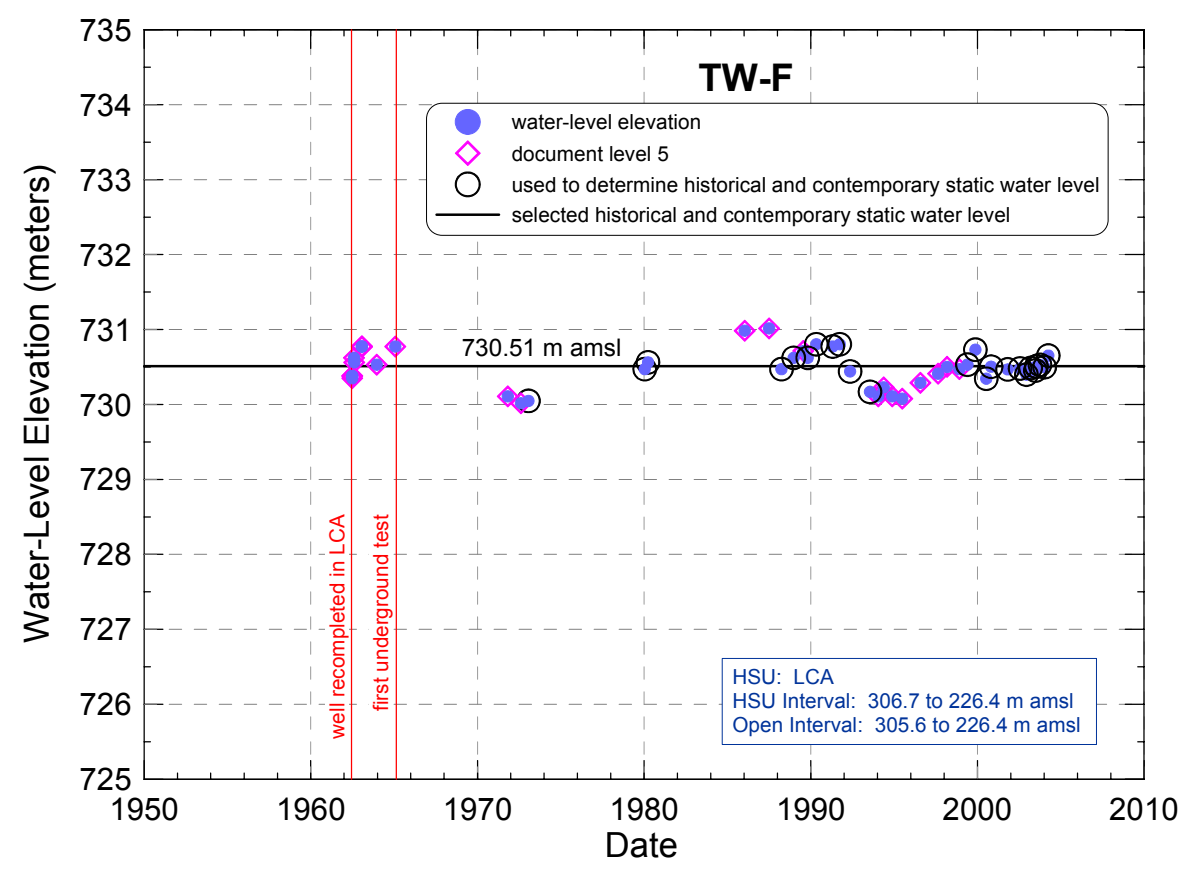

Figure 8-18

Well TW-F Water-Level History

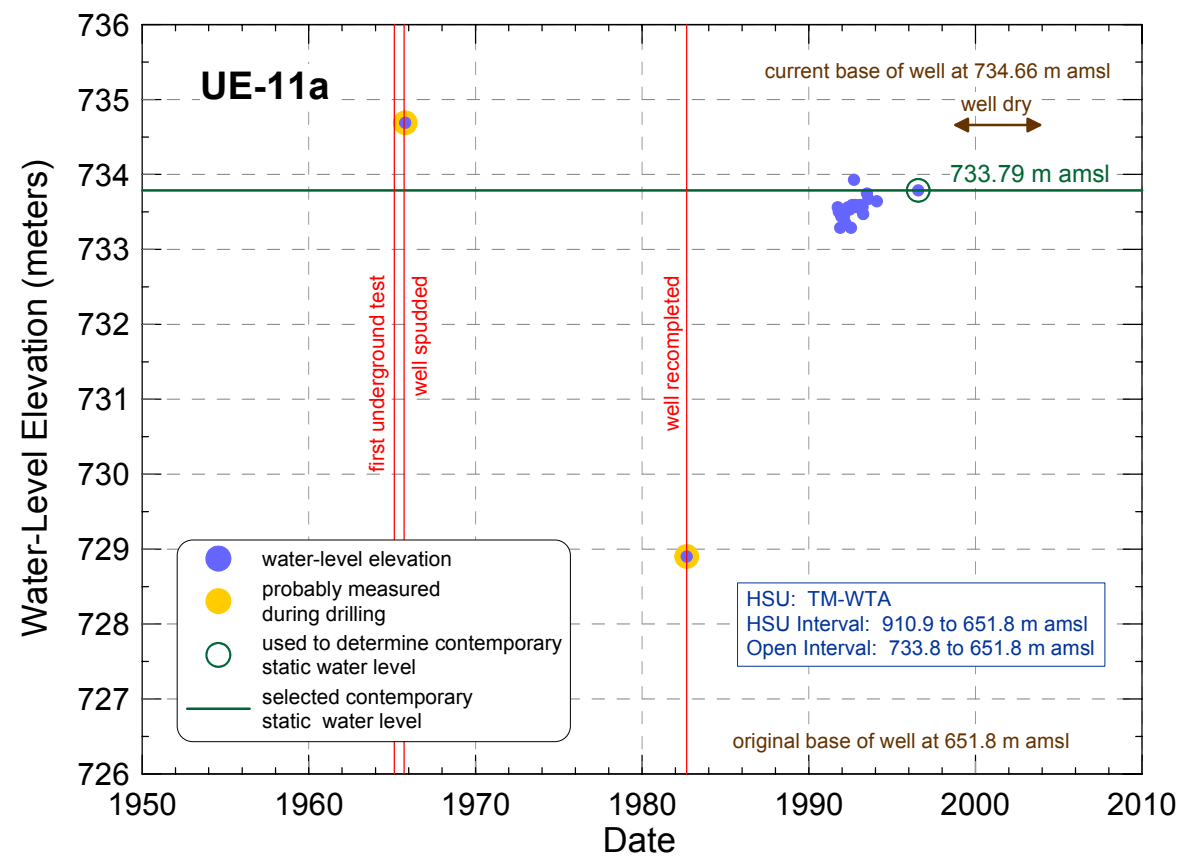

Figure 8-19

Well UE-11a Water-Level History 
the contemporary, steady-state value. The uncertainty in this steady-state value is estimated to be $1.21 \mathrm{~m}$. Note that the steady-state head is at an elevation lower than the current depth of the well. A historical, steady-state head could not be determined for this well due to the paucity of data.

\section{UE-11b}

UE-11b is an underground exploratory well located north of Frenchmen Flat in Area 11 (see Figure 8-1). This well was completed in October 1965 and is open to the lower $70 \mathrm{~m}$ of the TM-LVTA, the underlying TM-LVTA and TSA, and the upper $15 \mathrm{~m}$ of the LVTA. The water level in this well has been measured only twice (Figure 8-20), once during drilling activities and a second time in December 1985. This latter measurement of $743.71 \mathrm{~m}$ amsl was selected as the historical and contemporary steady-state head elevation. The uncertainty in this steady-state value is estimated to be $1.16 \mathrm{~m}$.

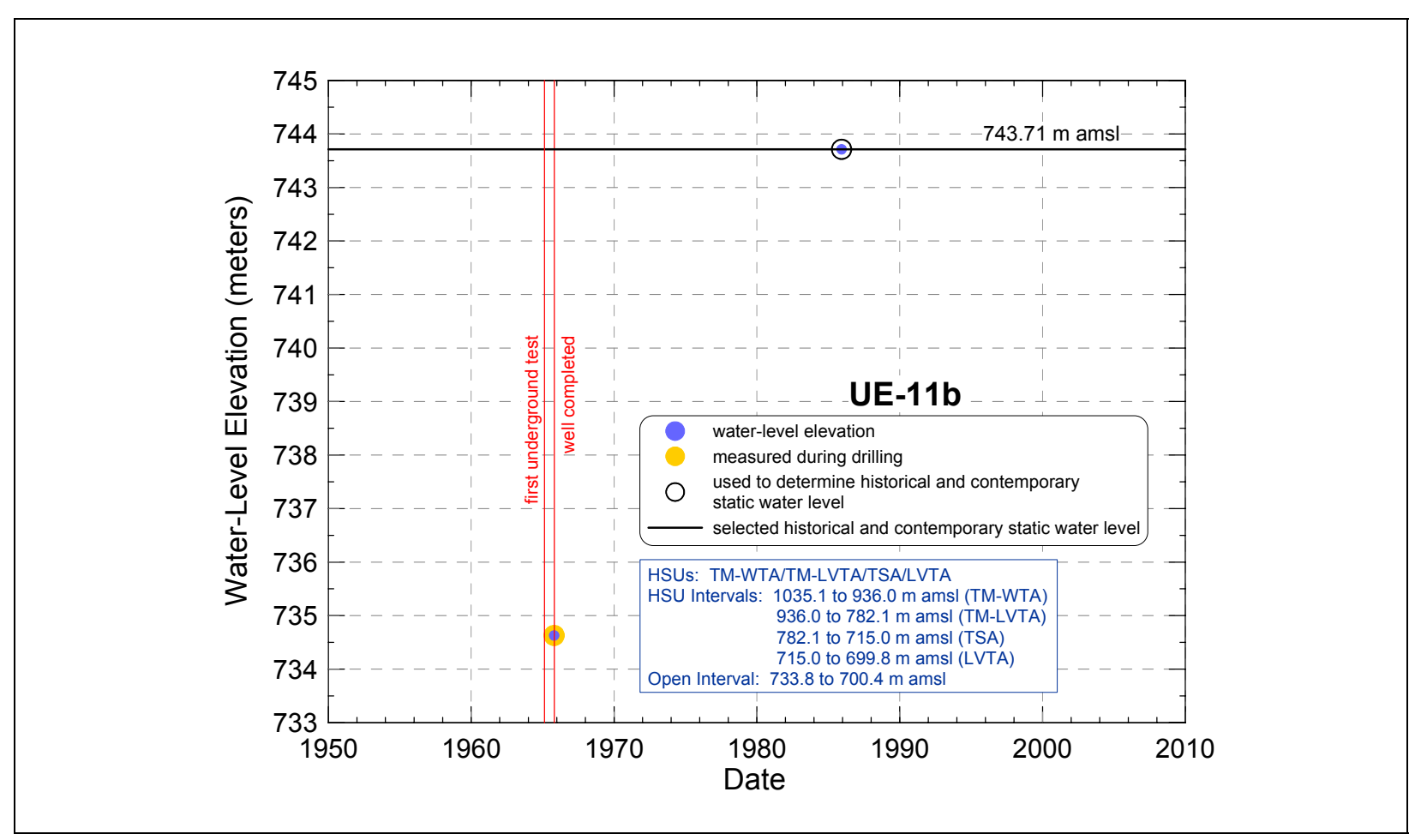

Figure 8-20

Well UE-11b Water-Level History

\section{UE-5 PW-1}

UE-5 PW-1 is an Area 5 Radioactive Waste Management Site (RWMS) pilot well located in central Frenchman Flat (Figure 8-1). The well was completed to the AA in September 1992. The water level in this well has been measured consistently since it was completed (Figure 8-21). Three sources of water-level data are available for UE-5 PW-1. These are the USGS, Bechtel Nevada, and values report in the RNM-2S MWAT report (SNJV, 2004d). In general, the water level remained essentially stable until the late 1990s and has declined slightly but 


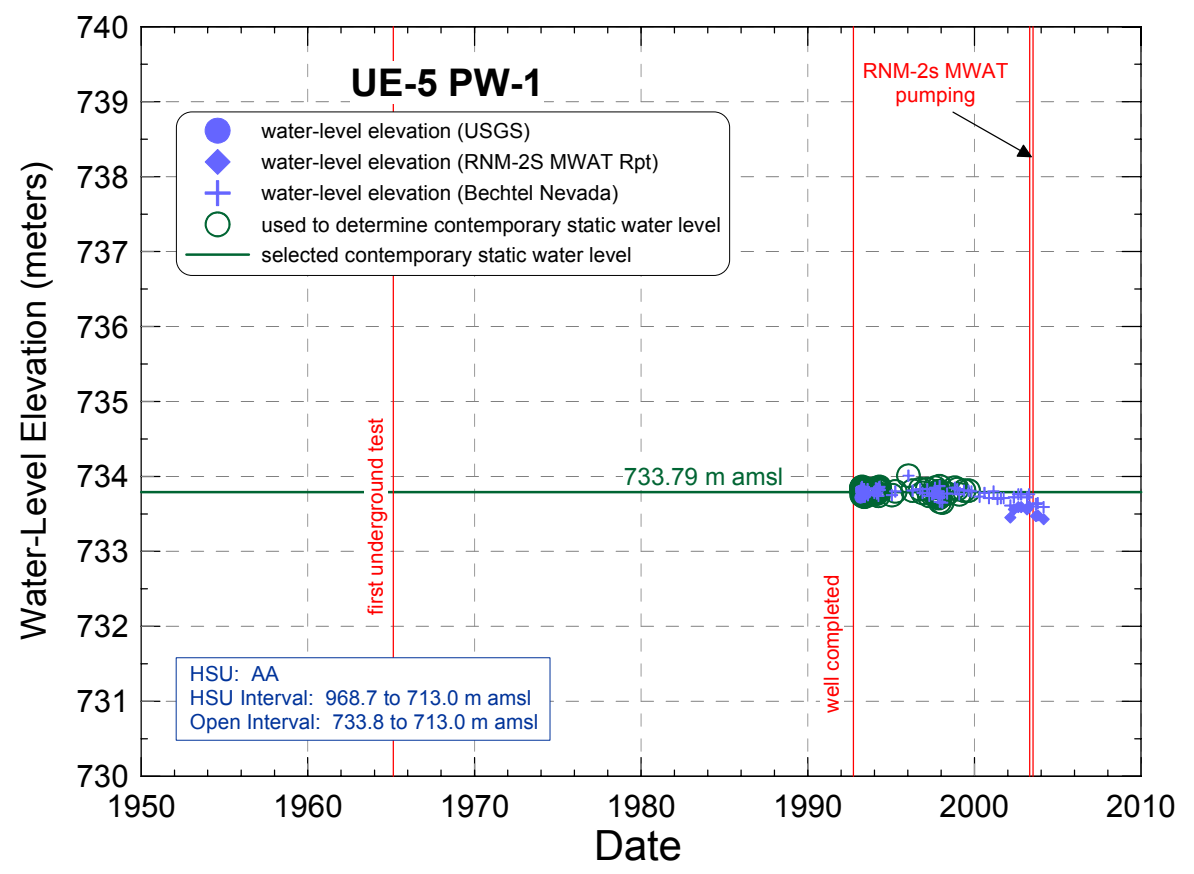

Figure 8-21

Well UE-5 PW-1 Water-Level History

steadily since that time. The water-level measurements by Bechtel Nevada since completion until the beginning of the decline were averaged to obtain a contemporary, steady-state value of $733.79 \mathrm{~m}$ amsl. The uncertainty in this steady-state value is estimated to be $0.71 \mathrm{~m}$.

\section{UE-5 PW-2}

UE-5 PW-2 is an Area 5 RWMS pilot well located in north-central Frenchman Flat (Figure 8-1). This well was completed to the AA in February 1993. The water-level in this well has been measured consistently since it was completed (Figure 8-22). Three sources of water-level data are available for UE-5 PW-2. These are the USGS, Bechtel Nevada, and values report in the RNM-2S MWAT report (SNJV, 2004d). Figure 8-22 shows a discrepancy between the water-level measurements by Bechtel Nevada and those reported in SNJV (2004d). The reason for this discrepancy is unknown. Possible reasons include the use of different reference point elevations or the use of different corrections for borehole deviation. Only corrected water-level elevations are given in SNJV (2004d), so it was not possible to determine why the corrected values differ. In general, the water-level measurements by Bechtel Nevada have remained stable over the period of record. All measurements by Bechtel Nevada were averaged to obtain a contemporary, steady-state value of $733.74 \mathrm{~m}$ amsl. The uncertainty in this steady-state value is estimated to be $0.75 \mathrm{~m}$. 


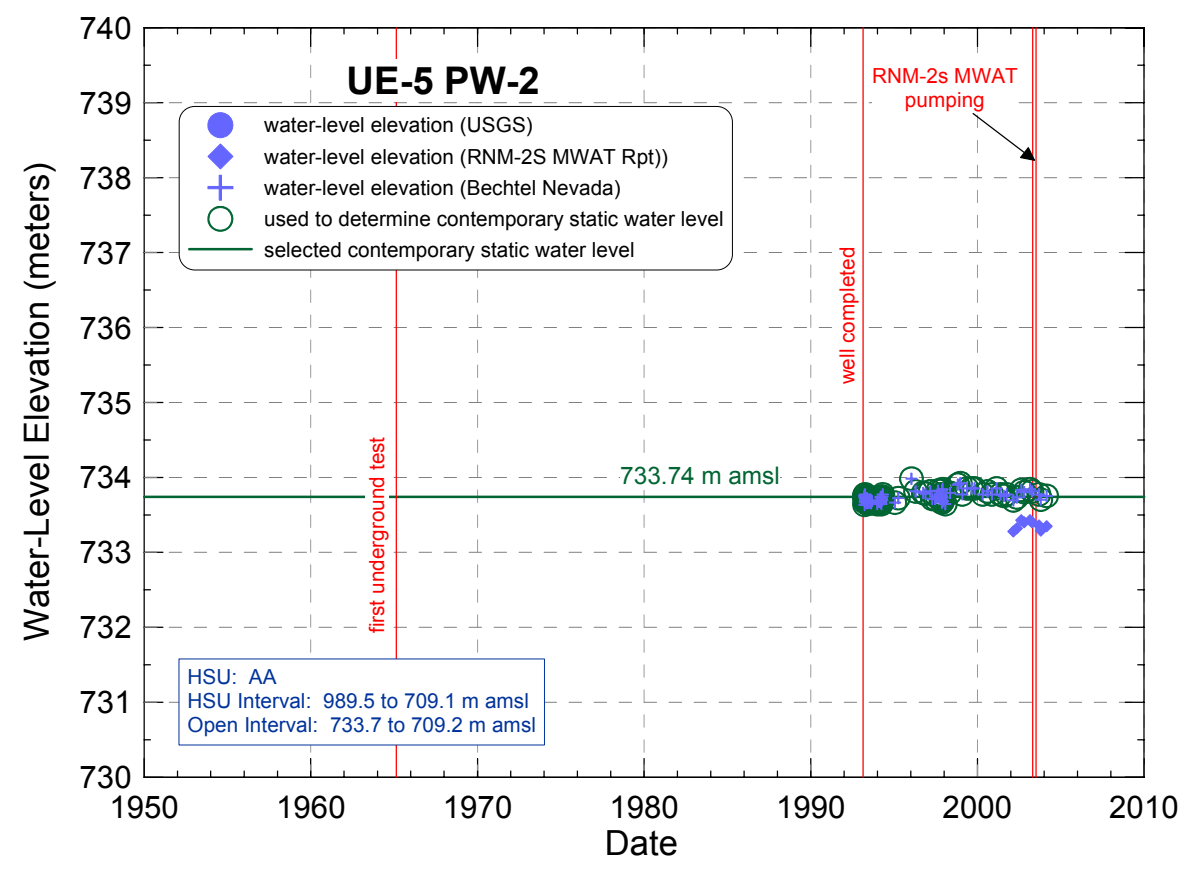

Figure 8-22

Well UE-5 PW-2 Water-Level History

\section{UE-5 PW-3}

UE-5 PW-3 is an Area 5 RWMS pilot well located in northwestern Frenchman Flat (Figure 8-1). This well was completed to the TM-WTA in January 1993. Three sources of water-level data are available for UE-5 PW-3. These are the USGS, Bechtel Nevada, and values report in the RNM-2S MWAT report

(SNJV, 2004d). The water level in this well has been measured consistently since it was completed (Figure 8-23). In general, the water level initially increased then stabilized. A contemporary, steady-state head of $733.75 \mathrm{~m}$ amsl was determined by averaging all of the Bechtel Nevada measurements after the water level in the well stopped rising. The uncertainty in this steady-state value is estimated to be $0.71 \mathrm{~m}$.

\section{UE-5c WW}

UE-5c WW is a water-supply well located northwest of the ER-5-4 well cluster, RNM-1, RNM-2, RNM-2S, and UE-5n (Figure 8-1). This well was completed in November 1964 and has two open intervals. The upper interval is completed in the AA and the lower interval is completed in the LTCU. Both intervals are open to the well during water-level measurements. A brief description of well construction/completion for UE-5c WW can be found in Gillespie et al. (1996). The pumping record for this well can be found in Figure 7-4 (see Section 7.0).

Few measurements of the water level in this well have been taken (Figure 8-24). The first measurement appears to be anonymously low compared to other 


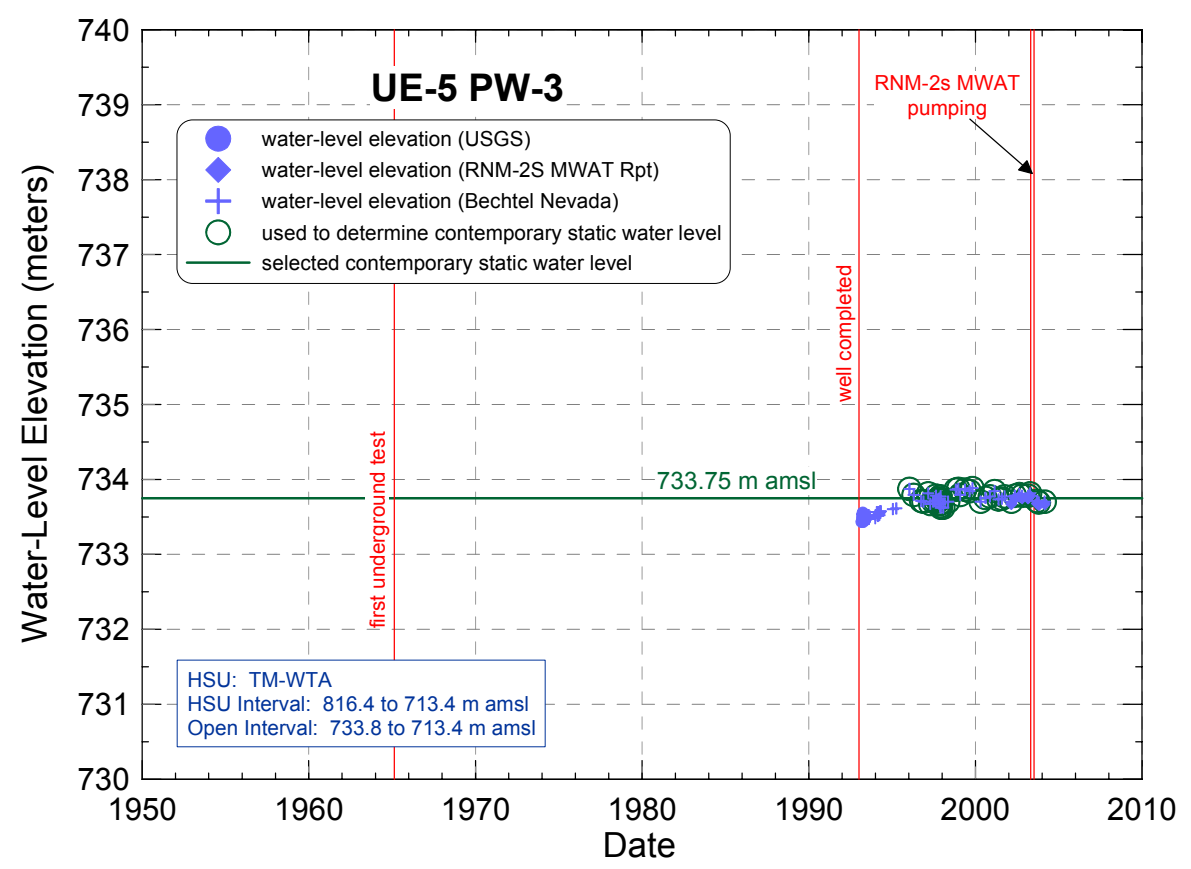

Figure 8-23

Well UE-5 PW-3 Water-Level History

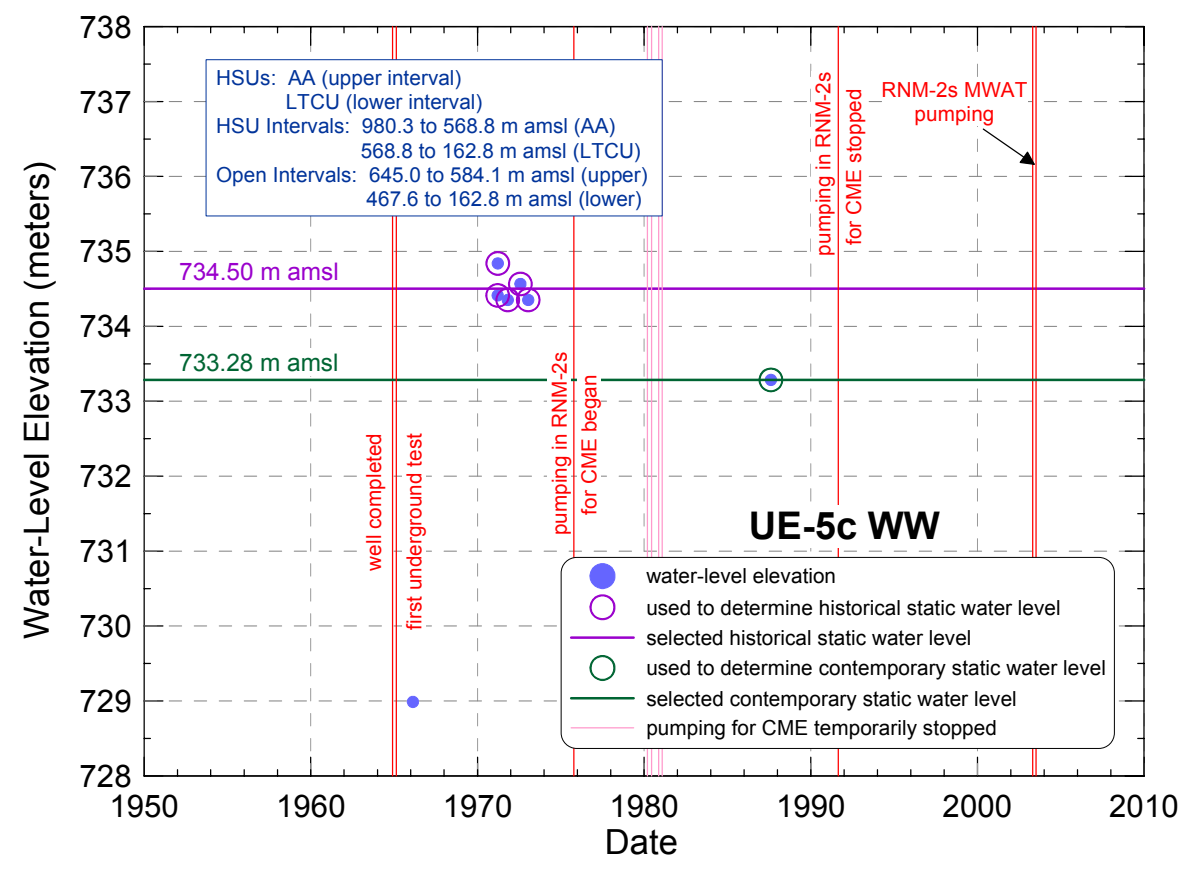

Figure 8-24

Well UE-5C WW Water-Level History 
measurements. Based on a comparison of the measurements made in the early 1970s and the measurement made in August 1987, pumping in this well appears to have drawn down the water level a little over a meter between these two time periods. Since the water level in the well appears to have decreased over time based on the limited number of measurements available, it is assumed that the water level for historical and contemporary conditions is different. The average of the $1970 \mathrm{~s}$ measurements $(734.50 \mathrm{~m}$ amsl) is assumed to be representative of historical, steady-state conditions. The uncertainty in this steady-state value is estimated to be $0.62 \mathrm{~m}$. The final measurement $(733.28 \mathrm{~m}$ amsl) was assigned as the contemporary, steady-state value. The uncertainty in this steady-state value is estimated to be $0.91 \mathrm{~m}$. It is possible that the water level in the well has continued to decline. It is also possible that the water level began to increase once pumping in RNM-2S for the CME stopped. The difference between the historical and contemporary heads is $1.22 \mathrm{~m}$.

\section{UE-5f}

UE-5f is an underground exploratory well located in the northern portion of Frenchman Flat southwest of the ER-5-3 well cluster (Figure 8-1). This well was drilled in June 1965 and is completed to the AA. The water level in this well has been measured only once. That measurement was taken in the same month that the well was completed. The exact completion date could not be found, only the month and year. Therefore, the proximity of the water-level measurement to drilling activities is unknown. However, the measured water level appears to be reasonable based on the evaluation of all of the water-level data for the Frenchman Flat area and vicinity. The single measurement of $734.82 \mathrm{~m}$ amsl was assumed to be representative of historical, steady-state conditions. The uncertainty in this steady-state value is estimated to be $1.43 \mathrm{~m}$.

\section{UE-5j}

$\mathrm{UE}-5 \mathrm{j}$ is an underground exploratory well located on the northern border between Areas 5 and 6 almost due west of the ER-5-3 well cluster (Figure 8-1). This well was drilled in March 1966 and is completed to the lower $309 \mathrm{~m}$ of the AA and the upper $47 \mathrm{~m}$ of the TM-WTA. The water level in this well has been measured only once. That measurement was taken in the same month that the well was completed. The exact completion date could not be found, only the month and year. Therefore, the proximity of the water-level measurement to drilling activities is unknown. Based on the evaluation of water-level data for the Frenchman Flat area and vicinity, the measured water level of $847.95 \mathrm{~m}$ amsl appears to be too high for the AA, and was considered to represent disturbed rather than undisturbed conditions at the site. As a result, no reliable steady-state head could be determined for this well.

\section{UE-5k}

UE-5k is an underground exploratory well located in Frenchman Flat southeast of the ER-5-3 well cluster (Figure 8-1). This well was drilled in February 1968 and is completed to the AA, BLFA, and the upper $21 \mathrm{~m}$ of the TM-WTA. Only one water-level has been measured in this well. The date for that measurement is May 1966, two years prior to the completion date for the well. Since the date for 
the water-level measurement is inconsistent with the well completion date, no steady-state head could be determined for UE-5k.

\section{$U E-5 m$}

UE-5m is an underground exploratory well located southwest of Frenchmen Flat near the border between Areas 5 and 27 (Figure 8-1). This well was drilled in April 1966 and is completed to the lower $24 \mathrm{~m}$ of the AA, the underlying $285-\mathrm{m}$ thick Wahmonie Confining Unit (WCU) and 55-m thick LTCU, and the upper $68 \mathrm{~m}$ of the VCU. The water level in this well was measured only once. That measurement was taken in the same month that the well was completed. The exact completion date could not be found, only the month and year. Therefore, the proximity of the water-level measurement to drilling activities is unknown. Based on the evaluation of water-level data for the Frenchman Flat area and vicinity, the measured water level of $908.91 \mathrm{~m}$ amsl appears to be anomalously high. However, no other water-level measurements for the WCU are available for comparison. Since it is probable that the only water level for UE- $5 \mathrm{~m}$ was measured under disturbed rather than undisturbed site conditions, no reliable steady-state head could be determined for this well.

\section{UE-5n}

UE-5 $\mathrm{n}$ is an underground exploratory well located in the southern portion of Frenchman Flat near the ER-5-4 well cluster, RNM-1, RNM-2, and RNM-2S (Figure 8-1). This well was drilled in March 1976 and is completed to the AA. The water level in UE-5n has been measured fairly consistently since well completion (Figure 8-25). The highest density of measurements occurs from the middle to late 1980s through present (Spring 2004). The water level in the well has continuously decreased from the time pumping in RNM-2S for the CME stopped to about mid-2001. The water level has remained somewhat stable since that time. From the time of well completion to the time pumping in RNM-2S for the CME stopped, the water level in the well was erratic, fluctuating within about a 1-m range. Water pumped from RNM-2S during the CME was discharged to a ditch located near UE-5n. Both the water discharge from RNM-2S and water sampled in UE-5n during the CME contained tritium at elevated concentrations (Bright et al., 2001). This suggests that water in the ditch infiltrated into the AA and recharged the aquifer in the vicinity of UE- $5 \mathrm{n}$. The erratic water level in UE- $5 n$ between well completion and the end of the CME is probably a function of variable rates of infiltration of the water discharged to the ditch. The decrease in the water level in the well since the end of the CME probably reflects the gradual decrease in recharge of the AA once discharge to the ditch was stopped.

Because the early water-level in UE-5n was effected by infiltration of water discharged from RNM-2S during the CME, no historical, steady-state head was determined for this well. A contemporary, steady-state head of $733.84 \mathrm{~m}$ amsl was determined by averaging the fairly constant measurements from mid-2001 to present (Spring 2004). The uncertainty in this steady-state value is estimated to be $0.47 \mathrm{~m}$. 


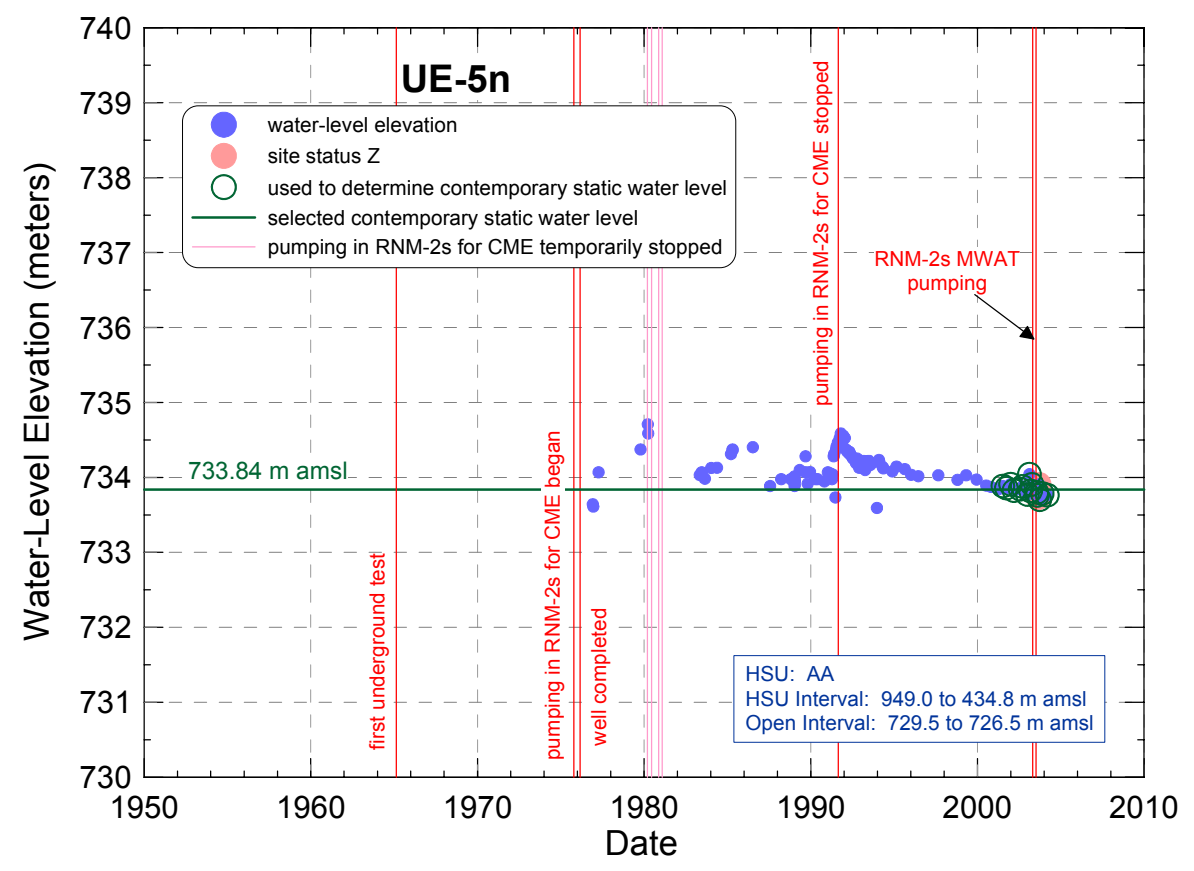

Figure 8-25

Well UE-5n Water-Level History

$W W-1$

WW-1 is a water-supply well located east of Frenchman Flat (Figure 8-1). This well was drilled in 1950 and is completed to the AA. A brief description of well construction/completion and well lithology for WW-1 can be found in Moore (1962). The pumping record for this well is illustrated in Figure 7-5 (see Section 7.0). The water level in WW-1 has been measured only once. That measurement was taken in December 1950. An obstruction was found above the water-level in February 2001 during a second attempt to measure the depth to water in this well. The exact completion date for WW-1 could not be found, only that it was completed in 1950 . Therefore, the proximity of the water-level measurement to drilling activities is unknown. However, the measured water-level appears to be reasonable based on the evaluation of all of the water-level data for the Frenchman Flat area and vicinity. The single measurement of $727.25 \mathrm{~m}$ amsl was assumed to be representative of historical, steady-state conditions. The uncertainty in this steady-state value is estimated to be $4.40 \mathrm{~m}$.

$W W-4$

WW-4 is a water-supply well located in CP Basin northwest of Frenchman Flat in Area 6 adjacent to WW-4A (Figure 8-1). This well was drilled in November 1981 and is completed to the lower $89 \mathrm{~m}$ of the TM-WTA, the underlying $18-\mathrm{m}$ thick LTCU and 27-m thick TSA, and the upper $42 \mathrm{~m}$ of the LTCU. A brief description of well construction/completion for WW-4 can be found in Gillespie et al. (1996). 
Construction and hydrogeologic characteristics diagrams for WW-4 can be found in Appendix D, Figure D.1-9. The pumping record for this well can be found in Figure 7-6 (see Section 7.0).

The water level in WW-4 was measured twice in the 9-year period between the time of well completion and February 1990 (Figure 8-26). Regular measurements in the well since early 1990 show, in general, a decline in water level of about $1.2 \mathrm{~m}$ over the past 13 years. Since WW-4 is a water-supply well, this decline is assumed to reflect the affects of pumping in this well and also in nearby water well WW-4A. The two water-level measurements made about 2 years after well completion were averaged to obtain a historical, steady-state head of $844.62 \mathrm{~m}$ amsl. The uncertainty in this steady-state value is estimated to be $2.02 \mathrm{~m}$. A contemporary, steady-state head was not determined for WW-4 because the recent water-level data for the well reflect pumping rather than steady-state conditions.

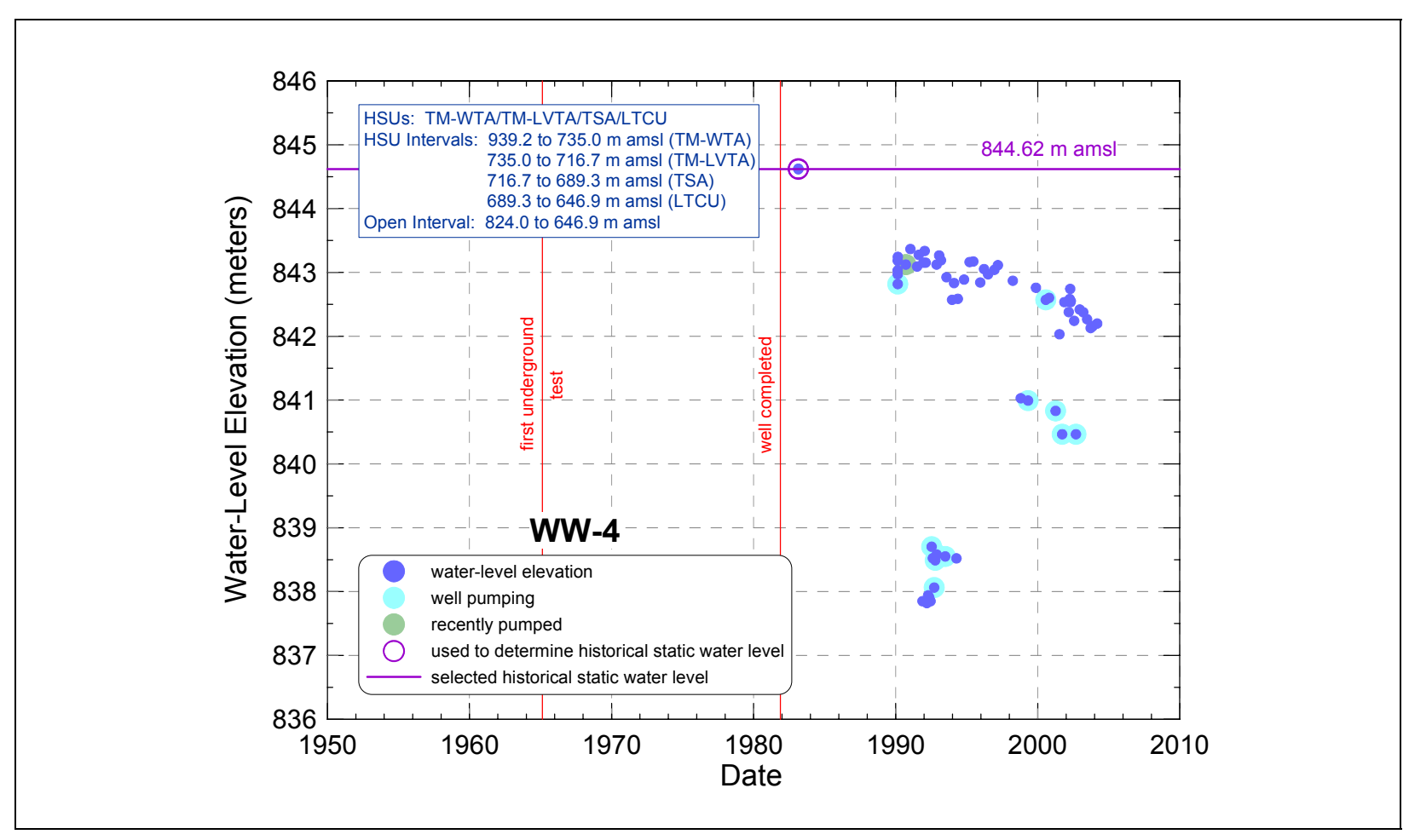

Figure 8-26

WW-4 Water-Level History

$W W-4 A$

WW-4A is a water-supply well located in CP Basin northwest of Frenchman Flat in Area 6 adjacent to WW-4 (Figure 8-1). This well was drilled in February 1990 and is completed to the lower $99 \mathrm{~m}$ of the TM-WTA, the underlying $17-\mathrm{m}$ thick TM-LVTA and 38-m thick TSA, and the upper $16 \mathrm{~m}$ of the LTCU. A brief description of well construction/completion for WW-4A can be found in Gillespie et al. (1996). Construction and hydrogeologic characteristics diagrams for 
WW-4A can be found in Appendix D, Figure D.1-9. The pumping record for this well can be found in Figure 7-7 (see Section 7.0).

The water level in WW-4A remained fairly stable for the first several years after completion (Figure 8-27). Since about March 1995, the water-level in the well has, in general, steadily declined. Since WW-4A is a water-supply well, this decline is assumed to reflect the affects of pumping in this well and in nearby water well WW-4A. Many of the early water-level measurements were affected by drilling activities or pumping at a nearby site. Excluding those values, the remaining early measurements were averaged to obtain a historical, steady-state hydraulic head of $844.59 \mathrm{~m}$ amsl. The uncertainty in this steady-state value is estimated to be $1.21 \mathrm{~m}$. A contemporary, steady-state head was not determined for WW-4A because the recent water-level data for the well reflect pumping rather than steady-state conditions.

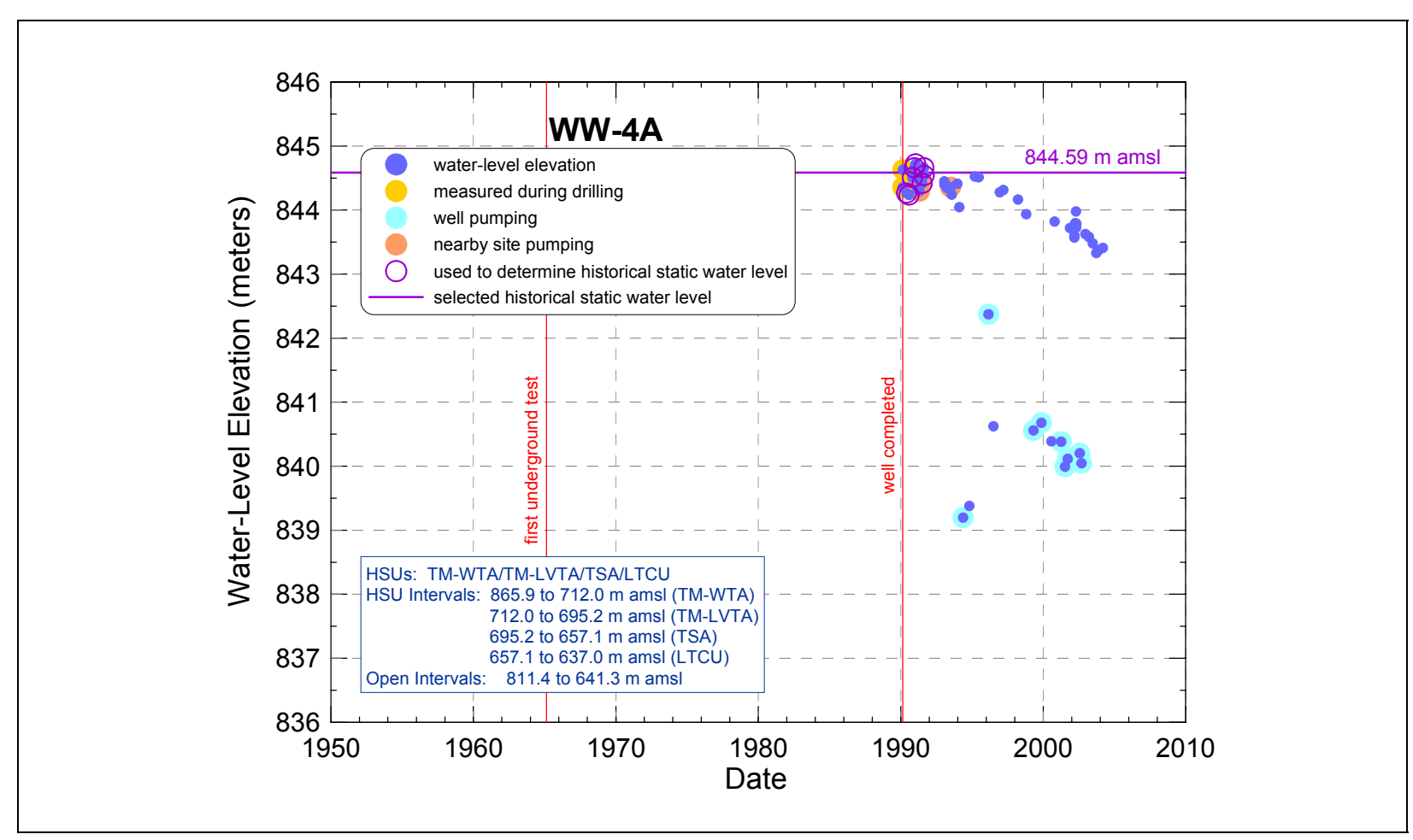

Figure 8-27

WW-4A Water-Level History

$W W-5 A$

WW-5A is an inactive water-supply well located south of Frenchmen Flat (Figure 8-1). This well was drilled in March 1951 and is completed in the AA. Pumping of WW-5A for water-supply purposes discontinued in early 1970 (see Figure 7-8 in Section 7.0). WW-5A was recompleted in November and December 1991 as part of the DOE Groundwater Characterization Project. A brief description of the original completion and a comprehensive description of the recompletion of this well can be found in IT (1993). Construction and hydrogeologic characteristics diagrams for WW-5A can be found in Appendix D, 
Figure D.1-10. WW-5A is one of the few wells in the area completed prior to detonation of the first underground test in Frenchman Flat.

Only a few water-level measurements have been made in this well from the time of completion until early 1980 (Figure 8-28). These measurements show an overall decline in water-level of about $4 \mathrm{~m}$ between September 1959 and January 1980. The continued decline of the water level in this well after the pump was removed is attributed to pumping in neighboring well WW-5C. The September 1959 measurement of $730.91 \mathrm{~m}$ amsl is the highest recorded for the well and is considered to be representative of historical, steady-state conditions in the well. The uncertainty in this steady-state value is estimated to be $1.14 \mathrm{~m}$.

Numerous water-level measurements have been made in WW-5A since February 1992. These measurements show short-term fluctuations of about $\pm 1.5 \mathrm{~m}$, but no overall decreasing or increasing trend. All of the measurements from early 1992 were averaged to determine a contemporary, steady-state head of $726.17 \mathrm{~m}$ amsl for WW-5A. The uncertainty in this steady-state value is estimated to be $0.90 \mathrm{~m}$. This contemporary, steady-state head is $4.74 \mathrm{~m}$ lower than the historical, steady-state head.

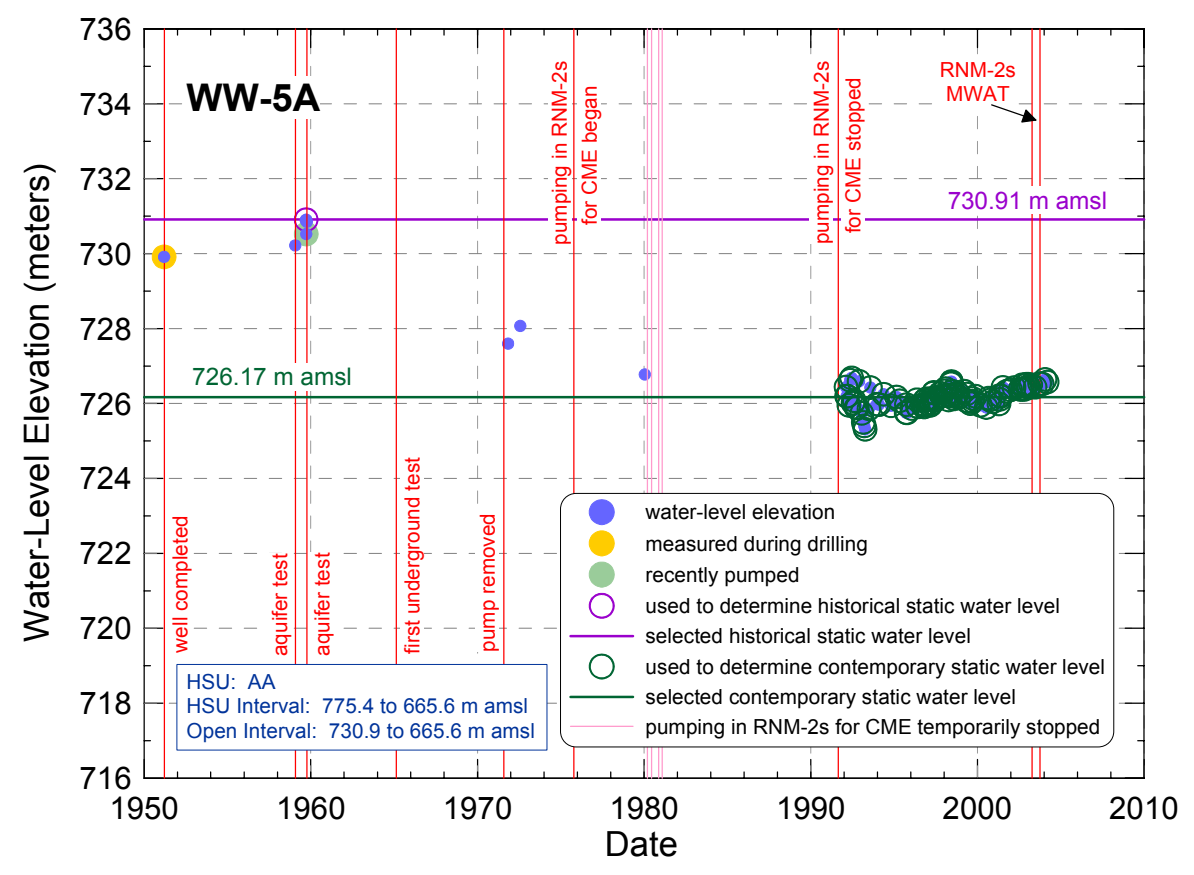

Figure 8-28

WW-5A Water-Level History

$W W-5 B$

WW-5B is a water-supply located south of Frenchmen Flat (Figure 8-1). This well was drilled in May 1951 and is completed in the AA. A brief description of well construction/completion for WW-5B can be found in Gillespie et al. (1996). 
Construction and hydrogeologic characteristics diagrams for WW-5B can be found in Appendix D, Figure D.1-10. The pumping record for this well can be found in Figure 7-9 (see Section 7.0). WW-5B is one of the few wells in the area completed prior to detonation of the first underground test in Frenchman Flat.

The water-level in WW-5B was fairly stable for approximately 13 years from August 1959 to July 1972 (Figure 8-29). These measurements were averaged to determine a historical, steady-state hydraulic head of $734.68 \mathrm{~m}$ amsl. The uncertainty in this steady-state value is estimated to be $1.15 \mathrm{~m}$. Between July 1972 and May 1992, the water level in the well was measured four times and showed a decline of a little over $1.5 \mathrm{~m}$. The water level in the well was not measured again until January 2003. Several additional water-level measurements have been made since that time. One of these measurements was affected by recent pumping of the well. The remaining measurements were averaged to determine a contemporary, steady-state head of $733.31 \mathrm{~m}$ amsl. The uncertainty in this steady-state value is estimated to be $1.00 \mathrm{~m}$. The difference between the historical and contemporary heads is $1.37 \mathrm{~m}$.

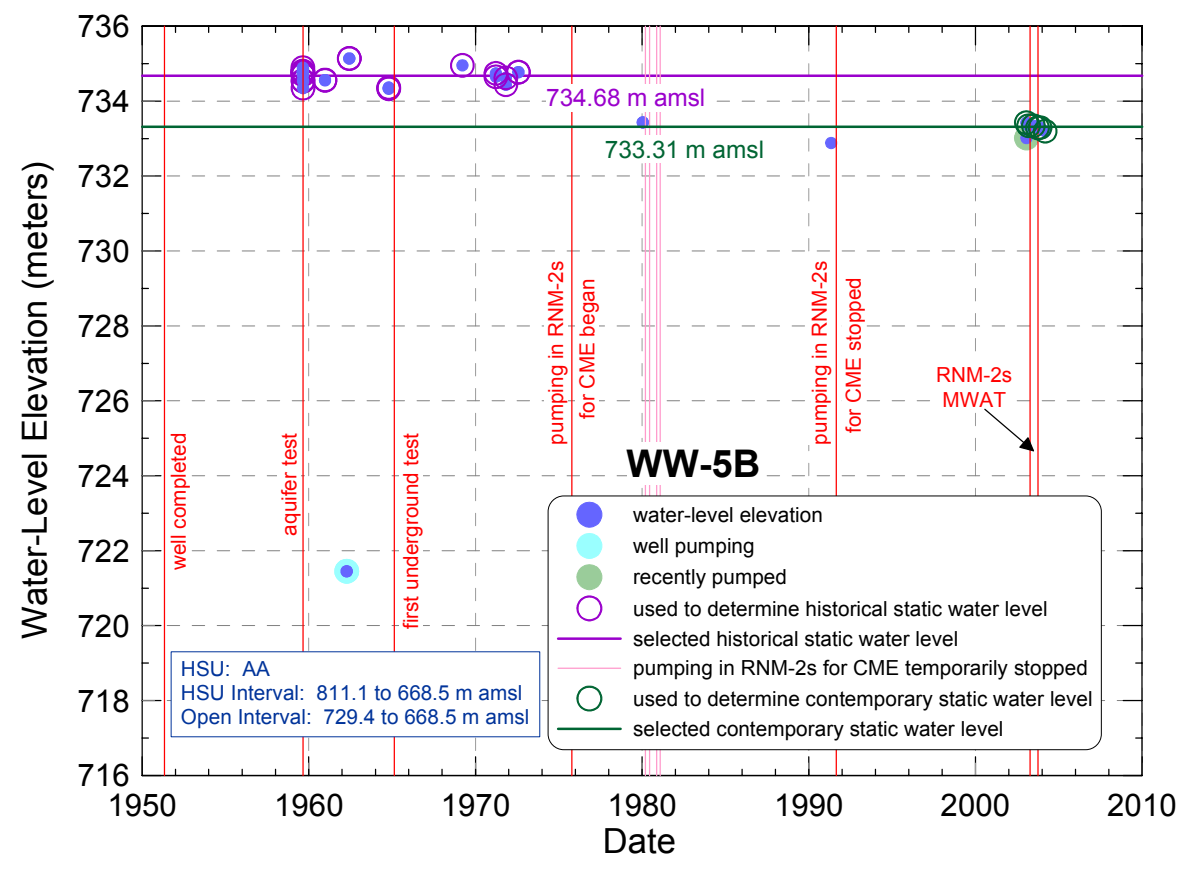

Figure 8-29

WW-5B Water-Level History

$W W-5 C$

WW-5C is a water-supply located south of Frenchmen Flat (Figure 8-1). This well was drilled in March 1954 and is completed in the AA. A brief description of well construction/completion for WW-5C can be found in Gillespie et al. (1996). Construction and hydrogeologic characteristics diagrams for WW-5C can be found in Appendix D, Figure D.1-10. The pumping record for this well is shown 
in Figure 7-10 (see Section 7.0). WW-5C is one of the few wells in the area completed prior to detonation of the first underground test in Frenchman Flat.

Two hydrographs were created for the WW-5C water-level data. The first shows all of the water-level measurements which span a range of over $80 \mathrm{~m}$

(Figure 8-30a). The second shows the water level in WW-5C at the same vertical scale as was used for the WW-5A and WW-5B water-level data (Figure 8-30b).

The water level in this well has been measured only occasionally in the 50 years since it was completed. In general, the water level in the well declined between the early 1960s to about January 1980. A rise in water level from January 1980 to August 1993 is suggested by the data. This rise is uncertain because it its defined by only one data point. No water level has been measured in WW-5C since August 1993. The highest water level $(729.68 \mathrm{~m}$ amsl) measured in the well in May 1961 is assumed to be representative of historical, steady-state conditions. The uncertainty in this steady-state value is estimated to be $1.29 \mathrm{~m}$. The final water-level measurement for the well $(720.59 \mathrm{~m}$ amsl) is assumed to be representative of contemporary, steady-state conditions. The uncertainty in this steady-state value is estimated to be $1.29 \mathrm{~m}$. The difference between the historical and contemporary heads is $9.09 \mathrm{~m}$.

\section{$W W-C$}

WW-C is a water-supply well located adjacent to WW-C1 in southern Yucca Flat northwest of Frenchman Flat in Area 6 (Figure 8-1). This well was drilled in March 1961 and is completed to the LCA. A summary of well construction, lithologic data, and aquifer tests for WW-C can be found in Garber and Thordarson (1962). A brief description of well construction/completion for this well can be found in Gillespie et al. (1996). A brief description of a preliminary tracer experiment to determine hydraulic connection between WW-C and WW-C1 is given in Winograd and West (1962). The pumping record for WW-C is shown in Figure 7-11 (see Section 7.0).

The water level in WW-C was measured periodically between the time of completion and October 1975 and not at all since then (Figure 8-31). All of the water-level data were averaged to determine a historical, steady-state head of $726.00 \mathrm{~m}$ amsl for this well. The uncertainty in this steady-state value is estimated to be $1.45 \mathrm{~m}$.

\section{$W W-C 1$}

WW-C1 is a water-supply well located adjacent to WW-C in southern Yucca Flat northwest of Frenchman Flat in Area 6 (Figure 8-1). This well was drilled in June 1962 and is completed to the LCA. A brief description of well construction/completion for WW-C1 can be found in Gillespie et al. (1996). A brief description of a preliminary tracer experiment to determine hydraulic connection between WW-C and WW-C1 is given in Winograd and West (1962). The pumping record for WW-C1 is shown in Figure 7-12 (see Section 7.0).

The water-level in WW-C1 was measured several times between the time of completion and August 1972 (Figure 8-32). The water level in this well was not 


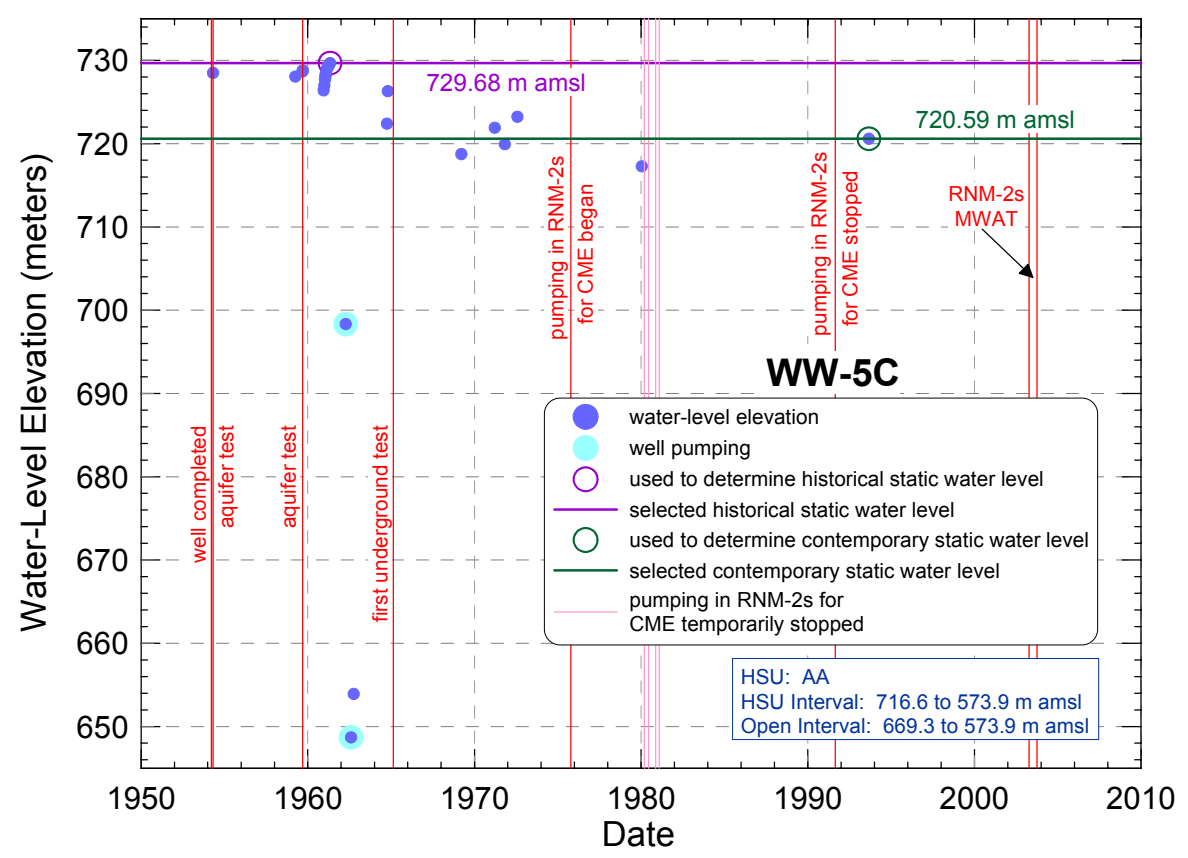

A

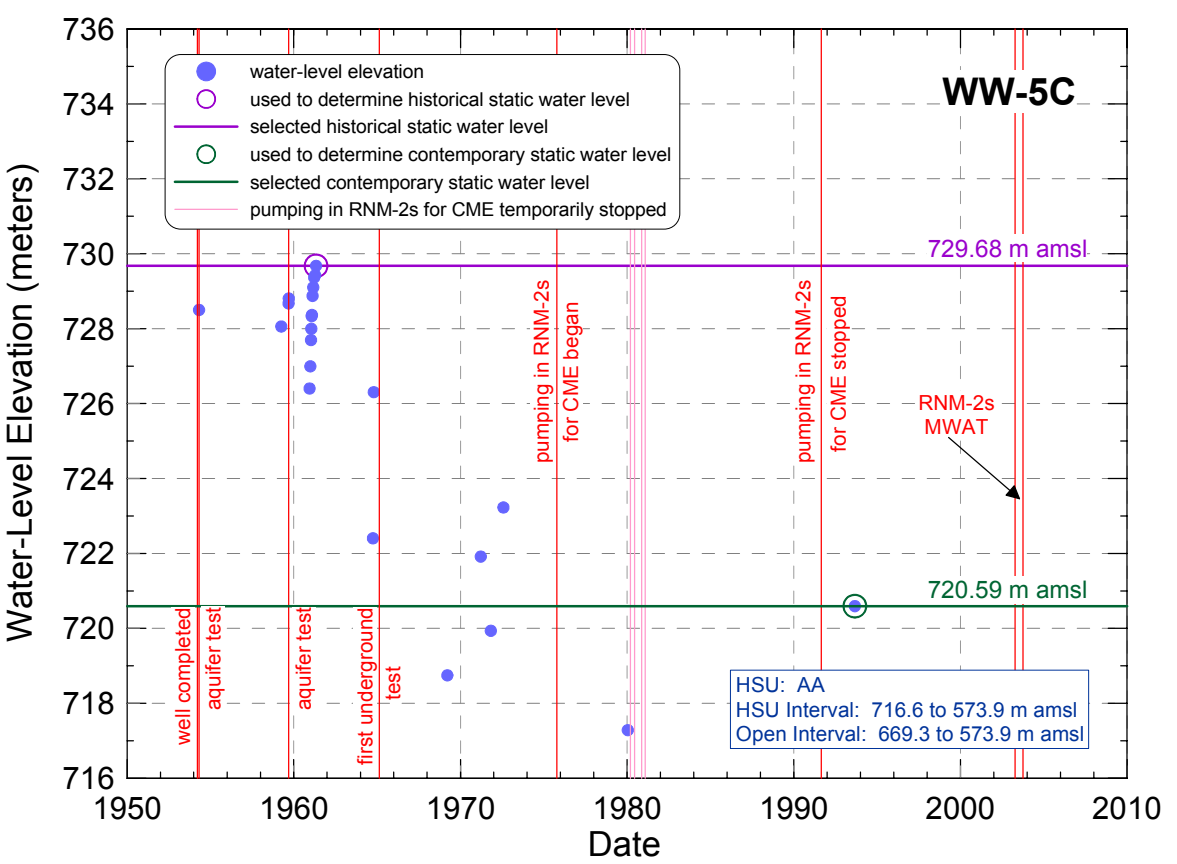

B

Figure 8-30

WW-5C Water-Level History 


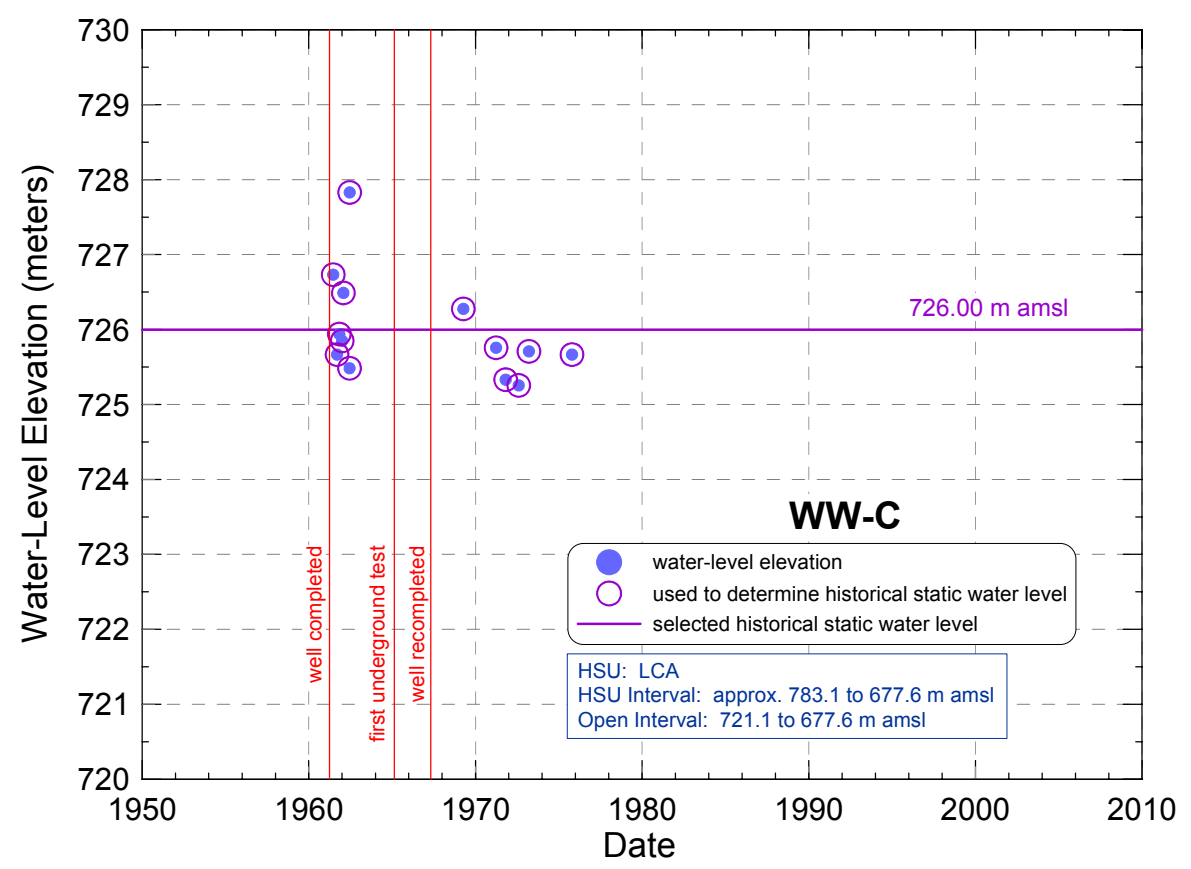

Figure 8-31

WW-C Water-Level History

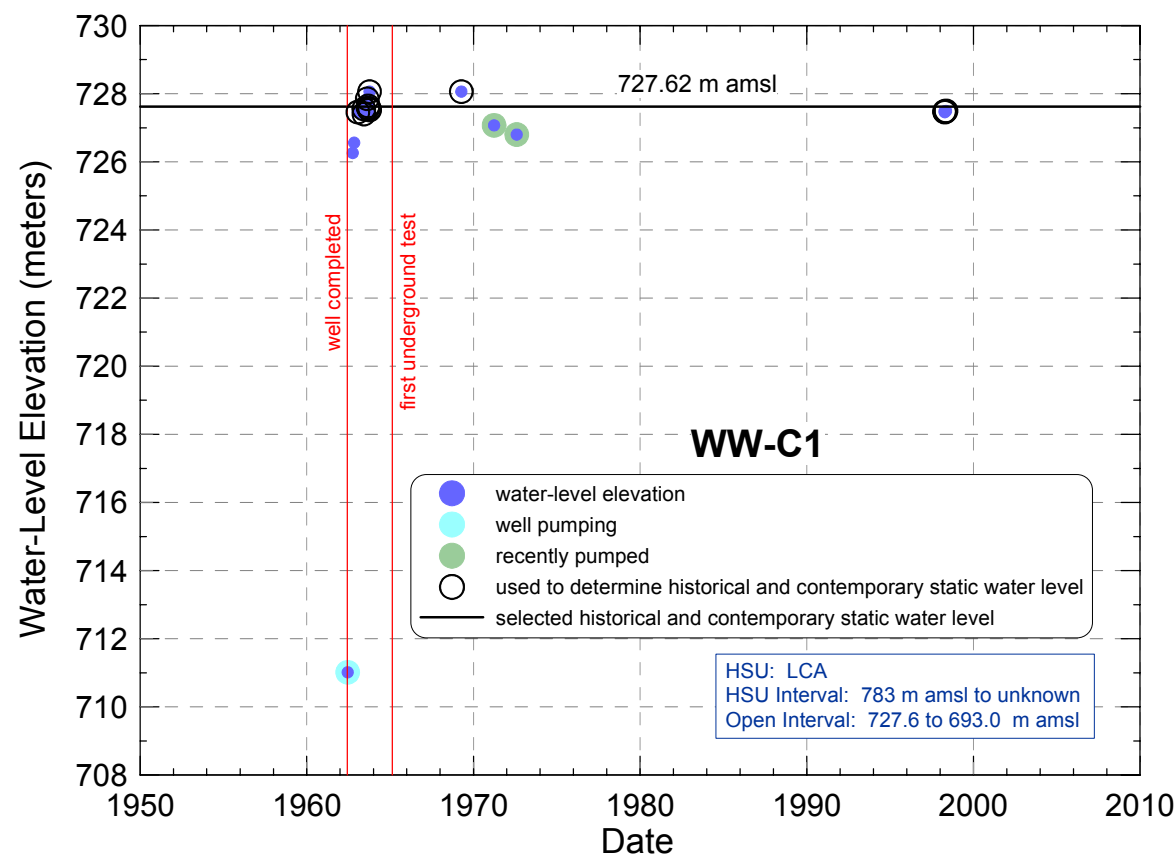

Figure 8-32

WW-C1 Water-Level History 
measured again until 1998. Two water-level measurements were made shortly after the well had been pumped. Two other measurements fall below those measured after pumping. These latter two were also considered to have been affected by pumping. No trend in the water-level data is apparent from the hydrograph. Therefore, all of the measurements not affected by pumping were averaged to obtain a steady-state head of $727.62 \mathrm{~m}$ amsl, which is assumed to be representative of both historical and contemporary conditions. The uncertainty in this steady-state value is estimated to be $1.02 \mathrm{~m}$.

\subsection{Flow System Behavior}

The steady-state heads determined from the hydrographs were used to evaluate horizontal and vertical groundwater flow in the Frenchman Flat area and vicinity. The results of this analysis will be used to guide calibration of the CAU-scale steady-state groundwater flow model. General conclusions regarding flow in the region are presented below.

\subsubsection{Horizontal Flow Analysis}

As discussed in Section 8.6, the water-level data for the Frenchman Flat area suggest two different steady-state flow conditions, historical and contemporary, for several wells located in the southern portion of the study area and completed to the AA. For these wells, the water level measured late in the well's history is lower than that measured early in its history. The best example of this behavior is illustrated in the hydrograph for WW-5A (Figure 8-28). For this well, the water level decreased from September 1959 to February 1992 and then has remained fairly constant over the last 10 years. This latter fact indicates development of a new steady-state condition. The wells showing this change are RNM-2S, WW-5A, WW-5B, and WW-5C. The decline in RNM-2S is less certain than for the other wells because the size of the decline falls within the uncertainty of the steady-state heads. The difference between the historical and contemporary steady-state heads is about $1 \mathrm{~m}$ for RNM-2S and over $9 \mathrm{~m}$ for WW-5C. A change in the steady-state heads for historical and contemporary time periods could not be determined for the wells located in the northern portion of Frenchman Flat due to a paucity of data. Recall that the contemporary, steady-state heads were developed for this analysis only and will not be used in the steady-state flow model of the CAU. However, they may be useful if future modeling includes pumping.

Historical steady-state hydraulic head data for the AA are available for nine wells at seven locations in and around Frenchman Flat. A post plot of the data, with the uncertainty, is given in Figure 8-33. This figure shows a difference in the steady-state heads for the RNM wells, with RNM-1 having the lowest value and RNM-2S having the highest value. The uncertainty in the head for RNM-1 is high due to the fact that this well was, by design, drilled at a high deviation from vertical but no deviation survey data are available. Based on this post plot, the head in RNM-1 is anomalously low and the assigned uncertainty is probably too low. There is little difference in the steady-state heads for UE-5f, UE-5c WW, 


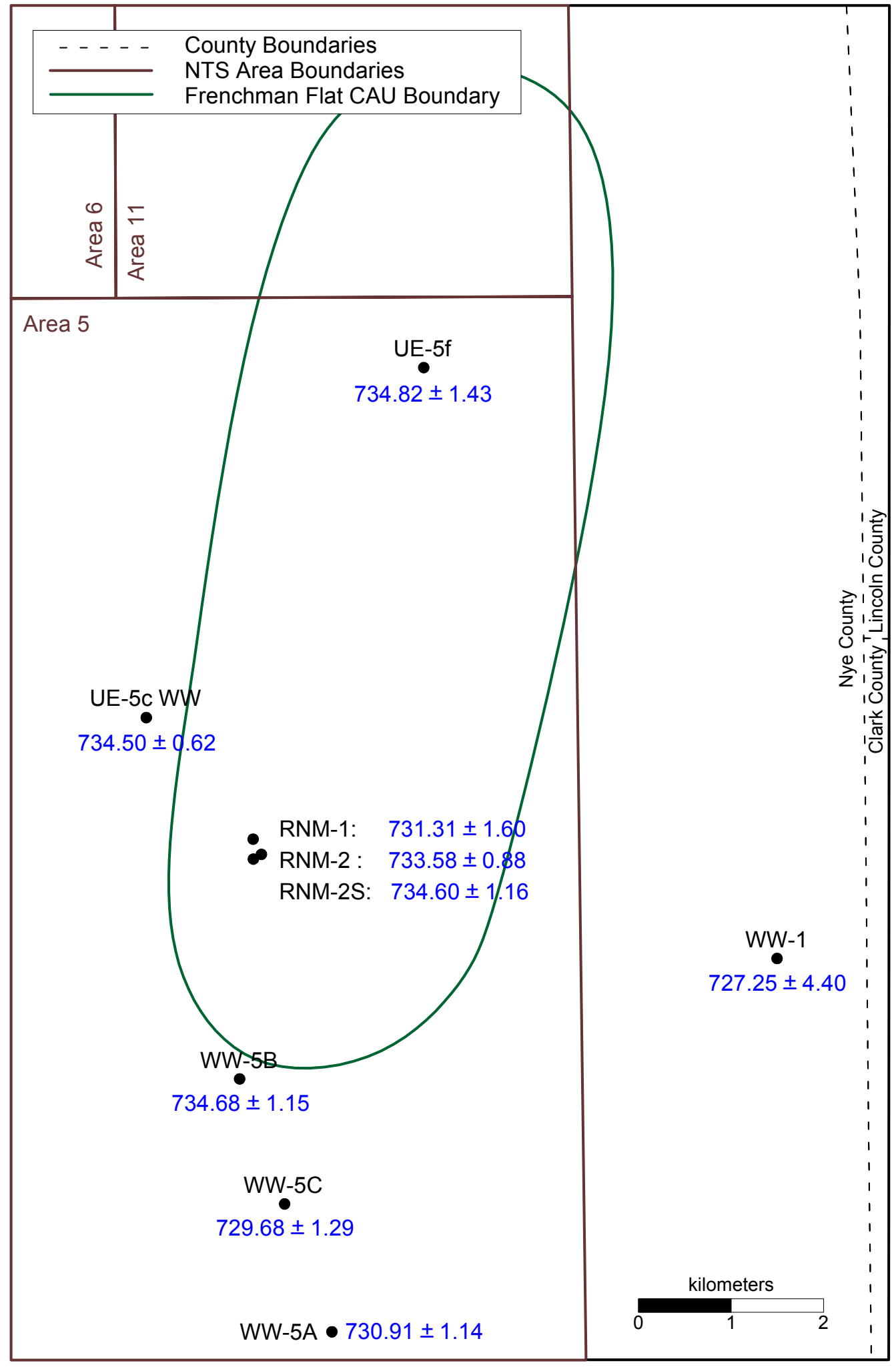

Figure 8-33

Post of Historical, Steady-State Heads in the AA 
RNM-2S, and WW-5B. A low in the heads is observed east and south of the CAU in WW-1, WW-5A, and WW-5C. The low heads south of the CAU are consistent with the general conceptualization that flow in the AA is from north to south. The low head in WW-1 is inconsistent with that conceptualization. The head in WW-1 is highly uncertain due to the fact that only one measurement has been made in that well and may be even more uncertainty than estimated here. Excluding the head in WW-1, the historical, steady-state heads for the AA suggest a general flow direction from north to south across the CAU.

Contemporary, steady-state hydraulic head data for the AA are available for 15 wells/completions at 8 locations in and around Frenchman Flat. A post plot of that data is shown in Figure 8-34. The low at WW-5C is much larger for contemporary conditions than it is for historical conditions. As with the plot of historical heads, the head in RNM-1 is anonymously lower than the heads in nearby wells. The heads are essentially the same in the wells from UE-5 PW-2 in the north to WW-5B in the south suggesting a flat gradient. The contemporary, steady-state heads for the AA suggest a general flow direction from north to south across the CAU.

The differences between the contemporary and historical steady-state heads in the AA are posted in Figure 8-35. At wells having both a historical and a contemporary steady-state head, the difference between these heads is shown. A negative value indicates that the contemporary, steady-state head is lower than the historical, steady-state head. The largest difference is observed at WW-5C where the contemporary, steady-state head is over $9 \mathrm{~m}$ lower than the historical, steady-state head. Differences between historical and contemporary conditions could not be determined in the northern portion of the CAU. This is because all wells in that area have either been constructed since 1992 and have no historical data or were constructed in the 1960s and have no contemporary water-level measurements.

A historical steady-state head in the TM-WTA could be determined at only WW-4 and WW-4A (Figure 8-1). These two wells are located adjacent to one another in CP Basin. Contemporary, steady-state heads for the TM-WTA could be determined for four completions at three locations (Figure 8-36). This post plot shows a variation of less than $1 \mathrm{~m}$ in the water level in the TM-WTA, which is close to the uncertainty. Data are available only for sites in the northern portion of Frenchman Flat. Therefore, the general direction of flow in the TM-WTA across the CAU could not be estimated.

The lowest measured water level for the TM-WTA in WW-4 and WW-4a is over $100 \mathrm{~m}$ higher than measured water level in this aquifer in wells located in northern Frenchman Flat. Assuming these two portions of the aquifer are hydraulically connected, this difference suggests groundwater is flowing in the southeastern direction in this area. It is possible, however, that these two areas are not hydraulically connected due to the large degree of faulting in the region.

Seven wells in the Frenchman Flat area and vicinity are completed in the LCA. These wells are WW-C, WW-C1, TW-3, SM-23-1, TW-F, Army-1 WW, and ER-5-3 \#2. A steady-state hydraulic head could be determined for all of these 


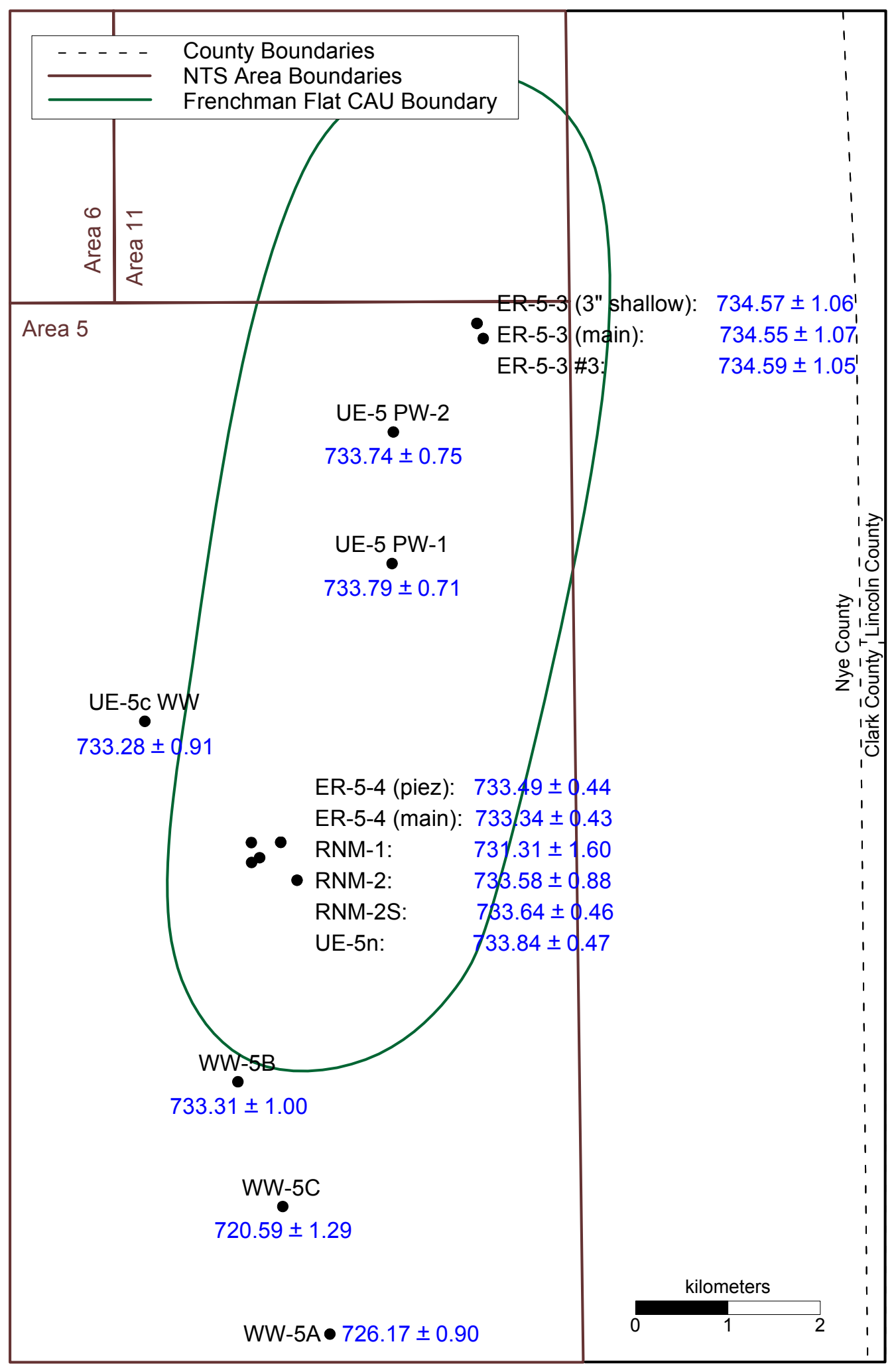

Figure 8-34

Post of Contemporary, Steady-State Heads in the AA 


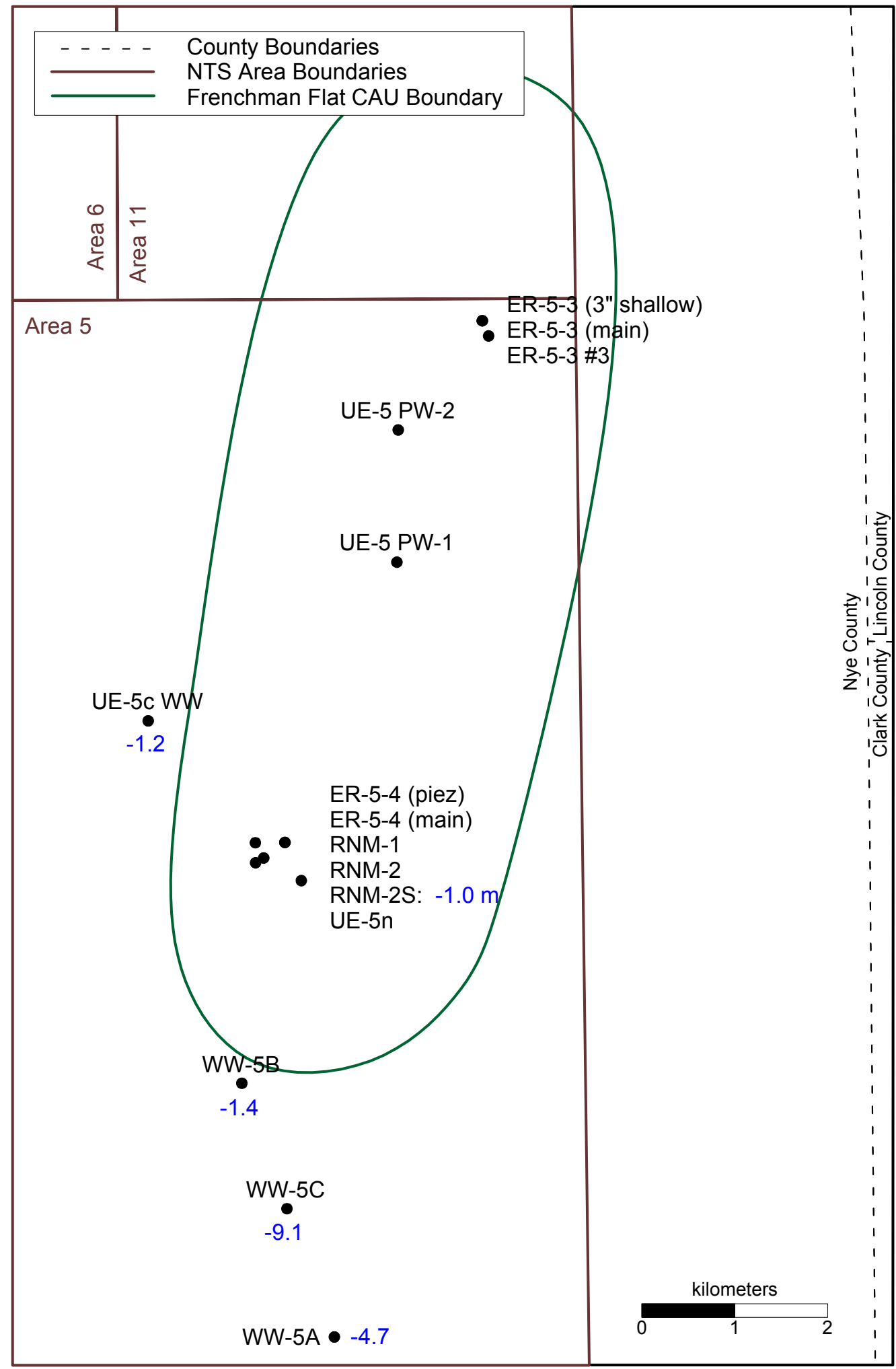

Figure 8-35

Post of Head Differences in the AA 


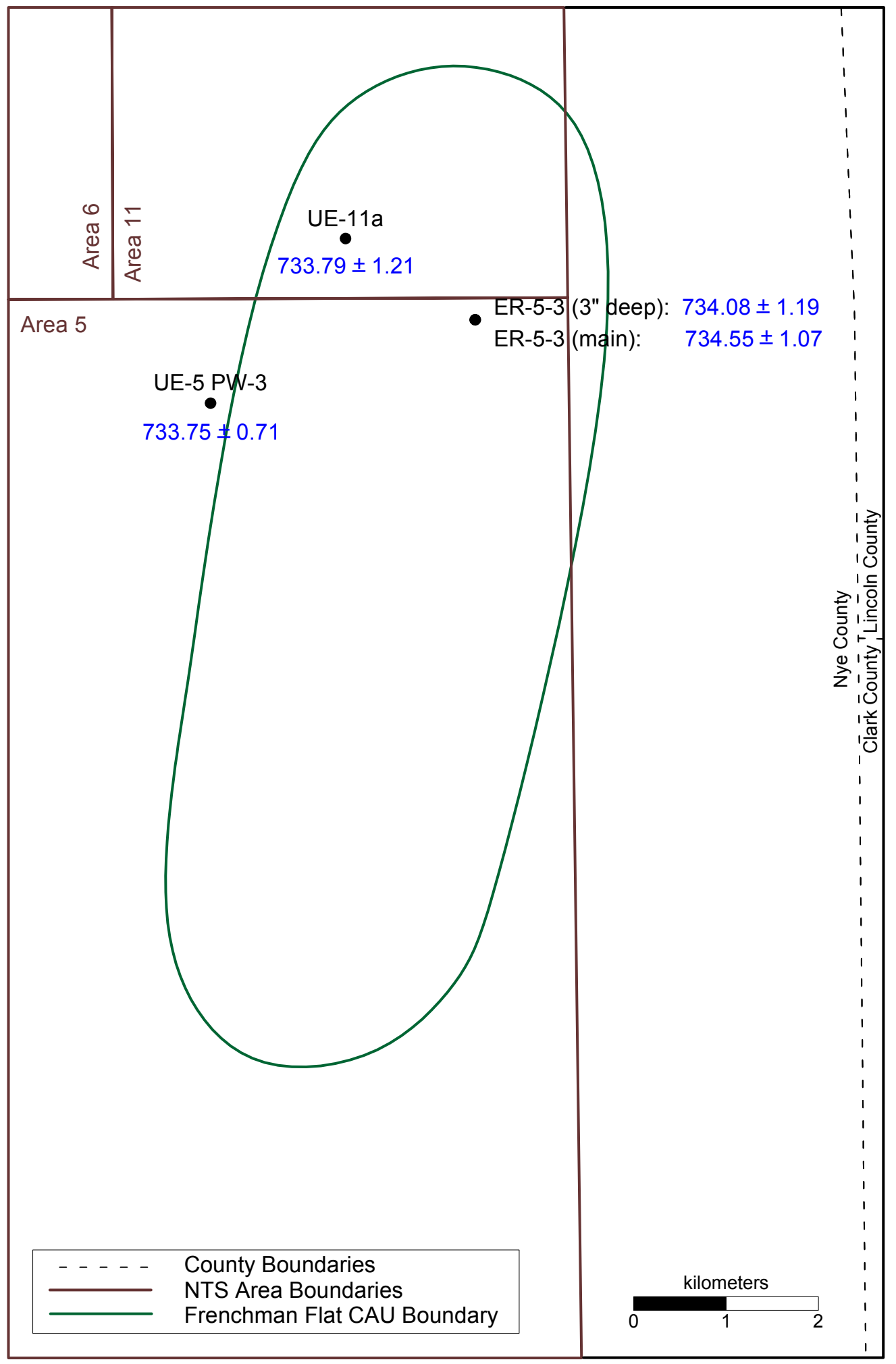

Figure 8-36

Post of Contemporary, Steady-State Heads in the TM-WTA 
wells with the exception of ER-5-3 \#2 in which the water level has been rising and has not yet stabilized and no clear reason for the rise is known. The historical and contemporary heads are identical in WW-C1, TW-3, TW-F, and Army-1 WW.

Only a historical head could be determined for WW-C, due to a lack of recent data, and only a contemporary head could be determined for SM-23-1, which was completed in 1996. Post plots of the historical and contemporary steady-state hydraulic heads are provided in Figure 8-37 and Figure 8-38, respectively. The highest head in the LCA is observed in TW-F. Recall that this is the well for which a correction was made to the measured depths to water due to elevated temperatures of the water in the well. Information regarding the temperature profile in this well is limited. Additional temperature information for water in this well and other wells completed to the LCA could allow for a more accurate temperature correction that may reduce the head in TW-F relative to the head in other wells completed to the LCA. It is likely that the uncertainty in the head at TW-F is higher than that estimated here. Excluding the head in TW-F, the posted heads suggest north to south flow in the LCA.

\subsubsection{Transient Flow System Behavior}

Ten water-supply wells are located in the Frenchman Flat area and vicinity (see Section 7.0). In addition, RNM-2S was pumped for 16 years as part of the CME (Bryant, 1992). The rate of water withdrawal in the water-supply wells has, in general, remained below 10 million gallons per month (231 gpm). The pumping rate for RNM-2S during the CME was much higher at between 25 and 30 million gallons per month (579 to $694 \mathrm{gpm}$ ) from October 1975 to August 1991.

Little transient behavior has been observed in Army-1 WW, WW-C, and WW-C1, all completed to the LCA (Figures 8-2, 8-31, and 8-32, respectively). Drawdown is about $2.4 \mathrm{~m}$ in WW-4 (Figure 8-26) and about $1 \mathrm{~m}$ in WW-4A (Figure 8-27) due to pumping. Both of these wells are completed to the TM-WTA. The affects of pumping in the vicinity of these five wells could not be determined due to the absence of nearby wells. Bright et al. (2001) conducted a trend analysis on water-levels in wells completed to the LCA and TM-WTA in Frenchman Flat. Their report includes a detailed discussion of trends in the water levels and the potential causes of those trends.

Drawdowns of about 5, 1, and $9 \mathrm{~m}$ have been observed in WW-5A, WW-5B, and WW-5C, respectively, due to pumping in these wells. All three of these wells are completed to the AA. The hydrograph for WW-5A (Figure 8-28) indicates drawdown on the order of $3 \mathrm{~m}$ due to pumping in this well from March 1951 to July 1971 when the pump was removed. Additional drawdown of about $1.5 \mathrm{~m}$ occurred from July 1971 to January 1980. The water level in WW-5A has fluctuated slightly since 1990 but has remained fairly constant overall. These minor fluctuations appear to be responses to pumping in WW-5C located nearby. The stable water level observed since 1990 is about $5 \mathrm{~m}$ lower than the level observed in 1960 during the early history of the well.

Pumping of water-supply wells WW-5A, WW-5B, and WW-5C appears to have had little affect on the water level in WW-5B until about 1972 based on the 


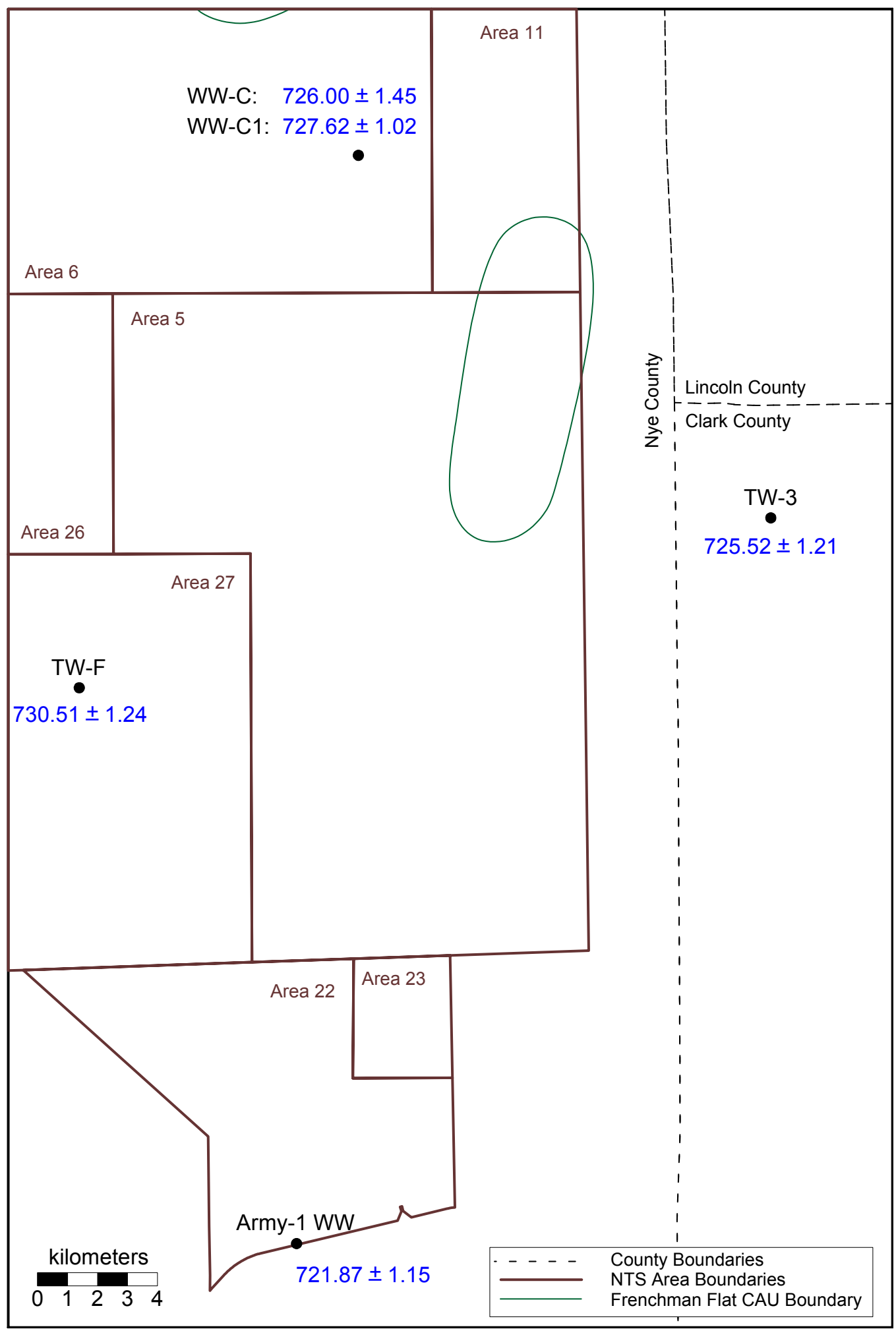

Figure 8-37

Post of Historical, Steady-State Heads in the LCA 


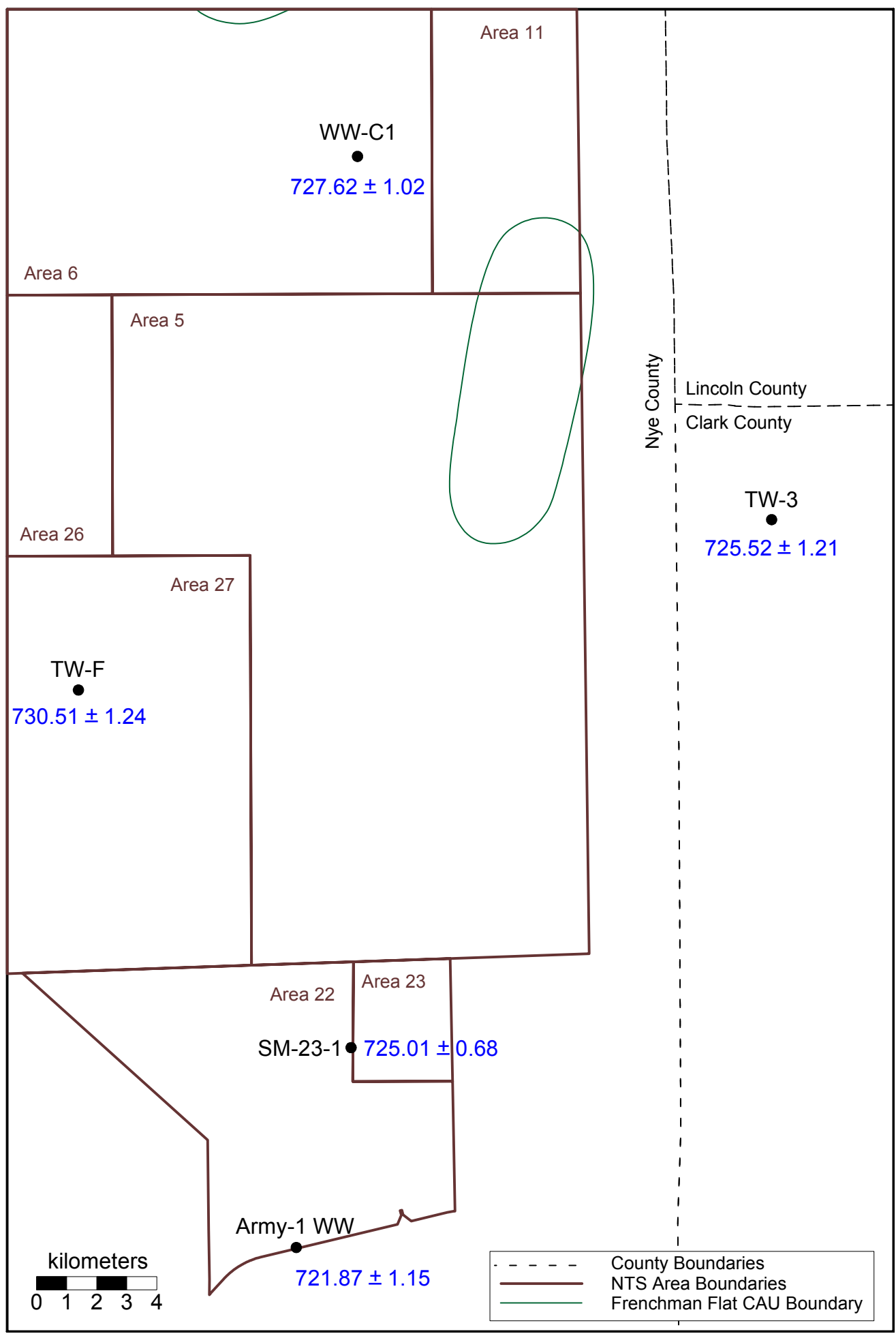

Figure 8-38

Post of Contemporary, Steady-State Heads in the LCA 
hydrograph data (Figure 8-29). The water level in this well began to decline between August 1972 and January 1980. Sometime after May 1991, the water-level in WW-5B began to recover slightly and has remained fairly stable since January 2003. This is probably due to the reduced pumping in WW-5B and WW-5C since the mid-1990s, and the recent constant pumping in these wells (see Figures 7-9 and 7-10 in Section 7.0).

WW-5C shows the largest decline in water level of any well in the Frenchman Flat area and vicinity. The water level in this well has declined due to pumping of the well based on the transient data from well completion to the early 1980s

(Figure 8-30b). The water level in WW-5C recovered about $4 \mathrm{~m}$ between January 1980 and May 1991. This increase does not correspond to full recovery of the well to pre-pumping conditions. This observation indicates that pumping in this well and WW-5B continues to drawdown the water level in WW-5C.

RNM-1, RNM-2, and UE-5n, completed in the AA, are located in close proximity to RNM-2S and were completed prior to or near the start of the CME. The water-level in RNM-2 shows a response to pumping in RNM-2S for the CME (Figure 8-14). Drawdown of about $1.5 \mathrm{~m}$ is observed during the time period RNM-2S was pumping for the CME and recovery of about $1.5 \mathrm{~m}$ is observed since pumping in RNM-2S stopped. A lack of data for RNM-1 prevents assessment of the water-level response in that well due to RNM-2S pumping for the CME (Figure 8-13). The somewhat erratic water level observed in UE-5n during the CME (Figure 8-25) is attributed to infiltration of water from a nearby ditch into which water pumped from RNM-2S was discharged. Because the water level in UE-5n was effected by the infiltration of water pumped from RNM-2S, it is not possible to determined whether pumping for the CME caused drawdown in the AA at the location of UE-5n. The decline of the water level in this well after pumping for the CME stopped is most likely due to the reduction in recharge from the ditch once the source of water to the ditch was removed.

Water-supply well UE-5c WW is located northwest of RNM-2S and is also completed to the AA. Water-level data for this well show little response to pumping in the well itself based on measurements between the time of well completion and the start of pumping in RNM-2S (Figure 8-24). Only one water level has been measured in this well since the start of the CME. That water level is about $1 \mathrm{~m}$ lower than the water levels observed prior to the start of the CME. This observation suggests that pumping in RNM-2S caused a decline in the water-level in UE-5c WW.

Very few water-level data are available for RNM-2S during the CME (Figure 8-15b). However, a high density of data is available near the end of and after the CME. These latter data show the water level in RNM-2S recovering after pumping stopped. The level to which water recovered in this well after pumping stopped is lower than the water level observed prior to the start of pumping. The lower water-level observed after the CME relative to before the CME in this well suggests an overall decline in water level in the well. Due to a lack of data, the extent of this decline can not be determined. However, the post plots of steady-state heads in the AA presented in Section 8.7.1 (Figures 8-33 through 8-35) suggest that the entire southern portion of Frenchman Flat has experienced a 
decline in water-level, with the center of that decline located in the vicinity of WW-5C.

Transient flow behavior in the northern portion of Frenchman Flat could not be determined for two main reasons. First, most of the wells located in this area have been completed since 1990 and, therefore, have no historical water-level data. Second, the data available for older wells in the area are insufficient for assessing transient trends in water levels. A discussion of the results of a trend analysis performed on the water level observed in wells completed to the AA can be found in Bright et al. (2001). That report provides a detailed discussion of, and potential causes for, observed water-level fluctuations.

\subsubsection{Vertical Flow Analysis}

To assess vertical flow between HSUs, water-level data are available for only the AA, TM-WTA, and LCA. The post plots of data generated for these three HSUs (Section 8.7.1) indicate that water levels are highest in the AA and lowest in the LCA. The magnitude of this difference is on the order of $6 \mathrm{~m}$. Water levels in the TM-WTA are less than a meter lower than those in the AA based on the limited available data. Discrete vertical head data are available at two locations, the ER-5-3 Well Cluster and the ER-5-4 well cluster.

\subsubsection{ER-5-3 Well Cluster}

The ER-5-3 well cluster consists of three wells (ER-5-3, ER-5-3 \#2, and ER-5-3 \#3) and two piezometers (ER-5-3 shallow and ER-5-3 deep). The ER-5-3 well is completed to both the AA and the TM-WTA. Table 8-5 lists each well in this cluster, the HSU for the well, and the contemporary, steady-state head determined for the well. The table is organized such that the shallowest completion is given at the top of the table and the deepest completion is given at the bottom of the table. Data from the ER-5-3 well cluster indicates that the water-levels in the AA and TM-WTA are almost identical, and are about $6 \mathrm{~m}$ higher than the water-level in the LCA.

Table 8-5

Vertical Hydraulic Heads at the ER 5-3 Well Cluster

\begin{tabular}{|c|c|c||}
\hline Well/Piezometer & HSU & $\begin{array}{c}\text { Steady-State Hydraulic Head } \\
(\mathbf{m})\end{array}$ \\
\hline \hline ER-5-3 (shallow piezometer) & AA & 734.57 \\
\hline ER-5-3 \#3 & AA & 734.59 \\
\hline ER-5-3 (main) & AA & 734.55 \\
\hline ER-5-3 (deep piezometer) & TM-WTA & 734.08 \\
\hline ER-5-3 (main) & TM-WTA & 734.55 \\
\hline ER-5-3 \#2 & LCA & $<728$ \\
\hline
\end{tabular}




\subsubsection{ER-5-4 Well Cluster}

The ER-5-4 well cluster consists of two wells (ER-5-4 and ER-5-4 \#2) and one piezometer. The ER-5-4 well has two open intervals, both completed to the AA. ER-5-4 \#2 is completed to the LTCU. A steady-state water level could be determined for both the ER-5-4 main and the ER-5-4 piezometer. A steady-state water level could not be determined for ER-5-4 \#2 because the water level in that well has not yet stabilized. However, the data for ER-5-4 \#2 indicate that the water level in this well will stabilize at a value substantially higher than the water level in the ER-5-4 completions in the AA. The water-level elevation in ER-5-4 $\# 2$ will be at least $750 \mathrm{~m}$ amsl which is over $16 \mathrm{~m}$ higher than the average steady-state head of about $733.4 \mathrm{~m}$ amsl in the AA completions. This suggests upward flow from the LTCU to the AA at the location of the ER 5-4 well cluster.

In summary, water-level data in Frenchman Flat indicate vertical flow downward from the AA to the LCA. The difference in head between these two units appears to be on the order of 6 to $7 \mathrm{~m}$. However, the magnitude of this head difference is uncertain due to the paucity of data. At the one location with data in the AA and the LTCU (at the ER 5-4 well cluster), upward flow from the LTCU to the AA is indicated. When all three units are present, the LTCU is located between the AA and the LCA. Therefore, it will be important to know whether (1) the LTCU separates the AA and the LCA across the entire Frenchmen Flat area and (2) the LTCU has a higher head than the AA across the entire Frenchmen Flat area. If these are true, the higher heads in the LTCU will prevent flow from the AA to the LCA. Since the water level in the LTCU has been measured at only one location, the role of this HSU in vertical flow is really unknown, and additional data should be collected in order to fully analyze vertical flow in the Frenchman Flat area and vicinity.

As part of the 2003 MWAT conducted in RNM-2S (SNJV, 2004d), a bridge plug was set in the ER-5-4 main borehole to isolate the upper and lower completion zones. Pressures for each completion, measured using in situ pressure transducers in each zone, were continuously recorded between April 17, 2003 and September 24, 2003. In addition, the depth-to-water for the upper completion zone was measured intermittently during this same time period. In the upper completion zone, neither the pressure nor the depth to water measurements made after the bridge plug was installed varied significantly from each other or from pre-installation measurements. In contrast, pressures measured in the lower completion zone after installation of the bridge plug dropped a total of 1.723 pounds per square inch (psi). Adjusting for water density as a function of temperature, the pressure differential between the upper and lower completion zones is equivalent to a head differential of $1.2 \mathrm{~m}$. Using this head differential and the difference in depth between the center of the upper and lower completion intervals, a downward vertical gradient of 0.003 is calculated. Several thin (tens-of-meters scale) silt/clay layers are located in the alluvium between the completion zones indicating that a head gradient between the two zones is reasonable given these localized low permeability units. The agreement between pressure and depth-to-water measurements in the upper completion zone with the bridge plug installed and depth-to-water measurements prior to bridge plug 
installation suggests that the composite depth-to-water measurements for this borehole reflect the water-level for the upper completion zone only.

\subsection{Limitations}

The major limitation associated with the hydraulic head analysis for the Frenchman Flat area and vicinity is the sparse data environment. Data are sparse with respect to time, horizontal distribution, and vertical distribution. The density of data for many wells has been good since 1990. Prior to that time, however, few measurements were made in any of the wells. As few as one water-level measurement has been made in several of the wells. Older wells located in the southern portion of the CAU have sufficient data to illustrate an overall decline in heads in this area through time. Analysis of head changes with time could not be conducted for wells in the northern portion of the CAU because of a lack of data in wells completed prior to 1990. Most of the wells in the northern portion of the CAU were completed after 1990.

Numerous wells are located in both the northern and southern portions of the Frenchman Flat CAU (Figure 8-1). Fewer wells are located in the middle of the CAU. In addition, little data are available around the CAU for use in constraining the relationship between groundwater flow in the CAU with the surrounding areas.

Fourteen HSUs have been defined in the Frenchman Flat area and vicinity for the CAU model. Head data are available for six of those HSUs. For those six HSUs, data at various horizontal locations is available for three.

The variation in head across the CAU is small in all HSUs with data. Due to these small variations, it is important to have highly accurate water-level data to assess flow direction. At least two factors contribute to potential inaccuracy in the water-level data. First, the temperature of the water column in the wells will effect the depth-to-water measurement by effecting the water density and, thus, water-column height. If the density of the water in all wells is not the same, or a density correction can not be made, the applicability of comparing heads between boreholes is limited. The lack of temperature data for water in the wells prevents determination and correction, if necessary, of density differences. Second, water-level elevations are calculated as the land surface-elevation minus the depth to water. Any slight errors in the land-surface elevations will result in inaccuracies in the calculated water-level elevations. Therefore, it is critical that the measured land-surface elevations can be reproduced and are know to a high degree of accuracy.

The spatial distribution of water-level data for the Frenchman Flat area and vicinity will make it difficult to use CAU-specific data to define the hydraulic head boundary conditions for the CAU-scale model. 


\subsection{Summary}

The primary objective of the water-level data analysis was development of a set of hydraulic heads representative of predevelopment, steady-state conditions for use as calibration targets for the steady-state groundwater flow model of the Frenchman Flat CAU. This dataset was prepared through the collection, compilation, and qualification of existing depth-to-water data, analysis of temporal trends using hydrographs, and statistical analyses. Recall from Figure 8.1 that the term steady state is used here to refer to stable conditions and heads and is not intended to suggest true steady-state conditions. This is because geochemical data for the NTS suggest that groundwater flow in the Frenchman Flat basin was not at steady-state prior to the start of human activities in the area and very little water-level data are available to assess conditions prior to the start of pumping and underground testing.

Two steady-state time periods were identified in the analysis of temporal trends. The historical steady-state heads are the suggested target heads to be used for calibration of the CAU-scale steady-state flow model. The contemporary, steady-state heads were development for analysis purposes only and will not be used for any modeling planned at this time. These heads may be useful if future modeling plans include incorporation of pumping.

A secondary objective of this data analysis was to evaluate general flow directions. The spatial distribution of data is too limited to enable generation of potentiometric surface maps. Post plots of the data for the AA, TM-WTA, and LCA were generated. These plots show, in general, historical horizontal flow to the south in both the AA and LCA. Horizontal head gradients within the AA appear to be low. In the vertical direction, groundwater appears to flow from the AA to the LCA based on data at several locations. At one location (the ER 5-4 well cluster), heads in the LTCU are much higher than in the AA indicating upward flow between these two HSUs. Since no other head data are available for the LTCU, this conclusion is tentative. Groundwater withdrawal from the AA via pumping has resulted in an overall decrease in hydraulic head in the southern portion of the CAU. Pumping from the LCA appears to have had little affect on hydraulic heads in that aquifer. 


\subsection{Lateral Boundary Fluxes}

Inflow and outflow through the lateral boundaries of the Frenchman Flat CAU-scale groundwater flow model will constitute an important portion of the water budget of the modeled system. Because there are no natural discharge areas within the Frenchman Flat model boundary, the important components of the water budget consist of the lateral fluxes and surface recharge. Unfortunately, there is no practical means of directly measuring groundwater fluxes at the scale and spatial frequency needed to represent the conditions at the CAU flow-model boundary. Nor is it practical to measure hydraulic gradients and hydraulic conductivities with which to derive the necessary groundwater fluxes (e.g., the type of estimates made by Blankennagel and Weir [1973]). Instead, the lateral boundary fluxes for the CAU-flow model were estimated indirectly through use of a regional-scale flow model. A series of alternative regional-scale flow models were developed and calibrated to capture the variability in the boundary fluxes resulting from differences in the conceptualizations of the Frenchman Flat geologic model (Section 2.0) and regional recharge distribution (Section 6.0).

The objective of the regional-scale modeling was to provide a range of lateral boundary fluxes that could be used as calibration guidelines for the CAU model. Variation in boundary flux was estimated by modifying the NTS regional groundwater flow model (DOE/NV, 1997) and calibrating 30 regional-scale flow models using MODFLOW 2000 (Harbaugh et al., 2000). MODFLOW 2000 is a finite-difference numerical modeling code developed by the USGS. The net fluxes into and out of each of the CAU-scale model boundaries were then calculated for each calibrated model using the MODFLOW utility package ZONEBUDGET (Harbaugh, 1990). The use of 30 regional-flow models allowed for boundary-flux calculations that encompassed the uncertainty associated with several plausible hydrostratigraphic models (Section 2.0) that honor site data and numerous recharge models developed using different scientific approaches (Section 6.0).

The boundary fluxes derived from the regional model are intended to constrain boundary flow into the Frenchman Flat CAU-scale model. Specifically, the fluxes into and out of the CAU-scale model should remain within the range of values derived from the regional model, which account for the uncertainty associated with different hydrostratigraphic models and recharge scenarios. In addition, the hydraulic heads from the regional model can be used to augment the boundary conditions for the CAU model. 


\subsection{Approach}

Water budgets for the approximate CAU-flow model domain were generated from a series of regional-scale flow models using a base and alternative HSU models. These water budgets are approximate because regional model MODFLOW cells may not be exactly coincident with the planned CAU model along its boundary. The CAU model will have a considerably finer grid that may be rotated with respect to the regional model grid. The regional model is expected to provide an adequate description of the boundary fluxes at the CAU-flow model boundaries because the majority of the flux occurs through the regionally connected LCA.

The NTS regional groundwater flow model with the base HSU model for Pahute Mesa-Oasis Valley (SNJV, 2004a) served as the base model. The Frenchman Flat area of the model was updated with alternative hydrostratigraphic models to provide additional HSU detail in the regional model. During the final stages of Frenchman Flat hydrostratigraphic model development, magnetotelluric data of the CP Basin became available that resulted in a change to the base hydrostratigraphic model. As a result, the configuration of the CP Basin in each of the alternative hydrostratigraphic models used for calculating lateral boundary fluxes is consistent with hydrostratigraphic model Alternative \#4. The base and alternative hydrostratigraphic models are detailed in Section 2.0 of this document. Appendix $\mathrm{E}$ has detailed information concerning the model discretization. The naming convention for the hydrostratigraphic models is presented in Table 9-1.

Table 9-1

Hydrostratigraphic Model Code Conventions

\begin{tabular}{|c|c|}
\hline $\begin{array}{c}\text { Hydrostratigraphic } \\
\text { Model Code }\end{array}$ & Description \\
\hline \hline G0 & Base Case \\
\hline G1 & Alternative \#1: Aquifer Juxtaposition \\
\hline G2 & Alternative \#2: More Extensive Basalt Flow \\
\hline G3 & Alternative \#3: No Detachment Fault \\
\hline G4 & Alternative \#4: CP Basin \\
\hline
\end{tabular}

In addition to considering the uncertainty in the flux boundary conditions caused by differences in conceptual geologic models, uncertainty associated with various methods of approximating recharge was also considered (Section 6.0). The three methods used to approximate the recharge distribution were an empirical mass-balance method and two derivatives of this method, a deterministic method, and a chloride mass-balance method (see Section 6.0). The naming convention for the six recharge models is described in Table 9-2. The first method (R1), a modified Maxey and Eakin approach (Section 6.0; Maxey and Eakin, 1949; and Eakin et al., 1951), is an empirically-derived approach relating recharge to precipitation zones from a base precipitation map that was calibrated during the initial NTS regional groundwater flow calibration (UGTA Original). The Maxey and Eakin method was also used to generate a revised submodel (R2), which included updates in the amount of precipitation needed to generate recharge 
(UGTA Revised). The second method (R3) is DRI's chloride mass-balance approach, which estimates recharge by analyzing and comparing the chloride ratios of precipitation and groundwater (Section 6.0; and Russell and Minor, 2002). A submodel of the of the DRI approach (R4), where no recharge occurred below an elevation of $1,237 \mathrm{~m}$, was used to generate another possible recharge distribution. The third approach (used by USGS) is a deterministic approach using a distributed parameter watershed model to simulate the processes that affect the net rate of infiltration past the root zone (Section 6.0; and Hevesi, et al., 2003). This method constituted two submodels (R5 and R6) which used redistribution and no redistribution of areal recharge, respectively.

Table 9-2

Recharge Model Code Convention

\begin{tabular}{|c|c|c|}
\hline $\begin{array}{c}\text { Recharge Model } \\
\text { Code }\end{array}$ & Recharge Model & Recharge Rate $\left(\mathbf{m}^{\mathbf{3}} / \mathbf{d}\right)$ \\
\hline \hline R1 & UGTA Original & 220,000 \\
\hline R2 & UGTA Revised & 212,000 \\
\hline R3 & DRI & 275,000 \\
\hline R4 & DRI - no recharge below $1,237 \mathrm{~m}$ & 268,000 \\
\hline R5 & USGS - redistribution & 173,000 \\
\hline R6 & USGS - no redistribution & 143,000 \\
\hline
\end{tabular}

By combining the six recharge models and five HSU models, a total of 30 groundwater-flow conceptualizations were generated. To accommodate the significant computational effort associated with calibrating 30 groundwater-flow models, a methodical, automated method of calibration was selected. The parameter estimation tool PEST (Doherty, 2002) was used to aid in the automation of the calibration process and enabled model calibration to be consistent and reproducible. The calibration process and results are described, in detail, in Appendix E.

Lateral-boundary fluxes for the FF CAU were calculated for each of the 30 alternate regional-scale flow models by using the utility package ZONEBUDGET which processes the cell-by-cell flow file generated by MODFLOW. The ZONEBUDGET (Harbaugh, 1990) output included inflow and outflow fluxes for each lateral boundary of the proposed Frenchman Flat CAU-flow model and the HSU model boundary.

\subsection{Analysis Results}

The lateral fluxes derived from the regional groundwater-flow model simulations using the 30 alternate conceptual models are presented. A comparison of the results and the effects of the hydrostratigraphic and recharge models on fluxes are included. 


\subsubsection{Lateral Fluxes Derived from Regional Model Flow Simulations}

Each of the alternate-flow-model simulations at the regional scale were calibrated to regional hydraulic head and discharge flow data (Appendix E) prior to the calculation of boundary fluxes. The simulation results include a set of files containing the MODFLOW cell-by-cell flow budgets for each of the 30 simulations. The cell-by-cell flow budgets contain the volumetric flow rates across the front, right, and bottom faces of each finite-difference block within the regional-scale flow model. Using the cell-by-cell flows, the net inflow and outflow crossing the lateral boundaries of the CAU-scale model were calculated with ZONEBUDGET.

Tables 9-3 and 9-4 summarize the simulated inflows and outflows, respectively, through each of the lateral boundaries. It is clear from these tables that groundwater tends to flow from the North and East and to the South and West through the Frenchman Flat CAU-flow model domain. This is generally true regardless of the recharge or HSU model. The majority of this flow occurs in the regionally connected Carbonate Aquifer with the locally isolated Alluvial Aquifer contributing very little to the boundary fluxes.

The performance of each model with respect to calibration targets is discussed in detail in Appendix E. The HSU model had little effect on either the calibration or the boundary fluxes. Overall, the simulation using the UGTA Original recharge model (R1) performed the best in mimicking the observed values of both hydraulic head and discharge and may be considered the most reliable alternative for the regional model area.

Table 9-5 summarizes the water budget for each simulation. The recharge is the total inflow from areal recharge over the model area. Only two significant digits are presented for the flow rates in Table 9-5. This masks the slight differences between total inflow and outflow so the percent difference is calculated on the raw numbers. The 30 cases presented in Table 9-5 are thought to encompass the range of possible outcomes for Frenchman Flat. 
Table 9-3

Regional Model Inflows $\left(\mathrm{m}^{3} / \mathrm{d}\right)$ at Geologic Model Boundaries

\begin{tabular}{|c|c|c|c|c|}
\hline $\begin{array}{l}\text { Model } \\
\text { Number }\end{array}$ & $\begin{array}{l}\text { Northern } \\
\text { Boundary }\end{array}$ & $\begin{array}{l}\text { Southern } \\
\text { Boundary }\end{array}$ & $\begin{array}{c}\text { Eastern } \\
\text { Boundary }\end{array}$ & $\begin{array}{l}\text { Western } \\
\text { Boundary }\end{array}$ \\
\hline G0R1 & 42000 & 9700 & 84000 & 770 \\
\hline G0R2 & 46000 & 8800 & 81000 & 770 \\
\hline G0R3 & 48000 & 11000 & 83000 & 650 \\
\hline G0R4 & 46000 & 11000 & 83000 & 650 \\
\hline G0R5 & 32000 & 9200 & 65000 & 1100 \\
\hline G0R6 & 20000 & 11000 & 60000 & 1300 \\
\hline G1R1 & 42000 & 9700 & 85000 & 720 \\
\hline G1R2 & 46000 & 8800 & 81000 & 690 \\
\hline G1R3 & 48000 & 11000 & 83000 & 550 \\
\hline G1R4 & 52000 & 11000 & 83000 & 760 \\
\hline G1R5 & 32000 & 9200 & 65000 & 1000 \\
\hline G1R6 & 20000 & 11000 & 60000 & 970 \\
\hline G2R1 & 42000 & 9700 & 84000 & 720 \\
\hline G2R2 & 46000 & 8800 & 81000 & 690 \\
\hline G2R3 & 46000 & 11000 & 84000 & 610 \\
\hline G2R4 & 43000 & 11000 & 82000 & 550 \\
\hline G2R5 & 32000 & 9200 & 65000 & 1000 \\
\hline G2R6 & 20000 & 11000 & 60000 & 980 \\
\hline G3R1 & 42000 & 9700 & 84000 & 720 \\
\hline G3R2 & 46000 & 8800 & 81000 & 690 \\
\hline G3R3 & 49000 & 11000 & 83000 & 560 \\
\hline G3R4 & 47000 & 11000 & 83000 & 550 \\
\hline G3R5 & 32000 & 9200 & 65000 & 1000 \\
\hline G3R6 & 19000 & 11000 & 60000 & 1000 \\
\hline G4R1 & 42000 & 9700 & 84000 & 720 \\
\hline G4R2 & 46000 & 8800 & 81000 & 690 \\
\hline G4R3 & 48000 & 11000 & 83000 & 580 \\
\hline G4R4 & 50000 & 11000 & 82000 & 630 \\
\hline G4R5 & 32000 & 9200 & 65000 & 1000 \\
\hline G4R6 & 19000 & 11000 & 60000 & 1100 \\
\hline
\end{tabular}


Table 9-4

Regional Model Outflows $\left(\mathrm{m}^{3} / \mathrm{d}\right)$ at Geologic Model Boundaries

\begin{tabular}{|c|c|c|c|c|}
\hline $\begin{array}{l}\text { Model } \\
\text { Number }\end{array}$ & $\begin{array}{l}\text { Northern } \\
\text { Boundary }\end{array}$ & $\begin{array}{l}\text { Southern } \\
\text { Boundary }\end{array}$ & $\begin{array}{c}\text { Eastern } \\
\text { Boundary }\end{array}$ & $\begin{array}{l}\text { Western } \\
\text { Boundary }\end{array}$ \\
\hline G0R1 & 610 & 9200 & 0.0071 & 130000 \\
\hline G0R2 & 450 & 6800 & 0.02 & 130000 \\
\hline G0R3 & 190 & 17000 & 0.0058 & 130000 \\
\hline G0R4 & 220 & 18000 & 0.0051 & 120000 \\
\hline G0R5 & 290 & 19000 & 0.0033 & 89000 \\
\hline G0R6 & 330 & 33000 & 0.00041 & 59000 \\
\hline G1R1 & 610 & 9200 & 0.0071 & 130000 \\
\hline G1R2 & 450 & 6800 & 0.02 & 130000 \\
\hline G1R3 & 160 & 17000 & 0.0056 & 130000 \\
\hline G1R4 & 20 & 18000 & 0.005 & 120000 \\
\hline G1R5 & 290 & 19000 & 0.0033 & 89000 \\
\hline G1R6 & 330 & 33000 & 0.00041 & 59000 \\
\hline G2R1 & 610 & 9200 & 0.0071 & 130000 \\
\hline G2R2 & 450 & 6800 & 0.02 & 130000 \\
\hline G2R3 & 280 & 17000 & 0.0061 & 130000 \\
\hline G2R4 & 230 & 18000 & 0.0045 & 130000 \\
\hline G2R5 & 300 & 19000 & 0.0033 & 89000 \\
\hline G2R6 & 350 & 33000 & 0.00042 & 59000 \\
\hline G3R1 & 610 & 9200 & 0.0071 & 130000 \\
\hline G3R2 & 450 & 6800 & 0.02 & 130000 \\
\hline G3R3 & 150 & 17000 & 0.0056 & 130000 \\
\hline G3R4 & 200 & 18000 & 0.0051 & 120000 \\
\hline G3R5 & 300 & 19000 & 0.0033 & 89000 \\
\hline G3R6 & 380 & 33000 & 0.00044 & 59000 \\
\hline G4R1 & 610 & 9200 & 0.0071 & 130000 \\
\hline G4R2 & 450 & 6800 & 0.02 & 130000 \\
\hline G4R3 & 190 & 17000 & 0.0058 & 130000 \\
\hline G4R4 & 65 & 18000 & 0.0045 & 130000 \\
\hline G4R5 & 300 & 19000 & 0.0033 & 89000 \\
\hline G4R6 & 360 & 33000 & 0.00043 & 59000 \\
\hline
\end{tabular}


Table 9-5

Total Water Balance $\left(\mathrm{m}^{3} / \mathrm{d}\right)$ for the Geologic Model Boundaries

\begin{tabular}{|c|c|c|c|c|}
\hline $\begin{array}{l}\text { Model } \\
\text { Number }\end{array}$ & $\begin{array}{l}\text { Perimeter } \\
\text { Influx }\end{array}$ & $\begin{array}{l}\text { Perimeter } \\
\text { Outflux }\end{array}$ & Recharge & $\begin{array}{c}\text { Percent } \\
\text { Difference }\end{array}$ \\
\hline G0R1 & 140000 & 140000 & 2100 & $-0.01 \%$ \\
\hline G0R2 & 140000 & 140000 & 760 & $0.00 \%$ \\
\hline G0R3 & 140000 & 140000 & 1600 & $-0.04 \%$ \\
\hline G0R4 & 140000 & 140000 & 850 & $0.00 \%$ \\
\hline G0R5 & 110000 & 110000 & 680 & $-0.01 \%$ \\
\hline G0R6 & 92000 & 92000 & 610 & $0.20 \%$ \\
\hline G1R1 & 140000 & 140000 & 2100 & $-0.01 \%$ \\
\hline G1R2 & 140000 & 140000 & 760 & $-0.01 \%$ \\
\hline G1R3 & 140000 & 140000 & 1600 & $-0.61 \%$ \\
\hline G1R4 & 150000 & 140000 & 850 & $4.50 \%$ \\
\hline G1R5 & 110000 & 110000 & 680 & $-0.01 \%$ \\
\hline G1R6 & 92000 & 92000 & 610 & $-0.01 \%$ \\
\hline G2R1 & 140000 & 140000 & 2100 & $-0.01 \%$ \\
\hline G2R2 & 140000 & 140000 & 760 & $-0.01 \%$ \\
\hline G2R3 & 140000 & 140000 & 1600 & $-0.76 \%$ \\
\hline G2R4 & 140000 & 140000 & 850 & $-5.00 \%$ \\
\hline G2R5 & 110000 & 110000 & 680 & $0.00 \%$ \\
\hline G2R6 & 91000 & 92000 & 610 & $-0.07 \%$ \\
\hline G3R1 & 140000 & 140000 & 2100 & $-0.01 \%$ \\
\hline G3R2 & 140000 & 140000 & 760 & $-0.01 \%$ \\
\hline G3R3 & 140000 & 150000 & 1600 & $-0.03 \%$ \\
\hline G3R4 & 140000 & 140000 & 850 & $-0.01 \%$ \\
\hline G3R5 & 110000 & 110000 & 680 & $0.00 \%$ \\
\hline G3R6 & 91000 & 92000 & 610 & $0.01 \%$ \\
\hline G4R1 & 140000 & 140000 & 2100 & $-0.01 \%$ \\
\hline G4R2 & 140000 & 140000 & 760 & $-0.01 \%$ \\
\hline G4R3 & 140000 & 140000 & 1600 & $0.15 \%$ \\
\hline G4R4 & 140000 & 150000 & 850 & $-0.87 \%$ \\
\hline G4R5 & 110000 & 110000 & 680 & $-0.01 \%$ \\
\hline G4R6 & 91000 & 92000 & 610 & $-0.18 \%$ \\
\hline
\end{tabular}




\subsubsection{Results Comparison}

\section{Effect of Changing the HSU Model}

Alternative hydrostratigraphic models had little effect on the calibrated hydraulic heads in the model. This resulted in the residuals (observed minus simulated hydraulic heads) being insensitive to the hydrostratigraphic model. Similarly, the effect of the HSU model on the lateral boundary fluxes was also small. Direct comparisons of each geologic model using the UGTA calibrated (R1) recharge model are shown in Tables 9-6 through 9-9. Only two significant digits are presented for the flow rates, so slight differences in total inflow and outflow are masked. The percent differences are calculated on the raw numbers. The regional model is applicable to the groundwater flow system at a regional scale with the majority of the lateral flow through the LCA in the Frenchman Flat area. It is not necessarily representative of the flow within the isolated alluvial aquifer in the Frenchman Flat basin. The fact that the alternative HSU models alter only a small percentage of the central portion of the model may be the reason why inflows and outflows at the distant model boundaries are essentially unchanged with changes in HSU configuration.

Table 9-6

Regional Model Inflows ( $\left.\mathrm{m}^{3} / \mathrm{d}\right)$ for UGTA Original Recharge Model

\begin{tabular}{||l|c|c|c|c|}
\hline \multicolumn{1}{|c|}{ Geologic Model } & $\begin{array}{c}\text { Northern } \\
\text { Boundary }\end{array}$ & $\begin{array}{c}\text { Southern } \\
\text { Boundary }\end{array}$ & $\begin{array}{c}\text { Eastern } \\
\text { Boundary }\end{array}$ & $\begin{array}{c}\text { Western } \\
\text { Boundary }\end{array}$ \\
\hline \hline Base Model & 42000 & 9700 & 84000 & 770 \\
\hline Aquifer Juxtaposition & 42000 & 9700 & 85000 & 720 \\
\hline More Extensive BF & 42000 & 9700 & 84000 & 720 \\
\hline No Detachment Fault & 42000 & 9700 & 84000 & 720 \\
\hline CP Basin & 42000 & 9700 & 84000 & 720 \\
\hline
\end{tabular}

Table 9-7

Regional Model Outflows $\left(\mathrm{m}^{3} / \mathrm{d}\right)$ for UGTA Original Recharge Model

\begin{tabular}{||c|c|c|c|c|}
\hline $\begin{array}{c}\text { Geologic } \\
\text { Model }\end{array}$ & $\begin{array}{c}\text { Northern } \\
\text { Boundary }\end{array}$ & $\begin{array}{c}\text { Southern } \\
\text { Boundary }\end{array}$ & $\begin{array}{c}\text { Eastern } \\
\text { Boundary }\end{array}$ & $\begin{array}{c}\text { Western } \\
\text { Boundary }\end{array}$ \\
\hline \hline Base Model & 610 & 9200 & 0.0071 & 130000 \\
\hline $\begin{array}{c}\text { Aquifer } \\
\text { Juxtaposition }\end{array}$ & 610 & 9200 & 0.0071 & 130000 \\
\hline $\begin{array}{c}\text { More Extensive } \\
\text { BF }\end{array}$ & 610 & 9200 & 0.0071 & 130000 \\
\hline $\begin{array}{c}\text { No Detachment } \\
\text { Fault }\end{array}$ & 610 & 9200 & 0.0071 & 130000 \\
\hline CP Basin & 610 & 9200 & 0.0071 & 130000 \\
\hline
\end{tabular}


Table 9-8

Total Water Balance $\left(\mathrm{m}^{3} / \mathrm{d}\right)$ for Various HSU Models with UGTA Original Recharge Model

\begin{tabular}{||l|c|c|c|c|}
\hline \multicolumn{1}{|c|}{ Geologic Model } & $\begin{array}{c}\text { Perimeter } \\
\text { Inflow }\end{array}$ & $\begin{array}{c}\text { Perimeter } \\
\text { Outflow }\end{array}$ & Recharge & $\begin{array}{c}\text { Percent } \\
\text { Difference }\end{array}$ \\
\hline \hline Base Model & 140000 & 140000 & 2100 & $-0.01 \%$ \\
\hline Aquifer Juxtaposition & 140000 & 140000 & 2100 & $-0.01 \%$ \\
\hline More Extensive BF & 140000 & 140000 & 2100 & $-0.01 \%$ \\
\hline No Detachment Fault & 140000 & 140000 & 2100 & $-0.01 \%$ \\
\hline CP Basin & 140000 & 140000 & 2100 & $-0.01 \%$ \\
\hline
\end{tabular}

Table 9-9

Inflow and Outflow Differences between Base and Alternative HSU Models with UGTA Original Recharge Model

\begin{tabular}{|c|c|c|c|}
\hline Geologic Model & $\begin{array}{c}\% \text { Difference } \\
\text { Inflow }\end{array}$ & $\begin{array}{c}\% \text { Difference } \\
\text { Outflow }\end{array}$ & $\begin{array}{c}\% \text { Difference } \\
\text { Recharge }\end{array}$ \\
\hline \hline Aquifer Juxtaposition & $-0.04 \%$ & $-0.03 \%$ & $0.0 \%$ \\
\hline More Extensive BF & $-0.08 \%$ & $-0.07 \%$ & $0.0 \%$ \\
\hline No Detachment Fault & $-0.10 \%$ & $-0.09 \%$ & $0.0 \%$ \\
\hline CP Basin & $-0.10 \%$ & $-0.09 \%$ & $0.0 \%$ \\
\hline
\end{tabular}

\section{Effect of Changing the Recharge Model}

In contrast to the geologic model, varying the recharge model affected both the simulated hydraulic heads and the lateral boundary fluxes to varying degrees. Direct comparisons of each recharge model using the Base Case (G0) HSU model are shown in Tables 9-10 through 9-13.

Table 9-10

Regional Model Inflows $\left(\mathrm{m}^{3} / \mathrm{d}\right)$ for Base HSU Model

\begin{tabular}{||c|c|c|c|c|}
\hline $\begin{array}{c}\text { Recharge } \\
\text { Model }\end{array}$ & $\begin{array}{c}\text { Northern } \\
\text { Boundary }\end{array}$ & $\begin{array}{c}\text { Southern } \\
\text { Boundary }\end{array}$ & $\begin{array}{c}\text { Eastern } \\
\text { Boundary }\end{array}$ & $\begin{array}{c}\text { Western } \\
\text { Boundary }\end{array}$ \\
\hline \hline UGTA Original & 42000 & 9700 & 84000 & 770 \\
\hline $\begin{array}{c}\text { UGTA Revised } \\
\text { DRI-alluvial } \\
\text { mask }\end{array}$ & 46000 & 8800 & 81000 & 770 \\
\hline $\begin{array}{c}\text { DRI-alluvial and } \\
\text { elevation mask }\end{array}$ & 46000 & 11000 & 83000 & 650 \\
\hline $\begin{array}{c}\text { USGS } \\
\text { redistribution }\end{array}$ & 32000 & 9200 & 63000 & 650 \\
\hline $\begin{array}{c}\text { USGS no } \\
\text { redistribution }\end{array}$ & 20000 & 11000 & 60000 & 1300 \\
\hline
\end{tabular}


Table 9-11

Regional Model Outflows $\left(\mathrm{m}^{3} / \mathrm{d}\right)$ for Base HSU Model

\begin{tabular}{||c|c|c|c|c|}
\hline $\begin{array}{c}\text { Recharge } \\
\text { Model }\end{array}$ & $\begin{array}{c}\text { Northern } \\
\text { Boundary }\end{array}$ & $\begin{array}{c}\text { Southern } \\
\text { Boundary }\end{array}$ & $\begin{array}{c}\text { Eastern } \\
\text { Boundary }\end{array}$ & $\begin{array}{c}\text { Western } \\
\text { Boundary }\end{array}$ \\
\hline \hline UGTA Original & 610 & 9200 & 0.0071 & 130000 \\
\hline $\begin{array}{c}\text { UGTA Revised } \\
\text { DRI-alluvial } \\
\text { mask }\end{array}$ & 190 & 6800 & 0.02 & 130000 \\
\hline $\begin{array}{c}\text { DRI-alluvial and } \\
\text { elevation mask }\end{array}$ & 220 & 18000 & 0.0058 & 130000 \\
\hline $\begin{array}{c}\text { USGS } \\
\text { redistribution } \\
\text { USGS no } \\
\text { redistribution }\end{array}$ & 290 & 19000 & 0.0051 & 120000 \\
\hline
\end{tabular}

Table 9-12

Total Water Balance $\left(\mathrm{m}^{3} / \mathrm{d}\right)$ for Various Recharge Models for Base HSU Model

\begin{tabular}{|c|c|c|c|c|}
\hline $\begin{array}{c}\text { Recharge } \\
\text { Model }\end{array}$ & $\begin{array}{c}\text { Perimeter } \\
\text { Inflow }\end{array}$ & $\begin{array}{c}\text { Perimeter } \\
\text { Outflow }\end{array}$ & Recharge & $\begin{array}{c}\text { Percent } \\
\text { Difference }\end{array}$ \\
\hline \hline UGTA Original & 140000 & 140000 & 2100 & $-0.01 \%$ \\
\hline UGTA Revised & 140000 & 140000 & 760 & $0.00 \%$ \\
\hline $\begin{array}{c}\text { DRI-alluvial } \\
\text { mask }\end{array}$ & 140000 & 140000 & 1600 & $-0.04 \%$ \\
\hline $\begin{array}{c}\text { DRI-alluvial and } \\
\text { elevation mask }\end{array}$ & 140000 & 140000 & 850 & $0.00 \%$ \\
\hline $\begin{array}{c}\text { USGS } \\
\text { redistribution }\end{array}$ & 110000 & 110000 & 680 & $-0.01 \%$ \\
\hline $\begin{array}{c}\text { USGS no } \\
\text { redistribution }\end{array}$ & 92000 & 92000 & 610 & $0.20 \%$ \\
\hline
\end{tabular}

Table 9-13

Inflow and Outflow Differences from UGTA Original Recharge for Base HSU Model

\begin{tabular}{|c|c|c|c|}
\hline Recharge Model & $\begin{array}{c}\text { \% Difference } \\
\text { Inflow }\end{array}$ & $\begin{array}{c}\% \text { Difference } \\
\text { Outflow }\end{array}$ & $\begin{array}{c}\% \text { Difference } \\
\text { Recharge }\end{array}$ \\
\hline \hline UGTA Revised & $-1 \%$ & $-1 \%$ & $-64 \%$ \\
\hline DRI-alluvial mask & $4 \%$ & $3 \%$ & $-25 \%$ \\
\hline $\begin{array}{c}\text { DRI-alluvial and } \\
\text { elevation mask }\end{array}$ & $2 \%$ & $1 \%$ & $-59 \%$ \\
\hline $\begin{array}{c}\text { USGS redistribution } \\
\text { USGS no } \\
\text { redistribution }\end{array}$ & $-21 \%$ & $-22 \%$ & $-68 \%$ \\
\hline
\end{tabular}


The recharge cases R3 and R4 using the DRI recharge models have the highest total recharge rates and produce the largest drain discharge at most of the discharge areas. These cases actually have a smaller recharge rate within the Frenchman Flat CAU model boundary than the UGTA Original recharge model (R1); however, they produce slightly higher lateral boundary fluxes than the two UGTA recharge models.

From the 30 alternative conceptual models and simulations presented, it appears possible to set reasonable bounds on perimeter fluxes for the Frenchman Flat CAU model area.

\section{$9.4 \quad$ Limitations}

The primary limitation in estimating lateral boundary fluxes to be used for the CAU flow model stems from the indirect method of deriving the estimates. There is no practical means of directly measuring groundwater fluxes at the scale and spatial frequency needed. Nor is it practical to measure hydraulic gradients and hydraulic conductivities with which to derive the necessary groundwater fluxes.

The limitations associated with deriving the fluxes from the regional-scale flow model are directly related to the degree to which the model accurately represents the physical system. The model's representation of the physical system is a function of: (1) the appropriateness of the conceptual model; (2) the accuracy of the geologic model used to define parameter heterogeneity; (3) the applicability of the recharge model; and (4) the degree to which the model can be calibrated. The calibration of the model is dependent not only on how well the model mimics measured data but how the spatial distribution of target measurements compares to the spatial complexity of the system. Any complexity of either the physical system or the conceptual model in areas with no measurements is inherently ill-constrained. In addition, the model cannot be calibrated better than the uncertainty associated with the targets themselves.

Although hydraulic head targets exist within the interior of the Frenchman Flat CAU-model boundary, a paucity of water-level measurements exists near the edges of the boundary where the fluxes are actually calculated. In addition, based on existing data, the simulated water table appears relatively flat in and around the Frenchman Flat CAU-model boundary. Even very small errors in the simulated water-level elevation caused by a lack of data to constrain heads near the boundaries could result in poor estimation of the lateral boundary fluxes.

The regional model is applicable to the groundwater flow system at the regional scale with the majority of flow through the LCA and not necessarily representative of the flow within the isolated alluvial aquifer in the Frenchman Flat basin. The lateral boundary fluxes are also dominated by the flow through the LCA and targets in the alluvial aquifer will provide little constraint on these fluxes. 


\subsection{Summary}

A set of boundary fluxes to be used with the CAU flow model have been developed based on results generated for 30 regional-scale flow models using MODFLOW 2000. The 30 models represent different HSU conceptual models and recharge models.

The range in net boundary flux across each of the CAU model boundaries is summarized in Table 9-14. This approach does not specify the location on the boundary where the flux occurs, rather the bounds on the net inflow or outflow.

In addition to the fluxes calculated at the original Frenchman Flat HSU model boundaries, fluxes were also calculated at a smaller, proposed CAU-model boundary. The proposed boundary is shown in relation to the original CAU model boundary in Figure 9-1. The range in net-boundary flux across each of the faces of this proposed boundary is summarized in Table 9-15.

Table 9-14

Summary of Net Boundary Flux Ranges $\left(\mathrm{m}^{3} / \mathrm{d}\right)$ for HSU Model Boundaries

\begin{tabular}{|c|c|c|}
\hline Model Boundary & Range in Net Inflow & Range in Net Outflow \\
\hline \hline Northern & 19000 to 52000 & 20 to 610 \\
\hline Southern & 8800 to 11000 & 6800 to 33000 \\
\hline Eastern & 60000 to 85000 & 0.00041 to 0.02 \\
\hline Western & 550 to 1300 & 59000 to 130000 \\
\hline
\end{tabular}

Table 9-15

$$
\begin{gathered}
\text { Summary of Net Boundary Flux Ranges }\left(\mathrm{m}^{3} / \mathrm{d}\right) \text { for Proposed } \\
\text { CAU-Model Boundaries }
\end{gathered}
$$

\begin{tabular}{|c|c|c|}
\hline Model Boundary & Range in Net Inflow & $\begin{array}{c}\text { Range in Net } \\
\text { Outflow }\end{array}$ \\
\hline \hline Northern & 17000 to 48000 & 20 to 610 \\
\hline Southern & 4300 to 5700 & 49000 to 82000 \\
\hline Eastern & 44000 to 87000 & 5500 to 17000 \\
\hline Western & 550 to 1300 & 14000 to 38000 \\
\hline
\end{tabular}




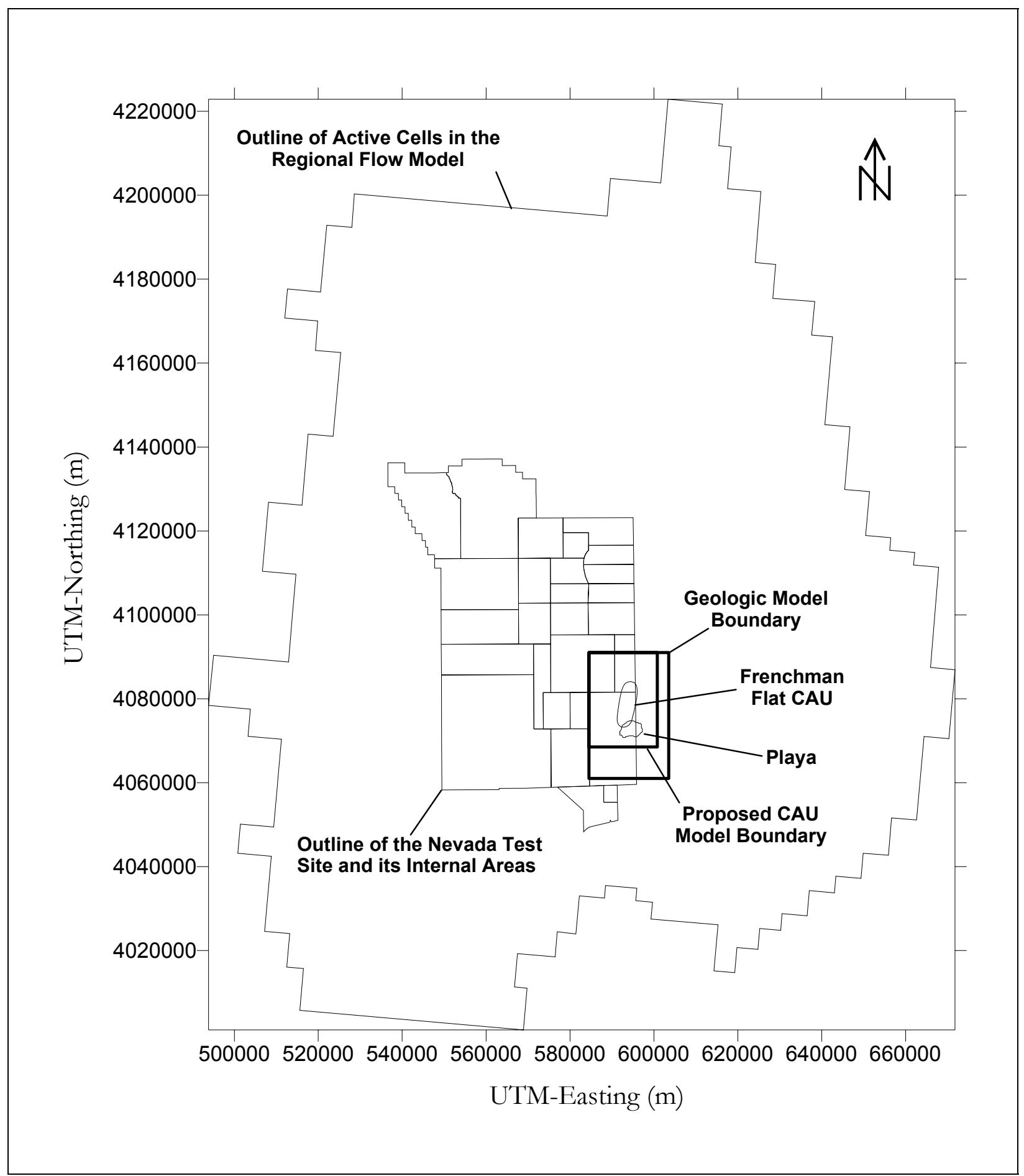

Figure 9-1

Geologic and Proposed CAU Model Boundaries 


\subsection{Groundwater Chemistry}

Groundwater chemistry data provide a means for determining the origin, pathway, and timescale of groundwater flow that is independent of estimates based on conventional hydraulic data and are an important consideration during the evaluation of the groundwater flow system. Geochemical and hydraulic data reflect distinct but complimentary aspects of a groundwater flow system, and must be considered in unison in order to develop a consistent, comprehensive, and defensible flow system assessment. For example, geochemical data may identify flow paths and source areas that would otherwise not be recognized on the basis of hydraulic information alone; however, these flow paths must be consistent with potentiometric data in order to be valid (and vice versa). Geochemical data, specifically groundwater chemistry and reactive mineral distribution, are also important constraints on solute transport. As described in the Pahute Mesa transport report (Rehfeldt et al., 2003), these data comprise fundamental components in defining distribution coefficients for assessing solute mobility. Groundwater chemistry data aid in the calibration of groundwater flow and transport models and are essential to understanding the fate and transport of contaminants of potential concern in the subsurface environment.

The assessment of groundwater chemistry data for the FF CAU fulfills several project needs. First, the dataset compiled for this task represents the current repository for groundwater geochemical data pertinent to the FF CAU. Second, the flow path, water budget, and travel time evaluations presented here are based on geochemical data and methodologies that can provide an independent means to verify flow and contaminant transport modeling efforts for the FF CAU.

\subsection{Objectives}

The specific objectives of this groundwater chemistry assessment include the following:

- Describe the groundwater chemistry dataset for the FF CAU and surrounding area

- Using this dataset, present a characterization of the groundwater chemistry of this area

- Based on the chemistry characterization, present the evaluation of sources, flowpaths, and travel times for groundwater in the FF CAU. 
The assessment provided in this chapter is based primarily upon geochemical data from wells within the FF CAU. Since only one well within Frenchman Flat penetrates the LCA, geochemical data from several wells located north of Frenchman Flat (located in southern Yucca Flat and penetrating the LCA) were included in the evaluation. Springs from the Spring Mountains, and springs and wells located south and southwest of Frenchman Flat are also included to assess recharge and potential mixing components for the groundwater flow system within which the FF CAU is located. The groundwater geochemistry data used in this evaluation include general chemical parameters, major ions, and stable and environmental isotopes. Data are available for groundwater hosted by various geologic formations including Quaternary and Tertiary alluvial materials, Tertiary volcanic rocks, and Paleozoic carbonate rocks. The data evaluation also includes geochemical modeling results.

\subsection{Approach}

The primary purpose of this assessment is to support conceptual model development and refinement, and to assist with the verification of groundwater flow and transport modeling efforts for the FF CAU. The following steps were taken in the course of this assessment.

1. Available geochemical data from wells and springs within the study area were compiled from the UGTA groundwater quality database (GEOCHEM03.mdb). The dataset was then supplemented with additional data obtained following the release of the database (Supplemented data were then added to a subsequent version of this database). These data are summarized in Table 10-1. A representative water chemistry and isotopic composition was then identified for each sampling location. The process where representative groundwater data were defined and selected for use in these geochemical evaluations (based on data quality, distribution, and completeness of the necessary parameter suite) is discussed in Section 10.4.2.

2. Using the data from Step 1, Groundwater mixing models were tested for several conceptual flow paths using conservative tracer data.

Conservative tracers are those geochemical species that exhibit little or no tendency to interact with aquifer material and that are transported with the groundwater. Conservative tracers used in this study include isotopes of hydrogen $(\delta \mathrm{D})$ and oxygen $\left(\delta^{18} \mathrm{O}\right)$, as well as chloride. Evaluation of the conservative tracers is discussed in Section 10.5.3.

3. Conceptual flow paths were also evaluated by examining strontium ( $\mathrm{Sr}$ ) concentrations and ${ }^{87} \mathrm{Sr} /{ }^{86} \mathrm{Sr}$ isotopic ratios. Strontium, a non-conservative, reactive element can act as an indicator of chemically distinct aquifer mineralogy and provides insight on a particular flow path independent of the conservative tracers (Section 10.5.4).

4. Flow paths identified by conservative mixing and $\mathrm{Sr}$ reaction models were then evaluated using the geochemical modeling program NETPATH 
Table 10-1

Summary of Groundwater Quality Data Parameters from Wells in and Around the FF CAU

\begin{tabular}{|c|c|c|c|c|c|c|c|}
\hline \multirow[b]{2}{*}{ Well Name } & \multirow[b]{2}{*}{ Primary HSU } & \multicolumn{6}{|c|}{ Parameter Group Types } \\
\hline & & $\begin{array}{c}\text { Minor and } \\
\text { Trace } \\
\text { Elements }\end{array}$ & $\begin{array}{c}\text { Environmental } \\
\text { Tracers }\end{array}$ & Radionuclides & $\begin{array}{c}\text { Organic } \\
\text { Compounds }\end{array}$ & $\begin{array}{c}\text { Other } \\
\text { Parameters }\end{array}$ & $\begin{array}{c}\text { Major } \\
\text { lons }\end{array}$ \\
\hline Army \#1 WW & LCA & 37 & 9 & 64 & 9 & 165 & 37 \\
\hline ER-5-3 & $\begin{array}{c}\text { AA (upper) } \\
\text { TM-WTA (lower) }\end{array}$ & 6 & 3 & 6 & 0 & 6 & 6 \\
\hline ER-5-3\#2 & LCA & 2 & 1 & 2 & 0 & 2 & 2 \\
\hline ER-5-4 & AA & 2 & 1 & 2 & 0 & 2 & 2 \\
\hline ER-5-4\#2 & LTCU & 3 & 2 & 3 & 0 & 2 & 2 \\
\hline RNM-1 & AA & 9 & 5 & 25 & 2 & 9 & 8 \\
\hline RNM-2S & AA & 8 & 11 & 381 & 2 & 12 & 9 \\
\hline TW-F & LCA & 9 & 0 & 5 & 0 & 13 & 6 \\
\hline TW-3 & LCA & 2 & 3 & 2 & 0 & 2 & 2 \\
\hline UE-11a & TM-WTA & 1 & 0 & 0 & 0 & 1 & 1 \\
\hline UE-5 PW-1 & AA & 13 & 2 & 16 & 16 & 17 & 11 \\
\hline UE-5 PW-2 & AA & 12 & 2 & 13 & 12 & 19 & 9 \\
\hline UE-5 PW-3 & TM-WTA & 15 & 5 & 14 & 14 & 20 & 12 \\
\hline UE-5c WW & $\begin{array}{c}\text { AA (Upper) } \\
\text { LTCU (Lower) }\end{array}$ & 13 & 2 & 89 & 2 & 51 & 13 \\
\hline UE-5n & AA & 4 & 3 & 6 & 0 & 4 & 5 \\
\hline WW-1 & AA & 3 & 0 & 0 & 1 & 3 & 3 \\
\hline WW-4 & TM-WTA & 9 & 2 & 126 & 4 & 48 & 9 \\
\hline WW-4A & TM-WTA & 2 & 1 & 23 & 2 & 2 & 2 \\
\hline WW-5A & AA & 9 & 1 & 7 & 0 & 9 & 9 \\
\hline WW-5B & $\mathrm{AA}$ & 27 & 4 & 63 & 5 & 68 & 28 \\
\hline WW-5C & AA & 36 & 2 & 260 & 6 & 302 & 36 \\
\hline WW-C & LCA & 59 & 11 & 259 & 12 & 413 & 51 \\
\hline WW-C1 & LCA & 26 & 4 & 77 & 7 & 47 & 26 \\
\hline
\end{tabular}

AA - Alluvial Aquifer

LCA - Lower Carbonate Aquifer

LTCU - Lower Tuff Confining unit

TM-LVTA - Timber Mountain lower vitric tuff aquifer

TM-WTA - Timber Mountain welded tuff aquifer 
(Plummer et al., 1994). This program is used to interpret net geochemical mass-balance between initial and final water compositions along a flow path. NETPATH also provides estimates of groundwater travel times (Section 10.5.5).

5. Principal flow paths identified during Steps 1 through 4 were also evaluated using the program PHREEQC. This program provides insight into mineral saturation states and allows the direct comparison of predicted dissolution-precipitation reactions with the mineral compositions observed in borehole core samples. PHREEQC also provides a means of quantifying uncertainties in mixing ratios and the quantities of the minerals dissolved or precipitated during water - rock interaction.

The focus of the conceptual models was groundwater flow in the alluvial aquifer. The concern being the potential migration of radionuclides associated with underground tests in Frenchman Flat alluvium would be transported by groundwater to the LCA where they could then exit the basin. The emphasis of the geochemical evaluations (described in Hershey et al., 2004 and summarized in Section 10.5.3, Section 10.5.4, and Section 10.5.5) was on three conceptual models:

- North-to-South Flow - Groundwater in Frenchman Flat flows predominantly from north to south with a slight northeast to southwest orientation. The water in Frenchman Flat drains to the LCA in the south. The CP Basin, west of Frenchman Flat, is assumed to be in a separate flow system, isolated from the rest of Frenchman Flat.

- Bathtub Model - Groundwater, particularly in northern and central Frenchman Flat, leaks vertically downward until it reaches the LCA with vertical hydraulic gradients much stronger than horizontal gradients. The primary source of water in the basin is recharge from infiltration. The CP Basin again is assumed to be isolated from Frenchman Flat.

- West-to-East Flow - The west-to-east model assumes lateral groundwater flow. In this model, the CP Basin and Mt. Salyer regions are the source of most of the water in the Frenchman Flat alluvium with a small component from recharge. Groundwater entering the alluvium from the west flows laterally to the LCA surrounding the basin. In the northern part of Frenchman Flat, groundwater flows northward. In the eastern part of the basin, groundwater in the alluvial and volcanic aquifers flows eastward, and in the southern part of the basin, groundwater flows southward. 
One flowpath not considered by Hershey, et al. (2004) is the westward movement out of Frenchman Flat, along Rock Valley, into Eastern Jackass Flats.

\subsection{Data Description}

The groundwater chemistry dataset for the FF CAU includes data generated during 2,241 recorded sampling events at 23 different wells within the area shown in Figure 8-1 and Figure 10-1. A sampling event is defined as a particular date of sampling. The geochemical data parameter groups are as follows:

- Minor and Trace Elements - includes elements such as arsenic, lead, or selenium that typically occur at low concentrations in groundwater;

- Environmental Tracers - includes carbon, hydrogen, and oxygen isotopes and ${ }^{7} \mathrm{Sr} /{ }^{86} \mathrm{Sr}$ isotopic ratios that can be key indicators of water origins;

- Radionuclides - includes radioisotopes such as tritium $\left({ }^{3} \mathrm{H}\right)$

- Organic Compounds - includes volatile organic compounds (VOC), semivolatile organic compounds (SVOC), and pesticides

- Other Parameters - includes physical, field, and miscellaneous parameters such as $\mathrm{pH}$, TDS, or temperature

- Major Ions - includes major cation and anions such as sodium or bicarbonate

Table 10-1 summarizes the number of sampling events that have taken place for each parameter group for each well within the FF CAU. Groundwater samples have been collected by multiple agencies from several of the wells during a single sampling event. For instance, several wells (WW-4A, -5A, -5B, and -5C, UE-5C WW, and UE-5 PW3) were sampled by four organizations and analyzed for up to 80 parameters during single sampling events that took place in August of 2000. Several of the parameter groups were analyzed by two or more agencies. The recently completed wells (ER-5-3, ER-5-3\#2, ER-5-4, and ER-5-4\#2) were sampled by five organizations during single sampling events and again, several of the parameter groups were analyzed by two or more agencies. In addition, depth discrete bailer samples were collected from each of these four wells and analyzed for all parameter groups except environmental isotopes and organic parameters. The three near-field wells (RNM-1, RNM-2S, and UE-5n) are sampled every three years as a part of the Hot Well sampling effort initiated in 2001. These sampling events have produced the most complete and up-to-date water quality data available for the FF CAU.

The completeness of the suite of water quality parameters measured and the associated data quality is largely a function of sample location and date of sampling. The data have been generated over a significant period of time using various sampling and analytical methods to accomplish a variety of objectives. For instance, as shown in Table 10-1, there are locations with only a single 


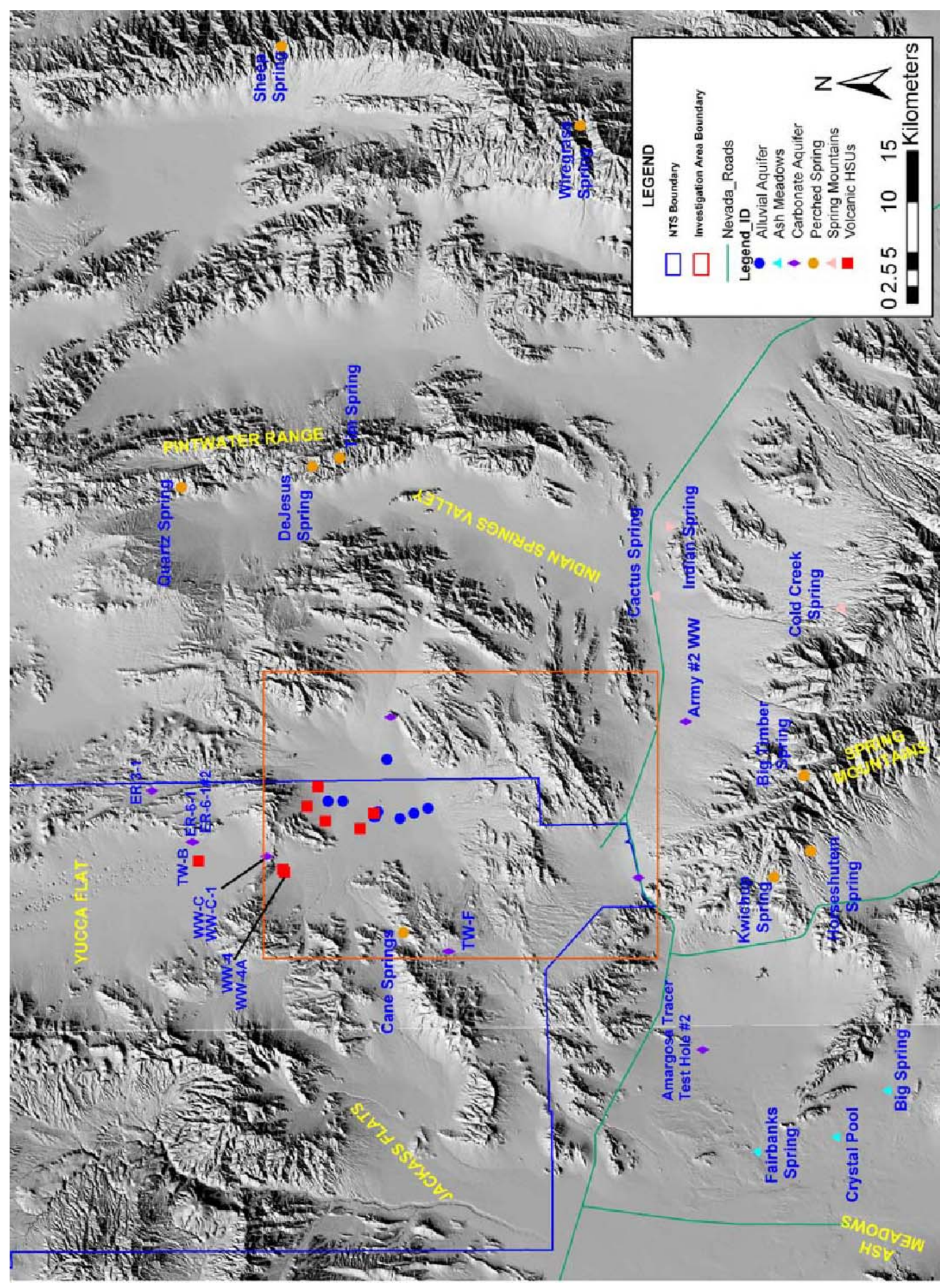

Figure 10-1

Groundwater Quality Sample Locations 
sampling event and a minimal number of measured parameters (e.g., UE-11a) while other locations (Army \#1 WW and WW-5B, -5C, $-\mathrm{C}$, and -C1) have been sampled numerous times for most parameter categories. The earliest sampling event is dated 1957. Although updated datasets have been obtained for many of the wells within the FF CAU, a few wells (WW-1, UE-11a, and TW-F) are limited to data obtained in 1966, 1988, and 1980, respectively. No environmental isotope data are available for two of these wells, WW-1 and TW-F (Table 10-1).

Water quality samples are typically collected as composite samples either from wells with single completions that transect multiple hydrostratigraphic unit boundaries or from wells with multiple completions that are all pumped simultaneously. Local vertical variability in water quality can only be evaluated at well clusters ER-5-3 and ER-5-4. Depth discrete sampling was performed for each of the wells, ER-5-3, ER-5-3 \#2, ER-5-4, and ER-5-4 \#2. The HSUs corresponding to completion intervals for these wells are listed in Table 10-1. Depth discrete sampling provides additional information on the vertical variability in groundwater quality at multiple completion wells located within the area of interest.

To the extent possible, in the process of compiling GEOCHEM03.mdb, data have been made internally consistent (i.e., parameter names, units, and data qualifiers have been standardized). All data entry and modifications to the dataset were documented and verified in accordance with the UGTA QAPP (DOE/NV, 2000b). Most non-radiological parameters are reported in concentration units of $\mathrm{mg} / \mathrm{L}$, and most radiological parameters are reported in activity units of picocuries per liter $(\mathrm{pCi} / \mathrm{L})$. Other parameters are reported in the appropriate conventional units (e.g., water temperature is reported in ${ }^{\circ} \mathrm{C}, \mathrm{pH}$ is reported in standard units). Analytical data qualifiers are also included in the groundwater chemistry dataset. Qualifier definitions are as follows:

- $\quad<-$ Compound was analyzed for, but not detected above the reported sample quantitation limit. The reporting limit (quantitation limit) is listed in the value field.

- B - Reported value is less than the Contract Required Detection Limit, but greater than the instrument detection limit.

- J - Estimated value. 


\subsection{Data Evaluation}

The groundwater chemistry data, within Geochem03.mdb, were evaluated with respect to the level of available data documentation and with respect to the quality and/or diagnostic utility value of the reported data measurements.

\subsubsection{Data Documentation Evaluation}

The available data documentation for the groundwater chemistry dataset has been evaluated and flags (Levels 1 to 5) were assigned in accordance with the data documentation requirements described in Section 4.3.

\subsubsection{Data Quality Evaluation}

In addition to the data documentation evaluation flag which is used to rank the level of documentation, a data evaluation Flag, DEF, was assigned to qualitatively rank the reported chemical values in terms of the relative confidence that might be expected. The following levels of relative confidence have been defined and assigned to the groundwater chemistry data:

- Level C: Consistent - Analytical results are consistent with historical or regional trends for the reported location(s); or, for a given sample there are no anomalous results within the suite of parameters that would indicate sample contamination due to improper sample collection or erroneous laboratory procedures.

- Level NC: Not Consistent - Analytical results are not consistent with historical or regional trends for the reported location(s); or, for a given sample there are data anomalies within the suite of parameters that may indicate sample contamination or laboratory errors.

- Unknown - Data has not been formally evaluated in order to assess the accuracy and/or consistency of the data; or there is insufficient information (e.g., regionally, temporally, or within the dataset) to determine whether or not the data is consistent with historical or regional trends for the reported location.

Other data quality criteria exist and are commonly applied in the course of conducting evaluations of groundwater geochemical data. For example, the evaluation of major ion charge balance (Hem, 1985) serves as an indicator that the analytical data quality and/or verification account for the predominant constituents in a given water sample. The presence of bromide concentrations above background levels can be an indication of groundwater samples that have been contaminated by residual drilling fluids and are, therefore, not representative of ambient conditions. These data quality criteria have been applied in the process of 
evaluating groundwater data from the FF CAU and are discussed in the following section.

\subsection{Analysis Process and Results}

The geochemical processes that accompany the movement of groundwater at the NTS include a variety of interactions (e.g., water-rock, solute-solute, and water-atmospheric) that occur in response to changes in the hydrogeologic environment. These geochemical processes, and the changes in the hydrogeologic environment that they are indicative of, are identified through the evaluation of a diverse suite of geochemical parameters. The parameters occur as groups (e.g., major ions, stable isotopes) that tend to respond in systematic ways to similar geochemical processes. The following subsections discuss these groups of geochemical parameters in terms of their respective utility as diagnostic hydrogeological indicators in the FF CAU. The utility of geochemical data in evaluating groundwater systems is a function of having data (that meet data quality criteria) for the suite of parameters that have diagnostic value for the system or hydrogeologic processes of interest.

Within the Frenchman Flat region groundwater quality dataset, samples collected from 23 individual locations generated representative major ion data that satisfy charge balance criteria ( \pm 5 percent). Twenty-one of these locations have also provided environmental tracer data (i.e., delta deuterium $[\delta \mathrm{D}]$ and delta oxygen- 18 $\left.\left[\delta^{18} \mathrm{O}\right]\right)$. Twenty of these locations also have provided Carbon-13 $\left[{ }^{13} \mathrm{C}\right]$ and Carbon-14 $\left[{ }^{14} \mathrm{C}\right]$ data.

\subsubsection{Major Ion Chemistry}

The dissolved constituents in groundwater provide a record of the minerals encountered as water moves through geologic materials. Accordingly, major ion water chemistry can be used to characterize the interaction and help trace the movement of groundwater through aquifer materials. The group of parameters comprising the major ions typically consists of calcium $\left(\mathrm{Ca}^{2+}\right)$, potassium $\left(\mathrm{K}^{+}\right)$, magnesium $\left(\mathrm{Mg}^{2+}\right)$, sodium $\left(\mathrm{Na}^{+}\right)$, chloride $\left(\mathrm{Cl}^{-}\right)$, sulfate $\left(\mathrm{SO}_{4}{ }^{2-}\right)$, bicarbonate $\left(\mathrm{HCO}_{3}{ }^{-}\right)$, and carbonate $\left(\mathrm{CO}_{3}{ }^{2-}\right)$. Other constituents (such as silica or boron) are occasionally at concentrations high enough to be considered major constituents of groundwater. These constituents, however, more commonly occur as minor or trace constituents at significantly lower concentration levels. The techniques (Hem, 1985) used to evaluate data quality (charge balance) and to characterize and categorize principal groundwater types focus on the major ionic species listed above.

Evaluation of the major ion characteristics of groundwater can provide insights on the source areas and flow directions for groundwater movement. Using the dissolved constituents in groundwater to provide a record of the minerals encountered as water moves through an aquifer, Schoff and Moore (1964), Blankennagel and Weir (1973), and Winograd and Thordarson (1975) identified 
three distinct hydrochemical water types, or facies, in NTS groundwaters. These include a Na-K- $\mathrm{HCO}_{3}$ groundwater facies commonly found in volcanic rock aquifers, a Ca-Mg- $\mathrm{HCO}_{3}$ facies commonly occurring in Paleozoic carbonate aquifers, and a Ca-Mg-Na- $\mathrm{HCO}_{3}$ facies assumed to be a mixture of the volcanic and carbonate facies. These hydrochemical facies are defined as follows (Schoff and Moore, 1964):

- $\mathrm{Na}-\mathrm{K}-\mathrm{HCO}_{3}$ water type - Sodium and potassium together are 60 percent or more of the total cations.

- $\mathrm{Ca}-\mathrm{Mg}-\mathrm{HCO}_{3}$ water type - Calcium plus magnesium are 60 percent or more of the total cations. Calcium concentrations are generally slightly greater than magnesium concentrations.

- $\quad \mathrm{Ca}-\mathrm{Mg}-\mathrm{Na}-\mathrm{HCO}_{3}$ water type (mixed type) - Neither cation pair $(\mathrm{Ca}+\mathrm{Mg}$ or $\mathrm{Na}+\mathrm{K}$ ) amounts to as much as 60 percent of the total cations.

The dominant anion ( $>60$ percent) is $\mathrm{HCO}_{3}$ in each of the three hydrochemical facies identified for the NTS.

The source of calcium and magnesium in LCA groundwater is dissolution of calcite and dolomite. Groundwater in volcanic HSUs and the alluvial aquifer gains sodium from reaction with volcanic glass (White et al., 1980). Where wells exist in the alluvial aquifer beneath Frenchman Flat, the alluvium must consist primarily of material derived from volcanic bedrock, because the groundwater chemical signature of the alluvial aquifer is similar to that of the volcanic HSUs. The predominant anionic constituent in groundwater (bicarbonate), is derived from incorporation of carbon dioxide $\left(\mathrm{CO}_{2}\right)$ gas and dissolution of carbonate minerals.

A Piper diagram is a graphical tool used to represent the relative concentrations of major ions in a groundwater sample or group of samples (Hem, 1985). Ion concentrations are expressed in percent milliequivalents per liter and are used to classify the groundwater as a particular hydrochemical type. A Piper diagram consists of three different component representations of major-ion chemistry. Cation (i.e., $\mathrm{Ca}^{2+}, \mathrm{K}^{+}, \mathrm{Mg}^{2+}, \mathrm{Na}^{+}$) and anion (i.e., $\mathrm{Cl}^{-}, \mathrm{SO}_{4}{ }^{2-}, \mathrm{HCO}_{3}^{-}$, and $\mathrm{CO}_{3}{ }^{2-}$ ) data are plotted in separate triangles. Both cation and anion data are then projected on to a central diamond-shaped area so that compositional relationships (such as mixing or evolutionary trends) within or between a group or groups of groundwater sample locations can be visually presented.

A Piper diagram for groundwater from the alluvial, volcanic, and carbonate aquifers is shown in Figure 10-2. The data used in the construction of the Piper diagram are the most recent major ion analyses for each location that meet charge balance criteria ( \pm 5 percent). In addition, Piper diagrams presenting each sampling event, for each well, are shown in Appendix F. Only samples with a charge balance of less than or equal to 10 percent are presented (Appendix F). The 


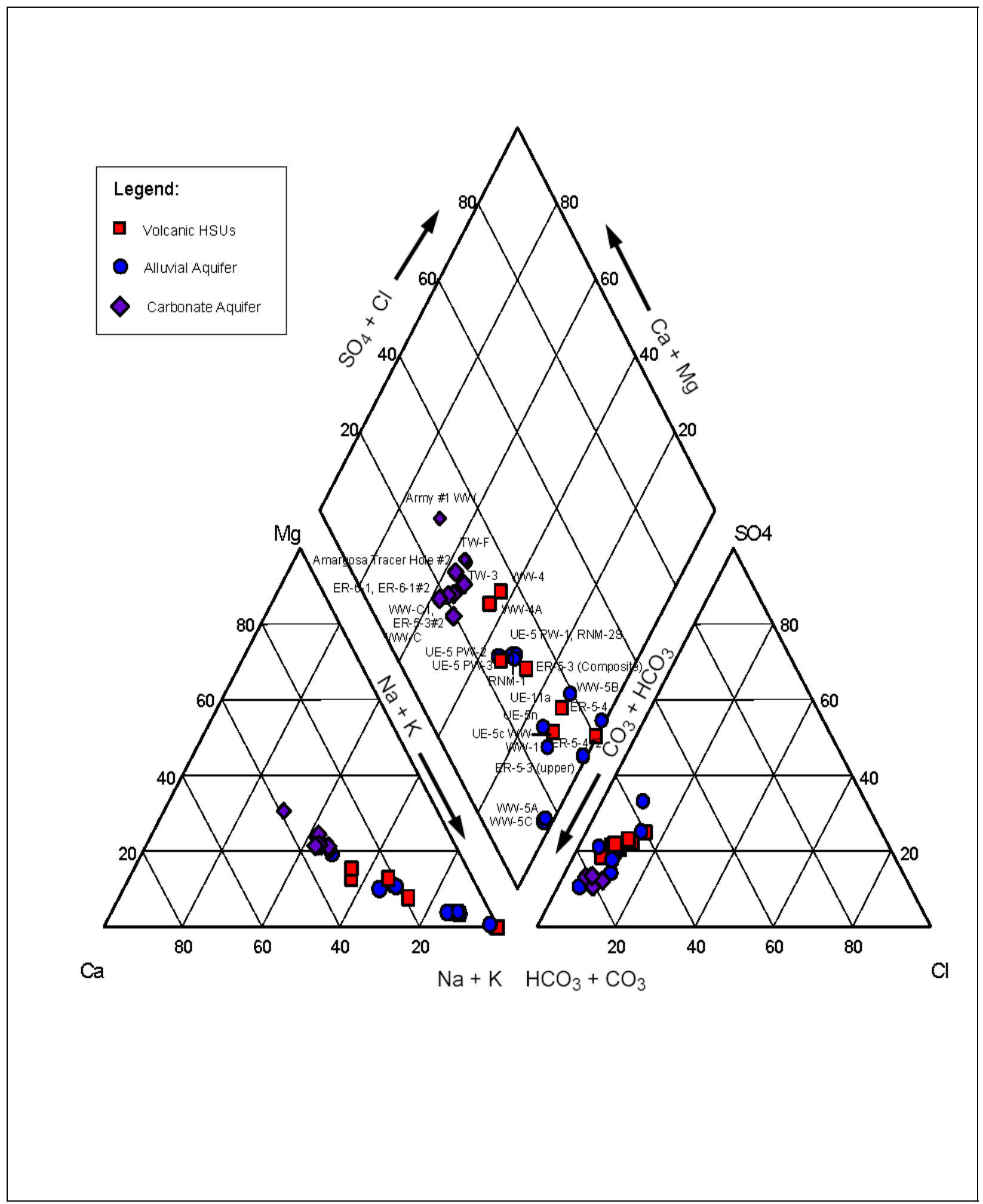

Figure 10-2

Piper Diagram Showing Percent Milliequivalents per Liter of Major lons in Groundwaters of Frenchman Flat and the Vicinity 
sample that is represented in the combined Piper Diagram (Figure 10-2) is identified in Appendix F with a solid marker.

Two samples collected from Well ER-5-3 are identified in Figure 10-2. One sample is a composite from two completion zones within the well. The upper completion zone samples groundwater from the alluvial aquifer, and the lower completion zone samples groundwater from the TM-WTA and the UTCU HSUs. Because the majority of the groundwater (97 to 100 percent) flow comes from the lower interval in this well, this sample is designated as representing the volcanic aquifer. The other ER-5-3 sample was collected from only the upper completion zone and is, therefore, identified as a sample representing the AA. These samples are designated as ER-5-3 (composite) and ER-5-3 (upper) in the Piper diagrams.

As shown in Figure 10-2, the groundwater from the volcanic HSUs within Frenchman Flat are primarily the $\mathrm{Na}-\mathrm{K}-\mathrm{HCO}_{3}$ water type. Sodium is the dominant cation and $\mathrm{HCO}_{3}{ }^{-}$is the dominant anion. Mixed $\left(\mathrm{Ca}-\mathrm{Mg}-\mathrm{Na}-\mathrm{HCO}_{3}\right)$ to $\mathrm{Na}-\mathrm{K}-\mathrm{HCO}_{3}$ is observed at WW-4 and WW-4a. The groundwater of the volcanic HSUs plot along a trend line of decreasing calcium plus magnesium and increasing sodium in the Piper diagram (Figure 10-2). The greatest relative percentages of calcium plus magnesium are observed in the groundwaters of wells WW-4 (42 percent) and WW-4A (43 percent), the next greatest are observed for wells ER-5-3 (26 percent) and UE-PW-3 (34 percent), and the lowest are observed in UE-11a (13 percent), UE-5c WW (11 percent) and ER-5-4\#2 (0.3 percent). This trend appears to correspond with the particular volcanic HSU sampled. For instance, two of the groundwater samples plotting at the lower end of the trend (UE-5c WW and ER-5-4\#2) are sampled from the LTCU HSUs. These samples are clearly dominated by $\mathrm{Na}(>88$ percent) with very little $\mathrm{Ca}$ or $\mathrm{Mg}$ present. The LTCU unit consists primarily of zeolitized tuffs. Conversely, the primary HSU sampled for the other wells is the TM-WTA which consists primarily of nonzeolitized, welded tuffs. The deepest well of the volcanic HSUs, ER-5-4\#2, also has the greatest percent composition of sulfate ( 25 percent) and may, therefore, be classified as a $\mathrm{Na}-\mathrm{HCO}_{3}-\mathrm{SO}_{4}$ water type.

The Na-K- $-\mathrm{HCO}_{3}$ water type is also observed in the majority of the groundwater of the alluvial aquifer (Figure 10-2). A similar cation trend observed in the volcanic HSUs, is observed for groundwater of the alluvial aquifer. The relative percent of $\mathrm{SO}_{4}^{2-}$ is also greatest in the two deepest wells of the alluvial aquifer, ER-5-4 (26 percent) and WW-5B (25 percent). The groundwater of these wells may be classified as a $\mathrm{Na}-\mathrm{HCO}_{3}-\mathrm{SO}_{4}$ water type.

Alteration products of volcanic rocks and alluvium derived from volcanic rocks include mineral phases with high cation exchange capacities, e.g., montmorillonite and zeolites (Borg et al., 1976 and White et al., 1980). Based on the ion exchange series for montmorillonite presented in Fiero et al. (1974), calcium and magnesium will be preferentially removed from groundwater and replaced with sodium. Another possible explanation for the observed cation trend in FF CAU alluvial and volcanic aquifers may be precipitation of mineral phases such as carbonates, and the phases discussed above, montmorillonite and zeolites. Claassen (1985) attributed a similar cation trend in tuffaceous aquifer groundwater to precipitation of montmorillonite and clinoptilolite (a zeolite). Thus, the 
observed differences in cation chemistry within the Frenchman Flat alluvial aquifer and volcanic-HSU groundwaters may result from reactive mineral phases (e.g., smectite group clays [such as montorillonite] or zeolites) in the aquifer.

The LCA is considered to be the most likely conduit for transporting radionuclides in groundwater beyond Frenchman Flat. Since there is only one well in Frenchman Flat that penetrates the LCA, major-ion chemistry from nearby wells penetrating the LCA surrounding Frenchman Flat were examined (Figure 10-1). In general, the groundwaters of the LCA included in this study are of the mixed $\mathrm{Ca}-\mathrm{Mg}-\mathrm{Na}-\mathrm{HCO}_{3}$ type. Army \#1 WW, which is the $\mathrm{Ca}-\mathrm{Mg}-\mathrm{HCO}_{3}$ type, is the only exception. This mixed type groundwater observed in the LCA groundwaters in the vicinity of Frenchman Flat suggest some degree of intermingling between groundwaters of the alluvial aquifer or volcanic HSUs and groundwater in the underlying carbonate aquifer.

Trends in the major ion chemistry data were further illustrated using Stiff diagrams (Appendix F). For Stiff diagrams, the concentration of each ion, in milliequivalents per Liter, are plotted with the cations on the left and anions on the right side of the diagram. Stiff diagrams are useful for comparing total concentrations in addition to comparing relative compositions of each ion within a given groundwater sample (Hem, 1985). Stiff diagrams can be useful for identifying distinct water types as well as trends in overall concentration that may occur along groundwater flow paths as a result of water-rock interaction or groundwater mixing.

The Stiff diagrams again illustrate the dominance of $\mathrm{Na}$ in the alluvial aquifer (Figure F.1-13). Based on the available data, there appears to be spatially distinct differences in the major-ion chemistry within the alluvial aquifer. Data from the existing wells do not clearly identify any evidence for lateral movement and mixing between these waters in the alluvial aquifer. Chapman and Lyles (1993) noted these areal differences in ion concentrations in the alluvial aquifer in Frenchman Flat and suggested that these differences demonstrated a "lack of well-developed lateral flow systems that would homogenize chemical character" within Frenchman Flat. They suggested that this implied that "vertical flow dominates in the alluvium." These laterally distinct areas identified based on differences in major-ion groundwater chemistry are consistent with spatial variability in alluvial mineralogy within the Frenchman Flat basin (Warren et al., 2002). Differences in total dissolved solids (TDS) in the alluvial aquifer are also apparent (Figure F.1-13). The most dilute alluvial groundwater has a TDS of about $200 \mathrm{mg} / \mathrm{L}$ (calculated as total concentration of $\mathrm{Ca}, \mathrm{Mg}, \mathrm{Na}, \mathrm{K}, \mathrm{Cl}, \mathrm{SO}_{4}$, silicon dioxide $\left(\mathrm{SiO}_{2}\right)$ and $\left.1 / 2 \mathrm{HCO}_{3}+\mathrm{CO}_{3}\right)$ while the most concentrated alluvial groundwater has a TDS of about $570 \mathrm{mg} / \mathrm{L}$. While a clear trend is not observed between sampling depth and TDS, the greatest TDS is observed in the deepest alluvial well (Hershey et al., 2004).

In the volcanic hydrostratigraphic units, similar to groundwater in the alluvium, there are notable differences in TDS (Figure F.1-14). The TDS of the dilute groundwater samples are approximately 270 to $290 \mathrm{mg} / \mathrm{L}$ with a couple somewhat higher (UE-5c WW $=336 \mathrm{mg} / \mathrm{L}$; UE-11a $=373 \mathrm{mg} / \mathrm{L}$ ) and one substantially higher (ER-5-4 \#2=754 mg/L). Also, similar to the alluvial aquifer, there is no 
discernible spatial pattern in major-ion chemistry in the volcanic hydrostratigraphic units suggesting limited lateral groundwater flow.

Total dissolved solids concentrations show two distinct groups of water in the LCA near Frenchman Flat, more dilute and more concentrated (Figure F.1-15). The more dilute groundwater is found in southern Yucca Flat, which is considered to be upgradient of Frenchman Flat in the LCA, with TDS of about $300 \mathrm{mg} / \mathrm{L}$ (ER-6-1 and ER-6-1 \#2). More dilute carbonate groundwater is also found down gradient of Frenchman Flat to the west, east, and south where TDS is approximately 400 mg/L (TW-F, TW-3, Army \#1 WW, Amargosa Tracer Well \#2). The more concentrated LCA groundwater, with TDS concentrations greater than $650 \mathrm{mg} / \mathrm{L}$, is found in southeastern Yucca Flat (ER-3-1, WW-C, and WW-C1) and in northern Frenchman Flat (ER-5-3 \#2). In the more dilute groundwater, calcium and sodium concentrations expressed as equivalents per liter are approximately equal while the more concentrated groundwater has greater sodium than calcium.

\subsubsection{Stable and Environmental Isotopes}

The stable isotopes of hydrogen $\left({ }^{2} \mathrm{H} /{ }^{1} \mathrm{H}\right)$ and ${ }^{18} \mathrm{O} /{ }^{16} \mathrm{O}$ are perhaps the most conservative of all environmental tracers because they are uniquely intrinsic to the water molecule. In the water cycle, hydrogen and oxygen isotopes are fractionated (partitioned) between the liquid and vapor phases during evaporation and condensation processes. Once the precipitation has infiltrated the water table, the stable isotope values are unaffected by water-rock interaction at temperatures below approximately $100^{\circ} \mathrm{C}$, and can be used to trace the groundwater origin and flow path, and to quantitatively determine mixing ratios of different water masses. The carbon isotopes are strongly influenced by recharge processes and water-rock interaction. The stable isotopes of carbon $\left({ }^{13} \mathrm{C} /{ }^{12} \mathrm{C}\right)$ provide a means to identify the degree of interaction with the available carbon reservoirs along the flow path while radiocarbon $\left({ }^{14} \mathrm{C}\right)$ provides a means by which apparent groundwater travel times or apparent groundwater ages can be estimated.

Stable isotopes are reported as the abundance ratio of the two most common isotopes of a given element relative to a standard. For example, considering hydrogen isotopes in groundwater, it is the ratio of the hydrogen-2, or deuterium $\left({ }^{2} \mathrm{H}\right.$ or $\left.\mathrm{D}\right)$, isotope to the more common hydrogen-1 $\left({ }^{1} \mathrm{H}\right.$ or $\left.\mathrm{H}\right)$ isotope. Isotopic concentrations are expressed as the difference between the measured ratios of the sample and a reference over the measured ratio of a reference using the delta $(\delta)$ notation in units of per mil. The reference standard for hydrogen and oxygen isotopes is known as the "Vienna Standard Mean Ocean Water" (VSMOW). The stable isotopes of hydrogen, oxygen, and carbon are important indicators of geochemical processes. Each of these elements is relatively light and the relative mass differences between the isotopes for a given element are relatively large. This mass difference can result in significant fractionation during physical processes and associated chemical reactions. Fractionation occurring in the natural environment during hydrogeological processes can provide information on the origin and evolution of groundwater. As a result, the stable isotopes of carbon, 
hydrogen, and oxygen function as tracers for water, carbon, and nutrient and solute movement and cycling.

Radioactive environmental isotopes are also important geochemical indicators. Groundwater residence times can be inferred from the decay of radioactive tracers present in the water if the input concentration of the tracer is reasonably well known and constant over time. Naturally occurring radionuclides such as ${ }^{14} \mathrm{C}$ or ${ }^{3} \mathrm{H}$ can be used to estimate the apparent age or travel time of groundwater.

\subsubsection{Hydrogen and Oxygen Isotopes}

Under ambient conditions (and temperatures $<100^{\circ} \mathrm{C}$ ) significant isotopic fractionation of hydrogen and oxygen does not occur in the subsurface environment. The observed variability in groundwater $\delta^{18} \mathrm{O}$ and $\delta \mathrm{D}$ measurements result from fractionation effects that have occurred during evaporation and precipitation before recharge has occurred or in response to the mixing of groundwaters that have recharged under different conditions. Therefore, an evaluation of the hydrogen and oxygen isotopic composition of groundwater can provide information on prevailing environmental conditions (i.e., latitude, elevation, and distance from the ocean) at the time of groundwater recharge. The isotopic composition of precipitation can be used to delineate different sources of groundwaters.

Figure 10-3 is a plot of the $\delta^{18} \mathrm{O}$ composition versus the $\delta \mathrm{D}$ composition of groundwaters from wells within Frenchman Flat, LCA groundwaters in the vicinity of Frenchman Flat, and groundwaters from springs within Ash Meadows and the Spring Mountains. For reference, the global meteoric water line (GMWL) and the local meteoric water line (LMWL) are included in this figure. The GMWL represents the observed correlations in $\delta^{18} \mathrm{O}-\delta \mathrm{D}$ values of precipitation samples from around the world and is defined by the equation $\delta \mathrm{D}=8 \delta^{18} \mathrm{O}+10$ (Craig, 1961). The LMWL ( $\left.\delta \mathrm{D}=6.87 \delta^{18} \mathrm{O}-6.5\right)$, represents the observed correlations in $\delta^{18} \mathrm{O}-\delta \mathrm{D}$ values of precipitation samples collected by DRI at 14 sites at the NTS from 1982 through 1986 (Ingraham et al., 1990).

An evaluation of isotopic composition of two springs, Whiterock and Cane, within the NTS is described in Hershey et al. (2004). Samples from both springs were shown to plot along an enrichment line that intersects the local meterioric water line at a $\delta^{18} \mathrm{O}$ and $\delta \mathrm{D}$ of approximately -13 and -97 , respectively. It was also noted by Hershey et al. (2004) that these represent reasonable values for recharge taking place in response to local precipitation.

A comparison of the isotopic signature of local recent recharge to Frenchman Flat groundwater (Figure 10-3) shows that most Frenchman Flat groundwater is substantially depleted isotopically. This, coupled with the fact that most of the Frenchman Flat groundwater isotopic signatures fall well off the GMWL, suggests that Frenchman Flat groundwater was recharged elsewhere or was recharged under climatic conditions significantly different than those present today. An isotopic signature similar to local recent recharge is observed in WW \#4 and WW 4A in northwest Frenchman Flat in the CP basin (Hershey, 2004). This suggests 


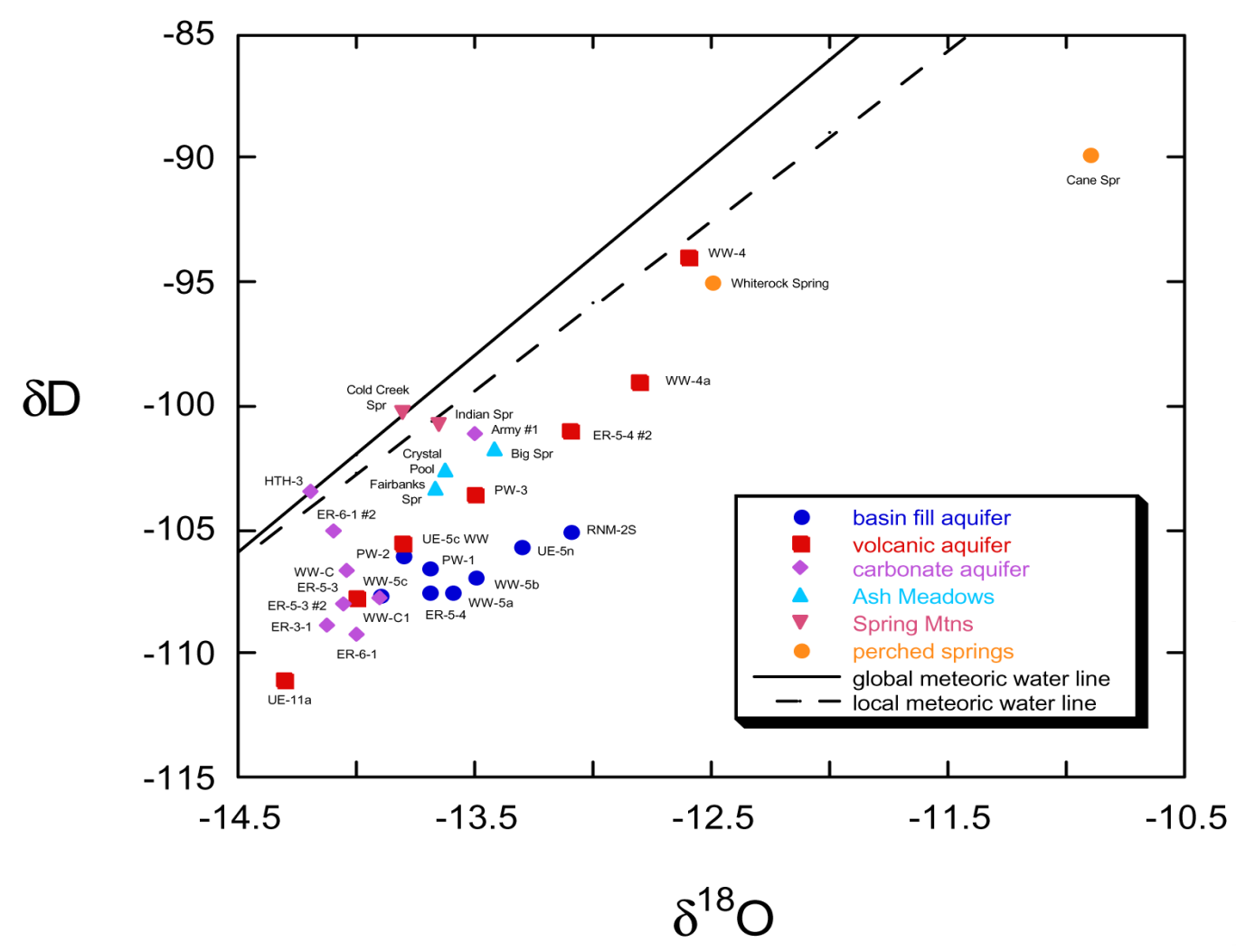

Figure 10-3

Stable Isotopic Plot of $\delta^{18} O$ vs. $\delta$ D Values for Springs and Wells Within the Frenchman Flat Study Area

that recharge from local precipitation has taken place in the CP Basin. The ${ }^{18} \mathrm{O}$ and $\delta$ D data for TW-3 (identified as HTH-3) plots on the GMWL (Figure 10-3); however, the isotope data from this well may be unreliable.

\subsubsection{Carbon Isotopes}

The geochemical behavior of carbon in groundwater systems is very complex and includes interactions with the atmosphere, biosphere, and geosphere involving multiple sources and sinks of carbon that can vary in both time and space (Kalin, 2000). Nevertheless, ${ }^{14} \mathrm{C}$ is the tracer most often used to estimate the residence time of groundwaters that are less than $\sim 40,000$ years in age. By tracking the evolution of the stable isotope $\left({ }^{13} \mathrm{C} /{ }^{12} \mathrm{C}\right)$ composition of the groundwater as it interacts with the various carbon reservoirs, it is often possible to develop corrections for carbon mass transfer effects (Mook, 1980). Carbon isotope values were measured in Frenchman Flat groundwater samples for both dissolved inorganic carbon (DIC) and dissolved organic carbon (DOC) fractions. The DIC isotopic data are used to constrain geochemical mass transfer models 
(e.g., NETPATH) whereas the DOC isotopic data provide an estimate of the mean organic carbon residence time in the groundwater.

Most of the DIC in groundwater is the product of biochemical production of $\mathrm{CO}_{2}$ gas in the soil zone and the chemical dissolution of carbonate minerals. Variations in the stable isotope $\left(\delta^{13} \mathrm{C}\right)$ and ${ }^{14} \mathrm{C}$ characteristics of these two main carbon reservoirs provides insight into the chemical evolution of DIC in groundwater. Table 10-2 summarizes the DIC isotope data for Frenchman Flat groundwaters, and identifies the primary HSU associated with each sample location. Figure 10-4 is a plot of the mean $\delta^{13} \mathrm{C}$ versus ${ }^{14} \mathrm{C}$ values for these samples. Perched groundwater at Cane Spring has a ${ }^{14} \mathrm{C}$ activity close to the modern atmospheric value (approximately 100 percent modern carbon [pmc]) and a relatively "light" (negative) $\delta^{13} \mathrm{C}$ value that is distinctive of biogenic soil $\mathrm{CO}_{2}$ gas. This sample is typical of recent groundwater recharge that has undergone very little reaction with carbonate minerals (e.g., Rose and Davisson, 2003). All other groundwaters shown in Figure 10-4 are from the regional water table. These samples have mean ${ }^{14} \mathrm{C}$ values ranging from 36.9 to $0.9 \mathrm{pmc}$ and $\delta^{13} \mathrm{C}$ values between -10.9 and -0.1 per mil. The carbon isotope values for most of these samples likely reflect the combined effects of radioactive decay and chemical dissolution of carbonate minerals.

Radioactive decay (without chemical reaction) will drive DIC carbon isotope compositions toward lower ${ }^{14} \mathrm{C}$ values at constant $\delta^{13} \mathrm{C}$ values. In contrast, groundwater interaction with carbonate minerals tends to drive the composition of the DIC toward higher (less negative) $\delta^{13} \mathrm{C}$ values and lower ${ }^{14} \mathrm{C}$ values (due to the absence of ${ }^{14} \mathrm{C}$ in the calcite). Secondary calcite that is present in the alluvial and volcanic HSUs in nearby Yucca Flat has an average $\delta^{13} \mathrm{C}$ value between about -2.5 and -3.0 per mil, whereas carbonate bedrock samples from the NTS have an average $\delta^{13} \mathrm{C}$ value near +0.5 per mil (see Hershey et al., 2004 for data summary). Many of the Frenchman Flat groundwaters plotted in Figure 10-4 show evidence of reaction with carbonate minerals, the sample from ER-5-4 \#2 being the most extreme example.

In general, groundwater from the different HSUs in Frenchman Flat show significant overlap in their DIC isotopic compositions. Samples from the alluvial aquifer appear to cluster into two groups (Figure 10-4). Wells UE-5 PW-1, UE-5 $\mathrm{PW}-2$, and WW-5b are characterized by lighter $\delta^{13} \mathrm{C}$ values (-9.8 to -8.2 per mil) and higher ${ }^{14} \mathrm{C}$ values (13.1 and $30.4 \mathrm{pmc}$ ) that suggest very modest reaction with carbonate minerals. A second group of samples (ER-5-4, WW-5a, WW-5c) exhibit heavier $\delta^{13} \mathrm{C}$ values (-6.0 to -4.6 per mil) and lower ${ }^{14} \mathrm{C}$ values $(1.5$ to $3.3 \mathrm{pmc}$ ) that are consistent with a greater extent of water-rock reaction. The lowest ${ }^{14} \mathrm{C}$ value in this group is observed at ER-5-4, which is also the deepest well completed in the FF alluvial aquifer. A general inverse trend in ${ }^{14} \mathrm{C}$ values with well depth is also observed within both the TCU and TM-WTA HSUs. For example, the lowest ${ }^{14} \mathrm{C}$ value $(1.0 \mathrm{pmc})$ is observed for the deepest well within the FF volcanic aquifers, ER-5-4\#2. In general, samples from wells completed in the shallower TM-WTA tend to overlap in composition with the light- ${ }^{13} \mathrm{C}$ AA data cluster (Figure 10-4). In comparison, samples from the LCA tend to exhibit heavier $\delta^{13} \mathrm{C}$ and lower ${ }^{14} \mathrm{C}$ values than most of the alluvial and volcanic aquifer samples. This is consistent with more extensive reaction with the carbonate host 
Table 10-2

Carbon Isotope Data for Frenchman Flat Wells

\begin{tabular}{|c|c|c|c|c|c|c|c|}
\hline \multirow{2}{*}{ Well Name } & \multirow{2}{*}{$\begin{array}{c}\text { Primary } \\
\text { HSU }\end{array}$} & \multicolumn{3}{|c|}{$\underset{\text { (permil) }}{\delta^{13} \mathbf{C}}$} & \multicolumn{3}{|c|}{$\begin{array}{c}{ }^{14} \mathrm{C} \\
\text { (pmc) }\end{array}$} \\
\hline & & Range & Mean & $\mathbf{n}$ & Range & Mean & $\mathbf{n}$ \\
\hline ER-5-4 & AA & $-4.7 /-4.6$ & -4.7 & 2 & 1.5 & 1.5 & 1 \\
\hline UE-5 PW-1 & $A A$ & $-8.7 /-7.3$ & -8.2 & 5 & 14.4 / 28.4 & 20.2 & 4 \\
\hline UE-5 PW-2 & AA & $-9.0 /-8.1$ & -8.6 & 2 & $27.1 / 33.8$ & 30.4 & 2 \\
\hline WW-5A & $\mathrm{AA}$ & $-4.8 /-4.3$ & -4.6 & 2 & 2.6 & 2.6 & 1 \\
\hline WW-5B & $\mathrm{AA}$ & $-10 /-9.5$ & -9.8 & 2 & 13.1 & 13.1 & 1 \\
\hline WW-5C & $A A$ & $-6.1 /-6.0$ & -6.0 & 3 & $3.13 / 3.4$ & 3.3 & 2 \\
\hline Army \#1 WW & LCA & $-7.1 /-5.6$ & -6.2 & 3 & $2.8 / 5.4$ & 4.1 & 2 \\
\hline ER-5-3\#2 & LCA & $-4.4 /-4.3$ & -4.4 & 2 & 1.6 & 1.6 & 1 \\
\hline TW-3 & LCA & -9.2 & -9.2 & 1 & 36.9 & 36.9 & 1 \\
\hline WW-C & LCA & $-4.2 /-3.8$ & -4.07 & 3 & $0.61 / 1.0$ & 0.81 & 2 \\
\hline WW-C1 & LCA & $-3.8 /-3.1$ & -3.5 & 2 & $0.8 / 1.03$ & 0.9 & 2 \\
\hline ER-5-4\#2 & LTCU & $-0.4 / 0.2$ & -0.1 & 2 & 1.0 & 1.0 & 1 \\
\hline UE-5c WW & LTCU & $-7.7 /-7.2$ & -7.5 & 3 & $6.5 / 6.7$ & 6.6 & 2 \\
\hline ER-5-3 & TM-WTA & $-8.0 /-7.8$ & -7.9 & 2 & 8.5 & 8.5 & 1 \\
\hline UE-5 PW-3 & TM-WTA & $-8.5 /-7.4$ & -7.9 & 5 & $16 / 21.0$ & 18 & 3 \\
\hline WW-4a & TM-WTA & $-9.3 /-8.4$ & -8.9 & 2 & 18.3 & 18.3 & 1 \\
\hline WW-4 & TM-WTA & -10.9 & -10.9 & 1 & $18.2 / 19.8$ & 19.0 & 2 \\
\hline Cane & $\begin{array}{c}\text { Perched } \\
\text { Spring }\end{array}$ & -10.1 & -10.1 & 1 & 92.8 & 92.8 & 1 \\
\hline
\end{tabular}

AA - Alluvial Aquifer

LCA - Lower Carbonate Aquifer

LTCU - Lower Tuff Confining unit

TM-WTA - Timber Mountain welded tuff aquifer

rock. One exception is TW-3 which is significantly lighter (more negative) in $\delta^{13} \mathrm{C}$ relative to the other LCA waters, and has an unusually high ${ }^{14} \mathrm{C}$ value $(36.9 \mathrm{pmc})$ for a LCA water. TW-3 also plots on the global meteoric water line (Figure 10-3). These characteristics may suggest that TW-3 contains a substantial component of recent groundwater recharge.

The interpretation of DIC ${ }^{14} \mathrm{C}$ ages requires significant corrections based on the careful evaluation of mineral dissolution and isotope exchange processes

(Mook, 1980). Uncertainties associated with these age estimates are quite large. Due to the relatively low organic content of many of the HSUs at the Nevada Test Site, DOC ${ }^{14} \mathrm{C}$ ages are generally considered to be more reliable indicators of the mean aquifer residence time of the dissolved carbon in groundwater.

Groundwater samples for DOC analysis were only recently sampled at select locations and analyzed for $\delta^{13} \mathrm{C}$ and ${ }^{14} \mathrm{C}$. These data provide an independent estimate of groundwater age that can be compared with groundwater travel times 


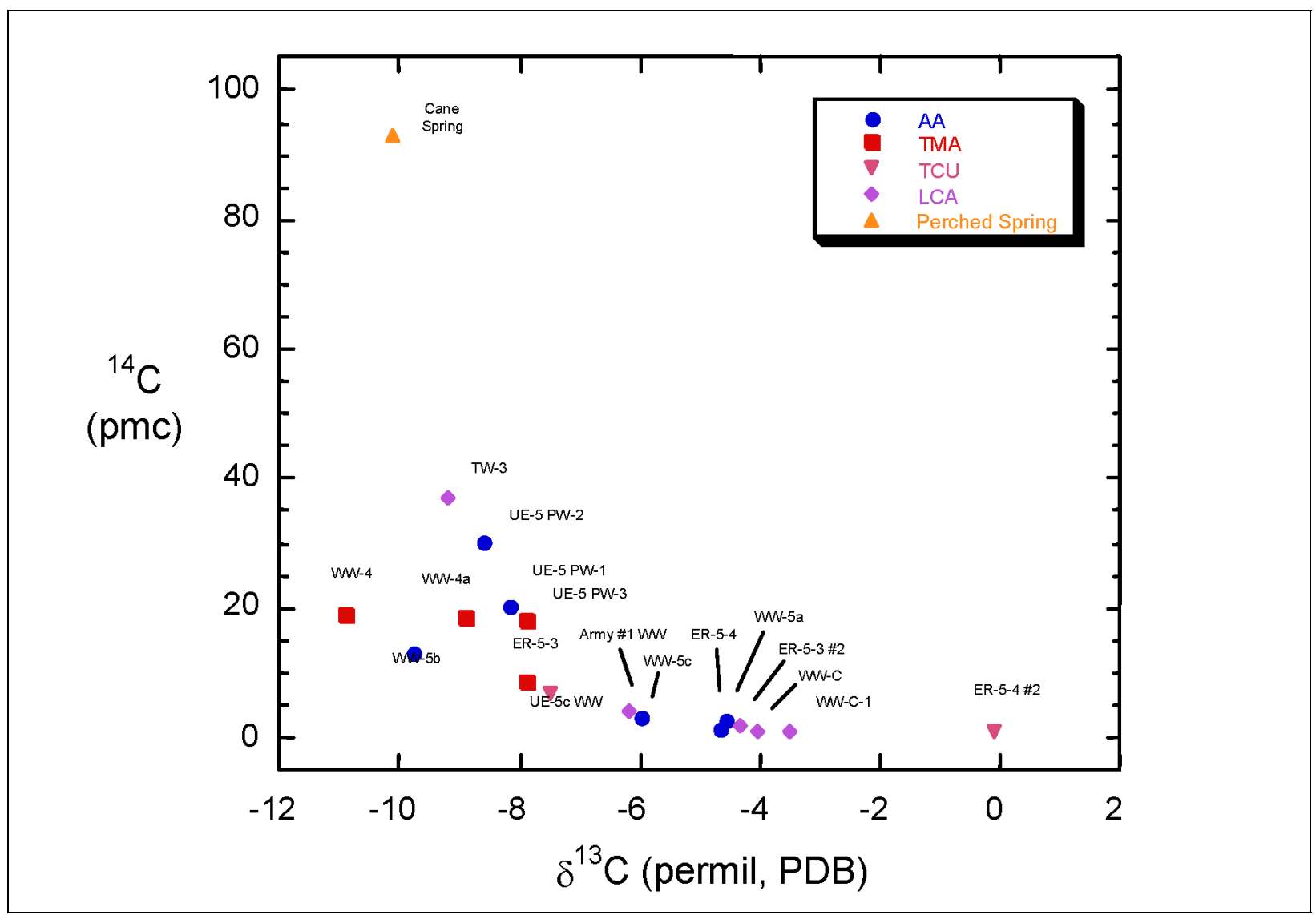

Figure 10-4

Plot of $\delta^{13} \mathrm{C}$ vs. ${ }^{14} \mathrm{C}$ Values for Springs and Wells Within the Frenchman Flat Study Area

calculated using $\mathrm{DI}^{14} \mathrm{C}$ data. Whereas travel times represent the mean groundwater transit time along a flow path, $\mathrm{DO}^{14} \mathrm{C}$ values should more closely reflect the average time elapsed since groundwater recharge. This assumes that water-rock reactions will not have an appreciable impact on $\mathrm{DO}^{14} \mathrm{C}$ values, in accordance with the low organic content of the volcanic and carbonate rock aquifers and endolithic bacteria are not affecting carbon isotope compositions at depth.

Calculated DOC ages are presented in Table 10-3. $\mathrm{DO}^{14} \mathrm{C}$ ages range from 3,000 to 14,000 years for groundwater in the Frenchman Flat area, assuming that an initial ${ }^{14} \mathrm{C}$ value (during recharge) is similar to that measured in wells UE-29a \#1 and UE-29a \#2 in Fortymile Wash. The average DOC ages increase with depth from the alluvial aquifer with an average age of 4,400 to 7,200 years for the volcanic aquifers to 14,000 years for ER-5-3 \#2 in the LCA. All ages represent a maximum age since any DOC added to the groundwater would contain ${ }^{14} \mathrm{C}$.

Additionally, the ages reflect the travel time of groundwater from recharge areas to the Frenchman Flat area. 
Table 10-3

$\mathrm{DO}^{14} \mathrm{C}$ Calculated Groundwater Ages

\begin{tabular}{|c|c|c|c|c|}
\hline Site Name & $\begin{array}{l}\text { DOC } \\
\text { (mg/L) }\end{array}$ & $\begin{array}{c}\mathrm{DO}^{13} \mathrm{C} \\
(\%)\end{array}$ & $\begin{array}{c}\mathrm{DO}^{14} \mathrm{C} \\
\text { (percent modern) }\end{array}$ & $\begin{array}{l}\begin{array}{c}\text { Age } \\
\text { (yrs) }\end{array} \\
\end{array}$ \\
\hline \multicolumn{5}{|c|}{ Alluvial Aquifer } \\
\hline WW 5A & 0.44 & -26.6 & 24.8 & 8,100 \\
\hline WW 5B & 0.10 & -29.1 & 42.3 & 3,700 \\
\hline WW 5C & 0.35 & -62.7 & 42.2 & 3,700 \\
\hline ER-5-4 & 0.19 & -29.2 & 45.9 & 3,000 \\
\hline Average & & & 38.8 & 4,400 \\
\hline \multicolumn{5}{|c|}{ Volcanic Aquifers } \\
\hline WW 4A & 0.20 & -46.6 & 16.1 & 12,000 \\
\hline ER-5-4 \#2 & 0.52 & -25.4 & 19.6 & 10,000 \\
\hline UE-5 PW-3 & 0.14 & -30.3 & 41.3 & 3,900 \\
\hline UE-5c WW & 0.17 & NA & 32.9 & 5,800 \\
\hline Average & & & 27.5 & 7,200 \\
\hline \multicolumn{5}{|c|}{ Lower Carbonate Aquifer } \\
\hline ER-5-3 \#2 & 0.61 & -36.8 & 12.0 & 14,000 \\
\hline
\end{tabular}

Source: Hershey et al. (2004)

\subsubsection{Conservative Tracer Data}

Conservative tracers are geochemical species that move with groundwater, exhibiting little or no change in concentration because of reactive processes. Conservative tracers can be used to support the identification of groundwater flow paths, mixing ratios, and time scales of environmental processes (Cook and Bohlke, 2000). Stable isotopes intrinsic to the water molecule $\left(\delta \mathrm{D}\right.$ and $\left.\delta^{18} \mathrm{O}\right)$ and dissolved $\mathrm{Cl}$ are considered to be the most conservative geochemical tracers.

Chloride is considered conservative in that no significant retardation mechanisms exist that would reduce its concentration along a flow path. The concentration of chloride may increase along a flowpath due to rock water interaction (see discussion associated with Figure 10-8). In some systems, dissolved $\mathrm{SO}_{4}$ may also behave conservatively although in the case of Frenchman Flat it was determined that $\mathrm{SO}_{4}$ is probably not conservative (Hershey et al., 2004).

Conservative tracers can provide valuable insight into potential groundwater pathways and mixing processes. Graphical methods are commonly used to identify mixing trends. More precise mixing ratios are then estimated mathematically, following the method outlined in Rose et al. (2002). The conceptual flow paths identified using this approach are then tested using 
independent data and chemical models to determine whether a consistent set of geochemical processes can describe all or most of the data.

The conservative tracer dataset used for the geochemical modeling consisted of the most recent sample with a charge balance within \pm 5 percent for major solute data and the mean for the multiple reported stable isotopes (Hershey et al., 2004).

\subsubsection{Conservative Tracer Evaluation}

The conservative tracer evaluation, performed by Hershey et al. (2004) focused on three conceptual flow models. These include north-to-south flow, west-to-east flow, and the "bathtub" model (vertical leakage from the alluvium to the LCA). The ability to analyze these conceptual flow paths using geochemical data is limited by two factors: (1) existing wells are not evenly distributed geographically within the study area, and (2) there is a significant paucity of wells completed in the LCA, both within the Frenchman Flat basin and to the south of the basin. Plots of $\delta \mathrm{D}$ versus $\delta^{18} \mathrm{O}$ (Figure 10-3) and $\mathrm{Cl}$ versus $\delta^{18} \mathrm{O}$ (Figure 10-5) were used to make a preliminary analysis of the conceptual flow models. Note that groundwater-mixing trends are linear on both plots.

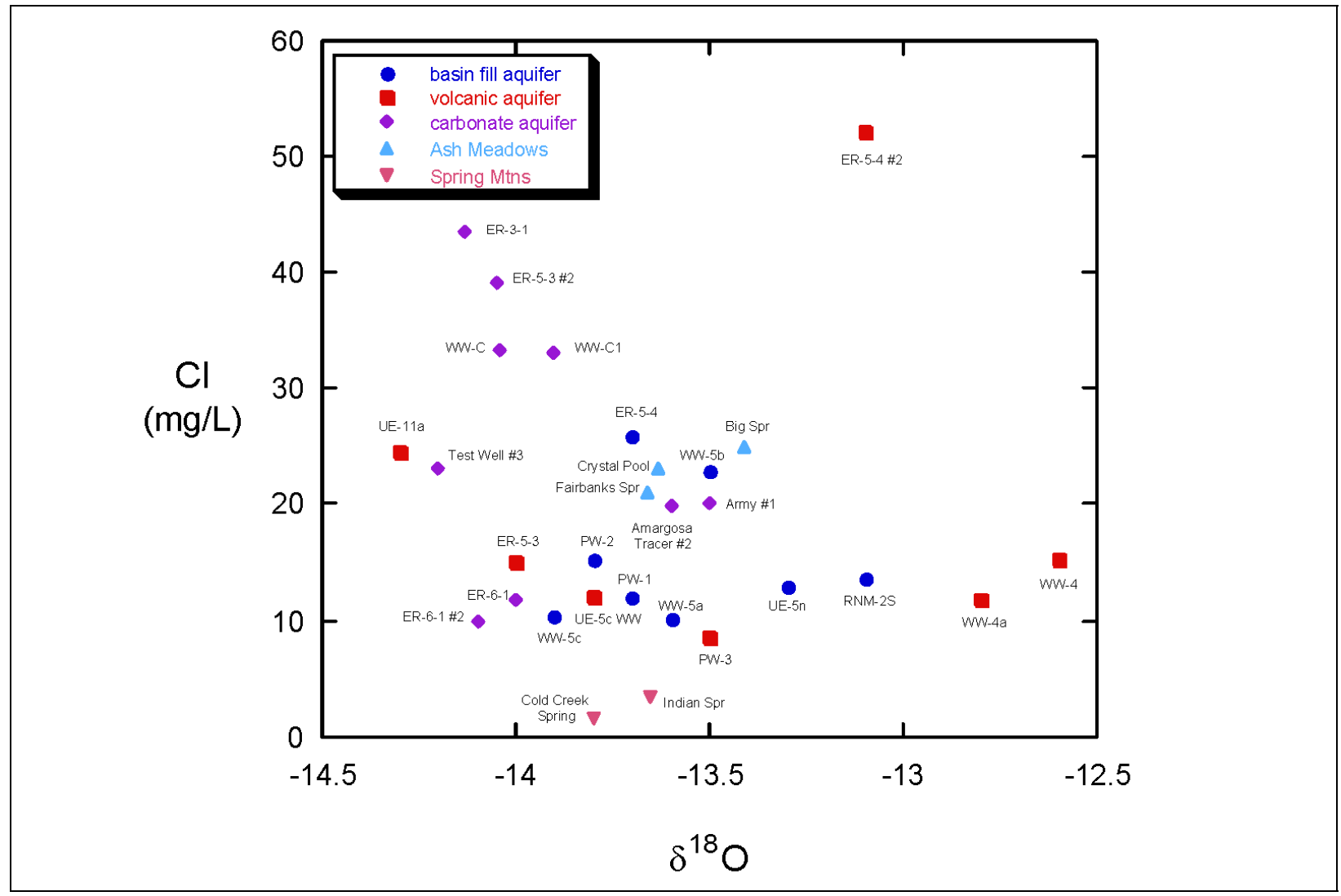

Figure 10-5

Plot of $\delta^{18} \mathrm{O}$ vs. Cl Values for Springs and Wells Within the Frenchman Flat Study Area 
Only the flow paths successfully supported by conservative tracer models were examined by the other geochemical modeling techniques (i.e., strontium and NETPATH modeling). This section provides the reasoning behind the development of these flow path models. For this reason, the following section that describes the conservative tracer evaluation is taken directly from Hershey et al. (2004).

\subsection{North-to-South Flow}

The north-south flow path within the alluvial aquifer is perhaps most readily evaluated because the greatest density of wells in Frenchman Flat are located along an approximate north-south trend extending from the northeast part of Area 5 to south of the Frenchman Playa (Figure 10-1). Although water levels tend to decrease toward the south, a systematic variation in the conservative tracer data is not evident. For example, the two southernmost wells (WW-5A and WW-5C) contain lower $\mathrm{Cl}$ concentrations than the wells that lie up gradient. Chloride values should either remain constant or increase slightly along a flow path unless groundwater mixing dilutes the water. On a $\mathrm{Cl}$ vs. $\delta^{18} \mathrm{O}$ graph (Figure 10-5), a suitable dilution component is not apparent unless it is assumed that groundwater recharge from the Spring Mountains can flow into southern Frenchman Flat. On the basis of water-level and structural data, Winograd and Thordarson (1975) did not consider this scenario to be likely. In addition, mixing with groundwater from the Spring Mountains would require WW-5A and WW-5C to increase in $\delta \mathrm{D}$ relative to other alluvial groundwaters in Frenchman Flat (Figure 10-3), but this is clearly not observed. Based on existing data, this particular model can be rejected.

The extrapolation of flow paths southward out of Frenchman Flat requires the development of geochemical models for Army \#1 WW-- the nearest well to the south along the inferred pathway to Ash Meadows. Army \#1 WW does not fall on a trend with any of the alluvial groundwater samples from Frenchman Flat (e.g., Figure 10-3). Hence, the existing data do not substantiate a north-to-south pathway from the alluvial aquifer to the LCA south of Frenchman Flat. Other possible models involving southward pathways within the LCA will be considered later in this section.

It is worth noting that $\delta \mathrm{D}, \delta^{18} \mathrm{O}$, and $\mathrm{Cl}$ data all yield a consistent mixing model for Army \#1 WW involving 66 to 73 percent Indian Springs (recharge from Spring Mountains) and 27 to 34 percent ER-5-4 \#2. The latter is the deepest well in Frenchman Flat, producing high $\mathrm{Na}-\mathrm{HCO}_{3}-\mathrm{SO}_{4}$ groundwater from a volcanic aquifer approximately $6,500 \mathrm{ft}$ below the surface. This model is intriguing because previous studies predicted similar mixing ratios for groundwater in these geographic areas (cf. Winograd and Friedman, 1972; Thomas et al., 1996). If this model were found to be consistent with other chemical data, it might imply a 
relatively deep lateral pathway through the volcanic aquifers beneath Frenchman Flat.

\subsection{West-to-East Flow}

The conceptual model involving west-to-east groundwater flow from the alluvial aquifer to the LCA in eastern Frenchman Flat was more difficult to evaluate because there are fewer wells that lie along this trend. Mixing scenarios using conservative tracer data to model the composition of TW-3 in eastern Frenchman Flat were completely unsuccessful. This is largely because TW-3 has an unusual $\delta \mathrm{D}-\delta^{18} \mathrm{O}$ pair compared to most groundwater in this region, plotting on the meteoric water line (Figure 10-3). As a result, no pathways or mixing models were identified to account for this composition as an end product of west-to-east flow.

WW-1 is the easternmost well completed in the alluvial aquifer, but we could not develop models for this site because of a lack of stable isotope data. It should be noted, however, that WW-1 groundwater contains only $6 \mathrm{mg} / \mathrm{L} \mathrm{Cl}$ - much less than expected at the down gradient end of the proposed flow path. This observation does not necessarily negate the west-to-east path, but does call into question the likelihood that WW-1 is linked to such a flow system. All wells that lie to the west of WW-1 in Frenchman Flat contain $\mathrm{Cl}>6 \mathrm{mg} / \mathrm{L}$.

Although it is conceptually plausible that groundwater from CP Basin could flow into central Frenchman Flat, attempts to develop conservative mixing models involving WW-4 and WW-4A were largely unsuccessful, and provided no real insight into whether groundwater is moving from the alluvial aquifer into the LCA in eastern Frenchman Flat. The basic conclusion of this analysis is that the available geochemical data do not strongly support the concept of west-to-east flow in Frenchman Flat (Hershey et al., 2004).

\subsection{Bathtub Model}

The potential for vertical leakage of groundwater from the alluvium to the LCA (the so-called "Bathtub" model) can only be addressed at one location within the Frenchman Flat basin - at well ER-5-3 \#2. Although both TW-3 and TW-F are also completed in the carbonate aquifer (Figure 10-1), TW-3 does not have saturated alluvium or volcanic rocks overlying the LCA (Lyles et al., 1991), and TW-F is lacking stable isotope data.

To conduct an assessment of vertical leakage at ER-5-3 \#2, it was necessary to consider data from nearby LCA wells in southern Yucca Flat as a frame of reference. In particular, it was essential to demonstrate whether a "less diluted" LCA end-member composition could be identified up gradient of ER-5-3 \#2. If 
ER-5-3 \#2 were found to be the least diluted LCA groundwater in the region, it would suggest that vertical leakage is less likely.

From a conservative tracer perspective, Well ER-3-1, located on the eastern edge of Yucca Flat, appears to meet all of the necessary criteria for a "less dilute" end-member, including more depleted $\delta \mathrm{D}$ and $\delta^{18} \mathrm{O}$ values, and a higher $\mathrm{Cl}$ concentration relative to Well ER-5-3 \#2. In addition, the water-level elevation at ER-3-1 (2,392 ft) is above that at ER-5-3 \#2 (2,387 ft), indicating the potentiometric surface favors southward flow. It should be noted, however, that the hydrogeologic setting of the eastern NTS was not carefully considered in the analysis. The primary interest was in determining the conceptual possibility that a "less dilute" groundwater (like ER-3-1) may be flowing into the NTS from the northeast, following the generally accepted (but poorly constrained) "Pahranagat Valley" regional flow path (Winograd and Friedman, 1972; Thomas et al., 1996; DOE, 1997).

One potential groundwater mixing scenario involving ER-3-1 and UE-5 PW-3 is shown on a plot of $\mathrm{Cl}$ versus $\delta \mathrm{D}$ values (Figure 10-6). A mixing line marked with ten equally spaced increments is included to help visualize the relative proportion of each end-member needed to derive the ER-5-3 \#2 composition. On the basis of this plot, Well ER-5-3 \#2 appears to contain a mixture of about 15 percent Well UE-5 PW-3 and 85 percent Well ER-3-1. Similar mixing fractions were obtained for all three conservative tracers $\left(\delta \mathrm{D}, \delta^{18} \mathrm{O}\right.$, and $\left.\mathrm{Cl}\right)$ using the two component mixing equation:

$$
\mathrm{C}_{\text {mix }}=\mathrm{C}_{1} X_{1}+\mathrm{C}_{2} X_{2}
$$

where

$\mathrm{C}_{\text {mix }}=$ The tracer concentration (or $\delta$-value) of the final mixed water $\mathrm{C}_{1}$ and $\mathrm{C}_{2}=$ The concentrations (or $\delta$-values) of the two mixing components $X_{1}$ and $X_{2}=$ The relative fractions of each component, where $X_{1}+X_{2}=1$

Note that WW-C and WW-C1 in southern Yucca Flat also plot along this mixing trend, but appear to contain a mixture that is closer to 30 percent Well UE-5 PW-3 and 70 percent Well ER-3-1.

While the ER-3-1 + UE-5 PW-3 mixing model gives a plausible estimate of the relative amount of vertical leakage at Well ER-5-3 \#2, this model is not unique. For example, using $\delta \mathrm{D}$ and $\mathrm{Cl}$ data, it is also possible to model the composition of ER-5-3 \#2 (and WW-C) using a mixture of ER-3-1 and TW-3. In this case, ER-5-3 \#2 is predicted to contain approximately 23 percent TW-3 and approximately 77 percent ER-3-1, whereas the model for WW-C predicts a nearly equal mix of both end-members (note the co-linearity of these data points in Figure 10-6). This model is significant in that it suggests ER-3-1 can be diluted to produce ER-5-3 \#2 without adding groundwater from the overlying alluvial and volcanic units in Frenchman Flat. However, it is important to acknowledge that this model is invalid for $\delta^{18} \mathrm{O}$ because the end-member compositions are isotopically lighter than either ER-5-3 \#2 or WW-C. There is some question 


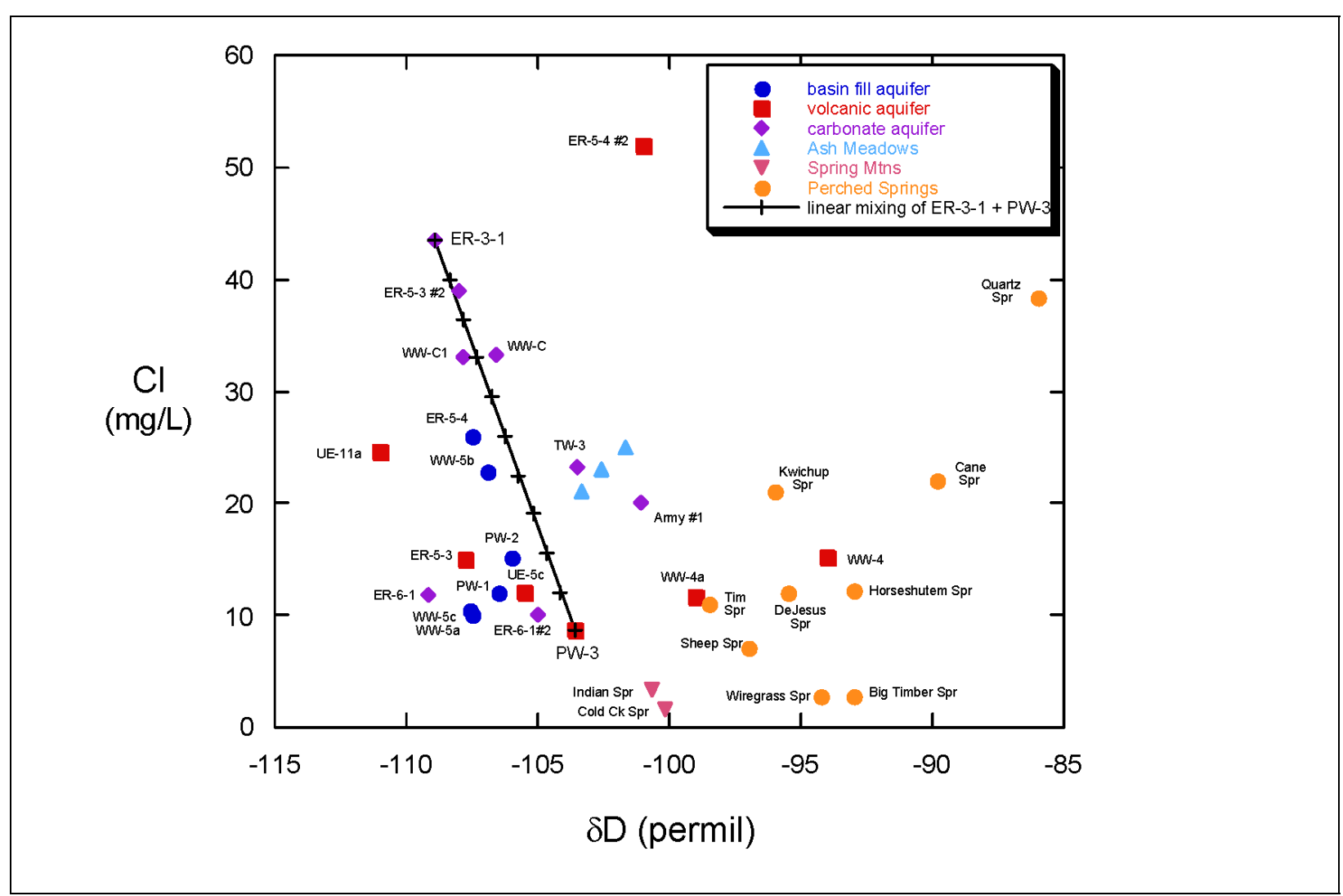

Figure 10-6

Plot of $\delta$ D vs. CI Values for Springs and Wells Within the Frenchman Flat Study Area

regarding the validity of the TW-3 $\delta^{18} \mathrm{O}$ value, but the currently accepted value of $-14.2 \%$ could not be verified during this study.

If it is assumed that Frenchman Flat LCA groundwater moves southward toward Army \#1 WW (and eventually to Ash Meadows), it is of interest to model the mixing process needed to attain an Army \#1 WW composition when starting with ER-5-3 \#2 (or WW- C and WW-C1). This analysis provides useful insight into the overall fraction of Frenchman Flat LCA water that moves beyond the boundaries of the NTS. Several studies have shown that Ash Meadows and Army \#1 WW are likely to contain a significant fraction of groundwater originating from the Spring Mountains (see Thomas et al., 1996; Hershey and Acheampong, 1997). Thus, mixing models that included Frenchman Flat LCA water as well as a Spring Mountains mixing component - either Cold Creek Spring or Indian Springs were examined.

Army \#1 WW does not lie along a mixing line between ER-5-3 \#2 and Indian Springs or Cold Creek Spring (e.g., Figure 10-6); therefore, a third end-member is required to develop the model. Since Army $\# 1 \mathrm{WW}$ is enriched in $\delta \mathrm{D}$ and $\delta^{18} \mathrm{O}$ compared to the Frenchman Flat-Spring Mountains mixing line, the third component must also be enriched in heavy isotopes. Figure 10-6 shows the compositions of perched springs that are located in the Pintwater and Sheep Ranges (east of Frenchman Flat), and the westernmost part of the Spring 
Mountains (southeast of Frenchman Flat). Also included is Cane Spring, a perched spring located on the west side of Mt. Salyer, just west of Frenchman Flat. All of the perched springs in the region are enriched in heavy isotopes relative to Army \#1 WW, and hence, there are a number of potential mixing models that can be developed using perched springs as a "local recharge" end-member.

One possible model (illustrated in Figure 10-7) is the three-component mixture involving ER-5-3 \#2 + Indian Springs + Cane Spring = Army \#1 WW. To determine mixing fractions for this model, it was necessary to solve equation 10-1 for two of the components, and then insert the resulting value for $\mathrm{C}_{\text {mix }}$ into a new mixing equation containing the third component. This process is iterative, and the relative fraction of each component is varied until the system of equations converges on a mixing model that is consistent for all three tracers $\left(\delta \mathrm{D}, \delta^{18} \mathrm{O}\right.$, and $\mathrm{Cl})$. A worked example of this process is found in Rose et al. (2002). In many cases, there is no solution that is acceptable for all three tracers (to within \pm 10 percent). For the model shown in Figure 10-7, the predicted mixing fractions needed to produce an Army \#1 WW composition were:

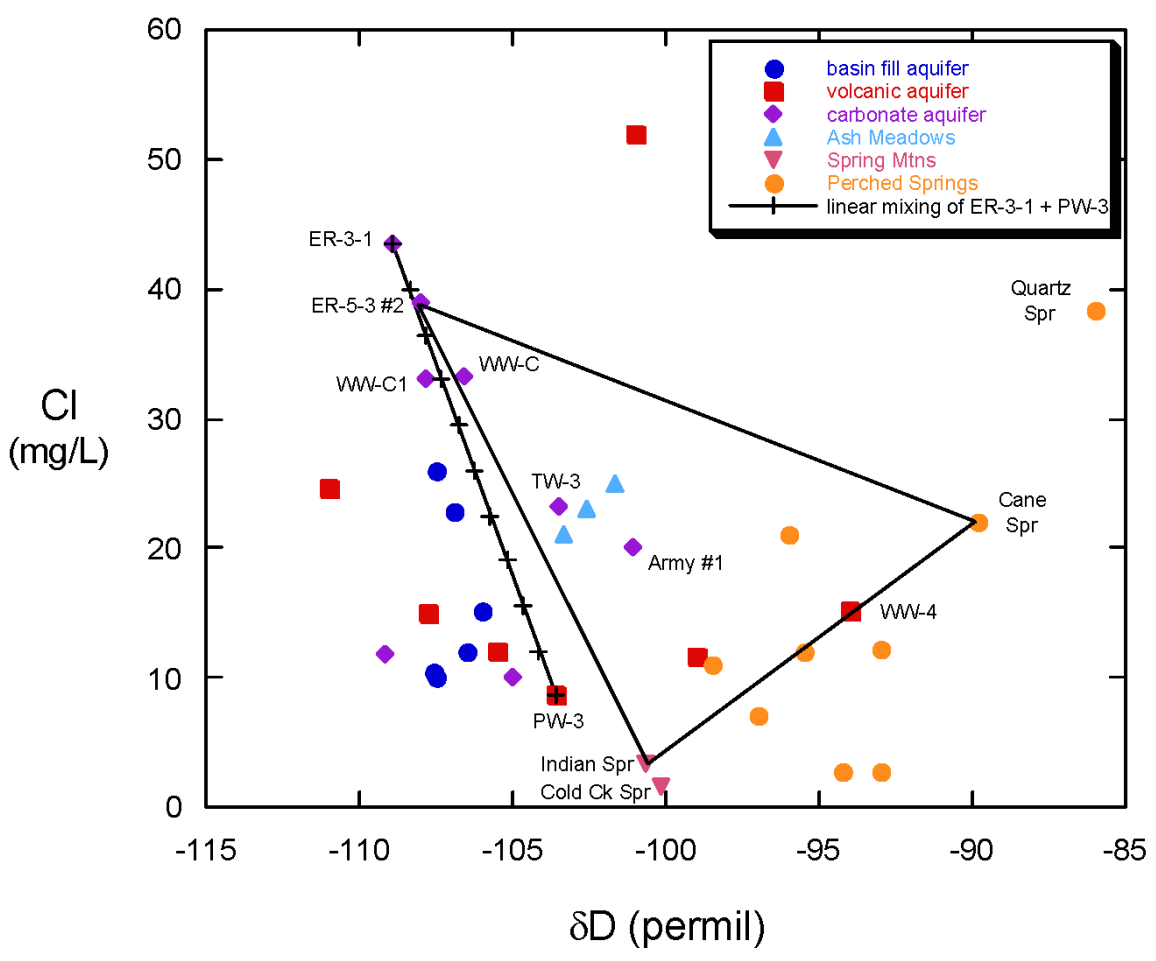

Figure 10-7

Plot of $\mathrm{Cl}$ vs. $\delta$ D Values for Groundwater Samples From Frenchman Flat and Vicinity Showing One Possible Three Component Mixing Model to Explain the Observed Groundwater Composition of Army \#1 WW 
$(0.362$ - 0.404) ER-5-3 \#2 + (0.433 - 0.483) Indian Springs $+(0.113-0.205)$ Cane Spring

The numbers in parentheses show the variation in the mixing fractions of the different tracers. A number of conservative tracer models were successfully developed for Army \#1 WW using a Frenchman Flat LCA groundwater (ER-5-3 \#2 or WW-C) + Spring Mountains carbonate groundwater (Cold Creek Spring or Indian Springs) + various perched springs (or WW-4). Using a more evapoconcentrated perched spring such as Cane or Quartz Spring tended to minimize the local recharge contribution to the mixture.

The conservative tracer models for Army \#1 WW show a fairly consistent mixing fraction for the Frenchman Flat LCA component (either ER-5-3 \#2 or WW-C) in the range of 36 to 48 percent. In contrast, the mixing fraction of the Spring Mountains component showed a much wider range that was mostly dependent on the perched spring composition used in the model. The following two models for Army \#1 WW illustrate this variability:

$$
\begin{aligned}
& (0.358-0.360) \text { ER-5-3 \#2+(0.503 - 0.506) Cold Ck Spr }+(0.134-0.139) \text { Quartz Spring } \\
& (0.454-0.480) \text { ER-5-3 \#2+(0.100 - 0.105) Cold Ck Spr }+(0.415-0.446) \text { Wiregrass Spring }
\end{aligned}
$$

Models that require a very large fraction of the "local recharge" component are probably less realistic from a mass balance perspective since it is known that the Spring Mountains are a volumetrically significant source of recharge, but the Pintwater Range is not.

Given that the models presently considered involve somewhat lengthy flow paths within the carbonate aquifer, it is essential to point out that the assumption of $\mathrm{Cl}$ conservatism may not be valid for all parts of this system. Moran and Rose (2003) demonstrated that the geochemical evolution of ${ }^{36} \mathrm{Cl}$ in the LCA is strongly controlled by water-rock interaction with the carbonate host rock. Groundwater that has followed a long flow path through the LCA tends to evolve toward a low ${ }^{36} \mathrm{Cl} / \mathrm{Cl}$ ratio and a high $\mathrm{Cl}$ concentration. This trend is thought to reflect the leaching of ${ }^{36} \mathrm{Cl}$-absent $\mathrm{Cl}$ from the carbonate rock. Well ER-3-1 is a good example of an LCA groundwater that has undergone extensive water-rock reaction (see Figure 10-8).

Cold Creek Spring, which is located close to its source in the Spring Mountains, has a low chloride concentration $(1.6 \mathrm{mg} / \mathrm{L})$ and a ${ }^{36} \mathrm{Cl} / \mathrm{Cl}$ ratio $\left(5.22 \times 10^{-13}\right)$ very similar to the modern atmospheric value for this region (Fabryka-Martin et al., 1993). Hence, it has undergone very little evolution from water-rock reaction since recharge. Indian Springs, located slightly further down gradient has a $\mathrm{Cl}$ value of $3.3 \mathrm{mg} / \mathrm{L}$, but the ${ }^{36} \mathrm{Cl} / \mathrm{Cl}$ ratio has not been measured for this site. However, we anticipate the ${ }^{36} \mathrm{Cl} / \mathrm{Cl}$ ratio would gradually evolve toward lower values along the Spring Mountains pathway to Ash Meadows. These points are of interest because Army \#1 WW lies along this same pathway.

In this study, Army \#1 WW was modeled using Spring Mountains end-members that are very dilute in $\mathrm{Cl}$. If chloride is non-conservative in the LCA, then the 


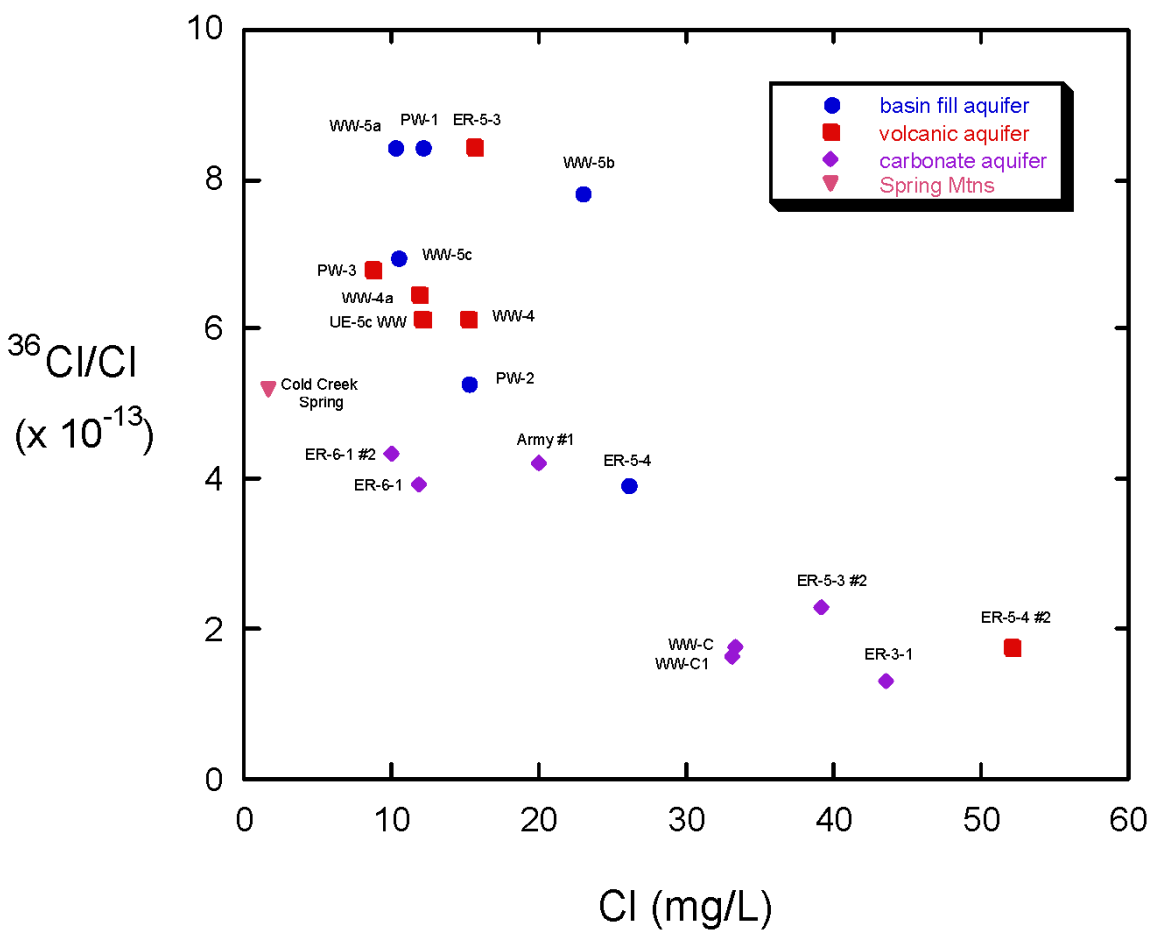

Figure 10-8

Plot of ${ }^{36} \mathrm{Cl} / \mathrm{Cl}$ vs. $\mathrm{Cl}$ for Groundwater Samples From Frenchman Flat and Vicinity

actual concentration of $\mathrm{Cl}$ in the Spring Mountains mixing component arriving at Army \#1 WW may be much higher than assumed in the models.

Of course, it could be argued that Frenchman Flat LCA groundwater may also increase in chloride on its way to Army \#1 WW. However, it is expected that the biggest changes in $\mathrm{Cl}$ concentrations and ${ }^{36} \mathrm{Cl}$ values will occur along the initial part of a flow path, when the water is furthest from equilibrium with the rock. As a hypothetical example, suppose the same three-component model shown in Figure 10-7 was used, but now assume that Indian Springs contains $10 \mathrm{mg} / \mathrm{L} \mathrm{Cl}$ instead of $3.3 \mathrm{mg} / \mathrm{L}$. This is equivalent to moving the Indian Springs data point closer to the Army \#1 WW data point on Figure 10-7. The three-component model would now predict a 57 to 60 percent contribution from Indian Spring, 28 to 30 percent from ER-5-3 \#2, and 10 to 15 percent Cane Spring. If the $\mathrm{Cl}$ value is increased to $15 \mathrm{mg} / \mathrm{L}$ in Indian Springs, its mixing fraction increases to 73 percent, and the ER-5-3 \#2 contribution drops to 18 percent.

This hypothetical exercise highlights the uncertainty associated with the mixing models for Army \#1 WW given the nonconservative nature of $\mathrm{Cl}$ in the LCA. If the mixing fraction of Spring Mountains water at Army \#1 WW is assumed to be higher than originally predicted, then the volume of LCA groundwater exiting Frenchman Flat will almost certainly be smaller than predicted by our conservative tracer models. Therefore it is important to analyze other types of 
geochemical data together with chemical modeling predictions to determine which of the conservative tracer mixing scenarios are most plausible.

\subsubsection{Strontium and Strontium Isotope $\left({ }^{87} \mathrm{Sr} /{ }^{86} \mathrm{Sr}\right)$ Evaluation}

Strontium is commonly present as a trace metal dispersed in rock forming minerals, particularly in Ca-rich phases such as calcite. Water/rock reactions involving precipitation or dissolution of mineral phases along groundwater flow paths can modify both the $\mathrm{Sr}$ concentration and ${ }^{87} \mathrm{Sr} /{ }^{86} \mathrm{Sr}$ composition of advecting water. Although chemical processes can change the concentration of Sr during groundwater flow, a number of them (mineral precipitation, sorption) do not fractionate isotopic compositions in solution. Therefore, ${ }^{87} \mathrm{Sr} /{ }^{86} \mathrm{Sr}$ ratios have the potential to provide additional insight into processes of flow and transport in regional groundwater studies (Hershey et al., 2004). In addition, the ${ }^{87} \mathrm{Sr} /{ }^{86} \mathrm{Sr}$ composition of different aquifers is often very distinct, and may provide the ability to distinguish different groundwater domains. A summary of the $\mathrm{Sr}$ and ${ }^{87} \mathrm{Sr} /{ }^{86} \mathrm{Sr}$ evaluations described in Hershey et al. (2004) is presented in this section. Further details regarding these evaluations, and the data that were used, can be obtained from Hershey et al. (2004).

Concentrations of dissolved Sr vary widely in Frenchman Flat groundwater ranging from low concentrations (less than about $0.2 \mathrm{mg} / \mathrm{L}$ ) in alluvial and volcanic samples to relatively high concentrations $(0.8$ to $0.9 \mathrm{mg} / \mathrm{L})$ observed in most of the LCA samples. The Sr concentration in the LCA waters of Indian Springs (Spring Mountain recharge water), ER-6-1, and ER-6-1\#2 are notably less $(0.2$ to $0.3 \mathrm{mg} / \mathrm{L}$ ) than those of the Frenchman Flat LCA (Hershey et al, 2004).

The concentrations of $\mathrm{Sr}$ and $\mathrm{Ca}$ in groundwaters of Frenchman Flat and Yucca Flat as well as the mean $\mathrm{Sr} / \mathrm{Ca}$ ratios for Cenozoic seawater carbonates, Jurassic dolostones, Miocene felsic volcanic rocks, and NTS ephemeral streamflow are shown in Figure 10-9. The $\mathrm{Sr}$ and $\mathrm{Ca}$ values in stream flow reflect the readily soluble alkali earth elements from soil carbonate that may contribute to groundwater recharge (Hershey et al., 2004). Low Sr samples (excluding Cold Creek and Cane Springs) have an average $\mathrm{Sr} / \mathrm{Ca}$ weight ratio of 0.0058 (Line 1, Figure 10-9). $\mathrm{The} \mathrm{Sr} / \mathrm{Ca}$ regression line for these waters lies between that of the felsic volcanic rocks (Line 5, Figure 10-9) and ephemeral streamflow (Line 4, Figure 10-9). This suggests that in addition to Sr derived from the dissolution of the relatively Sr rich silicate materials (particularly glassy units in the Tertiary volcanic and alluvial aquifers), much of the $\mathrm{Sr}$ in these shallower aquifers may be derived from dissolution of carbonate-rich soils (Hershey et al., 2004).

Within the LCA, Sr/Ca ratios range from 0.010 for ER-3-1 to 0.018 for TW-3 (identified as HTH-3 in Figure 10-9) and Army \#1 WW (Hershey et al., 2004). This increase in $\mathrm{Sr} / \mathrm{Ca}$ ratio corresponds to the general north-to-south distribution of these samples. The $\mathrm{Sr} / \mathrm{Ca}$ ratios for the groundwaters of Frenchman Flat are larger than values commonly present in marine and pedogenic carbonates which 


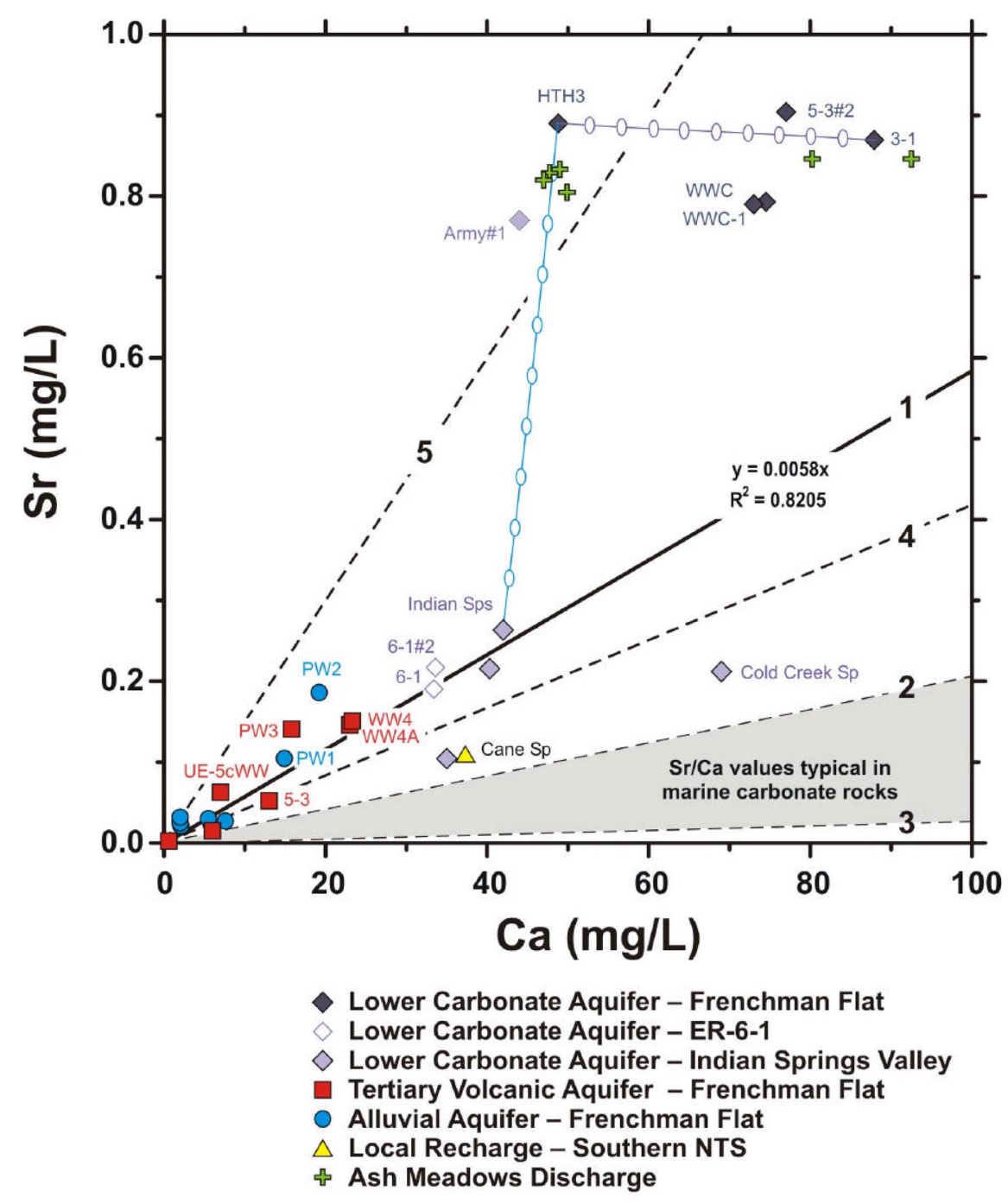

\section{$\mathrm{Sr} / \mathrm{Ca}$ for potential reservoirs contributing to Frenchman Flat groundwater}

1) Regression of low-Sr groundwater samples in this report

2) Mean Sr/Ca value for 58 Cenozoic seawater carbonates (Lear et al., 2003)

3) Mean Sr/Ca value for 36 Jurassic dolostones (Nader et al., 2004)

4) Mean Sr/Ca value in 16 samples of Nevada Test Site ephemeral streamflow representing soil carbonate (Savard, 1996; USGS unpublished data)

5) Mean Sr/Ca value for 84 analyses of Miocene felsic volcanic rocks from Yucca Mountain (Peterman et al., 1993, 1996;

Peterman and Futa, 1996; Peterman and Cloke, 2002)

Figure 10-9

Concentrations of $\mathrm{Sr}$ and $\mathrm{Ca}$ in Selected Groundwater Samples in the Frenchman Flat Vicinity 
indicates that the dissolved $\mathrm{Sr}$ contents are not a result of bulk dissolution of carbonate rocks and soils (Hershey et al., 2004).

Strontium concentrations are plotted along with the ${ }^{87} \mathrm{Sr} /{ }^{86} \mathrm{Sr}$ ratios in Figure 10-10. Note: TW-3 is identified as HTH3 in Figures 10-9 and 10-10. A general decreasing trend in ${ }^{87} \mathrm{Sr} /{ }^{86} \mathrm{Sr}$ values from north to south is observed in groundwater from the LCA (Figure 10-10). The observed ${ }^{87} \mathrm{Sr} /{ }^{86} \mathrm{Sr}$ values are the greatest in the groundwaters north of Frenchman Flat (ER-3-1), intermediate in southern Yucca Flat (WW-C and WW-C1) and northern Frenchman Flat (ER-5-3 \#2), and the lowest in southeastern Frenchman Flat (TW-3). Samples of the LCA farther to the south at Army \#1 WW and a number of discharge sites in Ash Meadows have ${ }^{87} \mathrm{Sr} /{ }^{86} \mathrm{Sr}$ values that are intermediate between those observed for southern Frenchman Flat and Spring Mountain recharge waters (Figure 10-10). In general, groundwaters from the LCA, have substantially larger ${ }^{87} \mathrm{Sr} /{ }^{86} \mathrm{Sr}$ values (0.71328 to 0.7182 ) than those of the shallower aquifers (Figure 10-10) and are more similar to ratios present in samples of the Eleana Formation argillite $(0.715$ to 0.724 ) (Hershey et al., 2004) than those expected for LCA host rock.

Samples from the alluvial and volcanic aquifers have ${ }^{87} \mathrm{Sr} /{ }^{86} \mathrm{Sr}$ values ranging from 0.70884 to 0.71116 (Hershey et al., 2004). Within the alluvial aquifer, $\mathrm{Sr}$ concentrations are greatest in samples from wells to the north (UE-5 PW-1 and UE-5 PW-2) and least in wells toward the south (WW-5A, 5B, 5C). However, all alluvial aquifer samples show relatively uniform ${ }^{87} \mathrm{Sr} /{ }^{86} \mathrm{Sr}$ compositions $(0.7101$ to 0.7112). These $\mathrm{Sr}$ and ${ }^{87} \mathrm{Sr} /{ }^{86} \mathrm{Sr}$ data are consistent either with progressive extraction of $\mathrm{Sr}$ from solution by sorption onto clay particles as water flows from north to south, or with increased dilution of groundwater to the south by a recharge component with a low $\mathrm{Sr}$ concentration and a similar ${ }^{87} \mathrm{Sr} /{ }^{86} \mathrm{Sr}$ value

(Hershey et al., 2004).

Strontium concentrations and ${ }^{87} \mathrm{Sr} /{ }^{86} \mathrm{Sr}$ values for volcanic aquifer, samples in Frenchman Flat do not show obvious correlations with their north-to-south spatial distributions (Figure 10-10). Four of the seven wells (WW-4, WW-4a, ER-5-3, and UE-5 PW-3) have very restricted ${ }^{87} \mathrm{Sr} /{ }^{86} \mathrm{Sr}$ values $(0.7101$ to 0.7105$)$ similar to values in most alluvial aquifer samples. Groundwater of ER-5-4 \#2 has a very low Sr concentration $(0.0023 \mathrm{mg} / \mathrm{L})$ and is likely affected by sorption of $\mathrm{Sr}$ onto the zeolitized tuffs of the LTCU. Low Sr concentrations in this water make modification of ${ }^{87} \mathrm{Sr} /{ }^{86} \mathrm{Sr}$ values much more sensitive to local variations in aquifer rock composition and may explain ${ }^{87} \mathrm{Sr} /{ }^{86} \mathrm{Sr}$ values that deviate from the other volcanic aquifer samples (Hershey et al., 2004).

The results of Sr modeling, as described in Hershey et al. (2004), are summarized as follows:

\section{North to South Flow}

Strontium data do not support the conservative tracer mixing models between the groundwaters of ER-5-4 \#2 (representative of the volcanic aquifer) and Indian springs LCA waters to derive the groundwater Sr compositions at Army \#1 WW. ER-5-4\#2 and Indian springs LCA waters have substantially lower $\mathrm{Sr}$ concentrations and lower ${ }^{87} \mathrm{Sr} /{ }^{86} \mathrm{Sr}$ values than Army \#1 WW (Figure 10-10). Substantial addition of $\mathrm{Sr}$ by reaction with a mineral component containing high 


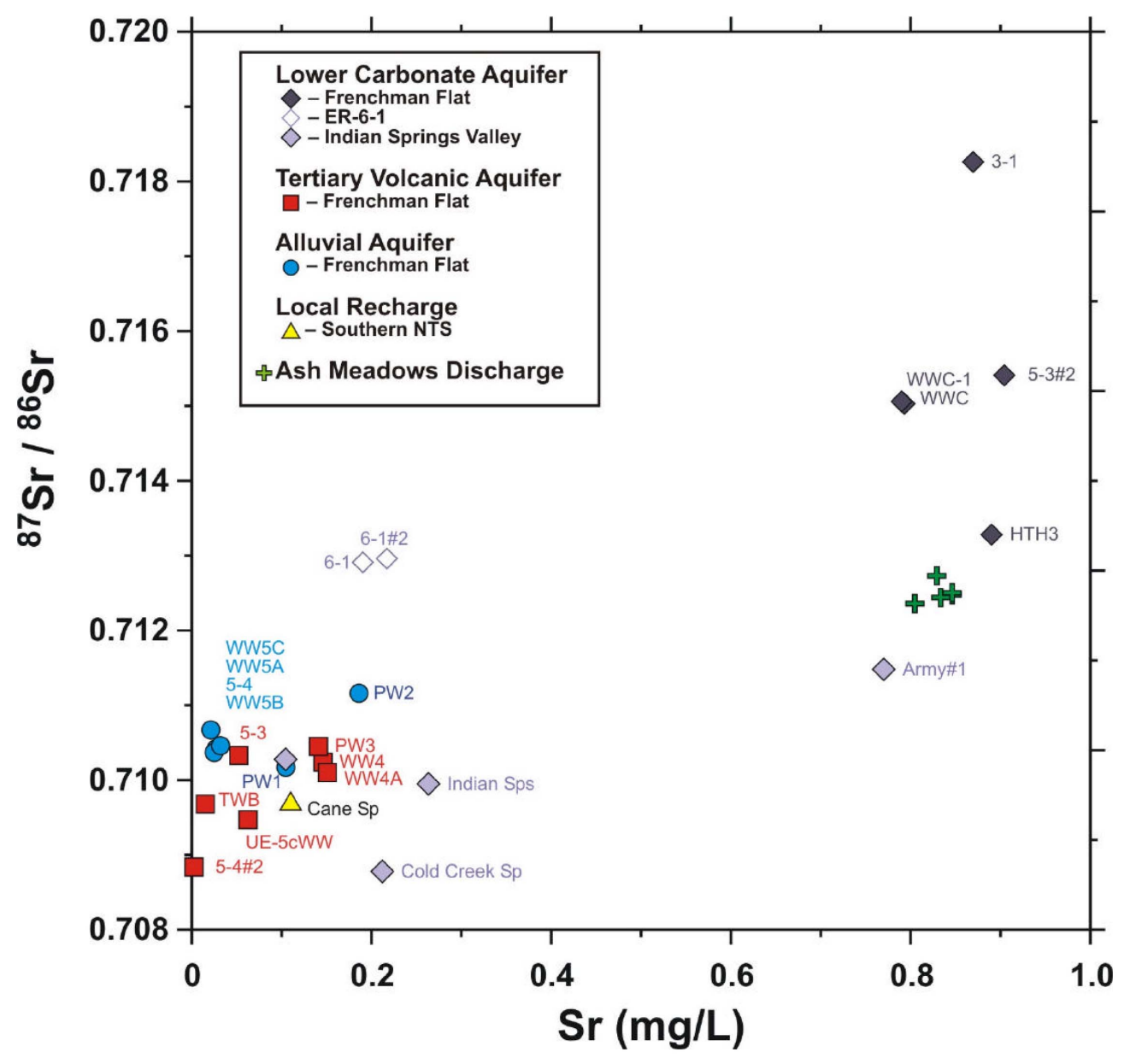

${ }^{87} \mathrm{Sr} /{ }^{86} \mathrm{Sr}$ Ratios and Sr Concentrations for Selected Water Samples in the Frenchman Flat Vicinity

${ }^{87} \mathrm{Sr} /{ }^{86} \mathrm{Sr}$ and $\mathrm{Sr} / \mathrm{Ca}$ would be required to produce the $\mathrm{Sr}$ compositions of Army \#1 WW from this mixture of groundwaters (Hershey et al., 2004).

\section{West-to-East flow}

Strontium isotope data do not support a model mixing water from the volcanic or alluvial aquifers with LCA groundwater (ER-5-3\#2, ER-3-1, WW-C, or WW-C1) to produce ${ }^{87} \mathrm{Sr} /{ }^{86} \mathrm{Sr}$ compositions similar to those observed in the southeastern Frenchman Flat LCA groundwaters of TW-3 (Hershey et al., 2004). Large differences between $\mathrm{Sr}$ characteristics in Frenchman Flat volcanic aquifer and LCA groundwater samples are present. Patterns of variation in Sr concentrations and ${ }^{87} \mathrm{Sr} /{ }^{86} \mathrm{Sr}$ compositions are distinct for volcanic and alluvial aquifer 
groundwater compared to values observed in the LCA beneath Frenchman Flat suggesting little mixing between these shallower aquifers and the LCA.

\section{Bathtub Model}

Strontium data suggests that little or no leakage occurs between the shallower alluvial and volcanic aquifer into the deeper LCA within Frenchman Flat (Hershey et al., 2004). Assuming that the "less dilute" ER-3-1 sample represents the LCA member, Sr data require as much as 80 percent of a volcanic aquifer component to yield ${ }^{87} \mathrm{Sr} /{ }^{86} \mathrm{Sr}$ values equivalent to those observed in ER-5-3 \#2. This amount of a volcanic aquifer component should cause a noticeable decrease in Sr concentrations in the resulting mixture; a feature that is not observed. Mixtures of approximately 15 percent UE-5 PW-3 and 85 percent ER-3-1 derived using the conservative tracers, would barely shift the ${ }^{87} \mathrm{Sr} /{ }^{86} \mathrm{Sr}$ composition away from the values observed for ER-3-1 (Hershey et al., 2004). To obtain the above mixing proportions, dissolution of marine limestone or dolostone comprising the LCA host rock would likely lower the ${ }^{87} \mathrm{Sr} /{ }^{86} \mathrm{Sr}$ as dissolution proceeded while keeping Sr concentrations elevated. However this scenario would not account for the increasing $\mathrm{Sr} / \mathrm{Ca}$ ratios observed in Frenchman Flat LCA water as flow progresses from ER-3-1 southward to other LCA wells (Hershey et al., 2004).

Strontium data in LCA groundwater within Frenchman Flat is most consistent with flow to the south-southwest along the structural grain in the region that is largely isolated from the overlying aquifers. Compositions of LCA in northwestern Frenchman Flat and southernmost Yucca Flat have compositions that are intermediate between a least dilute and greater ${ }^{87} \mathrm{Sr} /{ }^{86} \mathrm{Sr} \mathrm{LCA}$ end member to the north (ER-3-1) and a more dilute ${ }^{87} \mathrm{Sr} /{ }^{86} \mathrm{Sr}$ LCA end member to the southeast (TW-3). Mixtures of this component with east-to-west flow from Indian Springs are likely to yield groundwater with compositions observed at Army \#1 WW. However, Sr data does not give consistent mixing proportions with conservative tracers and likely requires more complex mixing end members that have yet to be sampled, or advection-reaction processes. Isotope data for reservoir rocks are not available for modeling this more complex process (Hershey et al., 2004).

\subsubsection{NETPATH Modeling}

Flow paths successfully identified by conservative tracer mixing models, as defined by Hershey et al. (2004) and described in Section 10.5.3, were further evaluated using the NETPATH geochemical computer code (Plummer et al., 1994). NETPATH is a computer code for geochemical calculations developed by the U.S. Geological Survey and is freely available from their website. The specific code capabilities sought for use by Hershey et al. (2004) included geochemical speciation calculations, mass balance calculations, isotopic exchange, and the ability to calculate apparent water ages based on carbon isotope data $\left({ }^{13} \mathrm{C}\right.$ and $\left.{ }^{14} \mathrm{C}\right)$. Code options for a peer reviewed, non-proprietary geochemical code capable of conducting isotopic exchange and apparent water age calculations (without modifications), in addition to the other capabilities, are limited to NETPATH. The geochemical calculations performed using NETPATH were 
conducted in accordance with procedures described in Plummer et al. (1994) and summarized in Hershey et al. (2004).

The NETPATH program is used to define the net geochemical mass-transfer that takes place between initial and final water compositions (i.e., well locations) along a hydrologic flow path as a result of water-rock interaction processes. NETPATH can also compute the mixing proportions of up to five contributory source waters, along with the net geochemical reactions, required to account for the observed composition of the final water. Plausible flow paths that are consistently described using both the conservative tracer and NETPATH modeling approaches are considered to have a high probability of representing realistic groundwater pathways (Rose et al., 2002).

Geochemical modeling is used to evaluate the consistency between the groundwater sources, flow paths, and mixing processes identified using geochemical and hydrogeologic data and the water-rock interaction processes assumed to be taking place. As described in Section 10.5.3, conservative geochemical tracers were used first by Hershey et al. (2004) to delineate probable water sources, flow paths, and mixing ratios. The plausible flow paths identified were then modeled using NETPATH (Plummer et al., 1994).

NETPATH performs speciation calculations to determine mineral saturation states, net mass transfer of major ions during chemical reactions along a proposed flow path, and carbon isotope fractionations for carbon (both ${ }^{14} \mathrm{C}$ and $\delta^{13} \mathrm{C}$ ) entering and exiting the groundwater. The $\delta^{13} \mathrm{C}$ values calculated by NETPATH must match the $\delta^{13} \mathrm{C}$ values measured in the final water for the model to be considered valid. By modeling the isotopic evolution of DIC that occurs between individual wells along a flow path, it is also possible to calculate the apparent groundwater travel time between those wells. The evaluation of carbon isotopes of DOC has also been used to provide estimates of apparent groundwater travel times (Rose et al., 2002; Thomas et al., 2002; Hershey et al, 2004). As discussed in Rose et al. (2002), travel time estimates based on DOC fate and transport are considered less susceptible to the complex water-rock interaction processes that can strongly influence the fractionation of DIC.

The water-rock interaction process calculations performed within NETPATH are constrained by both user-defined aquifer mineralogical data and speciation calculations (using groundwater quality data) performed by the computer program. Representative mineral phases are determined using micrographic and chemical analyses of aquifer materials. As described in Hershey et al. (2004) relevant micrographic and chemical data for aquifer mineralogy of the Frenchman Flat flow system are available in various reports (Winograd and Thordarson, 1975; Thomas et al., 1996; Warren et al., 2002; Rose et al., 2000; Rose et al., 2002; Thomas et al., 2002; and Dickerson et al., 2004). These data support the definition of chemical composition and reactive tendencies of aquifer minerals to be used during the NETPATH modeling process. Minerals that have been identified to be under-saturated (based on speciation calculations) and/or dissolving (based on micrographic observation) are constrained in NETPATH to only dissolve. Similarly, those that are super-saturated and/or precipitating can only precipitate from groundwater or form by incongruent dissolution. NETPATH 
does not calculate the amount of mineral dissolution or precipitation needed to reach mineral saturation, rather the models use the measured water chemistries along a flow path and calculate the amounts of mineral dissolution or precipitation needed to explain the difference in measured water chemistry in the final target groundwater.

The NETPATH models are limited by (1) site-specific data (including the chemical and isotopic compositions) for aquifer minerals and gases, and (2) availability of groundwater chemistry data along specific flow paths. Since NETPATH model solutions are non-unique, and more than one model can, therefore, be calculated to describe the chemical changes along a particular flow path, the evaluation of potential flow paths using conservative tracers (as discussed in Section 10.5.3) is an effective verification process.

\subsubsection{NETPATH Modeling Approach}

As discussed in Hershey et al. (2004), the major solute data for the most recent samples from each well or spring that also met charge balance criteria ( \pm 5 percent) and the mean isotopic concentrations were used for individual NETPATH simulations. The reactive or exchangeable phases used in the geochemical models include calcite, dolomite, composite volcanic glass, composite feldspar, composite clay, composite biotite, $\mathrm{SiO}_{2}$, pyrite, gypsum, halite, and $\mathrm{Ca} / \mathrm{Mg}-\mathrm{Na}$ ion exchange. Although zeolite minerals are present in the alluvium and volcanic rock, they are not included as a phase in the geochemical modeling. Previous NETPATH modeling at the NTS has demonstrated that when zeolite minerals are included, from a mass balance perspective they essentially substitute for clay minerals and essentially the same results are obtained (Rose et al.,2002 and Thomas et al., 2002). The chemical and isotopic compositions of mineral and glass phases for the HSUs present in EOIs in individual wells were used to constrain the modeling of the specific flow paths which include those wells. For flow paths where groundwater moves through more than one HSU, or wells where EOI(s) are hosted by multiple HSUs, a composite chemical composition was calculated for each mineral phase using the compositions of the individual phases from each HSU present (Hershey et al., 2004).

NETPATH calculates the percentages of the different source waters required to obtain the target groundwater composition based on the best fit to the major-ion chemistry. This approach differs from mixing models defined based on the best fit to conservative tracers. Rather than calculating the optimal mixture of groundwater and recharge sources required to produce the final mixed composition, NETPATH calculates the mixing ratios on the basis of largely nonconservative parameters that can be influenced by chemical reactions that occur along the flow path. NETPATH calculations were made both with and without including $\delta \mathrm{D}$ in the calculation (Hershey et al., 2004). As described by Hershey et al. (2004), valid NETPATH mixing models must have predicted final water compositions with calculated $\delta \mathrm{D}$ values within 3 per mil of the observed value in the target well. Final calculated $\mathrm{Cl}$ values are required to be equal to or less than the observed concentration in the target well. If these criteria are met, 
then the mineral saturations calculated by NETPATH are checked. Valid NETPATH models are those in which predicted mineral dissolution and precipitation behavior is in accordance with aqueous speciation calculations and micrographic observations of aquifer materials. Mineral saturation indices for all of the groundwater samples considered in these models are listed in Table 10-4. Mass transfer in the NETPATH models was limited to a maximum of 5.0 millimoles of a given mineral per liter of water, for a model to be considered valid. Mass transfer greater than 5 millimoles per liter is assumed to indicate unrealistically large amounts of material moving into or out of solution (Hershey et al., 2004).

Table 10-4

Saturation Indices Derived Using NETPATH

(Negative values indicate undersaturation and positive values indicate oversaturation)

\begin{tabular}{|c|c|c|c|c|c|c|c|c|}
\hline Site Name & Calcite & $\begin{array}{c}\mathrm{SiO}_{2} \\
\text { (Chalcedony) }\end{array}$ & Albite & Anorthite & K-feldspar & Ca-smectite & Illite & Dolomite \\
\hline Army \#1 WW & -0.04 & -0.02 & -2.56 & -4.37 & -1.14 & 1.80 & -0.51 & 0.01 \\
\hline Cane Spring & -0.07 & 0.70 & 0.59 & -2.06 & 2.23 & 4.82 & 4.16 & -0.51 \\
\hline Cold Creek Spring & 0.42 & -0.20 & -2.79 & -2.38 & -0.78 & 3.09 & 2.00 & 0.35 \\
\hline ER-3-1 & 0.12 & 0.20 & -0.57 & -1.75 & 0.75 & 3.90 & 3.00 & 0.28 \\
\hline ER-5-3 \#2 & 0.54 & 0.15 & -1.77 & -4.16 & -0.42 & 0.24 & -0.19 & 1.09 \\
\hline ER-5-4 \#2 & -0.43 & 0.43 & -0.14 & -4.75 & 0.40 & -1.07 & -0.88 & -1.02 \\
\hline Indian Springs & -0.06 & -0.11 & -3.28 & -3.71 & -1.45 & 1.16 & 0.13 & -0.02 \\
\hline Quartz Spring & 0.08 & 0.73 & 0.98 & -1.87 & 2.06 & 5.97 & 4.85 & 0.04 \\
\hline UE-5 PW-3 & 0.18 & 0.63 & 0.21 & -2.64 & 1.49 & 2.46 & 2.23 & 0.22 \\
\hline TW-3 & 0.22 & -0.10 & -2.19 & -3.73 & -0.90 & 0.29 & -0.18 & 0.48 \\
\hline WW-C & 0.92 & 0.26 & -0.69 & -2.84 & 0.67 & 1.62 & 1.48 & 1.77 \\
\hline WW-C1 & -0.07 & 0.13 & -1.53 & -3.36 & -0.26 & 2.06 & 1.12 & -0.11 \\
\hline
\end{tabular}

Source Hershey et al. (2004)

\subsubsection{NETPATH Geochemical Modeling Results}

A summary of the conservative tracer and NETPATH geochemical models, for the proposed groundwater sources, mixing, and flow paths, is provided in Table 10-5. Complete modeling results are presented in Hershey et al. (2004). As discussed by Hershey et al. (2004) and summarized in Table 10-5, the final mixing ratios of the contributory end-members calculated using NETPATH tend to overlap with and occasionally differ somewhat from those calculated using conservative tracers. These differences have been attributed (Hershey et al., 2004) to differences in the respective geochemical modeling approaches and validation criteria. This is also consistent with the natural variability in water chemistry within the system. While the mixing "end-members" used in the models are specific in composition, the 
Table 10-5

Summary of Conservative Mixing and NETPATH Geochemical Models (Page 1 of 2)

\begin{tabular}{|c|c|c|c|}
\hline Geochemical Model & \multicolumn{3}{|c|}{ Groundwater And/or Recharge Source and Contributory Fractions } \\
\hline \multicolumn{4}{|c|}{ North to South Flow (Frenchman Flat LTCU groundwater + Spring Mountain Recharge = Army \#1 WW } \\
\hline & ER-5-4 \#2 & Indian Springs & \\
\hline Conservative & 0.27 to 0.34 & 0.66 to 0.73 & \\
\hline \multirow[t]{2}{*}{ *NETPATH } & 0.02 to 0.09 & 0.91 to 0.98 & \\
\hline & ER-5-4 \#2 & Cold Creek Spring & \\
\hline Conservative & 0.27 to 0.34 & 0.66 to 0.73 & \\
\hline *NETPATH & 0.07 to 0.09 & 0.91 to 0.93 & \\
\hline \multicolumn{4}{|c|}{ North to Southwest Flow (Frenchman Flat LCA Groundwater + Spring Mountain Recharge + Local Recharge = Army \#1 WV } \\
\hline & ER-5-3 \#2 & Cold Creek Spring & Cane Spring \\
\hline Conservative & 0.36 to 0.40 & 0.43 to 0.48 & 0.11 to 0.21 \\
\hline \multirow{2}{*}{ *NETPATH } & 0.06 & 0.94 & 0.00 \\
\hline & ER-5-3 \#2 & Cold Creek Spring & Quartz Spring \\
\hline Conservative & 0.36 & 0.50 to 0.51 & 0.13 to 0.14 \\
\hline \multirow[t]{2}{*}{ *NETPATH } & 0 & 0.87 & 0.13 \\
\hline & ER-5-3 \#2 & Indian Spring & Cane Spring \\
\hline Conservative & 0.36 to 0.40 & 0.43 to 0.48 & 0.11 to 0.21 \\
\hline NETPATH & 0.10 to 0.14 & 0.63 to 0.90 & 0.00 to 0.23 \\
\hline \multirow[t]{2}{*}{ NETPATH (with $\delta D$ ) } & 0.08 to 0.11 & 0.85 to 0.91 & 0.01 to 0.04 \\
\hline & ER-5-3 \#2 & Indian Spring & Quartz Spring \\
\hline Conservative & 0.36 to 0.40 & 0.43 to 0.48 & 0.11 to 0.21 \\
\hline NETPATH & 0.03 to 0.05 & 0.86 to 0.89 & 0.08 to 0.09 \\
\hline \multirow[t]{2}{*}{ NETPATH (with $\delta \mathrm{D}$ ) } & 0.07 to 0.09 & 0.89 to 0.92 & 0.01 to 0.02 \\
\hline & TW-3 & Cold Creek Springs & Cane Spring \\
\hline Conservative & 0.59 to 0.67 & 0.21 to 0.24 & 0.09 to 0.19 \\
\hline NETPATH & 0.32 to 0.41 & 0.48 to 0.59 & 0.00 to 0.20 \\
\hline \multirow[t]{2}{*}{ NETPATH (with $\delta D$ ) } & 0.39 & 0.57 & 0.04 \\
\hline & TW-3 & Cold Creek Springs & Quartz Spring \\
\hline Conservative & 0.67 to 0.70 & 0.15 & 0.14 to 0.19 \\
\hline NETPATH & 0.00 to 0.41 & 0.59 to 0.97 & 0.00 to 0.13 \\
\hline \multirow[t]{2}{*}{ NETPATH (with $\delta \mathrm{D}$ ) } & 0.35 & 0.63 & 0.02 \\
\hline & TW-3 & Indian Springs & Cane Spring \\
\hline Conservative & 0.56 to 0.62 & 0.27 to 0.29 & 0.09 to 0.17 \\
\hline NETPATH & 0.38 & 0.58 & 0.04 \\
\hline \multirow[t]{2}{*}{ NETPATH (with $\delta D$ ) } & 0.37 & 0.57 & 0.06 \\
\hline & TW-3 & Indian Springs & Quartz Spring \\
\hline Conservative & 0.67 to 0.70 & 0.15 & 0.14 to 0.19 \\
\hline NETPATH & 0.03 & 0.83 & 0.14 \\
\hline NETPATH (with $\delta \mathrm{D}$ ) & 0.29 & 0.68 & 0.03 \\
\hline
\end{tabular}


Table 10-5

Summary of Conservative Mixing and NETPATH Geochemical Models

(Page 2 of 2)

\begin{tabular}{|c|c|c|}
\hline Geochemical Model & \multicolumn{2}{|c|}{ Groundwater And/or Recharge Source and Contributory Fractions } \\
\hline \multicolumn{3}{|c|}{ Bathtub Model (Less Dilute LCA Groundwater + Frenchman Flat LTCU groundwater = ER-5-3 \#2 } \\
\hline & ER-3-1 & UE-5 PW-3 \\
\hline Conservative & 0.76 to 0.87 & 0.13 to 0.24 \\
\hline *NETPATH & 0.55 to 0.57 & 0.43 to 0.45 \\
\hline \multicolumn{3}{|c|}{ Bathtub Model (Less Dilute LCA Groundwater + Frenchman Flat LTCU groundwater = WW-C1 } \\
\hline & ER-3-1 & UE-5 PW-3 \\
\hline Conservative & 0.70 & 0.30 \\
\hline NETPATH & 0.70 & 0.30 \\
\hline NETPATH (with $\delta \mathrm{D}$ ) & 0.72 & 0.28 \\
\hline \multicolumn{3}{|c|}{ Bathtub Model (Less Dilute LCA Groundwater + Frenchman Flat LTCU groundwater = WW-C } \\
\hline & ER-3-1 & UE-5C WW \\
\hline Conservative & 0.70 & 0.30 \\
\hline *NETPATH & \multicolumn{2}{|c|}{ No reasonable models } \\
\hline \multicolumn{3}{|c|}{ Less Dilute LCA Groundwater + Frenchman Flat LCA groundwater = ER-5-3 \#2 } \\
\hline & ER-3-1 & TW-3 \\
\hline Conservative & 0.77 & 0.23 \\
\hline *NETPATH & 0.47 & 0.53 \\
\hline
\end{tabular}

*No reasonable NETPATH models were obtained when $\delta D$ was included

Source: Hershey et al. (2004)

groundwater composition within each sub-region of the flow system is likely to be more variable and, therefore, cannot be completely described by a small number of widely spaced wells.

Groundwaters in the Frenchman Flat area generally contain very low $(<10 \mathrm{pmc})$ amounts of ${ }^{14} \mathrm{C}$. Analytical precision of $10 \mathrm{w}{ }^{14} \mathrm{C}$ waters has an age uncertainty of about 1,000 years with a measured ${ }^{14} \mathrm{C}$ value of $10 \pm 1 \mathrm{pmc}$. Thus, these calculated ages likely have a variability that exceeds several thousand years (Hershey et al., 2004). Additionally, NETPATH models often have calculated $\delta^{13} \mathrm{C}$ values that are heavier (less negative) than the measured values indicating that the NETPATH models are not valid for the carbon containing phases, and should not be used to calculate ${ }^{14} \mathrm{C}$ ages. Isotopic exchange of Carbon- 13 with calcite provides a mechanism for producing lighter $\delta^{13} \mathrm{C}$ in the water without changing the macro chemistry. Carbon-13 values that are less negative than measured values indicate that (1) the carbon containing phases in the model are not all accounted for, (2) the $\delta^{13} \mathrm{C}$ values used for calcite and dolomite in the models are not accurate or have a greater variability than measured, (3) the groundwaters chosen for the models are 
not the representative of the true mixing waters, or (4) some combination of the above factors.

\subsubsection{North-to-South Flow}

As described in Section 10.5.3, no plausible north-to-south pathways from the alluvial aquifer to the LCA south of Frenchman Flat were identified using the existing conservative tracer data. The only plausible north-to-south flow derived with the available data is a mixture of Indian Springs groundwater (Spring Mountains recharge) and ER-5-4 \#2 groundwater to produce Army \#1 WW. Conservative tracers predict a mixture of 66 to 73 percent Indian Springs with 27 to 34 percent ER-5-4 \#2 to produce the groundwater composition at Army \#1 WW (Table 10-5). The most reasonable NETPATH models produce a mixture of 91 to 98 percent Spring Mountains recharge (Indian or Cold Creek springs) with 2 to 9 percent ER-5-4 \#2 (Table 10-5). When $\delta \mathrm{D}$ was included in the NETPATH model as a conservative mixing component, no reasonable models were found. A model calculated groundwater travel time for the mixture of groundwaters flowing to Army \#1 WW is approximately 4,300 years (using Indian Springs to represent Spring Mountain recharge). The 4,300 year travel time is for the mixture of Indian Springs and ER-5-4 \#2 groundwaters (Table 10-5). The calculated and measured $\delta^{13} \mathrm{C}$ values were the same for this NETPATH model (Hershey et al., 2004).

The conservative tracer modeling also considered previous investigations that indicated groundwater flowing southwest out of Frenchman Flat mixes with groundwater recharged in the Spring Mountains before it reaches Army \#1 WW (Winograd and Thordarson, 1975; Thomas et al., 1996; Hershey and Acheampong, 1997). Three component mixing models using Frenchman Flat LCA water (from wells ER-5-3 \#2, WW-C, WW-C1, and TW-3), Spring Mountain recharge (Indian Springs and Cold Creek Springs), and local recharge (Cane spring and Quartz spring) were developed to obtain the groundwater chemical compositions observed at Army \#1 WW. The conservative tracer modeling produced significantly different results for the mixture depending upon which well was used to represent Frenchman Flat LCA Water. First, using ER-5-3 \#2 (or WW-C) as the LCA water, a mixture of 36 to 40 percent Frenchman Flat LCA with 43 to 51 percent Spring Mountains recharge and 11 to 21 percent local recharge produced Army \#1 WW. NETPATH models resulted in a mixture of 0 to 14 percent Frenchman Flat LCA (ER-5-3\#2) with 63 to 94 percent Spring Mountains and 0 to 23 percent local recharge for Army \#1 WW (Table 10-5). Second, using the conservative tracer model with TW-3 as the LCA water, a mixture of 56 to 70 percent Frenchman Flat LCA with 15 to 29 percent Spring Mountains and 9 to 19 percent local recharge produced Army \#1 WW. The mixture of waters produced using NETPATH ranged from 0 to 41 percent Frenchman Flat LCA (TW-3) with 48 to 97 percent Spring Mountains recharge, and 0 to 20 percent local recharge. When using Sr data, three-component mixing with TW-3 representing Frenchman Flat LCA water, 10 to 20 percent TW-3 with Spring Mountains and local recharge varying between 0 and 100 percent produced Army \#1 WW. Given the uncertainty in the quality of the TW-3 water sample, the mixing ratios based on well ER-5-3 \#2 (or the chemically similar WW-C and $\mathrm{WW}-\mathrm{C} 1$ ) probably give the more realistic results. A model calculated 
groundwater travel time for the mixture of groundwaters flowing to Army \#1 WW is about 10,000 years. Most of the 10,000 year travel time can be attributed to the local recharge (Cane and Quartz springs), which contributes as much as 21 percent of the water at Army \#1 WW. This local recharge contains 93 to $98 \mathrm{pmc}{ }^{14} \mathrm{C}$.

\subsubsection{West-to-East Flow}

Available water chemistry and isotopic data do not support a west to east flow path as stated previously using conservative tracers and $\mathrm{Sr}$.

\subsubsection{Bathtub Model}

Conservative tracers were used to evaluate several potential flow paths from the alluvium through the volcanic HSUs to the LCA. First, the most concentrated groundwater end-member in the LCA within the study region, ER-3-1, was mixed with UE-5 PW-3 completed in the volcanic TMA, to produce the observed water chemistry at ER-5-3 \#2 (Table 10-5). Taking into account all valid models determined from both conservative tracers and NETPATH modeling, the mixing ratios for vertical flow included 55 to 87 percent ER-3-1 and 13 to 45 percent UE-5 PW-3 to produce ER-5-3 \#2 (Table 10-5). NETPATH model solutions were obtained by allowing a very small amount of calcite $(<0.05$ millimoles per liter) to precipitate, although all waters were above saturation with respect to calcite (Table 10-4). When $\delta \mathrm{D}$ was included in the NETPATH model as a conservative mixing component, no reasonable models were found. Strontium isotopic data indicate that there is no vertical flow. A model calculated groundwater travel time for the mixture of groundwaters flowing to ER-5-3 \#2 is 3,500 to 3,700 years; however, modeled $\delta^{13} \mathrm{C}$ values are more positive than measured indicating that the carbon fluxes in the model, or the $\delta^{13} \mathrm{C}$ values of the carbon containing phases, may not be correct, making the travel times only approximate (Hershey et al., 2004).

Both the conservative tracer and NETPATH models produced a mixture of about 30 percent UE-5 PW-3 and 70 percent ER-3-1 to produce WW-C1 water (Table 10-5). Similar models were produced when $\delta \mathrm{D}$ was included in the NETPATH model. However, the models including $\delta \mathrm{D}$ always contained at least two phases with small amounts of mass transfer $(<0.05$ millimoles $)$ out of solution that should have been dissolving. Although a similar mixing proportion was observed for the conservative tracer modeling of WW-C, no valid NETPATH models were produced (Table 10-5).

Another potential mixture of waters that could produce the LCA water in ER-5-3 \#2 includes only LCA waters with no vertical leakage. The LCA mixture of waters obtained using the conservative tracer model included 77 percent ER-3-1 (representing flow from the north) and 23 percent TW-3 (representing flow from the east) to produce the water chemistry observed at ER-5-3 \#2 (Table 10-5). Using Sr data, a mixture of about 40 percent ER-3-1 with 60 percent TW-3 produces the ${ }^{87} \mathrm{Sr} /{ }^{86} \mathrm{Sr}$ value in wells ER-5-3 \#2, WW-C, and WW-C1. NETPATH 
resulted in a mixture of 47 percent ER-3-1 with 53 percent TW- 3 to produce ER-5-3 \#2. The best model solution had a small amount of calcite $(0.14$ millimoles per liter) precipitating, although all waters were above saturation with respect to calcite (Table 10-4). A model calculated groundwater travel time for the mixture of groundwaters flowing to ER-5-3 \#2 is about 15,000 years, because of the high ${ }^{14} \mathrm{C}$ value TW-3 (36.9 pmc) as compared to all other LCA groundwaters in the Frenchman Flat and nearby areas $(<10 \mathrm{pmc})$. There is only one ${ }^{14} \mathrm{C}$ sample from TW-3, a bailed sample, so it is possible that the measured ${ }^{14} \mathrm{C}$ activity of this sample is not accurate. Therefore, the calculated age may not be valid. When $\delta \mathrm{D}$ was included in the NETPATH model as a conservative mixing component, no reasonable models were found.

\subsection{Limitations}

The ability to evaluate flow paths using geochemical data was limited by two factors: (1) existing wells are not evenly distributed geographically within the study area, and (2) the limited number of wells completed in the LCA, both within the Frenchman Flat basin and to the south of the basin. Compounded by the lack of stable isotope data (i.e., Wells TW-F and WW-1) or questionable quality of available stable isotope data (i.e., Well TW-3) for a few of the wells within Frenchman Flat.

In addition to the factors discussed above, a lack of discrete depth sampling was also noted. Water quality samples are typically collected as composite samples either from wells with single completions that transect multiple hydrostratigraphic unit boundaries or from wells with multiple completions that are all pumped simultaneously. The available groundwater chemistry data provide limited insights into vertical groundwater variability. Flow logging has demonstrated that, within multiple completion wells or wells with large effective open intervals that cross multiple HSUs, water production is often dominated by a single HSU. Corresponding depth discrete water quality sample data are very sparse. Geochemical evaluations have, therefore, not been able to directly support or corroborate flow logging results. Depth-discrete samples systematically collected from existing multiple completion wells and analyzed for the suite of geochemical parameters necessary to support the evaluation of water sources, flow paths, or time scales of movement would better support this evaluation.

\subsection{Summary}

The recent geochemical data analysis of Hershey et al. (2004) focused on testing potential groundwater flowpaths that were identified during the Frenchman Flat Phase I groundwater modeling effort. These pathways included:

(1) north-to-south flow, (2) east-to-west flow, and (3) vertical transport from the alluvial/volcanic aquifers to the LCA. In general, the analysis of conceptual groundwater flowpaths was limited by an uneven spatial distribution of wells within the study area and by a paucity of wells completed in the LCA. In addition, available water-level data are not consistent with one preferred direction of 
groundwater flow within the alluvial and volcanic units. Nevertheless, some general conclusions were drawn from the geochemical data assessment that will help delimit the number of conceptual models that need to be considered during subsequent flow and transport modeling efforts.

\section{North-to-South Flowpath}

This potential flowpath has perhaps the most optimal distribution of well sites for testing geochemical models, particularly within the alluvial aquifer in Frenchman Flat. Nevertheless, conservative tracer data (including $\delta \mathrm{D}, \delta^{18} \mathrm{O}$, and $\mathrm{Cl}$ ) do not support the presence of a major north-to-south flowpath within the alluvial aquifer. Similarly, a north-to-south flowpath from the alluvial aquifer to the down gradient LCA at Army \#1 Water Well could not be substantiated. The conservative tracer data yielded one successful north-to-south flowpath model involving a mixture of approximately 30 percent ER-5-4 \#2 groundwater +70 percent Spring Mountains water to produce the Army \#1 Water Well composition. This result suggested a relatively deep lateral pathway through the volcanic aquifers beneath Frenchman Flat was possible. However, this model was not supported by subsequent geochemical models, which required an ER-5-4 \#2 mixing component of $<10$ percent. The strontium isotopic data also tended to refute this model. On the basis of these results, it can be concluded that southward lateral transport of groundwater out of the alluvial or volcanic units in Frenchman Flat is improbable.

Geochemical models involving groundwater flow within the Frenchman Flat LCA southwest toward Ash Meadows were also considered. Conservative tracer models generally required a mixture of approximately 35 to 50 percent Frenchman Flat LCA (ER-5-3 \#2 or WW-C), approximately 10 to 50 percent Spring Mountains (Cold Creek or Indian Spring), and approximately 13 to 44 percent local recharge (represented by local springs) to produce the down gradient water chemistry at Army \#1 Water Well. Subsequent geochemical models using the same end-members predicted a much smaller Frenchman Flat LCA component (maximum 14 percent) and a larger Spring Mountains component (63 to 94 percent). Substituting Well TW-3 as the assumed Frenchman Flat LCA component did not improve the agreement in modeling results. This lack of consistency implies additional processes may be occurring that were not taken into account in the models.

Chemical reactions and/or mixing processes may go undetected due to large geographic distances between the assumed groundwater mixing end-members. For example, Moran and Rose (2003) recently used ${ }^{36} \mathrm{Cl}$ data to show that chloride concentrations gradually increase along regional LCA groundwater flowpaths. With regard to the present study, the lack of sampling locations between Indian Spring and Army \#1 Water Well translates to a large uncertainty regarding the evolution in LCA groundwater chloride values along the Spring Mountains pathway. Since chloride is one of the constituents used in conservative tracer models, this uncertainty may impact geochemical mixing model estimates.

Water-level data are generally consistent with a north-to-south LCA flowpath within the southeastern part of the NTS. Geochemical data tend to support this conclusion, although the fractional amount of Frenchman Flat LCA groundwater 
that contributes to the down gradient flux remains uncertain. At Army \#1 Water Well, conservative tracer models predict a minimum of approximately 35 percent Frenchman Flat LCA water whereas reactive transport models predict a maximum of approximately 14 percent. The "truth" may lie somewhere between. Dissolved inorganic ${ }^{14} \mathrm{C}$ travel times calculated by geochemical modeling for the Frenchman Flat to Army \#1 Water Well LCA flowpath ranged from 4,300 to 6,800 years.

\section{East-to-West Flowpath}

West-to-east flow in the alluvial aquifer to the LCA in eastern Frenchman Flat could not be substantiated with conservative tracers. Mixing models using groundwater from the CP Basin in western Frenchman Flat were unsuccessful because this water is isotopically heavy in deuterium and ${ }^{18} \mathrm{O}$, and is distinct from other Frenchman Flat groundwater. Evidence for an east-to-west flowpath was also lacking in the major ion chemistry and strontium isotope data. It should be noted, however, that it was not possible to adequately test this flowpath due to a paucity of appropriate well locations.

\section{Vertical Transport (“Bathtub Model”)}

The possibility that groundwater is moving in a vertical direction from the alluvial and volcanic aquifers into the LCA could only be tested at one location within the Frenchman Flat basin: at well ER-5-3 \#2. Mixing models used ER-3-1 groundwater as the upgradient (undiluted) LCA component, and UE-5 PW-3 or UE-5c WW as the alluvial/volcanic mixing component. Using conservative tracers, the relative mixing proportions were estimated to be approximately 76 to 87 percent undiluted LCA groundwater and approximately 13 to 24 percent alluvial/volcanic groundwater. However, these models were not supported by other lines of geochemical evidence. In contrast, a conceptually similar mixing model was successfully developed involving the mixing of 70 percent ER-3-1 + 30 percent UE-5 PW-3 to derive the composition of Water Well C-1, in southernmost Yucca Flat. The conservative tracer and chemical models were in good agreement in this case. Although the Sr isotope data did not support this conceptual flow path, the development of a consistent set of conservative tracer and geochemical transport models for Water Well C-1 suggests that vertical flow is a potential viable process in southern Yucca Flat. Given the similarities in hydrogeologic setting between southern Yucca Flat and Frenchman Flat, it is recommended that the vertical flow mechanism should also be considered during Phase II Frenchman Flat CAU flow and transport modeling. 


\subsection{References}

ARL/SORD, see Air Resources Laboratory/Special Operations and Research Division.

ASTM, see American Society for Testing and Materials.

Air Resources Laboratory/Special Operations and Research Division. 2004. "Air Resources Laboratory/Special Operations and Research Division Web Site." As accessed on 5 May at http://www.sord.nv.gov.

American Society for Testing and Materials. 1993. Standard Guide for Application of a Ground-Water Flow Model to a Site-Specific Problem, ASTM D 5447-93. Philadelphia, PA.

American Society for Testing and Materials. 2002a. Standard Guide for Comparing Ground-Water Flow Model Simulations to Site-Specific Information, ASTM D 5490-93. Philadelphia, PA.

American Society for Testing and Materials. 2002b. Standard Guide for Defining Boundary Conditions in Ground-Water Flow Modeling Designation, ASTM D 5609-94. Philadelphia, PA.

American Society for Testing and Materials. 2002c. Standard Guide for Defining Initial Conditions in Ground-Water Flow Modeling, ASTM D 5610-94. Philadelphia, PA.

American Society for Testing and Materials. 2002d. Standard Guide for Conducting a Sensitivity Analysis for a Ground-Water Flow Model Application, ASTM D 5611-94. Philadelphia, PA.

American Society for Testing and Materials. 2002e. Standard Guide for Documenting a Ground-Water Flow Model Application, ASTM D 5718-95. Philadelphia, PA.

American Society for Testing and Materials. 2002f. Standard for Calibrating a Ground-Water Flow Model Application, ASTM D 5981-96.

Philadelphia, PA.

Arteaga, F.E., C.S. Savard, M.E. Johnson, and J.C. Stone. 1991. Hydrogeologic Data from Selected Wells and Test Holes in and Adjacent to the Nevada Test Site, Nye County, Nevada, Through 1986. USGS Open-File Report 87-536. Denver, CO: U.S. Geological Survey. 
BN, see Bechtel Nevada.

Baugh, R. Bechtel Nevada. 2004. Personal communication from Ron Baugh to William Fryer (SNJV) regarding discharges into surface impoundments of water pumping from water supply wells, 3 November. Las Vegas, NV.

Bechtel Nevada. 1996. "Nevada Test Site Region Image Map," SIGIS-NTS-96038. Las Vegas, NV: Remote Sensing Laboratory.

Bechtel Nevada. 2002. Hydrostratigraphic Model for the Groundwater Flow and Contaminant Transport Model of Corrective Action Unit 98: Frenchman Flat, Nye County, Nevada. Prepared for U.S. Department of Energy, National Nuclear Security Administration Nevada Operations Office. Las Vegas, NV.

Bechtel Nevada. 2004a. A Hydrostratigraphic Model and Alternatives for the Groundwater Flow and Contaminant Transport Model of Corrective Action Unit 98: Frenchman Flat, Clark, Lincoln, and Nye Counties, Nevada. Prepared for U.S. Department of Energy, National Nuclear Security Administration Nevada Operations Office. Las Vegas, NV.

Bechtel Nevada. 2004b. Completion Report for Well Cluster ER-5-3. Las Vegas, NV.

Bechtel Nevada. 2004c. Completion Report for Well Cluster ER-5-4. Las Vegas, NV.

Benjamin, J.R., and C.A. Cornell. 1970. Probability, Statistics, and Decision for Civil Engineers. New York, NY: McGraw-Hill Book Co.

Blankennagel, R.K., and J.E. Weir, Jr. 1973. Geohydrology of the Eastern Part of Pahute Mesa, Nevada Test Site, Nye County, Nevada, USGS Professional Paper 712-B. Denver, CO: U.S. Geological Survey.

Borg, I.Y., R. Stone, H.B. Levy and L.D. Ramspott (1976). Information Pertinent to the Migration of Radionuclides in Groundwater at the Nevada Test Site. Part 1: Review and Analysis of Existing Information, UCRL-52078, Pt. 1. Livermore, CA: Lawrence Livermore National Laboratory.

Bowen, S.M., D.L. Finnegan, J.L. Thompson, C.M. Miller, P.L. Baca, L.F. Olivas, C.G. Geoffrion, D.K. Smith, W. Goishi, B.K. Esser, J.W. Meadows, N. Namboodiri, and J.F. Wild. 2001. Nevada Test Site Radionuclide Inventory, 1951-1992, LA-13959-MS. Los Alamos, NM: Los Alamos National Laboratory.

Bright, D.J., S.A. Watkins, and B.A. Lisle. 2001. Analysis of Water Levels in the Frenchman Flat Area, Nevada Test Site, USGS Water-Resource Investigations Report 00-4272. Denver, CO: U.S. Geological Survey. 
Bryant, E.A. 1992. The Cambric Migration Experiment, A Summary Report. LA-12335-MS. Los Alamos, NM: Los Alamos National Laboratory.

Buddemeier, R.W. (Comp.). 1988. Hydrology and Radionuclide Migration Program 1985-1986 Progress Report, UCRL-53779. Livermore, CA: Lawrence Livermore National Laboratory.

Buddemeier, R.W., and D. Isherwood. (Comp.). 1985. Radionuclide Migration Project 1984 Progress Report, UCRL-53628. Livermore, CA: Lawrence Livermore National Laboratory.

Burchfiel, B.C., R.J. Fleck, D.T. Secor, R.R. Vincelette, and G.A. Davis. 1974. "Geology of the Spring Mountains, Nevada." In Geological Society of America Bulletin, 85(7): 1013-1022. Boulder, CO: Geological Society of America, Inc.

CRWMS M\&O, see Civilian Radioactive Waste Management System Management and Operating Contractor.

CRC. 1992. CRC Handbook of Chemistry and Physics, $73^{\text {rd }}$ edition. Boca Raton, FL: CRC Press, Inc.

Chapman, J.B., and B.F. Lyles. 1993. Groundwater Chemistry at the Nevada Test Site: Data and Preliminary Interpretations, Publication No. 45100. Las Vegas, NV: Desert Research Institute.

Civilian Radioactive Waste Management System Management and Operating Contractor. 2000. Calibration of the Site-Scale Saturated Zone Flow Model, MDL-NBS-HS-000011, REV 00. Las Vegas, NV.

Claassen, H.C. 1973. Water Quality and Physical Characteristics of Nevada Test Site Water Supply Wells, USGS Open File Report 474-158. Denver, CO: U.S. Geological Survey.

Claassen, H.C. 1985. Sources and Mechanisms of Recharge for Ground Water in the West-Central Amargosa Desert, Nevada - A Geochemical Interpretation, USGS Professional Paper 712-F. Denver, CO: U.S. Geological Survey.

Cook, P., and J.K. Bohlke. 2000. "Determining Timescales for Groundwater Flow and Solute Transport." In Environmental Tracers in Subsurface Hydrology, pp.1-30. Boston, MA: Kluwer.

Craig, H. 1961. "Isotopic Variations in Meteoric Waters." In Science, Vol. 133: 1702-1703. Washington, DC: American Association for the Advancement of Science.

Czarnecki, J.B. 1985. Simulated Effects of Increased Recharge on the Ground-Water Flow System of Yucca Mountain and Vicinity, Nevada-California, USGS Water-Resource Investigations Report 84-4344. Denver, CO: U.S. Geological Survey. 
DOE, see U.S. Department of Energy.

DOE/NV, see U.S. Department of Energy, Nevada Operations Office.

D’Agnese, F.A., C.C. Faunt, A.K. Turner, and M.C. Hill. 1997. Hydrogeologic Evaluation and Numerical Simulation of the Death Valley Regional Ground-water Flow System, Nevada and California, USGS Water Resource Investigation Report 96-4300. Denver, CO: U.S. Geological Survey.

Daley, C., R.P. Nielson, and D.L. Phillips. 1994. "A Statistical-Topographic Model for Mapping Climatological Precipitation over Mountainous Terrain." In Journal of Applied Meteorology, Vol, 33:140-158. Boston, MA: American Meteorological Society.

Dash, Z.V. 2000. Validation Test Report (VTR) for the FEHM Application Version 2.10, Yucca Mountain Project Identification Numbers SAN: LANL-1999-046; STN: 10086-2.10-00. Los Alamos, NM: Los Alamos National Laboratory.

Dash, Z.V. 2001. Validation Test Report (VTR) for the FEHM Application Version 2.12, Yucca Mountain Project Identification Numbers SAN: LANL-2001-133; STN: 10086-2.12-00. Los Alamos, NM: Los Alamos National Laboratory.

Dash, Z.V., B.A. Robinson, and G.A. Zyvoloski. 1997. Software Requirements, Design, and Verification and Validation for the FEHM ApplicationA Finite-Element Heat- and Mass-Transfer Code, LA-13305-MS. Los Alamos, NM: Los Alamos National Laboratory.

Dettinger, M.D. 1989. "Reconnaissance Estimates of Natural Recharge to Desert Basins in Nevada, U.S.A., by Using Chloride-Balance Calculations." In Journal of Hydrology, Vol. 106: 55-78. New York, NY: Elsevier Publishing Co.

Dickerson, R., T. Rose, and G. Eaton. 2004. Letter Report: Underground Test Area Project, Mineralogical and Isotopic Analysis of Fracture-Coating and Alteration Minerals in the Yucca Flat Tuff Confining Unit, Nevada Test Site. Prepared for U.S. Department of Energy. Livermore, CA: Lawrence Livermore National Laboratory.

Doherty, J. 2002. Manual for PEST, $5^{\text {th }}$ edition. Brisbane, Australia: Watermark Numerical Computing.

Dynamic Graphics, Inc. 2002. Earth Vision 7: Software for 3-D Modeling and Visualization. Alameda, CA.

Eakin, T.E., G.B. Maxey, T.W. Robinson, J.C. Fredericks, and O.J. Loeltz. 1951. "Contributions to the Hydrology of Eastern Nevada." In Water Resources Bulletin, No. 12. Carson City, NV: State of Nevada, Office of the State Engineer, U.S. Geological Survey. 
Eriksson E., and V. Khunakasem. 1969. "Chloride Concentrations in Groundwater, Recharge Rate and Rate of Deposition of Chloride in the Israel Coastal Plain.” In Journal of Hydrology, 7:178-197. New York, NY: Elsevier Publishing Company.

FFACO, see Federal Facility Agreement and Consent Order.

Fabryka-Martin, J., S.J. Wightman, W.J. Murphy, M.P. Wickham, M.W. Caffee, G.J. Nimz, J.R. Southon and P. Sharma 1993. "Distribution of Chlorine-36 in the Unsaturated Zone at Yucca Mt.: An Indicator of Fast Transport Paths." In FOCUS'93: Site Characterization and Model Validation, Las Vegas, NV, 26-29 September 1993.

Faunt, C.C., D'Agnese, F.A., and Turner, A.K. 1997. A Hydrogeologic Map of the Death Valley Region, Nevada and California, Developed Using GIS Techniques, USGS Water Resource Investigation Report 95-4016. Denver, CO: U.S. Geological Survey.

Faure, G. 1986. Principles of Isotope Geology, $2^{\text {nd }}$ edition. New York: John Wiley and Sons.

Federal Facility Agreement and Consent Order. 1996 (as amended). Agreed to by the State of Nevada, the U.S. Department of Energy, and the U.S. Department of Defense.

Federal Facility Agreement and Consent Order, Appendix VI. 2000. Agreed to by the State of Nevada, the U.S. Department of Energy, and the U.S. Department of Defense. Revision No. 1.

Ferguson, J.F., A.H. Cogbill, and R.G. Warren. 1994. "A GeophysicalGeological Transect of the Silent Canyon Caldera Complex, Pahute Mesa, Nevada." In Groundwater, Vol. 99 (B3): 4323-4339. Columbus, OH: Groundwater Publishing Company.

Fiero, G.W., Jr., J.R. Illian, G.A. Dinwiddie, and L.J. Schroder. 1974. Use of Hydrochemistry for Interpreting Ground-Water Flow Systems in Central Nevada, USGS 474-178. Denver, CO: U.S. Geological Survey.

Fouty, S.C. 1989. Chloride Mass-balance as a Method for Determining Long-Term Groundwater Recharge Rates and Geomorphic-Surface Stability in Arid and Semi-Arid Regions, Whiskey Flat and Beatty, Nevada. Tucson, AZ: University of Arizona, Master of Science Thesis.

Freeze, R.A., and J.A. Cherry. 1979. Groundwater. Englewood Cliffs, NJ: Prentice Hall.

Freeze, R.A., J. Massmann, L. Smith, T. Sperling, and B. James. 1990. "Hydrogeological Decision Analysis: I. A Framework." In Groundwater, Vol. 28: (5) 738-766. Columbus, OH: Groundwater Publishing Company. 
French, R.H., Desert Research Institute. 1996. Memorandum to E. Jacobson, Desert Research Institute, regarding additional high altitude precipitation data, 21 August. Las Vegas, NV.

Garber, M.S., and W. Thordarson. 1962. Ground Water Test Well C, Nevada Test Site, Nye County, Nevada, A Summary of Lithologic Data, Aquifer Tests, and Well Construction, USGS TEI-818. Denver, CO: U.S. Geological Survey.

George, D.C. 1997. Unstructured 3D Grid Toolbox for Modeling and Simulation, LA-UR-97-3052. Los Alamos, NM: Los Alamos National Laboratory.

Gillespie, D., D. Donithan, and P. Seaber. 1996. Nevada Test Site Water-Supply Wells, DOE/NF/10845.56, Publication No. 45138. Las Vegas NV: Desert Research Institute.

Gonzales, J.L., S.L. Drellack, Jr., and M.J. Townsend. / Bechtel Nevada, Geology/Hydrology Group. 1998. Descriptive Narrative for the Hydrogeologic Model of the Yucca Flat Corrective Action Unit: An Interim Report. U.S. Department of Energy, Nevada Operations Office. Las Vegas, NV: Bechtel Nevada

Guth, P.L. 1986. Bedrock Geologic Map of the Black Hills, 1:24,000 Quadrangle, Nevada, USGS Open-File Map 86-438. Las Vegas, NV: U.S. Geological Survey.

Halford, K.J., U.S. Geologic Survey. 2002. Memorandum to S. Reiner, (USGS) entitled "Ground Water-Approval of Aquifer-Test Results; for Test Well WW-4A Welded-Tuff Aquifer, in Area 6, Nevada Test Site, Nye County, Nevada," July 12. Carson City, NV.

Halford, K.J., U.S. Geologic Survey. 2003. Memorandum to S. Reiner, (USGS) entitled "Ground Water-Approval of Aquifer-Test Results; for Test Well WW-5C Alluvial-Fill Aquifer, in Area 5, Nevada Test Site, Nye County, Nevada," July 16. Carson City, NV.

Harbaugh, A.W., Banta, E.R., Hill, M.C., and McDonald, M.G. 2000. MODFLOW-2000, the U.S. Geological Survey Modular Ground-water Model -- User Guide to Modularization Concepts and the Ground-water Flow Process, USGS Open-File Report 00-92. Reston, VA: U.S. Geological Survey.

Harbaugh, A.W. 1990. A Computer Program for Calculating Subregional Water Budgets Using Results from the U.S. Geological Survey Modular Three-dimensional Ground-water Flow Model, USGS Open-File Report 90-392. Reston, VA: U.S. Geological Survey.

Hardman, G. 1936. Nevada Precipitation and Acreages of Land by Rainfall Zones, Bulletin 183. Reno, NV: U.S. Department of Agriculture, University of Nevada Experimental Station. 
Hardman, G. 1965. Nevada Precipitation and Acreages of Land by Rainfall Zones. Reno, NV: U.S. Department of Agriculture, University of Nevada Experimental Station.

Harrill, J.R., J.S. Gates, and J.M. Thomas. 1988. "Major Groundwater Flow Systems in the Great Basin Region of Nevada, Utah, and Adjacent States." In U.S. Geological Survey Hydrologic Investigations Atlas, ATLAS-HA-694-C, Scale: 1,000,000. Denver, CO: U.S. Geological Survey.

Hem, J.D. 1985. Study and Interpretation of the Chemical Characteristics of Natural Water, USGS Water-Supply Paper 2254, 3rd. ed., p. 118. Denver, CO: U.S. Geological Survey.

Hershey, R.L., J.M. Thomas, T.P. Rose, J.B. Paces, I.M. Farnham and F.C. Benedict Jr. 2004. Evaluation of Groundwater Movement in the Frenchman Flat CAU Using Geochemical and Isotopic Analysis, Desert Research Institute, Division of Hydrologic Sciences, Publication No. 45207. Las Vegas, NV: Desert Research Institute.

Hershey, R.L. and S.Y. Acheampong. 1997. Estimation of Groundwater Velocities from Yucca Flat to the Amargosa Desert Using Geochemistry and Environmental Isotopes, Publication No. 45157. Las Vegas, NV: Desert Research Institute.

Hevesi, J.A., A.L. Flint, and J.D. Istok. 1992. "Precipitation Estimation in Mountainous Terrain Using Multivariate Geostatistics, Part II: Ishohetal Maps.” In Journal of Applied Meteorology, 31(7): 677-688. Boston, MA: American Meteorological Society.

Hevesi, J.A., A.L. Flint, and L.E. Flint. 2003. Simulation of Net Infiltration Using A Distributed Parameter Watershed Model for the Death Valley Regional Flow System, Nevada and California, U.S.Geological Survey report attached to a memorandum to files by W. Drici (Shaw Environmental, Inc.), 31 July. Las Vegas, NV.

Hockett, S.L. and R.H. French. 1998. Evaluation of Recharge Potential at Crater U5a (WISHBONE), DOE/NV/11508-32, Publ. \#45160. Las Vegas, NV: Desert Research Institute, Water Resources Center.

Hood. J.W. 1961. Water Wells in Frenchman and Yucca Valleys, Nevada Test Site, Nye County, Nevada. USGS TEI-788. Denver CO: U.S. Geological Survey.

IT, see IT Corporation.

IT Corporation. 1993. Well Recompletion Report for Water Well 5A, Groundwater Characterization Project, DOE/NV/10972-21. Las Vegas, NV. 
IT Corporation. 1996a. Groundwater Recharge and Discharge Data Documentation Package (Phase I Data Analysis Documentation, Volume III). Prepared for the U.S. Department of Energy, Nevada Operations Office. Las Vegas, NV.

IT Corporation. 1996b. Hydrologic Parameter Data Documentation Package (Phase 1 Data Analysis Documentation, Volume IV). Prepared for the U.S. Department of Energy, Nevada Operations Office. Las Vegas, NV.

IT Corporation. 1996c. Potentiometric Data Documentation Package (Phase 1 Data Analysis Documentation, Volume II). Prepared for the U.S. Department of Energy, Nevada Operations Office. Las Vegas, NV.

IT Corporation. 1996d. Regional Geologic Model Data Documentation Package (Phase 1 Data Analysis Documentation, Volume I), ITLV/10972-181. Prepared for the U.S. Department of Energy, Nevada Operations Office. Las Vegas, NV.

IT Corporation. 1997a. Groundwater Flow Model Documentation Package (Phase I Data Analysis Documentation, Volume VI). Prepared for the U.S. Department of Energy, Nevada Operations Office. Las Vegas, NV.

IT Corporation. 1997b. Value of Information Analysis for Corrective Action Unit No. 98: Frenchman Flat, ITLV/10972-192. Prepared for the U.S. Department of Energy, Nevada Operations Office. Las Vegas, NV.

IT Corporation. 1998. Underground Test Area Project Corrective Action Unit 98: Frenchman Flat Data Analysis Task: Vol. I - Hydrostratigraphic Model Documentation Package, DOE/NV/13052-044. Prepared for U.S. Department of Energy, Nevada Operations Office. Las Vegas, NV.

IT Corporation. 1999a. External Peer Review Group Report on Frenchman Flat Data Analysis and Modeling Task, Underground Test Area Project, Revision No. 0, ITLV/13052-077. Las Vegas, NV.

IT Corporation. 1999b. Underground Test Area Project Corrective Action Unit 98: Frenchman Flat, Vol. II - Groundwater Data Documentation Package, Rev. 0, DOE/NV/13052-044-V2. Prepared for U.S. Department of Energy, Nevada Operations Office. Las Vegas, NV.

IT Corporation. 1999c. Underground Test Area Project Corrective Action Unit 98: Frenchman Flat, Vol. III - Groundwater Flow and Contaminant Transport Model Data Documentation Package. Rev. 0. Prepared for U.S. Department of Energy, Nevada Operations Office. Las Vegas, NV.

IT Corporation. 2000a. Frenchman Flat Hydrogeologic Investigation Wells Drilling and Completion Criteria, ITLV/13052-094. Las Vegas, NV. 
IT Corporation. 2000b. Lessons Learned from the Frenchman Flat Corrective Action Groundwater Flow and Radionuclide Transport Model.

Las Vegas, NV.

IT Corporation. 2001a. Addendum to the Frenchman Flat Hydrogeologic Investigation Wells Drilling and Completion Criteria, ITLV/13052-094-Rev. 1-ADD. Las Vegas, NV.

IT Corporation. 2001b. Modeling Approach for Corrective Action Unit 98, Frenchman Flat, ITLV/13052--141. Las Vegas, NV.

Jacobson, B., Desert Research Institute. 1996. Personal Communication from B. Jacobson to O. Drici (IT Corporation) regarding Precipitation Data, 20 September. Reno, NV.

James, J.W., T. Hendricks, and K. Sorenson. 1993. Climate of the Death Valley Region, Nevada/California. Prepared for the National Park Service. Reno, NV: State of Nevada, Office of the State of Climatologist.

Kalin, R.M. 2000 Radiocarbon dating of groundwater systems. In: Cook, P.G. and Herczeg, A.L. (eds.), Environmental Tracers in Subsurface Hydrology, pp: 111-144. Boston, MA: Kluwer.

LLNL, see Lawrence Livermore National Laboratory.

Laczniak, R.J., J. Cole, D.A. Sawyer, and D.A. Trudeau. 1996. Summary of Hydrogeologic Controls and Ground-Water Flow at the Nevada Test Site, Nye County, Nevada, USGS-Water Resource Investigation Report 96-4109. Carson City, NV: U.S. Geological Survey.

Laczniak, R.J., J.L. Smith, P.E. Elliott, G.A. DeMeo, M.A. Chatigny, and G. Roemer. 2001. Ground-Water Discharge as Determined from Estimates of Evapotranspiration, Death Valley Regional Flow System, Nevada and California, USGS-Water Resource Investigation Report 01-4195. Carson City, NV: U.S. Geological Survey

Lamb, T.W. 1951. Soil Testing for Engineers. New York, NY: John Wiley \& Sons.

Lawrence Livermore National Laboratory. 1999. Evaluation of the Hydrologic Source Term from Underground Nuclear Tests in Frenchman Flat at the Nevada Test Site: The CAMBRIC Test, UCRL_ID-132300. Livermore, CA.

Lear, C.H., H. Elderfield, and P.A. Wilson. 2003. "A Cenozoic Seawater $\mathrm{Sr} / \mathrm{Ca}$ Record from Benthic Foraminiferal Calcite and Its Application in Determining Global Weathering Fluxes." In Earth and Planetary Science Letters, 208, p. 69-84. 
Lyles, B.F., W.A. McKay, J.B. Chapman, S.W. and Tyler 1991. Hydrogeologic Characterization of Wells HTH-1, UE18r, UE6e, and HTH-3, Nevada Test Site. Publication No. 45087. Las Vegas, NV: Desert Research Institute.

Malmberg, G.T. 1967. Hydrology of the Valley-fill and Carbonate-rock Reservoirs Pahrump Valley, Nevada-California, USGS Water Supply Paper 1832. Denver, CO: U.S. Geological Survey.

Maurer, D.K., D.L. Berger, and D.E. Prudic. 1996. Subsurface Flow to Eagle Valley from Vicee, Ash, and Kings Canyons, Carson City, Nevada, Estimated from Darcy's Law and the Chloride-Balance Method, USGS-Water Resource Investigation Report 96-4088, p. 38. Denver, CO: U.S. Geological Survey.

Maxey, G.B., and T.E. Eakin. 1949. Groundwater in White River Valley, White Pine, Nye and Lincoln Counties, Nevada, Water Resources Bulletin No. 8. Carson City, NV: State of Nevada, Office of the State Engineer.

Mook, W.G. 1980. "Carbon-14 in Hydrogeological Studies.” In Handbook of Environmental Isotope Geochemistry, Volume 1, The Terrestrial Environment, pp 49-74. Amsterdam, The Netherlands: A. Elsevier.

Moore, J.E., 1962. Selected Logs and Drilling Records of Wells and Test Holes Drilled at the Nevada Test Site Prior to 1960, USGS TEI 804. Denver, CO: U.S. Geologic Survey.

Moreo, M.T., K.J. Halford, R.J. La Camera, and R.J. Laczniak. 2003. Estimated Ground-Water Withdrawals from the Death Valley Regional Flow System, Nevada and California, 1913-98, USGS Water-Resource Investigations Report 03-4245. Denver, CO: U.S. Geological Survey.

Moran, J.E. and T.P. Rose. 2003. "A Chlorine-36 Study of Regional Groundwater Flow and Vertical Transport in Southern Nevada." In Environmental Geology, Vol.43, (5): 592-605. Heidelberg, Germany: Springer-Verlag Heidelberg.

Nader, F.H., R. Swennen, and R. Ellam. 2004. "Reflux Stratabound Dolostone and Dydrothermal Volcanism-associated Dolostone: A Two-stage Dolomitization Model.” In Sedimentology, 51, 339-360. Jurassic, Lebanon.

Oberlander, P.L. 2001. Hydraulic Conductivity Profile with Depth for Monitor Wells ER-5-3, ER-5-3 \#2, and ER-5-4. Reno, NV: Desert Research Institute.

Oberlander, P.L. 2003. Hydraulic Conductivity Profile with Depth for Well ER-5-4 \#2. Las Vegas, NV: Desert Research Institute.

Pavelko, M.T., and K.J. Halford. U.S. Geological Survey. 2004. Memorandum to D. Galloway (USGS) entitled "Aquifer Test - Analysis of Multiple Well Aquifer Test RNM-2s, Frenchman Flat, Nevada," 6 June. Henderson, NV. 
Peterman, Z.E., R.W. Spengler, F.R. Singe, and R.P. Dickerson. 1993. “Isotopic and Trace Element Variability in Altered and Unaltered Tuffs at Yucca Mountain, Nevada." In Proceedings of the Fourth Annual International Conference, High-Level Radioactive Waste Management, Las Vegas, NV, April 26-30, 1993, p. 1940-1947. LaGrange Park, IL: American Nuclear Society.

Peterman, Z.E., R.W. Spengler, F.R. Singer, and R.P. Dickerson. 1996. Geochemistry of Outcrop Samples from the Raven Canyon and Paintbrush Canyon Reference Sections, Yucca Mountain, Nevada, U.S. Geological Survey Open-File Report 94-550. Denver, CO: U.S. Geological Survey.

Peterman, Z.E., and K. Futa. 1996. Geochemistry of Core Samples of the Tiva Canyon Tuff from Drill Hole UE-25 NRG\#3, Yucca Mountain, Nevada, U.S. Geological Survey Open-File Report 95-325. Denver, CO: U.S. Geological Survey.

Peterman, Z.E., and P.L. Cloke. 2002. "Geochemistry of Rock Units at the Potential Repository Level, Yucca Mountain, Nevada." In Applied Geochemistry, 17, p. 683-698.

Plummer, L.N., E.C. Prestemon, and D.L. Parkurst. 1994. An Interactive Code (NETPATH) for Modeling Net Geochemical Reactions Along a Flow Path, Version 2.0, USGS Water Resource Investigation Report 94-4169. Denver, CO: U.S. Geological Survey.

Priestley, C.H.B., and R.J. Taylor. 1972. "On the Assessment of Surface Heat Flux and Evaporation Using Large-Scale Parameters: Mon. Weather Review." In Journal of Applied Meteorology, Vol. 100: 81-92. Boston, MA: American Meteorological Society.

Prothro, L.B., and S.L. Drellack, Jr. 1997. Nature and Extent of Lava-Flow Aquifers Beneath Pahute Mesa, Nevada Test Site, DOE/NV-11718-156. Las Vegas, NV: Bechtel Nevada.

Rehfeldt, K., W. Drici, D. Sloop, J. Watrus, T. Beard, M. Sully, C. Benedict, A. Wolfsberg and, and P. Reimus. 2003 Contaminant Transport Parameters for the Groundwater Flow and Contaminant Transport Model of Corrective Action Units 101 and 102: Central and Western Pahute Mesa, Nye County, Nevada, Shaw/13052-201, Rev. 0. Las Vegas, NV: Shaw Environmental, Inc.

Reiner, S.R., G.L. Locke, and L.S. Robie. 1995. Ground-Water Data for the Nevada Test Site and Selected Other Areas in South-Central Nevada, 1992-1993, USGS Open File Report 95-160. Denver, CO: U.S. Geological Survey. 
Rose, T.P., F.C. Benedict, J.M. Thomas, W.S. Sicke, R.L. Hershey, J.B. Paces, I.M. Farnham, and Z.E. Peterman. 2002. Geochemical Data Analysis and Interpretation of the Pahute Mesa - Oasis Valley Groundwater Flow System, Nye County, Nevada. Livermore, CA: Lawrence Livermore National Laboratory.

Rose, T.P. and Davisson, M.L. 2003. Isotopic and geochemical evidence for Holocene-age groundwater in regional flow systems of south-central Nevada. In: Enzel, Y., et al. (eds.), Paleoenvironments and Paleohydrology of the Mojave and Southern Great Basin Deserts, Geological Society of America Special Paper 368: 143-164. Boulder, CO: Geological Society of America, Inc.

Rose, T.P., Smith, D.K., and Werner, J.K., Jr. 2000. "Lithologic, Mineralogic, and Petrographic Characterization of Alluvium from the U-1a 102C and 102D Drifts of the U-1a Tunnel Complex, Nevada Test Site." In Smith, D.K., and Eaton, G.F. (eds.) Hydrologic Resources Management Program and Underground Test Area FY 1999 Progress Report, UCRL-ID-139226, July 2000: 77-110. Livermore, CA: Lawrence Livermore National Laboratory.

Rubin, Y., and J.J. Gomez-Hernandez. 1990. "A Stochastic Approach to the Problem of Upscaling of Conductivity in Disordered Media: Theory and Unconditional Numerical Simulations." In Water Resources Research, 26(4), p. 691-701. Washington, DC: American Geophysical Union.

Rush, F.E. 1970. Regional Ground-Water Systems in the Nevada Test Site Area, Nye, Lincoln, and Clark Counties, Nevada, Division of Water Resources, Reconnaissance Series, Report 54, p. 21. Carson City, NV: Nevada Department of Conservation and Natural Resources.

Russell, C. 2000. Memorandum to B. Bangerter, (Les Winfield and UGTA Project Managers entitled "Transmittal of CAMBRIC Results," November 1. Las Vegas, NV:

Russell, C.E., and T. Minor. 2002. Reconnaissance Estimates of Recharge Based on an Elevation-dependent Chloride Mass-balance Approach, DOE/NV/11508-37, Publication No. 45164. Prepared for the U.S. Department of Energy, National Nuclear Security Administration Nevada Operations Office. Las Vegas, NV: Desert Research Institute.

Sanchez-Vila, X., P.M. Meier, and J. Carrera. 1999. "Pumping Tests in Heterogeneous Aquifers: An analytical study of What can be Obtained from their interpretation using Jacob's method." In Water Resources Research, 35(4): 943-952. Washington, DC: American Geophysical Union.

Savard, C.S. 1994. "Groundwater Recharge in Fortymile Wash Near Yucca Mountain, Nevada, 1992-1993." In Radioactive Waste Management, Vol. 4: 1,805-1,813. Washington, DC: American Nuclear Society. 
Savard, C.S. 1996. Selected Hydrologic Data from Fortymile Wash in the Yucca Mountain Area, Nevada, Water Years 1993-94, U.S. Geological Survey Open-File Report 95-709. Denver, CO: U.S. Geological Survey.

Schoff, S.L., and J.E. Moore. 1964. Chemistry and Movement of Ground Water, Nevada Test Site, Report TEI-838, p. 75. Denver, CO: U.S. Geological Survey.

Scott, R.B., T.J. Smales, R.E. Rush, and A.S. Van Denburgh. 1971. Water for Nevada, Nevada's Water Resources, State of Nevada Department of Conservation and Natural Resource, Water for Nevada Report 3. Carson City, NV: Nevada Division of Water Resources.

Slate, J.L., M.E. Berry, P.D. Rowley, C.J. Fridrich, K.S. Morgan, J.B. Workman, O.D. Young, G.L. Dixon, V.S. Williams, E.H. McKee, D.A. Ponce, T.G. Hildenbrand, W.C. Swadley, S.C. Lundstrom, E.B. Ekren, R.G. Warren, J.C. Cole, R.J. Fleck, M.A. Lanphere, D.A. Sawyer, S.A. Minor, D.J. Grunwald, R.J. Laczniak, C.M. Menges, J.C. Yount, and A.S. Jayko. 1999. Digital Geologic Map of the Nevada Test Site and Vicinity, Nye, Lincoln, and Clark Counties, Nevada, and Inyo County, California, USGS-OFR-99-554-A. Denver, CO: U.S. Geological Survey.

Stoller-Navarro Joint Venture. 2004a. Hydrologic Data for the Groundwater Flow and Contaminant Transport Model of Corrective Action Units 101 and 102: Central and Western Pahute Mesa, Nye County, Nevada. Prepared for U.S. Department of Energy, S-N/99205-002. Las Vegas, NV.

Stoller-Navarro Joint Venture. 2004b. Interpretation of Hydraulic Test and Multiple-Well Aquifer Test Data at Frenchman Flat Well Cluster ER-5-3. Las Vegas, NV.

Stoller-Navarro Joint Venture. 2004c. Transferability of Data Related to the Underground Test Area Project, Nevada Test Site, Nye County, Nevada. Las Vegas, NV.

Stoller-Navarro Joint Venture. 2004d. Integrated Analysis Report for Single and Multiple-Well Aquifer Testing at Frenchman Flat Well Cluster RNM-2s Nevada Test Site, Nevada, Rev. 0. Las Vegas, NV.

Taylor, G.H., C. Daly, W.P. Gibson, and J. Sibul-Weisberg. 1997. Digital and Map Products Produced Using PRISM. In Proc., 10th AMS Conf. on Applied Climatology, Amer. Meteorological Soc., Reno, NV, Oct. 20-23, 217-218.

Thomas, J.M., A.H. Welch, and M.D. Dettinger. 1996. Geochemistry and Isotope Hydrology of Representative Aquifers in the Great Basin Region of Nevada, Utah, and Adjacent States, USGS Professional Paper 1409-C, p. 100. Denver, CO: U.S. Geological Survey. 
Thomas, J.M., F.C., Jr. Benedict, T.P. Rose, R.L. Hershey, J.B. Paces, Z.E. Peterman, I.M. Farnham, K.H. Johannesson, A.K. Singh, K.J. Stetzenbach, G.B. Hudson, J.M. Kenneally, G.F. Eaton, and D.K. Smith. 2002. Geochemical and Isotopic Interpretations of Groundwater Flow in the Oasis Valley Flow System, Southern Nevada, Water Resources Center, Publication 45190. Las Vegas, NV: Desert Research Institute.

Thordarson, W., R.A. Young, and I.J. Winograd. 1967. Records of Wells and Test Holes in the Nevada Test Site and Vicinity (through December 1966). USGS TEI-872. Denver, CO: U.S. Geological Survey.

USGS, see U.S. Geological Survey.

U.S. Department of Energy. 2000. Quality Assurance Requirements and Description, DOE/RW-0333P, Rev. 10. Washington, D.C.: U.S. Department of Energy, Office of Civilian Radioactive Waste Management. ACC: MOL.20000427.0422.

U.S. Department of Energy, National Nuclear Security Administration Nevada Site Office. 2004. UGTA Borehole Index Database as accessed on 16 June. Las Vegas, NV.

U.S. Department of Energy, Nevada Operations Office. 1997. Regional Groundwater Flow and Tritium Transport Modeling and Risk Assessment of the Underground Test Area, Nevada Test Site, Nevada, DOE/NV--477. Las Vegas, NV.

U.S. Department of Energy, Nevada Operations Office. 1999a. Corrective Action Investigation Plan for Corrective Action Unit 98: Frenchman Flat, Nevada Test Site, Nevada, DOE/NV--478-Rev. 1. Las Vegas, NV.

U.S. Department of Energy, Nevada Operations Office. 1999b. Corrective Action Investigation Plan for Corrective Action Units 101 and 102: Central and Western Pahute Mesa, Nevada Test Site, Nevada, DOE/NV--516. Las Vegas, NV.

U.S. Department of Energy, Nevada Operations Office. 2000a. Addendum to the Corrective Action Investigation Plan for Corrective Action Unit 98:

Frenchman Flat, Nevada Test Site, Nevada, Addendum Rev. 0, DOE/NV--478 REV. 1-ADD. Las Vegas, NV.

U.S. Department of Energy, Nevada Operations Office. 2000b. Underground Test Area Quality Assurance Project Plan, Nevada Test Site, Nevada, DOE/NV--341, Rev. 3. Las Vegas, NV.

U.S. Department of Energy, Nevada Operations Office. 2000c. United States Nuclear Tests, July 1945 through September 1992, DOE/NV--209, Rev. 15. Las Vegas, NV. 
U.S. Department of Energy, Nevada Operations Office. 2001. Addendum to Revision 1 of the Corrective Action Investigation Plan for Corrective Action Unit 98: Frenchman Flat, Nevada Test Site, Nevada, Rev. 1, DOE/NV--478 REV. 1-ADD. Las Vegas, NV.

U.S. Geological Survey. 1987. Digital Elevation Models: U.S. Geological Survey, National Mapping Program Technical Instructions Data Users Guide 5, p. 38. Denver, CO: U.S. Geological Survey.

U.S. Geological Survey. 1999. "National Elevation Dataset, NTS-E." As accessed at http://argis/mydata/NED_NLCD/ned.

U.S. Geological Survey. 2001. National Water Information System (NWISWeb). As accessed at http://waterdata.usgs.gov/nwis on multiple occasions between April 2004 through August 2004.

U.S. Geological Survey. 2004. "USGS/DOE Cooperative Studies in Nevada; Water-Use Wells, Nevada Test Site and Vicinity." As accessed on 23 July at http://nevada.usgs.gov/doe_nv/wateruse/wu_map.htm.

Vanmarcke, E. 1983. Random Fields: Analysis and Synthesis. Cambridge, MA: The MIT Press.

WRCC, see Western Regional Climate Center.

Wahl, R.R., D.A. Sawyer, S.A. Minor, M.D. Carr, J.C. Cole, W.C. Swadley, R.J. Laczniak, R.G. Warren, K.S. Green, and C.M. Engle. 1997. Digital Geologic Map of the Nevada Test Site Area, Nevada, USGS Open-File Report 97-140. Denver, CO: U.S. Geological Survey.

Walker, G.E. 1962. Ground Water in the Climax Stock, Nevada Test Site, Nye County, Nevada, USGS-TEI-813. Denver, CO: U.S. Geological Survey.

Walker, G.E., and T.E. Eakin. 1963. "Geology and Ground Water of Amargosa Desert, Nevada-California." In Ground-Water Resources - Reconnaissance Series Report 14. Denver, CO: Nevada Department of Conservation and Natural Resources and U.S. Geological Survey.

Warren, R.G., F.C. Benedict, Jr., T.P. Rose, D.K. Smith, S.J. Chipera, E.C. Kluk, and K.M. Raven. 2002. Alluvial Layering and Distribution of Reactive Phases within Drill Holes ER5/4 and UE5N of Frenchman Flat. LA-UR-02-6206. Los Alamos, NM: Los Alamos National Laboratory.

Watermark Numerical Computing and Waterloo Hydrogeologic. 2000. Visual PEST User's Manual (Includes PEST2000 \& WinPEST) - Graphical Model-Independent Parameter Estimation. Ontario, Canada, and Tampa, FL. 
Western Regional Climate Center. 2004. Western Regional Climate Center Historical Climate Information Website. As accessed on 22 April at http://www.wrcc.dri.edu/CLIMATEDATA.html.

White, A.F., H.C. Claassen, and L.V. Benson. 1980. The Effect of Dissolution of Volcanic Glass on the Water Chemistry in a Tuffaceous Aquifer, Rainier Mesa, Nevada, USGS Water-Supply Paper 1535-Q. Denver, CO: U.S. Geological Survey.

Winograd, I.J., and I. Friedman. 1972. Deuterium as a Tracer of Regional Groundwater Flow, Southern Great Basin, Nevada and California, Bulletin 83, 3691-3708. Boulder, CO: Geological Society of America, Inc.

Winograd, I.J., and W. Thordarson. 1975. Hydrogeologic and Hydrochemical Framework, South-Central Great Basin, Nevada-California, with Special Reference to the Nevada Test Site, USGS-PP-712-C. Denver, CO: U.S. Geological Survey.

Winograd, I.J., and L.R. West. 1962. Preliminary Tracer Experiment to Demonstrate Hydraulic Continuity Between Water Wells C and C-1, Yucca Flat, Nevada Test Site, USGS Technical Letter NTS-20. Denver, CO: U.S. Geological Survey.

Zlotnik, V.A., B.R. Zurburchen, T. Ptak, and G. Teutsch. 2000. "Support Volume and Scale Effect in Hydraulic Conductivity: Experimental Aspects." In Theory, Modeling, and Field Investigation in Hydrogeology: A Special Volume in Honor of Shlomo P. Neuman's 60th Birthday Special Paper, 348, p. 215-231. Boulder, CO: Geological Society of America, Inc.

Zyvoloski, G.A., B.A. Robinson, Z.V. Dash, and L.L. Trease. 1997a. Summary of Models and Methods for the FEHM Application - A Finite-Element Heatand Mass-Transfer Code, LA-13307-MS. Los Alamos, NM: Los Alamos National Laboratory.

Zyvoloski, G.A., B.A. Robinson, Z.V. Dash, and I.L. Trease. 1997b. User's Manual for the FEHM Application - A Finite-Element Heat- and Mass-Transfer Code, LA-13306-M. Los Alamos, NM: Los Alamos National Laboratory. 
Appendix A

Hydrostratigraphic Model Supporting Information 


\section{A.1.0 Alternative Hydrostratigraphic Models}

Multiple hydrostratigraphic models have been created to address uncertainties within the Frenchman Flat flow system. The flow system contains the Frenchman Flat CAU (the site of 10 underground nuclear tests) along with the HSUs through which the radionuclides from these tests could potentially leave the Frenchman Flat underground test areas. The flow system includes areas in and immediately east of the NTS. A summary description is provided here. The report titled: A Hydrostratigraphic Model and Alternatives for the Groundwater Flow and Contaminant Transport Model of Corrective Action Unit 98: Frenchman Flat, Lincoln, and Nye Counties, Nevada (BN, 2004) provides more detail.

Each of the alternative hydrostratigraphic models honor the data available, with differences between the models representing differences in interpretations of various features described by the data. Thus, each alternative model can be considered a possible representation of reality. The original list of alternatives was developed by an alternative scenario working group, under the auspices of the TWG. The complete list included 30 "alternative scenarios" (Table A.1-1). The list of 30 "alternative scenarios" was then distilled into four groups based upon the action deemed needed. The four groups were as follows:

- Group A: Recommended changes to the base model.

- Group B: Viable alternative scenarios.

- Group C: Proposed alternatives that would be better addressed during the hydromodeling phase rather than as alternatives to the geologic framework model.

- Group D: Suggested alternatives that were deemed to be of low priority or not necessary to model at this time.

The final listings for Group A, B, and C, based on the work of the alternative scenario working group, were as follows (note that because Group D scenarios are considered to be of lesser consequence to the potential mobility of the radionucludes from the Frenchman Flat test sites, they are not presented in this report).

\section{Group A-Recommended Changes to the Base Model}

- Subdivide the alluvial section.

- Portray the basalt lava flow aquifer as smaller and discontinuous flows.

- Use the gravity inversion model only as a rough guide.

- Modify CP Basin. 
Table A.1-1

Abridged List of Alternative Scenarios for the Frenchman Flat 3-D Hydrostratigraphic Model (Page 1 of 3 )

\begin{tabular}{|c|c|c|c|}
\hline & Alternative & $\begin{array}{l}\text { Priority } \\
\text { Group }\end{array}$ & Comment \\
\hline 1.0 & \multicolumn{3}{|c|}{ HYDROSTRATIGRAPHY-RELATED ALTERNATIVES } \\
\hline 1.1 & \multicolumn{3}{|c|}{ Alternatives to Simplify Hydrostratigraphy } \\
\hline 1.1 .1 & $\begin{array}{l}\text { Simplify HSUs above the } \\
\text { water table }\end{array}$ & $\mathbf{D}^{\mathbf{a}}$ & $\begin{array}{l}\text { Can HSUs in the unsaturated zone be lumped, simplified, or ignored? This would } \\
\text { affect the outcrop area in the northern portion of the model. }\end{array}$ \\
\hline 1.1 .2 & $\begin{array}{l}\text { Decrease the depth of the } \\
\text { model }\end{array}$ & D & $\begin{array}{l}\text { Is there any merit in raising the bottom of the model? Work on the regional model } \\
\text { demonstrated that even after removing the lowest } 2 \mathrm{~km}(1.2 \mathrm{mi}) \text { from the bottom of the } \\
\text { model, there was no difference in the outcome compared to the original model. } \\
\text { Conductivity below about } 3,000 \mathrm{~m} \text { may be negligible. The elevation of the bottom of } \\
\text { the framework model is now consistent with the regional model. }\end{array}$ \\
\hline 1.2 & \multicolumn{3}{|c|}{ Alternatives to Add Hydrostratigraphic Detail } \\
\hline 1.2 .1 & $\begin{array}{l}\text { Differentiate units of the } \\
\text { Lower Tuff Confining Unit } \\
\text { (LTCU) }\end{array}$ & D & $\begin{array}{l}\text { Hydraulic conductivity of the several interbedded ash-flow tuff units within the LTCU } \\
\text { may be worth considering (e.g., the Bullfrog Tuff at ER-5-4\#2). }\end{array}$ \\
\hline 1.2 .2 & $\begin{array}{l}\text { Subdivide the alluvium } \\
\text { based on relative abundance } \\
\text { of reactive minerals }\end{array}$ & $c^{b}$ & $\begin{array}{l}\text { Is there enough information (e.g., in Carle et al., 2002; Warren et al., 2002; Zavarin } \\
\text { et al., 2004), and are the differences significant and/or predictable enough to warrant } \\
\text { subdividing these units? Perhaps this should be a separate sub-CAU-scale model. }\end{array}$ \\
\hline 1.2 .3 & $\begin{array}{l}\text { Subdivide the Volcaniclastic } \\
\text { Confining Unit (VCU) in the } \\
\text { southern portion of the } \\
\text { model }\end{array}$ & C & $\begin{array}{l}\text { Although dominated by fine-grained clastics, the VCU also includes lenses of gravel } \\
\text { and thin freshwater carbonate beds. It might be possible to add more geologic detail } \\
\text { (in a conceptual manner), but almost no subsurface data and no hydrologic data are } \\
\text { available. }\end{array}$ \\
\hline 1.2 .4 & $\begin{array}{l}\text { Maximize detail within } \\
1,000 \mathrm{~m}(3,280 \mathrm{ft}) \text { of the } \\
\text { water table }\end{array}$ & D & $\begin{array}{l}\text { Will small differences at, or just beneath the water table make significant differences in } \\
\text { the flow and transport modeling results (e.g., raise or lower an HSU, or, add or remove } \\
\text { HSUs)? }\end{array}$ \\
\hline 1.2 .6 & $\begin{array}{l}\text { Vary the Paleozoic } \\
\text { stratigraphy }\end{array}$ & D & Would occurrences of the Dunderberg Shale or Eureka Quartzite alter flow in the LCA? \\
\hline 1.2 .7 & Basalt-flow geometry & $\begin{array}{l}A^{c} \\
D\end{array}$ & $\begin{array}{l}\text { a) The basalt is modeled as a continuous unit from ER-5-3 to the basin-forming faults to } \\
\text { the east (a "worst-case scenario"). What if this basalt is dissected by erosion, faulted, or } \\
\text { composed of separate lobes? } \\
\text { b) How would a basalt dike affect groundwater flow? What is the geometry and nature } \\
\text { of a basalt flow source? Can we define the hydrologic properties of such a thin tabular } \\
\text { body? }\end{array}$ \\
\hline 1.3 & \multicolumn{3}{|c|}{ Alternatives Addressing Different Distributions for Pre-Tertiary HSUs } \\
\hline $1.3 .1 \mathrm{a}$ & $\begin{array}{l}\text { Outcrop of Paleozoic } \\
\text { carbonate rocks; LCA versus } \\
\text { LCA3? }\end{array}$ & D & These outcrops are currently modeled as LCA. Should/could they be LCA3? \\
\hline $1.3 .1 b$ & $\begin{array}{l}\text { Vary the occurrence of the } \\
\text { LCA3 and UCCU }\end{array}$ & D & $\begin{array}{l}\text { Could the LCA3 and UCCU be present in other parts of the model area (e.g. south of } \\
\text { the Cane Spring fault)? }\end{array}$ \\
\hline 2.0 & \multicolumn{3}{|c|}{ STRUCTURE-RELATED ALTERNATIVES } \\
\hline 2.1 & Simplify the structural model & D & Omit all but the most profound structures and faults. \\
\hline 2.2 & $\begin{array}{l}\text { Remove faults along edge } \\
\text { of model }\end{array}$ & D & Remove faults in the southeast corner of the model. \\
\hline 2.3 & \multicolumn{3}{|l|}{ Add More Structural Detail } \\
\hline 2.3.1 & Faults & C & $\begin{array}{l}\text { Add width to faults, modifying them from simple two-dimensional surfaces to a 3-D } \\
\text { feature having some width. Can we predict where and why they might be a barrier } \\
\text { and/or conduit to groundwater flow? }\end{array}$ \\
\hline
\end{tabular}


Table A.1-1

Abridged List of Alternative Scenarios for the Frenchman Flat 3-D Hydrostratigraphic Model (Page 2 of 3 )

\begin{tabular}{|c|c|c|c|}
\hline \multicolumn{2}{|r|}{ Alternative } & $\begin{array}{l}\text { Priority } \\
\text { Group }\end{array}$ & Comment \\
\hline 2.3 .2 & $\begin{array}{l}\text { Add more Tertiary faults or } \\
\text { fault zones }\end{array}$ & D & $\begin{array}{l}\text { Perhaps begin by adding more of the mapped faults (shown on Slate et al. [1999] or the } \\
\text { individual USGS quadrangle maps). (Although, most reviewers thought that } \\
\text { structurally the model contained the appropriate level of detail.) }\end{array}$ \\
\hline 2.3.3 & $\begin{array}{l}\text { Extend the CP thrust fault } \\
\text { south of the Cane Spring } \\
\text { fault }\end{array}$ & D & $\begin{array}{l}\text { A component of } 1.3 \text { above. The CP thrust is a poorly characterized, } \\
\text { west-to-northwest-vergent thrust fault, that appears to be mostly outside the } \\
\text { boundaries of the model area. Is it critical to add this complexity to the northwest } \\
\text { corner of the model? Could the fault be elsewhere, too? See 1.3.1a and 1.3.1b. }\end{array}$ \\
\hline 2.3.4 & $\begin{array}{l}\text { Explore fault related } \\
\text { groundwater pathways }\end{array}$ & $\begin{array}{c}B^{d} \\
\text { (also C) }\end{array}$ & $\begin{array}{l}\text { Consider increasing or decreasing fault displacements so aquifers are juxtaposed } \\
\text { across faults. Conversely, if aquifers are juxtaposed, adjust relative fault displacement } \\
\text { to prevent aquifer-aquifer juxtaposition. Deliberately juxtapose aquifer units across } \\
\text { faults. Candidates for such adjustments would include the basin-forming faults in the } \\
\text { east. }\end{array}$ \\
\hline 2.3 .5 & Other fault variations & C & $\begin{array}{l}\text { Model faults as a zone with multiple planes. Typically, faults have been modeled as a } \\
\text { single plane. }\end{array}$ \\
\hline 2.4 & \multicolumn{3}{|c|}{ Develop Different Structural Scenarios } \\
\hline 2.4 .1 & Vary fault dips & C & $\begin{array}{l}\text { The basin-and-range normal faults are modeled using an } 75 \text {-degree dip. Varying fault } \\
\text { dips would present more consequences in the source areas, where fault proximity to } \\
\text { working points is important. This might be better addressed in sub-CAU-scale models. }\end{array}$ \\
\hline 2.4 .3 & $\begin{array}{l}\text { Vary the depth to basement } \\
\text { rocks }\end{array}$ & D & $\begin{array}{l}\text { The uncertainty in depth to basement based on geophysical data (gravity) is roughly } \\
300 \mathrm{~m}(1,000 \mathrm{ft}) \text {. This may not be geologically permissible in some areas. And where it } \\
\text { is possible, what units would be thinned or thickened? }\end{array}$ \\
\hline 2.4 .4 & $\begin{array}{l}\text { Explore variations of the } \\
\text { Cane Spring fault }\end{array}$ & B & $\begin{array}{l}\text { This strike-slip fault bounds the southeast side of the CP Basin. It seems to end at the } \\
\text { Massachusetts Mountain/CP Hogback juncture. Could it control deep inter-basin flow } \\
\text { from Yucca Flat, or relatively shallow recharge from Barren Wash? }\end{array}$ \\
\hline 2.4 .5 & $\begin{array}{l}\text { Vary the geometry/position } \\
\text { of the Rock Valley fault }\end{array}$ & D & $\begin{array}{l}\text { This northeast-southwest striking strike-slip fault is intimately related to basin formation. } \\
\text { Does it also control groundwater flow out of Frenchman Flat? }\end{array}$ \\
\hline 2.4 .6 & $\begin{array}{l}\text { Vary displacement on } \\
\text { basin-forming faults }\end{array}$ & D & $\begin{array}{l}\text { Distribute displacements along basin-forming faults along east side to better fit gravity } \\
\text { data. The emphasis here (as apposed to } 2.3 .4 \text { ) is to more closely match the gravity } \\
\text { data. }\end{array}$ \\
\hline 2.5 & \multicolumn{3}{|c|}{ Other Structure-Related Alternatives } \\
\hline 2.5 .1 & $\begin{array}{l}\text { "Smooth" versus "rough" } \\
\text { HSU surface }\end{array}$ & D & $\begin{array}{l}\text { Computer idiosyncracies have produced "hills" and "indentations" on HSU surfaces } \\
\text { where none were intended. Does it matter? A rough surface might better approximate } \\
\text { the effect of faulting (not represented now in the model). }\end{array}$ \\
\hline 2.5 .2 & $\begin{array}{l}\text { Consider defining } \\
\text { basin/slopes with faults }\end{array}$ & D & $\begin{array}{l}\text { The UGTA base model portrays many of the central basin gravity lows as a } \\
\text { moncline-type structure and not half-grabens related to basin-and-range extension } \\
\text { (e.g., northeast of the Well Cluster ER-5-4). Are there more faults (possibly } \\
\text { hydrologically significant) that are not discernable with geophysics? }\end{array}$ \\
\hline 2.5 .4 & $\begin{array}{l}\text { Explore variations of the } \\
\text { accommodation zone } \\
\text { between Frenchman and } \\
\text { Yucca Flat }\end{array}$ & C & $\begin{array}{l}\text { This feature appears as a gravity high between two extensional basins. How does this } \\
\text { area effect inter-basin groundwater flow? }\end{array}$ \\
\hline 2.5 .5 & $\begin{array}{l}\text { Remove the detachment } \\
\text { fault }\end{array}$ & B & $\begin{array}{l}\text { Model volcanics in the northern portion of basin as moderately dipping surfaces to the } \\
\text { south. }\end{array}$ \\
\hline 3.0 & \multicolumn{3}{|c|}{ HYDROLOGIC ALTERNATIVES } \\
\hline 3.1 & $\begin{array}{l}\text { Account for lower hydraulic } \\
\text { heads at Water Wells } 5 a \text { and } \\
5 c\end{array}$ & B & $\begin{array}{l}\text { These two wells show a significant downward gradient. This scenario will be } \\
\text { addressed with alternative 2.3.4. }\end{array}$ \\
\hline
\end{tabular}


Table A.1-1

Abridged List of Alternative Scenarios for the Frenchman Flat 3-D Hydrostratigraphic Model

(Page 3 of 3 )

\begin{tabular}{|c|c|c|c|}
\hline \multicolumn{2}{|r|}{ Alternative } & Priority & Comment \\
\hline 3.2 & $\begin{array}{l}\text { Consider effect on the CAU } \\
\text { boundary of contaminated } \\
\text { water flowing into } \\
\text { Frenchman Flat from Yucca } \\
\text { Flat }\end{array}$ & C & $\begin{array}{l}\text { Model the case in which contaminated water is already present in the regional } \\
\text { carbonate aquifer, and is flowing into the Frenchman Flat CAU from Yucca Flat. }\end{array}$ \\
\hline 3.3 & $\begin{array}{l}\text { Consider the effect of } \\
\text { significant groundwater flux } \\
\text { from the northwest }\end{array}$ & C & $\begin{array}{l}\text { Groundwater levels in CP Basin are considerably higher than in Yucca or Frenchman } \\
\text { Flat. Model the inflow of significant uncontaminated water from the CP basin northwest } \\
\text { of Frenchman Flat (ultimately from Mid Valley via Barren Wash). }\end{array}$ \\
\hline 3.4 & $\begin{array}{l}\text { Consider the effect of } \\
\text { significant groundwater from } \\
\text { the east }\end{array}$ & C & $\begin{array}{l}\text { The Phase I Regional Model indicates significant interbasin flow from the east and into } \\
\text { Frenchman Flat. Model the inflow of significant uncontaminated water from the east } \\
\text { (e.g., Pahranagat Valley). }\end{array}$ \\
\hline
\end{tabular}

${ }^{\text {a }}$ Suggested alternatives that were deemed to be of low priority or not necessary to make at this time.

${ }^{\mathrm{b}}$ Proposed alternatives that would be better addressed during the hydro modeling phase rather than as alternatives to the geologic framework model.

${ }^{\mathrm{c}}$ Recommended and implemented changes to the base model.

${ }^{\mathrm{d}}$ Viable alternative scenarios.

\section{Group B - Viable Alternative Scenarios}

- Portray the basalt HSU as a single, extensive, continuous lava flow extending eastward to the basin-forming fault (1.2.7, in Table A.1-1).

- $\quad$ Remove the detachment fault (2.5.5).

- Vary displacement of the basin-forming faults to force juxtaposition of HSUs (2.3.4).

\section{Group C - Alternatives to Address During the Hydrologic Modeling}

- Vary hydraulic properties for the alluvial HSUs (1.2.2).

- Model faults as 3-D features having the same width (2.3.1 and 2.3.5).

- $\quad$ Subdivide the volcaniclastic confining unit (VCU) (1.2.3).

- Explore variation of the accommodation zone between Frenchman Flat and Yucca Flat (2.5.4).

- Consider effect of contaminated interbasin flow from Yucca Flat (3.2).

- Consider effect of groundwater influx from the northwest (3.3).

- Consider effect of groundwater influx from the east (3.4).

- Vary hydraulic properties for the HSUs. 
The alternatives listed in Group A were considered to be of high priority and reflected the need to update the HSU model in order to examine the influence of the alternative interpretations on radionuclide mobility. The Frenchman Flat section of the base HSU model has been refined and modified by applying to it the recommendations presented in Group A. The regional flow model, updated to include the changes in structure associated with the updated Frenchman Flat geology, has been calibrated using the ModFlow 2000 in conjunction with PEST.

The alternatives posted in Group B represent the important alternatives that for full consideration would entail major modifications of both the HSU and numerical models. Associated calibrations would also become major efforts. A full calibration effort on all the alternatives would be hard to complete within the administration constraints associated with the efforts. The groundwater flow model grid for the base HSU geologic model will be designed to allow the modeling of the alternatives through variation of hydraulic properties.

Group C alternatives are important and can be implemented in the flow model without the need to update the HSU model. Group $\mathrm{C}$ alternatives will be simulated as part of the FEHM Frenchman Flat modeling effort. 


\section{A.2.0 References}

BN, see Bechtel Nevada.

Bechtel Nevada. 2004. A Hydrostratigraphic Model and Alternatives for the Groundwater Flow and Contaminant Transport Model of Corrective Action Unit 98: Frenchman Flat, Lincoln, and Nye Counties, Nevada. Las Vegas, NV.

Carle, S.F., M. Zavarin, and G.A. Pawloski. 2002. Geostatistical Analysis of Spatial Variability of Mineral Abundance and Kd in Frenchman Flat, NTS, Alluvium, UCRL-ID-150200. Livermore, CA: Lawrence Livermore National Laboratory.

Slate. J.L., M.E. Berry, P.D. Rowley, C.J. Fridrich, K.S. Morgan, J.B. Workman, O.D. Young, G.L. Dixon, V.S. Williams, E.H. McKee, D.A. Ponce, T.G. Hildenbrand, W.C. Swadley, S.C. Lundstrom, E.B. Ekren, R.G. Warren, J.C. Cole, R.J. Fleck, M.A. Lanphere, D.A. Sawyer, S.A. Minor, D.J.Grunwald, R.J. Laczniak, C.M. Menges, J.C. Yount, and A.S. Jayko. 1999. Digital Geologic Map of the Nevada Test Site and Vicinity, Nye, Lincoln, and Clark Counties, Nevada, and Inyo County, California, USGS-Open File Report 99-554-A. Denver, CO: U.S. Geological Survey.

Warren, R.G., F.C. Benedict, Jr., T.P. Rose, D.K. Smith, S.J. Chipera, E.C. Kluk, and K.M. Raven. 2002. Alluvial Layering and Distribution of Reactive Phases Within Drill Holes ER5/4 and UE5N of Frenchman Flat, LA-UR-02-6206. Los Alamos, NM: Los Alamos National Laboratory.

Zavarin, M., S.F. Carle, and R.M. Maxwell. 2004. Upscaling Radionuclide Retardation - Linking the Surface Complexation and Ion Exchange Mechanistic Approach to a Linear Kd Approach, UCRL-TR-204713. Livermore, CA: Livermore National Laboratory. 
Appendix B

\section{Well Discharge Data}




\section{B.1.0 Introduction}

This appendix contains groundwater discharge data for wells located in the Frenchman Flat area and vicinity. Included are wells Army-1 WW located south of Frenchman Flat, WW-1 located east of Frenchman Flat, RNM-2S, UE-5cWW, WW-5A, WW-5B, WW-5C located in Frenchman Flat, WW-4 and WW-4A located in CP Basin, and WW-C and WW-C1 located in southern Yucca Flat.

\section{B.2.0 Data Presentation}

The data are presented in individual tables for each pumping well. Information included in the table are month, year, monthly pumpage in million gallons, monthly pumpage in acre-feet, monthly pumpage in million liters, number of reporting dates in the month, and the source of the pumping data. Pumping records for WW-5A, WW-5B, and WW-5C are not available from the start of pumping in the well through August 1958 and from July 1967 through December 1982. Data for this latter time period are also not available for Army-1 WW, WW-C, and WW-C1. Annual pumping during these time periods were estimated by the USGS using reported and estimated values from Claassen (1973) or values reported in Moreo et al. (2003). To calculate a monthly volume withdrawn, the annual withdrawal estimated by the USGS minus any known monthly data were assumed to be evenly distributed over the months lacking data. For example, a yearly estimate and monthly data for the first six months are available for 1967. To calculate estimated monthly withdrawals for the last six months of 1967, the known monthly withdrawals were subtracted from the estimated annual withdrawal and the resulting volume was divided by six to calculate an estimated monthly withdrawal for the months with no known data. This process is summarized in the following equation:

$$
\mathrm{MU}_{\mathrm{w}}=\left(\mathrm{A}_{\mathrm{w}}-\mathrm{MK}_{\mathrm{w}}\right) / \mathrm{MU}_{\mathrm{n}(\mathrm{D}-1)}
$$

where:

$\mathrm{MU}_{\mathrm{w}}=$ The calculated withdrawal for months without data

$\mathrm{A}_{\mathrm{w}}=$ The USGS estimated annual withdrawal

$\mathrm{MK}_{\mathrm{w}}=$ The withdrawal for months with data

$\mathrm{MU}_{\mathrm{n}}=$ The number of months without data

A comment entry in the tables stating "estimated" indicates which monthly data were estimated using Equation B-1. 


\section{B.3.0 Access to Data}

The well discharge table can be found on the accompanying CD in pdf format. The data files are listed below.

- Table Army-1 WW Discharge Data.pdf

- Table UE-5c WW Discharge Data.pdf

- Table Well RNM-2S Discharge Data.pdf

- Table WW-1 Discharge Data.pdf

- Table WW-4 Discharge Data.pdf

- Table WW-4A Discharge Data.pdf

- Table WW-5a Discharge Data.pdf

- Table WW-5b Discharge Data.pdf

- Table WW-5c Discharge Data.pdf

- Table WW-C1 Discharge Data.pdf

- Table WW-C Discharge Data.pdf

\section{B.4.0 References}

Claassen, H.C. 1973. Water Quality and Physical Characteristics of Nevada Test Site Water Supply Wells, USGS Open File Report 474-158. Denver, CO: U.S. Geological Survey.

Moreo, M.T., K.J. Halford, R.J. La Camera, and R.J. Laczniak. 2003. Estimated Ground-Water Withdrawals from the Death Valley Regional Flow System, Nevada and California, 1913-98, USGS Water Resource Investigations Report 03-4245. Denver, CO: U.S. Geological Survey. 
Appendix C

Hydraulic-Head Dataset 


\section{C.1.0 Introduction}

This appendix contains the hydraulic-head data for wells located in the Frenchman Flat area and vicinity. Included are all wells in Frenchman Flat and wells Army-1 WW and SM-23-1 located south of Frenchman Flat, WW-1 located east of Frenchman Flat, WW-4 and WW-4A located in CP Basin, and WW-C and WW-C1 located in southern Yucca Flat.

\section{C.2.0 Data Presentation}

The hydraulic-head data are presented in an individual table for each well. Information included in the tables includes:

- Well name

- Reference point elevation

- Measured depth to water

- Corrected depth to water

- Measurement date

- Status of the site at the time of the depth-to-water measurement

- Water-level elevation

- Type of correction to the measured depth to water

- Source for the depth-to-water measurement.

Also included on these tables is an indication of the water-levels used to determine the historical and/or contemporary static water-level elevations. The historical static water-level elevations are the suggested targets heads for the flow model calibration.

Measured depths to water were corrected for borehole deviation (BD) and anomalous water temperature (WT) in the well if applicable (see Sections 8.5.2 and 8.5.1, respectively, in the main text of this document). In several instances, the water-level in a well was measured under disturbed conditions. These conditions are indicated by the site status and include such activities as pumping of the well, recent pumping of the well, pumping of a nearby well completed to the same hydraulic unit, and recent pumping of a nearby well completed to the same hydraulic unit. The water-level elevation was calculated as the reference point elevation minus the corrected depth to water. The sources for the depth-to-water measurements include the UGTA borehole database, the USGS website http://nevada.usgs.gov/doe_nv/, the data report for the RNM-2S multi-well aquifer test (SNJV, 2004), and water-levels measured by Bechtel Nevada for the Area 5 RWMS PW wells. 


\section{C.3.0 Access to Data}

The water-level tables can be found on the accompanying CD in pdf format. The data table files are listed below.

- Table Army $1 \mathrm{WW}$ Water Level Data.pdf

- Table ER-5-3-2 Water Level Data.pdf

- Table ER-5-3 \#3 Water Level Data.pdf

- Table ER-5-3 (3-in deep) Water Level Data.pdf

- Table ER-5-3 (3-in shallow) Water Level Data.pdf

- Table ER-5-3 (main-composite) Water Level Data.pdf

- Table ER-5-4 \#2 Water Level Data.pdf

- Table ER-5-4 (main-composite) Water Level Data.pdf

- Table ER-5-4 (piezometer) Water Level Data.pdf

- Table RNM-1 Water Level Data.pdf

- Table RNM-2 Water Level Data.pdf

- Table RNM-2S Water Level Data.pdf

- Table SM-23-1 Water Level Data.pdf

- Table TW-3 Water Level Data.pdf

- Table TW-F Water Level Data.pdf

- Table UE-5 PW-1 Water Level Data.pdf

- Table UE-5 PW-2 Water Level Data.pdf

- Table UE-5 PW-3 Water Level Data.pdf

- Table UE-5c WW Water Level Data.pdf

- Table UE-5f Water Level Data.pdf

- Table UE-5j Water Level Data.pdf

- Table UE-5k Water Level Data.pdf

- Table UE-5m Water Level Data.pdf

- Table UE-5n Water Level Data.pdf

- Table UE-11a Water Level Data.pdf

- Table UE-11b Water Level Data.pdf

- Table WW-1 Water Level Data.pdf

- $\quad$ Table WW-4 Water Level Data.pdf

- Table WW-4a Water Level Data.pdf

- Table WW-5A Water Level Data.pdf

- Table WW-5B Water Level Data.pdf

- Table WW-5C Water Level Data.pdf

- Table WW-C1 Water Level Data.pdf

- Table WW-C Water Level Data.pdf 


\section{C.4.0 References}

Nawrocki, F., Bechtel Nevada. 2004. Personal communication to William Fryer, (Stoller-Navarro Joint Venture), regarding Radioactive Waste Management Site Well Monitoring Data, May. Las Vegas, NV.

Stoller-Navarro Joint Venture. 2004. Integrated Data Report for the RNM-2s Multi-Well Aquifer Test at Frenchman Flat, Nevada Test Site, Nevada, Preliminary." Las Vegas, NV. 
Appendix D

\section{Well Construction Diagrams}




\section{D.1.0 Introduction}

This appendix consists of twelve well completion diagrams for wells drilled in the Frenchman Flat area and vicinity. The purpose of providing these diagrams is to present pertinent information specific to each individual well site. The wells that are included in this appendix are: Wells ER-5-3, ER-5-3 \#2, ER-5-3 \#3, ER-5-4, ER-5-4 \#2, RNM-1, RNM-2, RNM-2S, WW-4, WW-4A, WW-5A, WW-5B, and WW-5C. These wells were drilled and were completed during a time period that ranges between 1951 and 2001. An example of some of the information that appears on these well completion diagrams includes:

- Well completion date

- Surface elevation

- Static water-level

- Top and bottom of cased, perforated, and/or slotted intervals

- Completion zones

- Pump installation depth

- Piezometer strings

- HSUs

- Total depth

The well completion diagrams are presented in Figures D-1.1 to D-1.10. 


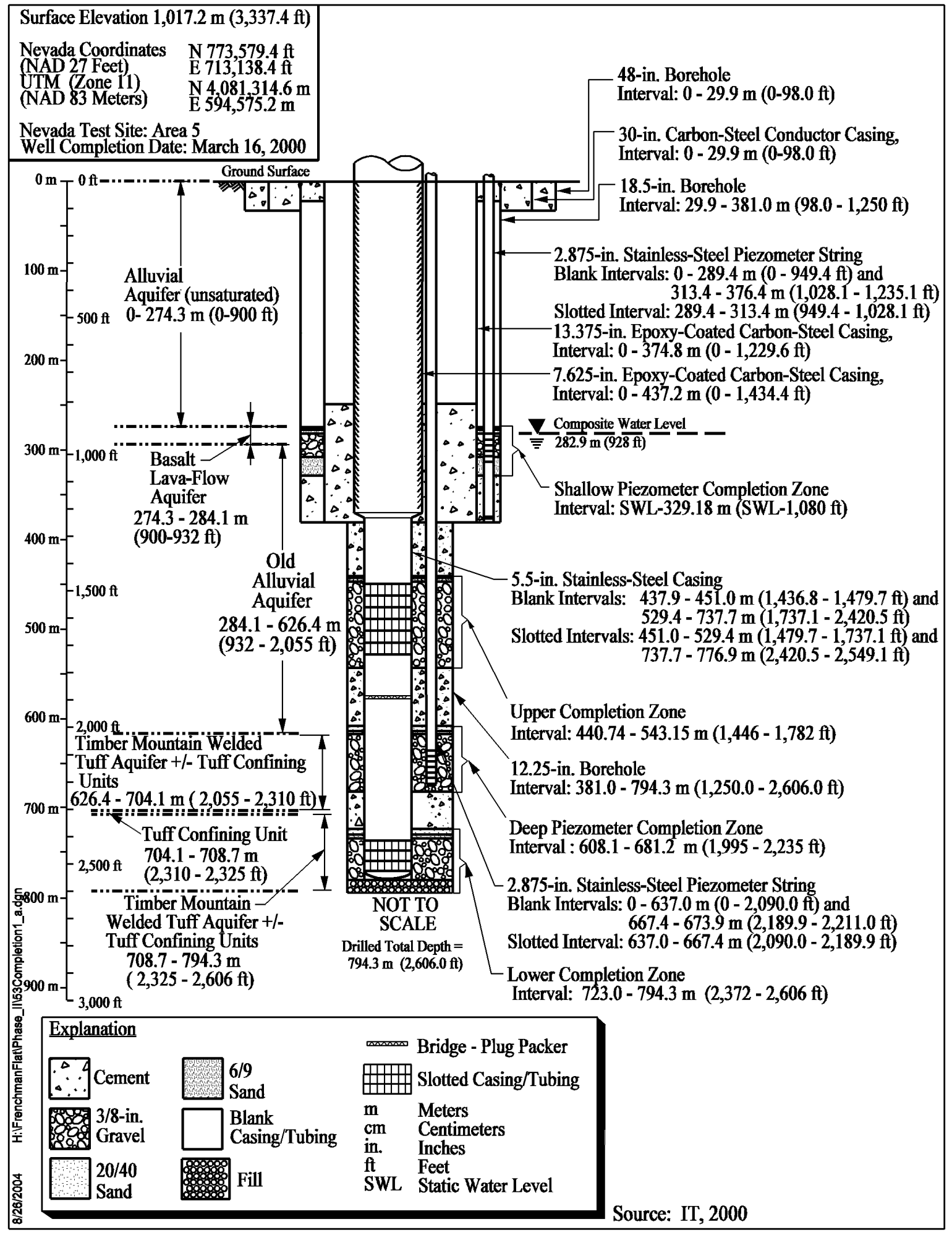

Figure D.1-1

Well ER-5-3 Completion Diagram 


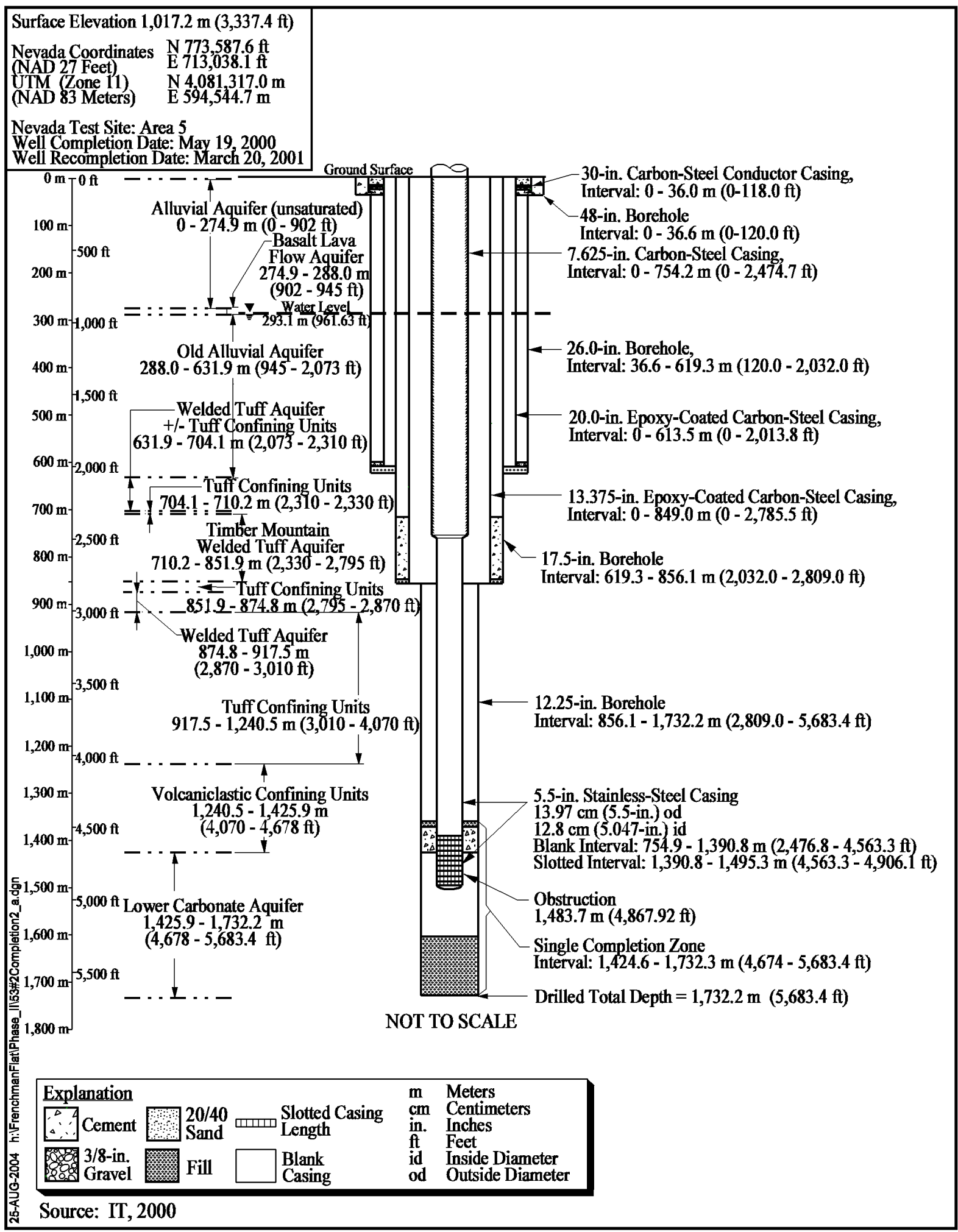

Figure D.1-2

Well ER-5-3 \#2 Completion Diagram 


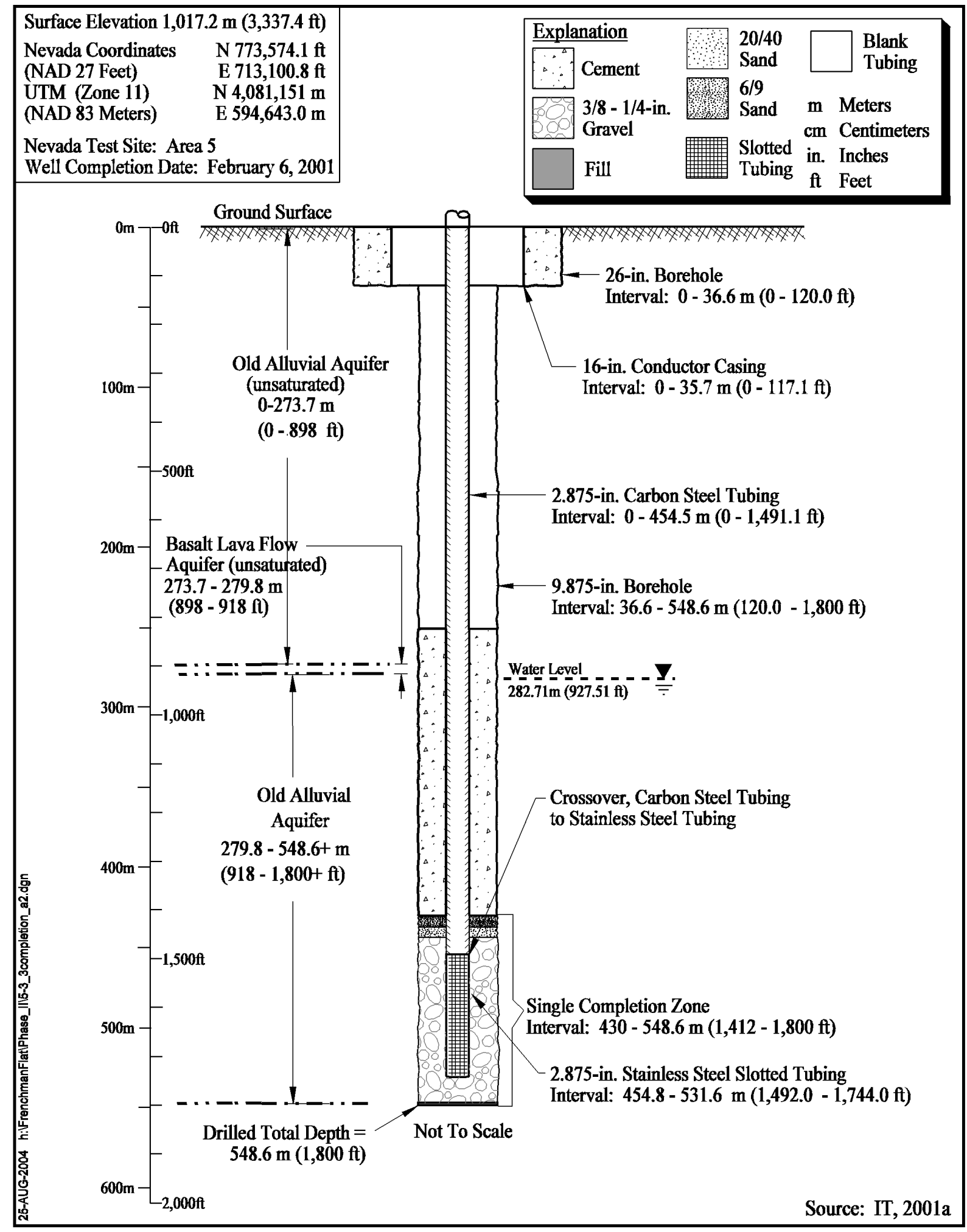

Figure D.1-3

Well ER-5-3 \#3 Completion Diagram 


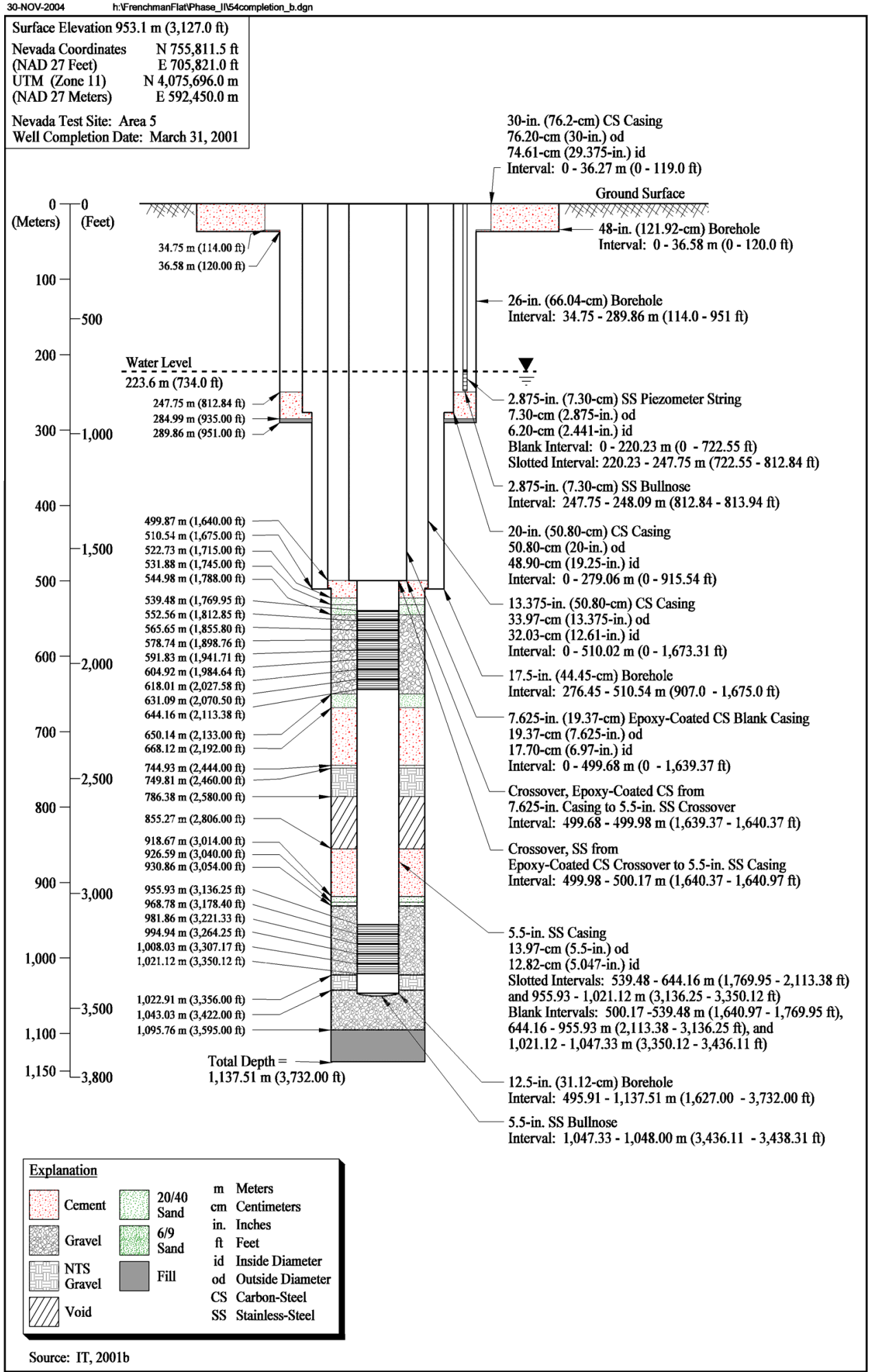

Figure D.1-4

Well Completion Diagram for Well ER-5-4 


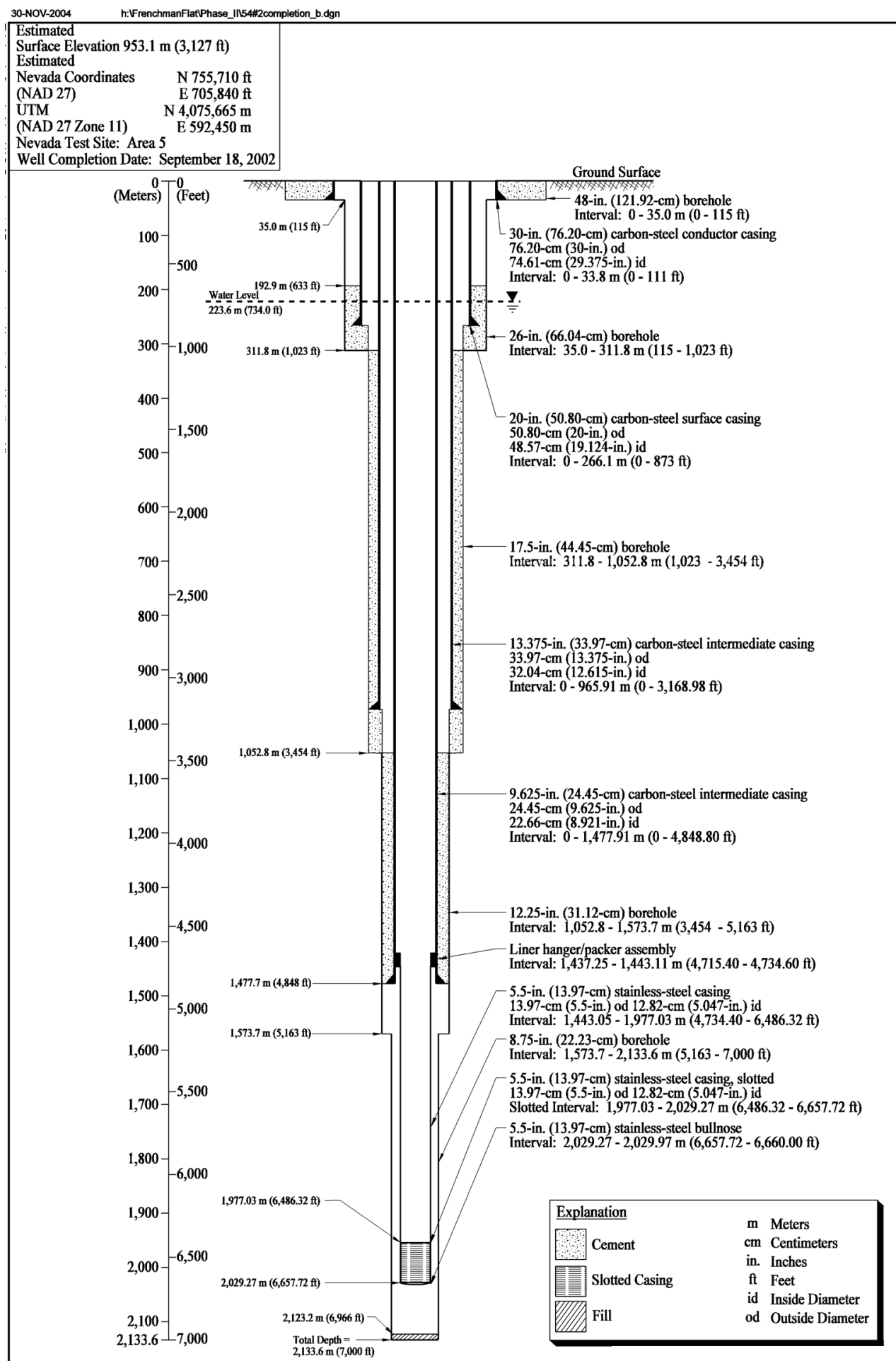

Source: IT (2003)

Figure D.1-5

Well Completion Diagram for Well ER-5-4 \#2 


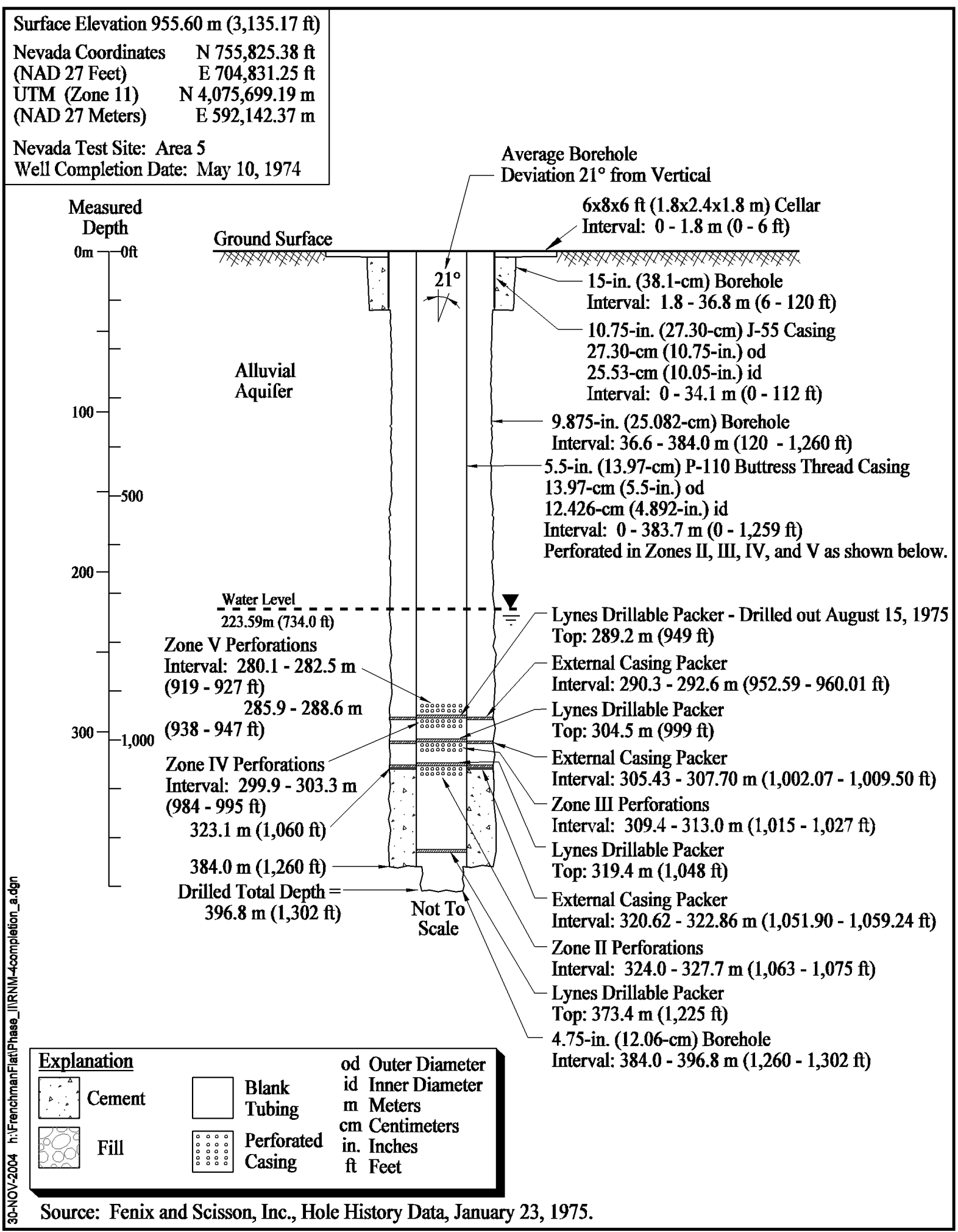

Figure D.1-6

Well Completion Diagram for Well RNM-1 
Surface Elevation $953.66 \mathrm{~m}(3,128.80 \mathrm{ft})$

Nevada Coordinates N $755,264.43 \mathrm{ft}$

(NAD 27 Feet) E 705,088.20 ft

UTM (Zone 11) N 4,075,528.53 m

(NAD 27 Meters) E 592,221.27 m

Nevada Test Site: Area 5

Well Completion Date: August 2, 1974

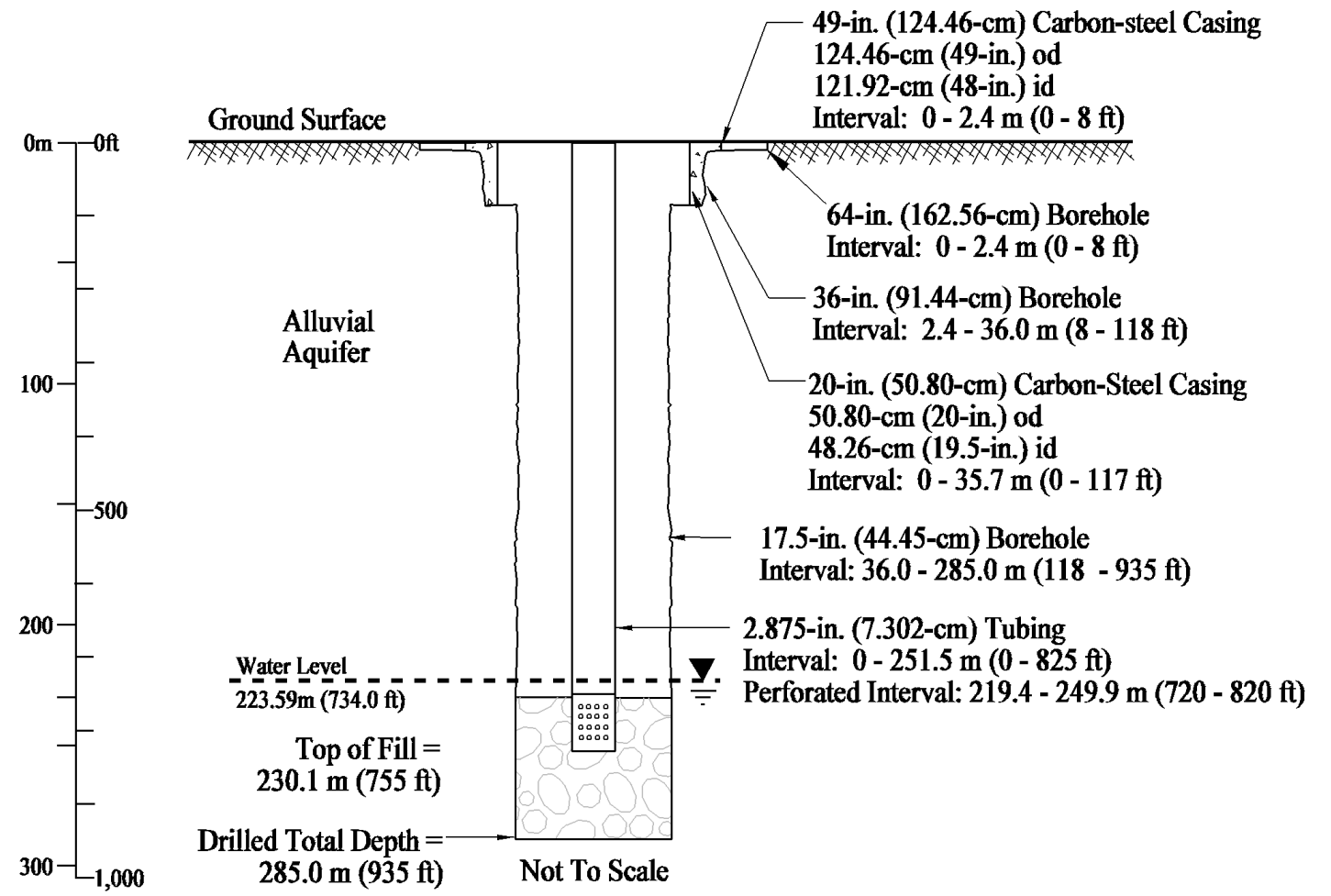

\begin{tabular}{|c|c|c|c|c|}
\hline \multicolumn{3}{|c|}{ Explanation } & \multirow[b]{2}{*}{$\begin{array}{l}\text { Blank } \\
\text { Tubing }\end{array}$} & \multirow{2}{*}{$\begin{array}{l}\text { od Outer Diameter } \\
\text { id Inner Diameter } \\
\text { m Meters }\end{array}$} \\
\hline \begin{tabular}{|l|}
$\because{ }^{\Delta}$ \\
$\therefore$
\end{tabular} & Cement & & & \\
\hline 509 & Fill & 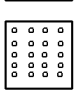 & $\begin{array}{l}\text { Perforated } \\
\text { Casing }\end{array}$ & $\begin{array}{l}\text { cm Centimeters } \\
\text { in. Inches } \\
\text { ft Feet }\end{array}$ \\
\hline
\end{tabular}

Source: Fenix and Scisson, Inc., Hole History Data, January 23, 1975.

Figure D.1-7

Well Completion Diagram for Well RNM-2 


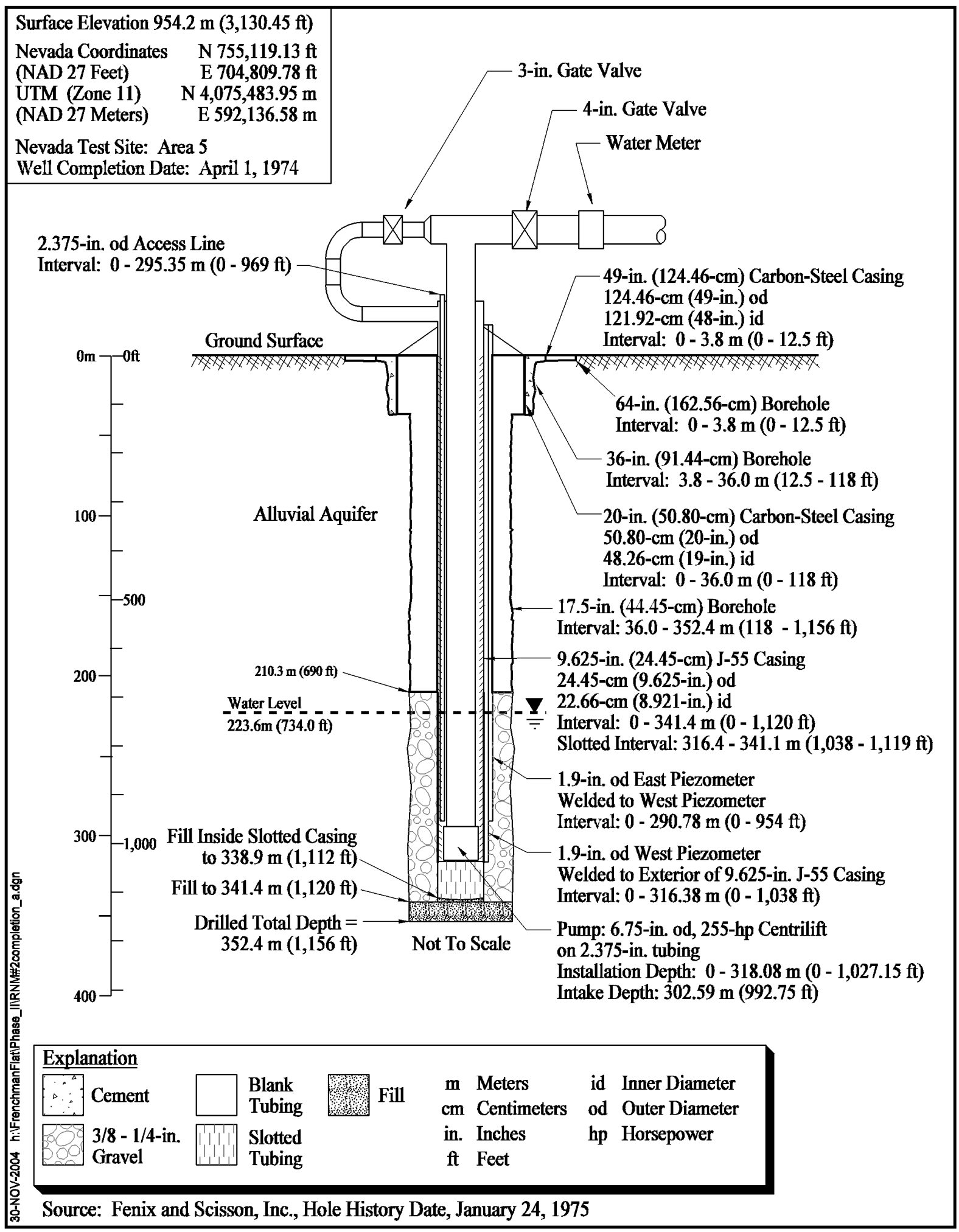

Figure D.1-8

Well Completion Diagram for Well RNM-2S 


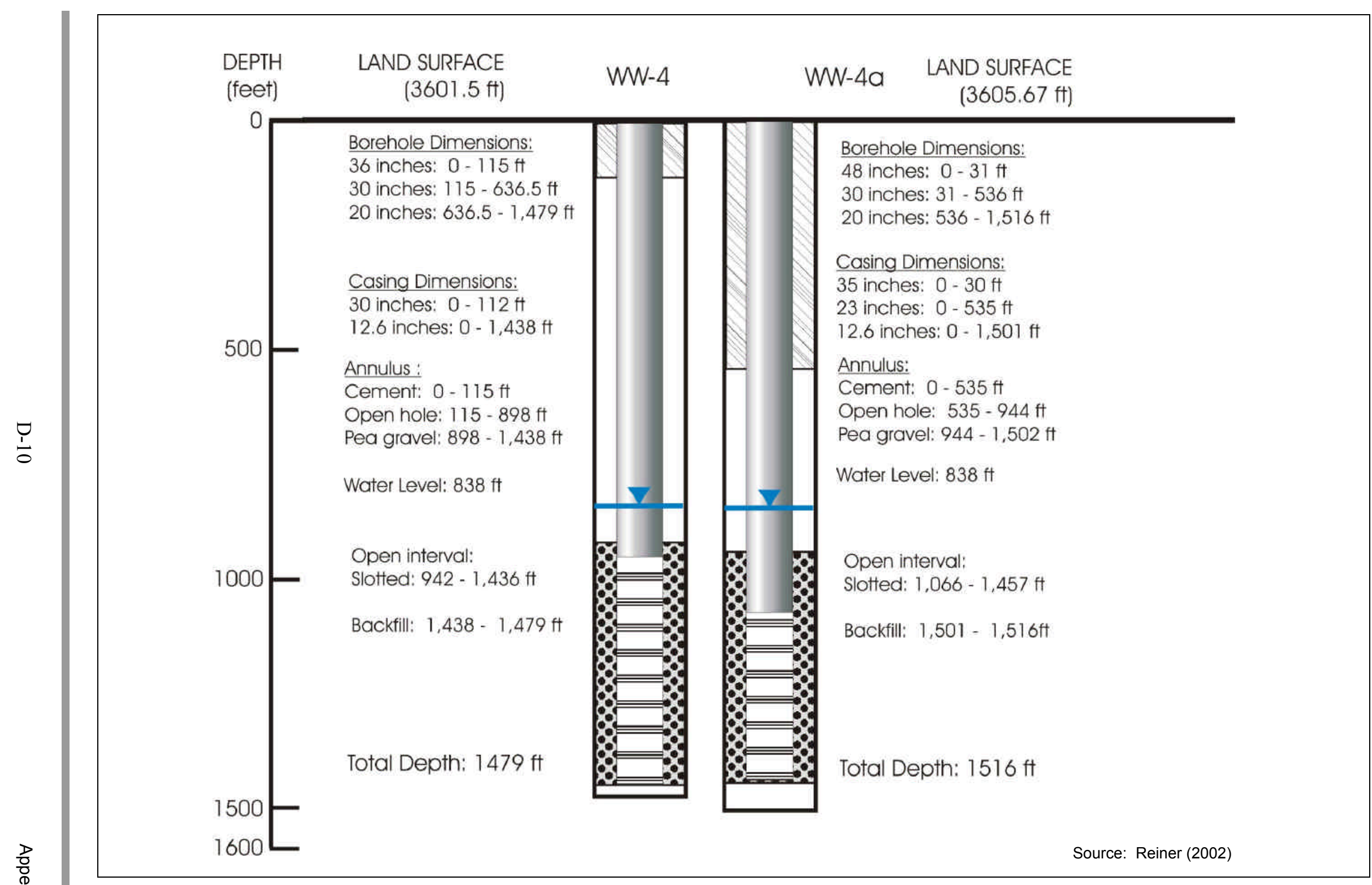

Figure D.1-9

Well Completion Diagram for Wells WW4 and WW-4A 


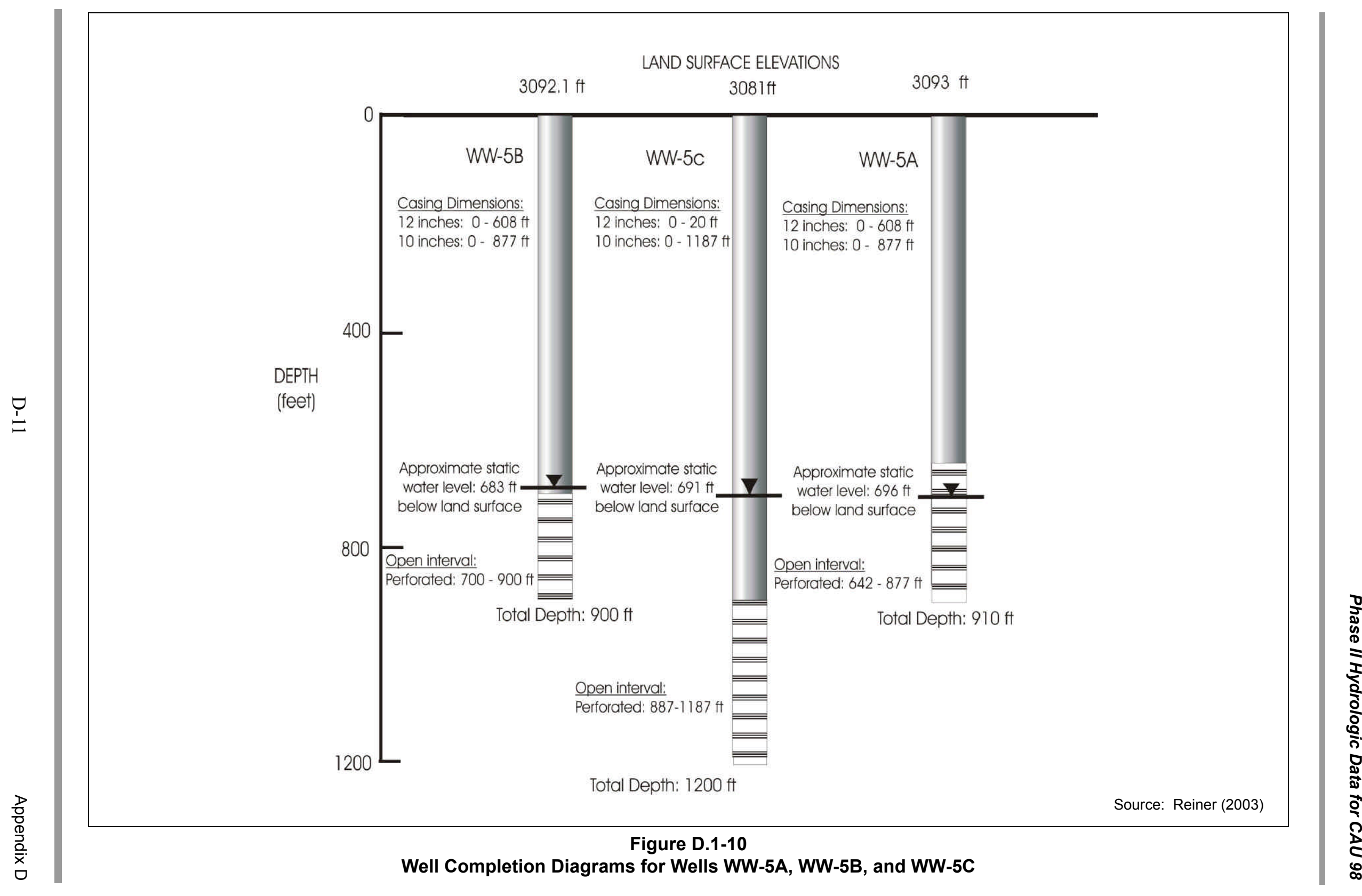




\section{D.2.0 References}

Fenix \& Scisson, Inc. 1975. Hole History Data. Las Vegas, NV.

IT Corporation. 2000. Frenchman Flat Well Cluster ER-5-3 and ER-5-3 \#2 Data Report, Preliminary. Rev. 0. Las Vegas, NV.

IT Corporation. 2001a. Addendum to the Frenchman Flat Well Cluster ER-5-3 \#3 Data Report, Preliminary. Rev. 0. Las Vegas. NV.

IT Corporation. 2001b. Frenchman Flat ER-5-4 Well Data Report, Preliminary, Rev. 0. Las Vegas, NV.

IT Corporation. 2003. Frenchman Flat ER-5-4 \#2 Well Data Report, Preliminary, Rev. 0. Las Vegas, NV.

Reiner, S. 2002. Aquifer-Test Report for WW-4A, Area 6, Nevada Test Site. Carson City, NV: U.S. Geological Survey.

Reiner, S. 2003. Aquifer-Test Report for WW-5C, Area 5, Nevada Test Site. Carson City, NV: U.S. Geological Survey. 
Appendix E

Boundary Flux Calculations 


\section{E.1.0 Introduction}

The Frenchman Flat CAU investigation area includes the Frenchman Flat basin located between the uplands defined by the Massachusetts Mountains to the north, the Ranger Mountains to the southeast, and Mount Salyer to the west. Frenchman Playa is located near the center of the basin. Frenchman Flat was the site of 10 underground nuclear tests with all but one test (CAMBRIC) located above the water table. Seven of the ten nuclear tests were conducted in the central portion of the Frenchman Flat alluvial basin, this portion of the investigation area contains the highest density of boreholes. The deepest HSU identified in the Frenchman Flat area is the Paleozoic LCCU. Above the LCCU, the entire Frenchman Flat basin is believed to be underlain by Paleozoic carbonates that constitute the dominant aquifer in southern Nevada. The flow system above the regional aquifer is comprised of volcanic and alluvial hydrostratigraphic units through which radionuclides from the nuclear tests may migrate to reach the regional groundwater aquifer. The flow system includes areas within and around the NTS as shown in Figure E.1-1. As a precursor to the CAU-scale modeling of the Frenchman Flat flow system, groundwater fluxes need to be estimated to serve as constraints for the lateral fluxes at the boundaries of the CAU-flow model.

It is impractical to directly measure the groundwater fluxes at the spatial frequency needed to describe the fluxes at the Frenchman Flat CAU-scale flow model boundaries. An acceptable alternative (deriving boundary fluxes for the CAU flow model) is based upon interpolation of fluxes generated from a calibrated regional-scale flow model. Such an approach is common practice and is described in Ward et al. (1987). For the case of Frenchman Flat, the NTS regional-flow model is the logical choice as a source for determining boundary fluxes for the more refined CAU-scale modeling effort.

In developing the data needed for the CAU-scale model, the uncertainty associated with the estimated boundary fluxes must also be considered. It is assumed that some measure of this uncertainty can be captured by considering a number of alternate recharge and HSU models in the regional-scale model and noting the variations in the simulated boundary fluxes.

The boundary fluxes generated from regional model simulations will be used to provide bounds on the net flux into or out of each of the CAU-scale model boundaries. The precise distribution of the flux in the regional model will not be required to be replicated in the $\mathrm{CAU}$ model; however, translation from the lateral boundary fluxes developed here into the CAU-scale model will be accomplished during the CAU model domain FEHM grid construction. In this way, differences in the amount of detail between the two models will not lead to an inappropriate comparison of fluxes at the CAU scale. 


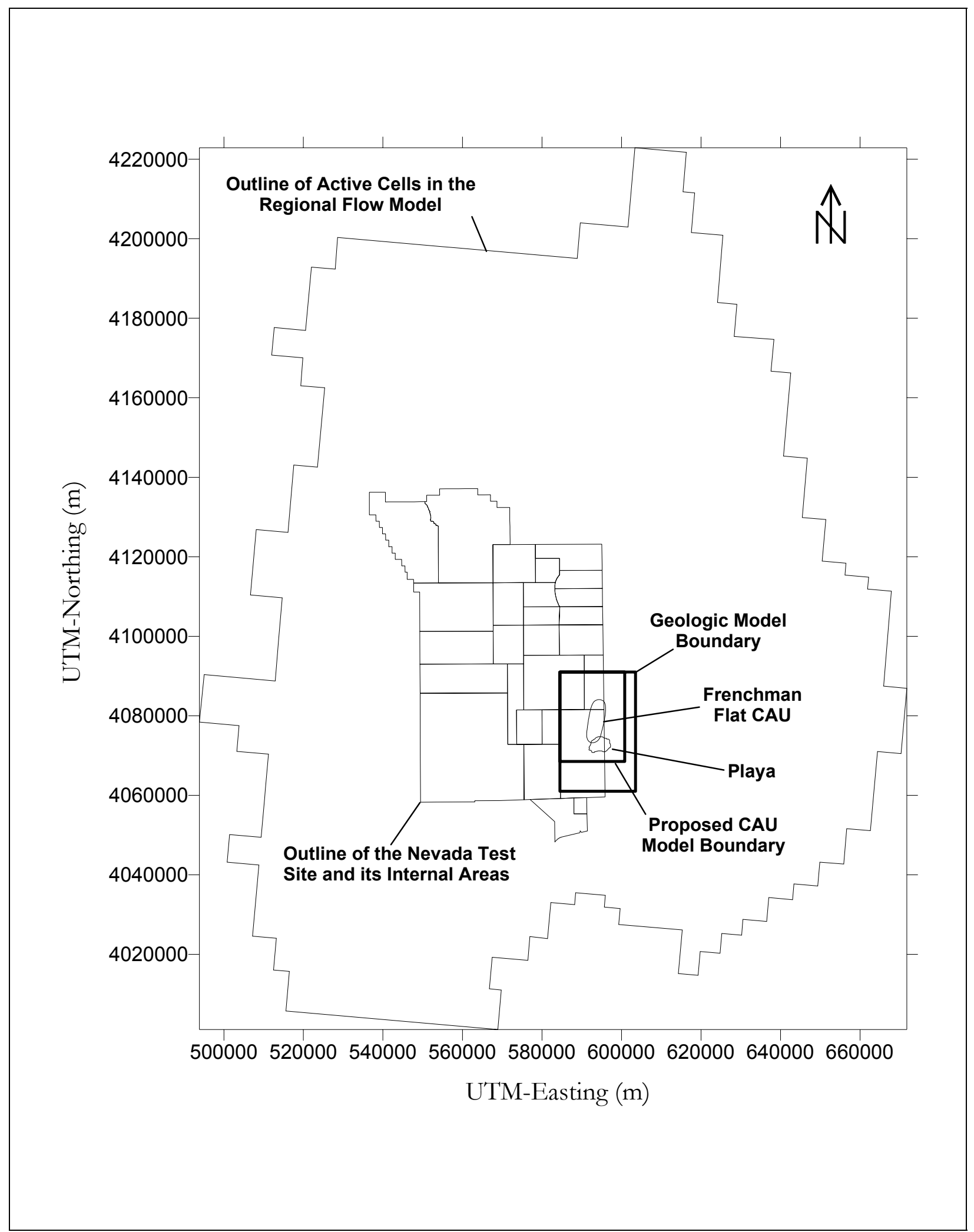

Figure E.1-1

Geologic and Proposed CAU Model Boundaries 
The numerical model grid was based on the regional model with the Pahute Mesa-Oasis Valley update (SNJV, 2004). The number of rows and columns and the horizontal discretization was not altered. Layer elevations were constant throughout the model area. Because the HSU elevations vary spatially and there are more HSU layers than model layers, each model layer may contain one or more HSU. For each model cell, the horizontal hydraulic conductivity was calculated as the weighted arithmetic average of the HSU conductivities in that cell. Vertical hydraulic conductivity was calculated as the weighted harmonic average of the HSU vertical conductivities in a given model cell. Although the same number of model layers was used as in the Pahute Mesa-Oasis Valley regional model, the vertical discretization was altered to focus refinement on the HSUs in the Frenchman Flat basin. This allowed better calculation of average properties in Frenchman Flat because highly transmissive units were kept together while confining units were grouped. Table E.1-1 lists the basal elevations and layer thicknesses of the model layers.

Table E.1-1

Model Layer Elevations and Thickness

\begin{tabular}{|c|c|c|}
\hline Layer & Basal Elevation (ft amsl) & Thickness (ft) \\
\hline 1 & 1,750 & 250 \\
\hline 2 & 1,500 & 250 \\
\hline 3 & 1,350 & 150 \\
\hline 4 & 1,200 & 150 \\
\hline 5 & 1,050 & 150 \\
\hline 6 & 900 & 150 \\
\hline 7 & 825 & 75 \\
\hline 8 & 775 & 50 \\
\hline 9 & 700 & 75 \\
\hline 10 & 550 & 150 \\
\hline 11 & 350 & 200 \\
\hline 12 & 250 & 100 \\
\hline 13 & 150 & 100 \\
\hline 14 & 50 & 100 \\
\hline 15 & -250 & 300 \\
\hline 16 & -450 & 200 \\
\hline 17 & -850 & 400 \\
\hline 18 & -1230 & 380 \\
\hline 19 & -1500 & 270 \\
\hline 20 & -2000 & 500 \\
\hline 21 & -3000 & 1,000 \\
\hline 22 & -4000 & 1,000 \\
\hline
\end{tabular}




\section{E.2.0 Models Evaluated in the Calibration Process}

\section{E.2.1 Hydrostratigraphic Model Alternatives}

The HSU model of the NTS regional groundwater flow model was updated with a base case Frenchman Flat HSU model and four alternatives to account for uncertainty of the boundary fluxes resulting from alternative geologic models. During the final stages of Frenchman Flat hydrostratigraphic model development, magnetotelluric data of the CP Basin became available that resulted in a change to the base hydrostratigraphic model. As a result, the configuration of CP Basin in each of the alternative hydrostratigraphic models used for calculating lateral-boundary fluxes is consistent with hydrostratigraphic model Alternative \#4. The base and alternative hydrostratigraphic models are detailed in Section 2.0 of this document.

\section{E.2.2 Recharge Distribution Models}

The recharge distribution models are described in detail in Section 6.0 of this document. The total rates of areal recharge for the six recharge models are listed in Table E.2-1. This table shows nearly a factor of two difference between the recharge model with the lowest total recharge rate (USGS with no redistribution) and that with the highest total rate (DRI with alluvial mask). Recharge into the Frenchman Flat Basin is very small (see Table 9-5 in Section 9.0) compared to model-wide recharge. Recharge in Frenchman Flat is also small compared to the total inflow and outflows shown in Table 9-5. Accordingly, the recharge in Frenchman Flat appears to have no correlation to the magnitude or direction of the lateral boundary fluxes.

Table E.2-1

Recharge Model Flux Rates

\begin{tabular}{|c|c|c|}
\hline Recharge Model Name & Recharge Model & Recharge Rate $\left(\mathbf{m}^{\mathbf{3}} / \mathbf{d}\right)$ \\
\hline \hline R1 & UGTA Original Regional & 220,000 \\
\hline R2 & UGTA Revised Regional & 212,000 \\
\hline R3 & DRI alluvial mask & 275,000 \\
\hline R4 & DRI - alluvial and elevation mask & 268,000 \\
\hline R5 & USGS - with redistribution & 173,000 \\
\hline R6 & USGS - no redistribution & 143,000 \\
\hline
\end{tabular}




\section{E.2.3 Models Calibrated}

Based upon the combinations of HSU and recharge models described above, 30 separate groundwater flow models were calibrated to produce a range of boundary fluxes for guiding the CAU flow modeling. The 30 model codes and the corresponding model names are listed in Table E.2-2.

Table E.2-2

Model Designations for the 30 Combinations of Hydrostratigraphic and Recharge Models

\begin{tabular}{||l|c|c|c|c|c|c|c||}
\hline \multicolumn{2}{|c|}{} & \multicolumn{7}{c|}{ Recharge Model } \\
\cline { 3 - 9 } & & $\begin{array}{c}\text { UGTA } \\
\text { Original } \\
\text { R1 }\end{array}$ & $\begin{array}{c}\text { UGTA } \\
\text { Revised } \\
\text { R2 }\end{array}$ & $\begin{array}{c}\text { DRI - } \\
\text { Alluvial } \\
\text { Mask } \\
\text { R3 }\end{array}$ & $\begin{array}{c}\text { DRI - Alluvial } \\
\text { and Elevation } \\
\text { Mask } \\
\text { R4 }\end{array}$ & $\begin{array}{c}\text { USGS - No } \\
\text { Redistribution } \\
\text { R5 }\end{array}$ & $\begin{array}{c}\text { USGS - } \\
\text { Redistribution } \\
\text { R6 }\end{array}$ \\
\hline \hline Base & G0 & G0R1 & G0R2 & G0R3 & G0R4 & G0R5 & G0R6 \\
\hline $\begin{array}{l}\text { Aquifer Juxtaposition } \\
\text { Alternative }\end{array}$ & G1 & G1R1 & G1R2 & G1R3 & G1R4 & G1R5 & G1R6 \\
\hline $\begin{array}{l}\text { More Extensive } \\
\text { Basalt Flow Alternative }\end{array}$ & G2 & G2R1 & G2R2 & G2R3 & G2R4 & G2R5 & G2R6 \\
\hline $\begin{array}{l}\text { No Detachment } \\
\text { Fault Alternative }\end{array}$ & G3 & G3R1 & G3R2 & G3R3 & G3R4 & G3R5 & G3R6 \\
\hline CP Basin Alternative & G4 & G4R1 & G4R2 & G4R3 & G4R4 & G4R5 & G4R6 \\
\hline
\end{tabular}




\section{E.3.0 Calibration Process}

The model calibration process is comprised of adjusting various model parameters until an acceptable agreement between simulated values and those measured in the groundwater system is achieved. For these simulations, the horizontal hydraulic conductivity was the model parameter that was adjusted until the optimal value was estimated.

Because of the large number of models to be calibrated (thirty), an automated calibration approach was deemed necessary. PEST (Doherty, 2002) was chosen as the tool for this parameter estimation exercise. Prior to running PEST, attempts were made to simplify the complexity of the model by reducing the number of parameters to be estimated. The vertical anisotropy in hydraulic conductivity and the depth decay parameters were held constant and only the horizontal hydraulic conductivity was varied during the calibration process.

In most cases, values for depth decay and anisotropy were taken from the regional model with the Pahute Mesa-Oasis Valley HSU framework (SNJV, 2004). Where the depth decay parameter was outside the 95 -percent confidence intervals presented in DOE/NV (1997) the depth decay parameter was changed to the mean value presented in the same report. In several cases, where the vertical anisotropy values for confining units appeared unreasonably high (e.g., 0.5), the vertical anisotropy parameter was lowered to 0.01 , a value more reasonable for regional scale models (Anderson and Woessner, 1992). Table E.3-1 lists the vertical anisotropy and depth decay parameter (lambda) for each HSU within the Frenchman Flat HSU model boundary. Figure E.3-1 depicts the zone maps for parameters that were varied by zone within the CAU-flow model domain.

In the Pahute Mesa-Oasis Valley regional model (SNJV, 2004), 14 of the HSUs were broken up into zones between which the hydraulic properties were varied during calibration. An attempt was made to simplify the model by removing these zones and applying uniform properties across a single HSU; however, this resulted in a significantly poorer calibration result. Therefore, the pre-existing zones were retained in this calibration. No additional zones were added to the HSUs. Four of the zone maps contained variations within the Frenchman Flat HSU model boundary as shown in Figure E.3-1.

The drain conductance at each of the 103 drains used to represent spring discharge zones in the model is a function of both the hydraulic conductivity surrounding the spring and the spring geometry. Because the spring geometry is unknown, the conductance value is also unknown. Accordingly, the conductance at the springs was adjusted during calibration to better match the hydraulic head and flow at the eight groups of springs representing discharge areas in the regional model domain. 
Table E.3-1

Vertical Anisotropy Factors and Depth Decay Coefficients for Frenchman Flat HSUs

\begin{tabular}{|c|c|c|c|c|}
\hline HSU Name & HSU Description & Zone & Anisotropy & Lambda \\
\hline \multirow{2}{*}{$\mathrm{AA}$} & \multirow{2}{*}{ Alluvial Aquifer } & $1,4,5$ & 0.22 & 0.00563 \\
\hline & & 7 & 0.016 & 0.00563 \\
\hline PCU2T & Playa Confining Unit & & 0.01 & 0.00563 \\
\hline PCU2B & Alluvial Aquifer & & 0.01 & 0.00563 \\
\hline OAA1 & Older Altered Alluvial Aquifer & & 0.22 & 0.00563 \\
\hline BLFA & Basalt Lava Flow Aquifer & & 0.02 & 0.0026 \\
\hline PCU1U & Older Playa Confining Unit - Upper & & 0.01 & 0.00563 \\
\hline AA1 & Alluvial Aquifer & & 0.22 & 0.00563 \\
\hline OAA & Older Altered Alluvial Aquifer & & 0.22 & 0.00563 \\
\hline PCU1L & Older Playa Confining Unit - Lower & & 0.01 & 0.00563 \\
\hline \multirow{2}{*}{ VA } & \multirow{2}{*}{ Volcanic Tuff Aquifer } & 1,2 & 0.02 & 0.0026 \\
\hline & & 4 & 0.002 & 0.0026 \\
\hline TMLVTA & Timber Mountain Lower Vitric Tuff Aquifer & & 0.08 & 0.0026 \\
\hline UTCU & Upper Tuff Confining Unit & & 0.01 & 0.0026 \\
\hline TSA & Topopah Spring Aquifer & & 0.08 & 0.0026 \\
\hline LVTA & Lower Vitric Tuff & & 0.08 & 0.0026 \\
\hline \multirow{2}{*}{ VCU } & \multirow{2}{*}{ Volcanic Confining Unit } & 1,4 & 0.01 & 0.0026 \\
\hline & & 2 & 0.002 & 0.0026 \\
\hline WCU & Wahmonie Confining Unit & & 0.01 & 0.0026 \\
\hline LTCU1 & Lower Tuff Confining Unit & & 0.01 & 0.0026 \\
\hline VCUff & Volcaniclastic Confining Unit & & 0.01 & 0.0026 \\
\hline LCA3 & Lower Carbonate Aquifer & & 0.02 & 0.001 \\
\hline UCCU & Upper Clastic Confining Unit & & 0.01 & 0.00102 \\
\hline LCA & Lower Carbonate Aquifer & 1,7 & 0.015 & 0.001 \\
\hline LCCU & Lower Clastic Confining Unit & & 0.01 & 0.00102 \\
\hline
\end{tabular}

Rather than adjust the conductance at the 103 drains individually, the conductance was adjusted only by spring group and remained uniform within each of the eight groups.

Preliminary runs of PEST showed that the model was insensitive to the hydraulic conductivity of several HSUs and HSU zones and these parameters were held constant at initial values during calibration. The total number of parameters estimated during the calibration was thereby reduced to 118 from 236 possible calibration parameters. During the PEST calibration, the 110 hydraulic conductivity and 8 conductance parameters were allowed to vary up or down one order of magnitude from their initial values. This variation was generally well within the 95-percent confidence limits for the hydraulic conductivity where it was estimated in Frenchman Flat (see Section 5.0). Confidence limits for hydraulic conductivity in the remaining HSUs could not be estimated from published data sets because depths have not been reported along with hydraulic conductivity ranges, thus making it difficult to assess whether the calibrated values are consistent with measurements. 


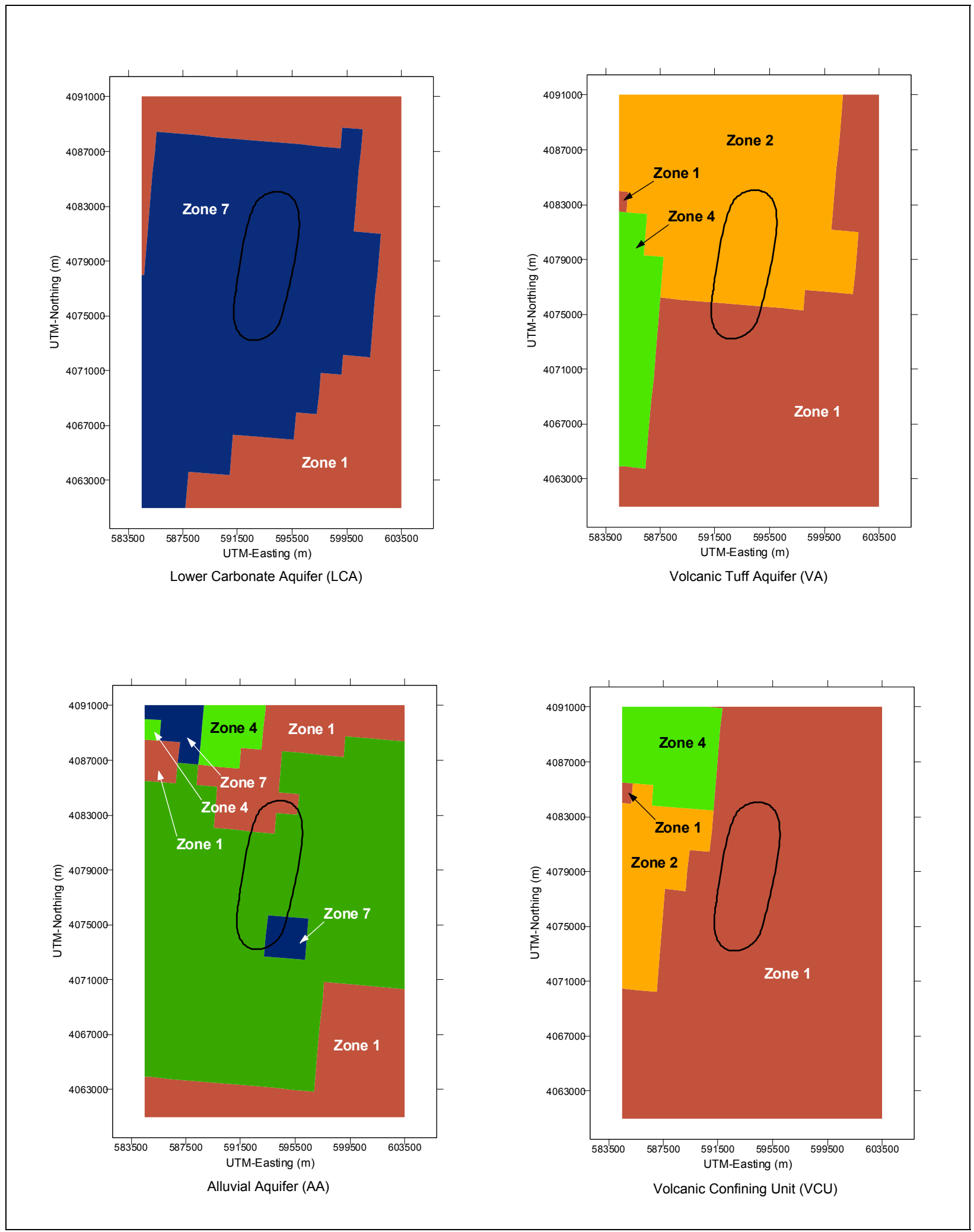

Figure E.3-1

Property Zone Maps for Frenchman Flat HSUs 
Applying the CP Basin alternative geologic model (G4), PEST was used to calibrate the regional-scale model for each of the six recharge models. Therefore, six different realizations of hydraulic conductivity distributions were derived. For a given recharge model, changing the geologic model had little impact on the hydraulic heads. In addition, calibration statistics were not improved by using PEST to calibrate for subsequent geologic models. Therefore, for a given recharge model, the calibrated hydraulic conductivity of each HSU that were derived for the first geologic model were used for all other geologic model cases. This effectively reduced the number of PEST calibration runs to six, one for each recharge model.

\section{E.3.1 Calibration Criteria}

The primary calibration target for the regional-scale model was hydraulic head with a total of 802 water-level measurements being included in the calibration process. In addition to hydraulic head, the net flows at eight grouped spring locations and two grouped general-head boundary location were included as calibration targets. The hydraulic heads at the discharge areas (103 drain cells) were also included as targets if the simulated head was more than 10 meters above the drain elevation or at any height below the drain elevation. This was done to avoid the situation of arbitrarily low drain conductances resulting in unrealistically high water-levels in the discharge cells in an attempt to meet the discharge flow targets. In this way, both the flows and hydraulic heads in the discharge cells were considered in the calibration.

The hydraulic heads in the Frenchman Flat area of the model were assigned a weight ten times higher than that of the other hydraulic head data in an effort to give this area of the model preference during the calibration. The flow targets at the springs and general-head-boundaries were assigned weights 100 times lower than the majority (not including those in the Frenchman Flat area) of the hydraulic head data based on the higher magnitude of the variation in simulated flows. Thus, the Frenchman Flat hydraulic heads and the discharge flows constituted a significant portion of the objective function used in PEST without outweighing the other calibration targets.

The calibration criteria as given in DOE/NV (1997) are presented in Table E.3-2. These criteria include grouping the hydraulic head targets by area and calculating summary statistics for each group. A map of the residual zones is depicted in Figure E.3-2. The calibration criteria for discharge areas are listed in Table E.3-3 and are based on minimum and maximum values in SNJV (2004). 
Table E.3-2

Calibration Criteria for Weighted

Hydraulic Head Residuals by Zone (DOE/NV, 1997)

\begin{tabular}{|c|c|c|c|c|}
\hline Zone & Area & Mean Weighted & $\begin{array}{c}\text { Root Mean } \\
\text { Square of } \\
\text { Weighted } \\
\text { Residuals (m) }\end{array}$ & $\begin{array}{c}\text { Range in } \\
\text { Measured } \\
\text { Heads (m) }\end{array}$ \\
\hline \hline All & Northern Area & 100 & 100 & 1687 \\
\hline 1 & Oasis Valley & 15 & 150 & 203 \\
\hline 2 & Pahute Mesa & 25 & 75 & 534 \\
\hline 3 & Barrier & 300 & 35 & 231 \\
\hline 4 & W Yucca Flat & 45 & 350 & 565 \\
\hline 5 & E Yucca Flat & 35 & 110 & 632 \\
\hline 6 & Shoshone & 20 & 80 & 101 \\
\hline 7 & Death Valley & 80 & 50 & 286 \\
\hline 8 & Lower Carbonate Aquifer & 5 & 100 & 728 \\
\hline 9 & SW of Pahranagat Valley & 40 & 40 & 205 \\
\hline 10 & Spring Mountain & 150 & 40 & 15 \\
\hline 11 & Sheep Range & 100 & 150 & 279 \\
\hline 12 & Timber Mountain & 100 & 100 & 40 \\
\hline 13 & Amargosa Farm & 10 & 50 & 221 \\
\hline 14 & Frenchman Flat & 10 & 58 & 21 \\
\hline 15 & & & & 5 \\
\hline
\end{tabular}

Table E.3-3

Calibration Target Range for Model-Area Discharge (SNJV, 2004)

\begin{tabular}{|c|c|}
\hline Discharge Area & Total Discharge Range $\left(\mathbf{m}^{3} / \mathbf{d}\right)$ \\
\hline Death Valley & $17,500-60,200$ \\
\hline Oasis Valley & $14,089-30,152$ \\
\hline Amargosa River & $2,400-5,100$ \\
\hline Ash Meadows & $33,484-95,527$ \\
\hline Franklin Lake/Alkali Flats & $800-42,600$ \\
\hline Alkali Flat (Peter's Playa) & $5,000-7,300$ \\
\hline Penoyer Valley & $13,000-27,000$ \\
\hline Indian Springs & $1,600-2,400$ \\
\hline Pahrump Valley & $(5,000)-(7,600)$ \\
\hline Eagle Mountain & $850-3,400$ \\
\hline
\end{tabular}

Brackets denotes inflow 


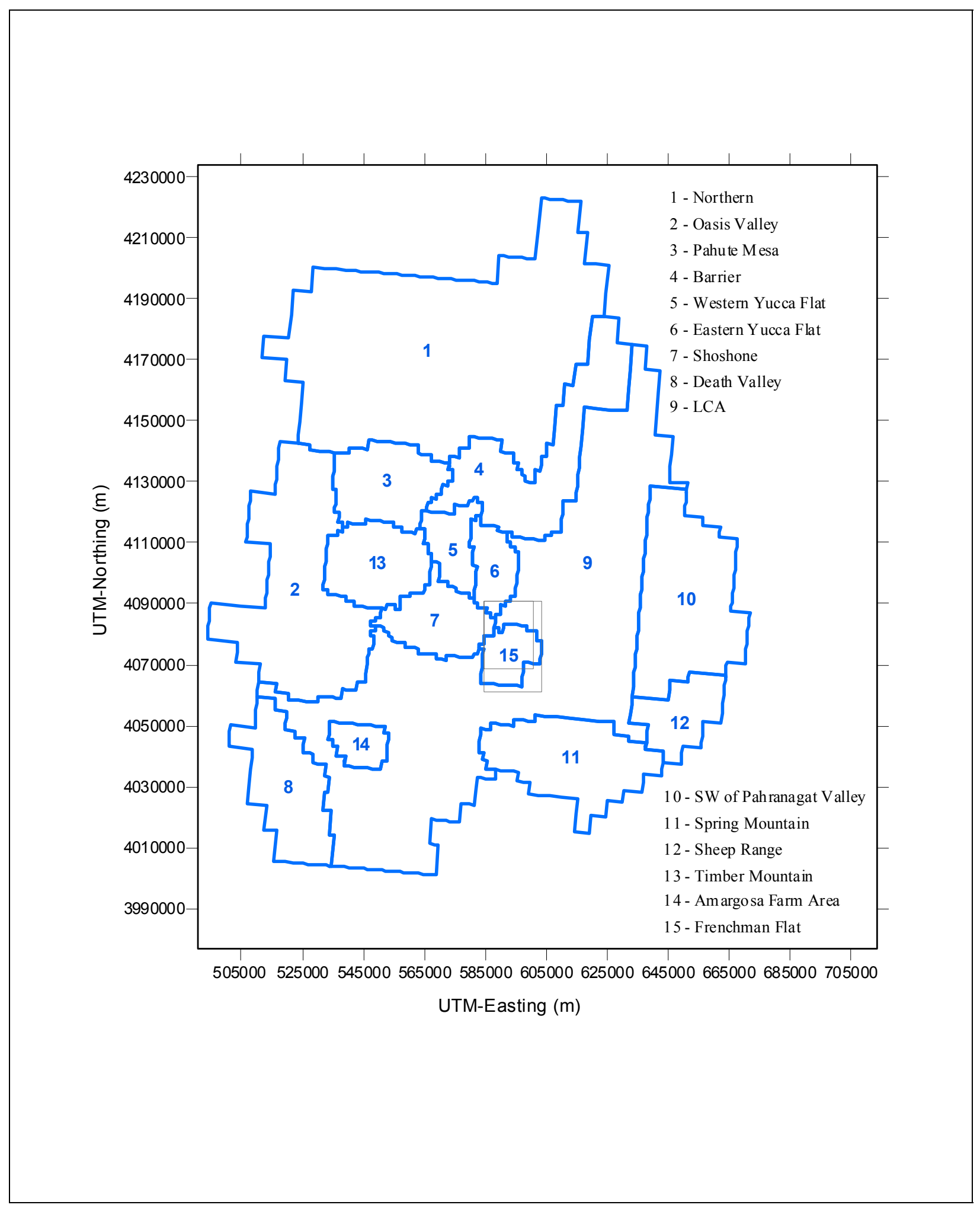

Figure E.3-2

Map of Residual Zones 


\section{E.4.0 Calibration Results}

The calibration efforts produced a set of thirty results that were used to generate boundary conditions for use in the CAU flow model. Root mean square (RMS) of weighted residual values for individual residual zones and all targets are presented in Table E.4-1. Residual values were calculated as the difference between the observed and simulated hydraulic heads. The weighted residual was calculated as the residual divided by the standard deviation in the measured values at a given target location. Mean weighted residual values are presented in Table E.4-2. The absolute residual (not weighted) for each of the wells completed within the alluvium in the Frenchman Flat area are shown in Table E.4-3. The DRI alluvial mask recharge model resulted in the least deviation from the targets in the FF alluvium. This observation was independent of the HSU model. Simulated discharge rates for each alternative model are presented in Table E.4-4.

Water table contours for six regional-scale flow models using the base case HSU model are presented in Figures E.4-1 through E.4-7. Figure E.4-2 through Figure E.4-7 each correspond to a different recharge model. Figure E.4-1 presents the same data for groundwater flow model GOR1 as Figure E.4-2, but on a topographic relief map for reference. For a given recharge model, water table contours for all other geologic models were very similar.

A satisfactory calibration was achieved for all cases. When all targets are considered, the root mean square of the weighted residuals are well within the criteria specified in Table E.3-2. When individual areas are considered, all but a few areas also meet their individual calibration criteria. The Oasis Valley RMS values exceed the criteria for recharge model R6 but by less than one meter. In Pahute Mesa, the RMS criteria are exceeded for recharge models R2 and R6 but only slightly. The RMS criteria are not met in the Shoshone area and the area southwest of Pahranagat Valley (for recharge models R1, R2 and R5) but these areas have only four and five target data, respectively. Small numbers of calibration targets within a given area cause significant increases in uncertainty and provide little constraint for PEST calibration. The Western Yucca Flat area residuals exceed the RMS criteria for recharge models R1, R2, R3, R4, and R6. This is probably a result of the extreme topographical and groundwater gradients in this region of the model resulting from the rapid change in depth of the UCCU (see Figures E.4-1 through E.4-7). In the majority of the Frenchman Flat area, RMS values are generally only a few meters, and are well within the calibration criterion for all of the alternative models.

The mean weighted residuals (Table E.4-2), when all targets are considered, are within the calibration criteria specified in Table E.3-2, with the exception of only three alternatives where the mean residuals are a few meters higher than the target 
Table E.4-1

Root Mean Square (m) of Weighted Residuals for Individual Residual Zones and Combined Zones

\begin{tabular}{|c|c|c|c|c|c|c|c|c|c|c|c|c|c|c|c|c|}
\hline $\begin{array}{l}\bar{d} \\
\frac{\Phi}{\Xi} \\
\Sigma \\
\Sigma\end{array}$ & $\bar{\varepsilon}$ & 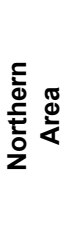 & 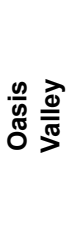 & 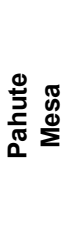 & 㐫 & 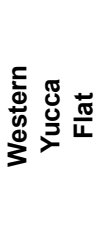 & 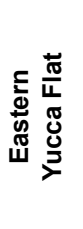 & $\begin{array}{l}\stackrel{0}{0} \\
\frac{0}{\omega} \\
\frac{5}{\omega} \\
\frac{1}{\omega}\end{array}$ & 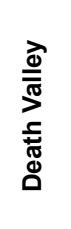 & 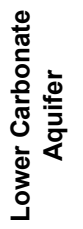 & 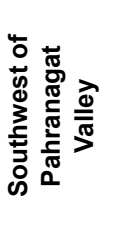 & 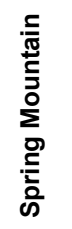 & 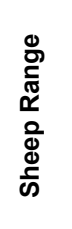 & 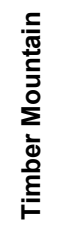 & 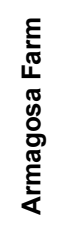 & 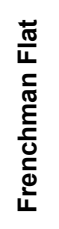 \\
\hline$\overline{\text { G0R1 }}$ & 49.3 & 59.5 & 55 & 28.9 & 126.5 & 137.4 & 36.7 & 159.3 & 27.2 & 16 & 255.5 & 477.4 & 30.7 & 32 & 6.3 & 2.7 \\
\hline G0R2 & 52.5 & 69.5 & 62.2 & 39.3 & 133.9 & 152.1 & 25 & 167.9 & 39 & 11.5 & 71.4 & 43.7 & 15.5 & 38.6 & 5.2 & 4.2 \\
\hline G0R3 & 56 & 74.3 & 51.7 & 27.7 & 123.4 & 185.7 & 37 & 151.2 & 29.4 & 20 & 23.5 & 48.4 & 43.5 & 30.3 & 10.1 & 2.8 \\
\hline G0R4 & 56.1 & 73.4 & 50 & 28.3 & 127.9 & 187.2 & 25.6 & 137.7 & 32.6 & 29.4 & 11.5 & 51.2 & 29.1 & 54.9 & 6.8 & 2.6 \\
\hline G0R5 & 44.9 & 59 & 58.8 & 33.6 & 133.8 & 97.8 & 23.5 & 159.4 & 30.1 & 15.4 & 83.1 & 52.2 & 23.5 & 38.4 & 5.1 & 2.8 \\
\hline G0R6 & 67.6 & 70.2 & 75.6 & 47.7 & 159.1 & 209.1 & 32.6 & 181.7 & 24.6 & 12.4 & 25.8 & 86.9 & 46.9 & 81.2 & 6.9 & 9.5 \\
\hline G1R1 & 49.5 & 59.5 & 55 & 28.9 & 126.6 & 139.6 & 36.7 & 157.7 & 27.2 & 16 & 55.6 & 47.3 & 30.7 & 32 & 6.3 & 2.7 \\
\hline G1R2 & 52.1 & 69.6 & 62.2 & 39.3 & 134.9 & 146.7 & 25.1 & 174 & 39 & 11.5 & 71.4 & 43.7 & 15.5 & 38.6 & 5.2 & 4.2 \\
\hline G1R3 & 57.9 & 74.8 & 51.6 & 27.3 & 123.6 & 198.7 & 36.1 & 150.1 & 29.3 & 20.3 & 23.5 & 48.5 & 43.5 & 31.4 & 10 & 2.9 \\
\hline G1R4 & 47.4 & 73.6 & 50.3 & 28.7 & 143.6 & 111.6 & 27.8 & 139 & 33 & 28.4 & 11.6 & 51.2 & 29 & 60 & 6.8 & 2.5 \\
\hline G1R5 & 45.1 & 59 & 58.8 & 33.6 & 133.3 & 100.1 & 23.5 & 158.4 & 30.1 & 15.4 & 83.1 & 52.2 & 23.5 & 38.3 & 5.1 & 2.8 \\
\hline G1R6 & 70.8 & 70.6 & 75.6 & 47.2 & 161.9 & 229.8 & 33.3 & 181.1 & 24.6 & 12.4 & 25.8 & 86.9 & 46.9 & 81.6 & 6.9 & 9.4 \\
\hline $\bar{G} 2 \mathrm{R} 1$ & 48.2 & 59.5 & 55 & 28.9 & 126.5 & 128.7 & 36.7 & 157.8 & 27.2 & 16 & 55.5 & 47.3 & 30.7 & 32.1 & 6.3 & 2.7 \\
\hline G2R2 & 52.5 & 69.6 & 62.2 & 39.3 & 134.8 & 150.5 & 25.1 & 174 & 39 & 11.5 & 71.4 & 43.7 & 15.5 & 38.7 & 5.2 & 4.2 \\
\hline G2R3 & 52 & 74.1 & 51.7 & 27.3 & 126.4 & 164.6 & 27.8 & 150.7 & 29.4 & 20 & 23.4 & 48.5 & 43.4 & 31.8 & 10.1 & 2.7 \\
\hline G2R4 & 48.3 & 73.8 & 50.2 & 29 & 141.9 & 123.1 & 24.8 & 136.7 & 32.6 & 29.4 & 11.4 & 51.2 & 29 & 59.5 & 6.8 & 2.4 \\
\hline G2R5 & 45.1 & 59 & 58.8 & 33.6 & 133.3 & 100.1 & 23.5 & 158.4 & 30.1 & 15.4 & 83.1 & 52.2 & 23.5 & 38.3 & 5.1 & 2.8 \\
\hline G2R6 & 61.3 & 69.7 & 75.6 & 46.2 & 151.1 & 165.8 & 33.2 & 181.3 & 24.6 & 12.4 & 25.8 & 86.9 & 46.9 & 81.3 & 6.9 & 9.5 \\
\hline G3R1 & 47.4 & 59.4 & 55 & 28.9 & 126.7 & 132.7 & 27 & 157.7 & 27.2 & 16 & 55.5 & 47.3 & 30.7 & 32 & 6.3 & 2.7 \\
\hline G3R2 & 52.7 & 69.5 & 62.2 & 39.3 & 133.9 & 152.1 & 25 & 174 & 39 & 11.5 & 71.4 & 43.7 & 15.5 & 38.6 & 5.2 & 4.2 \\
\hline G3R3 & 55.3 & 74.3 & 51.7 & 27.6 & 122.3 & 179.2 & 39.9 & 150.4 & 29.4 & 20 & 23.4 & 48.5 & 43.4 & 29.6 & 10.1 & 2.9 \\
\hline G3R4 & 46.7 & 73.4 & 50.1 & 28.1 & 124.5 & 121.5 & 23.2 & 137.7 & 32.6 & 29.2 & 11.2 & 51.3 & 29.4 & 56.2 & 6.6 & 2.7 \\
\hline G3R5 & 44.8 & 59.1 & 58.8 & 33.6 & 134 & 97.2 & 23.6 & 158.3 & 30.1 & 15.5 & 83.1 & 52.2 & 23.5 & 38.2 & 5.1 & 2.8 \\
\hline G3R6 & 57.7 & 69.5 & 75.6 & 46.1 & 151.3 & 135.8 & 32.3 & 181.4 & 24.6 & 12.4 & 25.8 & 86.9 & 46.9 & 81.1 & 6.9 & 9.5 \\
\hline G4R1 & 47.5 & 59.4 & 55 & 28.9 & 126.7 & 133.5 & 27 & 157.7 & 27.2 & 16 & 55.5 & 47.3 & 30.7 & 32 & 6.3 & 2.7 \\
\hline G4R2 & 52.7 & 69.5 & 62.2 & 39.3 & 133.9 & 152.1 & 25 & 174 & 39 & 11.5 & 71.4 & 43.7 & 15.5 & 38.6 & 5.2 & 4.2 \\
\hline G4R3 & 55.2 & 74.3 & 51.8 & 27.4 & 122.7 & 183.4 & 33.9 & 150.6 & 29.5 & 20.1 & 23.4 & 48.5 & 43.3 & 31.3 & 10.2 & 2.9 \\
\hline G4R4 & 52.5 & 73.5 & 50 & 28.5 & 132.8 & 159.6 & 27.7 & 136.4 & 33 & 29.8 & 11.3 & 51.2 & 29.1 & 50.9 & 6.8 & 2.4 \\
\hline G4R5 & 44.9 & 59 & 58.8 & 33.6 & 133.8 & 97.7 & 23.5 & 158.4 & 30.1 & 15.4 & 83.1 & 52.2 & 23.5 & 38.4 & 5.1 & 2.8 \\
\hline G4R6 & 57.8 & 68.6 & 75.6 & 45.8 & 154.2 & 135.2 & 32.4 & 181.4 & 24.6 & 12.4 & 25.8 & 86.9 & 46.9 & 80.8 & 6.9 & 9.5 \\
\hline
\end{tabular}


Table E.4-2

Mean Weighted Residuals (m) for Individual Residual Zones and Combined Zones

$\frac{T}{\square}$

\begin{tabular}{|c|c|c|c|c|c|c|c|c|c|c|c|c|c|c|c|c|}
\hline $\begin{array}{l}\bar{\Phi} \\
\frac{\Phi}{\tilde{\Xi}} \\
\Sigma \\
\Sigma\end{array}$ & $\overline{\bar{\alpha}}$ & 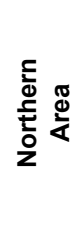 & 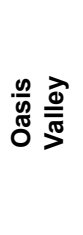 & 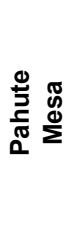 & 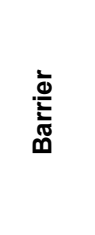 & 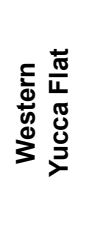 & 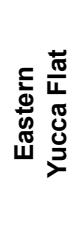 & $\begin{array}{l}\stackrel{0}{0} \\
\frac{0}{\infty} \\
\frac{0}{0} \\
\frac{0}{\omega}\end{array}$ & 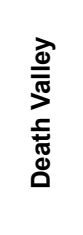 & 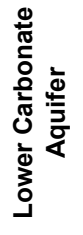 & 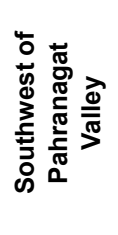 & 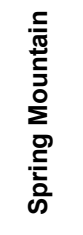 & 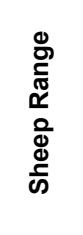 & 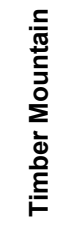 & 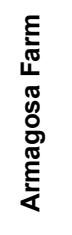 & 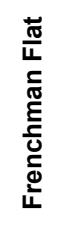 \\
\hline G0R1 & 5.4 & -0.1 & 26.3 & 8.8 & 72.4 & -2.5 & -3.3 & 119.4 & -14.9 & -1.7 & 56.3 & 14 & 30.9 & -15.5 & -2.6 & 0.5 \\
\hline G0R2 & 13.1 & 10.2 & 32.5 & 8.6 & 100.7 & 109.9 & 3.3 & 112.6 & -21.5 & 2 & 72.2 & -7.2 & 11.4 & 6.3 & -1 & 3.3 \\
\hline G0R3 & -5.6 & -21.5 & 19.3 & -5.1 & 67.3 & -91.3 & -13.1 & 124 & -5.4 & -4.4 & 23.6 & -13.2 & 44.4 & 2.7 & -8.9 & -1.8 \\
\hline G0R4 & 6.6 & -23 & 12.2 & 4.6 & 59.2 & 128.1 & 1.8 & 116.3 & -22.5 & $\begin{array}{l}-8.8 \\
\end{array}$ & -8.4 & 16.8 & 29.8 & 40 & -4.9 & 1 \\
\hline G0R5 & 11.9 & 6.7 & 35.6 & 15.5 & 93 & 49.5 & 3 & 120.1 & -7.6 & 0.8 & -82.3 & 13 & -12.2 & 22.6 & -0.4 & 1.8 \\
\hline G0R6 & 18.9 & 42.3 & 54.2 & 33.1 & 136.1 & -83.9 & 14.6 & 134.5 & 2.5 & 4.8 & 26.2 & 68.4 & 48.9 & 58.1 & -4 & 9 \\
\hline G1R1 & 5.3 & -0.1 & 26.3 & 8.7 & 72.4 & -4 & -3.3 & 116.2 & -14.9 & -1.7 & 56.3 & 14 & 30.9 & -15.7 & -2.6 & 0.5 \\
\hline G1R2 & 13 & 10.3 & 32.5 & 8.8 & 102 & 103.1 & 3.1 & 134.7 & -21.5 & 2 & 72.2 & -7.2 & 11.4 & 6.4 & -1 & 3.3 \\
\hline G1R3 & -6.5 & -20.3 & 18.9 & -2 & 77 & -118 & -15.9 & 122.6 & -5.3 & -4.6 & 23.6 & -13.3 & 44.3 & 5.1 & -8.8 & -1.9 \\
\hline G1R4 & 2.6 & -21.6 & 12.9 & 5.5 & 44.6 & 55.6 & -5.8 & 117.1 & -23.7 & -8.3 & -8.4 & 16.7 & 29.6 & 45.4 & -4.9 & 0.8 \\
\hline G1R5 & 11.9 & 6.8 & 35.6 & 15.4 & 92.2 & 52.1 & 3.1 & 118.3 & -7.6 & 0.8 & -82.2 & 13 & $\begin{array}{l}-12.2 \\
\end{array}$ & 22.5 & -0.4 & 1.8 \\
\hline G1R6 & 18.3 & 42.9 & 54.2 & 32.2 & 138.7 & -99.2 & 14.6 & 132.9 & 2.5 & 4.8 & 26.3 & 68.4 & 48.9 & 58.7 & -4 & 8.9 \\
\hline G2R1 & 5.7 & -0.1 & 26.3 & 8.7 & 72.3 & 5.7 & -3.3 & 116.4 & -14.9 & -1.7 & 56.3 & 14 & 30.9 & -15.8 & -2.6 & 0.5 \\
\hline G2R2 & 13.2 & 10.3 & 32.5 & 8.8 & 101.8 & 108 & 3 & 134.7 & -21.5 & 2 & 72.1 & -7.2 & 11.3 & 6.5 & -1 & 3.3 \\
\hline G2R3 & -1.2 & -22.6 & 19.1 & -4.6 & 64.1 & -7.3 & -6.3 & 123.2 & -5.4 & -4.4 & 23.5 & -13.3 & 44.3 & 6.1 & -9 & -1.7 \\
\hline G2R4 & 3.7 & -22.2 & 12.4 & 6.1 & 47.1 & 73.9 & -2.9 & 114.1 & -22.5 & $\begin{array}{l}-8.8 \\
\end{array}$ & $\begin{array}{l}-8.3 \\
\end{array}$ & 16.7 & 29.7 & 45.2 & -4.9 & 0.5 \\
\hline G2R5 & 11.9 & 6.8 & 35.6 & 15.4 & 92.2 & 52 & 3.1 & 118.3 & -7.6 & 0.8 & $\begin{array}{l}-82.3 \\
\end{array}$ & 13 & $\begin{array}{l}-12.2 \\
\end{array}$ & 22.5 & -0.4 & 1.8 \\
\hline G2R6 & 20.2 & 42 & 54.2 & 30.4 & 117.9 & -40.9 & 16.8 & 133.4 & 2.5 & 4.8 & 26.2 & 68.5 & 48.9 & 58.4 & -4.1 & 9 \\
\hline G3R1 & 5.4 & -0.2 & 26.2 & 8.6 & 71.8 & $\begin{array}{l}-13.8 \\
\end{array}$ & -0.1 & 116.1 & -14.9 & -1.7 & 56.3 & 14 & 30.9 & -15.7 & -2.6 & 0.5 \\
\hline G3R2 & 13.3 & 10.2 & 32.5 & 8.6 & 100.7 & 109.9 & 3.3 & 134.7 & -21.5 & 2 & 72.2 & -7.2 & 11.4 & 6.3 & -1 & 3.3 \\
\hline G3R3 & -6.2 & -21.5 & 19.3 & -5.7 & 70.8 & -95.5 & -15.1 & 122.9 & -5.4 & -4.4 & 23.5 & -13.3 & 44.3 & 0.9 & -9 & -1.9 \\
\hline G3R4 & 4.6 & -23 & 12.5 & 5.6 & 74.3 & 64.9 & 0.9 & 116.1 & -22.5 & -8.6 & -8 & 17.1 & 30.1 & 41.4 & -4.7 & 1.3 \\
\hline G3R5 & 11.7 & 6.7 & 35.6 & 15.4 & 93.3 & 44.9 & 3.2 & 118.1 & $\begin{array}{l}-7.6 \\
\end{array}$ & 0.8 & $\begin{array}{l}-82.3 \\
\end{array}$ & 13 & $\begin{array}{l}-12.2 \\
\end{array}$ & 22.2 & $\begin{array}{l}-0.4 \\
\end{array}$ & 1.8 \\
\hline G3R6 & 24.5 & 41.6 & 54.2 & 29.7 & 122.5 & 51.5 & 21.1 & 134 & 2.5 & 4.8 & 26.3 & 68.5 & 48.9 & 58.5 & -4 & 9 \\
\hline G4R1 & 5.4 & -0.2 & 26.2 & 8.6 & 71.8 & -14 & $\begin{array}{l}-0.1 \\
\end{array}$ & 116.1 & -14.9 & $\begin{array}{l}-1.7 \\
\end{array}$ & 56.3 & 14 & 30.9 & -15.7 & -2.6 & 0.5 \\
\hline G4R2 & 13.3 & 10.2 & 32.5 & 8.6 & 100.7 & 109.9 & 3.3 & 134.7 & -21.5 & 2 & 72.2 & -7.2 & 11.4 & 6.3 & -1 & 3.3 \\
\hline G4R3 & -5.8 & -20.8 & 18.5 & -4.8 & 70.3 & -96.5 & -13.1 & 123 & -5.4 & -4.5 & 23.4 & -13.3 & 44.2 & 5.8 & -9.1 & -2 \\
\hline G4R4 & $\begin{array}{l}-1.6 \\
\end{array}$ & -22.3 & 12.2 & 6.7 & 84.2 & $\begin{array}{l}-71.6 \\
\end{array}$ & -5.1 & 114.9 & -23.7 & -8.9 & -8.1 & 16.9 & 29.8 & 35.4 & -4.8 & 0.7 \\
\hline G4R5 & 11.9 & 6.7 & 35.6 & 15.5 & 93 & 49.4 & 3 & 118.3 & -7.6 & 0.8 & -82.3 & 13 & $\begin{array}{l}-12.2 \\
\end{array}$ & 22.6 & -0.4 & 1.7 \\
\hline G4R6 & 21.9 & 40.7 & 54.2 & 29.3 & 130 & -6.2 & 18.3 & 133.8 & 2.5 & 4.8 & 26.3 & 68.4 & 48.9 & 58.1 & -4 & 9 \\
\hline
\end{tabular}


Table E.4-3

Residuals (m) in Frenchman Flat Alluvium Wells

\begin{tabular}{|c|c|c|c|c|c|c|c|c|c|c|c|c|c|c|}
\hline \multirow{2}{*}{$\begin{array}{l}\text { Model } \\
\text { Name }\end{array}$} & \multicolumn{14}{|c|}{ Well Name } \\
\hline & WW-5A & RNM-2S & WW-5C & UE-5f & UE-5 PW-2 & RNM-2 & ER 5-3 & WW-5B & ER 5-3-3 & UE-5 PW-1 & WW-1 & ER 5-4 & RNM-1 & UE-5n \\
\hline G0R1 & 0.6 & 0.3 & -4.1 & 4.1 & 2.9 & -0.8 & 4.1 & -0.6 & 4 & 2.8 & -3.4 & 2 & -2.6 & 0.3 \\
\hline G0R2 & 4.4 & 3.9 & 0.3 & 6.2 & 5 & 2.9 & 6.1 & 4.1 & 6 & 4.9 & -0.2 & 4.3 & 0.8 & 4 \\
\hline G0R3 & 1.8 & -0.9 & -1.8 & 0.2 & -1 & -1.9 & 0.2 & 0.4 & 0.1 & -0.9 & -4.4 & -0.1 & -4 & -0.8 \\
\hline G0R4 & 4.5 & 2.6 & 1.4 & 2.5 & 1.4 & 1.5 & 2.5 & 4.2 & 2.4 & 1.5 & -2 & 2.8 & -0.6 & 2.7 \\
\hline G0R5 & 6.2 & 1.6 & 1.7 & 4.2 & 3 & 0.6 & 4.3 & 3 & 4 & 3 & -0.1 & 3.5 & -1.3 & 1.8 \\
\hline G0R6 & 9.2 & 9.6 & 6.3 & 12 & 11 & 8.6 & 12 & 9.6 & 12 & 11 & 5.1 & 9.7 & 6.5 & 9.8 \\
\hline G1R1 & 0.6 & 0.3 & -4.1 & 4.2 & 2.9 & -0.8 & 4.2 & -0.6 & 4.1 & 2.8 & -3.4 & 2.1 & -2.6 & 0.3 \\
\hline G1R2 & 4.4 & 3.9 & 0.3 & 6.2 & 5 & 2.9 & 6.1 & 4.1 & 6 & 4.9 & -0.2 & 4.3 & 0.8 & 4 \\
\hline G1R3 & 1.7 & -1.1 & -1.9 & 0.1 & -1.1 & -2.1 & 0 & 0.3 & -0.1 & -1 & -4.5 & -0.2 & -4.2 & -1 \\
\hline G1R4 & 4.5 & 2.4 & 1.4 & 2.2 & 1.2 & 1.3 & 2.2 & 4.1 & 2.1 & 1.3 & -2.1 & 2.7 & $\begin{array}{l}-0.7 \\
\end{array}$ & 2.5 \\
\hline G1R5 & 6.2 & 1.6 & 1.8 & 4.3 & 3.1 & 0.6 & 4.3 & 3 & 4.1 & 3.1 & 0 & 3.5 & -1.3 & 1.8 \\
\hline G1R6 & 9.2 & 9.6 & 6.3 & 12 & 11 & 8.6 & 12 & 9.6 & 12 & 11 & 5.2 & 9.7 & 6.4 & 9.8 \\
\hline G2R1 & 0.6 & 0.3 & -4.1 & 4.1 & 2.9 & -0.8 & 4.1 & -0.6 & 4 & 2.8 & -3.4 & 2 & -2.6 & 0.3 \\
\hline G2R2 & 4.3 & 3.9 & 0.2 & 6.2 & 5 & 2.9 & 6.1 & 4 & 6 & 4.9 & -0.2 & 4.3 & 0.8 & 4 \\
\hline G2R3 & 1.8 & -0.9 & -1.8 & 0.3 & -0.9 & -1.9 & 0.3 & 0.5 & 0.2 & -0.8 & -4.4 & 0 & -3.9 & -0.8 \\
\hline G2R4 & 4.4 & 2 & 1.1 & 2 & 0.9 & 0.9 & 2 & 3.7 & 1.8 & 1 & -2.1 & 2.4 & -1.1 & 2.1 \\
\hline G2R5 & 6.2 & 1.6 & 1.7 & 4.2 & 3 & 0.6 & 4.3 & 3 & 4 & 3 & -0.1 & 3.5 & -1.3 & 1.7 \\
\hline G2R6 & 9.2 & 9.6 & 6.3 & 12 & 11 & 8.6 & 12 & 9.6 & 12 & 11 & 5.1 & 9.7 & 6.5 & 9.8 \\
\hline G3R1 & 0.6 & 0.2 & -4.1 & 4.2 & 2.9 & -0.8 & 4.1 & -0.6 & 4 & 2.8 & -3.4 & 2 & -2.6 & 0.2 \\
\hline G3R2 & 4.4 & 3.9 & 0.3 & 6.2 & 5 & 2.9 & 6.1 & 4.1 & 6 & 4.9 & -0.2 & 4.3 & 0.9 & 4 \\
\hline G3R3 & 1.7 & -1.1 & -1.9 & 0 & -1.1 & -2.1 & 0 & 0.3 & -0.1 & -1.1 & -4.5 & -0.2 & -4.2 & -1 \\
\hline G3R4 & 4.9 & 2.9 & 1.7 & 2.8 & 1.7 & 1.8 & 2.8 & 4.5 & 2.7 & 1.8 & -1.6 & 3.2 & -0.3 & 3 \\
\hline G3R5 & 6.2 & 1.6 & 1.7 & 4.3 & 3 & 0.6 & 4.3 & 3 & 4.1 & 3 & -0.1 & 3.5 & -1.3 & 1.7 \\
\hline G3R6 & 9.3 & 9.7 & 6.4 & 12 & 11 & 8.7 & 12 & 9.7 & 12 & 11 & 5.2 & 9.8 & 6.5 & 9.9 \\
\hline G4R1 & 0.6 & 0.2 & -4.1 & 4.2 & 2.9 & -0.8 & 4.1 & -0.6 & 4 & 2.8 & -3.4 & 2.1 & -2.6 & 0.2 \\
\hline G4R2 & 4.4 & 3.9 & 0.3 & 6.2 & 5 & 2.9 & 6.1 & 4 & 6 & 4.9 & -0.2 & 4.3 & 0.8 & 4 \\
\hline G4R3 & 1.7 & -1.1 & -1.9 & 0 & -1.1 & -2.1 & 0 & 0.3 & -0.1 & -1.1 & -4.6 & -0.3 & -4.2 & -1 \\
\hline G4R4 & 4.5 & 2.2 & 1.3 & 2.1 & 1 & 1.2 & 2.1 & 3.9 & 1.9 & 1.1 & -2.1 & 2.5 & -0.9 & 2.3 \\
\hline G4R5 & 6.2 & 1.6 & 1.7 & 4.2 & 3 & 0.6 & 4.3 & 3 & 4 & 3 & -0.1 & 3.4 & -1.4 & 1.7 \\
\hline G4R6 & 9.3 & 9.7 & 6.4 & 12 & 11 & 8.7 & 12 & 9.7 & 12 & 11 & 5.2 & 9.8 & 6.5 & 9.9 \\
\hline
\end{tabular}


Table E.4-4

Simulated Discharge Rates $\left(\mathrm{m}^{3} / \mathrm{d}\right)$ at Discharge Calibration Zones

\begin{tabular}{|c|c|c|c|c|c|c|c|c|c|c|}
\hline $\begin{array}{l}\text { Model } \\
\text { Name }\end{array}$ & $\begin{array}{l}\text { Death } \\
\text { Valley }\end{array}$ & $\begin{array}{l}\text { Oasis } \\
\text { Valley }\end{array}$ & $\begin{array}{c}\text { Amargosa } \\
\text { River }\end{array}$ & $\begin{array}{c}\text { Ash } \\
\text { Meadows }\end{array}$ & $\begin{array}{c}\text { Franklin } \\
\text { Lake/ } \\
\text { Alkali } \\
\text { Flat }\end{array}$ & $\begin{array}{l}\text { Alkali } \\
\text { Flat } \\
\text { (Peter's } \\
\text { Playa) }\end{array}$ & $\begin{array}{c}\text { Penoyer } \\
\text { Valley }\end{array}$ & $\begin{array}{l}\text { Indian } \\
\text { Springs }\end{array}$ & $\begin{array}{l}\text { Pahrump } \\
\text { Valley }\end{array}$ & $\begin{array}{c}\text { Eagle } \\
\text { Mountain }\end{array}$ \\
\hline G0R1 & -71000 & -17000 & -9300 & -84000 & -32000 & -12000 & -14000 & 0 & 2300 & -5900 \\
\hline G0R2 & -88000 & -12000 & -11000 & -72000 & -31000 & -16000 & -4000 & -22 & 7460 & -7900 \\
\hline G0R3 & -63000 & -27000 & -18000 & -93000 & -39000 & -26000 & -24000 & -25 & 2510 & -11000 \\
\hline G0R4 & -82000 & -20000 & -13000 & -86000 & -40000 & -18000 & -24000 & 0 & 2400 & -11000 \\
\hline G0R5 & -61000 & -7900 & -5700 & -74000 & -24000 & -13000 & -6100 & 0 & 2080 & -6000 \\
\hline G0R6 & -64000 & -5600 & -7900 & -50000 & -16000 & -22000 & 0 & 0 & 3720 & -4700 \\
\hline G1R1 & -71000 & -17000 & -9300 & -84000 & -32000 & -12000 & -14000 & 0 & 2300 & -5900 \\
\hline G1R2 & -88000 & -12000 & -11000 & -72000 & -31000 & -16000 & -4000 & -22 & 7460 & -7900 \\
\hline G1R3 & -63000 & -27000 & -18000 & -93000 & -39000 & -26000 & -24000 & -25 & 2510 & -11000 \\
\hline G1R4 & -82000 & -19000 & -13000 & -86000 & -40000 & -18000 & -24000 & 0 & 2400 & -11000 \\
\hline G1R5 & -61000 & -8000 & -5700 & -74000 & -24000 & -13000 & -6000 & 0 & 2080 & -6000 \\
\hline G1R6 & -64000 & -5500 & -7900 & -50000 & -16000 & -22000 & 0 & 0 & 3720 & -4700 \\
\hline G2R1 & -71000 & -17000 & -9300 & -84000 & -32000 & -12000 & -14000 & 0 & 2300 & -5900 \\
\hline G2R2 & -88000 & -12000 & -11000 & -72000 & -31000 & -16000 & -4000 & -22 & 7460 & -7900 \\
\hline G2R3 & -63000 & -28000 & -18000 & -93000 & -39000 & -26000 & -24000 & -25 & 2510 & -11000 \\
\hline G2R4 & -82000 & -19000 & -13000 & -86000 & -40000 & -18000 & -24000 & 0 & 2400 & -11000 \\
\hline G2R5 & -61000 & -8000 & -5700 & -74000 & -24000 & -13000 & -6000 & 0 & 2080 & -6000 \\
\hline G2R6 & -64000 & -5600 & -7900 & -51000 & -16000 & -22000 & 0 & 0 & 3720 & -4700 \\
\hline G3R1 & -71000 & -17000 & -9300 & -84000 & -32000 & -12000 & -14000 & 0 & 2300 & -5900 \\
\hline G3R2 & -88000 & -12000 & -11000 & -72000 & -31000 & -16000 & -4000 & -22 & 7460 & -7900 \\
\hline G3R3 & -63000 & -27000 & -18000 & -93000 & -39000 & -26000 & -24000 & -25 & 2510 & -11000 \\
\hline G3R4 & -82000 & -20000 & -13000 & -85000 & -40000 & -18000 & -24000 & 0 & 2410 & -11000 \\
\hline G3R5 & -61000 & -8000 & -5700 & -74000 & -24000 & -13000 & -6100 & 0 & 2080 & -6000 \\
\hline G3R6 & -64000 & -5600 & -7800 & -50000 & -16000 & -22000 & 0 & 0 & 3720 & -4700 \\
\hline G4R1 & -71000 & -17000 & -9300 & -84000 & -32000 & -12000 & -14000 & 0 & 2300 & -5900 \\
\hline G4R2 & -88000 & -12000 & -11000 & -72000 & -31000 & -16000 & -4000 & -22 & 7460 & -7900 \\
\hline G4R3 & -63000 & -26000 & -19000 & -93000 & -39000 & -26000 & -24000 & -26 & 2510 & -11000 \\
\hline G4R4 & -82000 & -20000 & -13000 & -86000 & -40000 & -18000 & -24000 & 0 & 2400 & -11000 \\
\hline G4R5 & -61000 & -7900 & -5700 & -74000 & -24000 & -13000 & -6100 & 0 & 2080 & -6000 \\
\hline G4R6 & -64000 & -5700 & -7800 & -50000 & -16000 & -22000 & 0 & 0 & 3720 & -4700 \\
\hline
\end{tabular}

values. When individual areas are considered, most areas meet the individual calibration criteria. In the Frenchman Flat area, mean weighted residuals for all alternative models are within the calibration criterion for that area.

The residuals for the wells completed in the alluvium in Frenchman Flat indicate that the model successfully mimics the hydraulic heads in this area. In most cases, the residuals are a few meters or less for all wells. Model realizations involving the USGS recharge model with no redistribution (R6) have the highest residual values in the Frenchman Flat alluvium with simulated water levels approximately 10 meters too low in most wells. This is probably a result of the R6 recharge 


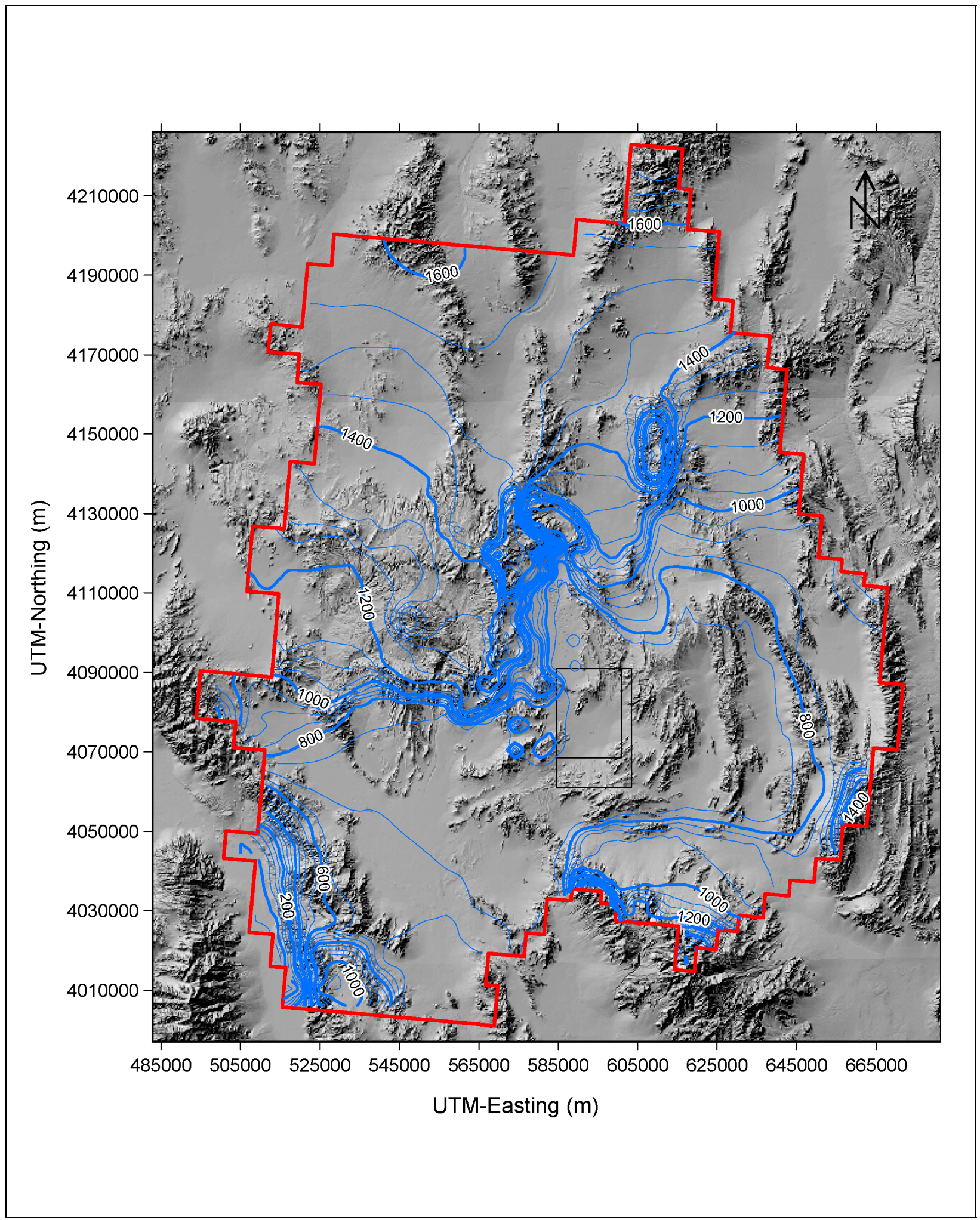

Figure E.4-1

GOR1 Water Table Contours on Topographic Relief Base Map 


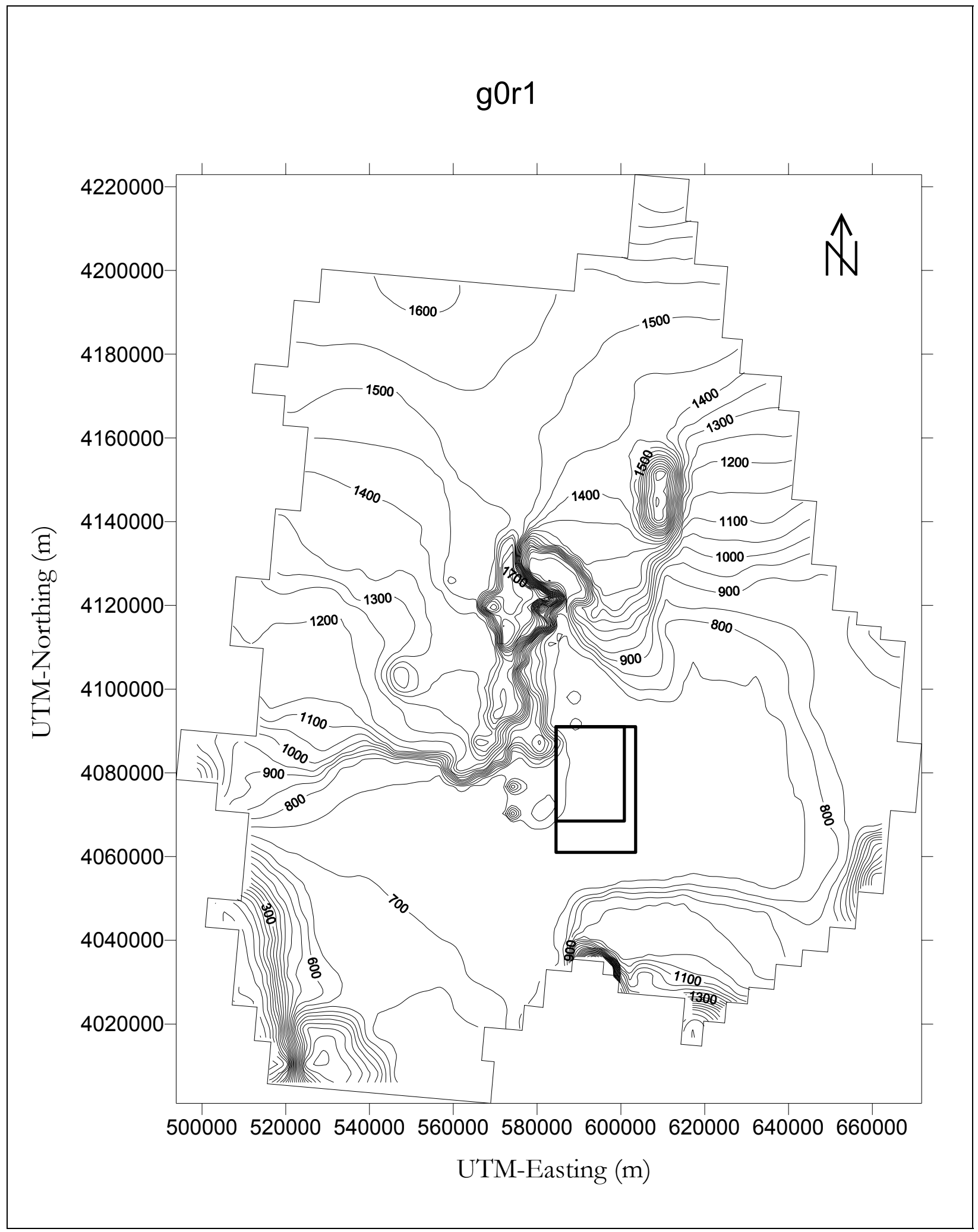

Figure E.4-2

Water Table Contours (m amsl) for Regional Groundwater Flow Model G0R1 


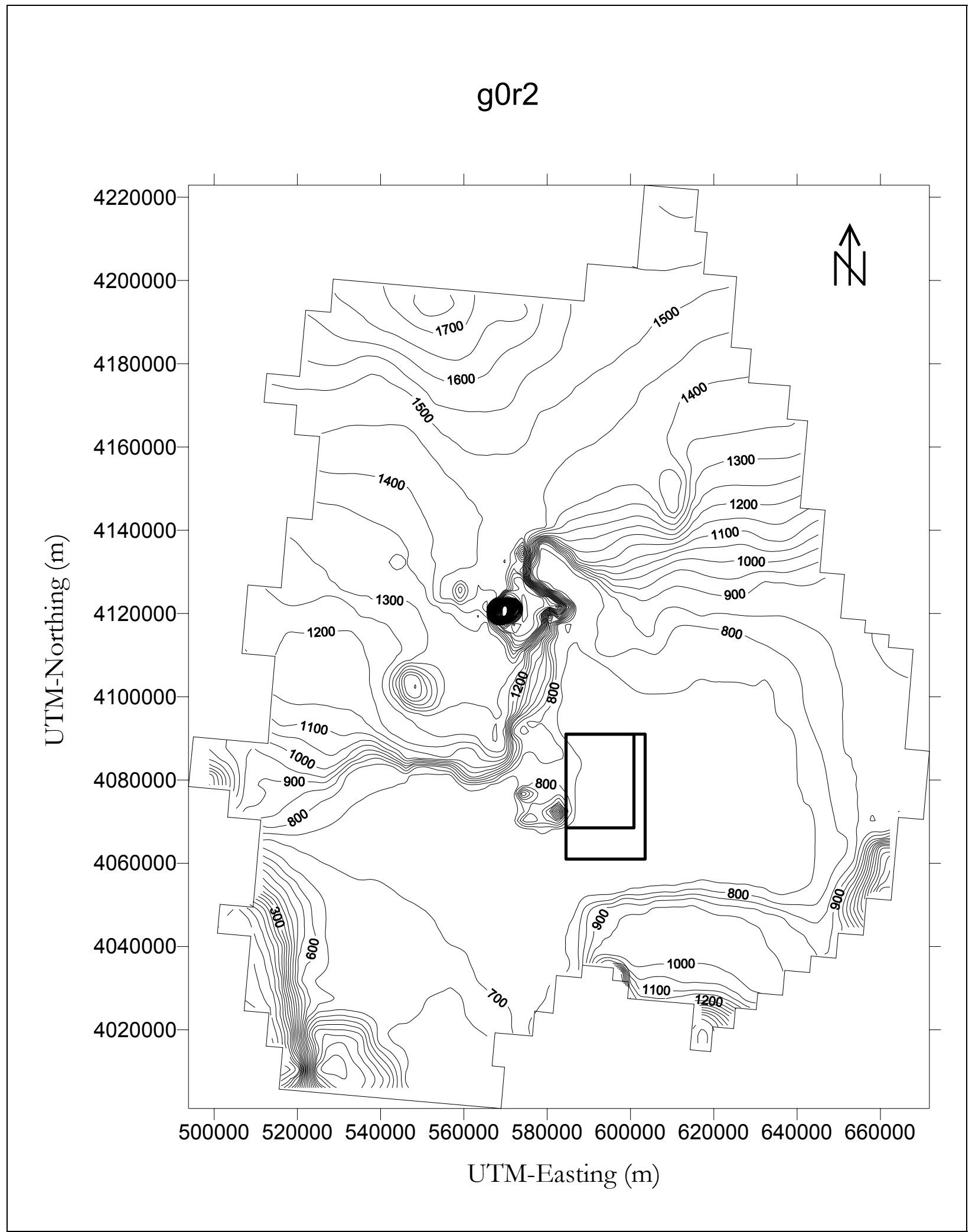

Figure E.4-3

Water Table Contours (m amsl) for Regional Groundwater Flow Model G0R2 


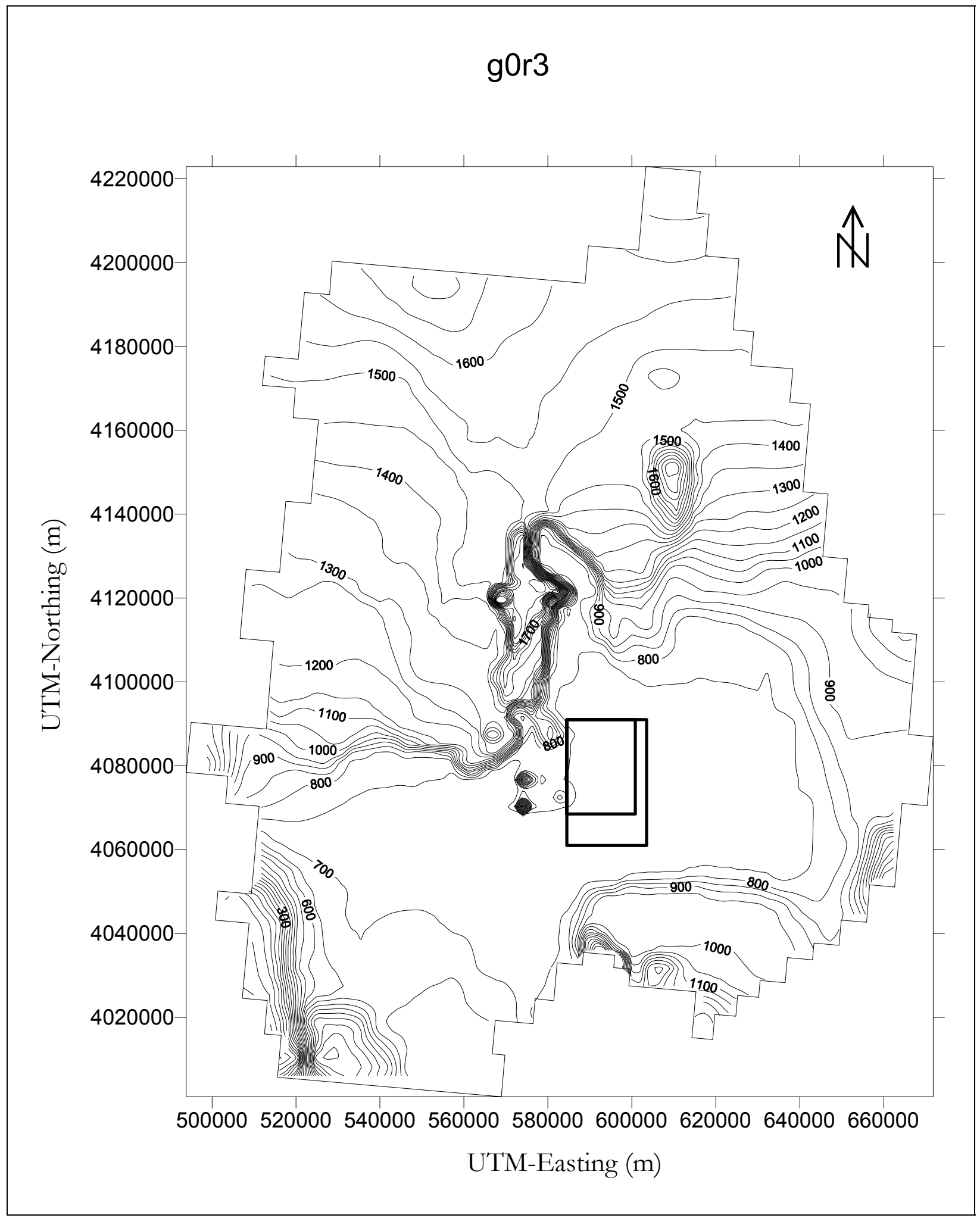

Figure E.4-4

Water Table Contours (m amsl) for Regional Groundwater Flow Model G0R3 


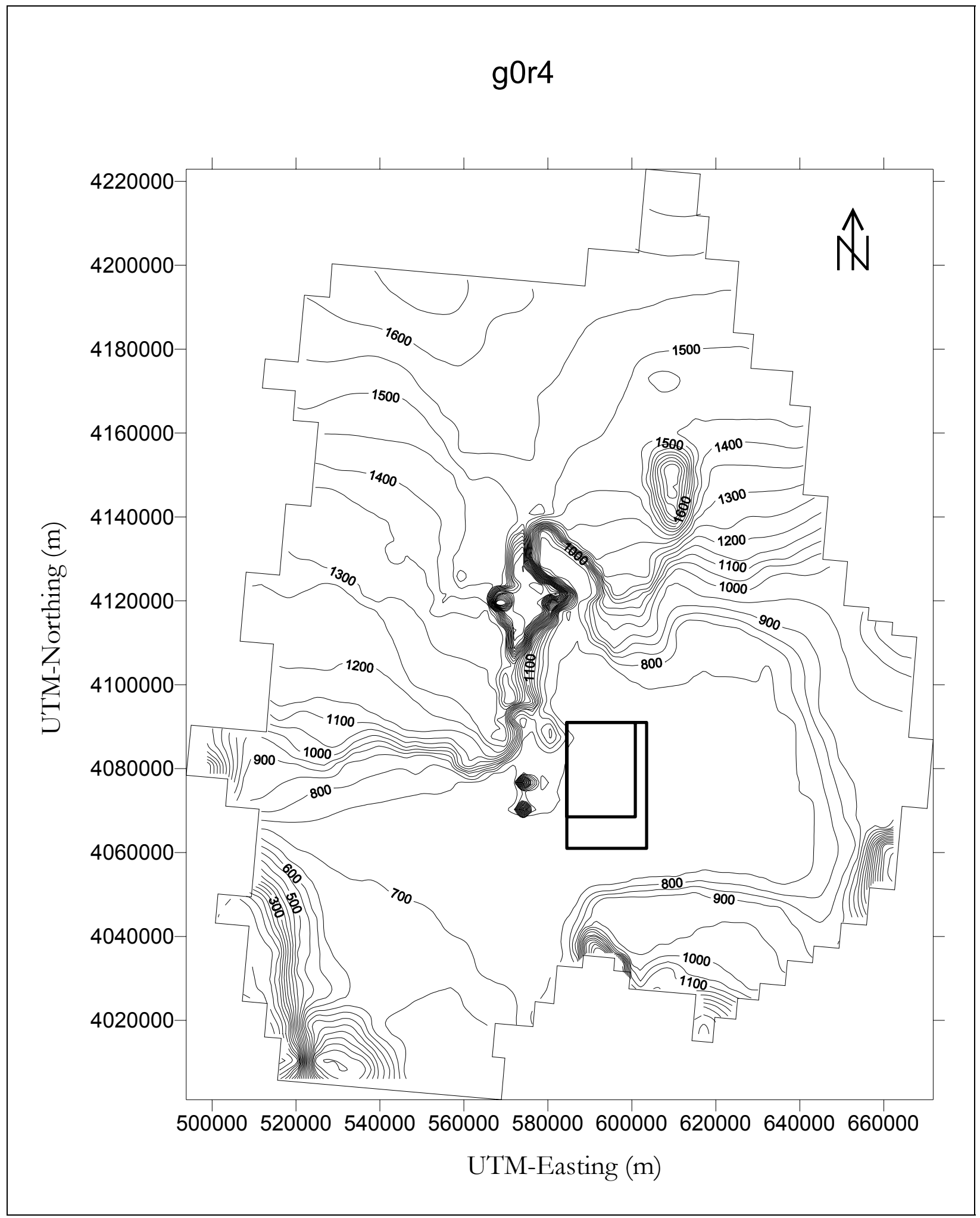

Figure E.4-5

Water Table Contours (m amsl) for Regional Groundwater Flow Model G0R4 


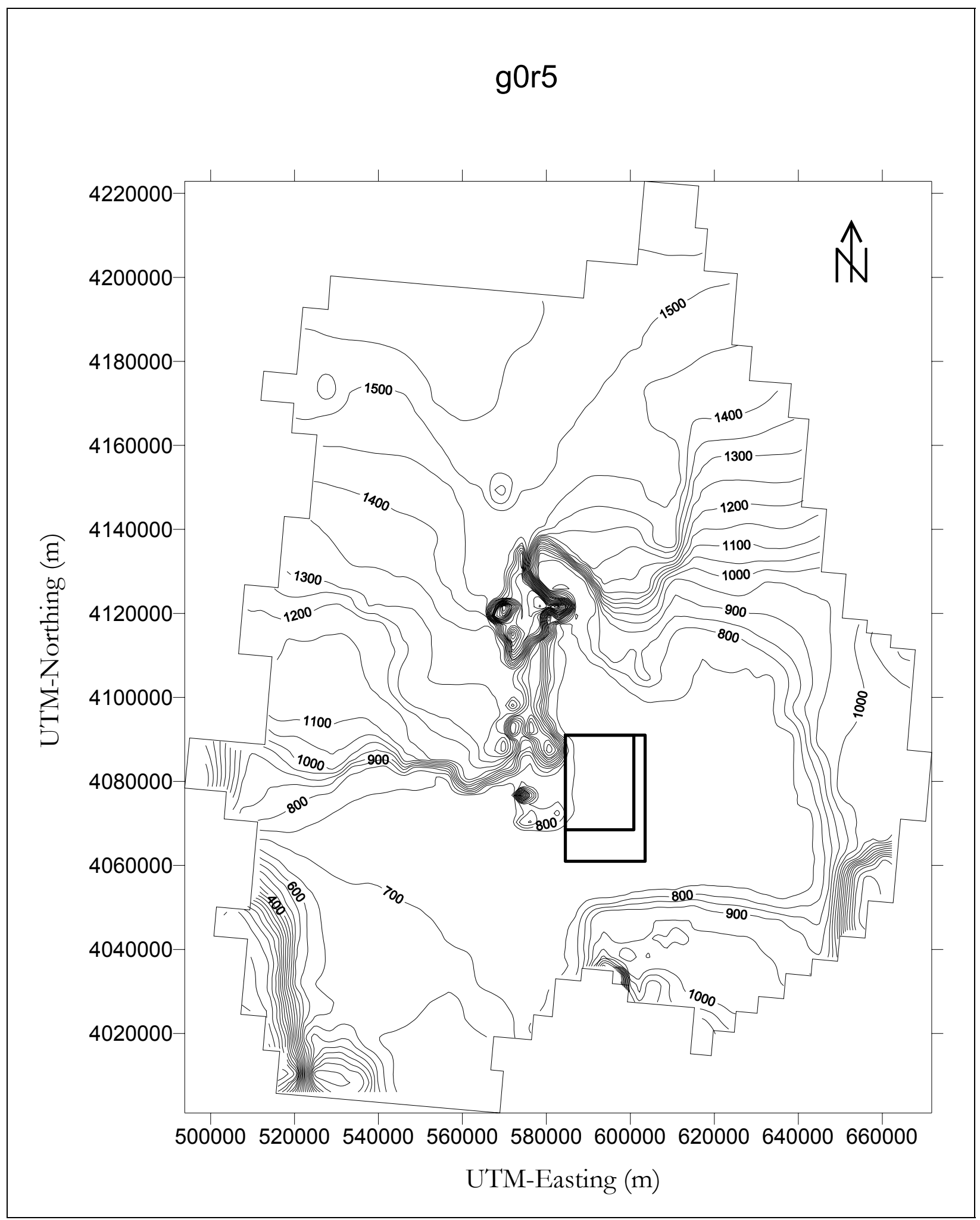

Figure E.4-6

Water Table Contours (m amsl) for Regional Groundwater Flow Model G0R5 


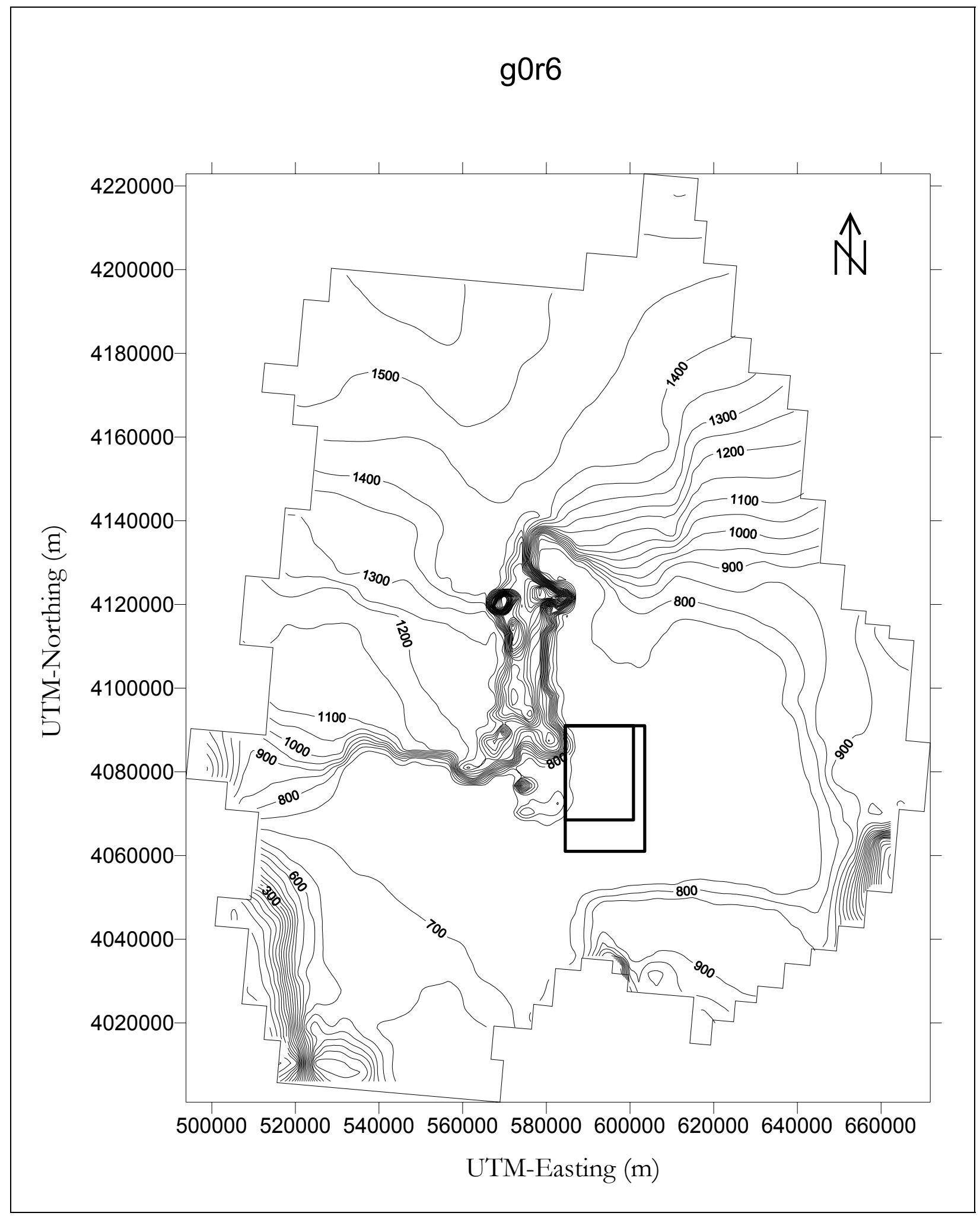

Figure E.4-7

Water Table Contours (m amsl) for Regional Groundwater Flow Model G0R6 
model having considerably lower recharge rates than the other models both regionally (see Table E.2-1) and within Frenchman Flat (see Table 9-12).

Simulated discharge values (Table E.4-4) are generally near the values listed in Table E.3-3 but tend to be systematically high. It is important to note that the recharge rate ranged from 143,000 to $275,000 \mathrm{~m}^{3} / \mathrm{d}$ between the different recharge models. However, the net discharge, considering all other model boundary conditions and the discharge ranges listed in Table E.3-3, ranges from 58,000 to $246,000 \mathrm{~m}^{3} / \mathrm{d}$. Obviously, when either 275,000 or $268,000 \mathrm{~m}^{3} / \mathrm{d}$ is recharged into the model as is the case for the DRI recharge models (R3 and R4), the simulated discharge will exceed the ranges listed in Table E.3-3 regardless of the values of the calibration parameters. The areas with the first and third largest discharge rates, Ash Meadows and Franklin Lake/Alkali Flats, exhibit simulated discharges within the calibration range. In the second largest discharge area, Death Valley, the simulated discharge exceeds the calibration range only slightly with the exception of recharge cases R2 and R4 where simulated values are nearly 1.5 times higher. The fourth and fifth largest discharge areas, Oasis Valley and Penoyer Valley, respectively, meet the calibration criteria except in the cases with the lowest recharge rates (R2, R5 and R6) where simulated flows are below the calibration range. Overall, the UGTA Original recharge model (R1) performed the best in mimicking the observed values of both hydraulic head and discharge.

The calibrated hydraulic conductivities within the Frenchman Flat HSUs for each recharge case are listed in Table E.4-5 along with the respective initial values. Zone maps for HSUs in which properties were varied are depicted in Figure E.3-1. The regional-scale model results for inflow at the CAU flow model lateral boundaries are presented in Table 9-3. Outflow rates for the CAU flow model lateral boundaries are presented in Table 9-4. 
Table E.4-5

Calibrated Horizontal Hydraulic Conductivity $(\mathrm{m} / \mathrm{d})$ at Land Surface $\left(\mathrm{K}_{0}\right)$ for Frenchman Flat HSUs

\begin{tabular}{|c|c|c|c|c|c|c|c|c|c|}
\hline \multirow{2}{*}{$\begin{array}{c}\text { HSU } \\
\text { Name }\end{array}$} & \multirow{2}{*}{ HSU Description } & \multirow{2}{*}{ Zone } & \multirow{2}{*}{$\underset{\mathbf{K}_{0}}{\text { Initial }}$} & \multicolumn{6}{|c|}{ Calibrated $\mathrm{K}_{0}$ for Each Recharge Model } \\
\hline & & & & R1 & $\mathbf{R 2}$ & R3 & R4 & R5 & R6 \\
\hline \multirow{4}{*}{ AA } & \multirow{4}{*}{ Alluvial Aquifer } & 1 & 6.1 & 3.1 & 1.1 & 1.5 & 1.5 & 0.96 & 2.6 \\
\hline & & 4 & 20 & 30 & 31 & 20 & 32 & 13 & 26 \\
\hline & & 5 & 5.5 & 14 & 18 & 5.5 & 7.1 & 5.7 & 17 \\
\hline & & 7 & 0.018 & 0.04 & 0.055 & 0.026 & 0.04 & 0.022 & 0.04 \\
\hline PCU2T & Playa Confining Unit & & 0.16 & 0.23 & 0.092 & 0.2 & 0.16 & 0.11 & 1.2 \\
\hline AA 2 & Alluvial Aquifer & & 0.16 & 0.25 & 1.5 & 0.29 & 0.19 & 0.24 & 0.58 \\
\hline OAA1 & Older Altered Alluvial Aquifer & & 29 & 39 & 6.7 & 31 & 26 & 37 & 27 \\
\hline BLFA & Basalt Lava Flow Aquifer & & 3.7 & 4 & 5.7 & 4.5 & 4.2 & 5.5 & 7.9 \\
\hline PCU1U & Older Playa Confining Unit - Upper & & 0.16 & 0.16 & 0.083 & 0.2 & 0.21 & 0.23 & 0.13 \\
\hline AA1 & Alluvial Aquifer & & 5.5 & 7.1 & 3.8 & 5.7 & 6.1 & 14 & 9.1 \\
\hline OAA & Older Altered Alluvial Aquifer & & 29 & 51 & 210 & 44 & 32 & 56 & 31 \\
\hline PCU1L & Older Playa Confining Unit - Lower & & 0.16 & 0.14 & 0.17 & 0.24 & 0.21 & 0.21 & 0.12 \\
\hline \multirow{3}{*}{ VA } & \multirow{3}{*}{ Volcanic Tuff Aquifer } & 1 & 5 & 7.4 & 11 & 12 & 7.2 & 6.6 & 6.3 \\
\hline & & 2 & 10 & 14 & 18 & 32 & 20 & 12 & 11 \\
\hline & & 4 & 3.3 & 1.6 & 0.33 & 2.3 & 3.2 & 3 & 4.2 \\
\hline TMLVTA & Timber Mountain Lower Vitric Tuff Aquifer & & 33 & 44 & 330 & 38 & 26 & 77 & 27 \\
\hline UTCU & Upper Tuff Confining Unit & & 0.16 & 0.2 & 0.095 & 0.15 & 0.18 & 0.2 & 0.11 \\
\hline TSA & Topopah Spring Aquifer & & 17 & 35 & 60 & 22 & 20 & 24 & 25 \\
\hline LVTA & Lower Vitric Tuff & & 33 & 51 & 71 & 27 & 47 & 23 & 44 \\
\hline \multirow{3}{*}{ VCU } & \multirow{3}{*}{ Volcanic Confining Unit } & 1 & 0.1 & 0.06 & 0.095 & 0.31 & 0.24 & 0.093 & 0.049 \\
\hline & & 2 & 0.057 & 0.08 & 0.006 & 0.071 & 0.07 & 0.072 & 0.058 \\
\hline & & 4 & 0.041 & 0.02 & 0.052 & 0.037 & 0.05 & 0.056 & 0.097 \\
\hline WCU & Wahmonie Confining Unit & & 0.1 & 0.12 & 0.15 & 0.12 & 0.11 & 0.15 & 0.13 \\
\hline LTCU1 & Lower Tuff Confining Unit & & 0.1 & 0.07 & 0.081 & 0.091 & 0.11 & 0.079 & 0.1 \\
\hline VCUff & Volcaniclastic Confining Unit & & 0.1 & 0.25 & 0.4 & 0.15 & 0.13 & 0.11 & 0.17 \\
\hline LCA3 & Lower Carbonate Aquifer & & 0.058 & 0.06 & 0.024 & 0.1 & 0.05 & 0.031 & 0.021 \\
\hline UCCU & Upper Clastic Confining Unit & & 0.01 & 0 & 0.01 & 0.006 & 0.01 & 0.006 & 0.002 \\
\hline \multirow{2}{*}{ LCA } & \multirow{2}{*}{ Lower Carbonate Aquifer } & 1 & 220 & 22 & 22 & 22 & 22 & 22 & 180 \\
\hline & & 7 & 290 & 430 & 510 & 220 & 200 & 130 & 400 \\
\hline LCCU & Lower Clastic Confining Unit & & 0.088 & 0.02 & 0.081 & 0.025 & 0.02 & 0.02 & 0.038 \\
\hline
\end{tabular}




\section{E.5.0 References}

Anderson, M.P., and W.W. Woessner. 1992. Applied Groundwater Modeling. San Diego, CA: Academic Press.

Bechtel Nevada. 2002. Hydrostratigraphic Model of the Pahute Mesa-Oasis Valley Area, Nye County, Nevada, DOE/NV/11718-646. Prepared for U.S. Department of Energy, National Nuclear Security Administration Nevada Operations Office. Las Vegas, NV.

DOE/NV, see U.S. Department of Energy, Nevada Operations Office.

Doherty, J. 2000. Visual Pest User's Manual (Includes Pest2000 \& WinPEST). Waterloo, Canada: Waterloo Hydrogeologic/Watermark Numerical Company.

Doherty, J. 2002. Manual for PEST, $5^{\text {th }}$ edition, Brisbane, Australia: Watermark Numerical Computing.

Eakin, T.E., G.B. Maxey, T.W. Robinson, J.C. Fredericks and O.J. Loeltz. 1951. "Contributions to the Hydrology of Eastern Nevada." In Water Resources Bulletin No. 12. Carson City, NV: State of Nevada, Office of the State Engineer/U.S. Geological Survey.

Hardman, G. 1965. Nevada Precipitation and Acreages of Land by Rainfall Zones. Reno, NV: U.S. Department of Agriculture, University of Nevada Experimental Station.

Hevesi, J.A., A.L. Flint, and J.D. Istok. 1992. "Precipitation Estimation in Mountainous Terrain Using Multivariate Geostatistics, Part II: Ishohetal Maps.” In Journal of Applied Meteorology, 31(7): 677-688. Sacramento, CA.

Hevesi, J.A., A.L. Flint, and L.E. Flint. 2003. Simulation of Net Infiltration Using A Distributed Parameter Watershed Model For The Death Valley Regional Flow System, Nevada And California. Sacramento, CA.

James, J.W. 1993. Climate of the Death Valley Region, Nevada/California. Prepared for the National Park Service. Reno, NV: State of Nevada, Office of the State Climatologist. 
Laczniak, R.J., J.L. Smith, P.E. Elliot, G.A. DeMeo, M.A. Chatigny, and G.A. Roemer. 2001. Ground-Water Discharge Determined from Estimates of Evapotranspiration, Death Valley Regional Flow System, Nevada and California, USGS Water-Resources Investigation Report 01-4195. Denver, CO: U.S. Geological Survey.

Maxey, G.B. and T.E. Eakin. 1949. Groundwater in White River Valley, White Pine, Nye and Lincoln Counties, Nevada, Water Resources Bulletin No. 8. Carson City, NV: State of Nevada, Office of the State Engineer.

Morelon, I. and D. Guerillot. 1995. Selection of 3D Geostatistical Reservoir Representations Based on Dynamic Production Criteria, AAPG Bulletin, Vol. 79, Issue 8.

Russell, C.E. and T. Minor. 2002. Reconnaissance Estimates of Recharge Based on an Elevation-dependent Chloride Mass-balance Approach, DOE/NV/11508-37, Prepared for U.S. Department of Energy, National Nuclear Security Administration Nevada Operations Office. Las Vegas, NV.

Stoller-Navarro Joint Venture. 2004. Hydrologic Data for the Groundwater Flow and Contaminant Transport Model of Corrective Action Units 101 and 102: Central and Western Pahute Mesa, Nye County, Nevada, S-N/99205--002, Shaw/13052-204, Rev. 0. Las Vegas, NV.

U.S. Department of Energy, Nevada Operations Office. 1997. Regional Groundwater Flow and Tritium Transport Modeling and Risk Assessment of the Underground Test Area, Nevada Test Site, Nevada, DOE/NV--477. Las Vegas, NV.

Ward, D.S., D.R. Buss, J.W. Mercer, and S.S. Hughes. 1987. "Evaluation of a Groundwater Corrective Action at the Chem-Dyne Hazardous Waste Site Using a Telescopic Mesh Refinement Modeling Approach." In Water Resources Research, Vol. 23 (4): 603-617. Washington, DC: American Geophysical Union. 


\section{Appendix F}

Piper and Stiff Diagrams for FF Wells 


\section{F.1.0 Geochemistry, Piper and Stiff Diagrams}

This appendix presents Piper and Stiff diagrams for each of the wells within the Frenchman Flat CAU. Each Piper diagram presents all major ion data with a charge balance within \pm 10 percent. The Stiff diagrams present the major ion data for the most recent samples that meet a charge balance criteria of \pm 5 percent and represent those samples used for geochemical modeling. 


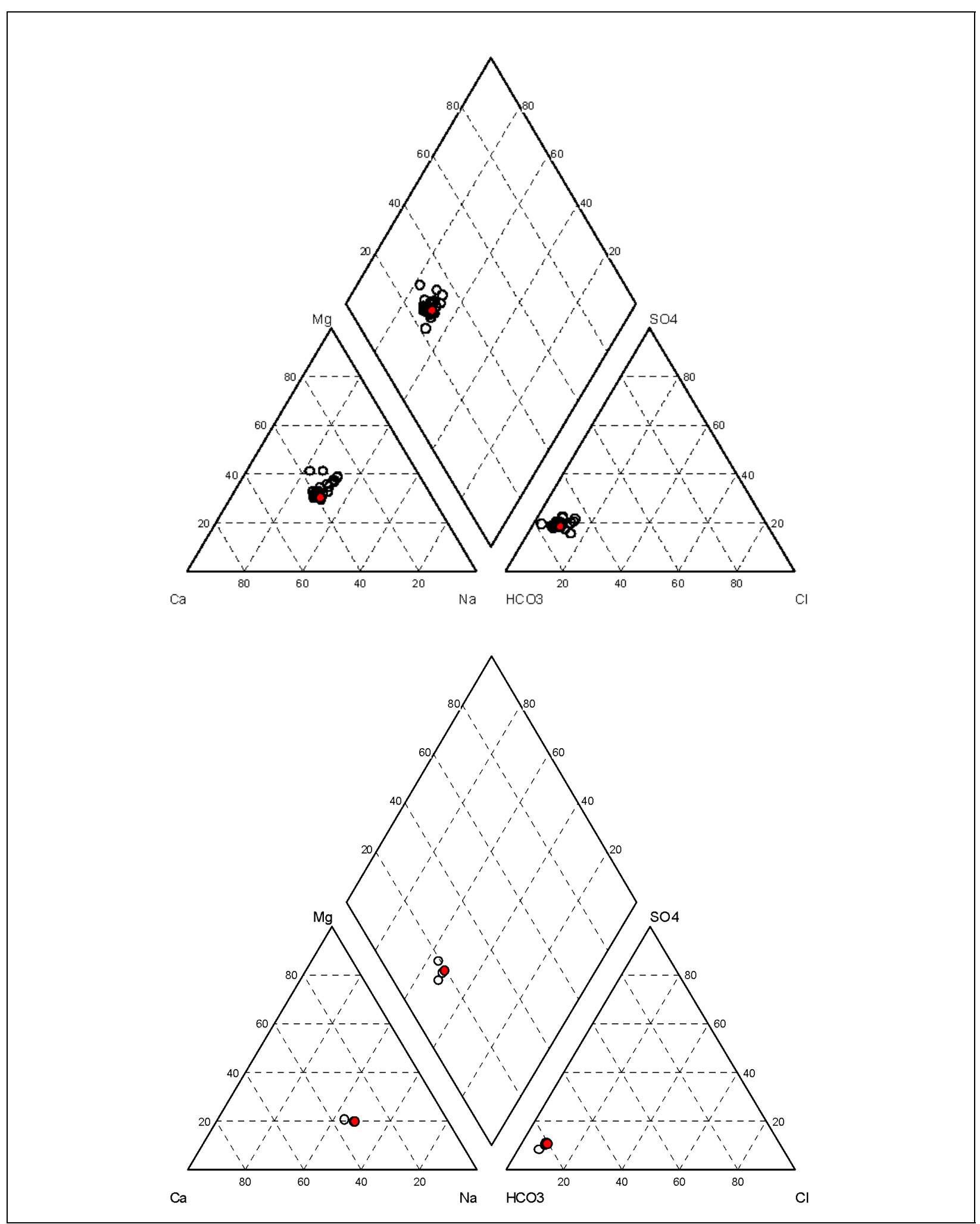

Figure F.1-1

Piper Diagram for Army \#1 WW (Top) and ER-5-3\#2 (Bottom) (Solid marker identifies the sample used for geochemical modeling) 

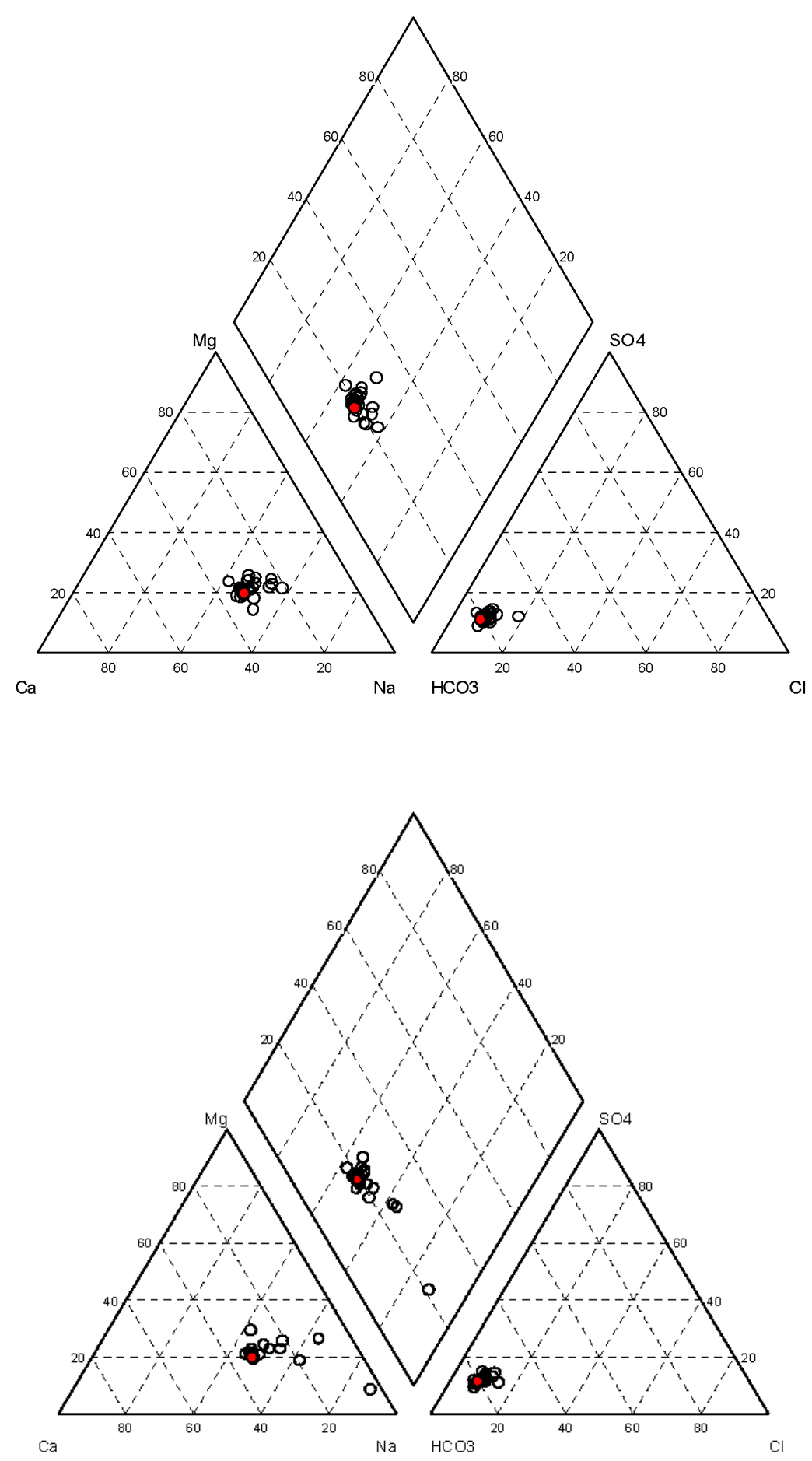

Figure F.1-2

Piper Diagram for Well WW-C (Top) and WW-C1 (Bottom)

(Solid marker identifies the sample used for geochemical modeling) 

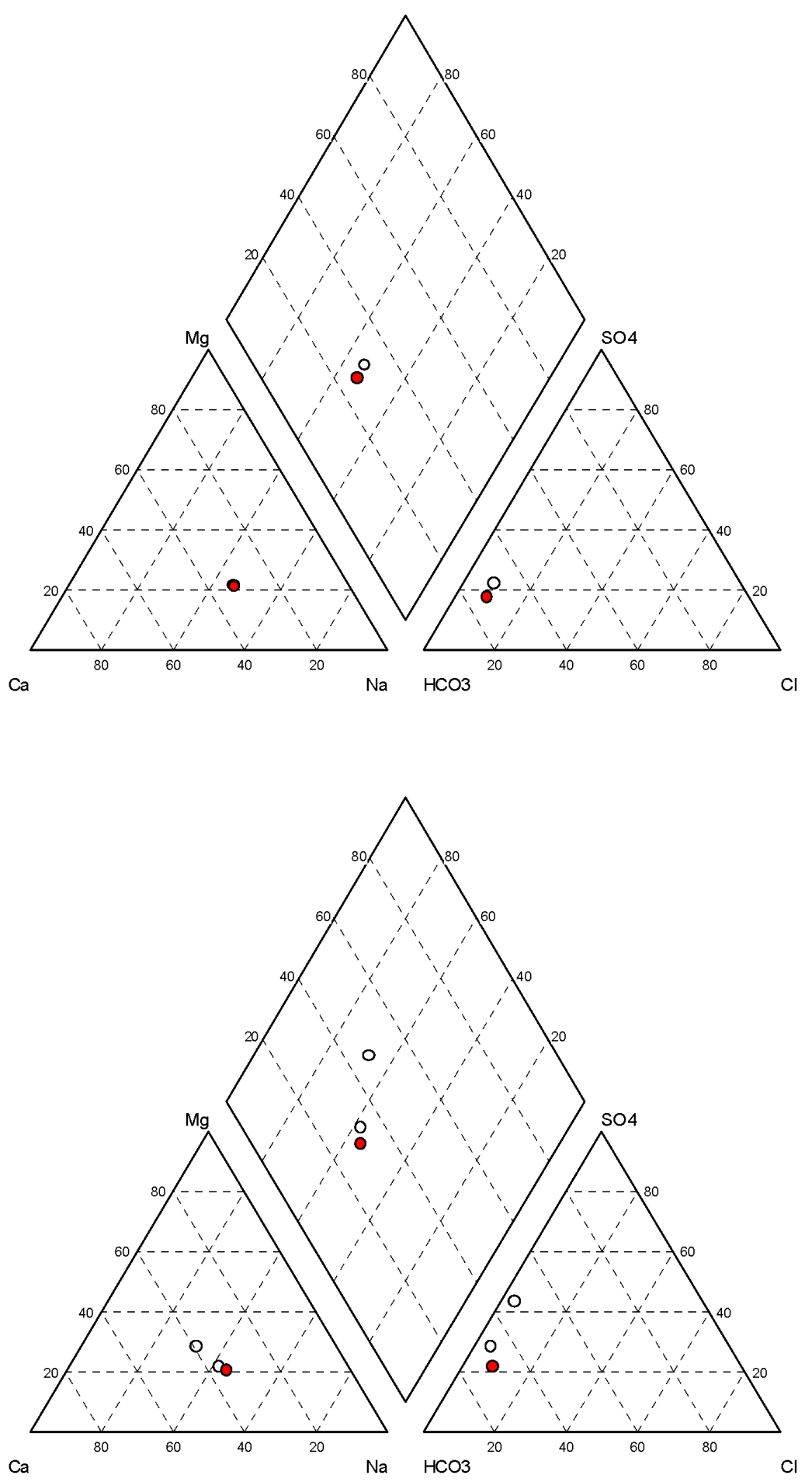

Figure F.1-3

Piper Diagram for Well TW-3 (Top) and TW-F (Bottom)

(Solid marker identifies the sample used for geochemical modeling) 

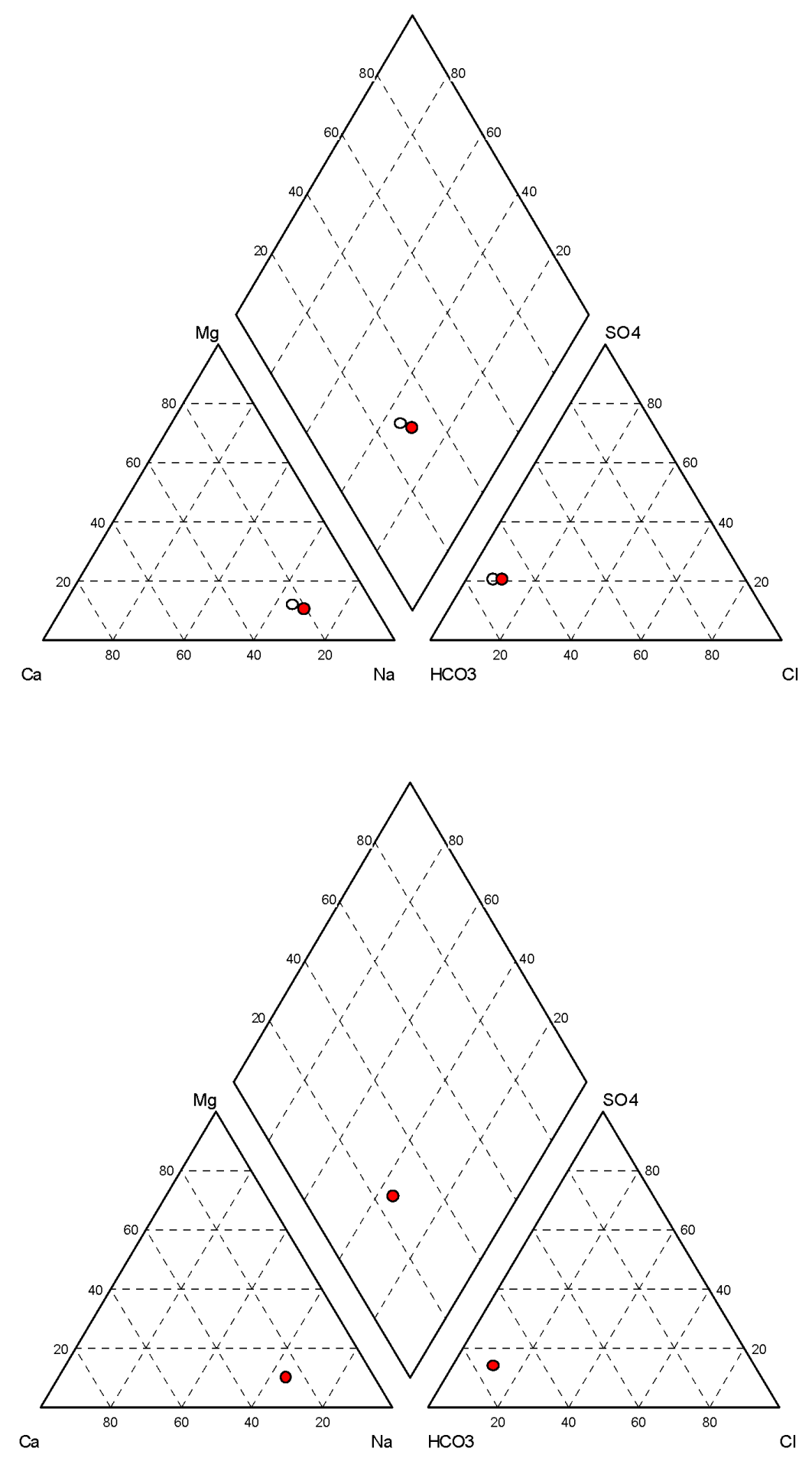

Figure F.1-4

Piper Diagram for UE-5 PW-1 (Top) and UE-5 PW-2 (Bottom)

(Solid marker identifies the sample used for geochemical modeling) 

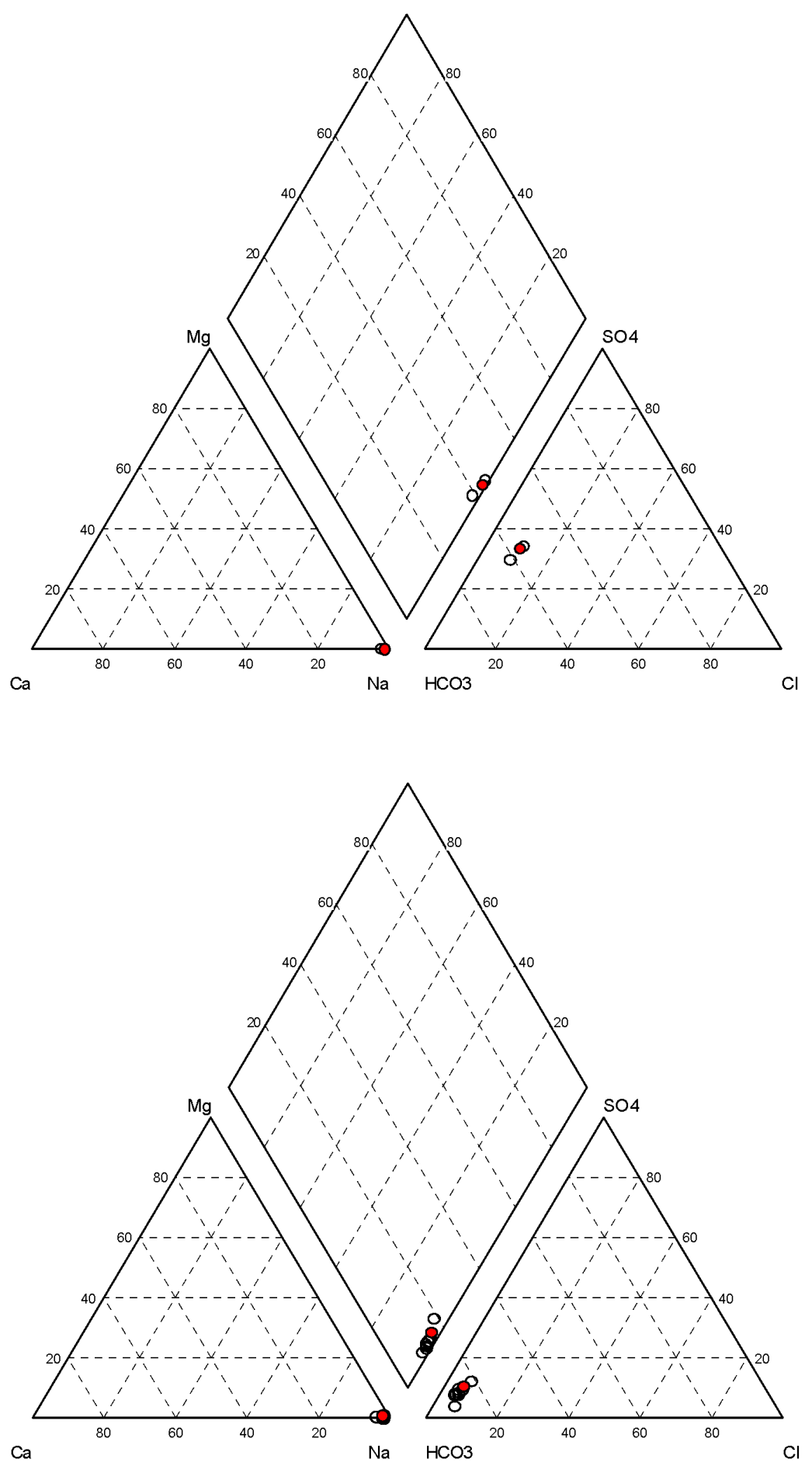

Figure F.1-5

Piper Diagram for ER-5-4 (Top) and WW-5a (Bottom)

(Solid marker identifies the sample used for geochemical modeling) 

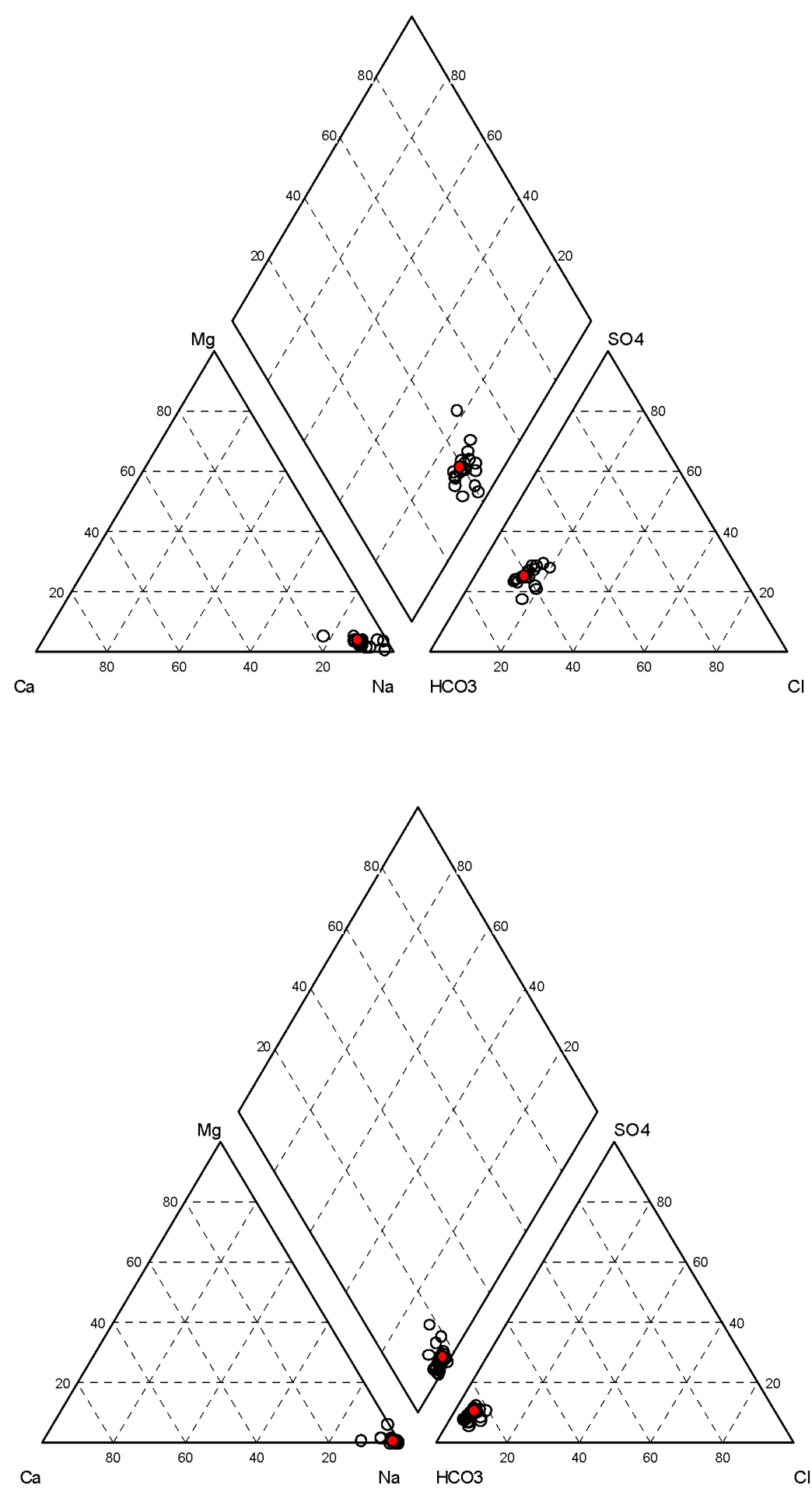

Figure F.1-6

Piper Diagram for WW-5b (Top) and WW-5c (Bottom)

(Solid marker identifies the sample used for geochemical modeling) 


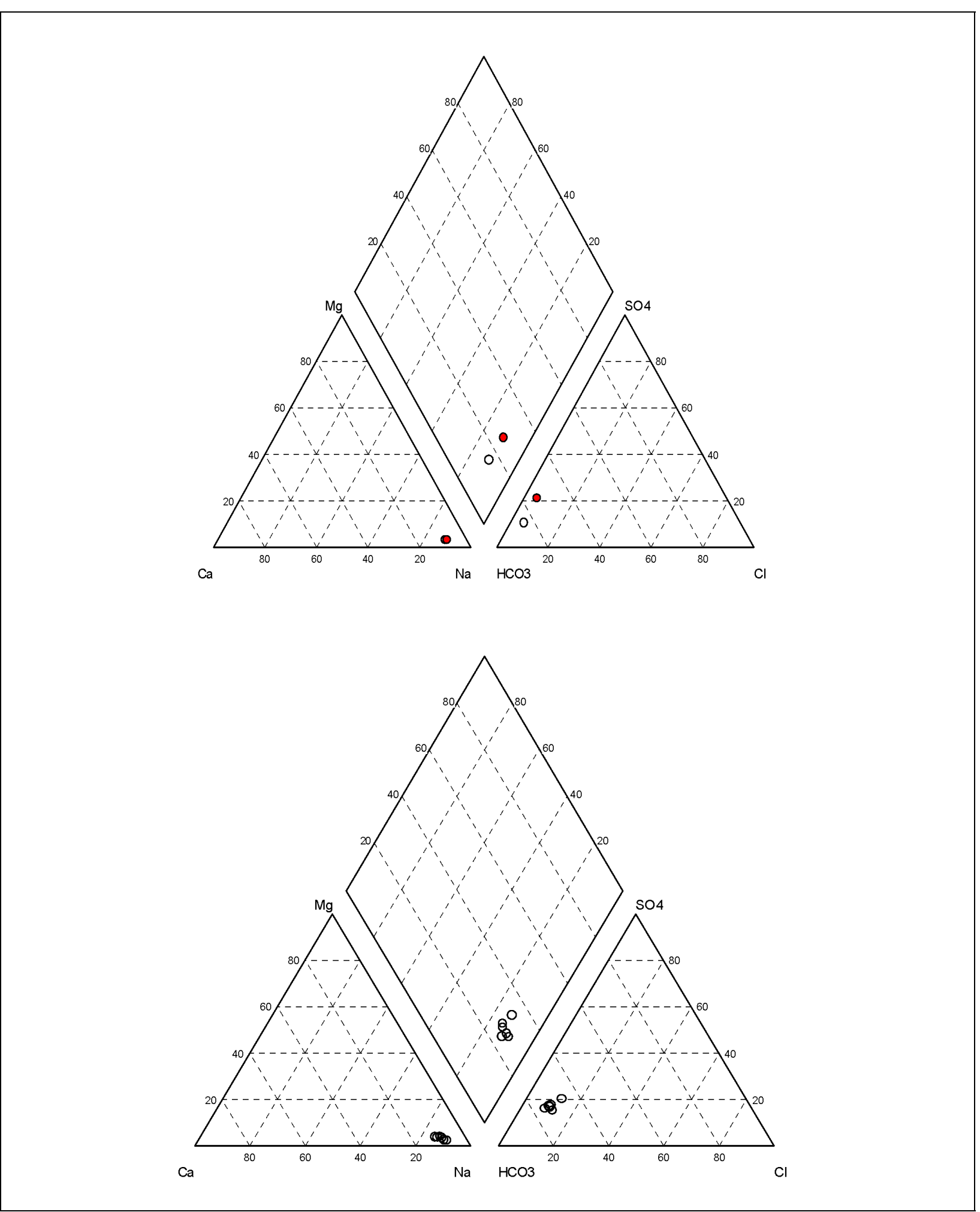

Figure F.1-7

Piper Diagram for WW-1 (Top) and UE-5n (Bottom)

(Solid marker identifies the sample used for geochemical modeling) 


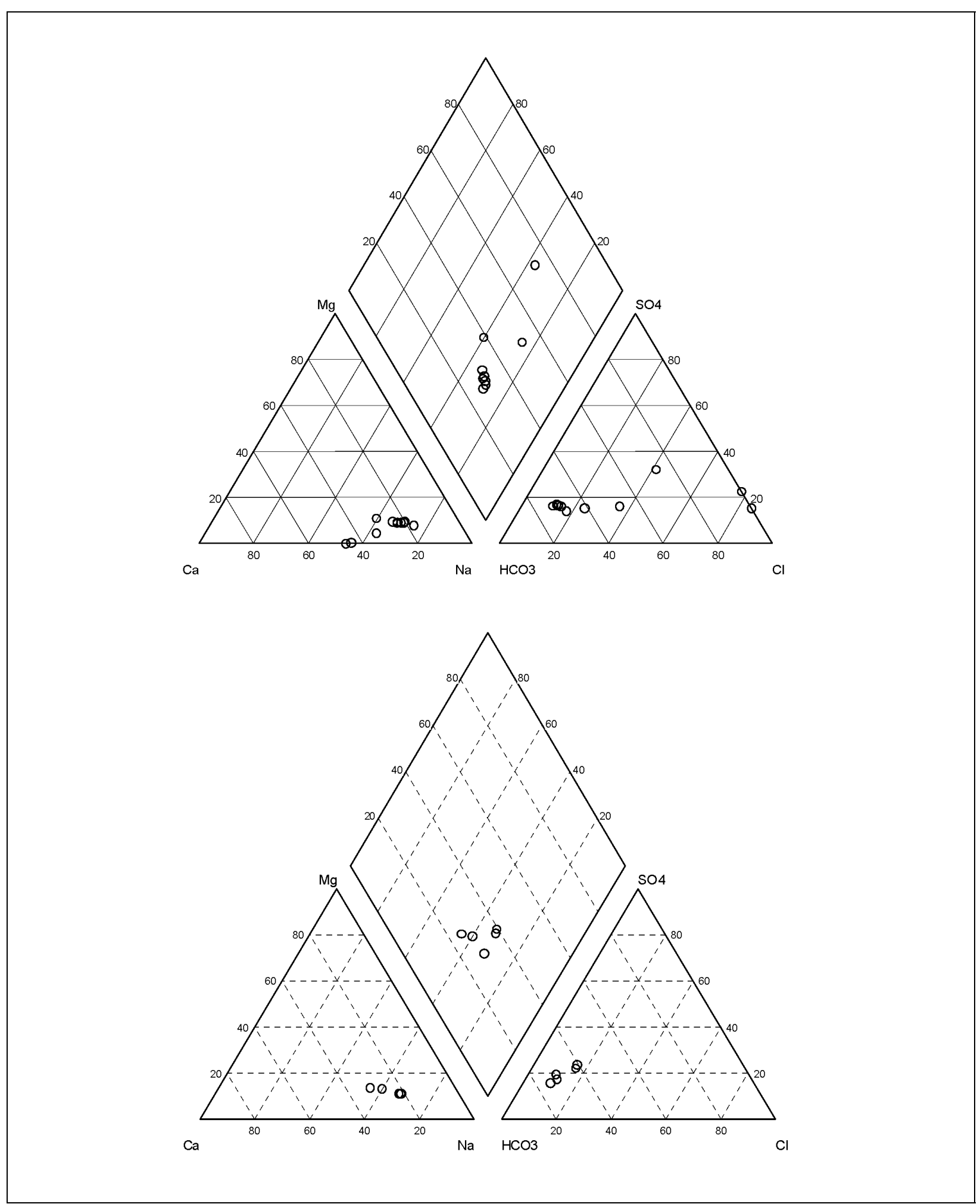

Figure F.1-8

Piper Diagram for RNM-1 (Top) and RNM-2S (Bottom) 

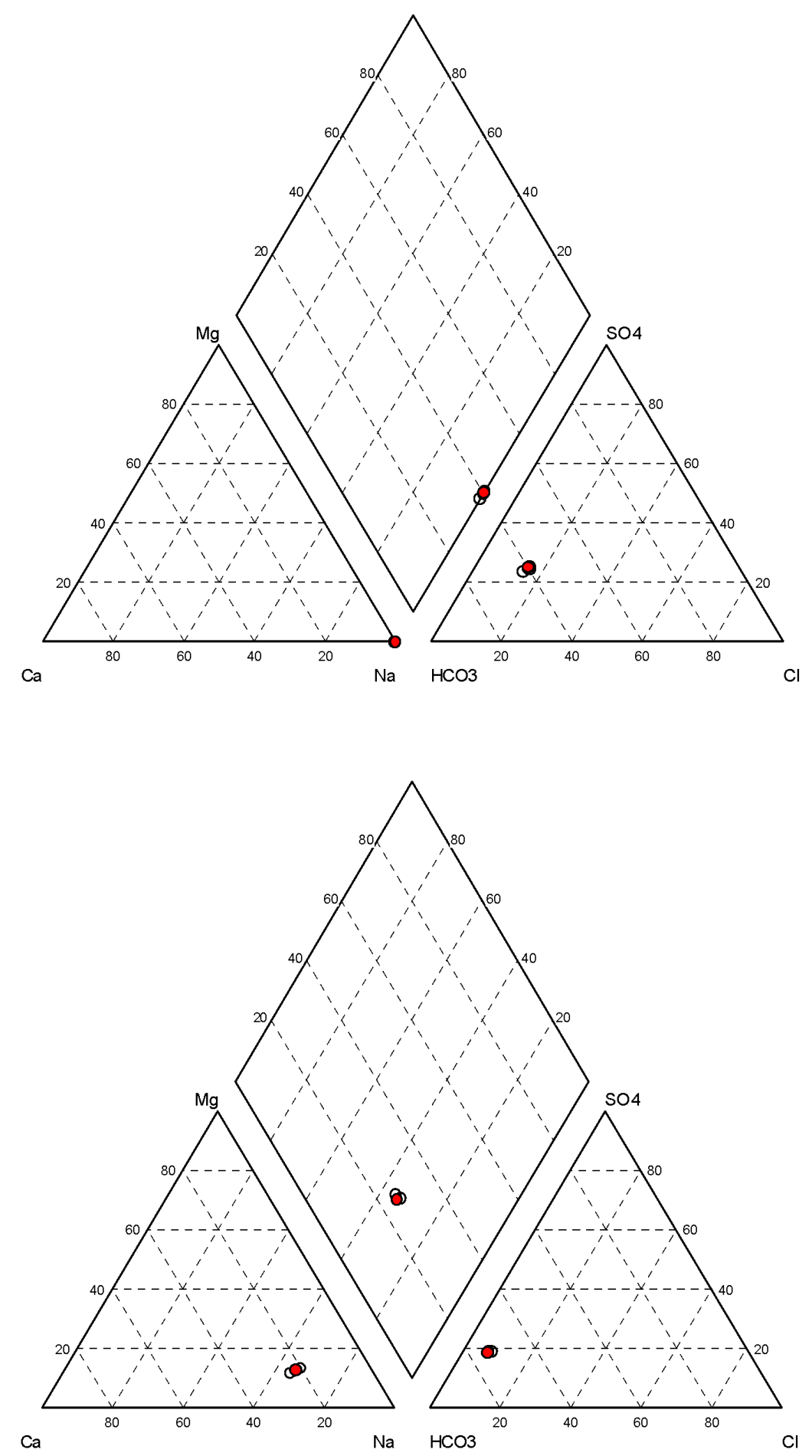

Figure F.1-9

Piper Diagram for ER-5-4 \#2 (Top) and UE-5 PW-3 (Bottom) (Solid marker identified the sample used for geochemical modeling) 

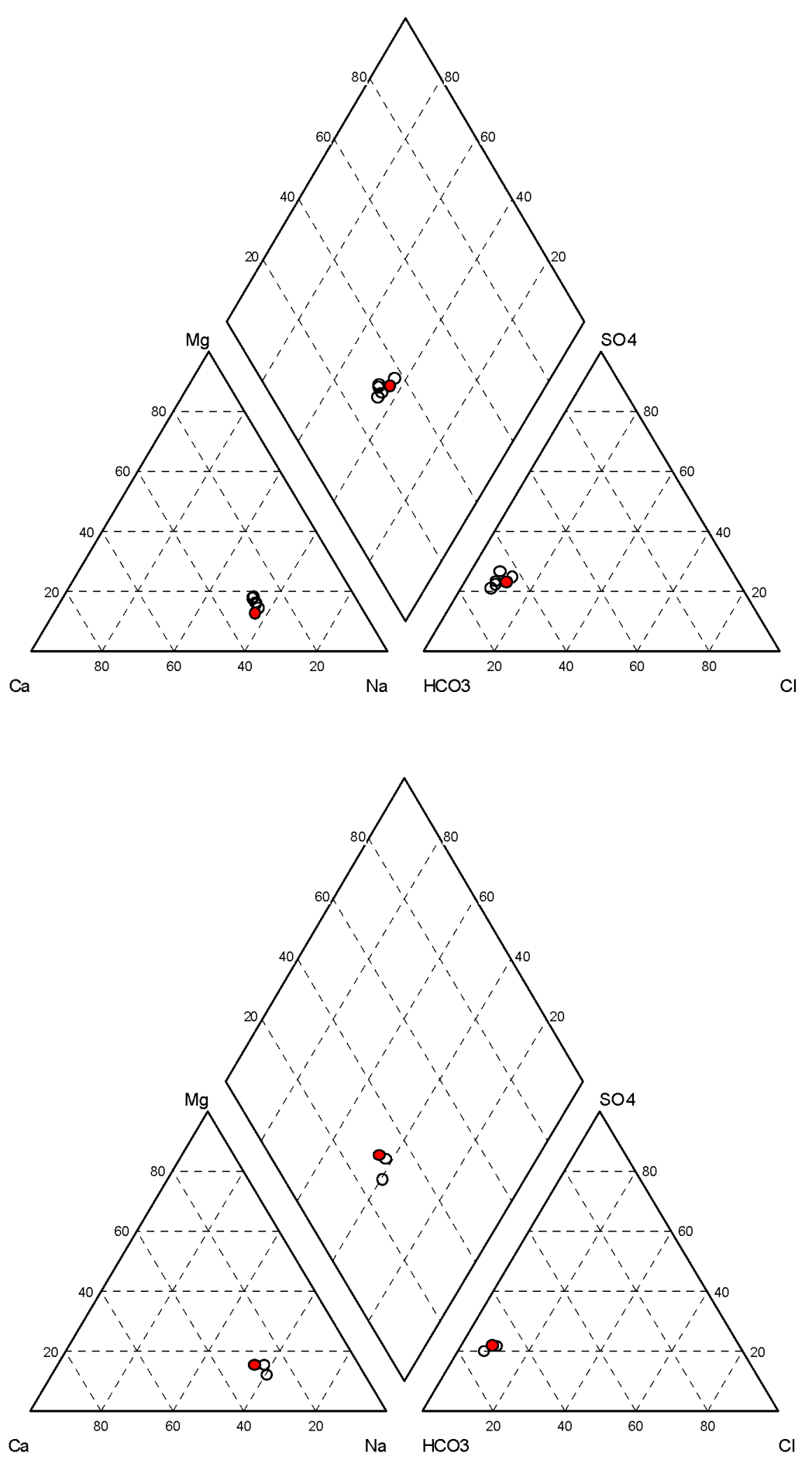

Figure F.1-10

Piper Diagram for Well WW-4 (Top) and WW-4a (Bottom)

(Solid marker identifies the sample used for geochemical modeling) 

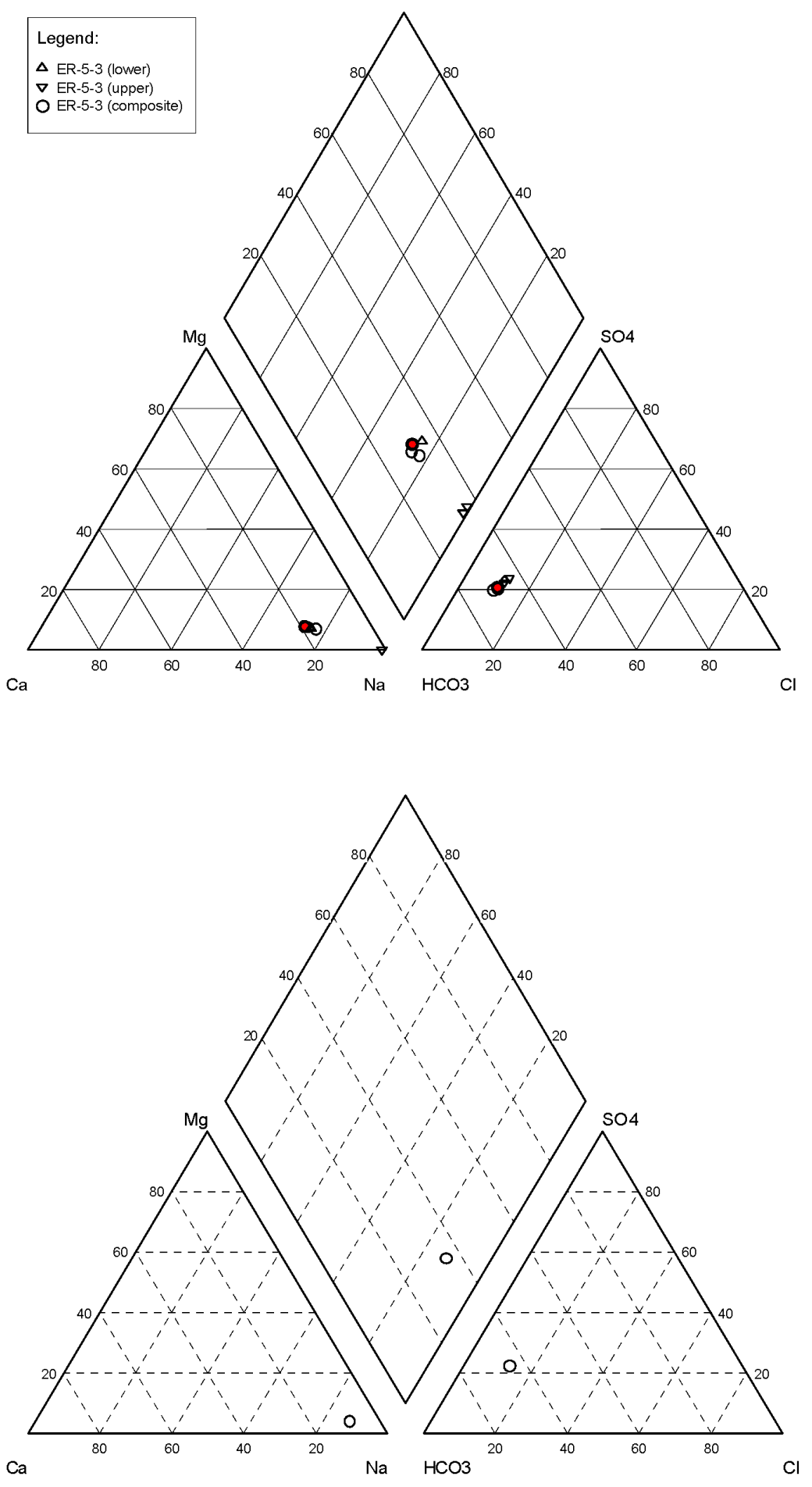

Figure F.1-11

Piper Diagram for ER-5-3 (Top) and UE-11a (Bottom)

(Solid marker identifies the sample used for geochemical modeling) 


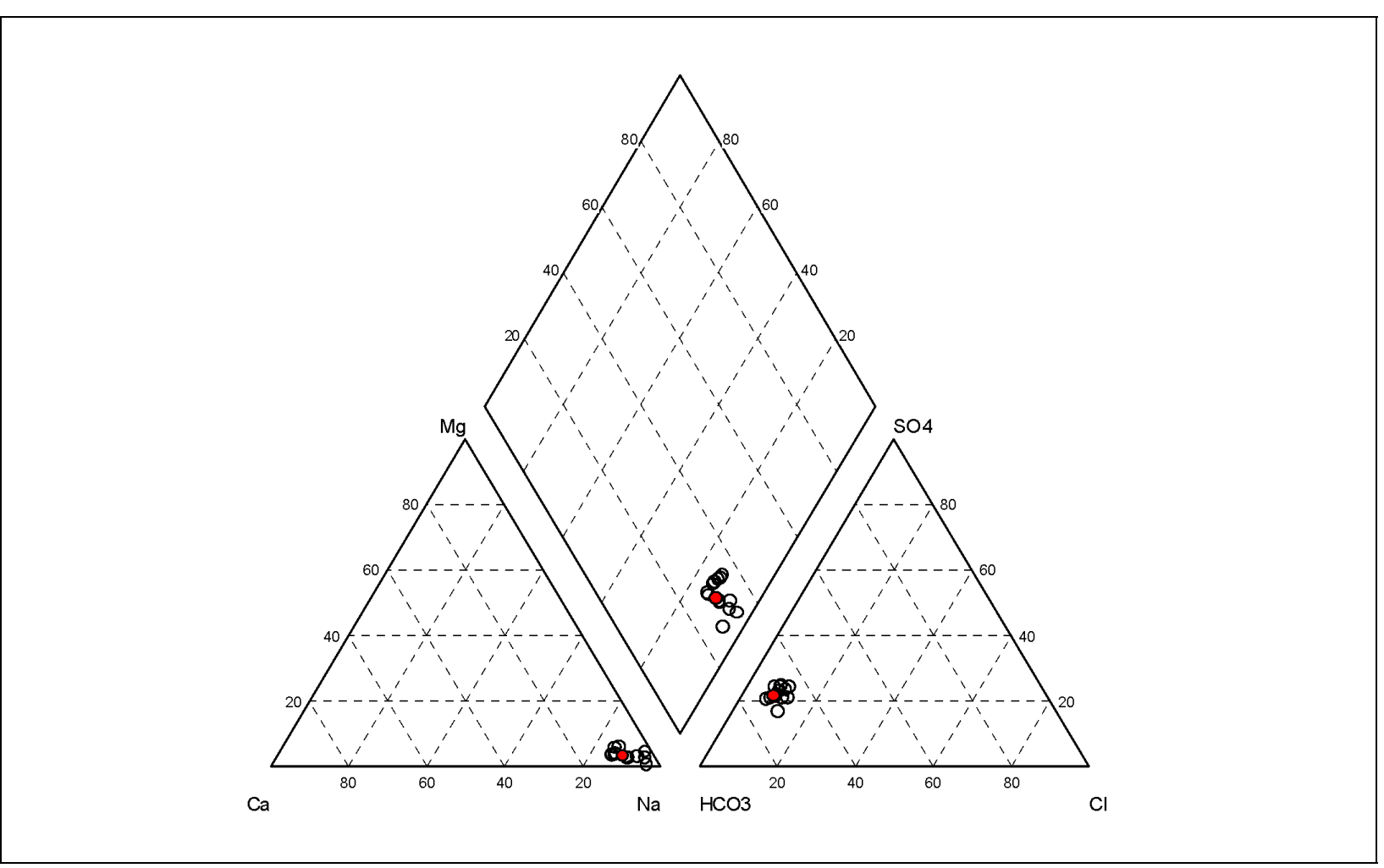

Figure F.1-12

Piper Diagram for UE-5c WW

(Solid marker identifies the sample used for geochemical modeling) 


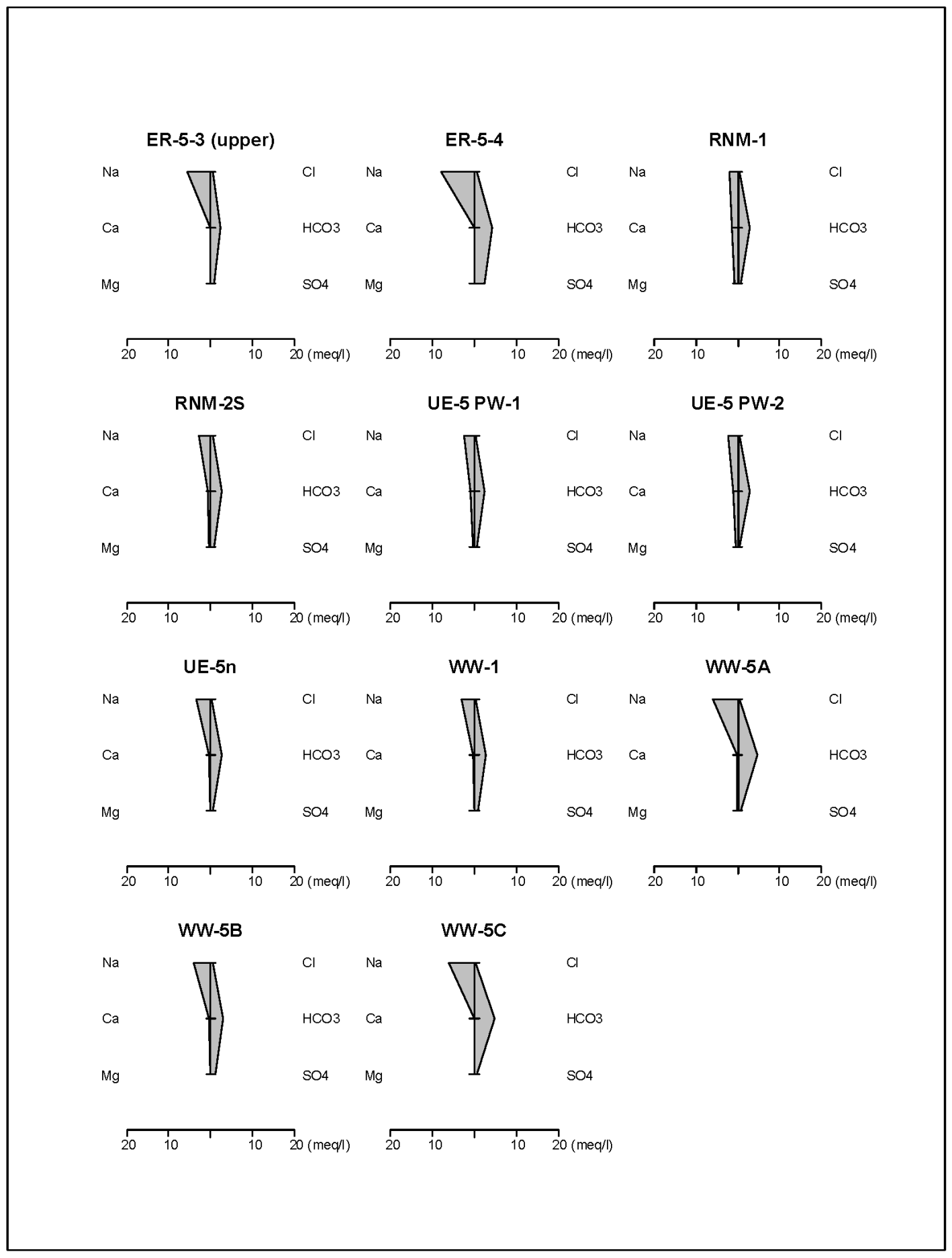

Figure F.1-13

Stiff Diagrams Based on Representative Concentrations for Alluvial Aquifer Groundwater 


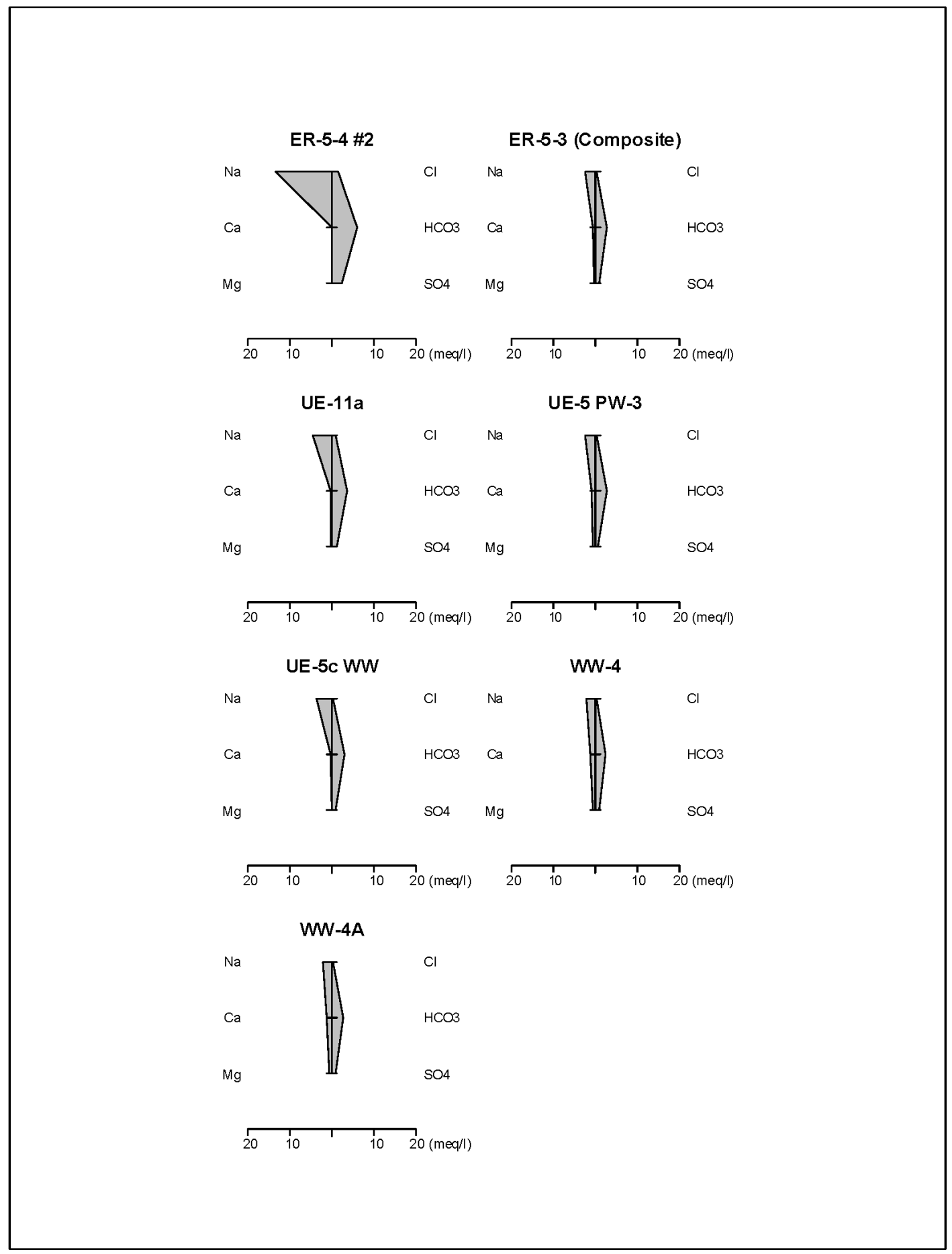

Figure F.1-14

Stiff Diagrams Based on Representative Concentrations for Groundwater of the Volcanic HSUs 
Amargosa Tracer Hole

$\mathrm{Na}$

$\mathrm{Na}$

$\mathrm{Ca}$

$\mathrm{Mg}$
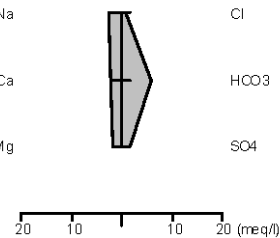

ER-3-1

$\mathrm{Na}$
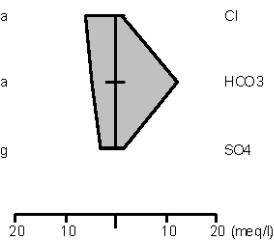

ER-6-1

$\mathrm{Na}$

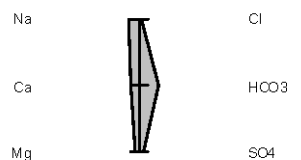

$\mathrm{Mg}$

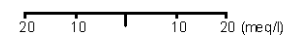

USGS HTH \#3
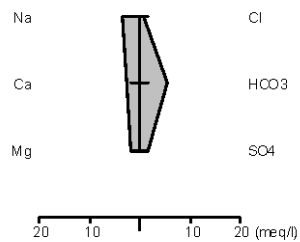

USGS Water Well C

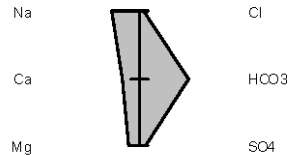

\begin{tabular}{ll|l}
$20 \quad 10 \quad 10 \quad 20$ & $($ meq/l)
\end{tabular}
Army \#1 Water Well

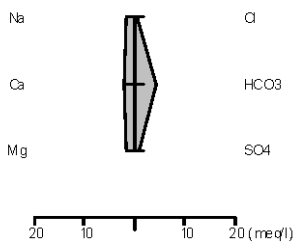

ER-5-3 \#2
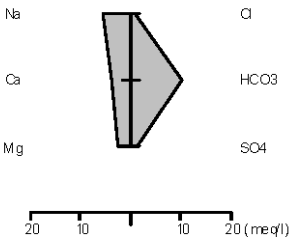

ER-6-1 \#2

$\mathrm{Na}$

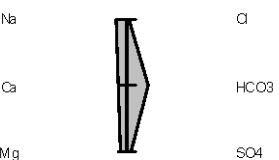

$\mathrm{Mg} \quad \mathrm{SO}$

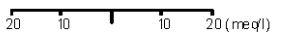

USGS Test Well F

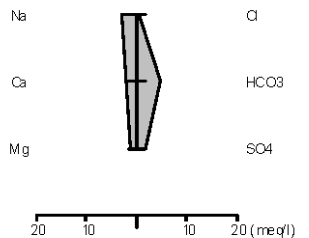

Water Well C-1
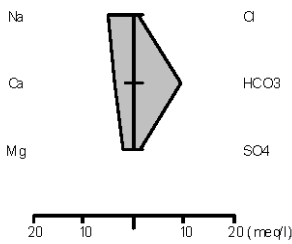

Figure F.1-15

Stiff Diagrams Based on Representative Concentrations

for Carbonate Aquifer Groundwater 


\section{Distribution}

W. R. Wilborn

Environmental Restoration Division

U.S. Department of Energy

National Nuclear Security Administration

Nevada Site Office

P.O. Box $98518, \mathrm{M} / \mathrm{S} 505$

Las Vegas, NV 89193-8518

Shirley Doty

Environmental Restoration Division

U.S. Department of Energy

National Nuclear Security Administration

Nevada Site Office

P.O. Box $98518, \mathrm{M} / \mathrm{S} 505$

Las Vegas, NV 89193-8518

TIRC

U.S. Department of Energy

National Nuclear Security Administration

Nevada Site Office

P.O. Box $98518, \mathrm{M} / \mathrm{S} 505$

Las Vegas, NV 89193-8518

U.S. Department of Energy

Office of Scientific and Technical Information

P.O. Box 62

Oak Ridge, TN 37831-0062

Manager, Northern Nevada FFACO

Public Reading Facility

c/o Nevada State Library \& Archives

Carson City, NV 89701-4285

Southern Nevada Public Reading Facility

c/o Nuclear Testing Archive

P. O. Box $98521, \mathrm{M} / \mathrm{S} 400$

Las Vegas, NV 89193

Tim Murphy

State of Nevada

Division of Environmental Protection

1771 E. Flamingo Road, Suite 121A

Las Vegas, NV 89119

Eric Noack

State of Nevada

Division of Environmental Protection

333 West Nye Lane, Suite 138

Carson City, NV 89706-0851
2 Hardcopy w/CD

$1 \mathrm{CD}$

$1 \mathrm{CD}$

$1 \mathrm{CD}$

1 Hardcopy w/CD

1 Hardcopy w/CD

1 Hardcopy w/CD

1 Hardcopy w/CD 
P. K. Ortego

Bechtel Nevada

P. O. Box 98521

MS/NLV082

Las Vegas, NV 89193-8521

C. Russell

Desert Research Institute

755 E. Flamingo

Las Vegas, NV 89119

N. Becker

Los Alamos National Laboratory

Hydrology, Geochemistry, and Geology Group, EES-6

Earth and Environmental Sciences Division

SM-30, Bikini Atoll Rd., MS F665

Los Alamos, NM 87545

G. A. Pawloski

Lawrence Livermore National Laboratory

7000 East Avenue, L-221

Livermore, CA 94551-0808

T. Rose

Lawrence Livermore National Laboratory

7000 East Avenue, L-231

Livermore, CA 94551-0808

J. McCord

Stoller-Navarro Joint Venture

7710 W. Cheyenne, Bldg. 3

Las Vegas, NV 89129

B. K. Thompson

USGS WRD

160 N. Stephanie St.

Henderson, NV 89074-8829

Stoller-Navarro Joint Venture

Central Files

7710 W. Cheyenne, Bldg. 3

Las Vegas, NV 89129
$1 \mathrm{CD}$

$1 \mathrm{CD}$

$1 \mathrm{CD}$

$1 \mathrm{CD}$

$1 \mathrm{CD}$

1 Hardcopy with CD

$1 \mathrm{CD}$

1 Hardcopy with CD 


\begin{tabular}{|c|c|c|c|c|c|c|c|}
\hline Month & Year & $\begin{array}{l}\text { Million } \\
\text { Gallons }\end{array}$ & Acre-Feet & $\begin{array}{l}\text { Million } \\
\text { Liters }\end{array}$ & $\begin{array}{c}\text { Days } \\
\text { Reported }\end{array}$ & Source $^{a}$ & Comment $^{b}$ \\
\hline July & 1962 & 0.70 & 2.15 & 2.65 & 0 & $\mathrm{R}$ & estimated \\
\hline August & 1962 & 0.70 & 2.15 & 2.65 & 0 & $\mathrm{R}$ & estimated \\
\hline September & 1962 & 0.70 & 2.15 & 2.65 & 0 & $\mathrm{R}$ & estimated \\
\hline October & 1962 & 0.70 & 2.15 & 2.65 & 0 & $\mathrm{R}$ & estimated \\
\hline November & 1962 & 0.70 & 2.15 & 2.65 & 0 & $\mathrm{R}$ & estimated \\
\hline December & 1962 & 0.70 & 2.15 & 2.65 & 0 & $\mathrm{R}$ & estimated \\
\hline January & 1963 & -- & -- & -- & 0 & $\bar{R}$ & -- \\
\hline February & 1963 & -- & -- & -- & 0 & $\mathrm{R}$ & -- \\
\hline March & 1963 & -- & -- & -- & 0 & $\mathrm{R}$ & -- \\
\hline April & 1963 & -- & -- & -- & 0 & $\mathrm{R}$ & -- \\
\hline May & 1963 & -- & -- & -- & 0 & $\mathrm{R}$ & -- \\
\hline June & 1963 & -- & -- & -- & 0 & $\mathrm{R}$ & -- \\
\hline July & 1963 & -- & -- & -- & 0 & $\mathrm{R}$ & -- \\
\hline August & 1963 & 2.70 & 8.29 & 10.23 & 31 & $M$ & -- \\
\hline September & 1963 & 0.00 & 0.00 & 0.00 & 30 & $\mathrm{M}$ & -- \\
\hline October & 1963 & 0.00 & 0.00 & 0.00 & 31 & $\mathrm{M}$ & -- \\
\hline November & 1963 & 0.00 & 0.00 & 0.00 & 30 & $M$ & -- \\
\hline December & 1963 & 0.00 & 0.00 & 0.00 & 31 & $M$ & -- \\
\hline January & 1964 & 0.00 & 0.00 & 0.00 & 31 & $M$ & -- \\
\hline February & 1964 & 0.00 & 0.00 & 0.00 & 29 & $M$ & -- \\
\hline March & 1964 & 0.00 & 0.00 & 0.00 & 31 & $\bar{M}$ & -- \\
\hline April & 1964 & 0.00 & 0.00 & 0.00 & 30 & $\mathrm{M}$ & -- \\
\hline May & 1964 & 0.00 & 0.00 & 0.00 & 31 & $\mathrm{M}$ & -- \\
\hline June & 1964 & 0.00 & 0.00 & 0.00 & 30 & $\mathrm{M}$ & -- \\
\hline July & 1964 & 1.99 & 6.10 & 7.52 & 31 & $\mathrm{M}$ & -- \\
\hline August & 1964 & 7.23 & 22.17 & 27.35 & 31 & $\mathrm{M}$ & -- \\
\hline September & 1964 & 7.25 & 22.24 & 27.43 & 30 & $M$ & -- \\
\hline October & 1964 & 8.88 & 27.25 & 33.61 & 31 & $\mathrm{M}$ & -- \\
\hline November & 1964 & 1.84 & 5.65 & 6.97 & 30 & $M$ & -- \\
\hline December & 1964 & 5.19 & 15.93 & 19.65 & 31 & $M$ & -- \\
\hline January & 1965 & 0.52 & 1.60 & 1.97 & 31 & $\mathrm{M}$ & -- \\
\hline February & 1965 & 0.21 & 0.63 & 0.77 & 28 & $M$ & -- \\
\hline March & 1965 & 0.00 & 0.00 & 0.00 & 31 & $\bar{M}$ & -- \\
\hline April & 1965 & 0.00 & 0.00 & 0.00 & 30 & $\bar{M}$ & -- \\
\hline May & 1965 & 0.00 & 0.00 & 0.00 & 31 & $\bar{M}$ & -- \\
\hline June & 1965 & 0.00 & 0.00 & 0.00 & 30 & $\mathrm{M}$ & -- \\
\hline July & 1965 & 4.18 & 12.82 & 15.81 & 31 & $\mathrm{M}$ & -- \\
\hline August & 1965 & 10.72 & 32.91 & 40.58 & 31 & $M$ & -- \\
\hline September & 1965 & 3.83 & 11.75 & 14.50 & 26 & $M$ & -- \\
\hline October & 1965 & -- & -- & -- & 0 & $\mathrm{I}$ & -- \\
\hline November & 1965 & 3.63 & 11.15 & 13.75 & 29 & $M$ & -- \\
\hline December & 1965 & 2.21 & 6.79 & 8.38 & 31 & $M$ & -- \\
\hline January & 1966 & 1.98 & 6.08 & 7.50 & 31 & $\mathrm{M}$ & -- \\
\hline February & 1966 & 4.17 & 12.79 & 15.78 & 28 & $M$ & -- \\
\hline March & 1966 & 4.93 & 15.14 & 18.67 & 31 & $\mathrm{M}$ & -- \\
\hline April & 1966 & 2.71 & 8.30 & 10.24 & 30 & $\mathrm{M}$ & -- \\
\hline May & 1966 & 1.29 & 3.95 & 4.87 & 29 & $\mathrm{M}$ & -- \\
\hline June & 1966 & $\overline{--}$ & -- & $\overline{--}$ & 0 & $\mathrm{I}$ & -- \\
\hline July & 1966 & -- & -- & -- & 0 & $\mathrm{I}$ & -- \\
\hline
\end{tabular}




\begin{tabular}{|c|c|c|c|c|c|c|c|}
\hline August & 1966 & 11.58 & 35.54 & 43.83 & 28 & $\bar{M}$ & -- \\
\hline September & 1966 & 0.82 & 2.52 & 3.10 & 5 & $\bar{M}$ & -- \\
\hline October & 1966 & 3.42 & 10.50 & 12.94 & 31 & $\bar{M}$ & $\overline{--}$ \\
\hline November & 1966 & 2.55 & 7.81 & 9.64 & 30 & $\bar{M}$ & -- \\
\hline December & 1966 & 4.11 & 12.61 & 15.55 & 31 & $\mathrm{M}$ & -- \\
\hline January & 1967 & 0.88 & 2.71 & 3.35 & 31 & $\mathrm{M}$ & -- \\
\hline February & 1967 & 2.92 & 8.96 & 11.05 & 28 & $\mathrm{M}$ & -- \\
\hline March & 1967 & 5.76 & 17.69 & 21.82 & 31 & $\bar{M}$ & -- \\
\hline April & 1967 & 4.68 & 14.36 & 17.71 & 30 & $\bar{M}$ & -- \\
\hline May & 1967 & 10.11 & 31.02 & 38.26 & 31 & $\bar{M}$ & -- \\
\hline June & 1967 & 10.45 & 32.08 & 39.56 & 30 & $M$ & -- \\
\hline July & 1967 & 3.55 & 10.89 & 13.43 & 365 & $\mathrm{R}$ & estimated \\
\hline August & 1967 & 3.55 & 10.89 & 13.43 & 365 & $\bar{R}$ & estimated \\
\hline September & 1967 & 3.55 & 10.89 & 13.43 & 365 & $\bar{R}$ & estimated \\
\hline October & 1967 & 3.55 & 10.89 & 13.43 & 365 & $\overline{\mathrm{R}}$ & estimated \\
\hline November & 1967 & 3.55 & 10.89 & 13.43 & 365 & $\bar{R}$ & estimated \\
\hline December & 1967 & 3.55 & 10.89 & 13.43 & 365 & $\mathrm{R}$ & estimated \\
\hline January & 1968 & 4.39 & 13.48 & 16.62 & 366 & $\mathrm{R}$ & estimated \\
\hline February & 1968 & 4.39 & 13.48 & 16.62 & 366 & $\mathrm{R}$ & estimated \\
\hline March & 1968 & 4.39 & 13.48 & 16.62 & 366 & $\mathrm{R}$ & estimated \\
\hline April & 1968 & 4.39 & 13.48 & 16.62 & 366 & $\bar{R}$ & estimated \\
\hline May & 1968 & 4.39 & 13.48 & 16.62 & 366 & $\bar{R}$ & estimated \\
\hline June & 1968 & 4.39 & 13.48 & 16.62 & 366 & $\mathrm{R}$ & estimated \\
\hline July & 1968 & 4.39 & 13.48 & 16.62 & 366 & $\overline{\mathrm{R}}$ & estimated \\
\hline August & 1968 & 4.39 & 13.48 & 16.62 & 366 & $\mathrm{R}$ & estimated \\
\hline September & 1968 & 4.39 & 13.48 & 16.62 & 366 & $\bar{R}$ & estimated \\
\hline October & 1968 & 4.39 & 13.48 & 16.62 & 366 & $\overline{\mathrm{R}}$ & estimated \\
\hline November & 1968 & 4.39 & 13.48 & 16.62 & 366 & $\bar{R}$ & estimated \\
\hline December & 1968 & 4.39 & 13.48 & 16.62 & 366 & $\bar{R}$ & estimated \\
\hline January & 1969 & 6.51 & 19.97 & 24.63 & 365 & $\mathrm{R}$ & estimated \\
\hline February & 1969 & 6.51 & 19.97 & 24.63 & 365 & $\mathrm{R}$ & estimated \\
\hline March & 1969 & 6.51 & 19.97 & 24.63 & 365 & $\mathrm{R}$ & estimated \\
\hline April & 1969 & 6.51 & 19.97 & 24.63 & 365 & $\bar{R}$ & estimated \\
\hline May & 1969 & 6.51 & 19.97 & 24.63 & 365 & $\bar{R}$ & estimated \\
\hline June & 1969 & 6.51 & 19.97 & 24.63 & 365 & $\mathrm{R}$ & estimated \\
\hline July & 1969 & 6.51 & 19.97 & 24.63 & 365 & $\mathrm{R}$ & estimated \\
\hline August & 1969 & 6.51 & 19.97 & 24.63 & 365 & $\bar{R}$ & estimated \\
\hline September & 1969 & 6.51 & 19.97 & 24.63 & 365 & $\mathrm{R}$ & estimated \\
\hline October & 1969 & 6.51 & 19.97 & 24.63 & 365 & $\overline{\mathrm{R}}$ & estimated \\
\hline November & 1969 & 6.51 & 19.97 & 24.63 & 365 & $\bar{R}$ & estimated \\
\hline December & 1969 & 6.51 & 19.97 & 24.63 & 365 & $\mathrm{R}$ & estimated \\
\hline January & 1970 & 5.78 & 17.75 & 21.89 & 365 & $\mathrm{R}$ & estimated \\
\hline February & 1970 & 5.78 & 17.75 & 21.89 & 365 & $\mathrm{R}$ & estimated \\
\hline March & 1970 & 5.78 & 17.75 & 21.89 & 365 & $\mathrm{R}$ & estimated \\
\hline April & 1970 & 5.78 & 17.75 & 21.89 & 365 & $\mathrm{R}$ & estimated \\
\hline May & 1970 & 5.78 & 17.75 & 21.89 & 365 & $\bar{R}$ & estimated \\
\hline June & 1970 & 5.78 & 17.75 & 21.89 & 365 & $\mathrm{R}$ & estimated \\
\hline July & 1970 & 5.78 & 17.75 & 21.89 & 365 & $\bar{R}$ & estimated \\
\hline August & 1970 & 5.78 & 17.75 & 21.89 & 365 & $\bar{R}$ & estimated \\
\hline September & 1970 & 5.78 & 17.75 & 21.89 & 365 & $\mathrm{R}$ & estimated \\
\hline October & 1970 & 5.78 & 17.75 & 21.89 & 365 & $\overline{\mathrm{R}}$ & estimated \\
\hline November & 1970 & 5.78 & 17.75 & 21.89 & 365 & $\bar{R}$ & estimated \\
\hline
\end{tabular}




\begin{tabular}{|c|c|c|c|c|c|c|c|}
\hline December & 1970 & 5.78 & 17.75 & 21.89 & 365 & $\mathrm{R}$ & estimated \\
\hline January & 1971 & 8.01 & 24.57 & 30.31 & 365 & $\bar{R}$ & estimated \\
\hline February & 1971 & 8.01 & 24.57 & 30.31 & 365 & $\bar{R}$ & estimated \\
\hline March & 1971 & 8.01 & 24.57 & 30.31 & 365 & $\bar{R}$ & estimated \\
\hline April & 1971 & 8.01 & 24.57 & 30.31 & 365 & $R$ & estimated \\
\hline May & 1971 & 8.01 & 24.57 & 30.31 & 365 & $\mathrm{R}$ & estimated \\
\hline June & 1971 & 8.01 & 24.57 & 30.31 & 365 & $\mathrm{R}$ & estimated \\
\hline July & 1971 & 8.01 & 24.57 & 30.31 & 365 & $R$ & estimated \\
\hline August & 1971 & 8.01 & 24.57 & 30.31 & 365 & $\bar{R}$ & estimated \\
\hline September & 1971 & 8.01 & 24.57 & 30.31 & 365 & $\bar{R}$ & estimated \\
\hline October & 1971 & 8.01 & 24.57 & 30.31 & 365 & $\mathrm{R}$ & estimated \\
\hline November & 1971 & 8.01 & 24.57 & 30.31 & 365 & $\bar{R}$ & estimated \\
\hline December & 1971 & 8.01 & 24.57 & 30.31 & 365 & $\mathrm{R}$ & estimated \\
\hline January & 1972 & 7.12 & 21.84 & 26.94 & 366 & $\overline{\mathrm{H}}$ & estimated \\
\hline February & 1972 & 7.12 & 21.84 & 26.94 & 366 & $\overline{\mathrm{H}}$ & estimated \\
\hline March & 1972 & 7.12 & 21.84 & 26.94 & 366 & $\bar{H}$ & estimated \\
\hline April & 1972 & 7.12 & 21.84 & 26.94 & 366 & $\mathrm{H}$ & estimated \\
\hline May & 1972 & 7.12 & 21.84 & 26.94 & 366 & $\mathrm{H}$ & estimated \\
\hline June & 1972 & 7.12 & 21.84 & 26.94 & 366 & $\mathrm{H}$ & estimated \\
\hline July & 1972 & 7.12 & 21.84 & 26.94 & 366 & $\bar{H}$ & estimated \\
\hline August & 1972 & 7.12 & 21.84 & 26.94 & 366 & $\overline{\mathrm{H}}$ & estimated \\
\hline September & 1972 & 7.12 & 21.84 & 26.94 & 366 & $\bar{H}$ & estimated \\
\hline October & 1972 & 7.12 & 21.84 & 26.94 & 366 & $\bar{H}$ & estimated \\
\hline November & 1972 & 7.12 & 21.84 & 26.94 & 366 & $\bar{H}$ & estimated \\
\hline December & 1972 & 7.12 & 21.84 & 26.94 & 366 & $\overline{\mathrm{H}}$ & estimated \\
\hline January & 1973 & 5.84 & 17.92 & 22.11 & 365 & $\overline{\mathrm{H}}$ & estimated \\
\hline February & 1973 & 5.84 & 17.92 & 22.11 & 365 & $\overline{\mathrm{H}}$ & estimated \\
\hline March & 1973 & 5.84 & 17.92 & 22.11 & 365 & $\bar{H}$ & estimated \\
\hline April & 1973 & 5.84 & 17.92 & 22.11 & 365 & $\bar{H}$ & estimated \\
\hline May & 1973 & 5.84 & 17.92 & 22.11 & 365 & $\bar{H}$ & estimated \\
\hline June & 1973 & 5.84 & 17.92 & 22.11 & 365 & $\mathrm{H}$ & estimated \\
\hline July & 1973 & 5.84 & 17.92 & 22.11 & 365 & $\bar{H}$ & estimated \\
\hline August & 1973 & 5.84 & 17.92 & 22.11 & 365 & $\overline{\mathrm{H}}$ & estimated \\
\hline September & 1973 & 5.84 & 17.92 & 22.11 & 365 & $\bar{H}$ & estimated \\
\hline October & 1973 & 5.84 & 17.92 & 22.11 & 365 & $\bar{H}$ & estimated \\
\hline November & 1973 & 5.84 & 17.92 & 22.11 & 365 & $\bar{H}$ & estimated \\
\hline December & 1973 & 5.84 & 17.92 & 22.11 & 365 & $\mathrm{H}$ & estimated \\
\hline January & 1974 & 6.49 & 19.92 & 24.57 & 365 & $\mathrm{H}$ & estimated \\
\hline February & 1974 & 6.49 & 19.92 & 24.57 & 365 & $\overline{\mathrm{H}}$ & estimated \\
\hline March & 1974 & 6.49 & 19.92 & 24.57 & 365 & $\overline{\mathrm{H}}$ & estimated \\
\hline April & 1974 & 6.49 & 19.92 & 24.57 & 365 & $\bar{H}$ & estimated \\
\hline May & 1974 & 6.49 & 19.92 & 24.57 & 365 & $\bar{H}$ & estimated \\
\hline June & 1974 & 6.49 & 19.92 & 24.57 & 365 & $\mathrm{H}$ & estimated \\
\hline July & 1974 & 6.49 & 19.92 & 24.57 & 365 & $\bar{H}$ & estimated \\
\hline August & 1974 & 6.49 & 19.92 & 24.57 & 365 & $\overline{\mathrm{H}}$ & estimated \\
\hline September & 1974 & 6.49 & 19.92 & 24.57 & 365 & $\overline{\mathrm{H}}$ & estimated \\
\hline October & 1974 & 6.49 & 19.92 & 24.57 & 365 & $\bar{H}$ & estimated \\
\hline November & 1974 & 6.49 & 19.92 & 24.57 & 365 & $\bar{H}$ & estimated \\
\hline December & 1974 & 6.49 & 19.92 & 24.57 & 365 & $\bar{H}$ & estimated \\
\hline January & 1975 & 6.38 & 19.59 & 24.16 & 365 & $\mathrm{H}$ & estimated \\
\hline February & 1975 & 6.38 & 19.59 & 24.16 & 365 & $\overline{\mathrm{H}}$ & estimated \\
\hline March & 1975 & 6.38 & 19.59 & 24.16 & 365 & $\bar{H}$ & estimated \\
\hline
\end{tabular}




\begin{tabular}{|c|c|c|c|c|c|c|c|}
\hline April & 1975 & 6.38 & 19.59 & 24.16 & 365 & $\mathrm{H}$ & estimated \\
\hline May & 1975 & 6.38 & 19.59 & 24.16 & 365 & $\overline{\mathrm{H}}$ & estimated \\
\hline June & 1975 & 6.38 & 19.59 & 24.16 & 365 & $\mathrm{H}$ & estimated \\
\hline July & 1975 & 6.38 & 19.59 & 24.16 & 365 & $\mathrm{H}$ & estimated \\
\hline August & 1975 & 6.38 & 19.59 & 24.16 & 365 & $\mathrm{H}$ & estimated \\
\hline September & 1975 & 6.38 & 19.59 & 24.16 & 365 & $\mathrm{H}$ & estimated \\
\hline October & 1975 & 6.38 & 19.59 & 24.16 & 365 & $\mathrm{H}$ & estimated \\
\hline November & 1975 & 6.38 & 19.59 & 24.16 & 365 & $\bar{H}$ & estimated \\
\hline December & 1975 & 6.38 & 19.59 & 24.16 & 365 & $\mathrm{H}$ & estimated \\
\hline January & 1976 & 5.41 & 16.60 & 20.47 & 366 & $\mathrm{H}$ & estimated \\
\hline February & 1976 & 5.41 & 16.60 & 20.47 & 366 & $\mathrm{H}$ & estimated \\
\hline \begin{tabular}{|l|} 
March \\
\end{tabular} & 1976 & 5.41 & 16.60 & 20.47 & 366 & $\overline{\mathrm{H}}$ & estimated \\
\hline April & 1976 & 5.41 & 16.60 & 20.47 & 366 & $\overline{\mathrm{H}}$ & estimated \\
\hline May & 1976 & 5.41 & 16.60 & 20.47 & 366 & $\overline{\mathrm{H}}$ & estimated \\
\hline June & 1976 & 5.41 & 16.60 & 20.47 & 366 & $\mathrm{H}$ & estimated \\
\hline July & 1976 & 5.41 & 16.60 & 20.47 & 366 & $\mathrm{H}$ & estimated \\
\hline August & 1976 & 5.41 & 16.60 & 20.47 & 366 & $\mathrm{H}$ & estimated \\
\hline September & 1976 & 5.41 & 16.60 & 20.47 & 366 & $\mathrm{H}$ & estimated \\
\hline October & 1976 & 5.41 & 16.60 & 20.47 & 366 & $\mathrm{H}$ & estimated \\
\hline November & 1976 & 5.41 & 16.60 & 20.47 & 366 & $\bar{H}$ & estimated \\
\hline December & 1976 & 5.41 & 16.60 & 20.47 & 366 & $\mathrm{H}$ & estimated \\
\hline January & 1977 & 4.81 & 14.75 & 18.20 & 365 & $\mathrm{H}$ & estimated \\
\hline February & 1977 & 4.81 & 14.75 & 18.20 & 365 & $\mathrm{H}$ & estimated \\
\hline March & 1977 & 4.81 & 14.75 & 18.20 & 365 & $\mathrm{H}$ & estimated \\
\hline April & 1977 & 4.81 & 14.75 & 18.20 & 365 & $\overline{\mathrm{H}}$ & estimated \\
\hline May & 1977 & 4.81 & 14.75 & 18.20 & 365 & $\overline{\mathrm{H}}$ & estimated \\
\hline June & 1977 & 4.81 & 14.75 & 18.20 & 365 & $\overline{\mathrm{H}}$ & estimated \\
\hline July & 1977 & 4.81 & 14.75 & 18.20 & 365 & $\mathrm{H}$ & estimated \\
\hline August & 1977 & 4.81 & 14.75 & 18.20 & 365 & $\mathrm{H}$ & estimated \\
\hline September & 1977 & 4.81 & 14.75 & 18.20 & 365 & $\mathrm{H}$ & estimated \\
\hline October & 1977 & 4.81 & 14.75 & 18.20 & 365 & $\mathrm{H}$ & estimated \\
\hline November & 1977 & 4.81 & 14.75 & 18.20 & 365 & $\bar{H}$ & estimated \\
\hline December & 1977 & 4.81 & 14.75 & 18.20 & 365 & $\bar{H}$ & estimated \\
\hline \begin{tabular}{|l|} 
January \\
\end{tabular} & 1978 & 5.00 & 15.34 & 18.93 & 365 & $\mathrm{H}$ & estimated \\
\hline February & 1978 & 5.00 & 15.34 & 18.93 & 365 & $\mathrm{H}$ & estimated \\
\hline \begin{tabular}{|l|} 
March \\
\end{tabular} & 1978 & 5.00 & 15.34 & 18.93 & 365 & $\mathrm{H}$ & estimated \\
\hline April & 1978 & 5.00 & 15.34 & 18.93 & 365 & $\overline{\mathrm{H}}$ & estimated \\
\hline May & 1978 & 5.00 & 15.34 & 18.93 & 365 & $\overline{\mathrm{H}}$ & estimated \\
\hline June & 1978 & 5.00 & 15.34 & 18.93 & 365 & $\overline{\mathrm{H}}$ & estimated \\
\hline July & 1978 & 5.00 & 15.34 & 18.93 & 365 & $\mathrm{H}$ & estimated \\
\hline August & 1978 & 5.00 & 15.34 & 18.93 & 365 & $\mathrm{H}$ & estimated \\
\hline September & 1978 & 5.00 & 15.34 & 18.93 & 365 & $\mathrm{H}$ & estimated \\
\hline October & 1978 & 5.00 & 15.34 & 18.93 & 365 & $\mathrm{H}$ & estimated \\
\hline November & 1978 & 5.00 & 15.34 & 18.93 & 365 & $\vec{H}$ & estimated \\
\hline December & 1978 & 5.00 & 15.34 & 18.93 & 365 & $\mathrm{H}$ & estimated \\
\hline January & 1979 & 4.29 & 13.17 & 16.24 & 365 & $\mathrm{H}$ & estimated \\
\hline February & 1979 & 4.29 & 13.17 & 16.24 & 365 & $\mathrm{H}$ & estimated \\
\hline March & 1979 & 4.29 & 13.17 & 16.24 & 365 & $\mathrm{H}$ & estimated \\
\hline April & 1979 & 4.29 & 13.17 & 16.24 & 365 & $\overline{\mathrm{H}}$ & estimated \\
\hline May & 1979 & 4.29 & 13.17 & 16.24 & 365 & $\overline{\mathrm{H}}$ & estimated \\
\hline June & 1979 & 4.29 & 13.17 & 16.24 & 365 & $\overline{\mathrm{H}}$ & estimated \\
\hline July & 1979 & 4.29 & 13.17 & 16.24 & 365 & $\overline{\mathrm{H}}$ & estimated \\
\hline
\end{tabular}




\begin{tabular}{|c|c|c|c|c|c|c|c|}
\hline August & 1979 & 4.29 & 13.17 & 16.24 & 365 & $\mathrm{H}$ & estimated \\
\hline September & 1979 & 4.29 & 13.17 & 16.24 & 365 & $\overline{\mathrm{H}}$ & estimated \\
\hline October & 1979 & 4.29 & 13.17 & 16.24 & 365 & $\bar{H}$ & estimated \\
\hline November & 1979 & 4.29 & 13.17 & 16.24 & 365 & $\overline{\mathrm{H}}$ & estimated \\
\hline December & 1979 & 4.29 & 13.17 & 16.24 & 365 & $\mathrm{H}$ & estimated \\
\hline January & 1980 & 4.94 & 15.16 & 18.70 & 366 & $\mathrm{H}$ & estimated \\
\hline February & 1980 & 4.94 & 15.16 & 18.70 & 366 & $\overline{\mathrm{H}}$ & estimated \\
\hline March & 1980 & 4.94 & 15.16 & 18.70 & 366 & $\overline{\mathrm{H}}$ & estimated \\
\hline April & 1980 & 4.94 & 15.16 & 18.70 & 366 & $\bar{H}$ & estimated \\
\hline May & 1980 & 4.94 & 15.16 & 18.70 & 366 & $\overline{\mathrm{H}}$ & estimated \\
\hline June & 1980 & 4.94 & 15.16 & 18.70 & 366 & $\bar{H}$ & estimated \\
\hline July & 1980 & 4.94 & 15.16 & 18.70 & 366 & $\mathrm{H}$ & estimated \\
\hline August & 1980 & 4.94 & 15.16 & 18.70 & 366 & $\overline{\mathrm{H}}$ & estimated \\
\hline September & 1980 & 4.94 & 15.16 & 18.70 & 366 & $\overline{\mathrm{H}}$ & estimated \\
\hline October & 1980 & 4.94 & 15.16 & 18.70 & 366 & $\overline{\mathrm{H}}$ & estimated \\
\hline November & 1980 & 4.94 & 15.16 & 18.70 & 366 & $\overline{\mathrm{H}}$ & estimated \\
\hline December & 1980 & 4.94 & 15.16 & 18.70 & 366 & $\mathrm{H}$ & estimated \\
\hline January & 1981 & 5.46 & 16.75 & 20.66 & 365 & $\mathrm{H}$ & estimated \\
\hline February & 1981 & 5.46 & 16.75 & 20.66 & 365 & $\overline{\mathrm{H}}$ & estimated \\
\hline March & 1981 & 5.46 & 16.75 & 20.66 & 365 & $\mathrm{H}$ & estimated \\
\hline April & 1981 & 5.46 & 16.75 & 20.66 & 365 & $\bar{H}$ & estimated \\
\hline May & 1981 & 5.46 & 16.75 & 20.66 & 365 & $\overline{\mathrm{H}}$ & estimated \\
\hline June & 1981 & 5.46 & 16.75 & 20.66 & 365 & $\bar{H}$ & estimated \\
\hline July & 1981 & 5.46 & 16.75 & 20.66 & 365 & $\mathrm{H}$ & estimated \\
\hline August & 1981 & 5.46 & 16.75 & 20.66 & 365 & $\mathrm{H}$ & estimated \\
\hline September & 1981 & 5.46 & 16.75 & 20.66 & 365 & $\overline{\mathrm{H}}$ & estimated \\
\hline October & 1981 & 5.46 & 16.75 & 20.66 & 365 & $\overline{\mathrm{H}}$ & estimated \\
\hline November & 1981 & 5.46 & 16.75 & 20.66 & 365 & $\overline{\mathrm{H}}$ & estimated \\
\hline December & 1981 & 5.46 & 16.75 & 20.66 & 365 & $\overline{\mathrm{H}}$ & estimated \\
\hline January & 1982 & 6.08 & 18.67 & 23.03 & 365 & $\mathrm{H}$ & estimated \\
\hline February & 1982 & 6.08 & 18.67 & 23.03 & 365 & $\overline{\mathrm{H}}$ & estimated \\
\hline March & 1982 & 6.08 & 18.67 & 23.03 & 365 & $\mathrm{H}$ & estimated \\
\hline April & 1982 & 6.08 & 18.67 & 23.03 & 365 & $\mathrm{H}$ & estimated \\
\hline May & 1982 & 6.08 & 18.67 & 23.03 & 365 & $\overline{\mathrm{H}}$ & estimated \\
\hline June & 1982 & 6.08 & 18.67 & 23.03 & 365 & $\bar{H}$ & estimated \\
\hline July & 1982 & 6.08 & 18.67 & 23.03 & 365 & $\overline{\mathrm{H}}$ & estimated \\
\hline August & 1982 & 6.08 & 18.67 & 23.03 & 365 & $\mathrm{H}$ & estimated \\
\hline September & 1982 & 6.08 & 18.67 & 23.03 & 365 & $\overline{\mathrm{H}}$ & estimated \\
\hline October & 1982 & 6.08 & 18.67 & 23.03 & 365 & $\overline{\mathrm{H}}$ & estimated \\
\hline November & 1982 & 6.08 & 18.67 & 23.03 & 365 & $\overline{\mathrm{H}}$ & estimated \\
\hline December & 1982 & 6.08 & 18.67 & 23.03 & 365 & $\mathrm{H}$ & estimated \\
\hline January & 1983 & 5.18 & 15.88 & 19.59 & 31 & $\mathrm{M}$ & -- \\
\hline February & 1983 & 4.29 & 13.17 & 16.24 & 28 & $\bar{M}$ & -- \\
\hline March & 1983 & 3.41 & 10.46 & 12.90 & 31 & $\bar{M}$ & -- \\
\hline April & 1983 & 5.57 & 17.08 & 21.07 & 30 & $\bar{M}$ & -- \\
\hline May & 1983 & 4.15 & 12.72 & 15.69 & 31 & $\bar{M}$ & -- \\
\hline June & 1983 & 2.00 & 6.13 & 7.56 & 30 & $\bar{M}$ & -- \\
\hline July & 1983 & 5.99 & 18.38 & 22.67 & 31 & $\mathrm{M}$ & -- \\
\hline August & 1983 & 5.41 & 16.60 & 20.48 & 31 & $\bar{M}$ & -- \\
\hline September & 1983 & 6.45 & 19.79 & 24.41 & 30 & $\bar{M}$ & -- \\
\hline October & 1983 & 4.80 & 14.74 & 18.18 & 31 & $\bar{M}$ & -- \\
\hline November & 1983 & 4.61 & 14.14 & 17.44 & 30 & $\bar{M}$ & $\overline{--}$ \\
\hline
\end{tabular}


Army-1 WW Monthly Pumping Data

\begin{tabular}{|c|c|c|c|c|c|c|c|}
\hline December & 1983 & 4.99 & 15.30 & 18.87 & 31 & $\mathrm{M}$ & -- \\
\hline January & 1984 & 4.01 & 12.30 & 15.18 & 31 & $\bar{M}$ & $\overline{--}$ \\
\hline February & 1984 & 5.43 & 16.67 & 20.56 & 29 & $\bar{M}$ & -- \\
\hline March & 1984 & 5.19 & 15.91 & 19.62 & 31 & $\bar{M}$ & -- \\
\hline April & 1984 & 5.82 & 17.87 & 22.04 & 30 & $\mathrm{M}$ & -- \\
\hline May & 1984 & 4.45 & 13.66 & 16.84 & 31 & $\mathrm{M}$ & - \\
\hline June & 1984 & 4.47 & 13.71 & 16.91 & 30 & $M$ & - \\
\hline July & 1984 & 7.25 & 22.24 & 27.44 & 31 & $\bar{M}$ & - \\
\hline August & 1984 & 10.27 & 31.50 & 38.86 & 31 & $\mathrm{M}$ & - \\
\hline September & 1984 & 10.15 & 31.13 & 38.40 & 30 & $\bar{M}$ & -- \\
\hline October & 1984 & 10.83 & 33.24 & 41.00 & 31 & $\mathrm{M}$ & -- \\
\hline November & 1984 & 9.35 & 28.69 & 35.39 & 30 & $\bar{M}$ & -- \\
\hline December & 1984 & 4.88 & 14.99 & 18.49 & 31 & $E$ & -- \\
\hline January & 1985 & 1.06 & 3.26 & 4.02 & 31 & $E$ & - \\
\hline February & 1985 & 1.50 & 4.59 & 5.66 & 28 & $\bar{M}$ & - \\
\hline March & 1985 & 1.59 & 4.88 & 6.02 & 31 & $\bar{M}$ & -- \\
\hline April & 1985 & 3.73 & 11.45 & 14.12 & 30 & $\mathrm{M}$ & -- \\
\hline May & 1985 & 2.18 & 6.70 & 8.26 & 31 & $\mathrm{M}$ & -- \\
\hline June & 1985 & 1.90 & 5.84 & 7.21 & 30 & $M$ & - \\
\hline July & 1985 & 4.88 & 14.97 & 18.46 & 31 & $\bar{M}$ & - \\
\hline August & 1985 & 6.93 & 21.27 & 26.24 & 31 & $\mathrm{M}$ & - \\
\hline September & 1985 & 4.04 & 12.40 & 15.29 & 30 & $\mathrm{M}$ & -- \\
\hline October & 1985 & 4.98 & 15.27 & 18.84 & 31 & $\mathrm{M}$ & - \\
\hline November & 1985 & 5.16 & 15.82 & 19.51 & 30 & $\bar{M}$ & - \\
\hline December & 1985 & 3.66 & 11.24 & 13.86 & 31 & $E$ & - \\
\hline January & 1986 & 5.33 & 16.36 & 20.18 & 31 & $\bar{M}$ & - \\
\hline February & 1986 & 2.32 & 7.11 & 8.77 & 28 & $\bar{M}$ & - \\
\hline March & 1986 & 1.47 & 4.50 & 5.55 & 31 & $\mathrm{M}$ & - \\
\hline April & 1986 & 1.75 & 5.37 & 6.62 & 30 & $\mathrm{M}$ & -- \\
\hline May & 1986 & 0.92 & 2.83 & 3.50 & 31 & $\mathrm{M}$ & -- \\
\hline June & 1986 & 4.59 & 14.07 & 17.36 & 30 & $\mathrm{M}$ & - \\
\hline July & 1986 & 5.67 & 17.41 & 21.47 & 31 & $M$ & - \\
\hline August & 1986 & 4.03 & 12.36 & 15.25 & 31 & $\mathrm{M}$ & - \\
\hline September & 1986 & 3.18 & 9.75 & 12.02 & 30 & $\mathrm{M}$ & -- \\
\hline October & 1986 & 1.01 & 3.09 & 3.81 & 31 & $M$ & -- \\
\hline November & 1986 & 1.91 & 5.87 & 7.24 & 30 & $\bar{M}$ & -- \\
\hline December & 1986 & 2.69 & 8.25 & 10.18 & 31 & $\bar{M}$ & - \\
\hline January & 1987 & 2.70 & 8.30 & 10.23 & 31 & $\bar{M}$ & - \\
\hline February & 1987 & 1.72 & 5.27 & 6.49 & 28 & $\mathrm{M}$ & - \\
\hline March & 1987 & 2.07 & 6.35 & 7.83 & 31 & $\bar{M}$ & - \\
\hline April & 1987 & 3.23 & 9.91 & 12.22 & 30 & $\mathrm{M}$ & -- \\
\hline May & 1987 & 3.61 & 11.08 & 13.67 & 31 & $\mathrm{M}$ & -- \\
\hline June & 1987 & 4.38 & 13.44 & 16.58 & 30 & $E$ & -- \\
\hline July & 1987 & 5.62 & 17.23 & 21.26 & 31 & $\bar{M}$ & - \\
\hline August & 1987 & 3.33 & 10.23 & 12.62 & 31 & $\bar{M}$ & - \\
\hline September & 1987 & 0.12 & 0.37 & 0.46 & 30 & $\mathrm{M}$ & - \\
\hline October & 1987 & 1.28 & 3.92 & 4.83 & 31 & $\mathrm{M}$ & - \\
\hline November & 1987 & 3.59 & 11.02 & 13.60 & 30 & $M$ & -- \\
\hline December & 1987 & 3.07 & 9.41 & 11.61 & 31 & $\bar{M}$ & - \\
\hline January & 1988 & 2.73 & 8.39 & 10.35 & 31 & $\bar{M}$ & -- \\
\hline February & 1988 & 1.49 & 4.58 & 5.65 & 29 & $\bar{M}$ & - \\
\hline March & 1988 & 7.24 & 22.22 & 27.40 & 31 & $\bar{M}$ & - \\
\hline
\end{tabular}




\begin{tabular}{|c|c|c|c|c|c|c|c|}
\hline April & 1988 & 2.89 & 8.86 & 10.93 & 30 & $\bar{M}$ & -- \\
\hline May & 1988 & 5.92 & 18.16 & 22.39 & 31 & $\bar{M}$ & - \\
\hline \begin{tabular}{|l|} 
June \\
\end{tabular} & 1988 & 5.89 & 18.08 & 22.30 & 30 & $\bar{M}$ & - \\
\hline July & 1988 & 3.80 & 11.67 & 14.39 & 31 & $\bar{M}$ & - \\
\hline August & 1988 & 4.44 & 13.61 & 16.79 & 31 & $\mathrm{M}$ & -- \\
\hline September & 1988 & 2.68 & 8.21 & 10.13 & 30 & $\bar{M}$ & -- \\
\hline October & 1988 & 3.70 & 11.35 & 14.00 & 31 & $\bar{M}$ & - \\
\hline November & 1988 & 5.73 & 17.58 & 21.68 & 30 & $E$ & - \\
\hline December & 1988 & 6.61 & 20.29 & 25.03 & 31 & $\bar{M}$ & - \\
\hline \begin{tabular}{|l|} 
January \\
\end{tabular} & 1989 & 6.29 & 19.29 & 23.79 & 31 & $\bar{M}$ & -- \\
\hline February & 1989 & 2.29 & 7.03 & 8.67 & 28 & $\bar{M}$ & -- \\
\hline March & 1989 & 8.29 & 25.43 & 31.36 & 31 & $\bar{M}$ & -- \\
\hline April & 1989 & 10.59 & 32.50 & 40.08 & 30 & $\bar{M}$ & - \\
\hline May & 1989 & 11.76 & 36.08 & 44.50 & 31 & $\bar{M}$ & - \\
\hline June & 1989 & 11.48 & 35.23 & 43.45 & 30 & $\bar{M}$ & - \\
\hline July & 1989 & 11.25 & 34.51 & 42.56 & 31 & $\bar{M}$ & - \\
\hline August & 1989 & 11.08 & 34.00 & 41.94 & 31 & $\mathrm{M}$ & -- \\
\hline September & 1989 & 10.72 & 32.91 & 40.59 & 30 & $\bar{M}$ & - \\
\hline October & 1989 & 10.72 & 32.91 & 40.59 & 31 & $M$ & - \\
\hline November & 1989 & 9.49 & 29.13 & 35.93 & 30 & $\bar{M}$ & - \\
\hline December & 1989 & 10.50 & 32.22 & 39.74 & 31 & $\bar{M}$ & - \\
\hline \begin{tabular}{|l|} 
January \\
\end{tabular} & 1990 & 11.43 & 35.07 & 43.26 & 31 & $M$ & - \\
\hline February & 1990 & 9.22 & 28.30 & 34.90 & 28 & $\mathrm{M}$ & -- \\
\hline March & 1990 & 10.64 & 32.64 & 40.25 & 31 & $\bar{M}$ & -- \\
\hline April & 1990 & 11.72 & 35.96 & 44.35 & 30 & $\bar{M}$ & - \\
\hline May & 1990 & 10.97 & 33.67 & 41.53 & 31 & $\bar{M}$ & - \\
\hline June & 1990 & 10.81 & 33.17 & 40.91 & 30 & $\bar{M}$ & - \\
\hline \begin{tabular}{|l|} 
July \\
\end{tabular} & 1990 & 10.90 & 33.46 & 41.27 & 31 & $\bar{M}$ & -- \\
\hline August & 1990 & 12.20 & 37.43 & 46.17 & 31 & $\mathrm{M}$ & -- \\
\hline September & 1990 & 9.57 & 29.37 & 36.23 & 30 & $\bar{M}$ & -- \\
\hline October & 1990 & 8.42 & 25.83 & 31.86 & 31 & $M$ & - \\
\hline November & 1990 & 9.94 & 30.51 & 37.62 & 30 & $\bar{M}$ & - \\
\hline December & 1990 & 10.23 & 31.38 & 38.71 & 31 & $E$ & - \\
\hline \begin{tabular}{|l|} 
January \\
\end{tabular} & 1991 & 11.32 & 34.74 & 42.84 & 31 & $E$ & -- \\
\hline February & 1991 & 4.37 & 13.41 & 16.55 & 28 & $\mathrm{M}$ & - \\
\hline March & 1991 & 6.12 & 18.78 & 23.16 & 31 & $\bar{M}$ & - \\
\hline April & 1991 & 8.00 & 24.54 & 30.26 & 30 & $\bar{M}$ & - \\
\hline May & 1991 & 12.24 & 37.56 & 46.32 & 31 & $\bar{M}$ & - \\
\hline $\begin{array}{l}\text { June } \\
\end{array}$ & 1991 & 11.99 & 36.81 & 45.40 & 30 & $\bar{M}$ & - \\
\hline July & 1991 & 7.07 & 21.70 & 26.77 & 31 & $\bar{M}$ & -- \\
\hline August & 1991 & 4.90 & 15.02 & 18.53 & 31 & $\mathrm{M}$ & -- \\
\hline September & 1991 & 11.37 & 34.89 & 43.04 & 30 & $\bar{M}$ & - \\
\hline October & 1991 & 12.83 & 39.37 & 48.55 & 31 & $M$ & - \\
\hline November & 1991 & 11.09 & 34.02 & 41.96 & 30 & $\bar{M}$ & -- \\
\hline December & 1991 & 8.61 & 26.43 & 32.60 & 31 & $\bar{M}$ & - \\
\hline \begin{tabular}{|l|} 
January \\
\end{tabular} & 1992 & 11.21 & 34.40 & 42.43 & 31 & $M$ & - \\
\hline February & 1992 & 11.26 & 34.56 & 42.62 & 29 & $\mathrm{M}$ & -- \\
\hline March & 1992 & 10.65 & 32.69 & 40.32 & 31 & M & - \\
\hline April & 1992 & 13.86 & 42.54 & 52.46 & 30 & $A$ & - \\
\hline May & 1992 & 13.52 & 41.49 & 51.18 & 31 & $\bar{A}$ & - \\
\hline June & 1992 & 13.00 & 39.91 & 49.22 & 30 & $\bar{M}$ & - \\
\hline \begin{tabular}{|l|} 
July \\
\end{tabular} & 1992 & 11.41 & 35.00 & 43.17 & 31 & $\bar{M}$ & - \\
\hline
\end{tabular}


Army-1 WW Monthly Pumping Data

\begin{tabular}{|c|c|c|c|c|c|c|c|}
\hline August & 1992 & 11.18 & 34.29 & 42.30 & 31 & $\mathrm{M}$ & -- \\
\hline September & 1992 & 10.32 & 31.67 & 39.06 & 30 & $\bar{A}$ & $\overline{--}$ \\
\hline October & 1992 & 9.84 & 30.21 & 37.26 & 31 & $\bar{A}$ & -- \\
\hline November & 1992 & 11.53 & 35.38 & 43.64 & 30 & $M$ & -- \\
\hline December & 1992 & 11.64 & 35.72 & 44.05 & 31 & $\mathrm{M}$ & -- \\
\hline January & 1993 & 11.69 & 35.88 & 44.25 & 31 & $\mathrm{M}$ & -- \\
\hline February & 1993 & 6.81 & 20.89 & 25.76 & 28 & $M$ & -- \\
\hline March & 1993 & 7.65 & 23.47 & 28.94 & 31 & $\bar{M}$ & -- \\
\hline April & 1993 & 8.44 & 25.91 & 31.95 & 30 & $\bar{M}$ & -- \\
\hline May & 1993 & 12.71 & 39.01 & 48.12 & 31 & $\bar{M}$ & -- \\
\hline June & 1993 & 9.70 & 29.77 & 36.72 & 30 & $\mathrm{M}$ & -- \\
\hline July & 1993 & 9.72 & 29.83 & 36.79 & 31 & $\mathrm{M}$ & -- \\
\hline August & 1993 & 8.51 & 26.11 & 32.21 & 31 & $\bar{M}$ & -- \\
\hline September & 1993 & 6.76 & 20.73 & 25.57 & 30 & $\bar{M}$ & -- \\
\hline October & 1993 & 8.71 & 26.73 & 32.97 & 31 & $\bar{M}$ & $\overline{--}$ \\
\hline November & 1993 & 7.20 & 22.11 & 27.27 & 30 & $\bar{M}$ & -- \\
\hline December & 1993 & 12.33 & 37.83 & 46.66 & 31 & $\mathrm{M}$ & -- \\
\hline January & 1994 & 10.57 & 32.43 & 39.99 & 31 & $A$ & -- \\
\hline February & 1994 & 8.75 & 26.85 & 33.12 & 28 & $M$ & -- \\
\hline March & 1994 & 12.22 & 37.51 & 46.26 & 31 & $M$ & -- \\
\hline April & 1994 & 10.81 & 33.17 & 40.91 & 30 & $\mathrm{M}$ & -- \\
\hline May & 1994 & 9.98 & 30.62 & 37.76 & 31 & $\bar{M}$ & -- \\
\hline June & 1994 & 9.79 & 30.05 & 37.07 & 30 & $\mathrm{M}$ & -- \\
\hline July & 1994 & 2.22 & 6.82 & 8.41 & 31 & $\bar{M}$ & -- \\
\hline August & 1994 & 1.46 & 4.49 & 5.54 & 31 & $\bar{M}$ & -- \\
\hline September & 1994 & 3.15 & 9.68 & 11.94 & 30 & $\bar{M}$ & -- \\
\hline October & 1994 & 2.11 & 6.46 & 7.97 & 31 & $\bar{M}$ & -- \\
\hline November & 1994 & 2.55 & 7.82 & 9.65 & 30 & $\mathrm{M}$ & - \\
\hline December & 1994 & 3.29 & 10.09 & 12.45 & 31 & $\mathrm{M}$ & -- \\
\hline January & 1995 & 3.81 & 11.70 & 14.43 & 31 & $\mathrm{M}$ & -- \\
\hline February & 1995 & 2.74 & 8.40 & 10.36 & 28 & $\mathrm{M}$ & -- \\
\hline March & 1995 & 0.47 & 1.43 & 1.77 & 31 & $M$ & -- \\
\hline April & 1995 & 0.64 & 1.98 & 2.44 & 30 & $\mathrm{M}$ & - \\
\hline May & 1995 & 2.07 & 6.36 & 7.84 & 31 & $\bar{M}$ & -- \\
\hline June & 1995 & 1.25 & 3.84 & 4.74 & 30 & $M$ & -- \\
\hline July & 1995 & 2.95 & 9.05 & 11.17 & 31 & $\mathrm{M}$ & -- \\
\hline August & 1995 & 0.74 & 2.26 & 2.79 & 31 & $\bar{M}$ & - \\
\hline September & 1995 & 2.99 & 9.17 & 11.31 & 30 & $\bar{M}$ & -- \\
\hline October & 1995 & 2.86 & 8.77 & 10.81 & 31 & $\bar{M}$ & -- \\
\hline November & 1995 & 1.64 & 5.03 & 6.20 & 30 & $\bar{M}$ & - \\
\hline December & 1995 & 1.97 & 6.05 & 7.46 & 31 & $\mathrm{M}$ & -- \\
\hline January & 1996 & 2.30 & 7.06 & 8.71 & 31 & $\mathrm{M}$ & -- \\
\hline February & 1996 & 0.86 & 2.64 & 3.25 & 29 & $\bar{M}$ & -- \\
\hline March & 1996 & 0.74 & 2.27 & 2.80 & 31 & $\bar{M}$ & -- \\
\hline April & 1996 & 2.04 & 6.25 & 7.70 & 30 & $\bar{M}$ & -- \\
\hline May & 1996 & 3.80 & 11.67 & 14.39 & 31 & $\bar{M}$ & - \\
\hline June & 1996 & 0.79 & 2.41 & 2.97 & 30 & $\bar{M}$ & -- \\
\hline July & 1996 & 1.26 & 3.86 & 4.76 & 31 & $\bar{M}$ & -- \\
\hline August & 1996 & 1.36 & 4.16 & 5.13 & 31 & $\bar{M}$ & - \\
\hline September & 1996 & 1.53 & 4.70 & 5.80 & 30 & $\bar{M}$ & -- \\
\hline October & 1996 & 1.45 & 4.44 & 5.48 & 31 & $\bar{M}$ & -- \\
\hline November & 1996 & 0.68 & 2.09 & 2.58 & 30 & $\bar{M}$ & -- \\
\hline
\end{tabular}


Army-1 WW Monthly Pumping Data

\begin{tabular}{|c|c|c|c|c|c|c|c|}
\hline December & 1996 & 0.85 & 2.62 & 3.23 & 31 & $\mathrm{M}$ & -- \\
\hline January & 1997 & 1.35 & 4.15 & 5.11 & 31 & $\bar{M}$ & $\overline{--}$ \\
\hline February & 1997 & 0.65 & 1.99 & 2.46 & 28 & $\bar{M}$ & -- \\
\hline March & 1997 & 0.61 & 1.86 & 2.29 & 31 & $M$ & -- \\
\hline April & 1997 & 0.53 & 1.63 & 2.01 & 30 & $\mathrm{M}$ & -- \\
\hline May & 1997 & 1.27 & 3.88 & 4.79 & 31 & $\mathrm{M}$ & -- \\
\hline June & 1997 & 0.65 & 2.00 & 2.47 & 30 & $M$ & -- \\
\hline July & 1997 & 0.93 & 2.85 & 3.52 & 31 & $\bar{M}$ & -- \\
\hline August & 1997 & 1.35 & 4.15 & 5.12 & 31 & $\mathrm{M}$ & -- \\
\hline September & 1997 & 1.23 & 3.77 & 4.64 & 30 & $\bar{M}$ & -- \\
\hline October & 1997 & 0.96 & 2.94 & 3.63 & 31 & $\mathrm{M}$ & -- \\
\hline November & 1997 & 1.08 & 3.32 & 4.10 & 30 & $\bar{M}$ & -- \\
\hline December & 1997 & 0.82 & 2.51 & 3.10 & 31 & $\bar{M}$ & -- \\
\hline January & 1998 & 0.91 & 2.78 & 3.43 & 31 & $\bar{M}$ & -- \\
\hline February & 1998 & 0.11 & 0.34 & 0.41 & 28 & $\bar{M}$ & -- \\
\hline March & 1998 & 0.00 & 0.00 & 0.00 & 31 & $\bar{M}$ & -- \\
\hline April & 1998 & 0.01 & 0.02 & 0.02 & 30 & $\mathrm{M}$ & -- \\
\hline May & 1998 & 0.01 & 0.02 & 0.02 & 31 & $\mathrm{M}$ & -- \\
\hline June & 1998 & 0.00 & 0.00 & 0.00 & 30 & $M$ & -- \\
\hline July & 1998 & 0.00 & 0.00 & 0.00 & 31 & $\bar{M}$ & -- \\
\hline August & 1998 & 0.00 & 0.00 & 0.00 & 31 & $\mathrm{M}$ & -- \\
\hline September & 1998 & 0.00 & 0.00 & 0.00 & 30 & $\mathrm{M}$ & -- \\
\hline October & 1998 & 0.00 & 0.00 & 0.00 & 31 & $\mathrm{M}$ & -- \\
\hline November & 1998 & 0.00 & 0.00 & 0.00 & 30 & $\bar{M}$ & -- \\
\hline December & 1998 & 0.00 & 0.00 & 0.00 & 31 & $\bar{M}$ & -- \\
\hline January & 1999 & 0.01 & 0.04 & 0.05 & 31 & $\bar{M}$ & -- \\
\hline February & 1999 & 0.01 & 0.01 & 0.02 & 28 & $\bar{M}$ & -- \\
\hline March & 1999 & 0.12 & 0.37 & 0.45 & 31 & $\mathrm{M}$ & - \\
\hline April & 1999 & 0.25 & 0.76 & 0.93 & 30 & $\mathrm{M}$ & -- \\
\hline May & 1999 & 0.63 & 1.94 & 2.39 & 31 & $\mathrm{M}$ & -- \\
\hline June & 1999 & 0.04 & 0.11 & 0.14 & 30 & $\mathrm{M}$ & -- \\
\hline July & 1999 & 0.19 & 0.57 & 0.70 & 31 & $M$ & -- \\
\hline August & 1999 & 0.10 & 0.32 & 0.39 & 31 & $\mathrm{M}$ & - \\
\hline September & 1999 & 0.08 & 0.25 & 0.31 & 30 & $\mathrm{M}$ & - \\
\hline October & 1999 & 0.06 & 0.20 & 0.24 & 31 & $M$ & -- \\
\hline November & 1999 & 0.01 & 0.04 & 0.05 & 30 & $\bar{M}$ & -- \\
\hline December & 1999 & 0.01 & 0.03 & 0.04 & 31 & $\bar{M}$ & - \\
\hline January & 2000 & 0.04 & 0.11 & 0.14 & 31 & $\bar{M}$ & -- \\
\hline February & 2000 & 0.02 & 0.04 & 0.05 & 29 & $\mathrm{M}$ & -- \\
\hline March & 2000 & 0.04 & 0.12 & 0.15 & 31 & $\bar{M}$ & - \\
\hline April & 2000 & 0.18 & 0.54 & 0.67 & 30 & $\mathrm{M}$ & -- \\
\hline May & 2000 & 0.14 & 0.42 & 0.52 & 31 & $\mathrm{M}$ & -- \\
\hline June & 2000 & 0.10 & 0.31 & 0.38 & 30 & $\mathrm{M}$ & -- \\
\hline July & 2000 & 0.04 & 0.13 & 0.16 & 31 & $M$ & -- \\
\hline August & 2000 & 0.00 & 0.00 & 0.00 & 31 & $M$ & -- \\
\hline September & 2000 & 0.01 & 0.01 & 0.02 & 30 & $\mathrm{M}$ & - \\
\hline October & 2000 & 0.08 & 0.24 & 0.29 & 31 & $\mathrm{M}$ & -- \\
\hline November & 2000 & 0.00 & 0.00 & 0.00 & 30 & $\mathrm{M}$ & -- \\
\hline December & 2000 & 0.00 & 0.00 & 0.00 & 31 & $\bar{M}$ & - \\
\hline January & 2001 & 0.00 & 0.00 & 0.00 & 31 & $\bar{M}$ & -- \\
\hline February & 2001 & 0.03 & 0.09 & 0.11 & 28 & $\bar{M}$ & -- \\
\hline March & 2001 & 0.00 & 0.00 & 0.00 & 31 & $\bar{M}$ & - \\
\hline
\end{tabular}




\begin{tabular}{|l|c|c|c|c|c|c|c|}
\hline April & 2001 & 2.15 & 6.59 & 8.13 & 30 & $\mathrm{M}$ & -- \\
\hline May & 2001 & 4.81 & 14.76 & 18.20 & 31 & $\mathrm{M}$ & -- \\
\hline June & 2001 & 4.74 & 14.53 & 17.92 & 30 & $\mathrm{M}$ & -- \\
\hline July & 2001 & 7.20 & 22.09 & 27.25 & 31 & $\mathrm{M}$ & -- \\
\hline August & 2001 & 4.61 & 14.14 & 17.44 & 31 & $\mathrm{M}$ & -- \\
\hline September & 2001 & 3.62 & 11.10 & 13.69 & 30 & $\mathrm{M}$ & -- \\
\hline October & 2001 & 4.40 & 13.51 & 16.66 & 31 & $\mathrm{M}$ & -- \\
\hline November & 2001 & 1.84 & 5.66 & 6.98 & 30 & $\mathrm{M}$ & -- \\
\hline December & 2001 & 4.16 & 12.78 & 15.76 & 31 & $\mathrm{M}$ & -- \\
\hline January & 2002 & 4.14 & 12.71 & 15.67 & 31 & $\mathrm{M}$ & -- \\
\hline February & 2002 & 3.78 & 11.59 & 14.29 & 28 & $\mathrm{M}$ & -- \\
\hline March & 2002 & 4.99 & 15.30 & 18.87 & 31 & $\mathrm{M}$ & -- \\
\hline April & 2002 & 4.94 & 15.15 & 18.69 & 30 & $\mathrm{M}$ & -- \\
\hline May & 2002 & 5.38 & 16.50 & 20.35 & 31 & $\mathrm{M}$ & -- \\
\hline June & 2002 & 5.42 & 16.65 & 20.53 & 30 & $\mathrm{M}$ & -- \\
\hline July & 2002 & 6.01 & 18.45 & 22.76 & 31 & $\mathrm{M}$ & -- \\
\hline August & 2002 & 4.94 & 15.15 & 18.69 & 31 & $\mathrm{M}$ & -- \\
\hline September & 2002 & 3.91 & 12.01 & 14.82 & 30 & $\mathrm{M}$ & -- \\
\hline October & 2002 & 4.39 & 13.48 & 16.63 & 31 & $\mathrm{M}$ & -- \\
\hline November & 2002 & 2.71 & 8.30 & 10.24 & 30 & $\mathrm{M}$ & -- \\
\hline December & 2002 & 2.41 & 7.39 & 9.12 & 31 & $\mathrm{M}$ & -- \\
\hline January & 2003 & 4.52 & 13.86 & 17.10 & 31 & $\mathrm{M}$ & -- \\
\hline February & 2003 & 4.34 & 13.31 & 16.42 & 28 & $\mathrm{M}$ & -- \\
\hline March & 2003 & 5.42 & 16.62 & 20.50 & 31 & $\mathrm{M}$ & -- \\
\hline April & 2003 & 4.89 & 15.01 & 18.52 & 30 & $\mathrm{M}$ & -- \\
\hline May & 2003 & 2.93 & 8.99 & 11.09 & 31 & $\mathrm{M}$ & -- \\
\hline June & 2003 & 1.87 & 5.74 & 7.07 & 30 & $\mathrm{M}$ & -- \\
\hline July & 2003 & 5.04 & 15.48 & 19.09 & 31 & $\mathrm{M}$ & -- \\
\hline August & 2003 & 4.11 & 12.61 & 15.55 & 31 & $\mathrm{M}$ & -- \\
\hline September & 2003 & 4.27 & 13.12 & 16.18 & 30 & $\mathrm{M}$ & -- \\
\hline October & 2003 & 4.74 & 14.54 & 17.94 & 31 & $\mathrm{M}$ & -- \\
\hline November & 2003 & 4.56 & 13.98 & 17.25 & 30 & $\mathrm{M}$ & -- \\
\hline December & 2003 & 4.25 & 13.04 & 16.08 & 31 & $\mathrm{M}$ & -- \\
\hline
\end{tabular}

aSource: $\mathrm{A}=$ Estimated from pump run times recorded on daily ammeter charts supplied by Bechtel, Nevada (Bechtel) or Reynolds Electrical and Engineering Company (REECo).

$E=$ Taken from Bechtel or REECo water production reports and includes estimated values.

$\mathrm{I}=$ Insufficient or no data to calculate monthly total; no water may have been withdrawn for month.

$M=$ Taken from Bechtel or REECo water production reports.

$\mathrm{R}=$ Insufficient data to determine monthly value. Annual value listed in annual data set as reported in [Claassen, H.C., 1973, Water quality and physical characteristics of Nevada Test Site water-supply wells: U.S. Geological Survey Open-File Report USGS-474-158, 145 p.].

${ }^{b}$ estimated indicates monthly value was estimated from yearly total 


\begin{tabular}{|c|c|c|c|c|c|c|}
\hline Month & Year & $\begin{array}{l}\text { Million } \\
\text { Gallons }\end{array}$ & Acre-Ft & $\begin{array}{c}\text { Million } \\
\text { Liters }\end{array}$ & $\begin{array}{c}\text { Days } \\
\text { Reported }\end{array}$ & Source ${ }^{a}$ \\
\hline April & 1966 & -- & -- & -- & 0 & $U$ \\
\hline May & 1966 & -- & -- & -- & 0 & $U$ \\
\hline June & 1966 & -- & -- & -- & 0 & $U$ \\
\hline July & 1966 & -- & -- & -- & 0 & $\mathrm{U}$ \\
\hline August & 1966 & -- & -- & -- & 0 & $\mathrm{U}$ \\
\hline September & 1966 & -- & -- & -- & 0 & $U$ \\
\hline October & 1966 & -- & -- & -- & 0 & $U$ \\
\hline November & 1966 & -- & -- & -- & 0 & $U$ \\
\hline December & 1966 & -- & -- & -- & 0 & $\bar{U}$ \\
\hline January & 1967 & -- & -- & -- & 0 & $\mathrm{U}$ \\
\hline February & 1967 & 1.16 & 3.55 & 4.37 & 28 & $\mathrm{M}$ \\
\hline March & 1967 & 6.71 & 20.60 & 25.40 & 31 & $\mathrm{M}$ \\
\hline April & 1967 & 2.54 & 7.78 & 9.60 & 30 & $\mathrm{M}$ \\
\hline May & 1967 & 0.00 & 0.00 & 0.00 & 31 & $M$ \\
\hline June & 1967 & 0.93 & 2.85 & 3.52 & 30 & $\mathrm{M}$ \\
\hline July & 1967 & -- & -- & -- & 0 & $\mathrm{I}$ \\
\hline August & 1967 & -- & -- & -- & 0 & 1 \\
\hline September & 1967 & -- & -- & -- & 0 & $\mathrm{I}$ \\
\hline October & 1967 & -- & -- & -- & 0 & $\mathrm{I}$ \\
\hline November & 1967 & -- & -- & -- & 0 & $\mathrm{I}$ \\
\hline December & 1967 & -- & -- & -- & 0 & $\mathrm{~T}$ \\
\hline January & 1968 & -- & -- & -- & 0 & $\mathrm{~T}$ \\
\hline February & 1968 & -- & -- & -- & 0 & $\mathrm{I}$ \\
\hline March & 1968 & -- & -- & -- & 0 & $\mathrm{I}$ \\
\hline April & 1968 & -- & -- & -- & 0 & $\mathrm{~T}$ \\
\hline May & 1968 & -- & -- & -- & 0 & $\mathrm{I}$ \\
\hline June & 1968 & -- & -- & -- & 0 & 1 \\
\hline July & 1968 & -- & -- & -- & 0 & $\mathrm{I}$ \\
\hline August & 1968 & -- & -- & -- & 0 & 1 \\
\hline September & 1968 & -- & -- & -- & 0 & $\mathrm{I}$ \\
\hline October & 1968 & -- & -- & -- & 0 & $\mathrm{I}$ \\
\hline November & 1968 & -- & -- & -- & 0 & $\mathrm{I}$ \\
\hline December & 1968 & -- & -- & -- & 0 & $\mathrm{I}$ \\
\hline January & 1969 & -- & -- & -- & 0 & $T$ \\
\hline February & 1969 & -- & -- & -- & 0 & $\mathrm{I}$ \\
\hline March & 1969 & -- & -- & -- & 0 & $\mathrm{I}$ \\
\hline April & 1969 & -- & -- & -- & 0 & $\mathrm{~T}$ \\
\hline May & 1969 & -- & -- & -- & 0 & 1 \\
\hline June & 1969 & -- & -- & -- & 0 & $\mathrm{I}$ \\
\hline July & 1969 & -- & -- & -- & 0 & $\mathrm{I}$ \\
\hline August & 1969 & -- & -- & -- & 0 & $\mathrm{I}$ \\
\hline September & 1969 & -- & -- & -- & 0 & $\mathrm{I}$ \\
\hline October & 1969 & -- & -- & -- & 0 & $\mathrm{I}$ \\
\hline November & 1969 & -- & -- & -- & 0 & $\mathrm{I}$ \\
\hline December & 1969 & -- & -- & -- & 0 & $\mathrm{I}$ \\
\hline January & 1970 & -- & -- & -- & 0 & $T$ \\
\hline February & 1970 & -- & -- & -- & 0 & $\mathrm{I}$ \\
\hline March & 1970 & -- & -- & -- & 0 & $\mathrm{I}$ \\
\hline April & 1970 & -- & -- & -- & 0 & $\mathrm{~T}$ \\
\hline
\end{tabular}




\begin{tabular}{|c|c|c|c|c|c|c|}
\hline May & 1970 & -- & -- & -- & 0 & I \\
\hline June & 1970 & $\overline{--}$ & $\overline{--}$ & -- & 0 & $T$ \\
\hline \begin{tabular}{|l} 
July \\
\end{tabular} & 1970 & -- & -- & -- & 0 & 1 \\
\hline August & 1970 & -- & -- & -- & 0 & I \\
\hline September & 1970 & -- & -- & -- & 0 & I \\
\hline October & 1970 & -- & -- & -- & 0 & I \\
\hline November & 1970 & -- & -- & -- & 0 & $\mathrm{~T}$ \\
\hline December & 1970 & -- & -- & -- & 0 & $\mathrm{I}$ \\
\hline \begin{tabular}{|l|} 
January \\
\end{tabular} & 1971 & -- & - & $\overline{--}$ & 0 & $\mathrm{~T}$ \\
\hline February & 1971 & -- & - & $\overline{--}$ & 0 & T \\
\hline March & 1971 & -- & -- & -- & 0 & $T$ \\
\hline April & 1971 & -- & - & -- & 0 & $\mathrm{~T}$ \\
\hline May & 1971 & -- & -- & -- & 0 & I \\
\hline June & 1971 & -- & -- & -- & 0 & T \\
\hline July & 1971 & -- & -- & -- & 0 & 1 \\
\hline August & 1971 & -- & -- & -- & 0 & I \\
\hline September & 1971 & -- & -- & -- & 0 & I \\
\hline October & 1971 & -- & -- & -- & 0 & I \\
\hline November & 1971 & -- & -- & -- & 0 & 1 \\
\hline December & 1971 & -- & -- & -- & 0 & I \\
\hline \begin{tabular}{|l|} 
January \\
\end{tabular} & 1972 & -- & - & $\overline{--}$ & 0 & I \\
\hline February & 1972 & -- & -- & $\overline{--}$ & 0 & T \\
\hline March & 1972 & -- & -- & -- & 0 & $T$ \\
\hline April & 1972 & -- & -- & -- & 0 & $T$ \\
\hline May & 1972 & -- & -- & -- & 0 & I \\
\hline June & 1972 & -- & -- & -- & 0 & T \\
\hline \begin{tabular}{|l} 
July \\
\end{tabular} & 1972 & -- & -- & -- & 0 & $\mathrm{~T}$ \\
\hline August & 1972 & -- & -- & -- & 0 & $\mathrm{I}$ \\
\hline September & 1972 & -- & -- & -- & 0 & I \\
\hline October & 1972 & -- & -- & -- & 0 & I \\
\hline November & 1972 & -- & -- & -- & 0 & 1 \\
\hline December & 1972 & -- & -- & -- & 0 & I \\
\hline \begin{tabular}{|l|} 
January \\
\end{tabular} & 1973 & -- & - & $\overline{--}$ & 0 & I \\
\hline \begin{tabular}{|l|} 
February \\
\end{tabular} & 1973 & -- & - & $\overline{--}$ & 0 & I \\
\hline March & 1973 & -- & -- & -- & 0 & $\mathrm{~T}$ \\
\hline April & 1973 & -- & -- & -- & 0 & $\mathrm{~T}$ \\
\hline May & 1973 & -- & -- & -- & 0 & $\mathrm{~T}$ \\
\hline June & 1973 & -- & -- & -- & 0 & $\mathrm{~T}$ \\
\hline \begin{tabular}{|l} 
July \\
\end{tabular} & 1973 & -- & -- & -- & 0 & I \\
\hline August & 1973 & -- & -- & -- & 0 & I \\
\hline September & 1973 & -- & -- & -- & 0 & I \\
\hline October & 1973 & -- & -- & -- & 0 & I \\
\hline November & 1973 & -- & -- & -- & 0 & 1 \\
\hline December & 1973 & -- & -- & -- & 0 & I \\
\hline \begin{tabular}{|l|} 
January \\
\end{tabular} & 1974 & $\overline{--}$ & - & $\overline{--}$ & $\overline{0}$ & I \\
\hline February & 1974 & -- & -- & $\overline{--}$ & $\overline{0}$ & I \\
\hline March & 1974 & -- & -- & -- & 0 & I \\
\hline April & 1974 & -- & -- & -- & 0 & I \\
\hline May & 1974 & -- & -- & -- & 0 & I \\
\hline June & 1974 & -- & -- & -- & 0 & T \\
\hline \begin{tabular}{|l} 
July \\
\end{tabular} & 1974 & -- & -- & -- & 0 & 1 \\
\hline August & 1974 & $\overline{--}$ & $\overline{--}$ & $\overline{--}$ & $\overline{0}$ & $T$ \\
\hline
\end{tabular}




\begin{tabular}{|c|c|c|c|c|c|c|}
\hline September & 1974 & -- & -- & -- & 0 & $T$ \\
\hline October & 1974 & -- & -- & -- & 0 & I \\
\hline November & 1974 & -- & -- & -- & 0 & I \\
\hline December & 1974 & -- & -- & -- & 0 & $\mathrm{I}$ \\
\hline January & 1975 & -- & -- & -- & 0 & $\mathrm{I}$ \\
\hline February & 1975 & -- & -- & -- & 0 & $\mathrm{I}$ \\
\hline March & 1975 & -- & -- & -- & 0 & I \\
\hline April & 1975 & -- & -- & -- & 0 & $T$ \\
\hline May & 1975 & -- & -- & -- & 0 & $\mathrm{~T}$ \\
\hline June & 1975 & -- & -- & -- & 0 & $\mathrm{I}$ \\
\hline July & 1975 & -- & -- & -- & 0 & $\mathrm{~T}$ \\
\hline August & 1975 & -- & -- & -- & 0 & $\mathrm{I}$ \\
\hline September & 1975 & -- & -- & -- & 0 & $\mathrm{~T}$ \\
\hline October & 1975 & -- & -- & -- & 0 & $\mathrm{~T}$ \\
\hline November & 1975 & -- & -- & -- & 0 & $T$ \\
\hline December & 1975 & -- & -- & -- & 0 & $\mathrm{I}$ \\
\hline January & 1976 & -- & -- & -- & 0 & $\mathrm{I}$ \\
\hline February & 1976 & -- & -- & -- & 0 & I \\
\hline March & 1976 & -- & -- & -- & 0 & $\mathrm{I}$ \\
\hline April & 1976 & -- & -- & -- & 0 & $\mathrm{I}$ \\
\hline May & 1976 & -- & -- & -- & 0 & $\mathrm{~T}$ \\
\hline June & 1976 & -- & -- & -- & 0 & I \\
\hline July & 1976 & -- & -- & -- & 0 & $\mathrm{~T}$ \\
\hline August & 1976 & -- & -- & -- & 0 & $\mathrm{~T}$ \\
\hline September & 1976 & -- & -- & -- & 0 & $\mathrm{I}$ \\
\hline October & 1976 & -- & -- & -- & 0 & 1 \\
\hline November & 1976 & -- & -- & -- & 0 & $\mathrm{~T}$ \\
\hline December & 1976 & -- & -- & -- & 0 & $\mathrm{I}$ \\
\hline January & 1977 & -- & -- & -- & 0 & 1 \\
\hline February & 1977 & -- & -- & -- & 0 & I \\
\hline March & 1977 & -- & -- & -- & 0 & I \\
\hline April & 1977 & -- & -- & -- & 0 & I \\
\hline May & 1977 & -- & -- & -- & 0 & $\mathrm{~T}$ \\
\hline June & 1977 & -- & -- & -- & 0 & I \\
\hline July & 1977 & -- & -- & -- & 0 & I \\
\hline August & 1977 & -- & -- & -- & 0 & $\mathrm{I}$ \\
\hline September & 1977 & -- & -- & -- & 0 & I \\
\hline October & 1977 & -- & -- & -- & 0 & I \\
\hline November & 1977 & -- & -- & -- & 0 & $\mathrm{~T}$ \\
\hline December & 1977 & -- & -- & -- & 0 & I \\
\hline January & 1978 & -- & -- & -- & 0 & 1 \\
\hline February & 1978 & -- & -- & -- & 0 & I \\
\hline March & 1978 & -- & -- & -- & 0 & I \\
\hline April & 1978 & -- & -- & -- & 0 & I \\
\hline May & 1978 & -- & -- & -- & 0 & $\mathrm{~T}$ \\
\hline June & 1978 & -- & -- & -- & 0 & I \\
\hline July & 1978 & -- & -- & -- & 0 & I \\
\hline August & 1978 & -- & -- & -- & 0 & $\mathrm{I}$ \\
\hline September & 1978 & -- & -- & -- & 0 & $\mathrm{~T}$ \\
\hline October & 1978 & -- & -- & -- & 0 & I \\
\hline November & 1978 & -- & -- & -- & 0 & $\mathrm{~T}$ \\
\hline December & 1978 & -- & $\overline{--}$ & -- & 0 & $\mathrm{~T}$ \\
\hline
\end{tabular}


UE-5c WW Monthly Data

\begin{tabular}{|c|c|c|c|c|c|c|}
\hline \begin{tabular}{|l|} 
January \\
\end{tabular} & 1979 & -- & -- & -- & 0 & 1 \\
\hline \begin{tabular}{|l} 
February \\
\end{tabular} & 1979 & -- & -- & -- & 0 & $\mathrm{I}$ \\
\hline March & 1979 & -- & -- & -- & 0 & $\mathrm{~T}$ \\
\hline April & 1979 & -- & -- & -- & 0 & $\mathrm{I}$ \\
\hline May & 1979 & -- & -- & -- & 0 & 1 \\
\hline June & 1979 & -- & -- & -- & 0 & I \\
\hline \begin{tabular}{|l} 
July \\
\end{tabular} & 1979 & -- & -- & -- & 0 & $\mathrm{I}$ \\
\hline August & 1979 & -- & -- & -- & 0 & $\mathrm{I}$ \\
\hline September & 1979 & -- & -- & -- & 0 & $T$ \\
\hline October & 1979 & -- & -- & -- & 0 & I \\
\hline November & 1979 & -- & -- & -- & 0 & $\mathrm{~T}$ \\
\hline December & 1979 & -- & -- & -- & 0 & I \\
\hline \begin{tabular}{|l|} 
January \\
\end{tabular} & 1980 & -- & -- & -- & 0 & $\mathrm{I}$ \\
\hline February & 1980 & -- & -- & -- & 0 & $\mathrm{I}$ \\
\hline March & 1980 & -- & -- & -- & 0 & $T$ \\
\hline April & 1980 & -- & -- & -- & 0 & $\mathrm{I}$ \\
\hline May & 1980 & -- & -- & -- & 0 & $\mathrm{I}$ \\
\hline June & 1980 & -- & -- & -- & 0 & I \\
\hline \begin{tabular}{|l} 
July \\
\end{tabular} & 1980 & -- & -- & -- & 0 & I \\
\hline August & 1980 & -- & -- & -- & 0 & I \\
\hline September & 1980 & -- & -- & -- & 0 & $T$ \\
\hline October & 1980 & -- & -- & -- & 0 & I \\
\hline November & 1980 & -- & -- & -- & 0 & $\mathrm{I}$ \\
\hline December & 1980 & -- & -- & -- & 0 & T \\
\hline \begin{tabular}{|l|} 
January \\
\end{tabular} & 1981 & -- & -- & -- & 0 & $\mathrm{I}$ \\
\hline February & 1981 & -- & -- & -- & 0 & $\mathrm{I}$ \\
\hline March & 1981 & -- & -- & -- & 0 & $T$ \\
\hline April & 1981 & -- & -- & -- & 0 & $T$ \\
\hline May & 1981 & -- & -- & -- & 0 & $\mathrm{I}$ \\
\hline June & 1981 & -- & -- & -- & 0 & I \\
\hline \begin{tabular}{|l} 
July \\
\end{tabular} & 1981 & -- & -- & -- & 0 & I \\
\hline August & 1981 & -- & -- & -- & 0 & I \\
\hline September & 1981 & -- & -- & -- & 0 & $T$ \\
\hline October & 1981 & -- & -- & -- & 0 & I \\
\hline November & 1981 & -- & -- & -- & 0 & $\mathrm{~T}$ \\
\hline December & 1981 & -- & -- & -- & 0 & I \\
\hline \begin{tabular}{|l|} 
January \\
\end{tabular} & 1982 & -- & -- & -- & 0 & $T$ \\
\hline February & 1982 & -- & -- & -- & 0 & $\mathrm{I}$ \\
\hline \begin{tabular}{|l} 
March \\
\end{tabular} & 1982 & -- & -- & -- & 0 & $\mathrm{I}$ \\
\hline April & 1982 & -- & $\overline{--}$ & -- & 0 & $\mathrm{~T}$ \\
\hline May & 1982 & -- & -- & -- & 0 & $\mathrm{I}$ \\
\hline June & 1982 & -- & -- & -- & 0 & I \\
\hline \begin{tabular}{|l|} 
July \\
\end{tabular} & 1982 & -- & -- & -- & 0 & I \\
\hline August & 1982 & -- & -- & -- & 0 & I \\
\hline September & 1982 & -- & -- & -- & 0 & $T$ \\
\hline October & 1982 & -- & -- & -- & 0 & $\mathrm{I}$ \\
\hline November & 1982 & -- & -- & -- & 0 & $\mathrm{I}$ \\
\hline December & 1982 & -- & -- & -- & 0 & $\mathrm{I}$ \\
\hline \begin{tabular}{|l|} 
January \\
\end{tabular} & 1983 & 0.12 & 0.36 & 0.45 & 31 & $\bar{M}$ \\
\hline February & 1983 & 0.06 & 0.20 & 0.24 & 28 & $\bar{M}$ \\
\hline March & 1983 & 0.21 & 0.63 & 0.78 & 31 & $\bar{M}$ \\
\hline April & 1983 & 0.00 & 0.00 & 0.00 & 30 & $\bar{M}$ \\
\hline
\end{tabular}


UE-5c WW Monthly Data

\begin{tabular}{|c|c|c|c|c|c|c|}
\hline May & 1983 & 0.18 & 0.56 & 0.69 & 31 & $\bar{M}$ \\
\hline June & 1983 & 0.08 & 0.25 & 0.30 & 30 & $\bar{M}$ \\
\hline \begin{tabular}{|l|l} 
July \\
\end{tabular} & 1983 & 0.22 & 0.68 & 0.84 & 31 & $\bar{M}$ \\
\hline August & 1983 & 0.09 & 0.27 & 0.33 & 31 & $\bar{M}$ \\
\hline September & 1983 & 0.11 & 0.33 & 0.40 & 30 & M \\
\hline October & 1983 & 0.11 & 0.33 & 0.41 & 31 & $\bar{M}$ \\
\hline November & 1983 & 0.05 & 0.14 & 0.17 & 30 & $\bar{M}$ \\
\hline December & 1983 & 0.04 & 0.12 & 0.15 & 31 & $\bar{M}$ \\
\hline \begin{tabular}{|l|} 
January \\
\end{tabular} & 1984 & 0.83 & 2.55 & 3.15 & 31 & $\bar{M}$ \\
\hline February & 1984 & 0.05 & 0.15 & 0.19 & 29 & $\bar{M}$ \\
\hline March & 1984 & 0.14 & 0.42 & 0.52 & 31 & $\bar{M}$ \\
\hline April & 1984 & 0.14 & 0.43 & 0.53 & 30 & $\bar{M}$ \\
\hline May & 1984 & 0.27 & 0.82 & 1.02 & 31 & $\bar{M}$ \\
\hline June & 1984 & 0.02 & 0.06 & 0.07 & 30 & $\bar{M}$ \\
\hline July & 1984 & 0.26 & 0.81 & 0.99 & 31 & $\bar{M}$ \\
\hline August & 1984 & 0.09 & 0.29 & 0.35 & 31 & $\bar{M}$ \\
\hline September & 1984 & 0.11 & 0.34 & 0.42 & 30 & M \\
\hline October & 1984 & 0.19 & 0.59 & 0.72 & 31 & $\mathrm{M}$ \\
\hline November & 1984 & 0.13 & 0.40 & 0.50 & 30 & $\bar{M}$ \\
\hline December & 1984 & 0.17 & 0.51 & 0.63 & 31 & $E$ \\
\hline January & 1985 & 0.54 & 1.66 & 2.04 & 31 & $E$ \\
\hline February & 1985 & 0.41 & 1.25 & 1.54 & 28 & $\bar{M}$ \\
\hline March & 1985 & 0.49 & 1.50 & 1.85 & 31 & $\bar{M}$ \\
\hline April & 1985 & 0.30 & 0.91 & 1.12 & 30 & $\bar{M}$ \\
\hline May & 1985 & 0.31 & 0.96 & 1.18 & 31 & $\bar{M}$ \\
\hline June & 1985 & 0.51 & 1.57 & 1.94 & 30 & $\bar{M}$ \\
\hline July & 1985 & 0.42 & 1.28 & 1.58 & 31 & $\bar{M}$ \\
\hline August & 1985 & 0.46 & 1.40 & 1.73 & 31 & $\bar{M}$ \\
\hline September & 1985 & 0.46 & 1.42 & 1.75 & 30 & $\bar{M}$ \\
\hline October & 1985 & 0.35 & 1.07 & 1.32 & 31 & $\bar{M}$ \\
\hline November & 1985 & 0.44 & 1.36 & 1.68 & 30 & $\bar{M}$ \\
\hline December & 1985 & 0.29 & 0.90 & 1.10 & 31 & $E$ \\
\hline January & 1986 & 0.14 & 0.44 & 0.54 & 31 & $\bar{M}$ \\
\hline February & 1986 & 0.37 & 1.13 & 1.39 & 28 & $\bar{M}$ \\
\hline March & 1986 & 0.37 & 1.13 & 1.40 & 31 & $\bar{M}$ \\
\hline April & 1986 & 0.44 & 1.36 & 1.68 & 30 & $\bar{M}$ \\
\hline May & 1986 & 0.47 & 1.43 & 1.77 & 31 & $\bar{M}$ \\
\hline June & 1986 & 0.50 & 1.53 & 1.88 & 30 & $\bar{M}$ \\
\hline July & 1986 & 0.30 & 0.92 & 1.14 & 31 & $\bar{M}$ \\
\hline August & 1986 & 0.54 & 1.66 & 2.05 & 31 & $\bar{M}$ \\
\hline September & 1986 & 0.34 & 1.03 & 1.27 & 30 & $\bar{M}$ \\
\hline October & 1986 & 0.07 & 0.22 & 0.27 & 31 & $M$ \\
\hline November & 1986 & 0.00 & 0.00 & 0.00 & 30 & $\bar{M}$ \\
\hline December & 1986 & 0.00 & 0.00 & 0.00 & 31 & $\bar{M}$ \\
\hline January & 1987 & 0.00 & 0.00 & 0.00 & 31 & $\bar{M}$ \\
\hline February & 1987 & 0.00 & 0.00 & 0.00 & 28 & $\bar{M}$ \\
\hline March & 1987 & 0.00 & 0.00 & 0.00 & 31 & $\bar{M}$ \\
\hline \begin{tabular}{|l|} 
April \\
\end{tabular} & 1987 & 0.16 & 0.49 & 0.60 & 30 & $\bar{M}$ \\
\hline May & 1987 & 0.00 & 0.00 & 0.00 & 31 & $\bar{M}$ \\
\hline June & 1987 & 0.00 & 0.00 & 0.00 & 30 & $\bar{M}$ \\
\hline July & 1987 & 0.00 & 0.00 & 0.00 & 31 & $\bar{M}$ \\
\hline August & 1987 & 2.80 & 8.60 & 10.60 & 31 & $\bar{M}$ \\
\hline
\end{tabular}


UE-5c WW Monthly Data

\begin{tabular}{|c|c|c|c|c|c|c|}
\hline September & 1987 & 0.86 & 2.64 & 3.26 & 30 & $\mathrm{M}$ \\
\hline October & 1987 & 1.75 & 5.38 & 6.63 & 31 & $\bar{M}$ \\
\hline November & 1987 & 1.51 & 4.62 & 5.70 & 30 & $\bar{M}$ \\
\hline December & 1987 & 1.28 & 3.93 & 4.85 & 31 & $\bar{M}$ \\
\hline January & 1988 & 0.66 & 2.02 & 2.50 & 31 & M \\
\hline February & 1988 & 0.74 & 2.26 & 2.79 & 29 & $\bar{M}$ \\
\hline March & 1988 & 0.57 & 1.73 & 2.14 & 31 & $\bar{M}$ \\
\hline April & 1988 & 0.65 & 2.00 & 2.46 & 30 & $\bar{M}$ \\
\hline May & 1988 & 0.97 & 2.98 & 3.67 & 31 & $\bar{M}$ \\
\hline \begin{tabular}{|l|} 
June \\
\end{tabular} & 1988 & 1.08 & 3.30 & 4.07 & 30 & $\bar{M}$ \\
\hline July & 1988 & 1.33 & 4.08 & 5.03 & 31 & $\bar{M}$ \\
\hline August & 1988 & 0.56 & 1.73 & 2.13 & 31 & $\bar{M}$ \\
\hline September & 1988 & 0.57 & 1.74 & 2.15 & 30 & $\bar{M}$ \\
\hline October & 1988 & 0.77 & 2.36 & 2.91 & 31 & $\bar{M}$ \\
\hline November & 1988 & 0.56 & 1.70 & 2.10 & 30 & $\bar{M}$ \\
\hline December & 1988 & 0.34 & 1.05 & 1.30 & 31 & $\bar{M}$ \\
\hline January & 1989 & 0.36 & 1.09 & 1.35 & 31 & M \\
\hline February & 1989 & 2.66 & 8.17 & 10.08 & 28 & $\mathrm{M}$ \\
\hline March & 1989 & 0.16 & 0.50 & 0.62 & 31 & $\bar{M}$ \\
\hline April & 1989 & 0.00 & 0.00 & 0.00 & 30 & $\bar{M}$ \\
\hline May & 1989 & 0.00 & 0.00 & 0.00 & 31 & $\bar{M}$ \\
\hline \begin{tabular}{|l|} 
June \\
\end{tabular} & 1989 & 0.00 & 0.00 & 0.00 & 30 & $\bar{M}$ \\
\hline July & 1989 & 0.00 & 0.00 & 0.00 & 31 & $\bar{M}$ \\
\hline August & 1989 & 0.00 & 0.00 & 0.00 & 31 & $\bar{M}$ \\
\hline September & 1989 & 0.00 & 0.00 & 0.00 & 30 & $\bar{M}$ \\
\hline October & 1989 & 0.00 & 0.00 & 0.00 & 31 & $\bar{M}$ \\
\hline November & 1989 & 0.00 & 0.00 & 0.00 & 30 & $\bar{M}$ \\
\hline December & 1989 & 0.00 & 0.00 & 0.00 & 31 & $\bar{M}$ \\
\hline January & 1990 & 0.00 & 0.00 & 0.00 & 31 & M \\
\hline February & 1990 & 0.00 & 0.00 & 0.00 & 28 & $\bar{M}$ \\
\hline March & 1990 & 0.00 & 0.00 & 0.00 & 31 & $\bar{M}$ \\
\hline April & 1990 & 0.00 & 0.00 & 0.00 & 30 & $\bar{M}$ \\
\hline May & 1990 & 0.00 & 0.00 & 0.00 & 31 & $\bar{M}$ \\
\hline \begin{tabular}{|l|} 
June \\
\end{tabular} & 1990 & 0.00 & 0.00 & 0.00 & 30 & $\bar{M}$ \\
\hline July & 1990 & 0.00 & 0.00 & 0.00 & 31 & $\bar{M}$ \\
\hline August & 1990 & 0.00 & 0.00 & 0.00 & 31 & $\bar{M}$ \\
\hline September & 1990 & 0.00 & 0.00 & 0.00 & 30 & $\bar{M}$ \\
\hline October & 1990 & 0.00 & 0.00 & 0.00 & 31 & $\bar{M}$ \\
\hline November & 1990 & 0.00 & 0.00 & 0.00 & 30 & $\bar{M}$ \\
\hline December & 1990 & 0.00 & 0.00 & 0.00 & 31 & $\bar{M}$ \\
\hline \begin{tabular}{|l|} 
January \\
\end{tabular} & 1991 & 0.00 & 0.00 & 0.00 & 31 & $\bar{M}$ \\
\hline February & 1991 & 0.00 & 0.00 & 0.00 & 28 & $\bar{M}$ \\
\hline March & 1991 & 0.14 & 0.42 & 0.52 & 31 & $\bar{M}$ \\
\hline April & 1991 & 0.37 & 1.14 & 1.40 & 30 & $\bar{M}$ \\
\hline May & 1991 & 0.41 & 1.26 & 1.55 & 31 & $\bar{M}$ \\
\hline \begin{tabular}{|l|} 
June \\
\end{tabular} & 1991 & 0.51 & 1.56 & 1.93 & 30 & $\bar{M}$ \\
\hline \begin{tabular}{|l|l|} 
July \\
\end{tabular} & 1991 & 0.57 & 1.74 & 2.15 & 31 & $\bar{M}$ \\
\hline August & 1991 & 0.40 & 1.22 & 1.51 & 31 & $\bar{M}$ \\
\hline September & 1991 & 0.50 & 1.55 & 1.91 & 30 & $\bar{M}$ \\
\hline October & 1991 & 0.87 & 2.68 & 3.31 & 31 & $\bar{M}$ \\
\hline November & 1991 & 0.44 & 1.35 & 1.66 & 30 & $\bar{M}$ \\
\hline December & 1991 & 0.34 & 1.04 & 1.28 & 31 & $\bar{M}$ \\
\hline
\end{tabular}


UE-5c WW Monthly Data

\begin{tabular}{|c|c|c|c|c|c|c|}
\hline January & 1992 & 0.16 & 0.48 & 0.59 & 31 & $\mathrm{M}$ \\
\hline February & 1992 & 0.39 & 1.19 & 1.47 & 29 & $\bar{M}$ \\
\hline March & 1992 & 0.16 & 0.49 & 0.60 & 31 & $\bar{M}$ \\
\hline April & 1992 & 0.25 & 0.75 & 0.93 & 30 & $\bar{M}$ \\
\hline May & 1992 & 0.48 & 1.47 & 1.81 & 31 & $\bar{M}$ \\
\hline June & 1992 & 0.46 & 1.40 & 1.72 & 30 & $\bar{M}$ \\
\hline July & 1992 & 0.68 & 2.10 & 2.59 & 31 & $\bar{M}$ \\
\hline August & 1992 & 0.91 & 2.79 & 3.44 & 31 & $\bar{M}$ \\
\hline September & 1992 & 0.77 & 2.37 & 2.93 & 30 & $\bar{M}$ \\
\hline October & 1992 & 0.19 & 0.57 & 0.70 & 31 & $\bar{M}$ \\
\hline November & 1992 & 0.57 & 1.75 & 2.15 & 30 & $\bar{M}$ \\
\hline December & 1992 & 0.28 & 0.87 & 1.07 & 31 & $\bar{M}$ \\
\hline January & 1993 & 1.07 & 3.29 & 4.05 & 31 & $\bar{M}$ \\
\hline February & 1993 & 0.30 & 0.92 & 1.13 & 28 & $\bar{M}$ \\
\hline March & 1993 & 0.45 & 1.38 & 1.70 & 31 & $\bar{M}$ \\
\hline April & 1993 & 0.47 & 1.45 & 1.79 & 30 & $\bar{M}$ \\
\hline May & 1993 & 1.06 & 3.25 & 4.01 & 31 & $\bar{M}$ \\
\hline June & 1993 & 0.49 & 1.49 & 1.84 & 30 & $\mathrm{M}$ \\
\hline July & 1993 & 0.49 & 1.49 & 1.84 & 31 & $\bar{M}$ \\
\hline August & 1993 & 0.60 & 1.84 & 2.27 & 31 & $\bar{M}$ \\
\hline September & 1993 & 0.56 & 1.72 & 2.12 & 30 & $\bar{M}$ \\
\hline October & 1993 & 0.70 & 2.16 & 2.66 & 31 & $\bar{M}$ \\
\hline November & 1993 & 0.52 & 1.60 & 1.97 & 30 & $\bar{M}$ \\
\hline December & 1993 & 0.59 & 1.79 & 2.21 & 31 & $\bar{M}$ \\
\hline January & 1994 & 0.71 & 2.17 & 2.68 & 31 & $\bar{M}$ \\
\hline February & 1994 & 0.61 & 1.89 & 2.33 & 28 & $\bar{M}$ \\
\hline March & 1994 & 0.54 & 1.64 & 2.03 & 31 & $\bar{M}$ \\
\hline April & 1994 & 0.00 & 0.00 & 0.00 & 30 & $\bar{M}$ \\
\hline May & 1994 & 0.61 & 1.86 & 2.30 & 31 & $\bar{M}$ \\
\hline June & 1994 & 0.45 & 1.38 & 1.70 & 30 & $\bar{M}$ \\
\hline July & 1994 & 0.36 & 1.10 & 1.35 & 31 & $\bar{M}$ \\
\hline August & 1994 & 0.92 & 2.82 & 3.48 & 31 & $\bar{M}$ \\
\hline September & 1994 & 0.72 & 2.21 & 2.73 & 30 & $\bar{M}$ \\
\hline October & 1994 & 1.04 & 3.20 & 3.94 & 31 & $\bar{M}$ \\
\hline November & 1994 & 0.14 & 0.42 & 0.52 & 30 & $\mathrm{M}$ \\
\hline December & 1994 & 0.39 & 1.21 & 1.49 & 31 & $\bar{M}$ \\
\hline January & 1995 & 0.53 & 1.61 & 1.99 & 31 & $\bar{M}$ \\
\hline February & 1995 & 0.93 & 2.85 & 3.52 & 28 & $\bar{M}$ \\
\hline March & 1995 & 0.00 & 0.00 & 0.00 & 31 & $\bar{M}$ \\
\hline April & 1995 & 0.00 & 0.00 & 0.00 & 30 & $\bar{M}$ \\
\hline May & 1995 & 0.00 & 0.01 & 0.02 & 31 & $\bar{M}$ \\
\hline June & 1995 & 1.05 & 3.23 & 3.98 & 30 & $\mathrm{M}$ \\
\hline July & 1995 & 1.79 & 5.50 & 6.79 & 31 & $\bar{M}$ \\
\hline August & 1995 & 0.67 & 2.04 & 2.52 & 31 & $\bar{M}$ \\
\hline September & 1995 & 0.79 & 2.41 & 2.98 & 30 & $\bar{M}$ \\
\hline October & 1995 & 0.40 & 1.24 & 1.53 & 31 & $\bar{M}$ \\
\hline November & 1995 & 0.00 & 0.00 & 0.00 & 30 & $\mathrm{M}$ \\
\hline December & 1995 & 0.94 & 2.89 & 3.56 & 31 & $\mathrm{M}$ \\
\hline January & 1996 & 0.49 & 1.49 & 1.84 & 31 & $\bar{M}$ \\
\hline February & 1996 & 0.10 & 0.31 & 0.38 & 29 & $\bar{M}$ \\
\hline March & 1996 & 0.42 & 1.28 & 1.58 & 31 & $\bar{M}$ \\
\hline April & 1996 & 0.00 & 0.00 & 0.00 & 30 & $\bar{M}$ \\
\hline
\end{tabular}


UE-5c WW Monthly Data

\begin{tabular}{|c|c|c|c|c|c|c|}
\hline May & 1996 & 2.07 & 6.36 & 7.84 & 31 & $\bar{M}$ \\
\hline June & 1996 & 0.00 & 0.00 & 0.00 & 30 & $\bar{M}$ \\
\hline July & 1996 & 0.94 & 2.89 & 3.56 & 31 & M \\
\hline August & 1996 & 0.00 & 0.00 & 0.00 & 31 & $\mathrm{M}$ \\
\hline September & 1996 & 0.48 & 1.49 & 1.83 & 30 & $\bar{M}$ \\
\hline October & 1996 & 0.87 & 2.66 & 3.28 & 31 & $\bar{M}$ \\
\hline November & 1996 & 0.87 & 2.68 & 3.31 & 30 & $\mathrm{M}$ \\
\hline December & 1996 & 0.00 & 0.00 & 0.00 & 31 & $\bar{M}$ \\
\hline \begin{tabular}{|l|} 
January \\
\end{tabular} & 1997 & 1.01 & 3.11 & 3.84 & 31 & $\bar{M}$ \\
\hline February & 1997 & 0.27 & 0.84 & 1.04 & 28 & $\bar{M}$ \\
\hline March & 1997 & 0.85 & 2.60 & 3.20 & 31 & $\bar{M}$ \\
\hline April & 1997 & 0.58 & 1.78 & 2.19 & 30 & $\bar{M}$ \\
\hline May & 1997 & 0.00 & 0.00 & 0.00 & 31 & $\bar{M}$ \\
\hline June & 1997 & 0.92 & 2.82 & 3.47 & 30 & $\bar{M}$ \\
\hline July & 1997 & 0.83 & 2.55 & 3.14 & 31 & $\bar{M}$ \\
\hline August & 1997 & 0.00 & 0.00 & 0.00 & 31 & $\mathrm{M}$ \\
\hline September & 1997 & 0.40 & 1.22 & 1.51 & 30 & M \\
\hline October & 1997 & 0.07 & 0.20 & 0.25 & 31 & $\bar{M}$ \\
\hline November & 1997 & 1.34 & 4.11 & 5.07 & 30 & $\mathrm{M}$ \\
\hline December & 1997 & 0.00 & 0.00 & 0.00 & 31 & $\bar{M}$ \\
\hline \begin{tabular}{|l|} 
January \\
\end{tabular} & 1998 & 1.31 & 4.01 & 4.94 & 31 & $\bar{M}$ \\
\hline February & 1998 & 0.00 & 0.00 & 0.00 & 28 & $\mathrm{M}$ \\
\hline March & 1998 & 0.00 & 0.00 & 0.00 & 31 & $\mathrm{M}$ \\
\hline April & 1998 & 0.99 & 3.04 & 3.74 & 30 & $\bar{M}$ \\
\hline May & 1998 & 0.00 & 0.00 & 0.00 & 31 & $\bar{M}$ \\
\hline June & 1998 & 0.00 & 0.00 & 0.00 & 30 & $\bar{M}$ \\
\hline July & 1998 & 0.46 & 1.42 & 1.75 & 31 & $\mathrm{M}$ \\
\hline August & 1998 & 0.00 & 0.00 & 0.00 & 31 & $\mathrm{M}$ \\
\hline September & 1998 & 0.00 & 0.00 & 0.00 & 30 & M \\
\hline October & 1998 & 0.00 & 0.00 & 0.00 & 31 & $\bar{M}$ \\
\hline November & 1998 & 0.01 & 0.03 & 0.04 & 30 & $\mathrm{M}$ \\
\hline December & 1998 & 0.00 & 0.00 & 0.00 & 31 & $\bar{M}$ \\
\hline \begin{tabular}{|l|} 
January \\
\end{tabular} & 1999 & 0.04 & 0.11 & 0.14 & 31 & $\bar{M}$ \\
\hline February & 1999 & 0.00 & 0.00 & 0.00 & 28 & $\mathrm{M}$ \\
\hline March & 1999 & 0.00 & 0.00 & 0.00 & 31 & $\mathrm{M}$ \\
\hline April & 1999 & 0.02 & 0.07 & 0.09 & 30 & $\bar{M}$ \\
\hline May & 1999 & 0.00 & 0.00 & 0.00 & 31 & $\bar{M}$ \\
\hline $\begin{array}{l}\text { June } \\
\end{array}$ & 1999 & 0.00 & 0.00 & 0.00 & 30 & $\bar{M}$ \\
\hline July & 1999 & 0.11 & 0.34 & 0.42 & 31 & $\bar{M}$ \\
\hline August & 1999 & 0.00 & 0.00 & 0.00 & 31 & $\mathrm{M}$ \\
\hline September & 1999 & 0.00 & 0.00 & 0.00 & 30 & M \\
\hline October & 1999 & 0.00 & 0.00 & 0.00 & 31 & $\bar{M}$ \\
\hline November & 1999 & 0.00 & 0.00 & 0.00 & 30 & $\mathrm{M}$ \\
\hline December & 1999 & 0.00 & 0.00 & 0.00 & 31 & $\bar{M}$ \\
\hline \begin{tabular}{|l|} 
January \\
\end{tabular} & 2000 & 0.00 & 0.00 & 0.00 & 31 & $\bar{M}$ \\
\hline February & 2000 & 0.00 & 0.00 & 0.00 & 29 & $\mathrm{M}$ \\
\hline March & 2000 & 0.00 & 0.00 & 0.00 & 31 & M \\
\hline April & 2000 & 0.05 & 0.14 & 0.17 & 30 & $\mathrm{M}$ \\
\hline May & 2000 & 0.00 & 0.00 & 0.00 & 31 & $\bar{M}$ \\
\hline June & 2000 & 0.00 & 0.00 & 0.00 & 30 & $\bar{M}$ \\
\hline \begin{tabular}{|l|} 
July \\
\end{tabular} & 2000 & 0.13 & 0.41 & 0.51 & 31 & $\bar{M}$ \\
\hline August & 2000 & 0.17 & 0.51 & 0.63 & 31 & $\bar{M}$ \\
\hline
\end{tabular}


UE-5c WW Monthly Data

\begin{tabular}{|l|c|c|c|c|c|c|}
\hline September & 2000 & 0.00 & 0.00 & 0.00 & 30 & $\mathrm{M}$ \\
\hline October & 2000 & 0.00 & 0.00 & 0.00 & 31 & $\mathrm{M}$ \\
\hline November & 2000 & 0.00 & 0.00 & 0.00 & 30 & $\mathrm{M}$ \\
\hline December & 2000 & 0.00 & 0.00 & 0.00 & 31 & $\mathrm{M}$ \\
\hline January & 2001 & 0.00 & 0.00 & 0.00 & 31 & $\mathrm{M}$ \\
\hline February & 2001 & 0.00 & 0.00 & 0.00 & 28 & $\mathrm{M}$ \\
\hline March & 2001 & 0.03 & 0.10 & 0.12 & 31 & $\mathrm{M}$ \\
\hline April & 2001 & 0.04 & 0.13 & 0.16 & 30 & $\mathrm{M}$ \\
\hline May & 2001 & 0.00 & 0.00 & 0.00 & 31 & $\mathrm{M}$ \\
\hline June & 2001 & 0.00 & 0.00 & 0.00 & 30 & $\mathrm{M}$ \\
\hline July & 2001 & 0.00 & 0.00 & 0.00 & 31 & $\mathrm{M}$ \\
\hline August & 2001 & 0.00 & 0.00 & 0.00 & 31 & $\mathrm{M}$ \\
\hline September & 2001 & 0.00 & 0.00 & 0.00 & 30 & $\mathrm{M}$ \\
\hline October & 2001 & 0.04 & 0.12 & 0.15 & 31 & $\mathrm{M}$ \\
\hline November & 2001 & 0.00 & 0.00 & 0.00 & 30 & $\mathrm{M}$ \\
\hline December & 2001 & 0.00 & 0.00 & 0.00 & 31 & $\mathrm{M}$ \\
\hline January & 2002 & 0.00 & 0.00 & 0.00 & 31 & $\mathrm{M}$ \\
\hline February & 2002 & 0.00 & 0.00 & 0.00 & 28 & $\mathrm{M}$ \\
\hline March & 2002 & 0.00 & 0.00 & 0.00 & 31 & $\mathrm{M}$ \\
\hline April & 2002 & 0.00 & 0.00 & 0.00 & 30 & $\mathrm{M}$ \\
\hline May & 2002 & 0.00 & 0.00 & 0.00 & 31 & $\mathrm{M}$ \\
\hline June & 2002 & 0.00 & 0.00 & 0.00 & 30 & $\mathrm{M}$ \\
\hline July & 2002 & 0.00 & 0.00 & 0.00 & 31 & $\mathrm{M}$ \\
\hline August & 2002 & 0.00 & 0.00 & 0.00 & 31 & $\mathrm{M}$ \\
\hline September & 2002 & 0.00 & 0.00 & 0.00 & 30 & $\mathrm{M}$ \\
\hline October & 2002 & 0.00 & 0.00 & 0.00 & 31 & $\mathrm{M}$ \\
\hline November & 2002 & 0.00 & 0.00 & 0.00 & 30 & $\mathrm{M}$ \\
\hline December & 2002 & 0.00 & 0.00 & 0.00 & 31 & $\mathrm{M}$ \\
\hline January & 2003 & 0.09 & 0.27 & 0.33 & 31 & $\mathrm{M}$ \\
\hline February & 2003 & 0.00 & 0.00 & 0.00 & 28 & $\mathrm{M}$ \\
\hline March & 2003 & 0.00 & 0.00 & 0.00 & 31 & $\mathrm{M}$ \\
\hline April & 2003 & 0.00 & 0.00 & 0.00 & 30 & $\mathrm{M}$ \\
\hline May & 2003 & 0.00 & 0.00 & 0.00 & 31 & $\mathrm{M}$ \\
\hline June & 2003 & 0.00 & 0.00 & 0.00 & 30 & $\mathrm{M}$ \\
\hline July & 2003 & 0.00 & 0.00 & 0.00 & 31 & $\mathrm{M}$ \\
\hline August & 2003 & 0.00 & 0.00 & 0.00 & 31 & $\mathrm{M}$ \\
\hline September & 2003 & 0.00 & 0.00 & 0.00 & 30 & $\mathrm{M}$ \\
\hline October & 2003 & 0.00 & 0.00 & 0.00 & 31 & $\mathrm{M}$ \\
\hline November & 2003 & 0.00 & 0.00 & 0.00 & 30 & $\mathrm{M}$ \\
\hline December & 2003 & 0.00 & 0.00 & 0.00 & 31 & $\mathrm{M}$ \\
\hline
\end{tabular}

a Source: $\mathrm{E}=$ Taken from Bechtel or REECo water production reports and includes estimated values.

$\mathrm{I}=$ Insufficient or no data to calculate monthly total; no water may have been withdrawn for month.

$M=$ Taken from Bechtel or REECo water production reports.

$\mathrm{U}=$ Unknown whether well was available or used for water supply. 
Well RNM-2s Monthly Data

\begin{tabular}{|c|c|c|c|c|c|c|}
\hline Month & Year & $\begin{array}{l}\text { Million } \\
\text { Gallons }\end{array}$ & Acre-Feet & $\begin{array}{c}\text { Million } \\
\text { Liters }\end{array}$ & $\begin{array}{c}\text { Days } \\
\text { Reported }\end{array}$ & Source $^{a}$ \\
\hline October & 1975 & 12.02 & 36.88 & 45.48 & 28 & $\mathrm{~L}$ \\
\hline November & 1975 & 13.53 & 41.53 & 51.22 & 30 & $\mathrm{~L}$ \\
\hline December & 1975 & 11.18 & 34.31 & 42.32 & 31 & $\mathrm{~L}$ \\
\hline January & 1976 & 8.87 & 27.21 & 33.56 & 31 & $\mathrm{~L}$ \\
\hline February & 1976 & 12.37 & 37.97 & 46.83 & 29 & $\bar{L}$ \\
\hline March & 1976 & 13.76 & 42.21 & 52.06 & 31 & $\bar{L}$ \\
\hline April & 1976 & 13.21 & 40.55 & 50.01 & 30 & $\bar{L}$ \\
\hline May & 1976 & 8.14 & 24.99 & 30.82 & 31 & $\bar{L}$ \\
\hline June & 1976 & 20.20 & 61.98 & 76.44 & 30 & $\mathrm{~L}$ \\
\hline July & 1976 & 16.48 & 50.56 & 62.36 & 31 & $\mathrm{~L}$ \\
\hline August & 1976 & 16.20 & 49.72 & 61.32 & 31 & $\mathrm{~L}$ \\
\hline September & 1976 & 16.15 & 49.56 & 61.13 & 30 & $\mathrm{~L}$ \\
\hline October & 1976 & 16.68 & 51.17 & 63.11 & 31 & $\bar{L}$ \\
\hline November & 1976 & 16.16 & 49.59 & 61.16 & 30 & $\mathrm{~L}$ \\
\hline December & 1976 & 13.32 & 40.87 & 50.40 & 31 & $\bar{L}$ \\
\hline January & 1977 & 16.55 & 50.79 & 62.64 & 31 & $\mathrm{~L}$ \\
\hline February & 1977 & 15.00 & 46.03 & 56.77 & 28 & $\mathrm{~L}$ \\
\hline March & 1977 & 16.00 & 49.10 & 60.56 & 31 & $\bar{L}$ \\
\hline April & 1977 & 13.96 & 42.83 & 52.83 & 30 & $\bar{L}$ \\
\hline May & 1977 & 16.61 & 50.97 & 62.87 & 31 & $\mathrm{~L}$ \\
\hline June & 1977 & 8.68 & 26.63 & 32.84 & 30 & $\bar{L}$ \\
\hline July & 1977 & 4.11 & 12.60 & 15.55 & 31 & $\bar{L}$ \\
\hline August & 1977 & 7.68 & 23.56 & 29.05 & 31 & $\mathrm{~L}$ \\
\hline September & 1977 & 2.59 & 7.94 & 9.80 & 30 & $\bar{L}$ \\
\hline October & 1977 & 22.79 & 69.93 & 86.25 & 31 & $\mathrm{~L}$ \\
\hline November & 1977 & 27.37 & 83.99 & 103.58 & 30 & $\mathrm{~L}$ \\
\hline December & 1977 & 28.47 & 87.36 & 107.75 & 31 & $\mathrm{~L}$ \\
\hline January & 1978 & 28.27 & 86.75 & 106.99 & 31 & $\mathrm{~L}$ \\
\hline February & 1978 & 17.73 & 54.42 & 67.12 & 28 & $\bar{L}$ \\
\hline March & 1978 & 28.19 & 86.52 & 106.71 & 31 & $\bar{L}$ \\
\hline April & 1978 & 27.10 & 83.17 & 102.57 & 30 & $\bar{L}$ \\
\hline May & 1978 & 28.08 & 86.16 & 106.26 & 31 & $\bar{L}$ \\
\hline June & 1978 & 27.30 & 83.78 & 103.33 & 30 & $\bar{L}$ \\
\hline July & 1978 & 27.90 & 85.62 & 105.60 & 31 & $\mathrm{~L}$ \\
\hline August & 1978 & 28.10 & 86.24 & 106.36 & 31 & $\bar{L}$ \\
\hline September & 1978 & 27.10 & 83.17 & 102.57 & 30 & $\mathrm{~L}$ \\
\hline October & 1978 & 28.10 & 86.24 & 106.36 & 31 & $\mathrm{~L}$ \\
\hline November & 1978 & 27.10 & 83.17 & 102.57 & 30 & $\mathrm{~L}$ \\
\hline December & 1978 & 26.27 & 80.61 & 99.42 & 31 & $\mathrm{~L}$ \\
\hline January & 1979 & 27.93 & 85.72 & 105.73 & 31 & $L$ \\
\hline February & 1979 & 24.90 & 76.42 & 94.25 & 28 & $\mathrm{~L}$ \\
\hline March & 1979 & 28.00 & 85.93 & 105.98 & 31 & $\bar{L}$ \\
\hline April & 1979 & 27.10 & 83.17 & 102.57 & 30 & $\bar{L}$ \\
\hline May & 1979 & 28.00 & 85.93 & 105.98 & 31 & $\mathrm{~L}$ \\
\hline June & 1979 & 25.15 & 77.18 & 95.19 & 30 & $\mathrm{~L}$ \\
\hline July & 1979 & 27.65 & 84.85 & 104.66 & 31 & $\mathrm{~L}$ \\
\hline August & 1979 & 27.50 & 84.39 & 104.09 & 31 & $\bar{L}$ \\
\hline September & 1979 & 26.93 & 82.63 & 101.91 & 30 & $\bar{L}$ \\
\hline October & 1979 & 27.64 & 84.83 & 104.62 & 31 & $\bar{L}$ \\
\hline
\end{tabular}


Well RNM-2s Monthly Data

\begin{tabular}{|c|c|c|c|c|c|c|}
\hline November & 1979 & 26.73 & 82.04 & 101.19 & 30 & $\bar{L}$ \\
\hline December & 1979 & 27.70 & 85.01 & 104.84 & 31 & $\mathrm{~L}$ \\
\hline January & 1980 & 27.70 & 85.01 & 104.84 & 31 & $\mathrm{~L}$ \\
\hline February & 1980 & 25.75 & $\overline{79.02}$ & 97.46 & 29 & $\bar{L}$ \\
\hline March & 1980 & 14.45 & 44.35 & 54.69 & 31 & $\bar{L}$ \\
\hline April & 1980 & 26.44 & 81.15 & 100.09 & 30 & $\bar{L}$ \\
\hline May & 1980 & 27.59 & 84.66 & 104.41 & 31 & $\mathrm{~L}$ \\
\hline June & 1980 & 21.35 & 65.51 & 80.80 & 30 & $\mathrm{~L}$ \\
\hline July & 1980 & 27.33 & 83.86 & 103.43 & 31 & $\mathrm{~L}$ \\
\hline August & 1980 & 26.93 & 82.66 & 101.94 & 31 & $\mathrm{~L}$ \\
\hline September & 1980 & 24.93 & 76.52 & 94.37 & 30 & $\mathrm{~L}$ \\
\hline October & 1980 & 27.08 & 83.12 & 102.51 & 31 & $\mathrm{~L}$ \\
\hline November & 1980 & 23.32 & 71.57 & 88.27 & 30 & $\mathrm{~L}$ \\
\hline December & 1980 & 27.83 & 85.41 & 105.34 & 31 & $\bar{L}$ \\
\hline January & 1981 & 13.58 & 41.66 & 51.38 & 31 & $\bar{L}$ \\
\hline February & 1981 & 19.93 & 61.15 & 75.42 & 28 & $\bar{L}$ \\
\hline March & 1981 & 27.84 & 85.43 & 105.36 & 31 & $\mathrm{~L}$ \\
\hline April & 1981 & 26.70 & 81.95 & 101.07 & 30 & $\mathrm{~L}$ \\
\hline May & 1981 & 26.72 & 81.99 & 101.12 & 31 & $\mathrm{~L}$ \\
\hline June & 1981 & 25.94 & 79.62 & 98.20 & 30 & $\mathrm{~L}$ \\
\hline July & 1981 & 26.51 & 81.36 & 100.34 & 31 & $\mathrm{~L}$ \\
\hline August & 1981 & 26.89 & 82.52 & 101.78 & 31 & $\mathrm{~L}$ \\
\hline September & 1981 & 25.75 & 79.02 & 97.46 & 30 & $\mathrm{~L}$ \\
\hline October & 1981 & 27.15 & 83.32 & 102.76 & 31 & $\mathrm{~L}$ \\
\hline November & 1981 & 25.94 & 79.62 & 98.19 & 30 & $\mathrm{~L}$ \\
\hline December & 1981 & 27.01 & 82.90 & 102.25 & 31 & $\bar{L}$ \\
\hline January & 1982 & 26.96 & 82.73 & 102.03 & 31 & $\mathrm{~L}$ \\
\hline February & 1982 & 23.77 & 72.93 & 89.95 & 28 & $\bar{L}$ \\
\hline March & 1982 & 26.87 & 82.46 & 101.70 & 31 & $\mathrm{~L}$ \\
\hline April & 1982 & 24.78 & 76.06 & 93.80 & 30 & L \\
\hline May & 1982 & 27.37 & 83.99 & 103.58 & 31 & $\bar{L}$ \\
\hline June & 1982 & 25.63 & 78.67 & 97.02 & 30 & $\mathrm{~L}$ \\
\hline July & 1982 & 26.22 & 80.46 & 99.23 & 31 & $\mathrm{~L}$ \\
\hline August & 1982 & 25.83 & 79.25 & 97.75 & 31 & $\bar{L}$ \\
\hline September & 1982 & 26.71 & 81.98 & 101.11 & 30 & $\mathrm{~L}$ \\
\hline October & 1982 & 26.77 & 82.15 & 101.32 & 31 & $\mathrm{~L}$ \\
\hline November & 1982 & 25.40 & 77.95 & 96.14 & 30 & $\bar{L}$ \\
\hline December & 1982 & 26.64 & 81.76 & 100.84 & 31 & $\bar{L}$ \\
\hline January & 1983 & 26.50 & 81.33 & 100.30 & 31 & $\mathrm{~L}$ \\
\hline February & 1983 & 22.20 & 68.13 & 84.03 & 28 & $\bar{L}$ \\
\hline March & 1983 & 26.36 & 80.90 & 99.77 & 31 & $\bar{L}$ \\
\hline April & 1983 & 25.72 & 78.92 & 97.34 & 30 & L \\
\hline May & 1983 & 26.38 & 80.95 & 99.84 & 31 & $\mathrm{~L}$ \\
\hline June & 1983 & 26.09 & 80.06 & 98.74 & 30 & $\mathrm{~L}$ \\
\hline July & 1983 & 26.55 & 81.48 & 100.49 & 31 & $\mathrm{~L}$ \\
\hline August & 1983 & 25.56 & 78.43 & 96.74 & 31 & $\bar{L}$ \\
\hline September & 1983 & 25.82 & 79.23 & 97.72 & 30 & $\bar{L}$ \\
\hline October & 1983 & 26.17 & 80.30 & 99.03 & 31 & $\mathrm{~L}$ \\
\hline November & 1983 & 25.87 & 79.38 & 97.91 & 30 & $\mathrm{~L}$ \\
\hline December & 1983 & 26.33 & 80.80 & 99.65 & 31 & $\bar{L}$ \\
\hline January & 1984 & 26.21 & 80.45 & 99.22 & 31 & $\bar{L}$ \\
\hline February & 1984 & 24.96 & 76.59 & 94.46 & 29 & $\bar{L}$ \\
\hline
\end{tabular}


Well RNM-2s Monthly Data

\begin{tabular}{|c|c|c|c|c|c|c|}
\hline March & 1984 & 26.37 & 80.93 & 99.82 & 31 & $\bar{L}$ \\
\hline April & 1984 & 25.51 & 78.30 & 96.57 & 30 & $\overline{\mathrm{L}}$ \\
\hline May & 1984 & 26.41 & 81.06 & 99.98 & 31 & $\bar{L}$ \\
\hline June & 1984 & 25.10 & 77.03 & 95.00 & 30 & $\mathrm{~L}$ \\
\hline July & 1984 & 24.69 & 75.76 & 93.44 & 31 & $L$ \\
\hline August & 1984 & 24.67 & 75.70 & 93.37 & 31 & $L$ \\
\hline September & 1984 & 24.96 & 76.60 & 94.47 & 30 & L \\
\hline October & 1984 & 26.16 & 80.28 & 99.01 & 31 & $\bar{L}$ \\
\hline November & 1984 & 25.26 & 77.51 & 95.59 & 30 & $\bar{L}$ \\
\hline December & 1984 & 25.62 & 78.63 & 96.98 & 31 & $\bar{L}$ \\
\hline January & 1985 & 25.50 & 78.27 & 96.53 & 31 & $\mathrm{~L}$ \\
\hline February & 1985 & 23.00 & 70.60 & 87.07 & 28 & $\bar{L}$ \\
\hline March & 1985 & 25.45 & 78.09 & 96.31 & 31 & $\bar{L}$ \\
\hline April & 1985 & 25.22 & 77.39 & 95.45 & 30 & $\bar{L}$ \\
\hline May & 1985 & 26.94 & 82.67 & 101.95 & 31 & $\overline{\mathrm{L}}$ \\
\hline June & 1985 & 25.74 & 78.99 & 97.42 & 30 & $\mathrm{~L}$ \\
\hline July & 1985 & 26.55 & 81.49 & 100.50 & 31 & $L$ \\
\hline August & 1985 & 26.57 & 81.55 & 100.58 & 31 & $L$ \\
\hline September & 1985 & 25.79 & 79.14 & 97.60 & 30 & $\bar{L}$ \\
\hline October & 1985 & 26.65 & 81.79 & 100.88 & 31 & $\bar{L}$ \\
\hline November & 1985 & 23.96 & 73.52 & 90.68 & 30 & $\bar{L}$ \\
\hline December & 1985 & 2.48 & 7.61 & 9.38 & 31 & $\bar{L}$ \\
\hline January & 1986 & 9.04 & 27.75 & 34.23 & 31 & $\mathrm{~L}$ \\
\hline February & 1986 & 24.81 & 76.13 & 93.89 & 28 & $\bar{L}$ \\
\hline March & 1986 & 27.10 & 83.18 & 102.58 & 31 & $\bar{L}$ \\
\hline April & 1986 & 26.15 & 80.25 & 98.97 & 30 & $\bar{L}$ \\
\hline May & 1986 & 27.02 & 82.93 & 102.29 & 31 & $\bar{L}$ \\
\hline June & 1986 & 26.24 & 80.54 & 99.33 & 30 & $\mathrm{~L}$ \\
\hline July & 1986 & 27.00 & 82.86 & 102.20 & 31 & $L$ \\
\hline August & 1986 & 26.50 & 81.33 & 100.30 & 31 & $L$ \\
\hline September & 1986 & 28.03 & 86.01 & 106.08 & 30 & $\mathrm{~L}$ \\
\hline October & 1986 & 31.18 & 95.69 & 118.02 & 31 & $\bar{L}$ \\
\hline November & 1986 & 23.86 & 73.22 & 90.31 & 30 & $\underline{L}$ \\
\hline December & 1986 & 24.74 & 75.92 & 93.64 & 31 & $\bar{L}$ \\
\hline January & 1987 & 27.49 & 84.36 & 104.05 & 31 & $\mathrm{~L}$ \\
\hline February & 1987 & 24.62 & 75.56 & 93.19 & 28 & $\bar{L}$ \\
\hline March & 1987 & 27.12 & 83.22 & 102.63 & 31 & $\bar{L}$ \\
\hline April & 1987 & 26.00 & $\overline{79.79}$ & 98.41 & 30 & $\bar{L}$ \\
\hline May & 1987 & 26.94 & 82.67 & 101.96 & 31 & $\bar{L}$ \\
\hline June & 1987 & 26.52 & 81.39 & 100.38 & 30 & L \\
\hline July & 1987 & 26.91 & 82.57 & 101.84 & 31 & $L$ \\
\hline August & 1987 & 26.31 & 80.74 & 99.58 & 31 & $L$ \\
\hline September & 1987 & 26.06 & 79.98 & 98.64 & 30 & $\mathrm{~L}$ \\
\hline October & 1987 & 26.57 & 81.54 & 100.57 & 31 & $\mathrm{~L}$ \\
\hline November & 1987 & 25.22 & 77.41 & 95.47 & 30 & $L$ \\
\hline December & 1987 & 25.59 & 78.53 & 96.85 & 31 & $\mathrm{~L}$ \\
\hline January & 1988 & 25.39 & 77.93 & 96.11 & 31 & $\mathrm{~L}$ \\
\hline February & 1988 & 23.37 & 71.73 & 88.47 & 29 & $L$ \\
\hline March & 1988 & 26.03 & 79.88 & 98.52 & 31 & L \\
\hline April & 1988 & 27.70 & 85.00 & 104.84 & 30 & $\bar{L}$ \\
\hline May & 1988 & 26.47 & 81.23 & 100.19 & 31 & $L$ \\
\hline June & 1988 & 25.35 & 77.78 & 95.93 & 30 & $\mathrm{~L}$ \\
\hline
\end{tabular}


Well RNM-2s Monthly Data

\begin{tabular}{|l|c|c|c|c|c|c|}
\hline July & 1988 & 29.33 & 90.01 & 111.02 & 31 & $\mathrm{~L}$ \\
\hline August & 1988 & 25.58 & 78.50 & 96.81 & 31 & $\mathrm{~L}$ \\
\hline September & 1988 & 22.49 & 69.02 & 85.13 & 30 & $\mathrm{~L}$ \\
\hline October & 1988 & 26.03 & 79.89 & 98.53 & 31 & $\mathrm{~L}$ \\
\hline November & 1988 & 25.55 & 78.40 & 96.70 & 30 & $\mathrm{~L}$ \\
\hline December & 1988 & 26.95 & 82.69 & 101.99 & 31 & $\mathrm{~L}$ \\
\hline January & 1989 & 27.65 & 84.84 & 104.64 & 31 & $\mathrm{~L}$ \\
\hline February & 1989 & 23.88 & 73.30 & 90.40 & 28 & $\mathrm{~L}$ \\
\hline March & 1989 & 26.46 & 81.21 & 100.16 & 31 & $\mathrm{~L}$ \\
\hline April & 1989 & 25.24 & 77.45 & 95.52 & 30 & $\mathrm{~L}$ \\
\hline May & 1989 & 26.51 & 81.37 & 100.35 & 31 & $\mathrm{~L}$ \\
\hline June & 1989 & 25.68 & 78.80 & 97.19 & 30 & $\mathrm{~L}$ \\
\hline July & 1989 & 26.51 & 81.35 & 100.34 & 31 & $\mathrm{~L}$ \\
\hline August & 1989 & 26.63 & 81.73 & 100.80 & 31 & $\mathrm{~L}$ \\
\hline September & 1989 & 23.84 & 73.15 & 90.22 & 30 & $\mathrm{~L}$ \\
\hline October & 1989 & 26.42 & 81.07 & 99.99 & 31 & $\mathrm{~L}$ \\
\hline November & 1989 & 26.67 & 81.86 & 100.96 & 30 & $\mathrm{~L}$ \\
\hline December & 1989 & 26.14 & 80.21 & 98.93 & 31 & $\mathrm{~L}$ \\
\hline January & 1990 & 26.46 & 81.20 & 100.15 & 31 & $\mathrm{~L}$ \\
\hline February & 1990 & 23.89 & 73.33 & 90.44 & 28 & $\mathrm{~L}$ \\
\hline March & 1990 & 24.24 & 74.38 & 91.74 & 31 & $\mathrm{~L}$ \\
\hline April & 1990 & 23.20 & 71.19 & 87.80 & 30 & $\mathrm{~L}$ \\
\hline May & 1990 & 28.56 & 87.65 & 108.10 & 31 & $\mathrm{~L}$ \\
\hline June & 1990 & 26.59 & 81.61 & 100.65 & 30 & $\mathrm{~L}$ \\
\hline July & 1990 & 25.44 & 78.06 & 96.27 & 31 & $\mathrm{~L}$ \\
\hline August & 1990 & 24.53 & 75.29 & 92.85 & 31 & $\mathrm{~L}$ \\
\hline September & 1990 & 17.89 & 54.89 & 67.70 & 30 & $\mathrm{~L}$ \\
\hline October & 1990 & 0.35 & 1.09 & 1.34 & 31 & $\mathrm{~L}$ \\
\hline November & 1990 & 0.34 & 1.05 & 1.30 & 30 & $\mathrm{~L}$ \\
\hline December & 1990 & 11.63 & 35.69 & 44.02 & 31 & $\mathrm{~L}$ \\
\hline January & 1991 & 2.21 & 6.77 & 8.35 & 31 & $\mathrm{~L}$ \\
\hline February & 1991 & 18.13 & 55.64 & 68.63 & 28 & $\mathrm{~L}$ \\
\hline March & 1991 & 23.27 & 71.40 & 88.06 & 31 & $\mathrm{~L}$ \\
\hline April & 1991 & 22.49 & 69.01 & 85.11 & 30 & $\mathrm{~L}$ \\
\hline May & 1991 & 21.69 & 66.55 & 82.08 & 31 & $\mathrm{~L}$ \\
\hline June & 1991 & 25.43 & 78.04 & 96.24 & 30 & $\mathrm{~L}$ \\
\hline July & 1991 & 23.30 & 71.51 & 88.19 & 31 & $\mathrm{~L}$ \\
\hline August & 1991 & 18.10 & 55.55 & 68.51 & 28 & $\mathrm{~L}$ \\
\hline
\end{tabular}

aSource: $L=$ Taken from data supplied by Los Alamos National Laboratory (LANL). 
WW-1 Monthly Pumping Data

\begin{tabular}{|c|c|c|c|c|c|c|}
\hline Month & Year & $\begin{array}{c}\text { Million } \\
\text { Gallons }\end{array}$ & Acre-Ft & $\begin{array}{l}\text { Million } \\
\text { Liters }\end{array}$ & $\begin{array}{c}\text { Days } \\
\text { Reported }\end{array}$ & Source ${ }^{a}$ \\
\hline January & 1950 & -- & -- & -- & 0 & $U$ \\
\hline February & 1950 & -- & -- & -- & 0 & $\bar{U}$ \\
\hline March & 1950 & -- & -- & -- & 0 & $\bar{U}$ \\
\hline April & 1950 & -- & -- & -- & 0 & $\bar{U}$ \\
\hline May & 1950 & -- & -- & -- & 0 & $\bar{U}$ \\
\hline June & 1950 & -- & -- & -- & 0 & $\mathrm{U}$ \\
\hline July & 1950 & -- & -- & -- & 0 & $\bar{U}$ \\
\hline August & 1950 & -- & -- & -- & 0 & $\mathrm{U}$ \\
\hline September & 1950 & -- & -- & -- & 0 & $\bar{U}$ \\
\hline October & 1950 & -- & -- & -- & 0 & $\bar{U}$ \\
\hline November & 1950 & -- & -- & -- & 0 & $\bar{U}$ \\
\hline December & 1950 & -- & -- & -- & 0 & $\bar{U}$ \\
\hline January & 1951 & -- & -- & -- & 0 & $U$ \\
\hline February & 1951 & -- & -- & -- & 0 & $\mathrm{U}$ \\
\hline March & 1951 & -- & -- & -- & 0 & $\mathrm{U}$ \\
\hline April & 1951 & -- & -- & -- & 0 & $\bar{U}$ \\
\hline May & 1951 & -- & -- & -- & 0 & $\bar{U}$ \\
\hline June & 1951 & -- & -- & -- & 0 & $\bar{U}$ \\
\hline July & 1951 & -- & -- & -- & 0 & $\mathrm{U}$ \\
\hline August & 1951 & -- & -- & -- & 0 & $\bar{U}$ \\
\hline September & 1951 & -- & -- & -- & 0 & $\bar{U}$ \\
\hline October & 1951 & -- & -- & -- & 0 & $\bar{U}$ \\
\hline November & 1951 & -- & -- & -- & 0 & $\bar{U}$ \\
\hline December & 1951 & -- & -- & -- & 0 & $\bar{U}$ \\
\hline January & 1952 & -- & -- & -- & 0 & $U$ \\
\hline February & 1952 & -- & -- & -- & 0 & $\mathrm{U}$ \\
\hline March & 1952 & -- & -- & -- & 0 & $\mathrm{U}$ \\
\hline April & 1952 & -- & -- & -- & 0 & $\mathrm{U}$ \\
\hline May & 1952 & -- & -- & -- & 0 & $\bar{U}$ \\
\hline June & 1952 & -- & -- & -- & 0 & $\bar{U}$ \\
\hline July & 1952 & -- & -- & -- & 0 & $\mathrm{U}$ \\
\hline August & 1952 & -- & -- & -- & 0 & $\bar{U}$ \\
\hline September & 1952 & -- & -- & -- & 0 & $\mathrm{U}$ \\
\hline October & 1952 & -- & -- & -- & 0 & $\bar{U}$ \\
\hline November & 1952 & -- & -- & -- & 0 & $\bar{U}$ \\
\hline December & 1952 & -- & -- & -- & 0 & $\bar{U}$ \\
\hline January & 1953 & -- & -- & -- & 0 & $U$ \\
\hline February & 1953 & -- & -- & -- & 0 & $\mathrm{U}$ \\
\hline March & 1953 & -- & -- & -- & 0 & $\mathrm{U}$ \\
\hline April & 1953 & -- & -- & -- & 0 & $\mathrm{U}$ \\
\hline May & 1953 & -- & -- & $\overline{--}$ & 0 & $\bar{U}$ \\
\hline June & 1953 & -- & -- & -- & 0 & $\mathrm{U}$ \\
\hline July & 1953 & -- & -- & -- & 0 & $\mathrm{U}$ \\
\hline August & 1953 & -- & -- & -- & 0 & $\bar{U}$ \\
\hline September & 1953 & -- & -- & -- & 0 & $\mathrm{U}$ \\
\hline October & 1953 & -- & -- & -- & 0 & $\bar{U}$ \\
\hline November & 1953 & -- & -- & -- & 0 & $\bar{U}$ \\
\hline December & 1953 & -- & -- & -- & 0 & $\bar{U}$ \\
\hline January & 1954 & -- & -- & -- & 0 & U \\
\hline
\end{tabular}


WW-1 Monthly Pumping Data

\begin{tabular}{|c|c|c|c|c|c|c|}
\hline February & 1954 & -- & -- & -- & 0 & $\bar{U}$ \\
\hline March & 1954 & -- & -- & -- & 0 & $\bar{U}$ \\
\hline April & 1954 & -- & -- & -- & 0 & $U$ \\
\hline May & 1954 & -- & -- & -- & 0 & $U$ \\
\hline June & 1954 & -- & -- & -- & 0 & $U$ \\
\hline July & 1954 & -- & -- & -- & 0 & $\bar{U}$ \\
\hline August & 1954 & -- & -- & -- & 0 & $U$ \\
\hline September & 1954 & -- & -- & -- & 0 & $\bar{U}$ \\
\hline October & 1954 & -- & -- & -- & 0 & $\bar{U}$ \\
\hline November & 1954 & -- & -- & -- & 0 & $\bar{U}$ \\
\hline December & 1954 & -- & -- & -- & 0 & $\bar{U}$ \\
\hline January & 1955 & -- & -- & -- & 0 & $\bar{U}$ \\
\hline February & 1955 & -- & -- & -- & 0 & $\bar{U}$ \\
\hline March & 1955 & -- & -- & -- & $\overline{0}$ & $\bar{U}$ \\
\hline April & 1955 & -- & -- & -- & 0 & $U$ \\
\hline May & 1955 & -- & -- & -- & 0 & U \\
\hline June & 1955 & -- & -- & -- & 0 & $\bar{U}$ \\
\hline July & 1955 & -- & -- & -- & 0 & $\bar{U}$ \\
\hline August & 1955 & -- & -- & -- & 0 & $\bar{U}$ \\
\hline September & 1955 & -- & -- & -- & 0 & $\bar{U}$ \\
\hline October & 1955 & -- & -- & -- & 0 & $\bar{U}$ \\
\hline November & 1955 & -- & -- & -- & 0 & $U$ \\
\hline December & 1955 & -- & -- & -- & 0 & $\bar{U}$ \\
\hline January & 1956 & -- & -- & -- & 0 & $\bar{U}$ \\
\hline February & 1956 & -- & -- & -- & 0 & $\bar{U}$ \\
\hline March & 1956 & -- & -- & -- & 0 & $\bar{U}$ \\
\hline April & 1956 & -- & -- & -- & $\overline{0}$ & $\bar{U}$ \\
\hline May & 1956 & -- & -- & -- & 0 & U \\
\hline June & 1956 & -- & -- & -- & 0 & $\bar{U}$ \\
\hline July & 1956 & -- & -- & -- & 0 & $\bar{U}$ \\
\hline August & 1956 & -- & -- & -- & 0 & $\bar{U}$ \\
\hline September & 1956 & -- & -- & -- & 0 & $\bar{U}$ \\
\hline October & 1956 & -- & -- & -- & 0 & $U$ \\
\hline November & 1956 & -- & -- & -- & 0 & $U$ \\
\hline December & 1956 & -- & -- & -- & 0 & $\bar{U}$ \\
\hline January & 1957 & -- & -- & -- & 0 & $\bar{U}$ \\
\hline February & 1957 & -- & -- & -- & 0 & $\bar{U}$ \\
\hline March & 1957 & -- & -- & -- & 0 & $\bar{U}$ \\
\hline April & 1957 & -- & -- & -- & 0 & $\mathrm{U}$ \\
\hline May & 1957 & -- & -- & -- & 0 & $\bar{U}$ \\
\hline June & 1957 & -- & -- & -- & 0 & $\bar{U}$ \\
\hline July & 1957 & -- & -- & -- & 0 & $\bar{U}$ \\
\hline August & 1957 & -- & -- & -- & 0 & $\bar{U}$ \\
\hline September & 1957 & -- & -- & -- & 0 & $\bar{U}$ \\
\hline October & 1957 & -- & -- & -- & 0 & $\bar{U}$ \\
\hline November & 1957 & -- & -- & -- & 0 & $\bar{U}$ \\
\hline December & 1957 & -- & -- & -- & 0 & 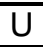 \\
\hline January & 1958 & -- & -- & -- & 0 & $\bar{U}$ \\
\hline February & 1958 & -- & -- & -- & 0 & $\bar{U}$ \\
\hline March & 1958 & -- & -- & -- & 0 & $\bar{U}$ \\
\hline April & 1958 & -- & -- & -- & 0 & $\bar{U}$ \\
\hline May & 1958 & -- & -- & -- & 0 & $U$ \\
\hline
\end{tabular}


WW-1 Monthly Pumping Data

\begin{tabular}{|c|c|c|c|c|c|c|}
\hline June & 1958 & -- & -- & -- & 0 & $\bar{U}$ \\
\hline July & 1958 & -- & -- & -- & 0 & $\bar{U}$ \\
\hline August & 1958 & -- & -- & -- & 0 & $\bar{U}$ \\
\hline September & 1958 & -- & -- & -- & $\overline{0}$ & $\bar{U}$ \\
\hline October & 1958 & -- & -- & $\overline{--}$ & 0 & $\bar{U}$ \\
\hline November & 1958 & -- & $\overline{--}$ & $\overline{--}$ & 0 & $\bar{U}$ \\
\hline December & 1958 & -- & -- & -- & 0 & $\bar{U}$ \\
\hline January & 1959 & -- & -- & -- & 0 & $\bar{U}$ \\
\hline February & 1959 & -- & -- & -- & 0 & $\bar{U}$ \\
\hline March & 1959 & -- & -- & -- & 0 & $\mathrm{U}$ \\
\hline April & 1959 & -- & -- & -- & 0 & $\bar{U}$ \\
\hline May & 1959 & -- & -- & -- & 0 & $\bar{U}$ \\
\hline June & 1959 & -- & -- & -- & 0 & $\bar{U}$ \\
\hline July & 1959 & -- & -- & -- & 0 & $\bar{U}$ \\
\hline August & 1959 & -- & -- & -- & 0 & $\bar{U}$ \\
\hline September & 1959 & -- & -- & -- & 0 & $\bar{U}$ \\
\hline October & 1959 & -- & -- & $\overline{--}$ & 0 & $\bar{U}$ \\
\hline November & 1959 & -- & $\overline{--}$ & $\overline{--}$ & 0 & $\bar{U}$ \\
\hline December & 1959 & -- & -- & -- & 0 & $\bar{U}$ \\
\hline January & 1960 & -- & -- & -- & 0 & $\bar{U}$ \\
\hline February & 1960 & -- & -- & -- & 0 & $\bar{U}$ \\
\hline March & 1960 & -- & -- & -- & 0 & $\bar{U}$ \\
\hline April & 1960 & -- & -- & -- & 0 & $\bar{U}$ \\
\hline May & 1960 & -- & -- & -- & 0 & $\bar{U}$ \\
\hline June & 1960 & -- & -- & -- & 0 & $\bar{U}$ \\
\hline July & 1960 & -- & -- & -- & 0 & $\bar{U}$ \\
\hline August & 1960 & -- & -- & -- & 0 & $\bar{U}$ \\
\hline September & 1960 & -- & -- & -- & $\overline{0}$ & $\bar{U}$ \\
\hline October & 1960 & -- & -- & -- & 0 & $\bar{U}$ \\
\hline November & 1960 & $\overline{--}$ & $\overline{--}$ & -- & 0 & $\bar{U}$ \\
\hline December & 1960 & -- & -- & -- & 0 & $\bar{U}$ \\
\hline January & 1961 & -- & -- & -- & 0 & $\bar{U}$ \\
\hline February & 1961 & -- & -- & -- & 0 & $\bar{U}$ \\
\hline March & 1961 & -- & -- & -- & 0 & $\bar{U}$ \\
\hline April & 1961 & -- & -- & -- & 0 & $\bar{U}$ \\
\hline May & 1961 & -- & -- & -- & 0 & $\bar{U}$ \\
\hline June & 1961 & -- & -- & -- & 0 & $\bar{U}$ \\
\hline July & 1961 & -- & -- & -- & 0 & $\bar{U}$ \\
\hline August & 1961 & -- & -- & -- & 0 & $\bar{U}$ \\
\hline September & 1961 & -- & -- & -- & $\overline{0}$ & $\bar{U}$ \\
\hline October & 1961 & -- & -- & -- & 0 & $\bar{U}$ \\
\hline November & 1961 & -- & -- & -- & 0 & $\bar{U}$ \\
\hline December & 1961 & -- & -- & -- & 0 & $\bar{U}$ \\
\hline January & 1962 & -- & -- & -- & 0 & $\bar{U}$ \\
\hline February & 1962 & -- & -- & -- & 0 & $\bar{U}$ \\
\hline March & 1962 & -- & -- & -- & $\overline{0}$ & $\bar{U}$ \\
\hline April & 1962 & -- & $\overline{--}$ & -- & $\overline{0}$ & $\bar{U}$ \\
\hline May & 1962 & -- & -- & -- & 0 & $\bar{U}$ \\
\hline June & 1962 & -- & -- & -- & 0 & $\bar{U}$ \\
\hline July & 1962 & -- & -- & -- & $\overline{0}$ & $\bar{U}$ \\
\hline August & 1962 & -- & -- & -- & 0 & $\bar{U}$ \\
\hline September & 1962 & -- & -- & -- & 0 & $\bar{U}$ \\
\hline
\end{tabular}


WW-1 Monthly Pumping Data

\begin{tabular}{|c|c|c|c|c|c|c|}
\hline October & 1962 & -- & -- & -- & 0 & $\bar{U}$ \\
\hline November & 1962 & -- & -- & -- & 0 & $\bar{U}$ \\
\hline December & 1962 & -- & -- & -- & 0 & $U$ \\
\hline January & 1963 & -- & -- & -- & 0 & $U$ \\
\hline February & 1963 & -- & -- & -- & 0 & $U$ \\
\hline March & 1963 & -- & -- & -- & 0 & $\bar{U}$ \\
\hline April & 1963 & -- & -- & -- & 0 & $U$ \\
\hline May & 1963 & -- & -- & -- & 0 & $\bar{U}$ \\
\hline June & 1963 & -- & -- & -- & 0 & $\bar{U}$ \\
\hline July & 1963 & -- & -- & -- & 0 & $\bar{U}$ \\
\hline August & 1963 & -- & -- & -- & 0 & U \\
\hline September & 1963 & -- & -- & -- & 0 & $\bar{U}$ \\
\hline October & 1963 & -- & -- & -- & 0 & $\bar{U}$ \\
\hline November & 1963 & -- & -- & -- & 0 & $\bar{U}$ \\
\hline December & 1963 & -- & -- & -- & 0 & U \\
\hline January & 1964 & -- & -- & -- & 0 & U \\
\hline February & 1964 & 4.98 & 15.29 & 18.86 & 29 & $\bar{M}$ \\
\hline March & 1964 & 7.34 & 22.53 & 27.78 & 31 & $\bar{M}$ \\
\hline April & 1964 & 5.96 & 18.28 & 22.54 & 30 & $\bar{M}$ \\
\hline May & 1964 & 8.28 & 25.40 & 31.33 & 31 & $\bar{M}$ \\
\hline June & 1964 & 7.37 & 22.62 & 27.90 & 30 & $\bar{M}$ \\
\hline July & 1964 & 6.34 & 19.45 & 23.99 & 31 & $\bar{M}$ \\
\hline August & 1964 & 7.34 & 22.53 & 27.79 & 31 & $\bar{M}$ \\
\hline September & 1964 & 1.25 & 3.84 & 4.74 & 30 & $\bar{M}$ \\
\hline October & 1964 & 4.06 & 12.46 & 15.37 & 31 & $\bar{M}$ \\
\hline November & 1964 & 1.81 & 5.56 & 6.86 & 30 & $\bar{M}$ \\
\hline December & 1964 & 0.37 & 1.14 & 1.40 & 31 & $\bar{M}$ \\
\hline January & 1965 & 2.25 & 6.91 & 8.52 & 31 & $\mathrm{M}$ \\
\hline February & 1965 & 3.07 & 9.42 & 11.62 & 28 & $\bar{M}$ \\
\hline March & 1965 & 1.36 & 4.17 & 5.14 & 31 & $\bar{M}$ \\
\hline April & 1965 & 4.22 & 12.94 & 15.96 & 30 & $\bar{M}$ \\
\hline May & 1965 & 0.91 & 2.80 & 3.45 & 31 & $\bar{M}$ \\
\hline June & 1965 & 1.78 & 5.46 & 6.74 & 30 & $\bar{M}$ \\
\hline July & 1965 & 2.40 & 7.37 & 9.09 & 31 & $\bar{M}$ \\
\hline August & 1965 & 3.16 & 9.69 & 11.95 & 31 & $\bar{M}$ \\
\hline September & 1965 & 2.91 & 8.92 & 11.00 & 26 & $\bar{M}$ \\
\hline October & 1965 & -- & -- & -- & 0 & $\mathrm{I}$ \\
\hline November & 1965 & 0.00 & 0.00 & 0.00 & 29 & $\bar{M}$ \\
\hline December & 1965 & 0.15 & 0.45 & 0.55 & 31 & $\bar{M}$ \\
\hline January & 1966 & 0.06 & 0.19 & 0.23 & 31 & $\mathrm{M}$ \\
\hline February & 1966 & 1.90 & 5.82 & 7.18 & 28 & $\bar{M}$ \\
\hline March & 1966 & 4.72 & 14.48 & 17.86 & 31 & $\mathrm{M}$ \\
\hline April & 1966 & 3.98 & 12.23 & 15.08 & 30 & $\bar{M}$ \\
\hline May & 1966 & 3.28 & 10.07 & 12.42 & 29 & $\bar{M}$ \\
\hline June & 1966 & -- & -- & -- & 0 & $\mathrm{I}$ \\
\hline July & 1966 & -- & -- & -- & 0 & $\mathrm{I}$ \\
\hline August & 1966 & 3.20 & 9.81 & 12.10 & 28 & $\mathrm{M}$ \\
\hline September & 1966 & 0.23 & 0.70 & 0.86 & 5 & $\mathrm{M}$ \\
\hline October & 1966 & 2.49 & 7.65 & 9.44 & 31 & $\bar{M}$ \\
\hline November & 1966 & 2.29 & 7.03 & 8.67 & 30 & $\bar{M}$ \\
\hline December & 1966 & 2.14 & 6.57 & 8.10 & 31 & $\bar{M}$ \\
\hline January & 1967 & 0.00 & 0.00 & 0.00 & 31 & $\mathrm{M}$ \\
\hline
\end{tabular}


WW-1 Monthly Pumping Data

\begin{tabular}{|c|c|c|c|c|c|c|}
\hline February & 1967 & 0.00 & 0.00 & 0.00 & 28 & $\bar{M}$ \\
\hline March & 1967 & 0.05 & 0.15 & 0.18 & 30 & $\bar{M}$ \\
\hline April & 1967 & -- & -- & -- & 0 & $U$ \\
\hline May & 1967 & -- & -- & -- & 0 & U \\
\hline June & 1967 & -- & -- & -- & 0 & $\bar{U}$ \\
\hline July & 1967 & -- & -- & -- & 0 & $\bar{U}$ \\
\hline August & 1967 & -- & -- & -- & 0 & $\bar{U}$ \\
\hline September & 1967 & -- & -- & -- & 0 & $\bar{U}$ \\
\hline October & 1967 & -- & -- & -- & 0 & $\bar{U}$ \\
\hline November & 1967 & -- & -- & -- & 0 & $\bar{U}$ \\
\hline December & 1967 & -- & -- & -- & 0 & $\bar{U}$ \\
\hline January & 1968 & -- & -- & -- & 0 & $\bar{U}$ \\
\hline February & 1968 & -- & -- & -- & 0 & $\bar{U}$ \\
\hline March & 1968 & -- & -- & -- & 0 & $\bar{U}$ \\
\hline April & 1968 & -- & -- & -- & 0 & U \\
\hline May & 1968 & -- & -- & -- & 0 & U \\
\hline June & 1968 & -- & -- & -- & 0 & $\bar{U}$ \\
\hline July & 1968 & -- & -- & -- & 0 & $\bar{U}$ \\
\hline August & 1968 & -- & -- & -- & 0 & $\bar{U}$ \\
\hline September & 1968 & -- & -- & -- & 0 & $\bar{U}$ \\
\hline October & 1968 & -- & -- & -- & 0 & $\bar{U}$ \\
\hline November & 1968 & -- & -- & -- & 0 & $U$ \\
\hline December & 1968 & -- & -- & -- & 0 & $U$ \\
\hline January & 1969 & -- & -- & -- & 0 & $\bar{U}$ \\
\hline February & 1969 & -- & -- & -- & 0 & $\bar{U}$ \\
\hline March & 1969 & -- & -- & -- & 0 & $\bar{U}$ \\
\hline April & 1969 & -- & -- & -- & 0 & $U$ \\
\hline May & 1969 & -- & -- & -- & 0 & U \\
\hline June & 1969 & -- & -- & -- & 0 & $\bar{U}$ \\
\hline July & 1969 & -- & -- & -- & 0 & $\bar{U}$ \\
\hline August & 1969 & -- & -- & -- & 0 & $\bar{U}$ \\
\hline September & 1969 & -- & -- & -- & 0 & $\bar{U}$ \\
\hline October & 1969 & -- & -- & -- & 0 & $\bar{U}$ \\
\hline November & 1969 & -- & -- & -- & 0 & $\bar{U}$ \\
\hline December & 1969 & -- & -- & -- & 0 & $\bar{U}$ \\
\hline January & 1970 & -- & -- & -- & 0 & $\bar{U}$ \\
\hline February & 1970 & -- & -- & -- & 0 & $\bar{U}$ \\
\hline March & 1970 & -- & -- & -- & 0 & $\bar{U}$ \\
\hline April & 1970 & -- & -- & -- & 0 & $\mathrm{U}$ \\
\hline May & 1970 & -- & -- & -- & 0 & U \\
\hline June & 1970 & -- & -- & -- & 0 & $\bar{U}$ \\
\hline July & 1970 & -- & -- & -- & 0 & $\bar{U}$ \\
\hline August & 1970 & -- & -- & -- & 0 & $\bar{U}$ \\
\hline September & 1970 & -- & -- & -- & 0 & $\bar{U}$ \\
\hline October & 1970 & -- & -- & -- & 0 & $\bar{U}$ \\
\hline November & 1970 & -- & -- & -- & 0 & $\bar{U}$ \\
\hline December & 1970 & -- & -- & -- & 0 & $U$ \\
\hline January & 1971 & -- & -- & -- & 0 & $\bar{U}$ \\
\hline February & 1971 & -- & -- & -- & 0 & $\bar{U}$ \\
\hline March & 1971 & -- & -- & -- & 0 & $\bar{U}$ \\
\hline April & 1971 & -- & -- & -- & 0 & $\bar{U}$ \\
\hline May & 1971 & -- & -- & -- & 0 & U \\
\hline
\end{tabular}


WW-1 Monthly Pumping Data

\begin{tabular}{|c|c|c|c|c|c|c|}
\hline June & 1971 & -- & -- & -- & 0 & $\bar{U}$ \\
\hline July & 1971 & -- & -- & -- & 0 & $\bar{U}$ \\
\hline August & 1971 & -- & -- & -- & 0 & $\bar{U}$ \\
\hline September & 1971 & -- & -- & -- & $\overline{0}$ & $\bar{U}$ \\
\hline October & 1971 & -- & -- & $\overline{--}$ & 0 & $\bar{U}$ \\
\hline November & 1971 & -- & $\overline{--}$ & $\overline{--}$ & 0 & $\bar{U}$ \\
\hline December & 1971 & -- & -- & -- & 0 & $\bar{U}$ \\
\hline January & 1972 & -- & -- & -- & 0 & $\bar{U}$ \\
\hline February & 1972 & -- & -- & -- & 0 & $\bar{U}$ \\
\hline March & 1972 & -- & -- & -- & 0 & $\mathrm{U}$ \\
\hline April & 1972 & -- & -- & $\overline{--}$ & 0 & $\bar{U}$ \\
\hline May & 1972 & -- & -- & -- & 0 & $\bar{U}$ \\
\hline June & 1972 & -- & -- & -- & 0 & $\bar{U}$ \\
\hline July & 1972 & -- & -- & -- & 0 & $\bar{U}$ \\
\hline August & 1972 & -- & -- & -- & 0 & $\bar{U}$ \\
\hline September & 1972 & -- & -- & -- & 0 & $\bar{U}$ \\
\hline October & 1972 & -- & -- & $\overline{--}$ & 0 & $\bar{U}$ \\
\hline November & 1972 & -- & $\overline{--}$ & $\overline{--}$ & 0 & $\bar{U}$ \\
\hline December & 1972 & -- & -- & -- & 0 & $\bar{U}$ \\
\hline January & 1973 & -- & -- & -- & 0 & $\bar{U}$ \\
\hline February & 1973 & -- & -- & -- & 0 & $\bar{U}$ \\
\hline March & 1973 & -- & -- & -- & 0 & $\bar{U}$ \\
\hline April & 1973 & -- & -- & -- & 0 & $\bar{U}$ \\
\hline May & 1973 & -- & -- & -- & 0 & $\bar{U}$ \\
\hline June & 1973 & -- & -- & -- & 0 & $\bar{U}$ \\
\hline July & 1973 & -- & -- & -- & 0 & $\bar{U}$ \\
\hline August & 1973 & -- & -- & -- & 0 & $\bar{U}$ \\
\hline September & 1973 & -- & -- & -- & $\overline{0}$ & $\bar{U}$ \\
\hline October & 1973 & -- & -- & -- & 0 & $\bar{U}$ \\
\hline November & 1973 & -- & $\overline{--}$ & -- & 0 & $\bar{U}$ \\
\hline December & 1973 & -- & -- & -- & 0 & $\bar{U}$ \\
\hline January & 1974 & -- & -- & -- & 0 & $\bar{U}$ \\
\hline February & 1974 & -- & -- & -- & 0 & $\bar{U}$ \\
\hline March & 1974 & -- & -- & -- & 0 & $\bar{U}$ \\
\hline April & 1974 & -- & -- & -- & 0 & $\bar{U}$ \\
\hline May & 1974 & -- & -- & -- & 0 & $\bar{U}$ \\
\hline June & 1974 & -- & -- & -- & 0 & $\bar{U}$ \\
\hline July & 1974 & -- & -- & -- & 0 & $\bar{U}$ \\
\hline August & 1974 & -- & -- & -- & 0 & $\bar{U}$ \\
\hline September & 1974 & $\overline{--}$ & -- & -- & $\overline{0}$ & $\bar{U}$ \\
\hline October & 1974 & -- & $\overline{--}$ & $\overline{--}$ & $\overline{0}$ & $\bar{U}$ \\
\hline November & 1974 & -- & -- & -- & 0 & $\bar{U}$ \\
\hline December & 1974 & -- & -- & -- & 0 & $\bar{U}$ \\
\hline January & 1975 & -- & -- & -- & 0 & $\bar{U}$ \\
\hline February & 1975 & -- & -- & -- & 0 & $\bar{U}$ \\
\hline March & 1975 & -- & -- & -- & $\overline{0}$ & $\bar{U}$ \\
\hline April & 1975 & -- & -- & -- & 0 & $\bar{U}$ \\
\hline May & 1975 & -- & -- & -- & 0 & $\bar{U}$ \\
\hline June & 1975 & -- & -- & -- & 0 & $\bar{U}$ \\
\hline July & 1975 & -- & -- & -- & 0 & $\bar{U}$ \\
\hline August & 1975 & -- & -- & -- & 0 & $\bar{U}$ \\
\hline September & 1975 & -- & -- & -- & 0 & $\bar{U}$ \\
\hline
\end{tabular}


WW-1 Monthly Pumping Data

\begin{tabular}{|c|c|c|c|c|c|c|}
\hline October & 1975 & -- & -- & -- & 0 & $\bar{U}$ \\
\hline November & 1975 & $\overline{--}$ & $\overline{--}$ & -- & 0 & $\bar{U}$ \\
\hline December & 1975 & -- & -- & -- & 0 & $U$ \\
\hline January & 1976 & -- & -- & -- & 0 & $U$ \\
\hline February & 1976 & -- & -- & -- & 0 & $U$ \\
\hline March & 1976 & -- & -- & -- & 0 & $\bar{U}$ \\
\hline April & 1976 & -- & -- & -- & 0 & $U$ \\
\hline May & 1976 & -- & -- & -- & 0 & $\bar{U}$ \\
\hline June & 1976 & -- & -- & -- & 0 & $\bar{U}$ \\
\hline July & 1976 & -- & -- & -- & 0 & $\bar{U}$ \\
\hline August & 1976 & -- & -- & -- & 0 & $\bar{U}$ \\
\hline September & 1976 & -- & -- & -- & 0 & $\bar{U}$ \\
\hline October & 1976 & -- & -- & -- & 0 & $\bar{U}$ \\
\hline November & 1976 & -- & -- & -- & 0 & $U$ \\
\hline December & 1976 & -- & -- & -- & 0 & $U$ \\
\hline January & 1977 & -- & -- & -- & 0 & U \\
\hline February & 1977 & -- & -- & -- & 0 & $\bar{U}$ \\
\hline March & 1977 & -- & -- & -- & 0 & $\bar{U}$ \\
\hline April & 1977 & -- & -- & -- & 0 & $\bar{U}$ \\
\hline May & 1977 & -- & -- & -- & 0 & $\bar{U}$ \\
\hline June & 1977 & -- & -- & -- & 0 & $\bar{U}$ \\
\hline July & 1977 & -- & -- & -- & 0 & $U$ \\
\hline August & 1977 & -- & -- & -- & 0 & $\bar{U}$ \\
\hline September & 1977 & -- & -- & -- & 0 & $\bar{U}$ \\
\hline October & 1977 & -- & -- & -- & 0 & $\bar{U}$ \\
\hline November & 1977 & -- & -- & -- & 0 & $\bar{U}$ \\
\hline December & 1977 & -- & -- & -- & 0 & $\bar{U}$ \\
\hline January & 1978 & -- & -- & -- & 0 & U \\
\hline February & 1978 & -- & -- & -- & 0 & $\bar{U}$ \\
\hline March & 1978 & -- & -- & -- & 0 & $\bar{U}$ \\
\hline April & 1978 & -- & -- & -- & 0 & $\bar{U}$ \\
\hline May & 1978 & -- & -- & -- & 0 & $\bar{U}$ \\
\hline June & 1978 & -- & -- & -- & 0 & $U$ \\
\hline July & 1978 & -- & -- & -- & 0 & $U$ \\
\hline August & 1978 & -- & -- & -- & 0 & $U$ \\
\hline September & 1978 & -- & -- & -- & 0 & $\bar{U}$ \\
\hline October & 1978 & -- & -- & -- & 0 & $\bar{U}$ \\
\hline November & 1978 & -- & -- & -- & 0 & $\bar{U}$ \\
\hline December & 1978 & -- & -- & -- & 0 & $\mathrm{U}$ \\
\hline January & 1979 & -- & -- & -- & 0 & U \\
\hline February & 1979 & -- & -- & -- & 0 & $\bar{U}$ \\
\hline March & 1979 & -- & -- & -- & 0 & $\bar{U}$ \\
\hline April & 1979 & -- & -- & -- & 0 & $\bar{U}$ \\
\hline May & 1979 & -- & -- & -- & 0 & $\bar{U}$ \\
\hline June & 1979 & -- & -- & -- & 0 & $\bar{U}$ \\
\hline July & 1979 & -- & -- & -- & 0 & $\bar{U}$ \\
\hline August & 1979 & -- & -- & -- & 0 & $U$ \\
\hline September & 1979 & -- & -- & -- & 0 & $\bar{U}$ \\
\hline October & 1979 & -- & -- & -- & 0 & $\bar{U}$ \\
\hline November & 1979 & -- & -- & -- & $\overline{0}$ & $\bar{U}$ \\
\hline December & 1979 & -- & -- & -- & 0 & $\mathrm{U}$ \\
\hline January & 1980 & -- & -- & -- & 0 & $\mathrm{U}$ \\
\hline
\end{tabular}


WW-1 Monthly Pumping Data

\begin{tabular}{|l|c|c|c|c|c|c|}
\hline February & 1980 & -- & -- & -- & 0 & $U$ \\
\hline March & 1980 & -- & -- & -- & 0 & $U$ \\
\hline April & 1980 & -- & -- & -- & 0 & $U$ \\
\hline May & 1980 & -- & -- & -- & 0 & $U$ \\
\hline June & 1980 & -- & -- & -- & 0 & $U$ \\
\hline July & 1980 & -- & -- & -- & 0 & $U$ \\
\hline August & 1980 & -- & -- & -- & 0 & $U$ \\
\hline September & 1980 & -- & -- & -- & 0 & $U$ \\
\hline October & 1980 & -- & -- & -- & 0 & $U$ \\
\hline November & 1980 & -- & -- & -- & 0 & $U$ \\
\hline December & 1980 & -- & -- & -- & 0 & $U$ \\
\hline January & 1981 & -- & -- & -- & 0 & $U$ \\
\hline February & 1981 & -- & -- & -- & 0 & $U$ \\
\hline March & 1981 & -- & -- & -- & 0 & $U$ \\
\hline April & 1981 & -- & -- & -- & 0 & $U$ \\
\hline May & 1981 & -- & -- & -- & 0 & $U$ \\
\hline June & 1981 & -- & -- & -- & 0 & $U$ \\
\hline July & 1981 & -- & -- & -- & 0 & $U$ \\
\hline August & 1981 & -- & -- & -- & 0 & $U$ \\
\hline September & 1981 & -- & -- & -- & 0 & $U$ \\
\hline October & 1981 & -- & -- & -- & 0 & $U$ \\
\hline November & 1981 & -- & -- & -- & 0 & $U$ \\
\hline December & 1981 & -- & -- & -- & 0 & $U$ \\
\hline January & 1982 & -- & -- & -- & 0 & $U$ \\
\hline February & 1982 & -- & -- & -- & 0 & $U$ \\
\hline March & 1982 & -- & -- & -- & 0 & $U$ \\
\hline April & 1982 & -- & -- & -- & 0 & $U$ \\
\hline May & 1982 & -- & -- & -- & 0 & $U$ \\
\hline June & 1982 & -- & -- & -- & 0 & $\mathrm{U}$ \\
\hline July & 1982 & -- & -- & -- & 0 & $\mathrm{U}$ \\
\hline August & 1982 & -- & -- & -- & 0 & $\mathrm{U}$ \\
\hline September & 1982 & -- & -- & -- & 0 & $\mathrm{U}$ \\
\hline October & 1982 & -- & -- & -- & 0 & $\mathrm{U}$ \\
\hline November & 1982 & -- & -- & -- & 0 & $\mathrm{U}$ \\
\hline December & 1982 & -- & -- & -- & 0 & $\mathrm{U}$ \\
\hline & & & & & & \\
\hline
\end{tabular}

aSource: I = Insufficient or no data to calculate monthly total; no water may have been withdrawn for month.

$M=$ Taken from Bechtel or REECo water production reports.

$\mathrm{U}=$ Unknown whether well was available or used for water supply. 
WW-4 Monthly Pumping Data

\begin{tabular}{|c|c|c|c|c|c|c|}
\hline Month & Year & $\begin{array}{c}\text { Million } \\
\text { Gallons }\end{array}$ & Acre-Ft & $\begin{array}{l}\text { Million } \\
\text { Liters }\end{array}$ & $\begin{array}{c}\text { Days } \\
\text { Reported }\end{array}$ & Source $^{\mathrm{a}}$ \\
\hline January & 1983 & 0.00 & 0.00 & 0.00 & 31 & $\mathrm{M}$ \\
\hline February & 1983 & 0.00 & 0.00 & 0.00 & 28 & $\mathrm{M}$ \\
\hline March & 1983 & 0.00 & 0.00 & 0.00 & 31 & $\bar{M}$ \\
\hline April & 1983 & 1.26 & 3.87 & 4.77 & 30 & $\bar{M}$ \\
\hline May & 1983 & 1.21 & 3.71 & 4.57 & 31 & $\bar{M}$ \\
\hline June & 1983 & 2.12 & 6.50 & 8.02 & 30 & $M$ \\
\hline July & 1983 & 1.81 & 5.54 & 6.83 & 31 & $\bar{M}$ \\
\hline August & 1983 & 2.16 & 6.64 & 8.19 & 31 & $\mathrm{M}$ \\
\hline September & 1983 & 3.21 & 9.84 & 12.14 & 30 & $M$ \\
\hline October & 1983 & 5.51 & 16.91 & 20.85 & 31 & $M$ \\
\hline November & 1983 & 2.39 & 7.34 & 9.06 & 30 & $M$ \\
\hline December & 1983 & 4.45 & 13.64 & 16.82 & 31 & M \\
\hline January & 1984 & 5.27 & 16.16 & 19.94 & 31 & $\mathrm{M}$ \\
\hline February & 1984 & 3.34 & 10.24 & 12.62 & 29 & $M$ \\
\hline March & 1984 & 4.90 & 15.02 & 18.53 & 31 & $M$ \\
\hline April & 1984 & 4.14 & 12.69 & 15.65 & 30 & $\bar{M}$ \\
\hline May & 1984 & 4.90 & 15.05 & 18.56 & 31 & $\bar{M}$ \\
\hline June & 1984 & 5.08 & 15.60 & 19.24 & 30 & $M$ \\
\hline July & 1984 & 4.54 & 13.94 & 17.20 & 31 & $M$ \\
\hline August & 1984 & 3.75 & 11.50 & 14.18 & 31 & $\mathrm{M}$ \\
\hline September & 1984 & 5.51 & 16.92 & 20.87 & 30 & $M$ \\
\hline October & 1984 & 3.16 & 9.71 & 11.98 & 31 & $M$ \\
\hline November & 1984 & 2.01 & 6.16 & 7.60 & 30 & $M$ \\
\hline December & 1984 & 1.81 & 5.56 & 6.86 & 31 & $E$ \\
\hline January & 1985 & 1.22 & 3.73 & 4.60 & 31 & $E$ \\
\hline February & 1985 & 4.03 & 12.36 & 15.25 & 28 & $\mathrm{M}$ \\
\hline March & 1985 & 4.56 & 13.99 & 17.25 & 31 & $M$ \\
\hline April & 1985 & 6.00 & 18.40 & 22.70 & 30 & $M$ \\
\hline May & 1985 & 4.19 & 12.85 & 15.84 & 31 & $\bar{M}$ \\
\hline June & 1985 & 4.51 & 13.84 & 17.07 & 30 & $M$ \\
\hline July & 1985 & 4.04 & 12.40 & 15.30 & 31 & $M$ \\
\hline August & 1985 & 3.75 & 11.50 & 14.18 & 31 & $\mathrm{M}$ \\
\hline September & 1985 & 2.33 & 7.15 & 8.82 & 30 & $M$ \\
\hline October & 1985 & 3.16 & 9.70 & 11.96 & 31 & $M$ \\
\hline November & 1985 & 1.52 & 4.68 & 5.77 & 30 & $M$ \\
\hline December & 1985 & 3.64 & 11.18 & 13.78 & 31 & $E$ \\
\hline January & 1986 & 3.33 & 10.20 & 12.59 & 31 & $\mathrm{M}$ \\
\hline February & 1986 & 1.42 & 4.36 & 5.38 & 28 & $M$ \\
\hline March & 1986 & 2.17 & 6.67 & 8.23 & 31 & $M$ \\
\hline April & 1986 & 1.76 & 5.39 & 6.64 & 30 & $M$ \\
\hline May & 1986 & 2.28 & 7.01 & 8.65 & 31 & $M$ \\
\hline June & 1986 & 3.01 & 9.23 & 11.38 & 30 & $\mathrm{M}$ \\
\hline July & 1986 & 3.92 & 12.04 & 14.85 & 31 & $M$ \\
\hline August & 1986 & 3.04 & 9.33 & 11.51 & 31 & M \\
\hline September & 1986 & 2.13 & 6.53 & 8.05 & 30 & $\mathrm{M}$ \\
\hline October & 1986 & 1.91 & 5.85 & 7.22 & 31 & $\mathrm{M}$ \\
\hline November & 1986 & 2.87 & 8.81 & 10.87 & 30 & $\mathrm{M}$ \\
\hline December & 1986 & 0.35 & 1.06 & 1.31 & 31 & $M$ \\
\hline January & 1987 & 0.72 & 2.22 & 2.74 & 31 & $\bar{M}$ \\
\hline
\end{tabular}


WW-4 Monthly Pumping Data

\begin{tabular}{|c|c|c|c|c|c|c|}
\hline February & 1987 & 1.38 & 4.23 & 5.22 & 28 & $\bar{M}$ \\
\hline March & 1987 & 2.18 & 6.68 & 8.24 & 31 & $\bar{M}$ \\
\hline April & 1987 & 2.43 & 7.45 & 9.19 & 30 & M \\
\hline May & 1987 & 2.30 & 7.05 & 8.70 & 31 & $\mathrm{M}$ \\
\hline June & 1987 & 2.75 & 8.43 & 10.40 & 30 & $\bar{M}$ \\
\hline July & 1987 & 4.09 & 12.56 & 15.50 & 31 & $\bar{M}$ \\
\hline August & 1987 & 4.52 & 13.86 & 17.10 & 31 & $\bar{M}$ \\
\hline September & 1987 & 1.40 & 4.29 & 5.29 & 30 & $\bar{M}$ \\
\hline October & 1987 & 2.51 & 7.71 & 9.51 & 31 & $M$ \\
\hline November & 1987 & 1.51 & 4.64 & 5.72 & 30 & $\bar{M}$ \\
\hline December & 1987 & 2.41 & 7.39 & 9.11 & 31 & M \\
\hline January & 1988 & 1.35 & 4.15 & 5.12 & 31 & $\bar{M}$ \\
\hline February & 1988 & 1.85 & 5.68 & 7.00 & 29 & $\bar{M}$ \\
\hline March & 1988 & 3.67 & 11.26 & 13.89 & 31 & $\bar{M}$ \\
\hline April & 1988 & 3.16 & 9.70 & 11.96 & 30 & M \\
\hline May & 1988 & 4.47 & 13.72 & 16.92 & 31 & $\mathrm{M}$ \\
\hline June & 1988 & 4.12 & 12.65 & 15.60 & 30 & $\bar{M}$ \\
\hline July & 1988 & 4.66 & 14.30 & 17.64 & 31 & $\bar{M}$ \\
\hline August & 1988 & 4.36 & 13.37 & 16.49 & 31 & $\bar{M}$ \\
\hline September & 1988 & 3.47 & 10.65 & 13.13 & 30 & $\bar{M}$ \\
\hline October & 1988 & 6.84 & 21.00 & 25.90 & 31 & $\bar{M}$ \\
\hline November & 1988 & 4.73 & 14.50 & 17.88 & 30 & $\bar{M}$ \\
\hline December & 1988 & 4.03 & 12.38 & 15.26 & 31 & $\mathrm{M}$ \\
\hline January & 1989 & 6.12 & 18.79 & 23.17 & 31 & $\bar{M}$ \\
\hline February & 1989 & 8.62 & 26.47 & 32.64 & 28 & $\bar{M}$ \\
\hline March & 1989 & 10.23 & 31.39 & 38.71 & 31 & $\bar{M}$ \\
\hline April & 1989 & 13.65 & 41.90 & 51.67 & 30 & $\bar{M}$ \\
\hline May & 1989 & 14.76 & 45.29 & 55.86 & 31 & $\bar{M}$ \\
\hline June & 1989 & 16.93 & 51.96 & 64.09 & 30 & $\bar{M}$ \\
\hline July & 1989 & 19.16 & 58.79 & 72.51 & 31 & $\bar{M}$ \\
\hline August & 1989 & 22.96 & 70.45 & 86.89 & 31 & $\bar{M}$ \\
\hline September & 1989 & 22.86 & 70.15 & 86.52 & 30 & $\bar{M}$ \\
\hline October & 1989 & 25.63 & 78.64 & 96.99 & 31 & $\bar{M}$ \\
\hline November & 1989 & 17.31 & 53.13 & 65.53 & 30 & $\bar{M}$ \\
\hline December & 1989 & 13.82 & 42.41 & 52.30 & 31 & $\mathrm{M}$ \\
\hline January & 1990 & 9.95 & 30.52 & 37.64 & 31 & $\bar{M}$ \\
\hline February & 1990 & 5.77 & 17.70 & 21.83 & 28 & $\bar{M}$ \\
\hline March & 1990 & 9.80 & 30.06 & 37.08 & 31 & $\bar{M}$ \\
\hline April & 1990 & 12.57 & 38.57 & 47.57 & 30 & $\bar{M}$ \\
\hline May & 1990 & 7.53 & 23.12 & 28.51 & 31 & $\bar{M}$ \\
\hline June & 1990 & 2.66 & 8.16 & 10.06 & 30 & $\bar{M}$ \\
\hline July & 1990 & 0.86 & 2.64 & 3.26 & 31 & $\mathrm{M}$ \\
\hline August & 1990 & 2.41 & 7.39 & 9.11 & 31 & $E$ \\
\hline September & 1990 & 3.76 & 11.52 & 14.21 & 30 & $E$ \\
\hline October & 1990 & 5.21 & 15.98 & 19.71 & 31 & $\bar{M}$ \\
\hline November & 1990 & 3.89 & 11.92 & 14.70 & 30 & $\bar{M}$ \\
\hline December & 1990 & 3.79 & 11.63 & 14.35 & 31 & $\mathrm{M}$ \\
\hline January & 1991 & 7.63 & 23.43 & 28.90 & 31 & $\mathrm{M}$ \\
\hline February & 1991 & 7.22 & 22.15 & 27.32 & 28 & $\bar{M}$ \\
\hline March & 1991 & 5.65 & 17.33 & 21.37 & 31 & $\bar{M}$ \\
\hline April & 1991 & 5.57 & 17.08 & 21.07 & 30 & $\bar{M}$ \\
\hline May & 1991 & 6.35 & 19.49 & 24.03 & 31 & $\bar{M}$ \\
\hline
\end{tabular}


WW-4 Monthly Pumping Data

\begin{tabular}{|c|c|c|c|c|c|c|}
\hline June & 1991 & 6.42 & 19.71 & 24.30 & 30 & $\bar{M}$ \\
\hline July & 1991 & 5.77 & 17.70 & 21.83 & 31 & $\bar{M}$ \\
\hline August & 1991 & 4.37 & 13.42 & 16.55 & 31 & $\bar{M}$ \\
\hline September & 1991 & 4.95 & 15.19 & 18.73 & 30 & $\bar{M}$ \\
\hline October & 1991 & 5.71 & 17.53 & 21.63 & 31 & $\bar{M}$ \\
\hline November & 1991 & 5.48 & 16.82 & 20.74 & 30 & $\bar{M}$ \\
\hline December & 1991 & 5.55 & 17.04 & 21.02 & 31 & $\bar{M}$ \\
\hline January & 1992 & 3.89 & 11.93 & 14.71 & 31 & $\bar{M}$ \\
\hline February & 1992 & 5.50 & 16.88 & 20.82 & 29 & $\bar{M}$ \\
\hline March & 1992 & 5.90 & 18.09 & 22.31 & 31 & $\mathrm{M}$ \\
\hline April & 1992 & 7.18 & 22.02 & 27.16 & 30 & $M$ \\
\hline May & 1992 & 8.01 & 24.59 & 30.33 & 31 & $\bar{M}$ \\
\hline June & 1992 & 7.68 & 23.55 & 29.05 & 30 & $\bar{M}$ \\
\hline July & 1992 & 7.34 & 22.52 & 27.77 & 31 & $\bar{M}$ \\
\hline August & 1992 & 9.00 & 27.62 & 34.07 & 31 & $\bar{M}$ \\
\hline September & 1992 & 11.19 & 34.34 & 42.35 & 30 & $\bar{M}$ \\
\hline October & 1992 & 8.93 & 27.42 & 33.82 & 31 & $\bar{M}$ \\
\hline November & 1992 & 4.94 & 15.17 & 18.71 & 30 & $\bar{M}$ \\
\hline December & 1992 & 4.96 & 15.21 & 18.76 & 31 & $\bar{M}$ \\
\hline January & 1993 & 5.03 & 15.44 & 19.05 & 31 & $\bar{M}$ \\
\hline February & 1993 & 5.77 & 17.72 & 21.85 & 28 & $\bar{M}$ \\
\hline March & 1993 & 6.79 & 20.82 & 25.68 & 31 & $\bar{M}$ \\
\hline April & 1993 & 6.11 & 18.74 & 23.11 & 30 & $\bar{M}$ \\
\hline May & 1993 & 8.75 & 26.85 & 33.11 & 31 & $\bar{M}$ \\
\hline June & 1993 & 5.89 & 18.08 & 22.30 & 30 & $\bar{M}$ \\
\hline July & 1993 & 9.09 & 27.89 & 34.39 & 31 & $\bar{M}$ \\
\hline August & 1993 & 9.17 & 28.15 & 34.72 & 31 & $\bar{M}$ \\
\hline September & 1993 & 3.82 & 11.72 & 14.46 & 30 & $\bar{M}$ \\
\hline October & 1993 & 5.47 & 16.78 & 20.70 & 31 & $\bar{M}$ \\
\hline November & 1993 & 4.98 & 15.29 & 18.86 & 30 & $\bar{M}$ \\
\hline December & 1993 & 4.58 & 14.07 & 17.35 & 31 & $\bar{M}$ \\
\hline January & 1994 & 5.10 & 15.66 & 19.32 & 31 & $\bar{M}$ \\
\hline February & 1994 & 3.01 & 9.24 & 11.39 & 28 & $\bar{M}$ \\
\hline March & 1994 & 5.34 & 16.38 & 20.20 & 31 & $\bar{M}$ \\
\hline April & 1994 & 6.67 & 20.48 & 25.26 & 30 & $\bar{M}$ \\
\hline May & 1994 & 7.50 & 23.03 & 28.40 & 31 & $\bar{M}$ \\
\hline June & 1994 & 8.21 & 25.19 & 31.07 & 30 & $\bar{M}$ \\
\hline July & 1994 & 7.67 & 23.54 & 29.03 & 31 & $\bar{M}$ \\
\hline August & 1994 & 1.90 & 5.84 & 7.20 & 31 & $\bar{M}$ \\
\hline September & 1994 & 1.40 & 4.29 & 5.29 & 30 & $\bar{M}$ \\
\hline October & 1994 & 2.69 & 8.27 & 10.20 & 31 & $\bar{M}$ \\
\hline November & 1994 & 2.39 & 7.35 & 9.06 & 30 & $\bar{M}$ \\
\hline December & 1994 & 1.09 & 3.33 & 4.11 & 31 & $M$ \\
\hline January & 1995 & 0.61 & 1.86 & 2.29 & 31 & $M$ \\
\hline February & 1995 & 0.48 & 1.46 & 1.80 & 28 & $\bar{M}$ \\
\hline March & 1995 & 0.53 & 1.61 & 1.99 & 31 & $\mathrm{M}$ \\
\hline April & 1995 & 0.84 & 2.58 & 3.18 & 30 & $\mathrm{M}$ \\
\hline May & 1995 & 0.44 & 1.34 & 1.65 & 31 & $\bar{M}$ \\
\hline June & 1995 & 0.53 & 1.61 & 1.99 & 30 & $\bar{M}$ \\
\hline July & 1995 & 2.18 & 6.67 & 8.23 & 31 & $\bar{M}$ \\
\hline August & 1995 & 4.97 & 15.26 & 18.83 & 31 & $\bar{M}$ \\
\hline September & 1995 & 1.78 & 5.48 & 6.75 & 30 & $\bar{M}$ \\
\hline
\end{tabular}


WW-4 Monthly Pumping Data

\begin{tabular}{|c|c|c|c|c|c|c|}
\hline October & 1995 & 0.58 & 1.79 & 2.21 & 31 & $\bar{M}$ \\
\hline November & 1995 & 0.90 & 2.75 & 3.39 & 30 & $\bar{M}$ \\
\hline December & 1995 & 2.41 & 7.40 & 9.13 & 31 & M \\
\hline January & 1996 & 2.71 & 8.30 & 10.24 & 31 & $\mathrm{M}$ \\
\hline February & 1996 & 2.16 & 6.63 & 8.18 & 29 & $\bar{M}$ \\
\hline March & 1996 & 1.14 & 3.50 & 4.32 & 31 & $\bar{M}$ \\
\hline April & 1996 & 0.86 & 2.63 & 3.24 & 30 & $\bar{M}$ \\
\hline May & 1996 & 2.79 & 8.55 & 10.55 & 31 & $\bar{M}$ \\
\hline June & 1996 & 1.22 & 3.74 & 4.61 & 30 & $M$ \\
\hline July & 1996 & 0.12 & 0.36 & 0.44 & 31 & $\bar{M}$ \\
\hline August & 1996 & 1.39 & 4.27 & 5.26 & 31 & M \\
\hline September & 1996 & 1.33 & 4.07 & 5.01 & 30 & $\bar{M}$ \\
\hline October & 1996 & 0.34 & 1.05 & 1.30 & 31 & $\bar{M}$ \\
\hline November & 1996 & 0.83 & 2.53 & 3.12 & 30 & $\bar{M}$ \\
\hline December & 1996 & 0.63 & 1.94 & 2.40 & 31 & $\mathrm{M}$ \\
\hline January & 1997 & 0.58 & 1.77 & 2.18 & 31 & $\mathrm{M}$ \\
\hline February & 1997 & 0.56 & 1.72 & 2.13 & 28 & $\bar{M}$ \\
\hline March & 1997 & 0.62 & 1.89 & 2.33 & 31 & $\bar{M}$ \\
\hline April & 1997 & 0.58 & 1.77 & 2.18 & 30 & $\bar{M}$ \\
\hline May & 1997 & 1.46 & 4.46 & 5.51 & 31 & $\bar{M}$ \\
\hline June & 1997 & 1.20 & 3.67 & 4.52 & 30 & $\bar{M}$ \\
\hline July & 1997 & 1.44 & 4.42 & 5.45 & 31 & $\bar{M}$ \\
\hline August & 1997 & 1.84 & 5.64 & 6.95 & 31 & $\bar{M}$ \\
\hline September & 1997 & 1.57 & 4.82 & 5.94 & 30 & $\bar{M}$ \\
\hline October & 1997 & 1.40 & 4.28 & 5.28 & 31 & $\bar{M}$ \\
\hline November & 1997 & 1.22 & 3.74 & 4.61 & 30 & $\bar{M}$ \\
\hline December & 1997 & 1.65 & 5.07 & 6.25 & 31 & $\bar{M}$ \\
\hline January & 1998 & 1.41 & 4.33 & 5.35 & 31 & $\mathrm{M}$ \\
\hline February & 1998 & 0.78 & 2.39 & 2.95 & 28 & M \\
\hline March & 1998 & 0.82 & 2.51 & 3.09 & 31 & $\bar{M}$ \\
\hline April & 1998 & 1.12 & 3.43 & 4.23 & 30 & $\bar{M}$ \\
\hline May & 1998 & 0.62 & 1.91 & 2.35 & 31 & $\bar{M}$ \\
\hline June & 1998 & 1.23 & 3.77 & 4.65 & 30 & $\bar{M}$ \\
\hline July & 1998 & 1.27 & 3.90 & 4.81 & 31 & $\bar{M}$ \\
\hline August & 1998 & 1.52 & 4.66 & 5.75 & 31 & $\mathrm{M}$ \\
\hline September & 1998 & 0.93 & 2.85 & 3.52 & 30 & $\bar{M}$ \\
\hline October & 1998 & 1.92 & 5.89 & 7.26 & 31 & $\bar{M}$ \\
\hline November & 1998 & 0.58 & 1.76 & 2.18 & 30 & $\bar{M}$ \\
\hline December & 1998 & 0.51 & 1.57 & 1.94 & 31 & $\mathrm{M}$ \\
\hline January & 1999 & 0.60 & 1.84 & 2.27 & 31 & $\mathrm{M}$ \\
\hline February & 1999 & 0.57 & 1.76 & 2.17 & 28 & $\bar{M}$ \\
\hline March & 1999 & 0.95 & 2.90 & 3.57 & 31 & $\mathrm{M}$ \\
\hline April & 1999 & 1.88 & 5.77 & 7.11 & 30 & $\bar{M}$ \\
\hline May & 1999 & 2.63 & 8.06 & 9.94 & 31 & $\bar{M}$ \\
\hline June & 1999 & 1.05 & 3.22 & 3.97 & 30 & $\mathrm{M}$ \\
\hline July & 1999 & 0.20 & 0.60 & 0.74 & 31 & $\bar{M}$ \\
\hline August & 1999 & 0.00 & 0.00 & 0.00 & 31 & $\mathrm{M}$ \\
\hline September & 1999 & 0.18 & 0.56 & 0.69 & 30 & $\mathrm{M}$ \\
\hline October & 1999 & 0.22 & 0.66 & 0.82 & 31 & $\bar{M}$ \\
\hline November & 1999 & 0.18 & 0.55 & 0.68 & 30 & $\bar{M}$ \\
\hline December & 1999 & 0.00 & 0.00 & 0.00 & 31 & $\bar{M}$ \\
\hline January & 2000 & 0.00 & 0.00 & 0.00 & 31 & $\mathrm{M}$ \\
\hline
\end{tabular}


WW-4 Monthly Pumping Data

\begin{tabular}{|c|c|c|c|c|c|c|}
\hline February & 2000 & 0.09 & 0.29 & 0.36 & 29 & $\bar{M}$ \\
\hline March & 2000 & 0.58 & 1.79 & 2.21 & 31 & $\bar{M}$ \\
\hline April & 2000 & 1.35 & 4.13 & 5.09 & 30 & $\bar{M}$ \\
\hline May & 2000 & 1.12 & 3.45 & 4.26 & 31 & $\bar{M}$ \\
\hline June & 2000 & 0.69 & 2.12 & 2.61 & 30 & $\bar{M}$ \\
\hline July & 2000 & 0.71 & 2.19 & 2.70 & 31 & $\mathrm{M}$ \\
\hline August & 2000 & 1.26 & 3.87 & 4.77 & 31 & $\bar{M}$ \\
\hline September & 2000 & 1.08 & 3.32 & 4.10 & 30 & $\bar{M}$ \\
\hline October & 2000 & 1.10 & 3.39 & 4.18 & 31 & $\bar{M}$ \\
\hline November & 2000 & 1.26 & 3.87 & 4.77 & 30 & $\bar{M}$ \\
\hline December & 2000 & 0.71 & 2.18 & 2.69 & 31 & $\bar{M}$ \\
\hline January & 2001 & 0.77 & 2.36 & 2.91 & 31 & $\bar{M}$ \\
\hline February & 2001 & 1.43 & 4.38 & 5.40 & 28 & $\mathrm{M}$ \\
\hline March & 2001 & 1.84 & 5.64 & 6.95 & 31 & $\bar{M}$ \\
\hline April & 2001 & 1.52 & 4.67 & 5.76 & 30 & $\bar{M}$ \\
\hline May & 2001 & 2.39 & 7.34 & 9.06 & 31 & $\bar{M}$ \\
\hline June & 2001 & 3.33 & 10.21 & 12.60 & 30 & $\bar{M}$ \\
\hline July & 2001 & 3.04 & 9.32 & 11.49 & 31 & $\mathrm{M}$ \\
\hline August & 2001 & 1.38 & 4.24 & 5.22 & 31 & $\bar{M}$ \\
\hline September & 2001 & 1.57 & 4.83 & 5.96 & 30 & $\bar{M}$ \\
\hline October & 2001 & 2.00 & 6.13 & 7.56 & 31 & $\bar{M}$ \\
\hline November & 2001 & 1.21 & 3.71 & 4.57 & 30 & $\bar{M}$ \\
\hline December & 2001 & 0.49 & 1.50 & 1.85 & 31 & $\bar{M}$ \\
\hline January & 2002 & 0.88 & 2.70 & 3.33 & 31 & $\bar{M}$ \\
\hline February & 2002 & 1.57 & 4.81 & 5.93 & 28 & $\mathrm{M}$ \\
\hline March & 2002 & 0.30 & 0.92 & 1.13 & 31 & $\bar{M}$ \\
\hline April & 2002 & 0.55 & 1.70 & 2.09 & 30 & $\bar{M}$ \\
\hline May & 2002 & 0.99 & 3.04 & 3.75 & 31 & $\bar{M}$ \\
\hline June & 2002 & 1.02 & 3.12 & 3.85 & 30 & $\mathrm{M}$ \\
\hline July & 2002 & 1.09 & 3.35 & 4.13 & 31 & $\mathrm{M}$ \\
\hline August & 2002 & 2.40 & 7.36 & 9.08 & 31 & $\bar{M}$ \\
\hline September & 2002 & 2.97 & 9.12 & 11.25 & 30 & $\bar{M}$ \\
\hline October & 2002 & 3.54 & 10.86 & 13.39 & 31 & $\bar{M}$ \\
\hline November & 2002 & 2.68 & 8.21 & 10.13 & 30 & $\bar{M}$ \\
\hline December & 2002 & 1.78 & 5.46 & 6.74 & 31 & $\bar{M}$ \\
\hline January & 2003 & 2.27 & 6.95 & 8.58 & 31 & $\mathrm{M}$ \\
\hline February & 2003 & 0.13 & 0.39 & 0.49 & 28 & $\mathrm{M}$ \\
\hline March & 2003 & 1.23 & 3.77 & 4.64 & 31 & $\bar{M}$ \\
\hline April & 2003 & 2.18 & 6.70 & 8.27 & 30 & $\bar{M}$ \\
\hline May & 2003 & 1.98 & 6.08 & 7.50 & 31 & $\bar{M}$ \\
\hline June & 2003 & 3.66 & 11.24 & 13.87 & 30 & $\mathrm{M}$ \\
\hline July & 2003 & 3.63 & 11.13 & 13.73 & 31 & $\mathrm{M}$ \\
\hline August & 2003 & 3.76 & 11.53 & 14.22 & 31 & $\mathrm{M}$ \\
\hline September & 2003 & 3.42 & 10.48 & 12.93 & 30 & $\bar{M}$ \\
\hline October & 2003 & 2.93 & 8.99 & 11.09 & 31 & $\bar{M}$ \\
\hline November & 2003 & 1.72 & 5.27 & 6.50 & 30 & $\bar{M}$ \\
\hline December & 2003 & 0.18 & 0.54 & 0.66 & 31 & $\bar{M}$ \\
\hline
\end{tabular}

aSource: $\mathrm{E}=$ Taken from Bechtel or REECo water production reports and includes estimated values. $\mathrm{M}=$ Taken from Bechtel or REECo water production reports. 
WW-4A Monthly Pumping Data

\begin{tabular}{|c|c|c|c|c|c|c|}
\hline Month & Year & $\begin{array}{l}\text { Million } \\
\text { Gallons }\end{array}$ & Acre-Ft & $\begin{array}{c}\text { Million } \\
\text { Liters }\end{array}$ & $\begin{array}{c}\text { Days } \\
\text { Reported }\end{array}$ & Source $^{a}$ \\
\hline December & 1993 & 0.21 & 0.65 & 0.80 & 31 & $M$ \\
\hline January & 1994 & 0.00 & 0.00 & 0.00 & 31 & $\mathrm{M}$ \\
\hline February & 1994 & 0.00 & 0.00 & 0.00 & 28 & $\mathrm{M}$ \\
\hline March & 1994 & 0.00 & 0.00 & 0.00 & 31 & $\mathrm{M}$ \\
\hline April & 1994 & 0.00 & 0.00 & 0.00 & 30 & $\mathrm{M}$ \\
\hline May & 1994 & 0.29 & 0.90 & 1.11 & 31 & $\mathrm{M}$ \\
\hline \begin{tabular}{|l|} 
June \\
\end{tabular} & 1994 & 0.00 & 0.00 & 0.00 & 30 & $\bar{M}$ \\
\hline July & 1994 & 1.30 & 3.98 & 4.91 & 31 & $M$ \\
\hline August & 1994 & 6.92 & 21.25 & 26.21 & 31 & $\mathrm{M}$ \\
\hline September & 1994 & 4.74 & 14.54 & 17.93 & 30 & $\mathrm{M}$ \\
\hline October & 1994 & 3.78 & 11.61 & 14.32 & 31 & $\mathrm{M}$ \\
\hline November & 1994 & 1.57 & 4.81 & 5.93 & 30 & $\mathrm{M}$ \\
\hline December & 1994 & 2.90 & 8.89 & 10.97 & 31 & $\mathrm{M}$ \\
\hline January & 1995 & 2.47 & 7.57 & 9.34 & 31 & $M$ \\
\hline February & 1995 & 3.17 & 9.73 & 12.01 & 28 & $\mathrm{M}$ \\
\hline March & 1995 & 2.95 & 9.07 & 11.18 & 31 & $\mathrm{M}$ \\
\hline April & 1995 & 3.78 & 11.59 & 14.30 & 30 & $\mathrm{M}$ \\
\hline May & 1995 & 3.56 & 10.93 & 13.48 & 31 & $\mathrm{M}$ \\
\hline \begin{tabular}{|l|} 
June \\
\end{tabular} & 1995 & 3.58 & 10.97 & 13.53 & 30 & $\bar{M}$ \\
\hline July & 1995 & 1.31 & 4.03 & 4.97 & 31 & $M$ \\
\hline August & 1995 & 1.81 & 5.55 & 6.84 & 31 & $\mathrm{M}$ \\
\hline September & 1995 & 3.67 & 11.26 & 13.88 & 30 & $\bar{M}$ \\
\hline October & 1995 & 2.29 & 7.01 & 8.65 & 31 & $\mathrm{M}$ \\
\hline November & 1995 & 0.03 & 0.09 & 0.12 & 30 & $\mathrm{M}$ \\
\hline December & 1995 & 2.27 & 6.97 & 8.59 & 31 & $\mathrm{M}$ \\
\hline January & 1996 & 1.89 & 5.81 & 7.16 & 31 & $M$ \\
\hline February & 1996 & 1.92 & 5.88 & 7.26 & 29 & $\mathrm{M}$ \\
\hline March & 1996 & 1.79 & 5.48 & 6.76 & 31 & $M$ \\
\hline April & 1996 & 1.01 & 3.09 & 3.81 & 30 & $\mathrm{M}$ \\
\hline May & 1996 & 0.87 & 2.68 & 3.31 & 31 & $\mathrm{M}$ \\
\hline June & 1996 & 3.96 & 12.16 & 15.00 & 30 & $\bar{M}$ \\
\hline July & 1996 & 4.18 & 12.83 & 15.82 & 31 & $M$ \\
\hline August & 1996 & 3.29 & 10.08 & 12.44 & 31 & $\mathrm{M}$ \\
\hline September & 1996 & 4.02 & 12.33 & 15.20 & 30 & $\bar{M}$ \\
\hline October & 1996 & 3.83 & 11.74 & 14.48 & 31 & $\mathrm{M}$ \\
\hline November & 1996 & 3.15 & 9.65 & 11.90 & 30 & $\mathrm{M}$ \\
\hline December & 1996 & 2.31 & 7.09 & 8.75 & 31 & $\bar{M}$ \\
\hline January & 1997 & 2.32 & 7.13 & 8.79 & 31 & $M$ \\
\hline February & 1997 & 2.41 & 7.39 & 9.11 & 28 & $\mathrm{M}$ \\
\hline March & 1997 & 3.21 & 9.85 & 12.15 & 31 & $\mathrm{M}$ \\
\hline April & 1997 & 3.43 & 10.51 & 12.96 & 30 & $\mathrm{M}$ \\
\hline May & 1997 & 3.84 & 11.78 & 14.53 & 31 & $\mathrm{M}$ \\
\hline \begin{tabular}{|l|} 
June \\
\end{tabular} & 1997 & 4.08 & 12.51 & 15.42 & 30 & $\bar{M}$ \\
\hline July & 1997 & 4.18 & 12.82 & 15.81 & 31 & $M$ \\
\hline August & 1997 & 4.95 & 15.19 & 18.73 & 31 & $\mathrm{M}$ \\
\hline September & 1997 & 3.74 & 11.46 & 14.14 & 30 & $\bar{M}$ \\
\hline October & 1997 & 4.10 & 12.58 & 15.52 & 31 & $M$ \\
\hline November & 1997 & 4.55 & 13.97 & 17.23 & 30 & $\bar{M}$ \\
\hline December & 1997 & 5.25 & 16.11 & 19.87 & 31 & $\mathrm{M}$ \\
\hline
\end{tabular}


WW-4A Monthly Pumping Data

\begin{tabular}{|c|c|c|c|c|c|c|}
\hline January & 1998 & 2.97 & 9.11 & 11.23 & 31 & $\bar{M}$ \\
\hline February & 1998 & 3.29 & 10.10 & 12.45 & 28 & $\bar{M}$ \\
\hline \begin{tabular}{|l|l} 
March \\
\end{tabular} & 1998 & 3.49 & 10.72 & 13.22 & 31 & $\bar{M}$ \\
\hline April & 1998 & 2.64 & 8.09 & 9.98 & 30 & $\bar{M}$ \\
\hline May & 1998 & 10.88 & 33.38 & 41.18 & 31 & $\mathrm{M}$ \\
\hline June & 1998 & 9.28 & 28.48 & 35.13 & 30 & $\mathrm{M}$ \\
\hline July & 1998 & 4.09 & 12.55 & 15.48 & 31 & $\bar{M}$ \\
\hline August & 1998 & 5.36 & 16.44 & 20.28 & 31 & $\bar{M}$ \\
\hline September & 1998 & 3.58 & 10.98 & 13.55 & 30 & $\bar{M}$ \\
\hline October & 1998 & 3.55 & 10.88 & 13.42 & 31 & $\bar{M}$ \\
\hline November & 1998 & 3.38 & 10.36 & 12.77 & 30 & $\bar{M}$ \\
\hline December & 1998 & 2.68 & 8.22 & 10.14 & 31 & $\bar{M}$ \\
\hline January & 1999 & 4.03 & 12.38 & 15.26 & 31 & $\bar{M}$ \\
\hline February & 1999 & 3.56 & 10.92 & 13.46 & 28 & $\bar{M}$ \\
\hline March & 1999 & 4.75 & 14.58 & 17.98 & 31 & $\bar{M}$ \\
\hline April & 1999 & 3.71 & 11.38 & 14.04 & 30 & $\bar{M}$ \\
\hline May & 1999 & 5.00 & 15.34 & 18.92 & 31 & $\bar{M}$ \\
\hline \begin{tabular}{|l|} 
June \\
\end{tabular} & 1999 & 4.15 & 12.72 & 15.69 & 30 & $\bar{M}$ \\
\hline July & 1999 & 5.04 & 15.47 & 19.08 & 31 & $\mathrm{M}$ \\
\hline August & 1999 & 5.24 & 16.09 & 19.84 & 31 & $\bar{M}$ \\
\hline September & 1999 & 4.96 & 15.22 & 18.77 & 30 & $\bar{M}$ \\
\hline October & 1999 & 4.37 & 13.40 & 16.53 & 31 & $\bar{M}$ \\
\hline November & 1999 & 3.46 & 10.60 & 13.08 & 30 & $\bar{M}$ \\
\hline December & 1999 & 5.74 & 17.60 & 21.71 & 31 & $\bar{M}$ \\
\hline January & 2000 & 5.99 & 18.37 & 22.66 & 31 & $\bar{A}$ \\
\hline February & 2000 & 5.19 & 15.94 & 19.66 & 29 & $\bar{M}$ \\
\hline March & 2000 & 6.76 & 20.73 & 25.57 & 31 & $\bar{M}$ \\
\hline April & 2000 & 6.96 & 21.36 & 26.34 & 30 & $\bar{M}$ \\
\hline May & 2000 & 7.96 & 24.42 & 30.12 & 31 & $\bar{M}$ \\
\hline \begin{tabular}{|l|} 
June \\
\end{tabular} & 2000 & 8.28 & 25.40 & 31.32 & 30 & $\bar{M}$ \\
\hline July & 2000 & 5.53 & 16.97 & 20.94 & 31 & $\mathrm{M}$ \\
\hline August & 2000 & 4.60 & 14.11 & 17.40 & 31 & $\bar{M}$ \\
\hline September & 2000 & 3.90 & 11.97 & 14.77 & 30 & $\bar{M}$ \\
\hline October & 2000 & 3.23 & 9.93 & 12.24 & 31 & $\bar{M}$ \\
\hline November & 2000 & 3.83 & 11.75 & 14.49 & 30 & $\bar{M}$ \\
\hline December & 2000 & 5.68 & 17.42 & 21.49 & 31 & $\bar{M}$ \\
\hline January & 2001 & 3.18 & 9.76 & 12.03 & 31 & $\bar{M}$ \\
\hline February & 2001 & 3.79 & 11.64 & 14.36 & 28 & $\bar{M}$ \\
\hline March & 2001 & 3.89 & 11.95 & 14.74 & 31 & $\bar{M}$ \\
\hline April & 2001 & 2.54 & 7.81 & 9.63 & 30 & $\bar{M}$ \\
\hline May & 2001 & 4.16 & 12.77 & 15.75 & 31 & $\bar{M}$ \\
\hline June & 2001 & 4.45 & 13.67 & 16.86 & 30 & $\bar{M}$ \\
\hline July & 2001 & 9.34 & 28.67 & 35.37 & 31 & $\mathrm{M}$ \\
\hline August & 2001 & 7.02 & 21.54 & 26.56 & 31 & $\bar{M}$ \\
\hline September & 2001 & 4.63 & 14.22 & 17.53 & 30 & $\bar{M}$ \\
\hline October & 2001 & 3.68 & 11.29 & 13.93 & 31 & $\bar{M}$ \\
\hline November & 2001 & 3.39 & 10.39 & 12.82 & 30 & $\bar{M}$ \\
\hline December & 2001 & 4.09 & 12.56 & 15.49 & 31 & $\bar{M}$ \\
\hline January & 2002 & 5.16 & 15.84 & 19.54 & 31 & $\bar{M}$ \\
\hline February & 2002 & 5.86 & 17.99 & 22.19 & 28 & $\bar{M}$ \\
\hline March & 2002 & 5.56 & 17.05 & 21.03 & 31 & $\bar{M}$ \\
\hline April & 2002 & 4.46 & 13.69 & 16.89 & 30 & $\mathrm{M}$ \\
\hline
\end{tabular}


WW-4A Monthly Pumping Data

\begin{tabular}{|l|c|c|c|c|c|c|}
\hline May & 2002 & 5.15 & 15.79 & 19.48 & 31 & $\mathrm{M}$ \\
\hline June & 2002 & 6.03 & 18.52 & 22.84 & 30 & $\mathrm{M}$ \\
\hline July & 2002 & 7.89 & 24.20 & 29.86 & 31 & $\mathrm{M}$ \\
\hline August & 2002 & 8.39 & 25.76 & 31.77 & 31 & $\mathrm{M}$ \\
\hline September & 2002 & 6.67 & 20.46 & 25.24 & 30 & $\mathrm{M}$ \\
\hline October & 2002 & 5.68 & 17.44 & 21.51 & 31 & $\mathrm{M}$ \\
\hline November & 2002 & 5.79 & 17.78 & 21.93 & 30 & $\mathrm{M}$ \\
\hline December & 2002 & 4.87 & 14.94 & 18.42 & 31 & $\mathrm{M}$ \\
\hline January & 2003 & 6.68 & 20.50 & 25.28 & 31 & $\mathrm{M}$ \\
\hline February & 2003 & 6.93 & 21.26 & 26.22 & 28 & $\mathrm{M}$ \\
\hline March & 2003 & 6.03 & 18.51 & 22.83 & 31 & $\mathrm{M}$ \\
\hline April & 2003 & 4.31 & 13.23 & 16.32 & 30 & $\mathrm{M}$ \\
\hline May & 2003 & 5.39 & 16.55 & 20.41 & 31 & $\mathrm{M}$ \\
\hline June & 2003 & 6.89 & 21.13 & 26.07 & 30 & $\mathrm{M}$ \\
\hline July & 2003 & 6.05 & 18.56 & 22.89 & 31 & $\mathrm{M}$ \\
\hline August & 2003 & 6.06 & 18.60 & 22.94 & 31 & $\mathrm{M}$ \\
\hline September & 2003 & 6.78 & 20.81 & 25.67 & 30 & $\mathrm{M}$ \\
\hline October & 2003 & 5.84 & 17.94 & 22.12 & 31 & $\mathrm{M}$ \\
\hline November & 2003 & 5.66 & 17.35 & 21.41 & 30 & $\mathrm{M}$ \\
\hline December & 2003 & 4.38 & 13.45 & 16.59 & 31 & $\mathrm{M}$ \\
\hline
\end{tabular}

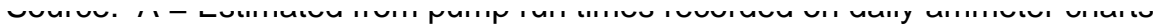

supplied by Bechtel, Nevada (Bechtel) or Reynolds Electrical and Engineering

Company (REECo).

$M=$ Taken from Bechtel or REECo water production reports. 


\begin{tabular}{|c|c|c|c|c|c|c|c|}
\hline Month & Year & $\begin{array}{l}\text { Million } \\
\text { Gallons }\end{array}$ & Acre-Ft & $\begin{array}{l}\text { Million } \\
\text { Liters }\end{array}$ & $\begin{array}{c}\text { Days } \\
\text { Reported }\end{array}$ & Source $^{a}$ & Comment \\
\hline March & 1951 & 0.97 & 2.98 & 3.67 & 365 & Z & estimated \\
\hline April & 1951 & 0.97 & 2.98 & 3.67 & 365 & Z & estimated \\
\hline May & 1951 & 0.97 & 2.98 & 3.67 & 365 & Z & estimated \\
\hline June & 1951 & 0.97 & 2.98 & 3.67 & 365 & $\bar{Z}$ & estimated \\
\hline July & 1951 & 0.97 & 2.98 & 3.67 & 365 & $\bar{Z}$ & estimated \\
\hline August & 1951 & 0.97 & 2.98 & 3.67 & 365 & $\bar{Z}$ & estimated \\
\hline September & 1951 & 0.97 & 2.98 & 3.67 & 365 & $\bar{Z}$ & estimated \\
\hline October & 1951 & 0.97 & 2.98 & 3.67 & 365 & $\bar{Z}$ & estimated \\
\hline November & 1951 & 0.97 & 2.98 & 3.67 & 365 & $Z$ & estimated \\
\hline December & 1951 & 0.97 & 2.98 & 3.67 & 365 & Z & estimated \\
\hline January & 1952 & 0.81 & 2.48 & 3.06 & 366 & $\bar{Z}$ & estimated \\
\hline February & 1952 & 0.81 & 2.48 & 3.06 & 366 & $\bar{Z}$ & estimated \\
\hline March & 1952 & 0.81 & 2.48 & 3.06 & 366 & $\bar{Z}$ & estimated \\
\hline April & 1952 & 0.81 & 2.48 & 3.06 & 366 & Z & estimated \\
\hline May & 1952 & 0.81 & 2.48 & 3.06 & 366 & Z & estimated \\
\hline June & 1952 & 0.81 & 2.48 & 3.06 & 366 & $\bar{Z}$ & estimated \\
\hline July & 1952 & 0.81 & 2.48 & 3.06 & 366 & $\bar{Z}$ & estimated \\
\hline August & 1952 & 0.81 & 2.48 & 3.06 & 366 & $\bar{Z}$ & estimated \\
\hline September & 1952 & 0.81 & 2.48 & 3.06 & 366 & $\bar{Z}$ & estimated \\
\hline October & 1952 & 0.81 & 2.48 & 3.06 & 366 & $\bar{Z}$ & estimated \\
\hline November & 1952 & 0.81 & 2.48 & 3.06 & 366 & $\bar{Z}$ & estimated \\
\hline December & 1952 & 0.81 & 2.48 & 3.06 & 366 & $\bar{Z}$ & estimated \\
\hline January & 1953 & 0.81 & 2.48 & 3.06 & 365 & $\bar{Z}$ & estimated \\
\hline February & 1953 & 0.81 & 2.48 & 3.06 & 365 & $\bar{Z}$ & estimated \\
\hline March & 1953 & 0.81 & 2.48 & 3.06 & 365 & $\bar{Z}$ & estimated \\
\hline April & 1953 & 0.81 & 2.48 & 3.06 & 365 & $\bar{Z}$ & estimated \\
\hline May & 1953 & 0.81 & 2.48 & 3.06 & 365 & $Z$ & estimated \\
\hline June & 1953 & 0.81 & 2.48 & 3.06 & 365 & $\bar{Z}$ & estimated \\
\hline July & 1953 & 0.81 & 2.48 & 3.06 & 365 & $\bar{Z}$ & estimated \\
\hline August & 1953 & 0.81 & 2.48 & 3.06 & 365 & $\bar{Z}$ & estimated \\
\hline September & 1953 & 0.81 & 2.48 & 3.06 & 365 & $\bar{Z}$ & estimated \\
\hline October & 1953 & 0.81 & 2.48 & 3.06 & 365 & $\bar{Z}$ & estimated \\
\hline November & 1953 & 0.81 & 2.48 & 3.06 & 365 & $\bar{Z}$ & estimated \\
\hline December & 1953 & 0.81 & 2.48 & 3.06 & 365 & $\bar{Z}$ & estimated \\
\hline January & 1954 & 0.81 & 2.48 & 3.06 & 365 & $\bar{Z}$ & estimated \\
\hline February & 1954 & 0.81 & 2.48 & 3.06 & 365 & $\bar{Z}$ & estimated \\
\hline March & 1954 & 0.81 & 2.48 & 3.06 & 365 & $\bar{Z}$ & estimated \\
\hline April & 1954 & 0.81 & 2.48 & 3.06 & 365 & $Z$ & estimated \\
\hline May & 1954 & 0.81 & 2.48 & 3.06 & 365 & $Z$ & estimated \\
\hline June & 1954 & 0.81 & 2.48 & 3.06 & 365 & $\bar{Z}$ & estimated \\
\hline July & 1954 & 0.81 & 2.48 & 3.06 & 365 & $\bar{Z}$ & estimated \\
\hline August & 1954 & 0.81 & 2.48 & 3.06 & 365 & $\bar{Z}$ & estimated \\
\hline September & 1954 & 0.81 & 2.48 & 3.06 & 365 & $\bar{Z}$ & estimated \\
\hline October & 1954 & 0.81 & 2.48 & 3.06 & 365 & $\bar{Z}$ & estimated \\
\hline November & 1954 & 0.81 & 2.48 & 3.06 & 365 & $\bar{Z}$ & estimated \\
\hline December & 1954 & 0.81 & 2.48 & 3.06 & 365 & $\bar{Z}$ & estimated \\
\hline January & 1955 & 0.81 & 2.48 & 3.06 & 365 & $\bar{Z}$ & estimated \\
\hline February & 1955 & 0.81 & 2.48 & 3.06 & 365 & $\bar{Z}$ & estimated \\
\hline March & 1955 & 0.81 & 2.48 & 3.06 & 365 & $\bar{Z}$ & estimated \\
\hline
\end{tabular}




\begin{tabular}{|c|c|c|c|c|c|c|c|}
\hline April & 1955 & 0.81 & 2.48 & 3.06 & 365 & Z & estimated \\
\hline May & 1955 & 0.81 & 2.48 & 3.06 & 365 & $\bar{Z}$ & estimated \\
\hline June & 1955 & 0.81 & 2.48 & 3.06 & 365 & Z & estimated \\
\hline July & 1955 & 0.81 & 2.48 & 3.06 & 365 & $\bar{Z}$ & estimated \\
\hline August & 1955 & 0.81 & 2.48 & 3.06 & 365 & $Z$ & estimated \\
\hline September & 1955 & 0.81 & 2.48 & 3.06 & 365 & $Z$ & estimated \\
\hline October & 1955 & 0.81 & 2.48 & 3.06 & 365 & Z & estimated \\
\hline November & 1955 & 0.81 & 2.48 & 3.06 & 365 & $\bar{Z}$ & estimated \\
\hline December & 1955 & 0.81 & 2.48 & 3.06 & 365 & $Z$ & estimated \\
\hline January & 1956 & 0.81 & 2.48 & 3.06 & 366 & $\bar{Z}$ & estimated \\
\hline February & 1956 & 0.81 & 2.48 & 3.06 & 366 & $\mathrm{Z}$ & estimated \\
\hline March & 1956 & 0.81 & 2.48 & 3.06 & 366 & Z & estimated \\
\hline April & 1956 & 0.81 & 2.48 & 3.06 & 366 & $\bar{Z}$ & estimated \\
\hline May & 1956 & 0.81 & 2.48 & 3.06 & 366 & $\bar{Z}$ & estimated \\
\hline June & 1956 & 0.81 & 2.48 & 3.06 & 366 & Z & estimated \\
\hline July & 1956 & 0.81 & 2.48 & 3.06 & 366 & Z & estimated \\
\hline August & 1956 & 0.81 & 2.48 & 3.06 & 366 & 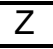 & estimated \\
\hline September & 1956 & 0.81 & 2.48 & 3.06 & 366 & $Z$ & estimated \\
\hline October & 1956 & 0.81 & 2.48 & 3.06 & 366 & $\bar{Z}$ & estimated \\
\hline November & 1956 & 0.81 & 2.48 & 3.06 & 366 & $\bar{Z}$ & estimated \\
\hline December & 1956 & 0.81 & 2.48 & 3.06 & 366 & Z & estimated \\
\hline January & 1957 & 0.81 & 2.48 & 3.06 & 365 & $\bar{Z}$ & estimated \\
\hline February & 1957 & 0.81 & 2.48 & 3.06 & 365 & $Z$ & estimated \\
\hline March & 1957 & 0.81 & 2.48 & 3.06 & 365 & $\bar{Z}$ & estimated \\
\hline April & 1957 & 0.81 & 2.48 & 3.06 & 365 & $\bar{Z}$ & estimated \\
\hline May & 1957 & 0.81 & 2.48 & 3.06 & 365 & $\bar{Z}$ & estimated \\
\hline June & 1957 & 0.81 & 2.48 & 3.06 & 365 & Z & estimated \\
\hline July & 1957 & 0.81 & 2.48 & 3.06 & 365 & Z & estimated \\
\hline August & 1957 & 0.81 & 2.48 & 3.06 & 365 & 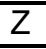 & estimated \\
\hline September & 1957 & 0.81 & 2.48 & 3.06 & 365 & $Z$ & estimated \\
\hline October & 1957 & 0.81 & 2.48 & 3.06 & 365 & Z & estimated \\
\hline November & 1957 & 0.81 & 2.48 & 3.06 & 365 & $\bar{Z}$ & estimated \\
\hline December & 1957 & 0.81 & 2.48 & 3.06 & 365 & $Z$ & estimated \\
\hline \begin{tabular}{|l|} 
January \\
\end{tabular} & 1958 & 0.37 & 1.12 & 1.39 & 365 & $\mathrm{R}$ & estimated \\
\hline February & 1958 & 0.37 & 1.12 & 1.39 & 365 & $\mathrm{R}$ & estimated \\
\hline \begin{tabular}{|l|} 
March \\
\end{tabular} & 1958 & 0.37 & 1.12 & 1.39 & 365 & $\mathrm{R}$ & estimated \\
\hline April & 1958 & 0.37 & 1.12 & 1.39 & 365 & $\bar{R}$ & estimated \\
\hline May & 1958 & 0.37 & 1.12 & 1.39 & 365 & $\bar{R}$ & estimated \\
\hline June & 1958 & 0.37 & 1.12 & 1.39 & 365 & $\mathrm{R}$ & estimated \\
\hline July & 1958 & 0.37 & 1.12 & 1.39 & 365 & $\mathrm{R}$ & estimated \\
\hline August & 1958 & 0.37 & 1.12 & 1.39 & 365 & $R$ & estimated \\
\hline September & 1958 & 1.66 & 5.09 & 6.28 & 30 & $M$ & -- \\
\hline October & 1958 & 1.90 & 5.82 & 7.18 & 31 & $M$ & -- \\
\hline November & 1958 & 0.70 & 2.14 & 2.64 & 30 & $\bar{M}$ & -- \\
\hline December & 1958 & 0.02 & 0.05 & 0.06 & 31 & $\bar{M}$ & $\overline{--}$ \\
\hline January & 1959 & 0.59 & 1.82 & 2.25 & 31 & $M$ & -- \\
\hline February & 1959 & 0.87 & 2.65 & 3.27 & 28 & $\bar{M}$ & -- \\
\hline March & 1959 & 0.89 & 2.74 & 3.38 & 31 & $\mathrm{M}$ & -- \\
\hline April & 1959 & 0.91 & 2.79 & 3.44 & 30 & $\bar{M}$ & -- \\
\hline May & 1959 & 0.69 & 2.11 & 2.60 & 31 & $\bar{M}$ & -- \\
\hline June & 1959 & 1.01 & 3.09 & 3.81 & 30 & $\mathrm{M}$ & -- \\
\hline July & 1959 & 0.00 & 0.00 & 0.00 & 31 & $\mathrm{M}$ & -- \\
\hline
\end{tabular}


WW-5A Monthly Pumping Data

\begin{tabular}{|c|c|c|c|c|c|c|c|}
\hline August & 1959 & 1.01 & 3.10 & 3.82 & 31 & $\bar{M}$ & -- \\
\hline September & 1959 & 1.15 & 3.52 & 4.34 & 30 & $\bar{M}$ & -- \\
\hline October & 1959 & 0.45 & 1.36 & 1.68 & 31 & $\mathrm{M}$ & -- \\
\hline November & 1959 & 0.70 & 2.16 & 2.66 & 30 & $\mathrm{M}$ & -- \\
\hline December & 1959 & 0.56 & 1.72 & 2.12 & 31 & $\mathrm{M}$ & -- \\
\hline January & 1960 & 0.42 & 1.29 & 1.59 & 31 & $\bar{M}$ & -- \\
\hline February & 1960 & 0.42 & 1.27 & 1.57 & 29 & $\mathrm{M}$ & -- \\
\hline March & 1960 & 0.43 & 1.31 & 1.62 & 31 & $\bar{M}$ & -- \\
\hline April & 1960 & 0.41 & 1.26 & 1.55 & 30 & $\bar{M}$ & -- \\
\hline May & 1960 & 0.52 & 1.60 & 1.98 & 31 & $\bar{M}$ & -- \\
\hline June & 1960 & 0.73 & 2.24 & 2.77 & 30 & $\bar{M}$ & -- \\
\hline July & 1960 & 1.50 & 4.60 & 5.67 & 31 & $M$ & -- \\
\hline August & 1960 & 1.90 & 5.82 & 7.18 & 31 & $\bar{M}$ & -- \\
\hline September & 1960 & 1.98 & 6.09 & 7.51 & 30 & $\bar{M}$ & -- \\
\hline October & 1960 & 2.18 & 6.69 & 8.25 & 31 & $\bar{M}$ & -- \\
\hline November & 1960 & 1.19 & 3.64 & 4.49 & 30 & $\mathrm{M}$ & -- \\
\hline December & 1960 & 1.04 & 3.18 & 3.92 & 31 & $\mathrm{M}$ & -- \\
\hline January & 1961 & 1.30 & 3.98 & 4.91 & 31 & $\bar{M}$ & -- \\
\hline February & 1961 & 1.26 & 3.86 & 4.76 & 28 & $M$ & -- \\
\hline March & 1961 & 1.41 & 4.32 & 5.33 & 31 & $\bar{M}$ & -- \\
\hline April & 1961 & 1.67 & 5.11 & 6.31 & 30 & $\bar{M}$ & -- \\
\hline May & 1961 & 0.71 & 2.16 & 2.67 & 31 & $M$ & -- \\
\hline June & 1961 & 1.28 & 3.92 & 4.84 & 30 & $\mathrm{M}$ & -- \\
\hline July & 1961 & 1.50 & 4.59 & 5.66 & 31 & $\bar{M}$ & -- \\
\hline August & 1961 & 1.51 & 4.64 & 5.73 & 31 & $\bar{M}$ & -- \\
\hline September & 1961 & 1.27 & 3.90 & 4.81 & 30 & $\bar{M}$ & -- \\
\hline October & 1961 & 2.26 & 6.93 & 8.54 & 31 & $\bar{M}$ & $\overline{--}$ \\
\hline November & 1961 & 2.78 & 8.53 & 10.52 & 30 & $\mathrm{M}$ & -- \\
\hline December & 1961 & 2.62 & 8.03 & 9.90 & 31 & $\bar{M}$ & -- \\
\hline January & 1962 & 2.88 & 8.84 & 10.90 & 31 & $\bar{M}$ & -- \\
\hline February & 1962 & 2.54 & 7.79 & 9.61 & 28 & $M$ & -- \\
\hline March & 1962 & 3.60 & 11.03 & 13.61 & 31 & $\bar{M}$ & -- \\
\hline April & 1962 & 4.07 & 12.49 & 15.41 & 30 & $\bar{M}$ & - \\
\hline May & 1962 & 4.25 & 13.05 & 16.09 & 31 & $M$ & -- \\
\hline June & 1962 & 3.32 & 10.18 & 12.56 & 30 & $\bar{M}$ & -- \\
\hline July & 1962 & 3.11 & 9.53 & 11.75 & 31 & $\bar{M}$ & -- \\
\hline August & 1962 & 2.81 & 8.61 & 10.62 & 31 & $\bar{M}$ & -- \\
\hline September & 1962 & 1.98 & 6.08 & 7.50 & 30 & $\bar{M}$ & -- \\
\hline October & 1962 & 1.66 & 5.09 & 6.28 & 31 & $\bar{M}$ & - \\
\hline November & 1962 & 2.18 & 6.69 & 8.25 & 30 & $\mathrm{M}$ & -- \\
\hline December & 1962 & 1.98 & 6.06 & 7.48 & 31 & $\mathrm{M}$ & -- \\
\hline January & 1963 & 1.89 & 5.80 & 7.16 & 31 & $M$ & -- \\
\hline February & 1963 & 1.58 & 4.85 & 5.98 & 28 & $M$ & -- \\
\hline March & 1963 & 1.84 & 5.65 & 6.97 & 31 & $\bar{M}$ & -- \\
\hline April & 1963 & 1.76 & 5.41 & 6.67 & 30 & $\bar{M}$ & - \\
\hline May & 1963 & 2.60 & 7.98 & 9.84 & 31 & $M$ & -- \\
\hline June & 1963 & 2.40 & 7.35 & 9.06 & 30 & $M$ & -- \\
\hline July & 1963 & 2.40 & 7.36 & 9.07 & 31 & M & -- \\
\hline August & 1963 & 2.62 & 8.03 & 9.90 & 31 & $M$ & -- \\
\hline September & 1963 & 1.83 & 5.63 & 6.94 & 30 & $M$ & -- \\
\hline October & 1963 & 2.02 & 6.20 & 7.64 & 31 & $\mathrm{M}$ & - \\
\hline November & 1963 & 1.61 & 4.94 & 6.10 & 30 & $\bar{M}$ & $\overline{--}$ \\
\hline
\end{tabular}




\begin{tabular}{|c|c|c|c|c|c|c|c|}
\hline December & 1963 & 1.70 & 5.20 & 6.41 & 31 & $\mathrm{M}$ & -- \\
\hline January & 1964 & 1.75 & 5.38 & 6.63 & 31 & $\bar{M}$ & $\overline{--}$ \\
\hline February & 1964 & 1.63 & 5.01 & 6.18 & 29 & $\bar{M}$ & -- \\
\hline March & 1964 & 1.73 & 5.30 & 6.53 & 31 & $\bar{M}$ & -- \\
\hline April & 1964 & 1.97 & 6.03 & 7.44 & 30 & $\mathrm{M}$ & -- \\
\hline May & 1964 & 2.36 & 7.23 & 8.91 & 31 & $M$ & -- \\
\hline June & 1964 & 2.38 & 7.29 & 9.00 & 30 & $\bar{M}$ & -- \\
\hline July & 1964 & 2.56 & 7.85 & 9.68 & 31 & $M$ & -- \\
\hline August & 1964 & 1.80 & 5.52 & 6.80 & 31 & $\bar{M}$ & $\overline{--}$ \\
\hline September & 1964 & 1.18 & 3.61 & 4.45 & 30 & $\bar{M}$ & $\overline{--}$ \\
\hline October & 1964 & 0.76 & 2.32 & 2.86 & 31 & $\bar{M}$ & -- \\
\hline November & 1964 & 0.82 & 2.51 & 3.09 & 30 & $\mathrm{M}$ & -- \\
\hline December & 1964 & 0.99 & 3.04 & 3.75 & 31 & $M$ & -- \\
\hline January & 1965 & 1.60 & 4.91 & 6.05 & 31 & $M$ & -- \\
\hline February & 1965 & 0.30 & 0.91 & 1.12 & 28 & $\bar{M}$ & -- \\
\hline March & 1965 & 0.46 & 1.40 & 1.72 & 31 & $\bar{M}$ & -- \\
\hline April & 1965 & 0.53 & 1.63 & 2.01 & 30 & $\mathrm{M}$ & -- \\
\hline May & 1965 & 0.23 & 0.71 & 0.88 & 31 & $M$ & -- \\
\hline June & 1965 & 0.67 & 2.06 & 2.54 & 30 & $M$ & -- \\
\hline July & 1965 & 1.10 & 3.37 & 4.16 & 31 & $M$ & -- \\
\hline August & 1965 & 0.03 & 0.10 & 0.12 & 31 & $\bar{M}$ & $\overline{--}$ \\
\hline September & 1965 & 0.31 & 0.95 & 1.17 & 26 & $\bar{M}$ & $\overline{--}$ \\
\hline October & 1965 & -- & -- & -- & 0 & 1 & -- \\
\hline November & 1965 & 1.18 & 3.62 & 4.46 & 29 & $\bar{M}$ & -- \\
\hline December & 1965 & 1.38 & 4.23 & 5.21 & 31 & $M$ & -- \\
\hline January & 1966 & 2.61 & 8.02 & 9.90 & 31 & $M$ & -- \\
\hline February & 1966 & 1.01 & 3.09 & 3.81 & 28 & $\bar{M}$ & -- \\
\hline March & 1966 & 1.20 & 3.69 & 4.55 & 31 & $\bar{M}$ & $\overline{--}$ \\
\hline April & 1966 & 1.74 & 5.33 & 6.58 & 30 & $\mathrm{M}$ & -- \\
\hline May & 1966 & 1.30 & 3.99 & 4.92 & 29 & $M$ & -- \\
\hline June & 1966 & -- & -- & -- & 0 & 1 & -- \\
\hline July & 1966 & -- & -- & -- & 0 & 1 & -- \\
\hline August & 1966 & 0.35 & 1.07 & 1.32 & 28 & $\bar{M}$ & $\overline{--}$ \\
\hline September & 1966 & 0.18 & 0.54 & 0.67 & 5 & $\bar{M}$ & $\overline{--}$ \\
\hline October & 1966 & 1.62 & 4.96 & 6.12 & 31 & $M$ & -- \\
\hline November & 1966 & 1.37 & 4.20 & 5.17 & 30 & $\mathrm{M}$ & -- \\
\hline December & 1966 & 0.74 & 2.28 & 2.81 & 31 & $M$ & -- \\
\hline January & 1967 & 1.64 & 5.02 & 6.19 & 31 & $M$ & -- \\
\hline February & 1967 & 1.11 & 3.41 & 4.20 & 28 & $\bar{M}$ & -- \\
\hline March & 1967 & 1.49 & 4.57 & 5.63 & 31 & $\mathrm{M}$ & -- \\
\hline April & 1967 & 0.84 & 2.56 & 3.16 & 30 & $\mathrm{M}$ & -- \\
\hline May & 1967 & 0.09 & 0.29 & 0.36 & 31 & $M$ & -- \\
\hline June & 1967 & 0.26 & 0.79 & 0.97 & 30 & $M$ & -- \\
\hline July & 1967 & 1.86 & 5.69 & 7.02 & 365 & $\mathrm{R}$ & estimated \\
\hline August & 1967 & 1.86 & 5.69 & 7.02 & 365 & $\mathrm{R}$ & estimated \\
\hline September & 1967 & 1.86 & 5.69 & 7.02 & 365 & $\mathrm{R}$ & estimated \\
\hline October & 1967 & 1.86 & 5.69 & 7.02 & 365 & $\mathrm{R}$ & estimated \\
\hline November & 1967 & 1.86 & 5.69 & 7.02 & 365 & $\mathrm{R}$ & estimated \\
\hline December & 1967 & 1.86 & 5.69 & 7.02 & 365 & $\mathrm{R}$ & estimated \\
\hline January & 1968 & 1.35 & 4.14 & 5.11 & 366 & $R$ & estimated \\
\hline February & 1968 & 1.35 & 4.14 & 5.11 & 366 & $\mathrm{R}$ & estimated \\
\hline March & 1968 & 1.35 & 4.14 & 5.11 & 366 & $\bar{R}$ & estimated \\
\hline
\end{tabular}




\begin{tabular}{|l|l|l|l|l|l|l|l|}
\hline April & 1968 & 1.35 & 4.14 & 5.11 & 366 & $\mathrm{R}$ & estimated \\
\hline May & 1968 & 1.35 & 4.14 & 5.11 & 366 & $\mathrm{R}$ & estimated \\
\hline June & 1968 & 1.35 & 4.14 & 5.11 & 366 & $\mathrm{R}$ & estimated \\
\hline July & 1968 & 1.35 & 4.14 & 5.11 & 366 & $\mathrm{R}$ & estimated \\
\hline August & 1968 & 1.35 & 4.14 & 5.11 & 366 & $\mathrm{R}$ & estimated \\
\hline September & 1968 & 1.35 & 4.14 & 5.11 & 366 & $\mathrm{R}$ & estimated \\
\hline October & 1968 & 1.35 & 4.14 & 5.11 & 366 & $\mathrm{R}$ & estimated \\
\hline November & 1968 & 1.35 & 4.14 & 5.11 & 366 & $\mathrm{R}$ & estimated \\
\hline December & 1968 & 1.35 & 4.14 & 5.11 & 366 & $\mathrm{R}$ & estimated \\
\hline January & 1969 & 0.48 & 1.46 & 1.80 & 365 & $\mathrm{R}$ & estimated \\
\hline February & 1969 & 0.48 & 1.46 & 1.80 & 365 & $\mathrm{R}$ & estimated \\
\hline March & 1969 & 0.48 & 1.46 & 1.80 & 365 & $\mathrm{R}$ & estimated \\
\hline April & 1969 & 0.48 & 1.46 & 1.80 & 365 & $\mathrm{R}$ & estimated \\
\hline May & 1969 & 0.48 & 1.46 & 1.80 & 365 & $\mathrm{R}$ & estimated \\
\hline June & 1969 & 0.48 & 1.46 & 1.80 & 365 & $\mathrm{R}$ & estimated \\
\hline July & 1969 & 0.48 & 1.46 & 1.80 & 365 & $\mathrm{R}$ & estimated \\
\hline August & 1969 & 0.48 & 1.46 & 1.80 & 365 & $\mathrm{R}$ & estimated \\
\hline September & 1969 & 0.48 & 1.46 & 1.80 & 365 & $\mathrm{R}$ & estimated \\
\hline October & 1969 & 0.48 & 1.46 & 1.80 & 365 & $\mathrm{R}$ & estimated \\
\hline November & 1969 & 0.48 & 1.46 & 1.80 & 365 & $\mathrm{R}$ & estimated \\
\hline December & 1969 & 0.48 & 1.46 & 1.80 & 365 & $\mathrm{R}$ & estimated \\
\hline January & 1970 & 0.29 & 0.89 & 1.10 & 365 & $\mathrm{R}$ & estimated \\
\hline February & 1970 & 0.29 & 0.89 & 1.10 & 365 & $\mathrm{R}$ & estimated \\
\hline March & 1970 & 0.29 & 0.89 & 1.10 & 365 & $\mathrm{R}$ & estimated \\
\hline April & 1970 & 0.29 & 0.89 & 1.10 & 365 & $\mathrm{R}$ & estimated \\
\hline May & 1970 & 0.29 & 0.89 & 1.10 & 365 & $\mathrm{R}$ & estimated \\
\hline June & 1970 & 0.29 & 0.89 & 1.10 & 365 & $\mathrm{R}$ & estimated \\
\hline July & 1970 & 0.29 & 0.89 & 1.10 & 365 & $\mathrm{R}$ & estimated \\
\hline August & 1970 & 0.29 & 0.89 & 1.10 & 365 & $\mathrm{R}$ & estimated \\
\hline September & 1970 & 0.29 & 0.89 & 1.10 & 365 & $\mathrm{R}$ & estimated \\
\hline October & 1970 & 0.29 & 0.89 & 1.10 & 365 & $\mathrm{R}$ & estimated \\
\hline November & 1970 & 0.29 & 0.89 & 1.10 & 365 & $\mathrm{R}$ & estimated \\
\hline December & 1970 & 0.29 & 0.89 & 1.10 & 365 & $\mathrm{R}$ & estimated \\
\hline
\end{tabular}

aSource: I = Insufficient or no data to calculate monthly total; no water may have been withdrawn for month. $M=$ Taken from Bechtel or REECo water production reports.

$\mathrm{R}=$ Insufficient data to determine monthly value. Annual value listed in annual data set as reported in [Claassen, H.C., 1973, Water quality and physical characteristics of Nevada Test Site water-supply wells: U.S. Geological Survey Open-File Report USGS-474-158, 145 p.].

$Z=$ Insufficient data to determine monthly value . Annual value listed in annual data set as estimated in [Claassen, H.C., 1973, Water quality and physical characteristics of Nevada Test Site water-supply wells: U.S. Geological Survey OpenFile Report USGS-474-158, 145 p.].

${ }^{b}$ estimated indicates monthly value was estimated from yearly total 
WW-5B Monthly Pumping Data

\begin{tabular}{|c|c|c|c|c|c|c|c|}
\hline Month & Year & $\begin{array}{c}\text { Million } \\
\text { Gallons }\end{array}$ & Acre-Ft & $\begin{array}{l}\text { Million } \\
\text { Liters }\end{array}$ & $\begin{array}{c}\text { Days } \\
\text { Reported }\end{array}$ & Source $^{a}$ & Comment $^{b}$ \\
\hline May & 1951 & 2.54 & 7.79 & 9.60 & 365 & $Z$ & estimated \\
\hline June & 1951 & 2.54 & 7.79 & 9.60 & 365 & $\bar{Z}$ & estimated \\
\hline July & 1951 & 2.54 & 7.79 & 9.60 & 365 & Z & estimated \\
\hline August & 1951 & 2.54 & 7.79 & 9.60 & 365 & $\bar{Z}$ & estimated \\
\hline September & 1951 & 2.54 & 7.79 & 9.60 & 365 & Z & estimated \\
\hline October & 1951 & 2.54 & 7.79 & 9.60 & 365 & $\bar{Z}$ & estimated \\
\hline November & 1951 & 2.54 & 7.79 & 9.60 & 365 & $\bar{Z}$ & estimated \\
\hline December & 1951 & 2.54 & 7.79 & 9.60 & 365 & $\bar{Z}$ & estimated \\
\hline January & 1952 & 1.69 & 5.19 & 6.40 & 366 & $\bar{Z}$ & estimated \\
\hline February & 1952 & 1.69 & 5.19 & 6.40 & 366 & $\bar{Z}$ & estimated \\
\hline March & 1952 & 1.69 & 5.19 & 6.40 & 366 & $\bar{Z}$ & estimated \\
\hline April & 1952 & 1.69 & 5.19 & 6.40 & 366 & $\bar{Z}$ & estimated \\
\hline May & 1952 & 1.69 & 5.19 & 6.40 & 366 & $\bar{Z}$ & estimated \\
\hline June & 1952 & 1.69 & 5.19 & 6.40 & 366 & Z & estimated \\
\hline July & 1952 & 1.69 & 5.19 & 6.40 & 366 & $\bar{Z}$ & estimated \\
\hline August & 1952 & 1.69 & 5.19 & 6.40 & 366 & $\bar{Z}$ & estimated \\
\hline September & 1952 & 1.69 & 5.19 & 6.40 & 366 & Z & estimated \\
\hline October & 1952 & 1.69 & 5.19 & 6.40 & 366 & $\bar{Z}$ & estimated \\
\hline November & 1952 & 1.69 & 5.19 & 6.40 & 366 & $\bar{Z}$ & estimated \\
\hline December & 1952 & 1.69 & 5.19 & 6.40 & 366 & $\bar{Z}$ & estimated \\
\hline January & 1953 & 1.69 & 5.19 & 6.40 & 365 & $\bar{Z}$ & estimated \\
\hline February & 1953 & 1.69 & 5.19 & 6.40 & 365 & $\bar{Z}$ & estimated \\
\hline March & 1953 & 1.69 & 5.19 & 6.40 & 365 & $\bar{Z}$ & estimated \\
\hline April & 1953 & 1.69 & 5.19 & 6.40 & 365 & $\bar{Z}$ & estimated \\
\hline May & 1953 & 1.69 & 5.19 & 6.40 & 365 & $\bar{Z}$ & estimated \\
\hline June & 1953 & 1.69 & 5.19 & 6.40 & 365 & $\bar{Z}$ & estimated \\
\hline July & 1953 & 1.69 & 5.19 & 6.40 & 365 & $\bar{Z}$ & estimated \\
\hline August & 1953 & 1.69 & 5.19 & 6.40 & 365 & $\bar{Z}$ & estimated \\
\hline September & 1953 & 1.69 & 5.19 & 6.40 & 365 & Z & estimated \\
\hline October & 1953 & 1.69 & 5.19 & 6.40 & 365 & $\bar{Z}$ & estimated \\
\hline November & 1953 & 1.69 & 5.19 & 6.40 & 365 & $\bar{Z}$ & estimated \\
\hline December & 1953 & 1.69 & 5.19 & 6.40 & 365 & $\bar{Z}$ & estimated \\
\hline January & 1954 & 1.69 & 5.19 & 6.40 & 365 & $Z$ & estimated \\
\hline February & 1954 & 1.69 & 5.19 & 6.40 & 365 & $\bar{Z}$ & estimated \\
\hline March & 1954 & 1.69 & 5.19 & 6.40 & 365 & $\bar{Z}$ & estimated \\
\hline April & 1954 & 1.69 & 5.19 & 6.40 & 365 & $\bar{Z}$ & estimated \\
\hline May & 1954 & 1.69 & 5.19 & 6.40 & 365 & $\bar{Z}$ & estimated \\
\hline June & 1954 & 1.69 & 5.19 & 6.40 & 365 & $\bar{Z}$ & estimated \\
\hline July & 1954 & 1.69 & 5.19 & 6.40 & 365 & $\bar{Z}$ & estimated \\
\hline August & 1954 & 1.69 & 5.19 & 6.40 & 365 & $\bar{Z}$ & estimated \\
\hline September & 1954 & 1.69 & 5.19 & 6.40 & 365 & Z & estimated \\
\hline October & 1954 & 1.69 & 5.19 & 6.40 & 365 & $\bar{Z}$ & estimated \\
\hline November & 1954 & 1.69 & 5.19 & 6.40 & 365 & $\bar{Z}$ & estimated \\
\hline December & 1954 & 1.69 & 5.19 & 6.40 & 365 & $\bar{Z}$ & estimated \\
\hline January & 1955 & 1.69 & 5.19 & 6.40 & 365 & $\bar{Z}$ & estimated \\
\hline February & 1955 & 1.69 & 5.19 & 6.40 & 365 & $\bar{Z}$ & estimated \\
\hline March & 1955 & 1.69 & 5.19 & 6.40 & 365 & $\bar{Z}$ & estimated \\
\hline April & 1955 & 1.69 & 5.19 & 6.40 & 365 & $\bar{Z}$ & estimated \\
\hline May & 1955 & 1.69 & 5.19 & 6.40 & 365 & $\bar{Z}$ & estimated \\
\hline
\end{tabular}


WW-5B Monthly Pumping Data

\begin{tabular}{|c|c|c|c|c|c|c|c|}
\hline June & 1955 & 1.69 & 5.19 & 6.40 & 365 & Z & estimated \\
\hline July & 1955 & 1.69 & 5.19 & 6.40 & 365 & $\bar{Z}$ & estimated \\
\hline August & 1955 & 1.69 & 5.19 & 6.40 & 365 & $\bar{Z}$ & estimated \\
\hline September & 1955 & 1.69 & 5.19 & 6.40 & 365 & $\bar{Z}$ & estimated \\
\hline October & 1955 & 1.69 & 5.19 & 6.40 & 365 & Z & estimated \\
\hline November & 1955 & 1.69 & 5.19 & 6.40 & 365 & $Z$ & estimated \\
\hline December & 1955 & 1.69 & 5.19 & 6.40 & 365 & Z & estimated \\
\hline January & 1956 & 1.69 & 5.19 & 6.40 & 366 & Z & estimated \\
\hline February & 1956 & 1.69 & 5.19 & 6.40 & 366 & $\bar{Z}$ & estimated \\
\hline March & 1956 & 1.69 & 5.19 & 6.40 & 366 & $\bar{Z}$ & estimated \\
\hline April & 1956 & 1.69 & 5.19 & 6.40 & 366 & $\mathrm{Z}$ & estimated \\
\hline May & 1956 & 1.69 & 5.19 & 6.40 & 366 & $\bar{Z}$ & estimated \\
\hline June & 1956 & 1.69 & 5.19 & 6.40 & 366 & Z & estimated \\
\hline July & 1956 & 1.69 & 5.19 & 6.40 & 366 & $\bar{Z}$ & estimated \\
\hline August & 1956 & 1.69 & 5.19 & 6.40 & 366 & Z & estimated \\
\hline September & 1956 & 1.69 & 5.19 & 6.40 & 366 & $\bar{Z}$ & estimated \\
\hline October & 1956 & 1.69 & 5.19 & 6.40 & 366 & Z & estimated \\
\hline November & 1956 & 1.69 & 5.19 & 6.40 & 366 & Z & estimated \\
\hline December & 1956 & 1.69 & 5.19 & 6.40 & 366 & Z & estimated \\
\hline January & 1957 & 1.69 & 5.19 & 6.40 & 365 & Z & estimated \\
\hline February & 1957 & 1.69 & 5.19 & 6.40 & 365 & $Z$ & estimated \\
\hline March & 1957 & 1.69 & 5.19 & 6.40 & 365 & $\bar{Z}$ & estimated \\
\hline April & 1957 & 1.69 & 5.19 & 6.40 & 365 & $\mathrm{Z}$ & estimated \\
\hline May & 1957 & 1.69 & 5.19 & 6.40 & 365 & Z & estimated \\
\hline June & 1957 & 1.69 & 5.19 & 6.40 & 365 & Z & estimated \\
\hline July & 1957 & 1.69 & 5.19 & 6.40 & 365 & $\bar{Z}$ & estimated \\
\hline August & 1957 & 1.69 & 5.19 & 6.40 & $\overline{365}$ & Z & estimated \\
\hline September & 1957 & 1.69 & 5.19 & 6.40 & 365 & $\bar{Z}$ & estimated \\
\hline October & 1957 & 1.69 & 5.19 & 6.40 & 365 & $\mathrm{Z}$ & estimated \\
\hline November & 1957 & 1.69 & 5.19 & 6.40 & 365 & $Z$ & estimated \\
\hline December & 1957 & 1.69 & 5.19 & 6.40 & 365 & Z & estimated \\
\hline January & 1958 & 2.10 & 6.45 & 7.96 & 365 & $\mathrm{R}$ & estimated \\
\hline February & 1958 & 2.10 & 6.45 & 7.96 & 365 & $\bar{R}$ & estimated \\
\hline March & 1958 & 2.10 & 6.45 & 7.96 & 365 & $\mathrm{R}$ & estimated \\
\hline April & 1958 & 2.10 & 6.45 & 7.96 & 365 & $R$ & estimated \\
\hline May & 1958 & 2.10 & 6.45 & 7.96 & 365 & $\mathrm{R}$ & estimated \\
\hline June & 1958 & 2.10 & 6.45 & 7.96 & 365 & $\mathrm{R}$ & estimated \\
\hline July & 1958 & 2.10 & 6.45 & 7.96 & 365 & $\bar{R}$ & estimated \\
\hline August & 1958 & 2.10 & 6.45 & 7.96 & 365 & $\bar{R}$ & estimated \\
\hline September & 1958 & 1.66 & 5.09 & 6.28 & 30 & $\bar{M}$ & -- \\
\hline October & 1958 & 1.90 & 5.82 & 7.18 & 31 & $M$ & -- \\
\hline November & 1958 & 0.70 & 2.14 & 2.64 & 30 & $M$ & -- \\
\hline December & 1958 & 0.02 & 0.05 & 0.06 & 31 & $\bar{M}$ & -- \\
\hline January & 1959 & 0.59 & 1.82 & 2.25 & 31 & $M$ & -- \\
\hline February & 1959 & 0.87 & 2.65 & 3.27 & 28 & $\mathrm{M}$ & -- \\
\hline March & 1959 & 0.89 & 2.74 & 3.38 & 31 & $\bar{M}$ & -- \\
\hline April & 1959 & 0.91 & 2.79 & 3.44 & 30 & $M$ & -- \\
\hline May & 1959 & 0.69 & 2.11 & 2.60 & 31 & $M$ & -- \\
\hline June & 1959 & 1.01 & 3.09 & 3.81 & 30 & $M$ & -- \\
\hline July & 1959 & 0.00 & 0.00 & 0.00 & 31 & $\bar{M}$ & -- \\
\hline August & 1959 & 1.01 & 3.10 & 3.82 & 31 & $\bar{M}$ & $\overline{--}$ \\
\hline September & 1959 & 1.15 & 3.52 & 4.34 & 30 & $\bar{M}$ & $\overline{--}$ \\
\hline
\end{tabular}


WW-5B Monthly Pumping Data

\begin{tabular}{|c|c|c|c|c|c|c|c|}
\hline October & 1959 & 0.45 & 1.36 & 1.68 & 31 & $M$ & -- \\
\hline November & 1959 & 0.70 & 2.16 & 2.66 & 30 & $M$ & -- \\
\hline December & 1959 & 0.56 & 1.72 & 2.12 & 31 & $\mathrm{M}$ & -- \\
\hline January & 1960 & 0.42 & 1.29 & 1.59 & 31 & $M$ & -- \\
\hline February & 1960 & 0.42 & 1.27 & 1.57 & 29 & $M$ & -- \\
\hline March & 1960 & 0.43 & 1.31 & 1.62 & 31 & $M$ & -- \\
\hline April & 1960 & 0.41 & 1.26 & 1.55 & 30 & $M$ & -- \\
\hline May & 1960 & 0.52 & 1.60 & 1.98 & 31 & $M$ & -- \\
\hline June & 1960 & 0.73 & 2.24 & 2.77 & 30 & $M$ & -- \\
\hline July & 1960 & 1.50 & 4.60 & 5.67 & 31 & $M$ & -- \\
\hline August & 1960 & 1.90 & 5.82 & 7.18 & 31 & $M$ & -- \\
\hline September & 1960 & 1.98 & 6.09 & 7.51 & 30 & $M$ & -- \\
\hline October & 1960 & 2.18 & 6.69 & 8.25 & 31 & $\bar{M}$ & -- \\
\hline November & 1960 & 1.19 & 3.64 & 4.49 & 30 & M & -- \\
\hline December & 1960 & 1.04 & 3.18 & 3.92 & 31 & $\mathrm{M}$ & -- \\
\hline January & 1961 & 1.30 & 3.98 & 4.91 & 31 & $\mathrm{M}$ & -- \\
\hline February & 1961 & 1.26 & 3.86 & 4.76 & 28 & $M$ & -- \\
\hline March & 1961 & 1.41 & 4.32 & 5.33 & 31 & $M$ & -- \\
\hline April & 1961 & 1.67 & 5.11 & 6.31 & 30 & $M$ & -- \\
\hline May & 1961 & 0.71 & 2.16 & 2.67 & 31 & $M$ & -- \\
\hline June & 1961 & 1.28 & 3.92 & 4.84 & 30 & $\mathrm{M}$ & -- \\
\hline July & 1961 & 1.50 & 4.59 & 5.66 & 31 & $M$ & -- \\
\hline August & 1961 & 1.51 & 4.64 & 5.73 & 31 & $M$ & -- \\
\hline September & 1961 & 1.27 & 3.90 & 4.81 & 30 & $M$ & -- \\
\hline October & 1961 & 2.26 & 6.93 & 8.54 & 31 & $\mathrm{M}$ & -- \\
\hline November & 1961 & 2.78 & 8.53 & 10.52 & 30 & M & -- \\
\hline December & 1961 & 2.62 & 8.03 & 9.90 & 31 & $\mathrm{M}$ & -- \\
\hline January & 1962 & 2.88 & 8.84 & 10.90 & 31 & $\mathrm{M}$ & -- \\
\hline February & 1962 & 2.54 & 7.79 & 9.61 & 28 & $M$ & -- \\
\hline March & 1962 & 3.60 & 11.03 & 13.61 & 31 & $\mathrm{M}$ & -- \\
\hline April & 1962 & 4.07 & 12.49 & 15.41 & 30 & $M$ & - \\
\hline May & 1962 & 4.25 & 13.05 & 16.09 & 31 & $M$ & - \\
\hline June & 1962 & 3.32 & 10.18 & 12.56 & 30 & $M$ & - \\
\hline July & 1962 & 3.11 & 9.53 & 11.75 & 31 & $M$ & - \\
\hline August & 1962 & 2.81 & 8.61 & 10.62 & 31 & $M$ & - \\
\hline September & 1962 & 1.98 & 6.08 & 7.50 & 30 & $M$ & - \\
\hline October & 1962 & 1.66 & 5.09 & 6.28 & 31 & $\mathrm{M}$ & -- \\
\hline November & 1962 & 2.18 & 6.69 & 8.25 & 30 & M & -- \\
\hline December & 1962 & 1.98 & 6.06 & 7.48 & 31 & $M$ & - \\
\hline January & 1963 & 1.89 & 5.80 & 7.16 & 31 & $M$ & - \\
\hline February & 1963 & 1.58 & 4.85 & 5.98 & 28 & $M$ & - \\
\hline March & 1963 & 1.84 & 5.65 & 6.97 & 31 & $\mathrm{M}$ & - \\
\hline April & 1963 & 1.76 & 5.41 & 6.67 & 30 & $M$ & - \\
\hline May & 1963 & 2.60 & 7.98 & 9.84 & 31 & $M$ & - \\
\hline June & 1963 & 2.40 & 7.35 & 9.06 & 30 & $\mathrm{M}$ & - \\
\hline July & 1963 & 2.40 & 7.36 & 9.07 & 31 & $M$ & - \\
\hline August & 1963 & 2.62 & 8.03 & 9.90 & 31 & $M$ & - \\
\hline September & 1963 & 1.83 & 5.63 & 6.94 & 30 & $\mathrm{M}$ & - \\
\hline October & 1963 & 2.02 & 6.20 & 7.64 & 31 & $\mathrm{M}$ & - \\
\hline November & 1963 & 1.61 & 4.94 & 6.10 & 30 & M & -- \\
\hline December & 1963 & 1.70 & 5.20 & 6.41 & 31 & $\mathrm{M}$ & -- \\
\hline January & 1964 & 1.75 & 5.38 & 6.63 & 31 & $\mathrm{M}$ & - \\
\hline
\end{tabular}


WW-5B Monthly Pumping Data

\begin{tabular}{|c|c|c|c|c|c|c|c|}
\hline February & 1964 & 1.63 & 5.01 & 6.18 & 29 & $\bar{M}$ & -- \\
\hline March & 1964 & 1.73 & 5.30 & 6.53 & 31 & $\bar{M}$ & -- \\
\hline April & 1964 & 1.97 & 6.03 & 7.44 & 30 & $\bar{M}$ & -- \\
\hline May & 1964 & 2.36 & 7.23 & 8.91 & 31 & $\bar{M}$ & $\overline{--}$ \\
\hline June & 1964 & 2.38 & 7.29 & 9.00 & 30 & $\mathrm{M}$ & -- \\
\hline July & 1964 & 2.56 & 7.85 & 9.68 & 31 & $\bar{M}$ & -- \\
\hline August & 1964 & 1.80 & 5.52 & 6.80 & 31 & $\mathrm{M}$ & -- \\
\hline September & 1964 & 1.18 & 3.61 & 4.45 & 30 & $\bar{M}$ & -- \\
\hline October & 1964 & 0.76 & 2.32 & 2.86 & 31 & $\bar{M}$ & $\overline{--}$ \\
\hline November & 1964 & 0.82 & 2.51 & 3.09 & 30 & $\bar{M}$ & -- \\
\hline December & 1964 & 0.99 & 3.04 & 3.75 & 31 & $\bar{M}$ & -- \\
\hline January & 1965 & 1.60 & 4.91 & 6.05 & 31 & $M$ & -- \\
\hline February & 1965 & 0.30 & 0.91 & 1.12 & 28 & $\bar{M}$ & -- \\
\hline March & 1965 & 0.46 & 1.40 & 1.72 & 31 & $\bar{M}$ & -- \\
\hline April & 1965 & 0.53 & 1.63 & 2.01 & 30 & $\bar{M}$ & $\overline{--}$ \\
\hline May & 1965 & 0.23 & 0.71 & 0.88 & 31 & $\bar{M}$ & -- \\
\hline June & 1965 & 0.67 & 2.06 & 2.54 & 30 & $\mathrm{M}$ & -- \\
\hline July & 1965 & 1.10 & 3.37 & 4.16 & 31 & M & -- \\
\hline August & 1965 & 0.03 & 0.10 & 0.12 & 31 & $\mathrm{M}$ & -- \\
\hline September & 1965 & 0.31 & 0.95 & 1.17 & 26 & $\bar{M}$ & $\overline{--}$ \\
\hline October & 1965 & -- & -- & -- & 0 & $\mathrm{I}$ & $\overline{--}$ \\
\hline November & 1965 & 1.18 & 3.62 & 4.46 & 29 & $\bar{M}$ & $\overline{--}$ \\
\hline December & 1965 & 1.38 & 4.23 & 5.21 & 31 & $\bar{M}$ & -- \\
\hline January & 1966 & 2.61 & 8.02 & 9.90 & 31 & $\bar{M}$ & -- \\
\hline February & 1966 & 1.01 & 3.09 & 3.81 & 28 & $\bar{M}$ & -- \\
\hline March & 1966 & 1.20 & 3.69 & 4.55 & 31 & $\bar{M}$ & -- \\
\hline April & 1966 & 1.74 & 5.33 & 6.58 & 30 & $\bar{M}$ & -- \\
\hline May & 1966 & 1.30 & 3.99 & 4.92 & 29 & $\bar{M}$ & -- \\
\hline June & 1966 & -- & -- & -- & 0 & 1 & -- \\
\hline July & 1966 & -- & -- & -- & 0 & $\mathrm{I}$ & -- \\
\hline August & 1966 & 0.35 & 1.07 & 1.32 & 28 & $\mathrm{M}$ & -- \\
\hline September & 1966 & 0.18 & 0.54 & 0.67 & 5 & $\bar{M}$ & -- \\
\hline October & 1966 & 1.62 & 4.96 & 6.12 & 31 & $\bar{M}$ & -- \\
\hline November & 1966 & 1.37 & 4.20 & 5.17 & 30 & $\bar{M}$ & $\overline{--}$ \\
\hline December & 1966 & 0.74 & 2.28 & 2.81 & 31 & $\bar{M}$ & -- \\
\hline \begin{tabular}{|l|} 
January \\
\end{tabular} & 1967 & 1.64 & 5.02 & 6.19 & 31 & $\bar{M}$ & -- \\
\hline February & 1967 & 1.11 & 3.41 & 4.20 & 28 & $\mathrm{M}$ & -- \\
\hline March & 1967 & 1.49 & 4.57 & 5.63 & 31 & $\bar{M}$ & -- \\
\hline April & 1967 & 0.84 & 2.56 & 3.16 & 30 & $\bar{M}$ & -- \\
\hline May & 1967 & 0.09 & 0.29 & 0.36 & 31 & $\bar{M}$ & $\overline{--}$ \\
\hline \begin{tabular}{|l|} 
June \\
\end{tabular} & 1967 & 0.26 & 0.79 & 0.97 & 30 & $\bar{M}$ & - \\
\hline July & 1967 & 0.69 & 2.12 & 2.62 & 365 & $\mathrm{R}$ & estimated \\
\hline August & 1967 & 0.69 & 2.12 & 2.62 & 365 & $\mathrm{R}$ & estimated \\
\hline September & 1967 & 0.69 & 2.12 & 2.62 & 365 & $\mathrm{R}$ & estimated \\
\hline October & 1967 & 0.69 & 2.12 & 2.62 & 365 & $\mathrm{R}$ & estimated \\
\hline November & 1967 & 0.69 & 2.12 & 2.62 & 365 & $\mathrm{R}$ & estimated \\
\hline December & 1967 & 0.69 & 2.12 & 2.62 & 365 & $\mathrm{R}$ & estimated \\
\hline \begin{tabular}{|l|} 
January \\
\end{tabular} & 1968 & 0.87 & 2.66 & 3.28 & 366 & $\mathrm{R}$ & estimated \\
\hline February & 1968 & 0.87 & 2.66 & 3.28 & 366 & $\bar{R}$ & estimated \\
\hline March & 1968 & 0.87 & 2.66 & 3.28 & 366 & $\bar{R}$ & estimated \\
\hline April & 1968 & 0.87 & 2.66 & 3.28 & 366 & $\bar{R}$ & estimated \\
\hline May & 1968 & 0.87 & 2.66 & 3.28 & 366 & $\bar{R}$ & estimated \\
\hline
\end{tabular}


WW-5B Monthly Pumping Data

\begin{tabular}{|c|c|c|c|c|c|c|c|}
\hline June & 1968 & 0.87 & 2.66 & 3.28 & 366 & $\mathrm{R}$ & estimated \\
\hline \begin{tabular}{|l|} 
July \\
\end{tabular} & 1968 & 0.87 & 2.66 & 3.28 & 366 & $\overline{\mathrm{R}}$ & estimated \\
\hline August & 1968 & 0.87 & 2.66 & 3.28 & 366 & $\bar{R}$ & estimated \\
\hline September & 1968 & 0.87 & 2.66 & 3.28 & 366 & $\bar{R}$ & estimated \\
\hline October & 1968 & 0.87 & 2.66 & 3.28 & 366 & $\bar{R}$ & estimated \\
\hline November & 1968 & 0.87 & 2.66 & 3.28 & 366 & $\bar{R}$ & estimated \\
\hline December & 1968 & 0.87 & 2.66 & 3.28 & 366 & $\mathrm{R}$ & estimated \\
\hline January & 1969 & 0.57 & 1.74 & 2.14 & 365 & $\bar{R}$ & estimated \\
\hline February & 1969 & 0.57 & 1.74 & 2.14 & 365 & $\bar{R}$ & estimated \\
\hline March & 1969 & 0.57 & 1.74 & 2.14 & 365 & $\bar{R}$ & estimated \\
\hline April & 1969 & 0.57 & 1.74 & 2.14 & 365 & $\bar{R}$ & estimated \\
\hline May & 1969 & 0.57 & 1.74 & 2.14 & 365 & $\mathrm{R}$ & estimated \\
\hline June & 1969 & 0.57 & 1.74 & 2.14 & 365 & $\bar{R}$ & estimated \\
\hline July & 1969 & 0.57 & 1.74 & 2.14 & 365 & $\bar{R}$ & estimated \\
\hline August & 1969 & 0.57 & 1.74 & 2.14 & 365 & $\overline{\mathrm{R}}$ & estimated \\
\hline September & 1969 & 0.57 & 1.74 & 2.14 & 365 & $\overline{\mathrm{R}}$ & estimated \\
\hline October & 1969 & 0.57 & 1.74 & 2.14 & 365 & $\bar{R}$ & estimated \\
\hline November & 1969 & 0.57 & 1.74 & 2.14 & 365 & $\mathrm{R}$ & estimated \\
\hline December & 1969 & 0.57 & 1.74 & 2.14 & 365 & $\bar{R}$ & estimated \\
\hline January & 1970 & 1.97 & 6.03 & 7.44 & 365 & $\bar{R}$ & estimated \\
\hline February & 1970 & 1.97 & 6.03 & 7.44 & 365 & $\bar{R}$ & estimated \\
\hline March & 1970 & 1.97 & 6.03 & 7.44 & 365 & $\bar{R}$ & estimated \\
\hline April & 1970 & 1.97 & 6.03 & 7.44 & 365 & $\bar{R}$ & estimated \\
\hline May & 1970 & 1.97 & 6.03 & 7.44 & 365 & $\overline{\mathrm{R}}$ & estimated \\
\hline June & 1970 & 1.97 & 6.03 & 7.44 & 365 & $\bar{R}$ & estimated \\
\hline July & 1970 & 1.97 & 6.03 & 7.44 & 365 & $\bar{R}$ & estimated \\
\hline August & 1970 & 1.97 & 6.03 & 7.44 & 365 & $\overline{\mathrm{R}}$ & estimated \\
\hline September & 1970 & 1.97 & 6.03 & 7.44 & 365 & $\overline{\mathrm{R}}$ & estimated \\
\hline October & 1970 & 1.97 & 6.03 & 7.44 & 365 & $\bar{R}$ & estimated \\
\hline November & 1970 & 1.97 & 6.03 & 7.44 & 365 & $\bar{R}$ & estimated \\
\hline December & 1970 & 1.97 & 6.03 & 7.44 & 365 & $\mathrm{R}$ & estimated \\
\hline \begin{tabular}{|l|} 
January \\
\end{tabular} & 1971 & 0.68 & 2.07 & 2.55 & 365 & $\bar{R}$ & estimated \\
\hline February & 1971 & 0.68 & 2.07 & 2.55 & 365 & $\bar{R}$ & estimated \\
\hline March & 1971 & 0.68 & 2.07 & 2.55 & 365 & $\mathrm{R}$ & estimated \\
\hline April & 1971 & 0.68 & 2.07 & 2.55 & 365 & $\bar{R}$ & estimated \\
\hline May & 1971 & 0.68 & 2.07 & 2.55 & 365 & $\bar{R}$ & estimated \\
\hline \begin{tabular}{|l|} 
June \\
\end{tabular} & 1971 & 0.68 & 2.07 & 2.55 & 365 & $\bar{R}$ & estimated \\
\hline July & 1971 & 0.68 & 2.07 & 2.55 & 365 & $\bar{R}$ & estimated \\
\hline August & 1971 & 0.68 & 2.07 & 2.55 & 365 & $\overline{\mathrm{R}}$ & estimated \\
\hline September & 1971 & 0.68 & 2.07 & 2.55 & 365 & $\bar{R}$ & estimated \\
\hline October & 1971 & 0.68 & 2.07 & 2.55 & 365 & $\bar{R}$ & estimated \\
\hline November & 1971 & 0.68 & 2.07 & 2.55 & 365 & $\mathrm{R}$ & estimated \\
\hline December & 1971 & 0.68 & 2.07 & 2.55 & 365 & $\mathrm{R}$ & estimated \\
\hline January & 1972 & 1.47 & 4.50 & 5.55 & 366 & $\mathrm{H}$ & estimated \\
\hline February & 1972 & 1.47 & 4.50 & 5.55 & 366 & $\mathrm{H}$ & estimated \\
\hline \begin{tabular}{|l|} 
March \\
\end{tabular} & 1972 & 1.47 & 4.50 & 5.55 & 366 & $\mathrm{H}$ & estimated \\
\hline April & 1972 & 1.47 & 4.50 & 5.55 & 366 & $\mathrm{H}$ & estimated \\
\hline May & 1972 & 1.47 & 4.50 & 5.55 & 366 & $\overline{\mathrm{H}}$ & estimated \\
\hline June & 1972 & 1.47 & 4.50 & 5.55 & 366 & $\mathrm{H}$ & estimated \\
\hline July & 1972 & 1.47 & 4.50 & 5.55 & 366 & $\overline{\mathrm{H}}$ & estimated \\
\hline August & 1972 & 1.47 & 4.50 & 5.55 & 366 & $\overline{\mathrm{H}}$ & estimated \\
\hline September & 1972 & 1.47 & 4.50 & 5.55 & 366 & $\overline{\mathrm{H}}$ & estimated \\
\hline
\end{tabular}


WW-5B Monthly Pumping Data

\begin{tabular}{|c|c|c|c|c|c|c|c|}
\hline October & 1972 & 1.47 & 4.50 & 5.55 & 366 & $\mathrm{H}$ & estimated \\
\hline November & 1972 & 1.47 & 4.50 & 5.55 & 366 & $\overline{\mathrm{H}}$ & estimated \\
\hline December & 1972 & 1.47 & 4.50 & 5.55 & 366 & $\bar{H}$ & estimated \\
\hline January & 1973 & 1.36 & 4.17 & 5.14 & 365 & $\overline{\mathrm{H}}$ & estimated \\
\hline February & 1973 & 1.36 & 4.17 & 5.14 & 365 & $\mathrm{H}$ & estimated \\
\hline March & 1973 & 1.36 & 4.17 & 5.14 & 365 & $\overline{\mathrm{H}}$ & estimated \\
\hline April & 1973 & 1.36 & 4.17 & 5.14 & 365 & $\overline{\mathrm{H}}$ & estimated \\
\hline May & 1973 & 1.36 & 4.17 & 5.14 & 365 & $\overline{\mathrm{H}}$ & estimated \\
\hline \begin{tabular}{|l|} 
June \\
\end{tabular} & 1973 & 1.36 & 4.17 & 5.14 & 365 & $\bar{H}$ & estimated \\
\hline \begin{tabular}{|l|l|} 
July \\
\end{tabular} & 1973 & 1.36 & 4.17 & 5.14 & 365 & $\overline{\mathrm{H}}$ & estimated \\
\hline August & 1973 & 1.36 & 4.17 & 5.14 & 365 & $\bar{H}$ & estimated \\
\hline September & 1973 & 1.36 & 4.17 & 5.14 & 365 & $\overline{\mathrm{H}}$ & estimated \\
\hline October & 1973 & 1.36 & 4.17 & 5.14 & 365 & $\mathrm{H}$ & estimated \\
\hline November & 1973 & 1.36 & 4.17 & 5.14 & 365 & $\overline{\mathrm{H}}$ & estimated \\
\hline December & 1973 & 1.36 & 4.17 & 5.14 & 365 & $\overline{\mathrm{H}}$ & estimated \\
\hline \begin{tabular}{|l|} 
January \\
\end{tabular} & 1974 & 1.71 & 5.24 & 6.47 & 365 & $\overline{\mathrm{H}}$ & estimated \\
\hline February & 1974 & 1.71 & 5.24 & 6.47 & 365 & $\mathrm{H}$ & estimated \\
\hline March & 1974 & 1.71 & 5.24 & 6.47 & 365 & $\mathrm{H}$ & estimated \\
\hline April & 1974 & 1.71 & 5.24 & 6.47 & 365 & $\overline{\mathrm{H}}$ & estimated \\
\hline May & 1974 & 1.71 & 5.24 & 6.47 & 365 & $\mathrm{H}$ & estimated \\
\hline \begin{tabular}{|l|} 
June \\
\end{tabular} & 1974 & 1.71 & 5.24 & 6.47 & 365 & $\overline{\mathrm{H}}$ & estimated \\
\hline July & 1974 & 1.71 & 5.24 & 6.47 & 365 & $\mathrm{H}$ & estimated \\
\hline August & 1974 & 1.71 & 5.24 & 6.47 & 365 & $\mathrm{H}$ & estimated \\
\hline September & 1974 & 1.71 & 5.24 & 6.47 & 365 & $\overline{\mathrm{H}}$ & estimated \\
\hline October & 1974 & 1.71 & 5.24 & 6.47 & 365 & $\mathrm{H}$ & estimated \\
\hline November & 1974 & 1.71 & 5.24 & 6.47 & 365 & $\overline{\mathrm{H}}$ & estimated \\
\hline December & 1974 & 1.71 & 5.24 & 6.47 & 365 & $\overline{\mathrm{H}}$ & estimated \\
\hline January & 1975 & 1.88 & 5.75 & 7.10 & 365 & $\overline{\mathrm{H}}$ & estimated \\
\hline February & 1975 & 1.88 & 5.75 & 7.10 & 365 & $\mathrm{H}$ & estimated \\
\hline March & 1975 & 1.88 & 5.75 & 7.10 & 365 & $\mathrm{H}$ & estimated \\
\hline April & 1975 & 1.88 & 5.75 & 7.10 & 365 & $\overline{\mathrm{H}}$ & estimated \\
\hline May & 1975 & 1.88 & 5.75 & 7.10 & 365 & $\overline{\mathrm{H}}$ & estimated \\
\hline June & 1975 & 1.88 & 5.75 & 7.10 & 365 & $\overline{\mathrm{H}}$ & estimated \\
\hline \begin{tabular}{|l|} 
July \\
\end{tabular} & 1975 & 1.88 & 5.75 & 7.10 & 365 & $\mathrm{H}$ & estimated \\
\hline August & 1975 & 1.88 & 5.75 & 7.10 & 365 & $\mathrm{H}$ & estimated \\
\hline September & 1975 & 1.88 & 5.75 & 7.10 & 365 & $\bar{H}$ & estimated \\
\hline October & 1975 & 1.88 & 5.75 & 7.10 & 365 & $\overline{\mathrm{H}}$ & estimated \\
\hline November & 1975 & 1.88 & 5.75 & 7.10 & 365 & $\overline{\mathrm{H}}$ & estimated \\
\hline December & 1975 & 1.88 & 5.75 & 7.10 & 365 & $\overline{\mathrm{H}}$ & estimated \\
\hline January & 1976 & 1.77 & 5.42 & 6.69 & 366 & $\overline{\mathrm{H}}$ & estimated \\
\hline February & 1976 & 1.77 & 5.42 & 6.69 & 366 & $\mathrm{H}$ & estimated \\
\hline \begin{tabular}{|l|} 
March \\
\end{tabular} & 1976 & 1.77 & 5.42 & 6.69 & 366 & $\overline{\mathrm{H}}$ & estimated \\
\hline April & 1976 & 1.77 & 5.42 & 6.69 & 366 & $\mathrm{H}$ & estimated \\
\hline May & 1976 & 1.77 & 5.42 & 6.69 & 366 & $\mathrm{H}$ & estimated \\
\hline June & 1976 & 1.77 & 5.42 & 6.69 & 366 & $\mathrm{H}$ & estimated \\
\hline July & 1976 & 1.77 & 5.42 & 6.69 & 366 & $\mathrm{H}$ & estimated \\
\hline August & 1976 & 1.77 & 5.42 & 6.69 & 366 & $\mathrm{H}$ & estimated \\
\hline September & 1976 & 1.77 & 5.42 & 6.69 & 366 & $\mathrm{H}$ & estimated \\
\hline October & 1976 & 1.77 & 5.42 & 6.69 & 366 & $\overline{\mathrm{H}}$ & estimated \\
\hline November & 1976 & 1.77 & 5.42 & 6.69 & 366 & $\overline{\mathrm{H}}$ & estimated \\
\hline December & 1976 & 1.77 & 5.42 & 6.69 & 366 & $\overline{\mathrm{H}}$ & estimated \\
\hline January & 1977 & 1.74 & 5.34 & 6.59 & 365 & $\bar{H}$ & estimated \\
\hline
\end{tabular}


WW-5B Monthly Pumping Data

\begin{tabular}{|c|c|c|c|c|c|c|c|}
\hline February & 1977 & 1.74 & 5.34 & 6.59 & 365 & $\bar{H}$ & estimated \\
\hline March & 1977 & 1.74 & 5.34 & 6.59 & 365 & $\bar{H}$ & estimated \\
\hline April & 1977 & 1.74 & 5.34 & 6.59 & 365 & $\bar{H}$ & estimated \\
\hline May & 1977 & 1.74 & 5.34 & 6.59 & 365 & $\mathrm{H}$ & estimated \\
\hline \begin{tabular}{|l|} 
June \\
\end{tabular} & 1977 & 1.74 & 5.34 & 6.59 & 365 & $\bar{H}$ & estimated \\
\hline \begin{tabular}{|l|} 
July \\
\end{tabular} & 1977 & 1.74 & 5.34 & 6.59 & 365 & $\bar{H}$ & estimated \\
\hline August & 1977 & 1.74 & 5.34 & 6.59 & 365 & $\bar{H}$ & estimated \\
\hline September & 1977 & 1.74 & 5.34 & 6.59 & 365 & $\mathrm{H}$ & estimated \\
\hline October & 1977 & 1.74 & 5.34 & 6.59 & 365 & $\mathrm{H}$ & estimated \\
\hline November & 1977 & 1.74 & 5.34 & 6.59 & 365 & $\mathrm{H}$ & estimated \\
\hline December & 1977 & 1.74 & 5.34 & 6.59 & 365 & $\mathrm{H}$ & estimated \\
\hline \begin{tabular}{|l|} 
January \\
\end{tabular} & 1978 & 2.01 & 6.16 & 7.60 & 365 & $\bar{H}$ & estimated \\
\hline February & 1978 & 2.01 & 6.16 & 7.60 & 365 & $\vec{H}$ & estimated \\
\hline March & 1978 & 2.01 & 6.16 & 7.60 & 365 & $\bar{H}$ & estimated \\
\hline April & 1978 & 2.01 & 6.16 & 7.60 & 365 & $\mathrm{H}$ & estimated \\
\hline May & 1978 & 2.01 & 6.16 & 7.60 & 365 & $\bar{H}$ & estimated \\
\hline \begin{tabular}{|l|} 
June \\
\end{tabular} & 1978 & 2.01 & 6.16 & 7.60 & 365 & $\bar{H}$ & estimated \\
\hline \begin{tabular}{|l|} 
July \\
\end{tabular} & 1978 & 2.01 & 6.16 & 7.60 & 365 & $\bar{H}$ & estimated \\
\hline August & 1978 & 2.01 & 6.16 & 7.60 & 365 & $\mathrm{H}$ & estimated \\
\hline September & 1978 & 2.01 & 6.16 & 7.60 & 365 & $\mathrm{H}$ & estimated \\
\hline October & 1978 & 2.01 & 6.16 & 7.60 & 365 & $\mathrm{H}$ & estimated \\
\hline November & 1978 & 2.01 & 6.16 & 7.60 & 365 & $\mathrm{H}$ & estimated \\
\hline December & 1978 & 2.01 & 6.16 & 7.60 & 365 & $\mathrm{H}$ & estimated \\
\hline \begin{tabular}{|l|} 
January \\
\end{tabular} & 1979 & 1.90 & 5.83 & 7.19 & 365 & $\bar{H}$ & estimated \\
\hline February & 1979 & 1.90 & 5.83 & 7.19 & 365 & $\mathrm{H}$ & estimated \\
\hline March & 1979 & 1.90 & 5.83 & 7.19 & 365 & $\bar{H}$ & estimated \\
\hline April & 1979 & 1.90 & 5.83 & 7.19 & 365 & $\bar{H}$ & estimated \\
\hline May & 1979 & 1.90 & 5.83 & 7.19 & 365 & $\overline{\mathrm{H}}$ & estimated \\
\hline \begin{tabular}{|l|} 
June \\
\end{tabular} & 1979 & 1.90 & 5.83 & 7.19 & 365 & $\bar{H}$ & estimated \\
\hline \begin{tabular}{|l|} 
July \\
\end{tabular} & 1979 & 1.90 & 5.83 & 7.19 & 365 & $\bar{H}$ & estimated \\
\hline August & 1979 & 1.90 & 5.83 & 7.19 & 365 & $\mathrm{H}$ & estimated \\
\hline September & 1979 & 1.90 & 5.83 & 7.19 & 365 & $\mathrm{H}$ & estimated \\
\hline October & 1979 & 1.90 & 5.83 & 7.19 & 365 & $\mathrm{H}$ & estimated \\
\hline November & 1979 & 1.90 & 5.83 & 7.19 & 365 & $\mathrm{H}$ & estimated \\
\hline December & 1979 & 1.90 & 5.83 & 7.19 & 365 & $\mathrm{H}$ & estimated \\
\hline January & 1980 & 2.39 & 7.34 & 9.05 & 366 & $\mathrm{H}$ & estimated \\
\hline February & 1980 & 2.39 & 7.34 & 9.05 & 366 & $\overline{\mathrm{H}}$ & estimated \\
\hline March & 1980 & 2.39 & 7.34 & 9.05 & 366 & $\mathrm{H}$ & estimated \\
\hline April & 1980 & 2.39 & 7.34 & 9.05 & 366 & $\overline{\mathrm{H}}$ & estimated \\
\hline May & 1980 & 2.39 & 7.34 & 9.05 & 366 & $\overline{\mathrm{H}}$ & estimated \\
\hline June & 1980 & 2.39 & 7.34 & 9.05 & 366 & $\mathrm{H}$ & estimated \\
\hline \begin{tabular}{|l} 
July \\
\end{tabular} & 1980 & 2.39 & 7.34 & 9.05 & 366 & $\mathrm{H}$ & estimated \\
\hline August & 1980 & 2.39 & 7.34 & 9.05 & 366 & $\mathrm{H}$ & estimated \\
\hline September & 1980 & 2.39 & 7.34 & 9.05 & 366 & $\mathrm{H}$ & estimated \\
\hline October & 1980 & 2.39 & 7.34 & 9.05 & 366 & $\mathrm{H}$ & estimated \\
\hline November & 1980 & 2.39 & 7.34 & 9.05 & 366 & $\mathrm{H}$ & estimated \\
\hline December & 1980 & 2.39 & 7.34 & 9.05 & 366 & $\mathrm{H}$ & estimated \\
\hline January & 1981 & 2.91 & 8.92 & 11.01 & 365 & $\mathrm{H}$ & estimated \\
\hline February & 1981 & 2.91 & 8.92 & 11.01 & 365 & $\mathrm{H}$ & estimated \\
\hline March & 1981 & 2.91 & 8.92 & 11.01 & 365 & $\mathrm{H}$ & estimated \\
\hline April & 1981 & 2.91 & 8.92 & 11.01 & 365 & $\bar{H}$ & estimated \\
\hline May & 1981 & 2.91 & 8.92 & 11.01 & 365 & $\bar{H}$ & estimated \\
\hline
\end{tabular}


WW-5B Monthly Pumping Data

\begin{tabular}{|c|c|c|c|c|c|c|c|}
\hline June & 1981 & 2.91 & 8.92 & 11.01 & 365 & $\mathrm{H}$ & estimated \\
\hline July & 1981 & 2.91 & 8.92 & 11.01 & 365 & $\overline{\mathrm{H}}$ & estimated \\
\hline August & 1981 & 2.91 & 8.92 & 11.01 & 365 & $\mathrm{H}$ & estimated \\
\hline September & 1981 & 2.91 & 8.92 & 11.01 & 365 & $\overline{\mathrm{H}}$ & estimated \\
\hline October & 1981 & 2.91 & 8.92 & 11.01 & 365 & $\mathrm{H}$ & estimated \\
\hline November & 1981 & 2.91 & 8.92 & 11.01 & 365 & $\mathrm{H}$ & estimated \\
\hline December & 1981 & 2.91 & 8.92 & 11.01 & 365 & $\mathrm{H}$ & estimated \\
\hline \begin{tabular}{|l|} 
January \\
\end{tabular} & 1982 & 3.56 & 10.92 & 13.47 & 365 & $\bar{H}$ & estimated \\
\hline February & 1982 & 3.56 & 10.92 & 13.47 & 365 & $\mathrm{H}$ & estimated \\
\hline March & 1982 & 3.56 & 10.92 & 13.47 & 365 & $\mathrm{H}$ & estimated \\
\hline April & 1982 & 3.56 & 10.92 & 13.47 & 365 & $\mathrm{H}$ & estimated \\
\hline May & 1982 & 3.56 & 10.92 & 13.47 & 365 & $\mathrm{H}$ & estimated \\
\hline June & 1982 & 3.56 & 10.92 & 13.47 & 365 & $\overline{\mathrm{H}}$ & estimated \\
\hline July & 1982 & 3.56 & 10.92 & 13.47 & 365 & $\overline{\mathrm{H}}$ & estimated \\
\hline August & 1982 & 3.56 & 10.92 & 13.47 & 365 & $\mathrm{H}$ & estimated \\
\hline September & 1982 & 3.56 & 10.92 & 13.47 & 365 & $\overline{\mathrm{H}}$ & estimated \\
\hline October & 1982 & 3.56 & 10.92 & 13.47 & 365 & $\mathrm{H}$ & estimated \\
\hline November & 1982 & 3.56 & 10.92 & 13.47 & 365 & $\mathrm{H}$ & estimated \\
\hline December & 1982 & 3.56 & 10.92 & 13.47 & 365 & $\mathrm{H}$ & estimated \\
\hline January & 1983 & 1.49 & 4.58 & 5.65 & 31 & $\mathrm{M}$ & -- \\
\hline February & 1983 & 1.87 & 5.73 & 7.07 & 28 & $\mathrm{M}$ & -- \\
\hline March & 1983 & 3.51 & 10.78 & 13.30 & 31 & $\mathrm{M}$ & -- \\
\hline April & 1983 & 2.67 & 8.19 & 10.10 & 30 & $\mathrm{M}$ & -- \\
\hline May & 1983 & 4.95 & 15.19 & 18.73 & 31 & $\mathrm{M}$ & -- \\
\hline \begin{tabular}{|l|} 
June \\
\end{tabular} & 1983 & 3.49 & 10.71 & 13.20 & 30 & $\mathrm{M}$ & -- \\
\hline \begin{tabular}{|l|} 
July \\
\end{tabular} & 1983 & 3.49 & 10.71 & 13.20 & 31 & $\mathrm{M}$ & -- \\
\hline August & 1983 & 2.67 & 8.20 & 10.11 & 31 & $\mathrm{M}$ & -- \\
\hline September & 1983 & 2.38 & 7.29 & 8.99 & 30 & $\mathrm{M}$ & -- \\
\hline October & 1983 & 2.26 & 6.95 & 8.57 & 31 & $\mathrm{M}$ & -- \\
\hline November & 1983 & 1.55 & 4.74 & 5.85 & 30 & $\mathrm{M}$ & -- \\
\hline December & 1983 & 1.85 & 5.67 & 7.00 & 31 & $\mathrm{M}$ & -- \\
\hline January & 1984 & 2.39 & 7.32 & 9.03 & 31 & $\mathrm{M}$ & -- \\
\hline February & 1984 & 6.57 & 20.16 & 24.86 & 29 & $\mathrm{M}$ & -- \\
\hline March & 1984 & 5.84 & 17.91 & 22.09 & 31 & $\mathrm{M}$ & -- \\
\hline April & 1984 & 5.10 & 15.65 & 19.30 & 30 & $\mathrm{M}$ & -- \\
\hline May & 1984 & 3.77 & 11.56 & 14.26 & 31 & $\mathrm{M}$ & -- \\
\hline June & 1984 & 3.23 & 9.90 & 12.21 & 30 & $\mathrm{M}$ & -- \\
\hline \begin{tabular}{|l} 
July \\
\end{tabular} & 1984 & 7.27 & 22.32 & 27.53 & 31 & $\mathrm{M}$ & -- \\
\hline August & 1984 & 5.79 & 17.77 & 21.92 & 31 & $\mathrm{M}$ & -- \\
\hline September & 1984 & 4.89 & 15.02 & 18.52 & 30 & M & -- \\
\hline October & 1984 & 4.66 & 14.29 & 17.62 & 31 & $\mathrm{M}$ & -- \\
\hline November & 1984 & 4.18 & 12.82 & 15.81 & 30 & $M$ & -- \\
\hline December & 1984 & 4.18 & 12.82 & 15.81 & 31 & $E$ & -- \\
\hline \begin{tabular}{|l|} 
January \\
\end{tabular} & 1985 & 6.38 & 19.58 & 24.15 & 31 & $E$ & -- \\
\hline February & 1985 & 5.46 & 16.76 & 20.67 & 28 & $\mathrm{M}$ & -- \\
\hline March & 1985 & 5.86 & 17.99 & 22.19 & 31 & $\mathrm{M}$ & -- \\
\hline April & 1985 & 6.01 & 18.43 & 22.73 & 30 & $\mathrm{M}$ & -- \\
\hline
\end{tabular}


WW-5B Monthly Pumping Data

\begin{tabular}{|c|c|c|c|c|c|c|c|}
\hline May & 1985 & 6.40 & 19.65 & 24.24 & 31 & $M$ & -- \\
\hline June & 1985 & 5.32 & 16.31 & 20.12 & 30 & $M$ & -- \\
\hline July & 1985 & 3.18 & 9.76 & 12.04 & 31 & $M$ & - \\
\hline August & 1985 & 3.14 & 9.62 & 11.87 & 31 & $M$ & -- \\
\hline September & 1985 & 6.61 & 20.29 & 25.02 & 30 & $M$ & -- \\
\hline October & 1985 & 6.39 & 19.60 & 24.17 & 31 & $\mathrm{M}$ & - \\
\hline November & 1985 & 6.05 & 18.55 & 22.88 & 30 & $M$ & -- \\
\hline December & 1985 & 7.05 & 21.63 & 26.68 & 31 & $E$ & - \\
\hline January & 1986 & 6.16 & 18.89 & 23.30 & 31 & $M$ & -- \\
\hline February & 1986 & 4.02 & 12.35 & 15.23 & 28 & $M$ & -- \\
\hline March & 1986 & 5.84 & 17.92 & 22.10 & 31 & $M$ & -- \\
\hline April & 1986 & 5.21 & 16.00 & 19.73 & 30 & $\mathrm{M}$ & -- \\
\hline May & 1986 & 4.99 & 15.31 & 18.88 & 31 & $M$ & -- \\
\hline June & 1986 & 3.94 & 12.08 & 14.90 & 30 & $\mathrm{M}$ & - \\
\hline July & 1986 & 5.19 & 15.93 & 19.64 & 31 & $M$ & -- \\
\hline August & 1986 & 6.25 & 19.17 & 23.64 & 31 & $\mathrm{M}$ & - \\
\hline September & 1986 & 5.87 & 18.00 & 22.20 & 30 & $M$ & -- \\
\hline October & 1986 & 3.63 & 11.14 & 13.74 & 31 & $\mathrm{M}$ & - \\
\hline November & 1986 & 4.08 & 12.51 & 15.43 & 30 & $M$ & - \\
\hline December & 1986 & 3.34 & 10.25 & 12.64 & 31 & $\mathrm{M}$ & - \\
\hline \begin{tabular}{|l|} 
January \\
\end{tabular} & 1987 & 3.34 & 10.26 & 12.65 & 31 & $M$ & -- \\
\hline February & 1987 & 3.55 & 10.90 & 13.45 & 28 & $\mathrm{M}$ & - \\
\hline March & 1987 & 3.64 & 11.17 & 13.78 & 31 & $M$ & -- \\
\hline April & 1987 & 3.93 & 12.05 & 14.87 & 30 & $\mathrm{M}$ & - \\
\hline May & 1987 & 3.69 & 11.32 & 13.96 & 31 & $M$ & -- \\
\hline June & 1987 & 3.70 & 11.37 & 14.02 & 30 & $M$ & -- \\
\hline July & 1987 & 3.73 & 11.46 & 14.13 & 31 & $M$ & -- \\
\hline August & 1987 & 4.96 & 15.22 & 18.77 & 31 & $\mathrm{M}$ & - \\
\hline September & 1987 & 4.98 & 15.27 & 18.83 & 30 & $M$ & -- \\
\hline October & 1987 & 6.60 & 20.24 & 24.96 & 31 & $\mathrm{M}$ & -- \\
\hline November & 1987 & 4.69 & 14.39 & 17.74 & 30 & $M$ & -- \\
\hline December & 1987 & 3.68 & 11.28 & 13.91 & 31 & $\mathrm{M}$ & -- \\
\hline January & 1988 & 3.73 & 11.44 & 14.11 & 31 & $\mathrm{M}$ & - \\
\hline February & 1988 & 4.62 & 14.16 & 17.47 & 29 & $\mathrm{M}$ & -- \\
\hline March & 1988 & 9.01 & 27.66 & 34.11 & 31 & $\mathrm{M}$ & -- \\
\hline April & 1988 & 6.53 & 20.05 & 24.73 & 30 & $\mathrm{M}$ & - \\
\hline May & 1988 & 7.19 & 22.05 & 27.20 & 31 & $M$ & -- \\
\hline June & 1988 & 5.65 & 17.34 & 21.38 & 30 & $\mathrm{M}$ & - \\
\hline July & 1988 & 6.20 & 19.03 & 23.47 & 31 & $M$ & -- \\
\hline August & 1988 & 5.09 & 15.63 & 19.28 & 31 & $\mathrm{M}$ & -- \\
\hline September & 1988 & 5.12 & 15.71 & 19.37 & 30 & $\mathrm{M}$ & -- \\
\hline October & 1988 & 4.32 & 13.26 & 16.35 & 31 & $M$ & -- \\
\hline November & 1988 & 0.00 & 0.00 & 0.00 & 30 & $M$ & -- \\
\hline December & 1988 & 0.00 & 0.00 & 0.00 & 31 & $M$ & -- \\
\hline
\end{tabular}




\begin{tabular}{|c|c|c|c|c|c|c|c|}
\hline January & 1989 & 0.00 & 0.00 & 0.00 & 31 & $\bar{M}$ & -- \\
\hline February & 1989 & 0.00 & 0.00 & 0.00 & 28 & $M$ & -- \\
\hline March & 1989 & 0.00 & 0.00 & 0.00 & 31 & $\bar{M}$ & -- \\
\hline April & 1989 & 0.00 & 0.00 & 0.00 & 30 & $M$ & -- \\
\hline May & 1989 & 0.00 & 0.00 & 0.00 & 31 & $M$ & -- \\
\hline June & 1989 & 0.00 & 0.00 & 0.00 & 30 & $\bar{M}$ & -- \\
\hline July & 1989 & 0.00 & 0.00 & 0.00 & 31 & $M$ & -- \\
\hline August & 1989 & 0.00 & 0.00 & 0.00 & 31 & $M$ & -- \\
\hline September & 1989 & 0.00 & 0.00 & 0.00 & 30 & $M$ & - \\
\hline October & 1989 & 0.00 & 0.00 & 0.00 & 31 & $\bar{M}$ & -- \\
\hline November & 1989 & 0.00 & 0.00 & 0.00 & 30 & $\bar{M}$ & -- \\
\hline December & 1989 & 0.00 & 0.00 & 0.00 & 31 & $\bar{M}$ & -- \\
\hline January & 1990 & 0.00 & 0.00 & 0.00 & 31 & $\bar{M}$ & -- \\
\hline February & 1990 & 0.00 & 0.00 & 0.00 & 28 & $M$ & -- \\
\hline March & 1990 & 0.00 & 0.00 & 0.00 & 31 & $\bar{M}$ & -- \\
\hline April & 1990 & 0.00 & 0.00 & 0.00 & 30 & $M$ & -- \\
\hline May & 1990 & 0.00 & 0.00 & 0.00 & 31 & $M$ & -- \\
\hline June & 1990 & 0.00 & 0.00 & 0.00 & 30 & $\bar{M}$ & -- \\
\hline July & 1990 & 0.00 & 0.00 & 0.00 & 31 & $M$ & -- \\
\hline August & 1990 & 0.00 & 0.00 & 0.00 & 31 & $M$ & -- \\
\hline September & 1990 & 0.00 & 0.00 & 0.00 & 30 & $M$ & -- \\
\hline October & 1990 & 0.00 & 0.00 & 0.00 & 31 & $\bar{M}$ & -- \\
\hline November & 1990 & 0.00 & 0.00 & 0.00 & 30 & $M$ & - \\
\hline December & 1990 & 0.00 & 0.00 & 0.00 & 31 & $\bar{M}$ & - \\
\hline January & 1991 & 0.00 & 0.00 & 0.00 & 31 & $\bar{M}$ & - \\
\hline February & 1991 & 0.00 & 0.00 & 0.00 & 28 & $M$ & - \\
\hline March & 1991 & 0.00 & 0.00 & 0.00 & 31 & $M$ & - \\
\hline April & 1991 & 0.00 & 0.00 & 0.00 & 30 & $M$ & - \\
\hline May & 1991 & 0.00 & 0.00 & 0.00 & 31 & $\mathrm{M}$ & - \\
\hline June & 1991 & 0.00 & 0.00 & 0.00 & 30 & $\mathrm{M}$ & - \\
\hline July & 1991 & 0.00 & 0.00 & 0.00 & 31 & $M$ & - \\
\hline August & 1991 & 0.00 & 0.00 & 0.00 & 31 & $\mathrm{M}$ & - \\
\hline September & 1991 & 0.00 & 0.00 & 0.00 & 30 & $\mathrm{M}$ & - \\
\hline October & 1991 & 0.00 & 0.00 & 0.00 & 31 & $\mathrm{M}$ & - \\
\hline November & 1991 & 0.00 & 0.00 & 0.00 & 30 & $M$ & - \\
\hline December & 1991 & 0.00 & 0.00 & 0.00 & 31 & $\bar{M}$ & - \\
\hline January & 1992 & 0.00 & 0.00 & 0.00 & 31 & $\bar{M}$ & - \\
\hline February & 1992 & 0.00 & 0.00 & 0.00 & 29 & $\mathrm{M}$ & - \\
\hline March & 1992 & 0.00 & 0.00 & 0.00 & 31 & $M$ & - \\
\hline April & 1992 & 0.00 & 0.00 & 0.00 & 30 & $M$ & - \\
\hline May & 1992 & 0.00 & 0.00 & 0.00 & 31 & $M$ & - \\
\hline June & 1992 & 0.00 & 0.00 & 0.00 & 30 & $\mathrm{M}$ & - \\
\hline July & 1992 & 0.00 & 0.00 & 0.00 & 31 & $M$ & - \\
\hline August & 1992 & 0.00 & 0.00 & 0.00 & 31 & $\mathrm{M}$ & - \\
\hline
\end{tabular}




\begin{tabular}{|c|c|c|c|c|c|c|c|}
\hline September & 1992 & 0.00 & 0.00 & 0.00 & 30 & $M$ & -- \\
\hline October & 1992 & 0.00 & 0.00 & 0.00 & 31 & $M$ & -- \\
\hline November & 1992 & 0.00 & 0.00 & 0.00 & 30 & $M$ & - \\
\hline December & 1992 & 0.00 & 0.00 & 0.00 & 31 & $M$ & -- \\
\hline January & 1993 & 0.00 & 0.00 & 0.00 & 31 & $M$ & -- \\
\hline February & 1993 & 0.00 & 0.00 & 0.00 & 28 & $\mathrm{M}$ & - \\
\hline March & 1993 & 0.00 & 0.00 & 0.00 & 31 & $M$ & -- \\
\hline April & 1993 & 0.00 & 0.00 & 0.00 & 30 & $\mathrm{M}$ & -- \\
\hline May & 1993 & 0.57 & 1.74 & 2.14 & 31 & $\mathrm{M}$ & - \\
\hline June & 1993 & 1.25 & 3.82 & 4.72 & 30 & $M$ & -- \\
\hline July & 1993 & 6.66 & 20.45 & 25.22 & 31 & $M$ & -- \\
\hline August & 1993 & 9.77 & 29.97 & 36.96 & 31 & $\mathrm{M}$ & -- \\
\hline September & 1993 & 4.53 & 13.91 & 17.15 & 30 & $M$ & -- \\
\hline October & 1993 & 3.39 & 10.39 & 12.82 & 31 & $\mathrm{M}$ & - \\
\hline November & 1993 & 2.21 & 6.78 & 8.36 & 30 & $M$ & -- \\
\hline December & 1993 & 1.39 & 4.26 & 5.26 & 31 & $\mathrm{M}$ & - \\
\hline January & 1994 & 2.05 & 6.29 & 7.75 & 31 & $M$ & -- \\
\hline February & 1994 & 1.89 & 5.78 & 7.13 & 28 & $M$ & -- \\
\hline March & 1994 & 3.04 & 9.34 & 11.52 & 31 & $M$ & - \\
\hline April & 1994 & 3.29 & 10.10 & 12.46 & 30 & $\mathrm{M}$ & - \\
\hline May & 1994 & 3.90 & 11.97 & 14.76 & 31 & $M$ & -- \\
\hline June & 1994 & 3.30 & 10.12 & 12.48 & 30 & $\mathrm{M}$ & - \\
\hline July & 1994 & 6.96 & 21.35 & 26.34 & 31 & $M$ & -- \\
\hline August & 1994 & 5.76 & 17.68 & 21.80 & 31 & $\mathrm{M}$ & - \\
\hline September & 1994 & 4.13 & 12.66 & 15.62 & 30 & $M$ & -- \\
\hline October & 1994 & 8.31 & 25.49 & 31.44 & 31 & $M$ & -- \\
\hline November & 1994 & 6.64 & 20.38 & 25.14 & 30 & $M$ & -- \\
\hline December & 1994 & 5.92 & 18.17 & 22.41 & 31 & $\mathrm{M}$ & - \\
\hline January & 1995 & 6.86 & 21.04 & 25.94 & 31 & $M$ & -- \\
\hline February & 1995 & 7.72 & 23.69 & 29.21 & 28 & $\mathrm{M}$ & -- \\
\hline March & 1995 & 9.33 & 28.63 & 35.31 & 31 & $M$ & -- \\
\hline April & 1995 & 9.71 & 29.80 & 36.75 & 30 & $\mathrm{M}$ & -- \\
\hline May & 1995 & 9.96 & 30.58 & 37.71 & 31 & $\mathrm{M}$ & - \\
\hline June & 1995 & 7.99 & 24.51 & 30.22 & 30 & $\mathrm{M}$ & -- \\
\hline July & 1995 & 7.76 & 23.83 & 29.39 & 31 & $\mathrm{M}$ & -- \\
\hline August & 1995 & 9.59 & 29.44 & 36.31 & 31 & $\mathrm{M}$ & - \\
\hline September & 1995 & 4.79 & 14.69 & 18.11 & 30 & $M$ & -- \\
\hline October & 1995 & 4.40 & 13.50 & 16.65 & 31 & $\mathrm{M}$ & - \\
\hline November & 1995 & 4.98 & 15.30 & 18.86 & 30 & $M$ & -- \\
\hline December & 1995 & 4.58 & 14.06 & 17.35 & 31 & $\mathrm{M}$ & -- \\
\hline January & 1996 & 4.32 & 13.25 & 16.34 & 31 & $\mathrm{M}$ & -- \\
\hline February & 1996 & 4.24 & 13.02 & 16.06 & 29 & $\mathrm{M}$ & -- \\
\hline March & 1996 & 4.93 & 15.14 & 18.67 & 31 & $M$ & -- \\
\hline April & 1996 & 4.20 & 12.89 & 15.90 & 30 & $M$ & -- \\
\hline
\end{tabular}


WW-5B Monthly Pumping Data

\begin{tabular}{|c|c|c|c|c|c|c|c|}
\hline May & 1996 & 3.66 & 11.23 & 13.85 & 31 & $M$ & -- \\
\hline June & 1996 & 3.56 & 10.92 & 13.46 & 30 & $M$ & -- \\
\hline July & 1996 & 4.22 & 12.94 & 15.96 & 31 & $M$ & - \\
\hline August & 1996 & 3.16 & 9.70 & 11.96 & 31 & $M$ & -- \\
\hline September & 1996 & 3.80 & 11.67 & 14.40 & 30 & $M$ & -- \\
\hline October & 1996 & 3.66 & 11.24 & 13.86 & 31 & $\mathrm{M}$ & - \\
\hline November & 1996 & 3.73 & 11.43 & 14.10 & 30 & $M$ & -- \\
\hline December & 1996 & 4.37 & 13.40 & 16.53 & 31 & $\mathrm{M}$ & - \\
\hline January & 1997 & 3.27 & 10.04 & 12.38 & 31 & $M$ & -- \\
\hline February & 1997 & 3.49 & 10.70 & 13.20 & 28 & $M$ & -- \\
\hline March & 1997 & 4.16 & 12.76 & 15.74 & 31 & $M$ & -- \\
\hline April & 1997 & 3.50 & 10.73 & 13.23 & 30 & $\mathrm{M}$ & -- \\
\hline May & 1997 & 4.04 & 12.40 & 15.30 & 31 & $M$ & -- \\
\hline June & 1997 & 3.57 & 10.95 & 13.51 & 30 & $\mathrm{M}$ & - \\
\hline July & 1997 & 3.60 & 11.04 & 13.62 & 31 & $M$ & -- \\
\hline August & 1997 & 3.73 & 11.44 & 14.11 & 31 & $\mathrm{M}$ & - \\
\hline September & 1997 & 3.21 & 9.85 & 12.14 & 30 & $M$ & -- \\
\hline October & 1997 & 3.38 & 10.37 & 12.79 & 31 & $M$ & -- \\
\hline November & 1997 & 3.55 & 10.89 & 13.43 & 30 & $M$ & -- \\
\hline December & 1997 & 3.15 & 9.67 & 11.93 & 31 & $\mathrm{M}$ & - \\
\hline \begin{tabular}{|l|} 
January \\
\end{tabular} & 1998 & 3.49 & 10.70 & 13.20 & 31 & $M$ & -- \\
\hline February & 1998 & 3.46 & 10.62 & 13.09 & 28 & $\mathrm{M}$ & - \\
\hline March & 1998 & 4.04 & 12.39 & 15.28 & 31 & $M$ & -- \\
\hline April & 1998 & 3.21 & 9.84 & 12.14 & 30 & $\mathrm{M}$ & - \\
\hline May & 1998 & 0.91 & 2.78 & 3.43 & 31 & $\mathrm{M}$ & -- \\
\hline June & 1998 & 1.25 & 3.82 & 4.71 & 30 & $M$ & -- \\
\hline July & 1998 & 5.18 & 15.90 & 19.61 & 31 & $M$ & -- \\
\hline August & 1998 & 3.14 & 9.62 & 11.87 & 31 & $\mathrm{M}$ & - \\
\hline September & 1998 & 3.42 & 10.48 & 12.93 & 30 & $M$ & -- \\
\hline October & 1998 & 3.53 & 10.84 & 13.37 & 31 & $\mathrm{M}$ & -- \\
\hline November & 1998 & 3.20 & 9.83 & 12.12 & 30 & $M$ & -- \\
\hline December & 1998 & 3.17 & 9.71 & 11.98 & 31 & $\mathrm{M}$ & -- \\
\hline January & 1999 & 4.28 & 13.13 & 16.19 & 31 & $\mathrm{M}$ & - \\
\hline February & 1999 & 3.52 & 10.81 & 13.33 & 28 & $\mathrm{M}$ & -- \\
\hline March & 1999 & 3.85 & 11.81 & 14.57 & 31 & $\mathrm{M}$ & -- \\
\hline April & 1999 & 3.07 & 9.43 & 11.63 & 30 & $\mathrm{M}$ & - \\
\hline May & 1999 & 3.58 & 10.98 & 13.54 & 31 & $M$ & -- \\
\hline June & 1999 & 4.05 & 12.42 & 15.32 & 30 & $\mathrm{M}$ & - \\
\hline July & 1999 & 3.85 & 11.82 & 14.58 & 31 & $M$ & -- \\
\hline August & 1999 & 3.59 & 11.01 & 13.58 & 31 & $\mathrm{M}$ & -- \\
\hline September & 1999 & 3.52 & 10.80 & 13.32 & 30 & $\mathrm{M}$ & -- \\
\hline October & 1999 & 3.32 & 10.19 & 12.57 & 31 & $M$ & -- \\
\hline November & 1999 & 3.32 & 10.18 & 12.55 & 30 & $M$ & -- \\
\hline December & 1999 & 0.10 & 0.31 & 0.38 & 31 & $M$ & -- \\
\hline
\end{tabular}


WW-5B Monthly Pumping Data

\begin{tabular}{|c|c|c|c|c|c|c|c|}
\hline January & 2000 & 0.00 & 0.00 & 0.00 & 31 & $M$ & -- \\
\hline February & 2000 & 0.00 & 0.00 & 0.00 & 29 & $\mathrm{M}$ & - \\
\hline March & 2000 & 0.00 & 0.00 & 0.00 & 31 & $M$ & -- \\
\hline April & 2000 & 0.00 & 0.00 & 0.00 & 30 & $\mathrm{M}$ & -- \\
\hline May & 2000 & 0.33 & 1.02 & 1.26 & 31 & $\mathrm{M}$ & - \\
\hline June & 2000 & 0.84 & 2.59 & 3.19 & 30 & $\mathrm{M}$ & - \\
\hline July & 2000 & 4.56 & 13.98 & 17.25 & 31 & $M$ & -- \\
\hline August & 2000 & 3.85 & 11.82 & 14.58 & 31 & $M$ & - \\
\hline September & 2000 & 4.16 & 12.77 & 15.75 & 30 & $M$ & -- \\
\hline October & 2000 & 3.65 & 11.21 & 13.82 & 31 & $M$ & - \\
\hline November & 2000 & 3.29 & 10.11 & 12.47 & 30 & $\mathrm{M}$ & -- \\
\hline December & 2000 & 3.38 & 10.39 & 12.81 & 31 & $M$ & -- \\
\hline January & 2001 & 3.84 & 11.78 & 14.53 & 31 & $\mathrm{M}$ & -- \\
\hline February & 2001 & 3.46 & 10.62 & 13.10 & 28 & $\mathrm{M}$ & - \\
\hline March & 2001 & 3.79 & 11.64 & 14.35 & 31 & $M$ & -- \\
\hline April & 2001 & 2.08 & 6.39 & 7.88 & 30 & $\mathrm{M}$ & - \\
\hline May & 2001 & 1.55 & 4.74 & 5.85 & 31 & $M$ & -- \\
\hline June & 2001 & 1.80 & 5.53 & 6.83 & 30 & $\mathrm{M}$ & - \\
\hline July & 2001 & 1.92 & 5.90 & 7.28 & 31 & $M$ & -- \\
\hline August & 2001 & 2.50 & 7.66 & 9.45 & 31 & $M$ & - \\
\hline September & 2001 & 2.06 & 6.32 & 7.79 & 30 & $M$ & -- \\
\hline October & 2001 & 2.33 & 7.15 & 8.82 & 31 & $\mathrm{M}$ & - \\
\hline November & 2001 & 2.44 & 7.47 & 9.22 & 30 & $M$ & -- \\
\hline December & 2001 & 1.48 & 4.55 & 5.62 & 31 & $\mathrm{M}$ & - \\
\hline January & 2002 & 2.40 & 7.37 & 9.09 & 31 & $M$ & -- \\
\hline February & 2002 & 1.61 & 4.94 & 6.09 & 28 & $\mathrm{M}$ & - \\
\hline March & 2002 & 2.44 & 7.48 & 9.22 & 31 & $M$ & -- \\
\hline April & 2002 & 2.41 & 7.40 & 9.12 & 30 & $\mathrm{M}$ & - \\
\hline May & 2002 & 2.71 & 8.32 & 10.26 & 31 & $M$ & -- \\
\hline June & 2002 & 3.57 & 10.95 & 13.50 & 30 & $\mathrm{M}$ & - \\
\hline July & 2002 & 3.61 & 11.07 & 13.66 & 31 & $M$ & -- \\
\hline August & 2002 & 3.07 & 9.42 & 11.62 & 31 & $\mathrm{M}$ & - \\
\hline September & 2002 & 2.94 & 9.01 & 11.12 & 30 & $M$ & -- \\
\hline October & 2002 & 2.57 & 7.90 & 9.74 & 31 & $\mathrm{M}$ & -- \\
\hline November & 2002 & 2.37 & 7.26 & 8.95 & 30 & $\mathrm{M}$ & -- \\
\hline December & 2002 & 3.47 & 10.65 & 13.14 & 31 & $M$ & -- \\
\hline January & 2003 & 1.63 & 5.00 & 6.17 & 31 & $M$ & -- \\
\hline February & 2003 & 2.44 & 7.50 & 9.25 & 28 & $M$ & -- \\
\hline March & 2003 & 3.26 & 10.00 & 12.34 & 31 & $M$ & - \\
\hline April & 2003 & 2.45 & 7.51 & 9.26 & 30 & $\mathrm{M}$ & -- \\
\hline May & 2003 & 2.84 & 8.70 & 10.74 & 31 & $M$ & -- \\
\hline June & 2003 & 2.60 & 7.97 & 9.82 & 30 & $\mathrm{M}$ & -- \\
\hline July & 2003 & 2.16 & 6.62 & 8.17 & 31 & $M$ & -- \\
\hline August & 2003 & 2.31 & 7.07 & 8.72 & 31 & $\mathrm{M}$ & -- \\
\hline
\end{tabular}




\begin{tabular}{|l|c|c|c|c|c|c|c|}
\hline September & 2003 & 2.57 & 7.89 & 9.74 & 30 & $\mathrm{M}$ & -- \\
\hline October & 2003 & 2.78 & 8.54 & 10.53 & 31 & $\mathrm{M}$ & -- \\
\hline November & 2003 & 2.41 & 7.40 & 9.13 & 30 & $\mathrm{M}$ & -- \\
\hline December & 2003 & 2.51 & 7.69 & 9.49 & 31 & $\mathrm{M}$ & -- \\
\hline
\end{tabular}

${ }^{a}$ Source: $\mathrm{E}=$ Taken from Bechtel or REECo water production reports and includes estimated values.

$\mathrm{H}=$ Insufficient data to determine monthly value. Annual value listed in annual data set as reported in [Moreo and others, 2003, WRIR 03-4245, Estimated Ground-Water Withdrawals from the Death Valley Regional Flow System, Nevada and California, 1913-98].

$I$ = Insufficient or no data to calculate monthly total; no water may have been withdrawn for month.

$\mathrm{M}=$ Taken from Bechtel or REECo water production reports.

$\mathrm{R}=$ Insufficient data to determine monthly value. Annual value listed in annual data set as reported in [Claassen, H.C., 1973, Water quality and physical characteristics of Nevada Test Site water-supply wells: U.S. Geological Survey Open-File Report USGS-474-158, 145 p.].

$Z$ = Insufficient data to determine monthly value. Annual value listed in annual data set as estimated in [Claassen, H.C., 1973, Water quality and physical characteristics of Nevada Test Site water-supply wells: U.S. Geological Survey Open-File Report USGS-474-158, 145 p.].

I I

b estimated indicates monthly value was estimated from yearly total 


\begin{tabular}{|c|c|c|c|c|c|c|c|}
\hline Month & Year & $\begin{array}{c}\text { Million } \\
\text { Gallons } \\
\end{array}$ & Acre-Ft & $\begin{array}{c}\text { Million } \\
\text { Liters } \\
\end{array}$ & $\begin{array}{c}\text { Days } \\
\text { Reported }\end{array}$ & Source $^{a}$ & Comment $^{b}$ \\
\hline March & 1954 & 1.81 & 5.55 & 6.85 & 365 & $Z$ & estimated \\
\hline April & 1954 & 1.81 & 5.55 & 6.85 & 365 & $\bar{Z}$ & estimated \\
\hline May & 1954 & 1.81 & 5.55 & 6.85 & 365 & $Z$ & estimated \\
\hline June & 1954 & 1.81 & 5.55 & 6.85 & 365 & $\bar{Z}$ & estimated \\
\hline July & 1954 & 1.81 & 5.55 & 6.85 & 365 & $Z$ & estimated \\
\hline August & 1954 & 1.81 & 5.55 & 6.85 & 365 & $\bar{Z}$ & estimated \\
\hline September & 1954 & 1.81 & 5.55 & 6.85 & 365 & $\bar{Z}$ & estimated \\
\hline October & 1954 & 1.81 & 5.55 & 6.85 & 365 & $Z$ & estimated \\
\hline November & 1954 & 1.81 & 5.55 & 6.85 & 365 & Z & estimated \\
\hline December & 1954 & 1.81 & 5.55 & 6.85 & 365 & $\bar{Z}$ & estimated \\
\hline January & 1955 & 1.51 & 4.63 & 5.71 & 365 & $Z$ & estimated \\
\hline February & 1955 & 1.51 & 4.63 & 5.71 & 365 & $Z$ & estimated \\
\hline March & 1955 & 1.51 & 4.63 & 5.71 & 365 & $\bar{Z}$ & estimated \\
\hline April & 1955 & 1.51 & 4.63 & 5.71 & 365 & $\bar{Z}$ & estimated \\
\hline May & 1955 & 1.51 & 4.63 & 5.71 & 365 & $\bar{Z}$ & estimated \\
\hline June & 1955 & 1.51 & 4.63 & 5.71 & 365 & $Z$ & estimated \\
\hline July & 1955 & 1.51 & 4.63 & 5.71 & 365 & $Z$ & estimated \\
\hline August & 1955 & 1.51 & 4.63 & 5.71 & 365 & $Z$ & estimated \\
\hline September & 1955 & 1.51 & 4.63 & 5.71 & 365 & $\bar{Z}$ & estimated \\
\hline October & 1955 & 1.51 & 4.63 & 5.71 & 365 & $\bar{Z}$ & estimated \\
\hline November & 1955 & 1.51 & 4.63 & 5.71 & 365 & $Z$ & estimated \\
\hline December & 1955 & 1.51 & 4.63 & 5.71 & 365 & Z & estimated \\
\hline January & 1956 & 1.51 & 4.63 & 5.71 & 366 & Z & estimated \\
\hline February & 1956 & 1.51 & 4.63 & 5.71 & 366 & $Z$ & estimated \\
\hline March & 1956 & 1.51 & 4.63 & 5.71 & 366 & $\bar{Z}$ & estimated \\
\hline April & 1956 & 1.51 & 4.63 & 5.71 & 366 & $\bar{Z}$ & estimated \\
\hline May & 1956 & 1.51 & 4.63 & 5.71 & 366 & $\bar{Z}$ & estimated \\
\hline June & 1956 & 1.51 & 4.63 & 5.71 & 366 & $\bar{Z}$ & estimated \\
\hline July & 1956 & 1.51 & 4.63 & 5.71 & 366 & $Z$ & estimated \\
\hline August & 1956 & 1.51 & 4.63 & 5.71 & 366 & $Z$ & estimated \\
\hline September & 1956 & 1.51 & 4.63 & 5.71 & 366 & $\bar{Z}$ & estimated \\
\hline October & 1956 & 1.51 & 4.63 & 5.71 & 366 & $\bar{Z}$ & estimated \\
\hline November & 1956 & 1.51 & 4.63 & 5.71 & 366 & $Z$ & estimated \\
\hline December & 1956 & 1.51 & 4.63 & 5.71 & 366 & Z & estimated \\
\hline January & 1957 & 1.51 & 4.63 & 5.71 & 365 & Z & estimated \\
\hline February & 1957 & 1.51 & 4.63 & 5.71 & 365 & $Z$ & estimated \\
\hline March & 1957 & 1.51 & 4.63 & 5.71 & 365 & $\bar{Z}$ & estimated \\
\hline April & 1957 & 1.51 & 4.63 & 5.71 & 365 & $\bar{Z}$ & estimated \\
\hline May & 1957 & 1.51 & 4.63 & 5.71 & 365 & $\bar{Z}$ & estimated \\
\hline June & 1957 & 1.51 & 4.63 & 5.71 & 365 & $Z$ & estimated \\
\hline July & 1957 & 1.51 & 4.63 & 5.71 & 365 & $\bar{Z}$ & estimated \\
\hline August & 1957 & 1.51 & 4.63 & 5.71 & 365 & $Z$ & estimated \\
\hline September & 1957 & 1.51 & 4.63 & 5.71 & 365 & $\bar{Z}$ & estimated \\
\hline October & 1957 & 1.51 & 4.63 & 5.71 & 365 & $\bar{Z}$ & estimated \\
\hline November & 1957 & 1.51 & 4.63 & 5.71 & 365 & $\bar{Z}$ & estimated \\
\hline December & 1957 & 1.51 & 4.63 & 5.71 & 365 & $Z$ & estimated \\
\hline January & 1958 & 1.61 & 4.92 & 6.07 & 365 & $\mathrm{R}$ & estimated \\
\hline February & 1958 & 1.61 & 4.92 & 6.07 & 365 & $\mathrm{R}$ & estimated \\
\hline March & 1958 & 1.61 & 4.92 & 6.07 & 365 & $\bar{R}$ & estimated \\
\hline April & 1958 & 1.61 & 4.92 & 6.07 & 365 & $\bar{R}$ & estimated \\
\hline
\end{tabular}




\begin{tabular}{|c|c|c|c|c|c|c|c|}
\hline May & 1958 & 1.61 & 4.92 & 6.07 & 365 & $\mathrm{R}$ & estimated \\
\hline June & 1958 & 1.61 & 4.92 & 6.07 & 365 & $\mathrm{R}$ & estimated \\
\hline \begin{tabular}{|l|l|} 
July \\
\end{tabular} & 1958 & 1.61 & 4.92 & 6.07 & 365 & $\bar{R}$ & estimated \\
\hline August & 1958 & 1.61 & 4.92 & 6.07 & 365 & $\bar{R}$ & estimated \\
\hline September & 1958 & 2.10 & 6.44 & 7.95 & 30 & $\mathrm{M}$ & -- \\
\hline October & 1958 & 2.61 & 8.01 & 9.87 & 31 & $M$ & -- \\
\hline November & 1958 & 1.08 & 3.31 & 4.08 & 30 & $\bar{M}$ & -- \\
\hline December & 1958 & 1.57 & 4.83 & 5.95 & 31 & $\bar{M}$ & -- \\
\hline \begin{tabular}{|l|} 
January \\
\end{tabular} & 1959 & 0.96 & 2.95 & 3.64 & 31 & $\bar{M}$ & $\overline{--}$ \\
\hline February & 1959 & 0.62 & 1.90 & 2.34 & 28 & $\bar{M}$ & -- \\
\hline March & 1959 & 1.08 & 3.32 & 4.09 & 31 & $\mathrm{M}$ & -- \\
\hline April & 1959 & 1.27 & 3.89 & 4.80 & 30 & $\bar{M}$ & -- \\
\hline May & 1959 & 1.22 & 3.74 & 4.62 & 31 & $\bar{M}$ & -- \\
\hline June & 1959 & 1.35 & 4.14 & 5.11 & 30 & $\bar{M}$ & -- \\
\hline \begin{tabular}{|l|} 
July \\
\end{tabular} & 1959 & 0.00 & 0.00 & 0.00 & 31 & $\bar{M}$ & $\overline{--}$ \\
\hline August & 1959 & 1.48 & 4.54 & 5.59 & 31 & $\bar{M}$ & -- \\
\hline September & 1959 & 0.99 & 3.04 & 3.75 & 30 & $\mathrm{M}$ & -- \\
\hline October & 1959 & 1.07 & 3.29 & 4.06 & 31 & $\mathrm{M}$ & -- \\
\hline November & 1959 & 0.67 & 2.05 & 2.52 & 30 & $\bar{M}$ & -- \\
\hline December & 1959 & 0.74 & 2.26 & 2.78 & 31 & $\bar{M}$ & -- \\
\hline \begin{tabular}{|l|} 
January \\
\end{tabular} & 1960 & 0.80 & 2.44 & 3.01 & 31 & $\bar{M}$ & $\overline{--}$ \\
\hline February & 1960 & 0.89 & 2.73 & 3.36 & 29 & $\mathrm{M}$ & -- \\
\hline March & 1960 & 0.88 & 2.70 & 3.33 & 31 & $\bar{M}$ & -- \\
\hline April & 1960 & 1.10 & 3.37 & 4.16 & 30 & $\bar{M}$ & -- \\
\hline May & 1960 & 1.09 & 3.34 & 4.12 & 31 & $\bar{M}$ & -- \\
\hline June & 1960 & 1.26 & 3.86 & 4.76 & 30 & $\bar{M}$ & -- \\
\hline \begin{tabular}{|l|} 
July \\
\end{tabular} & 1960 & 2.15 & 6.59 & 8.13 & 31 & $\bar{M}$ & -- \\
\hline August & 1960 & 2.36 & 7.25 & 8.94 & 31 & $\bar{M}$ & -- \\
\hline September & 1960 & 2.38 & 7.29 & 8.99 & 30 & $\mathrm{M}$ & -- \\
\hline October & 1960 & 3.14 & 9.65 & 11.90 & 31 & $\bar{M}$ & -- \\
\hline November & 1960 & 2.25 & 6.92 & 8.53 & 30 & $M$ & -- \\
\hline December & 1960 & 1.26 & 3.87 & 4.77 & 31 & $\bar{M}$ & -- \\
\hline \begin{tabular}{|l|} 
January \\
\end{tabular} & 1961 & 0.00 & 0.00 & 0.00 & 31 & $\bar{M}$ & -- \\
\hline February & 1961 & 0.00 & 0.00 & 0.00 & 28 & $\bar{M}$ & -- \\
\hline March & 1961 & 0.00 & 0.00 & 0.00 & 31 & $\bar{M}$ & -- \\
\hline April & 1961 & 0.00 & 0.00 & 0.00 & 30 & $\bar{M}$ & -- \\
\hline May & 1961 & 2.30 & 7.05 & 8.69 & 31 & $\bar{M}$ & -- \\
\hline June & 1961 & 2.18 & 6.68 & 8.23 & 30 & $\bar{M}$ & -- \\
\hline \begin{tabular}{|l|} 
July \\
\end{tabular} & 1961 & 2.08 & 6.40 & 7.89 & 31 & $\bar{M}$ & -- \\
\hline August & 1961 & 2.08 & 6.37 & 7.86 & 31 & $\mathrm{M}$ & -- \\
\hline September & 1961 & 1.78 & 5.48 & 6.75 & 30 & $\mathrm{M}$ & -- \\
\hline October & 1961 & 3.51 & 10.78 & 13.30 & 31 & $\mathrm{M}$ & -- \\
\hline November & 1961 & 4.68 & 14.35 & 17.70 & 30 & $\bar{M}$ & -- \\
\hline December & 1961 & 3.53 & 10.83 & 13.36 & 31 & $\bar{M}$ & -- \\
\hline \begin{tabular}{|l|} 
January \\
\end{tabular} & 1962 & 4.64 & 14.25 & 17.57 & 31 & $\bar{M}$ & $\overline{--}$ \\
\hline February & 1962 & 4.26 & 13.06 & 16.11 & 28 & $\mathrm{M}$ & -- \\
\hline March & 1962 & 6.23 & 19.10 & 23.56 & 31 & $\mathrm{M}$ & -- \\
\hline April & 1962 & 6.35 & 19.49 & 24.04 & 30 & $\bar{M}$ & -- \\
\hline May & 1962 & 6.59 & 20.22 & 24.94 & 31 & $\bar{M}$ & -- \\
\hline June & 1962 & 7.23 & 22.19 & 27.37 & 30 & $\bar{M}$ & -- \\
\hline \begin{tabular}{|l|} 
July \\
\end{tabular} & 1962 & 9.27 & 28.46 & 35.10 & 31 & $\bar{M}$ & -- \\
\hline August & 1962 & 9.20 & 28.24 & 34.83 & 31 & $\bar{M}$ & $\overline{--}$ \\
\hline
\end{tabular}


WW-5C Monthly Pumping Data

\begin{tabular}{|c|c|c|c|c|c|c|c|}
\hline September & 1962 & 6.47 & 19.85 & 24.48 & 30 & $\bar{M}$ & - \\
\hline October & 1962 & 5.21 & 15.99 & 19.72 & 31 & $\bar{M}$ & $\overline{--}$ \\
\hline November & 1962 & 2.61 & 8.00 & 9.86 & 30 & $\bar{M}$ & - \\
\hline December & 1962 & 4.79 & 14.70 & 18.13 & 31 & $\bar{M}$ & -- \\
\hline \begin{tabular}{|l|} 
January \\
\end{tabular} & 1963 & 5.04 & 15.48 & 19.09 & 31 & $M$ & -- \\
\hline February & 1963 & 4.28 & 13.13 & 16.19 & 28 & $M$ & - \\
\hline March & 1963 & 5.57 & 17.10 & 21.09 & 31 & $\bar{M}$ & - \\
\hline April & 1963 & 5.80 & 17.79 & 21.94 & 30 & $\bar{M}$ & - \\
\hline May & 1963 & 7.59 & 23.29 & 28.73 & 31 & $\bar{M}$ & -- \\
\hline \begin{tabular}{|l|} 
June \\
\end{tabular} & 1963 & 7.30 & 22.41 & 27.64 & 30 & $M$ & - \\
\hline \begin{tabular}{|l|} 
July \\
\end{tabular} & 1963 & 7.37 & 22.63 & 27.91 & 31 & $M$ & -- \\
\hline August & 1963 & 7.71 & 23.65 & 29.17 & 31 & $\bar{M}$ & - \\
\hline September & 1963 & 5.43 & 16.66 & 20.54 & 30 & $\bar{M}$ & - \\
\hline October & 1963 & 5.44 & 16.68 & 20.58 & 31 & $\bar{M}$ & -- \\
\hline November & 1963 & 4.34 & 13.31 & 16.41 & 30 & $\bar{M}$ & - \\
\hline December & 1963 & 5.04 & 15.46 & 19.07 & 31 & $\bar{M}$ & -- \\
\hline \begin{tabular}{|l|} 
January \\
\end{tabular} & 1964 & 5.11 & 15.67 & 19.33 & 31 & $M$ & -- \\
\hline February & 1964 & 4.81 & 14.75 & 18.19 & 29 & $M$ & -- \\
\hline March & 1964 & 5.07 & 15.57 & 19.20 & 31 & $\bar{M}$ & - \\
\hline April & 1964 & 5.42 & 16.62 & 20.50 & 30 & $\bar{M}$ & -- \\
\hline May & 1964 & 7.06 & 21.65 & 26.71 & 31 & $M$ & -- \\
\hline June & 1964 & 6.78 & 20.80 & 25.65 & 30 & $\bar{M}$ & - \\
\hline July & 1964 & 7.16 & 21.97 & 27.09 & 31 & $M$ & -- \\
\hline August & 1964 & 4.97 & 15.25 & 18.80 & 31 & $\bar{M}$ & - \\
\hline September & 1964 & 0.77 & 2.36 & 2.91 & 30 & $\bar{M}$ & - \\
\hline October & 1964 & 0.23 & 0.72 & 0.88 & 31 & $\bar{M}$ & -- \\
\hline November & 1964 & 0.43 & 1.33 & 1.64 & 30 & $\bar{M}$ & - \\
\hline December & 1964 & 0.93 & 2.84 & 3.50 & 31 & $\bar{M}$ & - \\
\hline January & 1965 & 1.40 & 4.30 & 5.30 & 31 & $\mathrm{M}$ & - \\
\hline February & 1965 & 5.66 & 17.38 & 21.44 & 28 & $M$ & -- \\
\hline March & 1965 & 7.31 & 22.42 & 27.65 & 31 & $\bar{M}$ & - \\
\hline April & 1965 & 7.67 & 23.53 & 29.03 & 30 & $\bar{M}$ & -- \\
\hline May & 1965 & 3.62 & 11.11 & 13.70 & 31 & $M$ & -- \\
\hline June & 1965 & 2.86 & 8.79 & 10.84 & 30 & $\bar{M}$ & - \\
\hline \begin{tabular}{|l|} 
July \\
\end{tabular} & 1965 & 5.61 & 17.21 & 21.23 & 31 & $M$ & -- \\
\hline August & 1965 & 4.54 & 13.94 & 17.19 & 31 & $M$ & -- \\
\hline September & 1965 & 4.67 & 14.32 & 17.66 & 26 & $\bar{M}$ & - \\
\hline November & 1965 & 3.41 & 10.46 & 12.90 & 29 & $\bar{M}$ & - \\
\hline December & 1965 & 4.74 & 14.54 & 17.94 & 31 & $\bar{M}$ & - \\
\hline January & 1966 & 5.39 & 16.53 & 20.38 & 31 & $\bar{M}$ & - \\
\hline February & 1966 & 3.83 & 11.75 & 14.50 & 28 & $\bar{M}$ & -- \\
\hline March & 1966 & 4.01 & 12.32 & 15.19 & 31 & $M$ & -- \\
\hline April & 1966 & 5.64 & 17.29 & 21.33 & 30 & $\bar{M}$ & -- \\
\hline May & 1966 & 7.64 & 23.43 & 28.90 & 29 & $\mathrm{M}$ & -- \\
\hline June & 1966 & -- & $\overline{--}$ & -- & 0 & $\mathrm{I}$ & - \\
\hline July & 1966 & $\overline{--}$ & $\overline{--}$ & -- & 0 & $\mathrm{~T}$ & - \\
\hline August & 1966 & 2.17 & 6.64 & 8.19 & 28 & $M$ & -- \\
\hline September & 1966 & 0.58 & 1.79 & 2.21 & 5 & $M$ & - \\
\hline October & 1966 & 5.68 & 17.43 & 21.50 & 31 & $\bar{M}$ & - \\
\hline November & 1966 & 4.41 & 13.54 & 16.70 & 30 & $\bar{M}$ & - \\
\hline December & 1966 & 3.89 & 11.94 & 14.73 & 31 & $\bar{M}$ & - \\
\hline \begin{tabular}{|l|} 
January \\
\end{tabular} & 1967 & 5.69 & 17.46 & 21.53 & 31 & $\bar{M}$ & - \\
\hline
\end{tabular}




\begin{tabular}{|c|c|c|c|c|c|c|c|}
\hline February & 1967 & 3.94 & 12.09 & 14.91 & 28 & $\bar{M}$ & -- \\
\hline March & 1967 & 3.13 & 9.61 & 11.86 & 31 & $M$ & -- \\
\hline April & 1967 & 1.74 & 5.33 & 6.57 & 30 & $\mathrm{M}$ & -- \\
\hline May & 1967 & 0.00 & 0.00 & 0.00 & 31 & $M$ & -- \\
\hline June & 1967 & 0.29 & 0.90 & 1.11 & 30 & $M$ & -- \\
\hline \begin{tabular}{|l} 
July \\
\end{tabular} & 1967 & 4.80 & 14.73 & 18.17 & 365 & $\bar{R}$ & estimated \\
\hline August & 1967 & 4.80 & 14.73 & 18.17 & 365 & $\mathrm{R}$ & estimated \\
\hline September & 1967 & 4.80 & 14.73 & 18.17 & 365 & $\mathrm{R}$ & estimated \\
\hline October & 1967 & 4.80 & 14.73 & 18.17 & 365 & $\mathrm{R}$ & estimated \\
\hline November & 1967 & 4.80 & 14.73 & 18.17 & 365 & $R$ & estimated \\
\hline December & 1967 & 4.80 & 14.73 & 18.17 & 365 & $\mathrm{R}$ & estimated \\
\hline \begin{tabular}{|l|} 
January \\
\end{tabular} & 1968 & 4.96 & 15.21 & 18.77 & 366 & $R$ & estimated \\
\hline February & 1968 & 4.96 & 15.21 & 18.77 & 366 & $R$ & estimated \\
\hline March & 1968 & 4.96 & 15.21 & 18.77 & 366 & $\mathrm{R}$ & estimated \\
\hline April & 1968 & 4.96 & 15.21 & 18.77 & 366 & $\bar{R}$ & estimated \\
\hline May & 1968 & 4.96 & 15.21 & 18.77 & 366 & $\bar{R}$ & estimated \\
\hline June & 1968 & 4.96 & 15.21 & 18.77 & 366 & $\mathrm{R}$ & estimated \\
\hline \begin{tabular}{|l} 
July \\
\end{tabular} & 1968 & 4.96 & 15.21 & 18.77 & 366 & $R$ & estimated \\
\hline August & 1968 & 4.96 & 15.21 & 18.77 & 366 & $\mathrm{R}$ & estimated \\
\hline September & 1968 & 4.96 & 15.21 & 18.77 & 366 & $\mathrm{R}$ & estimated \\
\hline October & 1968 & 4.96 & 15.21 & 18.77 & 366 & $\mathrm{R}$ & estimated \\
\hline November & 1968 & 4.96 & 15.21 & 18.77 & 366 & $\mathrm{R}$ & estimated \\
\hline December & 1968 & 4.96 & 15.21 & 18.77 & 366 & $\mathrm{R}$ & estimated \\
\hline January & 1969 & 3.33 & 10.20 & 12.59 & 365 & $\bar{R}$ & estimated \\
\hline February & 1969 & 3.33 & 10.20 & 12.59 & 365 & $R$ & estimated \\
\hline March & 1969 & 3.33 & 10.20 & 12.59 & 365 & $\bar{R}$ & estimated \\
\hline April & 1969 & 3.33 & 10.20 & 12.59 & 365 & $\mathrm{R}$ & estimated \\
\hline May & 1969 & 3.33 & 10.20 & 12.59 & 365 & $\bar{R}$ & estimated \\
\hline June & 1969 & 3.33 & 10.20 & 12.59 & 365 & $\mathrm{R}$ & estimated \\
\hline July & 1969 & 3.33 & 10.20 & 12.59 & 365 & $\mathrm{R}$ & estimated \\
\hline August & 1969 & 3.33 & 10.20 & 12.59 & 365 & $\mathrm{R}$ & estimated \\
\hline September & 1969 & 3.33 & 10.20 & 12.59 & 365 & $\mathrm{R}$ & estimated \\
\hline October & 1969 & 3.33 & 10.20 & 12.59 & 365 & $\mathrm{R}$ & estimated \\
\hline November & 1969 & 3.33 & 10.20 & 12.59 & 365 & $\mathrm{R}$ & estimated \\
\hline December & 1969 & 3.33 & 10.20 & 12.59 & 365 & $\mathrm{R}$ & estimated \\
\hline January & 1970 & 3.43 & 10.51 & 12.96 & 365 & $\mathrm{R}$ & estimated \\
\hline February & 1970 & 3.43 & 10.51 & 12.96 & 365 & $R$ & estimated \\
\hline March & 1970 & 3.43 & 10.51 & 12.96 & 365 & $\bar{R}$ & estimated \\
\hline April & 1970 & 3.43 & 10.51 & 12.96 & 365 & $\bar{R}$ & estimated \\
\hline May & 1970 & 3.43 & 10.51 & 12.96 & 365 & $\bar{R}$ & estimated \\
\hline June & 1970 & 3.43 & 10.51 & 12.96 & 365 & $\mathrm{R}$ & estimated \\
\hline July & 1970 & 3.43 & 10.51 & 12.96 & 365 & $\mathrm{R}$ & estimated \\
\hline August & 1970 & 3.43 & 10.51 & 12.96 & 365 & $\mathrm{R}$ & estimated \\
\hline September & 1970 & 3.43 & 10.51 & 12.96 & 365 & $\mathrm{R}$ & estimated \\
\hline October & 1970 & 3.43 & 10.51 & 12.96 & 365 & $\mathrm{R}$ & estimated \\
\hline November & 1970 & 3.43 & 10.51 & 12.96 & 365 & $\mathrm{R}$ & estimated \\
\hline December & 1970 & 3.43 & 10.51 & 12.96 & 365 & $\mathrm{R}$ & estimated \\
\hline January & 1971 & 3.68 & 11.30 & 13.94 & 365 & $\mathrm{R}$ & estimated \\
\hline February & 1971 & 3.68 & 11.30 & 13.94 & 365 & $R$ & estimated \\
\hline March & 1971 & 3.68 & 11.30 & 13.94 & 365 & $\bar{R}$ & estimated \\
\hline April & 1971 & 3.68 & 11.30 & 13.94 & 365 & $R$ & estimated \\
\hline May & 1971 & 3.68 & 11.30 & 13.94 & 365 & $\bar{R}$ & estimated \\
\hline
\end{tabular}




\begin{tabular}{|c|c|c|c|c|c|c|c|}
\hline June & 1971 & 3.68 & 11.30 & 13.94 & 365 & $\bar{R}$ & estimated \\
\hline July & 1971 & 3.68 & 11.30 & 13.94 & 365 & $\mathrm{R}$ & estimated \\
\hline August & 1971 & 3.68 & 11.30 & 13.94 & 365 & $\bar{R}$ & estimated \\
\hline September & 1971 & 3.68 & 11.30 & 13.94 & 365 & $\bar{R}$ & estimated \\
\hline October & 1971 & 3.68 & 11.30 & 13.94 & 365 & $\bar{R}$ & estimated \\
\hline November & 1971 & 3.68 & 11.30 & 13.94 & 365 & $\bar{R}$ & estimated \\
\hline December & 1971 & 3.68 & 11.30 & 13.94 & 365 & $R$ & estimated \\
\hline January & 1972 & 3.58 & 11.00 & 13.56 & 366 & $\mathrm{H}$ & estimated \\
\hline February & 1972 & 3.58 & 11.00 & 13.56 & 366 & $\mathrm{H}$ & estimated \\
\hline March & 1972 & 3.58 & 11.00 & 13.56 & 366 & $\bar{H}$ & estimated \\
\hline April & 1972 & 3.58 & 11.00 & 13.56 & 366 & $\overline{\mathrm{H}}$ & estimated \\
\hline May & 1972 & 3.58 & 11.00 & 13.56 & 366 & $\vec{H}$ & estimated \\
\hline \begin{tabular}{|l|} 
June \\
\end{tabular} & 1972 & 3.58 & 11.00 & 13.56 & 366 & $\bar{H}$ & estimated \\
\hline July & 1972 & 3.58 & 11.00 & 13.56 & 366 & $\mathrm{H}$ & estimated \\
\hline August & 1972 & 3.58 & 11.00 & 13.56 & 366 & $\bar{H}$ & estimated \\
\hline September & 1972 & 3.58 & 11.00 & 13.56 & 366 & $\overline{\mathrm{H}}$ & estimated \\
\hline October & 1972 & 3.58 & 11.00 & 13.56 & 366 & $\bar{H}$ & estimated \\
\hline November & 1972 & 3.58 & 11.00 & 13.56 & 366 & $\bar{H}$ & estimated \\
\hline December & 1972 & 3.58 & 11.00 & 13.56 & 366 & $\mathrm{H}$ & estimated \\
\hline January & 1973 & 3.02 & 9.26 & 11.42 & 365 & $\mathrm{H}$ & estimated \\
\hline February & 1973 & 3.02 & 9.26 & 11.42 & 365 & $\bar{H}$ & estimated \\
\hline March & 1973 & 3.02 & 9.26 & 11.42 & 365 & $\mathrm{H}$ & estimated \\
\hline April & 1973 & 3.02 & 9.26 & 11.42 & 365 & $\overline{\mathrm{H}}$ & estimated \\
\hline May & 1973 & 3.02 & 9.26 & 11.42 & 365 & $\overline{\mathrm{H}}$ & estimated \\
\hline June & 1973 & 3.02 & 9.26 & 11.42 & 365 & $\vec{H}$ & estimated \\
\hline July & 1973 & 3.02 & 9.26 & 11.42 & 365 & $\overline{\mathrm{H}}$ & estimated \\
\hline August & 1973 & 3.02 & 9.26 & 11.42 & 365 & $\bar{H}$ & estimated \\
\hline September & 1973 & 3.02 & 9.26 & 11.42 & 365 & $\overline{\mathrm{H}}$ & estimated \\
\hline October & 1973 & 3.02 & 9.26 & 11.42 & 365 & $\bar{H}$ & estimated \\
\hline November & 1973 & 3.02 & 9.26 & 11.42 & 365 & $\bar{H}$ & estimated \\
\hline December & 1973 & 3.02 & 9.26 & 11.42 & 365 & $\mathrm{H}$ & estimated \\
\hline January & 1974 & 3.45 & 10.59 & 13.06 & 365 & $\mathrm{H}$ & estimated \\
\hline February & 1974 & 3.45 & 10.59 & 13.06 & 365 & $\mathrm{H}$ & estimated \\
\hline March & 1974 & 3.45 & 10.59 & 13.06 & 365 & $\mathrm{H}$ & estimated \\
\hline April & 1974 & 3.45 & 10.59 & 13.06 & 365 & $\overline{\mathrm{H}}$ & estimated \\
\hline May & 1974 & 3.45 & 10.59 & 13.06 & 365 & $\bar{H}$ & estimated \\
\hline \begin{tabular}{|l|} 
June \\
\end{tabular} & 1974 & 3.45 & 10.59 & 13.06 & 365 & $\vec{H}$ & estimated \\
\hline \begin{tabular}{|l} 
July \\
\end{tabular} & 1974 & 3.45 & 10.59 & 13.06 & 365 & $\overline{\mathrm{H}}$ & estimated \\
\hline August & 1974 & 3.45 & 10.59 & 13.06 & 365 & $\bar{H}$ & estimated \\
\hline September & 1974 & 3.45 & 10.59 & 13.06 & 365 & $\bar{H}$ & estimated \\
\hline October & 1974 & 3.45 & 10.59 & 13.06 & 365 & $\overline{\mathrm{H}}$ & estimated \\
\hline November & 1974 & 3.45 & 10.59 & 13.06 & 365 & $\bar{H}$ & estimated \\
\hline December & 1974 & 3.45 & 10.59 & 13.06 & 365 & $\mathrm{H}$ & estimated \\
\hline \begin{tabular}{|l|} 
January \\
\end{tabular} & 1975 & 3.48 & 10.66 & 13.15 & 365 & $\overline{\mathrm{H}}$ & estimated \\
\hline February & 1975 & 3.48 & 10.66 & 13.15 & 365 & $\mathrm{H}$ & estimated \\
\hline \begin{tabular}{|l|l} 
March \\
\end{tabular} & 1975 & 3.48 & 10.66 & 13.15 & 365 & $\bar{H}$ & estimated \\
\hline April & 1975 & 3.48 & 10.66 & 13.15 & 365 & $\overline{\mathrm{H}}$ & estimated \\
\hline May & 1975 & 3.48 & 10.66 & 13.15 & 365 & $\mathrm{H}$ & estimated \\
\hline \begin{tabular}{|l|} 
June \\
\end{tabular} & 1975 & 3.48 & 10.66 & 13.15 & 365 & $\vec{H}$ & estimated \\
\hline \begin{tabular}{|l|l|} 
July \\
\end{tabular} & 1975 & 3.48 & 10.66 & 13.15 & 365 & $\bar{H}$ & estimated \\
\hline August & 1975 & 3.48 & 10.66 & 13.15 & 365 & $\mathrm{H}$ & estimated \\
\hline September & 1975 & 3.48 & 10.66 & 13.15 & 365 & $\bar{H}$ & estimated \\
\hline
\end{tabular}




\begin{tabular}{|c|c|c|c|c|c|c|c|}
\hline October & 1975 & 3.48 & 10.66 & 13.15 & 365 & $\overline{\mathrm{H}}$ & estimated \\
\hline November & 1975 & 3.48 & 10.66 & 13.15 & 365 & $\bar{H}$ & estimated \\
\hline December & 1975 & 3.48 & 10.66 & 13.15 & 365 & $\overline{\mathrm{H}}$ & estimated \\
\hline January & 1976 & 3.02 & 9.26 & 11.42 & 366 & $\bar{H}$ & estimated \\
\hline February & 1976 & 3.02 & 9.26 & 11.42 & 366 & $\bar{H}$ & estimated \\
\hline \begin{tabular}{|l} 
March \\
\end{tabular} & 1976 & 3.02 & 9.26 & 11.42 & 366 & $\overline{\mathrm{H}}$ & estimated \\
\hline April & 1976 & 3.02 & 9.26 & 11.42 & 366 & $\overline{\mathrm{H}}$ & estimated \\
\hline May & 1976 & 3.02 & 9.26 & 11.42 & 366 & $\mathrm{H}$ & estimated \\
\hline June & 1976 & 3.02 & 9.26 & 11.42 & 366 & $\mathrm{H}$ & estimated \\
\hline July & 1976 & 3.02 & 9.26 & 11.42 & 366 & $\mathrm{H}$ & estimated \\
\hline August & 1976 & 3.02 & 9.26 & 11.42 & 366 & $\overline{\mathrm{H}}$ & estimated \\
\hline September & 1976 & 3.02 & 9.26 & 11.42 & 366 & $\bar{H}$ & estimated \\
\hline October & 1976 & 3.02 & 9.26 & 11.42 & 366 & $\bar{H}$ & estimated \\
\hline November & 1976 & 3.02 & 9.26 & 11.42 & 366 & $\bar{H}$ & estimated \\
\hline December & 1976 & 3.02 & 9.26 & 11.42 & 366 & $\overline{\mathrm{H}}$ & estimated \\
\hline January & 1977 & 2.77 & 8.49 & 10.47 & 365 & $\bar{H}$ & estimated \\
\hline February & 1977 & 2.77 & 8.49 & 10.47 & 365 & $\bar{H}$ & estimated \\
\hline \begin{tabular}{|l|l} 
March \\
\end{tabular} & 1977 & 2.77 & 8.49 & 10.47 & 365 & $\overline{\mathrm{H}}$ & estimated \\
\hline April & 1977 & 2.77 & 8.49 & 10.47 & 365 & $\bar{H}$ & estimated \\
\hline May & 1977 & 2.77 & 8.49 & 10.47 & 365 & $\mathrm{H}$ & estimated \\
\hline June & 1977 & 2.77 & 8.49 & 10.47 & 365 & $\overline{\mathrm{H}}$ & estimated \\
\hline July & 1977 & 2.77 & 8.49 & 10.47 & 365 & $\mathrm{H}$ & estimated \\
\hline August & 1977 & 2.77 & 8.49 & 10.47 & 365 & $\mathrm{H}$ & estimated \\
\hline September & 1977 & 2.77 & 8.49 & 10.47 & 365 & $\overline{\mathrm{H}}$ & estimated \\
\hline October & 1977 & 2.77 & 8.49 & 10.47 & 365 & $\mathrm{H}$ & estimated \\
\hline November & 1977 & 2.77 & 8.49 & 10.47 & 365 & $\bar{H}$ & estimated \\
\hline December & 1977 & 2.77 & 8.49 & 10.47 & 365 & $\overline{\mathrm{H}}$ & estimated \\
\hline January & 1978 & 2.96 & 9.08 & 11.20 & 365 & $\bar{H}$ & estimated \\
\hline February & 1978 & 2.96 & 9.08 & 11.20 & 365 & $\bar{H}$ & estimated \\
\hline \begin{tabular}{|l|l} 
March \\
\end{tabular} & 1978 & 2.96 & 9.08 & 11.20 & 365 & $\bar{H}$ & estimated \\
\hline April & 1978 & 2.96 & 9.08 & 11.20 & 365 & $\mathrm{H}$ & estimated \\
\hline May & 1978 & 2.96 & 9.08 & 11.20 & 365 & $\mathrm{H}$ & estimated \\
\hline June & 1978 & 2.96 & 9.08 & 11.20 & 365 & $\bar{H}$ & estimated \\
\hline July & 1978 & 2.96 & 9.08 & 11.20 & 365 & $\overline{\mathrm{H}}$ & estimated \\
\hline August & 1978 & 2.96 & 9.08 & 11.20 & 365 & $\mathrm{H}$ & estimated \\
\hline September & 1978 & 2.96 & 9.08 & 11.20 & 365 & $\overline{\mathrm{H}}$ & estimated \\
\hline October & 1978 & 2.96 & 9.08 & 11.20 & 365 & $\mathrm{H}$ & estimated \\
\hline November & 1978 & 2.96 & 9.08 & 11.20 & 365 & $\overline{\mathrm{H}}$ & estimated \\
\hline December & 1978 & 2.96 & 9.08 & 11.20 & 365 & $\mathrm{H}$ & estimated \\
\hline January & 1979 & 2.61 & 8.00 & 9.87 & 365 & $\overline{\mathrm{H}}$ & estimated \\
\hline February & 1979 & 2.61 & 8.00 & 9.87 & 365 & $\bar{H}$ & estimated \\
\hline March & 1979 & 2.61 & 8.00 & 9.87 & 365 & $\overline{\mathrm{H}}$ & estimated \\
\hline April & 1979 & 2.61 & 8.00 & 9.87 & 365 & $\mathrm{H}$ & estimated \\
\hline May & 1979 & 2.61 & 8.00 & 9.87 & 365 & $\overline{\mathrm{H}}$ & estimated \\
\hline June & 1979 & 2.61 & 8.00 & 9.87 & 365 & $\bar{H}$ & estimated \\
\hline July & 1979 & 2.61 & 8.00 & 9.87 & 365 & $\mathrm{H}$ & estimated \\
\hline August & 1979 & 2.61 & 8.00 & 9.87 & 365 & $\mathrm{H}$ & estimated \\
\hline September & 1979 & 2.61 & 8.00 & 9.87 & 365 & $\mathrm{H}$ & estimated \\
\hline October & 1979 & 2.61 & 8.00 & 9.87 & 365 & $\mathrm{H}$ & estimated \\
\hline November & 1979 & 2.61 & 8.00 & 9.87 & 365 & $\overline{\mathrm{H}}$ & estimated \\
\hline December & 1979 & 2.61 & 8.00 & 9.87 & 365 & $\mathrm{H}$ & estimated \\
\hline \begin{tabular}{|l|} 
January \\
\end{tabular} & 1980 & 3.10 & 9.51 & 11.73 & 366 & $\overline{\mathrm{H}}$ & estimated \\
\hline
\end{tabular}




\begin{tabular}{|c|c|c|c|c|c|c|c|}
\hline February & 1980 & 3.10 & 9.51 & 11.73 & 366 & $\mathrm{H}$ & estimated \\
\hline March & 1980 & 3.10 & 9.51 & 11.73 & 366 & $\overline{\mathrm{H}}$ & estimated \\
\hline April & 1980 & 3.10 & 9.51 & 11.73 & 366 & $\bar{H}$ & estimated \\
\hline May & 1980 & 3.10 & 9.51 & 11.73 & 366 & $\mathrm{H}$ & estimated \\
\hline June & 1980 & 3.10 & 9.51 & 11.73 & 366 & $\mathrm{H}$ & estimated \\
\hline July & 1980 & 3.10 & 9.51 & 11.73 & 366 & $\mathrm{H}$ & estimated \\
\hline August & 1980 & 3.10 & 9.51 & 11.73 & 366 & $\overline{\mathrm{H}}$ & estimated \\
\hline September & 1980 & 3.10 & 9.51 & 11.73 & 366 & $\overline{\mathrm{H}}$ & estimated \\
\hline October & 1980 & 3.10 & 9.51 & 11.73 & 366 & $\bar{H}$ & estimated \\
\hline November & 1980 & 3.10 & 9.51 & 11.73 & 366 & $\overline{\mathrm{H}}$ & estimated \\
\hline December & 1980 & 3.10 & 9.51 & 11.73 & 366 & $\bar{H}$ & estimated \\
\hline January & 1981 & 3.56 & 10.92 & 13.47 & 365 & $\mathrm{H}$ & estimated \\
\hline February & 1981 & 3.56 & 10.92 & 13.47 & 365 & $\mathrm{H}$ & estimated \\
\hline March & 1981 & 3.56 & 10.92 & 13.47 & 365 & $\overline{\mathrm{H}}$ & estimated \\
\hline April & 1981 & 3.56 & 10.92 & 13.47 & 365 & $\bar{H}$ & estimated \\
\hline May & 1981 & 3.56 & 10.92 & 13.47 & 365 & $\overline{\mathrm{H}}$ & estimated \\
\hline June & 1981 & 3.56 & 10.92 & 13.47 & 365 & $\mathrm{H}$ & estimated \\
\hline July & 1981 & 3.56 & 10.92 & 13.47 & 365 & $\mathrm{H}$ & estimated \\
\hline August & 1981 & 3.56 & 10.92 & 13.47 & 365 & $\overline{\mathrm{H}}$ & estimated \\
\hline September & 1981 & 3.56 & 10.92 & 13.47 & 365 & $\overline{\mathrm{H}}$ & estimated \\
\hline October & 1981 & 3.56 & 10.92 & 13.47 & 365 & $\overline{\mathrm{H}}$ & estimated \\
\hline November & 1981 & 3.56 & 10.92 & 13.47 & 365 & $\overline{\mathrm{H}}$ & estimated \\
\hline December & 1981 & 3.56 & 10.92 & 13.47 & 365 & $\mathrm{H}$ & estimated \\
\hline January & 1982 & 4.10 & 12.58 & 15.52 & 365 & $\overline{\mathrm{H}}$ & estimated \\
\hline February & 1982 & 4.10 & 12.58 & 15.52 & 365 & $\mathrm{H}$ & estimated \\
\hline March & 1982 & 4.10 & 12.58 & 15.52 & 365 & $\overline{\mathrm{H}}$ & estimated \\
\hline April & 1982 & 4.10 & 12.58 & 15.52 & 365 & $\overline{\mathrm{H}}$ & estimated \\
\hline May & 1982 & 4.10 & 12.58 & 15.52 & 365 & $\overline{\mathrm{H}}$ & estimated \\
\hline June & 1982 & 4.10 & 12.58 & 15.52 & 365 & $\overline{\mathrm{H}}$ & estimated \\
\hline July & 1982 & 4.10 & 12.58 & 15.52 & 365 & $\mathrm{H}$ & estimated \\
\hline August & 1982 & 4.10 & 12.58 & 15.52 & 365 & $\bar{H}$ & estimated \\
\hline September & 1982 & 4.10 & 12.58 & 15.52 & 365 & $\overline{\mathrm{H}}$ & estimated \\
\hline October & 1982 & 4.10 & 12.58 & 15.52 & 365 & $\overline{\mathrm{H}}$ & estimated \\
\hline November & 1982 & 4.10 & 12.58 & 15.52 & 365 & $\overline{\mathrm{H}}$ & estimated \\
\hline December & 1982 & 4.10 & 12.58 & 15.52 & 365 & $\bar{H}$ & estimated \\
\hline January & 1983 & 4.51 & 13.82 & 17.05 & 31 & $\bar{M}$ & -- \\
\hline February & 1983 & 3.63 & 11.15 & 13.75 & 28 & $\bar{M}$ & -- \\
\hline March & 1983 & 4.82 & 14.78 & 18.22 & 31 & $\bar{M}$ & -- \\
\hline April & 1983 & 3.37 & 10.33 & 12.74 & 30 & $\bar{M}$ & -- \\
\hline May & 1983 & 5.74 & 17.62 & 21.73 & 31 & $\bar{M}$ & $\overline{--}$ \\
\hline June & 1983 & 4.21 & 12.93 & 15.95 & 30 & $\bar{M}$ & -- \\
\hline July & 1983 & 3.97 & 12.19 & 15.03 & 31 & M & -- \\
\hline August & 1983 & 3.25 & 9.98 & 12.31 & 31 & $\bar{M}$ & -- \\
\hline September & 1983 & 2.35 & 7.20 & 8.88 & 30 & $\bar{M}$ & $\overline{--}$ \\
\hline October & 1983 & 2.50 & 7.67 & 9.47 & 31 & $\bar{M}$ & -- \\
\hline November & 1983 & 1.52 & 4.66 & 5.74 & 30 & $M$ & $\overline{--}$ \\
\hline December & 1983 & 2.23 & 6.85 & 8.44 & 31 & $M$ & -- \\
\hline January & 1984 & 2.62 & 8.02 & 9.90 & 31 & $\bar{M}$ & -- \\
\hline February & 1984 & 6.89 & 21.15 & 26.08 & 29 & $\bar{M}$ & -- \\
\hline March & 1984 & 5.94 & 18.23 & 22.48 & 31 & $\bar{M}$ & -- \\
\hline April & 1984 & 4.65 & 14.26 & 17.59 & 30 & $\bar{M}$ & -- \\
\hline May & 1984 & 3.54 & 10.85 & 13.38 & 31 & $\bar{M}$ & $\overline{--}$ \\
\hline
\end{tabular}


WW-5C Monthly Pumping Data

\begin{tabular}{|c|c|c|c|c|c|c|c|}
\hline June & 1984 & 3.88 & 11.90 & 14.67 & 30 & $\bar{M}$ & - \\
\hline July & 1984 & 6.67 & 20.48 & 25.26 & 31 & $\bar{M}$ & $\overline{--}$ \\
\hline August & 1984 & 5.48 & 16.83 & 20.75 & 31 & $\bar{M}$ & - \\
\hline September & 1984 & 4.79 & 14.70 & 18.13 & 30 & $\bar{M}$ & -- \\
\hline October & 1984 & 4.42 & 13.56 & 16.72 & 31 & $M$ & -- \\
\hline November & 1984 & 4.69 & 14.39 & 17.75 & 30 & $\mathrm{M}$ & -- \\
\hline December & 1984 & 5.12 & 15.72 & 19.39 & 31 & $E$ & - \\
\hline January & 1985 & 7.42 & 22.78 & 28.09 & 31 & $E$ & -- \\
\hline February & 1985 & 6.42 & 19.70 & 24.30 & 28 & $\bar{M}$ & -- \\
\hline \begin{tabular}{|l|l} 
March \\
\end{tabular} & 1985 & 7.00 & 21.47 & 26.49 & 31 & $M$ & - \\
\hline April & 1985 & 5.94 & 18.24 & 22.49 & 30 & $M$ & -- \\
\hline May & 1985 & 6.65 & 20.41 & 25.17 & 31 & $M$ & -- \\
\hline June & 1985 & 6.15 & 18.88 & 23.29 & 30 & $\bar{M}$ & - \\
\hline July & 1985 & 5.04 & 15.47 & 19.08 & 31 & $\bar{M}$ & - \\
\hline August & 1985 & 2.42 & 7.44 & 9.18 & 31 & $\bar{M}$ & - \\
\hline September & 1985 & 0.07 & 0.20 & 0.24 & 30 & $\bar{M}$ & -- \\
\hline October & 1985 & 0.00 & 0.00 & 0.00 & 31 & $M$ & -- \\
\hline November & 1985 & 0.00 & 0.00 & 0.00 & 30 & $M$ & -- \\
\hline December & 1985 & 0.00 & 0.00 & 0.00 & 31 & $E$ & - \\
\hline January & 1986 & 0.59 & 1.80 & 2.22 & 31 & $\bar{M}$ & -- \\
\hline February & 1986 & 4.70 & 14.42 & 17.79 & 28 & $M$ & -- \\
\hline March & 1986 & 6.69 & 20.53 & 25.32 & 31 & $M$ & - \\
\hline April & 1986 & 5.62 & 17.24 & 21.27 & 30 & $M$ & -- \\
\hline May & 1986 & 5.61 & 17.22 & 21.24 & 31 & $\bar{M}$ & -- \\
\hline June & 1986 & 4.56 & 13.98 & 17.25 & 30 & $\bar{M}$ & -- \\
\hline July & 1986 & 6.80 & 20.88 & 25.75 & 31 & $\bar{M}$ & - \\
\hline August & 1986 & 8.24 & 25.30 & 31.20 & 31 & $\bar{M}$ & - \\
\hline September & 1986 & 6.02 & 18.46 & 22.77 & 30 & $\bar{M}$ & - \\
\hline October & 1986 & 5.70 & 17.48 & 21.56 & 31 & $M$ & -- \\
\hline November & 1986 & 4.91 & 15.05 & 18.57 & 30 & $M$ & -- \\
\hline December & 1986 & 4.53 & 13.91 & 17.15 & 31 & $\bar{M}$ & - \\
\hline January & 1987 & 4.30 & 13.18 & 16.26 & 31 & $\bar{M}$ & -- \\
\hline February & 1987 & 4.13 & 12.68 & 15.64 & 28 & $M$ & -- \\
\hline March & 1987 & 4.93 & 15.12 & 18.65 & 31 & $M$ & - \\
\hline April & 1987 & 4.42 & 13.57 & 16.74 & 30 & $M$ & -- \\
\hline May & 1987 & 4.74 & 14.53 & 17.92 & 31 & $M$ & -- \\
\hline June & 1987 & 4.22 & 12.94 & 15.96 & 30 & $\bar{M}$ & -- \\
\hline July & 1987 & 3.91 & 12.01 & 14.81 & 31 & $\bar{M}$ & - \\
\hline August & 1987 & 5.44 & 16.69 & 20.58 & 31 & $\bar{M}$ & - \\
\hline September & 1987 & 5.98 & 18.34 & 22.62 & 30 & $\bar{M}$ & -- \\
\hline October & 1987 & 2.30 & 7.05 & 8.69 & 31 & $M$ & -- \\
\hline November & 1987 & 1.67 & 5.12 & 6.31 & 30 & $M$ & -- \\
\hline December & 1987 & 4.26 & 13.07 & 16.12 & 31 & $\bar{M}$ & -- \\
\hline \begin{tabular}{|l|} 
January \\
\end{tabular} & 1988 & 4.76 & 14.61 & 18.01 & 31 & $\bar{M}$ & -- \\
\hline February & 1988 & 5.03 & 15.45 & 19.05 & 29 & $M$ & -- \\
\hline \begin{tabular}{|l|} 
March \\
\end{tabular} & 1988 & 8.81 & 27.05 & 33.36 & 31 & $\bar{M}$ & - \\
\hline April & 1988 & 6.30 & 19.33 & 23.84 & 30 & $\bar{M}$ & -- \\
\hline May & 1988 & 6.48 & 19.90 & 24.54 & 31 & $M$ & - \\
\hline \begin{tabular}{|l|} 
June \\
\end{tabular} & 1988 & 4.36 & 13.37 & 16.49 & 30 & $\bar{M}$ & - \\
\hline July & 1988 & 7.08 & 21.72 & 26.79 & 31 & $\bar{M}$ & - \\
\hline August & 1988 & 5.54 & 17.01 & 20.97 & 31 & $\bar{M}$ & - \\
\hline September & 1988 & 4.98 & 15.29 & 18.86 & 30 & $\bar{M}$ & - \\
\hline
\end{tabular}


WW-5C Monthly Pumping Data

\begin{tabular}{|c|c|c|c|c|c|c|c|}
\hline October & 1988 & 5.11 & 15.68 & 19.34 & 31 & $\bar{M}$ & - \\
\hline November & 1988 & 4.19 & 12.85 & 15.85 & 30 & $\mathrm{M}$ & $\overline{--}$ \\
\hline December & 1988 & 5.14 & 15.77 & 19.45 & 31 & $\mathrm{M}$ & -- \\
\hline \begin{tabular}{|l|} 
January \\
\end{tabular} & 1989 & 5.79 & 17.77 & 21.92 & 31 & $\bar{M}$ & -- \\
\hline February & 1989 & 8.23 & 25.26 & 31.15 & 28 & $\mathrm{M}$ & -- \\
\hline March & 1989 & 3.55 & 10.88 & 13.42 & 31 & $\mathrm{M}$ & -- \\
\hline April & 1989 & 1.77 & 5.42 & 6.68 & 30 & $\mathrm{M}$ & -- \\
\hline May & 1989 & 2.13 & 6.53 & 8.05 & 31 & $\bar{M}$ & -- \\
\hline June & 1989 & 2.14 & 6.56 & 8.09 & 30 & $M$ & - \\
\hline \begin{tabular}{|l} 
July \\
\end{tabular} & 1989 & 2.60 & 7.98 & 9.84 & 31 & $\bar{M}$ & -- \\
\hline August & 1989 & 2.69 & 8.25 & 10.18 & 31 & $M$ & -- \\
\hline September & 1989 & 2.71 & 8.33 & 10.27 & 30 & $\bar{M}$ & -- \\
\hline October & 1989 & 0.95 & 2.90 & 3.58 & 31 & $\mathrm{M}$ & -- \\
\hline November & 1989 & 1.73 & 5.31 & 6.55 & 30 & $M$ & -- \\
\hline December & 1989 & 1.13 & 3.45 & 4.26 & 31 & $\mathrm{M}$ & - \\
\hline \begin{tabular}{|l|} 
January \\
\end{tabular} & 1990 & 1.67 & 5.13 & 6.33 & 31 & $\bar{M}$ & -- \\
\hline February & 1990 & 3.46 & 10.60 & 13.08 & 28 & $M$ & -- \\
\hline March & 1990 & 5.14 & 15.78 & 19.46 & 31 & $\mathrm{M}$ & -- \\
\hline April & 1990 & 4.41 & 13.52 & 16.67 & 30 & $\mathrm{M}$ & -- \\
\hline May & 1990 & 4.08 & 12.51 & 15.43 & 31 & $M$ & -- \\
\hline June & 1990 & 4.65 & 14.27 & 17.61 & 30 & $M$ & -- \\
\hline July & 1990 & 4.42 & 13.57 & 16.74 & 31 & $\mathrm{M}$ & - \\
\hline August & 1990 & 2.22 & 6.82 & 8.42 & 31 & $M$ & -- \\
\hline September & 1990 & 2.58 & 7.92 & 9.77 & 30 & $\mathrm{M}$ & -- \\
\hline October & 1990 & 2.87 & 8.80 & 10.85 & 31 & $\mathrm{M}$ & - \\
\hline November & 1990 & 1.09 & 3.35 & 4.13 & 30 & $M$ & - \\
\hline December & 1990 & 1.80 & 5.53 & 6.82 & 31 & $\mathrm{M}$ & -- \\
\hline \begin{tabular}{|l|} 
January \\
\end{tabular} & 1991 & 1.18 & 3.63 & 4.48 & 31 & $\bar{M}$ & -- \\
\hline February & 1991 & 1.87 & 5.74 & 7.07 & 28 & $M$ & - \\
\hline March & 1991 & 0.90 & 2.77 & 3.42 & 31 & $\mathrm{M}$ & -- \\
\hline April & 1991 & 1.87 & 5.75 & 7.09 & 30 & $\mathrm{M}$ & - \\
\hline May & 1991 & 3.15 & 9.65 & 11.91 & 31 & $M$ & - \\
\hline June & 1991 & 1.62 & 4.98 & 6.15 & 30 & $M$ & -- \\
\hline July & 1991 & 2.23 & 6.85 & 8.45 & 31 & $\mathrm{M}$ & -- \\
\hline August & 1991 & 2.70 & 8.29 & 10.22 & 31 & $M$ & -- \\
\hline September & 1991 & 2.10 & 6.43 & 7.93 & 30 & $\bar{M}$ & -- \\
\hline October & 1991 & 2.87 & 8.81 & 10.87 & 31 & $\mathrm{M}$ & -- \\
\hline November & 1991 & 3.01 & 9.24 & 11.39 & 30 & $\mathrm{M}$ & - \\
\hline December & 1991 & 5.27 & 16.17 & 19.95 & 31 & $\mathrm{M}$ & -- \\
\hline January & 1992 & 5.70 & 17.49 & 21.57 & 31 & $M$ & -- \\
\hline February & 1992 & 4.48 & 13.75 & 16.96 & 29 & $M$ & - \\
\hline March & 1992 & 5.34 & 16.40 & 20.22 & 31 & $\mathrm{M}$ & -- \\
\hline April & 1992 & 6.60 & 20.26 & 24.99 & 30 & $\mathrm{M}$ & -- \\
\hline May & 1992 & 3.64 & 11.18 & 13.79 & 31 & $M$ & -- \\
\hline June & 1992 & 3.60 & 11.05 & 13.63 & 30 & $M$ & -- \\
\hline July & 1992 & 6.95 & 21.34 & 26.32 & 31 & $\mathrm{M}$ & -- \\
\hline August & 1992 & 6.87 & 21.09 & 26.01 & 31 & $\mathrm{M}$ & -- \\
\hline September & 1992 & 6.85 & 21.03 & 25.94 & 30 & $M$ & -- \\
\hline October & 1992 & 4.91 & 15.06 & 18.57 & 31 & $\mathrm{M}$ & -- \\
\hline November & 1992 & 2.39 & 7.32 & 9.03 & 30 & $\mathrm{M}$ & - \\
\hline December & 1992 & 3.80 & 11.67 & 14.39 & 31 & $M$ & - \\
\hline \begin{tabular}{|l|} 
January \\
\end{tabular} & 1993 & 4.05 & 12.43 & 15.33 & 31 & $\mathrm{M}$ & - \\
\hline
\end{tabular}


WW-5C Monthly Pumping Data

\begin{tabular}{|c|c|c|c|c|c|c|c|}
\hline February & 1993 & 8.67 & 26.61 & 32.82 & 28 & $\bar{M}$ & - \\
\hline March & 1993 & 9.66 & 29.66 & 36.58 & 31 & $\mathrm{M}$ & $\overline{--}$ \\
\hline April & 1993 & 9.26 & 28.41 & 35.04 & 30 & $\mathrm{M}$ & -- \\
\hline May & 1993 & 5.67 & 17.39 & 21.45 & 31 & $\bar{M}$ & -- \\
\hline June & 1993 & 7.28 & 22.34 & 27.56 & 30 & $\bar{M}$ & - \\
\hline July & 1993 & 0.00 & 0.00 & 0.00 & 31 & $\mathrm{M}$ & -- \\
\hline August & 1993 & 0.69 & 2.12 & 2.62 & 31 & $\mathrm{M}$ & -- \\
\hline September & 1993 & 5.92 & 18.16 & 22.40 & 30 & $\mathrm{M}$ & - \\
\hline October & 1993 & 4.54 & 13.93 & 17.18 & 31 & $M$ & - \\
\hline November & 1993 & 5.58 & 17.11 & 21.11 & 30 & $M$ & -- \\
\hline December & 1993 & 1.84 & 5.64 & 6.96 & 31 & $M$ & -- \\
\hline \begin{tabular}{|l} 
January \\
\end{tabular} & 1994 & 3.02 & 9.25 & 11.41 & 31 & $M$ & -- \\
\hline February & 1994 & 3.93 & 12.05 & 14.87 & 28 & $\bar{M}$ & -- \\
\hline March & 1994 & 2.45 & 7.52 & 9.28 & 31 & $\bar{M}$ & -- \\
\hline April & 1994 & 2.03 & 6.22 & 7.67 & 30 & $\bar{M}$ & - \\
\hline May & 1994 & 2.55 & 7.81 & 9.64 & 31 & $\bar{M}$ & -- \\
\hline June & 1994 & 2.86 & 8.78 & 10.82 & 30 & $M$ & -- \\
\hline July & 1994 & 5.25 & 16.11 & 19.87 & 31 & $\mathrm{M}$ & -- \\
\hline August & 1994 & 8.09 & 24.83 & 30.63 & 31 & $\mathrm{M}$ & -- \\
\hline September & 1994 & 6.37 & 19.55 & 24.11 & 30 & $M$ & -- \\
\hline October & 1994 & 3.51 & 10.78 & 13.29 & 31 & $M$ & - \\
\hline November & 1994 & 3.59 & 11.00 & 13.57 & 30 & $\bar{M}$ & -- \\
\hline December & 1994 & 3.18 & 9.75 & 12.02 & 31 & $M$ & -- \\
\hline January & 1995 & 2.34 & 7.18 & 8.85 & 31 & $\mathrm{M}$ & -- \\
\hline February & 1995 & 2.69 & 8.27 & 10.19 & 28 & $\mathrm{M}$ & - \\
\hline March & 1995 & 2.55 & 7.83 & 9.65 & 31 & $\mathrm{M}$ & - \\
\hline April & 1995 & 3.21 & 9.86 & 12.16 & 30 & $\mathrm{M}$ & -- \\
\hline May & 1995 & 4.21 & 12.91 & 15.93 & 31 & $\bar{M}$ & -- \\
\hline June & 1995 & 5.34 & 16.39 & 20.21 & 30 & $\mathrm{M}$ & - \\
\hline July & 1995 & 5.60 & 17.20 & 21.21 & 31 & $\mathrm{M}$ & -- \\
\hline August & 1995 & 3.76 & 11.55 & 14.24 & 31 & $\mathrm{M}$ & - \\
\hline September & 1995 & 3.51 & 10.77 & 13.28 & 30 & $\mathrm{M}$ & - \\
\hline October & 1995 & 4.14 & 12.69 & 15.65 & 31 & $M$ & -- \\
\hline November & 1995 & 3.27 & 10.02 & 12.36 & 30 & $\mathrm{M}$ & -- \\
\hline December & 1995 & 3.68 & 11.28 & 13.91 & 31 & $M$ & -- \\
\hline January & 1996 & 3.61 & 11.08 & 13.67 & 31 & $\mathrm{M}$ & -- \\
\hline February & 1996 & 3.87 & 11.87 & 14.64 & 29 & $\mathrm{M}$ & - \\
\hline March & 1996 & 4.12 & 12.63 & 15.58 & 31 & $\mathrm{M}$ & - \\
\hline April & 1996 & 3.16 & 9.69 & 11.95 & 30 & $\mathrm{M}$ & -- \\
\hline May & 1996 & 2.01 & 6.17 & 7.61 & 31 & $M$ & -- \\
\hline June & 1996 & 2.95 & 9.04 & 11.15 & 30 & $M$ & -- \\
\hline July & 1996 & 3.04 & 9.33 & 11.50 & 31 & $\mathrm{M}$ & -- \\
\hline August & 1996 & 2.42 & 7.44 & 9.18 & 31 & $\mathrm{M}$ & -- \\
\hline September & 1996 & 2.31 & 7.08 & 8.73 & 30 & $\mathrm{M}$ & - \\
\hline October & 1996 & 2.35 & 7.22 & 8.91 & 31 & $M$ & -- \\
\hline November & 1996 & 2.47 & 7.57 & 9.34 & 30 & $\bar{M}$ & -- \\
\hline December & 1996 & 2.73 & 8.38 & 10.34 & 31 & $M$ & -- \\
\hline \begin{tabular}{|l|} 
January \\
\end{tabular} & 1997 & 2.42 & 7.42 & 9.16 & 31 & $M$ & -- \\
\hline February & 1997 & 2.73 & 8.39 & 10.35 & 28 & $\mathrm{M}$ & -- \\
\hline March & 1997 & 3.04 & 9.32 & 11.49 & 31 & $\mathrm{M}$ & - \\
\hline April & 1997 & 2.56 & 7.86 & 9.70 & 30 & $M$ & - \\
\hline May & 1997 & 2.29 & 7.04 & 8.68 & 31 & $\mathrm{M}$ & - \\
\hline
\end{tabular}


WW-5C Monthly Pumping Data

\begin{tabular}{|c|c|c|c|c|c|c|c|}
\hline June & 1997 & 2.75 & 8.44 & 10.41 & 30 & $\bar{M}$ & -- \\
\hline July & 1997 & 2.71 & 8.33 & 10.27 & 31 & $\bar{M}$ & -- \\
\hline August & 1997 & 2.61 & 8.00 & 9.86 & 31 & $\bar{M}$ & -- \\
\hline September & 1997 & 2.35 & 7.20 & 8.88 & 30 & $\bar{M}$ & - \\
\hline October & 1997 & 2.43 & 7.44 & 9.18 & 31 & $\bar{M}$ & -- \\
\hline November & 1997 & 1.12 & 3.43 & 4.24 & 30 & $\bar{M}$ & - \\
\hline December & 1997 & 0.21 & 0.63 & 0.78 & 31 & $\mathrm{M}$ & - \\
\hline January & 1998 & 2.91 & 8.94 & 11.02 & 31 & $\bar{M}$ & - \\
\hline February & 1998 & 2.93 & 9.00 & 11.11 & 28 & $\bar{M}$ & -- \\
\hline March & 1998 & 3.47 & 10.64 & 13.12 & 31 & $\bar{M}$ & - \\
\hline April & 1998 & 2.63 & 8.08 & 9.96 & 30 & $\bar{M}$ & -- \\
\hline May & 1998 & 0.71 & 2.18 & 2.69 & 31 & $\bar{M}$ & - \\
\hline June & 1998 & 0.96 & 2.95 & 3.64 & 30 & $\bar{M}$ & -- \\
\hline July & 1998 & 4.12 & 12.64 & 15.59 & 31 & $\bar{M}$ & - \\
\hline August & 1998 & 3.26 & 10.02 & 12.35 & 31 & $\bar{M}$ & -- \\
\hline September & 1998 & 2.92 & 8.97 & 11.06 & 30 & $\bar{M}$ & - \\
\hline October & 1998 & 3.04 & 9.34 & 11.52 & 31 & $\bar{M}$ & - \\
\hline November & 1998 & 2.86 & 8.76 & 10.81 & 30 & $\bar{M}$ & - \\
\hline December & 1998 & 2.59 & 7.96 & 9.82 & 31 & $\mathrm{M}$ & - \\
\hline January & 1999 & 3.15 & 9.65 & 11.90 & 31 & $M$ & - \\
\hline February & 1999 & 2.80 & 8.60 & 10.60 & 28 & $\bar{M}$ & - \\
\hline March & 1999 & 3.08 & 9.46 & 11.67 & 31 & $\bar{M}$ & - \\
\hline April & 1999 & 2.52 & 7.73 & 9.53 & 30 & $\bar{M}$ & - \\
\hline May & 1999 & 2.85 & 8.73 & 10.77 & 31 & $\bar{M}$ & - \\
\hline June & 1999 & 2.80 & 8.60 & 10.60 & 30 & $\bar{M}$ & - \\
\hline \begin{tabular}{|l} 
July \\
\end{tabular} & 1999 & 3.09 & 9.47 & 11.68 & 31 & $\bar{M}$ & - \\
\hline August & 1999 & 2.92 & 8.97 & 11.07 & 31 & $\bar{M}$ & - \\
\hline September & 1999 & 2.60 & 7.98 & 9.85 & 30 & $\bar{M}$ & - \\
\hline October & 1999 & 2.76 & 8.47 & 10.44 & 31 & $M$ & - \\
\hline November & 1999 & 2.99 & 9.19 & 11.33 & 30 & $\bar{M}$ & - \\
\hline December & 1999 & 3.33 & 10.21 & 12.59 & 31 & $\mathrm{M}$ & - \\
\hline \begin{tabular}{|l} 
January \\
\end{tabular} & 2000 & 3.41 & 10.46 & 12.90 & 31 & $M$ & -- \\
\hline February & 2000 & 3.05 & 9.35 & 11.53 & 29 & $\bar{M}$ & - \\
\hline March & 2000 & 3.30 & 10.12 & 12.49 & 31 & $\bar{M}$ & - \\
\hline April & 2000 & 3.25 & 9.96 & 12.28 & 30 & $\bar{M}$ & - \\
\hline May & 2000 & 3.50 & 10.74 & 13.24 & 31 & $\bar{M}$ & - \\
\hline June & 2000 & 3.19 & 9.78 & 12.07 & 30 & $\bar{M}$ & - \\
\hline \begin{tabular}{|l} 
July \\
\end{tabular} & 2000 & 2.88 & 8.82 & 10.88 & 31 & $\mathrm{M}$ & - \\
\hline August & 2000 & 2.71 & 8.33 & 10.27 & 31 & $\bar{M}$ & - \\
\hline September & 2000 & 2.92 & 8.95 & 11.04 & 30 & $\bar{M}$ & - \\
\hline October & 2000 & 2.57 & 7.90 & 9.74 & 31 & $\bar{M}$ & -- \\
\hline November & 2000 & 2.42 & 7.42 & 9.15 & 30 & $\bar{M}$ & - \\
\hline December & 2000 & 2.62 & 8.03 & 9.90 & 31 & $\bar{M}$ & - \\
\hline January & 2001 & 2.74 & 8.40 & 10.37 & 31 & $\mathrm{M}$ & - \\
\hline February & 2001 & 2.44 & 7.50 & 9.25 & 28 & $M$ & - \\
\hline March & 2001 & 2.61 & 8.02 & 9.89 & 31 & $\bar{M}$ & - \\
\hline April & 2001 & 2.14 & 6.56 & 8.09 & 30 & $\bar{M}$ & - \\
\hline May & 2001 & 1.64 & 5.04 & 6.22 & 31 & $\mathrm{M}$ & -- \\
\hline June & 2001 & 1.34 & 4.13 & 5.09 & 30 & $\mathrm{M}$ & - \\
\hline \begin{tabular}{|l} 
July \\
\end{tabular} & 2001 & 0.97 & 2.96 & 3.65 & 31 & $\bar{M}$ & - \\
\hline August & 2001 & 1.74 & 5.35 & 6.60 & 31 & $\mathrm{M}$ & - \\
\hline September & 2001 & 1.46 & 4.47 & 5.51 & 30 & $\bar{M}$ & - \\
\hline
\end{tabular}




\begin{tabular}{|l|l|l|l|l|l|l|l|}
\hline October & 2001 & 1.43 & 4.39 & 5.42 & 31 & $\mathrm{M}$ & -- \\
\hline November & 2001 & 1.83 & 5.62 & 6.94 & 30 & $\mathrm{M}$ & -- \\
\hline December & 2001 & 1.22 & 3.75 & 4.62 & 31 & $\mathrm{M}$ & -- \\
\hline January & 2002 & 1.81 & 5.56 & 6.86 & 31 & $\mathrm{M}$ & -- \\
\hline February & 2002 & 0.74 & 2.28 & 2.81 & 28 & $\mathrm{M}$ & -- \\
\hline March & 2002 & 1.59 & 4.89 & 6.03 & 31 & $\mathrm{M}$ & -- \\
\hline April & 2002 & 1.63 & 5.00 & 6.17 & 30 & $\mathrm{M}$ & -- \\
\hline May & 2002 & 1.77 & 5.44 & 6.71 & 31 & $\mathrm{M}$ & -- \\
\hline June & 2002 & 2.37 & 7.27 & 8.97 & 30 & $\mathrm{M}$ & -- \\
\hline July & 2002 & 2.55 & 7.83 & 9.66 & 31 & $\mathrm{M}$ & -- \\
\hline August & 2002 & 1.98 & 6.07 & 7.49 & 31 & $\mathrm{M}$ & -- \\
\hline September & 2002 & 1.98 & 6.08 & 7.50 & 30 & $\mathrm{M}$ & -- \\
\hline October & 2002 & 1.70 & 5.22 & 6.44 & 31 & $\mathrm{M}$ & -- \\
\hline November & 2002 & 2.30 & 7.07 & 8.71 & 30 & $\mathrm{M}$ & -- \\
\hline December & 2002 & 2.56 & 7.87 & 9.71 & 31 & $\mathrm{M}$ & -- \\
\hline January & 2003 & 2.02 & 6.19 & 7.64 & 31 & $\mathrm{M}$ & -- \\
\hline February & 2003 & 1.68 & 5.16 & 6.37 & 28 & $\mathrm{M}$ & -- \\
\hline March & 2003 & 2.21 & 6.77 & 8.35 & 31 & $\mathrm{M}$ & -- \\
\hline April & 2003 & 1.77 & 5.42 & 6.68 & 30 & $\mathrm{M}$ & -- \\
\hline May & 2003 & 1.93 & 5.94 & 7.32 & 31 & $\mathrm{M}$ & -- \\
\hline June & 2003 & 1.12 & 3.44 & 4.24 & 30 & $\mathrm{M}$ & -- \\
\hline July & 2003 & 1.06 & 3.26 & 4.02 & 31 & $\mathrm{M}$ & -- \\
\hline August & 2003 & 1.53 & 4.69 & 5.78 & 31 & $\mathrm{M}$ & -- \\
\hline September & 2003 & 1.65 & 5.07 & 6.25 & 30 & $\mathrm{M}$ & -- \\
\hline October & 2003 & 1.49 & 4.58 & 5.65 & 31 & $\mathrm{M}$ & -- \\
\hline November & 2003 & 1.67 & 5.13 & 6.33 & 30 & $\mathrm{M}$ & -- \\
\hline December & 2003 & 1.66 & 5.08 & 6.26 & 31 & $\mathrm{M}$ & -- \\
\hline
\end{tabular}

aSource: $\mathrm{E}=$ Taken from Bechtel or REECo water production reports and includes estimated values.

$\mathrm{H}=$ Insufficient data to determine monthly value. Annual value listed in annual data set as reported in [Moreo and others, 2003, WRIR 03-4245, Estimated Ground-Water Withdrawals from the Death Valley Regional Flow System, Nevada and California, 1913-98].

$\mathrm{I}=$ Insufficient or no data to calculate monthly total; no water may have been withdrawn for month.

$\mathrm{M}=$ Taken from Bechtel or REECo water production reports.

$\mathrm{R}=$ Insufficient data to determine monthly value. Annual value listed in annual data set as reported in [Claassen, H.C., 1973, Water quality and physical characteristics of Nevada Test Site water-supply wells: U.S. Geological Survey Open-File Report USGS-474-158, 145 p.].

$\mathrm{Z}=$ Insufficient data to determine monthly value. Annual value listed in annual data set as estimated in [Claassen, H.C., 1973, Water quality and physical characteristics of Nevada Test Site water-supply wells: U.S. Geological Survey Open-File Report USGS-474-158, 145 p.].

b

${ }^{b}$ estimated indicates monthly value was estimated from yearly total 
WW-C1 Monthly Pumping Data

\begin{tabular}{|c|c|c|c|c|c|c|c|}
\hline Month & Year & $\begin{array}{l}\text { Million } \\
\text { Gallons }\end{array}$ & Acre-Ft & $\begin{array}{l}\text { Million } \\
\text { Liters }\end{array}$ & $\begin{array}{c}\text { Days } \\
\text { Reported }\end{array}$ & Source $^{a}$ & Comment \\
\hline June & 1962 & 3.78 & 11.61 & 14.32 & 30 & $\bar{M}$ & -- \\
\hline July & 1962 & 5.35 & 16.42 & 20.26 & 31 & $\mathrm{M}$ & -- \\
\hline August & 1962 & 2.34 & 7.17 & 8.84 & 31 & $\mathrm{M}$ & -- \\
\hline September & 1962 & 0.00 & 0.00 & 0.00 & 30 & $\mathrm{M}$ & -- \\
\hline October & 1962 & 1.31 & 4.03 & 4.97 & 31 & $\mathrm{M}$ & -- \\
\hline November & 1962 & 2.50 & 7.67 & 9.46 & 30 & $\mathrm{M}$ & -- \\
\hline December & 1962 & 0.90 & 2.75 & 3.39 & 31 & $\bar{M}$ & -- \\
\hline January & 1963 & 0.21 & 0.64 & 0.79 & 31 & $\mathrm{M}$ & -- \\
\hline February & 1963 & 2.45 & 7.53 & 9.28 & 28 & $\mathrm{M}$ & -- \\
\hline March & 1963 & 1.37 & 4.21 & 5.19 & 31 & $\bar{M}$ & -- \\
\hline April & 1963 & 0.00 & 0.00 & 0.00 & 30 & $\mathrm{M}$ & $\overline{--}$ \\
\hline May & 1963 & 0.33 & 1.00 & 1.24 & 31 & $\mathrm{M}$ & -- \\
\hline June & 1963 & 6.04 & 18.52 & 22.84 & 30 & $\bar{M}$ & -- \\
\hline July & 1963 & 3.64 & 11.18 & 13.78 & 31 & $\mathrm{M}$ & -- \\
\hline August & 1963 & 3.28 & 10.06 & 12.41 & 31 & $\mathrm{M}$ & -- \\
\hline September & 1963 & 5.65 & 17.35 & 21.40 & 30 & $\mathrm{M}$ & -- \\
\hline October & 1963 & 2.67 & 8.20 & 10.11 & 31 & $\bar{M}$ & -- \\
\hline November & 1963 & 2.95 & 9.06 & 11.17 & 30 & $\mathrm{M}$ & -- \\
\hline December & 1963 & 5.36 & 16.45 & 20.29 & 31 & $\mathrm{M}$ & -- \\
\hline January & 1964 & 2.74 & 8.41 & 10.37 & 31 & $M$ & -- \\
\hline February & 1964 & 0.00 & 0.00 & 0.00 & 29 & $\bar{M}$ & -- \\
\hline March & 1964 & 0.00 & 0.00 & 0.00 & 31 & $\mathrm{M}$ & -- \\
\hline April & 1964 & 8.18 & 25.10 & 30.96 & 30 & $\mathrm{M}$ & -- \\
\hline May & 1964 & 1.45 & 4.45 & 5.49 & 31 & $\bar{M}$ & $\overline{--}$ \\
\hline June & 1964 & 7.58 & 23.25 & 28.68 & 30 & $\bar{M}$ & -- \\
\hline July & 1964 & 11.66 & 35.77 & 44.12 & 31 & $\mathrm{M}$ & -- \\
\hline August & 1964 & 9.93 & 30.48 & 37.59 & 31 & $\mathrm{M}$ & -- \\
\hline September & 1964 & 10.42 & 31.98 & 39.44 & 30 & $\mathrm{M}$ & -- \\
\hline October & 1964 & 8.96 & 27.49 & 33.90 & 31 & $\bar{M}$ & -- \\
\hline November & 1964 & 2.05 & 6.29 & 7.75 & 30 & $\mathrm{M}$ & -- \\
\hline December & 1964 & 6.91 & 21.22 & 26.17 & 31 & $\mathrm{M}$ & -- \\
\hline January & 1965 & 5.87 & 18.00 & 22.21 & 31 & $M$ & -- \\
\hline February & 1965 & 5.64 & 17.31 & 21.35 & 28 & $\bar{M}$ & -- \\
\hline March & 1965 & 8.54 & 26.21 & 32.33 & 31 & $\mathrm{M}$ & -- \\
\hline April & 1965 & 3.32 & 10.20 & 12.58 & 30 & $\mathrm{M}$ & -- \\
\hline May & 1965 & 2.56 & 7.86 & 9.69 & 31 & $\mathrm{M}$ & $\overline{--}$ \\
\hline June & 1965 & 1.62 & 4.98 & 6.14 & 30 & $\bar{M}$ & -- \\
\hline July & 1965 & 3.73 & 11.44 & 14.11 & 31 & $\mathrm{M}$ & -- \\
\hline August & 1965 & 4.73 & 14.51 & 17.89 & 31 & $\mathrm{M}$ & -- \\
\hline September & 1965 & 2.65 & 8.14 & 10.04 & 26 & $\mathrm{M}$ & -- \\
\hline October & 1965 & -- & -- & -- & 0 & 1 & -- \\
\hline November & 1965 & 1.88 & 5.78 & 7.13 & 29 & $\mathrm{M}$ & -- \\
\hline December & 1965 & 1.79 & 5.49 & 6.77 & 31 & $\mathrm{M}$ & -- \\
\hline January & 1966 & 1.53 & 4.69 & 5.79 & 31 & $\mathrm{M}$ & -- \\
\hline February & 1966 & 2.68 & 8.23 & 10.15 & 28 & $M$ & -- \\
\hline March & 1966 & 3.60 & 11.05 & 13.63 & 31 & $\mathrm{M}$ & -- \\
\hline April & 1966 & 6.80 & 20.88 & 25.75 & 30 & $\mathrm{M}$ & -- \\
\hline May & 1966 & 7.84 & 24.05 & 29.67 & 29 & $\mathrm{M}$ & $\overline{--}$ \\
\hline June & 1966 & -- & -- & -- & 0 & I & -- \\
\hline
\end{tabular}


WW-C1 Monthly Pumping Data

\begin{tabular}{|c|c|c|c|c|c|c|c|}
\hline July & 1966 & -- & -- & -- & 0 & $\mathrm{I}$ & -- \\
\hline August & 1966 & 7.44 & 22.85 & 28.18 & 28 & $\bar{M}$ & -- \\
\hline September & 1966 & 0.46 & 1.42 & 1.75 & 5 & $\bar{M}$ & -- \\
\hline October & 1966 & 10.28 & 31.55 & 38.91 & 31 & $\bar{M}$ & $\overline{--}$ \\
\hline November & 1966 & 6.32 & 19.39 & 23.91 & 30 & $\bar{M}$ & -- \\
\hline December & 1966 & 3.96 & 12.14 & 14.98 & 31 & $\bar{M}$ & -- \\
\hline January & 1967 & 3.33 & 10.23 & 12.61 & 31 & $\bar{M}$ & -- \\
\hline February & 1967 & 3.48 & 10.69 & 13.18 & 28 & $\bar{M}$ & -- \\
\hline March & 1967 & 6.69 & 20.54 & 25.33 & 31 & $\bar{M}$ & -- \\
\hline April & 1967 & 3.91 & 12.01 & 14.81 & 30 & $\bar{M}$ & $\overline{--}$ \\
\hline May & 1967 & 2.77 & 8.49 & 10.48 & 31 & $\bar{M}$ & -- \\
\hline June & 1967 & 1.23 & 3.77 & 4.65 & 30 & $\bar{M}$ & -- \\
\hline July & 1967 & 2.10 & 6.44 & 7.94 & 365 & $\mathrm{R}$ & estimated \\
\hline August & 1967 & 2.10 & 6.44 & 7.94 & 365 & $\mathrm{R}$ & estimated \\
\hline September & 1967 & 2.10 & 6.44 & 7.94 & 365 & $\bar{R}$ & estimated \\
\hline October & 1967 & 2.10 & 6.44 & 7.94 & 365 & $\bar{R}$ & estimated \\
\hline November & 1967 & 2.10 & 6.44 & 7.94 & 365 & $\mathrm{R}$ & estimated \\
\hline December & 1967 & 2.10 & 6.44 & 7.94 & 365 & $\mathrm{R}$ & estimated \\
\hline January & 1968 & 2.24 & 6.88 & 8.48 & 366 & $\mathrm{R}$ & estimated \\
\hline February & 1968 & 2.24 & 6.88 & 8.48 & 366 & $\mathrm{R}$ & estimated \\
\hline March & 1968 & 2.24 & 6.88 & 8.48 & 366 & $\mathrm{R}$ & estimated \\
\hline April & 1968 & 2.24 & 6.88 & 8.48 & 366 & $\bar{R}$ & estimated \\
\hline May & 1968 & 2.24 & 6.88 & 8.48 & 366 & $R$ & estimated \\
\hline June & 1968 & 2.24 & 6.88 & 8.48 & 366 & $\mathrm{R}$ & estimated \\
\hline July & 1968 & 2.24 & 6.88 & 8.48 & 366 & $\mathrm{R}$ & estimated \\
\hline August & 1968 & 2.24 & 6.88 & 8.48 & 366 & $\mathrm{R}$ & estimated \\
\hline September & 1968 & 2.24 & 6.88 & 8.48 & 366 & $\mathrm{R}$ & estimated \\
\hline October & 1968 & 2.24 & 6.88 & 8.48 & 366 & $\bar{R}$ & estimated \\
\hline November & 1968 & 2.24 & 6.88 & 8.48 & 366 & $R$ & estimated \\
\hline December & 1968 & 2.24 & 6.88 & 8.48 & 366 & $\mathrm{R}$ & estimated \\
\hline January & 1969 & 3.03 & 9.31 & 11.48 & 365 & $\mathrm{R}$ & estimated \\
\hline February & 1969 & 3.03 & 9.31 & 11.48 & 365 & $\mathrm{R}$ & estimated \\
\hline March & 1969 & 3.03 & 9.31 & 11.48 & 365 & $\mathrm{R}$ & estimated \\
\hline April & 1969 & 3.03 & 9.31 & 11.48 & 365 & $\bar{R}$ & estimated \\
\hline May & 1969 & 3.03 & 9.31 & 11.48 & 365 & $R$ & estimated \\
\hline June & 1969 & 3.03 & 9.31 & 11.48 & 365 & $\mathrm{R}$ & estimated \\
\hline July & 1969 & 3.03 & 9.31 & 11.48 & 365 & $\mathrm{R}$ & estimated \\
\hline August & 1969 & 3.03 & 9.31 & 11.48 & 365 & $\mathrm{R}$ & estimated \\
\hline September & 1969 & 3.03 & 9.31 & 11.48 & 365 & $\mathrm{R}$ & estimated \\
\hline October & 1969 & 3.03 & 9.31 & 11.48 & 365 & $\bar{R}$ & estimated \\
\hline November & 1969 & 3.03 & 9.31 & 11.48 & 365 & $R$ & estimated \\
\hline December & 1969 & 3.03 & 9.31 & 11.48 & 365 & $\mathrm{R}$ & estimated \\
\hline January & 1970 & 1.53 & 4.68 & 5.77 & 365 & $\mathrm{R}$ & estimated \\
\hline February & 1970 & 1.53 & 4.68 & 5.77 & 365 & $\mathrm{R}$ & estimated \\
\hline March & 1970 & 1.53 & 4.68 & 5.77 & 365 & $\mathrm{R}$ & estimated \\
\hline April & 1970 & 1.53 & 4.68 & 5.77 & 365 & $\mathrm{R}$ & estimated \\
\hline May & 1970 & 1.53 & 4.68 & 5.77 & 365 & $\bar{R}$ & estimated \\
\hline June & 1970 & 1.53 & 4.68 & 5.77 & 365 & $\mathrm{R}$ & estimated \\
\hline July & 1970 & 1.53 & 4.68 & 5.77 & 365 & $\bar{R}$ & estimated \\
\hline August & 1970 & 1.53 & 4.68 & 5.77 & 365 & $\mathrm{R}$ & estimated \\
\hline September & 1970 & 1.53 & 4.68 & 5.77 & 365 & $\bar{R}$ & estimated \\
\hline October & 1970 & 1.53 & 4.68 & 5.77 & 365 & $\bar{R}$ & estimated \\
\hline
\end{tabular}


WW-C1 Monthly Pumping Data

\begin{tabular}{|c|c|c|c|c|c|c|c|}
\hline November & 1970 & 1.53 & 4.68 & 5.77 & 365 & $\mathrm{R}$ & estimated \\
\hline December & 1970 & 1.53 & 4.68 & 5.77 & 365 & $\overline{\mathrm{R}}$ & estimated \\
\hline January & 1971 & 1.70 & 5.22 & 6.43 & 365 & $\mathrm{R}$ & estimated \\
\hline February & 1971 & 1.70 & 5.22 & 6.43 & 365 & $\bar{R}$ & estimated \\
\hline March & 1971 & 1.70 & 5.22 & 6.43 & 365 & $\mathrm{R}$ & estimated \\
\hline April & 1971 & 1.70 & 5.22 & 6.43 & 365 & $\mathrm{R}$ & estimated \\
\hline May & 1971 & 1.70 & 5.22 & 6.43 & 365 & $\bar{R}$ & estimated \\
\hline June & 1971 & 1.70 & 5.22 & 6.43 & 365 & $\bar{R}$ & estimated \\
\hline July & 1971 & 1.70 & 5.22 & 6.43 & 365 & $\bar{R}$ & estimated \\
\hline August & 1971 & 1.70 & 5.22 & 6.43 & 365 & $\bar{R}$ & estimated \\
\hline September & 1971 & 1.70 & 5.22 & 6.43 & 365 & $\bar{R}$ & estimated \\
\hline October & 1971 & 1.70 & 5.22 & 6.43 & 365 & $\bar{R}$ & estimated \\
\hline November & 1971 & 1.70 & 5.22 & 6.43 & 365 & $\bar{R}$ & estimated \\
\hline December & 1971 & 1.70 & 5.22 & 6.43 & 365 & $\overline{\mathrm{R}}$ & estimated \\
\hline January & 1972 & 1.66 & 5.09 & 6.28 & 366 & $\overline{\mathrm{H}}$ & estimated \\
\hline February & 1972 & 1.66 & 5.09 & 6.28 & 366 & $\overline{\mathrm{H}}$ & estimated \\
\hline March & 1972 & 1.66 & 5.09 & 6.28 & 366 & $\overline{\mathrm{H}}$ & estimated \\
\hline April & 1972 & 1.66 & 5.09 & 6.28 & 366 & $\mathrm{H}$ & estimated \\
\hline May & 1972 & 1.66 & 5.09 & 6.28 & 366 & $\overline{\mathrm{H}}$ & estimated \\
\hline June & 1972 & 1.66 & 5.09 & 6.28 & 366 & $\overline{\mathrm{H}}$ & estimated \\
\hline July & 1972 & 1.66 & 5.09 & 6.28 & 366 & $\overline{\mathrm{H}}$ & estimated \\
\hline August & 1972 & 1.66 & 5.09 & 6.28 & 366 & $\overline{\mathrm{H}}$ & estimated \\
\hline September & 1972 & 1.66 & 5.09 & 6.28 & 366 & $\overline{\mathrm{H}}$ & estimated \\
\hline October & 1972 & 1.66 & 5.09 & 6.28 & 366 & $\overline{\mathrm{H}}$ & estimated \\
\hline November & 1972 & 1.66 & 5.09 & 6.28 & 366 & $\overline{\mathrm{H}}$ & estimated \\
\hline December & 1972 & 1.66 & 5.09 & 6.28 & 366 & $\overline{\mathrm{H}}$ & estimated \\
\hline January & 1973 & 1.44 & 4.42 & 5.46 & 365 & $\overline{\mathrm{H}}$ & estimated \\
\hline February & 1973 & 1.44 & 4.42 & 5.46 & 365 & $\mathrm{H}$ & estimated \\
\hline March & 1973 & 1.44 & 4.42 & 5.46 & 365 & $\overline{\mathrm{H}}$ & estimated \\
\hline April & 1973 & 1.44 & 4.42 & 5.46 & 365 & $\mathrm{H}$ & estimated \\
\hline May & 1973 & 1.44 & 4.42 & 5.46 & 365 & $\overline{\mathrm{H}}$ & estimated \\
\hline June & 1973 & 1.44 & 4.42 & 5.46 & 365 & $\overline{\mathrm{H}}$ & estimated \\
\hline July & 1973 & 1.44 & 4.42 & 5.46 & 365 & $\overline{\mathrm{H}}$ & estimated \\
\hline August & 1973 & 1.44 & 4.42 & 5.46 & 365 & $\overline{\mathrm{H}}$ & estimated \\
\hline September & 1973 & 1.44 & 4.42 & 5.46 & 365 & $\overline{\mathrm{H}}$ & estimated \\
\hline October & 1973 & 1.44 & 4.42 & 5.46 & 365 & $\overline{\mathrm{H}}$ & estimated \\
\hline November & 1973 & 1.44 & 4.42 & 5.46 & 365 & $\mathrm{H}$ & estimated \\
\hline December & 1973 & 1.44 & 4.42 & 5.46 & 365 & $\overline{\mathrm{H}}$ & estimated \\
\hline January & 1974 & 1.68 & 5.17 & 6.37 & 365 & $\overline{\mathrm{H}}$ & estimated \\
\hline February & 1974 & 1.68 & 5.17 & 6.37 & 365 & $\overline{\mathrm{H}}$ & estimated \\
\hline March & 1974 & 1.68 & 5.17 & 6.37 & 365 & $\overline{\mathrm{H}}$ & estimated \\
\hline April & 1974 & 1.68 & 5.17 & 6.37 & 365 & $\mathrm{H}$ & estimated \\
\hline May & 1974 & 1.68 & 5.17 & 6.37 & 365 & $\overline{\mathrm{H}}$ & estimated \\
\hline June & 1974 & 1.68 & 5.17 & 6.37 & 365 & $\overline{\mathrm{H}}$ & estimated \\
\hline July & 1974 & 1.68 & 5.17 & 6.37 & 365 & $\overline{\mathrm{H}}$ & estimated \\
\hline August & 1974 & 1.68 & 5.17 & 6.37 & 365 & $\bar{H}$ & estimated \\
\hline September & 1974 & 1.68 & 5.17 & 6.37 & 365 & $\overline{\mathrm{H}}$ & estimated \\
\hline October & 1974 & 1.68 & 5.17 & 6.37 & 365 & $\overline{\mathrm{H}}$ & estimated \\
\hline November & 1974 & 1.68 & 5.17 & 6.37 & 365 & $\mathrm{H}$ & estimated \\
\hline December & 1974 & 1.68 & 5.17 & 6.37 & 365 & $\overline{\mathrm{H}}$ & estimated \\
\hline January & 1975 & 1.77 & 5.42 & 6.69 & 365 & $\overline{\mathrm{H}}$ & estimated \\
\hline February & 1975 & 1.77 & 5.42 & 6.69 & 365 & $\overline{\mathrm{H}}$ & estimated \\
\hline
\end{tabular}


WW-C1 Monthly Pumping Data

\begin{tabular}{|c|c|c|c|c|c|c|c|}
\hline March & 1975 & 1.77 & 5.42 & 6.69 & 365 & $\mathrm{H}$ & estimated \\
\hline April & 1975 & 1.77 & 5.42 & 6.69 & 365 & $\overline{\mathrm{H}}$ & estimated \\
\hline May & 1975 & 1.77 & 5.42 & 6.69 & 365 & $\overline{\mathrm{H}}$ & estimated \\
\hline June & 1975 & 1.77 & 5.42 & 6.69 & 365 & $\bar{H}$ & estimated \\
\hline July & 1975 & 1.77 & 5.42 & 6.69 & 365 & $\mathrm{H}$ & estimated \\
\hline August & 1975 & 1.77 & 5.42 & 6.69 & 365 & $\overline{\mathrm{H}}$ & estimated \\
\hline September & 1975 & 1.77 & 5.42 & 6.69 & 365 & $\overline{\mathrm{H}}$ & estimated \\
\hline October & 1975 & 1.77 & 5.42 & 6.69 & 365 & $\overline{\mathrm{H}}$ & estimated \\
\hline November & 1975 & 1.77 & 5.42 & 6.69 & 365 & $\overline{\mathrm{H}}$ & estimated \\
\hline December & 1975 & 1.77 & 5.42 & 6.69 & 365 & $\overline{\mathrm{H}}$ & estimated \\
\hline January & 1976 & 1.58 & 4.83 & 5.96 & 366 & $\overline{\mathrm{H}}$ & estimated \\
\hline February & 1976 & 1.58 & 4.83 & 5.96 & 366 & $\overline{\mathrm{H}}$ & estimated \\
\hline March & 1976 & 1.58 & 4.83 & 5.96 & 366 & $\overline{\mathrm{H}}$ & estimated \\
\hline April & 1976 & 1.58 & 4.83 & 5.96 & 366 & $\overline{\mathrm{H}}$ & estimated \\
\hline May & 1976 & 1.58 & 4.83 & 5.96 & 366 & $\overline{\mathrm{H}}$ & estimated \\
\hline June & 1976 & 1.58 & 4.83 & 5.96 & 366 & $\overline{\mathrm{H}}$ & estimated \\
\hline July & 1976 & 1.58 & 4.83 & 5.96 & 366 & $\overline{\mathrm{H}}$ & estimated \\
\hline August & 1976 & 1.58 & 4.83 & 5.96 & 366 & $\mathrm{H}$ & estimated \\
\hline September & 1976 & 1.58 & 4.83 & 5.96 & 366 & $\overline{\mathrm{H}}$ & estimated \\
\hline October & 1976 & 1.58 & 4.83 & 5.96 & 366 & $\overline{\mathrm{H}}$ & estimated \\
\hline November & 1976 & 1.58 & 4.83 & 5.96 & 366 & $\overline{\mathrm{H}}$ & estimated \\
\hline December & 1976 & 1.58 & 4.83 & 5.96 & 366 & $\overline{\mathrm{H}}$ & estimated \\
\hline January & 1977 & 1.49 & 4.58 & 5.65 & 365 & $\overline{\mathrm{H}}$ & estimated \\
\hline February & 1977 & 1.49 & 4.58 & 5.65 & 365 & $\overline{\mathrm{H}}$ & estimated \\
\hline March & 1977 & 1.49 & 4.58 & 5.65 & 365 & $\overline{\mathrm{H}}$ & estimated \\
\hline April & 1977 & 1.49 & 4.58 & 5.65 & 365 & $\overline{\mathrm{H}}$ & estimated \\
\hline May & 1977 & 1.49 & 4.58 & 5.65 & 365 & $\overline{\mathrm{H}}$ & estimated \\
\hline June & 1977 & 1.49 & 4.58 & 5.65 & 365 & $\overline{\mathrm{H}}$ & estimated \\
\hline July & 1977 & 1.49 & 4.58 & 5.65 & 365 & $\overline{\mathrm{H}}$ & estimated \\
\hline August & 1977 & 1.49 & 4.58 & 5.65 & 365 & $\overline{\mathrm{H}}$ & estimated \\
\hline September & 1977 & 1.49 & 4.58 & 5.65 & 365 & $\overline{\mathrm{H}}$ & estimated \\
\hline October & 1977 & 1.49 & 4.58 & 5.65 & 365 & $\overline{\mathrm{H}}$ & estimated \\
\hline November & 1977 & 1.49 & 4.58 & 5.65 & 365 & $\bar{H}$ & estimated \\
\hline December & 1977 & 1.49 & 4.58 & 5.65 & 365 & $\bar{H}$ & estimated \\
\hline January & 1978 & 1.63 & 5.01 & 6.18 & 365 & $\overline{\mathrm{H}}$ & estimated \\
\hline February & 1978 & 1.63 & 5.01 & 6.18 & 365 & $\mathrm{H}$ & estimated \\
\hline March & 1978 & 1.63 & 5.01 & 6.18 & 365 & $\overline{\mathrm{H}}$ & estimated \\
\hline April & 1978 & 1.63 & 5.01 & 6.18 & 365 & $\overline{\mathrm{H}}$ & estimated \\
\hline May & 1978 & 1.63 & 5.01 & 6.18 & 365 & $\overline{\mathrm{H}}$ & estimated \\
\hline June & 1978 & 1.63 & 5.01 & 6.18 & 365 & $\overline{\mathrm{H}}$ & estimated \\
\hline July & 1978 & 1.63 & 5.01 & 6.18 & 365 & $\overline{\mathrm{H}}$ & estimated \\
\hline August & 1978 & 1.63 & 5.01 & 6.18 & 365 & $\overline{\mathrm{H}}$ & estimated \\
\hline September & 1978 & 1.63 & 5.01 & 6.18 & 365 & $\overline{\mathrm{H}}$ & estimated \\
\hline October & 1978 & 1.63 & 5.01 & 6.18 & 365 & $\overline{\mathrm{H}}$ & estimated \\
\hline November & 1978 & 1.63 & 5.01 & 6.18 & 365 & $\bar{H}$ & estimated \\
\hline December & 1978 & 1.63 & 5.01 & 6.18 & 365 & $\bar{H}$ & estimated \\
\hline January & 1979 & 1.49 & 4.58 & 5.65 & 365 & $\bar{H}$ & estimated \\
\hline February & 1979 & 1.49 & 4.58 & 5.65 & 365 & $\overline{\mathrm{H}}$ & estimated \\
\hline March & 1979 & 1.49 & 4.58 & 5.65 & 365 & $\overline{\mathrm{H}}$ & estimated \\
\hline April & 1979 & 1.49 & 4.58 & 5.65 & 365 & $\overline{\mathrm{H}}$ & estimated \\
\hline May & 1979 & 1.49 & 4.58 & 5.65 & 365 & $\bar{H}$ & estimated \\
\hline June & 1979 & 1.49 & 4.58 & 5.65 & 365 & $\overline{\mathrm{H}}$ & estimated \\
\hline
\end{tabular}


WW-C1 Monthly Pumping Data

\begin{tabular}{|c|c|c|c|c|c|c|c|}
\hline July & 1979 & 1.49 & 4.58 & 5.65 & 365 & $\mathrm{H}$ & estimated \\
\hline August & 1979 & 1.49 & 4.58 & 5.65 & 365 & $\overline{\mathrm{H}}$ & estimated \\
\hline September & 1979 & 1.49 & 4.58 & 5.65 & 365 & $\bar{H}$ & estimated \\
\hline October & 1979 & 1.49 & 4.58 & 5.65 & 365 & $\bar{H}$ & estimated \\
\hline November & 1979 & 1.49 & 4.58 & 5.65 & 365 & $\bar{H}$ & estimated \\
\hline December & 1979 & 1.49 & 4.58 & 5.65 & 365 & $\bar{H}$ & estimated \\
\hline January & 1980 & 1.82 & 5.57 & 6.88 & 366 & $\vec{H}$ & estimated \\
\hline February & 1980 & 1.82 & 5.57 & 6.88 & 366 & $\mathrm{H}$ & estimated \\
\hline March & 1980 & 1.82 & 5.57 & 6.88 & 366 & $\mathrm{H}$ & estimated \\
\hline April & 1980 & 1.82 & 5.57 & 6.88 & 366 & $\bar{H}$ & estimated \\
\hline May & 1980 & 1.82 & 5.57 & 6.88 & 366 & $\mathrm{H}$ & estimated \\
\hline June & 1980 & 1.82 & 5.57 & 6.88 & 366 & $\overline{\mathrm{H}}$ & estimated \\
\hline July & 1980 & 1.82 & 5.57 & 6.88 & 366 & $\mathrm{H}$ & estimated \\
\hline August & 1980 & 1.82 & 5.57 & 6.88 & 366 & $\overline{\mathrm{H}}$ & estimated \\
\hline September & 1980 & 1.82 & 5.57 & 6.88 & 366 & $\bar{H}$ & estimated \\
\hline October & 1980 & 1.82 & 5.57 & 6.88 & 366 & $\bar{H}$ & estimated \\
\hline November & 1980 & 1.82 & 5.57 & 6.88 & 366 & $\bar{H}$ & estimated \\
\hline December & 1980 & 1.82 & 5.57 & 6.88 & 366 & $\overline{\mathrm{H}}$ & estimated \\
\hline January & 1981 & 2.14 & 6.57 & 8.11 & 365 & $\bar{H}$ & estimated \\
\hline February & 1981 & 2.14 & 6.57 & 8.11 & 365 & $\mathrm{H}$ & estimated \\
\hline March & 1981 & 2.14 & 6.57 & 8.11 & 365 & $\mathrm{H}$ & estimated \\
\hline April & 1981 & 2.14 & 6.57 & 8.11 & 365 & $\bar{H}$ & estimated \\
\hline May & 1981 & 2.14 & 6.57 & 8.11 & 365 & $\mathrm{H}$ & estimated \\
\hline June & 1981 & 2.14 & 6.57 & 8.11 & 365 & $\mathrm{H}$ & estimated \\
\hline July & 1981 & 2.14 & 6.57 & 8.11 & 365 & $\mathrm{H}$ & estimated \\
\hline August & 1981 & 2.14 & 6.57 & 8.11 & 365 & $\vec{H}$ & estimated \\
\hline September & 1981 & 2.14 & 6.57 & 8.11 & 365 & $\overline{\mathrm{H}}$ & estimated \\
\hline October & 1981 & 2.14 & 6.57 & 8.11 & 365 & $\overline{\mathrm{H}}$ & estimated \\
\hline November & 1981 & 2.14 & 6.57 & 8.11 & 365 & $\bar{H}$ & estimated \\
\hline December & 1981 & 2.14 & 6.57 & 8.11 & 365 & $\mathrm{H}$ & estimated \\
\hline January & 1982 & 2.55 & 7.82 & 9.65 & 365 & $\mathrm{H}$ & estimated \\
\hline February & 1982 & 2.55 & 7.82 & 9.65 & 365 & $\mathrm{H}$ & estimated \\
\hline March & 1982 & 2.55 & 7.82 & 9.65 & 365 & $\mathrm{H}$ & estimated \\
\hline April & 1982 & 2.55 & 7.82 & 9.65 & 365 & $\mathrm{H}$ & estimated \\
\hline May & 1982 & 2.55 & 7.82 & 9.65 & 365 & $\mathrm{H}$ & estimated \\
\hline June & 1982 & 2.55 & 7.82 & 9.65 & 365 & $\mathrm{H}$ & estimated \\
\hline July & 1982 & 2.55 & 7.82 & 9.65 & 365 & $\mathrm{H}$ & estimated \\
\hline August & 1982 & 2.55 & 7.82 & 9.65 & 365 & $\bar{H}$ & estimated \\
\hline September & 1982 & 2.55 & 7.82 & 9.65 & 365 & $\mathrm{H}$ & estimated \\
\hline October & 1982 & 2.55 & 7.82 & 9.65 & 365 & $\mathrm{H}$ & estimated \\
\hline November & 1982 & 2.55 & 7.82 & 9.65 & 365 & $\mathrm{H}$ & estimated \\
\hline December & 1982 & 2.55 & 7.82 & 9.65 & 365 & $\mathrm{H}$ & estimated \\
\hline January & 1983 & 4.36 & 13.36 & 16.48 & 31 & $\bar{M}$ & -- \\
\hline February & 1983 & 2.89 & 8.87 & 10.94 & 28 & $\bar{M}$ & $\overline{--}$ \\
\hline March & 1983 & 3.71 & 11.40 & 14.05 & 31 & $\bar{M}$ & -- \\
\hline April & 1983 & 4.60 & 14.10 & 17.39 & 30 & $\bar{M}$ & -- \\
\hline May & 1983 & 3.64 & 11.17 & 13.77 & 31 & $\bar{M}$ & -- \\
\hline June & 1983 & 3.19 & 9.78 & 12.06 & 30 & $M$ & -- \\
\hline July & 1983 & 5.14 & 15.77 & 19.45 & 31 & $\bar{M}$ & -- \\
\hline August & 1983 & 3.00 & 9.21 & 11.36 & 31 & $\bar{M}$ & -- \\
\hline September & 1983 & 2.50 & 7.68 & 9.47 & 30 & $\bar{M}$ & -- \\
\hline October & 1983 & 2.36 & 7.23 & 8.92 & 31 & $\bar{M}$ & $\overline{--}$ \\
\hline
\end{tabular}


WW-C1 Monthly Pumping Data

\begin{tabular}{|c|c|c|c|c|c|c|c|}
\hline November & 1983 & 0.76 & 2.34 & 2.89 & 30 & $\bar{M}$ & -- \\
\hline December & 1983 & 1.49 & 4.58 & 5.65 & 31 & $\mathrm{M}$ & -- \\
\hline January & 1984 & 1.90 & 5.84 & 7.20 & 31 & $\mathrm{M}$ & -- \\
\hline February & 1984 & 2.94 & 9.02 & 11.13 & 29 & $\bar{M}$ & $\overline{--}$ \\
\hline March & 1984 & 2.71 & 8.30 & 10.24 & 31 & $\mathrm{M}$ & -- \\
\hline April & 1984 & 1.41 & 4.33 & 5.34 & 30 & $\mathrm{M}$ & -- \\
\hline May & 1984 & 3.66 & 11.24 & 13.86 & 31 & $\mathrm{M}$ & -- \\
\hline June & 1984 & 2.81 & 8.62 & 10.63 & 30 & $\mathrm{M}$ & -- \\
\hline July & 1984 & 1.59 & 4.86 & 6.00 & 31 & $\mathrm{M}$ & -- \\
\hline August & 1984 & 1.12 & 3.44 & 4.24 & 31 & $\mathrm{M}$ & -- \\
\hline September & 1984 & 1.93 & 5.92 & 7.30 & 30 & $\mathrm{M}$ & -- \\
\hline October & 1984 & 1.60 & 4.90 & 6.04 & 31 & $\mathrm{M}$ & -- \\
\hline November & 1984 & 0.50 & 1.54 & 1.90 & 30 & $\bar{M}$ & -- \\
\hline December & 1984 & 1.15 & 3.53 & 4.35 & 31 & $E$ & -- \\
\hline January & 1985 & 1.57 & 4.82 & 5.94 & 31 & $\bar{E}$ & -- \\
\hline February & 1985 & 0.90 & 2.75 & 3.39 & 28 & $\bar{M}$ & -- \\
\hline March & 1985 & 2.21 & 6.78 & 8.36 & 31 & $\mathrm{M}$ & -- \\
\hline April & 1985 & 2.72 & 8.35 & 10.30 & 30 & $\mathrm{M}$ & -- \\
\hline May & 1985 & 3.44 & 10.56 & 13.03 & 31 & $\mathrm{M}$ & -- \\
\hline June & 1985 & 3.68 & 11.28 & 13.91 & 30 & $\mathrm{M}$ & -- \\
\hline July & 1985 & 3.94 & 12.10 & 14.92 & 31 & $\mathrm{M}$ & -- \\
\hline August & 1985 & 3.19 & 9.78 & 12.06 & 31 & $\mathrm{M}$ & -- \\
\hline September & 1985 & 2.10 & 6.45 & 7.96 & 30 & $\mathrm{M}$ & -- \\
\hline October & 1985 & 1.91 & 5.88 & 7.25 & 31 & $\mathrm{M}$ & -- \\
\hline November & 1985 & 1.52 & 4.67 & 5.75 & 30 & $\bar{M}$ & -- \\
\hline December & 1985 & 1.77 & 5.44 & 6.71 & 31 & $E$ & -- \\
\hline January & 1986 & 2.09 & 6.42 & 7.92 & 31 & $\mathrm{M}$ & -- \\
\hline February & 1986 & 1.80 & 5.52 & 6.80 & 28 & $\bar{M}$ & -- \\
\hline March & 1986 & 2.94 & 9.01 & 11.11 & 31 & $\mathrm{M}$ & -- \\
\hline April & 1986 & 2.76 & 8.47 & 10.44 & 30 & $\mathrm{M}$ & -- \\
\hline May & 1986 & 2.83 & 8.69 & 10.72 & 31 & $\mathrm{M}$ & -- \\
\hline June & 1986 & 2.67 & 8.20 & 10.11 & 30 & $\mathrm{M}$ & -- \\
\hline July & 1986 & 2.89 & 8.87 & 10.94 & 31 & $\mathrm{M}$ & -- \\
\hline August & 1986 & 3.16 & 9.69 & 11.95 & 31 & $\mathrm{M}$ & -- \\
\hline September & 1986 & 2.53 & 7.76 & 9.57 & 30 & $\mathrm{M}$ & -- \\
\hline October & 1986 & 2.27 & 6.97 & 8.60 & 31 & $\mathrm{M}$ & -- \\
\hline November & 1986 & 2.02 & 6.18 & 7.62 & 30 & $\bar{M}$ & -- \\
\hline December & 1986 & 2.10 & 6.45 & 7.96 & 31 & $\mathrm{M}$ & -- \\
\hline January & 1987 & 2.22 & 6.82 & 8.41 & 31 & $\mathrm{M}$ & -- \\
\hline February & 1987 & 1.72 & 5.27 & 6.50 & 28 & $\mathrm{M}$ & -- \\
\hline March & 1987 & 1.65 & 5.05 & 6.23 & 31 & $\mathrm{M}$ & -- \\
\hline April & 1987 & 1.73 & 5.32 & 6.56 & 30 & $\mathrm{M}$ & -- \\
\hline May & 1987 & 1.81 & 5.55 & 6.85 & 31 & $\mathrm{M}$ & - \\
\hline June & 1987 & 1.87 & 5.74 & 7.08 & 30 & $\mathrm{M}$ & - \\
\hline July & 1987 & 2.08 & 6.39 & 7.88 & 31 & $\mathrm{M}$ & -- \\
\hline August & 1987 & 2.37 & 7.28 & 8.98 & 31 & $\mathrm{M}$ & - \\
\hline September & 1987 & 2.20 & 6.73 & 8.31 & 30 & $\mathrm{M}$ & - \\
\hline October & 1987 & 1.65 & 5.07 & 6.25 & 31 & $\mathrm{M}$ & -- \\
\hline November & 1987 & 1.25 & 3.85 & 4.74 & 30 & $\bar{M}$ & -- \\
\hline December & 1987 & 1.78 & 5.47 & 6.75 & 31 & $\mathrm{M}$ & -- \\
\hline January & 1988 & 2.13 & 6.54 & 8.06 & 31 & $\bar{M}$ & - \\
\hline February & 1988 & 2.01 & 6.15 & 7.59 & 29 & $\mathrm{M}$ & -- \\
\hline
\end{tabular}


WW-C1 Monthly Pumping Data

\begin{tabular}{|c|c|c|c|c|c|c|c|}
\hline March & 1988 & 2.14 & 6.58 & 8.12 & 31 & $\mathrm{M}$ & -- \\
\hline April & 1988 & 2.00 & 6.14 & 7.57 & 30 & $\mathrm{M}$ & -- \\
\hline May & 1988 & 2.49 & 7.63 & 9.42 & 31 & $\mathrm{M}$ & -- \\
\hline June & 1988 & 2.32 & 7.11 & 8.77 & 30 & $\bar{M}$ & $\overline{--}$ \\
\hline July & 1988 & 3.15 & 9.66 & 11.91 & 31 & $\mathrm{M}$ & -- \\
\hline August & 1988 & 1.74 & 5.32 & 6.57 & 31 & $\mathrm{M}$ & -- \\
\hline September & 1988 & 0.99 & 3.04 & 3.75 & 30 & $E$ & -- \\
\hline October & 1988 & 2.17 & 6.66 & 8.21 & 31 & $\bar{M}$ & $\overline{--}$ \\
\hline November & 1988 & 1.92 & 5.88 & 7.25 & 30 & $\bar{M}$ & -- \\
\hline December & 1988 & 1.79 & 5.48 & 6.76 & 31 & $\mathrm{M}$ & -- \\
\hline January & 1989 & 1.08 & 3.33 & 4.10 & 31 & $\mathrm{M}$ & -- \\
\hline February & 1989 & 1.66 & 5.10 & 6.29 & 28 & $\mathrm{M}$ & -- \\
\hline March & 1989 & 1.83 & 5.63 & 6.94 & 31 & $\bar{M}$ & -- \\
\hline April & 1989 & 2.25 & 6.91 & 8.52 & 30 & $\mathrm{M}$ & -- \\
\hline May & 1989 & 2.26 & 6.92 & 8.54 & 31 & $\mathrm{M}$ & -- \\
\hline June & 1989 & 2.72 & 8.34 & 10.28 & 30 & $\bar{M}$ & -- \\
\hline July & 1989 & 3.06 & 9.40 & 11.59 & 31 & $\mathrm{M}$ & -- \\
\hline August & 1989 & 4.46 & 13.69 & 16.89 & 31 & $\mathrm{M}$ & - \\
\hline September & 1989 & 3.16 & 9.69 & 11.95 & 30 & $\mathrm{M}$ & -- \\
\hline October & 1989 & 2.41 & 7.41 & 9.13 & 31 & $\mathrm{M}$ & -- \\
\hline November & 1989 & 1.49 & 4.57 & 5.63 & 30 & $\mathrm{M}$ & -- \\
\hline December & 1989 & 1.68 & 5.16 & 6.37 & 31 & $\mathrm{M}$ & -- \\
\hline January & 1990 & 1.52 & 4.67 & 5.76 & 31 & $\mathrm{M}$ & -- \\
\hline February & 1990 & 1.57 & 4.81 & 5.93 & 28 & $\mathrm{M}$ & -- \\
\hline March & 1990 & 1.84 & 5.64 & 6.96 & 31 & $\bar{M}$ & -- \\
\hline April & 1990 & 0.84 & 2.57 & 3.17 & 30 & $\mathrm{M}$ & -- \\
\hline May & 1990 & 1.90 & 5.84 & 7.21 & 31 & $\mathrm{M}$ & -- \\
\hline June & 1990 & 2.65 & 8.13 & 10.03 & 30 & $\bar{M}$ & -- \\
\hline July & 1990 & 2.29 & 7.02 & 8.66 & 31 & $\mathrm{M}$ & -- \\
\hline August & 1990 & 2.18 & 6.69 & 8.25 & 31 & $\mathrm{M}$ & -- \\
\hline September & 1990 & 1.95 & 5.98 & 7.38 & 30 & $\mathrm{M}$ & -- \\
\hline October & 1990 & 2.46 & 7.54 & 9.30 & 31 & $\mathrm{M}$ & -- \\
\hline November & 1990 & 1.99 & 6.10 & 7.52 & 30 & $\mathrm{M}$ & -- \\
\hline December & 1990 & 2.16 & 6.64 & 8.18 & 31 & $\mathrm{M}$ & -- \\
\hline January & 1991 & 2.85 & 8.73 & 10.77 & 31 & $\mathrm{M}$ & -- \\
\hline February & 1991 & 0.67 & 2.05 & 2.53 & 28 & $\mathrm{M}$ & -- \\
\hline March & 1991 & 1.40 & 4.31 & 5.31 & 31 & $\bar{M}$ & -- \\
\hline April & 1991 & 1.84 & 5.64 & 6.96 & 30 & $\bar{M}$ & -- \\
\hline May & 1991 & 2.01 & 6.17 & 7.61 & 31 & $\mathrm{M}$ & -- \\
\hline June & 1991 & 1.73 & 5.30 & 6.54 & 30 & $\mathrm{M}$ & -- \\
\hline July & 1991 & 1.89 & 5.81 & 7.16 & 31 & $\mathrm{M}$ & -- \\
\hline August & 1991 & 2.19 & 6.71 & 8.28 & 31 & $\mathrm{M}$ & - \\
\hline September & 1991 & 2.55 & 7.83 & 9.65 & 30 & $\mathrm{M}$ & - \\
\hline October & 1991 & 2.87 & 8.80 & 10.85 & 31 & $\mathrm{M}$ & - \\
\hline November & 1991 & 1.78 & 5.45 & 6.72 & 30 & $\mathrm{M}$ & -- \\
\hline December & 1991 & 2.02 & 6.19 & 7.64 & 31 & $\mathrm{M}$ & - \\
\hline January & 1992 & 2.46 & 7.54 & 9.29 & 31 & $\mathrm{M}$ & - \\
\hline February & 1992 & 1.91 & 5.87 & 7.24 & 29 & $\mathrm{M}$ & -- \\
\hline March & 1992 & 1.93 & 5.93 & 7.31 & 31 & $\bar{M}$ & -- \\
\hline April & 1992 & 1.87 & 5.75 & 7.09 & 30 & $\bar{M}$ & -- \\
\hline May & 1992 & 1.59 & 4.87 & 6.01 & 31 & $\bar{M}$ & -- \\
\hline June & 1992 & 1.84 & 5.65 & 6.97 & 30 & $\mathrm{M}$ & - \\
\hline
\end{tabular}


WW-C1 Monthly Pumping Data

\begin{tabular}{|c|c|c|c|c|c|c|c|}
\hline July & 1992 & 2.55 & 7.82 & 9.64 & 31 & $\bar{M}$ & -- \\
\hline August & 1992 & 3.15 & 9.66 & 11.92 & 31 & $\bar{M}$ & -- \\
\hline September & 1992 & 3.22 & 9.89 & 12.19 & 30 & $\bar{M}$ & -- \\
\hline October & 1992 & 3.71 & 11.37 & 14.02 & 31 & $\overline{\mathrm{M}}$ & $\overline{--}$ \\
\hline November & 1992 & 3.67 & 11.27 & 13.90 & 30 & $\bar{M}$ & -- \\
\hline December & 1992 & 2.41 & 7.38 & 9.11 & 31 & $\bar{M}$ & -- \\
\hline January & 1993 & 2.51 & 7.70 & 9.50 & 31 & $\bar{M}$ & -- \\
\hline February & 1993 & 1.31 & 4.02 & 4.96 & 28 & $\bar{M}$ & -- \\
\hline March & 1993 & 0.51 & 1.57 & 1.94 & 31 & $\bar{M}$ & -- \\
\hline April & 1993 & 0.20 & 0.61 & 0.75 & 30 & $\bar{M}$ & -- \\
\hline May & 1993 & 0.75 & 2.30 & 2.84 & 31 & $\bar{M}$ & -- \\
\hline June & 1993 & 1.19 & 3.64 & 4.49 & 30 & $\bar{M}$ & -- \\
\hline July & 1993 & 0.30 & 0.91 & 1.12 & 31 & $\overline{\mathrm{M}}$ & -- \\
\hline August & 1993 & 0.28 & 0.86 & 1.06 & 31 & $\bar{M}$ & -- \\
\hline September & 1993 & 0.50 & 1.53 & 1.89 & 30 & $\bar{M}$ & -- \\
\hline October & 1993 & 0.87 & 2.66 & 3.29 & 31 & $\overline{\mathrm{M}}$ & -- \\
\hline November & 1993 & 0.63 & 1.94 & 2.39 & 30 & $\bar{M}$ & -- \\
\hline December & 1993 & 0.40 & 1.22 & 1.50 & 31 & $\bar{M}$ & - \\
\hline January & 1994 & 0.61 & 1.88 & 2.32 & 31 & $\bar{M}$ & -- \\
\hline February & 1994 & 0.51 & 1.56 & 1.93 & 28 & $\bar{M}$ & -- \\
\hline March & 1994 & 0.69 & 2.11 & 2.61 & 31 & $\bar{M}$ & -- \\
\hline April & 1994 & 0.81 & 2.49 & 3.07 & 30 & $\bar{M}$ & -- \\
\hline May & 1994 & 0.66 & 2.01 & 2.49 & 31 & $\bar{M}$ & -- \\
\hline June & 1994 & 0.76 & 2.33 & 2.88 & 30 & $\bar{M}$ & -- \\
\hline July & 1994 & 0.64 & 1.97 & 2.43 & 31 & $\overline{\mathrm{M}}$ & -- \\
\hline August & 1994 & 0.27 & 0.84 & 1.04 & 31 & $\overline{\mathrm{M}}$ & -- \\
\hline September & 1994 & 0.01 & 0.02 & 0.03 & 30 & $\bar{M}$ & -- \\
\hline October & 1994 & 0.10 & 0.31 & 0.38 & 31 & $\bar{M}$ & - \\
\hline November & 1994 & 0.23 & 0.71 & 0.87 & 30 & $\bar{M}$ & -- \\
\hline December & 1994 & 0.81 & 2.47 & 3.05 & 31 & $\bar{M}$ & -- \\
\hline January & 1995 & 0.51 & 1.57 & 1.93 & 31 & $\bar{M}$ & -- \\
\hline February & 1995 & 0.28 & 0.85 & 1.05 & 28 & $\bar{M}$ & -- \\
\hline March & 1995 & 0.27 & 0.82 & 1.01 & 31 & $\bar{M}$ & -- \\
\hline April & 1995 & 0.52 & 1.59 & 1.97 & 30 & $\bar{M}$ & -- \\
\hline May & 1995 & 0.59 & 1.82 & 2.24 & 31 & $\bar{M}$ & -- \\
\hline June & 1995 & 0.67 & 2.06 & 2.54 & 30 & $\bar{M}$ & -- \\
\hline July & 1995 & 1.14 & 3.51 & 4.33 & 31 & $\overline{\mathrm{M}}$ & -- \\
\hline August & 1995 & 2.31 & 7.09 & 8.75 & 31 & $\bar{M}$ & -- \\
\hline September & 1995 & 2.41 & 7.39 & 9.11 & 30 & $\bar{M}$ & -- \\
\hline October & 1995 & 2.09 & 6.42 & 7.92 & 31 & $\bar{M}$ & - \\
\hline November & 1995 & 1.82 & 5.58 & 6.88 & 30 & $\bar{M}$ & -- \\
\hline December & 1995 & 1.28 & 3.94 & 4.85 & 31 & $\bar{M}$ & -- \\
\hline January & 1996 & 1.12 & 3.43 & 4.23 & 31 & $\bar{M}$ & - \\
\hline February & 1996 & 1.94 & 5.95 & 7.34 & 29 & $\bar{M}$ & - \\
\hline March & 1996 & 1.37 & 4.21 & 5.19 & 31 & $\bar{M}$ & -- \\
\hline April & 1996 & 2.69 & 8.24 & 10.17 & 30 & $\bar{M}$ & - \\
\hline May & 1996 & 2.16 & 6.64 & 8.19 & 31 & $\bar{M}$ & - \\
\hline June & 1996 & 3.59 & 11.03 & 13.60 & 30 & $\bar{M}$ & -- \\
\hline July & 1996 & 3.72 & 11.42 & 14.09 & 31 & $\bar{M}$ & -- \\
\hline August & 1996 & 4.84 & 14.85 & 18.31 & 31 & $\overline{\mathrm{M}}$ & -- \\
\hline September & 1996 & 3.35 & 10.29 & 12.69 & 30 & $\bar{M}$ & -- \\
\hline October & 1996 & 3.43 & 10.51 & 12.96 & 31 & $\bar{M}$ & - \\
\hline
\end{tabular}


WW-C1 Monthly Pumping Data

\begin{tabular}{|c|c|c|c|c|c|c|c|}
\hline November & 1996 & 1.48 & 4.54 & 5.60 & 30 & $\mathrm{M}$ & -- \\
\hline December & 1996 & 1.75 & 5.36 & 6.62 & 31 & $\mathrm{M}$ & -- \\
\hline January & 1997 & 1.73 & 5.30 & 6.54 & 31 & $\mathrm{M}$ & -- \\
\hline February & 1997 & 1.59 & 4.88 & 6.02 & 28 & $\bar{M}$ & $\overline{--}$ \\
\hline March & 1997 & 2.57 & 7.88 & 9.72 & 31 & $\mathrm{M}$ & -- \\
\hline April & 1997 & 2.48 & 7.62 & 9.40 & 30 & $\mathrm{M}$ & -- \\
\hline May & 1997 & 3.08 & 9.45 & 11.65 & 31 & $\mathrm{M}$ & -- \\
\hline June & 1997 & 3.74 & 11.49 & 14.17 & 30 & $\mathrm{M}$ & -- \\
\hline July & 1997 & 2.98 & 9.15 & 11.29 & 31 & $\mathrm{M}$ & -- \\
\hline August & 1997 & 2.64 & 8.09 & 9.97 & 31 & $\mathrm{M}$ & -- \\
\hline September & 1997 & 2.42 & 7.41 & 9.14 & 30 & $\mathrm{M}$ & -- \\
\hline October & 1997 & 2.38 & 7.31 & 9.01 & 31 & $\mathrm{M}$ & -- \\
\hline November & 1997 & 2.08 & 6.37 & 7.86 & 30 & $\bar{M}$ & -- \\
\hline December & 1997 & 0.90 & 2.77 & 3.42 & 31 & $\mathrm{M}$ & -- \\
\hline January & 1998 & 0.00 & 0.00 & 0.00 & 31 & $\mathrm{M}$ & -- \\
\hline February & 1998 & 0.00 & 0.00 & 0.00 & 28 & $\bar{M}$ & -- \\
\hline March & 1998 & 0.00 & 0.00 & 0.00 & 31 & $\mathrm{M}$ & -- \\
\hline April & 1998 & 0.00 & 0.00 & 0.00 & 30 & $\mathrm{M}$ & -- \\
\hline May & 1998 & 0.00 & 0.00 & 0.00 & 31 & $\mathrm{M}$ & -- \\
\hline June & 1998 & 0.00 & 0.00 & 0.00 & 30 & $\mathrm{M}$ & -- \\
\hline July & 1998 & 0.55 & 1.68 & 2.07 & 31 & $\mathrm{M}$ & -- \\
\hline August & 1998 & 0.67 & 2.04 & 2.52 & 31 & $\mathrm{M}$ & -- \\
\hline September & 1998 & 0.67 & 2.06 & 2.54 & 30 & $\mathrm{M}$ & - \\
\hline October & 1998 & 0.87 & 2.67 & 3.30 & 31 & $\mathrm{M}$ & -- \\
\hline November & 1998 & 0.53 & 1.62 & 2.00 & 30 & $\bar{M}$ & -- \\
\hline December & 1998 & 0.44 & 1.35 & 1.67 & 31 & $\mathrm{M}$ & -- \\
\hline January & 1999 & 0.90 & 2.77 & 3.41 & 31 & $\mathrm{M}$ & -- \\
\hline February & 1999 & 0.73 & 2.23 & 2.76 & 28 & $\bar{M}$ & -- \\
\hline March & 1999 & 1.42 & 4.34 & 5.36 & 31 & $\mathrm{M}$ & -- \\
\hline April & 1999 & 2.15 & 6.61 & 8.15 & 30 & $\mathrm{M}$ & -- \\
\hline May & 1999 & 3.78 & 11.60 & 14.31 & 31 & $\mathrm{M}$ & -- \\
\hline June & 1999 & 1.20 & 3.67 & 4.53 & 30 & $\mathrm{M}$ & -- \\
\hline July & 1999 & 0.93 & 2.85 & 3.51 & 31 & $\mathrm{M}$ & -- \\
\hline August & 1999 & 1.95 & 6.00 & 7.39 & 31 & $\mathrm{M}$ & -- \\
\hline September & 1999 & 1.52 & 4.67 & 5.76 & 30 & $\mathrm{M}$ & -- \\
\hline October & 1999 & 1.57 & 4.81 & 5.93 & 31 & $\mathrm{M}$ & -- \\
\hline November & 1999 & 1.18 & 3.63 & 4.47 & 30 & $\bar{M}$ & -- \\
\hline December & 1999 & 1.16 & 3.57 & 4.41 & 31 & $\mathrm{M}$ & -- \\
\hline January & 2000 & 1.12 & 3.44 & 4.25 & 31 & $\mathrm{M}$ & -- \\
\hline February & 2000 & 1.02 & 3.12 & 3.85 & 29 & $\mathrm{M}$ & -- \\
\hline March & 2000 & 0.87 & 2.67 & 3.29 & 31 & $\mathrm{M}$ & -- \\
\hline April & 2000 & 0.25 & 0.78 & 0.96 & 30 & $\mathrm{M}$ & -- \\
\hline May & 2000 & 0.82 & 2.51 & 3.09 & 31 & $\mathrm{M}$ & - \\
\hline June & 2000 & 0.38 & 1.17 & 1.44 & 30 & $\mathrm{M}$ & - \\
\hline July & 2000 & 0.43 & 1.33 & 1.64 & 31 & $\mathrm{M}$ & -- \\
\hline August & 2000 & 0.72 & 2.20 & 2.72 & 31 & $\mathrm{M}$ & - \\
\hline September & 2000 & 0.78 & 2.39 & 2.94 & 30 & $\mathrm{M}$ & - \\
\hline October & 2000 & 0.55 & 1.69 & 2.08 & 31 & $\mathrm{M}$ & -- \\
\hline November & 2000 & 0.77 & 2.36 & 2.91 & 30 & $\bar{M}$ & -- \\
\hline December & 2000 & 0.18 & 0.55 & 0.68 & 31 & $\bar{M}$ & -- \\
\hline January & 2001 & 0.01 & 0.02 & 0.03 & 31 & $\mathrm{M}$ & - \\
\hline February & 2001 & 0.26 & 0.81 & 0.99 & 28 & $\mathrm{M}$ & -- \\
\hline
\end{tabular}


WW-C1 Monthly Pumping Data

\begin{tabular}{|c|c|c|c|c|c|c|c|}
\hline March & 2001 & 1.28 & 3.93 & 4.85 & 31 & $\mathrm{M}$ & -- \\
\hline April & 2001 & 1.59 & 4.88 & 6.02 & 30 & $\mathrm{M}$ & -- \\
\hline May & 2001 & 1.91 & 5.86 & 7.23 & 31 & $\mathrm{M}$ & -- \\
\hline June & 2001 & 1.69 & 5.18 & 6.39 & 30 & $\mathrm{M}$ & -- \\
\hline July & 2001 & 2.39 & 7.33 & 9.04 & 31 & $\mathrm{M}$ & -- \\
\hline August & 2001 & 2.19 & 6.71 & 8.27 & 31 & $\mathrm{M}$ & -- \\
\hline September & 2001 & 1.44 & 4.43 & 5.47 & 30 & $\mathrm{M}$ & -- \\
\hline October & 2001 & 1.38 & 4.22 & 5.21 & 31 & $\mathrm{M}$ & -- \\
\hline November & 2001 & 1.03 & 3.15 & 3.89 & 30 & $\mathrm{M}$ & -- \\
\hline December & 2001 & 0.91 & 2.79 & 3.45 & 31 & $\mathrm{M}$ & -- \\
\hline January & 2002 & 1.07 & 3.27 & 4.04 & 31 & $\mathrm{M}$ & -- \\
\hline February & 2002 & 1.61 & 4.93 & 6.08 & 28 & $\mathrm{M}$ & -- \\
\hline March & 2002 & 0.87 & 2.67 & 3.29 & 31 & $\mathrm{M}$ & -- \\
\hline April & 2002 & 0.95 & 2.91 & 3.59 & 30 & $\mathrm{M}$ & -- \\
\hline May & 2002 & 1.15 & 3.54 & 4.37 & 31 & $\mathrm{M}$ & -- \\
\hline June & 2002 & 0.99 & 3.05 & 3.76 & 30 & $\mathrm{M}$ & -- \\
\hline July & 2002 & 1.73 & 5.32 & 6.56 & 31 & $\mathrm{M}$ & -- \\
\hline August & 2002 & 2.49 & 7.65 & 9.43 & 31 & $\mathrm{M}$ & -- \\
\hline September & 2002 & 2.55 & 7.82 & 9.65 & 30 & $\mathrm{M}$ & -- \\
\hline October & 2002 & 2.65 & 8.13 & 10.03 & 31 & $\mathrm{M}$ & -- \\
\hline November & 2002 & 1.04 & 3.20 & 3.94 & 30 & $\mathrm{M}$ & -- \\
\hline December & 2002 & 1.74 & 5.33 & 6.57 & 31 & $\mathrm{M}$ & -- \\
\hline January & 2003 & 1.38 & 4.25 & 5.24 & 31 & $\mathrm{M}$ & -- \\
\hline February & 2003 & 0.34 & 1.05 & 1.29 & 28 & $\mathrm{M}$ & -- \\
\hline March & 2003 & 0.94 & 2.90 & 3.57 & 31 & $\mathrm{M}$ & -- \\
\hline April & 2003 & 1.84 & 5.63 & 6.95 & 30 & $\mathrm{M}$ & -- \\
\hline May & 2003 & 2.03 & 6.22 & 7.67 & 31 & $\mathrm{M}$ & -- \\
\hline June & 2003 & 2.10 & 6.46 & 7.96 & 30 & $\mathrm{M}$ & -- \\
\hline July & 2003 & 1.41 & 4.33 & 5.35 & 31 & $\mathrm{M}$ & -- \\
\hline August & 2003 & 1.16 & 3.57 & 4.41 & 31 & $\mathrm{M}$ & -- \\
\hline September & 2003 & 1.10 & 3.38 & 4.17 & 30 & $\mathrm{M}$ & -- \\
\hline October & 2003 & 0.90 & 2.77 & 3.42 & 31 & $\mathrm{M}$ & -- \\
\hline November & 2003 & 1.37 & 4.19 & 5.17 & 30 & $\mathrm{M}$ & -- \\
\hline December & 2003 & 1.27 & 3.90 & 4.81 & 31 & $\mathrm{M}$ & -- \\
\hline
\end{tabular}

aSource: $\mathrm{E}=$ Taken from Bechtel or REECo water production reports and includes estimated values.

$\mathrm{H}=$ Insufficient data to determine monthly value. Annual value listed in annual data set as reported in [Moreo and others, 2003, WRIR 03-4245, Estimated Ground-Water Withdrawals from the Death Valley Regional Flow System, Nevada and California, 1913-98].

I = Insufficient or no data to calculate monthly total; no water may have been withdrawn for month.

$M=$ Taken from Bechtel or REECo water production reports.

$\mathrm{R}=$ Insufficient data to determine monthly value. Annual value listed in annual data set as reported in

[Claassen, H.C., 1973, Water quality and physical characteristics of Nevada Test Site water-supply wells: U.S.

Geological Survey Open-File Report USGS-474-158, 145 p.].

${ }^{b}$ estimated indicates monthly value was estimated from yearly total 
WW-C Monthly Pumping Data

\begin{tabular}{|c|c|c|c|c|c|c|c|}
\hline Month & Year & $\begin{array}{c}\text { Million } \\
\text { Gallons }\end{array}$ & Acre-Ft & $\begin{array}{c}\text { Million } \\
\text { Liters }\end{array}$ & $\begin{array}{c}\text { Days } \\
\text { Reported }\end{array}$ & Source ${ }^{a}$ & Comment $^{b}$ \\
\hline September & 1961 & 1.01 & 3.11 & 3.84 & 30 & $\mathrm{M}$ & -- \\
\hline October & 1961 & 2.55 & 7.84 & 9.67 & 31 & $\mathrm{M}$ & -- \\
\hline November & 1961 & 0.79 & 2.41 & 2.97 & 30 & $\mathrm{M}$ & -- \\
\hline December & 1961 & 0.59 & 1.81 & 2.23 & 31 & $\mathrm{M}$ & -- \\
\hline January & 1962 & 0.56 & 1.71 & 2.11 & 31 & $\bar{M}$ & -- \\
\hline February & 1962 & 0.59 & 1.81 & 2.23 & 28 & $\bar{M}$ & -- \\
\hline March & 1962 & 1.00 & 3.08 & 3.80 & 31 & $\mathrm{M}$ & -- \\
\hline April & 1962 & 9.35 & 28.70 & 35.39 & 30 & $\mathrm{M}$ & -- \\
\hline May & 1962 & 8.31 & 25.49 & 31.43 & 31 & $\mathrm{M}$ & -- \\
\hline June & 1962 & 1.44 & 4.41 & 5.44 & 30 & $\mathrm{M}$ & -- \\
\hline July & 1962 & 0.00 & 0.00 & 0.00 & 31 & $\mathrm{M}$ & -- \\
\hline August & 1962 & 4.17 & 12.81 & 15.80 & 31 & $\mathrm{M}$ & $\overline{--}$ \\
\hline September & 1962 & 5.38 & 16.51 & 20.36 & 30 & $\mathrm{M}$ & -- \\
\hline October & 1962 & 2.10 & 6.43 & 7.93 & 31 & $\mathrm{M}$ & -- \\
\hline November & 1962 & 1.72 & 5.27 & 6.49 & 30 & $\bar{M}$ & -- \\
\hline December & 1962 & 2.90 & 8.89 & 10.97 & 31 & $\mathrm{M}$ & -- \\
\hline January & 1963 & 0.83 & 2.55 & 3.15 & 31 & $\mathrm{M}$ & -- \\
\hline February & 1963 & 2.18 & 6.68 & 8.24 & 28 & $\bar{M}$ & -- \\
\hline March & 1963 & 4.83 & 14.82 & 18.28 & 31 & $\mathrm{M}$ & -- \\
\hline April & 1963 & 7.06 & 21.68 & 26.74 & 30 & $\mathrm{M}$ & -- \\
\hline May & 1963 & 8.67 & 26.60 & 32.81 & 31 & $\mathrm{M}$ & -- \\
\hline June & 1963 & 1.08 & 3.31 & 4.08 & 30 & $\mathrm{M}$ & -- \\
\hline July & 1963 & 1.77 & 5.44 & 6.71 & 31 & $\mathrm{M}$ & -- \\
\hline August & 1963 & 2.67 & 8.18 & 10.09 & 31 & $\mathrm{M}$ & $\overline{--}$ \\
\hline September & 1963 & 1.55 & 4.75 & 5.86 & 30 & $\mathrm{M}$ & -- \\
\hline October & 1963 & 3.30 & 10.14 & 12.51 & 31 & $\mathrm{M}$ & -- \\
\hline November & 1963 & 4.94 & 15.17 & 18.71 & 30 & $\mathrm{M}$ & -- \\
\hline December & 1963 & 6.22 & 19.10 & 23.55 & 31 & $\bar{M}$ & -- \\
\hline January & 1964 & 4.96 & 15.23 & 18.78 & 31 & $\mathrm{M}$ & -- \\
\hline February & 1964 & 4.95 & 15.18 & 18.73 & 29 & $\bar{M}$ & -- \\
\hline March & 1964 & 8.92 & 27.37 & 33.76 & 31 & $\mathrm{M}$ & -- \\
\hline April & 1964 & 8.07 & 24.75 & 30.53 & 30 & $\mathrm{M}$ & -- \\
\hline May & 1964 & 11.40 & 34.98 & 43.14 & 31 & $\mathrm{M}$ & -- \\
\hline June & 1964 & 3.69 & 11.32 & 13.96 & 30 & $\mathrm{M}$ & -- \\
\hline July & 1964 & 2.44 & 7.50 & 9.25 & 31 & $\mathrm{M}$ & -- \\
\hline August & 1964 & 2.86 & 8.78 & 10.83 & 31 & $\mathrm{M}$ & -- \\
\hline September & 1964 & 0.06 & 0.19 & 0.24 & 30 & $\mathrm{M}$ & -- \\
\hline October & 1964 & 4.10 & 12.58 & 15.52 & 31 & $\mathrm{M}$ & -- \\
\hline November & 1964 & 2.15 & 6.59 & 8.13 & 30 & $\mathrm{M}$ & -- \\
\hline December & 1964 & 3.97 & 12.18 & 15.02 & 31 & $M$ & -- \\
\hline January & 1965 & 0.00 & 0.00 & 0.00 & 31 & $\mathrm{M}$ & -- \\
\hline February & 1965 & 0.00 & 0.00 & 0.00 & 28 & $\bar{M}$ & -- \\
\hline March & 1965 & 1.76 & 5.39 & 6.64 & 31 & $\bar{M}$ & -- \\
\hline April & 1965 & 2.45 & 7.52 & 9.27 & 30 & $\mathrm{M}$ & -- \\
\hline May & 1965 & 1.30 & 3.99 & 4.92 & 31 & $\mathrm{M}$ & -- \\
\hline June & 1965 & 0.99 & 3.03 & 3.73 & 30 & $\mathrm{M}$ & -- \\
\hline July & 1965 & 3.26 & 10.00 & 12.33 & 31 & $\mathrm{M}$ & -- \\
\hline August & 1965 & 2.58 & 7.91 & 9.76 & 31 & $\mathrm{M}$ & - \\
\hline September & 1965 & 3.05 & 9.37 & 11.56 & 26 & $\mathrm{M}$ & $\overline{--}$ \\
\hline
\end{tabular}


WW-C Monthly Pumping Data

\begin{tabular}{|c|c|c|c|c|c|c|c|}
\hline October & 1965 & -- & -- & -- & 0 & $T$ & -- \\
\hline November & 1965 & 4.30 & 13.20 & 16.28 & 29 & $\mathrm{M}$ & $\overline{--}$ \\
\hline December & 1965 & 5.35 & 16.41 & 20.24 & 31 & $\mathrm{M}$ & -- \\
\hline January & 1966 & 5.72 & 17.54 & 21.63 & 31 & $\mathrm{M}$ & -- \\
\hline February & 1966 & 2.06 & 6.31 & 7.78 & 28 & $\mathrm{M}$ & -- \\
\hline March & 1966 & 5.28 & 16.21 & 20.00 & 31 & $\mathrm{M}$ & -- \\
\hline April & 1966 & 5.99 & 18.38 & 22.67 & 30 & $\mathrm{M}$ & -- \\
\hline May & 1966 & 4.23 & 12.96 & 15.99 & 29 & $\bar{M}$ & -- \\
\hline June & 1966 & -- & -- & -- & 0 & 1 & -- \\
\hline July & 1966 & -- & -- & -- & 0 & $T$ & -- \\
\hline August & 1966 & 0.14 & 0.42 & 0.52 & 28 & $\bar{M}$ & -- \\
\hline September & 1966 & 0.00 & 0.00 & 0.00 & 5 & $\bar{M}$ & -- \\
\hline October & 1966 & 0.00 & 0.00 & 0.00 & 31 & $\mathrm{M}$ & -- \\
\hline November & 1966 & 0.00 & 0.00 & 0.00 & 30 & $\mathrm{M}$ & -- \\
\hline December & 1966 & 0.00 & 0.00 & 0.00 & 31 & $\mathrm{M}$ & -- \\
\hline January & 1967 & 0.00 & 0.00 & 0.00 & 31 & $\mathrm{M}$ & -- \\
\hline February & 1967 & 0.00 & 0.00 & 0.00 & 28 & $\mathrm{M}$ & -- \\
\hline March & 1967 & 0.00 & 0.00 & 0.00 & 31 & $\mathrm{M}$ & -- \\
\hline April & 1967 & 0.00 & 0.00 & 0.00 & 30 & $\mathrm{M}$ & -- \\
\hline May & 1967 & 3.30 & 10.11 & 12.47 & 31 & $\bar{M}$ & -- \\
\hline June & 1967 & 5.53 & 16.96 & 20.92 & 30 & $\mathrm{M}$ & -- \\
\hline July & 1967 & 3.35 & 10.27 & 12.67 & 365 & $\mathrm{R}$ & estimateo \\
\hline August & 1967 & 3.35 & 10.27 & 12.67 & 365 & $\mathrm{R}$ & estimated \\
\hline September & 1967 & 3.35 & 10.27 & 12.67 & 365 & $\bar{R}$ & estimated \\
\hline October & 1967 & 3.35 & 10.27 & 12.67 & 365 & $\overline{\mathrm{R}}$ & estimateo \\
\hline November & 1967 & 3.35 & 10.27 & 12.67 & 365 & $\mathrm{R}$ & estimateo \\
\hline December & 1967 & 3.35 & 10.27 & 12.67 & 365 & $\mathrm{R}$ & estimated \\
\hline January & 1968 & 6.75 & 20.71 & 25.55 & 366 & $R$ & estimated \\
\hline February & 1968 & 6.75 & 20.71 & 25.55 & 366 & $\bar{R}$ & estimateo \\
\hline March & 1968 & 6.75 & 20.71 & 25.55 & 366 & $\bar{R}$ & estimateo \\
\hline April & 1968 & 6.75 & 20.71 & 25.55 & 366 & $\mathrm{R}$ & estimateo \\
\hline May & 1968 & 6.75 & 20.71 & 25.55 & 366 & $\mathrm{R}$ & estimated \\
\hline June & 1968 & 6.75 & 20.71 & 25.55 & 366 & $\bar{R}$ & estimateo \\
\hline July & 1968 & 6.75 & 20.71 & 25.55 & 366 & $\mathrm{R}$ & estimated \\
\hline August & 1968 & 6.75 & 20.71 & 25.55 & 366 & $\mathrm{R}$ & estimated \\
\hline September & 1968 & 6.75 & 20.71 & 25.55 & 366 & $\bar{R}$ & estimateo \\
\hline October & 1968 & 6.75 & 20.71 & 25.55 & 366 & $\bar{R}$ & estimateo \\
\hline November & 1968 & 6.75 & 20.71 & 25.55 & 366 & $\mathrm{R}$ & estimateo \\
\hline December & 1968 & 6.75 & 20.71 & 25.55 & 366 & $\bar{R}$ & estimateo \\
\hline January & 1969 & 7.97 & 24.45 & 30.15 & 365 & $\mathrm{R}$ & estimated \\
\hline February & 1969 & 7.97 & 24.45 & 30.15 & 365 & $\mathrm{R}$ & estimated \\
\hline March & 1969 & 7.97 & 24.45 & 30.15 & 365 & $\bar{R}$ & estimateo \\
\hline April & 1969 & 7.97 & 24.45 & 30.15 & 365 & $\mathrm{R}$ & estimateo \\
\hline May & 1969 & 7.97 & 24.45 & 30.15 & 365 & $\mathrm{R}$ & estimated \\
\hline June & 1969 & 7.97 & 24.45 & 30.15 & 365 & $\bar{R}$ & estimateo \\
\hline July & 1969 & 7.97 & 24.45 & 30.15 & 365 & $\mathrm{R}$ & estimated \\
\hline August & 1969 & 7.97 & 24.45 & 30.15 & 365 & $\mathrm{R}$ & estimated \\
\hline September & 1969 & 7.97 & 24.45 & 30.15 & 365 & $\bar{R}$ & estimated \\
\hline October & 1969 & 7.97 & 24.45 & 30.15 & 365 & $\bar{R}$ & estimateo \\
\hline November & 1969 & 7.97 & 24.45 & 30.15 & 365 & R & estimated \\
\hline December & 1969 & 7.97 & 24.45 & 30.15 & 365 & $\bar{R}$ & estimateo \\
\hline January & 1970 & 5.20 & 15.96 & 19.68 & 365 & R & estimated \\
\hline
\end{tabular}


WW-C Monthly Pumping Data

\begin{tabular}{|c|c|c|c|c|c|c|c|}
\hline February & 1970 & 5.20 & 15.96 & 19.68 & 365 & $\bar{R}$ & estimated \\
\hline March & 1970 & 5.20 & 15.96 & 19.68 & 365 & $\mathrm{R}$ & estimated \\
\hline April & 1970 & 5.20 & 15.96 & 19.68 & 365 & $\mathrm{R}$ & estimated \\
\hline May & 1970 & 5.20 & 15.96 & 19.68 & 365 & $\mathrm{R}$ & estimated \\
\hline June & 1970 & 5.20 & 15.96 & 19.68 & 365 & $\bar{R}$ & estimated \\
\hline July & 1970 & 5.20 & 15.96 & 19.68 & 365 & $\bar{R}$ & estimated \\
\hline August & 1970 & 5.20 & 15.96 & 19.68 & 365 & $\bar{R}$ & estimated \\
\hline September & 1970 & 5.20 & 15.96 & 19.68 & 365 & $\bar{R}$ & estimated \\
\hline October & 1970 & 5.20 & 15.96 & 19.68 & 365 & $\bar{R}$ & estimated \\
\hline November & 1970 & 5.20 & 15.96 & 19.68 & 365 & $\mathrm{R}$ & estimated \\
\hline December & 1970 & 5.20 & 15.96 & 19.68 & 365 & $\overline{\mathrm{R}}$ & estimated \\
\hline January & 1971 & 6.95 & 21.33 & 26.31 & 365 & $\overline{\mathrm{R}}$ & estimated \\
\hline February & 1971 & 6.95 & 21.33 & 26.31 & 365 & $\bar{R}$ & estimated \\
\hline March & 1971 & 6.95 & 21.33 & 26.31 & 365 & $\mathrm{R}$ & estimated \\
\hline April & 1971 & 6.95 & 21.33 & 26.31 & 365 & R & estimated \\
\hline May & 1971 & 6.95 & 21.33 & 26.31 & 365 & $\mathrm{R}$ & estimated \\
\hline June & 1971 & 6.95 & 21.33 & 26.31 & 365 & $\mathrm{R}$ & estimated \\
\hline July & 1971 & 6.95 & 21.33 & 26.31 & 365 & $\bar{R}$ & estimated \\
\hline August & 1971 & 6.95 & 21.33 & 26.31 & 365 & $\bar{R}$ & estimated \\
\hline September & 1971 & 6.95 & 21.33 & 26.31 & 365 & $\bar{R}$ & estimated \\
\hline October & 1971 & 6.95 & 21.33 & 26.31 & 365 & $\bar{R}$ & estimated \\
\hline November & 1971 & 6.95 & 21.33 & 26.31 & 365 & $\mathrm{R}$ & estimated \\
\hline December & 1971 & 6.95 & 21.33 & 26.31 & 365 & $\overline{\mathrm{R}}$ & estimated \\
\hline January & 1972 & 6.43 & 19.74 & 24.35 & 366 & $\mathrm{H}$ & estimated \\
\hline February & 1972 & 6.43 & 19.74 & 24.35 & 366 & $\mathrm{H}$ & estimated \\
\hline March & 1972 & 6.43 & 19.74 & 24.35 & 366 & $\mathrm{H}$ & estimated \\
\hline April & 1972 & 6.43 & 19.74 & 24.35 & 366 & $\mathrm{H}$ & estimated \\
\hline May & 1972 & 6.43 & 19.74 & 24.35 & 366 & $\mathrm{H}$ & estimated \\
\hline June & 1972 & 6.43 & 19.74 & 24.35 & 366 & $\mathrm{H}$ & estimated \\
\hline July & 1972 & 6.43 & 19.74 & 24.35 & 366 & $\mathrm{H}$ & estimated \\
\hline August & 1972 & 6.43 & 19.74 & 24.35 & 366 & $\mathrm{H}$ & estimated \\
\hline September & 1972 & 6.43 & 19.74 & 24.35 & 366 & $\mathrm{H}$ & estimated \\
\hline October & 1972 & 6.43 & 19.74 & 24.35 & 366 & $\mathrm{H}$ & estimated \\
\hline November & 1972 & 6.43 & 19.74 & 24.35 & 366 & $\mathrm{H}$ & estimated \\
\hline December & 1972 & 6.43 & 19.74 & 24.35 & 366 & $\mathrm{H}$ & estimated \\
\hline January & 1973 & 5.13 & 15.75 & 19.43 & 365 & $\mathrm{H}$ & estimated \\
\hline February & 1973 & 5.13 & 15.75 & 19.43 & 365 & $\mathrm{H}$ & estimated \\
\hline March & 1973 & 5.13 & 15.75 & 19.43 & 365 & $\mathrm{H}$ & estimated \\
\hline April & 1973 & 5.13 & 15.75 & 19.43 & 365 & $\mathrm{H}$ & estimated \\
\hline May & 1973 & 5.13 & 15.75 & 19.43 & 365 & $\mathrm{H}$ & estimated \\
\hline June & 1973 & 5.13 & 15.75 & 19.43 & 365 & $\mathrm{H}$ & estimated \\
\hline July & 1973 & 5.13 & 15.75 & 19.43 & 365 & $\mathrm{H}$ & estimated \\
\hline August & 1973 & 5.13 & 15.75 & 19.43 & 365 & $\mathrm{H}$ & estimated \\
\hline September & 1973 & 5.13 & 15.75 & 19.43 & 365 & $\mathrm{H}$ & estimated \\
\hline October & 1973 & 5.13 & 15.75 & 19.43 & 365 & $\mathrm{H}$ & estimated \\
\hline November & 1973 & 5.13 & 15.75 & 19.43 & 365 & $\mathrm{H}$ & estimated \\
\hline December & 1973 & 5.13 & 15.75 & 19.43 & 365 & $\mathrm{H}$ & estimated \\
\hline January & 1974 & 5.54 & 17.00 & 20.98 & 365 & $\mathrm{H}$ & estimated \\
\hline February & 1974 & 5.54 & 17.00 & 20.98 & 365 & $\mathrm{H}$ & estimated \\
\hline March & 1974 & 5.54 & 17.00 & 20.98 & 365 & $\mathrm{H}$ & estimated \\
\hline April & 1974 & 5.54 & 17.00 & 20.98 & 365 & $\mathrm{H}$ & estimated \\
\hline May & 1974 & 5.54 & 17.00 & 20.98 & 365 & $\mathrm{H}$ & estimated \\
\hline
\end{tabular}


WW-C Monthly Pumping Data

\begin{tabular}{|c|c|c|c|c|c|c|c|}
\hline June & 1974 & 5.54 & 17.00 & 20.98 & 365 & $\mathrm{H}$ & estimated \\
\hline July & 1974 & 5.54 & 17.00 & 20.98 & 365 & $\mathrm{H}$ & estimated \\
\hline August & 1974 & $\overline{5.54}$ & 17.00 & 20.98 & 365 & H & estimated \\
\hline September & 1974 & 5.54 & 17.00 & 20.98 & 365 & $\mathrm{H}$ & estimated \\
\hline October & 1974 & 5.54 & 17.00 & 20.98 & 365 & $\mathrm{H}$ & estimated \\
\hline November & 1974 & 5.54 & 17.00 & 20.98 & 365 & $\mathrm{H}$ & estimated \\
\hline December & 1974 & 5.54 & 17.00 & 20.98 & 365 & $\mathrm{H}$ & estimated \\
\hline January & 1975 & 5.27 & 16.16 & 19.93 & 365 & $\mathrm{H}$ & estimated \\
\hline February & 1975 & 5.27 & 16.16 & 19.93 & 365 & $\mathrm{H}$ & estimated \\
\hline March & 1975 & 5.27 & 16.16 & 19.93 & 365 & $\mathrm{H}$ & estimated \\
\hline April & 1975 & 5.27 & 16.16 & 19.93 & 365 & $\mathrm{H}$ & estimated \\
\hline May & 1975 & 5.27 & 16.16 & 19.93 & 365 & $\mathrm{H}$ & estimated \\
\hline June & 1975 & 5.27 & 16.16 & 19.93 & 365 & $\mathrm{H}$ & estimated \\
\hline July & 1975 & 5.27 & 16.16 & 19.93 & 365 & $\mathrm{H}$ & estimated \\
\hline August & 1975 & 5.27 & 16.16 & 19.93 & 365 & $\mathrm{H}$ & estimated \\
\hline September & 1975 & 5.27 & 16.16 & 19.93 & 365 & $\mathrm{H}$ & estimated \\
\hline October & 1975 & 5.27 & 16.16 & 19.93 & 365 & $\mathrm{H}$ & estimated \\
\hline November & 1975 & 5.27 & 16.16 & 19.93 & 365 & $\mathrm{H}$ & estimated \\
\hline December & 1975 & 5.27 & 16.16 & 19.93 & 365 & $\mathrm{H}$ & estimated \\
\hline January & 1976 & 4.29 & 13.17 & 16.24 & 366 & $\mathrm{H}$ & estimated \\
\hline February & 1976 & 4.29 & 13.17 & 16.24 & 366 & $\mathrm{H}$ & estimated \\
\hline March & 1976 & 4.29 & 13.17 & 16.24 & 366 & $\mathrm{H}$ & estimated \\
\hline April & 1976 & 4.29 & 13.17 & 16.24 & 366 & $\mathrm{H}$ & estimated \\
\hline May & 1976 & 4.29 & 13.17 & 16.24 & 366 & $\bar{H}$ & estimated \\
\hline June & 1976 & 4.29 & 13.17 & 16.24 & 366 & $\mathrm{H}$ & estimated \\
\hline July & 1976 & 4.29 & 13.17 & 16.24 & 366 & $\mathrm{H}$ & estimated \\
\hline August & 1976 & 4.29 & 13.17 & 16.24 & 366 & $\mathrm{H}$ & estimated \\
\hline September & 1976 & 4.29 & 13.17 & 16.24 & 366 & $\mathrm{H}$ & estimated \\
\hline October & 1976 & 4.29 & 13.17 & 16.24 & 366 & $\mathrm{H}$ & estimated \\
\hline November & 1976 & 4.29 & 13.17 & 16.24 & 366 & $\mathrm{H}$ & estimated \\
\hline December & 1976 & 4.29 & 13.17 & 16.24 & 366 & $\mathrm{H}$ & estimated \\
\hline January & 1977 & 3.64 & 11.17 & 13.78 & 365 & $\mathrm{H}$ & estimated \\
\hline February & 1977 & 3.64 & 11.17 & 13.78 & 365 & $\mathrm{H}$ & estimated \\
\hline March & 1977 & 3.64 & 11.17 & 13.78 & 365 & $\mathrm{H}$ & estimated \\
\hline April & 1977 & 3.64 & 11.17 & 13.78 & 365 & $\mathrm{H}$ & estimated \\
\hline May & 1977 & 3.64 & 11.17 & 13.78 & 365 & $\mathrm{H}$ & estimated \\
\hline June & 1977 & 3.64 & 11.17 & 13.78 & 365 & $\mathrm{H}$ & estimated \\
\hline July & 1977 & 3.64 & 11.17 & 13.78 & 365 & $\mathrm{H}$ & estimated \\
\hline August & 1977 & 3.64 & 11.17 & 13.78 & 365 & $\mathrm{H}$ & estimated \\
\hline September & 1977 & 3.64 & 11.17 & 13.78 & 365 & $\mathrm{H}$ & estimated \\
\hline October & 1977 & 3.64 & 11.17 & 13.78 & 365 & $\mathrm{H}$ & estimated \\
\hline November & 1977 & 3.64 & 11.17 & 13.78 & 365 & $\mathrm{H}$ & estimated \\
\hline December & 1977 & 3.64 & 11.17 & 13.78 & 365 & $\mathrm{H}$ & estimated \\
\hline January & 1978 & 3.61 & 11.07 & 13.66 & 365 & $\mathrm{H}$ & estimated \\
\hline February & 1978 & 3.61 & 11.07 & 13.66 & 365 & $\mathrm{H}$ & estimated \\
\hline March & 1978 & 3.61 & 11.07 & 13.66 & 365 & $\mathrm{H}$ & estimated \\
\hline April & 1978 & 3.61 & 11.07 & 13.66 & 365 & $\mathrm{H}$ & estimated \\
\hline May & 1978 & 3.61 & 11.07 & 13.66 & 365 & $\mathrm{H}$ & estimated \\
\hline June & 1978 & 3.61 & 11.07 & 13.66 & 365 & $\mathrm{H}$ & estimated \\
\hline July & 1978 & 3.61 & 11.07 & 13.66 & 365 & H & estimated \\
\hline August & 1978 & 3.61 & 11.07 & 13.66 & 365 & $\mathrm{H}$ & estimated \\
\hline September & 1978 & 3.61 & 11.07 & 13.66 & 365 & $\mathrm{H}$ & estimated \\
\hline
\end{tabular}


WW-C Monthly Pumping Data

\begin{tabular}{|c|c|c|c|c|c|c|c|}
\hline October & 1978 & 3.61 & 11.07 & 13.66 & 365 & $\mathrm{H}$ & estimated \\
\hline November & 1978 & 3.61 & 11.07 & 13.66 & 365 & $\mathrm{H}$ & estimated \\
\hline December & 1978 & 3.61 & 11.07 & 13.66 & 365 & H & estimated \\
\hline January & 1979 & 2.93 & 9.00 & 11.10 & 365 & $\mathrm{H}$ & estimated \\
\hline February & 1979 & 2.93 & 9.00 & 11.10 & 365 & $\mathrm{H}$ & estimated \\
\hline March & 1979 & 2.93 & 9.00 & 11.10 & 365 & $\mathrm{H}$ & estimated \\
\hline April & 1979 & 2.93 & 9.00 & 11.10 & 365 & $\mathrm{H}$ & estimated \\
\hline May & 1979 & 2.93 & 9.00 & 11.10 & 365 & $\mathrm{H}$ & estimated \\
\hline June & 1979 & 2.93 & 9.00 & 11.10 & 365 & $\mathrm{H}$ & estimated \\
\hline July & 1979 & 2.93 & 9.00 & 11.10 & 365 & $\mathrm{H}$ & estimated \\
\hline August & 1979 & 2.93 & 9.00 & 11.10 & 365 & $\mathrm{H}$ & estimated \\
\hline September & 1979 & 2.93 & 9.00 & 11.10 & 365 & $\mathrm{H}$ & estimated \\
\hline October & 1979 & 2.93 & 9.00 & 11.10 & 365 & $\mathrm{H}$ & estimated \\
\hline November & 1979 & 2.93 & 9.00 & 11.10 & 365 & $\mathrm{H}$ & estimated \\
\hline December & 1979 & 2.93 & 9.00 & 11.10 & 365 & H & estimated \\
\hline January & 1980 & 3.15 & 9.67 & 11.92 & 366 & $\mathrm{H}$ & estimated \\
\hline February & 1980 & 3.15 & 9.67 & 11.92 & 366 & $\mathrm{H}$ & estimated \\
\hline March & 1980 & 3.15 & 9.67 & 11.92 & 366 & $\mathrm{H}$ & estimated \\
\hline April & 1980 & 3.15 & 9.67 & 11.92 & 366 & $\mathrm{H}$ & estimated \\
\hline May & 1980 & 3.15 & 9.67 & 11.92 & 366 & $\mathrm{H}$ & estimated \\
\hline June & 1980 & 3.15 & 9.67 & 11.92 & 366 & $\mathrm{H}$ & estimated \\
\hline July & 1980 & 3.15 & 9.67 & 11.92 & 366 & $\mathrm{H}$ & estimated \\
\hline August & 1980 & 3.15 & 9.67 & 11.92 & 366 & $\mathrm{H}$ & estimated \\
\hline September & 1980 & 3.15 & 9.67 & 11.92 & 366 & $\mathrm{H}$ & estimated \\
\hline October & 1980 & 3.15 & 9.67 & 11.92 & 366 & $\mathrm{H}$ & estimated \\
\hline November & 1980 & 3.15 & 9.67 & 11.92 & 366 & $\mathrm{H}$ & estimated \\
\hline December & 1980 & 3.15 & 9.67 & 11.92 & 366 & $\mathrm{H}$ & estimated \\
\hline January & 1981 & 3.23 & 9.92 & 12.24 & 365 & $\mathrm{H}$ & estimated \\
\hline February & 1981 & 3.23 & 9.92 & 12.24 & 365 & $\mathrm{H}$ & estimated \\
\hline March & 1981 & 3.23 & 9.92 & 12.24 & 365 & $\mathrm{H}$ & estimated \\
\hline April & 1981 & 3.23 & 9.92 & 12.24 & 365 & $\mathrm{H}$ & estimated \\
\hline May & 1981 & 3.23 & 9.92 & 12.24 & 365 & $\mathrm{H}$ & estimated \\
\hline June & 1981 & 3.23 & 9.92 & 12.24 & 365 & $\mathrm{H}$ & estimated \\
\hline July & 1981 & 3.23 & 9.92 & 12.24 & 365 & $\mathrm{H}$ & estimated \\
\hline August & 1981 & 3.23 & 9.92 & 12.24 & 365 & $\mathrm{H}$ & estimated \\
\hline September & 1981 & 3.23 & 9.92 & 12.24 & 365 & $\mathrm{H}$ & estimated \\
\hline October & 1981 & 3.23 & 9.92 & 12.24 & 365 & $\mathrm{H}$ & estimated \\
\hline November & 1981 & 3.23 & 9.92 & 12.24 & 365 & $\mathrm{H}$ & estimated \\
\hline December & 1981 & 3.23 & 9.92 & 12.24 & 365 & H & estimated \\
\hline January & 1982 & 3.32 & 10.18 & 12.55 & 365 & $\mathrm{H}$ & estimated \\
\hline February & 1982 & 3.32 & 10.18 & 12.55 & 365 & $\mathrm{H}$ & estimated \\
\hline March & 1982 & 3.32 & 10.18 & 12.55 & 365 & $\mathrm{H}$ & estimated \\
\hline April & 1982 & 3.32 & 10.18 & 12.55 & 365 & $\mathrm{H}$ & estimated \\
\hline May & 1982 & 3.32 & 10.18 & 12.55 & 365 & $\mathrm{H}$ & estimated \\
\hline June & 1982 & 3.32 & 10.18 & 12.55 & 365 & $\mathrm{H}$ & estimated \\
\hline July & 1982 & 3.32 & 10.18 & 12.55 & 365 & $\mathrm{H}$ & estimated \\
\hline August & 1982 & 3.32 & 10.18 & 12.55 & 365 & $\mathrm{H}$ & estimated \\
\hline September & 1982 & 3.32 & 10.18 & 12.55 & 365 & $\mathrm{H}$ & estimated \\
\hline October & 1982 & 3.32 & 10.18 & 12.55 & 365 & $\mathrm{H}$ & estimated \\
\hline November & 1982 & 3.32 & 10.18 & 12.55 & 365 & $\mathrm{H}$ & estimated \\
\hline December & 1982 & 3.32 & 10.18 & 12.55 & 365 & H & estimated \\
\hline January & 1983 & 1.72 & 5.29 & 6.53 & 31 & $\mathrm{M}$ & -- \\
\hline
\end{tabular}


WW-C Monthly Pumping Data

\begin{tabular}{|c|c|c|c|c|c|c|c|}
\hline February & 1983 & 1.73 & 5.30 & 6.54 & 28 & $\bar{M}$ & -- \\
\hline March & 1983 & 1.86 & 5.71 & 7.04 & 31 & $\mathrm{M}$ & - \\
\hline April & 1983 & 2.17 & 6.66 & 8.21 & 30 & $\mathrm{M}$ & -- \\
\hline May & 1983 & 3.25 & 9.97 & 12.30 & 31 & $\mathrm{M}$ & -- \\
\hline June & 1983 & 3.06 & 9.38 & 11.56 & 30 & $\mathrm{M}$ & -- \\
\hline July & 1983 & 3.23 & 9.91 & 12.23 & 31 & $\mathrm{M}$ & - \\
\hline August & 1983 & 2.85 & 8.73 & 10.77 & 31 & $\mathrm{M}$ & - \\
\hline September & 1983 & 2.95 & 9.05 & 11.17 & 30 & $\mathrm{M}$ & -- \\
\hline October & 1983 & 1.87 & 5.73 & 7.07 & 31 & $\bar{M}$ & - \\
\hline November & 1983 & 1.67 & 5.14 & 6.34 & 30 & $\mathrm{M}$ & -- \\
\hline December & 1983 & 1.36 & 4.18 & 5.16 & 31 & $\mathrm{M}$ & -- \\
\hline January & 1984 & 1.89 & 5.81 & 7.17 & 31 & $\mathrm{M}$ & -- \\
\hline February & 1984 & 1.83 & 5.63 & 6.94 & 29 & $\mathrm{M}$ & - \\
\hline March & 1984 & 1.95 & 5.98 & 7.37 & 31 & $\mathrm{M}$ & - \\
\hline April & 1984 & 2.07 & 6.36 & 7.84 & 30 & $\mathrm{M}$ & -- \\
\hline May & 1984 & 3.34 & 10.26 & 12.65 & 31 & $\mathrm{M}$ & -- \\
\hline June & 1984 & 2.72 & 8.36 & 10.30 & 30 & $\mathrm{M}$ & -- \\
\hline July & 1984 & 2.84 & 8.72 & 10.75 & 31 & $\bar{M}$ & - \\
\hline August & 1984 & 2.88 & 8.84 & 10.91 & 31 & $\mathrm{M}$ & - \\
\hline September & 1984 & 2.54 & 7.79 & 9.61 & 30 & $\mathrm{M}$ & -- \\
\hline October & 1984 & 2.78 & 8.52 & 10.50 & 31 & $\bar{M}$ & - \\
\hline November & 1984 & 2.77 & 8.50 & 10.49 & 30 & $\mathrm{M}$ & - \\
\hline December & 1984 & 3.58 & 10.98 & 13.54 & 31 & $E$ & -- \\
\hline January & 1985 & 3.21 & 9.86 & 12.16 & 31 & $E$ & -- \\
\hline February & 1985 & 2.56 & 7.85 & 9.68 & 28 & $\bar{M}$ & - \\
\hline March & 1985 & 3.20 & 9.81 & 12.11 & 31 & $\mathrm{M}$ & -- \\
\hline April & 1985 & 2.66 & 8.16 & 10.07 & 30 & $\mathrm{M}$ & -- \\
\hline May & 1985 & 1.96 & 6.00 & 7.40 & 31 & $\mathrm{M}$ & -- \\
\hline June & 1985 & 0.62 & 1.91 & 2.36 & 30 & $\mathrm{M}$ & - \\
\hline July & 1985 & 0.74 & 2.26 & 2.79 & 31 & $\mathrm{M}$ & - \\
\hline August & 1985 & 1.09 & 3.36 & 4.14 & 31 & $\mathrm{M}$ & - \\
\hline September & 1985 & 1.03 & 3.16 & 3.89 & 30 & $\mathrm{M}$ & -- \\
\hline October & 1985 & 0.66 & 2.01 & 2.48 & 31 & $\bar{M}$ & - \\
\hline November & 1985 & 1.06 & 3.25 & 4.01 & 30 & $\mathrm{M}$ & - \\
\hline December & 1985 & 0.59 & 1.80 & 2.22 & 31 & $E$ & -- \\
\hline January & 1986 & 0.13 & 0.38 & 0.47 & 31 & $\mathrm{M}$ & -- \\
\hline February & 1986 & 0.88 & 2.69 & 3.32 & 28 & $\mathrm{M}$ & - \\
\hline March & 1986 & 2.66 & 8.15 & 10.05 & 31 & $\mathrm{M}$ & - \\
\hline April & 1986 & 1.96 & 6.01 & 7.42 & 30 & $\mathrm{M}$ & -- \\
\hline May & 1986 & 1.14 & 3.51 & 4.33 & 31 & $\mathrm{M}$ & -- \\
\hline June & 1986 & 1.11 & 3.41 & 4.21 & 30 & $\mathrm{M}$ & - \\
\hline July & 1986 & 1.24 & 3.81 & 4.70 & 31 & $\bar{M}$ & -- \\
\hline August & 1986 & 1.15 & 3.54 & 4.37 & 31 & $\mathrm{M}$ & - \\
\hline September & 1986 & 2.68 & 8.21 & 10.13 & 30 & $E$ & -- \\
\hline October & 1986 & 2.23 & 6.85 & 8.45 & 31 & $\mathrm{M}$ & -- \\
\hline November & 1986 & 1.36 & 4.17 & 5.14 & 30 & $\mathrm{M}$ & - \\
\hline December & 1986 & 0.72 & 2.22 & 2.74 & 31 & $\mathrm{M}$ & -- \\
\hline January & 1987 & 0.96 & 2.96 & 3.65 & 31 & $\mathrm{M}$ & -- \\
\hline February & 1987 & 0.51 & 1.56 & 1.92 & 28 & $\mathrm{M}$ & -- \\
\hline March & 1987 & 0.90 & 2.77 & 3.42 & 31 & $\mathrm{M}$ & -- \\
\hline April & 1987 & 0.93 & 2.85 & 3.51 & 30 & $\mathrm{M}$ & - \\
\hline May & 1987 & 0.50 & 1.54 & 1.90 & 31 & $\mathrm{M}$ & -- \\
\hline
\end{tabular}


WW-C Monthly Pumping Data

\begin{tabular}{|c|c|c|c|c|c|c|c|}
\hline June & 1987 & 1.03 & 3.16 & 3.89 & 30 & $\bar{M}$ & -- \\
\hline July & 1987 & 1.03 & 3.15 & 3.89 & 31 & $\mathrm{M}$ & -- \\
\hline August & 1987 & 0.54 & 1.65 & 2.03 & 31 & $\mathrm{M}$ & -- \\
\hline September & 1987 & 0.37 & 1.14 & 1.41 & 30 & $\mathrm{M}$ & -- \\
\hline October & 1987 & 0.30 & 0.91 & 1.12 & 31 & $\bar{M}$ & -- \\
\hline November & 1987 & 0.09 & 0.29 & 0.35 & 30 & $\mathrm{M}$ & -- \\
\hline December & 1987 & 0.00 & 0.00 & 0.00 & 31 & $\mathrm{M}$ & - \\
\hline January & 1988 & 1.86 & 5.70 & 7.03 & 31 & $\bar{M}$ & -- \\
\hline February & 1988 & 1.17 & 3.60 & 4.44 & 29 & $\bar{M}$ & - \\
\hline March & 1988 & 0.48 & 1.47 & 1.81 & 31 & $\mathrm{M}$ & -- \\
\hline April & 1988 & 1.14 & 3.50 & 4.31 & 30 & $\bar{M}$ & -- \\
\hline May & 1988 & 1.46 & 4.49 & 5.54 & 31 & $\mathrm{M}$ & -- \\
\hline June & 1988 & 1.14 & 3.51 & 4.33 & 30 & $\mathrm{M}$ & -- \\
\hline July & 1988 & 1.61 & 4.93 & 6.08 & 31 & $\mathrm{M}$ & - \\
\hline August & 1988 & 1.50 & 4.61 & 5.68 & 31 & $\mathrm{M}$ & -- \\
\hline September & 1988 & 1.11 & 3.39 & 4.19 & 30 & $\mathrm{M}$ & -- \\
\hline October & 1988 & 1.79 & 5.49 & 6.76 & 31 & $\mathrm{M}$ & -- \\
\hline November & 1988 & 1.76 & 5.40 & 6.66 & 30 & $\mathrm{M}$ & -- \\
\hline December & 1988 & 2.39 & 7.33 & 9.04 & 31 & $\mathrm{M}$ & - \\
\hline January & 1989 & 1.39 & 4.26 & 5.25 & 31 & $\mathrm{M}$ & - \\
\hline February & 1989 & 0.12 & 0.35 & 0.44 & 28 & $\bar{M}$ & -- \\
\hline March & 1989 & 0.00 & 0.00 & 0.01 & 31 & $\mathrm{M}$ & -- \\
\hline April & 1989 & 0.00 & 0.00 & 0.00 & 30 & $\mathrm{M}$ & - \\
\hline May & 1989 & 0.00 & 0.00 & 0.00 & 31 & $\bar{M}$ & -- \\
\hline June & 1989 & 0.19 & 0.57 & 0.71 & 30 & $\mathrm{M}$ & -- \\
\hline July & 1989 & 3.50 & 10.75 & 13.25 & 31 & $\mathrm{M}$ & - \\
\hline August & 1989 & 8.30 & 25.46 & 31.40 & 31 & $\mathrm{M}$ & -- \\
\hline September & 1989 & 7.62 & 23.39 & 28.84 & 30 & $\mathrm{M}$ & -- \\
\hline October & 1989 & 8.70 & 26.68 & 32.91 & 31 & $\bar{M}$ & -- \\
\hline November & 1989 & 1.79 & 5.50 & 6.79 & 30 & $\mathrm{M}$ & -- \\
\hline December & 1989 & 0.00 & 0.00 & 0.00 & 31 & $\mathrm{M}$ & - \\
\hline January & 1990 & 0.00 & 0.00 & 0.00 & 31 & $\mathrm{M}$ & - \\
\hline February & 1990 & 0.46 & 1.40 & 1.73 & 28 & $\bar{M}$ & -- \\
\hline March & 1990 & 4.94 & 15.17 & 18.71 & 31 & $\mathrm{M}$ & -- \\
\hline April & 1990 & 4.04 & 12.39 & 15.28 & 30 & $\mathrm{M}$ & -- \\
\hline May & 1990 & 4.38 & 13.44 & 16.58 & 31 & $\bar{M}$ & -- \\
\hline June & 1990 & 3.30 & 10.12 & 12.48 & 30 & $\mathrm{M}$ & -- \\
\hline July & 1990 & 3.26 & 10.01 & 12.35 & 31 & $\mathrm{M}$ & -- \\
\hline August & 1990 & 2.78 & 8.54 & 10.53 & 31 & $\mathrm{M}$ & -- \\
\hline September & 1990 & 0.97 & 2.99 & 3.69 & 30 & $E$ & -- \\
\hline October & 1990 & 2.24 & 6.87 & 8.47 & 31 & $\bar{M}$ & -- \\
\hline November & 1990 & 1.70 & 5.21 & 6.43 & 30 & $\mathrm{M}$ & -- \\
\hline December & 1990 & 1.60 & 4.92 & 6.07 & 31 & $\bar{M}$ & -- \\
\hline January & 1991 & 0.24 & 0.74 & 0.91 & 31 & $\mathrm{M}$ & - \\
\hline February & 1991 & 1.81 & 5.55 & 6.85 & 28 & $\mathrm{M}$ & -- \\
\hline March & 1991 & 2.10 & 6.45 & 7.96 & 31 & $\mathrm{M}$ & -- \\
\hline April & 1991 & 2.84 & 8.71 & 10.75 & 30 & $\mathrm{M}$ & -- \\
\hline May & 1991 & 3.93 & 12.06 & 14.87 & 31 & $\bar{M}$ & -- \\
\hline June & 1991 & 2.38 & 7.31 & 9.01 & 30 & $\mathrm{M}$ & -- \\
\hline July & 1991 & 2.99 & 9.17 & 11.31 & 31 & $\mathrm{M}$ & -- \\
\hline August & 1991 & 3.06 & 9.40 & 11.59 & 31 & $\mathrm{M}$ & -- \\
\hline September & 1991 & 2.35 & 7.22 & 8.91 & 30 & $\mathrm{M}$ & - \\
\hline
\end{tabular}


WW-C Monthly Pumping Data

\begin{tabular}{|c|c|c|c|c|c|c|c|}
\hline October & 1991 & 2.42 & 7.44 & 9.17 & 31 & $\bar{M}$ & -- \\
\hline November & 1991 & 2.17 & 6.64 & 8.19 & 30 & $\mathrm{M}$ & -- \\
\hline December & 1991 & 1.36 & 4.18 & 5.15 & 31 & $\mathrm{M}$ & - \\
\hline January & 1992 & 1.02 & 3.14 & 3.87 & 31 & $\mathrm{M}$ & -- \\
\hline February & 1992 & 1.90 & 5.84 & 7.21 & 29 & $\mathrm{M}$ & - \\
\hline March & 1992 & 3.67 & 11.26 & 13.89 & 31 & $\mathrm{M}$ & - \\
\hline April & 1992 & 4.98 & 15.28 & 18.84 & 30 & $\bar{M}$ & - \\
\hline May & 1992 & 2.37 & 7.28 & 8.98 & 31 & $\bar{M}$ & - \\
\hline June & 1992 & 0.90 & 2.75 & 3.39 & 30 & $\bar{M}$ & -- \\
\hline July & 1992 & 0.00 & 0.00 & 0.00 & 31 & $\bar{M}$ & - \\
\hline August & 1992 & 0.00 & 0.00 & 0.00 & 31 & $\bar{M}$ & -- \\
\hline September & 1992 & 0.00 & 0.00 & 0.00 & 30 & $\mathrm{M}$ & - \\
\hline October & 1992 & 0.00 & 0.00 & 0.00 & 31 & $\mathrm{M}$ & - \\
\hline November & 1992 & 0.00 & 0.00 & 0.00 & 30 & $\mathrm{M}$ & - \\
\hline December & 1992 & 0.00 & 0.00 & 0.00 & 31 & $\mathrm{M}$ & -- \\
\hline January & 1993 & 1.43 & 4.37 & 5.39 & 31 & $\mathrm{M}$ & -- \\
\hline February & 1993 & 1.13 & 3.46 & 4.26 & 28 & $\mathrm{M}$ & -- \\
\hline March & 1993 & 1.82 & 5.58 & 6.88 & 31 & $\bar{M}$ & -- \\
\hline April & 1993 & 3.37 & 10.33 & 12.74 & 30 & $\bar{M}$ & - \\
\hline May & 1993 & 3.01 & 9.24 & 11.39 & 31 & $\mathrm{M}$ & - \\
\hline June & 1993 & 1.19 & 3.65 & 4.51 & 30 & $\mathrm{M}$ & - \\
\hline July & 1993 & 1.38 & 4.23 & 5.22 & 31 & $\mathrm{M}$ & - \\
\hline August & 1993 & 3.04 & 9.33 & 11.51 & 31 & $\mathrm{M}$ & - \\
\hline September & 1993 & 3.47 & 10.64 & 13.12 & 30 & $\bar{M}$ & - \\
\hline October & 1993 & 1.32 & 4.06 & 5.01 & 31 & $\bar{M}$ & - \\
\hline November & 1993 & 0.59 & 1.80 & 2.22 & 30 & $\mathrm{M}$ & - \\
\hline December & 1993 & 0.46 & 1.40 & 1.73 & 31 & $\mathrm{M}$ & -- \\
\hline January & 1994 & 1.94 & 5.96 & 7.36 & 31 & $\mathrm{M}$ & - \\
\hline February & 1994 & 1.09 & 3.33 & 4.11 & 28 & $\mathrm{M}$ & - \\
\hline March & 1994 & 1.31 & 4.01 & 4.94 & 31 & $\bar{M}$ & -- \\
\hline April & 1994 & 2.44 & 7.49 & 9.24 & 30 & $\mathrm{M}$ & - \\
\hline May & 1994 & 0.76 & 2.32 & 2.86 & 31 & $\bar{M}$ & - \\
\hline June & 1994 & 2.53 & 7.77 & 9.58 & 30 & $\bar{M}$ & -- \\
\hline July & 1994 & 1.29 & 3.97 & 4.90 & 31 & $\mathrm{M}$ & - \\
\hline August & 1994 & 1.11 & 3.40 & 4.20 & 31 & $\bar{M}$ & - \\
\hline September & 1994 & 0.43 & 1.31 & 1.62 & 30 & $\mathrm{M}$ & - \\
\hline October & 1994 & 0.62 & 1.89 & 2.33 & 31 & $\bar{M}$ & - \\
\hline November & 1994 & 0.93 & 2.86 & 3.52 & 30 & $\mathrm{M}$ & - \\
\hline December & 1994 & 2.10 & 6.44 & 7.95 & 31 & $\mathrm{M}$ & -- \\
\hline January & 1995 & 0.62 & 1.89 & 2.33 & 31 & $\mathrm{M}$ & - \\
\hline February & 1995 & 0.69 & 2.12 & 2.61 & 28 & $\mathrm{M}$ & - \\
\hline March & 1995 & 1.02 & 3.14 & 3.87 & 31 & $\mathrm{M}$ & - \\
\hline April & 1995 & 0.80 & 2.44 & 3.01 & 30 & $\mathrm{M}$ & - \\
\hline May & 1995 & 0.06 & 0.18 & 0.22 & 31 & $\mathrm{M}$ & - \\
\hline June & 1995 & 0.49 & 1.50 & 1.85 & 30 & $\bar{M}$ & -- \\
\hline July & 1995 & 0.55 & 1.70 & 2.09 & 31 & $\bar{M}$ & -- \\
\hline
\end{tabular}

aSource: $\mathrm{E}=$ Taken from Bechtel or REECo water production reports and includes estimated values. $\mathrm{H}=$ Insufficient data to determine monthly value. Annual value listed in annual data set as reported in [Moreo and others, 2003, WRIR 03-4245, Estimated Ground-Water Withdrawals from the Death Valley Regional Flow System, Nevada and California, 1913-98].

$\mathrm{I}=$ Insufficient or no data to calculate monthly total; no water may have been withdrawn for month. 
$M=$ Taken from Bechtel or REECo water production reports.

$\mathrm{R}=$ Insufficient data to determine monthly value. Annual value listed in annual data set as reported in [Claassen, H.C., 1973, Water quality and physical characteristics of Nevada Test Site water-supply wells: U.S. Geological Survey Open-File Report USGS-474-158, 145 p.].

${ }^{b}$ estimated indicates monthly value was estimated from yearly total 


\begin{tabular}{|c|c|c|c|c|c|c|c|c|}
\hline $\begin{array}{c}\text { Well } \\
\text { Reporting } \\
\text { Name }\end{array}$ & \begin{tabular}{|c|} 
Reference \\
Point \\
Elevation \\
(m)
\end{tabular} & $\begin{array}{c}\text { Measured } \\
\text { Depth to } \\
\text { Water } \\
(\mathrm{mbrp})^{\mathrm{a}}\end{array}$ & \begin{tabular}{|c|} 
Corrected \\
Depth to \\
Water \\
(mbrp)
\end{tabular} & $\begin{array}{c}\text { Measure- } \\
\text { ment Date }\end{array}$ & $\begin{array}{c}\text { Site } \\
\text { Status }^{b}\end{array}$ & $\begin{array}{c}\text { Water } \\
\text { Level } \\
\text { Elevation } \\
\text { (masl) }^{c}\end{array}$ & $\begin{array}{c}\text { Type } \\
\text { Correction }^{d}\end{array}$ & Source \\
\hline Army-1 WW & 961.13 & 239.57 & \begin{tabular}{|r|}
239.39 \\
\end{tabular} & 7/1/1962 & -- & 721.74 & $\mathrm{BD}$ & database \\
\hline Army-1 WW & 961.13 & 239.45 & 239.27 & $7 / 17 / 1962$ & -- & 721.86 & $\mathrm{BD}$ & database \\
\hline Army-1 WW & 961.13 & 239.21 & 239.02 & 7/17/1962 & -- & 722.10 & $\mathrm{BD}$ & database \\
\hline Army-1 WW & 961.13 & 239.45 & 239.27 & $7 / 17 / 1962$ & $Z$ & 721.86 & $\mathrm{BD}$ & database \\
\hline Army-1 WW & 961.13 & 239.21 & 239.02 & \begin{tabular}{|l|}
$7 / 17 / 1962$ \\
\end{tabular} & $\mathrm{R}$ & 722.10 & $\mathrm{BD}$ & database \\
\hline Army-1 WW & 961.13 & 238.96 & 238.78 & 9/11/1962 & -- & 722.35 & $\mathrm{BD}$ & database \\
\hline Army-1 WW & 961.13 & 238.96 & 238.78 & 9/11/1962 & -- & 722.35 & $\mathrm{BD}$ & database \\
\hline Army-1 WW & 961.13 & 238.84 & 238.66 & $1 / 25 / 1963$ & -- & 722.47 & $\mathrm{BD}$ & database \\
\hline Army-1 WW & 961.13 & 238.84 & 238.66 & $1 / 25 / 1963$ & -- & 722.47 & $\mathrm{BD}$ & database \\
\hline Army-1 WW & 961.13 & 239.27 & 239.08 & 11/7/1963 & -- & 722.04 & $\mathrm{BD}$ & database \\
\hline Army-1 WW & 961.13 & 239.27 & 239.08 & 11/7/1963 & -- & 722.04 & $\mathrm{BD}$ & database \\
\hline Army-1 WW & 961.13 & 239.88 & 239.69 & $4 / 22 / 1969$ & -- & 721.43 & $\mathrm{BD}$ & database \\
\hline Army-1 WW & 961.13 & 240.40 & 240.21 & $3 / 18 / 1971$ & $\mathrm{R}$ & 720.92 & $\mathrm{BD}$ & database \\
\hline Army-1 WW & 961.13 & 240.18 & 240.00 & $3 / 18 / 1971$ & -- & 721.13 & $\mathrm{BD}$ & database \\
\hline Army-1 WW & 961.13 & 239.82 & 239.63 & 10/26/1971 & $\mathrm{R}$ & 721.49 & $\mathrm{BD}$ & database \\
\hline Army-1 WW & 961.13 & 239.94 & 239.75 & 10/26/1971 & -- & 721.37 & $\mathrm{BD}$ & database \\
\hline Army-1 WW & 961.13 & 241.07 & 240.88 & $8 / 12 / 1972$ & -- & 720.25 & $\mathrm{BD}$ & database \\
\hline Army-1 WW & 961.13 & 241.16 & 240.97 & $8 / 12 / 1972$ & $\mathrm{R}$ & 720.15 & $\mathrm{BD}$ & database \\
\hline Army-1 WW & 961.13 & 239.05 & 238.87 & 10/15/1987 & -- & 722.26 & $\mathrm{BD}$ & database \\
\hline Army-1 WW & 961.13 & 239.14 & 238.96 & $10 / 15 / 1987$ & -- & 722.17 & $\mathrm{BD}$ & database \\
\hline Army-1 WW & 961.13 & 239.32 & 239.14 & $7 / 6 / 1995$ & -- & 721.99 & $\mathrm{BD}$ & database \\
\hline Army-1 WW & 961.13 & 239.36 & 239.18 & $7 / 7 / 1995$ & -- & 721.95 & $\mathrm{BD}$ & database \\
\hline Army-1 WW & 961.13 & 239.36 & 239.17 & $7 / 7 / 1995$ & -- & 721.95 & $\mathrm{BD}$ & database \\
\hline Army-1 WW & 961.13 & 239.36 & 239.17 & $7 / 7 / 1995$ & -- & 721.95 & $\mathrm{BD}$ & database \\
\hline Army-1 WW & 961.13 & 239.31 & 239.13 & $7 / 10 / 1995$ & -- & 722.00 & $\mathrm{BD}$ & database \\
\hline Army-1 WW & 961.13 & 239.33 & 239.15 & 7/10/1995 & -- & 721.98 & $\mathrm{BD}$ & database \\
\hline Army-1 WW & 961.13 & 239.29 & 239.11 & $7 / 11 / 1995$ & -- & 722.02 & $\mathrm{BD}$ & database \\
\hline Army-1 WW & 961.13 & 239.52 & 239.33 & $12 / 12 / 1996$ & $Z$ & 721.79 & $\mathrm{BD}$ & database \\
\hline Army-1 WW & 961.13 & 239.61 & 239.43 & $1 / 30 / 1997$ & $Z$ & 721.70 & $\mathrm{BD}$ & database \\
\hline Army-1 WW & 961.13 & 239.50 & 239.31 & $3 / 20 / 1997$ & $Z$ & 721.81 & $\mathrm{BD}$ & database \\
\hline Army-1 WW & 961.13 & 239.43 & 239.25 & $4 / 24 / 1997$ & $Z$ & 721.88 & $\mathrm{BD}$ & database \\
\hline Army-1 WW & 961.13 & 239.56 & 239.38 & $5 / 22 / 1997$ & $Z$ & 721.75 & $\mathrm{BD}$ & database \\
\hline Army-1 WW & 961.13 & 239.45 & 239.27 & $6 / 12 / 1997$ & $Z$ & 721.86 & $\mathrm{BD}$ & database \\
\hline Army-1 WW & 961.13 & 239.51 & 239.32 & $7 / 10 / 1997$ & $Z$ & 721.80 & $\mathrm{BD}$ & database \\
\hline Army-1 WW & 961.13 & 239.54 & 239.35 & $8 / 21 / 1997$ & $Z$ & 721.77 & $\mathrm{BD}$ & database \\
\hline Army-1 WW & 961.13 & 239.43 & 239.25 & 9/23/1997 & $Z$ & 721.88 & $\mathrm{BD}$ & database \\
\hline Army-1 WW & 961.13 & 239.39 & 239.20 & 10/23/1997 & $Z$ & 721.92 & $\mathrm{BD}$ & database \\
\hline Army-1 WW & 961.13 & 239.52 & 239.34 & 11/20/1997 & $Z$ & 721.79 & $\mathrm{BD}$ & database \\
\hline Army-1 WW & 961.13 & 239.46 & 239.27 & 12/16/1997 & $Z$ & 721.85 & $\mathrm{BD}$ & database \\
\hline
\end{tabular}




\begin{tabular}{|c|c|c|c|c|c|c|c|c|}
\hline $\begin{array}{c}\text { Well } \\
\text { Reporting } \\
\text { Name }\end{array}$ & \begin{tabular}{|c|} 
Reference \\
Point \\
Elevation \\
$(\mathrm{m})$
\end{tabular} & $\begin{array}{c}\text { Measured } \\
\text { Depth to } \\
\text { Water } \\
(\text { mbrp) } \\
\end{array}$ & $\begin{array}{c}\text { Corrected } \\
\text { Depth to } \\
\text { Water } \\
\text { (mbrp) }\end{array}$ & \begin{tabular}{c|} 
Measure- \\
ment Date
\end{tabular} & $\begin{array}{c}\text { Site } \\
\text { Status }^{b}\end{array}$ & $\begin{array}{c}\text { Water } \\
\text { Level } \\
\text { Elevation } \\
\text { (masl) }^{c} \\
\end{array}$ & $\begin{array}{c}\text { Type } \\
\text { Correction }^{d}\end{array}$ & Source ${ }^{e}$ \\
\hline Army-1 WW & 961.13 & 239.37 & 239.18 & $1 / 26 / 1998$ & Z & 721.94 & $\mathrm{BD}$ & database \\
\hline Army-1 WW & 961.13 & 239.40 & 239.21 & $2 / 19 / 1998$ & $Z$ & 721.91 & $\mathrm{BD}$ & database \\
\hline Army-1 WW & 961.13 & 239.34 & 239.15 & $3 / 19 / 1998$ & $Z$ & 721.97 & $\mathrm{BD}$ & database \\
\hline Army-1 WW & 961.13 & 239.37 & 239.18 & 4/16/1998 & $Z$ & 721.94 & $\mathrm{BD}$ & database \\
\hline Army-1 WW & 961.13 & 239.32 & 239.14 & $5 / 21 / 1998$ & $Z$ & 721.99 & $\mathrm{BD}$ & database \\
\hline Army-1 WW & 961.13 & 239.31 & 239.13 & $6 / 29 / 1998$ & $Z$ & 722.00 & $\mathrm{BD}$ & database \\
\hline Army-1 WW & 961.13 & 239.31 & 239.13 & 7/16/1998 & $Z$ & 722.00 & $\mathrm{BD}$ & database \\
\hline Army-1 WW & 961.13 & 239.32 & 239.13 & $8 / 27 / 1998$ & $Z$ & 721.99 & $\mathrm{BD}$ & database \\
\hline Army-1 WW & 961.13 & 239.30 & 239.12 & 9/17/1998 & $Z$ & 722.01 & $\mathrm{BD}$ & database \\
\hline Army-1 WW & 961.13 & 239.24 & 239.06 & $10 / 29 / 1998$ & Z & 722.07 & $\mathrm{BD}$ & database \\
\hline Army-1 WW & 961.13 & 239.34 & 239.16 & $11 / 25 / 1998$ & $Z$ & 721.97 & $\mathrm{BD}$ & database \\
\hline Army-1 WW & 961.13 & 239.29 & 239.11 & 12/22/1998 & $\bar{Z}$ & 722.02 & $\mathrm{BD}$ & database \\
\hline Army-1 WW & 961.13 & 239.37 & 239.18 & $1 / 28 / 1999$ & $Z$ & 721.94 & $\mathrm{BD}$ & database \\
\hline Army-1 WW & 961.13 & 239.19 & 239.00 & $2 / 25 / 1999$ & $Z$ & 722.12 & $\mathrm{BD}$ & database \\
\hline Army-1 WW & 961.13 & 239.25 & 239.07 & $3 / 25 / 1999$ & $Z$ & 722.06 & $\mathrm{BD}$ & database \\
\hline Army-1 WW & 961.13 & 239.24 & 239.05 & $4 / 27 / 1999$ & $Z$ & 722.07 & $B D$ & database \\
\hline Army-1 WW & 961.13 & 239.30 & 239.11 & $5 / 20 / 1999$ & $Z$ & 722.01 & $B D$ & database \\
\hline Army-1 WW & 961.13 & 239.28 & 239.10 & $6 / 17 / 1999$ & $Z$ & 722.03 & $\mathrm{BD}$ & database \\
\hline Army-1 WW & 961.13 & 239.30 & 239.12 & $7 / 28 / 1999$ & $Z$ & 722.01 & $\mathrm{BD}$ & database \\
\hline Army-1 WW & 961.13 & 239.28 & 239.09 & $8 / 9 / 1999$ & $Z$ & 722.03 & $B D$ & database \\
\hline Army-1 WW & 961.13 & 239.26 & 239.07 & 9/27/1999 & $Z$ & 722.05 & $\mathrm{BD}$ & database \\
\hline Army-1 WW & 961.13 & 239.34 & 239.16 & 10/19/1999 & $Z$ & 721.97 & $\mathrm{BD}$ & database \\
\hline Army-1 WW & 961.13 & 239.25 & 239.07 & \begin{tabular}{|l|}
$11 / 4 / 1999$ \\
\end{tabular} & $Z$ & 722.06 & $\mathrm{BD}$ & database \\
\hline Army-1 WW & 961.13 & 239.35 & 239.17 & 12/14/1999 & $Z$ & 721.96 & $\mathrm{BD}$ & database \\
\hline Army-1 WW & 961.13 & 239.24 & 239.06 & \begin{tabular}{|l|}
$1 / 26 / 2000$ \\
\end{tabular} & $Z$ & 722.07 & $\mathrm{BD}$ & database \\
\hline Army-1 WW & 961.13 & 239.30 & 239.11 & $2 / 29 / 2000$ & $Z$ & 722.01 & $\mathrm{BD}$ & database \\
\hline Army-1 WW & 961.13 & 239.27 & 239.09 & $3 / 23 / 2000$ & $Z$ & 722.04 & $\mathrm{BD}$ & database \\
\hline Army-1 WW & 961.13 & 239.33 & 239.14 & $4 / 26 / 2000$ & $Z$ & 721.98 & $\mathrm{BD}$ & database \\
\hline Army-1 WW & 961.13 & 239.29 & 239.11 & $5 / 9 / 2000$ & Z & 722.02 & $\mathrm{BD}$ & database \\
\hline Army-1 WW & 961.13 & 239.32 & 239.14 & $6 / 8 / 2000$ & $Z$ & 721.99 & $\mathrm{BD}$ & database \\
\hline Army-1 WW & 961.13 & 239.33 & 239.14 & $7 / 11 / 2000$ & $Z$ & 721.98 & $\mathrm{BD}$ & database \\
\hline Army-1 WW & 961.13 & 239.34 & 239.15 & $8 / 18 / 2000$ & Z & 721.98 & $\mathrm{BD}$ & database \\
\hline Army-1 WW & 961.13 & 239.30 & 239.11 & 9/20/2000 & $Z$ & 722.01 & $\mathrm{BD}$ & database \\
\hline Army-1 WW & 961.13 & 239.37 & 239.19 & $10 / 12 / 2000$ & $Z$ & 721.94 & $\mathrm{BD}$ & database \\
\hline Army-1 WW & 961.13 & 239.35 & 239.16 & \begin{tabular}{|l|}
$11 / 9 / 2000$ \\
\end{tabular} & $Z$ & 721.96 & $B D$ & database \\
\hline Army-1 WW & 961.13 & 239.39 & 239.20 & $12 / 6 / 2000$ & Z & 721.92 & $\mathrm{BD}$ & database \\
\hline Army-1 WW & 961.13 & 239.30 & 239.12 & $1 / 10 / 2001$ & $Z$ & 722.01 & $\mathrm{BD}$ & database \\
\hline Army-1 WW & 961.13 & 239.39 & 239.20 & $2 / 15 / 2001$ & $Z$ & 721.92 & $\mathrm{BD}$ & database \\
\hline Army-1 WW & 961.13 & 239.30 & 239.11 & $3 / 28 / 2001$ & $Z$ & 722.01 & $\mathrm{BD}$ & database \\
\hline
\end{tabular}




\begin{tabular}{|c|c|c|c|c|c|c|c|c|}
\hline $\begin{array}{c}\text { Well } \\
\text { Reporting } \\
\text { Name }\end{array}$ & \begin{tabular}{|c|} 
Reference \\
Point \\
Elevation \\
$(\mathrm{m})$
\end{tabular} & $\begin{array}{c}\text { Measured } \\
\text { Depth to } \\
\text { Water } \\
(\mathrm{mbrp})^{\mathrm{a}}\end{array}$ & \begin{tabular}{|c|} 
Corrected \\
Depth to \\
Water \\
(mbrp)
\end{tabular} & $\begin{array}{c}\text { Measure- } \\
\text { ment Date }\end{array}$ & $\begin{array}{c}\text { Site } \\
\text { Status }^{b}\end{array}$ & $\begin{array}{c}\text { Water } \\
\text { Level } \\
\text { Elevation } \\
\text { (masl) }^{c}\end{array}$ & $\begin{array}{c}\text { Type } \\
\text { Correction }^{d}\end{array}$ & Source ${ }^{e}$ \\
\hline Army-1 WW & 961.13 & 239.79 & \begin{tabular}{|l|}
239.60 \\
\end{tabular} & $4 / 19 / 2001$ & $Z$ & 721.52 & $\mathrm{BD}$ & database \\
\hline Army-1 WW & 961.13 & 240.71 & 240.52 & $5 / 24 / 2001$ & $\mathrm{R}$ & 720.60 & $\mathrm{BD}$ & database \\
\hline Army-1 WW & 961.13 & 239.66 & 239.48 & $6 / 24 / 2001$ & $Z$ & 721.65 & $\mathrm{BD}$ & database \\
\hline Army-1 WW & 961.13 & 239.75 & 239.56 & $7 / 23 / 2001$ & -- & 721.56 & $\mathrm{BD}$ & database \\
\hline Army-1 WW & 961.13 & 239.69 & 239.50 & $8 / 20 / 2001$ & -- & 721.62 & $\mathrm{BD}$ & database \\
\hline Army-1 WW & 961.13 & 239.64 & 239.46 & $9 / 10 / 2001$ & -- & 721.67 & $\mathrm{BD}$ & database \\
\hline Army-1 WW & 961.13 & 239.62 & 239.43 & $10 / 22 / 2001$ & $Z$ & 721.69 & $\mathrm{BD}$ & database \\
\hline Army-1 WW & 961.13 & 239.51 & 239.33 & $11 / 26 / 2001$ & $Z$ & 721.80 & $\mathrm{BD}$ & database \\
\hline Army-1 WW & 961.13 & 239.43 & 239.24 & 12/10/2001 & $Z$ & 721.88 & $\mathrm{BD}$ & database \\
\hline Army-1 WW & 961.13 & 239.58 & 239.40 & \begin{tabular}{|l|}
$1 / 14 / 2002$ \\
\end{tabular} & $Z$ & 721.73 & $\mathrm{BD}$ & database \\
\hline Army-1 WW & 961.13 & 239.69 & 239.50 & $2 / 11 / 2002$ & $Z$ & 721.62 & $\mathrm{BD}$ & database \\
\hline Army-1 WW & 961.13 & 239.74 & 239.55 & $3 / 25 / 2002$ & $Z$ & 721.57 & $\mathrm{BD}$ & database \\
\hline Army-1 WW & 961.13 & 239.75 & 239.56 & $4 / 29 / 2002$ & $Z$ & 721.56 & $\mathrm{BD}$ & database \\
\hline Army-1 WW & 961.13 & 239.83 & 239.64 & $5 / 13 / 2002$ & $Z$ & 721.48 & $\mathrm{BD}$ & database \\
\hline Army-1 WW & 961.13 & 239.87 & 239.69 & $6 / 24 / 2002$ & $Z$ & 721.44 & $\mathrm{BD}$ & database \\
\hline Army-1 WW & 961.13 & 239.82 & 239.64 & $7 / 29 / 2002$ & $Z$ & 721.49 & $\mathrm{BD}$ & database \\
\hline Army-1 WW & 961.13 & 239.79 & 239.60 & $8 / 26 / 2002$ & $Z$ & 721.52 & $\mathrm{BD}$ & database \\
\hline Army-1 WW & 961.13 & 239.78 & 239.60 & 9/23/2002 & $Z$ & 721.53 & $\mathrm{BD}$ & database \\
\hline Army-1 WW & 961.13 & 239.73 & 239.54 & $10 / 28 / 2002$ & $Z$ & 721.58 & $\mathrm{BD}$ & database \\
\hline Army-1 WW & 961.13 & 239.83 & 239.65 & $11 / 12 / 2002$ & $Z$ & 721.48 & $\mathrm{BD}$ & database \\
\hline Army-1 WW & 961.13 & 239.54 & 239.35 & $12 / 9 / 2002$ & $Z$ & 721.77 & $\mathrm{BD}$ & database \\
\hline Army-1 WW & 961.13 & 239.73 & 239.54 & $1 / 27 / 2003$ & $Z$ & 721.59 & $\mathrm{BD}$ & database \\
\hline Army-1 WW & 961.13 & 240.10 & 239.92 & $2 / 26 / 2003$ & $\mathrm{R}$ & 721.21 & $\mathrm{BD}$ & database \\
\hline Army-1 WW & 961.13 & 239.69 & 239.51 & $3 / 17 / 2003$ & $Z$ & 721.62 & $\mathrm{BD}$ & database \\
\hline Army-1 WW & 961.13 & 239.73 & 239.55 & $4 / 21 / 2003$ & $Z$ & 721.58 & $\mathrm{BD}$ & database \\
\hline Army-1 WW & 961.13 & 239.83 & 239.64 & $5 / 27 / 2003$ & $Z$ & 721.48 & $\mathrm{BD}$ & database \\
\hline Army-1 WW & 961.13 & 239.78 & 239.60 & $6 / 23 / 2003$ & $Z$ & 721.53 & $\mathrm{BD}$ & database \\
\hline Army-1 WW & 961.13 & 239.78 & 239.60 & $7 / 28 / 2003$ & $Z$ & 721.53 & $\mathrm{BD}$ & USGS website \\
\hline Army-1 WW & 961.13 & 239.74 & 239.56 & $8 / 25 / 2003$ & $Z$ & 721.57 & $\mathrm{BD}$ & USGS website \\
\hline Army-1 WW & 961.13 & 239.73 & 239.55 & 9/29/2003 & $Z$ & 721.58 & $\mathrm{BD}$ & USGS website \\
\hline Army-1 WW & 961.13 & 239.78 & 239.60 & $10 / 27 / 2003$ & $Z$ & 721.53 & $\mathrm{BD}$ & USGS website \\
\hline Army-1 WW & 961.13 & 239.74 & 239.56 & $11 / 17 / 2003$ & $Z$ & 721.57 & $\mathrm{BD}$ & USGS website \\
\hline Army-1 WW & 961.13 & 239.73 & 239.54 & $12 / 8 / 2003$ & $Z$ & 721.59 & $\mathrm{BD}$ & USGS website \\
\hline Army-1 WW & 961.13 & 239.69 & 239.51 & $1 / 20 / 2004$ & -- & 721.62 & $\mathrm{BD}$ & USGS website \\
\hline Army-1 WW & 961.13 & 239.67 & 239.48 & $2 / 23 / 2004$ & -- & 721.64 & $\mathrm{BD}$ & USGS website \\
\hline Army-1 WW & 961.13 & 239.86 & 239.67 & $3 / 8 / 2004$ & -- & 721.45 & $\mathrm{BD}$ & USGS website \\
\hline Army-1 WW & 961.13 & 239.90 & 239.71 & $4 / 19 / 2004$ & -- & 721.41 & $\mathrm{BD}$ & USGS website \\
\hline Army-1 WW & 961.13 & 240.23 & 240.05 & $5 / 17 / 2004$ & -- & 721.08 & $\mathrm{BD}$ & USGS website \\
\hline
\end{tabular}


Army-1 WW

Water Level Data

\begin{tabular}{|c|c|c|c|c|c|c|c|c|}
\hline $\begin{array}{c}\text { Well } \\
\text { Reporting } \\
\text { Name }\end{array}$ & $\begin{array}{c}\text { Reference } \\
\text { Point } \\
\text { Elevation } \\
(\mathrm{m})\end{array}$ & $\begin{array}{c}\text { Measured } \\
\text { Depth to } \\
\text { Water } \\
(\mathrm{mbrp})^{\mathrm{a}}\end{array}$ & $\begin{array}{c}\text { Corrected } \\
\text { Depth to } \\
\text { Water } \\
(\mathrm{mbrp})\end{array}$ & $\begin{array}{c}\text { Measure- } \\
\text { ment Date }\end{array}$ & $\begin{array}{c}\text { Site } \\
\text { Status }\end{array}$ & $\begin{array}{c}\text { Water } \\
\text { Level } \\
\text { Elevation } \\
(\mathrm{masl})^{\mathrm{c}}\end{array}$ & $\begin{array}{c}\text { Type } \\
\text { Correction }^{\mathrm{d}}\end{array}$ & Source $^{\mathrm{e}}$ \\
\hline
\end{tabular}

${ }^{a}$ meters below reference point

${ }^{b}$ Site Status: $R$ = Site had been pumped recently.

$Z$ = "Other conditions at the well may have affected the water level measurement" (SNJV 2004).

$--=$ Not applicable

${ }^{\mathrm{c}}$ meters above sea level

used to determine historical and contemporary static water level

used to determine historical static water level

not applicable

used to determine contemporary static water level not applicable

d Type Correction: BD = water level corrected for borehole deviation

eSource: database = UGTA borehole database

USGS website $=$ http://nevada.usgs.gov/doe_nv/ 
ER 5-3 \#2

Water-Level Data

\begin{tabular}{|c|c|c|c|c|c|c|c|c|}
\hline $\begin{array}{c}\text { Well } \\
\text { Reporting } \\
\text { Name }\end{array}$ & $\begin{array}{c}\text { Reference } \\
\text { Point } \\
\text { Elevation } \\
(\mathrm{m}) \\
\end{array}$ & $\begin{array}{c}\text { Measured } \\
\text { Depth to } \\
\text { Water } \\
(\mathrm{mbrp})^{\mathrm{a}}\end{array}$ & $\begin{array}{c}\text { Corrected } \\
\text { Depth to } \\
\text { Water } \\
\text { (mbrp) } \\
\end{array}$ & $\begin{array}{l}\text { Measure- } \\
\text { ment Date }\end{array}$ & $\begin{array}{c}\text { Site } \\
\text { Status }^{b}\end{array}$ & $\begin{array}{c}\text { Water } \\
\text { Level } \\
\text { Elevation } \\
\text { (masl) }^{c}\end{array}$ & $\begin{array}{c}\text { Type } \\
\text { Correction }^{d}\end{array}$ & Source $^{e}$ \\
\hline ER 5-3 \#2 & 1017.24 & 265.69 & -- & $9 / 20 / 2000$ & $Z$ & 751.55 & none & database \\
\hline ER 5-3 \#2 & 1017.24 & 265.98 & -- & $11 / 21 / 2000$ & $Z$ & 751.26 & none & database \\
\hline ER 5-3 \#2 & 1017.24 & 296.96 & -- & $3 / 20 / 2001$ & $Z$ & 720.28 & none & database \\
\hline ER 5-3 \#2 & 1017.24 & 296.96 & -- & $3 / 20 / 2001$ & Z & 720.28 & none & database \\
\hline ER 5-3 \#2 & 1017.24 & 295.84 & -- & $3 / 21 / 2001$ & $Z$ & 721.39 & none & database \\
\hline ER 5-3 \#2 & 1017.24 & 295.84 & -- & $3 / 21 / 2001$ & $Z$ & 721.39 & none & database \\
\hline ER 5-3 \#2 & 1017.24 & 293.33 & -- & $3 / 30 / 2001$ & -- & 723.91 & none & database \\
\hline ER 5-3 \#2 & 1017.24 & 293.32 & -- & $3 / 31 / 2001$ & -- & 723.92 & none & database \\
\hline ER 5-3 \#2 & 1017.24 & 293.34 & -- & $4 / 4 / 2001$ & $Z$ & 723.90 & none & database \\
\hline ER 5-3 \#2 & 1017.24 & 293.41 & -- & $4 / 6 / 2001$ & $Z$ & 723.83 & none & database \\
\hline ER 5-3 \#2 & 1017.24 & 289.92 & -- & $4 / 7 / 2001$ & $\bar{Z}$ & 727.32 & none & database \\
\hline ER 5-3 \#2 & 1017.24 & 290.91 & -- & $4 / 11 / 2001$ & $Z$ & 726.33 & none & database \\
\hline ER 5-3 \#2 & 1017.24 & 291.72 & -- & $4 / 12 / 2001$ & $\bar{Z}$ & 725.52 & none & database \\
\hline ER 5-3 \#2 & 1017.24 & 288.79 & -- & $4 / 13 / 2001$ & $P$ & 728.45 & none & database \\
\hline ER 5-3 \#2 & 1017.24 & 322.05 & -- & $4 / 13 / 2001$ & $P$ & 695.19 & none & database \\
\hline ER 5-3 \#2 & 1017.24 & 289.33 & -- & $4 / 17 / 2001$ & $\mathrm{R}$ & 727.91 & none & database \\
\hline ER 5-3 \#2 & 1017.24 & 290.21 & -- & $4 / 19 / 2001$ & $\mathrm{R}$ & 727.03 & none & database \\
\hline ER 5-3 \#2 & 1017.24 & 51.91 & -- & $5 / 1 / 2001$ & $\mathrm{R}$ & 965.33 & none & database \\
\hline ER 5-3 \#2 & 1017.24 & 26.52 & -- & $5 / 3 / 2001$ & Z & 990.72 & none & database \\
\hline ER 5-3 \#2 & 1017.24 & 291.73 & -- & $5 / 7 / 2001$ & $\mathrm{R}$ & 725.51 & none & database \\
\hline ER 5-3 \#2 & 1017.24 & 291.40 & -- & $5 / 18 / 2001$ & $P$ & 725.84 & none & database \\
\hline ER 5-3 \#2 & 1017.24 & 293.10 & -- & $9 / 6 / 2001$ & $Z$ & 724.13 & none & database \\
\hline ER 5-3 \#2 & 1017.24 & 292.28 & -- & $1 / 14 / 2002$ & -- & 724.96 & none & database \\
\hline ER 5-3 \#2 & 1017.24 & 292.07 & -- & $2 / 21 / 2002$ & -- & 725.17 & none & database \\
\hline ER 5-3 \#2 & 1017.24 & 291.85 & -- & $3 / 12 / 2002$ & -- & 725.39 & none & database \\
\hline ER 5-3 \#2 & 1017.24 & 291.11 & -- & $7 / 3 / 2002$ & -- & 726.13 & none & database \\
\hline ER 5-3 \#2 & 1017.24 & 291.01 & -- & 9/9/2002 & -- & 726.23 & none & database \\
\hline ER 5-3 \#2 & 1017.24 & 291.04 & -- & $9 / 11 / 2002$ & -- & 726.20 & none & database \\
\hline ER 5-3 \#2 & 1017.24 & 291.02 & -- & $9 / 11 / 2002$ & -- & 726.22 & none & database \\
\hline ER 5-3 \#2 & 1017.24 & 291.02 & -- & 9/11/2002 & $Z$ & 726.22 & none & database \\
\hline ER 5-3 \#2 & 1017.24 & 291.04 & -- & $9 / 11 / 2002$ & Z & 726.20 & none & database \\
\hline ER 5-3 \#2 & 1017.24 & 290.72 & -- & $1 / 14 / 2003$ & -- & 726.52 & none & database \\
\hline ER 5-3 \#2 & 1017.24 & 290.72 & -- & $1 / 14 / 2003$ & $Z$ & 726.52 & none & database \\
\hline ER 5-3 \#2 & 1017.24 & 290.50 & -- & $3 / 10 / 2003$ & -- & 726.74 & none & database \\
\hline ER 5-3 \#2 & 1017.24 & 290.37 & -- & $6 / 18 / 2003$ & -- & 726.87 & none & database \\
\hline ER 5-3 \#2 & 1017.24 & 290.44 & -- & $8 / 6 / 2003$ & -- & 726.80 & none & database \\
\hline ER 5-3 \#2 & 1017.24 & 290.30 & -- & 9/25/2003 & -- & 726.94 & none & database \\
\hline ER 5-3 \#2 & 1017.24 & 290.26 & -- & $11 / 20 / 2003$ & -- & 726.98 & none & database \\
\hline ER 5-3 \#2 & 1017.24 & 289.93 & -- & $1 / 27 / 2004$ & -- & 727.31 & none & USGS website \\
\hline
\end{tabular}


ER 5-3 \#2

Water-Level Data

\begin{tabular}{|c|c|c|c|c|c|c|c|c|}
\hline $\begin{array}{c}\text { Well } \\
\text { Reporting } \\
\text { Name }\end{array}$ & $\begin{array}{c}\text { Reference } \\
\text { Point } \\
\text { Elevation } \\
(\mathrm{m}) \\
\end{array}$ & $\begin{array}{c}\text { Measured } \\
\text { Depth to } \\
\text { Water } \\
\text { (mbrp) }^{\mathrm{a}} \\
\end{array}$ & $\begin{array}{c}\text { Corrected } \\
\text { Depth to } \\
\text { Water } \\
\text { (mbrp) } \\
\end{array}$ & $\begin{array}{l}\text { Measure- } \\
\text { ment Date }\end{array}$ & $\begin{array}{c}\text { Site } \\
\text { Status }^{b}\end{array}$ & $\begin{array}{c}\text { Water } \\
\text { Level } \\
\text { Elevation } \\
\text { (masl) }^{c}\end{array}$ & $\begin{array}{c}\text { Type } \\
\text { Correction }^{d}\end{array}$ & Source $^{e}$ \\
\hline ER 5-3 \#2 & 1017.24 & 290.01 & -- & $3 / 11 / 2004$ & -- & 727.23 & none & USGS website \\
\hline
\end{tabular}

${ }^{a}$ meters below reference point

${ }^{\mathrm{b}}$ Site Status: $\mathrm{P}=$ Site was being pumped.

$R=$ Site had been pumped recently.

$Z$ = "Other conditions at the well may have affected the water level measurement" (SNJV 2004).

$--=$ Not applicable

${ }^{c}$ meters above sea level

static water level could not be determined

${ }^{\mathrm{d}}$ Type Correction: none $=$ no correction made to water level

eSource: database = UGTA borehole database

USGS website $=$ http://nevada.usgs.gov/doe_nv/ 
Well ER 5-3 \#3

Water Level Data

\begin{tabular}{|c|c|c|c|c|c|c|c|c|}
\hline $\begin{array}{c}\text { Well } \\
\text { Reporting } \\
\text { Name }\end{array}$ & $\begin{array}{c}\text { Reference } \\
\text { Point } \\
\text { Elevation } \\
(\mathrm{m}) \\
\end{array}$ & $\begin{array}{c}\text { Measured } \\
\text { Depth to } \\
\text { Water } \\
(\mathrm{mbrp})^{\mathrm{a}} \\
\end{array}$ & $\begin{array}{c}\text { Corrected } \\
\text { Depth to } \\
\text { Water } \\
\text { (mbrp) } \\
\end{array}$ & $\begin{array}{c}\text { Measure- } \\
\text { ment Date }\end{array}$ & $\begin{array}{c}\text { Site } \\
\text { Status }^{b}\end{array}$ & $\begin{array}{c}\text { Water } \\
\text { Level } \\
\text { Elevation } \\
\text { (masl) }^{c} \\
\end{array}$ & $\begin{array}{c}\text { Type } \\
\text { Correction }^{d}\end{array}$ & Source $^{e}$ \\
\hline ER 5-3 \#3 & 1017.24 & 282.72 & 282.70 & $2 / 21 / 2001$ & -- & 734.54 & $B D$ & database \\
\hline ER 5-3 \#3 & 1017.24 & 282.55 & 282.53 & $2 / 23 / 2001$ & -- & 734.70 & BD & database \\
\hline ER 5-3 \#3 & 1017.24 & 282.54 & 282.52 & $2 / 23 / 2001$ & $Z$ & 734.72 & $B D$ & database \\
\hline ER 5-3 \#3 & 1017.24 & 282.67 & 282.65 & $2 / 27 / 2001$ & $Z$ & 734.59 & $B D$ & database \\
\hline ER 5-3 \#3 & 1017.24 & 282.74 & 282.72 & $5 / 11 / 2001$ & $\bar{Z}$ & 734.52 & $B D$ & database \\
\hline ER 5-3 \#3 & 1017.24 & 282.71 & 282.69 & $9 / 6 / 2001$ & $Z$ & 734.55 & $B D$ & database \\
\hline ER 5-3 \#3 & 1017.24 & 282.57 & 282.55 & $1 / 15 / 2002$ & -- & 734.68 & $B D$ & database \\
\hline ER 5-3 \#3 & 1017.24 & 282.74 & 282.73 & $2 / 21 / 2002$ & -- & 734.51 & $B D$ & database \\
\hline ER 5-3 \#3 & 1017.24 & 282.60 & 282.58 & $3 / 12 / 2002$ & -- & 734.66 & $B D$ & database \\
\hline ER 5-3 \#3 & 1017.24 & 282.64 & 282.62 & $7 / 3 / 2002$ & -- & 734.61 & $B D$ & database \\
\hline ER 5-3 \#3 & 1017.24 & 282.64 & 282.63 & 9/9/2002 & -- & 734.61 & $\mathrm{BD}$ & database \\
\hline ER 5-3 \#3 & 1017.24 & 282.63 & 282.61 & $12 / 24 / 2002$ & -- & 734.63 & $B D$ & database \\
\hline ER 5-3 \#3 & 1017.24 & 282.66 & 282.64 & $3 / 10 / 2003$ & -- & 734.60 & $B D$ & database \\
\hline ER 5-3 \#3 & 1017.24 & 282.70 & 282.68 & $4 / 25 / 2003$ & $Z$ & 734.56 & $B D$ & database \\
\hline ER 5-3 \#3 & 1017.24 & 282.71 & 282.69 & $7 / 21 / 2003$ & $Z$ & 734.54 & $B D$ & database \\
\hline ER 5-3 \#3 & 1017.24 & 282.74 & 282.73 & $8 / 6 / 2003$ & -- & 734.51 & $B D$ & database \\
\hline ER 5-3 \#3 & 1017.24 & 282.64 & 282.63 & $9 / 25 / 2003$ & -- & 734.61 & $B D$ & database \\
\hline ER 5-3 \#3 & 1017.24 & 282.58 & 282.56 & $11 / 20 / 2003$ & -- & 734.68 & $B D$ & database \\
\hline ER 5-3 \#3 & 1017.24 & 282.63 & 282.61 & 1/27/2004 & -- & 734.63 & $B D$ & USGS website \\
\hline ER 5-3 \#3 & 1017.24 & 282.63 & 282.61 & $3 / 11 / 2004$ & -- & 734.63 & $B D$ & USGS website \\
\hline
\end{tabular}

${ }^{a}$ meters below reference point

${ }^{b}$ Site Status: $Z$ = "Other conditions at the well may have affected the water level measurement" (SNJV 2004).

-- = Not applicable

${ }^{\mathrm{c}}$ meters above sea level

used to determine historical and contemporary static water level not applicable

used to determine historical static water level not applicable

used to determine contemporary static water level

' Type Correction: BD = water level corrected for borehole deviation

'Source: database = UGTA borehole database

USGS website = http://nevada.usgs.gov/doe_nv/ 
Well ER 5-3 (3" deep)

Water Level Data

\begin{tabular}{|c|c|c|c|c|c|c|c|c|}
\hline $\begin{array}{c}\text { Well } \\
\text { Reporting } \\
\text { Name }\end{array}$ & \begin{tabular}{|c|}
$\begin{array}{c}\text { Reference } \\
\text { Point } \\
\text { Elevation } \\
(\mathrm{m})\end{array}$ \\
\end{tabular} & $\begin{array}{l}\text { Measured } \\
\text { Depth to } \\
\text { Water } \\
\text { (mbrp) }^{\mathrm{a}}\end{array}$ & \begin{tabular}{|c|} 
Corrected \\
Depth to \\
Water \\
(mbrp) \\
\end{tabular} & $\begin{array}{c}\text { Measure- } \\
\text { ment Date }\end{array}$ & $\begin{array}{c}\text { Site } \\
\text { Status }^{b}\end{array}$ & $\begin{array}{c}\text { Water } \\
\text { Level } \\
\text { Elevation } \\
\text { (masl) }^{c}\end{array}$ & $\begin{array}{c}\text { Type } \\
\text { Correction }^{d}\end{array}$ & Source $^{e}$ \\
\hline \begin{tabular}{|l|} 
ER 5-3 (3" \\
deep) \\
\end{tabular} & 1017.24 & 282.28 & 282.18 & $3 / 19 / 2000$ & Z & 735.06 & $\mathrm{BD}$ & database \\
\hline $\begin{array}{l}\text { ER 5-3 (3" } \\
\text { deep) }\end{array}$ & 1017.24 & 283.48 & 283.38 & $12 / 6 / 2000$ & -- & 733.86 & $\mathrm{BD}$ & database \\
\hline $\begin{array}{l}\text { ER 5-3 (3" } \\
\text { deep) }\end{array}$ & 1017.24 & 282.68 & 282.58 & $3 / 2 / 2001$ & -- & 734.66 & $\mathrm{BD}$ & database \\
\hline $\begin{array}{l}\text { ER 5-3 (3" } \\
\text { deep) }\end{array}$ & 1017.24 & 282.86 & 282.76 & $4 / 8 / 2001$ & Z & 734.48 & $\mathrm{BD}$ & database \\
\hline $\begin{array}{l}\text { ER 5-3 (3" } \\
\text { deep) }\end{array}$ & 1017.24 & 282.81 & 282.71 & $4 / 19 / 2001$ & $Z^{f}$ & 734.53 & $\mathrm{BD}$ & database \\
\hline $\begin{array}{l}\text { ER 5-3 (3" } \\
\text { deep) }\end{array}$ & 1017.24 & 283.00 & 282.90 & $9 / 6 / 2001$ & Z & 734.34 & $\mathrm{BD}$ & database \\
\hline $\begin{array}{l}\text { ER 5-3 (3" } \\
\text { deep) }\end{array}$ & 1017.24 & 283.21 & 283.11 & $2 / 21 / 2002$ & -- & 734.13 & $\mathrm{BD}$ & database \\
\hline $\begin{array}{l}\text { ER 5-3 (3" } \\
\text { deep) }\end{array}$ & 1017.24 & 283.06 & 282.96 & $3 / 12 / 2002$ & -- & 734.28 & $\mathrm{BD}$ & database \\
\hline $\begin{array}{l}\text { ER 5-3 (3" } \\
\text { deep) }\end{array}$ & 1017.24 & 283.15 & 283.05 & $7 / 3 / 2002$ & -- & 734.19 & $\mathrm{BD}$ & database \\
\hline $\begin{array}{l}\text { ER 5-3 (3" } \\
\text { deep) }\end{array}$ & 1017.24 & 283.20 & 283.10 & $9 / 9 / 2002$ & -- & 734.14 & $\mathrm{BD}$ & database \\
\hline $\begin{array}{l}\text { ER 5-3 (3" } \\
\text { deep) }\end{array}$ & 1017.24 & 283.22 & 283.12 & $12 / 24 / 2002$ & -- & 734.12 & $\mathrm{BD}$ & database \\
\hline $\begin{array}{l}\text { ER 5-3 (3" } \\
\text { deep) }\end{array}$ & 1017.24 & 283.20 & 283.10 & $3 / 10 / 2003$ & -- & 734.14 & $\mathrm{BD}$ & database \\
\hline $\begin{array}{l}\text { ER 5-3 (3" } \\
\text { deep) }\end{array}$ & 1017.24 & 283.15 & 283.05 & $6 / 18 / 2003$ & -- & 734.19 & $\mathrm{BD}$ & database \\
\hline $\begin{array}{l}\text { ER 5-3 (3" } \\
\text { deep) }\end{array}$ & 1017.24 & 283.38 & 283.28 & $8 / 6 / 2003$ & -- & 733.96 & $\mathrm{BD}$ & database \\
\hline $\begin{array}{l}\text { ER 5-3 (3" } \\
\text { deep) }\end{array}$ & 1017.24 & 283.23 & 283.13 & $9 / 25 / 2003$ & -- & 734.11 & $\mathrm{BD}$ & database \\
\hline $\begin{array}{l}\text { ER 5-3 (3" } \\
\text { deep) }\end{array}$ & 1017.24 & 283.14 & 283.04 & $11 / 20 / 2003$ & -- & 734.20 & $\mathrm{BD}$ & database \\
\hline $\begin{array}{l}\text { ER 5-3 (3" } \\
\text { deep) }\end{array}$ & 1017.24 & 283.22 & 283.12 & $1 / 26 / 2004$ & -- & 734.12 & $\mathrm{BD}$ & USGS website \\
\hline \begin{tabular}{|l|} 
ER 5-3 (3" \\
deep)
\end{tabular} & 1017.24 & 283.17 & 283.07 & $3 / 11 / 2004$ & -- & 734.17 & $\mathrm{BD}$ & USGS website \\
\hline
\end{tabular}

${ }^{a}$ meters below reference point

'Site Status: $Z$ = "Other conditions at the well may have affected the water level measurement" (SNJV 2004).

$--=$ Not applicable

${ }^{c}$ meters above sea level

used to determine historical and contemporary static water level not applicable

used to determine historical static water level not applicable

used to determine contemporary static water level 
Well ER 5-3 (3" deep)

Water Level Data

\begin{tabular}{|c|c|c|c|c|c|c|c|c|}
\hline $\begin{array}{c}\text { Well } \\
\text { Reporting } \\
\text { Name }\end{array}$ & $\begin{array}{c}\text { Reference } \\
\text { Point } \\
\text { Elevation } \\
(\mathrm{m})\end{array}$ & $\begin{array}{c}\text { Measured } \\
\text { Depth to } \\
\text { Water } \\
(\mathrm{mbrp})^{\mathrm{a}}\end{array}$ & $\begin{array}{c}\text { Corrected } \\
\text { Depth to } \\
\text { Water } \\
(\mathrm{mbrp})\end{array}$ & $\begin{array}{c}\text { Measure- } \\
\text { ment Date }\end{array}$ & $\begin{array}{c}\text { Site } \\
\text { Status }\end{array}$ & $\begin{array}{c}\text { Water } \\
\text { Level } \\
\text { Elevation } \\
(\text { masl })^{c}\end{array}$ & $\begin{array}{c}\text { Type } \\
\text { Correction }^{\mathrm{d}}\end{array}$ & Source $^{\mathrm{e}}$ \\
\hline
\end{tabular}

${ }^{d}$ Type Correction: $\mathrm{BD}=$ water level corrected for borehole deviation

'Source: database $=$ UGTA borehole database

USGS website $=$ http://nevada.usgs.gov/doe_nv/

'measurement performed prior to transducer installation, measurement assumed to represent

undisturbed conditions 


\begin{tabular}{|c|c|c|c|c|c|c|c|c|}
\hline $\begin{array}{c}\text { Well } \\
\text { Reporting } \\
\text { Name }\end{array}$ & \begin{tabular}{|c|} 
Reference \\
Point \\
Elevation \\
$(\mathrm{m})$
\end{tabular} & $\begin{array}{c}\text { Measured } \\
\text { Depth to } \\
\text { Water } \\
(\mathrm{mbrp})^{\mathrm{a}}\end{array}$ & $\begin{array}{l}\text { Corrected } \\
\text { Depth to } \\
\text { Water } \\
\text { (mbrp) }\end{array}$ & \begin{tabular}{|l|} 
Measure- \\
ment Date
\end{tabular} & $\begin{array}{c}\text { Site } \\
\text { Status }^{b}\end{array}$ & $\begin{array}{c}\text { Water } \\
\text { Level } \\
\text { Elevation } \\
\text { (masl) }^{c}\end{array}$ & $\begin{array}{c}\text { Type } \\
\text { Correction }^{d}\end{array}$ & Source $^{e}$ \\
\hline $\begin{array}{l}\text { ER 5-3 (3" } \\
\text { shallow) } \\
\end{array}$ & 1017.24 & 282.42 & 282.32 & $3 / 19 / 2000$ & Z & 734.92 & $B D$ & database \\
\hline $\begin{array}{l}\text { ER 5-3 (3" } \\
\text { shallow) }\end{array}$ & 1017.24 & 282.65 & 282.55 & $12 / 6 / 2000$ & -- & 734.69 & $B D$ & database \\
\hline $\begin{array}{l}\text { ER 5-3 (3" } \\
\text { shallow) }\end{array}$ & 1017.24 & 282.59 & 282.49 & $3 / 2 / 2001$ & -- & 734.75 & $B D$ & database \\
\hline $\begin{array}{l}\text { ER 5-3 (3" } \\
\text { shallow) }\end{array}$ & 1017.24 & 282.73 & 282.63 & $3 / 5 / 2001$ & -- & 734.61 & $B D$ & database \\
\hline $\begin{array}{l}\text { ER 5-3 (3" } \\
\text { shallow) }\end{array}$ & 1017.24 & 282.61 & 282.51 & $4 / 7 / 2001$ & Z & 734.73 & BD & database \\
\hline $\begin{array}{l}\text { ER 5-3 (3" } \\
\text { shallow) } \\
\end{array}$ & 1017.24 & 282.71 & 282.61 & $4 / 13 / 2001$ & Z & 734.63 & BD & database \\
\hline $\begin{array}{l}\text { ER 5-3 (3" } \\
\text { shallow) }\end{array}$ & 1017.24 & 282.64 & 282.54 & $4 / 19 / 2001$ & $Z^{f}$ & 734.70 & $\mathrm{BD}$ & database \\
\hline $\begin{array}{l}\text { ER 5-3 (3" } \\
\text { shallow) }\end{array}$ & 1017.24 & 282.71 & 282.61 & $9 / 6 / 2001$ & Z & 734.63 & $\mathrm{BD}$ & database \\
\hline $\begin{array}{l}\text { ER 5-3 (3" } \\
\text { shallow) }\end{array}$ & 1017.24 & 282.54 & 282.44 & $1 / 14 / 2002$ & -- & 734.80 & BD & database \\
\hline $\begin{array}{l}\text { ER 5-3 (3" } \\
\text { shallow) } \\
\end{array}$ & 1017.24 & 282.78 & 282.68 & $2 / 21 / 2002$ & -- & 734.56 & $\mathrm{BD}$ & database \\
\hline $\begin{array}{l}\text { ER 5-3 (3" } \\
\text { shallow) }\end{array}$ & 1017.24 & 282.61 & 282.51 & $3 / 12 / 2002$ & -- & 734.73 & $\mathrm{BD}$ & database \\
\hline $\begin{array}{l}\text { ER 5-3 (3" } \\
\text { shallow) }\end{array}$ & 1017.24 & 282.67 & 282.57 & $7 / 3 / 2002$ & -- & 734.67 & $\mathrm{BD}$ & database \\
\hline $\begin{array}{l}\text { ER 5-3 (3" } \\
\text { shallow) } \\
\end{array}$ & 1017.24 & 282.69 & 282.59 & $9 / 9 / 2002$ & -- & 734.65 & BD & database \\
\hline $\begin{array}{l}\text { ER 5-3 (3" } \\
\text { shallow) } \\
\end{array}$ & 1017.24 & 282.70 & 282.60 & $12 / 24 / 2002$ & -- & 734.64 & BD & database \\
\hline $\begin{array}{l}\text { ER 5-3 (3" } \\
\text { shallow) }\end{array}$ & 1017.24 & 282.71 & 282.61 & $3 / 10 / 2003$ & -- & 734.63 & $\mathrm{BD}$ & database \\
\hline $\begin{array}{l}\text { ER 5-3 (3" } \\
\text { shallow) } \\
\end{array}$ & 1017.24 & 282.61 & 282.51 & $6 / 18 / 2003$ & -- & 734.73 & $\mathrm{BD}$ & database \\
\hline $\begin{array}{l}\text { ER 5-3 (3" } \\
\text { shallow) }\end{array}$ & 1017.24 & 282.76 & 282.66 & 8/6/2003 & -- & 734.58 & $\mathrm{BD}$ & database \\
\hline $\begin{array}{l}\text { ER 5-3 (3" } \\
\text { shallow) } \\
\end{array}$ & 1017.24 & 282.69 & 282.59 & 9/25/2003 & -- & 734.65 & BD & database \\
\hline $\begin{array}{l}\text { ER 5-3 (3" } \\
\text { shallow) }\end{array}$ & 1017.24 & 282.63 & 282.53 & $11 / 20 / 2003$ & -- & 734.71 & BD & database \\
\hline $\begin{array}{l}\text { ER 5-3 (3" } \\
\text { shallow) } \\
\end{array}$ & 1017.24 & 282.71 & 282.60 & $1 / 27 / 2004$ & -- & 734.63 & BD & USGS website \\
\hline $\begin{array}{l}\text { ER 5-3 (3" } \\
\text { shallow) }\end{array}$ & 1017.24 & 282.67 & 282.57 & $3 / 11 / 2004$ & -- & 734.67 & $\mathrm{BD}$ & USGS website \\
\hline
\end{tabular}

${ }^{a}$ meters below reference point

bSite Status: $Z$ = "Other conditions at the well may have affected the water level measurement" (SNJV 2004). $--=$ Not applicable 


\begin{tabular}{|c|c|c|c|c|c|c|c|c|}
\hline $\begin{array}{c}\text { Well } \\
\text { Reporting } \\
\text { Name }\end{array}$ & $\begin{array}{l}\text { Reference } \\
\text { Point } \\
\text { Elevation } \\
\text { (m) }\end{array}$ & $\begin{array}{c}\text { Measured } \\
\text { Depth to } \\
\text { Water } \\
(m b r n)^{a}\end{array}$ & $\begin{array}{l}\text { Corrected } \\
\text { Depth to } \\
\text { Water } \\
\text { (mbro) }\end{array}$ & $\begin{array}{l}\text { Measure- } \\
\text { ment Date }\end{array}$ & $\begin{array}{c}\text { Site } \\
\text { Status }^{b}\end{array}$ & $\begin{array}{c}\text { Water } \\
\text { Level } \\
\text { Elevation } \\
\text { (masl)c }\end{array}$ & $\begin{array}{c}\text { Type } \\
\text { Correction }^{d}\end{array}$ & Source ${ }^{e}$ \\
\hline
\end{tabular}

${ }^{\mathrm{C}}$ meters above sea level

used to determine historical and contemporary static water level not applicable used to determine historical static water level

used to determine contemporary static water level

${ }^{\mathrm{d}}$ Type Correction: $\mathrm{BD}=$ water level corrected for borehole deviation

${ }^{\mathrm{e}}$ Source: database $=$ UGTA borehole database

USGS website $=$ http://nevada.usgs.gov/doe_nv/

${ }^{\mathrm{f}}$ measurement performed prior to transducer installation, measurement assumed to represent undisturbed conditions 
Well ER 5-3 (main/composite)

Water Level Data

\begin{tabular}{|c|c|c|c|c|c|c|c|c|}
\hline $\begin{array}{l}\text { Well Reporting } \\
\text { Name }\end{array}$ & $\begin{array}{c}\text { Reference } \\
\text { Point } \\
\text { Elevation } \\
(\mathrm{m}) \\
\end{array}$ & $\begin{array}{c}\text { Measured } \\
\text { Depth to } \\
\text { Water } \\
\text { (mbrp) }^{\mathrm{a}} \\
\end{array}$ & $\begin{array}{c}\text { Corrected } \\
\text { Depth to } \\
\text { Water } \\
\text { (mbrp) } \\
\end{array}$ & $\begin{array}{c}\text { Measure- } \\
\text { ment Date }\end{array}$ & $\begin{array}{c}\text { Site } \\
\text { Status }^{b}\end{array}$ & $\begin{array}{c}\text { Water } \\
\text { Level } \\
\text { Elevation } \\
\text { (masl) }^{c} \\
\end{array}$ & $\begin{array}{c}\text { Type } \\
\text { Correction }^{\mathrm{d}}\end{array}$ & Source ${ }^{e}$ \\
\hline $\begin{array}{l}\text { ER 5-3 } \\
\text { (main/composite) }\end{array}$ & 1017.24 & 85.85 & 85.82 & $2 / 28 / 2000$ & C & 931.42 & $B D$ & database \\
\hline $\begin{array}{l}\text { ER 5-3 } \\
\text { (main/composite) }\end{array}$ & 1017.24 & 282.21 & 282.11 & $3 / 19 / 2000$ & Z & 735.13 & $B D$ & database \\
\hline $\begin{array}{l}\text { ER 5-3 } \\
\text { (main/composite) }\end{array}$ & 1017.24 & 282.80 & 282.70 & $7 / 10 / 2000$ & -- & 734.54 & BD & database \\
\hline $\begin{array}{l}\text { ER 5-3 } \\
\text { (main/composite) }\end{array}$ & 1017.24 & 282.74 & 282.64 & $9 / 20 / 2000$ & $Z^{f}$ & 734.60 & BD & database \\
\hline $\begin{array}{l}\text { ER 5-3 } \\
\text { (main/composite) }\end{array}$ & 1017.24 & 282.82 & 282.72 & $11 / 21 / 2000$ & $Z^{f}$ & 734.52 & BD & database \\
\hline $\begin{array}{l}\text { ER 5-3 } \\
\text { (main/composite) }\end{array}$ & 1017.24 & 282.71 & 282.61 & $12 / 6 / 2000$ & -- & 734.63 & $B D$ & database \\
\hline $\begin{array}{l}\text { ER 5-3 } \\
\text { (main/composite) }\end{array}$ & 1017.24 & 282.76 & 282.66 & $3 / 1 / 2001$ & -- & 734.58 & $B D$ & database \\
\hline $\begin{array}{l}\text { ER 5-3 } \\
\text { (main/composite) }\end{array}$ & 1017.24 & 282.66 & 282.56 & $3 / 14 / 2001$ & $P$ & 734.68 & $B D$ & database \\
\hline $\begin{array}{l}\text { ER 5-3 } \\
\text { (main/composite) }\end{array}$ & 1017.24 & 282.74 & 282.64 & $3 / 17 / 2001$ & $\mathrm{R}$ & 734.60 & BD & database \\
\hline $\begin{array}{l}\text { ER 5-3 } \\
\text { (main/composite) }\end{array}$ & 1017.24 & 282.88 & 282.78 & $4 / 8 / 2001$ & Z & 734.46 & BD & database \\
\hline $\begin{array}{l}\text { ER 5-3 } \\
\text { (main/composite) }\end{array}$ & 1017.24 & 282.78 & 282.68 & $4 / 12 / 2001$ & $S$ & 734.56 & BD & database \\
\hline $\begin{array}{l}\text { ER 5-3 } \\
\text { (main/composite) }\end{array}$ & 1017.24 & 282.85 & 282.75 & $4 / 12 / 2001$ & Z & 734.49 & BD & database \\
\hline $\begin{array}{l}\text { ER 5-3 } \\
\text { (main/composite) }\end{array}$ & 1017.24 & 282.77 & 282.67 & $4 / 13 / 2001$ & Z & 734.57 & BD & database \\
\hline $\begin{array}{l}\text { ER 5-3 } \\
\text { (main/composite) }\end{array}$ & 1017.24 & 282.69 & 282.59 & $4 / 18 / 2001$ & Z & 734.65 & $B D$ & database \\
\hline $\begin{array}{l}\text { ER 5-3 } \\
\text { (main/composite) }\end{array}$ & 1017.24 & 373.61 & 373.47 & $5 / 23 / 2001$ & Z & 643.77 & $B D$ & database \\
\hline $\begin{array}{l}\text { ER 5-3 } \\
\text { (main/composite) }\end{array}$ & 1017.24 & 282.69 & 282.59 & $9 / 6 / 2001$ & Z & 734.65 & $B D$ & database \\
\hline $\begin{array}{l}\text { ER 5-3 } \\
\text { (main/composite) }\end{array}$ & 1017.24 & 282.81 & 282.71 & $10 / 9 / 2001$ & Z & 734.53 & BD & database \\
\hline $\begin{array}{l}\text { ER 5-3 } \\
\text { (main/composite) }\end{array}$ & 1017.24 & 282.83 & 282.73 & $10 / 11 / 2001$ & Z & 734.51 & $\mathrm{BD}$ & database \\
\hline $\begin{array}{l}\text { ER 5-3 } \\
\text { (main/composite) }\end{array}$ & 1017.24 & 283.10 & 283.00 & $10 / 15 / 2001$ & Z & 734.24 & $\mathrm{BD}$ & database \\
\hline $\begin{array}{l}\text { ER 5-3 } \\
\text { (main/composite) }\end{array}$ & 1017.24 & 282.56 & 282.46 & $1 / 14 / 2002$ & -- & 734.78 & BD & database \\
\hline $\begin{array}{l}\text { ER 5-3 } \\
\text { (main/composite) }\end{array}$ & 1017.24 & 282.73 & 282.63 & $2 / 21 / 2002$ & -- & 734.61 & BD & database \\
\hline $\begin{array}{l}\text { ER 5-3 } \\
\text { (main/composite) }\end{array}$ & 1017.24 & 282.62 & 282.52 & $3 / 12 / 2002$ & -- & 734.72 & BD & database \\
\hline $\begin{array}{l}\text { ER 5-3 } \\
\text { (main/composite) }\end{array}$ & 1017.24 & 282.66 & 282.56 & $7 / 3 / 2002$ & -- & 734.68 & BD & database \\
\hline
\end{tabular}


Well ER 5-3 (main/composite)

Water Level Data

\begin{tabular}{|c|c|c|c|c|c|c|c|c|}
\hline $\begin{array}{l}\text { Well Reporting } \\
\text { Name }\end{array}$ & $\begin{array}{c}\text { Reference } \\
\text { Point } \\
\text { Elevation } \\
(\mathrm{m}) \\
\end{array}$ & $\begin{array}{c}\text { Measured } \\
\text { Depth to } \\
\text { Water } \\
\text { (mbrp) }^{\mathrm{a}} \\
\end{array}$ & $\begin{array}{c}\text { Corrected } \\
\text { Depth to } \\
\text { Water } \\
\text { (mbrp) } \\
\end{array}$ & $\begin{array}{l}\text { Measure- } \\
\text { ment Date }\end{array}$ & $\begin{array}{c}\text { Site } \\
\text { Status }^{b}\end{array}$ & $\begin{array}{c}\text { Water } \\
\text { Level } \\
\text { Elevation } \\
\text { (masl) }^{\mathrm{c}} \\
\end{array}$ & $\begin{array}{c}\text { Type } \\
\text { Correction }^{\mathrm{d}}\end{array}$ & Source $^{e}$ \\
\hline $\begin{array}{l}\text { ER 5-3 } \\
\text { (main/composite) }\end{array}$ & 1017.24 & 282.67 & 282.57 & 9/9/2002 & -- & 734.67 & $\mathrm{BD}$ & database \\
\hline $\begin{array}{l}\text { ER 5-3 } \\
\text { (main/composite) }\end{array}$ & 1017.24 & 282.64 & 282.54 & $12 / 24 / 2002$ & -- & 734.70 & $\mathrm{BD}$ & database \\
\hline $\begin{array}{l}\text { ER 5-3 } \\
\text { (main/composite) }\end{array}$ & 1017.24 & 282.68 & 282.58 & $3 / 10 / 2003$ & -- & 734.66 & $\mathrm{BD}$ & database \\
\hline $\begin{array}{l}\text { ER 5-3 } \\
\text { (main/composite) }\end{array}$ & 1017.24 & 282.62 & 282.52 & $6 / 18 / 2003$ & -- & 734.72 & $\mathrm{BD}$ & database \\
\hline $\begin{array}{l}\text { ER 5-3 } \\
\text { (main/composite) }\end{array}$ & 1017.24 & 282.76 & 282.66 & $8 / 6 / 2003$ & -- & 734.58 & $\mathrm{BD}$ & database \\
\hline $\begin{array}{l}\text { ER 5-3 } \\
\text { (main/composite) }\end{array}$ & 1017.24 & 282.68 & 282.58 & 9/25/2003 & -- & 734.66 & $\mathrm{BD}$ & database \\
\hline $\begin{array}{l}\text { ER 5-3 } \\
\text { (main/composite) }\end{array}$ & 1017.24 & 282.61 & 282.51 & $11 / 20 / 2003$ & -- & 734.73 & BD & database \\
\hline $\begin{array}{l}\text { ER 5-3 } \\
\text { (main/composite) }\end{array}$ & 1017.24 & 282.66 & 282.56 & $1 / 26 / 2004$ & -- & 734.68 & $\mathrm{BD}$ & USGS website \\
\hline $\begin{array}{l}\text { ER 5-3 } \\
\text { (main/composite) }\end{array}$ & 1017.24 & 282.67 & 282.57 & $3 / 11 / 2004$ & -- & 734.67 & $\mathrm{BD}$ & USGS website \\
\hline
\end{tabular}

${ }^{a}$ meters below reference point

${ }^{b}$ Site Status: $C=$ Water level was measured prior to well completion.

$\mathrm{P}=$ Site was being pumped.

$R=$ Site had been pumped recently.

$S=A$ nearby site that taps the same aquifer was being pumped.

$Z=$ "Other conditions at the well may have affected the water level measurement" (SNJV 2004).

-- = Not applicable

${ }^{c}$ meters above sea level

used to determine historical and contemporary static water level not applicable

used to determine historical static water level not applicable

used to determine contemporary static water level

d Type Correction: BD = water level corrected for borehole deviation

e Source: database = UGTA borehole database

USGS website $=$ http://nevada.usgs.gov/doe_nv/

f predevelopment monitoring, measurement assumed to represent undisturbed conditions 
ER 5-4 \#2

Water-Level Data

\begin{tabular}{|c|c|c|c|c|c|c|c|c|}
\hline $\begin{array}{c}\text { Well } \\
\text { Reporting } \\
\text { Name }\end{array}$ & $\begin{array}{c}\text { Reference } \\
\text { Point } \\
\text { Elevation } \\
\text { (m) }\end{array}$ & $\begin{array}{c}\text { Measured } \\
\text { Depth to } \\
\text { Water } \\
(\mathrm{mbrp})^{\mathrm{a}}\end{array}$ & $\begin{array}{c}\text { Corrected } \\
\text { Depth to } \\
\text { Water } \\
\text { (mbrp) }\end{array}$ & $\begin{array}{c}\text { Measure- } \\
\text { ment Date }\end{array}$ & $\begin{array}{c}\text { Site } \\
\text { Status }^{b}\end{array}$ & $\begin{array}{c}\text { Water } \\
\text { Level } \\
\text { Elevation } \\
\text { (masl) }^{c}\end{array}$ & $\begin{array}{c}\text { Type } \\
\text { Correction }^{d}\end{array}$ & Source ${ }^{e}$ \\
\hline ER 5-4 \#2 & 954.54 & 148.20 & 148.19 & $8 / 6 / 2002$ & C & 806.36 & $\mathrm{BD}$ & database \\
\hline ER 5-4 \#2 & 954.54 & 150.62 & 150.60 & $8 / 6 / 2002$ & $\mathrm{C}$ & 803.94 & $B D$ & database \\
\hline ER 5-4 \#2 & 954.54 & 152.37 & 152.36 & $8 / 6 / 2002$ & $\mathrm{C}$ & 802.19 & $B D$ & database \\
\hline ER 5-4 \#2 & 954.54 & 158.08 & 158.07 & $8 / 6 / 2002$ & $C$ & 796.48 & $B D$ & database \\
\hline ER 5-4 \#2 & 954.54 & 158.28 & 158.27 & $8 / 6 / 2002$ & $C$ & 796.27 & $B D$ & database \\
\hline ER 5-4 \#2 & 954.54 & 170.41 & 170.40 & $8 / 6 / 2002$ & $C$ & 784.14 & $B D$ & database \\
\hline ER 5-4 \#2 & 954.54 & 156.25 & 156.23 & $8 / 7 / 2002$ & $\mathrm{C}$ & 798.31 & $B D$ & database \\
\hline ER 5-4 \#2 & 954.54 & 157.25 & 157.23 & $8 / 7 / 2002$ & $C$ & 797.31 & $B D$ & database \\
\hline ER 5-4 \#2 & 954.54 & 110.41 & 110.40 & $8 / 7 / 2002$ & $\mathrm{C}$ & 844.14 & $B D$ & database \\
\hline ER 5-4 \#2 & 954.54 & 98.81 & 98.80 & $8 / 11 / 2002$ & $\mathrm{C}$ & 855.74 & $B D$ & database \\
\hline ER 5-4 \#2 & 954.54 & 152.57 & 152.56 & $8 / 13 / 2002$ & $C$ & 801.99 & $B D$ & database \\
\hline ER 5-4 \#2 & 954.54 & 152.77 & 152.75 & $8 / 13 / 2002$ & $\mathrm{C}$ & 801.79 & $B D$ & database \\
\hline ER 5-4 \#2 & 954.54 & 224.26 & 224.23 & $8 / 15 / 2002$ & $C$ & 730.31 & $B D$ & database \\
\hline ER 5-4 \#2 & 954.54 & 207.93 & 207.91 & $8 / 17 / 2002$ & C & 746.63 & BD & database \\
\hline ER 5-4 \#2 & 954.54 & 18.72 & 18.72 & $8 / 18 / 2002$ & $C$ & 935.83 & $B D$ & database \\
\hline ER 5-4 \#2 & 954.54 & 72.70 & 72.69 & $8 / 18 / 2002$ & $C$ & 881.85 & $B D$ & database \\
\hline ER 5-4 \#2 & 954.54 & 117.57 & 117.56 & $8 / 18 / 2002$ & $\mathrm{C}$ & 836.98 & $B D$ & database \\
\hline ER 5-4 \#2 & 954.54 & 62.75 & 62.74 & $8 / 18 / 2002$ & $\mathrm{C}$ & 891.80 & $B D$ & database \\
\hline ER 5-4 \#2 & 954.54 & 54.02 & 54.02 & $8 / 18 / 2002$ & $C$ & 900.53 & $B D$ & database \\
\hline ER 5-4 \#2 & 954.54 & 359.87 & 359.84 & $8 / 30 / 2002$ & $\mathrm{C}$ & 594.70 & $B D$ & database \\
\hline ER 5-4 \#2 & 954.54 & 359.85 & 359.81 & $8 / 30 / 2002$ & $C$ & 594.73 & $B D$ & database \\
\hline ER 5-4 \#2 & 954.54 & 215.68 & 215.66 & $8 / 30 / 2002$ & $\mathrm{C}$ & 738.89 & $B D$ & database \\
\hline ER 5-4 \#2 & 954.54 & 215.68 & 215.66 & $8 / 30 / 2002$ & $\mathrm{C}$ & 738.89 & $B D$ & database \\
\hline ER 5-4 \#2 & 954.54 & 215.69 & 215.67 & $8 / 30 / 2002$ & $\mathrm{C}$ & 738.87 & $B D$ & database \\
\hline ER 5-4 \#2 & 954.54 & 215.69 & 215.67 & $8 / 30 / 2002$ & C & 738.87 & $B D$ & database \\
\hline ER 5-4 \#2 & 954.54 & 214.21 & 214.19 & 9/25/2002 & $Z$ & 740.35 & $B D$ & database \\
\hline ER 5-4 \#2 & 954.54 & 211.63 & 211.61 & 10/14/2002 & $Z$ & 742.93 & $B D$ & database \\
\hline ER 5-4 \#2 & 954.54 & 211.63 & 211.61 & $10 / 18 / 2002$ & Z & 742.94 & $B D$ & database \\
\hline ER 5-4 \#2 & 954.54 & 215.08 & 215.06 & $10 / 26 / 2002$ & $\mathrm{R}$ & 739.48 & $B D$ & database \\
\hline ER 5-4 \#2 & 954.54 & 225.71 & 225.69 & \begin{tabular}{|l|}
$12 / 2 / 2002$ \\
\end{tabular} & $\mathrm{R}$ & 728.85 & $B D$ & database \\
\hline ER 5-4 \#2 & 954.54 & 221.15 & 221.13 & $12 / 14 / 2002$ & -- & 733.42 & $B D$ & database \\
\hline ER 5-4 \#2 & 954.54 & 221.76 & 221.74 & $12 / 14 / 2002$ & -- & 732.81 & $B D$ & database \\
\hline ER 5-4 \#2 & 954.54 & 221.10 & 221.08 & \begin{tabular}{|l|}
$1 / 23 / 2003$ \\
\end{tabular} & $Z$ & 733.46 & $B D$ & database \\
\hline ER 5-4 \#2 & 954.54 & 212.32 & 212.30 & $2 / 7 / 2003$ & $Z$ & 742.24 & $B D$ & database \\
\hline ER 5-4 \#2 & 954.54 & 209.28 & 209.26 & $3 / 12 / 2003$ & -- & 745.29 & $B D$ & database \\
\hline ER 5-4 \#2 & 954.54 & 206.39 & 206.37 & $4 / 22 / 2003$ & $Z$ & 748.17 & $B D$ & database \\
\hline ER 5-4 \#2 & 954.54 & 206.34 & 206.32 & $4 / 24 / 2003$ & $Z$ & 748.22 & $B D$ & database \\
\hline ER 5-4 \#2 & 954.54 & 206.29 & 206.27 & $4 / 24 / 2003$ & $\mathrm{Z}$ & 748.27 & $B D$ & database \\
\hline ER 5-4 \#2 & 954.54 & 202.17 & 202.15 & 9/13/2003 & Z & 752.39 & $B D$ & database \\
\hline
\end{tabular}


ER 5-4 \#2

Water-Level Data

\begin{tabular}{|c|c|c|c|c|c|c|c|c|}
\hline $\begin{array}{c}\text { Well } \\
\text { Reporting } \\
\text { Name }\end{array}$ & $\begin{array}{c}\text { Reference } \\
\text { Point } \\
\text { Elevation } \\
(\mathrm{m}) \\
\end{array}$ & $\begin{array}{c}\text { Measured } \\
\text { Depth to } \\
\text { Water } \\
(\mathrm{mbrp})^{\mathrm{a}} \\
\end{array}$ & $\begin{array}{c}\text { Corrected } \\
\text { Depth to } \\
\text { Water } \\
\text { (mbrp) } \\
\end{array}$ & $\begin{array}{l}\text { Measure- } \\
\text { ment Date }\end{array}$ & $\begin{array}{c}\text { Site } \\
\text { Status }^{b}\end{array}$ & $\begin{array}{c}\text { Water } \\
\text { Level } \\
\text { Elevation } \\
\text { (masl) }^{c} \\
\end{array}$ & $\begin{array}{c}\text { Type } \\
\text { Correction }^{d}\end{array}$ & Source $^{e}$ \\
\hline ER 5-4 \#2 & 954.54 & 201.97 & 201.95 & 9/29/2003 & -- & 752.59 & $\mathrm{BD}$ & database \\
\hline ER 5-4 \#2 & 954.54 & 201.44 & 201.42 & $11 / 20 / 2003$ & -- & 753.13 & $B D$ & database \\
\hline ER 5-4 \#2 & 954.54 & 200.69 & 200.67 & $3 / 11 / 2004$ & -- & 753.87 & $\mathrm{BD}$ & USGS website \\
\hline
\end{tabular}

${ }^{a}$ meters below reference point

${ }^{b}$ Site Status: $C=$ Water level was measured prior to well completion.

$\mathrm{R}=$ Site had been pumped recently.

$Z$ = "Other conditions at the well may have affected the water level measurement" (SNJV 2004).

-- = Not applicable

${ }^{\mathrm{c}}$ meters above sea level

static water level could not be determined

d Type Correction: BD = water level corrected for borehole deviation

eSource: database = UGTA borehole database

USGS website $=$ http://nevada.usgs.gov/doe_nv/ 
Well ER 5-4 (main/composite)

Water Level Data

\begin{tabular}{|c|c|c|c|c|c|c|c|c|}
\hline $\begin{array}{l}\text { Well Reporting } \\
\text { Name }\end{array}$ & \begin{tabular}{|c|} 
Reference \\
Point \\
Elevation \\
$(\mathrm{m})$ \\
\end{tabular} & $\begin{array}{c}\text { Measured } \\
\text { Depth to } \\
\text { Water } \\
\text { (mbrp) }^{\mathrm{a}}\end{array}$ & $\begin{array}{c}\text { Corrected } \\
\text { Depth to } \\
\text { Water } \\
\text { (mbrp) } \\
\end{array}$ & $\begin{array}{l}\text { Measure- } \\
\text { ment Date }\end{array}$ & $\begin{array}{c}\text { Site } \\
\text { Status }^{b}\end{array}$ & $\begin{array}{c}\text { Water } \\
\text { Level } \\
\text { Elevation } \\
\text { (masl) }^{\mathrm{c}}\end{array}$ & $\begin{array}{c}\text { Type } \\
\text { Correction }^{d}\end{array}$ & Source ${ }^{e}$ \\
\hline $\begin{array}{l}\text { ER-5-4 } \\
\text { (main/composite) }\end{array}$ & 954.54 & 17.97 & 17.97 & $2 / 23 / 2001$ & C & 936.58 & BD & database \\
\hline $\begin{array}{l}\text { ER-5-4 } \\
\text { (main/composite) }\end{array}$ & 954.54 & 222.01 & 221.95 & $5 / 4 / 2001$ & -- & 732.59 & BD & database \\
\hline $\begin{array}{l}\text { ER-5-4 } \\
\text { (main/composite) }\end{array}$ & 954.54 & 221.99 & 221.93 & $5 / 6 / 2001$ & -- & 732.61 & BD & database \\
\hline $\begin{array}{l}\text { ER-5-4 } \\
\text { (main/composite) }\end{array}$ & 954.54 & 221.94 & 221.88 & $5 / 9 / 2001$ & -- & 732.66 & BD & database \\
\hline $\begin{array}{l}\text { ER-5-4 } \\
\text { (main/composite) }\end{array}$ & 954.54 & 222.66 & 222.61 & $5 / 13 / 2001$ & -- & 731.94 & BD & database \\
\hline $\begin{array}{l}\text { ER-5-4 } \\
\text { (main/composite) }\end{array}$ & 954.54 & 222.56 & 222.50 & $5 / 15 / 2001$ & -- & 732.04 & BD & database \\
\hline $\begin{array}{l}\text { ER-5-4 } \\
\text { (main/composite) }\end{array}$ & 954.54 & 221.25 & 221.19 & $6 / 5 / 2001$ & Z & 733.35 & $B D$ & database \\
\hline $\begin{array}{l}\text { ER-5-4 } \\
\text { (main/composite) }\end{array}$ & 954.54 & 224.93 & 224.88 & $6 / 18 / 2001$ & $\mathrm{P}$ & 729.67 & BD & database \\
\hline $\begin{array}{l}\text { ER-5-4 } \\
\text { (main/composite) }\end{array}$ & 954.54 & 223.45 & 223.39 & $6 / 21 / 2001$ & $\mathrm{R}$ & 731.15 & BD & database \\
\hline $\begin{array}{l}\text { ER-5-4 } \\
\text { (main/composite) }\end{array}$ & 954.54 & 221.79 & 221.73 & $7 / 10 / 2001$ & $\mathrm{R}$ & 732.81 & $B D$ & database \\
\hline $\begin{array}{l}\text { ER-5-4 } \\
\text { (main/composite) }\end{array}$ & 954.54 & 221.10 & 221.04 & $1 / 15 / 2002$ & -- & 733.50 & BD & database \\
\hline $\begin{array}{l}\text { ER-5-4 } \\
\text { (main/composite) }\end{array}$ & 954.54 & 221.23 & 221.17 & $2 / 21 / 2002$ & -- & 733.37 & BD & database \\
\hline $\begin{array}{l}\text { ER-5-4 } \\
\text { (main/composite) }\end{array}$ & 954.54 & 221.15 & 221.09 & $3 / 12 / 2002$ & -- & 733.45 & BD & database \\
\hline $\begin{array}{l}\text { ER-5-4 } \\
\text { (main/composite) }\end{array}$ & 954.54 & 220.99 & 220.93 & $7 / 30 / 2002$ & Z & 733.61 & $B D$ & database \\
\hline $\begin{array}{l}\text { ER-5-4 } \\
\text { (main/composite) }\end{array}$ & 954.54 & 221.39 & 221.33 & $8 / 16 / 2002$ & Z & 733.21 & BD & database \\
\hline $\begin{array}{l}\text { ER-5-4 } \\
\text { (main/composite) }\end{array}$ & 954.54 & 221.10 & 221.05 & $10 / 9 / 2002$ & Z & 733.50 & BD & database \\
\hline $\begin{array}{l}\text { ER-5-4 } \\
\text { (main/composite) }\end{array}$ & 954.54 & 221.18 & 221.12 & $4 / 17 / 2003$ & Z & 733.42 & $B D$ & database \\
\hline $\begin{array}{l}\text { ER-5-4 } \\
\text { (main/composite) }\end{array}$ & 954.54 & 221.16 & 221.10 & $4 / 17 / 2003$ & Z & 733.44 & $B D$ & database \\
\hline $\begin{array}{l}\text { ER-5-4 } \\
\text { (main/composite) }\end{array}$ & 954.54 & 221.32 & 221.26 & $9 / 10 / 2003$ & Z & 733.28 & BD & database \\
\hline $\begin{array}{l}\text { ER-5-4 } \\
\text { (main/composite) }\end{array}$ & 954.54 & 221.32 & 221.26 & $9 / 10 / 2003$ & Z & 733.28 & $\mathrm{BD}$ & database \\
\hline $\begin{array}{l}\text { ER-5-4 } \\
\text { (main/composite) }\end{array}$ & 954.54 & 221.44 & 221.39 & $9 / 22 / 2003$ & Z & 733.16 & BD & database \\
\hline $\begin{array}{l}\text { ER-5-4 } \\
\text { (main/composite) }\end{array}$ & 954.54 & 221.45 & 221.39 & $9 / 23 / 2003$ & Z & 733.15 & BD & database \\
\hline $\begin{array}{l}\text { ER-5-4 } \\
\text { (main/composite) }\end{array}$ & 954.54 & 221.50 & 221.44 & 9/24/2003 & Z & 733.10 & BD & database \\
\hline
\end{tabular}


Well ER 5-4 (main/composite)

Water Level Data

\begin{tabular}{|l|r|r|r|r|r|r|r|l|}
\hline $\begin{array}{l}\text { Well Reporting } \\
\text { Name }\end{array}$ & $\begin{array}{c}\text { Reference } \\
\text { Point } \\
\text { Elevation } \\
(\mathbf{m})\end{array}$ & $\begin{array}{c}\text { Measured } \\
\text { Depth to } \\
\text { Water } \\
(\mathbf{m b r p})^{\mathbf{a}}\end{array}$ & $\begin{array}{c}\text { Corrected } \\
\text { Depth to } \\
\text { Water } \\
\text { (mbrp) }\end{array}$ & $\begin{array}{c}\text { Measure- } \\
\text { ment Date }\end{array}$ & $\begin{array}{c}\text { Site } \\
\text { Status }\end{array}$ & $\begin{array}{c}\text { Water } \\
\text { Level } \\
\text { Elevation } \\
\text { (masl) }\end{array}$ & $\begin{array}{c}\text { Type } \\
\text { Correction }^{\mathrm{d}}\end{array}$ & Source $^{\mathrm{e}}$ \\
\hline $\begin{array}{l}\text { ER-5-4 } \\
\text { (main/composite) }\end{array}$ & 954.54 & 221.27 & 221.21 & $9 / 29 / 2003$ & -- & 733.33 & BD & database \\
\hline $\begin{array}{l}\text { ER-5-4 } \\
\text { (main/composite) }\end{array}$ & 954.54 & 221.23 & 221.18 & $11 / 20 / 2003$ & -- & 733.37 & BD & database \\
\hline $\begin{array}{l}\text { ER-5-4 } \\
\text { (main/composite) }\end{array}$ & 954.54 & 221.25 & 221.19 & $1 / 22 / 2004$ & -- & 733.35 & BD & USGS website \\
\hline $\begin{array}{l}\text { ER-5-4 } \\
\text { (main/composite) }\end{array}$ & 954.54 & 221.17 & 221.12 & $3 / 11 / 2004$ & -- & 733.43 & BD & USGS website \\
\hline
\end{tabular}

${ }^{a}$ meters below reference point

${ }^{b}$ Site Status: $C=$ Water level was measured prior to well completion.

$\mathrm{P}=$ Site was being pumped.

$\mathrm{R}=$ Site had been pumped recently.

$Z$ = "Other conditions at the well may have affected the water level measurement" (SNJV 2004).

$--=$ Not applicable

${ }^{\mathrm{c}}$ meters above sea level

used to determine historical and contemporary static water level not applicable

used to determine historical static water level not applicable

used to determine contemporary static water level

d Type Correction: BD = water level corrected for borehole deviation

'Source: database = UGTA borehole database

USGS website = http://nevada.usgs.gov/doe_nv/ 
Well ER 5-4 (piezometer)

Water Level Data

\begin{tabular}{|c|c|c|c|c|c|c|c|c|}
\hline $\begin{array}{c}\text { Well } \\
\text { Reporting } \\
\text { Name }\end{array}$ & \begin{tabular}{|c|} 
Reference \\
Point \\
Elevation \\
(m)
\end{tabular} & \begin{tabular}{|c|} 
Measured \\
Depth to \\
Water \\
(mbrp) $^{\mathrm{a}}$
\end{tabular} & $\begin{array}{c}\text { Corrected } \\
\text { Depth to } \\
\text { Water } \\
\text { (mbrp) }\end{array}$ & $\begin{array}{l}\text { Measure- } \\
\text { ment Date }\end{array}$ & $\begin{array}{c}\text { Site } \\
\text { Status }^{b}\end{array}$ & $\begin{array}{c}\text { Water } \\
\text { Level } \\
\text { Elevation } \\
\text { (masl) }^{\mathrm{c}}\end{array}$ & $\begin{array}{c}\text { Type } \\
\text { Correction }^{d}\end{array}$ & Source ${ }^{e}$ \\
\hline \begin{tabular}{|l|} 
ER 5-4 \\
(piezometer)
\end{tabular} & 954.54 & 161.95 & 161.91 & $5 / 4 / 2001$ & Z & 792.63 & $\mathrm{BD}$ & database \\
\hline \begin{tabular}{|l}
$\begin{array}{l}\text { ER 5-4 } \\
\text { (piezometer) }\end{array}$ \\
\end{tabular} & 954.54 & 220.36 & 220.30 & $5 / 6 / 2001$ & -- & 734.24 & $\mathrm{BD}$ & database \\
\hline \begin{tabular}{|l} 
ER 5-4 \\
(piezometer)
\end{tabular} & 954.54 & 220.54 & 220.49 & $5 / 9 / 2001$ & -- & 734.05 & BD & database \\
\hline \begin{tabular}{|l}
$\begin{array}{l}\text { ER 5-4 } \\
\text { (piezometer) }\end{array}$ \\
\end{tabular} & 954.54 & 220.69 & 220.63 & $5 / 13 / 2001$ & -- & 733.91 & $\mathrm{BD}$ & database \\
\hline $\begin{array}{l}\text { ER 5-4 } \\
\text { (piezometer) }\end{array}$ & 954.54 & 220.75 & 220.69 & $5 / 15 / 2001$ & -- & 733.85 & $\mathrm{BD}$ & database \\
\hline \begin{tabular}{|l}
$\begin{array}{l}\text { ER 5-4 } \\
\text { (piezometer) }\end{array}$ \\
\end{tabular} & 954.54 & 221.00 & 220.94 & $6 / 5 / 2001$ & -- & 733.60 & $\mathrm{BD}$ & database \\
\hline \begin{tabular}{|l} 
ER 5-4 \\
(piezometer)
\end{tabular} & 954.54 & 221.24 & 221.18 & $7 / 10 / 2001$ & $\mathrm{R}$ & 733.36 & $\mathrm{BD}$ & database \\
\hline $\begin{array}{l}\text { ER 5-4 } \\
\text { (piezometer) }\end{array}$ & 954.54 & 221.04 & 220.98 & $7 / 16 / 2001$ & -- & 733.56 & $\mathrm{BD}$ & database \\
\hline $\begin{array}{l}\text { ER 5-4 } \\
\text { (piezometer) }\end{array}$ & 954.54 & 221.11 & 221.05 & $7 / 16 / 2001$ & $\mathrm{R}$ & 733.49 & $\mathrm{BD}$ & database \\
\hline \begin{tabular}{|l} 
ER 5-4 \\
(piezometer)
\end{tabular} & 954.54 & 221.00 & 220.95 & $1 / 15 / 2002$ & -- & 733.59 & $\mathrm{BD}$ & database \\
\hline $\begin{array}{l}\text { ER 5-4 } \\
\text { (piezometer) }\end{array}$ & 954.54 & 221.02 & 220.97 & $2 / 21 / 2002$ & -- & 733.58 & $\mathrm{BD}$ & database \\
\hline $\begin{array}{l}\text { ER 5-4 } \\
\text { (piezometer) }\end{array}$ & 954.54 & 221.01 & 220.95 & $3 / 12 / 2002$ & -- & 733.59 & $\mathrm{BD}$ & database \\
\hline $\begin{array}{l}\text { ER 5-4 } \\
\text { (piezometer) }\end{array}$ & 954.54 & 221.06 & 221.00 & $7 / 22 / 2002$ & Z & 733.54 & $\mathrm{BD}$ & database \\
\hline $\begin{array}{l}\text { ER 5-4 } \\
\text { (piezometer) }\end{array}$ & 954.54 & 220.92 & 220.86 & $10 / 9 / 2002$ & Z & 733.68 & $\mathrm{BD}$ & database \\
\hline $\begin{array}{l}\text { ER 5-4 } \\
\text { (piezometer) }\end{array}$ & 954.54 & 221.44 & 221.38 & $4 / 11 / 2003$ & Z & 733.16 & $\mathrm{BD}$ & database \\
\hline $\begin{array}{l}\text { ER 5-4 } \\
\text { (piezometer) }\end{array}$ & 954.54 & 221.84 & 221.78 & 9/12/2003 & Z & 732.76 & $\mathrm{BD}$ & database \\
\hline $\begin{array}{l}\text { ER 5-4 } \\
\text { (piezometer) }\end{array}$ & 954.54 & 221.79 & 221.73 & $9 / 22 / 2003$ & Z & 732.81 & $\mathrm{BD}$ & database \\
\hline $\begin{array}{l}\text { ER 5-4 } \\
\text { (piezometer) }\end{array}$ & 954.54 & 221.52 & 221.47 & 9/29/2003 & $\mathrm{T}$ & 733.08 & $\mathrm{BD}$ & database \\
\hline $\begin{array}{l}\text { ER 5-4 } \\
\text { (piezometer) }\end{array}$ & 954.54 & 221.19 & 221.13 & $11 / 20 / 2003$ & -- & 733.41 & $\mathrm{BD}$ & database \\
\hline $\begin{array}{l}\text { ER 5-4 } \\
\text { (piezometer) }\end{array}$ & 954.54 & 221.07 & 221.01 & $1 / 22 / 2004$ & -- & 733.53 & $\mathrm{BD}$ & USGS website \\
\hline \begin{tabular}{|l} 
ER 5-4 \\
(piezometer)
\end{tabular} & 954.54 & 221.03 & 220.98 & $3 / 11 / 2004$ & -- & 733.57 & $\mathrm{BD}$ & USGS website \\
\hline
\end{tabular}

${ }^{a}$ meters below reference point

${ }^{b}$ Site Status: $R$ = Site had been pumped recently. 
Well ER 5-4 (piezometer)

Water Level Data

\begin{tabular}{|c|c|c|c|c|c|c|c|c|}
\hline $\begin{array}{c}\text { Well } \\
\text { Reporting } \\
\text { Name }\end{array}$ & $\begin{array}{l}\text { Reference } \\
\text { Point } \\
\text { Elevation } \\
\text { (m) }\end{array}$ & $\begin{array}{l}\text { Measured } \\
\text { Depth to } \\
\text { Water } \\
\text { (mbrp) }^{\text {a }}\end{array}$ & $\begin{array}{c}\text { Corrected } \\
\text { Depth to } \\
\text { Water } \\
\text { (mbrp) }\end{array}$ & $\begin{array}{l}\text { Measure- } \\
\text { ment Date }\end{array}$ & $\begin{array}{c}\text { Site } \\
\text { Status }^{b}\end{array}$ & $\begin{array}{c}\text { Water } \\
\text { Level } \\
\text { Elevation } \\
\text { (masl) }^{c}\end{array}$ & $\begin{array}{c}\text { Type } \\
\text { Correction }^{d}\end{array}$ & Source ${ }^{e}$ \\
\hline
\end{tabular}

$\mathrm{T}=\mathrm{A}$ nearby site that taps the same aquifer had been pumped recently.

$Z$ = "Other conditions at the well may have affected the water level measurement" (SNJV 2004).

$--=$ Not applicable

${ }^{\mathrm{c}}$ meters above sea level

used to determine historical and contemporary static water level not applicable

used to determine historical static water level

used to determine contemporary static water level

${ }^{\mathrm{d}}$ Type Correction: BD = water level corrected for borehole deviation

eSource: database = UGTA borehole database

USGS website $=$ http://nevada.usgs.gov/doe_nv/ 
RNM-1

Water-Level Data

\begin{tabular}{|c|c|c|c|c|c|c|c|c|}
\hline $\begin{array}{c}\text { Well } \\
\text { Reporting } \\
\text { Name }\end{array}$ & $\begin{array}{c}\text { Reference } \\
\text { Point } \\
\text { Elevation } \\
(\mathrm{m}) \\
\end{array}$ & $\begin{array}{c}\text { Measured } \\
\text { Depth to } \\
\text { Water } \\
(\mathrm{mbrp})^{\mathrm{a}} \\
\end{array}$ & $\begin{array}{c}\text { Corrected } \\
\text { Depth to } \\
\text { Water } \\
\text { (mbrp) } \\
\end{array}$ & $\begin{array}{l}\text { Measure- } \\
\text { ment Date }\end{array}$ & $\begin{array}{c}\text { Site } \\
\text { Status }^{b}\end{array}$ & $\begin{array}{c}\text { Water } \\
\text { Level } \\
\text { Elevation } \\
\text { (masl) }^{c} \\
\end{array}$ & $\begin{array}{c}\text { Type } \\
\text { Correction }^{d}\end{array}$ & Source \\
\hline RNM-1 & 955.60 & 240.18 & 224.23 & $7 / 30 / 1975$ & -- & 731.37 & $B D$ & database \\
\hline RNM-1 & 955.60 & 241.71 & 225.65 & $8 / 4 / 1975$ & -- & 729.95 & $B D$ & database \\
\hline RNM-1 & 955.60 & 239.57 & 223.66 & $8 / 6 / 1975$ & -- & 731.94 & $B D$ & database \\
\hline RNM-1 & 955.60 & 238.05 & 222.24 & $8 / 12 / 1975$ & -- & 733.36 & $B D$ & database \\
\hline RNM-1 & 955.60 & 240.18 & 224.23 & $8 / 15 / 1975$ & -- & 731.37 & $\mathrm{BD}$ & database \\
\hline RNM-1 & 955.60 & 240.38 & 224.42 & $12 / 7 / 1976$ & -- & 731.18 & $\mathrm{BD}$ & database \\
\hline RNM-1 & 955.60 & 240.49 & 224.51 & $7 / 8 / 1977$ & -- & 731.09 & $B D$ & database \\
\hline RNM-1 & 955.60 & 240.68 & 224.70 & $2 / 13 / 2003$ & -- & 730.90 & $\mathrm{BD}$ & database \\
\hline RNM-1 & 955.60 & 240.85 & 224.85 & $4 / 11 / 2003$ & $Z$ & 730.75 & $\mathrm{BD}$ & database \\
\hline RNM-1 & 955.60 & 241.04 & 225.03 & 9/12/2003 & $Z$ & 730.56 & $\mathrm{BD}$ & database \\
\hline
\end{tabular}

${ }^{a}$ meters below reference point

bSite Status: $Z$ = "Other conditions at the well may have affected the water level measurement" (SNJV 2004).

-- = Not applicable

${ }^{c}$ meters above sea level

used to determine historical and contemporary static water level

used to determine historical static water level not applicable used to determine contemporary static water level not applicable

${ }^{\mathrm{d}}$ Type Correction: $\mathrm{BD}=$ water level corrected for borehole deviation

${ }^{\text {e}}$ Source: database $=$ UGTA borehole database 
Well RNM-2

Water Level Data

\begin{tabular}{|c|c|c|c|c|c|c|c|c|}
\hline $\begin{array}{c}\text { Well } \\
\text { Reporting } \\
\text { Name }\end{array}$ & \begin{tabular}{|c} 
Reference \\
Point \\
Elevation \\
$(\mathrm{m})$
\end{tabular} & $\begin{array}{c}\text { Measured } \\
\text { Depth to } \\
\text { Water } \\
\text { (mbrp) }^{\mathrm{a}} \\
\end{array}$ & $\begin{array}{c}\text { Corrected } \\
\text { Depth to } \\
\text { Water } \\
\text { (mbrp) }\end{array}$ & $\begin{array}{c}\text { Measure- } \\
\text { ment Date }\end{array}$ & $\begin{array}{c}\text { Site } \\
\text { Status }^{b}\end{array}$ & $\begin{array}{c}\text { Water } \\
\text { Level } \\
\text { Elevation } \\
\text { (masl) }^{\mathrm{c}} \\
\end{array}$ & $\begin{array}{c}\text { Type } \\
\text { Correction }^{d}\end{array}$ & Source \\
\hline RNM-2 & 953.66 & 219.46 & -- & $3 / 13 / 1974$ & C & 734.20 & none & database \\
\hline RNM-2 & 953.66 & 219.46 & -- & $3 / 20 / 1974$ & $\mathrm{C}$ & 734.20 & none & database \\
\hline RNM-2 & 953.66 & 219.76 & -- & $5 / 22 / 1974$ & $C$ & 733.90 & none & database \\
\hline RNM-2 & 953.66 & 220.37 & -- & $8 / 1 / 1974$ & $\mathrm{C}$ & 733.29 & none & database \\
\hline RNM-2 & 953.66 & 220.14 & -- & $7 / 12 / 1976$ & -- & 733.51 & none & database \\
\hline RNM-2 & 953.66 & 221.52 & -- & $7 / 20 / 1976$ & -- & 732.14 & none & database \\
\hline RNM-2 & 953.66 & 220.76 & -- & $8 / 19 / 1976$ & -- & 732.89 & none & database \\
\hline RNM-2 & 953.66 & 221.04 & -- & $12 / 6 / 1976$ & -- & 732.61 & none & database \\
\hline RNM-2 & 953.66 & 220.46 & -- & $3 / 22 / 1980$ & -- & 733.20 & none & database \\
\hline RNM-2 & 953.66 & 220.46 & -- & $3 / 22 / 1980$ & -- & 733.19 & none & database \\
\hline RNM-2 & 953.66 & 221.83 & -- & $3 / 19 / 1985$ & -- & 731.83 & none & database \\
\hline RNM-2 & 953.66 & 220.08 & -- & $4 / 21 / 2003$ & $Z^{f}$ & 733.58 & none & database \\
\hline RNM-2 & 953.66 & 220.32 & -- & $9 / 12 / 2003$ & $Z$ & 733.33 & none & database \\
\hline
\end{tabular}

${ }^{a}$ meters below reference point

${ }^{b}$ Site Status: $C=$ Water level was measured prior to well completion.

$Z$ = "Other conditions at the well may have affected the water level measurement" (SNJV 2004).

$--=$ Not applicable

${ }^{c}$ meters above sea level

\section{used to determine historical and contemporary static water level}

\section{used to determine historical static water level}

not applicable

used to determine contemporary static water level not applicable

${ }^{\mathrm{d}}$ Type Correction: none $=$ no correction made to water level

${ }^{e}$ Source: database = UGTA borehole database

'measurement performed prior to transducer installation, measurement assumed to represent

undisturbed conditions 
Well RNM-2s

Water Level Data

\begin{tabular}{|c|c|c|c|c|c|c|c|c|}
\hline $\begin{array}{c}\text { Well } \\
\text { Reporting } \\
\text { Name }\end{array}$ & \begin{tabular}{|c} 
Reference \\
Point \\
Elevation \\
$(\mathrm{m})$
\end{tabular} & \begin{tabular}{|c|}
$\begin{array}{c}\text { Measured } \\
\text { Depth to } \\
\text { Water } \\
\text { (mbrp) }^{\mathrm{a}}\end{array}$ \\
\end{tabular} & $\begin{array}{l}\text { Corrected } \\
\text { Depth to } \\
\text { Water } \\
\text { (mbrp) }\end{array}$ & $\begin{array}{c}\text { Measure- } \\
\text { ment Date }\end{array}$ & $\begin{array}{c}\text { Site } \\
\text { Status }^{b}\end{array}$ & $\begin{array}{c}\text { Water } \\
\text { Level } \\
\text { Elevation } \\
\text { (masl) }^{c}\end{array}$ & $\begin{array}{c}\text { Type } \\
\text { Correction }^{d}\end{array}$ & Source \\
\hline RNM-2s & 954.16 & 219.56 & $\begin{array}{l}-- \\
\end{array}$ & 8/2/1974 & -- & 734.60 & none & database \\
\hline RNM-2s & 954.16 & 221.12 & -- & $3 / 21 / 1980$ & -- & 733.04 & none & database \\
\hline RNM-2s & 954.16 & 221.32 & -- & $6 / 13 / 1980$ & -- & 732.84 & none & database \\
\hline RNM-2s & 954.16 & 221.96 & -- & $9 / 27 / 1990$ & -- & 732.21 & none & database \\
\hline RNM-2s & 954.16 & 222.02 & -- & $10 / 3 / 1990$ & -- & 732.14 & none & database \\
\hline RNM-2s & 954.16 & 221.92 & -- & $10 / 12 / 1990$ & -- & 732.24 & none & database \\
\hline RNM-2s & 954.16 & 221.77 & -- & $10 / 19 / 1990$ & -- & 732.39 & none & database \\
\hline RNM-2s & 954.16 & 221.74 & -- & $10 / 26 / 1990$ & -- & 732.42 & none & database \\
\hline RNM-2s & 954.16 & 221.38 & -- & $11 / 2 / 1990$ & -- & 732.78 & none & database \\
\hline RNM-2s & 954.16 & 221.32 & -- & $11 / 15 / 1990$ & -- & 732.85 & none & database \\
\hline RNM-2s & 954.16 & \begin{tabular}{l|}
-- \\
\end{tabular} & -- & $12 / 12 / 1990$ & $\mathrm{P}$ & \begin{tabular}{l|}
-- \\
\end{tabular} & -- & database \\
\hline RNM-2s & 954.16 & 224.88 & -- & $1 / 10 / 1991$ & -- & 729.28 & none & database \\
\hline RNM-2s & 954.16 & 221.47 & -- & $1 / 16 / 1991$ & -- & 732.69 & none & database \\
\hline RNM-2s & 954.16 & 221.41 & -- & $1 / 24 / 1991$ & -- & 732.75 & none & database \\
\hline RNM-2s & 954.16 & -- & -- & $2 / 5 / 1991$ & $\mathrm{P}$ & \begin{tabular}{l|}
-- \\
\end{tabular} & -- & database \\
\hline RNM-2s & 954.16 & -- & -- & $2 / 21 / 1991$ & $\mathrm{P}$ & -- & -- & database \\
\hline RNM-2s & 954.16 & -- & -- & $4 / 11 / 1991$ & $P$ & -- & -- & database \\
\hline RNM-2s & 954.16 & -- & -- & $4 / 26 / 1991$ & $P$ & -- & -- & database \\
\hline RNM-2s & 954.16 & 221.83 & -- & $5 / 6 / 1991$ & $\mathrm{R}$ & 732.33 & none & database \\
\hline RNM-2s & 954.16 & \begin{tabular}{l|}
-- \\
\end{tabular} & -- & $5 / 17 / 1991$ & $P$ & \begin{tabular}{l|l}
-- & \\
\end{tabular} & -- & database \\
\hline RNM-2s & 954.16 & -- & -- & $5 / 29 / 1991$ & $P$ & -- & -- & database \\
\hline RNM-2s & 954.16 & -- & -- & $6 / 25 / 1991$ & $\mathrm{P}$ & -- & -- & database \\
\hline RNM-2s & 954.16 & -- & -- & $7 / 9 / 1991$ & $\mathrm{P}$ & -- & -- & database \\
\hline RNM-2s & 954.16 & -- & -- & $8 / 16 / 1991$ & $\mathrm{P}$ & -- & -- & database \\
\hline RNM-2s & 954.16 & -- & -- & $8 / 28 / 1991$ & $\mathrm{P}$ & -- & -- & database \\
\hline RNM-2s & 954.16 & 221.53 & -- & 9/27/1991 & -- & 732.63 & none & database \\
\hline RNM-2s & 954.16 & 221.38 & -- & 10/21/1991 & -- & 732.78 & none & database \\
\hline RNM-2s & 954.16 & 221.80 & -- & $11 / 20 / 1991$ & -- & 732.36 & none & database \\
\hline RNM-2s & 954.16 & 221.16 & -- & $12 / 11 / 1991$ & -- & 733.00 & none & database \\
\hline RNM-2s & 954.16 & 221.07 & -- & $1 / 17 / 1992$ & -- & 733.09 & none & database \\
\hline RNM-2s & 954.16 & 221.10 & -- & $2 / 11 / 1992$ & -- & 733.06 & none & database \\
\hline RNM-2s & 954.16 & 221.07 & -- & $3 / 12 / 1992$ & -- & 733.09 & none & database \\
\hline RNM-2s & 954.16 & 220.98 & -- & $4 / 14 / 1992$ & -- & 733.18 & none & database \\
\hline RNM-2s & 954.16 & 220.95 & -- & $5 / 11 / 1992$ & -- & 733.21 & none & database \\
\hline RNM-2s & 954.16 & 220.92 & -- & $6 / 15 / 1992$ & -- & 733.24 & none & database \\
\hline RNM-2s & 954.16 & 220.89 & -- & $7 / 13 / 1992$ & -- & 733.27 & none & database \\
\hline RNM-2s & 954.16 & 220.86 & -- & $8 / 11 / 1992$ & -- & 733.30 & none & database \\
\hline RNM-2s & 954.16 & 220.83 & -- & 9/17/1992 & -- & 733.33 & none & database \\
\hline RNM-2s & 954.16 & 220.77 & -- & 10/14/1992 & -- & 733.39 & none & database \\
\hline
\end{tabular}


Well RNM-2s

Water Level Data

\begin{tabular}{|c|c|c|c|c|c|c|c|c|}
\hline $\begin{array}{c}\text { Well } \\
\text { Reporting } \\
\text { Name }\end{array}$ & $\begin{array}{c}\text { Reference } \\
\text { Point } \\
\text { Elevation } \\
(\mathrm{m})\end{array}$ & $\begin{array}{c}\text { Measured } \\
\text { Depth to } \\
\text { Water } \\
(\mathrm{mbrp})^{\mathrm{a}}\end{array}$ & $\begin{array}{c}\text { Corrected } \\
\text { Depth to } \\
\text { Water } \\
\text { (mbrp) }\end{array}$ & \begin{tabular}{|l|} 
Measure- \\
ment Date
\end{tabular} & $\begin{array}{c}\text { Site } \\
\text { Status }^{b}\end{array}$ & $\begin{array}{c}\text { Water } \\
\text { Level } \\
\text { Elevation } \\
\text { (masl) }^{c}\end{array}$ & $\begin{array}{c}\text { Type } \\
\text { Correction }^{d}\end{array}$ & Source $^{e}$ \\
\hline RNM-2s & 954.16 & 220.83 & -- & 11/24/1992 & -- & 733.33 & none & database \\
\hline RNM-2s & 954.16 & 220.80 & -- & 1/21/1993 & -- & 733.36 & none & database \\
\hline RNM-2s & 954.16 & 220.64 & -- & $2 / 24 / 1993$ & -- & 733.52 & none & database \\
\hline RNM-2s & 954.16 & 220.68 & -- & $3 / 17 / 1993$ & -- & 733.49 & none & database \\
\hline RNM-2s & 954.16 & 220.74 & -- & $4 / 6 / 1993$ & -- & 733.43 & none & database \\
\hline RNM-2s & 954.16 & 220.55 & -- & $6 / 28 / 1993$ & -- & 733.61 & none & database \\
\hline RNM-2s & 954.16 & 220.60 & -- & $7 / 29 / 1993$ & -- & 733.56 & none & database \\
\hline RNM-2s & 954.16 & 221.11 & -- & $12 / 20 / 1993$ & -- & 733.05 & none & database \\
\hline RNM-2s & 954.16 & 220.49 & -- & 2/2/1994 & -- & 733.67 & none & database \\
\hline RNM-2s & 954.16 & 220.49 & -- & $5 / 17 / 1994$ & -- & 733.67 & none & database \\
\hline RNM-2s & 954.16 & 220.49 & -- & $7 / 26 / 1994$ & -- & 733.67 & none & database \\
\hline RNM-2s & 954.16 & 220.54 & -- & $11 / 21 / 1994$ & -- & 733.62 & none & database \\
\hline RNM-2s & 954.16 & 220.54 & -- & $3 / 30 / 1995$ & -- & 733.62 & none & database \\
\hline RNM-2s & 954.16 & 220.53 & -- & $6 / 19 / 1995$ & -- & 733.64 & none & database \\
\hline RNM-2s & 954.16 & 220.52 & -- & $1 / 8 / 1996$ & -- & 733.64 & none & database \\
\hline RNM-2s & 954.16 & 220.49 & -- & 8/21/1997 & -- & 733.67 & none & database \\
\hline RNM-2s & 954.16 & 220.48 & -- & 10/21/1998 & -- & 733.68 & none & database \\
\hline RNM-2s & 954.16 & 220.39 & -- & 4/28/1999 & -- & 733.78 & none & database \\
\hline RNM-2s & 954.16 & 220.67 & -- & $7 / 10 / 2000$ & -- & 733.49 & none & database \\
\hline RNM-2s & 954.16 & 220.52 & -- & $10 / 25 / 2000$ & -- & 733.64 & none & database \\
\hline RNM-2s & 954.16 & 220.49 & -- & \begin{tabular}{|l|}
$4 / 4 / 2001$ \\
\end{tabular} & -- & 733.67 & none & database \\
\hline RNM-2s & 954.16 & 220.52 & -- & $7 / 12 / 2001$ & -- & 733.64 & none & database \\
\hline RNM-2s & 954.16 & 220.49 & -- & $9 / 26 / 2001$ & -- & 733.67 & none & database \\
\hline RNM-2s & 954.16 & 220.44 & -- & $12 / 27 / 2001$ & -- & 733.72 & none & database \\
\hline RNM-2s & 954.16 & 220.50 & -- & $3 / 11 / 2002$ & -- & 733.66 & none & database \\
\hline RNM-2s & 954.16 & 220.49 & -- & $7 / 25 / 2002$ & -- & 733.67 & none & database \\
\hline RNM-2s & 954.16 & 220.44 & -- & 9/10/2002 & -- & 733.72 & none & database \\
\hline RNM-2s & 954.16 & 220.53 & -- & $12 / 30 / 2002$ & -- & 733.64 & none & database \\
\hline RNM-2s & 954.16 & 220.49 & -- & $3 / 10 / 2003$ & -- & 733.67 & none & database \\
\hline RNM-2s & 954.16 & 220.76 & -- & $9 / 25 / 2003$ & $\mathrm{R}$ & 733.40 & none & database \\
\hline RNM-2s & 954.16 & 220.64 & -- & $11 / 20 / 2003$ & -- & 733.52 & none & database \\
\hline RNM-2s & 954.16 & 264.65 & -- & $6 / 6 / 2003$ & Z & 689.51 & none & database \\
\hline RNM-2s & 954.16 & 220.84 & -- & $9 / 12 / 2003$ & Z & 733.32 & none & database \\
\hline RNM-2s & 954.16 & 220.61 & -- & $2 / 18 / 2003$ & -- & 733.55 & none & database \\
\hline RNM-2s & 954.16 & 207.17 & -- & $2 / 18 / 2003$ & Z & 746.99 & none & database \\
\hline RNM-2s & 954.16 & 220.53 & -- & $4 / 12 / 2003$ & Z & 733.64 & none & database \\
\hline RNM-2s & 954.16 & -- & -- & $2 / 18 / 2003$ & $\mathrm{O}$ & \begin{tabular}{l|l}
-- \\
\end{tabular} & none & database \\
\hline RNM-2s & 954.16 & 220.61 & -- & $2 / 18 / 2003$ & -- & 733.55 & none & database \\
\hline RNM-2s & 954.16 & 220.54 & -- & $4 / 18 / 2003$ & Z & 733.62 & none & database \\
\hline
\end{tabular}


Well RNM-2s

Water Level Data

\begin{tabular}{|l|c|c|c|c|c|c|c|c|}
\hline $\begin{array}{c}\text { Well } \\
\text { Reporting } \\
\text { Name }\end{array}$ & $\begin{array}{c}\text { Reference } \\
\text { Point } \\
\text { Elevation } \\
(\mathbf{m})\end{array}$ & $\begin{array}{c}\text { Measured } \\
\text { Depth to } \\
\text { Water } \\
(\mathbf{m b r p})^{\mathbf{a}}\end{array}$ & $\begin{array}{c}\text { Corrected } \\
\text { Depth to } \\
\text { Water } \\
(\mathbf{m b r p})\end{array}$ & $\begin{array}{c}\text { Measure- } \\
\text { ment Date }\end{array}$ & $\begin{array}{c}\text { Site } \\
\text { Status }\end{array}$ & $\begin{array}{c}\text { Water } \\
\text { Level } \\
\text { Elevation }^{(\text {masl })^{\mathbf{c}}}\end{array}$ & $\begin{array}{c}\text { Type } \\
\text { Correction }^{\mathrm{d}}\end{array}$ & Source $^{\mathbf{e}}$ \\
\hline RNM-2s & 954.16 & 225.20 & -- & $9 / 12 / 2003$ & $Z$ & 728.96 & none & database \\
\hline RNM-2s & 954.16 & 220.61 & -- & $3 / 11 / 2004$ & -- & 733.56 & none & USGS website \\
\hline
\end{tabular}

${ }^{\mathrm{a}}$ meters below reference point

${ }^{b}$ Site Status: $O=$ An obstruction was encountered in the well above the water surface (no water level recorded).

$P=$ Site was being pumped.

$\mathrm{R}=$ Site had been pumped recently.

$Z$ = "Other conditions at the well may have affected the water level measurement" (SNJV 2004).

$--=$ Not applicable

${ }^{\mathrm{c}}$ meters above sea level

used to determine historical and contemporary static water level not applicable used to determine historical static water level

used to determine contemporary static water level

${ }^{\mathrm{d}}$ Type Correction: none $=$ no correction made to water level

e Source: database = UGTA borehole database

USGS website $=$ http://nevada.usgs.gov/doe_nv/ 
SM-23-1

Water Level Data

\begin{tabular}{|c|c|c|c|c|c|c|c|c|}
\hline $\begin{array}{c}\text { Well } \\
\text { Reporting } \\
\text { Name }\end{array}$ & \begin{tabular}{|c|} 
Reference \\
Point \\
Elevation \\
$(\mathrm{m})$
\end{tabular} & $\begin{array}{c}\text { Measured } \\
\text { Depth to } \\
\text { Water } \\
\text { (mbrp) }^{\mathrm{a}}\end{array}$ & $\begin{array}{l}\text { Corrected } \\
\text { Depth to } \\
\text { Water } \\
\text { (mbrp) }\end{array}$ & $\begin{array}{c}\text { Measure- } \\
\text { ment Date }\end{array}$ & $\begin{array}{c}\text { Site } \\
\text { Status }\end{array}$ & $\begin{array}{c}\text { Water } \\
\text { Level } \\
\text { Elevation } \\
\text { (masl) }^{c}\end{array}$ & $\begin{array}{c}\text { Type } \\
\text { Correction }^{d}\end{array}$ & Source ${ }^{e}$ \\
\hline SM-23-1 & 1079.91 & 355.00 & -- & $6 / 27 / 1996$ & -- & 724.91 & none & USGS website \\
\hline SM-23-1 & 1079.91 & 355.01 & -- & $6 / 27 / 1996$ & -- & 724.90 & none & USGS website \\
\hline SM-23-1 & 1079.91 & 354.99 & -- & 7/17/1996 & -- & 724.92 & none & USGS website \\
\hline SM-23-1 & 1079.91 & 355.00 & -- & 10/22/1996 & -- & 724.91 & none & USGS website \\
\hline SM-23-1 & 1079.91 & 355.02 & -- & 10/31/1996 & -- & 724.89 & none & USGS website \\
\hline SM-23-1 & 1079.91 & 355.10 & -- & 11/7/1996 & -- & 724.81 & none & USGS website \\
\hline SM-23-1 & 1079.91 & 354.99 & -- & 12/10/1996 & -- & 724.92 & none & USGS website \\
\hline SM-23-1 & 1079.91 & 355.00 & -- & 1/8/1997 & -- & 724.91 & none & USGS website \\
\hline SM-23-1 & 1079.91 & 354.95 & -- & $2 / 4 / 1997$ & -- & 724.96 & none & USGS website \\
\hline SM-23-1 & 1079.91 & 354.90 & -- & $3 / 3 / 1997$ & -- & 725.01 & none & USGS website \\
\hline SM-23-1 & 1079.91 & 355.00 & -- & 4/7/1997 & -- & 724.91 & none & USGS website \\
\hline SM-23-1 & 1079.91 & 354.93 & -- & $5 / 1 / 1997$ & -- & 724.98 & none & USGS website \\
\hline SM-23-1 & 1079.91 & 354.94 & -- & $6 / 3 / 1997$ & -- & 724.97 & none & USC \\
\hline SM-23-1 & 1079.91 & 354.95 & -- & 7/9/1997 & -- & 724.96 & none & USGS website \\
\hline SM-23-1 & 1079.91 & 354.98 & -- & $7 / 28 / 1997$ & -- & 724.93 & none & USGS we \\
\hline SM-23-1 & & 354.95 & -- & 9/29/1997 & -- & 724.96 & one & site \\
\hline SM-23-1 & 1079.91 & 354.95 & -- & 10/21/1997 & -- & 724.96 & none & USGS we \\
\hline SM-23-1 & 1079.91 & 354.95 & -- & 12/15/1997 & -- & 724.96 & none & USGS website \\
\hline SM-23-1 & & 55.02 & -- & & -- & 724.89 & & \\
\hline SM-23-1 & 1079.91 & 354.94 & -- & 6/18/1998 & -- & 724.97 & none & USGS website \\
\hline SM-23-1 & 1079.91 & 354.86 & -- & 9/29/1998 & -- & 725.05 & none & USGS website \\
\hline SM-23-1 & 1079.91 & 354.86 & -- & 12/14/1998 & -- & 725.05 & & osite \\
\hline SM-23-1 & 79.91 & 354.87 & -- & $3 / 17 / 1999$ & -- & 725.04 & none & USGS website \\
\hline SM-23-1 & 1079.91 & 354.87 & -- & $6 / 30 / 1999$ & -- & 725.04 & none & USGS website \\
\hline SM-23-1 & 1079.91 & 354.88 & -- & 9/16/1999 & -- & 725.03 & one & S website \\
\hline SM-23-1 & 1079.91 & 354.96 & -- & $12 / 8 / 1999$ & -- & 724.95 & none & USGS website \\
\hline SM-23-1 & 1079.91 & 354.90 & -- & $4 / 5 / 2000$ & -- & 725.01 & none & USGS website \\
\hline SM-23-1 & 1079.91 & 354.90 & -- & $10 / 3 / 2000$ & -- & 725.01 & none & USGS website \\
\hline SM-23-1 & 1079.91 & 354.87 & -- & $12 / 7 / 2000$ & -- & 725.04 & none & USGS website \\
\hline SM-23-1 & 1079.91 & 354.88 & -- & 9/27/2001 & -- & 725.03 & none & USGS website \\
\hline SM-23-1 & 1079.91 & 355.00 & -- & 12/13/2001 & -- & 724.91 & none & USGS website \\
\hline SM-23-1 & 1079.91 & 354.81 & -- & 3/13/2002 & -- & 725.10 & none & USGS website \\
\hline SM-23-1 & 1079.91 & 354.92 & -- & $7 / 29 / 2002$ & -- & 724.99 & none & USGS website \\
\hline SM-23-1 & 1079.91 & 354.89 & -- & 9/11/2002 & -- & 725.02 & none & USGS website \\
\hline SM-23-1 & 1079.91 & 354.89 & -- & $12 / 31 / 2002$ & -- & 725.02 & none & USGS website \\
\hline SM-23-1 & 1079.91 & 354.92 & -- & $3 / 20 / 2003$ & -- & 724.99 & none & USGS website \\
\hline SM-23-1 & 1079.91 & 354.92 & -- & $6 / 24 / 2003$ & -- & 724.99 & none & USGS website \\
\hline SM-23-1 & 1079.91 & 354.90 & -- & 9/29/2003 & -- & 725.01 & none & USGS website \\
\hline SM-23-1 & 1079.91 & 354.91 & -- & 11/24/2003 & -- & 725.00 & none & USGS website \\
\hline SM-23-1 & 1079.91 & 354.92 & -- & $3 / 11 / 2004$ & -- & 724.99 & none & USGS website \\
\hline
\end{tabular}


SM-23-1

Water Level Data

${ }^{a}$ meters below reference point

bite Status: -- = Not applicable

${ }^{c}$ meters above sea level

used to determine historical and contemporary static water le I not applicable

used to determine historical static water level not applicable

used to determine contemporary static water level

d Type Correction: none $=$ no correction made to water level

${ }^{\text {e}}$ Source: USGS website = http://nevada.usgs.gov/doe_nv/ 
Well TW-3

Water Level Data

\begin{tabular}{|c|c|c|c|c|c|c|c|c|}
\hline $\begin{array}{c}\text { Well } \\
\text { Reporting } \\
\text { Name }\end{array}$ & $\begin{array}{c}\text { Reference } \\
\text { Point } \\
\text { Elevation } \\
(\mathrm{m}) \\
\end{array}$ & $\begin{array}{c}\text { Measured } \\
\text { Depth to } \\
\text { Water } \\
(\text { mbrp) } \\
\end{array}$ & $\begin{array}{l}\text { Corrected } \\
\text { Depth to } \\
\text { Water } \\
\text { (mbrp) }\end{array}$ & $\begin{array}{c}\text { Measure- } \\
\text { ment Date }\end{array}$ & $\begin{array}{c}\text { Site } \\
\text { Status }^{b}\end{array}$ & $\begin{array}{c}\text { Water } \\
\text { Level } \\
\text { Elevation } \\
\text { (masl) }^{c}\end{array}$ & $\begin{array}{c}\text { Type } \\
\text { Correction }^{\mathrm{d}}\end{array}$ & Source \\
\hline TW-3 & 1061.96 & 336.22 & -- & $5 / 9 / 1962$ & $\mathrm{C}$ & 725.73 & none & database \\
\hline TW-3 & 1061.96 & 335.95 & -- & $5 / 10 / 1962$ & $\mathrm{C}$ & 726.01 & none & database \\
\hline TW-3 & 1061.96 & 336.32 & -- & $1 / 25 / 1963$ & -- & 725.64 & none & database \\
\hline TW-3 & 1061.96 & 336.07 & -- & 12/12/1963 & -- & 725.89 & none & database \\
\hline TW-3 & 1061.96 & 336.22 & -- & $3 / 20 / 1971$ & -- & 725.73 & none & database \\
\hline TW-3 & 1061.96 & 336.10 & -- & 10/27/1971 & -- & 725.86 & none & database \\
\hline TW-3 & 1061.96 & 336.35 & -- & 7/27/1972 & -- & 725.61 & none & database \\
\hline TW-3 & 1061.96 & 336.71 & -- & $1 / 27 / 1973$ & -- & 725.25 & none & database \\
\hline TW-3 & 1061.96 & 336.71 & -- & $8 / 22 / 1978$ & -- & 725.25 & none & database \\
\hline TW-3 & 1061.96 & 336.38 & -- & $1 / 11 / 1980$ & -- & 725.58 & none & database \\
\hline TW-3 & 1061.96 & 335.83 & -- & $6 / 9 / 1990$ & -- & 726.13 & none & database \\
\hline TW-3 & 1061.96 & 336.26 & -- & 11/16/1990 & -- & 725.70 & none & database \\
\hline TW-3 & 1061.96 & 336.26 & -- & 4/26/1991 & -- & 725.70 & none & database \\
\hline TW-3 & 1061.96 & 336.32 & -- & 9/27/1991 & -- & 725.64 & none & database \\
\hline TW-3 & 1061.96 & 336.35 & -- & $5 / 11 / 1992$ & -- & 725.61 & none & database \\
\hline TW-3 & 1061.96 & 336.52 & -- & $1 / 19 / 1994$ & -- & 725.44 & none & database \\
\hline TW-3 & 1061.96 & 336.54 & -- & $5 / 16 / 1994$ & -- & 725.42 & none & database \\
\hline TW-3 & 1061.96 & 336.54 & -- & $11 / 21 / 1994$ & -- & 725.42 & none & database \\
\hline TW-3 & 1061.96 & 336.61 & -- & $6 / 19 / 1995$ & -- & 725.35 & none & database \\
\hline TW-3 & 1061.96 & 336.63 & -- & $1 / 4 / 1996$ & -- & 725.33 & none & database \\
\hline TW-3 & 1061.96 & 336.62 & -- & $7 / 29 / 1996$ & -- & 725.34 & none & database \\
\hline TW-3 & 1061.96 & 336.61 & -- & $8 / 21 / 1997$ & -- & 725.35 & none & database \\
\hline TW-3 & 1061.96 & 336.60 & -- & $3 / 9 / 1998$ & -- & 725.36 & none & database \\
\hline TW-3 & 1061.96 & 336.86 & -- & $4 / 28 / 1999$ & -- & 725.10 & none & database \\
\hline TW-3 & 1061.96 & 336.52 & -- & $11 / 15 / 1999$ & -- & 725.44 & none & database \\
\hline TW-3 & 1061.96 & 336.64 & -- & $7 / 10 / 2000$ & -- & 725.32 & none & database \\
\hline TW-3 & 1061.96 & 336.53 & -- & $10 / 25 / 2000$ & -- & 725.43 & none & database \\
\hline TW-3 & 1061.96 & 336.44 & -- & $1 / 22 / 2002$ & -- & 725.52 & none & database \\
\hline
\end{tabular}

${ }^{a}$ meters below reference point

${ }^{\mathrm{b}}$ Site Status: $\mathrm{C}=$ Water level was measured prior to well completion.

$--=$ Not applicable

${ }^{\mathrm{c}}$ meters above sea level

\section{used to determine historical and contemporary static water level}

\section{used to determine historical static water level not applicable}

used to determine contemporary static water level not applicable

d Type Correction: none $=$ no correction made to water level

${ }^{e}$ Source: database $=$ UGTA borehole database 
TW-F

Water-Level Data

\begin{tabular}{|c|c|c|c|c|c|c|c|c|}
\hline $\begin{array}{c}\text { Well } \\
\text { Reporting } \\
\text { Name }\end{array}$ & $\begin{array}{c}\text { Reference } \\
\text { Point } \\
\text { Elevation } \\
(\mathrm{m})\end{array}$ & $\begin{array}{c}\text { Measured } \\
\text { Depth to } \\
\text { Water } \\
(\text { mbrp) }\end{array}$ & $\begin{array}{c}\text { Corrected } \\
\text { Depth to } \\
\text { Water } \\
\text { (mbrp) }\end{array}$ & $\begin{array}{l}\text { Measure- } \\
\text { ment Date }\end{array}$ & $\begin{array}{c}\text { Site } \\
\text { Status }^{b}\end{array}$ & $\begin{array}{c}\text { Water } \\
\text { Level } \\
\text { Elevation } \\
\text { (masl) }^{c}\end{array}$ & $\begin{array}{c}\text { Type } \\
\text { Correction }^{d}\end{array}$ & Source ${ }^{e}$ \\
\hline TW-F & 1262.69 & 529.10 & 532.31 & $6 / 28 / 1962$ & -- & 730.38 & $\mathrm{BD}, \mathrm{WT}$ & database \\
\hline TW-F & 1262.69 & 529.13 & 532.34 & 6/28/1962 & -- & 730.35 & $\mathrm{BD}, \mathrm{WT}$ & database \\
\hline TW-F & 1262.69 & 529.10 & 532.31 & $6 / 28 / 1962$ & -- & 730.38 & $\mathrm{BD}, \mathrm{WT}$ & database \\
\hline TW-F & 1262.69 & 528.86 & 532.07 & 8/7/1962 & -- & 730.62 & $\mathrm{BD}, \mathrm{WT}$ & database \\
\hline TW-F & 1262.69 & 528.92 & 532.13 & $8 / 11 / 1962$ & -- & 730.56 & $\mathrm{BD}, \mathrm{WT}$ & database \\
\hline TW-F & 1262.69 & 528.71 & 531.92 & $1 / 24 / 1963$ & -- & 730.77 & $\mathrm{BD}, \mathrm{WT}$ & database \\
\hline TW-F & 1262.69 & 528.71 & 531.92 & $1 / 24 / 1963$ & -- & 730.77 & $\mathrm{BD}, \mathrm{WT}$ & database \\
\hline TW-F & 1262.69 & 528.71 & 531.92 & $1 / 24 / 1963$ & -- & 730.77 & $\mathrm{BD}, \mathrm{WT}$ & database \\
\hline TW-F & 1262.69 & 528.95 & 532.16 & 12/17/1963 & -- & 730.53 & $\mathrm{BD}, \mathrm{WT}$ & database \\
\hline TW-F & 1262.69 & 528.71 & 531.92 & $1 / 28 / 1965$ & -- & 730.77 & $\mathrm{BD}, \mathrm{WT}$ & database \\
\hline TW-F & 1262.69 & 529.38 & 532.59 & 10/27/1971 & -- & 730.11 & $\mathrm{BD}, \mathrm{WT}$ & database \\
\hline TW-F & 1262.69 & 529.47 & 532.68 & $8 / 12 / 1972$ & -- & 730.02 & $\mathrm{BD}, \mathrm{WT}$ & database \\
\hline TW-F & 1262.69 & 529.44 & 532.65 & $1 / 23 / 1973$ & -- & 730.05 & $\mathrm{BD}, \mathrm{WT}$ & database \\
\hline TW-F & 1262.69 & 529.01 & 532.22 & $1 / 15 / 1980$ & -- & 730.47 & $\mathrm{BD}, \mathrm{WT}$ & database \\
\hline TW-F & 1262.69 & 528.92 & 532.13 & $3 / 27 / 1980$ & -- & 730.56 & $\mathrm{BD}, \mathrm{WT}$ & database \\
\hline TW-F & 1262.69 & 528.49 & 531.71 & $1 / 14 / 1986$ & -- & 730.98 & $\mathrm{BD}, \mathrm{WT}$ & database \\
\hline TW-F & 1262.69 & 528.46 & 531.68 & $7 / 2 / 1987$ & -- & 731.02 & $\mathrm{BD}, \mathrm{WT}$ & database \\
\hline TW-F & 1262.69 & 529.01 & 532.22 & $3 / 30 / 1988$ & -- & 730.47 & $\mathrm{BD}, \mathrm{WT}$ & database \\
\hline TW-F & 1262.69 & 528.86 & 532.07 & 12/22/1988 & -- & 730.62 & $\mathrm{BD}, \mathrm{WT}$ & database \\
\hline TW-F & 1262.69 & 528.77 & 531.98 & $7 / 20 / 1989$ & -- & 730.71 & $\mathrm{BD}, \mathrm{WT}$ & database \\
\hline TW-F & 1262.69 & 528.86 & 532.07 & 10/26/1989 & -- & 730.62 & $\mathrm{BD}, \mathrm{WT}$ & database \\
\hline TW-F & 1262.69 & 528.68 & 531.89 & $5 / 2 / 1990$ & -- & 730.80 & $\mathrm{BD}, \mathrm{WT}$ & database \\
\hline TW-F & 1262.69 & 528.71 & 531.92 & $4 / 26 / 1991$ & -- & 730.77 & $\mathrm{BD}, \mathrm{WT}$ & database \\
\hline TW-F & 1262.69 & 528.68 & 531.89 & 9/27/1991 & -- & 730.80 & $\mathrm{BD}, \mathrm{WT}$ & database \\
\hline TW-F & 1262.69 & 529.04 & 532.25 & $5 / 11 / 1992$ & -- & 730.44 & $\mathrm{BD}, \mathrm{WT}$ & database \\
\hline TW-F & 1262.69 & 529.32 & 532.53 & $7 / 21 / 1993$ & -- & 730.17 & $\mathrm{BD}, \mathrm{WT}$ & database \\
\hline TW-F & 1262.69 & 529.38 & 532.59 & $1 / 19 / 1994$ & -- & 730.11 & $\mathrm{BD}, \mathrm{WT}$ & database \\
\hline TW-F & 1262.69 & 529.25 & 532.47 & $5 / 17 / 1994$ & -- & 730.23 & $\mathrm{BD}, \mathrm{WT}$ & database \\
\hline TW-F & 1262.69 & 529.38 & 532.59 & $11 / 21 / 1994$ & -- & 730.11 & $\mathrm{BD}, \mathrm{WT}$ & database \\
\hline TW-F & 1262.69 & 529.41 & 532.62 & 6/29/1995 & -- & 730.08 & $\mathrm{BD}, \mathrm{WT}$ & database \\
\hline TW-F & 1262.69 & 529.19 & 532.41 & $7 / 30 / 1996$ & -- & 730.29 & $\mathrm{BD}, \mathrm{WT}$ & database \\
\hline TW-F & 1262.69 & 529.07 & 532.28 & $8 / 21 / 1997$ & -- & 730.41 & $\mathrm{BD}, \mathrm{WT}$ & database \\
\hline TW-F & 1262.69 & 528.98 & 532.19 & $3 / 5 / 1998$ & -- & 730.50 & $\mathrm{BD}, \mathrm{WT}$ & database \\
\hline TW-F & 1262.69 & 529.01 & 532.22 & 12/1/1998 & -- & 730.47 & $\mathrm{BD}, \mathrm{WT}$ & database \\
\hline TW-F & 1262.69 & 528.95 & 532.16 & $5 / 27 / 1999$ & -- & 730.53 & $\mathrm{BD}, \mathrm{WT}$ & database \\
\hline TW-F & 1262.69 & 528.75 & 531.96 & 11/17/1999 & -- & 730.73 & $\mathrm{BD}, \mathrm{WT}$ & database \\
\hline TW-F & 1262.69 & 529.14 & 532.35 & $7 / 12 / 2000$ & -- & 730.34 & $\mathrm{BD}, \mathrm{WT}$ & database \\
\hline TW-F & 1262.69 & 528.98 & 532.19 & $10 / 26 / 2000$ & -- & 730.50 & $\mathrm{BD}, \mathrm{WT}$ & database \\
\hline TW-F & 1262.69 & 529.01 & 532.23 & 10/24/2001 & -- & 730.47 & $\mathrm{BD}, \mathrm{WT}$ & database \\
\hline
\end{tabular}


TW-F

Water-Level Data

\begin{tabular}{|c|c|c|c|c|c|c|c|c|}
\hline $\begin{array}{c}\text { Well } \\
\text { Reporting } \\
\text { Name }\end{array}$ & $\begin{array}{c}\text { Reference } \\
\text { Point } \\
\text { Elevation } \\
(\mathrm{m}) \\
\end{array}$ & $\begin{array}{c}\text { Measured } \\
\text { Depth to } \\
\text { Water } \\
(\mathrm{mbrp})^{\mathrm{a}} \\
\end{array}$ & $\begin{array}{c}\text { Corrected } \\
\text { Depth to } \\
\text { Water } \\
\text { (mbrp) } \\
\end{array}$ & $\begin{array}{c}\text { Measure- } \\
\text { ment Date }\end{array}$ & $\begin{array}{c}\text { Site } \\
\text { Status }^{b}\end{array}$ & $\begin{array}{c}\text { Water } \\
\text { Level } \\
\text { Elevation } \\
\text { (masl) }^{c}\end{array}$ & $\begin{array}{c}\text { Type } \\
\text { Correction }^{d}\end{array}$ & Source ${ }^{e}$ \\
\hline TW-F & 1262.69 & 529.00 & 532.21 & $7 / 23 / 2002$ & -- & 730.48 & $\mathrm{BD}, \mathrm{WT}$ & database \\
\hline TW-F & 1262.69 & 529.08 & 532.30 & 12/9/2002 & -- & 730.40 & $\mathrm{BD}, \mathrm{WT}$ & database \\
\hline TW-F & 1262.69 & 529.00 & 532.21 & $3 / 11 / 2003$ & - & 730.49 & $\mathrm{BD}, \mathrm{WT}$ & database \\
\hline TW-F & 1262.69 & 529.03 & 532.24 & $6 / 25 / 2003$ & -- & 730.45 & $\mathrm{BD}, \mathrm{WT}$ & database \\
\hline TW-F & 1262.69 & 528.97 & 532.19 & 7/14/2003 & -- & 730.51 & $\mathrm{BD}, \mathrm{WT}$ & database \\
\hline TW-F & 1262.69 & 528.97 & 532.19 & $7 / 14 / 2003$ & -- & 730.51 & $\mathrm{BD}, \mathrm{WT}$ & database \\
\hline TW-F & 1262.69 & 528.95 & 532.17 & $10 / 2 / 2003$ & -- & 730.53 & $\mathrm{BD}, \mathrm{WT}$ & database \\
\hline TW-F & 1262.69 & 528.98 & 532.20 & $1 / 12 / 2004$ & -- & 730.50 & $\mathrm{BD}, \mathrm{WT}$ & database \\
\hline TW-F & 1262.69 & 528.83 & 532.04 & $4 / 1 / 2004$ & -- & 730.65 & $\mathrm{BD}, \mathrm{WT}$ & USGS website \\
\hline
\end{tabular}

${ }^{a}$ meters below reference point

bite Status: -- = Not applicable

${ }^{c}$ meters above sea level

used to determine historical and contemporary static water level

used to determine historical static water level

not applicable

used to determine contemporary static water level not applicable

${ }^{\mathrm{d}}$ Type Correction: $\mathrm{BD}=$ water level corrected for borehole deviation

WT $=$ water level corrected for water temperature

eSource: database = UGTA borehole database

USGS website $=$ http://nevada.usgs.gov/doe_nv/ 
UE-5 PW-1

Water-Level Data

\begin{tabular}{|c|c|c|c|c|c|c|c|c|}
\hline $\begin{array}{c}\text { Well } \\
\text { Reporting } \\
\text { Name }\end{array}$ & \begin{tabular}{|c|} 
Reference \\
Point \\
Elevation \\
(m)
\end{tabular} & $\begin{array}{c}\text { Measured } \\
\text { Depth to } \\
\text { Water } \\
(\mathrm{mbrp})^{\mathrm{a}}\end{array}$ & $\begin{array}{c}\text { Corrected } \\
\text { Depth to } \\
\text { Water } \\
\text { (mbrp) }\end{array}$ & $\begin{array}{l}\text { Measure- } \\
\text { ment Date }\end{array}$ & $\begin{array}{c}\text { Site } \\
\text { Status }^{b}\end{array}$ & $\begin{array}{c}\text { Water } \\
\text { Level } \\
\text { Elevation } \\
\text { (masl) }^{c}\end{array}$ & $\begin{array}{c}\text { Type } \\
\text { Correction }^{\mathrm{d}}\end{array}$ & Source ${ }^{e}$ \\
\hline UE-5 PW-1 & 968.73 & 235.09 & 235.01 & $3 / 2 / 1993$ & -- & 733.72 & $\mathrm{BD}$ & database \\
\hline UE-5 PW-1 & 968.73 & 235.00 & 234.92 & $3 / 17 / 1993$ & -- & 733.81 & $\mathrm{BD}$ & database \\
\hline UE-5 PW-1 & 968.73 & 234.99 & 234.91 & $3 / 22 / 1993$ & -- & 733.82 & $B D$ & Bechtel \\
\hline UE-5 PW-1 & 968.73 & 234.96 & 234.88 & $3 / 23 / 1993$ & -- & 733.85 & $B D$ & Bechtel \\
\hline UE-5 PW-1 & 968.73 & 234.97 & 234.89 & $3 / 24 / 1993$ & -- & 733.84 & $\mathrm{BD}$ & Bechtel \\
\hline UE-5 PW-1 & 968.73 & 234.96 & 234.88 & $3 / 25 / 1993$ & -- & 733.85 & $B D$ & Bechtel \\
\hline UE-5 PW-1 & 968.73 & 235.00 & 234.91 & $3 / 29 / 1993$ & -- & 733.81 & $B D$ & database \\
\hline UE-5 PW-1 & 968.73 & 235.03 & 234.95 & $3 / 29 / 1993$ & -- & 733.78 & $B D$ & Bechtel \\
\hline UE-5 PW-1 & 968.73 & 235.06 & 234.98 & $3 / 30 / 1993$ & -- & 733.75 & $B D$ & Bechtel \\
\hline UE-5 PW-1 & 968.73 & 235.06 & 234.98 & $3 / 31 / 1993$ & -- & 733.75 & $\mathrm{BD}$ & Bechtel \\
\hline UE-5 PW-1 & 968.73 & 234.98 & 234.90 & $4 / 1 / 1993$ & -- & 733.83 & $B D$ & Bechtel \\
\hline UE-5 PW-1 & 968.73 & 234.95 & 234.87 & $4 / 5 / 1993$ & -- & 733.86 & $B D$ & Bechtel \\
\hline UE-5 PW-1 & 968.73 & 235.06 & 234.98 & $4 / 6 / 1993$ & -- & 733.75 & $B D$ & database \\
\hline UE-5 PW-1 & 968.73 & 235.03 & 234.95 & $4 / 6 / 1993$ & -- & 733.78 & $B D$ & Bechtel \\
\hline UE-5 PW-1 & 968.73 & 235.08 & 235.00 & $5 / 10 / 1993$ & -- & 733.73 & $\mathrm{BD}$ & Bechtel \\
\hline UE-5 PW-1 & 968.73 & 235.00 & 234.92 & $5 / 11 / 1993$ & -- & 733.81 & $B D$ & Bechtel \\
\hline UE-5 PW-1 & 968.73 & 234.98 & 234.90 & $5 / 12 / 1993$ & -- & 733.83 & $\mathrm{BD}$ & Bechtel \\
\hline UE-5 PW-1 & 968.73 & 235.05 & 234.97 & $5 / 13 / 1993$ & -- & 733.76 & $B D$ & Bechtel \\
\hline UE-5 PW-1 & 968.73 & 235.05 & 234.97 & $5 / 17 / 1993$ & -- & 733.76 & $\mathrm{BD}$ & Bechtel \\
\hline UE-5 PW-1 & 968.73 & 235.03 & 234.95 & $5 / 18 / 1993$ & -- & 733.78 & $\mathrm{BD}$ & Bechtel \\
\hline UE-5 PW-1 & 968.73 & 235.03 & 234.95 & $5 / 19 / 1993$ & -- & 733.78 & $\mathrm{BD}$ & Bechtel \\
\hline UE-5 PW-1 & 968.73 & 234.98 & 234.90 & $5 / 20 / 1993$ & -- & 733.83 & $B D$ & Bechtel \\
\hline UE-5 PW-1 & 968.73 & 235.04 & 234.96 & $5 / 24 / 1993$ & -- & 733.77 & $\mathrm{BD}$ & Bechtel \\
\hline UE-5 PW-1 & 968.73 & 235.05 & 234.97 & $5 / 25 / 1993$ & -- & 733.76 & $B D$ & Bechtel \\
\hline UE-5 PW-1 & 968.73 & 235.02 & 234.94 & $6 / 1 / 1993$ & -- & 733.79 & $B D$ & Bechtel \\
\hline UE-5 PW-1 & 968.73 & 235.08 & 235.00 & 6/7/1993 & -- & 733.73 & $B D$ & Bechtel \\
\hline UE-5 PW-1 & 968.73 & 235.05 & 234.97 & $6 / 14 / 1993$ & -- & 733.76 & $B D$ & Bechtel \\
\hline UE-5 PW-1 & 968.73 & 235.02 & 234.94 & $6 / 21 / 1993$ & -- & 733.79 & $B D$ & Bechtel \\
\hline UE-5 PW-1 & 968.73 & 235.03 & 234.95 & $7 / 26 / 1993$ & -- & 733.78 & $B D$ & Bechtel \\
\hline UE-5 PW-1 & 968.73 & 234.98 & 234.90 & $8 / 3 / 1993$ & -- & 733.83 & $B D$ & Bechtel \\
\hline UE-5 PW-1 & 968.73 & 235.06 & 234.98 & $8 / 9 / 1993$ & -- & 733.75 & $B D$ & Bechtel \\
\hline UE-5 PW-1 & 968.73 & 235.03 & 234.95 & $8 / 16 / 1993$ & -- & 733.78 & $B D$ & Bechtel \\
\hline UE-5 PW-1 & 968.73 & 235.02 & 234.94 & $8 / 30 / 1993$ & -- & 733.79 & $B D$ & Bechtel \\
\hline UE-5 PW-1 & 968.73 & 235.03 & 234.95 & $12 / 28 / 1993$ & -- & 733.78 & $B D$ & Bechtel \\
\hline UE-5 PW-1 & 968.73 & 235.01 & 234.93 & \begin{tabular}{|l|}
$1 / 3 / 1994$ \\
\end{tabular} & -- & 733.80 & $B D$ & Bechtel \\
\hline UE-5 PW-1 & 968.73 & 234.97 & 234.89 & $2 / 2 / 1994$ & -- & 733.84 & $\mathrm{BD}$ & Bechtel \\
\hline UE-5 PW-1 & 968.73 & 235.04 & 234.96 & $2 / 22 / 1994$ & -- & 733.77 & $\mathrm{BD}$ & Bechtel \\
\hline UE-5 PW-1 & 968.73 & 235.03 & 234.95 & $2 / 28 / 1994$ & -- & 733.78 & $B D$ & Bechtel \\
\hline UE-5 PW-1 & 968.73 & 234.98 & 234.90 & $3 / 7 / 1994$ & -- & 733.83 & $B D$ & Bechtel \\
\hline UE-5 PW-1 & 968.73 & 234.99 & 234.91 & $3 / 14 / 1994$ & -- & 733.82 & $\mathrm{BD}$ & Bechtel \\
\hline UE-5 PW-1 & 968.73 & 235.00 & 234.92 & 3/21/1994 & -- & 733.81 & $\mathrm{BD}$ & Bechtel \\
\hline
\end{tabular}


UE-5 PW-1

Water-Level Data

\begin{tabular}{|c|c|c|c|c|c|c|c|c|}
\hline $\begin{array}{c}\text { Well } \\
\text { Reporting } \\
\text { Name }\end{array}$ & \begin{tabular}{|c|} 
Reference \\
Point \\
Elevation \\
$(m)$
\end{tabular} & $\begin{array}{c}\text { Measured } \\
\text { Depth to } \\
\text { Water } \\
(\mathrm{mbrp})^{\mathrm{a}}\end{array}$ & $\begin{array}{c}\text { Corrected } \\
\text { Depth to } \\
\text { Water } \\
\text { (mbrp) }\end{array}$ & \begin{tabular}{|l|} 
\\
Measure- \\
ment Date
\end{tabular} & $\begin{array}{c}\text { Site } \\
\text { Status }^{b}\end{array}$ & $\begin{array}{c}\text { Water } \\
\text { Level } \\
\text { Elevation } \\
\text { (masl) }^{c} \\
\end{array}$ & $\begin{array}{c}\text { Type } \\
\text { Correction }^{d}\end{array}$ & Source ${ }^{e}$ \\
\hline UE-5 PW-1 & 968.73 & 235.07 & 234.99 & $3 / 28 / 1994$ & -- & 733.74 & $\mathrm{BD}$ & Bechtel \\
\hline UE-5 PW-1 & 968.73 & 234.96 & 234.88 & $4 / 4 / 1994$ & -- & 733.85 & $\mathrm{BD}$ & Bechtel \\
\hline UE-5 PW-1 & 968.73 & 234.99 & 234.91 & $4 / 13 / 1994$ & -- & 733.82 & $\mathrm{BD}$ & Bechtel \\
\hline UE-5 PW-1 & 968.73 & 234.95 & 234.87 & $4 / 20 / 1994$ & -- & 733.86 & $\mathrm{BD}$ & Bechtel \\
\hline UE-5 PW-1 & 968.73 & 234.99 & 234.91 & $4 / 26 / 1994$ & -- & 733.82 & $\mathrm{BD}$ & Bechtel \\
\hline UE-5 PW-1 & 968.73 & 235.06 & 234.98 & $1 / 18 / 1995$ & -- & 733.75 & $\mathrm{BD}$ & Bechtel \\
\hline UE-5 PW-1 & 968.73 & 235.01 & 234.93 & $4 / 3 / 1995$ & -- & 733.80 & $\mathrm{BD}$ & Bechtel \\
\hline UE-5 PW-1 & 968.73 & 234.80 & 234.72 & $1 / 16 / 1996$ & -- & 734.01 & $\mathrm{BD}$ & Bechtel \\
\hline UE-5 PW-1 & 968.73 & 235.00 & 234.92 & $4 / 15 / 1996$ & -- & 733.81 & $\mathrm{BD}$ & Bechtel \\
\hline UE-5 PW-1 & 968.73 & 234.98 & 234.90 & $10 / 1 / 1996$ & -- & 733.83 & $\mathrm{BD}$ & Bechtel \\
\hline UE-5 PW-1 & 968.73 & 235.03 & 234.95 & $11 / 19 / 1996$ & -- & 733.78 & $\mathrm{BD}$ & Bechtel \\
\hline UE-5 PW-1 & 968.73 & 234.98 & 234.90 & $3 / 3 / 1997$ & -- & 733.83 & $\mathrm{BD}$ & Bechtel \\
\hline UE-5 PW-1 & 968.73 & 235.07 & 234.99 & $4 / 15 / 1997$ & -- & 733.74 & $\mathrm{BD}$ & Bechtel \\
\hline UE-5 PW-1 & 968.73 & 235.05 & 234.97 & $6 / 18 / 1997$ & -- & 733.76 & $\mathrm{BD}$ & Bechtel \\
\hline UE-5 PW-1 & 968.73 & 235.04 & 234.96 & $7 / 28 / 1997$ & -- & 733.77 & $\mathrm{BD}$ & Bechtel \\
\hline UE-5 PW-1 & 968.73 & 234.96 & 234.88 & $8 / 20 / 1997$ & -- & 733.85 & $\mathrm{BD}$ & Bechtel \\
\hline UE-5 PW-1 & 968.73 & 235.03 & 234.95 & 9/25/1997 & -- & 733.78 & $\mathrm{BD}$ & Bechtel \\
\hline UE-5 PW-1 & 968.73 & 235.01 & 234.93 & $10 / 27 / 1997$ & -- & 733.80 & $\mathrm{BD}$ & Bechtel \\
\hline UE-5 PW-1 & 968.73 & 235.09 & 235.01 & $11 / 3 / 1997$ & -- & 733.72 & $\mathrm{BD}$ & Bechtel \\
\hline UE-5 PW-1 & 968.73 & 235.01 & 234.93 & $11 / 6 / 1997$ & -- & 733.80 & $\mathrm{BD}$ & Bechtel \\
\hline UE-5 PW-1 & 968.73 & 235.10 & 235.02 & $11 / 12 / 1997$ & -- & 733.71 & $\mathrm{BD}$ & Bechtel \\
\hline UE-5 PW-1 & 968.73 & 235.04 & 234.96 & $11 / 13 / 1997$ & -- & 733.77 & $\mathrm{BD}$ & Bechtel \\
\hline UE-5 PW-1 & 968.73 & 235.07 & 234.99 & $11 / 19 / 1997$ & -- & 733.74 & $\mathrm{BD}$ & Bechtel \\
\hline UE-5 PW-1 & 968.73 & 235.09 & 235.01 & $11 / 20 / 1997$ & -- & 733.72 & $\mathrm{BD}$ & Bechtel \\
\hline UE-5 PW-1 & 968.73 & 235.08 & 235.00 & $11 / 25 / 1997$ & -- & 733.73 & $\mathrm{BD}$ & Bechtel \\
\hline UE-5 PW-1 & 968.73 & 234.94 & 234.86 & $11 / 26 / 1997$ & -- & 733.87 & $\mathrm{BD}$ & Bechtel \\
\hline UE-5 PW-1 & 968.73 & 235.15 & 235.07 & $12 / 3 / 1997$ & -- & 733.66 & $\mathrm{BD}$ & Bechtel \\
\hline UE-5 PW-1 & 968.73 & 235.16 & 235.08 & $1 / 26 / 1998$ & -- & 733.65 & $\mathrm{BD}$ & Bechtel \\
\hline UE-5 PW-1 & 968.73 & 235.04 & 234.96 & $5 / 12 / 1998$ & -- & 733.77 & $\mathrm{BD}$ & Bechtel \\
\hline UE-5 PW-1 & 968.73 & 234.96 & 234.88 & $10 / 27 / 1998$ & -- & 733.85 & $\mathrm{BD}$ & Bechtel \\
\hline UE-5 PW-1 & 968.73 & 234.98 & 234.90 & 12/22/1998 & -- & 733.83 & $\mathrm{BD}$ & Bechtel \\
\hline UE-5 PW-1 & 968.73 & 235.05 & 234.97 & $2 / 2 / 1999$ & -- & 733.76 & $\mathrm{BD}$ & Bechtel \\
\hline UE-5 PW-1 & 968.73 & 235.00 & 234.92 & $5 / 18 / 1999$ & -- & 733.81 & $\mathrm{BD}$ & Bechtel \\
\hline UE-5 PW-1 & 968.73 & 235.00 & 234.92 & $8 / 25 / 1999$ & -- & 733.81 & $\mathrm{BD}$ & Bechtel \\
\hline UE-5 PW-1 & 968.73 & 235.01 & 234.93 & $10 / 26 / 1999$ & -- & 733.80 & $\mathrm{BD}$ & Bechtel \\
\hline UE-5 PW-1 & 968.73 & 235.08 & 235.00 & $4 / 24 / 2000$ & -- & 733.73 & $\mathrm{BD}$ & Bechtel \\
\hline UE-5 PW-1 & 968.73 & 235.03 & 234.95 & $8 / 7 / 2000$ & -- & 733.78 & $\mathrm{BD}$ & Bechtel \\
\hline UE-5 PW-1 & 968.73 & 235.10 & 235.02 & $11 / 13 / 2000$ & -- & 733.71 & $\mathrm{BD}$ & Bechtel \\
\hline UE-5 PW-1 & 968.73 & 235.01 & 234.93 & $2 / 22 / 2001$ & -- & 733.80 & $\mathrm{BD}$ & Bechtel \\
\hline UE-5 PW-1 & 968.73 & 235.11 & 235.03 & $5 / 21 / 2001$ & -- & 733.70 & $\mathrm{BD}$ & Bechtel \\
\hline UE-5 PW-1 & 968.73 & 235.10 & 235.02 & $8 / 1 / 2001$ & -- & 733.71 & $\mathrm{BD}$ & Bechtel \\
\hline
\end{tabular}


UE-5 PW-1

Water-Level Data

\begin{tabular}{|c|c|c|c|c|c|c|c|c|}
\hline $\begin{array}{c}\text { Well } \\
\text { Reporting } \\
\text { Name }\end{array}$ & $\begin{array}{c}\text { Reference } \\
\text { Point } \\
\text { Elevation } \\
\text { (m) }\end{array}$ & $\begin{array}{c}\text { Measured } \\
\text { Depth to } \\
\text { Water } \\
\text { (mbrp) }^{\mathrm{a}}\end{array}$ & $\begin{array}{c}\text { Corrected } \\
\text { Depth to } \\
\text { Water } \\
\text { (mbrp) }\end{array}$ & $\begin{array}{l}\text { Measure- } \\
\text { ment Date }\end{array}$ & $\begin{array}{c}\text { Site } \\
\text { Status }^{b}\end{array}$ & $\begin{array}{c}\text { Water } \\
\text { Level } \\
\text { Elevation } \\
\text { (masl) }^{c}\end{array}$ & $\begin{array}{c}\text { Type } \\
\text { Correction }^{d}\end{array}$ & Source $^{e}$ \\
\hline UE-5 PW-1 & 968.73 & 235.10 & 235.02 & $10 / 1 / 2001$ & -- & 733.71 & $\mathrm{BD}$ & Bechtel \\
\hline UE-5 PW-1 & 968.73 & \begin{tabular}{l|l}
-- & \\
\end{tabular} & \begin{tabular}{l|}
-- \\
\end{tabular} & $2 / 26 / 2002$ & -- & 733.45 & $\mathrm{BD}$ & RNM-2s MWAT \\
\hline UE-5 PW-1 & 968.73 & 235.20 & 235.12 & $2 / 26 / 2002$ & -- & 733.61 & $\mathrm{BD}$ & Bechtel \\
\hline UE-5 PW-1 & 968.73 & -- & -- & $5 / 13 / 2002$ & -- & 733.56 & $\mathrm{BD}$ & RNM-2s MWAT \\
\hline UE-5 PW-1 & 968.73 & 235.09 & 235.01 & $5 / 13 / 2002$ & -- & 733.72 & $\mathrm{BD}$ & Bechtel \\
\hline UE-5 PW-1 & 968.73 & \begin{tabular}{l|}
-- \\
\end{tabular} & -- & $8 / 19 / 2002$ & - & 733.59 & $\mathrm{BD}$ & RNM-2s MWAT \\
\hline UE-5 PW-1 & 968.73 & 235.05 & 234.97 & 8/19/2002 & -- & 733.76 & $\mathrm{BD}$ & Bechtel \\
\hline UE-5 PW-1 & 968.73 & \begin{tabular}{l|}
-- \\
\end{tabular} & \begin{tabular}{l|}
-- \\
\end{tabular} & 10/21/2002 & -- & 733.59 & $\mathrm{BD}$ & RNM-2s MWAT \\
\hline UE-5 PW-1 & 968.73 & 235.05 & 234.97 & $10 / 21 / 2002$ & - & 733.76 & $\mathrm{BD}$ & Bechtel \\
\hline UE-5 PW-1 & 968.73 & -- & -- & 2/26/2003 & -- & 733.56 & $\mathrm{BD}$ & RNM-2s MWAT \\
\hline UE-5 PW-1 & 968.73 & 235.09 & 235.01 & $2 / 26 / 2003$ & -- & 733.72 & $\mathrm{BD}$ & Bechtel \\
\hline UE-5 PW-1 & 968.73 & \begin{tabular}{l|l}
-- \\
\end{tabular} & -- & 4/10/2003 & -- & 733.60 & $\mathrm{BD}$ & RNM-2s MWAT \\
\hline UE-5 PW-1 & 968.73 & 235.05 & 234.97 & 4/10/2003 & -- & 733.76 & $\mathrm{BD}$ & Bechtel \\
\hline UE-5 PW-1 & 968.73 & -- & -- & 9/10/2003 & -- & 733.47 & $\mathrm{BD}$ & RNM-2s MWAT \\
\hline UE-5 PW-1 & 968.73 & 235.18 & 235.10 & 9/10/2003 & -- & 733.63 & $\mathrm{BD}$ & Bechtel \\
\hline UE-5 PW-1 & 968.73 & -- & -- & $10 / 20 / 2003$ & -- & 733.48 & BD & RNM-2s MWAT \\
\hline UE-5 PW-1 & 968.73 & 235.17 & 235.09 & $10 / 20 / 2003$ & -- & 733.64 & $\mathrm{BD}$ & Bechtel \\
\hline UE-5 PW-1 & 968.73 & -- & -- & 2/25/2004 & -- & 733.43 & $\mathrm{BD}$ & RNM-2s MWAT \\
\hline UE-5 PW-1 & 968.73 & 235.22 & 235.14 & $2 / 25 / 2004$ & -- & 733.59 & $\mathrm{BD}$ & Bechtel \\
\hline
\end{tabular}

${ }^{a}$ meters below reference point

bite Status: -- = Not Applicable

${ }^{\mathrm{C}}$ meters above sea level

used to determine historical and contemporary static water level not applicable

used to determine historical static water level not applicable used to determine contemporary static water level

${ }^{d}$ Type Correction: BD = water level corrected for borehole deviation

eSource: database = UGTA borehole database

RNM-2s MWAT = Integrated Data Report for the RNM-2s Multi-Well Aquifer Test at Frenchman Flat, Nevada Test Site, Nevada (SNJV, 2004) (corrected water-level elevation given)

Bechtel $=$ personal communication from Fred Nawrocki with Bechtel Nevada 
UE-5 PW-2

Water-Level Data

\begin{tabular}{|c|c|c|c|c|c|c|c|c|}
\hline $\begin{array}{c}\text { Well } \\
\text { Reporting } \\
\text { Name }\end{array}$ & $\begin{array}{c}\text { Reference } \\
\text { Point } \\
\text { Elevation } \\
(\mathrm{m})\end{array}$ & \begin{tabular}{|l|} 
Measured \\
Depth to \\
Water \\
$(\mathrm{mbrp})^{\mathrm{a}}$
\end{tabular} & \begin{tabular}{|l|} 
Corrected \\
Depth to \\
Water \\
(mbrp)
\end{tabular} & $\begin{array}{c}\text { Measure- } \\
\text { ment Date }\end{array}$ & $\begin{array}{c}\text { Site } \\
\text { Status }^{b}\end{array}$ & $\begin{array}{c}\text { Water } \\
\text { Level } \\
\text { Elevation } \\
\text { (masl) }^{c}\end{array}$ & $\begin{array}{c}\text { Type } \\
\text { Correction }^{d}\end{array}$ & Source ${ }^{e}$ \\
\hline UE-5 PW-2 & 989.54 & 256.15 & 255.95 & $3 / 2 / 1993$ & -- & 733.59 & $\mathrm{BD}$ & database \\
\hline UE-5 PW-2 & 989.54 & 256.01 & 255.81 & $3 / 22 / 1993$ & -- & 733.73 & $B D$ & Bechtel \\
\hline UE-5 PW-2 & 989.54 & 256.11 & 255.91 & $3 / 23 / 1993$ & -- & 733.63 & $\mathrm{BD}$ & Bechtel \\
\hline UE-5 PW-2 & 989.54 & 255.99 & 255.79 & $3 / 24 / 1993$ & -- & 733.75 & $\mathrm{BD}$ & Bechtel \\
\hline UE-5 PW-2 & 989.54 & 255.98 & 255.78 & $3 / 25 / 1993$ & -- & 733.76 & $B D$ & Bechtel \\
\hline UE-5 PW-2 & 989.54 & 255.96 & 255.75 & $3 / 29 / 1993$ & -- & 733.79 & $\mathrm{BD}$ & database \\
\hline UE-5 PW-2 & 989.54 & 256.01 & 255.81 & $3 / 29 / 1993$ & -- & 733.73 & $\mathrm{BD}$ & Bechtel \\
\hline UE-5 PW-2 & 989.54 & 256.06 & 255.86 & $3 / 30 / 1993$ & -- & 733.68 & $\mathrm{BD}$ & Bechtel \\
\hline UE-5 PW-2 & 989.54 & 256.07 & 255.87 & $3 / 31 / 1993$ & -- & 733.67 & $\mathrm{BD}$ & Bechtel \\
\hline UE-5 PW-2 & 989.54 & 256.00 & 255.80 & $4 / 1 / 1993$ & -- & 733.74 & $\mathrm{BD}$ & Bechtel \\
\hline UE-5 PW-2 & 989.54 & 255.97 & 255.77 & $4 / 5 / 1993$ & -- & 733.77 & $B D$ & Bechtel \\
\hline UE-5 PW-2 & 989.54 & 256.06 & 255.86 & $4 / 6 / 1993$ & -- & 733.68 & $\mathrm{BD}$ & database \\
\hline UE-5 PW-2 & 989.54 & 256.03 & 255.83 & $4 / 6 / 1993$ & -- & 733.71 & $B D$ & Bechtel \\
\hline UE-5 PW-2 & 989.54 & 256.09 & 255.89 & $5 / 10 / 1993$ & -- & 733.65 & $B D$ & Bechtel \\
\hline UE-5 PW-2 & 989.54 & 256.04 & 255.84 & $5 / 11 / 1993$ & -- & 733.70 & $\mathrm{BD}$ & Bechtel \\
\hline UE-5 PW-2 & 989.54 & 256.03 & 255.83 & $5 / 12 / 1993$ & -- & 733.71 & $\mathrm{BD}$ & Bechtel \\
\hline UE-5 PW-2 & 989.54 & 256.08 & 255.88 & $5 / 13 / 1993$ & -- & 733.66 & $B D$ & Bechtel \\
\hline UE-5 PW-2 & 989.54 & 256.08 & 255.88 & $5 / 17 / 1993$ & -- & 733.66 & $\mathrm{BD}$ & Bechtel \\
\hline UE-5 PW-2 & 989.54 & 256.07 & 255.87 & $5 / 18 / 1993$ & -- & 733.67 & $\mathrm{BD}$ & Bechtel \\
\hline UE-5 PW-2 & 989.54 & 256.07 & 255.87 & $5 / 19 / 1993$ & -- & 733.67 & $B D$ & Bechtel \\
\hline UE-5 PW-2 & 989.54 & 256.02 & 255.82 & $5 / 20 / 1993$ & -- & 733.72 & $B D$ & Bechtel \\
\hline UE-5 PW-2 & 989.54 & 256.06 & 255.86 & $5 / 24 / 1993$ & -- & 733.68 & $\mathrm{BD}$ & Bechtel \\
\hline UE-5 PW-2 & 989.54 & 256.08 & 255.88 & $5 / 25 / 1993$ & -- & 733.66 & $B D$ & Bechtel \\
\hline UE-5 PW-2 & 989.54 & 256.06 & 255.86 & $6 / 1 / 1993$ & - & 733.68 & $B D$ & Bechtel \\
\hline UE-5 PW-2 & 989.54 & 256.08 & 255.88 & $6 / 7 / 1993$ & -- & 733.66 & $B D$ & Bechtel \\
\hline UE-5 PW-2 & 989.54 & 256.08 & 255.88 & $6 / 14 / 1993$ & -- & 733.66 & $\mathrm{BD}$ & Bechtel \\
\hline UE-5 PW-2 & 989.54 & 256.06 & 255.86 & $6 / 21 / 1993$ & -- & 733.68 & $B D$ & Bechtel \\
\hline UE-5 PW-2 & 989.54 & 256.08 & 255.88 & $7 / 26 / 1993$ & -- & 733.66 & $\mathrm{BD}$ & Bechtel \\
\hline UE-5 PW-2 & 989.54 & 256.05 & 255.85 & $8 / 3 / 1993$ & -- & 733.69 & $\mathrm{BD}$ & Bechtel \\
\hline UE-5 PW-2 & 989.54 & 256.09 & 255.88 & $8 / 9 / 1993$ & -- & 733.65 & $B D$ & Bechtel \\
\hline UE-5 PW-2 & 989.54 & 256.05 & 255.85 & $8 / 16 / 1993$ & -- & 733.69 & $\mathrm{BD}$ & Bechtel \\
\hline UE-5 PW-2 & 989.54 & 256.06 & 255.86 & \begin{tabular}{|c|}
$8 / 30 / 1993$ \\
\end{tabular} & -- & 733.68 & $\mathrm{BD}$ & Bechtel \\
\hline UE-5 PW-2 & 989.54 & 256.10 & 255.90 & $12 / 28 / 1993$ & -- & 733.64 & $\mathrm{BD}$ & Bechtel \\
\hline UE-5 PW-2 & 989.54 & 256.07 & 255.87 & \begin{tabular}{|l|}
$1 / 3 / 1994$ \\
\end{tabular} & -- & 733.67 & $\mathrm{BD}$ & Bechtel \\
\hline UE-5 PW-2 & 989.54 & 256.07 & 255.87 & $2 / 2 / 1994$ & -- & 733.67 & $\mathrm{BD}$ & Bechtel \\
\hline UE-5 PW-2 & 989.54 & 256.06 & 255.86 & $2 / 22 / 1994$ & -- & 733.68 & $\mathrm{BD}$ & Bechtel \\
\hline UE-5 PW-2 & 989.54 & 256.07 & 255.87 & $2 / 28 / 1994$ & -- & 733.67 & $\mathrm{BD}$ & Bechtel \\
\hline UE-5 PW-2 & 989.54 & 256.01 & 255.81 & $3 / 7 / 1994$ & -- & 733.73 & $\mathrm{BD}$ & Bechtel \\
\hline UE-5 PW-2 & 989.54 & 256.08 & 255.88 & 3/14/1994 & -- & 733.66 & $\mathrm{BD}$ & Bechtel \\
\hline
\end{tabular}


UE-5 PW-2

Water-Level Data

\begin{tabular}{|c|c|c|c|c|c|c|c|c|}
\hline $\begin{array}{c}\text { Well } \\
\text { Reporting } \\
\text { Name }\end{array}$ & $\begin{array}{c}\text { Reference } \\
\text { Point } \\
\text { Elevation } \\
(\mathrm{m})\end{array}$ & \begin{tabular}{|l|} 
Measured \\
Depth to \\
Water \\
$(\mathrm{mbrp})^{\mathrm{a}}$
\end{tabular} & \begin{tabular}{|l|} 
Corrected \\
Depth to \\
Water \\
(mbrp)
\end{tabular} & $\begin{array}{c}\text { Measure- } \\
\text { ment Date }\end{array}$ & $\begin{array}{c}\text { Site } \\
\text { Status }^{b}\end{array}$ & $\begin{array}{c}\text { Water } \\
\text { Level } \\
\text { Elevation } \\
\text { (masl) }^{c}\end{array}$ & $\begin{array}{c}\text { Type } \\
\text { Correction }^{d}\end{array}$ & Source ${ }^{e}$ \\
\hline UE-5 PW-2 & 989.54 & 256.00 & 255.80 & $3 / 21 / 1994$ & -- & 733.74 & $\mathrm{BD}$ & Bechtel \\
\hline UE-5 PW-2 & 989.54 & 256.10 & 255.90 & $3 / 28 / 1994$ & -- & 733.64 & $\mathrm{BD}$ & Bechtel \\
\hline UE-5 PW-2 & 989.54 & 256.03 & 255.83 & $4 / 4 / 1994$ & -- & 733.71 & $B D$ & Bechtel \\
\hline UE-5 PW-2 & 989.54 & 256.05 & 255.85 & $4 / 13 / 1994$ & -- & 733.69 & $\mathrm{BD}$ & Bechtel \\
\hline UE-5 PW-2 & 989.54 & 256.00 & 255.80 & $4 / 20 / 1994$ & -- & 733.74 & $B D$ & Bechtel \\
\hline UE-5 PW-2 & 989.54 & 255.97 & 255.77 & $4 / 26 / 1994$ & -- & 733.77 & $\mathrm{BD}$ & Bechtel \\
\hline UE-5 PW-2 & 989.54 & 256.08 & 255.88 & $1 / 18 / 1995$ & -- & 733.66 & $\mathrm{BD}$ & Bechtel \\
\hline UE-5 PW-2 & 989.54 & 256.02 & 255.82 & $4 / 3 / 1995$ & -- & 733.72 & $\mathrm{BD}$ & Bechtel \\
\hline UE-5 PW-2 & 989.54 & 255.76 & 255.56 & $1 / 16 / 1996$ & -- & 733.98 & $\mathrm{BD}$ & Bechtel \\
\hline UE-5 PW-2 & 989.54 & 255.93 & 255.73 & $4 / 15 / 1996$ & -- & 733.81 & $\mathrm{BD}$ & Bechtel \\
\hline UE-5 PW-2 & 989.54 & 255.95 & 255.75 & $10 / 1 / 1996$ & -- & 733.79 & $B D$ & Bechtel \\
\hline UE-5 PW-2 & 989.54 & 255.96 & 255.76 & $11 / 19 / 1996$ & -- & 733.78 & $\mathrm{BD}$ & Bechtel \\
\hline UE-5 PW-2 & 989.54 & 255.93 & 255.73 & $3 / 3 / 1997$ & -- & 733.81 & $\mathrm{BD}$ & Bechtel \\
\hline UE-5 PW-2 & 989.54 & 256.03 & 255.83 & $4 / 15 / 1997$ & -- & 733.71 & $B D$ & Bechtel \\
\hline UE-5 PW-2 & 989.54 & 256.03 & 255.83 & $6 / 18 / 1997$ & -- & 733.71 & $\mathrm{BD}$ & Bechtel \\
\hline UE-5 PW-2 & 989.54 & 256.00 & 255.80 & $7 / 28 / 1997$ & -- & 733.74 & $\mathrm{BD}$ & Bechtel \\
\hline UE-5 PW-2 & 989.54 & 255.92 & 255.72 & $8 / 20 / 1997$ & -- & 733.82 & $B D$ & Bechtel \\
\hline UE-5 PW-2 & 989.54 & 255.98 & 255.78 & $9 / 25 / 1997$ & -- & 733.76 & $\mathrm{BD}$ & Bechtel \\
\hline UE-5 PW-2 & 989.54 & 255.97 & 255.77 & $10 / 27 / 1997$ & -- & 733.77 & $\mathrm{BD}$ & Bechtel \\
\hline UE-5 PW-2 & 989.54 & 256.03 & 255.83 & $11 / 3 / 1997$ & -- & 733.71 & $B D$ & Bechtel \\
\hline UE-5 PW-2 & 989.54 & 255.99 & 255.79 & $11 / 6 / 1997$ & -- & 733.75 & $B D$ & Bechtel \\
\hline UE-5 PW-2 & 989.54 & 256.08 & 255.88 & $11 / 12 / 1997$ & -- & 733.66 & $\mathrm{BD}$ & Bechtel \\
\hline UE-5 PW-2 & 989.54 & 255.92 & 255.72 & $11 / 13 / 1997$ & -- & 733.82 & $B D$ & Bechtel \\
\hline UE-5 PW-2 & 989.54 & 256.05 & 255.85 & $11 / 19 / 1997$ & -- & 733.69 & $B D$ & Bechtel \\
\hline UE-5 PW-2 & 989.54 & 256.06 & 255.86 & $11 / 20 / 1997$ & -- & 733.68 & $B D$ & Bechtel \\
\hline UE-5 PW-2 & 989.54 & 256.01 & 255.81 & $11 / 25 / 1997$ & -- & 733.73 & $\mathrm{BD}$ & Bechtel \\
\hline UE-5 PW-2 & 989.54 & 255.90 & 255.70 & $11 / 26 / 1997$ & -- & 733.84 & $B D$ & Bechtel \\
\hline UE-5 PW-2 & 989.54 & 256.06 & 255.86 & $12 / 3 / 1997$ & -- & 733.68 & $\mathrm{BD}$ & Bechtel \\
\hline UE-5 PW-2 & 989.54 & 256.10 & 255.90 & $1 / 26 / 1998$ & -- & 733.64 & $\mathrm{BD}$ & Bechtel \\
\hline UE-5 PW-2 & 989.54 & 255.95 & 255.75 & $5 / 12 / 1998$ & -- & 733.79 & $B D$ & Bechtel \\
\hline UE-5 PW-2 & 989.54 & 255.84 & 255.64 & $10 / 27 / 1998$ & -- & 733.90 & $\mathrm{BD}$ & Bechtel \\
\hline UE-5 PW-2 & 989.54 & 255.82 & 255.62 & $12 / 22 / 1998$ & -- & 733.92 & $\mathrm{BD}$ & Bechtel \\
\hline UE-5 PW-2 & 989.54 & 255.97 & 255.76 & $2 / 2 / 1999$ & -- & 733.77 & $\mathrm{BD}$ & Bechtel \\
\hline UE-5 PW-2 & 989.54 & 255.89 & 255.69 & $5 / 18 / 1999$ & -- & 733.85 & $\mathrm{BD}$ & Bechtel \\
\hline UE-5 PW-2 & 989.54 & 255.89 & 255.69 & 8/25/1999 & -- & 733.85 & $\mathrm{BD}$ & Bechtel \\
\hline UE-5 PW-2 & 989.54 & 255.89 & 255.69 & $10 / 26 / 1999$ & -- & 733.85 & $\mathrm{BD}$ & Bechtel \\
\hline UE-5 PW-2 & 989.54 & 255.97 & 255.77 & $4 / 24 / 2000$ & -- & 733.77 & $\mathrm{BD}$ & Bechtel \\
\hline UE-5 PW-2 & 989.54 & 255.93 & 255.73 & $8 / 7 / 2000$ & -- & 733.81 & $\mathrm{BD}$ & Bechtel \\
\hline UE-5 PW-2 & 989.54 & 255.97 & 255.77 & $11 / 13 / 2000$ & -- & 733.77 & $\mathrm{BD}$ & Bechtel \\
\hline
\end{tabular}


UE-5 PW-2

Water-Level Data

\begin{tabular}{|c|c|c|c|c|c|c|c|c|}
\hline $\begin{array}{c}\text { Well } \\
\text { Reporting } \\
\text { Name }\end{array}$ & $\begin{array}{c}\text { Reference } \\
\text { Point } \\
\text { Elevation } \\
(\mathrm{m})\end{array}$ & \begin{tabular}{|l|} 
Measured \\
Depth to \\
Water \\
$(\mathrm{mbrp})^{\mathrm{a}}$
\end{tabular} & $\begin{array}{l}\text { Corrected } \\
\text { Depth to } \\
\text { Water } \\
\text { (mbrp) }\end{array}$ & $\begin{array}{l}\text { Measure- } \\
\text { ment Date }\end{array}$ & $\begin{array}{c}\text { Site } \\
\text { Status }^{b}\end{array}$ & $\begin{array}{c}\text { Water } \\
\text { Level } \\
\text { Elevation } \\
\text { (masl) }^{c}\end{array}$ & $\begin{array}{c}\text { Type } \\
\text { Correction }^{d}\end{array}$ & Source $^{e}$ \\
\hline UE-5 PW-2 & 989.54 & \begin{tabular}{|l|}
255.89 \\
\end{tabular} & 255.69 & $2 / 22 / 2001$ & -- & 733.85 & $\mathrm{BD}$ & Bechtel \\
\hline UE-5 PW-2 & 989.54 & 255.97 & 255.77 & $5 / 21 / 2001$ & -- & 733.77 & $\mathrm{BD}$ & Bechtel \\
\hline UE-5 PW-2 & 989.54 & 255.99 & 255.79 & $8 / 1 / 2001$ & -- & 733.75 & $B D$ & Bechtel \\
\hline UE-5 PW-2 & 989.54 & 255.97 & 255.77 & $10 / 1 / 2001$ & -- & 733.77 & $\mathrm{BD}$ & Bechtel \\
\hline UE-5 PW-2 & 989.54 & \begin{tabular}{l|l}
-- \\
\end{tabular} & \begin{tabular}{l|}
-- \\
\end{tabular} & 2/26/2002 & -- & 733.28 & $\mathrm{BD}$ & RNM-2s MWAT \\
\hline UE-5 PW-2 & 989.54 & 256.05 & 255.85 & $2 / 26 / 2002$ & -- & 733.69 & $\mathrm{BD}$ & Bechtel \\
\hline UE-5 PW-2 & 989.54 & -- & -- & $5 / 13 / 2002$ & -- & 733.32 & $\mathrm{BD}$ & RNM-2s MWAT \\
\hline UE-5 PW-2 & 989.54 & 256.01 & 255.81 & $5 / 13 / 2002$ & -- & 733.73 & $\mathrm{BD}$ & Bechtel \\
\hline UE-5 PW-2 & 989.54 & -- & -- & $8 / 19 / 2002$ & -- & 733.43 & $\mathrm{BD}$ & RNM-2s MWAT \\
\hline UE-5 PW-2 & 989.54 & 255.91 & 255.71 & $8 / 19 / 2002$ & -- & 733.83 & $\mathrm{BD}$ & Bechtel \\
\hline UE-5 PW-2 & 989.54 & -- & -- & $10 / 21 / 2002$ & -- & 733.40 & $\mathrm{BD}$ & RNM-2s MWAT \\
\hline UE-5 PW-2 & 989.54 & 255.94 & 255.74 & 10/21/2002 & -- & 733.80 & $\mathrm{BD}$ & Bechtel \\
\hline UE-5 PW-2 & 989.54 & -- & -- & 2/26/2003 & -- & 733.43 & $\mathrm{BD}$ & RNM-2s MWAT \\
\hline UE-5 PW-2 & 989.54 & 255.90 & 255.70 & $2 / 26 / 2003$ & -- & 733.84 & $\mathrm{BD}$ & Bechtel \\
\hline UE-5 PW-2 & 989.54 & \begin{tabular}{l|l|}
-- \\
\end{tabular} & -- & $4 / 10 / 2003$ & -- & 733.40 & $\mathrm{BD}$ & RNM-2s MWAT \\
\hline UE-5 PW-2 & 989.54 & 255.93 & 255.73 & 4/10/2003 & -- & 733.81 & $\mathrm{BD}$ & Bechtel \\
\hline UE-5 PW-2 & 989.54 & -- & -- & $9 / 10 / 2003$ & -- & 733.36 & $\mathrm{BD}$ & RNM-2s MWAT \\
\hline UE-5 PW-2 & 989.54 & 255.97 & 255.77 & 9/10/2003 & -- & 733.77 & $\mathrm{BD}$ & Bechtel \\
\hline UE-5 PW-2 & 989.54 & -- & -- & 10/20/2003 & -- & 733.29 & $\mathrm{BD}$ & RNM-2s MWAT \\
\hline UE-5 PW-2 & 989.54 & 256.04 & 255.84 & $10 / 20 / 2003$ & -- & 733.70 & $\mathrm{BD}$ & Bechtel \\
\hline UE-5 PW-2 & 989.54 & -- & -- & 2/25/2004 & -- & 733.35 & $\mathrm{BD}$ & RNM-2s MWAT \\
\hline UE-5 PW-2 & 989.54 & 255.99 & 255.79 & 2/25/2004 & -- & 733.75 & $\mathrm{BD}$ & Bechtel \\
\hline
\end{tabular}

${ }^{a}$ meters below reference point

bite Status: -- = Not Applicable

${ }^{\mathrm{c}}$ meters above sea level

used to determine historical and contemporary static water level not applicable

\section{used to determine historical static water level not applicable}

used to determine contemporary static water level

d Type Correction: BD = water level corrected for borehole deviation

eSource: database = UGTA borehole database

RNM-2s MWAT = Integrated Data Report for the RNM-2s Multi-Well Aquifer Test at Frenchman Flat, Nevada

Test Site, Nevada (SNJV, 2004) (corrected water-level elevation given)

Bechtel $=$ personal communication from Fred Nawrocki with Bechtel Nevada 
Well UE-5 PW-3

Water Level Data

\begin{tabular}{|c|c|c|c|c|c|c|c|c|}
\hline $\begin{array}{c}\text { Well } \\
\text { Reporting } \\
\text { Name }\end{array}$ & $\begin{array}{c}\text { Reference } \\
\text { Point } \\
\text { Elevation } \\
(\mathrm{m}) \\
\end{array}$ & $\begin{array}{c}\text { Measured } \\
\text { Depth to } \\
\text { Water } \\
\text { (mbrp) }^{\mathrm{a}}\end{array}$ & $\begin{array}{c}\text { Corrected } \\
\text { Depth to } \\
\text { Water } \\
\text { (mbrp) }\end{array}$ & $\begin{array}{l}\text { Measure- } \\
\text { ment Date }\end{array}$ & $\begin{array}{c}\text { Site } \\
\text { Status }^{b}\end{array}$ & $\begin{array}{c}\text { Water } \\
\text { Level } \\
\text { Elevation } \\
\text { (masl) }^{\mathrm{c}}\end{array}$ & $\begin{array}{c}\text { Type } \\
\text { Correction }^{d}\end{array}$ & Source $^{e}$ \\
\hline UE-5 PW-3 & 1004.50 & 271.09 & \begin{tabular}{|r|}
271.07 \\
\end{tabular} & $3 / 2 / 1993$ & -- & 733.43 & $\mathrm{BD}$ & database \\
\hline UE-5 PW-3 & 1004.50 & 271.03 & 271.01 & $3 / 17 / 1993$ & -- & 733.50 & $\mathrm{BD}$ & database \\
\hline UE-5 PW-3 & 1004.50 & 270.99 & 270.97 & $3 / 22 / 1993$ & -- & 733.53 & $\mathrm{BD}$ & Bechtel \\
\hline UE-5 PW-3 & 1004.50 & 270.98 & 270.96 & $3 / 23 / 1993$ & -- & 733.54 & $\mathrm{BD}$ & Bechtel \\
\hline UE-5 PW-3 & 1004.50 & 270.99 & 270.97 & $3 / 24 / 1993$ & -- & 733.53 & $\mathrm{BD}$ & Bechtel \\
\hline UE-5 PW-3 & 1004.50 & 270.99 & 270.97 & $3 / 25 / 1993$ & -- & 733.53 & $\mathrm{BD}$ & Bechtel \\
\hline UE-5 PW-3 & 1004.50 & 270.97 & 270.95 & $3 / 29 / 1993$ & -- & 733.56 & $\mathrm{BD}$ & database \\
\hline UE-5 PW-3 & 1004.50 & 271.03 & 271.01 & $3 / 29 / 1993$ & -- & 733.49 & $B D$ & Bechtel \\
\hline UE-5 PW-3 & 1004.50 & 271.06 & 271.04 & $3 / 30 / 1993$ & -- & 733.47 & $\mathrm{BD}$ & Bechtel \\
\hline UE-5 PW-3 & 1004.50 & 271.04 & 271.02 & $3 / 31 / 1993$ & -- & 733.48 & $\mathrm{BD}$ & Bechtel \\
\hline UE-5 PW-3 & 1004.50 & 270.99 & 270.97 & $4 / 1 / 1993$ & -- & 733.53 & $\mathrm{BD}$ & Bechtel \\
\hline UE-5 PW-3 & 1004.50 & 270.98 & 270.96 & 4/5/1993 & -- & 733.55 & $\mathrm{BD}$ & Bechtel \\
\hline UE-5 PW-3 & 1004.50 & 271.09 & 271.07 & $4 / 6 / 1993$ & -- & 733.43 & $\mathrm{BD}$ & database \\
\hline UE-5 PW-3 & 1004.50 & 271.05 & 271.03 & $4 / 6 / 1993$ & -- & 733.47 & $\mathrm{BD}$ & Bechtel \\
\hline UE-5 PW-3 & 1004.50 & 271.06 & 271.05 & $5 / 10 / 1993$ & -- & 733.46 & $\mathrm{BD}$ & Bechtel \\
\hline UE-5 PW-3 & 1004.50 & 271.01 & 270.99 & $5 / 11 / 1993$ & -- & 733.52 & $\mathrm{BD}$ & Bechtel \\
\hline UE-5 PW-3 & 1004.50 & 271.02 & 271.00 & $5 / 12 / 1993$ & -- & 733.50 & $\mathrm{BD}$ & Bechtel \\
\hline UE-5 PW-3 & 1004.50 & 271.06 & 271.04 & $5 / 13 / 1993$ & -- & 733.47 & $\mathrm{BD}$ & Bechtel \\
\hline UE-5 PW-3 & 1004.50 & 271.04 & 271.02 & $5 / 17 / 1993$ & -- & 733.49 & $\mathrm{BD}$ & Bechtel \\
\hline UE-5 PW-3 & 1004.50 & 271.04 & 271.03 & $5 / 18 / 1993$ & -- & 733.48 & $\mathrm{BD}$ & Bechtel \\
\hline UE-5 PW-3 & 1004.50 & 271.03 & 271.02 & $5 / 19 / 1993$ & -- & 733.49 & $\mathrm{BD}$ & Bechtel \\
\hline UE-5 PW-3 & 1004.50 & 271.01 & 270.99 & $5 / 20 / 1993$ & -- & 733.52 & $\mathrm{BD}$ & Bechtel \\
\hline UE-5 PW-3 & 1004.50 & 271.04 & 271.03 & $5 / 24 / 1993$ & -- & 733.48 & $\mathrm{BD}$ & Bechtel \\
\hline UE-5 PW-3 & 1004.50 & 271.04 & 271.03 & $5 / 25 / 1993$ & -- & 733.48 & $\mathrm{BD}$ & Bechtel \\
\hline UE-5 PW-3 & 1004.50 & 271.03 & 271.01 & $6 / 1 / 1993$ & -- & 733.49 & $\mathrm{BD}$ & Bechtel \\
\hline UE-5 PW-3 & 1004.50 & 271.06 & 271.04 & 6/7/1993 & -- & 733.46 & $\mathrm{BD}$ & Bechtel \\
\hline UE-5 PW-3 & 1004.50 & 271.04 & 271.02 & $6 / 14 / 1993$ & -- & 733.49 & $\mathrm{BD}$ & Bechtel \\
\hline UE-5 PW-3 & 1004.50 & 271.03 & 271.01 & $6 / 21 / 1993$ & -- & 733.50 & $\mathrm{BD}$ & Bechtel \\
\hline UE-5 PW-3 & 1004.50 & 271.04 & 271.02 & $7 / 26 / 1993$ & -- & 733.49 & $\mathrm{BD}$ & Bechtel \\
\hline UE-5 PW-3 & 1004.50 & 271.00 & 270.99 & $8 / 3 / 1993$ & -- & 733.52 & $\mathrm{BD}$ & Bechtel \\
\hline UE-5 PW-3 & 1004.50 & 271.05 & 271.03 & $8 / 9 / 1993$ & -- & 733.47 & $\mathrm{BD}$ & Bechtel \\
\hline UE-5 PW-3 & 1004.50 & 271.03 & 271.01 & $8 / 16 / 1993$ & -- & 733.50 & $B D$ & Bechtel \\
\hline UE-5 PW-3 & 1004.50 & 271.02 & 271.00 & $8 / 30 / 1993$ & -- & 733.50 & $\mathrm{BD}$ & Bechtel \\
\hline UE-5 PW-3 & 1004.50 & 271.04 & 271.03 & $12 / 28 / 1993$ & -- & 733.48 & $\mathrm{BD}$ & Bechtel \\
\hline UE-5 PW-3 & 1004.50 & 271.00 & 270.98 & \begin{tabular}{|l|}
$1 / 3 / 1994$ \\
\end{tabular} & -- & 733.53 & $\mathrm{BD}$ & Bechtel \\
\hline UE-5 PW-3 & 1004.50 & 270.96 & 270.94 & 2/2/1994 & -- & 733.57 & $\mathrm{BD}$ & Bechtel \\
\hline UE-5 PW-3 & 1004.50 & 271.01 & 270.99 & 2/22/1994 & -- & 733.51 & $\mathrm{BD}$ & Bechtel \\
\hline UE-5 PW-3 & 1004.50 & 271.00 & 270.98 & 2/28/1994 & -- & 733.53 & $\mathrm{BD}$ & Bechtel \\
\hline UE-5 PW-3 & 1004.50 & 270.96 & 270.94 & $3 / 7 / 1994$ & -- & 733.56 & $\mathrm{BD}$ & Bechtel \\
\hline
\end{tabular}


Well UE-5 PW-3

Water Level Data

\begin{tabular}{|c|c|c|c|c|c|c|c|c|}
\hline $\begin{array}{c}\text { Well } \\
\text { Reporting } \\
\text { Name }\end{array}$ & $\begin{array}{c}\text { Reference } \\
\text { Point } \\
\text { Elevation } \\
(\mathrm{m}) \\
\end{array}$ & $\begin{array}{c}\text { Measured } \\
\text { Depth to } \\
\text { Water } \\
\text { (mbrp) }^{\mathrm{a}}\end{array}$ & $\begin{array}{c}\text { Corrected } \\
\text { Depth to } \\
\text { Water } \\
\text { (mbrp) }\end{array}$ & \begin{tabular}{c|} 
Measure- \\
ment Date
\end{tabular} & $\begin{array}{c}\text { Site } \\
\text { Status }^{b}\end{array}$ & $\begin{array}{c}\text { Water } \\
\text { Level } \\
\text { Elevation } \\
\text { (masl) }^{\mathrm{c}}\end{array}$ & $\begin{array}{c}\text { Type } \\
\text { Correction }^{d}\end{array}$ & Source $^{e}$ \\
\hline UE-5 PW-3 & 1004.50 & 270.97 & 270.95 & $3 / 14 / 1994$ & -- & 733.55 & $\mathrm{BD}$ & Bechtel \\
\hline UE-5 PW-3 & 1004.50 & 270.98 & 270.96 & $3 / 21 / 1994$ & -- & 733.54 & $\mathrm{BD}$ & Bechtel \\
\hline UE-5 PW-3 & 1004.50 & 271.00 & 270.98 & $3 / 28 / 1994$ & -- & 733.53 & $\mathrm{BD}$ & Bechtel \\
\hline UE-5 PW-3 & 1004.50 & 270.96 & 270.94 & $4 / 4 / 1994$ & -- & 733.56 & $\mathrm{BD}$ & Bechtel \\
\hline UE-5 PW-3 & 1004.50 & 270.95 & 270.93 & $4 / 13 / 1994$ & -- & 733.57 & $\mathrm{BD}$ & Bechtel \\
\hline UE-5 PW-3 & 1004.50 & 270.95 & 270.93 & 4/20/1994 & -- & 733.58 & $\mathrm{BD}$ & Bechtel \\
\hline UE-5 PW-3 & 1004.50 & 270.95 & 270.93 & $4 / 26 / 1994$ & -- & 733.57 & $\mathrm{BD}$ & Bechtel \\
\hline UE-5 PW-3 & 1004.50 & 270.92 & 270.90 & $1 / 18 / 1995$ & -- & 733.60 & $\mathrm{BD}$ & Bechtel \\
\hline UE-5 PW-3 & 1004.50 & 270.91 & 270.89 & $4 / 3 / 1995$ & -- & 733.61 & $\mathrm{BD}$ & Bechtel \\
\hline UE-5 PW-3 & 1004.50 & 270.65 & 270.63 & $1 / 16 / 1996$ & -- & 733.87 & $\mathrm{BD}$ & Bechtel \\
\hline UE-5 PW-3 & 1004.50 & 270.73 & 270.71 & $4 / 16 / 1996$ & -- & 733.79 & $\mathrm{BD}$ & Bechtel \\
\hline UE-5 PW-3 & 1004.50 & 270.81 & 270.79 & $10 / 1 / 1996$ & -- & 733.71 & $\mathrm{BD}$ & Bechtel \\
\hline UE-5 PW-3 & 1004.50 & 270.82 & 270.80 & $11 / 19 / 1996$ & -- & 733.70 & $\mathrm{BD}$ & Bechtel \\
\hline UE-5 PW-3 & 1004.50 & 270.71 & 270.70 & \begin{tabular}{|l|}
$3 / 3 / 1997$ \\
\end{tabular} & -- & 733.81 & $\mathrm{BD}$ & Bechtel \\
\hline UE-5 PW-3 & 1004.50 & 270.85 & 270.83 & $4 / 15 / 1997$ & -- & 733.68 & $\mathrm{BD}$ & Bechtel \\
\hline UE-5 PW-3 & 1004.50 & 270.82 & 270.80 & $6 / 18 / 1997$ & -- & 733.71 & $\mathrm{BD}$ & Bechtel \\
\hline UE-5 PW-3 & 1004.50 & 270.81 & 270.79 & $7 / 28 / 1997$ & -- & 733.71 & $\mathrm{BD}$ & Bechtel \\
\hline UE-5 PW-3 & 1004.50 & 270.74 & 270.73 & $8 / 20 / 1997$ & -- & 733.78 & $\mathrm{BD}$ & Bechtel \\
\hline UE-5 PW-3 & 1004.50 & 270.79 & 270.77 & 9/25/1997 & -- & 733.73 & $\mathrm{BD}$ & Bechtel \\
\hline UE-5 PW-3 & 1004.50 & 270.78 & 270.77 & $10 / 27 / 1997$ & -- & 733.74 & $\mathrm{BD}$ & Bechtel \\
\hline UE-5 PW-3 & 1004.50 & 270.85 & 270.84 & $11 / 3 / 1997$ & -- & 733.67 & $\mathrm{BD}$ & Bechtel \\
\hline UE-5 PW-3 & 1004.50 & 270.78 & 270.77 & $11 / 6 / 1997$ & -- & 733.74 & $\mathrm{BD}$ & Bechtel \\
\hline UE-5 PW-3 & 1004.50 & 270.85 & 270.83 & $11 / 12 / 1997$ & -- & 733.68 & $\mathrm{BD}$ & Bechtel \\
\hline UE-5 PW-3 & 1004.50 & 270.80 & 270.78 & $11 / 13 / 1997$ & -- & 733.73 & $\mathrm{BD}$ & Bechtel \\
\hline UE-5 PW-3 & 1004.50 & 270.85 & 270.83 & $11 / 19 / 1997$ & -- & 733.67 & $\mathrm{BD}$ & Bechtel \\
\hline UE-5 PW-3 & 1004.50 & 270.88 & 270.86 & $11 / 20 / 1997$ & -- & 733.65 & $\mathrm{BD}$ & Bechtel \\
\hline UE-5 PW-3 & 1004.50 & 270.84 & 270.82 & $11 / 25 / 1997$ & -- & 733.68 & $\mathrm{BD}$ & Bechtel \\
\hline UE-5 PW-3 & 1004.50 & 270.75 & 270.74 & $11 / 26 / 1997$ & -- & 733.77 & $\mathrm{BD}$ & Bechtel \\
\hline UE-5 PW-3 & 1004.50 & 270.90 & 270.88 & \begin{tabular}{|c|}
$12 / 3 / 1997$ \\
\end{tabular} & -- & 733.62 & $\mathrm{BD}$ & Bechtel \\
\hline UE-5 PW-3 & 1004.50 & 270.90 & 270.88 & $1 / 26 / 1998$ & -- & 733.62 & $\mathrm{BD}$ & Bechtel \\
\hline UE-5 PW-3 & 1004.50 & 270.82 & 270.80 & $5 / 12 / 1998$ & -- & 733.70 & $\mathrm{BD}$ & Bechtel \\
\hline UE-5 PW-3 & 1004.50 & 270.66 & 270.64 & $10 / 27 / 1998$ & -- & 733.86 & $B D$ & Bechtel \\
\hline UE-5 PW-3 & 1004.50 & 270.65 & 270.63 & $12 / 22 / 1998$ & -- & 733.87 & $\mathrm{BD}$ & Bechtel \\
\hline UE-5 PW-3 & 1004.50 & 270.73 & 270.71 & 2/2/1999 & -- & 733.80 & $\mathrm{BD}$ & Bechtel \\
\hline UE-5 PW-3 & 1004.50 & 270.66 & 270.64 & $5 / 18 / 1999$ & -- & 733.87 & $\mathrm{BD}$ & Bechtel \\
\hline UE-5 PW-3 & 1004.50 & 270.68 & 270.67 & $8 / 25 / 1999$ & -- & 733.84 & $\mathrm{BD}$ & Bechtel \\
\hline UE-5 PW-3 & 1004.50 & 270.64 & 270.63 & $10 / 26 / 1999$ & -- & 733.88 & $\mathrm{BD}$ & Bechtel \\
\hline UE-5 PW-3 & 1004.50 & 270.82 & 270.80 & $4 / 24 / 2000$ & -- & 733.71 & $\mathrm{BD}$ & Bechtel \\
\hline UE-5 PW-3 & 1004.50 & 270.77 & 270.75 & $8 / 7 / 2000$ & -- & 733.75 & $\mathrm{BD}$ & Bechtel \\
\hline
\end{tabular}


Well UE-5 PW-3

Water Level Data

\begin{tabular}{|c|c|c|c|c|c|c|c|c|}
\hline $\begin{array}{c}\text { Well } \\
\text { Reporting } \\
\text { Name }\end{array}$ & $\begin{array}{c}\text { Reference } \\
\text { Point } \\
\text { Elevation } \\
(\mathrm{m})\end{array}$ & $\begin{array}{l}\text { Measured } \\
\text { Depth to } \\
\text { Water } \\
\text { (mbrp) }^{\mathrm{a}}\end{array}$ & $\begin{array}{c}\text { Corrected } \\
\text { Depth to } \\
\text { Water } \\
\text { (mbrp) }\end{array}$ & $\begin{array}{l}\text { Measure- } \\
\text { ment Date }\end{array}$ & $\begin{array}{c}\text { Site } \\
\text { Status }^{b}\end{array}$ & $\begin{array}{c}\text { Water } \\
\text { Level } \\
\text { Elevation } \\
\text { (masl) }^{c}\end{array}$ & $\begin{array}{c}\text { Type } \\
\text { Correction }^{d}\end{array}$ & Source ${ }^{e}$ \\
\hline UE-5 PW-3 & 1004.50 & 270.75 & 270.74 & $11 / 13 / 2000$ & -- & 733.77 & $\mathrm{BD}$ & Bechtel \\
\hline UE-5 PW-3 & 1004.50 & 270.68 & 270.66 & $2 / 22 / 2001$ & -- & 733.85 & $\mathrm{BD}$ & Bechtel \\
\hline UE-5 PW-3 & 1004.50 & 270.79 & 270.78 & $5 / 21 / 2001$ & -- & 733.73 & $\mathrm{BD}$ & Bechtel \\
\hline UE-5 PW-3 & 1004.50 & 270.78 & 270.76 & $8 / 1 / 2001$ & -- & 733.74 & $\mathrm{BD}$ & Bechtel \\
\hline UE-5 PW-3 & 1004.50 & 270.75 & 270.74 & 10/1/2001 & -- & 733.77 & $\mathrm{BD}$ & Bechtel \\
\hline UE-5 PW-3 & 1004.50 & -- & -- & $2 / 26 / 2002$ & -- & 733.67 & $\mathrm{BD}$ & RNM-2s MWAT \\
\hline UE-5 PW-3 & 1004.50 & 270.82 & 270.81 & $2 / 26 / 2002$ & -- & 733.70 & $\mathrm{BD}$ & Bechtel \\
\hline UE-5 PW-3 & 1004.50 & -- & -- & 5/13/2002 & -- & 733.75 & $\mathrm{BD}$ & RNM-2s MWAT \\
\hline UE-5 PW-3 & 1004.50 & 270.74 & 270.72 & $5 / 13 / 2002$ & -- & 733.78 & $\mathrm{BD}$ & Bechtel \\
\hline UE-5 PW-3 & 1004.50 & -- & -- & $8 / 19 / 2002$ & -- & 733.77 & $\mathrm{BD}$ & RNM-2s MWAT \\
\hline UE-5 PW-3 & 1004.50 & 270.72 & 270.70 & $8 / 19 / 2002$ & -- & 733.81 & $\mathrm{BD}$ & Bechtel \\
\hline UE-5 PW-3 & 1004.50 & -- & -- & 10/21/2002 & -- & 733.75 & $\mathrm{BD}$ & RNM-2s MWAT \\
\hline UE-5 PW-3 & 1004.50 & 270.74 & 270.72 & $10 / 21 / 2002$ & -- & 733.78 & $\mathrm{BD}$ & Bechtel \\
\hline UE-5 PW-3 & 1004.50 & -- & -- & 2/26/2003 & -- & 733.75 & $\mathrm{BD}$ & RNM-2s MWAT \\
\hline UE-5 PW-3 & 1004.50 & 270.74 & 270.72 & $2 / 26 / 2003$ & -- & 733.79 & $\mathrm{BD}$ & Bechtel \\
\hline UE-5 PW-3 & 1004.50 & -- & -- & 4/10/2003 & -- & 733.78 & $\mathrm{BD}$ & RNM-2s MWAT \\
\hline UE-5 PW-3 & 1004.50 & 270.71 & 270.69 & 4/10/2003 & -- & 733.82 & $\mathrm{BD}$ & Bechtel \\
\hline UE-5 PW-3 & 1004.50 & -- & -- & 9/10/2003 & -- & 733.68 & $\mathrm{BD}$ & RNM-2s MWAT \\
\hline UE-5 PW-3 & 1004.50 & 270.81 & 270.79 & 9/10/2003 & -- & 733.72 & $\mathrm{BD}$ & Bechtel \\
\hline UE-5 PW-3 & 1004.50 & -- & -- & 10/20/2003 & -- & 733.66 & $\mathrm{BD}$ & RNM-2s MWAT \\
\hline UE-5 PW-3 & 1004.50 & 270.83 & 270.81 & $10 / 20 / 2003$ & -- & 733.69 & $\mathrm{BD}$ & Bechtel \\
\hline UE-5 PW-3 & 1004.50 & -- & -- & 2/25/2004 & -- & 733.67 & $\mathrm{BD}$ & RNM-2s MWAT \\
\hline UE-5 PW-3 & 1004.50 & 270.82 & 270.80 & $2 / 25 / 2004$ & -- & 733.70 & $\mathrm{BD}$ & Bechtel \\
\hline
\end{tabular}

${ }^{a}$ meters below reference point

${ }^{\text {b }}$ Site Status: -- = Not Applicable

${ }^{\mathrm{C}}$ meters above sea level

used to determine historical and contemporary static water level not applicable

used to determine historical static water level not applicable used to determine contemporary static water level

' Type Correction: $\mathrm{BD}=$ water level corrected for borehole deviation

'Source: database = UGTA borehole database

RNM-2s MWAT = Integrated Data Report for the RNM-2s Multi-Well Aquifer Test at Frenchman Flat, Nevada

Test Site, Nevada (SNJV, 2004) (corrected water-level elevation given)

Bechtel $=$ personal communication from Fred Nawrocki with Bechtel Nevada (Nawrocki, 2004) 
Well UE-5c WW

Water Level Data

\begin{tabular}{|c|c|c|c|c|c|c|c|c|}
\hline $\begin{array}{c}\text { Well } \\
\text { Reporting } \\
\text { Name }\end{array}$ & $\begin{array}{l}\text { Reference } \\
\text { Point } \\
\text { Elevation } \\
\text { (m) }\end{array}$ & $\begin{array}{l}\text { Measured } \\
\text { Depth to } \\
\text { Water } \\
\text { (mbrp) }^{\text {a }}\end{array}$ & $\begin{array}{l}\text { Corrected } \\
\text { Depth to } \\
\text { Water } \\
\text { (mbrp) }\end{array}$ & $\begin{array}{c}\text { Measure- } \\
\text { ment Date }\end{array}$ & $\begin{array}{c}\text { Site } \\
\text { Status }^{b}\end{array}$ & $\begin{array}{c}\text { Water } \\
\text { Level } \\
\text { Elevation } \\
\text { (masl) }^{c}\end{array}$ & $\begin{array}{c}\text { Type } \\
\text { Correction }^{d}\end{array}$ & Source $^{e}$ \\
\hline UE-5c WW & 980.32 & 251.34 & 251.33 & $2 / 17 / 1966$ & -- & 728.99 & $B D$ & database \\
\hline UE-5c WW & 980.32 & 245.91 & 245.91 & $3 / 20 / 1971$ & -- & 734.41 & $\mathrm{BD}$ & database \\
\hline UE-5c WW & 980.32 & 245.49 & 245.48 & $3 / 23 / 1971$ & -- & 734.84 & $B D$ & database \\
\hline UE-5c WW & 980.32 & 245.97 & 245.97 & $10 / 27 / 1971$ & -- & 734.35 & $B D$ & database \\
\hline UE-5c WW & 980.32 & 245.76 & 245.75 & 7/30/1972 & -- & 734.56 & $\mathrm{BD}$ & database \\
\hline UE-5c WW & 980.32 & 245.97 & 245.97 & $1 / 18 / 1973$ & -- & 734.35 & $B D$ & database \\
\hline UE-5c WW & 980.32 & 247.04 & 247.03 & $8 / 11 / 1987$ & -- & 733.28 & $\mathrm{BD}$ & database \\
\hline
\end{tabular}

${ }^{a}$ meters below reference point

${ }^{\mathrm{b}}$ Site Status: -- = Not applicable

${ }^{c}$ meters above sea level

used to determine historical and contemporary static water level not applicable

used to determine historical static water level

used to determine contemporary static water level

${ }^{\mathrm{d}}$ Type Correction: BD = water level corrected for borehole deviation

eSource: database = UGTA borehole database 
Well UE-5f

Water Level Data

\begin{tabular}{|c|c|c|c|c|c|c|c|c|}
\hline $\begin{array}{c}\text { Well } \\
\text { Reporting } \\
\text { Name }\end{array}$ & $\begin{array}{c}\text { Reference } \\
\text { Point } \\
\text { Elevation } \\
(m) \\
\end{array}$ & $\begin{array}{c}\text { Measured } \\
\text { Depth to } \\
\text { Water } \\
\text { (mbrp) }^{\mathrm{a}} \\
\end{array}$ & $\begin{array}{c}\text { Corrected } \\
\text { Depth to } \\
\text { Water } \\
\text { (mbrp) }\end{array}$ & $\begin{array}{c}\text { Measure- } \\
\text { ment Date }\end{array}$ & $\begin{array}{c}\text { Site } \\
\text { Status }^{b}\end{array}$ & $\begin{array}{c}\text { Water } \\
\text { Level } \\
\text { Elevation } \\
\text { (masl) }^{c}\end{array}$ & $\begin{array}{c}\text { Type } \\
\text { Correction }^{d}\end{array}$ & Source \\
\hline UE-5f & 1006.09 & 271.27 & -- & $6 / 15 / 1965$ & -- & 734.82 & none & datebase \\
\hline UE-5f & 1006.09 & -- & -- & $2 / 21 / 1991$ & 0 & & -- & datebase \\
\hline UE-5f & 1006.09 & -- & -- & 10/15/1997 & 0 & & -- & datebase \\
\hline
\end{tabular}

${ }^{a}$ meters below reference point

${ }^{b}$ Site Status: $\mathrm{O}=$ An obstruction was encountered in the well above the water surface (no water level recorded).

$--=$ Not applicable

${ }^{\mathrm{c}}$ meters above sea level

used to determine historical and contemporary static water level not applicable

used to determine historical static water level

used to determine contemporary static water level not applicable

d Type Correction: none $=$ no correction made to water level

e Source: database = UGTA borehole database 


\section{UE-5j \\ Water Level Data}

\begin{tabular}{|l|c|c|c|c|c|c|c|c|}
\hline $\begin{array}{c}\text { Well } \\
\text { Reporting } \\
\text { Name }\end{array}$ & $\begin{array}{c}\text { Reference } \\
\text { Point } \\
\text { Elevation } \\
(\mathbf{m})\end{array}$ & $\begin{array}{c}\text { Measured } \\
\text { Depth to } \\
\text { Water } \\
(\mathbf{m b r p})^{\mathrm{a}}\end{array}$ & $\begin{array}{c}\text { Corrected } \\
\text { Depth to } \\
\text { Water } \\
(\mathbf{m b r p})\end{array}$ & $\begin{array}{c}\text { Measure- } \\
\text { ment Date }\end{array}$ & $\begin{array}{c}\text { Site } \\
\text { Status }\end{array}$ & $\begin{array}{c}\text { Water } \\
\text { Level } \\
\text { Elevation }^{(\text {masl })^{c}}\end{array}$ & $\begin{array}{c}\text { Type } \\
\text { Correction }^{\mathrm{d}}\end{array}$ & Source $^{\mathrm{e}}$ \\
\hline $\mathrm{UE}-5 \mathrm{j}$ & 1090.57 & 242.62 & -- & $3 / 29 / 1966$ & -- & 847.95 & none & datebase \\
\hline
\end{tabular}

${ }^{a}$ meters below reference point

${ }^{\text {b}}$ Site Status: -- = Not applicable

${ }^{c}$ meters above sea level

static water level could not be determined

${ }^{\mathrm{d}}$ Type Correction: none $=$ no correction made to water level

${ }^{\mathrm{e}}$ Source: database = UGTA borehole database 
Well UE-5k

Water Level Data

\begin{tabular}{|l|c|c|c|c|c|c|c|c|}
\hline $\begin{array}{c}\text { Well } \\
\text { Reporting } \\
\text { Name }\end{array}$ & $\begin{array}{c}\text { Reference } \\
\text { Point } \\
\text { Elevation } \\
(\mathbf{m})\end{array}$ & $\begin{array}{c}\text { Measured } \\
\text { Depth to } \\
\text { Water }_{(\mathbf{m b r p})^{\mathrm{a}}}\end{array}$ & $\begin{array}{c}\text { Corrected } \\
\text { Depth to } \\
\text { Water } \\
(\mathbf{m b r p})\end{array}$ & $\begin{array}{c}\text { Measure- } \\
\text { ment Date }\end{array}$ & $\begin{array}{c}\text { Site } \\
\text { Status }\end{array}$ & $\begin{array}{c}\text { Water } \\
\text { Level } \\
\text { Elevation } \\
\left(\mathbf{m a s l}^{\mathrm{c}}\right.\end{array}$ & $\begin{array}{c}\text { Type } \\
\text { Correction }^{\mathrm{d}}\end{array}$ & Source $^{\mathrm{e}}$ \\
\hline UE-5k & 1020.65 & 286.21 & -- & $5 / 25 / 1966$ & $\mathrm{C}$ & 734.45 & none & database \\
\hline
\end{tabular}

${ }^{a}$ meters below reference point

${ }^{b}$ Site Status: $C$ = Water level was measured prior to well completion.

${ }^{c}$ meters above sea level

static water level could not be determined

d Type Correction: none $=$ no correction made to water level

e Source: database = UGTA borehole database 
Well UE-5m

Water Level Data

\begin{tabular}{|c|c|c|c|c|c|c|c|c|}
\hline $\begin{array}{c}\text { Well } \\
\text { Reporting } \\
\text { Name }\end{array}$ & $\begin{array}{c}\text { Reference } \\
\text { Point } \\
\text { Elevation } \\
(\mathbf{m})\end{array}$ & $\begin{array}{c}\text { Measured } \\
\text { Depth to } \\
\text { Water }_{(\mathbf{m b r p})^{\mathrm{a}}}\end{array}$ & $\begin{array}{c}\text { Corrected } \\
\text { Depth to } \\
\text { Water } \\
(\mathbf{m b r p})\end{array}$ & $\begin{array}{c}\text { Measure- } \\
\text { ment Date }\end{array}$ & $\begin{array}{c}\text { Site } \\
\text { Status }\end{array}$ & $\begin{array}{c}\text { Water } \\
\text { Level } \\
\text { Elevation } \\
(\text { masl })^{\mathrm{c}}\end{array}$ & $\begin{array}{c}\text { Type } \\
\text { Correction }^{\mathrm{d}}\end{array}$ & Source $^{\mathrm{e}}$ \\
\hline $\mathrm{UE}-5 \mathrm{~m}$ & 1066.80 & 157.89 & -- & $4 / 26 / 1966$ & $\mathrm{C}$ & 908.91 & none & database \\
\hline
\end{tabular}

${ }^{a}$ meters below reference point

${ }^{b}$ Site Status: $C$ = Water level was measured prior to well completion.

${ }^{c}$ meters above sea level

static water level could not be determined

d Type Correction: none $=$ no correction made to water level

eSource: database = UGTA borehole database 
UE-5n

Water-Level Data

\begin{tabular}{|c|c|c|c|c|c|c|c|c|}
\hline $\begin{array}{c}\text { Well } \\
\text { Reporting } \\
\text { Name }\end{array}$ & $\begin{array}{c}\text { Reference } \\
\text { Point } \\
\text { Elevation } \\
(\mathrm{m})\end{array}$ & $\begin{array}{c}\text { Measured } \\
\text { Depth to } \\
\text { Water } \\
(\mathrm{mbrp})^{\mathrm{a}}\end{array}$ & $\begin{array}{l}\text { Corrected } \\
\text { Depth to } \\
\text { Water } \\
\text { (mbrp) }\end{array}$ & \begin{tabular}{|l|} 
Measure- \\
ment Date
\end{tabular} & $\begin{array}{c}\text { Site } \\
\text { Status }^{b}\end{array}$ & $\begin{array}{c}\text { Water } \\
\text { Level } \\
\text { Elevation } \\
\text { (masl) }^{c}\end{array}$ & $\begin{array}{c}\text { Type } \\
\text { Correction }^{d}\end{array}$ & Source ${ }^{e}$ \\
\hline UE-5n & 948.95 & 215.31 & -- & $12 / 3 / 1976$ & -- & 733.64 & none & database \\
\hline UE-5n & 948.95 & 215.34 & -- & $12 / 14 / 1976$ & -- & 733.61 & none & database \\
\hline UE-5n & 948.95 & 214.88 & -- & \begin{tabular}{|l|}
$4 / 8 / 1977$ \\
\end{tabular} & -- & 734.07 & none & database \\
\hline UE-5n & 948.95 & 214.58 & -- & $10 / 15 / 1979$ & -- & 734.37 & none & database \\
\hline UE-5n & 948.95 & 214.24 & -- & 3/22/1980 & -- & 734.71 & none & database \\
\hline UE-5n & 948.95 & 214.37 & -- & $3 / 31 / 1980$ & -- & 734.59 & none & database \\
\hline UE-5n & 948.95 & 214.92 & -- & $5 / 5 / 1983$ & -- & 734.03 & none & database \\
\hline UE-5n & 948.95 & 214.88 & -- & $6 / 16 / 1983$ & -- & 734.07 & none & database \\
\hline UE-5n & 948.95 & 214.97 & -- & $8 / 25 / 1983$ & -- & 733.98 & none & database \\
\hline UE-5n & 948.95 & 214.83 & -- & $1 / 10 / 1984$ & -- & 734.13 & none & database \\
\hline UE-5n & 948.95 & 214.82 & -- & $5 / 17 / 1984$ & -- & 734.13 & none & database \\
\hline UE-5n & 948.95 & 214.64 & -- & $3 / 19 / 1985$ & -- & 734.31 & none & database \\
\hline UE-5n & 948.95 & 214.59 & -- & $4 / 23 / 1985$ & -- & 734.36 & none & database \\
\hline UE-5n & 948.95 & 214.58 & -- & $4 / 23 / 1985$ & -- & 734.37 & none & database \\
\hline UE-5n & 948.95 & 214.55 & -- & $7 / 10 / 1986$ & -- & 734.40 & none & database \\
\hline UE-5n & 948.95 & 215.07 & -- & $7 / 24 / 1987$ & -- & 733.89 & none & database \\
\hline UE-5n & 948.95 & 214.98 & -- & $3 / 24 / 1988$ & -- & 733.98 & none & database \\
\hline UE-5n & 948.95 & 214.98 & -- & 10/21/1988 & -- & 733.98 & none & database \\
\hline UE-5n & 948.95 & 214.94 & -- & \begin{tabular}{|c|}
$1 / 10 / 1989$ \\
\end{tabular} & -- & 734.01 & none & database \\
\hline UE-5n & 948.95 & 214.96 & -- & $1 / 10 / 1989$ & -- & 733.99 & none & database \\
\hline UE-5n & 948.95 & 215.07 & -- & $1 / 11 / 1989$ & -- & 733.89 & none & database \\
\hline UE-5n & 948.95 & 215.05 & -- & $1 / 11 / 1989$ & -- & 733.91 & none & database \\
\hline UE-5n & 948.95 & 215.00 & -- & $1 / 13 / 1989$ & -- & 733.96 & none & database \\
\hline UE-5n & 948.95 & 215.01 & -- & $1 / 13 / 1989$ & -- & 733.95 & none & database \\
\hline UE-5n & 948.95 & 214.85 & -- & $5 / 3 / 1989$ & -- & 734.10 & none & database \\
\hline UE-5n & 948.95 & 214.67 & -- & 9/8/1989 & -- & 734.28 & none & database \\
\hline UE-5n & 948.95 & 214.88 & -- & 9/8/1989 & -- & 734.07 & none & database \\
\hline UE-5n & 948.95 & 215.04 & -- & $10 / 26 / 1989$ & -- & 733.92 & none & database \\
\hline UE-5n & 948.95 & 214.88 & -- & $12 / 15 / 1989$ & -- & 734.07 & none & database \\
\hline UE-5n & 948.95 & 214.98 & -- & 4/13/1990 & -- & 733.98 & none & database \\
\hline UE-5n & 948.95 & 214.98 & -- & $5 / 29 / 1990$ & -- & 733.98 & none & database \\
\hline UE-5n & 948.95 & 215.01 & -- & $10 / 26 / 1990$ & -- & 733.95 & none & database \\
\hline UE-5n & 948.95 & 214.88 & -- & \begin{tabular}{|l|}
$1 / 10 / 1991$ \\
\end{tabular} & -- & 734.07 & none & database \\
\hline UE-5n & 948.95 & 214.91 & -- & $2 / 21 / 1991$ & -- & 734.04 & none & database \\
\hline UE-5n & 948.95 & 214.90 & -- & $3 / 5 / 1991$ & -- & 734.05 & none & database \\
\hline UE-5n & 948.95 & 214.98 & -- & $4 / 11 / 1991$ & -- & 733.98 & none & database \\
\hline UE-5n & 948.95 & 214.91 & -- & $4 / 26 / 1991$ & -- & 734.04 & none & database \\
\hline UE-5n & 948.95 & 214.67 & -- & $5 / 17 / 1991$ & -- & 734.28 & none & database \\
\hline UE-5n & 948.95 & 214.64 & -- & $5 / 29 / 1991$ & -- & 734.31 & none & database \\
\hline
\end{tabular}


UE-5n

Water-Level Data

\begin{tabular}{|c|c|c|c|c|c|c|c|c|}
\hline $\begin{array}{c}\text { Well } \\
\text { Reporting } \\
\text { Name }\end{array}$ & $\begin{array}{c}\text { Reference } \\
\text { Point } \\
\text { Elevation } \\
(\mathrm{m})\end{array}$ & $\begin{array}{c}\text { Measured } \\
\text { Depth to } \\
\text { Water } \\
(\mathrm{mbrp})^{\mathrm{a}}\end{array}$ & $\begin{array}{l}\text { Corrected } \\
\text { Depth to } \\
\text { Water } \\
\text { (mbrp) }\end{array}$ & $\begin{array}{c}\text { Measure- } \\
\text { ment Date }\end{array}$ & $\begin{array}{c}\text { Site } \\
\text { Status }^{b}\end{array}$ & $\begin{array}{c}\text { Water } \\
\text { Level } \\
\text { Elevation } \\
\text { (masl) }^{c}\end{array}$ & $\begin{array}{c}\text { Type } \\
\text { Correction }^{d}\end{array}$ & Source ${ }^{e}$ \\
\hline UE-5n & 948.95 & 215.22 & -- & $6 / 25 / 1991$ & -- & 733.73 & none & database \\
\hline UE-5n & 948.95 & 214.58 & -- & $7 / 9 / 1991$ & -- & 734.37 & none & database \\
\hline UE-5n & 948.95 & 214.54 & -- & $7 / 19 / 1991$ & -- & 734.41 & none & database \\
\hline UE-5n & 948.95 & 214.49 & -- & $8 / 16 / 1991$ & -- & 734.46 & none & database \\
\hline UE-5n & 948.95 & 214.52 & -- & $8 / 28 / 1991$ & -- & 734.43 & none & database \\
\hline UE-5n & 948.95 & 214.43 & -- & $9 / 27 / 1991$ & -- & 734.53 & none & database \\
\hline UE-5n & 948.95 & 214.37 & -- & 10/21/1991 & -- & 734.59 & none & database \\
\hline UE-5n & 948.95 & 214.52 & -- & $11 / 20 / 1991$ & -- & 734.43 & none & database \\
\hline UE-5n & 948.95 & 214.40 & -- & $12 / 11 / 1991$ & -- & 734.56 & none & database \\
\hline UE-5n & 948.95 & 214.43 & -- & $1 / 17 / 1992$ & -- & 734.53 & none & database \\
\hline UE-5n & 948.95 & 214.58 & -- & $2 / 11 / 1992$ & -- & 734.37 & none & database \\
\hline UE-5n & 948.95 & 214.61 & -- & $3 / 12 / 1992$ & -- & 734.34 & none & database \\
\hline UE-5n & 948.95 & 214.61 & -- & $4 / 14 / 1992$ & -- & 734.34 & none & database \\
\hline UE-5n & 948.95 & 214.62 & -- & $4 / 28 / 1992$ & -- & 734.33 & none & database \\
\hline UE-5n & 948.95 & 214.61 & -- & $4 / 28 / 1992$ & -- & 734.34 & none & database \\
\hline UE-5n & 948.95 & 214.64 & -- & $4 / 28 / 1992$ & -- & 734.32 & none & database \\
\hline UE-5n & 948.95 & 214.64 & -- & $5 / 11 / 1992$ & -- & 734.31 & none & database \\
\hline UE-5n & 948.95 & 214.67 & -- & $6 / 15 / 1992$ & -- & 734.28 & none & database \\
\hline UE-5n & 948.95 & 214.70 & -- & $7 / 13 / 1992$ & -- & 734.25 & none & database \\
\hline UE-5n & 948.95 & 214.70 & -- & $8 / 11 / 1992$ & -- & 734.25 & none & database \\
\hline UE-5n & 948.95 & 214.76 & -- & $9 / 17 / 1992$ & -- & 734.19 & none & database \\
\hline UE-5n & 948.95 & 214.70 & -- & $10 / 14 / 1992$ & -- & 734.25 & none & database \\
\hline UE-5n & 948.95 & 214.82 & -- & $11 / 24 / 1992$ & -- & 734.13 & none & database \\
\hline UE-5n & 948.95 & 214.82 & -- & $1 / 21 / 1993$ & -- & 734.13 & none & database \\
\hline UE-5n & 948.95 & 214.73 & -- & 2/24/1993 & -- & 734.22 & none & database \\
\hline UE-5n & 948.95 & 214.76 & -- & $3 / 17 / 1993$ & -- & 734.19 & none & database \\
\hline UE-5n & 948.95 & 214.85 & -- & $4 / 6 / 1993$ & -- & 734.10 & none & database \\
\hline UE-5n & 948.95 & 214.74 & -- & 4/9/1993 & -- & 734.21 & none & database \\
\hline UE-5n & 948.95 & 214.79 & -- & $4 / 13 / 1993$ & -- & 734.17 & none & database \\
\hline UE-5n & 948.95 & 214.79 & -- & $4 / 20 / 1993$ & -- & 734.17 & none & database \\
\hline UE-5n & 948.95 & 214.73 & -- & $4 / 21 / 1993$ & -- & 734.22 & none & database \\
\hline UE-5n & 948.95 & 214.76 & -- & $4 / 26 / 1993$ & -- & 734.20 & none & database \\
\hline UE-5n & 948.95 & 214.73 & -- & $6 / 28 / 1993$ & -- & 734.22 & none & database \\
\hline UE-5n & 948.95 & 214.79 & -- & $7 / 29 / 1993$ & -- & 734.17 & none & database \\
\hline UE-5n & 948.95 & 215.36 & -- & $12 / 20 / 1993$ & -- & 733.59 & none & database \\
\hline UE-5n & 948.95 & 214.72 & -- & 2/2/1994 & -- & 734.23 & none & database \\
\hline UE-5n & 948.95 & 214.75 & -- & $2 / 14 / 1994$ & -- & 734.20 & none & database \\
\hline UE-5n & 948.95 & 214.81 & -- & $4 / 26 / 1994$ & -- & 734.14 & none & database \\
\hline UE-5n & 948.95 & 214.83 & -- & $5 / 10 / 1994$ & -- & 734.12 & none & database \\
\hline
\end{tabular}


UE-5n

Water-Level Data

\begin{tabular}{|c|c|c|c|c|c|c|c|c|}
\hline $\begin{array}{c}\text { Well } \\
\text { Reporting } \\
\text { Name }\end{array}$ & $\begin{array}{c}\text { Reference } \\
\text { Point } \\
\text { Elevation } \\
(\mathrm{m})\end{array}$ & $\begin{array}{c}\text { Measured } \\
\text { Depth to } \\
\text { Water } \\
(\mathrm{mbrp})^{\mathrm{a}}\end{array}$ & $\begin{array}{c}\text { Corrected } \\
\text { Depth to } \\
\text { Water } \\
\text { (mbrp) }\end{array}$ & $\begin{array}{c}\text { Measure- } \\
\text { ment Date }\end{array}$ & $\begin{array}{c}\text { Site } \\
\text { Status }^{b}\end{array}$ & $\begin{array}{c}\text { Water } \\
\text { Level } \\
\text { Elevation } \\
\text { (masl) }^{c}\end{array}$ & $\begin{array}{c}\text { Type } \\
\text { Correction }^{d}\end{array}$ & Source $^{e}$ \\
\hline UE-5n & 948.95 & 214.87 & \begin{tabular}{|l|}
-- \\
\end{tabular} & $11 / 21 / 1994$ & -- & 734.08 & none & database \\
\hline UE-5n & 948.95 & 214.81 & -- & $2 / 22 / 1995$ & -- & 734.14 & none & database \\
\hline UE-5n & 948.95 & 214.84 & -- & $8 / 22 / 1995$ & -- & 734.11 & none & database \\
\hline UE-5n & 948.95 & 214.92 & -- & $1 / 8 / 1996$ & -- & 734.03 & none & database \\
\hline UE-5n & 948.95 & 214.94 & -- & $6 / 14 / 1996$ & -- & 734.02 & none & database \\
\hline UE-5n & 948.95 & 214.92 & -- & $8 / 26 / 1997$ & -- & 734.03 & none & database \\
\hline UE-5n & 948.95 & 214.98 & -- & $10 / 21 / 1998$ & -- & 733.97 & none & database \\
\hline UE-5n & 948.95 & 214.92 & -- & $4 / 28 / 1999$ & -- & 734.03 & none & database \\
\hline UE-5n & 948.95 & 214.98 & -- & $12 / 13 / 1999$ & -- & 733.97 & none & database \\
\hline UE-5n & 948.95 & 215.06 & -- & $7 / 10 / 2000$ & -- & 733.89 & none & database \\
\hline UE-5n & 948.95 & 215.08 & -- & $10 / 25 / 2000$ & -- & 733.87 & none & database \\
\hline UE-5n & 948.95 & 215.11 & -- & $4 / 4 / 2001$ & -- & 733.84 & none & database \\
\hline UE-5n & 948.95 & 215.07 & -- & $7 / 11 / 2001$ & -- & 733.89 & none & database \\
\hline UE-5n & 948.95 & 215.09 & -- & $9 / 26 / 2001$ & -- & 733.86 & none & database \\
\hline UE-5n & 948.95 & 215.04 & -- & $12 / 27 / 2001$ & -- & 733.91 & none & database \\
\hline UE-5n & 948.95 & 215.13 & -- & $3 / 11 / 2002$ & -- & 733.82 & none & database \\
\hline UE-5n & 948.95 & 215.11 & -- & $7 / 25 / 2002$ & -- & 733.84 & none & database \\
\hline UE-5n & 948.95 & 215.07 & -- & $9 / 10 / 2002$ & -- & 733.88 & none & database \\
\hline UE-5n & 948.95 & 215.18 & -- & $12 / 30 / 2002$ & -- & 733.77 & none & database \\
\hline UE-5n & 948.95 & 215.13 & -- & $3 / 10 / 2003$ & -- & 733.82 & none & database \\
\hline UE-5n & 948.95 & 215.25 & -- & 9/25/2003 & -- & 733.70 & none & database \\
\hline UE-5n & 948.95 & 215.17 & -- & $11 / 20 / 2003$ & -- & 733.78 & none & database \\
\hline UE-5n & 948.95 & 214.91 & -- & $2 / 13 / 2003$ & -- & 734.04 & none & database \\
\hline UE-5n & 948.95 & 215.05 & -- & $4 / 10 / 2003$ & -- & 733.91 & none & database \\
\hline UE-5n & 948.95 & 215.15 & -- & $7 / 26 / 2003$ & -- & 733.80 & none & database \\
\hline UE-5n & 948.95 & 215.19 & -- & 8/5/2003 & -- & 733.76 & none & database \\
\hline UE-5n & 948.95 & 215.20 & -- & $8 / 23 / 2003$ & $Z$ & 733.75 & none & database \\
\hline UE-5n & 948.95 & 215.22 & -- & $8 / 24 / 2003$ & Z & 733.73 & none & database \\
\hline UE-5n & 948.95 & 215.05 & -- & 9/12/2003 & $Z$ & 733.91 & none & database \\
\hline UE-5n & 948.95 & 215.19 & -- & $3 / 11 / 2004$ & -- & 733.76 & none & USGS website \\
\hline
\end{tabular}

${ }^{a}$ meters below reference point

bite Status: $Z$ = "Other conditions at the well may have affected the water level measurement."

-- = Not applicable

${ }^{c}$ meters above sea level

used to determine historical and contemporary static water level not applicable

used to determine historical static water level not applicable

used to determine contemporary static water level

${ }^{\mathrm{d}}$ Type Correction: none $=$ no correction made to water level 
UE-5n

Water-Level Data

\begin{tabular}{|c|c|c|c|c|c|c|c|c|}
\hline $\begin{array}{c}\text { Well } \\
\text { Reporting } \\
\text { Name }\end{array}$ & $\begin{array}{c}\text { Reference } \\
\text { Point } \\
\text { Elevation } \\
\text { (m) }\end{array}$ & $\begin{array}{l}\text { Measured } \\
\text { Depth to } \\
\text { Water } \\
(\mathrm{mbrp})^{\mathrm{a}}\end{array}$ & $\begin{array}{c}\text { Corrected } \\
\text { Depth to } \\
\text { Water } \\
\text { (mbrp) }\end{array}$ & $\begin{array}{l}\text { Measure- } \\
\text { ment Date }\end{array}$ & $\begin{array}{c}\text { Site } \\
\text { Status }^{b}\end{array}$ & $\begin{array}{c}\text { Water } \\
\text { Level } \\
\text { Elevation } \\
\text { (masl) }^{c}\end{array}$ & $\begin{array}{c}\text { Type } \\
\text { Correction }^{d}\end{array}$ & Source \\
\hline
\end{tabular}

${ }^{\mathrm{e}}$ Source: database = UGTA borehole database

USGS website = http://nevada.usgs.gov/doe_nv/ 
Well UE-11a

Water Level Data

\begin{tabular}{|c|c|c|c|c|c|c|c|c|}
\hline $\begin{array}{c}\text { Well } \\
\text { Reporting } \\
\text { Name }\end{array}$ & \begin{tabular}{|c|}
$\begin{array}{c}\text { Reference } \\
\text { Point } \\
\text { Elevation } \\
(\mathrm{m})\end{array}$ \\
\end{tabular} & \begin{tabular}{|c|}
$\begin{array}{c}\text { Measured } \\
\text { Depth to } \\
\text { Water } \\
\text { (mbrp) }\end{array}$ \\
\end{tabular} & $\begin{array}{c}\text { Corrected } \\
\text { Depth to } \\
\text { Water } \\
\text { (mbrp) } \\
\end{array}$ & $\begin{array}{l}\text { Measure- } \\
\text { ment Date }\end{array}$ & $\begin{array}{c}\text { Site } \\
\text { Status }^{b}\end{array}$ & $\begin{array}{c}\text { Water } \\
\text { Level } \\
\text { Elevation } \\
\text { (masl) }^{c} \\
\end{array}$ & $\begin{array}{c}\text { Type } \\
\text { Correction }^{d}\end{array}$ & Source ${ }^{e}$ \\
\hline UE-11a & 1078.48 & 343.81 & 343.79 & $10 / 15 / 1965$ & C & 734.69 & $\mathrm{BD}$ & database \\
\hline UE-11a & 1078.48 & 349.61 & 349.58 & 9/4/1982 & $\mathrm{C}$ & 728.90 & $B D$ & database \\
\hline UE-11a & 1078.48 & 344.94 & 344.91 & 9/27/1991 & -- & 733.56 & $B D$ & database \\
\hline UE-11a & 1078.48 & 345.00 & 344.97 & $10 / 21 / 1991$ & -- & 733.50 & $\mathrm{BD}$ & database \\
\hline UE-11a & 1078.48 & 345.22 & 345.19 & $11 / 20 / 1991$ & -- & 733.29 & $\mathrm{BD}$ & database \\
\hline UE-11a & 1078.48 & 345.06 & 345.04 & $12 / 11 / 1991$ & -- & 733.44 & $B D$ & database \\
\hline UE-11a & 1078.48 & 345.06 & 345.04 & \begin{tabular}{|l|}
$1 / 17 / 1992$ \\
\end{tabular} & -- & 733.44 & $\mathrm{BD}$ & database \\
\hline UE-11a & 1078.48 & 345.06 & 345.04 & $2 / 11 / 1992$ & -- & 733.44 & $\mathrm{BD}$ & database \\
\hline UE-11a & 1078.48 & 345.16 & 345.13 & $3 / 12 / 1992$ & -- & 733.35 & $B D$ & database \\
\hline UE-11a & 1078.48 & 344.97 & 344.94 & $4 / 14 / 1992$ & -- & 733.53 & $B D$ & database \\
\hline UE-11a & 1078.48 & 344.94 & 344.91 & $5 / 11 / 1992$ & -- & 733.56 & $\mathrm{BD}$ & database \\
\hline UE-11a & 1078.48 & 344.97 & 344.94 & $6 / 15 / 1992$ & -- & 733.53 & $B D$ & database \\
\hline UE-11a & 1078.48 & 345.22 & 345.19 & $7 / 13 / 1992$ & -- & 733.29 & $B D$ & database \\
\hline UE-11a & 1078.48 & 344.91 & 344.88 & $8 / 11 / 1992$ & -- & 733.59 & $B D$ & database \\
\hline UE-11a & 1078.48 & 344.58 & 344.55 & 9/17/1992 & -- & 733.93 & $B D$ & database \\
\hline UE-11a & 1078.48 & 344.91 & 344.88 & 10/14/1992 & -- & 733.59 & $B D$ & database \\
\hline UE-11a & 1078.48 & 344.94 & 344.91 & $11 / 24 / 1992$ & -- & 733.56 & $\mathrm{BD}$ & database \\
\hline UE-11a & 1078.48 & 344.91 & 344.88 & $1 / 27 / 1993$ & -- & 733.59 & $B D$ & database \\
\hline UE-11a & 1078.48 & 344.94 & 344.91 & 2/24/1993 & -- & 733.56 & $\mathrm{BD}$ & database \\
\hline UE-11a & 1078.48 & 344.94 & 344.91 & $3 / 25 / 1993$ & -- & 733.56 & $B D$ & database \\
\hline UE-11a & 1078.48 & 345.03 & 345.01 & $4 / 6 / 1993$ & -- & 733.47 & $B D$ & database \\
\hline UE-11a & 1078.48 & 344.76 & 344.73 & $6 / 28 / 1993$ & -- & 733.75 & $\mathrm{BD}$ & database \\
\hline UE-11a & 1078.48 & 344.83 & 344.80 & $7 / 29 / 1993$ & -- & 733.67 & $\mathrm{BD}$ & database \\
\hline UE-11a & 1078.48 & 344.86 & 344.83 & $1 / 31 / 1994$ & -- & 733.64 & $\mathrm{BD}$ & database \\
\hline UE-11a & 1078.48 & -- & -- & $5 / 17 / 1994$ & $\mathrm{O}$ & & -- & database \\
\hline UE-11a & 1078.48 & -- & -- & $7 / 15 / 1994$ & $\mathrm{O}$ & & -- & database \\
\hline UE-11a & 1078.48 & -- & -- & $10 / 24 / 1994$ & $\mathrm{O}$ & & -- & database \\
\hline UE-11a & 1078.48 & 344.72 & 344.69 & $7 / 26 / 1996$ & -- & 733.79 & $\mathrm{BD}$ & database \\
\hline UE-11a & 1078.48 & -- & -- & $10 / 21 / 1998$ & $D$ & & -- & database \\
\hline UE-11a & 1078.48 & -- & -- & $4 / 28 / 1999$ & D & & -- & database \\
\hline UE-11a & 1078.48 & -- & -- & $11 / 4 / 1999$ & $D$ & & -- & database \\
\hline UE-11a & 1078.48 & -- & -- & $7 / 19 / 2001$ & $D$ & & -- & database \\
\hline UE-11a & 1078.48 & -- & -- & $12 / 23 / 2002$ & $D$ & & -- & database \\
\hline UE-11a & 1078.48 & -- & -- & 3/10/2003 & $D$ & & -- & database \\
\hline UE-11a & 1078.48 & -- & -- & $11 / 20 / 2003$ & $D$ & & -- & database \\
\hline
\end{tabular}

${ }^{a}$ meters below reference point

${ }^{b}$ Site Status: C = Water level was measured prior to well completion.

$\mathrm{D}=$ Site was dry (no water level recorded). 
Well UE-11a

Water Level Data

\begin{tabular}{|c|c|c|c|c|c|c|c|c|}
\hline $\begin{array}{c}\text { Well } \\
\begin{array}{c}\text { Reporting } \\
\text { Name }\end{array}\end{array}$ & $\begin{array}{c}\text { Reference } \\
\text { Point } \\
\text { Elevation } \\
(\mathrm{m})\end{array}$ & $\begin{array}{c}\text { Measured } \\
\text { Depth to } \\
\text { Water } \\
(\mathrm{mbrp})^{\mathrm{a}}\end{array}$ & $\begin{array}{c}\text { Corrected } \\
\text { Depth to } \\
\text { Water } \\
(\mathrm{mbrp})\end{array}$ & $\begin{array}{c}\text { Measure- } \\
\text { ment Date }\end{array}$ & $\begin{array}{c}\text { Site } \\
\text { Status }\end{array}$ & $\begin{array}{c}\text { Water } \\
\text { Level } \\
\text { Elevation } \\
(\mathrm{masl})^{\mathrm{c}}\end{array}$ & $\begin{array}{c}\text { Type } \\
\text { Correction }^{\mathrm{d}}\end{array}$ & Source $^{\mathrm{e}}$ \\
\hline
\end{tabular}

$\mathrm{O}=$ An obstruction was encountered in the well above the water surface (no water level recorded).

-- = Not applicable

${ }^{\mathrm{c}}$ meters above sea level

used to determine historical and contemporary static water level not applicable

used to determine historical static water level

not applicable

used to determine contemporary static water level

${ }^{\mathrm{d}}$ Type Correction: $\mathrm{BD}=$ water level corrected for borehole deviation

-- = Not applicable

${ }^{\mathrm{e}}$ Source: database $=$ UGTA borehole database 
Well UE-11b

Water Level Data

\begin{tabular}{|c|c|c|c|c|c|c|c|c|}
\hline $\begin{array}{c}\text { Well } \\
\text { Reporting } \\
\text { Name }\end{array}$ & \begin{tabular}{|c} 
Reference \\
Point \\
Elevation \\
$(\mathrm{m})$
\end{tabular} & $\begin{array}{c}\text { Measured } \\
\text { Depth to } \\
\text { Water } \\
\text { (mbrp) }^{\mathrm{a}} \\
\end{array}$ & \begin{tabular}{|c|}
$\begin{array}{c}\text { Corrected } \\
\text { Depth to } \\
\text { Water } \\
\text { (mbrp) }\end{array}$ \\
\end{tabular} & $\begin{array}{c}\text { Measure- } \\
\text { ment Date }\end{array}$ & $\begin{array}{c}\text { Site } \\
\text { Status }^{b}\end{array}$ & $\begin{array}{c}\text { Water } \\
\text { Level } \\
\text { Elevation } \\
\text { (masl) }^{c} \\
\end{array}$ & $\begin{array}{c}\text { Type } \\
\text { Correction }^{d}\end{array}$ & Source \\
\hline UE-11b & 1093.01 & 358.38 & -- & $10 / 22 / 1965$ & $\mathrm{C}$ & 734.63 & none & database \\
\hline UE-11b & 1093.01 & 349.30 & -- & \begin{tabular}{|l|}
$12 / 6 / 1985$ \\
\end{tabular} & -- & 743.71 & none & database \\
\hline
\end{tabular}

${ }^{a}$ meters below reference point

${ }^{b}$ Site Status: $C=$ Water level was measured prior to well completion.

-- = Not applicable

${ }^{\mathrm{c}}$ meters above sea level

used to determine historical and contemporary static water level

used to determine historical static water level not applicable

used to determine contemporary static water level not applicable

d Type Correction: none $=$ no correction made to water level

esource: database = UGTA borehole database 
WW-1

Water Level Data

\begin{tabular}{|l|c|c|c|c|c|c|c|c|}
\hline $\begin{array}{c}\text { Well } \\
\text { Reporting } \\
\text { Name }\end{array}$ & $\begin{array}{c}\text { Reference } \\
\text { Point } \\
\text { Elevation } \\
(\mathbf{m})\end{array}$ & $\begin{array}{c}\text { Measured } \\
\text { Depth to } \\
\text { Water } \\
(\mathrm{mbrp})^{\mathrm{a}}\end{array}$ & $\begin{array}{c}\text { Corrected } \\
\text { Depth to } \\
\text { Water } \\
(\mathbf{m b r p})\end{array}$ & $\begin{array}{c}\text { Measure- } \\
\text { ment Date }\end{array}$ & $\begin{array}{c}\text { Site } \\
\text { Status }\end{array}$ & $\begin{array}{c}\text { Water } \\
\text { Level } \\
\text { Elevation } \\
(\text { masl })^{\text {c }}\end{array}$ & $\begin{array}{c}\text { Type } \\
\text { Correction }^{\mathrm{d}}\end{array}$ & Source $^{\mathrm{e}}$ \\
\hline WW-1 & 944.88 & 217.63 & -- & $12 / 17 / 1950$ & -- & 727.25 & none & database \\
\hline WW-1 & 944.88 & -- & -- & $2 / 5 / 2001$ & 0 & -- & -- & database \\
\hline
\end{tabular}

${ }^{a}$ meters below reference point

${ }^{b}$ Site Status: $\mathrm{O}=$ An obstruction was encountered in the well above the water surface (no water level recorded).

$--=$ Not applicable

${ }^{\mathrm{c}}$ meters above sea level

used to determine historical and contemporary static water level not applicable

used to determine historical static water level

used to determine contemporary static water level not applicable

d Type Correction: none $=$ no correction made to water level

${ }^{\text {e}}$ Source: database = UGTA borehole database 
WW-4

Water Level Data

\begin{tabular}{|c|c|c|c|c|c|c|c|c|}
\hline $\begin{array}{c}\text { Well } \\
\text { Reporting } \\
\text { Name }\end{array}$ & \begin{tabular}{|c|} 
Reference \\
Point \\
Elevation \\
$(\mathrm{m})$
\end{tabular} & $\begin{array}{c}\text { Measured } \\
\text { Depth to } \\
\text { Water } \\
\left(\text { mbrp) }{ }^{\mathrm{a}}\right. \\
\end{array}$ & $\begin{array}{c}\text { Corrected } \\
\text { Depth to } \\
\text { Water } \\
\text { (mbrp) }\end{array}$ & $\begin{array}{c}\text { Measure- } \\
\text { ment Date }\end{array}$ & $\begin{array}{c}\text { Site } \\
\text { Status }^{b}\end{array}$ & $\begin{array}{c}\text { Water } \\
\text { Level } \\
\text { Elevation } \\
\text { (masl) }^{c}\end{array}$ & $\begin{array}{c}\text { Type } \\
\text { Correction }^{d}\end{array}$ & Source \\
\hline WW-4 & 1097.74 & 253.13 & 253.11 & $2 / 24 / 1983$ & -- & 844.63 & $\mathrm{BD}$ & database \\
\hline WW-4 & 1097.74 & 253.14 & 253.12 & $2 / 24 / 1983$ & -- & 844.62 & $\mathrm{BD}$ & database \\
\hline WW-4 & 1097.74 & 254.72 & 254.71 & $2 / 21 / 1990$ & -- & 843.03 & $\mathrm{BD}$ & database \\
\hline WW-4 & 1097.74 & 254.78 & 254.77 & $2 / 22 / 1990$ & -- & 842.97 & $\mathrm{BD}$ & database \\
\hline WW-4 & 1097.74 & 254.57 & 254.55 & $2 / 22 / 1990$ & -- & 843.18 & $\mathrm{BD}$ & database \\
\hline WW-4 & 1097.74 & 254.93 & 254.92 & $2 / 23 / 1990$ & $P$ & 842.82 & $\mathrm{BD}$ & database \\
\hline WW-4 & 1097.74 & 254.51 & 254.49 & $2 / 26 / 1990$ & -- & 843.24 & $\mathrm{BD}$ & database \\
\hline WW-4 & 1097.74 & 254.63 & 254.61 & $9 / 19 / 1990$ & $\mathrm{R}$ & 843.12 & $\mathrm{BD}$ & database \\
\hline WW-4 & 1097.74 & \begin{tabular}{l|l}
-- \\
\end{tabular} & -- & $11 / 5 / 1990$ & $P$ & \begin{tabular}{l|}
-- \\
\end{tabular} & $\mathrm{BD}$ & database \\
\hline WW-4 & 1097.74 & 254.39 & 254.37 & $1 / 14 / 1991$ & -- & 843.37 & $\mathrm{BD}$ & database \\
\hline WW-4 & 1097.74 & \begin{tabular}{l|l}
-- \\
\end{tabular} & -- & $2 / 19 / 1991$ & $\mathrm{P}$ & -- & $\mathrm{BD}$ & database \\
\hline WW-4 & 1097.74 & -- & -- & $3 / 18 / 1991$ & $\mathrm{P}$ & -- & $\mathrm{BD}$ & database \\
\hline WW-4 & 1097.74 & -- & -- & $4 / 26 / 1991$ & $\mathrm{P}$ & -- & $\mathrm{BD}$ & database \\
\hline WW-4 & 1097.74 & -- & -- & $5 / 6 / 1991$ & $\mathrm{P}$ & -- & $\mathrm{BD}$ & database \\
\hline WW-4 & 1097.74 & -- & -- & $6 / 10 / 1991$ & $\mathrm{P}$ & -- & $\mathrm{BD}$ & database \\
\hline WW-4 & 1097.74 & 254.66 & 254.65 & $7 / 5 / 1991$ & -- & 843.09 & $\mathrm{BD}$ & database \\
\hline WW-4 & 1097.74 & 254.48 & 254.46 & $8 / 16 / 1991$ & -- & 843.27 & $\mathrm{BD}$ & database \\
\hline WW-4 & 1097.74 & -- & -- & $8 / 28 / 1991$ & $\mathrm{P}$ & -- & $\mathrm{BD}$ & database \\
\hline WW-4 & 1097.74 & -- & -- & 9/27/1991 & $\mathrm{P}$ & -- & $\mathrm{BD}$ & database \\
\hline WW-4 & 1097.74 & -- & -- & 10/21/1991 & $P$ & -- & $\mathrm{BD}$ & database \\
\hline WW-4 & 1097.74 & 259.90 & 259.89 & 11/20/1991 & -- & 837.85 & $\mathrm{BD}$ & database \\
\hline WW-4 & 1097.74 & 254.60 & 254.58 & 12/11/1991 & -- & 843.15 & $\mathrm{BD}$ & database \\
\hline WW-4 & 1097.74 & 254.42 & 254.40 & \begin{tabular}{|c|}
$1 / 17 / 1992$ \\
\end{tabular} & -- & 843.34 & $\mathrm{BD}$ & database \\
\hline WW-4 & 1097.74 & 254.60 & 254.58 & $2 / 11 / 1992$ & -- & 843.15 & $\mathrm{BD}$ & database \\
\hline WW-4 & 1097.74 & 259.93 & 259.92 & $3 / 12 / 1992$ & -- & 837.82 & $\mathrm{BD}$ & database \\
\hline WW-4 & 1097.74 & 259.81 & 259.80 & $4 / 14 / 1992$ & -- & 837.94 & $\mathrm{BD}$ & database \\
\hline WW-4 & 1097.74 & 259.84 & 259.83 & $5 / 11 / 1992$ & -- & 837.91 & $\mathrm{BD}$ & database \\
\hline WW-4 & 1097.74 & 259.90 & 259.89 & $6 / 15 / 1992$ & -- & 837.85 & $\mathrm{BD}$ & database \\
\hline WW-4 & 1097.74 & 259.05 & 259.03 & $7 / 13 / 1992$ & $\mathrm{P}$ & 838.70 & $\mathrm{BD}$ & database \\
\hline WW-4 & 1097.74 & 259.23 & 259.21 & $8 / 11 / 1992$ & -- & 838.52 & $\mathrm{BD}$ & database \\
\hline WW-4 & 1097.74 & 259.69 & 259.67 & 9/17/1992 & $\mathrm{P}$ & 838.06 & $\mathrm{BD}$ & database \\
\hline WW-4 & 1097.74 & 259.26 & 259.25 & 10/14/1992 & $\mathrm{P}$ & 838.49 & $\mathrm{BD}$ & database \\
\hline WW-4 & 1097.74 & 254.63 & 254.61 & \begin{tabular}{|l|}
$11 / 17 / 1992$ \\
\end{tabular} & -- & 843.12 & $\mathrm{BD}$ & database \\
\hline WW-4 & 1097.74 & 259.17 & 259.16 & 11/20/1992 & $\mathrm{P}$ & 838.58 & $\mathrm{BD}$ & database \\
\hline WW-4 & 1097.74 & 254.49 & 254.47 & \begin{tabular}{|c|}
$1 / 22 / 1993$ \\
\end{tabular} & -- & 843.27 & $\mathrm{BD}$ & database \\
\hline WW-4 & 1097.74 & 254.56 & 254.55 & $3 / 10 / 1993$ & -- & 843.19 & $\mathrm{BD}$ & database \\
\hline WW-4 & 1097.74 & 259.20 & 259.19 & $6 / 28 / 1993$ & $\mathrm{P}$ & 838.55 & $\mathrm{BD}$ & database \\
\hline WW-4 & 1097.74 & 254.83 & 254.81 & \begin{tabular}{|c|}
$7 / 29 / 1993$ \\
\end{tabular} & -- & 842.92 & $\mathrm{BD}$ & database \\
\hline WW-4 & 1097.74 & 255.18 & 255.17 & 12/20/1993 & -- & 842.57 & $\mathrm{BD}$ & database \\
\hline
\end{tabular}


WW-4

Water Level Data

\begin{tabular}{|c|c|c|c|c|c|c|c|c|}
\hline $\begin{array}{c}\text { Well } \\
\text { Reporting } \\
\text { Name }\end{array}$ & $\begin{array}{c}\text { Reference } \\
\text { Point } \\
\text { Elevation } \\
(\mathrm{m})\end{array}$ & $\begin{array}{c}\text { Measured } \\
\text { Depth to } \\
\text { Water } \\
(\text { mbrp) }\end{array}$ & $\begin{array}{c}\text { Corrected } \\
\text { Depth to } \\
\text { Water } \\
\text { (mbrp) }\end{array}$ & $\begin{array}{l}\text { Measure- } \\
\text { ment Date }\end{array}$ & $\begin{array}{c}\text { Site } \\
\text { Status }^{b}\end{array}$ & $\begin{array}{c}\text { Water } \\
\text { Level } \\
\text { Elevation } \\
\text { (masl) }^{c}\end{array}$ & $\begin{array}{c}\text { Type } \\
\text { Correction }^{d}\end{array}$ & Source ${ }^{e}$ \\
\hline WW-4 & 1097.74 & 254.92 & 254.90 & $2 / 9 / 1994$ & -- & 842.83 & $B D$ & database \\
\hline WW-4 & 1097.74 & 259.23 & 259.22 & $4 / 12 / 1994$ & -- & 838.52 & $B D$ & database \\
\hline WW-4 & 1097.74 & 255.17 & 255.15 & $5 / 17 / 1994$ & -- & 842.59 & $B D$ & database \\
\hline WW-4 & 1097.74 & 254.86 & 254.85 & 10/24/1994 & -- & 842.89 & $B D$ & database \\
\hline WW-4 & 1097.74 & 254.59 & 254.58 & 3/16/1995 & -- & 843.16 & $B D$ & database \\
\hline WW-4 & 1097.74 & 254.58 & 254.57 & $6 / 19 / 1995$ & -- & 843.17 & $B D$ & database \\
\hline WW-4 & 1097.74 & 254.91 & 254.90 & 12/15/1995 & -- & 842.84 & $B D$ & database \\
\hline WW-4 & 1097.74 & 254.70 & 254.68 & $3 / 21 / 1996$ & -- & 843.05 & $B D$ & database \\
\hline WW-4 & 1097.74 & 254.78 & 254.77 & $7 / 3 / 1996$ & -- & 842.97 & $B D$ & database \\
\hline WW-4 & 1097.74 & 254.71 & 254.70 & 12/12/1996 & -- & 843.04 & $B D$ & database \\
\hline WW-4 & 1097.74 & 254.64 & 254.62 & 3/13/1997 & -- & 843.11 & $B D$ & database \\
\hline WW-4 & 1097.74 & 254.88 & 254.87 & $3 / 31 / 1998$ & -- & 842.87 & $B D$ & database \\
\hline WW-4 & 1097.74 & 256.72 & 256.71 & 10/21/1998 & -- & 841.03 & $B D$ & database \\
\hline WW-4 & 1097.74 & 256.76 & 256.75 & 4/27/1999 & $P$ & 840.99 & $B D$ & database \\
\hline WW-4 & 1097.74 & 254.99 & 254.98 & $11 / 15 / 1999$ & -- & 842.76 & $B D$ & database \\
\hline WW-4 & 1097.74 & 255.18 & 255.17 & $7 / 26 / 2000$ & $\mathrm{P}$ & 842.57 & $B D$ & database \\
\hline WW-4 & 1097.74 & 255.15 & 255.14 & $10 / 18 / 2000$ & -- & 842.60 & $B D$ & database \\
\hline WW-4 & 1097.74 & 256.92 & 256.91 & $4 / 4 / 2001$ & $P$ & 840.83 & $B D$ & database \\
\hline WW-4 & 1097.74 & 255.72 & 255.71 & $7 / 12 / 2001$ & -- & 842.03 & $B D$ & database \\
\hline WW-4 & 1097.74 & 257.29 & 257.27 & 9/20/2001 & $\mathrm{P}$ & 840.46 & $B D$ & database \\
\hline WW-4 & 1097.74 & 255.22 & 255.20 & $11 / 15 / 2001$ & -- & 842.53 & $B D$ & database \\
\hline WW-4 & 1097.74 & 255.37 & 255.36 & 3/8/2002 & -- & 842.38 & $B D$ & database \\
\hline WW-4 & 1097.74 & 255.17 & 255.15 & $4 / 1 / 2002$ & -- & 842.58 & $B D$ & database \\
\hline WW-4 & 1097.74 & 255.21 & 255.20 & 4/8/2002 & -- & 842.54 & $B D$ & database \\
\hline WW-4 & 1097.74 & 255.01 & 255.00 & $4 / 15 / 2002$ & -- & 842.74 & $\mathrm{BD}$ & database \\
\hline WW-4 & 1097.74 & 255.22 & 255.20 & 4/22/2002 & -- & 842.53 & $\mathrm{BD}$ & database \\
\hline WW-4 & 1097.74 & 255.20 & 255.18 & 4/29/2002 & -- & 842.55 & $B D$ & database \\
\hline WW-4 & 1097.74 & 255.51 & 255.50 & $7 / 25 / 2002$ & -- & 842.24 & $\mathrm{BD}$ & database \\
\hline WW-4 & 1097.74 & 257.29 & 257.27 & 9/9/2002 & $\mathrm{P}$ & 840.46 & $\mathrm{BD}$ & database \\
\hline WW-4 & 1097.74 & 255.33 & 255.32 & 12/16/2002 & -- & 842.42 & $B D$ & database \\
\hline WW-4 & 1097.74 & 255.38 & 255.36 & $3 / 17 / 2003$ & -- & 842.38 & $\mathrm{BD}$ & database \\
\hline WW-4 & 1097.74 & 255.49 & 255.47 & $6 / 23 / 2003$ & -- & 842.27 & $B D$ & database \\
\hline WW-4 & 1097.74 & 255.62 & 255.61 & 9/22/2003 & -- & 842.13 & $\mathrm{BD}$ & database \\
\hline WW-4 & 1097.74 & 255.59 & 255.58 & $11 / 17 / 2003$ & -- & 842.16 & $B D$ & database \\
\hline WW-4 & 1097.74 & 255.55 & 255.54 & $3 / 8 / 2004$ & -- & 842.20 & $B D$ & USGS websit \\
\hline
\end{tabular}

${ }^{\mathrm{a}}$ meters below reference point

${ }^{\mathrm{b}}$ Site Status: $\mathrm{P}=$ Site was being pumped.

$R=$ Site had been pumped recently. 
WW-4

Water Level Data

\begin{tabular}{|c|c|c|c|c|c|c|c|c|}
\hline $\begin{array}{c}\text { Well } \\
\text { Reporting } \\
\text { Name }\end{array}$ & $\begin{array}{c}\text { Reference } \\
\text { Point } \\
\begin{array}{c}\text { Elevation } \\
(\mathrm{m})\end{array}\end{array}$ & $\begin{array}{c}\text { Measured } \\
\text { Depth to } \\
\text { Water } \\
(\mathrm{mbrp})^{\mathrm{a}}\end{array}$ & $\begin{array}{c}\text { Corrected } \\
\text { Depth to } \\
\text { Water } \\
(\mathrm{mbrp})\end{array}$ & $\begin{array}{c}\text { Measure- } \\
\text { ment Date }\end{array}$ & $\begin{array}{c}\text { Site } \\
\text { Status }\end{array}$ & $\begin{array}{c}\text { Water } \\
\text { Level } \\
\text { Elevation } \\
(\text { masl })^{c}\end{array}$ & $\begin{array}{c}\text { Type } \\
\text { Correction }^{\mathrm{d}}\end{array}$ & Source $^{\mathrm{e}}$ \\
\hline
\end{tabular}

-- = Not applicable

${ }^{\mathrm{c}}$ meters above sea level

used to determine historical and contemporary static water level not applicable

used to determine historical static water level

used to determine contemporary static water level not applicable

d Type Correction: BD = water level corrected for borehole deviation

e Source: database = UGTA borehole database

USGS website $=$ http://nevada.usgs.gov/doe_nv/ 
WW-4A

Water Level Data

\begin{tabular}{|c|c|c|c|c|c|c|c|c|}
\hline $\begin{array}{l}\text { Well } \\
\text { Reporting } \\
\text { Name }\end{array}$ & \begin{tabular}{|c|} 
Reference \\
Point \\
Elevation \\
$(\mathrm{m})$
\end{tabular} & \begin{tabular}{|c|} 
Measured \\
Depth to \\
Water \\
(mbrp) $^{\mathrm{a}}$
\end{tabular} & $\begin{array}{l}\text { Corrected } \\
\text { Depth to } \\
\text { Water } \\
\text { (mbrp) }\end{array}$ & \begin{tabular}{|l|} 
Measure- \\
ment Date
\end{tabular} & $\begin{array}{c}\text { Site } \\
\text { Status }^{b}\end{array}$ & $\begin{array}{c}\text { Water } \\
\text { Level } \\
\text { Elevation } \\
\text { (masl) }^{c}\end{array}$ & $\begin{array}{c}\text { Type } \\
\text { Correction }^{d}\end{array}$ & Source ${ }^{e}$ \\
\hline WW-4A & 1099.11 & 254.75 & -- & $2 / 22 / 1990$ & -- & 844.36 & none & database \\
\hline WW-4A & 1099.11 & \begin{tabular}{l|l}
-- & \\
\end{tabular} & -- & $2 / 23 / 1990$ & $P$ & \begin{tabular}{l|l}
-- & \\
\end{tabular} & none & database \\
\hline WW-4A & 1099.11 & 254.48 & -- & $2 / 26 / 1990$ & -- & 844.63 & none & database \\
\hline WW-4A & 1099.11 & 254.84 & -- & $5 / 29 / 1990$ & -- & 844.27 & none & database \\
\hline WW-4A & 1099.11 & 254.87 & -- & $7 / 30 / 1990$ & -- & 844.24 & none & database \\
\hline WW-4A & 1099.11 & 254.60 & -- & $10 / 26 / 1990$ & -- & 844.51 & none & database \\
\hline WW-4A & 1099.11 & 254.45 & -- & $12 / 12 / 1990$ & -- & 844.66 & none & database \\
\hline WW-4A & 1099.11 & 254.39 & -- & $1 / 14 / 1991$ & -- & 844.72 & none & database \\
\hline WW-4A & 1099.11 & 254.78 & -- & $2 / 19 / 1991$ & $S$ & 844.33 & none & database \\
\hline WW-4A & 1099.11 & 254.63 & -- & $3 / 18 / 1991$ & $S$ & 844.48 & none & database \\
\hline WW-4A & 1099.11 & 254.81 & -- & $4 / 26 / 1991$ & $S$ & 844.30 & none & database \\
\hline WW-4A & 1099.11 & 254.66 & -- & $5 / 6 / 1991$ & $S$ & 844.45 & none & database \\
\hline WW-4A & 1099.11 & 254.66 & -- & $6 / 10 / 1991$ & $S$ & 844.45 & none & database \\
\hline WW-4A & 1099.11 & 254.69 & -- & $7 / 5 / 1991$ & -- & 844.42 & none & database \\
\hline WW-4A & 1099.11 & 254.45 & -- & $8 / 16 / 1991$ & -- & 844.66 & none & database \\
\hline WW-4A & 1099.11 & 254.57 & -- & $8 / 23 / 1991$ & -- & 844.54 & none & database \\
\hline WW-4A & 1099.11 & 254.66 & -- & $1 / 20 / 1993$ & -- & 844.45 & none & database \\
\hline WW-4A & 1099.11 & 254.71 & -- & $1 / 21 / 1993$ & -- & 844.40 & none & database \\
\hline WW-4A & 1099.11 & 254.76 & -- & $3 / 30 / 1993$ & -- & 844.34 & none & database \\
\hline WW-4A & 1099.11 & 254.75 & -- & $6 / 28 / 1993$ & $S$ & 844.36 & none & database \\
\hline WW-4A & 1099.11 & 254.87 & -- & $7 / 29 / 1993$ & -- & 844.24 & none & database \\
\hline WW-4A & 1099.11 & 254.70 & -- & $12 / 20 / 1993$ & -- & 844.41 & none & database \\
\hline WW-4A & 1099.11 & 255.06 & -- & \begin{tabular}{|l|}
$2 / 9 / 1994$ \\
\end{tabular} & -- & 844.05 & none & database \\
\hline WW-4A & 1099.11 & 259.91 & -- & $5 / 17 / 1994$ & $P$ & 839.20 & none & database \\
\hline WW-4A & 1099.11 & 259.73 & -- & $10 / 24 / 1994$ & -- & 839.38 & none & database \\
\hline WW-4A & 1099.11 & 254.58 & -- & $3 / 16 / 1995$ & -- & 844.52 & none & database \\
\hline WW-4A & 1099.11 & 254.60 & -- & $6 / 19 / 1995$ & -- & 844.51 & none & database \\
\hline WW-4A & 1099.11 & 256.74 & -- & $2 / 27 / 1996$ & $\mathrm{P}$ & 842.37 & none & database \\
\hline WW-4A & 1099.11 & 258.49 & -- & \begin{tabular}{|l|}
$7 / 3 / 1996$ \\
\end{tabular} & -- & 840.62 & none & database \\
\hline WW-4A & 1099.11 & 254.83 & -- & 12/12/1996 & -- & 844.28 & none & database \\
\hline WW-4A & 1099.11 & 254.79 & -- & 3/13/1997 & -- & 844.31 & none & database \\
\hline WW-4A & 1099.11 & 254.94 & -- & 3/24/1998 & -- & 844.16 & none & database \\
\hline WW-4A & 1099.11 & 255.17 & -- & 10/21/1998 & -- & 843.94 & none & database \\
\hline WW-4A & 1099.11 & 258.55 & -- & 4/27/1999 & $\mathrm{P}$ & 840.56 & none & database \\
\hline WW-4A & 1099.11 & 258.43 & -- & $11 / 15 / 1999$ & $\mathrm{P}$ & 840.68 & none & database \\
\hline WW-4A & 1099.11 & 258.72 & -- & $7 / 27 / 2000$ & -- & 840.39 & none & database \\
\hline WW-4A & 1099.11 & 255.29 & -- & $10 / 18 / 2000$ & -- & 843.82 & none & database \\
\hline WW-4A & 1099.11 & 258.73 & -- & \begin{tabular}{|l|}
$4 / 4 / 2001$ \\
\end{tabular} & $P$ & 840.38 & none & database \\
\hline WW-4A & 1099.11 & 259.12 & -- & $7 / 12 / 2001$ & $P$ & 839.99 & none & database \\
\hline
\end{tabular}


WW-4A

Water Level Data

\begin{tabular}{|l|c|c|c|c|c|c|c|l|}
\hline $\begin{array}{c}\text { Well } \\
\text { Reporting } \\
\text { Name }\end{array}$ & $\begin{array}{c}\text { Reference } \\
\text { Point } \\
\text { Elevation } \\
(\mathbf{m})\end{array}$ & $\begin{array}{c}\text { Measured } \\
\text { Depth to } \\
\text { Water } \\
(\mathbf{m b r p})^{\mathbf{a}}\end{array}$ & $\begin{array}{c}\text { Corrected } \\
\text { Depth to } \\
\text { Water } \\
(\mathbf{m b r p})\end{array}$ & $\begin{array}{c}\text { Measure- } \\
\text { ment Date }\end{array}$ & $\begin{array}{c}\text { Site } \\
\text { Status }\end{array}$ & $\begin{array}{c}\text { Water } \\
\text { Level } \\
\text { Elevation } \\
(\mathbf{m a s l})^{\mathbf{c}}\end{array}$ & $\begin{array}{c}\text { Type } \\
\text { Correction }^{d}\end{array}$ & Source $^{\mathbf{e}}$ \\
\hline WW-4A & 1099.11 & 258.99 & -- & $9 / 20 / 2001$ & P & 840.11 & none & database \\
\hline WW-4A & 1099.11 & 255.39 & -- & $11 / 15 / 2001$ & -- & 843.72 & none & database \\
\hline WW-4A & 1099.11 & 255.54 & -- & $3 / 8 / 2002$ & -- & 843.57 & none & database \\
\hline WW-4A & 1099.11 & 255.50 & -- & $3 / 8 / 2002$ & -- & 843.60 & none & database \\
\hline WW-4A & 1099.11 & 255.31 & -- & $4 / 1 / 2002$ & -- & 843.80 & none & database \\
\hline WW-4A & 1099.11 & 255.35 & -- & $4 / 8 / 2002$ & -- & 843.76 & none & database \\
\hline WW-4A & 1099.11 & 255.13 & -- & $4 / 18 / 2002$ & -- & 843.98 & none & database \\
\hline WW-4A & 1099.11 & 255.38 & -- & $4 / 22 / 2002$ & -- & 843.73 & none & database \\
\hline WW-4A & 1099.11 & 255.32 & -- & $4 / 29 / 2002$ & -- & 843.79 & none & database \\
\hline WW-4A & 1099.11 & 258.91 & -- & $7 / 25 / 2002$ & P & 840.20 & none & database \\
\hline WW-4A & 1099.11 & 259.06 & -- & $9 / 9 / 2002$ & P & 840.05 & none & database \\
\hline WW-4A & 1099.11 & 255.48 & -- & $12 / 16 / 2002$ & -- & 843.63 & none & database \\
\hline WW-4A & 1099.11 & 255.53 & -- & $3 / 17 / 2003$ & -- & 843.58 & none & database \\
\hline WW-4A & 1099.11 & 255.63 & -- & $6 / 23 / 2003$ & -- & 843.48 & none & database \\
\hline WW-4A & 1099.11 & 255.78 & -- & $9 / 22 / 2003$ & -- & 843.33 & none & database \\
\hline WW-4A & 1099.11 & 255.74 & -- & $11 / 17 / 2003$ & -- & 843.37 & none & database \\
\hline WW-4A & 1099.11 & 255.70 & -- & $3 / 8 / 2004$ & -- & 843.41 & none & USGS website \\
\hline
\end{tabular}

${ }^{a}$ meters below reference point

${ }^{\mathrm{b}}$ Site Status: $\mathrm{P}=$ Site was being pumped.

$\mathrm{S}=\mathrm{A}$ nearby site that taps the same aquifer was being pumped.

-- = Not applicable

${ }^{c}$ meters above sea level

used to determine historical and contemporary static water level not applicable used to determine historical static water level

used to determine contemporary static water level not applicable

d Type Correction: none $=$ no correction made to water level

eSource: database = UGTA borehole database

USGS website $=$ http://nevada.usgs.gov/doe_nv/ 
WW-5A

Water Level Data

\begin{tabular}{|c|c|c|c|c|c|c|c|c|}
\hline $\begin{array}{c}\text { Well } \\
\text { Reporting } \\
\text { Name }\end{array}$ & $\begin{array}{c}\text { Reference } \\
\text { Point } \\
\text { Elevation } \\
(\mathrm{m})\end{array}$ & $\begin{array}{c}\text { Measured } \\
\text { Depth to } \\
\text { Water } \\
\text { (mbrp) }^{\mathrm{a}}\end{array}$ & $\begin{array}{c}\text { Corrected } \\
\text { Depth to } \\
\text { Water } \\
\text { (mbrp) }\end{array}$ & $\begin{array}{c}\text { Measure- } \\
\text { ment Date }\end{array}$ & $\begin{array}{c}\text { Site } \\
\text { Status }^{b}\end{array}$ & $\begin{array}{c}\text { Water } \\
\text { Level } \\
\text { Elevation } \\
\text { (masl) }^{c}\end{array}$ & $\begin{array}{c}\text { Type } \\
\text { Correction }^{d}\end{array}$ & Source $^{e}$ \\
\hline WW-5A & 942.97 & 213.06 & \begin{tabular}{|l|}
-- \\
\end{tabular} & $3 / 15 / 1951$ & C & 729.91 & none & database \\
\hline WW-5A & 942.97 & 212.75 & -- & $1 / 26 / 1959$ & -- & 730.22 & none & database \\
\hline WW-5A & 942.97 & 212.08 & -- & $9 / 14 / 1959$ & $2^{f}$ & 730.89 & none & database \\
\hline WW-5A & 942.97 & 212.06 & -- & $9 / 23 / 1959$ & $12^{f}$ & 730.91 & none & database \\
\hline WW-5A & 942.97 & 212.45 & -- & 9/24/1959 & $\mathrm{R}$ & 730.52 & none & database \\
\hline WW-5A & 942.97 & 212.12 & -- & $10 / 7 / 1959$ & $6^{f}$ & 730.85 & none & database \\
\hline WW-5A & 942.97 & 215.37 & -- & $11 / 4 / 1971$ & -- & 727.60 & none & database \\
\hline WW-5A & 942.97 & 214.90 & -- & $7 / 27 / 1972$ & -- & 728.07 & none & database \\
\hline WW-5A & 942.97 & 216.19 & -- & $1 / 16 / 1980$ & -- & 726.77 & none & database \\
\hline WW-5A & 942.97 & 216.53 & -- & $2 / 11 / 1992$ & -- & 726.44 & none & database \\
\hline WW-5A & 942.97 & 216.77 & -- & $2 / 25 / 1992$ & -- & 726.20 & none & database \\
\hline WW-5A & 942.97 & 216.77 & -- & $3 / 12 / 1992$ & -- & 726.20 & none & database \\
\hline WW-5A & 942.97 & 217.02 & -- & $4 / 14 / 1992$ & -- & 725.95 & none & database \\
\hline WW-5A & 942.97 & 216.35 & -- & $5 / 11 / 1992$ & -- & 726.62 & none & database \\
\hline WW-5A & 942.97 & 216.29 & -- & $6 / 15 / 1992$ & -- & 726.68 & none & database \\
\hline WW-5A & 942.97 & 216.96 & -- & $7 / 13 / 1992$ & -- & 726.01 & none & database \\
\hline WW-5A & 942.97 & 216.90 & -- & $8 / 11 / 1992$ & -- & 726.07 & none & database \\
\hline WW-5A & 942.97 & 217.08 & -- & 9/17/1992 & -- & 725.89 & none & database \\
\hline WW-5A & 942.97 & 217.08 & -- & $10 / 14 / 1992$ & -- & 725.89 & none & database \\
\hline WW-5A & 942.97 & 216.38 & -- & $11 / 24 / 1992$ & -- & 726.59 & none & database \\
\hline WW-5A & 942.97 & 217.23 & -- & $1 / 21 / 1993$ & -- & 725.74 & none & database \\
\hline WW-5A & 942.97 & 217.47 & -- & 2/24/1993 & -- & 725.49 & none & database \\
\hline WW-5A & 942.97 & 217.57 & -- & $3 / 17 / 1993$ & -- & 725.40 & none & database \\
\hline WW-5A & 942.97 & 217.66 & -- & $4 / 6 / 1993$ & -- & 725.31 & none & database \\
\hline WW-5A & 942.97 & 217.11 & -- & $6 / 28 / 1993$ & -- & 725.86 & none & database \\
\hline WW-5A & 942.97 & 216.54 & -- & $7 / 29 / 1993$ & -- & 726.43 & none & database \\
\hline WW-5A & 942.97 & 216.98 & -- & $12 / 20 / 1993$ & -- & 725.98 & none & database \\
\hline WW-5A & 942.97 & 217.00 & -- & 2/2/1994 & -- & 725.97 & none & database \\
\hline WW-5A & 942.97 & 216.72 & -- & $5 / 16 / 1994$ & -- & 726.25 & none & database \\
\hline WW-5A & 942.97 & 217.03 & -- & $10 / 24 / 1994$ & -- & 725.94 & none & database \\
\hline WW-5A & 942.97 & 216.80 & -- & $2 / 21 / 1995$ & -- & 726.17 & none & database \\
\hline WW-5A & 942.97 & 216.90 & -- & $5 / 2 / 1995$ & -- & 726.07 & none & database \\
\hline WW-5A & 942.97 & 217.21 & -- & $9 / 20 / 1995$ & -- & 725.76 & none & database \\
\hline WW-5A & 942.97 & 217.00 & -- & 9/26/1995 & -- & 725.97 & none & database \\
\hline WW-5A & 942.97 & 217.22 & -- & $10 / 10 / 1995$ & -- & 725.75 & none & database \\
\hline WW-5A & 942.97 & 217.10 & -- & $1 / 22 / 1996$ & -- & 725.87 & none & database \\
\hline WW-5A & 942.97 & 216.87 & -- & $5 / 14 / 1996$ & -- & 726.10 & none & database \\
\hline WW-5A & 942.97 & 217.05 & -- & $5 / 28 / 1996$ & -- & 725.92 & none & database \\
\hline WW-5A & 942.97 & 217.06 & -- & $6 / 11 / 1996$ & -- & 725.91 & none & database \\
\hline
\end{tabular}


WW-5A

Water Level Data

\begin{tabular}{|c|c|c|c|c|c|c|c|c|}
\hline $\begin{array}{c}\text { Well } \\
\text { Reporting } \\
\text { Name }\end{array}$ & $\begin{array}{c}\text { Reference } \\
\text { Point } \\
\text { Elevation } \\
(\mathrm{m})\end{array}$ & $\begin{array}{c}\text { Measured } \\
\text { Depth to } \\
\text { Water } \\
(\mathrm{mbrp})^{\mathrm{a}}\end{array}$ & $\begin{array}{l}\text { Corrected } \\
\text { Depth to } \\
\text { Water } \\
\text { (mbrp) }\end{array}$ & $\begin{array}{l}\text { Measure- } \\
\text { ment Date }\end{array}$ & $\begin{array}{c}\text { Site } \\
\text { Status }^{b}\end{array}$ & $\begin{array}{c}\text { Water } \\
\text { Level } \\
\text { Elevation } \\
\text { (masl) }^{c}\end{array}$ & $\begin{array}{c}\text { Type } \\
\text { Correction }^{d}\end{array}$ & Source ${ }^{e}$ \\
\hline WW-5A & 942.97 & 217.02 & -- & 9/9/1996 & -- & 725.95 & none & database \\
\hline WW-5A & 942.97 & 217.00 & -- & $10 / 21 / 1996$ & -- & 725.97 & none & database \\
\hline WW-5A & 942.97 & 217.06 & -- & $10 / 22 / 1996$ & -- & 725.91 & none & database \\
\hline WW-5A & 942.97 & 216.89 & -- & $10 / 31 / 1996$ & -- & 726.08 & none & database \\
\hline WW-5A & 942.97 & 217.01 & -- & $11 / 7 / 1996$ & -- & 725.96 & none & database \\
\hline WW-5A & 942.97 & 216.84 & -- & $12 / 10 / 1996$ & -- & 726.13 & none & database \\
\hline WW-5A & 942.97 & 216.97 & -- & $1 / 8 / 1997$ & -- & 726.00 & none & database \\
\hline WW-5A & 942.97 & 216.85 & -- & $2 / 4 / 1997$ & -- & 726.12 & none & database \\
\hline WW-5A & 942.97 & 217.02 & -- & $3 / 4 / 1997$ & -- & 725.95 & none & database \\
\hline WW-5A & 942.97 & 216.96 & -- & $4 / 7 / 1997$ & -- & 726.01 & none & database \\
\hline WW-5A & 942.97 & 216.84 & -- & $5 / 1 / 1997$ & -- & 726.13 & none & database \\
\hline WW-5A & 942.97 & 216.69 & -- & $5 / 13 / 1997$ & -- & 726.28 & none & database \\
\hline WW-5A & 942.97 & 216.67 & -- & $5 / 20 / 1997$ & -- & 726.30 & none & database \\
\hline WW-5A & 942.97 & 216.82 & -- & $5 / 28 / 1997$ & -- & 726.15 & none & database \\
\hline WW-5A & 942.97 & 216.89 & -- & $6 / 3 / 1997$ & -- & 726.08 & none & database \\
\hline WW-5A & 942.97 & 216.86 & -- & 7/8/1997 & -- & 726.11 & none & database \\
\hline WW-5A & 942.97 & 216.69 & -- & $10 / 6 / 1997$ & -- & 726.27 & none & database \\
\hline WW-5A & 942.97 & 216.77 & -- & $11 / 6 / 1997$ & -- & 726.20 & none & database \\
\hline WW-5A & 942.97 & 216.63 & -- & $1 / 5 / 1998$ & -- & 726.34 & none & database \\
\hline WW-5A & 942.97 & 216.57 & -- & 2/4/1998 & -- & 726.40 & none & database \\
\hline WW-5A & 942.97 & 216.74 & -- & $3 / 3 / 1998$ & -- & 726.23 & none & database \\
\hline WW-5A & 942.97 & 216.87 & -- & 4/8/1998 & -- & 726.09 & none & database \\
\hline WW-5A & 942.97 & 216.77 & -- & $5 / 5 / 1998$ & -- & 726.20 & none & database \\
\hline WW-5A & 942.97 & 216.44 & -- & $6 / 1 / 1998$ & -- & 726.53 & none & database \\
\hline WW-5A & 942.97 & 216.38 & -- & $6 / 8 / 1998$ & -- & 726.59 & none & database \\
\hline WW-5A & 942.97 & 216.41 & -- & $6 / 10 / 1998$ & -- & 726.56 & none & database \\
\hline WW-5A & 942.97 & 216.64 & -- & $7 / 1 / 1998$ & -- & 726.33 & none & database \\
\hline WW-5A & 942.97 & 216.84 & -- & $8 / 5 / 1998$ & -- & 726.13 & none & database \\
\hline WW-5A & 942.97 & 216.72 & -- & 9/14/1998 & -- & 726.25 & none & database \\
\hline WW-5A & 942.97 & 216.77 & -- & 9/22/1998 & -- & 726.20 & none & database \\
\hline WW-5A & 942.97 & 216.69 & -- & $10 / 27 / 1998$ & -- & 726.27 & none & database \\
\hline WW-5A & 942.97 & 216.82 & -- & $11 / 12 / 1998$ & -- & 726.15 & none & database \\
\hline WW-5A & 942.97 & 216.64 & -- & 3/15/1999 & -- & 726.33 & none & database \\
\hline WW-5A & 942.97 & 216.72 & -- & $5 / 4 / 1999$ & -- & 726.25 & none & database \\
\hline WW-5A & 942.97 & 216.90 & -- & $5 / 5 / 1999$ & -- & 726.07 & none & database \\
\hline WW-5A & 942.97 & 216.92 & -- & $6 / 30 / 1999$ & -- & 726.05 & none & database \\
\hline WW-5A & 942.97 & 216.97 & -- & $7 / 29 / 1999$ & -- & 726.00 & none & database \\
\hline WW-5A & 942.97 & 216.90 & -- & 9/16/1999 & -- & 726.06 & none & database \\
\hline WW-5A & 942.97 & 216.83 & -- & 9/21/1999 & -- & 726.13 & none & database \\
\hline
\end{tabular}


WW-5A

Water Level Data

\begin{tabular}{|c|c|c|c|c|c|c|c|c|}
\hline $\begin{array}{c}\text { Well } \\
\text { Reporting } \\
\text { Name }\end{array}$ & \begin{tabular}{|c} 
Reference \\
Point \\
Elevation \\
$(\mathrm{m})$
\end{tabular} & \begin{tabular}{|c|} 
Measured \\
Depth to \\
Water \\
(mbrp) $^{\mathrm{a}}$
\end{tabular} & $\begin{array}{l}\text { Corrected } \\
\text { Depth to } \\
\text { Water } \\
\text { (mbrp) }\end{array}$ & $\begin{array}{c}\text { Measure- } \\
\text { ment Date }\end{array}$ & $\begin{array}{c}\text { Site } \\
\text { Status }^{b}\end{array}$ & $\begin{array}{c}\text { Water } \\
\text { Level } \\
\text { Elevation } \\
\text { (masl) }^{c}\end{array}$ & $\begin{array}{c}\text { Type } \\
\text { Correction }^{d}\end{array}$ & Source ${ }^{e}$ \\
\hline WW-5A & 942.97 & \begin{tabular}{|l|}
216.77 \\
\end{tabular} & -- & $11 / 16 / 1999$ & -- & 726.20 & none & database \\
\hline WW-5A & 942.97 & 217.02 & -- & $3 / 7 / 2000$ & -- & 725.95 & none & database \\
\hline WW-5A & 942.97 & 217.08 & -- & $7 / 12 / 2000$ & -- & 725.89 & none & database \\
\hline WW-5A & 942.97 & 216.83 & -- & $8 / 30 / 2000$ & -- & 726.14 & none & database \\
\hline WW-5A & 942.97 & 216.87 & -- & $10 / 3 / 2000$ & -- & 726.09 & none & database \\
\hline WW-5A & 942.97 & 216.92 & -- & $12 / 7 / 2000$ & -- & 726.05 & none & database \\
\hline WW-5A & 942.97 & 216.98 & -- & $4 / 16 / 2001$ & -- & 725.99 & none & database \\
\hline WW-5A & 942.97 & 216.86 & -- & $5 / 2 / 2001$ & -- & 726.11 & none & database \\
\hline WW-5A & 942.97 & 216.76 & -- & $5 / 7 / 2001$ & -- & 726.21 & none & database \\
\hline WW-5A & 942.97 & 216.78 & -- & $5 / 24 / 2001$ & -- & 726.19 & none & database \\
\hline WW-5A & 942.97 & 216.54 & -- & $7 / 12 / 2001$ & -- & 726.43 & none & database \\
\hline WW-5A & 942.97 & 216.65 & -- & $9 / 26 / 2001$ & -- & 726.32 & none & database \\
\hline WW-5A & 942.97 & 216.60 & -- & $12 / 27 / 2001$ & -- & 726.37 & none & database \\
\hline WW-5A & 942.97 & 216.55 & -- & \begin{tabular}{|c|}
$3 / 13 / 2002$ \\
\end{tabular} & -- & 726.42 & none & database \\
\hline WW-5A & 942.97 & 216.59 & -- & $7 / 25 / 2002$ & -- & 726.38 & none & database \\
\hline WW-5A & 942.97 & 216.59 & -- & 9/10/2002 & -- & 726.38 & none & database \\
\hline WW-5A & 942.97 & 216.47 & -- & $9 / 20 / 2002$ & -- & 726.50 & none & database \\
\hline WW-5A & 942.97 & 216.56 & -- & $10 / 23 / 2002$ & -- & 726.41 & none & database \\
\hline WW-5A & 942.97 & 216.59 & -- & $11 / 5 / 2002$ & -- & 726.38 & none & database \\
\hline WW-5A & 942.97 & 216.47 & -- & 11/25/2002 & -- & 726.50 & none & database \\
\hline WW-5A & 942.97 & 216.45 & -- & 12/30/2002 & -- & 726.52 & none & database \\
\hline WW-5A & 942.97 & 216.54 & -- & $1 / 28 / 2003$ & -- & 726.43 & none & database \\
\hline WW-5A & 942.97 & 216.54 & -- & $1 / 28 / 2003$ & -- & 726.43 & none & database \\
\hline WW-5A & 942.97 & 216.47 & -- & $3 / 10 / 2003$ & -- & 726.50 & none & database \\
\hline WW-5A & 942.97 & 216.54 & -- & $6 / 18 / 2003$ & -- & 726.43 & none & database \\
\hline WW-5A & 942.97 & 216.44 & -- & $9 / 25 / 2003$ & -- & 726.53 & none & database \\
\hline WW-5A & 942.97 & 216.45 & -- & $11 / 20 / 2003$ & -- & 726.52 & none & database \\
\hline WW-5A & 942.97 & 216.33 & -- & $1 / 22 / 2004$ & -- & 726.64 & none & USGS website \\
\hline WW-5A & 942.97 & 216.40 & -- & $3 / 8 / 2004$ & -- & 726.57 & none & USGS website \\
\hline
\end{tabular}

${ }^{a}$ meters below reference point

${ }^{b}$ Site Status: $C=$ Water level was measured prior to well completion.

$\mathrm{R}=$ Site had been pumped recently.

$--=$ Not applicable

${ }^{\mathrm{c}}$ meters above sea level

used to determine historical and contemporary static water level not applicable used to determine historical static water level used to determine contemporary static water level

${ }^{\mathrm{d}}$ Type Correction: none $=$ no correction made to water level 
WW-5A

Water Level Data

\begin{tabular}{|c|c|c|c|c|c|c|c|c|}
\hline $\begin{array}{c}\text { Well } \\
\text { Reporting } \\
\text { Name }\end{array}$ & $\begin{array}{l}\text { Reference } \\
\text { Point } \\
\text { Elevation } \\
\text { (m) }\end{array}$ & $\begin{array}{l}\text { Measured } \\
\text { Depth to } \\
\text { Water } \\
(\mathrm{mbrp})^{\mathrm{a}}\end{array}$ & $\begin{array}{l}\text { Corrected } \\
\text { Depth to } \\
\text { Water } \\
\text { (mbrp) }\end{array}$ & $\begin{array}{l}\text { Measure- } \\
\text { ment Date }\end{array}$ & $\begin{array}{c}\text { Site } \\
\text { Status }^{b}\end{array}$ & $\begin{array}{c}\text { Water } \\
\text { Level } \\
\text { Elevation } \\
\text { (masl) }^{c}\end{array}$ & $\begin{array}{c}\text { Type } \\
\text { Correction }^{d}\end{array}$ & Source \\
\hline
\end{tabular}

${ }^{\mathrm{e}}$ Source: database $=$ UGTA borehole database

USGS website $=$ http://nevada.usgs.gov/doe_nv/

'number of days pump was off prior to the water-level measurement as reported in Hood (1961) 
WW-5B

Water Level Data

\begin{tabular}{|c|c|c|c|c|c|c|c|c|}
\hline $\begin{array}{c}\text { Well } \\
\text { Reporting } \\
\text { Name }\end{array}$ & \begin{tabular}{|c|} 
Reference \\
Point \\
Elevation \\
$(m)$
\end{tabular} & $\begin{array}{c}\text { Measured } \\
\text { Depth to } \\
\text { Water } \\
\text { (mbrp) } \\
\end{array}$ & $\begin{array}{c}\text { Corrected } \\
\text { Depth to } \\
\text { Water } \\
\text { (mbrp) }\end{array}$ & $\begin{array}{c}\text { Measure- } \\
\text { ment Date }\end{array}$ & $\begin{array}{c}\text { Site } \\
\text { Status }^{b}\end{array}$ & $\begin{array}{c}\text { Water } \\
\text { Level } \\
\text { Elevation } \\
\text { (masl) }^{c}\end{array}$ & $\begin{array}{c}\text { Type } \\
\text { Correction }^{d}\end{array}$ & Source $^{e}$ \\
\hline WW-5B & 942.83 & 208.03 & -- & $8 / 25 / 1959$ & -- & 734.80 & none & database \\
\hline WW-5B & 942.83 & 208.06 & -- & $8 / 25 / 1959$ & -- & 734.77 & none & database \\
\hline WW-5B & 942.83 & 208.06 & -- & $8 / 25 / 1959$ & -- & 734.77 & none & database \\
\hline WW-5B & 942.83 & 207.93 & -- & $8 / 25 / 1959$ & -- & 734.89 & none & database \\
\hline WW-5B & 942.83 & 208.06 & -- & $8 / 26 / 1959$ & $6^{f}$ & 734.77 & none & database \\
\hline WW-5B & 942.83 & 208.12 & -- & $8 / 26 / 1959$ & -- & 734.71 & none & database \\
\hline WW-5B & 942.83 & 208.28 & -- & $8 / 27 / 1959$ & -- & 734.55 & none & database \\
\hline WW-5B & 942.83 & 208.12 & -- & $8 / 27 / 1959$ & -- & 734.71 & none & database \\
\hline WW-5B & 942.83 & 208.48 & -- & $8 / 29 / 1959$ & -- & 734.35 & none & database \\
\hline WW-5B & 942.83 & 208.30 & -- & $8 / 31 / 1959$ & $2^{f}$ & 734.53 & none & database \\
\hline WW-5B & 942.83 & 208.26 & -- & $12 / 23 / 1960$ & $4^{f}$ & 734.56 & none & database \\
\hline WW-5B & 942.83 & 208.28 & -- & $12 / 23 / 1960$ & -- & 734.55 & none & database \\
\hline WW-5B & 942.83 & 221.38 & -- & 4/12/1962 & $P^{g}$ & 721.45 & none & database \\
\hline WW-5B & 942.83 & 221.38 & -- & $4 / 12 / 1962$ & $P$ & 721.45 & none & database \\
\hline WW-5B & 942.83 & 207.69 & -- & $6 / 7 / 1962$ & -- & 735.14 & none & database \\
\hline WW-5B & 942.83 & 207.69 & -- & $6 / 7 / 1962$ & -- & 735.14 & none & database \\
\hline WW-5B & 942.83 & 208.50 & -- & 10/19/1964 & -- & 734.33 & none & database \\
\hline WW-5B & 942.83 & 208.48 & -- & 10/19/1964 & -- & 734.35 & none & database \\
\hline WW-5B & 942.83 & 208.46 & -- & $10 / 19 / 1964$ & -- & 734.36 & none & database \\
\hline WW-5B & 942.83 & 207.87 & -- & $3 / 21 / 1969$ & -- & 734.96 & none & database \\
\hline WW-5B & 942.83 & 208.18 & -- & $3 / 25 / 1971$ & -- & 734.65 & none & database \\
\hline WW-5B & 942.83 & 208.09 & -- & $3 / 25 / 1971$ & -- & 734.74 & none & database \\
\hline WW-5B & 942.83 & 208.21 & -- & 10/29/1971 & -- & 734.62 & none & database \\
\hline WW-5B & 942.83 & 208.39 & -- & 10/29/1971 & -- & 734.44 & none & database \\
\hline WW-5B & 942.83 & 208.06 & -- & 7/30/1972 & -- & 734.77 & none & database \\
\hline WW-5B & 942.83 & 208.06 & -- & 7/30/1972 & -- & 734.77 & none & database \\
\hline WW-5B & 942.83 & 209.40 & -- & $1 / 16 / 1980$ & -- & 733.43 & none & database \\
\hline WW-5B & 942.83 & 209.40 & -- & $1 / 16 / 1980$ & -- & 733.43 & none & database \\
\hline WW-5B & 942.83 & 209.95 & -- & $5 / 6 / 1991$ & -- & 732.88 & none & database \\
\hline WW-5B & 942.83 & 209.40 & -- & 1/21/2003 & -- & 733.43 & none & database \\
\hline WW-5B & 942.83 & 209.82 & -- & $1 / 22 / 2003$ & $\mathrm{R}$ & 733.01 & none & database \\
\hline WW-5B & 942.83 & 209.49 & -- & $3 / 10 / 2003$ & -- & 733.34 & none & database \\
\hline WW-5B & 942.83 & 209.49 & -- & $6 / 23 / 2003$ & -- & 733.34 & none & database \\
\hline WW-5B & 942.83 & 209.54 & -- & 9/22/2003 & -- & 733.29 & none & database \\
\hline WW-5B & 942.83 & 209.53 & -- & $11 / 17 / 2003$ & -- & 733.29 & none & database \\
\hline WW-5B & 942.83 & 209.63 & -- & $3 / 8 / 2004$ & -- & 733.20 & none & USGS website \\
\hline
\end{tabular}

${ }^{a}$ meters below reference point

${ }^{\mathrm{b}}$ Site Status: $\mathrm{P}=$ Site was being pumped. 
WW-5B

Water Level Data

\begin{tabular}{|c|c|c|c|c|c|c|c|c|}
\hline $\begin{array}{c}\text { Well } \\
\text { Reporting } \\
\text { Name }\end{array}$ & $\begin{array}{c}\text { Reference } \\
\text { Point } \\
\begin{array}{c}\text { Elevation } \\
(\mathrm{m})\end{array}\end{array}$ & $\begin{array}{c}\text { Measured } \\
\text { Depth to } \\
\text { Water } \\
(\mathrm{mbrp})^{\mathrm{a}}\end{array}$ & $\begin{array}{c}\text { Corrected } \\
\text { Depth to } \\
\text { Water } \\
(\mathrm{mbrp})\end{array}$ & $\begin{array}{c}\text { Measure- } \\
\text { ment Date }\end{array}$ & $\begin{array}{c}\text { Site } \\
\text { Status }\end{array}$ & $\begin{array}{c}\text { Water } \\
\text { Level } \\
\text { Elevation } \\
(\text { masl })^{c}\end{array}$ & $\begin{array}{c}\text { Type } \\
\text { Correction }^{\mathrm{d}}\end{array}$ & Source $^{\mathrm{e}}$ \\
\hline
\end{tabular}

$\mathrm{P}^{\mathrm{g}}=$ Assumed to be pumping

$\mathrm{R}=$ Site had been pumped recently.

-- = Not applicable

${ }^{\mathrm{C}}$ meters above sea level

used to determine historical and contemporary static water level not applicable

used to determine historical static water level

used to determine contemporary static water level

${ }^{\mathrm{d}}$ Type Correction: none $=$ no correction made to water level

e Source: database = UGTA borehole database

USGS website $=$ http://nevada.usgs.gov/doe_nv/

fnumber of days pump was off prior to the water-level measurement as reported in Hood (1961) 
WW-5C

Water Level Data

\begin{tabular}{|c|c|c|c|c|c|c|c|c|}
\hline $\begin{array}{c}\text { Well } \\
\text { Reporting } \\
\text { Name }\end{array}$ & $\begin{array}{l}\text { Reference } \\
\text { Point } \\
\text { Elevation } \\
\text { (m) }\end{array}$ & \begin{tabular}{|c|} 
Measured \\
Depth to \\
Water \\
(mbrp) $^{\mathrm{a}}$
\end{tabular} & $\begin{array}{l}\text { Corrected } \\
\text { Depth to } \\
\text { Water } \\
\text { (mbrp) }\end{array}$ & $\begin{array}{l}\text { Measure- } \\
\text { ment Date }\end{array}$ & $\begin{array}{c}\text { Site } \\
\text { Status }^{b}\end{array}$ & $\begin{array}{c}\text { Water } \\
\text { Level } \\
\text { Elevation } \\
\text { (masl) }^{c}\end{array}$ & $\begin{array}{c}\text { Type } \\
\text { Correction }^{d}\end{array}$ & Source \\
\hline WW-5C & 939.73 & 211.23 & -- & $4 / 26 / 1954$ & -- & 728.50 & none & database \\
\hline WW-5C & 939.73 & 211.67 & -- & $4 / 3 / 1959$ & -- & 728.06 & none & database \\
\hline WW-5C & 939.73 & 211.05 & -- & 9/9/1959 & $9^{f}$ & 728.67 & none & database \\
\hline WW-5C & 939.73 & 210.92 & -- & $9 / 14 / 1959$ & $4^{f}$ & 728.80 & none & database \\
\hline WW-5C & 939.73 & 213.32 & -- & $12 / 13 / 1960$ & $7^{f}$ & 726.40 & none & database \\
\hline WW-5C & 939.73 & 212.73 & -- & $12 / 30 / 1960$ & $3^{f}$ & 726.99 & none & database \\
\hline WW-5C & 939.73 & 212.03 & -- & $1 / 13 / 1961$ & $17^{f}$ & 727.69 & none & database \\
\hline WW-5C & 939.73 & 211.73 & -- & $1 / 20 / 1961$ & $24^{f}$ & 728.00 & none & database \\
\hline WW-5C & 939.73 & 211.39 & -- & $1 / 27 / 1961$ & $31^{f}$ & 728.33 & none & database \\
\hline WW-5C & 939.73 & 211.36 & -- & $2 / 3 / 1961$ & $38^{f}$ & 728.37 & none & database \\
\hline WW-5C & 939.73 & 210.85 & -- & $2 / 16 / 1961$ & $51^{f}$ & 728.87 & none & database \\
\hline WW-5C & 939.73 & 210.62 & -- & $3 / 3 / 1961$ & $66^{f}$ & 729.10 & none & database \\
\hline WW-5C & 939.73 & 210.36 & -- & $3 / 24 / 1961$ & -- & 729.37 & none & database \\
\hline WW-5C & 939.73 & 210.30 & -- & $4 / 14 / 1961$ & -- & 729.43 & none & database \\
\hline WW-5C & 939.73 & 210.05 & -- & $5 / 4 / 1961$ & -- & 729.68 & none & database \\
\hline WW-5C & 939.73 & 241.39 & -- & $4 / 12 / 1962$ & $P$ & 698.34 & none & database \\
\hline WW-5C & 939.73 & 291.02 & -- & $8 / 7 / 1962$ & $P$ & 648.70 & none & database \\
\hline WW-5C & 939.73 & 285.81 & -- & $10 / 4 / 1962$ & -- & 653.91 & none & database \\
\hline WW-5C & 939.73 & 217.32 & -- & $10 / 2 / 1964$ & -- & 722.40 & none & database \\
\hline WW-5C & 939.73 & 213.42 & -- & 10/20/1964 & -- & 726.30 & none & database \\
\hline WW-5C & 939.73 & 220.98 & -- & $3 / 20 / 1969$ & -- & 718.75 & none & database \\
\hline WW-5C & 939.73 & 217.81 & -- & $3 / 22 / 1971$ & -- & 721.92 & none & database \\
\hline WW-5C & 939.73 & 219.79 & -- & 10/29/1971 & -- & 719.93 & none & database \\
\hline WW-5C & 939.73 & 216.50 & -- & $7 / 30 / 1972$ & -- & 723.23 & none & database \\
\hline WW-5C & 939.73 & 222.44 & -- & $1 / 16 / 1980$ & -- & 717.28 & none & database \\
\hline WW-5C & 939.73 & -- & -- & $5 / 6 / 1991$ & $\mathrm{P}$ & & -- & database \\
\hline WW-5C & 939.73 & 219.13 & -- & $8 / 31 / 1993$ & -- & 720.59 & none & database \\
\hline
\end{tabular}

${ }^{a}$ meters below reference point

${ }^{\mathrm{b}}$ Site Status: $\mathrm{P}=$ Site was being pumped.

-- = Not applicable

${ }^{c}$ meters above sea level

used to determine historical and contemporary static water level not applicable used to determine historical static water level

used to determine contemporary static water level

${ }^{\mathrm{d}}$ Type Correction: none $=$ no correction made to water level

e Source: database = UGTA borehole database

'number of days pump was off prior to the water-level measurement as reported in Hood (1961) 
WW-C-1

Water Level Data

\begin{tabular}{|c|c|c|c|c|c|c|c|c|}
\hline $\begin{array}{c}\text { Well } \\
\text { Reporting } \\
\text { Name }\end{array}$ & $\begin{array}{c}\text { Reference } \\
\text { Point } \\
\text { Elevation } \\
(\mathrm{m})\end{array}$ & $\begin{array}{c}\text { Measured } \\
\text { Depth to } \\
\text { Water } \\
(\mathrm{mbrp})^{\mathrm{a}}\end{array}$ & $\begin{array}{c}\text { Corrected } \\
\text { Depth to } \\
\text { Water } \\
\text { (mbrp) }\end{array}$ & $\begin{array}{l}\text { Measure- } \\
\text { ment Date }\end{array}$ & $\begin{array}{c}\text { Site } \\
\text { Status }^{b}\end{array}$ & $\begin{array}{c}\text { Water } \\
\text { Level } \\
\text { Elevation } \\
\text { (masl) }^{c}\end{array}$ & $\begin{array}{c}\text { Type } \\
\text { Correction }^{d}\end{array}$ & Source \\
\hline WW-C1 & 1195.93 & 486.46 & 484.92 & $6 / 16 / 1962$ & $\mathrm{P}$ & 711.01 & $B D$ & database \\
\hline WW-C1 & 1195.93 & 470.98 & 469.67 & $10 / 5 / 1962$ & -- & 726.26 & $B D$ & database \\
\hline WW-C1 & 1195.93 & 470.67 & 469.37 & $11 / 5 / 1962$ & -- & 726.56 & $B D$ & database \\
\hline WW-C1 & 1195.93 & 469.76 & 468.47 & $1 / 25 / 1963$ & -- & 727.46 & $B D$ & database \\
\hline WW-C1 & 1195.93 & 469.67 & 468.38 & $6 / 6 / 1963$ & -- & 727.55 & $B D$ & database \\
\hline WW-C1 & 1195.93 & 469.82 & 468.53 & $6 / 7 / 1963$ & -- & 727.40 & $B D$ & database \\
\hline WW-C1 & 1195.93 & 469.36 & 468.08 & $8 / 20 / 1963$ & -- & 727.85 & $B D$ & database \\
\hline WW-C1 & 1195.93 & 469.57 & 468.29 & $9 / 7 / 1963$ & -- & 727.64 & $B D$ & database \\
\hline WW-C1 & 1195.93 & 469.64 & 468.35 & $9 / 8 / 1963$ & -- & 727.58 & $B D$ & database \\
\hline WW-C1 & 1195.93 & 469.67 & 468.38 & $10 / 8 / 1963$ & -- & 727.55 & $B D$ & database \\
\hline WW-C1 & 1195.93 & 469.15 & 467.87 & $10 / 8 / 1963$ & -- & 728.06 & $B D$ & database \\
\hline WW-C1 & 1195.93 & 469.70 & 468.41 & 10/10/1963 & -- & 727.52 & $B D$ & database \\
\hline WW-C1 & 1195.93 & 469.15 & 467.87 & $4 / 11 / 1969$ & -- & 728.06 & $B D$ & database \\
\hline WW-C1 & 1195.93 & 470.15 & 468.86 & $3 / 29 / 1971$ & $\mathrm{R}$ & 727.07 & $B D$ & database \\
\hline WW-C1 & 1195.93 & 470.43 & 469.13 & $8 / 6 / 1972$ & $\mathrm{R}$ & 726.80 & $B D$ & database \\
\hline WW-C1 & 1195.93 & 469.74 & 468.45 & $4 / 6 / 1998$ & -- & 727.48 & $B D$ & database \\
\hline WW-C1 & 1195.93 & 469.76 & 468.48 & $4 / 14 / 1998$ & -- & 727.46 & $\mathrm{BD}$ & database \\
\hline WW-C1 & 1195.93 & 469.72 & 468.44 & $5 / 11 / 1998$ & -- & 727.50 & $B D$ & database \\
\hline
\end{tabular}

${ }^{a}$ meters below reference point

${ }^{\mathrm{b}}$ Site Status: $\mathrm{P}=$ Site was being pumped.

$\mathrm{R}=$ Site had been pumped recently.

-- = Not applicable

${ }^{c}$ meters above sea level

used to determine historical and contemporary static water level

used to determine historical static water level not applicable used to determine contemporary static water level not applicable

d Type Correction: BD = water level corrected for borehole deviation

${ }^{\mathrm{e}}$ Source: database $=$ UGTA borehole database 
WW-C

Water Level Data

\begin{tabular}{|l|c|c|c|c|c|c|c|l|}
\hline $\begin{array}{c}\text { Well } \\
\text { Reporting } \\
\text { Name }\end{array}$ & $\begin{array}{c}\text { Reference } \\
\text { Point } \\
\text { Elevation } \\
(\mathbf{m})\end{array}$ & $\begin{array}{c}\text { Measured } \\
\text { Depth to } \\
\text { Water } \\
(\mathbf{m b r p})^{\text {a }}\end{array}$ & $\begin{array}{c}\text { Corrected } \\
\text { Depth to } \\
\text { Water } \\
(\mathbf{m b r p})\end{array}$ & $\begin{array}{c}\text { Measure- } \\
\text { ment Date }\end{array}$ & $\begin{array}{c}\text { Site } \\
\text { Status }\end{array}$ & $\begin{array}{c}\text { Water } \\
\text { Level } \\
\text { Elevation } \\
(\mathbf{m a s l})^{\mathbf{c}}\end{array}$ & $\begin{array}{c}\text { Type } \\
\text { Correction }\end{array}$ & Source $^{\text {e }}$ \\
\hline WW-C & 1196.08 & 469.54 & 469.35 & $6 / 20 / 1961$ & -- & 726.73 & BD & database \\
\hline WW-C & 1196.08 & 470.61 & 470.42 & $9 / 13 / 1961$ & -- & 725.67 & BD & database \\
\hline WW-C & 1196.08 & 470.34 & 470.14 & $11 / 1 / 1961$ & -- & 725.94 & BD & database \\
\hline WW-C & 1196.08 & 470.43 & 470.24 & $1 / 3 / 1962$ & -- & 725.85 & BD & database \\
\hline WW-C & 1196.08 & 469.79 & 469.60 & $1 / 29 / 1962$ & -- & 726.49 & BD & database \\
\hline WW-C & 1196.08 & 470.79 & 470.60 & $6 / 13 / 1962$ & -- & 725.48 & BD & database \\
\hline WW-C & 1196.08 & 468.45 & 468.26 & $6 / 16 / 1962$ & -- & 727.83 & BD & database \\
\hline WW-C & 1196.08 & 470.00 & 469.81 & $4 / 11 / 1969$ & -- & 726.28 & BD & database \\
\hline WW-C & 1196.08 & 470.52 & 470.33 & $3 / 29 / 1971$ & -- & 725.76 & BD & database \\
\hline WW-C & 1196.08 & 470.95 & 470.75 & $10 / 25 / 1971$ & -- & 725.33 & BD & database \\
\hline WW-C & 1196.08 & 471.02 & 470.83 & $8 / 6 / 1972$ & -- & 725.25 & BD & database \\
\hline WW-C & 1196.08 & 470.57 & 470.38 & $3 / 18 / 1973$ & -- & 725.71 & BD & database \\
\hline WW-C & 1196.08 & 470.61 & 470.42 & $10 / 18 / 1975$ & -- & 725.67 & BD & database \\
\hline
\end{tabular}

${ }^{a}$ meters below reference point

bite Status: -- = Not applicable

${ }^{c}$ meters above sea level

used to determine historical and contemporary static water level not applicable used to determine historical static water level

used to determine contemporary static water level not applicable

d Type Correction: BD = water level corrected for borehole deviation

${ }^{e}$ Source: database $=$ UGTA borehole database 